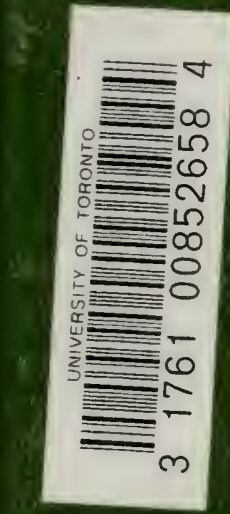

ow 
Digitized by the Internet Archive in 2008 with funding from Microsoft Corporation 


A TEXT-BOOK OF BOTANY 


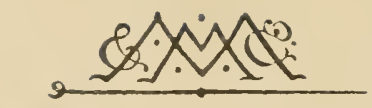

MACAILLAN AND CO, LIMITED

LONDON - BOMBAY • CALCUTTA MELBOLRNE

THE MACMLLAN COMPANY

NEW YORK - BUSTON - CHICAGO

DALLAS - SAN FRANCISCO

TIE MACMLLAN CO. OF CANADA, LTD. TORONTO 


\section{TEXT-BOOK OF BOTANY}

$\mathrm{BY}$

DR. EDUARD STRASBURGER

PROFESSOR IN THE UNIVERSITY

OF LON

DR. HEINRICH SCHENCK

I'ROFESSOR IN THE TECHNICAL

ACAEEMY OF DARMISTALT
I)R. LUDTVIG JOST

PROFESSOR IN THE UNIVERSITY

OF STRASBURG

DR. GEORGE KARSTEN

PROFESSOR IN THE UNIVERSITY OF HALLE

FOURTH ENGLISH EDITION

REVISED WITH THE TENTH GERMAN EDI'IUN BY

W. H. LANG, M.B., I).Sc., F.R.S.

BARKER PROFESSOR OF CRYPTOGAMIC BOTANY IN THE UNIVERSITY

OF MANCHESTER

WITH 782 ILLUSTRATIONS, IN PART COLOURED

MACMILLAN ANI) CO, LIMITED

ST. MARTIN'S STREET, LONDON 


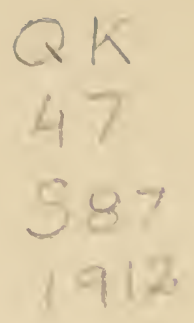

COPYRIGH'T

First Enylish Edition, 18:14

Second Enylish Ellition, 1!03

Third English Elition, 1908

Foneth Euglish Edition, 1912

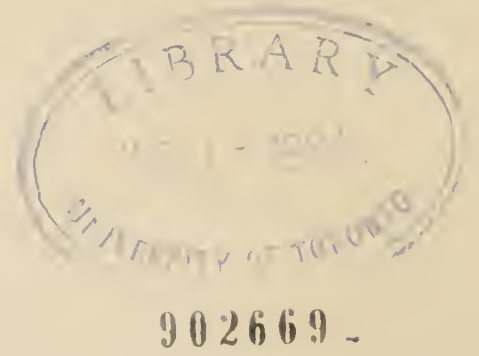




\section{PREFATORI NOTE}

TuE first edition of the English translation of this text-book was the work of Dr. H. C. Porter, Assistant Instructor of Botany, University of Penusylvania. The proofs of this edition were revised by Professor Seward, M.A., F.R.S. The seeond English edition was based upon I)r. I'orter's trumslation, which was revised with the fifth German edition. The present edition has been similarly revised throughout with the tenth German edition. Such extensive ehanges, including the substitution of completely new seetions on J'hysiology and Phanerogamia, have howerer been made in the work since it was first translated, and in the third and fourtl English editions, that it seems arvisable to give in ontline the history of the English translation instead of retaining Dr. Porter's name on the title-page.

The official plants mentioned under the Natural Orders are those of the British Pharmaeopoeia instead of those official in Germany, Switzerland, and Austria, which are given in the oricinal. In making this alteration I lave consulted Materia Merlice and Therapeutics, by J. Mitchell Bruce, M.A., LL.D), M.I.

I am indebted to my friend Mr. D. Thoday, M.A., Lecturer in Plant P'hysiology in Manehester University, for reading over the proofs of the translation of the section on Physiology.

WILLIAII H. IANG.

MANCHESTER, 1912. 



\section{CONTENTS}

INTRODUCTION

PACE

\section{PART I. GENERAL BOTANY}

\section{SECTION I. MORPHOLOGY}

\section{EXTERNAL MORPHOLOGY}

The development of form in the plant kingdom

Relations of symmetry .

Branch systems .

The shoot

Metamorphosis of the bud and shoot . . . . . 23

Leaves

Vernation and Aestivation

The arrangement' of leaves

Metamorphosis of leaves

The root .

Netamorphosis of roots .

Members of independent origin .

\section{INTERNAL MORPHOLOGY}

1. CELI

A. The Cell

1. Structure of the eell

Protoplasm

Inclusions of the protoplasts . . . . . . . 63

Cell-sap .

External Iroduets of the protoplasts . . . . . . 71

2. Ontogeny of the cell . . . . . . . . 81

3. The cell in the process of reproduetion . . . . . . 92

B. Cell-fusions 
2. TISSIES

Origin of tissues .

Mature tissues.

Systems of tissue-

A. Primary tissues.

B. Secondary tissues

Wounds .

Regeneration

Phylogeny of the internal strueture

Ontogeny of the form and structure of plants .

\section{SECTION II. PHYSTOLOGY}

Physiology

Sub-Section 1. Metabolism

1. The ehemieal composition of the plant .

2. Absorjtion and movement of substanees

3. The assimilation of food naterials

4. Transloeation and transformation of assimilates

5. Respiration and fermentation

1. The embryonal development of the organs . . . . 250

2. The phase of elongation.

3. The internal construetion of organs

4. Periodicity

5. Reproduction

6. Hybrids .

7. Variation and mutation.

1. Survey of the various kinds of movement . . . . . 291

2. Hygroscopic movements

3. Movements in the actively living plant

Antonomie movements

Paratonic movements .

Direetive movements

\section{PART II. SPECIAL BOTANY}

\section{SECTION I. CRYPTOGAMS}

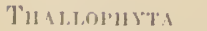


Cyanophyecae

Flagellata .

Myxomycetes

Periclineae.

Conjugatae .

Diatomeae .

Heterocontae

Chlorophyceae 356

Phaeophyceae 366

Rhodophyceac 374

Phycomycetes 379

Eumycetes .

Lichenes

Characeae

Beyophyta

Hepaticae

Musei

Pterinophyt .

Filicinae

Equisetinae .

Lycopodinae

Fussil Cripugams

\section{SECTION II. PHANEROGAMIA}

The Transition from the Cryptogans to the Phanerogams

Molphology and Orcology of the Phanerogamic Flowel and of its

Sexual Generatiun

The planerogamic flower . . . . . . 480

Intlorescences

Floral oecology

Development of the Sexull Generation in the Phanelugams . 502

The seed . . . . . . . . . . 515

Distribution of seeds . . . . . . . . 520

Germination . $\quad$. . . . . . . 523

Alrangement of Classes, Orders, and famlies . . . 525

Gymaspermae . . . . . . . . . . . . . . .

Cycadinae . . . . . . . . . . 528

Ginkgoinae . . . . . . . . . 530

Coniferae . . . . . . . . . . . . 531

Gnetinae . . . . . . . . . . . 540

Fossil Granuspelis . . . . . . . . . . 540 
A NGIOSPELMAE .

PAGE

SlB-Class I. Dreutrlat

Series I. Choripetalae .

A. Monochlamydeac

Verticillatae

Juglaudiflorat .

Quereiflorae

Saliciflorae

Urticinat:

Loranthiflorae .

Piperinae

Hamamelidinae

Tricoccae

Centrospermae .

B. Dialypetalac

Polyuarpicae

Rhoeadinae

Cistiflorae

Columniferae

Gruinales

Sapindinae

Frangulinae

Saxifraginae

liosillorae

Leguminosae

l'assitlorinae

Thymelaëinae

II yrtiflorie

Umbelliflorae

544

- 545

- 545

- 545

- 545

546

- 553

554

558

559

561

- 561

567

572

- 572

- 587

- „93

596

600

605

608

609

611

616

627

628

628

632

640

640

640

Ericinae

Diospyrinae

Primulinae

1). Tetracyclicae

Coutortae

Tubillorae

Personatae

limbiinate

Canpanulinae!

Aggregatac

641

641

644

- 641

651

656

662

670

675

684

IIstobiac

686

lilumillorate

687 


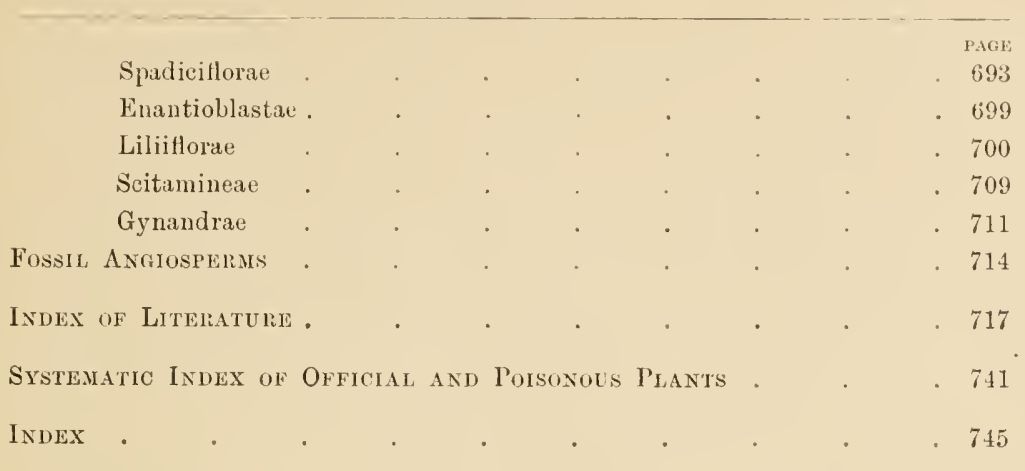





\section{INTRODUCTION}

IT is eustomary to place all living beings in either the animal or vegetable kingdoms, but in reality a sharp boundary line between animals and plants first becomes possible when they exhibit a complicated structure. In those of more simple organisation all distinctions disappear, and it becomes difficult to define the exact limits of Botany and Zoology. This, in fact, conld scarcely be otherwise, as all the processes of life, in both the animal and vegetable kingdoms, are dependent on the same substance, protoplasm. With more complicated organisation, the specific differences increase, and the charaeteristics distinguishing animal from vegetable life become more obvious. For the present, it must be confessed, the recognition of an organism, as an animal or a plant, is dependent upon its correspondence with an abstract idea of what a plant or animal should be, based on certain points of agreement between the members of each class. A satisfactory basis for the separation of all living organisms into the categories of animals or plants ean only be obtained when it is shown that all organisms distinguished as animals are in reality genetieally connected, and that a similar connection exists between all plants. The proof of this ean only be arrived at through the THEORY OF EVOLUTION.

From the study of the fossil remains and impressions of animals and plants, it has been established that in earlier epochs forms of life differing from those of the present age existed on the earth. It is also generally assumed that all living animals and plants have been derived by gradnal modification from previonsly existing forms. This leads to the further conclusion that those organisms possessing closely similar structure, which are uniter as speeies in a genus, are in reality related to one another. It is also probable that the union of corresponding genera into one family and of families into higher groups serves to give expression to a real relationship existing between them.

The presumable origin of a living organism from others previonsly existing has been distinguished by HAKCKFI ${ }^{1}$ ) as its PHYLOGENY. He termed the series of changes passed through by a living being in 
attilining its mature condition, its ONTOGENY. The supposition, that the successive steps in the ontogenetic development of an organism correspond to those of its plyylogenetic development, and that the ontogeny of an organism is accordingly a more or less complete repetition of its phylogeny, was asserted by Fritz MülLER $\left({ }^{2}\right)$, who based his conclusions on the results of comparative research.

The idea of the gradual evolution of higher organisms from lower was familiar to the Greek philosophers, but a scientifie basis was first given to this hypothesis in the last century. Through the work of CHARLES DARWIN $\left({ }^{3}\right)$ in particular, who accumulated evidence for a reconsideration of the whole problem of organic evolution, the belief in the immutalbility of species has been overturned.

DARWIN sought to explain the origin of species by natural causes, laying chief weight on a process of selection. In drawing his conclusions, he proeeeded from the variability of living organisms, as show by the fact that the offispring neither exactly resemble their parents nor each other. Further, he called attention to the constant over-production of offspring, the majority of which must inevitably be destroyed. If this were not so, and all the young produced by even a single pair attained their full development, they would, in a few generations, completely cover the whole surface of the earth. On ateount of insufficient space for all, the different claimants are angaged in an uninterrupted struggle, in which the victory is gained by those that, for any reason, have an advantage. Through this "STRUGGLE FOR EXISTENCE" a selective process goes on among the characters appearing in individual variations, and those which under the conditions of life are in any way advantageous tend to be preserved. In this manner DARwis arrived at the supposition of a process of NATULAL SELECTION, which is the essential of his theory. Newly developed peculiarities must be inherited in order to become permanent characteristics of a later generation. DARWIN solight in the experience of breeders evidence that such character's are inherited. The breeder selects individnals presenting any desired character's for' the purpose of breeling, and has thus formed the races of domesticated animals and enltivated plants. These have often departed so widely from their wilk ancestral forms that the latter are not certainly known. Natural selection will work in the same way as this artificial selection and, by repeated choice of individual peculiarities, which ean be inherited and thus combined with the pre-existing characters, ean give rise to new forms; these nltimately may depart widely from the ancestral form. By the continued operation of natural selection, organisms must result, which are, in the highest degree, fitted and arlapted to their anviromment. In this way the theory of selection sceks to explatin as clue to natural eauses that adaptalility to the environment which is such a striking characteristic of organic life. That the transitional forms in this process of phylogenetic development 
no longer exist, is aecourted for in the theory of natural selection by the assumption that the struggle for existence must necessarily have been most severe between similar organisms. For similar organisms have similar needs, and the new and better-equipped forms must ultimately prevail over the original less specialised organisms and exterminate them.

Since the publication of Darwin's works many investigators have laboured to advance and make clear our views on phylogeny. Difficulties in applying the results of artificial selection to the natural process became evident, for one main condition of successful artificial selection, the isolation of the organisms from which breeding is taking place, is not fulfilled under natural conditions. It might be expeeted that the new form would disappear by crossing with other individuals, but recent work on heredity has minimiserl this difficulty. A newly acquired character reappears in a portion of the descendants even after crossing, and can thus, if advantageous, be selected. HUGO DE VRIES has endeavoured to obtain an insight into the laws of phylogenetic development by systematic eultivation of particular plants. It would appear from such cultures $\left({ }^{4}\right)$ that the starting-point for the origin of new species is not afforded by the "fluctuating variations," which continually occur, but by more marked variations which have been termed "mutations"; these mutations appear suddenly and are inherited, reappearing according to special laws of heredity in the progeny. DE VRIES terded to assume the existence of a development of the organic world due to original innate capabilities of the living substance, and not dependent on selection. The origin of the large subdivisions of the animal and vegetable kingdoms, the "archetypes," wonld be due to this sort of evolution $\left(^{5}\right)$. The organisms have been, and are still, eontinually influenced by the environment, and by their reaction to external conditions have become more or less directly adapted. In this way striking resemblances in external form have arisen between organisms living under similar eonditions althongh belonging to different archetypes $\left({ }^{6}\right)$. Natural seleetion exercises a eonstant influenee on the process and tends to render species distinct by removing the less advantageous variations.

If the higher organisms have been evolved from the lower, a sharp distinction between plants and animals is excluded. For the characters which are distinctive of animals and plants have appeared in the eourse of the phylogenetie development of organisms, and were at first wanting. The simplest organisms which now exist are in all probability similar to those which formed the starting-point of this development. The walls which surround the cells eomposing the plant body, and the green chromatophores within the latter; are important indieations of the vegetable character of an organism. Surrounded by firm walls, the living substanee beeomes more isolated, and, consequently, independence of action in plants, as 
compared with animals, is diminished. By means of the green colouring matter, plants have the power of producing their own nutritive substinces from certain constituents of the air and water, and from the salts contained in the soil, and are thus able to exist independently; while animals are dependent, directly or indirectly, for their nourishment, and so for their rery existence, on plants. Almost all the other differences which distinguish plants from animals may be traced to the structure of plants, or to the manner in which they obtain their food. Another characteristic of plants is the unlimited duration of their ontogenetic development, which is continuous, at the growing points dnring their whole life. That none of these criteria are alone sufficient for distinguishing plants from animals is erident from the fact that all the Fungi are devoid of green pigment, and, like animals are dependent on substances produced by green plints for their nourishment. On the horderland of the two kingdoms, where all other distinctions are wanting, phylogenetic resemblances, according as they may indicate a probable relationship with plants or animals, serve as a guide in determining the position of an organism.

While it is thus impossible to distinguish sharply the two great groups of living organisms from one another, a distinction between them and lifeless hodies is readily recognised. Living organisms are endowed with the quality of IRRITABILITY, in which all lifeless bodies are deficient. External or internal stimnli influence living organisms to an activity, which is manifested in accordance with the requirements and conditions of their internal strneture. Even in the smallest and simplest known organisms the manifestations of life are ocensioned by a similar sensitiveness to external or internal stimuli. It is, therefore, probable that the lowest living beings must have possesserl essentially simpler properties than any organisms now known, which would enable us to comnect them with non-living substunces. The suljstance which serres as a basis for all development must be supposed to have had an inorganic origin. So far as is actually known, howerer, all living organisms have arisen only from similar organisms. So far as experience has shown, spontaneous generation is unknown. In the ollen times it wals a common supposition, which Aristotus himself held, that even highly organised animals and plants conld originate from sand and mud. In the same legree that knowlerlge of the actual derelopment of living urganisms was extended, the previously accepterl cases of spontaneous grencration leecame more and more restricted, and were finally limited to intestinil worms which eoull not otherwise, it was thought, be acconnterl for, and to microseopic organisms, the origin of which also was not molerstood. Now, for such organisms the possibility of a sprontaneons generation has been dirproverl by more modern investigations; the history of the development of intestinal worms is known, 
and the germs of minute organisms have been found to exist everywhere. SCHWANN and PASTEUR have been pioneers in this work, and have shown that it is possible to hinder the development of the lower organisms, in places where it is customary to find them, by destroying all existing germs and at the same time preventing the entrance of new ones. It is due to the results obtained by these men in their investigations on spontaneous generation that we are now able to preserve food in a scientific manner. The germs previously existing in the substance to be conserved are clestroyed by heat, while, by a proper mode of sealing, the entrance of new gelms is rendered impossible, and the decomposition, which their presence would occasion, is accordingly prevented.

All known living organisms have been derived from other living organisms. But the idea of the origin of living from dead substances on the other hand derires important support from the progress of chemical research. In the early decades of the last century it was customary to draw a distinct line of separation between organic and inorganic chemistry, and to assume that the substances dealt with by organic chemistry could only be produced by the vital action of organisms. The laws governing inorganic chemistry appeared to have no reference to organic chemistry, the formation of organic substance being due to a special force, the "vital force." In 1828 WöHLER obtained urea from ammonium cyanate, and thus for the first time produced an organic compound from an inorganic substance. In 1845 KOLBE completely synthesised trichloracetic acid, and in 1850 Berthelot synthesised alcohol and formic acid. The formel substance had been synthetically prepared by HeNNEL in 1828, but BERTHELOT was the first to recognise its identity with the substance formed in alcoholic fermentation. By these results the former distinction between organic and inorganic chemistry was destroyed. Organic chemistry has become the chemistry of carbon compounds. Pecently Euru Fischer has synthesised sugars, and attacked the problem of the synthesis of albuminous substances.

In some such way it is possible that living matter originated from non-living at some period in the evolution of the earth when the conditions for its formation existed. In order that the organic world should have developed from the first living matter, one of the original properties of the latter must have been a capability of continued existence among its surroundings. It must have been capable of variation and of retaining the new characters appearing in this way, of growth, i.e. the increase of itself at the cost of foreign substances, and of reproduction, i.e. multiplication by separation into a number of parts. Some observers have recently described the origin of microscopic structures, which behave similarly to living beings, in bouillon and other organic culture media when exposed to the action of radium $\left({ }^{7}\right)$. 
Botany, or the science of plants, maly lie divided into a general and a special part. In the general part, the structure and functions of plants as such will be considered; in the special part, their particular structure and functions in the separate divisions of the regetable kingdom will be discussed.

The stucly of the structure of plants is called MorPHOLOGY; that of the eauses of the vital phenomena of plants Phrsiology. To these may be added the study of the vital economy of plants, their Oxcologr. $\left({ }^{8}\right)$ Physiology attempts to explain the processes of life cansally. The teleological point of view is, on the other hand, adopted by oecology, which is mainly concerned with the relation of organisms to their environment.

In the general part of this text-book, the morphology and physiology of plants will be considered in relation to examples seleeted from the vegetable kingdom. In the special part, the various families of plants, with their special morphology, physiology, and oecology, will be described in order. 


\section{PART I \\ GENERAL BOTANY}

\section{SECTION I}

MOR P H O OG Y 



\title{
GENERAL BOTANY
}

\author{
SECTION I
}

\section{MOLPHOLOGY}

THE olject of regetable morphology is the scientific study of the forms of plants. It does not attempt to discover the causes of the development of specific forms, but rather has accomplished its purpose when it succeeds in showing how one form may be derived from another. The only real basis of morphological study is, accordingly, the genealogical development or phylogeny (p. 1). As phylogenetic development can only be inferred, and cammot be directly followed, the methods of morphology must also be indirect. They are dependent on the one hand upon ontogeny, i.e. on the study of the development passed through by an organism in attaining its mature condition, and on the other hand upon the comparison of existing organisms with one another and with those that have become extinct. To a certain extent the ontogenetic development of a plant repeats its phylogeny and helps to elucidate the latter, while, by means of comparative investigation, extreme forms may be connected by intermediate links. As, however, the ontogeny of a plant is neither a complete nor invariable repetition of its plyylogeny, and as connecting links between extreme forms are often wanting, the results of morphological study are frequently incomplete. Such parts or members of plants which it is reasonable to presume have had a common origin are distingnished as Hovologous; those which, while probably having different origins, yet exercise the same functions, are termed ANALOGOUS. Through the adaptation of different parts to the same function, a similarity in both external form and internal structure often results; and in this way the correct determination of morphological relationships is rendered difficult. Only homologous parts have the same "morphological value." This homology is determined by the facts of phylogeny and origin, and not by any correspondence in function. Though the function of any structure does not influence 
its morphological value, the need of making elear the intimate connection between form and function often introduces physiological considerations into morphologieal questions. When, for phylogenetic reasons, it seems possible to attribute to a number of different member's a common origin, such a hypothetical original form is termed the fundamental or primitive form. The various modifications which the primitive form has passed through constitute its METAmorphosis. In this way the theory of the metamorphosis of plants acquires an actual significance.

Slightly differentiated structures, which are found at the beginning of a series of progressively differentiating forms, are termed RUDIMENTARY ; imperfeet structures, which have arisen as the result of the deterioration of more perfect forms, are termed REDUCED.

$\checkmark$ egetable morphology includes the study of the extemal form and the internal strueture of plants. The descriptive study of the external form of plants has been termed organography. This term will not be used, since by the use of the word "organ," it would seem to have a physiological signification. Morphology takes no recognition of the parts of a plint as organs, but treats of them merely as members of the plant body. On the other hand, one of the most important aims of physiology is to place the exterual form and the internal structure of the living body in relation to the functions performed by the latter; physiology also investigates the causes of the organisation. The study of the internal structure of plants is often designater Anatomy or Phytotomy; but as it mainly deals with the study of the more minute internal structure, it resembles rather histology, in the sense in which that term is used by zoologists, and concerns itself to a much less degree with the coarse anatomy of the plant body. In any case, it is the simplest plan to designate the study of the outer form EXTERNAL MORPHOLOGY, and that of the immer structure INTERNAI, MOLPHOLOGY.

\section{EXTERNAL MORPHOLOGY $\left({ }^{9}\right)$}

Plants show a great diversity in the form and arrangement of their members; it is the task of morphology to determine the points of agreement existing between them. It seeks to do this by determining the common origin of the homologous parts or members.

\section{The Development of Form in the Plant Kingdom}

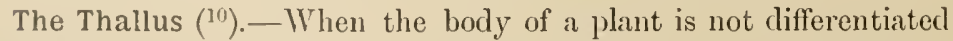
into separate meniliers, or is composed of members which (though they maty be similar) are not lomologous with those of the most highly 
organised plants, it is termed a THALrus. When the thallus is differentiated into members analogous to those of the higher plants

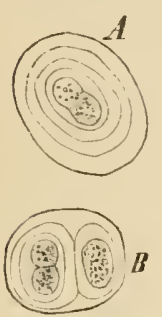
some confusion may arise from the same names being used for parts which, since their origin has been distinct, are F10. 2.- Sacharomyces not homologous.

The simplest form that we ean imagine for
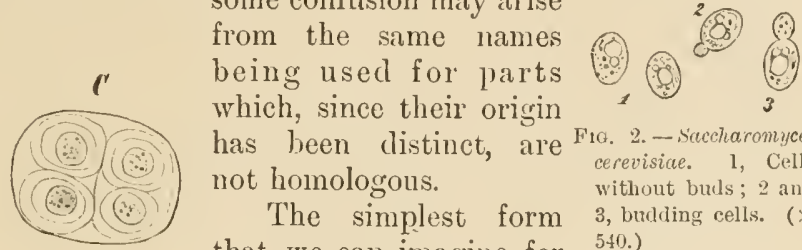
cerevisiae. 1, Cells without buds; 2 and 3 , budding cells. ( $x$ 540.)

an organism is that of a sphere, and this is aetually the form of some of the lower

Fir. 1.-Glocacapsa polydermatia.. A Commencement of division; $B$, (to the left) shortly after division; $C$, a resting stage. $(\times 540$.)

plants. A green growth often seen on damp walls consists of an aggregation of the mieroscopically small spherical bodies of Gloeocupsu polydermatica (Fig. 1), an Alga belonging to one of the lowest divisions of the vegetable kingdom. The single plants of the Beer-yeast (Saccharomyces cererisiae) are ellipsoidal; but, from their
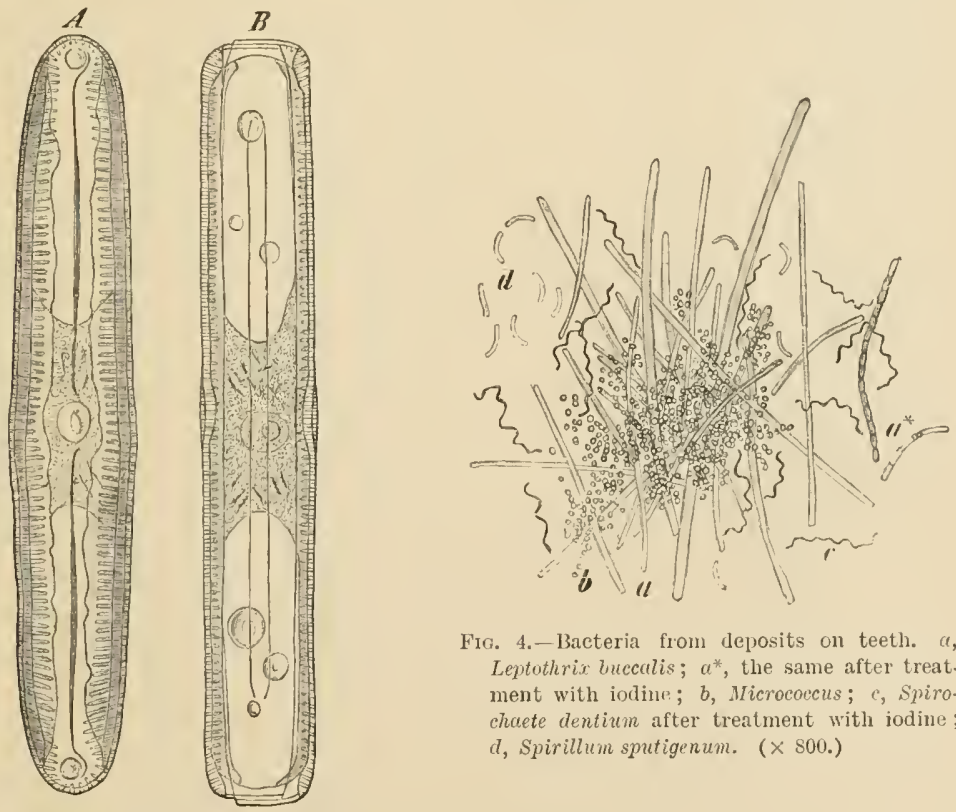

Fic. 4.-Bacteria from deposits on teeth. a, Leptothrix bucculis; $a^{*}$, the same after treat. ment with iodine; $b$, Micrococcus; c, spirochaete dentium after treatment with iodine; d, Spirillum sputigenum. ( $\times$ s00.)

F1G. 3.-Pinnularia viridis. A, Suface

view ; $L$, lateral view. ( $\times 540$.

peculiar manner of growth, by budding, they form lateral outgrowths, and thus often appear constrieted (Fig. 2). Cylindrical and also diseshaped forms are shown by various Algae. The Diatomeae (Fig. 3), 
in particular, exhibit a great variety of spindle, canoe, helmet, and fan-like shapes; but they may all be derived from the more simple spherieal, discoidal, or cylindrical forms. Among the Bacteria, which, as the cause of infeetious diseases and of decomposition, have been the object of so mueh recent investigation, we also meet with spherical, rod-shaped, filamentous, and spirally wound forms (Fig. 4). The next stage in the progressive development of external form in the regetable kingdom is exhibited by such plants as

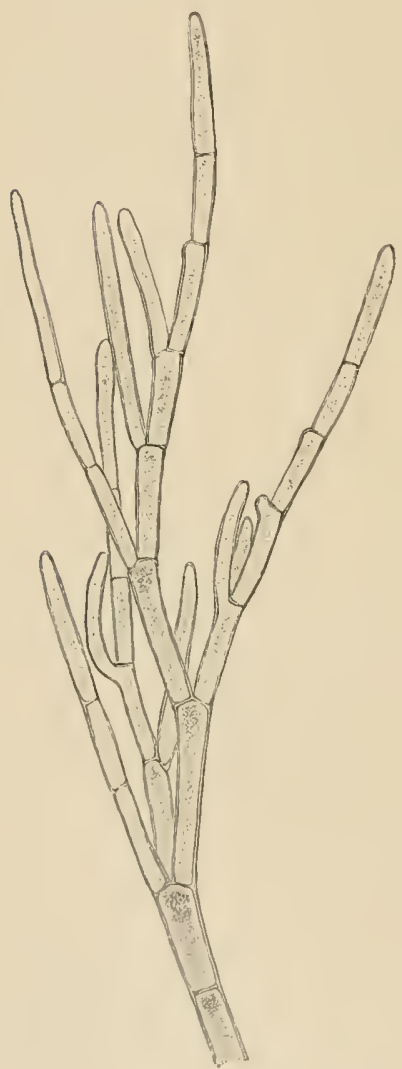

Firi. C. I'ortion of Cludophora glomerntu. ( $\times$ 1S.)
Fir: 5. - Uliü Lactuca, young stage, show. ing apex and base. $(\times 220$.
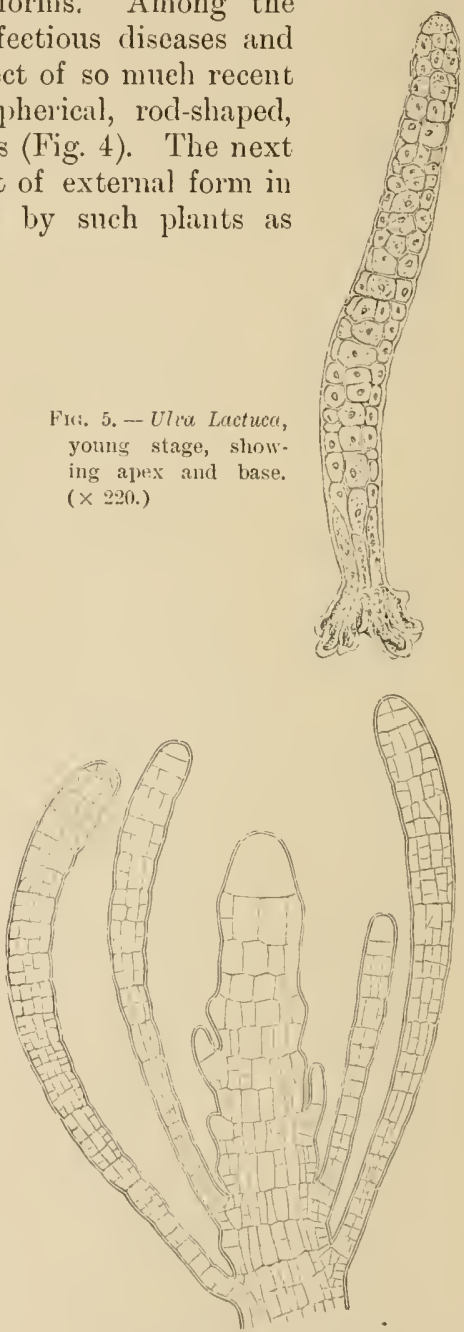

Fra. 7.-Cladostephus verticillatus. (After P'riNG:SHEIM, $\times 30$.)

Show a IHFHERNTIATION INTO APEX AND BASE. The base selves as a print of attachment, while growth is localised at the apex. In this way a growing point is leveloped at the apex. As an example of such it form, a young plint of the green Algai, Ulice Lactusa (Fig. 5), 
may be taken. The derelopment of a more complicated external form is represented lyy the brancherl filamentous, or ribbon-shaperl Algae, in which the origin of new formations is more and more restricted to the apex. An ACROPETAL orler of development, in which the youngest lateral members are always nearest the growing apex, is clearly shown by the branched filaments of the common green Alga, Cludophore glomeratu (Fig. 6). Still more pronounced is the apical growth in the brown seaweed Cladosteplaus

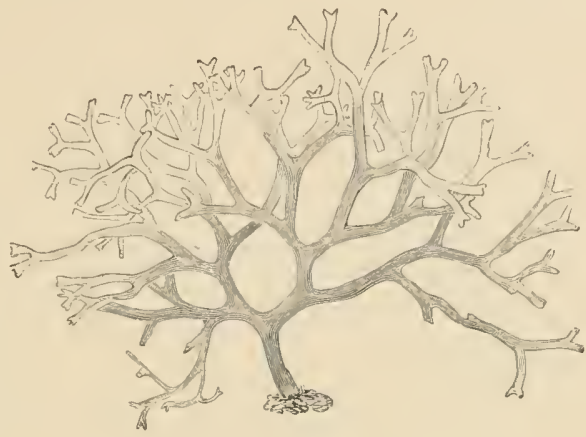

Fir, S.-Dictynte lichotoma. ( $\frac{2}{3}$ nat. size.) verticillatus (Fig. 7). The great variety in the form of the larger Fungi and Lichens, by which they are distinguished as club-, umbrella-,

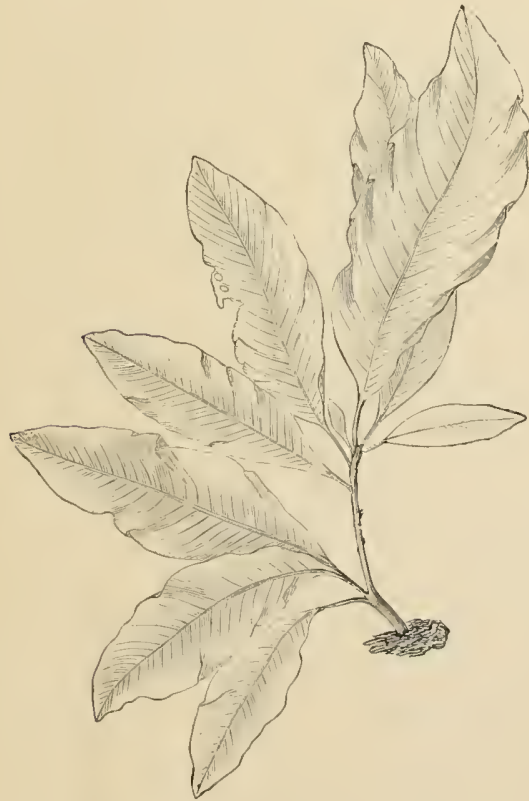

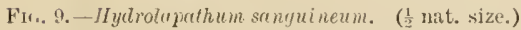
salver-, or bowl-shaped, or as bearded or shrub-like, comes about by the union or intertwining of apically growing filaments. This type of construction is limited to Fungi and Lichens. As the apex itself may undergo successive bifurcation, as in the case of Dictyuta dichotomu (Fig. \&), it does not always necessarily follow that new members must be formed beneath the original apex.

The highest degree of external differentiation among the lower plants is met with in certain groups of Red and Brown Sea-weeds (Rhodophyceae and Phaeoplyceae). Some representatives of these classes resemble the higher plants in the formation and arrangement of their members ; Hydrolupathum sanguineum (Fig. $9)$, for example, as is indicated by its name, resembles a species of liumex, and affords an instructive illustration of the analogy of form existing between plants pliylogenetically widely distinet from one another. 
The Cormus. - Nll pliunts the body of which ean be regarded as a thallus are gromped together as Thallophytes, and contrasted with Cormophytes in which a shoot is dereloped. The latter include two developmental series which, though assumed to have had a common
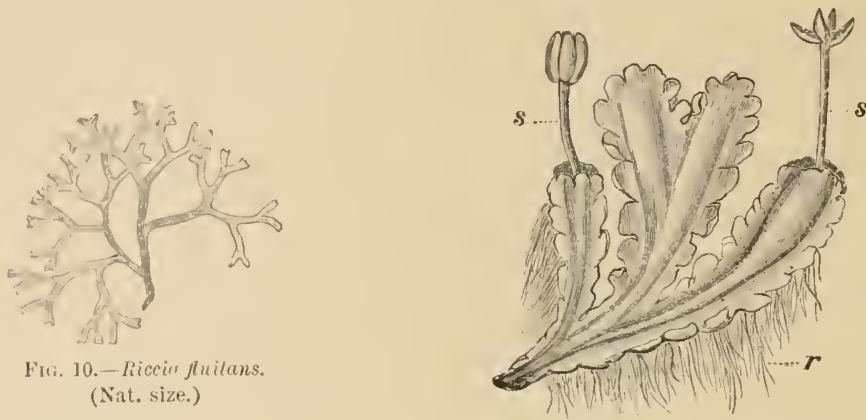

FIf, 11.-Blasiu pusilla. s, Sporogonium ; $r$, rhizoirls. $(\times 2$.

starting-point, have attained a eormophytic organisation independently. These two groups are the moss-like plants or Bryophyta and the Pteridophyta including the ferns and their allies; from the Pterido-

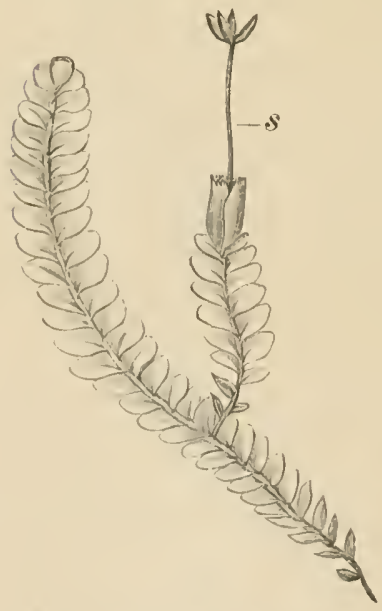

Fin., 12. Jleriochilu resplenioides. s, ș̣nrogentium. (Yat. size.) phyta the seed-plants, the highest group in the vegetable kingdom was derived. Among the Bryophytes forms oceur, as in some gromps of Liverworts (Hepaticae), with a completely thalloid body which is ribbon-shaped and only exhibits an imperfeet differentiation into members. Thus Piccia fluituns (Fig. 10) is ribbon-shaped and dichotomously branched, and its habit or general appearance recalls the Brown Alga Dictyota dichotoma mentioned above (Fig. 8) as an example of a thallus. Blasia milla (Fig. 11) has marginal indentations in its ribbon-shaped body. Lastly, Plagiochila asplenioides (Fig. 12), another Liverwort, has a distinction of stem-like and leaf-like members which is completely analogous to that exhibited by the most highly organised plants.

In addition to the distinetion of stem aurl leaf in their shoots, the Pteridophyta possess true roots, while even the most highly organised Bryophyta have only filamentons structures (rhizoils) (Fig. $11 \mathrm{r}$ ) in place of roots to attach them to the sulsstratum. 'T'rue roots, on the other liand, which appear for 
the first time in the Pteridophyta, are, for the most part, eylindrical structures with apical growth. Besides possessing a distinctive internal construction they are distinguished in their external form from the shoot by having a special sheath, the ROOT-CAP or CALYPTRA covering the growing point, and by the absence of leaves.

The Metamorphosis of the Primary Members of Cormophytes. After the differentiation into shoot and root had taken place, further changes have consisted essentially in a more or less profound modification of these primary members of the cormophytic plant-body. Such changes are spoken of as a metamorphosis (p. 10).

Members of Independent Origin.-Parts which cannot be derived by metamorphosis of the primary members of the cormophytic plant are sometimes met with. Though they are of infrequent occurrence they are of importance as showing that the natural evolutionary process is not to be limited by any formal scheme. Such structures will be discussed farther on.

The relationships between homologons members, which are often very striking, did not escape the notice of earlier observers. They suggested comparisons, although no real pliylogenetic hasis for snch comparisons existed. Thus, an idealistic conception of the form of extemal nembers was developed, and reached its seientific conclusion in the writings of Alexander Braun.

As the great variety exhibited in the external appearance of the lower plants precluded any possibility of assigning to them hypothetical primitive forms, the whole terminology of the external morphology of plants has been derived from conceptions applicable only to the Cormophytes. Even to-day, the same terms used in reference to the Cormophytes are applied to parts of the Thalloplyytes, which are evidently only analogons. On this account in treating here of the nature and aim of general morphology examples will be taken mainly from the Cormophytes.

\section{Relations of Symmetry}

Every section through a part of a plant, made in the direction from base to apex, is distinguished as a longitudinal section; those at right angles to it being termed cross or transverse sections. Parts of plants which may be divided by a number of longitudinal planes into like halves are termed either MULTILATERAL, RADIAL, or ACTINOMORPHic. Such parts are symmetrically constructed around their longitudinal axis. The degree of symmetry peculiar to any leafy shoot will be more apparent from a diagram, that is if the leaves which it bears be projecterl on a plane at right angles to its axis. The radial symmetry of a shoot with opposite leaves in alternating whorls is clearly shown in the adjoining diagram (Fig. 13A). A 
shoot with its leaves arranged alternately in two rows shows somewhat different relations of symmetry. The diagram of such a shoot

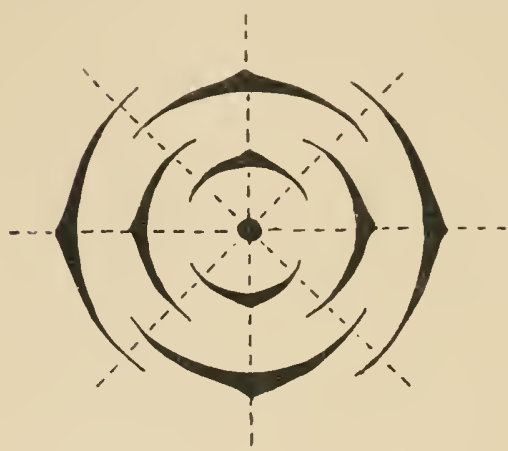

Fic. 13a.-Diagram showing the so-called de. cussate arrangement of leaves.

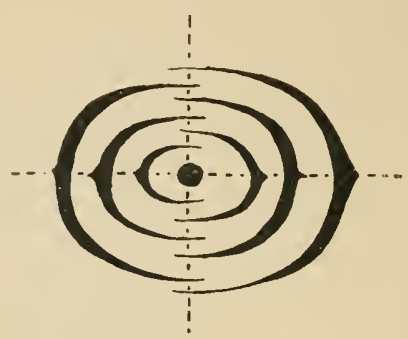

Frt. 13R.-1)iagram showing two-ranked alternate armangement of leaves.

(Fig. 138) can only be divided into similar halves by two planes. When such a condition exists, a member or plant is sairl to be

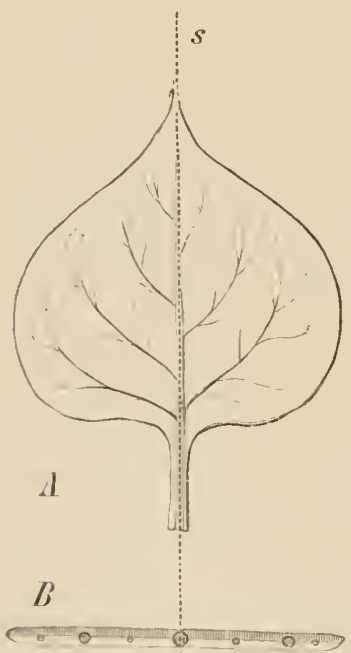

$S$ BILATERAL. When, however, a division into two similar halves is only possible in one plane, the degree of symmetry is indieated by the terms DORSIVENTRAL or ZYGOMORPHIC; since, while the right and left halves correspond to one another, differences exist between the dorsal and ventral surfaces. Ordinary foliage-leaves exhibit this dorsiventral structure. In the accompanying figure (Fig. 14) such a monosymmetrical, dorsiventral foliage-leaf is diagranmatically representerl. From the surface view $(A)$ and from the crosssection $(B)$, in which the distinction between the dorsal and ventral sides is indicated by shading, it is obvions that but one plane of symmetry $(s)$ can be drawn. Dorsiventral members are often ASYMMETRICAL, not being divided by any plane into corresponding halves: the leaves of many kinds of Begonia will serve as

Fu: 14. viagram of a folinge-leaf. 1. Surface view; $D$, trausverse sertion; s, jlane of symmetry. cxamples of this. In such eases-and the leaf of the Elm may be mentioned as another striking example-the asymmetry of the individual leaf is subordinaterl to the symmetry of the entire plant. 


\section{Branch Systems}

Thallophytes as well as Cormophytes exhibit systems of branching, resulting either from the formation of new growing points by the bifurcation of a previously existing growing point, or from the development of new growing points in addition to those already present. In this way there arise two systems of branching, the DICHOTOMOUs and the HONOPODIAL. By the uniform development of at continuously bifurcating stem, a typical dichotomous system of branching is
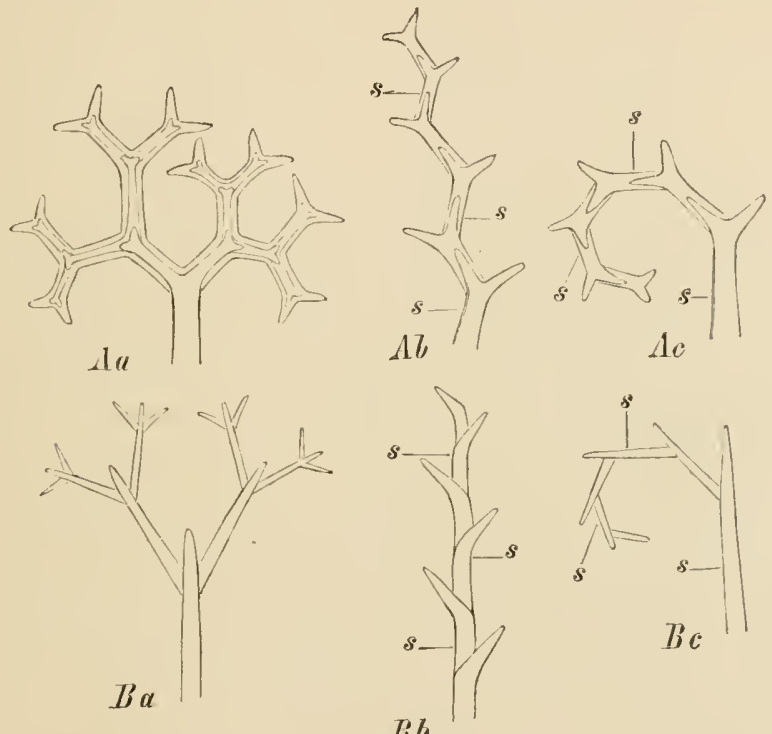

Fit. 15.-Diagiams of branch systems. A, Dichotomous branching; At, equal dichotomy ; $A b$, scorpioid dichotony ; $A c$, helicoid dichotomy. $B$, monoporlial branching; $B$ e, false dichotomy ; $B b$, scorpioirl cyme ; $B$, helicoid cyme ; $s, s$, sympodia.

produced, such as is shown in Dictyote dichotoma (Fig. 8), and is represented diagrammatically in Fig. $15 \mathrm{Au}$. In a typically developed example of the monopodial system there may always be distingnished a persisting main axis, the MONOPODIUM, giving rise to lateral branches from which, in turn, other lateral branches are developed. Good examples of this form of branching are afforled by many Conifers such as the Cryptomeria represented in Fig. 16. Where one of the two branches is regularly developed at the expense of the other, the dichotomous system assumes an appearance quite different from its typical forn. The more vigorous branches may then, apparently, form a main axis, from which the weaker branches seem to spring, just as if they were lateral branches. This mode of branching (Fig. 
$15 A b)$ is illustrated by the Selaginellas. Such an apparent main axis $(s, s)$ is termed, in accordance with its origin, a sYMPODIUM. On the other hand, in the monopodialsystem two or even several lateral branches may develop more strongly than the main axis, and so simulate truc DICHOTOMY or POLYTONY. Such monopodial forms of branching are referred to as FALSE DICHOTOMY (Fig. $15 \mathrm{Bu}$ ) or FALSE POLYTOMY, as the case may be. A good example of false dichotomy may be seen in the Mistletoe (I iscum album). If, however, a lateral branch so exceeds the main axis in development, pushing the apex of the latter to one side, that it seems ultimately to become a prolongation of the axis itself, a sympodium is again formed (Fig. $15 \mathrm{Bb}$ ). This is what occur's in many of our forest trees, e.g. the Lime and Beech; in both of these trees the terminal buds of each year's growth die, and the prolongation of the stem, in the following spring, is con tinued

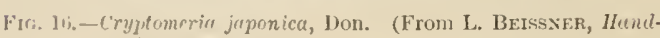
buik iler Niulclholzkunde. Greatly reduced.)

by a strong lateral bud, so that in a short time its sympodial origin is $n 0$ longer recognisal,le. In many rhizomes, on the other hand, the sympodial nature of the axis can be easily distinguished; as, for example, in the rhizome of Polygnnatum multiflorum (Fig. 23), in which, every year, the terminal bud gives rise to an acrial shoot, 
while an axillary bud provides for the continuance of the axis of the rhizome. In the flower-producing shoots or infloreseences of Phanerogams the different systems of branching assume very numerons forms. These will be more fully described in their proper place.

\section{The Shoot}

The Development of the Shoot.-Under the term shoot a stem and its leaves are collectively inelucled. A stem possesses an apical mode of growth (Fig. 17), and its unprotected growing point is described as naked, in contrast to that of the root with its sheathing root-cap. The apex of the shoot generally terminates in a conical protuberance, called the VEGETATIVE CONE. As it is usually too small to be clearly visible to the unaided eye, it is best seen in magnified median longitudinal sections. Su long as the apex of the shoot is still internally undifferentiated, it continues in the embryonic condition, and it is from the still embryonal vegetative cone that the leaves take their origin. They first appear in acropetal suecession as small, conical protuberances, and attain a larger size the farther removed they are from the apex of the stem. As the leaves usually grow more rapidly than the stem which produces them, they envelop the

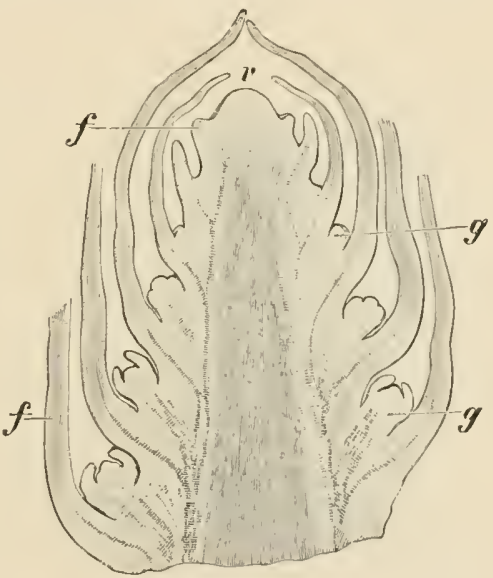

Fig. 17.-A Apex of a shoot of a phanerogamic plant. $v$, Vegetative cone; $f$, leaf rudiment; $g$, rudiment of an axillary bud. ( $x$ 40.) more rudimentary leaves, and, overarching the regetative cone, form a BUD. Buds are therefore merely undeveloped shoots. If they are to remain for a long time undeveloped, as for example is the case with winter buds, they are protected in a special manner during their period of rest.

The Origin of New Shoots.-The formation of new growing points by the bifurcation of an older growing point, in a manner similar to that already described for Dictyota dichotoma (Fig. 8), occurs also in the lower thalloid Hepaticae (liceia fluiturs, Fig. 10). Among the cormoplytes this method of producing new shoots is of less frequent occurrence, and is then mainly limited to the Pteridophytes, and is typically shown only in some Lycopodiaceae. In this ease, whenever a shoot is in process of bifurcation, two new vegetative cones are formed by the division of the growing point (Fig. 18). In most of the Lycopodiaceate the new shoots thus formed develop 
unequally; the weaker becomes pushed to one side and ultimately ippears as a lateral branch (Fig. 19). Although a relationship as regards position is generally apparent between the origin of leaves and the lateral shoots, in the system of branching resulting from such a hifurcation of the vegetative cone this comection does not exist. In the more highly developed Bryophytes, particularly in the true Mosses, new shoots arise obliquely below the still rudimentary leaves at some distance from the growing point. In the Phanerogams new shoots generally arise in the axils of the leaves. In the accompanying illustration of a longitudinal section of a phanerogamic shoot (Fig. 17) the rudiment of a shoot $(g)$ is just appearing in the axil of the third uppermost leaf; in the axils of the next older

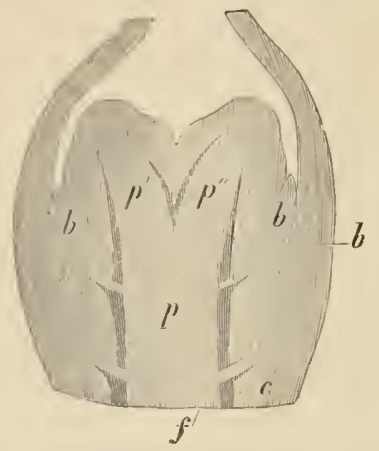

Fic, 15.-Longitulinal section of a bifurcat. ing shoot $(p)$ of Lycopodium alpinum, showing equal development of the rudimentary slioots, $p^{\prime}, p^{\prime \prime} ; b$, leaf rudiments ; $c$, cortex ; $f$, vascular strands. (After Hegeliaier, $\times 60$.) leaves the conical protuberances of the embryonic leaves are already beginning to appear on the still rudimentary sloot of the bud. Shoots thus produced in the axils of leaves are termed AXILLARY sHoots. The leaf, in the axil of which a shoot develops, is called

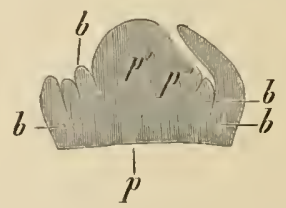

Fif. 19.-Bifurcating shoot $(p)$ of Lyconodium inundatum, showing urequal development of the rudimentary shoots, $p^{\prime}, p^{\prime \prime} ; b$, leaf rudiments. (After HEGELMAiER, $\times 40$.)

its SUBTENDING LEAF. An axillary shoot is usually situated in a line with the middle of its subtending leaf, although it sometimes becomes pushed to one side. As a rule, only one shoot develops in the axil of a leaf, yet there are instances where it is followed loy additional or ACCESSORY SHOOTS, which either stand over one another (serial buds), as in Lonicere, Gleditschia, Gymnocladus, or side by sirle (collateral buds), as in many Liliaceae, e.g. species of Allium and Muscuri.

Although in the vegetative regions, i.e. the regions in which merely regetative organs are produced, the rudiments of the new shoots of phanerogamic plants make their appearance much later thitn those of the leaves, in the generative or flower-producing regions the formation of the shoots follows directly upon that of their subtending leaves, or the shoots may even precede the leaves. In this last case the subtending leaves are usually either poorly developed or completely suppressed, as in the inflorescence of the Cruciferae. 
The bud forming the growing end of a sloot is called the terminal bud, while those borne on the sides of the shoot are the lateral buds.

Shoots developing in predetermined positions on young parts of the plant are designated NORMAL, in contrast to ADVENTITIOUS sHoots, which are prodneed irregularly from the old or young portions of a plant. Such adventitious shoots frequently spring from old stems, also from the roots of herbaceons plants (Brussica oleracea, Anemone sylvestris, Coniolvulus arvensis, Rumex Acetosella), or of bushes (liubus, Rosa, Corylus), or of trees (Populus, Ulmus, Roliniu). They may even develop from leaves, as in Curdumine pratensis, Nesturtium officinale, and a number of Ferns. An injury to a plant will frequently induce the formation of adventitious shoots, and they frequently arise from the cut surface of stumps of trees. Gardeners often make use of pieces of stems, rhizomes, or even leaves as cuttings from which to produce new plants.

Leaves and also normal shoots, which make their appearance as outgrowths from the portions of the parent shoot, still in an embryonie condition, have an external or Exogenous origin. Adventitious shoots, on the other hand, which arise from the older parts of stems or roots, are almost always ENDOCENOUs. They must penetrate the onter portions of their parent shoot before becoming visible. Adventitious shoots formed on leaves, however, arise, like normal shoots, exogenously.

Buds are formed in the marginal indentations of the fleslyy leaves of species of Bryophyllum (Crassulaceae). Although arising from the leaf these buds must properly be regarded as "normal," and as forming part of the normal ontogeny of the plant, since they arise in pre-determined positions from young tissue. In the strict sense of the term only those buds ean be called adventitious which are produced in casual positions lrom tissues which in their production enter into renewed activity, e.g. the buds which arise at the base of isolated leaves of Beyonia when these are laid on damp soil. The concept of "normal buds" is notwithstanding usually taken in a narrower sense and linited to buds which arise on the axis of the shoot in the normal course of development. Examples, however, occur which make it diflicult to draw a sharp distinction in this latter sense between normal and adventitious shoot formation ( ${ }^{11}$ ).

While, as a rule, new leaves arise beneath the apex of a stem, which continues to grow, exceptions to this oecur, especially in floral structures; the apical cone may be used up in the formation of a terminal leaf-rudiment. In this way some of the stamens and carlels of Phanerogams, which are rescribed as terminal, arise.

It was mentioned above that normal shoots arose from the embryonic tissue of the growing point of the parent shoot. When they are apparent at a greater distance from the apex (Fig. 17) it can usually be shown that embryonie substance has been reserved at the proper points for their formation. The growing points of adventitious shoots are for the most part derived from embryonic tissues which have persisted in the older portions of the plant and are capable of increase. They can, however, also arise from older tissues, uwing to the capability of the latter to return to the embryonic eondition and produce new growing points. 
Further Development of the Shoot. The processes of development, which result in the production of new members at the apex of a shoot, are followed by their increase in size and further growth. This growth is usually introduced by the vigorous elongation of the segments, which is spoken of as growth in length, while at the same time the bucls expand. The zone of most rapid growth in length is at some distance from the growing point. The growth in length and consequent elongation of the shoot is in some cases so slight that the leares remain close together, and leave no free spaces on the stem, thus forming so-called sHorT sHoots. The same plant may bear ordinary elongated shoots and short shoots. The diuration of life of the latter is usually shorter, and they fre-

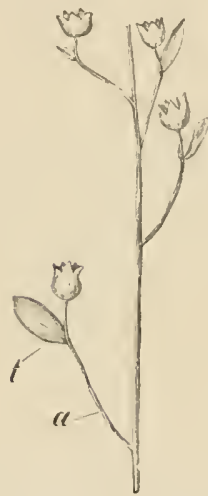

Fu: 20.-Samolus talerandi, each axillary shoot ( 1 ) bearing its subtunding leaf $(t)$, and terminating in a fruit. (Nat. size.) quently do not branch, and take no part in the permanent branch system of the tree. This is seen in the Larch, in which the short shoots with crowded needle-shaped leaves are borne on elongated shoots.

The stem of a shoot, as contrasted with the leaves, is often spoken of as the Axis; the portions of the stem axis between the insertions of the leaves are termed the INTERNODEs, and the parts of the axis from which the leaves arise, the NoDEs. When the base of the leaf encircles the stem, or when several leaves take their origin at the same node, the nodes often become strongly marked (Labiatae).

In some cases the growth in length of a shoot continues for a longer time at certain intermediate points by means of INTERCALARY GRowTH. Such regious of intercalary growtl are generally situated at the base of the internodes, as in the case of the Grasses. A displacement from the position origiually occupied by the members of a shoot frequently results from interealary growth. A bud may thus, for example, hecome pushed out of the axil of its subtending leaf, and so apparently have its origin higher on the stem; or a subtending leaf in the course of its growth may carry its axillary bud along with it, so that the short which afterwards develops seems to spring directly from its subtending leaf; or, finally, the subtending leaf may become attached to its axillary shoot, and growing ont with it, may thus appear to spring from it (Fig. 20).

In the inmual growth in length of a shoot of a tree, i.c. the increment formed luring one regetative period, the lowest interuodes which intervene between the lunt-scales are very short. By means of the closely erowded sears of the bud-scales the limits of the shoots former in sucessive years can be determined.

Resting Buds.- As a neans of protection against loss of water 
in our latitudes, the buds of shrubs and trees are usually invested, in winter, with scale-like leaves or BUD-SCALEs (Fig. 21). These are rendered still more effective as protective structures by hairy outgrowths and excretions of resin and gum, and also by the occurrence of spaces filled witl air between the scales. Not infrequently the subtending leaf takes part in the protection of its axillary bud, the base of the leaf-stalk, after the leaf itself has fallen, remaining on the shoot as a cap-like covering for the winter bud. The buds of tropical plants, which have to withstand a clry period, are similarly protected; but where the rainfall is evenly distributed throughout the year buds develop no such means of protection.

In many decidnous trees, such as the Willow, the terminal buds of the year's growth regularly die. In nearly all trees many buds, usually the first-formed buds of each year's shoot, seem able to remain dormant during many years without losing their vitality : these are termed nopmant buns. In the case of the Oak or Beech such latent buds can endure for hundreds of years; in the meantime, by the elongation of their con-

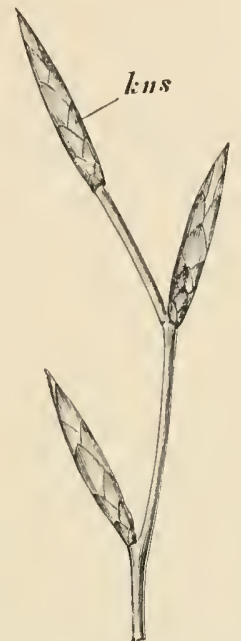

Fra. 21.-Winter buds of the Beech (Fugus silvatica). kns, Bud-scales. (Nat. size.)

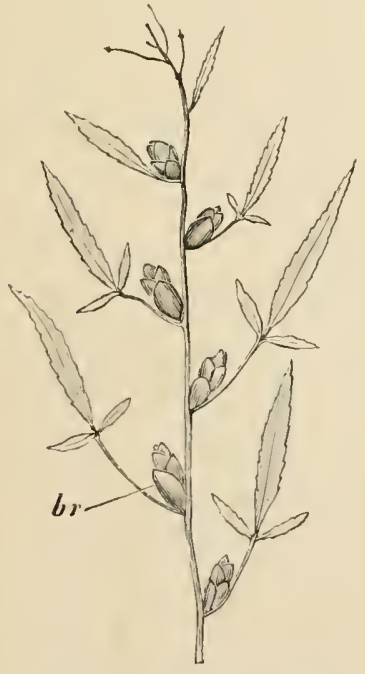

F1G. 22.-Shoot of Dentaria bulbifera, vearing bulbils, $b r$. (Nat. size.) nection with the stem, they continue on its surface. Often it is these, rather than adventitious buds, which give rise to the new growths formed on older parts of stems. It may sometimes happen that the latent buds lose their connection with the woody parts of their parent stem, but nevertheless grow in thickness, and develop their own wood; they then form remarkable spherical growths within the bark, which may attain the size of a hen's egg and can be easily separated from the surrounding bark. Such globular shoots are frequently found in Beech and Olive trees.

The Metamorphosis of the Bud.-The BULBILS and GEMMAE, which become separated from the parent plant and serve as a means of reproduction, are special forms of modified buds. To facilitate the storage of reserve nutritive substances they have usually the form of small tuberous bodies. Many plants owe their specific name to the fact that they produce such bulbils, as, for example, Lilium bulbiferum and Dentaria bullifere (Fig. 22). Bulbils are also produced in the inflorescences of Allium and Gagen. 
The Metamorphosis of Subterranean Shoots.-Shoots that live underground undergo characteristic modifications, and are then termed

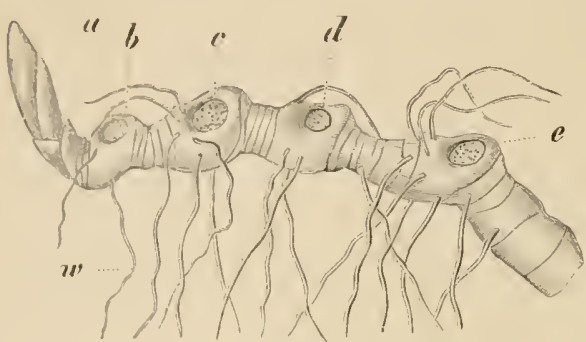

FıG. 23.-Rhizone of Polygonatum multiflorum. $\quad$, , Bud of next year's aerial slloot; $b$, scal of this sear's, and $c, d$, $\epsilon$, scars of three preceding years' aerial shoots; $w$, roots. (3 nat. size.) ROOT-STOCKS Or RHIZOMES. By means of such subterranean shoots many herbaceous perennial plants are enabled to persist through the winter. A rhizome develops only reduced leaves in the form of larger or smaller, sometimes scarely visible, scales. By the presence of such seale leaves, with their axillary buds, and by the absence of a root-cap, as well as by its internal structure, a rhizome may be distinguished from a root. Rhizomes usually produce numerons roots; but in a few cases these are wanting and the rhizome itself performs the functions of a root. Rlizomes often attain a considerable thickness and store up nutritive material for the formation of aerial shoots. In Fig. 23 is shown the rootstock of Solomon's Seal (Polygonatum multiflomum) which has been already referred to as an example of a sympodium. At $c, d$, and $e$ are seen the scars of the aerial shoots of the three preceding years; and at $b$ may be seen the base of the stem growing at the time the rhizome was taken from the ground, while at $a$ is shown the bud of the next year's aerial growth. The rhizome of Corallorkiza innutu, a sapropliytic Orchid, which grows in soil rich in humus, affords a good example of a rhizome performing the functions of a root (Fig. 24). BulBs, also, belong to the class of subterranean metamorphosed shoots. They represent a shortened shoot with a flattened, discoid stem (Fig. 25zk), the fleshy thiekened scale leaves ( $: s)$ of which are filled with reserve food material. The aerial shoot of a bulb derelops from its axis, while new bulbs

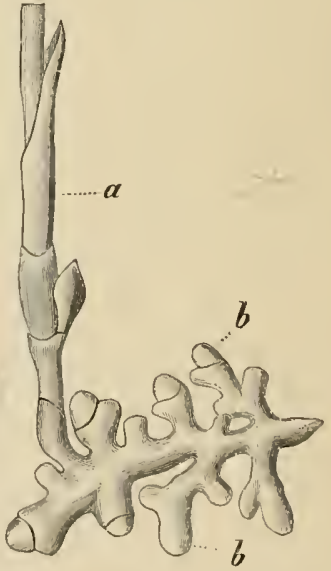

FIc. 24.-Rhizome of Corallorhiza innate. a, Floral shoot; $b$, rulinents of new rlizome branches. (After Snacur, nat. size.) are formed from buds $(k)$ in the axils of the scale leaves. Another form of underground shoot, allied to bulbs and comnected with them by transitional forms, is distinguished as a TUBER. The axis of a typical tuber, in contrast to that of a bulb, is fleshy and swollen, 
serving as a reservoir of reserve material, while the leaves are thin and scaly. Of such tubers those of the Meadow Saffiron (Colchicum autumnule) or of Crocus sativus are good examples. In the Meadow Saffron new tubers arise from axillary buds near the base of the modified shoot, but in the Crocus from buds near the apex. In eonsequence of this, in the one case the new tuber's appear to grow out of the side, and in the other to spring from the top of the old tubers. The tubers of the Potato (Fig. 26) or of the Jerusalem

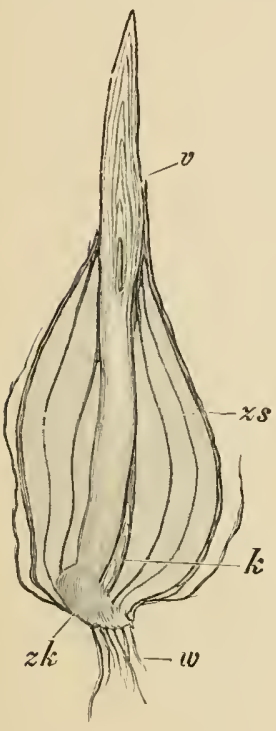

FıG. 25. - Longitudinal section of T'ulip bulb, Tulipa Gesneriana. zk, Modifiel stem; $z s$, scale leaves ; $v$, terminal bud; $k$, rudinent of a young bulb; $w$, roots. (Nat. size.)

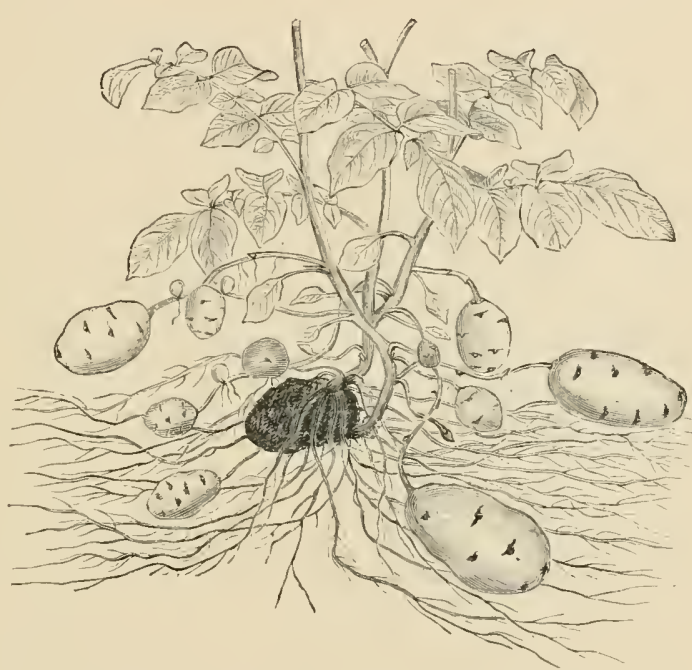

Fir: 26.-Part of a growing Potato plant, Solanum tuberosum. The whole plant lias been developed from the dark-coloured tuber in the centre. (From nature, copier from one of 13All.Los's illustrations, $\frac{1}{3}$ nat. size.)

Artichoke (Heliunthus tuberosus) are also subterranean shoots with swollen and reduced leaves. They are formed from the ends of branched, underground shoots or rumners (STOLONS) and thus develop at a little distance from the parent plant. The so-called eyes on the outside of a potato, from which the next year's growth arises, are in reality axillary buds, but the scales which represent their subtending leaves ean only be distinguished on very young tubers. The parent plant dies after the formation of the tubers, and the reserve food stored in the tubers nomrishes the shoots which afterwards develop from the eyes. Since, in their meultivated state, the tubers of the 
Potato plant remain in the ground and give rise to a large number of new plants, it is of great advantage to the new generation that the tubers are produced at the ends of runners, and are thus separated from one another.

The Metamorphosis of Aerial Shoots.--Similar advantages to those obtained by the elongation of the underground shoots in the Potato accrue from surface runners, such as are produced on Strawberry plants. Surface runners also bear scale-like leaves with axillary buds, while roots are developed from the nodes. The new plantlets, which arise from the axillary buds, ultimately form independent plants by the death of the intervening portions of the runners.

The rumer of Fragaria collina is a monopodium, a single elongated shoot, from the axillary buds of which the new plants arise. In other species of Strawberry the rumner is a sympodium, the elorgated shoot terminating in a rosette of foliage leaves and the rumer being continued by the axillary bud of the lowest of the leaves of the rosette $\left({ }^{12}\right)$.

A striking modification is exhibited by shoots which only develop reduced leaves, while the stems become flat and leaf-like and assume the functions of leaves. Such leaf-like shoots are called CLADODLS or PHYLLOCLADEs, and Goebel proposes to distinguish those flattened shoots which have limited growth and specially leaf-like appearance as phylloclades, and to term other flattened axes cladodes. Instructive examples of sucl formations are furnished by Ruscus aculeclus (Fig. 27), a small shrub whose stems bear in the axils of their scalelike leaves $(f)$ broad, sharp-pointed cladodes $(c l)$ which have altogether the appearance of leaves. The flowers arise from the upper surface of these cladodes, in the axils of scale leaves. In like manner the stems of the Opuntias (Fig. 28) are considerably flattened, while the leaves are reduced to small thorny protuberances. In this case the juicy flat shoots perform not only the functions of assimilatory organs, but also serve as water-reservoirs in time of drought.

On the other land, a plant may lose its leaves more or less completely without any marked flattening or thickening occurring in the stems, which then take on a green colour; this, for example, is the case in the Broom (Spurtium scoparium) which develops only a few quickly falling leaves on its long, naked twigs. As a rule, however, leaftess green Phanerogams will be found to have swollen stems, as in the variously shaped species of Euphortia and Cuctus.

Reduction of the Shoot in Parasites. - A great reduction in the leaves, and also in the stems, often occurs in phanerogamic parasites, in consequence of their parasitic mode of life. The leaves of the Dodder (Cusculu, Fig. 196 b) are only represented by very small yellowish scales, and the stem is similarly yellow instead of green. The green colour would, in fact, be superfluous, as the Dodder does not produce its own nourishment, but derives it from its host plant. 
Cuscutu Trifolii, one of the most frequent of these parasites, is often the cause of the large yellow areas frequently seen in the midst of clover fields. In certain tropical parasites belonging to the family Rafflesiaceae, the process of reduction has advanced so far that the flowers alone are left to represent the whole plant. Liufflesiu Amolcti, a plant growing in Sumatra, is a remarkable example of this; its flowers, although they are a metre wide, the largest flowers in existence, are situated directly on the roots of the species of Cissus upon which the plant is parasitic.

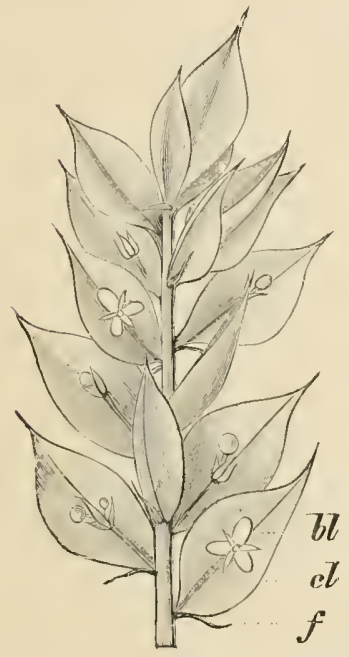

FIt. 27.-Twig of Ruscus aculculus. $f$, leaf ; cl, cladode; $\measuredangle$, tlower. (Nat, size.)

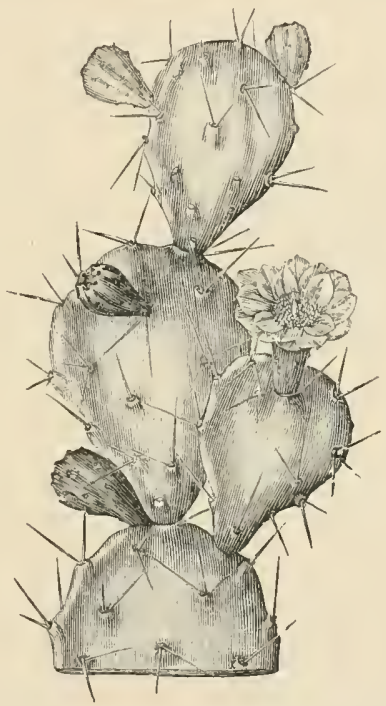

Fr. 2S.-Opuntia monceanthe, Haw., showing flower and fruit. (After Schumaxn, ${ }_{5}^{1}$ nat. size.)

Tendrillar Shoots. - A peculiar form of metamorphosis is exhibited by scme climbing plants through the transformation of certain of their shoots into TENDRILS. Such tendrils assist the parent plant in climbing, either by twining about a support or otherwise holding fast to it. The twining bifurcated tendrils of the Grape-vine, for example, are modified shoots. In some sub-species of the wild vine (Quinaric [Ampelopsis] quinquefolia) and in other species of the genus, e.g. Quinaria Veitchii (Fig. 29), the tendrils are able to form adhesive discs at the tips of the branches, and thus to cling to flat supports.

Stem-thorns.-Shoots may undergo a great reduction by their modification into THORNS, as a defence against the depredations of animals. Of shoots modified in this manner, the Black Thorn (Prumus spinosu), the White Thorn (Crutuegus), and the Honey Locust 
(Glelitschic) afford instructive examples. The thorns are simple or bramehed, hard, pointed bodies. In Gleditschic (Fig. 30) the thorns are developed primarily from the uppermost of several serial buds; while secondary thorns may develop on older portions of the stem from the lower buds of the series, and thus give rise to clusters of thorns. In Colletia cruciate all the shoots are flattened and spiny, so that, in addition to serving as protective structures, they perform the duties of the leares, which are quickly lost. This plant is an

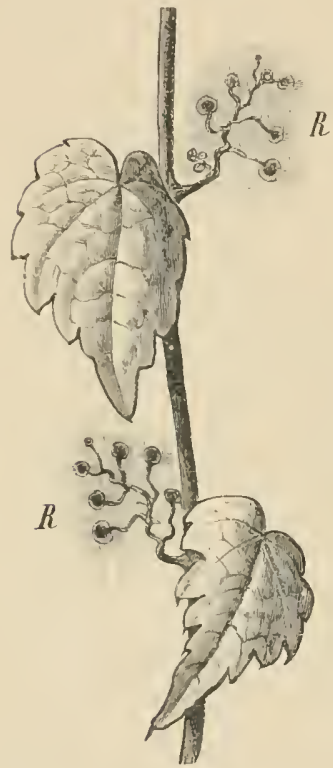

I'u, 29.-Quinaria I'eitehii. $R, R$, Stem-tendrils. (? nat. size.) American shrub belonging to the Rhamnaceae, and grows in dry, sunny situations.

Flowers.-The most marked changes in the form of the shoots, due to the displacement and union of their different members, take place in phanerogamic flowers (Fig. 39). The shoots from which flowers are developed are termed FLORAL SHOOTS, in contrast to the FOLIAGE sHoots, the functions of which are merely regetative. The axis of the floral shoot remains short, and becomes flattened or even depressed at the tip. The leaves which spring from the floral axis often become united with one another and with the axis itself. In such cases thorough investigation of the development and the comparative morphology of the flower is necessary to reveal the modifications which have

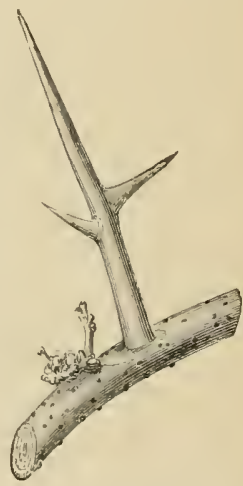

Fit. 30.-Stem.thorn of Gleditschia triacenthos. ( $\frac{1}{2}$ nat. size.)

taken place during its evolution. In most instances the rule seems to hold that axillary buds are not formed within a flower except in cases of abnormal rlevelopment.

The Order of Sequence of Shoots. - If the vegetative cone of the primary axis of a plant, after reaching maturity, is capable of reproduction, a plant with but one axis will result, and the plant is lesignated UNAAXIAL or HAPIOCAULESCENT. Usually, however, it is not until a plant has acquired axes of a second or third order, when it is sail to be InIPLOCAULESCEN' or TRIPLOCAULESCENT, or of the $n$th order, that the capracity for reprorlnetion is attained. A good illustration of a plant with a single axis is afforded by the Poppy, in which the first shoot produced from the embryo terminates in a flower, that is, in that organ of Phanerogams which includes the sexual 
organs. As an example of a triploeanleseent plant may be cited the common Plantain (Plintago major), whose primary axis proctuces only foliage and scale leaves; while the secondary axes give rise solely to bracteal leaves, from the axils of which finally spring the axes of the third order, which terminate in the flowers. In the case of trees, only shoots of the $n$th order can produce flowers. Thus a division of labour commonly occurs in a branched plant, which finds its expression in differences of form between the suceessive shoots. These differ in appearance aceording to the special function performed by them, whether nutrition, storage, or reproduction. In addition to the essential members in the succession of shoots developed in a determined order, there are non-essential members which repeat forms of shoot already present. These may appear simultaneously with the essential shoots, and serve to inerease the size of the plant, as in many annuals; in many perennial plants they arise as yearly innovations on the stock. Adventitious shoots, as a rule, repeat members which have already made their appearance. Exceptionally, they form necessary links in the suecession of shoots; this is the case in the Podostemaceae (an aquatic order of Dicotyledons found in the tropics, the plants belonging to which resemble Lichens or Liverworts in external form), where they bear the flowers.

The Habit or General Aspect of Plants is dependent upon the origin, number, mode of growth, and duration of their branches, and on the presence or absence of non-essential shoots. Cormophytes which develop herbaceous aerial shoots, and persist only so long as is requisite for the development and ripening of their fruit, be it one or several vegetative periods, are called HErBs. Herbaceous plants, however, which, although annually dying down to the ground, renew their existence each year by means of new shoots produced from underground shoots, rhizomes, or roots, are further distinguished as PERENNIALs or perennial herbs. SHRubs or TREes, on the other hand, have woody, persistent shoots, which bear fruit repeatedly. In these the reproductive shoots are shed annually, and, in some, vegetative branehes are also cast off, the remaining ones persisting and inereasing in thickness. In the Lime the ends of the leafy twigs, in the Scotch Fir the short shoots, and in the Oak, Elm, Willow, and Poplar weak lateral branches are thus lost. The leaves of evergreen trees remain alive for several years, while those of deciduous species only persist for a single vegetative period.

Shrubs retain their lateral shoots, so that their branches are formed near the ground ; trees, on the contrary, soon lose their lower lateral branches, and have a main stem or trunk, which bears a erown of branches and twigs. In many trees, shrubs, and herbs the main shoot is vertieal, while the lateral branehes assume a horizontal position, or are directed obliquely mpwards or downwards. In other cases the main axis is sympodial, a lateral branch eontinuing the 
direction of growth of the primary shoot. Sometimes a main axis is indistinguishable among the gronp of similarly directed branches. The general appearance of the plant is determined by the direction and thickness of its branches and leafy twigs. If these are all directed upwards the shape is pyramidal, while broadly pyramidal, oval, and jounded forms arise when the branches diverge more strongly. The "weeping varieties" of several familiar trees are clue to the branches becoming long and pendulous. Herbaceous plants often have stems which creep on the surface of the ground. Other plants, both herbaceous and woody, climb upon various supports by means of hooked hairs, prickles, and modified shoots, by means of roots or tendrils, or by twining movements. Climbing plants are termed LIANES, those which wind round a support being distinguished as TWINING PLANTS. It is the presence of numerous rope-like stems of lianes which renders the tropical forest so impenetrable. On creeping shoots the leaves tend to become displaced towards the dorsal surface of the stem, while branches spring from the sides and roots from the ventral surface.

In catalogues and descriptions of plants the duration of the period of growth is usually expressed by special symbols : thus $\odot$ indicates an annual ; $\odot$ a biennial, and 4 a perennial herb; $h$ is employed to designate both trees and shrubs, and for trees the sign $\hbar$ is also in use.

Development of the Leaf.-The first appearance of the leaf as a lateral protuberance (Fig. $17 \mathrm{f}$ ) on the vegetative cone of the shoot

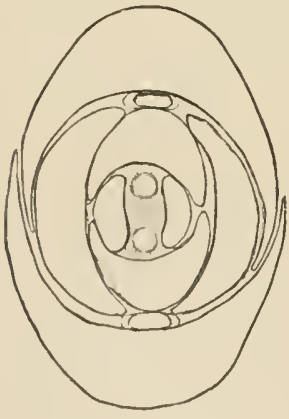

Fici. 31.-A - Alieal view of the vegetative conc of a shoot of Euorymus joyonicus. $(\times 12$. has already been referred to (p. 19). When the apex of a shoot is removed by a transverse section and viewed from above (Fig. 31), the origin of leaves as lateral protuberances is still more evident than in a longitudinal section. The embryonic leaf rudiment generally occupies but a small portion of the periphery of the vegetative cone ; it may, however, completely surround it. In like manner, when the mature leaves are arranged in whorls, the developing protuberances of the rudimentary leaves may form at first a continnons wall-like ring around the growing point and only give rise later to the separate leaf rudiments. Leaves take their origin only from snch parts of a plant as bave remained in an embryonic condition. A leaf never arises directly from the older parts of a plant. In cases where it apparently does so its development has been preceded by the formation of a growing point of a new shoot. The growing point of a shoot has usually an UNLIMTED riRowTI, while the growth of a leaf is LIMITED. A leaf usually continues to grow at its apex for a short time only, 
and then completes its segmentation and developnent by intercalary growth, which is usually localised near the base. It is true that some leares, such as those of Ferns, have apical growth and continne to grow for a long time (in some cases, e.g. Lygodium, the growth is unlimited), and bear their pinnae in acropetal order. On the other hand, the leaf-like cladodes, although they are in reality metamorphosed shoots, exhibit a limited apical growth like that of ordinary leaves.

We have already seen that in certain cases the apical cone may give rise to a terminal leaf. The apex of the leaf in many ferns (e.g. Adiantum Edysuorthii) may, on the other hand, be transformed into a bud from which a shoot will develop.

The unsegmented protuberance of the still rudimentary leaf, termerl by EICHLER $\left({ }^{13}\right)$ the primordial leaf (Fig. $32 A b$ ), first projects from the vegetative cone of the shoot $(A v)$. This is usually followed by a separation of the primordial leaf into the LEAF-BASE ( $g$ in $A$ and $\mathrm{B}$ ) and the rudimentary lamina or UPPER LEAF ( $O$ in $A$ and B). The leaf-base, or the part of the rudimentary leaf which inmediately adjoins the vegetative cone, either takes no further part in the succeeding differentiation of the leaf, or it develops into a LEAF-SHEATH (vagina) $\mathrm{Or}^{\circ}$

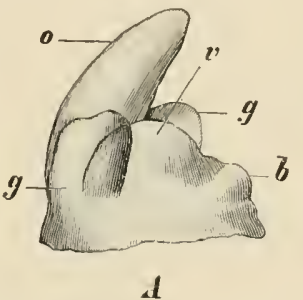

Fic. 32.-Apex of an Elm shoot, Ulmus compestris. A Showing the regetative cone $i$, with the rudiments of a young leaf $b$, still unsegmented, and of the next older leaf, exhibiting segmentation into the laminar rudiment, $O$, and leaf-base, $g ; B$, slowing the older leaf, viewed obliquely from behind. $(\times 58$.

into sTIPULEs. The mpper leaf, on the other hand, gives rise to the leaf-blade or LAMINA. If the fully developed leaf possesses a LEAFSTALK (petiole), this is later interposed by intercalary growth between the leaf-blade and the leaf-base.

The leaf-tip often develops more rapidly than the rest of the leaf, and GokneL regards this as an arrangement for the protection of the younger prarts of the bud $\left.{ }^{14}\right)$. This is seen most strikingly in some tropical plants, especially in climbers. In this ease, according to MI. Racibonski $\left({ }^{15}\right)$, the "fore-runner tips" serve for assimilation before the remainder of the leaf has attained the mature condition.

In leaves the laminae of which do not remain simple, but undergo segmentation as they develop, the lateral segments are as a rule formed in the basipetal direction, i.e. from the tip towards the base (Fig. 33); the opposite dircetion of development is, however, sometimes found. The segments of the palmate and pinnate lcaves of Palms originate by a process of splitting of the leaf-blade which is, to begin with, entire. The direction of the splits is determined by the folds which the lamina assumes when young $\left({ }^{16}\right)$.

Different forms of leaves are most clearly seen in the Phanerogams, in which the various leaf structures found at different regions 
of the shoot have been distinguished as SCALE LEAVES, FOLIAGE LEAVES, BRACTEAL LEAVES, and FLORAL LEAVES (Fig. 34). These usually succeed one another in definite order. However unlike the leaves may beeome, their first origin is similar. Since the scale leaves

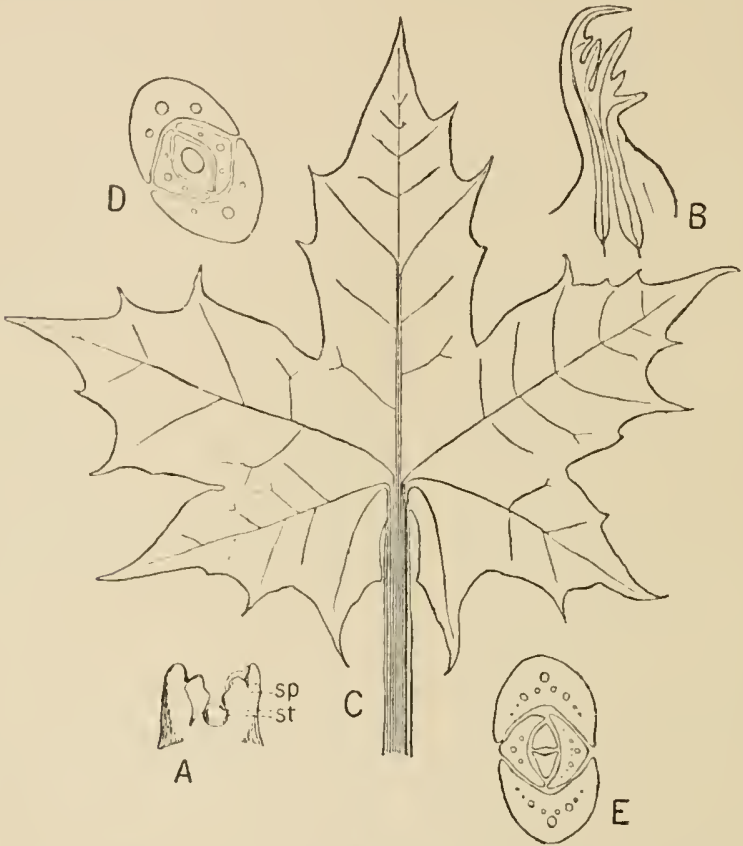

Fı. 33.-Acer platanoides. A, external view of a bud, with two young leaves between which the apical cone of the stem is visible; $s p$, the leaf-blade, in which five segments are indicated, the uppermost one being developerl first; st, the zone, by the growth of whicl the leaf-stalk wlll arise later. $\quad B$, an older leaf seen from the side; the young vascular bundles, which will later determine the venation, are indicated. $C$, fully-grown leaf, with the course of the vascular bundles indicated diagraminatically. $D$, a transverse section of the basal nortion of a bud showing thrce vascular bundles in each leaf. $F$, a similar section at a higher level; the number of vascular bundles has increased by branching. (After Deinega, from GOEBEL'S Orgenography. $A, B$, and $E$, slightly magnified.)

and bracts ean often be shown to be arrested forms of foliage leaves, the latter may le first considered.

Foliage Leaves, generally referred to simply as leaves, are the leaf structures on which devolve the task of providing nourishment for the plant. Since the exercise of this function is dependent upon the presence of the green pigment, folinge leaves have a green colonr. In certain cases, where their for'm is extremely simple, as in the needles of Conifers, the primordial leaf simply increases in length without any further differentiation into parts. In other undivided leaves, howerer, 
whether laneeolate, elliptical, ovate, or otherwise shaped, the flat leafblacle is distinct from the leaf-base, while a leaf-stalk may also be interpolated between them (Figs. 33, $36 \mathrm{~s}$ ). If no leaf-stalk is developed the leaf is said to be stssiLe, otherwise it is describerl as STALKED.

Sessile leaves usually elas] the stem by a broad base. Where, as in the case of the Poppy (Paparer somniferum), the leaf-base surrounds the stem, the leares are described as AMPLEXICAUL; if, as in species of Bupleurum, it completely surrounds the stem, the term PERFOLIATE is used. If the bases of two opposite leaves are united, as in the Honeysuckle (Lonicerce Caprifolium), they are said to be connate. Where the blade of the leaf continues downwards along the stem, as in the winged stems of the common Mullein (Verbascum thapsiforme), the leaves are distinguished as DECUIIEENT. The petiole of a leaf merges cither directly into the leaf-base, or it swells at its lower end into a LEAF-CUSHION or PULVINUS, and is thus articulated with the leafbase. This is the case, for instance, with many of the Leguminosae. The leaf-blade, in turn, may be either sharply marked off from the petiole, or it may be prolonged so that the petiole appears winged, or again it may expand at its junction with the petiole into ear-like lobes. A leaf is said to be Extrie if the margin of the leaf-blade is wholly free from indeutations, or if the latter are very shallow (Fig. $36 s p)$. When the incisions are deeper, but do not extend half-way to the middle of the leaf-blade, a leaf is distinguished as LoBED; when they reach more than halfway, as CLEFT (Fig. $37 s b$ ); if the incisions are still deeper the leaf is said to be PAntite (Fig. $38 l$ ), and if they penetrate to the midrib or

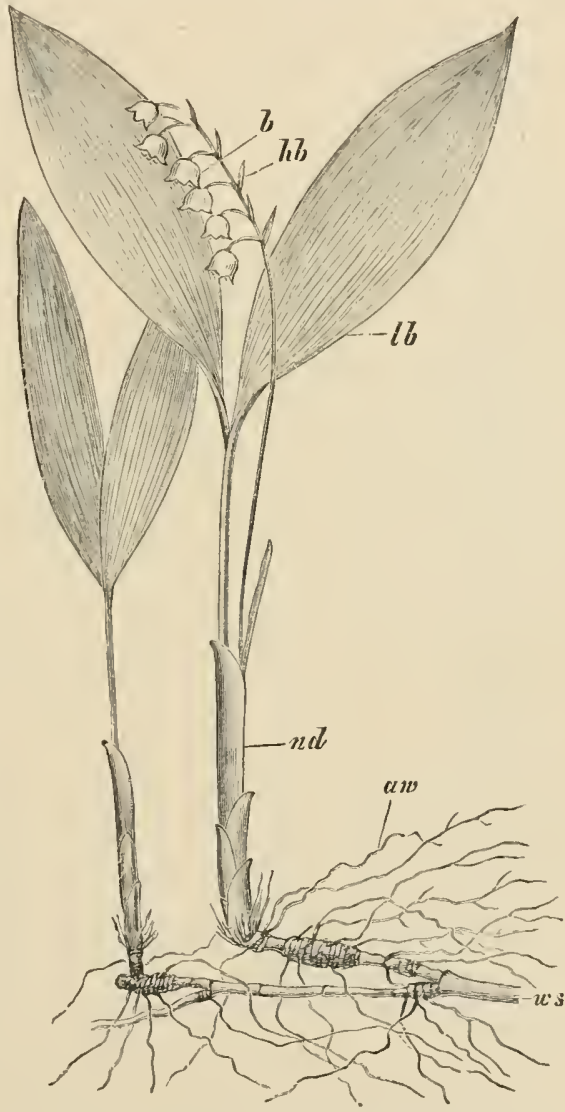

Fig. 34.-Lily of the Valley (Convallaria majalis). nd, Scale leaves; $l b$, foliage leaves; $h b$, bracts ; $b$, flower ; ws, rhizome; $a w$, adventitious roots. (Somewhat reduced.)

DIVIDEI. The divisions of the leaf-blade are said to be PINNATE or PALMATE, according as the incisions run towards the midrib or towards the base of the leaf-blade. Where the divisions of the leaf-blade are distinct and have a separate insertion on 
the common leaf-stalk or on the nidrib, then termed the spINuLE or riracuJs, a leaf is spoken of as compound (Fig. $37 u b)$; in all otler cases it is said to be simpLt. The single, separate divisions of a compound leaf are called leaflets. These leallets, in tmin, nay be entire, or may be divided and undergo the same segmentation as single leaves. In this way doubly and triply componnd leares may be formed. Simply and doubly PINNATE leaves in which the leaflets are attached to the two sides of the rhachis are of common occurrenee. The leaflets are either sessile or stalked; and sometimes also, as in Rotinio and Mimosa, their stalks

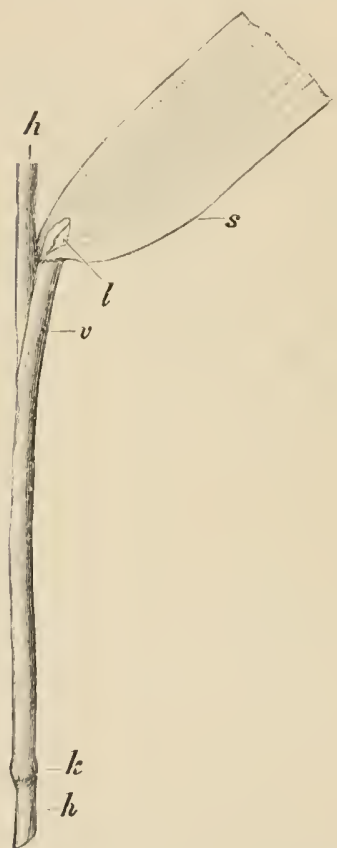

Frr. 35.-Part of stem and leaf of a grass. $h$, llaulm ; $v$, leaf-sheath; $l$, swelling of the leaf-sheath above the node; $s$, part of leaf-l, larte; $l$, ligule. (Nat. size.) articulate with the spindle by means of swollen pulrini. The term PEDATE is applied to leaves in which the segments are further rlivided on one side only, and the new segments are similarly divided (Fig 38 l). Variations in the ontline of leaves, whether they are entire, serrate, dentatc, erenate, incised, etc., as well as

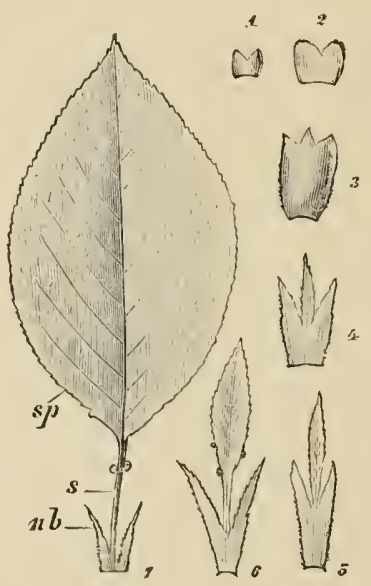

Fir. 36.-Bird Cherry (Prunus Avium). Burscales (1-3) and the transition forms (1-6) to the foliage leaf ( $(1)$; sp, leaf-blade; $s$, leaf-stalk ; $n b$, stipniles. (Reduced slightly.)

peenliarities in their slape and segmentation, are of use in the detcrmination of plants.

A system of strauds known as the VEINS or NERVEs traverses the flat leaf-blade. 'They project more or less from the surface, especially on the lower side where they often form definite rilos. Frenuently the nerve in the median line of the lamina is more strongly dereloped and is then termed the midrib; in other cases several equally developed main nerves are present. Lateral nerves spring from the one or more mailu nerves.

Arencling to their vindTION or NERVATRE leaves are described as PARALLEL 
VEINED or NETTED VEINED. In parallel venation the veins or nerves run either approximately paralleI with each other or in eurves, converging at the base and apex of the leaf (Fig. $35 s$ ); in netted veined leaves (Fig. 190) the veins branelı of' from one another, and gradually deerease in size until they form a fine anastomosing network. In leaves with parallel venation the parallel main nerves are usually united by weaker eross veins. Netted or retieulately veined leaves in which the side veins run from the median main nerve or MIDfIB are further distinguished as PINNATELY VEINED, or as PALMATELY VEINED when several equally strong ribs separate at the base of the leaf-blade, and give rise in turn to a network of weaker veins. Parallel venation is eharaeteristic, in general, of the Monocotyledons; reticulate venation, of Dicotyledons. Monoeotyledons have usually simple leaves, while the leaves of Dicotyledous are often compound, and are also more frequently provided with stalks.

The nerves or veins give to a leaf its necessary meehanieal rigidity and render possible its flattened form. Their distribution is usually sueh as to allow of conduetion taking place by the shortest possible routes throughout the leaf-blade $\left({ }^{17}\right)$. The branches of the veins parallel to the margin of most leaves prevent their tearing; when there are no such marginal nerves in large thin leaves, the lamina is easily torn into strips by the wind and rain. This frequently happens to the leaves of the Banana (Musa), which, eonsequently, when growing under natural conditions in the open air, presents quite a different appearanee from what it does when grown under glass. The leaves of the Banana, after becoming thus divided, otler less resistance to the wind. In a similar manner the leaves of Palms, although undivided in their bud state, beeome torn even during the process of their mufolding. A similar protection from injury is afforded to the Aroid, Nonstera, by the holes with which its large leaf-blades beeome perforated. Equally advantageons results are seeured by many plants whose leaves are, from their very inception, divided or dissected. The pointed extremities (DIIP Trrs) of the foliage leaves of many land plants, aceording to STAHL $\left({ }^{18}\right)$, facilitate the removal of water from the leaf surface. Fleshy so-called snceulent leaves, like fleshy stems, serve as reservoirs for storing water.

In Monocotyledons the leaf-base very often forms a SHEATI about the stem; in Dicotyledons this happens much less frequently. In the case of the Gramineae, the sheath is open on the side of the stem opposite the leaf-blade (Fig. $35 \mathrm{v}$ ), while in the Cyperaceae it is completely closed. The sheath of the Grasses is prolonged at the base of the lamina into a scaly outgrowth, the ligule $(l)$. Such a sheath, while protecting the lower part of the internodes, which remain soft and in a state of growth, gives them at the same time rigidity. STIPULES are lateral appendages sometimes found at the base of leaves. When present they may be either small and inconspicuous (Fig. $36 n b$ ), or may attain a considerable size. When their function is merely to protect the young parts in the bud, they are usually of a brown or yellow colour, and are not persistent; whereas, if destined to become assimilatory organs, and to assist in providing nourishment, they are green, and may assume the structure and form of the leaf-lolade, which sometimes becomes modified and adapted to other purposes (Figs. 48, 49). Normally, the stipules are two in number, that is, one on each 
side of the petiole. In many species of Galium, where the stipales resemble leaf-blades, the leaf-whorls appear to be composed of six members, but consist actually of but two leares with their four stipules, which may he easily distinguished by the absenee of any buds in their axils. In other species of the same genus (Galium cruiutum and palustre) there are only four members in the whorls, as each two arljoining stipules become united. In many cases, as in the

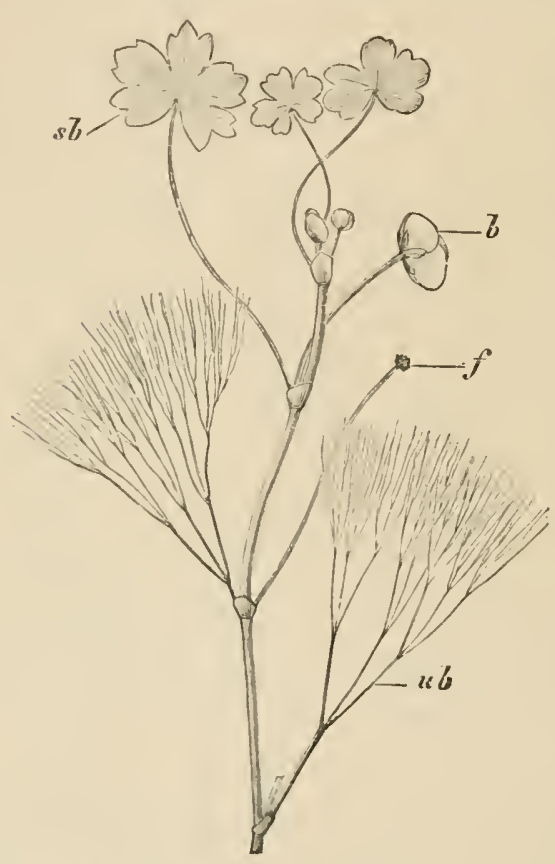

lis. 37.-Drinunculus aruatilis. ub, Submerged leaves ;

$s$, floating leaves; $b$, flower ; $f$, fruit. (Reduced.) Rose and the Clover, the stipules have the form of appendages to the enlarged leafbase. Sometimes both stipules are united into a single one, which then appears to have an axillary origin; or the stipules may completely encircle the stem, and thus form a sheath (OCIIREA) about the younger undeveloped leaves. This sheath-like fusion of the stipules may be easily observed on the Indiarubber tree (Ficus elastica), now so commonly grown as a decorative plant. In this ease the stipular sheath is burst by the unfolding of each new leaf and pushed npwards. In the Polygonaceae the stipular corering is similarly torn apart by the developing leaves, but remains on the stem in the form of a membranous sheath.

Heterophylly.-Some plants are characterised by the development of different forms of foliage leares. Such a condition is known as heterophylly. Thus the earlier leaves of Eucrilyptus globulus are sessile and oval, while those sul)sequently formed are stalked and sickle-shaped. It is common to find that the leaves of the seedling plant have a simple form and are only gratually succeeded by those of more complicated shape. In a similar way Goelsel $\left({ }^{19}\right)$ explains the relation of the ribbon-shaped or finely divided submerged leaves of amphibions plants to the aerial leaves with stalks and entire bliule which follow. 'The former he regards as youth forms, which are retainer in the water, and not as a special adaptation to the surrounding medimm. In Fig. 37 the two types of leaf are shown in the Water Crowfoot (Rununculus uquatilis). A number of 
epiphytic Ferns belonging to the genera Polypodium and Platycerium alternately bear stalked, pinnate leaves serving for assimilation, and broad, sessile, usually cordate NEsT-LEAvEs which serve to collect humus; when, as MANTLE-LEAVEs, they are closely appressed to the substratum they form humus by their rapid decay. The humns thus collected or produced is penetrated by the roots of the Fern $\left({ }^{19}\right)$.

Scale Leaves possess a simpler form than foliage leaves, and are attached direetly to the stem, without a leaf-stalk. They exercise no assimilatory functions, and are more especially of service as organs of protection. Scale leaves exereise their most important function as BUD-SCALES (Fig. 36); they are then hard and thick, and usually of a brown colour. They most frequently take their origin from the enlarged leaf-base; in that case the upper leaf either does not develop, or exists only in a reduced condition

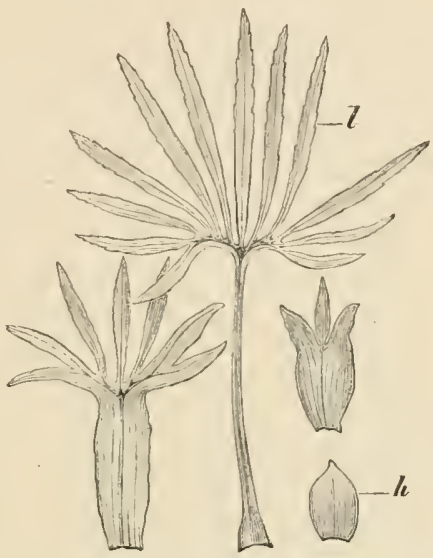

Fug. 38.-Hellehorus foetilus. Foliage leaf $(l)$ and intermediate forms between this and the bract $(h)$. (Reduced.) at the apex of the scale. The true morphological value of seale leaves of this nature is very evident in the bud-scales of the winter buds of the Horse-ehestnut (Aesculus

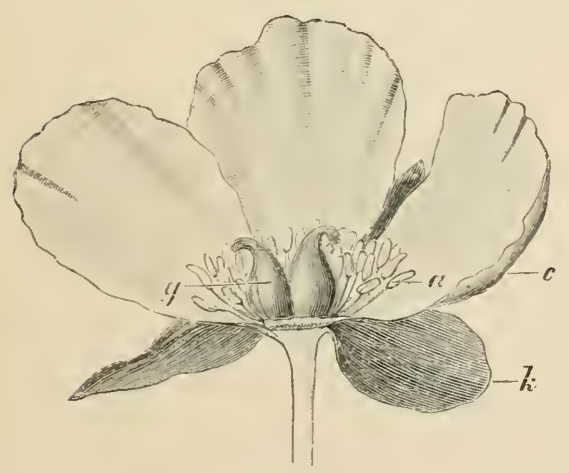

Fis. 39.-Flower of Paconia preregrina. $k$; Sepals ; $c$, petals ; $a$, stamens : $q$, earpels. Some of the sepals, petals, and stamens have been removed to show the pistil, consisting of two separate carpels. (Half nat. sizt.) colourless and in various stages of reduction, are found on rhizomes (Figs. 23, 34), bulbs (Fig. 25), and tubers (Fig. 26). On the aerial the outer seales show no perceptible indications of an upper leaf, small leaf-blades can be distinetly reeognised at the apices of the inner seales. In other eases the seale leaves are modified stipules (Fig. 36), and are then also derived from the leafbase; while, in other instances, they correspond to the enlarged, but still undifferentiated, primordial leaves. The bud-seales of the Oak are the stipules of leares the laminae of which are only represented by minute seales. Scale leaves, usually Hippocastanum); for, while 
stems arising from such subterranean shoots the formation of similar scale leaves generally precedes the development of the foliage leaves, with which they are connected by a series of transitional forms.

Bracteal Leaves resemble scale leaves in form, and have a similar origin (Fig. $3 \frac{4}{4} b$ ). They act as subtending leaves for the floral shoots, and are termed BRACTs. They are connected with foliage leaves by intermediate forms (Fig. 38). Though they are not infrequently green they may be otherwise coloured, or even colourless.

Floral Leaves.-The modified leaves which form the flowers of Phanerogams are termed floral leaves. In the highest development attained by a phanerogamic flower (Fig. 39), the successive floral leaves are distinguished as sepals $(k)$, petals $(c)$, stamens $(a)$, and carpels $(g)$. In form the sepals and petals approach the bracts. In most cases the sepals are green and of a firm structure; the petals, on the other hand, are more delicate and varionsly coloured. In some cases, as in the Christmas Rose (Ilelleborus) and the Monkshood (Aconitum) (Fig. 563), the petals are transformed into tubular nectaries and modified in accordance with this. The stamens are generally filamentous in shape, and produce the pollen in special receptacles. The carpels in Angiosperms by closing together form receptacles within which the ovules are produced. The stamens and carpels of Phanerogams correspond to the spore-bearing leaves of the Vascular Cryptogams. Such sporebearing leaves are termed sporophylus, and even in the Vascular Clyptogams exhibit a greater or less departure from the form of other foliage leaves.

It is evident that the seale and bracteal leaves are to be considered as rudimentary foliage leaves, not only from the mode of their development but also from the possibility of transforming them into foliage leaves. GoEber, by removing the growing tip and foliage leaves of a shoot, sueceeded in foreing it to develop other foliage leaves from its scale leaves $\left({ }^{20}\right)$. Rhizomes, grown in the light, levelop, loliage leaves in place of the usual seale leaves, and even on a potato it is possible to induce the formation of small foliage leaves instead of the eustomary seale leaves.

Leaf Scars.-After a leaf has fallen, its previous point of inscrtion on the stem is marked by the cicatrix or scar left by the fallen leaf. In winter, accordingly, when the trees have shed their leaves, the axillary buds are scen to be situaterl above the leaf-scar's.

Vernation and Aestivation. ${ }^{1}-\mathrm{A}$ section through a winter bud shows a wonderful adaptation of the young leaves to the narrow space in which they are confined. They may be so disposed that the separate leaves are spread ont flat, but more frequently they are folded, rolled (Fig. $40 \mathrm{l}$ ), or crumpled. The manner in which

I [The use of these terms in the following paragraph differs from that customary in Engliud. By vernatios is mulerstoon the arrangenent of the leaves in a regetative lmi as a whole. 'The folding of eaeh individual leat in the lud is termed pTxxis. The t.rII AESTIVATION is applied to the arrangement of the parts in a fower-bul.--Tizans.] 
each separate leaf is disposed in the lud is termed vernation. On the other hand, the arrangement of the leaves in the bud with respeet to one another is designated AEsTIVATION. In this respeet the leaves are distinguished as FREE when they do not touch, or VALVATE when merely touching, or IMBRICATED, in which case some of the leaves are overlapped by others (Fig. $40 \mathrm{k}$ ). If, as frequently occurs in flower-buds, the margins of the floral leaves suceessively overlap each other in one rlirection, the aestivation is said to be CONTORTED.

The Aprangement of Leaves.-In all ereet elongated shoots, and still more so in dwarf shoots, it is apparent that there is a marked regularity in the arrangement of leaves. This regularity may be

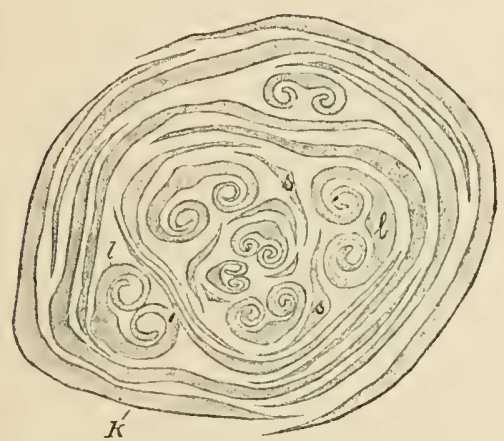

F1: 40.-Transverse section of a bud of lopulus nigru. $k$; Bud-seales showing imbricated aestivation [vernation]; $l$, foliage leaves with involute reruation [ptyxis]; s, each leaf has two stipules. $(\times 15$.

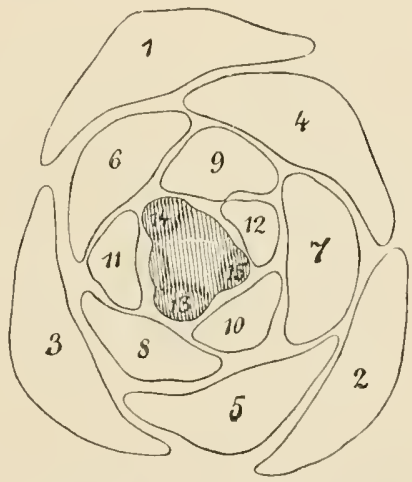

Fif. 41.-Transverse section of a leaf-burl of T'suga eanadensis, just butow the apex of the shoot, showing a $\frac{5}{13}$ divergence. ( $x$ cirea 20 , after Hormeister.)

most easily recognised in eross-sections of buds (Fig. 41), particularly in seetions showing the apex of the vegetative cone (Figs. 31,33E). From such sections it is evident that the developing leaf-rudiments stand in the relative position to the pre-existing leaves which best utilises the available space. Aceording to Schwendener $\left({ }^{21}\right)$ the arrangement of the leaves on the axis is determined by purely mechanical canses; it is dependent on the pressures and tensions indueed by the leaves whieh always stand in eontact at their origin. The original arrangement of the young leaves may be modified as growth continues owing to the mutual pressure they exert. If the axis does not grow in length, but only in thickness, as the rudimentary leaves increase in size, their points of insertion will be displaced laterally by longitudinal pressure; if the axis increases in length, and not in thickness, the insertion of the leaves will be displaced by a transverse pressure. The arrangement of the leaves would also be 
affected when the size of the rudimentary leaves diminishes while that of the vegetative cone remains the same, or when the leaf-rudiments remain of the same size but the circumferenee of the apical cone decreases.

In developing flowers sudden changes in the relative position of the parts often oceur in which the apical cone unclergoes rapid increase in size while the leaf rudiments become smaller. Changes in the usual position of the leaves may also be occasioned by the torsion of their parent stem. Thus the leaves of Pundamus first appear in three straight rows on the vegetative cone, and their subsequent spiral arrangement results from the torsion of the stem. Irregular arrangement of the leaves, such as occurs, for example, on the flower-stalk of the Crown Imperial (Fritillaria imperialis), may result from the unequal size of the leaves at the time of their inception on the regetative cone. Further observation has revealed

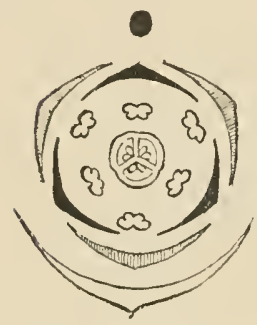

FiG. 42.-Diagram of a I.iliaceous flower. The main axis is indicated by a black dot, oplosite to which is the bract. an incrcasing number of cases in which definite leaf arrangements cannot be explained by the spatial relations, and as the effect of contact and pressure. It can only for the present be assumed that the cause of the leaf-arrangement in these cases lies in the inherited organisation of the plant $\left({ }^{22}\right)$.

A frequent mode of arrangement of foliage leaves is the decussate, in which two-leaved whorls alternate with each other (Figs. $31,33 \mathrm{E})$. A whorled arrangement

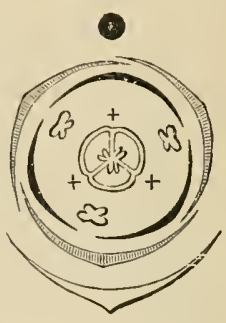

FIG. 43. - Theoretical diagram of the flower of the Tris. The absent whorl of stamens is indicated by crosses.

is characteristic of floral leaves. When the number of leaves in each whorl is the same the whorls nsually alternate. On the other hand, the number of members in the different whorls of floral leaves will often be found to change, especially on passing from the petals to the stamens, or from the latter to the carpels. In many eases a whorl, the existence of which wonld be expecterl from the position of other whorls and from a comparison with allied plants, may be altogether wanting. In this connection a comparison of the flowers of the Liliaceae and Iridaceae will be instrnetive. The flowers of the Liliacene (Fig. 42) are composed of five regnlarly alternating, three-leaved whorls or eycles, viz. a calyx and a corolla (each consisting of three leaves, and, on account of their similar appearance, usually referred to conjointly as the PERIANTH), an outer and an inner whorl of stamens, and finally, in the centre of the flower, an ovary of three carpels. In the flowers of the Iridicene (Fig. 43) the arrangement is exactly similar, except that one whorl, that of the immer cycle of stamens, is lacking, but the three carpels are situated exactly as if the missing whorl of 
stamens were present. From this similarity of arrangement, despite the absence of the one cycle of stamens, the conclusion has been drawn that, at one time, the inner row of stamens was actually present, but has now disappeared. In constructing a TIEORETICAL DIAGRAM of the Iridaceae the missing cycle of stamens is indieated by some special sign (by crosses in Fig. 43); a diagram in which theoretical suppositions are not taken into consideration is called an EMPIRICAL DIAGRAM. Diagrams showing the alternate arrangement of leaves, in eases where only a single leaf arises from each node, may be constructed by projecting the successive nodes of a stem upon a plane by means of a series of

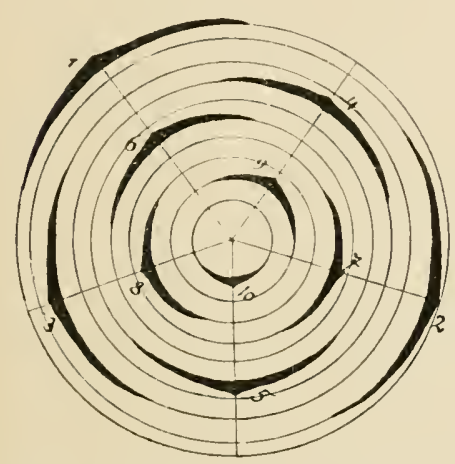

Fig, 44. - Diagram showing $\frac{2}{6}$ position of leaves. The leaves numbered according to their genetic sequence.

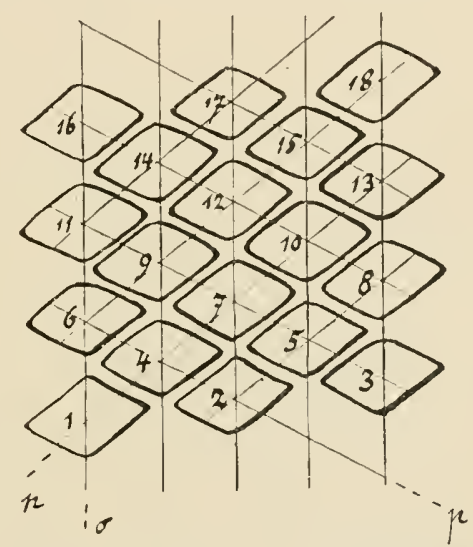

FIG. 45. - The ${ }_{5}^{2}$ position on the outspread surface of the axis. o, Orthostichies: $p$, parastichies. The leaves are numbered according to their genetic sequence.

concentric circles, on which the position of the leaves may be inclicated (Fig. 44). The angle made by the intersection of the median planes of any two successive leaves is called their DIVERGENCE, and is expressed in fractions of the circumference; for example, when the angnlar divergence between two suceessive leaves is $120^{\circ}$, their divergence is expressed by the fraction $\frac{1}{3}$. In the adjoining diagram (Fig. 44) a $\frac{2}{5}$ divergence is shown. Where the lateral distance between two successive leaves is $\frac{2}{5}$ of the circumference of the stem, the sixth leaf is above the first, the seventh above the second, and so on. The leaves form on the axis five vertical rows, which are spoken of as oRthostichies. Where the leaves are very much crowded, a set of spiral rows called parastichies, due to the contact of the nearest laterally adjacent members, lecomes much more noticeable than the orthostichies. If the surface of such an axis be regarded as spread ont horizontally, the parastichies become at once distinguishable (Fig. 45), and it will be evident that the 
sum of the parastichies cut by every cross-section through such an axis must erpual the number of the orthostichies. On objects like Pine cones, in which the parastichies are easily recognised, they may be used to determine the leaf arrangement. The leaves in Fig. 45 have been given the general form of the scales on a Pine cone. If a line be drawn on the surface of a stem, so as to pass in the shortest way successively through the points of insertion of every leaf, a spiral called the GENETIC SPIRAL will be constructed. That portion of the genetic spiral between any two leaves directly over each other on the same orthostichy is termed a cycLE. Where the divergence is $\frac{2}{5}$, a cycle will accordingly include five leaves, and will in such a case have made two turns about the stem. The most common divergences are the following, $\frac{1}{2}, \frac{1}{3}, \frac{2}{5}, \frac{2}{8}, \frac{5}{13}, \frac{8}{2}, \frac{1}{3} \frac{3}{4}$, etc. In this series it will be observed that in each fraction the mumerator and denominator are the sum of those of the two preceding fractions. The value of the different fractions varies accordingly between and $\frac{1}{3}$, while always approaching a divergence angle of $137^{\circ} 30^{\prime} 28^{\prime \prime}$. The great majority of leaf arrangements can be expressed by the terms of this main series of divergences.

This main series was diseovered by Call Schimper and Alexanner Biann. It exhibits a rational relation of the divergences to the cireumference of the axis, so that, as the number of leaves increases, definite leaves are situated aceurately above one another. As WIESNER $\left({ }^{23}\right)$ in particular has made elear, it dillers from all other possible series in attaining the most equal distribution of the leaves on the axis bearing them, while requiring the smallest number of leaves. This results in an advantageons ntilisation of the available sjace, a welldistributed loading of the axis and, when the latter is vertical, in the best utilisation of the illumination. The importanee of these advantages as determining the leaf-arrangement is seen in those eases in which a plant bears only a few $(2-4)$ leaves. These stand in a whorl at equal distances from one another and thus their weight is equally distributed, and they obtain equal amounts of light. When leaves are arranged alternately on a rertical axis, their size and shape, together with the length of the internodes, ensure each ol,taining the reguisite anount of light. This arrangement is not a convenient one, and as the leaves borne on a vertical axis increase in number their divergence becomes progressively higher. It is otherwise in inelined or horizontal axes; here the divergenee is relatively low, usually $\frac{1}{2}$ or an approximation to this, since this corresponds to the most fitvourable exposure of the leaves to the light. In most instanees this alvantageous result is attained by twisting of the internodes; thus when, is is often the casc, the leaves are decnssate on an erect axis, they form four vertieal rows; but when it is inclined they are bronght by twisting to stand in two rows. Similar secondary ehanges ex posing the leaf-blades to the light aflect alternately antuged leaves. The position of the foliage leaves is indeed always elearly alapited to the neerl of illumination. When the leaves form a rosette, the stalks of those lowest on the stem are frequently elongated, so that their blades are not sharderl hy the more eentral leaves. This is especially well seen in the floating rusettes of Trape nutans.

While the arrangenent of the foliage leaves conforms on the whole to the main 
series of divergenees, this is not usually suitable in the ease of the foliar structures of flowers and inflorescences, which have different purposes to serve. Other relations of prosition also occur in the vegetative region, as las been shown by GoEbEL $\left({ }^{24}\right)$, in particular in the case of dorsiventral shoots. The tijs of dorsiventral shoots are frequently coiled ventrally inwards, bearing their leaves either dorsally or on the sides, but, in the latter ease, approaching the dorsal surface. The creeping stems of many Ferns or the flower-bearing shoots of Forget-me-not (Myosotis) are good examples of such dorsiventral shoots. The line joining successive leaves in such eases is, at the best, but a zigzag. On the ground of sucl observations as these it may be concluded that the actual leafarrangenents represent adaptations to definite conditions of life, and that with alterations in the latter other arrangements must arise.

The longitudinal distance between the leaves of a shoot, i.e. the length of the successive internodes, also follows a definite rule. According to Percy Groom $\left({ }^{25}\right)$ the lengthis of the internodes of the main axis of a cormophytic plant most commonly increase at first and then diminish. The lower the lateral shoots stand on the main axis the more elosely do they correspond with it in this respeet. In lateral shoots inserted higher the region in which the length of the internorles is increasing tends to diminish and nltimately the shoots may exhibit only a succession of internodes diminishing in length.

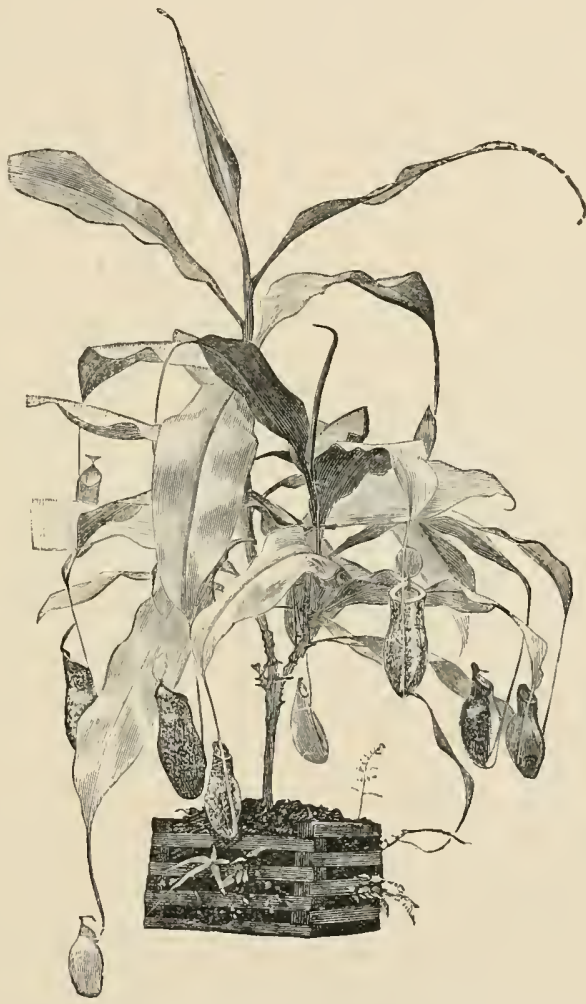

FIc. 40.-Nepenthes robustu. (1 nat, size.)

The Metamorphosis of Foliage Leaves. - The leaves of succulent plants, in which the leaf-blade is more or less fleshy and thickenerl, deviate from the typical form of a foliage leaf. Another striking modification of foliage leaves is seen in peltate leaves, in which the petioles are attached to the lower surfaces somewhat within the margin, as in the leaves of the Indian Cress (Tropacolum majus, Fig. 187). In the process of their development the young leaf-blades, in this case, grow not only in the same direction as the petioles, as a prolongation of them, but also horizontally in front of them. The tubular leaves 
of many insectivorons plants may have commenced their development in much the same way. The leaves of Nepenthes robusta (Fig. 46), for example, in the course of adaptation to the performance of their special function, have acquired the form of a pitcher with a lid which is closed in young leaves, but eventually opens. The piteher, as Gokbel has shown, arises as a modification of the leaf-blade. At the same time the leaf-base becomes expanded into a leaf-like body, while the petiole between the two parts sometimes fulfils the office of a tendril. By a similar metamorphosis of its leaflets, bladder-like cavities are developed on the submerged leaves of Utricularia (Fig. 47).

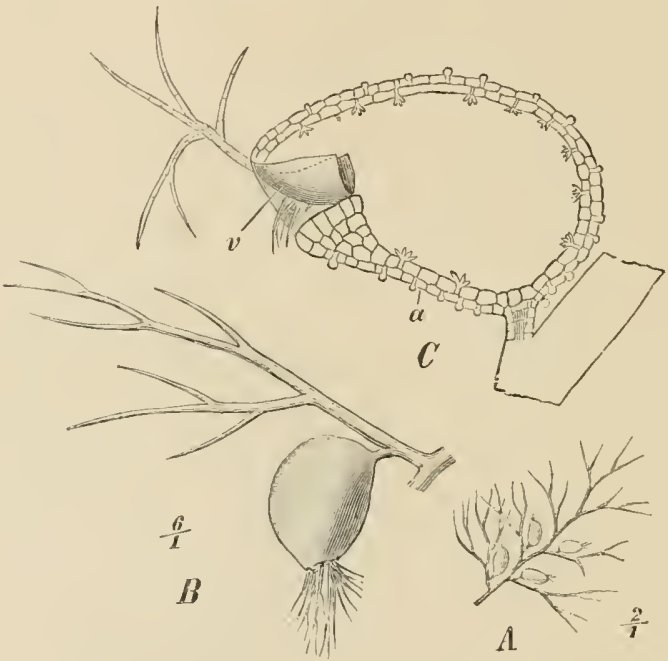

F'เ. 47.-Utricularia zulgaris. A, Part of leaf with several bladders $(\times 2)$. $\quad B$, Single pinnule of leaf with blarkler $(\times 6), C$ (after GOEBEL), Longitudinal section of a liadrler $(\times 2 s) ; r^{*}$, valve; $a$, wall of bladiler.

The entrance to each bladder is fitted with a small valve which permits the ingress but not the egress of small water-animals. While such leaves display a progressive metamorphosis the modification may be of the nature of a reduction, as is the case in many Ferns, which form leafrunners. Like the modified shoots of the same name these are elongated and enable the buxl prodnced at the end to develop at a distance from the parent plant. On this account Cumptosorus rhizopluyllus, an American Fern, is commonly known as the Walking Fern. Such leaf-rumners usually lose their pinnae and are reduced to the leaf stalk. A particularly striking appearance is presented in those cases in which. the first leaf of the bud in its turn forms a leaf-runner, so that a sympodiun of rimners results (Asplenium obtusifolimm, A. Munnii).

$\Lambda$ metamorphosis of the whole leaf lamina, or a part of it, into 
tendrils (LEAF-TENDRILS) is of comparatively frequent occurrence, especially among the Papilionaceate. In the leaf of the Pea (Fig. 48), the leaflets of the upper pairs have become transformed into delicate tendrils which have the power of twining about a support. In the case of the yellow Vetchling, Luthyrus Apluaca (Fig. 49), the whole leaf is redueed to a tendril and the function of the leaf-blade is assumed by the stipules $(n)$. A comparison of these two forms is phylogenetically instructive, as it indicates the steps of the gradually modifying processes which have resulted in the complete reduction of the leaf lamina of Lathyrus. The eomparison of the two preceding cases with Ampelopsis (Fig. 29) will make the distinction between

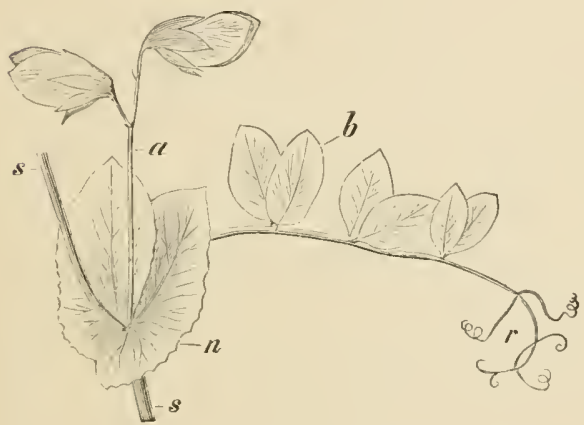

Fig. 4s.-Portion of stem and leaf of the common Pea, Pisum satiur. , Stem; $n$, stipules; $b$, leaflets of the compound leaf ; $r$, leaflets modified as tendrils ; $"$, floral shont. ( $\frac{1}{2}$ nat. size.)

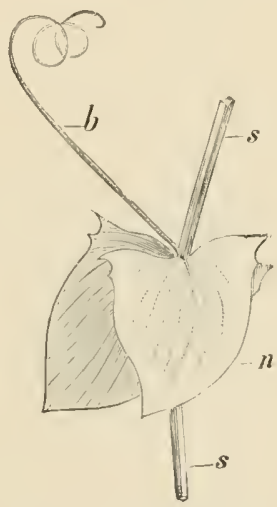

Fig, 49.-Lathyrus Aplaca. $s$, Stem; $n$, stipules ; $b$, leaf temiril. ( $\frac{1}{2}$ nat. size.)

these tendrils and stem-tendrils clear, and indicate the value of comparative morphological investigation.

In Lathyrus Aphace the stipules assume the function of the metamorphosed leaf laminae; in other instances, as in the case of the Australian species of Acacia (Fig. 174, 7, 8, 9, Fig. 183), it is the leaf petioles which, becoming flattened and leaf-like in appearance, supply the place of the undeveloped leaf-blades. Such a metamorphosed petiole is called a PHYLLODE, and, except that it is expanded perpendicularly, elosely resembles a phylloclade. From the latter, however, it is morphologically different, for the one represents a metamorphosed petiole, the other a metamorphosed shoot. In aceordance with this distinction phyllodes do not, like phylloclades, spring from the axils of leaves. Just as stems become morlified into thorus (Fig. 30), by a similar metamorphosis leaves may be converted into LEAF THORNS. Whole leaves on the main axis of the Barberry (Berberis vulguris) become thus transformed into thorns, either single or 
tri-radiate, hut in their character of leaves still subtend axillary shoots provided with foliage leaves. By a similar metamorphosis, the two stipules of the leaves of the common

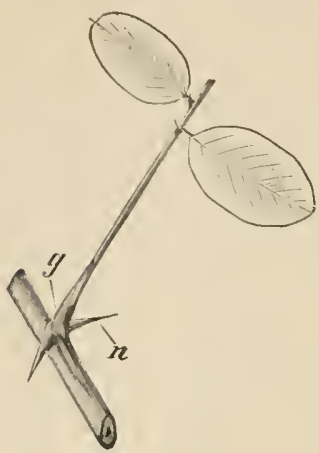

Fid. 50.-Part of stem and com. pound leaf of Robinia Pseud. acacia. $n$, stipules modified into thorns ; $g$, pulvinus. ( $\quad\left(\frac{1}{2}\right.$ nat. size.)

Locust (Robiniu Pseuducuciu) become modified into thorns, while the leaf lamina persists as a foliage leaf (Fig. 50).

\section{The Root.}

The third primary member of the cormophytic plant in its typical development as an underground root presents less marked differences in external form than were shown by the other members. This may be put in relation with the uniform conditions to which roots are exposed in the soil. Certain differences are, however, found between the roots of plants adapted to live in different situations. The root has as its most important function the absorption of water and nutrient substanees dissolved in it from the soil, and also serves to attach the plant firmly in the soil. Frequently it serves for storage of assimilated substances. The general appearance of an underground root differs as it is more specially adapted to perform one or other of these functions. Those roots which grow in water or mud become more elongated, are little branched, and are often provided with special arrangements for aeration which lead to localised swellings; they do not, however, undergo any fundamental ehange of form. Those roots which grow in the air, AERIAL ROOTs, tend to be more strikingly morlified.

The alssence of leaves and the existence of a root-eap protecting the growing point are characteristic of roots, and furnish an easy means of distinguishing them from undergromnd shoots. A ROOT-CAP or CALYPTRA affords the regetative cone of a root the protection that is provided to the apex of a stem by the leaves of the bud. Althongh, generally, the existence of a root-cap is only diselosed by a median, longitudinal seetion through the root-tip, in some roots it is plainly listinglishable as a cap-like covering. The very noticeable caps on the water roots of Inekweel (Lemmu) are not, in reality, root-caps; as they are not derived from the root, but from a sheath which envelops the rudimentary root at the time of its origin. They are accordingly termed rooT-Pockiss. As a general rule, however, roots without root-eaps are of rare occurrence, and in the case of the Duckweed the root-pockets perform all the functions of a root-eap. The short-lived root of the Dodder (p. 26) affords another example of a root devoid of a root-eap. Charaeteristie of most roots are also the 
root-HaIRs (Fig. $173 r$ ), which are found at a short distance from their tips. As the olfler root-hairs die at the same rate that the new ones are developed, only a small portion of a root is provided with root-hairs at the same time. In some few instances roots develop no root-hairs; this is true of the roots of many Conifers.

Branching of the Root.- Just as the shoot may become bifurcated by the division of its growing point ( $\mathrm{Fig}$. 18), so a root may become similarly branched. For the most part, this mode of branching takes place only in the roots of Lycopodiaceae, the shoots of which are also dichotomously branched (p. 19). The branches of roots usually occur in acropetal succession, but the lateral roots (Fig. $173 \mathrm{su}$ ) make their appearnce at a much greater distance from the growing point of the main root than lateral shoots from the apex of their parent stem. By reason of the internal structure of their parent root, lateral roots always develop in longitudinal rows (Fig. 173). They are of endogenous origin, and before reaching the surface must break through the surrounding and overlying tissue of the parent root, by the ruptured portions of which they are often invested at the base, as with a collar.

Generally the lateral roots are reinforced by the development on the parent root of specially strong ADVENTITIOUS RooTs. These arise first on the older and later on the younger parts of the root, withont, however, exhibiting a strictly acropetal succession. In Monocotyledous the root-system of the embryo plant is at once replaced by adventitious roots developed from the lower part of the stem. Adventitions roots are generally endogenons; they can, like adventitions shoots, be formed on various parts of the plant.

The place of origin of adventitious roots is not fixed beforehand but may (as is also the case with many adventitious shoots, 1.21 ) be more or less definite. This is especially the ease in marsh- and water-plants where the roots arise from the lower nodes of the stem between, and alternating with, the leaves; they replace the frimary root system which has been lost when the older part of the 1) lant died off ( $\left.{ }^{26}\right)$. The further development of the rudiments of adventitious roots is determined by the needs of the plant. They are especially numerons on the nuder side of rhizomes (Fig. $23 \mathrm{w}$ ), and also, when the external conditions are at all favouralle, they seem to develop very readily from the stem nodes. A young shoot, or a cutting planted in moist soil, quickly forms adventitious roots, and roots may also arise in a similar manner from the bases of leaves, especially from Begonia leaves when planted in soil. Dormant root rudiments ocenr in the same manner as dormant buds of shoots. Willow-twigs afford a special case of the presence of such dormant rudiments of adventitious roots, the further development of which is easily induced by darkness and moisture. When adventitious shoots are borne upon roots they mostly arise at some distance from the apex. In the Adder's Tongue Fern (Ophioglossum), the vegetative reproduction of which is effected by means of buds formed on the root, these arise close to the root-apex. Lastly, just as terninal leaves may arise from the apex of a stem and terminal shoots from the tips of the leaves of Ferns, in a few instances (species of Asplentum and Platycerium among Ferns, Neottia nidus avis in the Orehidaceae) a shoot may arise as the direct continuation of the growing point of a root $\left({ }^{27}\right)$. 
The Form of Subterranean Roots. - The customary nomenclature for the various root forms is based on their shape, size, and mode of branching. A root which is a prolongation downwards of the main stem is cilled the main root or TAP-ROOT; the other roots are termed, with reference to the tap-root, LATERAL ROOTs of different orders, according to the order of their development. A tap-root is present in Gymnosperms and many Dicotyledons, while it is, as a rule, wanting in Monocotyledons. The root system of most Monocotyledons and many Dicotyledons mainly consists of adventitious roots arising from the base of the stem or from underground stems or rhizomes. Roots

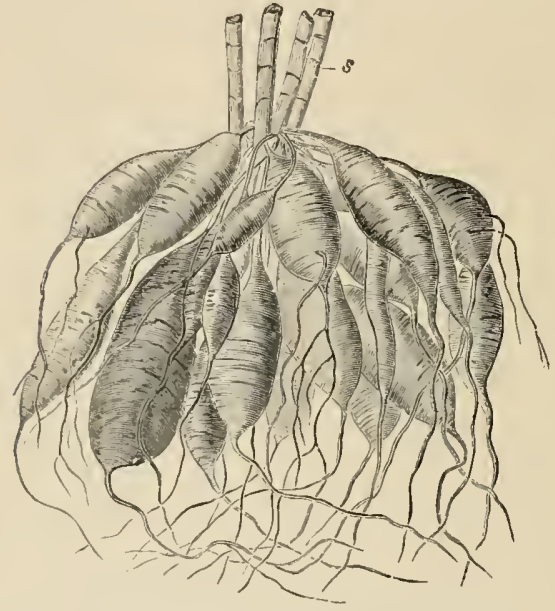

Fis. 51.-Root-tubers of Dahlia variabilis. $s$, The lower portions of the cut stems. (' nat. size.)

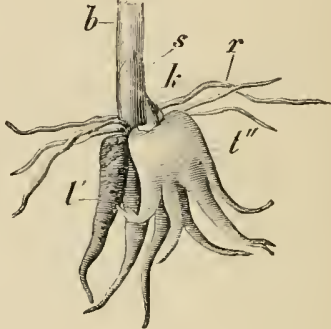

Fig, 52.-"rrehis latifolia. $t^{\prime}$, The old root-tuber; $t^{\prime \prime}$, the young root-tuber; $b$, floral shoot; $s$, scale leaf with axillary bud, $k$, from which the new tuber has arisen ; $r$, ordinary adventi. tious roots. ( $\frac{1}{2}$ nat. size.)

which serve for storage of reserve materials may enlarge and become turnip shaped or tuberous (Fig. 51). Such tuberous growths often greatly resemble stem tubers, but may be distingnished from them by their root-caps, by the absence of any indications of leaf development, and by their internal structure.

The morjhology of the tubers of the Orehidaceae is peculiar. They are, to a great extent, made up of a llesliy, swollen root terminating above in a shoot-bud ( $\left.{ }^{28}\right)$. At thir lower extremity the tubers are either simple or palmately segmented. In the adjoining figure (Fig. 52) both an old $\left(t^{\prime}\right)$ and a young tuber $\left(t^{\prime \prime}\right)$ are representerl still united together. The olsler tuber has jrodueed its flowering shoot $(b)$, and has begnn to shrivel; a bud, formed at the base of the shoot, in the axil of a scale leaf (s), lass already developed an adventitions root which has given rise to the younger tulser. Roots of ordinary form arise from the base of the stem above the tulier.

Metamorphosis of Roots.-The aerial roots of tropical EPIPHYTES, plints living upon others often at a considerable height from the 
ground, differ considerably in their structure from underground roots. 'The aerial roots of the Orchidaceae and of many Aroideae are provided with a spongy sheath, the VELAMEN, by means of which they are enabled to absorb moisture fron the atmosphere. Aerial roots, in some cases, grow straight downwards, and upon reaching the ground, branch and function as nutritive roots for the absorption of nourishment; in other instances they turn from the light, and, remaining comparatively short and unbranched, fasten themselves as CLIMBINe ROoTs to any support with which they come in contact. The climbing roots of many Orchids, Aroids, and Ferns branch and form lodgment places for humus; and into this absorbent branches of the climbing roots penetrate. Pendent aerial roots generally contain chlorophyll in their cortical tissue. In Orehids belonging to the genera Angraccum and Tueniophyllum, the task of nourishing the plant is left entirely to the aerial roots, which are then devoid of a velamen and rery much flattened. They are distinctly green-colourerl, and supply the place of the leaves which lose their green colour and are reduced to scales. The flat, dorsiventral, chlorophyll-containing roots of the tropical Podostemaceae $\left({ }^{29}\right)$, which have been referred to with regard to the seruence of shoots (p. 29), fulfil a similar function. The aerial roots of the epiphytic Bromeliacene are developed exclusively as climbing roots, while the leaves serve not only as assimilating organs, but also assume the whole task of water-absorption. All the aerial roots of epiphytes are, so far as their origin is concerned, adventitions.

The numerous adventitious roots which form a thiekly matted covering on the trunks of Tree-ferms become hard after death, and serve as organs of proteetion. In some Palms (Aermthorrhizo, Iriortea) the adventitious roots on the lower part of the sten become modified into thorns, nOOT-THORNs. The roots of eertain tropical plants, sneh as I'condonus and the swamp-inhabitating Mangrove trees, are specially modified. These plants develop on their stems adventitious roots, which grow obliquely downwards into the ground, so that the stems finally appear as if standing on stilts. The Banyan tree of India (Ficus indica) produees peculiar root-supports from the under side of its branehes, upon which they rest as upon columns. The lateral roots of eertain Nangrove trees become modified as peenliar breathing organs, and for this purpose grow upwards into the air out of the swampy soil or water in which the trees grow, and are provided with special aerating passages. Sueh respinatory or AEnativg roots surromind the Mangrore trees looking like vigorous Asparagus stalks, and enable the roots growing below in the mud to carry on the necessary exchange of gases with the atmosphere. (Cf. Fig. 193:)

Reduction of Roots.-There is a general relation between the degree of development of the leaf-surface and of the root-system. In saprophytic and parasitic plants, the leaves of which are as a rule more or less completely reduced, a corresponding reduction of the root-system can be recognised. Special absorbent organs or HaUstoria are often developed on the roots of parasites, e.g. on the roots of the green partial parasites Euphrusiu, Odontites, Thesium, etc., which become 
attached to the roots of their host plants by means of disc-shaped or wart-shaped haustoria. In extreme eases no subterranean roots may be developed, and the parasite only bears baustoria which penetrate the lost (Cuscuta, Fig. $196 \mathrm{H}$ )./ The haustoria of the liafllesiacene traverse the body of the host-plant as elongated filaments of cells, and are capalle of regenerating the parasite. The immense flowers of Rafflesin Arnoldi, which spring directly from the roots of Cissus, originate from similar haustoria. The reduetion of the roots may extend to such a degree that, in a number of plants,

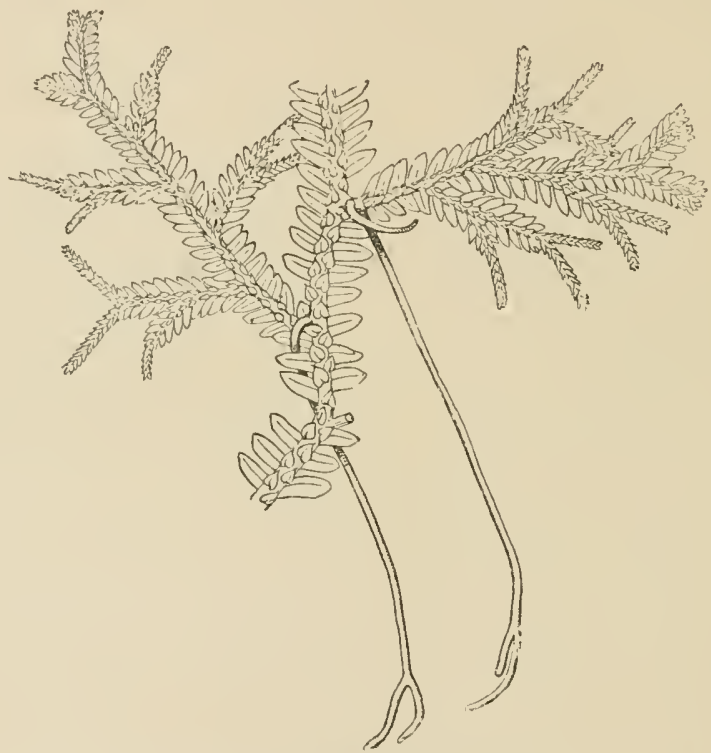

Fre. 53.-Part of the shoot of Selaginellu Murtensii with rhizophores.

(From Goeber, (rganography. Nat. size.)

no roots are formed. It has leen already mentioned that in the case of Corulliorrhiza innatu (Fig. 24) the rhizome assumes all the functions of the roots, which are entirely absent. Also in many aruatic plants (Sulrinia, Wolffu urhiza, Utriculariu, ('eratophylhum) roots are altogether absent since these plints no longer require them. The beard-like epiphytic Tillundsia usncoides, belonging to the Bromeliaceae, has no roots and obtains the water it requires by means of speeial seile-like hairs.

\section{Members of Independent Origin}

The existence of parts of the plant eombining the eharacters of distinct primary members, and to which an independent phylogenetic origin must be ascribed, has been pointed ont by GoEbeL $\left({ }^{30}\right)$. 
The rhizophores of Seluginellu (Fig. 53) which have been variously interpreted as leafless shoots, as roots, and as organs sui generis, find their place here. They resemble leafless shoots, attain a considerable length, and may branch dichotomously and give rise to endogenons roots close to the growing points. As a matter of faet they are in structure and general behaviour intermediate between shoot and root, and it is not probable that they have originated from either of these primary members.

Various outgrowths of the body of the plant to which an independent origin is to be ascribed are gromped together as EMERGENCLs. A phylogenetie significance eannot be attached to the term as here used. It inchules structures of the most different origin belonging both to the thallus and the cormus. The rhizoids, which serve to fasten the thallus of many Thallophytes and the mossplants to the substratum, as well as the massive attaehing organs of many Brown Sea-weeds (Fucaceae and Laminariaceae) are elassed here. So also are the organs which arise as microscopically small struetures on the horlies of both lower and higher plants, and contain the asexual and sexual reproduetive cells of the Cryptogams (sporangia and sexual organs). In the sense of the term implied here the hairs, prickles, and glands borne on the surface of the highly-organised plants must be included as well as the hanstoria deseribed above. As an extreme case the attaching organs (hapterie) of the previously mentioned Podostemaceae may be referrer to. These hapteræ serve to attach the mutritive roots of these plints firmly to the roeks upon which they grow exposed to rapidly flowing water. They are at first eonical outgrowths, but flatten out and become lobed when applied to the surface of the rock. The shoots originate from the fiat nutritive roots. There is, indeed, no reason why various ontgrowths of the vegetative body of the plant shonld not become adapted to the performance of particular functions. 


\title{
II. INTERNAL MORPHOLOGY
}

\author{
(Histulogy and Anatomy)
}

\section{A. The Cell}

\section{Structure of the Cell $\left({ }^{31}\right)$}

All plants and animals are composed of elementary organs called cells. In contrast to animal cells, typical vegetable cells are surrounded by firm walls, and are thus sharply marked oft

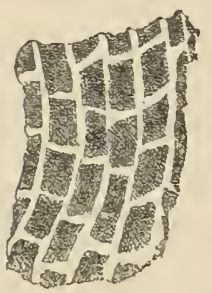

Fiv. 54.-Copy of a part of Hooke's illustration of lottle-cork, which he described as "Sclematism or texture of cork." from one another. In fact, it was due to the investigation of the cell walls that cells were recognised first in plants. An English micrographer, Rовент Hooke, was the first to notice vegetable cells. He gave them this name in his Micrographia in the year 1667 , because of their resemblance to the cells of a honeycomb, and published an illustration of a piece of bottle-cork having the appearance shown in the adjoining figure (Fig. 54). RoberT Hooke, however, was only desirous of exhibiting by means of different objects the capabilities of his microscope; consequently, the Italian, MaRCello Malpighi, and the Enghishman, Nenemia Grew, whose works appeared almost simultaneously a few years after Hooke's Hicrographiu, have heen regarded as the founder's of regetable histology. The living contents of the cell, the real body or substance, was not recognised in its full significance until the middle of last century. Only then was attention turned more earnestly to this study, which, based on the works of Meyen, Schleiden, Hugo v. Mohl, Nügeli, De Bary, Ferdinand Coin, Pringsiein, and Max Schultze continues to develop.

If an examination be made of a thin longitudinal section of the apex of a stem of a phanerogamic plant, with a higher mannifying power than that used in the

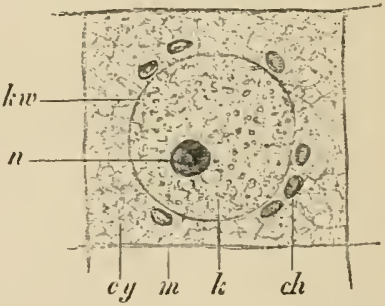

F16. 55.-Eubryonic cell from the regetative cone of a phanerogamic plant. $k$, Nucleus; $k w$, nuclear membrane; $n$, nucleolus; $c y$, cytoplasm ; ch, chromatophores ; $m$, cell wall. (Somewhat diagrammatic, $x$ (irca 1000.) previons investigation (Fig. 17) of the vegetative cone, it will be seen that it consists of nearly rectingular cells (Fig. 55), which are full of protoplasm and separated from one another by delicate walls. In 
each of the cells there will be clearly distinguishable a round body $(k)$, which fills up the greater part of the eell carity. This body is the cell NuCLEUS. If sections, made in different directions through the vegetative cone, be compared with one another, it will be seen that its component cells are nearly cubieal or tabular, while the nuclei are more or less spherieal or disc-shaped. The finely granular substance $(c y)$ filling in the space between the nucleus (li) and the ecll wall $(m)$ is the CELL PLASM or CrTOPLASM. In the cytoplasm there are to be found, about the nueleus, a number of colourless and highly refractive bodies : these are the pigment-bearers or CIROMATOPHORES $(c h)$. NuClEus, CYTOPLASM, AND CHROMATOPHORES, CONSTITUTE THE ELEMENTS OF THE LIVING BODY OF A TYPICAL VEGETABLE CELL. To designate all these collectively, it is eustomary to use the term ProtoPLASM, which is then to be understood as including all the living eonstituents of the cell-body or PROTOPLAST.

In many animal cells modern investigations have revealed, in addition to the constituents of the protoplasm just mentioned, a small structure situated close to the nucleus, which has been termerl the CENTROSOME, CENTRIoLE, or ATTRACTION-SPHERE. Similar structures have been demonstraterl in some Thallophyta and Bryophyta (Fig. $56 \mathrm{c}$ ); they appear to be wanting in the cells of the higher Cryptogams and the Phanerogams.

The mucleus and cytoplasm are the two most essential constituents of the cell, and its vital functions depend on

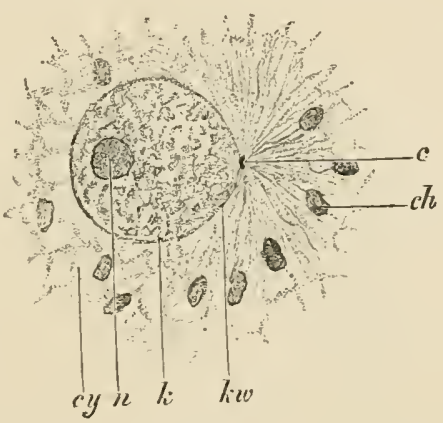

Fig. 56.-A nuclens of a cell of the young plant of Fucus serratus, a Brown Seaweed. cy, The surrounding cytoplasm; $k$, the nucleus ; $k w$, nuclear membrane; $n$, nucleolus ; $c$, centrosome ; $c h$, chromatophores. $(\times 1000$. $)$

the interaction between them. In the lowest plants (Cyanophyceae and Bacteria) such a division of labour in the protoplasm is not certainly proved, the existence of a nucleus being still a matter of rispute $\left({ }^{32}\right)$. Chromatophores are wanting in the Bacteria and Fungi, as in all animal cells.

While animal cells usually remain continuously filled with protoplasm, vegetable cells soon form large sAP CAVITIES. It is only the embryonic cells of plants that are entirely filled with protoplasm, as the cells, for example, of an embryo or of a growing point; they afterwards beeome larger and contain proportionally less protoplasm. This can be seen in any longitudinal section through a stem apex. At a short distance from the growing point the enlarged eells have already begun to show cavities or vacuoLes ( $r$ in $A$, Fig. 57 ) in their cytoplasm. These are filled with a watery fluid, the CELL SAP. The cells continue to inerease in size, and usually soon attain a condition 
in which their whole central portion is filled by a single, large sap cavity ( $v$ in $l$, Fig. 57). The cytoplasm then forms only a thin layer

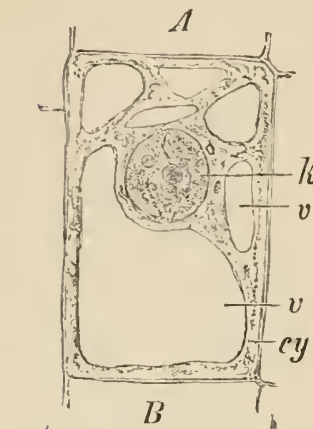
lining the cell wall, while the nuclens occupies a parietal position in the peripheral eytoplasmic layer. At other times, however, the sap cavity of a fully-developed cell may be traversed by bands and threads of cytoplasm; and in that case the nucleus is suspended in the centre of the cell. But whatever position the nucleus may occupy, it is always embedded in eytoplasm; and there is always a continmous peripheral layer of cytoplasm lining the cell wall. This cytoplasmic peripheral layer is in contact with the cell wall at all points, and, so long as the cell remains living, it continues in that condition. In old cells, however, it frequently becomes so thin as to escape direct observation, and is not perceptible until some reagent, which attracts water, causes it to recede from the wall, has been employed.

Dead cells lose their living protoplasmic contents, and, strictly speaking, should no longer be termed cells, although the name - cy was first applied to them when in that condition. In reality they represent only cell cavities. With their death, however, cells do not lose their importance to a plant. Witbout such cell cavities a highly-organised plant could not exist, as they perform for it the office of water-carriers, and afford mechanical support and rigidity. The heart wood of a tree consists exclusively of the walls of dead cells.

The Protoplasm.-In order to facilitate an insight into the real character of protoplasm, attention will first be directerl to the Slime FungI (Myxomycetes), a group of organisms which stand on the border between the animal and regetable kingloms. These Myxomyeetes are characterised at one stage of their development by the formation of a l'LASMOHUM, a large naked mass of protoplissm.

The plasmolinm is formed from the protoplism of the spores. 'These spores are unicellular bodies (Fig. 58 t, $)$ ), filled with cytoplasm, 
in which lies a central uncleus, and are surrounded by resistent eell walls. The spores germinate in water, their contents, breaking through the spore walls, come out $(c, l)$ and round themselves ofl: A change of form soon takes place; the protoplasmic mass elongates and assumes somewhat the shape of a pear, with the forward end prolonged into a
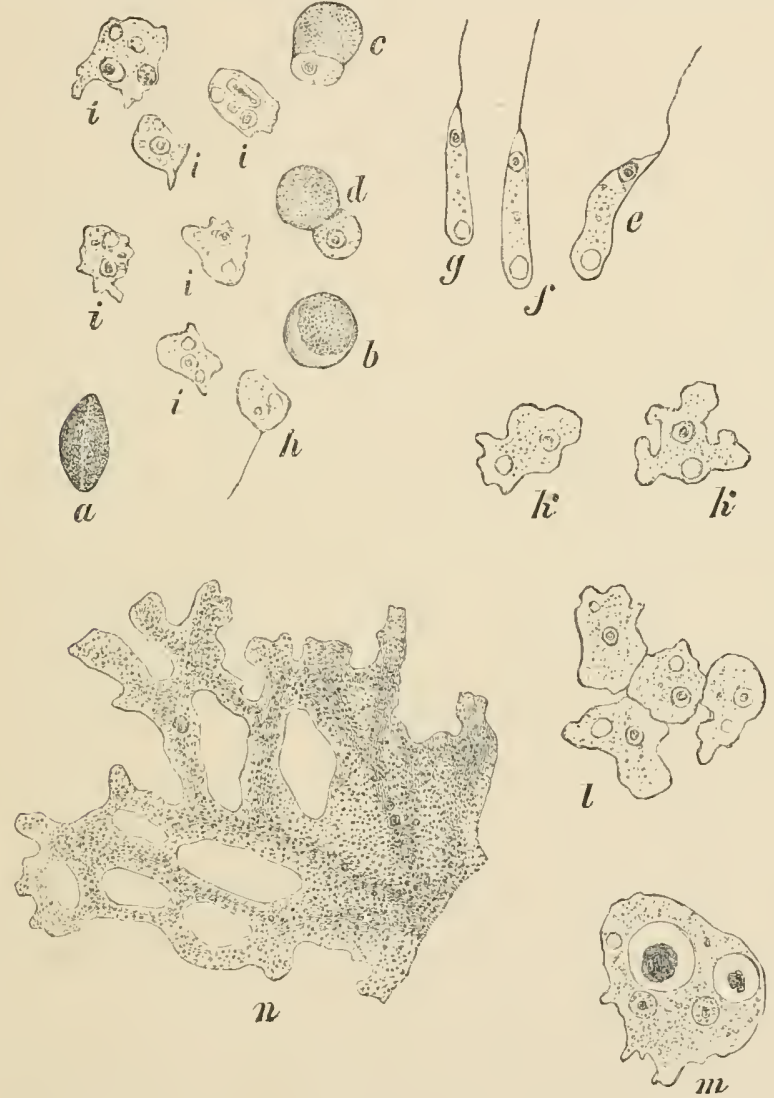

Fig. 58.-Chundriontermo difforme. ", 1)ry, shrivelled spore; $b$, sivollen spore; $c$ and $d$, spores showing escaping contents ; $c, f, y$, swarm-spores; $h$, swarm-spore changing to a myxamoeba ; $i$, younger, $k$, older myxinoebae ; 7 , nyxamoebae about to fuse ; $m$, small plasmodium; $n$, portion of fully-developed plasmodium. $(a-m, \times 540 ; n, \times 90$.

fine whip-like process or flagellum $(e, f, g)$. Thus the contents of the spore have become transformed into a sWAIM-SPORE, which now swims away by means of whip-like movements of its flagellum. In addition to the muclens, which is visible in the anterior end of every swarm-spore, a vesicle may be seen at the other end, which, after gradually increasing in size, snddenly vanishes, only to swell again into view. This 
vesicle is a CONTRACTLE VACUOLE. The presence of such a contractile vacuole in an organism was formerly considered a certain inclication of its animal nature. Now, however, contractile vacuoles have been observed in the swarm-spores of many grcen Algae, of whose regetable nature there cau be no doubt.

The swarm-spores of the Myxomycetes soon lose this characteristic swarm-movement, draw in their flagella, and pass into the amoeba stage of their development, in which, like animal amoebae, they assume irregular, constantly changing shapes, and are capable of performing only amoeboid creeping movements. Int the case of Chondrioderma lifforme, a Myxomycete of frequent occurrence in rotting parts of plants (Fig. 58), a number of the amoebae eventually collect together $(l)$ and coalesce. In this way, as is also the case with most other Myxomycetes, the amoebae ultimately give rise to a plasmodium $(n)\left({ }^{33}\right)$.

Although each one of the amoebae is so small that it can only be seen with the aid of a microscope, the plasmodium into which they become united may attain a considerable size.

The cytoplasm, both of the single amoeba and of the plasmodium, consists of a clear ground substance; through which granules are distributed. This substance is of the consistence of a tenacious fluid; its superficial region is denser and free from granules, while these are numerous in the less dense central portion. The granules enable the internal streaming movements of the cytoplasm to be recognised. The currents are constantly changing their direction, moving either towards or away from the margin. The formation and withelrawal of processes of the margin stand in relation to the direction of the currents. When naked masses of protoplasm such as these plasmodia eucounter foreign bodies, they can enclose them in vacuoles, and, when of use as food, digest them.

Deprived of its component water the protoplasm becomes hard and tenacious, and, withont losing its vitility, ceases to perform any of its vital functions until again awakened into activity by a fresh supply of water. In case of a scarcity of water the plasmodia of the Myxomycetes may form scLerotia, that is, masses of resting protoplasm of an almost wax-like consistency. Nonths and indeed sometimes years afterwards, it is possible for such sclerotial, if water be supplied, to again prodnce motile plasmorlia. Similarly, in seeds kept for a long time the protoplasm cousolidates into a hard mass, which may be ensily cut with a knife, while the nuclei will be found to have shrunk and lost their original shape. Nevertheless the protoplists, after absorljing water, may return again to a condition of activity.

Protoplasm is not a simple substance chemically; it eonsists rather of numerous different components which are subject to continual change. Since alluminous sulbstances are always present, protoplasm al ways gives a proteid reaction; when incinerated, fumes of ammonia are given off. 
Active protoplasm generally gives an alkaline, and, under certain conditions, a neutral reaction, but never an acid one. The protoplasm of the higher plants coagulates at a temperature not much over $50^{\circ} \mathrm{C}$., in the Schizophyta, however, often not below $75^{\circ} \mathrm{C}$. In the inactive dried condition, as in spores and seeds, it can endure a still higher temperature without coagulating. The spores of many Bacteria can withstand temperatures over $100^{\circ} \mathrm{C}$. for a considerable time. Treated with alcohol or ether, with acids of definite concentrations, with bichromates of the alkali metals, or with corrosive sublimate, protoplasm quickly coagulates, while at the same time insoluble proteid compounds are formed. Coagulating reagents, accordingly, play an important part in microscopic technique; of especial value are those, which, while fixing and hardening the protoplasm, change its structure in the least degree. As fixing and hardening reagents for vegetable tissues, alcohol, 1 per cent chromic acid, 1 per cent acetic acid, 0.5 to 1 per cent osmic acid, concentrated picric acid, or corresponting mixtures of these acids, solutions of mercuric chloride and formaldehyde, arc used. Iodine stains protoplasm brownish yellow; nitric acid, followed by caustic potash, yellowish brown (xanthoprotein reaction). Acid nitrate of mercury (Mrlcon's reagent) gives to protoplasm a brick-red colour; sulphuric acid, if sugar be present, rose-red. These reactions oceur with all proteid substances though they are not absolutely distinctive of them. Protoplasm is soluble in dilute caustic potash and also in eau de Javelle (potassium-hypochlorite), and accordingly both of these reagents may be recommended for clearing specimens when the cell contents are not to be investigated. All of the above-mentioned reagents kill protoplasm; nutil they have done so, their characteristic reactions are not manifested. A large number of albuminous bodies or albuminates have been named which are said to enter into the composition of living protoplasm. Most of these compounds are still ill-defined; in nuclei the nucleins are most important, but they are also found in the cytoplasm. They are characterised by containing much phosphorus, and are not attacked by pepsin, and only with difficulty by trypsin. Staining reagents have become an important help to microscopic investigations for determining the composition of protoplasm. This is due to the fact that the different constituents of protoplasm take up and retain the stain with different degrees of intensity and energy. As a general rule, only coagulated protoplasm can absorb colouring matter, although some few aniline stains can, to a limited extent, permeate living protoplasts. For staining vegetable protoplasts, which have been previously fixed, the various carmines, hæmatoxylin, safranin, iodine green, acid fuchsin, eosin, methylene blue, and aniline blue, gentian-violet and orange, have been found particularly convenient. The different components of the protoplasm absorb the stains with different intensities, and, when reagents are employed to remove the colouring matters, they exhibit differences in their power to retain them. The nucleus generally becomes more intensely coloured than the rest of the protoplasm, especially a part of its substance, which is therefore called crliomatr. In addition to those substances, which are to be regarded as integral parts of active protoplasm, it always includes derivative products of albuminates, particularly amides, such as asparagin, glutamin; also ferments, such as diastase, pepsin, invertin; at times alkaloids, and always carbohydrates and fats. The ash left after incineration also shows that protoplasm always contains mineral matter, even if only in small quantities. All snch substances which do not enter directly into the composition of protoplasm, but are only included within it, are designated by the term METAPLASM.

The Cytoplasm. - The cytoplasm of vegetable cells, which possess 
a cell wall, is a more or less tenucious colloid fluid. It partalies of the physical poperties of fluids, and on being artificially freed from the cell wall, tends to assume the spherical form. Its cohesion alplears to be greater in meristematic eells than in those which are older, while in ecrtin cases a still firmer consistence may be attained as in the cilia borne by swarm-spores (Fig. 58).

both in the case of the Myxomycete and of the regetable cell enclosed by a wall, the basis of the cytoplasm consists of a hyaline substance termerl the HYALOPLASI. When granules are distributed through the eytoplasm it is spoken of as GRANULAR PLASMA Or polioplasm. An extremely thin boundary layer (plasmoderma) is found at the periphery which is quite free from granules, and a similar layer bounds every vacuole present in the cytoplasm. The wall of the vacuole is characterised by a greater tenacity of life than the rest of the eytoplasm, remaining alive for some time after the latter has been killed by the action of a 10 per cent solution of potassium nitrate. Since the vacuole wall regulates the pressure exerted by the cell sap contained in the vacuole, HUGO DE VRIEs has applied the name TONOPLAST to this layer.

The small granules distributed through the granular plasma consist of various substances, and may be classed together as MICROSOMES.

Even though bounded by a cell wall the cytoplasm frequently exhiljits morements comparable to those of the naked amoebae and plasmodia of Myxomycetes. These movements mostly are found in somewhat old cells, but $\mathrm{N}$. GAIDUKov $\left({ }^{34}\right)$ has shown by means of the recently invented ultramicroscope that they are of widespread occurrence in regetable protoplasts; the principle of this method depends on the use of reflected light, and its dispersion by particles that are so snall as not to be visible on ordinary microscopic examination. The study of the morements in the Myxomycetes showed that various kinds of movements could be distinguished; the waving movement of the fligellum of the swarm-spore, the change in external form of amoelsae and plasmodia, to which their power of creeping ahout is due, and finally a streaming morement in the cytoplasm. The eytoplasm, enclosed by a cell-wall, may either exhibit isolated streaming movements, the direction of which may undergo reversals, or a single stream, the direction of which is constant. These two forms of morement are distingnished as circulation and rotation respectively. In rotation, which is found in cells with the cytoplasm reduccl to a layer lining the wall, the single continuous current follows the cell wall. In eirculation, on the other hand, the novement is fonnd both in the layer lining the cell wall and in the strands traversing the vacuole. In $n 0$ case does the boundary layer of the protuplasm take part in the movement. Cireulation is common in rells of limel-pliuts, while rotation is more usual in water-plants. 
The stimulus cansed by wounding the tissues in making the preparation frequently inereases the activity of the movement $\left({ }^{35}\right)$; apparently it runickens the transport of nutrient material toward the wound.

A particularly favourable object for the study of protoplasm in circulation is atforded by the staminal hairs of Tradescentic viryinica. In each cell (Fig. 59) small, fine currents of protoplasm flow in different directions in the peripheral cytoplasmic layer, as well as in the cytoplasmic threads, which penetrate the sap' cavity. These cytoplasmic threads gradually change their form and strueture, ant may thus alter the position of the cell nucleus.

When the protoplasm is in rotation, the cell nucleus and chromatophores are usually carried along by the current, but the chromatophores may remain in the boundary layer, and thus not undergo movement. This is the case with the Stoneworts (Characeae), whose long internodal cells, especially in the genus Nitelle, afford good examples of well-marked rotation.

Properly fixed cytoplasm has a finely reticulate or honeyconib-like structure, small granules being embedded in the network. At particular developmental stages this structure appears to be traversed by special filaments, which can be demonstrated by suitable staining (Fig. 56) ${ }^{36}$ ).

The portion of the cytoplasm which forms the network or loneycomb appears to be slecially conecrned with the nutritive processes, while the fibrillar plasma influences the process of development; they are respectively termed trophoplasm and kinoplasm; the latter has also been called archiplasm. When traced to their origins the limiting layer of the eytoplast is found to belong to the kinoplasm, the walls of vacuoles to the trophoplasm. Albuminous substances, precipitated by the fixing agent, liave not infrequently been mistaken for structural features of the eytoplasm $\left({ }^{37}\right)$.

The Cell Nucleus $\left({ }^{38}\right)$. - The resting nucleus has

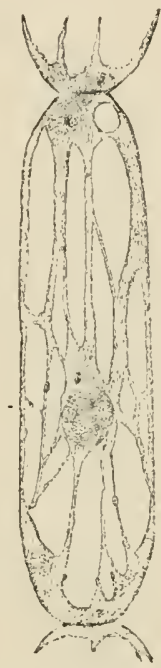

Fig. 59.-Cell from a staminal hair of Tret deserntice virginica, showing the nucleus suspended by protoplasuic strands. ( $x$ 240.) a reticulate or honeyeomb structure forming an anastomosing network (Fig. 56), which, however, in living objects ean only be distinguished by the finely dotted appearance it gives to the nuelens. Streaming movements do not take place within the nucleus. An insight into the nuclear structure is only to be attained with the help of properly fixed and stained preparations. It is then possible to determine that the greater part of this nuclear network is composed of delicate and, for the most part, unstained threads, in which lie deeply stained granules. The substance of the threads has been distinguisherl as LININ (l), that of the granules as curonatin ( $c h)$. One or more larger bodies, the NUCLEOLI ( $(n)$, occur at the intersections of some of the linin threads; these, althongh deeply stained, lo not take the same tint as the ehromatin granules. The network of the nucleus lies within the 
nuclear carity, which is filled with nuclear sap and surrounded by a membrane $(w)$. The nuclear membrane, strictly speaking, is a part of the surrounding cytoplasm, and is the protoplasmic layer by which the cytoplasm separates itself from the nuclear cavity. The nucleus in young cells with abundant protoplasm is, as a rule

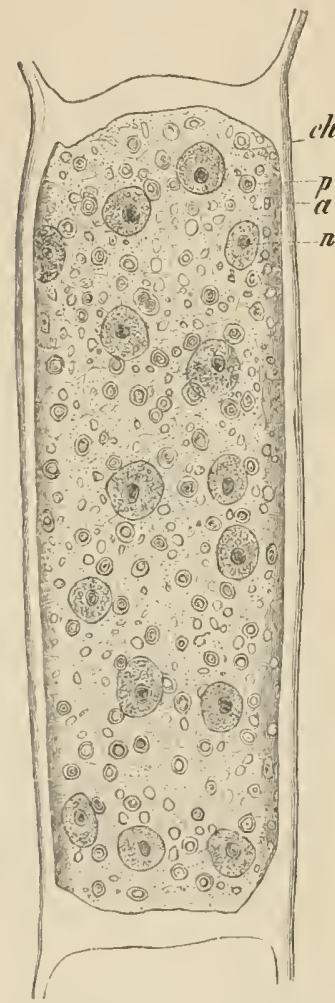

Firi. tio - A cell of clenlophore glomeratu, fixerl with I per cent chromic acirl anel stained witls carmine. $x$ Suclei; ch, cliromatophores: ; 2 , iyrenoids ; ", starch grains. $(\times 5.10$. spherical. When situated in the lining layer of cytoplasm of older cells, it is frequently of a flattened form, while in elongated cells it exhibits a corresponding elongation. Exceptionally in old cells the nucleus is forked, lobed, or of some other irregular shape. These changes in form of the nueleus are due to slow movements, which cannot, as a rule, be directly observed. In embryonic tissues the nuelei are relatively large in proportion to the size of the protoplasts. Glandular cells are also usually provided with large nuclei.

While the cells of the Cormophytes are almost always uninucleate, in the Thallophytes, on the contrary, multinucleate cells are by 110 means infrequent. In the Fungi, and in the Siphoneae among the Algre, they are the rule. The whole plant is then composed either of but one single multinucleate cell, which may be extensively branched and $e x$ libit a complicated external form (Fig. $286)$, or it may con-

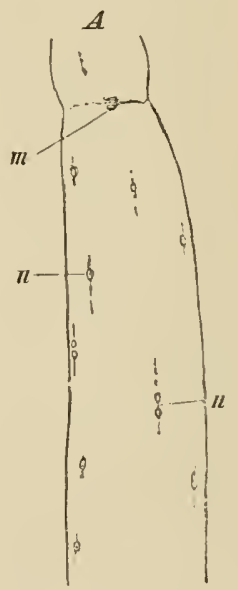

Fig. 61.-Portions of two alljacent cells in a liyjulia from the stalk of I'selliotre arrensis. $n$, Niclei; $m$, pits. ( $\times 540$.

sist of a large number of multinucleate cells, forming together one organism. Thus, on suitable treatment, several nuelei may be detected in the peripheral cytoplasm of each of the cells of the common filamentous fresh-water Alga Cladophoru glomerutu (Fig. 6, p. 12, Fig. 60).

The nuclei of the lons, multinucleate cells (Fig. $61 n$ ) of fungal filaments, or HYPHAE, and also of many Siphoneac, are characterised by their minute size. 
Centrioles and Centrosome-like structures in the lower divisions of the Vegetable Kingdom $\left.{ }^{(39}\right)$.- These appear as more or less sharply defined portions of the cytoplasm, which are surrounded by radiations. In the case of certain marine Alga (Fucus, Stypocaulon, Fig. 56) one or more small bodies, which may be compared to the centrioles of animal cells, can be distinguished within them. Such included bodies are wanting in the corresponding masses of active cytoplasm in Fungi. We may relate these structures to specially defined masses of cytoplasm in the mother-cells of the spermatozoids of the Bryophyta, Ptericlophyta, and certain Gymnosperms. These are termed blepharoplasts and supply the material for the formation of the cilia of the spermatozoids.

The Chromatophores $\left({ }^{40}\right)$.-- In the embryonic cells of the embryo and of growing points, where the chromatophores (Fig. $55 \mathrm{ch}$ ) are principally located around the mucleus, they first appear as small, colourless, highly refractive bodies. They may retain the same appearance in older cells (Fig. $121 A, l$ ), but in them they also attain a further development, as CHLOROPLASTS, LEUCOPLASTS, or CHRONOPLASTS. Since these bodies have the same origin they are all included in the one term, CHROMATOPHoRES.

Chloroplasts. - In parts of plants which are exposed to the light the chromatophores usually develop into chlorophyll bodies or chloroplasts. These are generally green granules of a somewhat flattened ellipsoidil shape (Fig. 62), and are scattered, in numbers, in the parietal cytoplasm of the cells. All the chloroplasts in the Cormophytes, anil, for the most part also, in the green Thallophytes, have this form. In the lower Algæ, however, the chlorophyll bodies may assume a

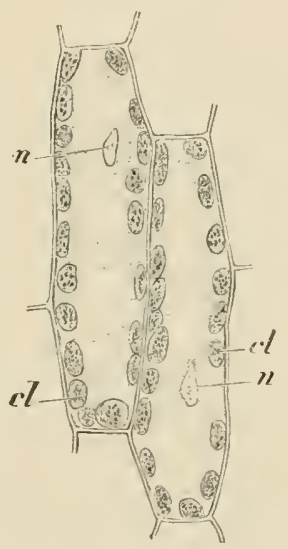

Fig. 62.-Two cells from a leaf of Funuria hygrometrica. cl, Chloroplasts; $n$, nucleus. ( $\times 30$ j.) band-like (Fig. $263 \mathrm{C}^{\prime}$ ), stellate, or tabular shape.

In these cases the chloroplast often inclndes one or more pyremoids; these are spherical protoplasmic bollies containing an albuminous crystalloil, and are surrounded by small grains of starch (Fig. 263, C p). The chlorophyll grains are said to be connected by special cytoplasmic filaments which allow of their changing their position; according to BENGT Lidforss $\left({ }^{40}\right)$, these are kinoplasmic filaments, while according to F. KNoLL $\left({ }^{(0)}\right)$ there is a special cy toplasmic reticulum. The whole apparatus is comnected by filanents with the nucleus. The ground substance of the chlorophyll grains is itself colonrless, but contains numerous colomred gramnles which are termed grana. The pigments can be extracted by means of alcohol. A strong solution of chlorophyll is most readily obtained from foliage leares by the use of bot alcohol. The pigments of chlorophyll are also soluble in acetone, ether, and chloroform; less completely in petrol-ether and petrol-benzine. The alcoholic solution is bright grcen by transmitted light, while, owing to its fluorescence, it is blood-red by reflected light. When an alcoholic solution of chlorophyll is 
shaken up with benzole, the latter, as Kraus first showed, on standing rises to the surface as a green solution, leaving the alcohol yellow.

According to recent researches $\left({ }^{41}\right)$ there are two components of the green ehlorophyll rigment; these are the erystallising and the amorphous ehloropliyll. Both are complex compounds, containing no trace of iron, and they perhaps differ somewhat in different plants. The yellow pigment in the chloroplyyll grains consists of carotin (which forms orange-red crystals, and appears to be a carbohyclrate) and of the amorplous xanthophyll, which is most probably an oxide of carotin. The alcolıolic solution of ehlorophyll is elaracterised by four absorption bands in the less refrangible half of the spreetrum, and three in the more refrangible portion. The amount of ehlorophyll in a green plant is very small. Tscirlich $\left(^{42}\right)$ has calculated that only $0 \cdot 2-1 \cdot 0 \mathrm{gr}$. of chlorophyll ean be obtained from a square metre of green foliage leaves.

From the investigations of L. Marchlewski, E. Schunck, and M. Nexchi it appears that a relationship exists between chloroplyyll and liemoglobin (the jigment contained in red blood corpuscles).

The green colour of the ehlorophyll in some groups of Algae is more or less masked by other pigments. In addition to the chlorophyll green, with its accompanying yellow pigments, many of the blue-green Schizophyceae contain a blue colouring matter, phyeocyanin, while the red Algae possess a red pigment termed phycoerythrin. These pigments are soluble in water, and are characterised by a beautiful fluorescence. The phycocyanin may often be found as a blue border surrounding a blue-green Fission-Alga which has been dried in a press. Whether these pigments are mixed with the chlorophyll or are chemically combined with it is as yet undecicted ( $\left.{ }^{43}\right)$. Recently HaNs MoLiscI ${ }^{44}$ ) has attempted to prove that the brown coloration of the Diatoms, the Brown Algae, and especially of a saprophytic Orchid (Neottiu nidus uvis), is not due to a mixture of a brown pigment with chlorophyll. He regards it as due, on the other hand, to a single pigment, phaeophyll, which is nearly related to chlorophyll and readily undergoes a chemical change into ordinary chlorophyll.

Before the leaves of trees fall in the antumn, the chloroplasts undergo disorganisation, and thus, according to ERNST STAHL $\left({ }^{45}\right)$, the derivatives of the chlorophyll, and to some extent other useful substances, are transported to the stem. There remains only a watery sul,stance in the eell cavity, in which a few oil globules and crystals, together with a few yellow, strongly refractive bodies, can be seen. Sometimes in presence of abundant sugar this liquid in the cell cavities becomes red, and thus imparts to the foliage its autumnal brillianey. In the leaves of coniferous trees, which only indicate the approaching winter by assuming a somewhat brownish tint, the canse is different. 'The chlorophyll-green of their chloroplasts changes to at brownish green pigment, but in the following spring regains its characteristic colonr.

In such phanerogamic parasites or humus-plants as are devoid of 
green colour, the chloroplasts either do not develop, or they are colourless, or have only a brownish or reddish colomr. No chromatophores are found in the Fungi.

Leucoplasts. - In the interior of plants, where light cannot penetrate, leucoplasts are developed from the rudiments of the chromatophores instead of chloroplasts. They are of a clenser consisteney than the chloroplasts, mostly spherical in shape, but often somewhat elongated in consequence of enclosed albuminous erystals. If the leneoplasts become at any time exposed to the light, they may change into ehloroplasts. This frequently oeeurs, for example, in the superficial portions of potato tubers.

Chromoplasts. - The chromoplasts of most flowers and fruits arise either clirectly from the rudiments of colourless ehromatophores, or

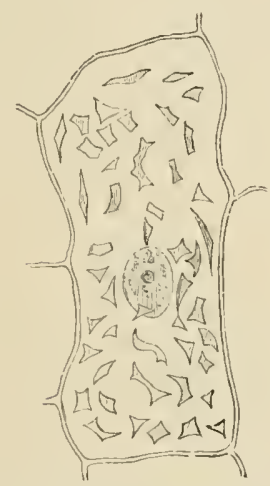

Fic. 63.-Cell from the upper surface of the calyx of Tropacolum majus, sliowing chromoplasts. $(\times 540$.

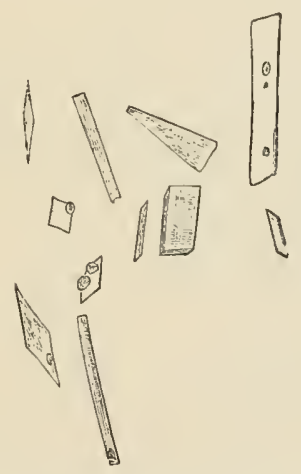

Fir. 64.-Chromoplasts of the Carrot, some with included starch grains. ( $\times$ 540.)

from previously formed chloroplasts. In shape the chromoplasts resemble the chloroplasts, except that they are usually smaller; in eonsequence of the crystallisation of their colouring pigment they sometimes assume triangnlar, tabular, needle, or fan-shaped shapes (Figs. 63, 64). The colour of the chromoplasts varies from yellow to red, aceording to the predominance of yellow xanthophyll or orange-red carotin. The name carotin $\left({ }^{46}\right)$ has been derived from the Carrot (Daucus Carotu), in the roots of which it is partienlarly abundant. (Fig. 64). The frequent crystalline form of the chromoplasts is, in a great part, due to the tendency of earotin to crystallisation, although it may be also occasioned by needle-like erystals of albumin. Xanthophyll, however, is never present in the ehromoplasts exeept in an amorphous eondition.

Inclusions of the Protoplasts.-The main inelusions of the protoplasts met with are starch, aleurone, organic and inorganic 
cristals, various substances which are elsewhere not crystalline, and the cell-sitp.

STARCH. - The chloroplasts in plants exposed to the light almost always contain starch grains. These grains of starch found in the chloroplasts are the first visible products of the assimilation of inorganic matter. They are formed in large numbers, but as they are continually dissolving, always remain small. Large starch grains are found only in the reservoirs of reserve material, where starch is formed from the deposited products of previous assimilation. Such starch is termed RESERVE STARCH, in contrast to the AssIMILATION STARCH formed in the chloroplasts. All starch used for economic
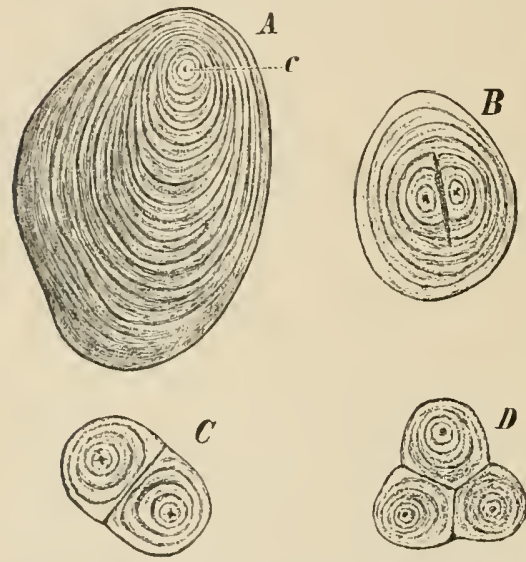

Fir. 65. - Starch grains from a jotato. $A$, simple; $B$, half-compound; $C$ and $D$, componud starch grains; c, organic centre of the starch grains, or nuclens of their formation. $(\times 540$.
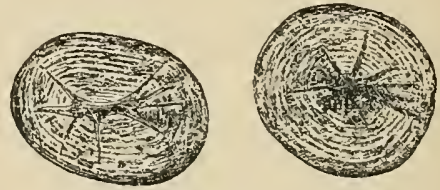

Fic. 66. - Starch grains from 1 he cotyletions of threseolus intyaris. $(\times 540$.
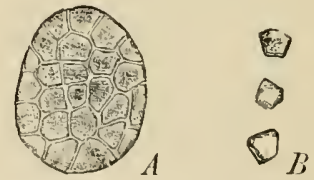

Fig. 67.-Starch grains of the oat, Alene setice. A, Componm grain; $B$, isolated component graius of a compound grain. $(\times 540$.

purposes is reserve starch. The starch grains stored as reserve material in potitoes are comparatively large, attaining an average size of $0.09 \mathrm{~mm}$. As shown in the above figure (Fig. $65 \mathrm{~A}$ ), they are plainly stratified. The stratification is due to the rarying densities of the successive layers; thicker denser layers which appear clear by trausmitted light alternate with thinner less dense layers which appear diuk. They are excentric in structure, since the organic centre, abont which the different layers are laid down, does not correspond with the centre of the grain but is nearer to one margin. The starch grains of the leguminous plants and cereals, on the other hasul, are concentric, and the nucleus of their formation is in the centre of the grain. The stareh grains of the kidney bean, Phuseolus vulyuris (Fig. 66), have the shape of flattened spheres or ellipsoids; they show a distinet stratification, and are crossed by fissures radiating 
from the centre. The disc-shaped starch grains of wheat are of unequal size, and only indistinctly stratified. A comparison of the accompanying figures (Figs. 65-67), all equally magnified, will give an jea of the varying size of the starch grains of different plants. The size of starch grains varies, in fact, from $0.002 \mathrm{~mm}$. to 0.170 $\mathrm{mm}$. Starch grains $0.170 \mathrm{~mm}$. large, such as those from the rhizome of C'anna, may be seer even with the naked eye, as minute bright bodies. In addition to the simple starch grains so far described, half-compound and compound starch grains are often found. Grains of the former kind are made up of two or more individual grains, surrounded by a zone of peripheral layers enveloping them in common. The compound grains consist merely of an aggregate of individual grains unprovided with any common enveloping layer's. Both half-compound (Fig. $65 \mathrm{~B}$ ) and compound starch grains (Fig. $65 C, D$ ) occur in potatoes, together with simple grains. In oats (Fig. 67) and rice all the starch grains are compound. According to NAGELI ( $\left.{ }^{47}\right)$, the compound starch grains of rice consist of from 4 to 100 single grains; those of the oat of about 300 , and those of Spinacia glabra sometimes of over 30,000 . Starch thus formed from previously assimilated organic substances also requires chromatophores for its production. The grains are formed by means of lencoplasts, which are, in consequence, often termed STARCHBUILDERS. If the starch grain is uniformly surrounded by the lencoplast
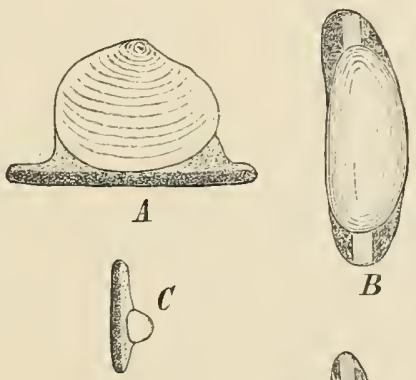

$B$
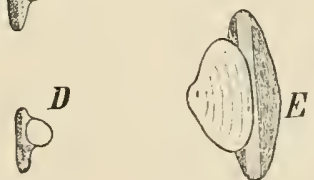

Fic. tis.-Lencoplasts from an aerial tuber of Ihajus grandifolius. $A, C, D, E$, viewed from the side; $L$, viewed from above ; $E$, leucoplast becoming green and changing to a chloroplast. ( $x$ 540$. during its formation it grows uniformly on all sides and is symmetrical about its centre. If the formation of a starch grain begins near the periphery of a leucoplast, the grain will grow more rapidly on the side on which the main mass of the leucoplast is present and the starch grain thus becomes excentric (Fig. 68). Should, however, several starch grains commence to form at the same time in one leucoplast, they become crowded together and form a compound starch grain, which, if additional starchy layers are laid down, gives rise to a half-compound grain.

It has been asserted that starch grains are crystalline bodies, so-called sphaerites or sphaero-crystals $\left({ }^{48}\right)$, and are composed of fine, radially arranged, needle-shaped erystals, which A. MEYE terms trichites. Their stratification, according to this view, is due to variations in the form and number of the crystal needles in the successive layers. On the other hand, H. Frscher $\left({ }^{49}\right)$ has explained 
the stratification as due to zonal splits rich in water, which originate by contraction taking place in the sulbstance of the grain at some distance from its growing surface. Stareh grains are composed of a carbohydrate, the formula of which is $\left(\mathrm{C}_{6} \mathrm{H}_{10} \mathrm{O}_{5}\right)$.n. Most starch-grains consist of amylose, and are coloured blue with iodine and with further treatment almost black. The grains swell in water at $60^{\circ}-70^{\circ} \mathrm{C}$, are but little soluble in water at $100^{\circ} \mathrm{C}$, , but are rapidly dissolved by super-heated water at $140^{\circ}-150^{\circ}$ C. Stareh swells very readily at ordinary temperatures in solutions of caustic potash or soda. Heated without addition of water, i.e. roasted, starch becomes transformed into dextrin, and is then soluble in water and correspondingly more digestible. According to

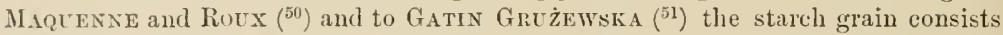
mainly of amylose, which stains blue with iodine, and of a lesser proportion of anylopectin which is colonred violet-blue by iodine; anylopectin is related to glycogen. The inner portion of the grain of potato starch consists of anylose, while the amylopectin forms a peripheral layer. The glutinous starch of varieties of Rice and Millet (Oryza satira, var. glutinosa, Sorghum vulgare, glutinosum) is in the completely nnswollen condition coloured brown with iodine; when swollen by a clilnte solution of iodine, it takes a red, wine-red, or purple colonr. According to $\mathrm{O}$. BütschLI $\left({ }^{52}\right)$ it consists of amyloerythrin, a carbohydrate resembling starch. In polarised light, stareh grains, like inorganic sphaerites, show a dark cross. This appearance is usually referred to the doubly refractive nature of the elements of which the starch grain is constructed.

The amount of starch contained in reservoirs of reserve material is often considerable; in the case of potatoes 25 per cent of their whole weight is reserve starch, and in wheat the proportion of starch is as high as 70 per cent. The starch flour of economic use is derived by washing out the starch from such reservoirs of reserve starch. In the preparation of ordinary flour, on the contrary, the tissues containing the starch are retained in the process of milling.

Aleurone.-Aleurone or proteid grains are prodnced in the seeds of numerons plants, esjecially in those containing oil. They are formed from vacuoles, the contents of which are rich in albumen, and harden into round grains or, sometimes, into irregularly shaped bodies. The albuminous substances of which they consist are mainly globulins $\left({ }^{53}\right)$. A portion of the albumen often crystallises, so that frequently one and occasionally several crystals are formed within the aleurone grain. In alenrone grains containing albumen crystals there may often be found globnlar bodies termed GLOBOIDs, which consist of a doulle phosphate of magnesinm and cillcium in combination with globulins $\left({ }^{54}\right)$. Crystals of calcium oxalate are also found enclosed in aleurone grains. Free globoids are found in the eytoplasm of some seeds.

The seeds of Ricivus (Fig. 69) furnish good exanples of alenrone grains with cuclosel albumen erystals and globoids. The alenrone grains themselves lie cubediled in a cytoplasm that is rieh in oil. In the cereals the aleurone grains, which lie only in the outer cell layer of the sceds (Fig. $70 \mathrm{al}$ ), are small, and free from all inclusions; they contain neither erystals nor globoids. As the outer cells of wheat grains contain only aleurone, and the inner almost exclusively 
starch, it follows that flour is the richer or poorer in albumen, the more or less completely this outer layer has been removed before the wheat is ground. The aleurone layer remains attached to the inner layer of the secd-coat, in the bran.

Reactions for aleurone are the same as those already mentioned for the albuminous substance of protoplasm. Treatment of a cross-section of a grain of wheat (Fig. 70) with a solution of iodine would give the aleurone layer a yellow-brown colour, while the starch layer's would be coloured blue.

Aleunen Crystals. - Crystals of albumen are of relatively frequent occurrence in vegetable tissues and are often found in aleurone grains (Fig. 69). Their appearance in the seed of Ricimus has been described above, and especially large crystals are found

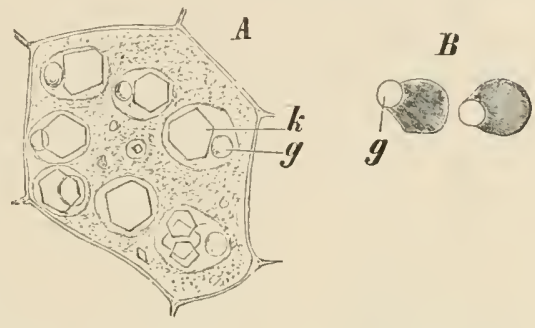
in the endosperm of the Brazil nut (Bertholletice cxcelses) belonging to the Lecythidaceae. They have previously been mentioned as occurring in the chromatophores. In the illustration of the lencoplasts of Phajus yrandifolizs (Fig. 68), the rod-shaped crystals are represented as light stripes (in $B$ and $E$ ). Albunen crystals may also occur directly in the cytoplasm; as, for instance, in

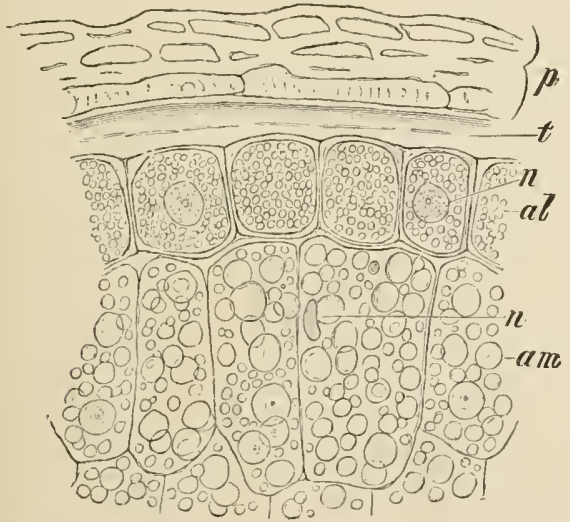

Fig. 70.-Part of a section of a grain of wheat, Triticum vulgare. 1 , Pericarp; $t$, seed coat, internal to which is the endosperm; $a$, aleurone grains ; $a m$, starch grains; $n$, cell nucleus. $(\times 240$. the cells poor in starch, in the peripheral layers of potatoes. Albumen crystals are sometimes found even in the cell nucleus. This is particularly the case in the Toothwort (Lathraca squamaria), and in many Serophulariaceae and Oleaceae $\left(^{55}\right)$. Albumen crystals usually belong either to the regular or to the hexagonal crystal system. They difler from other crystals in that, like dead albuminous substances, they may be stained, and also in that they are capable of swelling by imbibition. Subjected to tlie action of water or a dilute solution of caustic potash, they at first iucrease in size without losing their crystalline form.

\section{Crystals of Caleium}

Oxalate. - Few plants are devoid of such crystals. They are formed in the cytoplasm, within vacuoles which afterwards enlarge and sometimes almost fill the whole cell. In such cases the other components of the cell become greatly reduced; the cell walls at the same time often become corky, and the whole cell becomes merely a repository for the crystal. The crystals may be developed singly in a coll, in which case they are of consider- 
able size and can be seen to belong either to the tetragonal or monosymmetrical crystal system; or the crystals are so small and numerons that their form cannot be clearly made out and they appear as a crystalline sand filling the cell. Frequently they form CRYSTAL AGGREGATES, clusters of crystals radiating in all directions from a common centre. In the Liliaceate, Orchidaceae, and other Monocotyledons, compact bundles of needle-shaped crystals of calcium oxalate, the so-called RAPHIDES, are especially frequent (Fig. 71).

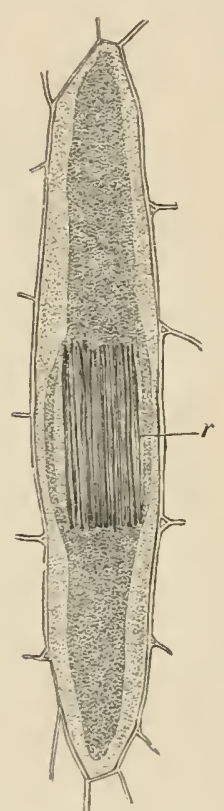

Fı: ;1,-Cell from the cortex of Dracuence rubra, filled with mucilaginous matter and containing a bundle of raphides, $r . \quad(\times] 60$.

Such crystal bundles are always enclosed in a large vacuole filled with a mucilaginous substance. The degree of concentration of the mother liquor from which the crystals have separated, determines, according to KNy ${ }^{(56)}$, their form, whether tetragonal or monoclinic.

Siliceous Bodies, which are only soluble in hydrofluoric acid, are found in the cytoplasm of many cells, especially of Palnis and Orchids, and often completely fill the whole cell.

Taxnix.-Highly refractive vacuoles filled with a concentrated solution of tannin are of frequent occurrence in the cytoplasm of cortical cells, and may often grow to a considerable size. The dark-blue or green colour reaction obtained on treatment with a solution of ferric chloride or ferric sulphate, and the reddishbrown precipitate formed with an aqueous solution of potassium bichromate, are usually accepted as tests for the recognition of tannin, although equally applicable for a whole group of similar substances.

FATs and OILs in plants are mixtures of fatty-acid esters. Frequently, as in most Monocotyledons, a fatty oil appears in the old chlorophyll grains. The occurrence of castor oil in the form of highly refractive drops in the cytoplasm of the alenrone-containing cells in the endosperm of the castor-oil seeds, has already been referred to. Oil usually occurs in this form. But fatty substances may also appear in the cytoplasm as irregularly shaped, more or less soft grains, as for example in the vegetable butters and in the wax of various seeds; they may even be erystalline, as in the needle-like crystals of Para-nuts (Bertholletia excelsa) and of Nutmeg (Myristica fragrans). Special cytoplasmic structures in which the drops of oil are cubediled, are of frecinent occurrence in the epidermal cells of Orchidaceac and Liliaceae and go lyy the name of elaioplasts. These appear to result from the fusion of oily, disorganised chromatophores, and thus resemble some of the products in autumnal leaves $\left({ }^{57}\right)$.

GLYogEx.- l'his sulstance ${ }^{58}$ ) related to starch, and of frequent oceurrence in animal tissues, fulfils, according to Errera $\left({ }^{5 y}\right)$, the same functions in the Fungi as sugar and starch in the higher plants; it also oceurs in the Nyxomycetes and the Cyanophyceac. Cytoplasm containing glycogen is coloured a reddish- 
brown with a solution of iodine. This colour almost wholly disappears if the preparation be warmed, but reaplears on cooling $\left({ }^{60}\right)$.

Ethelifal Olls axi Resixs. - In many cases the strongly refractive drops found disperser throughout the cytoplasm are globules of some ethereal oil. It is the presence of such oils in the petals of many flowers that gives to them their agreeable perfume. Under certain conditions the oil globules may become crystallised. This occurs, for example, in the petals of the Rose. In most cases, according to G. Bertholn and G. Habelilandt $\left({ }^{61}\right)$, ethereal oils or resins are formed in special protuberances of the cell wall and only later are stored in the interior of the cell or in special intercellular spaces formed by separation or destruction of cells. According to A. Tschl rсc ${ }^{62}$ ) on the other hand, the protoplast first deposits a mucilaginous layer within the existing cell wall; the limits between membrane and protoplasm becomes indistinct and in this zone oil-drops appear, which may later fuse to one large drop. Special cells, often with corky walls and filled with resin or ethereal oils, are found in the rhizomes of certain plants, as for instance in those of Acorns Calamus and of Ginger (Zingiber offieinale); also in the bark, as, for example, of Cinnamon trees (Cinnamomum); in the leaves, as in the Sweet Bay (Laurus nobilis); in the pericarp and seed of the Pepuer (Piper nigrum); in the pericarp of Anise (Illicium anisatum).

Mucilage is often found in the cells of bulbs, as in Allium Cepa and trginea Scilla; in the tubers of Orchids; also in aerial organs, especially in the leaves of succulents, which, living in dry places, are thus enabled to maintain their watersupply by means of their mucilaginous cells.

Gurs are in special cases, $\bullet . g$. the formation of cherry gum in the stem of the Cherry tree, formed from substances derived from the contents of the cell and accumulated between the limiting layer of the protoplast and the cell-wall. By the further conversion of the cell-walls into gum, cavities filled with the latter are produced. In other cases the gum is mainly derived from the cell walls. In all cases of gummosis we have, apparently, to do witl a pathological process $\left(^{63}\right)$.

Caortchouc Axd Gutta-percha.-These substances are found in a number of plants belonging to different groups, in particular in the Moraceae, Euphorbiaceae, and Sapotaceae. They occur in the latex of special cells in the form of small globules, which, suspended in the watery sap, gives it its milky appearance.

Exzymes AND Chronogexs $\left({ }^{64}\right)$. Enzymes are of general occurrence in living protoplasm and play an important part in metabolism. Chromogens also are widely distributed, and along with enzymes are concerned with the process of respiration.

Hyinocyanic Acid ANd derived Glucosines ( ${ }^{65}$ ) (e.g. amygdalin, phaseolunatin, etc.) have been of late years shown to be widely distributed in plants. Their occurrence in foliage leaves (Pangium edule, Phaseolus lunatus, Rosaceae) is of special interest, since according to Treu B it is related to the synthesis of proteid substances.

SULPHUR.-The presence of sulphur in the form of small refractive grains in the protoplasm of certain Bacteria, the Beggiatoae, is noteworthy. These Bacteria live in water containing small quantities of sulphuretted hydrogen. According to WiNogRADsky $\left({ }^{66}\right)$ they obtain sulphur from this, and then oxidise it to sulphuric acid according to their neerls.

The Cell Sap.-Under this term is included especially the fluid which in mature cells fills the inner sap cavity. It is generally more watery and clearer than the fluid contained in the smaller vacuoles 
of the cytoplasm. No sharp distinction can, however, be drawn between the sap cavity and vacuoles, and, moreover, a number of such vacuoles may take the place of the sap cavity itself. The cell sap usually gives an acid reaction, owing to the presence in it of organic acids or their salts. The suhstances held in solution by the cell sap are very various. The soluble carbohydrates, in particular the sugar's (cane sugar, the glucoses, and especially grape sugar), frequently occur in the cell sap. The glucoses may be recognised by their reducing properties.

If preparations containing glucose be placed in a solution of copper sulphate, and, after being washed out, are transferred to a solution of canstic potash and heated to boiling, they will give a brick-red precipitate of cuprous oxide. If cane sugar or saccharose be present, this same treatment gives only a blue colour to the cell sap.

Carbohydrates are transported in a plant principally in the form of glucose; cane sugar, on the contrary, is stored mp as a reserve material, as for example in the sugar-beet, in the stems of sugarcane, and in other plants from which the sugar of economic use is derived.

INULIN, a carbohydrate in solution in cell sap, behaves in the same way in the Compositae. Treated with alcohol, inulin is precipitated in the form of small granules, which may be redissolved in hot water. When portions of plants containing much inuliu, such as the root tubers of Dahlia variabitis, are placed in alcohol or dilute glycerine, the inulin crystallises out and forms sphaerites, spheroidal bodies composed of radiating crystal needles; these sphere-crystals often show distinct stratification aud are easily broken up into wedge-shaped portions. Amides such as GLUTAMIN and ASPARAGIN are also generally present in the cell sap. There are frequently found dissolved in the cell sap raxxiss, alKaloIDs, and GLUCOSIDEs, such as coniferin, hesperidin, amygdalin, solanin, aesculin, saponin, and also bitter principles related to the ghucosides. Organic acids (malic, acetic, and oxalic acids) are also of frequent occurrence in the cell sap; thus, malic acid is usually present in the leaves of the succulents. For the most part, these organic acids unite with bases, and the salts which are formed often crystallise. The Field Sorrel (Rumex) and Wood Sorrel (Oxalis) are rich in binoxalate of potassium. Species of Salicornia and Salsola contain sodium oxalate. The cell sap always contains dissolved inorganic salts, especially nitrates, sulphates, and phospliates. The different vacuoles of the sane protoplast nua have distinct contents; thus one may contain tannin and another be free from it, or one may have coloured and another colourless sap.

The ccll sap is often coloured, principally by the so-called ANTHOCYANIN, which Hans Molisch, at least in some cases, regards as being a non-nitrogenons glucoside $\left({ }^{(i}\right)$; it is probably a composite substance. It is blue in an alkaline, and red in an acid reacting cell sap, and, under certain conditions, also dark red, violet, dark blue, and even blackish-blue. Anthocyanin can be obtained from the supersaturated cell sap of a number of decply coloured parts of plants in a crystalline 
or amorphous form. Blood-coloured leaves, snch as those of the Copper Beech, owe their characteristic appearance to the united presence of green chlorophyll and anthocyanin. The autumnal colouring of leaves due to the reddening of the cell sap has already been considered in connection with the colour of the chromatophores. 'The different colours of flowers are due to the varying colour of the cell sap, to the different distribution of the cells containing the coloured cell sap, and also to the different combinations of dissolved colouring matter with the yellow, orange, or red chromoplasts and the green chloroplasts. There is occasionally found in the cell sap a yellow colouring matter known as xanthein; it is nearly related to xanthophyll, but soluble in water.

External Products of the Protoplasts.-Under this head may be considered the cell-walls which characteristically enclose the protoplasts of vegetable cells.

Origin and Structure of the Cell Wall (68).-The membrane which encloses the vegetable protoplast is a product of the protoplasm. Many low organisms belonging to the Algae liberate naked protoplasts from their cells; these swarm-spores (Fig. 98 A) serve to multiply the plant vegetatively. They soon settle down, form a thin cell membrane on the surface of the protoplast, and proceed to give rise to a filament. In more highly organised plants the ovnm, from which the development starts, has no cell wall mntil it has been fertilised; from this stage on, all the cells composing the plant are surrounded by cell walls. At the growing points of plants the cells are separated from one another only by extremely thin membranes or cell walls. As the cells increase in number by repeated division, new cell walls are being continually introduced between the existing ones. The rapid growth in length which sets in a short distance from the growing point, as a result of the increase in the size of the cells, must be accompanied by a corresponding GROWTH IN SURFACE of the cell walls. So long as this growth in surface continues, the cell walls remain thin. After the cells have attained their ultimate size, the GROWTH IN THICKNESS of the cell walls begins. The growth in surface of the cell wall may either involve the introduction of new material, or may take place without this. In the latter case the membrane would become thinner if new lamellae were not simultaneously applied to the surface. Growth of the wall by the introduction of new particles between those previously existing is termed GROWTH BY INTUSSUSCEPTION, while that which occurs by the laying down of new lamellae on the surface of the older ones is called GROWTH BY APPOSITION. The later growth in thickness of most cell walls takes place by apposition, and thus the stratification, which such thickener walls exhibit, is brought about (Fig. 72). Thicker, dense layers alternate with thinner less dense ones. The denser layers can be recognised by their high refractive power. In many cases lamellae, deposited 
by apposition, become further thickened and otherwise modified by a process of intussusception. Three distinct layers can frequently be

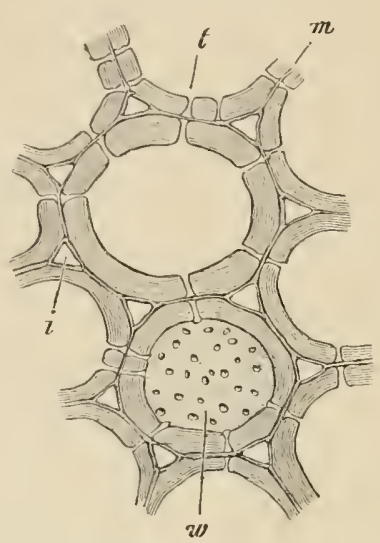

F16. 72.-Strongly thickenerl cell from the pith of Clematis vitulba. $m$, Mirldle lamella; $i$, intercellular space; $t$ pit; $"$, pitted cell wall in surface view. $(\times 300$.

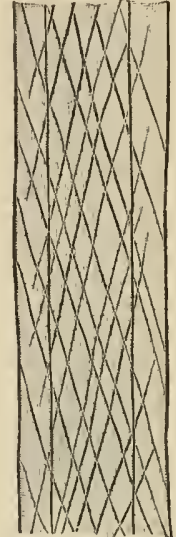

FIG. 73.-Part of a selerenehymatous fibre from Vinca major. The striations of the onter layers are more apparent than those of the inner layers. The thickness of the wall, as seen in optical section, is also shown. $(\times 500$.

distinguished in strongly thickened cell walls, such as those of the wood, a primary, a secondary, and a tertiary thickening layer; these

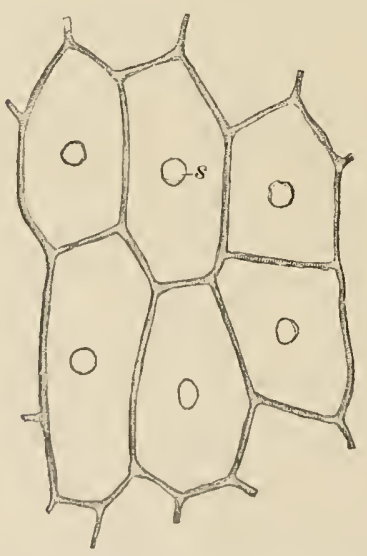

Fis. 74.-Surface view of cells from the sensitive side of the tendril of ('ucurbita l'epo, slowing tactile 1 its, $s . \quad(\times 540$. differ in their optical appearance and their chemical composition. The secondary thickening layer is usually the most strongly developed, and forms the chief part of the cell wall. The tertiary or innermost layer is usually more highly refractive.

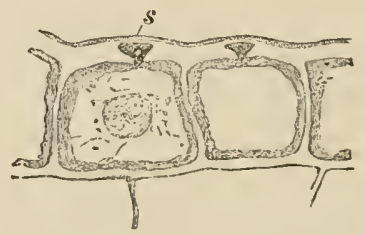

FIf. 75.-Transverse section tlurough similar cells to those in Fig. 68 ; a small crystal of calcium oxalate $(s)$ is present in the tretile jits. $(\times 450$.

Thicker eell walls or layers of the wall which appear homogeneous frequently exhibit a stratifieation when treated with strong acids or alkalies. In nany eases 
the thiekening layers exhibit delieate striations in surface view. The striations extend through the whole thiekness of the layers, usually running obliquely to the long axis of the cell, and often erossing one another in the different thiekening

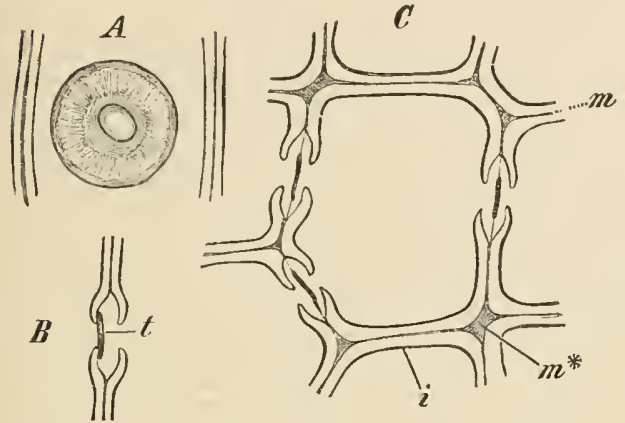

Fic. 76.-From the woor of the Pine, Pinus syleestris. A, Bordered pit in surface view; $B$, bordered jit in tangential section; $t$, torus; $C$, transverse section of a tracheide; $m$, middle lanella, with gusset, $m^{*} ; i$, inner peripheral layer. $(\times 5+0$.

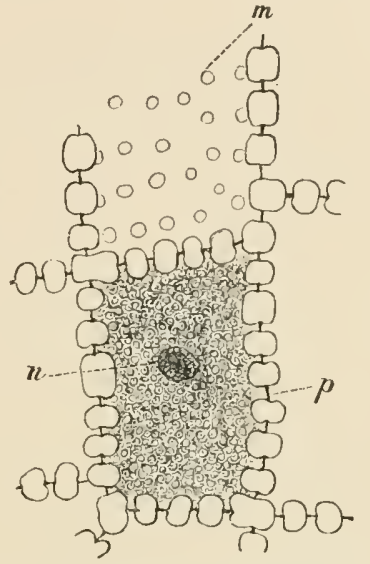

Fir. 77.-Cells from the endosperm of Omithogalum umbellatum. in, Pits in surface view; $p$, elosing membrane; $n$, nuclens. $(\times 2+0$.)

layers (Fig. 73). The striations depend on the presence of lamellae of different thiekness, the thicker ones projecting slightly into the cell eavity. A sinilar appearance of erossing of striations may result from the single thickening layers of two adjoining cells being visible at onee.

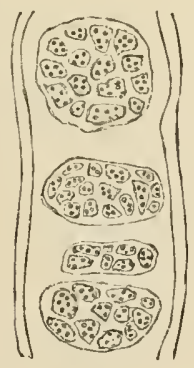

Fr. $7 s .-$ Sieve-plates on the terminal wall of a segment of a sieve-tube of the Scotch Fir. $(\times 750$.
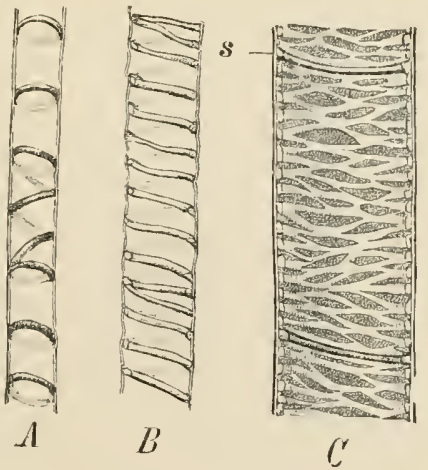

Fig. 79.-A, Part of an anular tracheide ; $B$, part of a spiral tracheide; $C$, longitudinal section through part of a reticulate vessel showing the remains of a partition wall, s. $(\times 240$.

The thickening of the cell wall seldom takes place uniformly over the whole surface; but some portions are thickened, while, at 
other points, the original cell wall remains thin. In this way eanals are formed which penetrate the thickening layers. These pores or PITs may be either circular (Figs. $72 w, 77 \mathrm{~m}$ ), elliptical, or elongated.

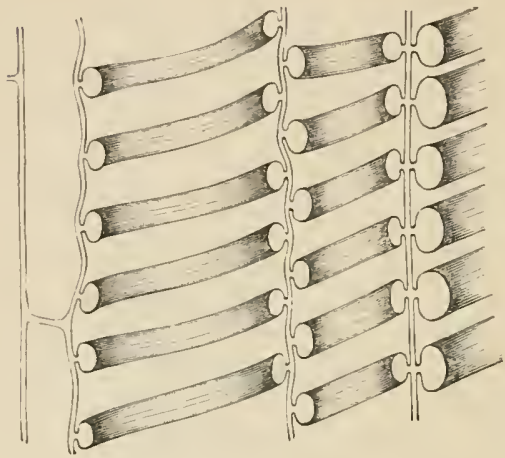

FIG. S0.-Portion of a longitudinal section through three spiral vessels and a row of jarenchyma cells of the Gourd (C'ucurlitu Pepo). (After W. Rотнект. $\times 560$. $)$ The pits in adjoining cells coincirle, and wonld form one continuous canal, were it not that the unthickened primary eell wall persists as a PIT MEMBRANE between the two pits. The openings of narrow elliptical pits into adjoining cells usually appear to cross one another obliquely. As a result of the continued thickening of the cell wall, the canals of several pits often unite, and so BRANCHED PITS are formed. Such branched pits have nsually very narrow eanals, and occur for the most part only in extremely thick and hard cell walls, as, for instance, in those of the so-called sclerotic cells or sclereides. Simple pits may, on the other hand, expand on approaching the primary cell wall.

Pits widened towards the membrane are fornd in the external cell walls of many tendrils $\left({ }^{69}\right)$. These pits, which are filled with eytoplasm, probably receive the stimulus, and may be termed tactile pits (Figs. 74, 75). The structures known as BORDERED PITS (Fig. 76) are a special type of simple pits widened towards the pit membrane. The pit may be present on one or both sides of the wall; the former is the case when the waterconducting element abuts on a cell with protoplasmic contents, the latter when the pitterl

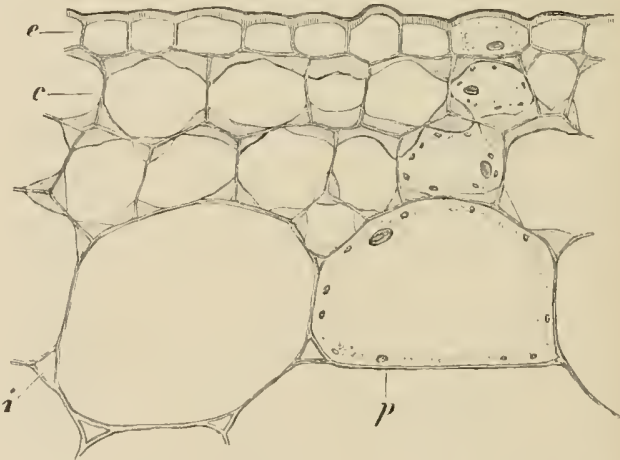

Fic. 81.-Part of transwerse siction of a stem of Impatiens parvifora. e, Epidermis; c, collenchyma ; $r$, thin-lvalled parenchymatous cells; $i$, intercellular space. $(\times 300$.

wall separates two water-condueting elements. In borlered pits the closing membrane is thickened at the eentre to form a Torus (Fig. 76, $B$ ). By the curving of the closing membrane to one side or the other the torus may so act as to close the pit canal (Fig. $76, I B, 1$ ). The bordererl 
pits apparently act as valves. Seen from the surface a bordered pit appears as two concentric rings (Fig. $76, d$ ). The smaller, inuer ring represents the narrow opening of the pit into the cell cavity; the larger, outer ring indicates the widest portion of the PIT CHAMBEl when it abuts on the primary cell wall.

The pit membrane of specially wide pits between cells with thin walls often shows thicker bands which give it a lattice-work appearance. The membranes of the sieve-pits are perforated like a sieve (Fig. 78).

In cases where the greater part of the cell wall remains m-

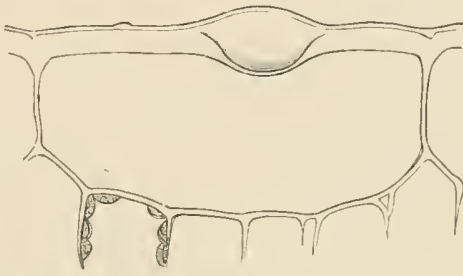

Fic. 82.-Epidermal cell from the marcin of a ralical leaf of Companule jersicifoliu. The lens-shaped thickening of the onter wall is silicified in this plant. (After II ABFirandT. $\times 515$.

thickened, its character is determined by its thickened rather than by its unthickened portions; it is in this sense that the terms

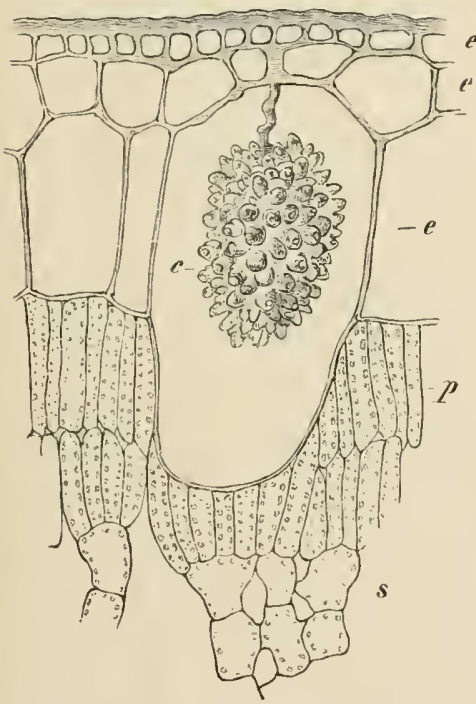

F1G. S3.-Purt of transverse section of a leaf of Ficus clusticu. e, Cystolith; $e, e$, e, threelayered epidermis ; $r$, palisade parenchyma; $s$ spongy parenchyma. ( $\times 240$. annular, spiral, and reticulate are used (Fig. 79). Just as in the case of cells with bordered pits, annular, spiral, and reticulate cell walls are only acquired by cells that soon lose their contents, and act as water-carriers. Such wall thickenings serve as mechanical supports, to give rigidity to the cells, and to enable the cell walls to withstand the pressure of the surrounding living cells.

The thickenet bands by which such thickenings of the cell wall are effected are attached by narrowed bases to the primary membrane $\left({ }^{70}\right)$. When the membrane separates two water-conducting elements its central portion is thickened like the torus of the bordered pit. The annular and spiral types of thickening characterise the water-conducting elements of growing parts of the plant, sinec they allow of extension of the wall chring growth. The thickening band can often be removerl as a continous spiral from the lamella to which it is attached.

Collenchymatous cells are living cells, the walls of which are thickened principally at the corners (Fig. 81 c); such cells occur commonly in the more highly organised plants and form a special kind 
of tissue (p. 127). Cells on the surface of plants have usually ouly their onter walls thickened (Figs \&1 e).

Uneyual thickening of the cell wall is most noticeable when it is limited to definite small areas. This is the ease with those lens-shaper thiekenings of the outer walls of the epidermal cells of the npper surface of foliage leaves, which are of frequent oceurrence and, aeeording to G. HABERLANDT $\left({ }^{71}\right)$, act as eonvex lenses to coneentrate the light (Fig. 82). By the thiekening of cell walls at special points, protuberances projeeting into the eell cavity are formed; in this way the formations known as Crstolitus arise. Certain large cells in the leaves of the India-rubber plant (Ficus clastica) contain peeuliar clustered bodies, formed by the thiekening of the eell wall at a single point (Fig. 83). In their formation a stem-like body or stalk first protrudes from the cell wall; by the

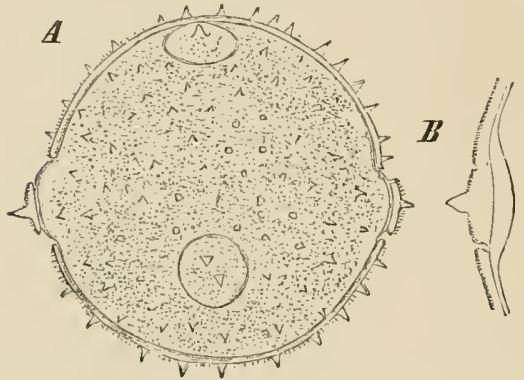

Fif, S4-A, Pollen-grain of Cucurbita Pepo in surface view, and partly in optical section, renderer transparent by treating with oil of lemons $(\times 240) ; B$, part of transverse section of pollen grain of Cucurbita rerrucosı $(\times 5+0)$. addition of freshly deposited layers this beeomes club shaped, and, by continued irregular deposits, it finally attains its warty surface.

So far only centripetal wall thickenings have been described. Cells, the walls of which are centrifugally thickened, can naturally only occur where the cell walls have free surfaces. The outer walls of hairs generally show small inequalities and projections. The surface walls of spores and pollen grains (Fig. 84) show a great variety of such centrifugally developed protuherances, in the form of spines, ridges, reticulations, and bands of characteristic structure.

Cell-Wall Substance ( $\left.{ }^{2}\right)$. - The most important constitutent of cell walls is cELlulose. It is present in the cell walls of all plants, except in those of the majority of Fungi.

Cellulose is a earboliydrate, one of the polysaceharides of which the chemical composition is expressed by the general formula $\left(\mathrm{C}_{6} \mathrm{H}_{10} \mathrm{O}_{5}\right) n$. It is insoluble in dilute acids or alkalies ; even encentrated potash solntion does not dissolve it. By the action of coneentrated sulphuric acid it is converted into dextrose and becomes soluble, and it is dissolved by ammonia oxide of copper. After treatment with sulpluric or phosphorie acid, iocline will colour it blue; it shows a similar reaction when exposed to the simultaneous action of a eoncentrated solution of certain salts such as zine chloride or ahminimm ehloride, and of ioline. Accorlingly, chlorzinc-ionlide, on accoun of the blue colour imilarted by it, is one of the most eonvenient tests for cellulose. Gruson $\left({ }^{73}\right)$ ohtained celluloşe in a erystalline conclition in the form of sphacrites or dendrites. The name of hemicellulose is given to a series of substances which are nearly related to cellulose but are liydrolysed by even dilute acids and yield sngars other than dextrose. 
The cell walls never consist entirely of pure cellulose, but contain a considerable amount of other substances, which are not stained blue by chlor-zinc-iodide. In mulignified cell walls PECTIN SUBSTANCEs are particularly prominent. They are easily distinguished by the readiness with which they dissolve in alkalies, after being previously acted upon by a dilute acid.

Susceptibility to certain stains-for example, congo red-is a characteristic of cellulose; while other stains such as safranin and methylene blue, colour pectin substances more deeply. According to Mangis, the partition wall formed in the higher plants during cell division consists almost wholly of pectin substances; the next developed lamellae, the secondary cell-wall layer, of a mixture of cellulose and pectin substances; the last formed, or tertiary layer, chiefly of cellulose.

Among the substances entering into the composition of cell walls, in addition to cellulose and the pectin substances, mention must be made of CALLOSE. It is characterised by its insolubility in cuprammonia and solubility in soda solution, and in a cold 1 per cent solution of caustic potash. It is coloured a red brown by chlor-zine-iodide, with aniline blue it takes an intense blue, and with corallin (rosolic acid) a brilliant red. Its presence in the higher plants is linited to a few speeial cascs; it envelops the sieve-pits and is always present in ealeified cell-wall layers, as, for example, in cystoliths (Fig. 83). Chitin, a proteid substance, according to GrLsos, takes the same place in the cell walls of the Fungi as cellulose in the cell walls of the ligher plants $\left({ }^{74}\right)$.

Where cell walls become LIGNIFIED or SUBERISED, it is particularly the secondary layer that receives the wood or cork substance, while the tertiary or internal layer retains its cellulose character.

Lignification depends on the introduction into the membrane of certain substances, and lignified cell-walls are characterised by staining yellow with acid aniline sulphate, violet with phloroglucin and hydrochloric acid, and red with ammonia after previous treatment with a one-per-cent solution of permanganate of potash. With chlor-zinc-iodide lignified walls stain yellow, not blue. The substances to which these lignin-reactions are due lave not yet been recognised with certainty. CzAPEK ( ${ }^{75}$ ) ascribed them to an aromatic aldehyde which he named hadromal, but this has been disputed and a return made to an older view which ascribes the same role to vanillin $\left({ }^{76}\right)$.

Special aromatic substances which increase the powers of resistance of the nembrane infiltrate the cell walls of Bryophyta (ii). A definite but not clearly recognised substance in pregnates the walls of various tissues in Ferns and gives them the characteristic dark brown colour. It may precede the deposit of lignin $\left({ }^{78}\right)$.

Corky cell walls contain suberin and take a yellowish brown colour with chlorzine-iodide; with eaustic potash, a yellow colour. VAN WIsSEL1NGH $\left({ }^{79}\right)$ has disputed the presence of cellulose in suberised cell walls, and regards the cork sulsintance or sUBERIN as a fatty body, which is composed of glycerine esters and other compound esters, as well as of one or more other substances which are infusible, insoluble in chloroform, and decomposed by a solntion of caustic potash.

Cutinisation, which is similar to but not identical with suberisation, is usually due to the subsequent deposition of eutin in cellulose cell walls. 
Vix Wissfixgu has shown that phellonic acid, which is always present in suberin, is constantly absent in cutin. The belaviour of cutin, as of suberin, varies according to the source from which it is derived. Cutin withstands better the action of caustic potash. In other respects, the reactions given by cutinised cell walls with chlor-zinc-iodide or solutions of eanstic potash are almost identical with those of subcrised cell walls. Both are insoluble in sulphuric acid and in cuprammonia.

Young cell walls are less elastic, but relatively more extensible than older ones. The power of resisting a stress is increased by lignification. The presence of cutinised and corky membranes diminishes the loss of water from the surface of the plant.

The layers of the cell walls of some cells, particularly the superficial cells of certain fruits, as of Sage, and of numerous seeds, such as Flax and Quince seeds, become mucilaginous, and swell in water to MUCILAGE, which serves the purpose of attaching the seeds to the soil. Firm cell walls can also be transformed into GUM, as is so often apparent in Cherry and Acacia trees, portions of the wood of which often succumb to GUMnosis (p. 69).

In such cases, however, only a small amount of the gum is derived by the change of the cell walls. In the case of Cherry gum this part is insoluble in water, while the gum formed within the cells is soluble $\left({ }^{63}\right)$.

The cell walls of the seeds of many Palms, as also those of Ornithogatum (Fig. 7 ), have strongly dereloped thickening layers, which are full of pits. These thickening layers are lustrons white, and, as in the case of the seeds of the Palm, Plyteleplias macrocurpo, may attain such a degree of hardness as to be technically valuable as vegetable ivory. Such thickening layers may contain other carbolyylrates in addition to cellulose, and by the action of ferments are clissolved during germination. They are accordingly to be considered as a reserve substance of the seeds.

Cell walls often become coloured by derivative substances of tannin; in this way, for instance, the dark colour is produced which is often seen in the coats of seeds and in old wood. The colours of the woods of economic value are dne to such discolonred cell walls. Inorganic substances are often deposited in large quantities in old cell walls. Among snch substances calcium oxalate is often met with, commonly in crystal form; also, though not so frequently, calcium carbonate. In the eystoliths of Ficus elustica (Fig. 83) so much calcium carbonate is deposited that it effervesces with hydrochloric acirl. In some plants, as, for instance, most of the Characeac, the quantity of calcium carbonate in the cell walls is so great as to render them stiff and brittle. Silica is also present in the superficial cell walls of the Gramineae, Equisetaceite, and many other plants, and gives them a very consirlerable firmness. The lens-shaped thickenings in the outer walls of the epiclermal cells of Campunulu persicifolia are also silicifierl (Fig. 82).

by withdrawing water from the cells a contraction of the protoplast and its 
conseyuent separation from the eell wall is brouglit about (see plasmolysis). Snch protoplasts are able under certain conditions to surromd themselves with a new cell-membrane. The removal of the cutiele or of the waxy eovering from the surface of eertain plants (Agove, Aloc, Ricinus, Salum), is followed by its regeneration $\left({ }^{80}\right)$.

Form of the Cell.-As cytoplasm is a viscous fluid, and would tend, if unimpeded, to take a spherical shape, it may be assumed that the natural and primary form of cells is spherical. Such a shape, however, could only be realised by cells which, in their living condition, were completely free and unconfined, or in such as were able to expand freely in all directions. Newly dereloped cells, in a continuons tissue, are, at first, nearly always polygonal. Through subsequent growth their shape may change. The cubical cells of the growing point, with a mean diameter of $1-2 \mu$, either elongate to a prism or remain, owing to repeated division, short and tabular. If the growth is limited to certain regularly arranged points of the surface, they become stellate; if these points are less uniformly arranged their outline is correspondingly unsymmetrical. In consequence of energetic growth in length, fibre-like, pointed cells are developed. If the walls of such cells become much thickened, they are called SCLERENCHYMA fibres (Fig. $85 A$ ). These show diagonal markings, due to their elongated pits, which are generally but few in number. When fully developed, the living contents of such cells are small in amount and frequently they contain only air. In the last case, they merely act as mechanical elements (stereides) and contribute to the rigidity of the plant as a whole. Cells

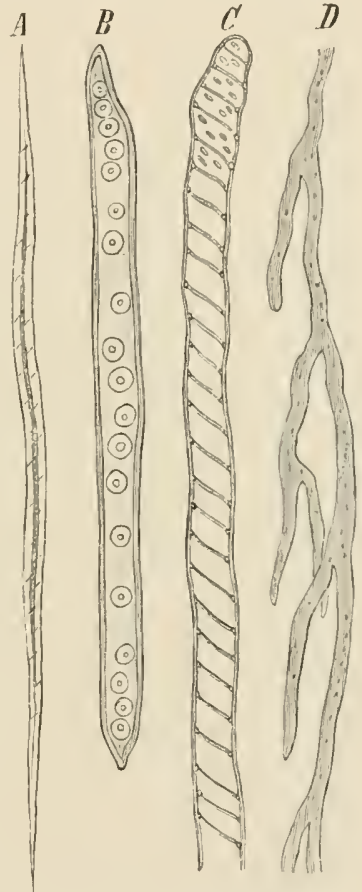

Fig. 85.-A, A selerenchymatous tibre; $E$, a traclieide; $C$, part of a spiral tracheide; $D$, part of a latex tube. $(A, B, C, \times 100 ; D, \times$ eirea 150.)

somewhat similar, but shorter and considerably wider, not pointed at the ends, and provided with bordered pits, are called TRACHEIDEs (Fig. $85 \mathrm{~B})$. The tracheides, in their fully-developed condition, never have any living contents, but selve as water-carriers for the plant. So long as they remain active, they contain only water and isolated air-bubbles; their active functions afterwards cease, and they become filled with air. Tracheides which are specially elongated, and at the same time have only a narrow lumen, and, like the sclerenchymatous fibres, serve merely mechanical purposes, are known as FIBRE TRACHEIDEs. Very long 
tracheides with a wide lumen and thin walls, serving, like typical tracheides, as water-earriers, are distinguished as vasiform or VASCULAR TRACHEIDES (Fig. $85 \mathrm{C}$ ). They are characterised by the annular, spiral, or reticulate markings of their thickening layers, and nuy also be provided with bordered pits. The walls of tracheides are always lignified, while those of the sclerenchyma fibres may or may not have undergone this change.

Of all the cells in the more highly organised plants, the LATEX CELLS or milk cells, also spoken of as latex tubes, attain the greatest length. In the Euphorbiaceac, Horaceae, Apocynaceae, and Asclepiadaceae they arise from cells which are already differentiated in the embryo. Growing as the embryo grows, they branch with it and penctrate all its members, and may thus ultimately bcome many metres long. The latex cells themselves have, for the most part, unthickened, smooth, elastic walls which give a cellulose reaction. They are provided (s1) with a peripheral layer of living eytoplasm and numerous nuclei. Their sap is a milky, usually white fluid, which contains gum-resins, i.e. mixtures of gums and resins, eaontehonc, fat and wax in emulsion. In addition, they sometimes hold in solution enzymes, leptomin, tannins, of ten poisonous alkaloids, and salts, especially calcium malate, also in the ease of Ficus Caricu and Carica Papaya peptonising ferments. Proteid granules often occur in the latex, and in the latex cells of the Euphorbiaceae there are also present peculiar dumb-bell-shaped starch grains. On exposure to the air the milky sap quickly coagulates. In the adjoining figure (Fig. $85 \mathrm{D}$ ) is shown a portion of an isolated latex cell dissected out of the stem of an Asclepiadaceous plant, Ceropegin stapelioides.

Special cells which differ in form, contents, or in their peculiar wall thickenings from their neighbouring cells, are distinguished as IDIOBLASTS. If strongly thickened and lignified, they are called sclerotic eells (stone cells) or sclereides (Fig. 168). They often contain ferments; in the Cruciferae and sone other order's myrosin is thus present, while Prunus laurocerasus contains emulsin. For the most part they contain excreted substances such as tannins and calcium oxalate. In Fig. 71 an idioblast, containing a bundle of raphides, is representerl. Idioblasts, resembling tracheides and functioning its water reservoirs, are found between the chlorophyll-containing eells in the lcaves of some of the Orchidaceae and Cactaccae.

Size of Cells. - The corresponding cells of equivalent members of the sime plant are usually of niearly the same size, even when the members show a rariation in size. In meristematic cells there is a definite relation hetween the amount of cytoplasm and the size of the nucleus. This has been recognised as the nuclens-plasm relation by R. HERT'IG $\left({ }^{82}\right)$.

Differentiation of the Protoplasts. - In organisms composed of one or of few cells the separate parts of the same protoplasts 
may under some circumstances exhibit marked differences. On the other hand, in multicellular organisms whole protoplasts are speeialised for functions with the performance of which their definite structure is connected.

\section{ONTOGENy OF THE Cell}

The Origin of the Living Elements of Protoplasm.-All the nuclei in an organism owe their origin to the nuclei of previous generations. The spontaneous formation of a nucleus never takes place. In the same manner, the cytoplasm, of every organism is derived from pre-existing eytoplasm, and, so far as is yet known, the chromatophores take their origin only from their own kind.

Nuclear Division.-Exeept in a few well defined cases, nuclei reproauce themselves by MITOTIC or INDIRECT DIVISION. This process, often referred to as KARYOKINESIS, is somewhat complicated, but seems necessary in order to effect an equal division of the substance of the mother nucleus between the two new daughter nuclei.

Indirect Nuclear Division ${ }^{(83)}$. - In its principal features the process is similar in the more highly organised plants and in animals. Its stages are represented in a somewhat diagrammatic manner in the following figure (Fig. 86), as they occur in a vegetative cell such as those which compose the growing point.

The fine network of the resting nucleus (Fig. 86, $1 n$ ) becomes drawn together at definite points and separated into a number of bodies (Fig. 86, $2 \mathrm{ch}$ ), the outline of whieh is at first irregular. Theil form soon becomes filamentous, and the filaments become denser and at the same time shorter and thicker (3), and stain more deeply. The stainable substance of the filament, which is called ehromatin, becomes arranged in more or less regular transverse discs united by the unstained linin (3). The filaments themselves are callerl chromosomes (Fig. 86, 3, 4). The chromosomes are moved into the plane of division where they constitute the nuclear or equatorial plate (5 kp, 6, 7 ). Each ehromosome has meanwhile undergone a longitudinal split which continues to become more marked $(5,6,7)$. The two halves of each chromosome thus separated move away from one another in opposite directions, and take part in the formation of the daughter nuclei $(9 t)$.

Other changes serve to direct the process thus briefly described. While the nuclear network is separating into the individual chromosomes, cytoplasmic filaments become applied to the nuclear membrane, surrounding it with a fibrous layer. This layer becomes raised up from the nuelear membrane at two opposite points $(3 k)$ and forms the polar caps. These are filled with a homogeneous substance in which fine filaments appear later. The filaments converge at the poles, without, however, coming into contact; they constitute two pointed bundles, since they diverge from one another as they pass from the polar regions $(4 \mathrm{l})$. At this stage the nucleoli $(n l)$ are dissolved and the 
nuclear membrane disappears. The fibres proceeding from the polar caps ean thus beeome prolonged into the nuclear cavity $(4,5)$. Here they either become attached to the chromosomes, or filaments from the two poles may come into contact and extend continuously from the one pole to the other. In this way the nuclear spindle is formed
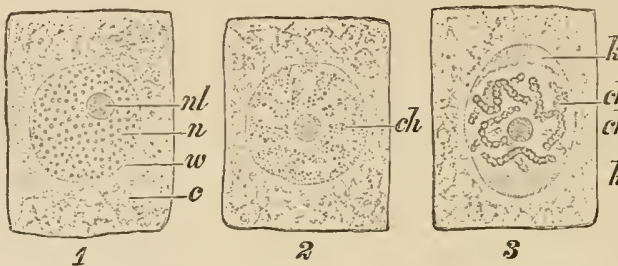

3

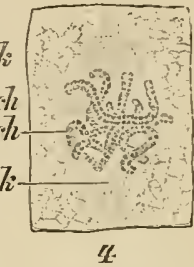

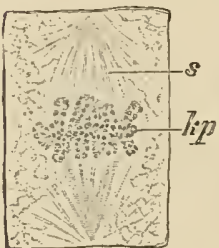

s

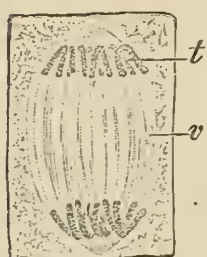

9

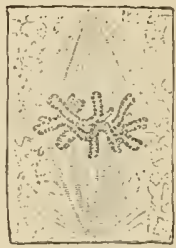

6

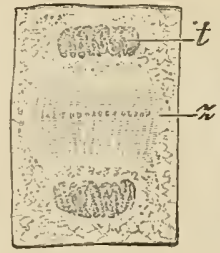

10

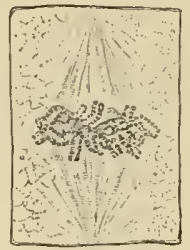

y

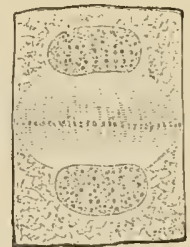

11

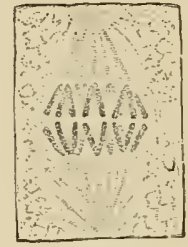

8

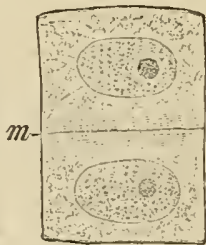

12 उु)

FIG. S6.-Successive stages of nuclear- and cell-division in a meristematic cell. $n$, Nueleus ; $n l$, nucleolus ; $w$, nuclear membrane ; $c$, cytoplasm ; $c h$, chromosomes ; $k$, polar caps ; $s$, spindle ; $k p$, nuclear plate; $t$, young daughter nuclei ; $v$, connecting fibres: $z$, cell-plate; $m$, new cellwall. In 1 , the resting nucleus ; 2 and 3 , separation of the chromosomes; 4 , ehromosomes with transverse tlises ; 5 , the arrangement of the chromosomes to form the cell-j)late and their longitudinal fission; 3.5 show the formation of the spindle from the polar eaps; 6 , the longitudinal fission of the chromosomes; 7 becinning of their separation to either pole; $s$, the complete separation of the daughter chromosomes; $n$, passage of the daughter chromosomes to either pole; 10-12, formation of the daughter nuclei; in :-11 the origin of the connecting fibres aud of the cell-plate is seen, while in 12 the new cell-wall is formed. ( $x$ about 600. )

$(5,6,7)$. The fibres of the spindle attached to the chromosomes may be termed traction-fibres, those which run from pole to pole supportingfibres. The nucleoli appear to constitute a reserve substance which serves to nourish the chromosomes and, later, has the special duty of provicling material for the formation of the spindle. Any excess of nucleolar substance passes into the surrounding cytoplasm, where it forms the so-called extra-nuclear nucleoli. The traction-fibres promote 
the arrangement of the chromosomes in the equatorial plane (5). After the chromosomes have split longitudinally into the daughter chromosomes, the latter are separated and drawn towards the two poles by the contraction of the traction-fibres $(8,9)$. The supporting-fibres afford the necessary resistance in the process. The spindle fibres ean often be traced to the limiting layer of the cytoplasm, and their attachment to this determined. In forming the daughter nuclei, the free ends of the chromosomes first become drawn in (10), and the surrounding cyptoplasm separates itself by means of a protoplasmic membrane, the nuclear membrane (11), from the developing nuelei. Within the nuclear cavities which are thus produced the chromosomes again assume a reticulate structure and unite with one another to form a network within which their individual limits are not distinguishable. We are compelled, however, to assume that the
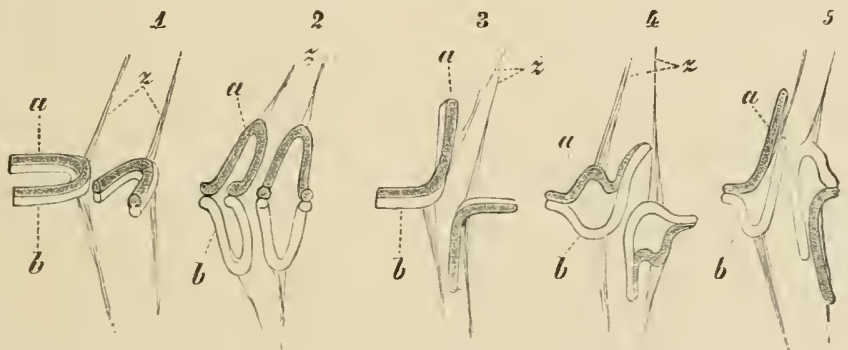

Fir. 87.-Diagrammatic represeutation of the different positions occupied by the chromosomes on the spinile and during their separation. $a$ and $b$, daughter chromosomes of one mother chromosome ; $z$ traction-fibres of the spindle.

individuality of the chromosomes is not lost.

The young nuclei enlarge, the extra-nuclear nucleoli disappear in the surrounding cytoplasm, and one or more nucleoli at length appear in the nuclei; finally the resting condition is again attained.

The process of nuclear division is described above as it usually takes place in the young tissues of more highly organised plants. The ehromosomes are usually loop-shaped, and the traction-fibres beeome attachel to the middle point of the loop, less commonly toward an end. The traction-fibres from the two poles attach themselves respeetively to the two danghter ehromosomes of each pair. The orientation of the pairs of daughter chromosomes on the nuclear spindle, and the way in which they separate from one another, are represented in the accompanying liagram (Fig. 87). In (1) the two shanks of each pair of chromosomes lie nearly in the equatorial plane, and each of the daughter chromosomes on their separation (2) assumes the form of the letter $U$, remaining attaehed by the shanks. More commonly, while one of the shanks of the paired chromosome lies in the equatorial plane, the other is directed towards one of the two poles (3). In this ease a condition of things results, when the daughter chromosomes separate, which is represented in 4 or 5 . The former shows the resulting appearanee when the daughter ehromosomes remain for a time attached to one another at both ends; the latter when separation soon follows at the end directed towards the nuclear 
pole. In ail cases the separation proceeds from the point of attachment of the traction-fibres. When a paired chromosome is attached to the spindle near one of its ends, the sejaration of the daughter chromosomes naturally commences near this end; when the attachment is by the middle of the chromosome the daughter chromosomes remain Ionger attached by their ends. In Fig. 86 the behaviour of the chromosomes is represented as in the diagrams 3 and 4 (Fig. 87). As a rule it does not appear so clearly, but more or less combined with the other type.

The changes occurring in a mother nucleus preparatory to division are termed the plivpliases of the karyokinesis. These changes extend to the formation of the nuclear plate, and include also the process of the longitudinal division of the chromosomes. The stage of the nuclear plate is the metapHase. The separation of the daughter cliromosomes is accomplished in the ANAPHAss, and the formation of the daughter nuclei in the TELOPHASE of the division. The real purpose of the whole process is attained in the quantitative and qualitative division of the chromosomes, resulting from their longitulinal splitting (Fig. S6, 5, 6, 7; Fig. 87). The auaphases and telophases of the karyokinesis are but a reverse repetition of the prophases. The reversal of the stages in the process of nuclear division commences with the separation of the daughter chromosomes. The stage of the nuclear plate at which the progressive is replaced by the regressive movement tends to last a considerable time.

The number of chromosomes occurring in any nucleus is a definite one, and when a deviation from the usual number is met with, it is due to some of the chromosomes having remained united end to end. The chromosomes of a nucleus mat be of different sizes; when such differences in size exist they persist in successive divisions. The smallest number of chromosomes which has yet been found in the nuclei of vegetative cells of the more highly organised plants has been eight; as a rule the number is larger, amounting often to several times this number.

A special type of nuclear division, to which the name of REDUCTION DIVIsion ( $\left.{ }^{84}\right)$ is given, is met with in those reproductive cells which start a new generation, such as the spore-mother-cells of the higher Cryptogams and Phanerogams. In the prophase of this division the chromosomes become united in pairs (Fig. 88, 1, 2), and there then occurs a marked contraction of the nuclear contents, which is eharacteristic of this process of division and is called synapsis (3). After this the double chromosomes become again loosened out as a delicate doulle thread (4), which soon unites to a correspondingly stont threarl, forming a loose skein (5). The doubled nature of this thread soon becomes recognisable again (6). The skein consisting of the as yet umbroken double thread now falls into segments ( 7 ), each of which corresponds to one paired chromosome. The number of these segments which are termed GEMINI is half as great as the number of chromosomes in the tissue eells of the same plant, since two ehromosomes are represented by each segment. The paired chromosomes become shorter and thicker and are distributed around the periphery of the nuclens; this is the condition that has been termed DIAKINEsis (8). At this stage kinoplasmic filaments are becoming applied to the muclear memlorane (8); the latter disappears and the nuclear spindle, which is at first multipolar (9), but ultimately becomes bipolar (10), 

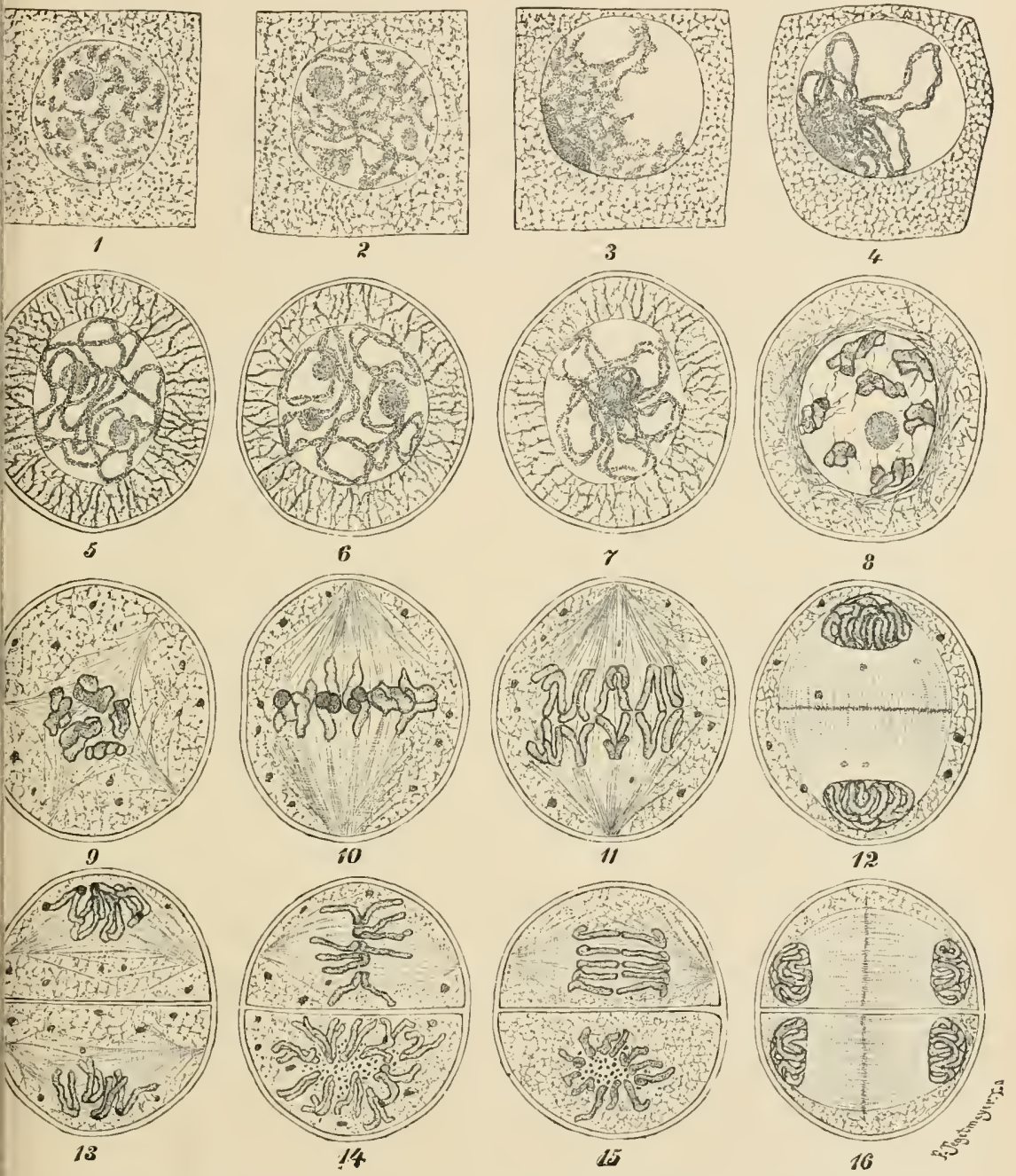

FIf. 8s.-Dividing pollen mother cells of a Lily, somewhat diagramnatic. 1. Mother cell with resting nucleus ; 2 , the separation of the chromosomes; 3 , the condition of contraction known as synapsis; 4, double filanent in process of fusion ; 5 , spirem consisting of an alparently single filament derived from the fused double filament; i, reappearance of the longitudinal split, the spiren still unsegmented; 7, spirem transversely segmented, into paired chromosomes; 8 , diakinesis; 9 , multipolar spindle; 10 , spindle of the mother nucleus, the nuclear plate composed of paired chromosomes; 11, reduction division, the separating chromosomes showing partial separation of their longitudinal halves; 12 , young daughter nuelei; 13 , the longitudinal halves of the chromosomes (danghter chromosomes) are arranged in pairs on the nuclear spindles; 14, the spindles of the daughter nuclei; 15 , separation of the danghter chromosomes; 16, young stage of the grand-laughter nuclei. ( $x$ about 800 .) 
originates from the kinoplasmic fibres. The paired chromosomes become attached to the fibres of the spindle and arranged in an equatorial nuclear plate (10). Shortly afterwards the separation of the chromosomes, until now united in pairs, takes place (11). In this process, in which the essential of the reduction division is effected, it is not longitudinal halves of chromosomes but entire chromosomes which separate from one another. The result of this is that each daughter pucleus receires only half as many chromosomes as were found in the tissue cells of the same plant. During their passage towards the poles of the spindle a longitudinal split can be detected in each chromosome. This split was indeed already complete in the prophase before the nuclear plate was formed, but was not followed as in an ordinary division by a separation of the halves. The two halves of each chromosome remain on the other hand in relation to one another and pass to the same daughter nucleus. The formation of the daughter nuclei is completed (12) as in an ordinary division, but following promptly on the first reduction division, which is also known as the HETEROTYPE division, comes a second or HOMOTYPE division. In this no new longitndinal splitting of the chromosomes takes place, but the two halves of each chromosome, which existed in the daughter nuclei, become separated from one another, and become the chromosomes of the grand-daughter nuclei.

The steps of this homotype division agree in other respects with those of an ordinary nuclear division, and will be clear from Fig. 8s, 13-16. In 13 an early stage and in 14 the completed condition of the spindles of the dividing daughter nuclei are seen; 15 shows the division of the nuclear plate, and in 16 the young grand-daughter nuclei are completed. One of the characteristic features of the whole process is that the two divisions succeed one another immediately or very quickly. The heterotype and homotype nuclear divisions, which may together be termed the MEIOTIC (meiosis) or ALLOTYPIC division, may be contrasted with the ordinary or typical nuclear division; this latter is also known as somatic division. At a particular stage of development corresponding phenomena to those of the meiotic division are met with in animals as well as in plants.

The smallest redueed number of gemini known for the nuclei of the sexual generation in the more highly organisel plants is three (in the Composite Cregis virens); this is the half of the smallest number found in the nuclei of the corresponrling asexual generation.

l'or certain of the lower Cryptogams, e.y. the Sea-weed Fucus, a division into two of the centrosome-like body ( 1 . 53) in relation to the nuclens is recorded at the ermmencement of karyokinesis. The halres separate from one another (Fig. $89 \mathrm{c}$ ) and ultimately come to occupy the poles of the nuelear spindle. Round the cytoplasm investing these centrosome-like bodies, kinoplasmic rarliations form (Fig. $89 \mathrm{~km}$ ). When the two bodies have reached the poles of the nucleus, the nuclear membrane disaplears at these points and spindle fibres aplear in the nuclear eavity and attach themselves to the chromosomes. The complete nuelear 
spindle (Fig. 90) agrees in structure with the spindle of more highly organised plants, and so do the proeesses of division and the formation of the daughter nuelei. The kinoplasmic radiations round the centrosome-like struetures only persist chring the karyokinesis. In other similar cases, as in the marine alga stypocaulem, the eorrespondence of the body visible in the midst of the rarliations during karyokinesis with animal centrosomes has been reeently questioned $\left({ }^{39}\right)$.

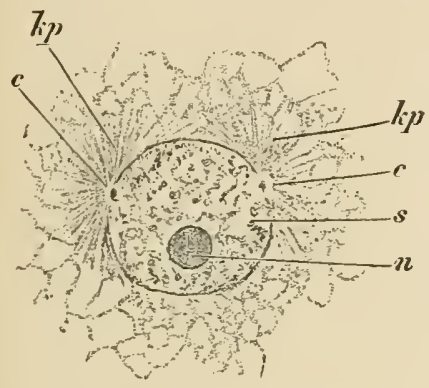

Fir. 89.-A nuelens of a young plant of the Brown Seaweed, Fucus serrutus, preparing to divide. The two centrioles (c), which have arisen by the division of a single one, have already sejarated from one another; $k p$, radiations of the kinoplasm ; $s$, chromosomes; $n$, nucleolus. $(\times 1000$.

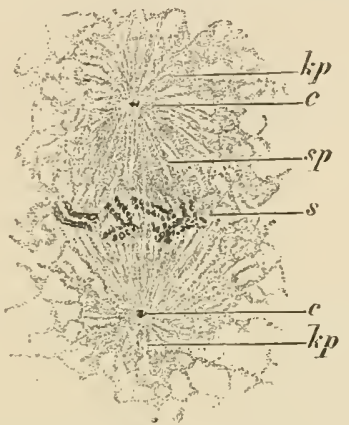

Fir. 90.-A nuclear spindle of a cell of a young jlant of the Brown Seaweed, Fueus serrutus, with split chromosomes in the nuclear plate. c, centrosome-like structures; $k p$, radiations of kinoplasm: $s p$, spindle fibres; $s$, longitudinally divided chromosomes forming the muclear piate. $(\times 1000$.

They also increase in number by division and form pernanent constituents of the protoplasts. Nevertheless the plasmatic masses in Fnngi and Bryophyta, which do not contain centrosome-like bodies, appear to arise during karyokinesis at the poles of the nucleus and not to persist after the division.

The fundamental difference between the typical and somatic nuclear division and the reduction division may be made clearer by
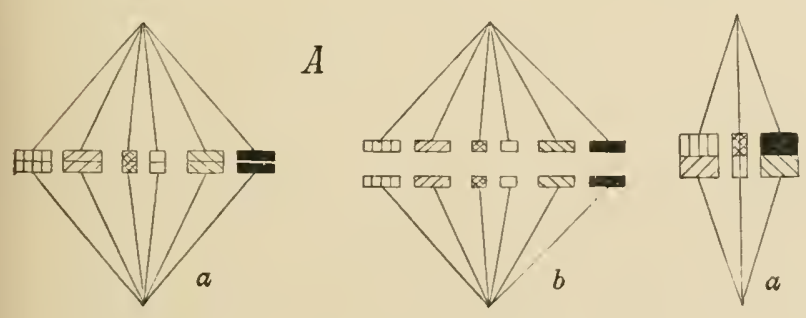

$B$

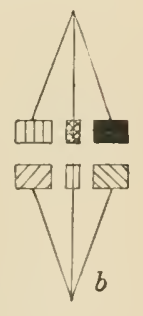

Fur, 91.-Diagrammatic representation of ordinary melear division (A) and of the reduction division (B).

means of a diagram. Fig. 91 A represents a somatic division with longitudinal splitting of the chromosomes. In A $\bullet$ six longitudinally split chromosomes, distinguished by the different shading, are shown arranged to form the nuclear plate. The two middle ones are seen from the end, the others from the side. In $A b$ the separated halves of 
these chromosomes are shown on their way to the poles of the spindle in order to form the daughter nuclei. In Fig. $91 \mathrm{~B}$ the reduction division is diagrammatically represented. The six chromosomes of Fig. $91 \mathrm{~A}$ are shown in $\mathrm{B} a$ similarly shaded and united in three gemini. The two lateral gemini are seen from the side, the midclle one from the end. The latter one shows the longitudinal split in the component chromosomes and the orientation of the plane of fission. In $\mathrm{B} b$ the chromosomes of each geminns have separated and are moving towards the poles of the spindle to form the two daughter nuclei. The two halves of each chromosome thus go to the same daughter nucleus.

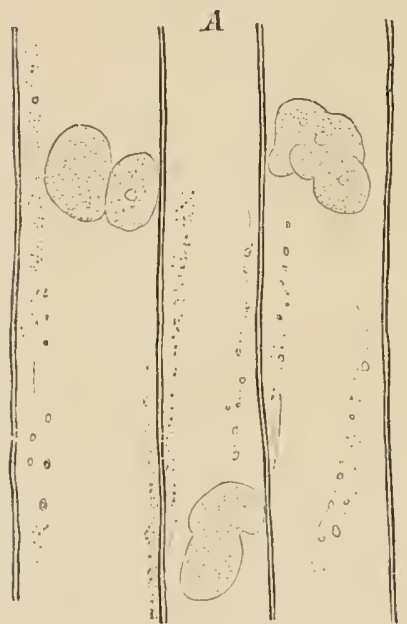

Furi, 92.-Old celly from the stem of Tradrscentia rirginica, showing nuclei in process of direct division. ( $\times 540$.

This division results in a reduction of the chromosome number from six to three. In contrast to this reduction division which, because whole chromosomes separate, results in a definite difference of the products of division, may be placed the somatic nuclear division. This, since the longitudinal halving of the chromosomes gives rise' to completely equivalent products of division, may be termed equation division.

Direct Nuclear Division ${ }^{\left({ }^{5}\right)}$. - - In addition to the mitotic or indirect nuclear division there is also a DIRECT or AMITOTIC division, sometimes called FRAGMENTATION (Fig. 92). In the lowest organisms many nuclear divisions are intermediate in nature between the two processes. It may be assumed that the more complicated mode of division proceeded from the simpler in both the animal and vegetable kingdoms. In the ligher plants direct division of the nucleus is a derived process which usually occurs as a result of excessive nutrition in nuclei which were themselves derived by indirect division.

Instructive examples of direct nuclear division are afforded by the long internodal cells of the Stoneworts (Characene), and also by the old internodal cells of Tradescentia (Fig. 92). The direct muclear division is chiefly a process of constriction which, howerer, necd not lesult in new nuclei of equal size. In the case of the Stoneworts, after a remarkable increase in the size of the nucleus, several successive rapirl divisions take place, so that a continuous row of beadlike muclei often results. The old internodal cells of Tradescuntic (Fig. 92) very frequently show half-constricterl nuclei of irregnlar shape. While in minucleate eells indirect nuclear division is followerl ly cell division, this is not the ease after direet nuclear division. 
Cell Division.-In the uninueleate cells of the higher plants cell division and nuclear division are, generally, closely associated. 'The supporting fibres of the spindle extending from pole to pole persist as CONNECTING FIBREs between the developing danghter nuclei (Fig. 86, $9 \mathrm{v}$; Fig. $88,12,16)$, and their number is increased by the interposition of others (Fig. 86, 10). In consequence of this a barrelshaped figure, the IHRAGIOPLAST, is formed, which either separates entirely from the developing daughter nuclei, or remains in connection with them by means of a peripheral sheath, the CONNECTING UTIICLE. The first is the ease in cells rich in eytoplasm, the latter when the cells are more abundantly supplied with eell sap. At the same time the connecting fibres become thickened (Fig. 86, 10) at the equatorial plane, and the short rod-shaper thickenings form what is known as the CELL PLATE. In the case of cells rich in protoplasm or small in diameter, the connecting fibres hecome more and more extended, and

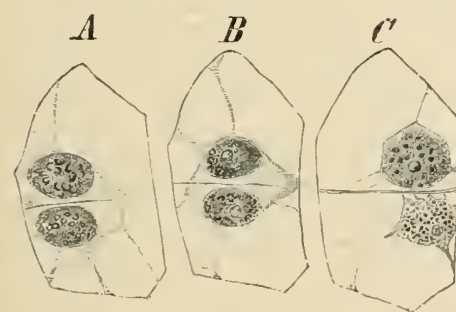

F14, 93.- Three stages in the division of a living cell of Epipactis prilustris. (After Treub, $\times 365$. tonch the eell wall at all points of the equatorial plane (Fig. 86,11 ). The elements of the cell plate unite and form a cytoplasmic limiting layer, which then splits into two. In the plane of separation the new partition wall is formed of cell-wall substance, and thus sIMUltaneously divides the mother cell into two daughter cells (Fig. 86, 12). If, however, the mother cell has a large sap eavity, the connecting utricle camnot at once become so extended, and the partition wall is then formed successively (Fig. 93). In that case, the partition wall first eommences to form at the point where the utricle is in contact with the side walls of the mother eell (Fig. $93 \mathrm{~A}$ ). The protoplasm then detaches itself from the part of the new wall in contact with the wall of the mother cell, and moves gradually across until the septum is completed (Fig. 93 l) and $C$ ); the new wall is thus built up by successive additions from the protoplasm.

The connecting fibres of the spindle consist of kinoplasm. The origin of the cell-plate from swelings of these fibres indicates its kinoplasmatic nature also. By the splitting of the cell-plate the limiting layers of the two sister cells are conpleted across the place of sepration. The separation of the complex of connecting fibres into two halves effects an equal division of the kinoplasm between the two new cells.

In the Thallophytes, even in the ease of uninueleate eells, the partition wall is not formed within connecting fibres, but arises either simultaneonsly from a previously formed cytoplasmic plate, or successively, by gradual projection inwards from the wall of the mother cell. It was a division process of this kind (Figs. 94, 95) 
first investigated in fresh-water Algae, that gave rise to the conception of eell division, which for a long time previiled in both animal and vegetable histology. In this form of cell division the new wall commences as a ring-like projection from the inside of the wall of the mother cell, and gradually pushing farther into the cell, finally extends completely across it (Figs. 94, 95). In a division of this sort, in uninucleate cells, nuclear division precedes cell division, and the new wall is formed midway between the daughter muclei (Fig. 94). In the multinucleate cells of the Thallophytes, on the other hand, although the nuclear division does not differ from that of uninucleate cells, cell division (Fig. 95) is altogether independent of nuclear division. And

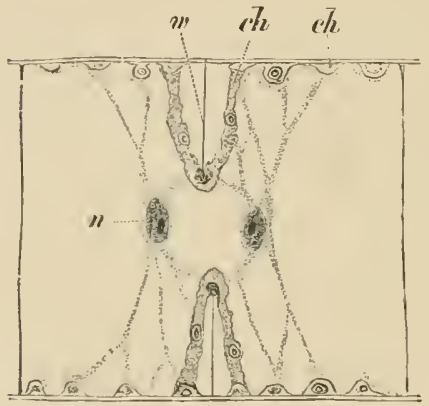

Fic. 94.-Cell of spirogyra in division. $n$ One of the daughter nuclei; $w$, developing partition wall: eh, chloroplast pushed inward by the newly forming wall. $(\times 230$.

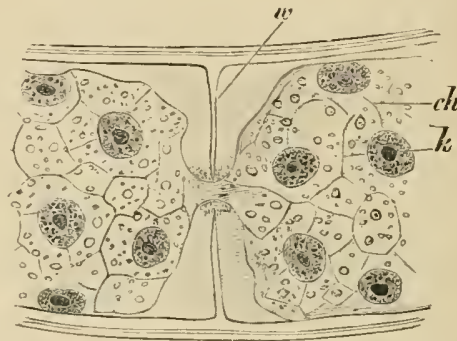

FIf. 95.-Portion of a dividing cell of Cludophora fracta. w, Newly forming lartition wall; ch, diviling chromatophore ; $k$, nuclei. $(\times 600$.

in multinucleate, unicellular Thallophytes, nuclear division is not followed by a cell division.

The interdependence of unclear and cell division in uninucleate cells is necessary to ensure a nucleus to each daughter cell. In multinucleate cells it is not essential that cell division should always be accompanied by nuclear division, as in any case a sufficient number of nuclei will be left to each daughter cell.

Free Nuclear Division and Multicellular Formation.- The nuclear division in the multinucleate cells of the Thallophytes may serve as an example of free nuclear division, that is, of nucleal division macempanied by cell division. In plants with typical uninucleate cells, examples of free unclear division also oeenr; althongh, in that ease, the muelear division is customarily followed by cell division. While the muelei increase in number by repreated division, this process is not accompranied by a corresponding cell division. "When, however, the number of nuclei is completed, the eytoplasm between the nuclei divides simultaneously into as many portions as there are nuelei. In this process we have an example of multieellular formation. This methor of developmeut is cspecially instructive in the embryo-sac of Phanerogams, a cell, often of remarkable size ani rapid growth, in which the future embryo is develojed. The nucleus of the rajidly growing embryo-sac 
divides, the two danghter muclei again divide, their successors repeat the process, and so on, until at last thousands of nuclei are often formed. No cell clivision accompanies these repeated nnclear divisions, but the unclei lie seattered thronghont the peripheral, cytoplasmic lining of the embryo-sac. When the embryo-sac ceases to enlarge, the nuclei surround themselves with connecting strands, which then radiate from them in all direetions (Fig. 96). Cell plates make their appearance in these connecting strands, and from them cell walls arise. In this mamer the peripheral protoplasm of the embryo-sac divides, simultancously, into as many cells as there are nuclei. All intemerliate stages between simnltaneous, multicellular formation and sncessive cell division can be found in embryo-sacs. Where the embryo-sac is small and of slow growth, successive cell division takes place, so that multicellular formation may be regarded as but a shortened jrocess of successive cell division, inducerl by an extremely rapid increase in the size of the cell.

Free Cell Formation. - Cells produced by this process ditfer conspicnously from those formed by the usual mode of cell division, in that the free nuclear division is followed by the formation of cells, which have no contact with each other, and in the formation of which the whole of the cytoplasm of the mother cell is not used up. This frocess can be seen in the developing embryo of the Gymnosperms, in Ephedra, for example, and also in the formation of the spores of the Ascomycetes. A single nucleus is present to begin with in each ascus of the Ascomycetes. By successive divisions eight nuclei lying free in the cytoplasm are

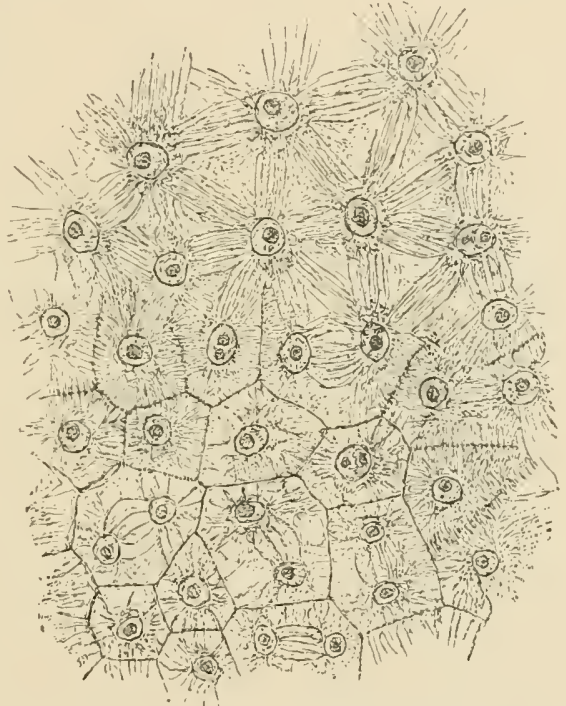

Fir. 96.-Fortion of the peripheral jrotoplasm of the embryo-sac of Reseda odorata, slowing the commencement of multicellular formation. The process progresses from above downwards. From a fixed and stained preparation. $(\times 240$. derived from this. A definite portion of cytoplasm around each of these nuclei becomes limited by a peripheral layer which then forms a cell wall. Thus eight separate spores arise (ef. Fig. 317). As the researches of Harper $\left({ }^{86}\right)$ have shown, the formation of the peripheral layer proceeds from a centrosome-like mass of kinoplasm which formed a pole of the spindle in the preceding nuclear division. The nuclens is drawn out towards this mass of kinoplasm. From the latter kinoplasmic radiations proceed which surround the spore as it becomes delimited, and finally fuse to form its peripheral layer (Fig. 97).

Cell-Budding.- This is simply a special variety of ordinary cell division, in which the cell is not divided in the middle, but, instead, pushes out a protuberance which, by constriction, becomes separated from the mother cell. This mode of cell multiplication is claracteristic of the Yeast plant (Figs. 2, 331); and the spores, known as conidia, which are produced hy numerous Fungi, have a similar origin (Fig. 343). 


\section{The Celi in the Prochss of Fertilisation}

In the organic world when a definite degree of phylogenetic development has been attained we find the development of a sexual differentiation in the organisms. Sexnal cells are formed which are incalpable of independent development and are only able to continue their development after fusion with another sexual cell. The two cells so uniting are either alike, and in that case are called GANETES, or unlike, and are then distinguished as EGG and SPERMATOZOIn. The spermatozoid is the male, the egg the

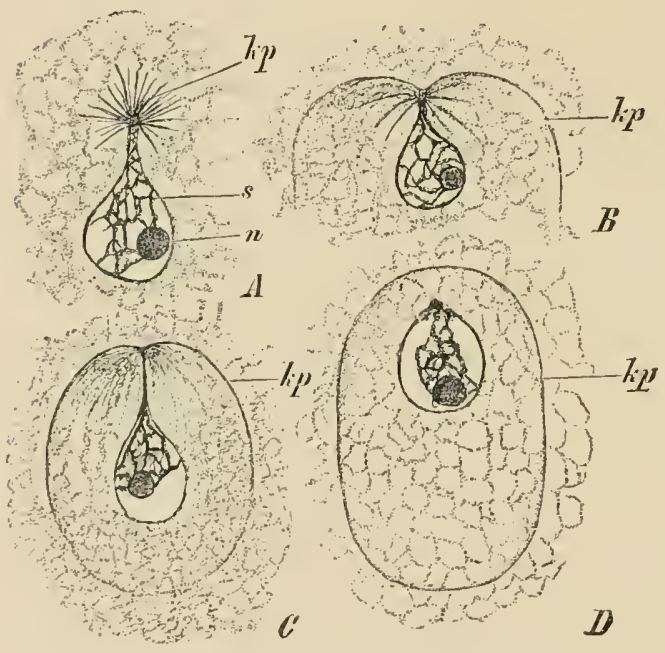

Fr. 97.-Successive stages of the delimitation of a spore in the ascus of Erysighe communis. A, Before flelimitation has begun; the fibrillar flasua $(k p)$ radiates into the cytoplasm around; in $B$ the fibrillar plasma has commenced to grow romd the mass of cytoplasm ; in $C$ this process is complete, but the liniting layer producer by the fusion of ruliations of the librillar plasma is still commecter with the polar side of the nucleus; in $I$ ) this kinoplasmatic comection betwcen muclens and limiting layer las disajlreared; $s$, melear network; $n$, nucleolus. (Alter ilarper, $\times$ 1500.)

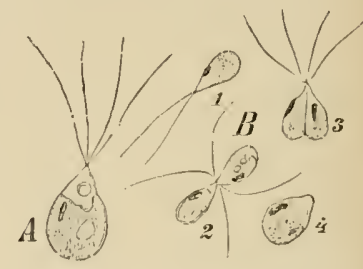

Frf. 98- $A$, An asexual swarm-spore of Ulothrix zonata ; $B, 1$, a ganete ; 2 and 3 conjugating gantetes; 4 , zygote, formed by the fusion of two gametes. ( $\times$.000.)

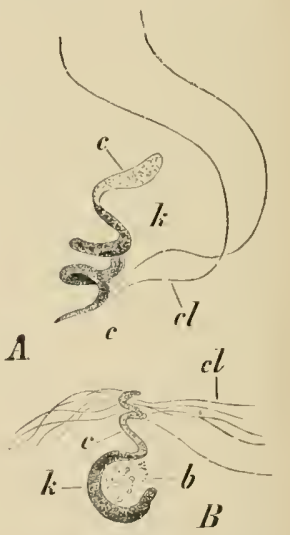

Fif. 99-1, Spermatozoid of Chare frayilis; $1, s_{1}$ permatozoid of the Fern, Onociec struthiopteris. (Aiter Sнaw.) The nucleus ( $\left.l_{i}\right)$ is more deeply shated ; $c$, the cytoplasmic portion ; $c l$, eilia which in $B$ arise from the thenser eflge of the spiral l)ant; $b$, resicle. $(A \times 540$, li $\times 850$.)

female sexual cell. The gametes may be motile (Fig. 98 li) or non-motile. The motile ganetes frequently resemble the swarm-spores (Fig. 98 $A$ ) generated by the same parent for the purpose of asexual reproduction. As a ruie, however, they are smaller than the swarm-spores, and have usually only half as many cilia. In the more highly speeialised sexual cells the egg usually l'etains the strueture of an embryonie cell, but the spermatozoid nudergoes profound modifications. $A$ cytoplasmic 
eell hody, a nneleus, and the rudiments of chromatophores are always present in the egg. The spermatozoid (Fig. 99), on the other hand, becomes transformed, in the more extreme cases, into a spirally twisted body, provided with eilia, and exhibiting an apparently homogeneous structure. Only a knowlerlge of the history of its development, and the greatest care in fixing and staining, have rendered it possible to recognise the lromology of the structure of such a spermatozoid with that of an embryonic cell. It has been shown that the hinder part of its spiral body corresponds to the cell nucleus $(k)$, the anterior, together with the cilia, to the cytoplasm, especially the kinoplasm (c), and the vesicle (b), at the other extremity, to the sap cavity of a cell ( $\left.{ }^{83}\right)$.

Motile male cells provided with cilia, oceur only in the Cryptogams and, as has been reeently demonstrated $\left({ }^{(99}\right)$, in some Gymnosperms (Cycallaceae, Ginkgo). In the Cryptogams the spermatozoids are set free from the sexual organs and require water for their dispersal. They reach the egg-eell, which usually remains in its place of origin, by swimming. In the Gymnosperms, which form motile spermatozoids, the latter are lirought near to the ovum by means of the pollen tube developed from the pollen grain. In a similar way the non-motile male cells of the other Gymmosperms and the Angiosperms are conducted to the egg throngh the pollen tube (Fig.

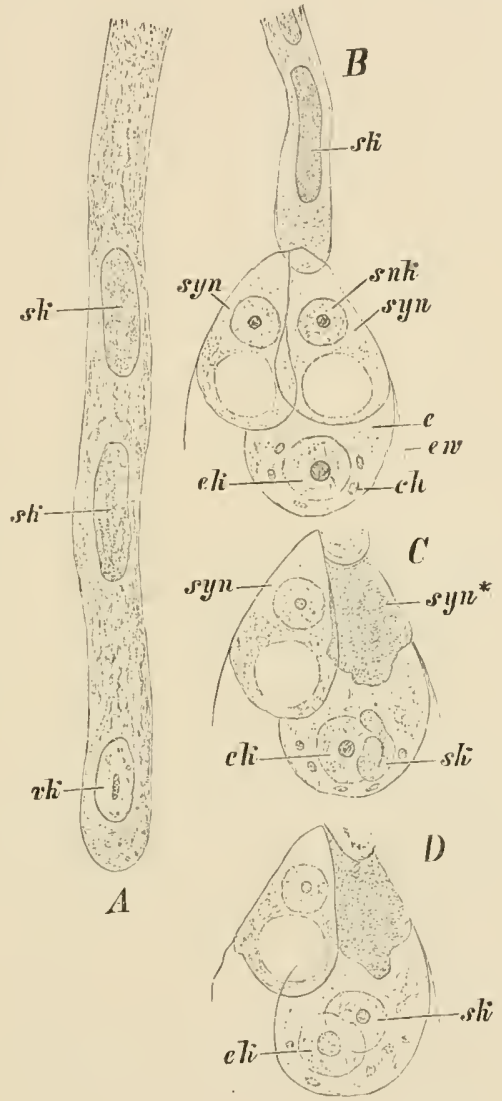

FIG. 100. Fertilisation in an Angiospermic phaneroganic jlant. Somewhat diagramatic. A. End of the pollen tube containing sk the generative or sperm-nuclei, $v \%$ the vegetative nucleus, which later breaks lown. B. Uyjer end of an embryo-sac with the entering end of the pollen tube. $e$ egg, $c k$, egg-nucleus; $c h$, rudiments of the chromatophores; syn, synergidae; snk, nucleus of the synergidae; $e w$, wall of the cmbryo-sac; C and D, eggs in succes. sive stages of fertilisation, $s k$, sperm-nucleus; $s y n^{*}$, the synergil that received the contents of the pollen tube, sk, sperm-nucleus; eli, esrgnucleus. In $D$ these are miting to form the nucleus of the embryo. ( $x$ about 500 .) 100). In the union of the two sexual cells in the act of fe"tilisation, the egg nucleus (efi) and the 
sperm nucleus (sk) fuse and form the nueleus of the fertilised eggcell. The eytoplasm and chromatophores of the embryo are derived from the egg-cell alone in the more highly organised plants; they are not introdnced by the male sexual cell. When the spermatozoid, as in animals and in Thallophytes, is provided with a centrosome like body this does not fuse with the centrosome-like body belonging to the ovum. The centrosome-like body of the fertilised egg-cell appear's to be derived from that of the spermatozoid only.

The ultimate limitation of the male sexual prodnct, as introduced into the ovum in Angiosperms, to a nucleus (sperm-nucleus) affords evidence that the nuclei of an organism are the bearers of its hereditary character's. This assumption is further supported by the eomplicated process by which the process of nuclear division proceeds in the more highly organised plants and animals; this process ensures at each

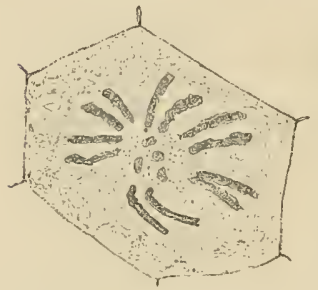

Fif: 101.-Young cells from a transverse section of the root-apex of Galtonia candicans, showing a nuelear plate in the polar view. The ehromosomes are grouped in pairs. $(\times 1600$. division equivalent halves and therefore the equivalenee of the suceessive generations of muclei derived in this way.

The number of ehromosomes remains unehanged in the propagation of asexual organisms. Sexual reproduction results in a cloubling of the ehromosome-number. In lower organisms the double number of chromosomes thus brought about is forthwith, at the commencement of germination, redueed to the single number by a reduction division (p. 84), and the single number is maintained in the divisions that follow. In the eourse of phylogenetic development a new generation, the nuelei of which had the double number of chromosomes, arose, the reduction division being deferred. The nuclei with the single number of chromosomes are termed HAPLOID, in contrast to those with the double number, which are termed DIPLOID. In each diploid nuelens one half of the chromosomes have been derived from the sperm-nuclens the other half from the nucleus of the egg; otherwise expressed half the chromosomes are paternal the other half maternal. In the diploid cells of plants it ean not infrequently be shown that the chromosomes constitute pairs $\left({ }^{10}\right)$, and we may assume that the two ehromosomes of exch pair correspond to one another. The grouping in pairs is most obvious in those nuclei in which the chromosomes show lifferences in size. Two chromosomes of the same size then form each pair, as is seen in the case represented in Fig. 101. In such eases also it is chromosomes of corresponding size that unite to form the gemini of the nuclear plate in the reduction division. These phenomena indicate that the chromosomes of a nueleus are not identical. The union of equivalent chromosomes in the gemini ensures the provision of the ranghter nuelei with a chromosome of each kind, when the separa- 
spores by a process of multicellular formation (p. 90). Fig. 102 will serve to make this process clearer. The four diagrams, A $a-d$, gire the scheme of the process as it happens in the pollen mother cell of the Lily; the natural appearance of this was shown in Fig. S8. In A $u$ the gemini are on the nuclear spindle and a longitudinal split is seen in each component ehromosome. In A $b$ the chromosomes are separating, the $V$-shape being given by the separation of their longitudinal halves. In $\mathrm{A} c$, the mother cell has divided and on the two nuclear spindles these longitudinal halves of the chromosomes are seen associated together. The separation of these longitudinal halves in $\mathrm{A} d$ shows that the homotypic division is one of the nucleus into equivalent nuclei. The division of the two nuclei here, as in Fig 88, is shown taking place in the same plane. The figures $B$ a-ll are only slightly diagrammatic. In $a$ four grand-danghter nuclei are seen in the same plane with the septa forming between them; this leads to the arrangements of the spores represented in B $b$. The grand-daughter nuclei in $B c$ are tetrahedrally arranged, so that only three of them are visible at the one time. The partition walls have formed between them. This leads to the tetrahedral arrangement of spores shown in $\mathrm{B} l$. The figures $\mathrm{B} b$ and $\mathrm{B} d$ further show how the protoplast of each spore surrounds itself with a special wall, differing in structure and chemical nature from the previous wall. The special membrane remains enclosing each spore while the old wall disappears.

Although it is by fertilisation that the further development of the sexual products is made possible, there are exeeptional cases in which a gamete or an egg forms an embryo without being fertilised. If development follows in this way from a gamete or egg with the reduced number of chromosomes, the phenonemon is called true PAITHENOGENESIS. This is as yet only known in the lowest groups of plants, especially among the Algae, e.g. in Chura crinita belonging to the Characeae. On the other hand the reduction of the number of ehromosomes may be omitter in the life-history of the plant; in place of a haploid generation with haploid nuclei a generation otherwise similar but with diploir nuclei and forming eggs with diploid nuclei develops. When such an egg, which alrearly possesses the double number of chromosomes, usually bronght about by fertilisation, proceeds to form an embryo withont being fertilised, we have to do not with true parthenogenesis but with a development process clue to loss of sexuality or APOGAly. The cases recorded for numerous families of the more highly organised plants (Compositale $\left({ }^{92}\right)$, liosiflorae $\left({ }^{93}\right)$ lianmenlacere $\left({ }^{91}\right)$ Thymelaceae $\left({ }^{95}\right)$, Urticacere $\left({ }^{96}\right)$ and Marsiliaceae $\left.\left({ }^{9 i}\right)\right)$, are of this nature.

In certain eases fertilisation is replaced by a fusion of muclei of adjoining tissue cells of the haploid generation and the product of fusion gives the starting point for the development of a diploid generation. This happens in certain varieties of Ferns (e.g. of 
Lastraed and Athyrium $\left({ }^{97}\right)$ ) where fusion takes place between cells of the prothallium or first generation. The product of fusion gires rise to the true fern plant, the diploid generation, while the sexual organs of the prothallus are fuuctionless.

\section{Multiplication of the Chromatophores.-} This is accomplished by a direct division, as a result of which, by a process of constriction, a chromatophore becomes divided into neaily equal halves. The stages of this division may best be observed in the chloroplasts (Fig. 103).

\section{B. Cell Fusions}

The connection of the living protoplasts

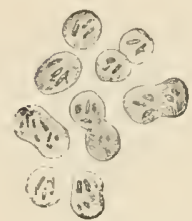

FIs, 103.-Chloroplyyll grains from the leaf of Funcric hygrometrice, resting, and in process of division. Smallincluded starch grains are present in the grains. ( $\times 540$.

with one another is less complete in plants than in the animal body. This is evident from the existence of the cell-wall which surrounds the vegetable protoplast. Recent researches bave, however, shown (18)

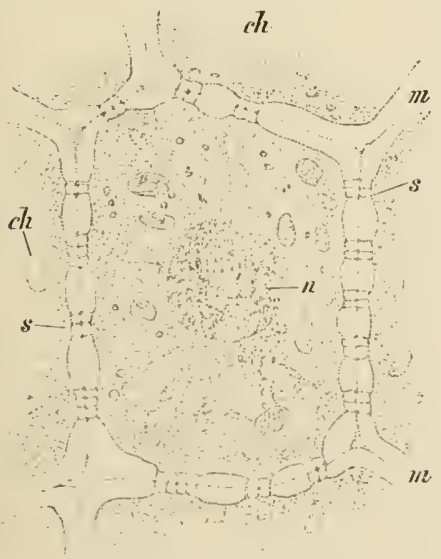

Fri. 104. - A cell from the cortex of the Mistletoe (Viscum album); the protoplast has been jroperly fixpl and stained and the wall $(m)$ swollen. The pit-membranes (s) are traversed by comnecting threads; ch, chloroplasts ; $n$, nucleus. (x 1000.)

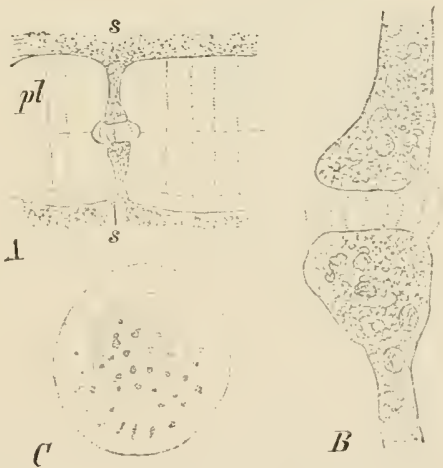

FIri, 105.-A, $A$ swollen portion of cell wall from the endosperm of the Vegetable lvory Palm (Phytelephas macrumerpu). At $s, s$, simple pits filled with cytoplasm; in the intervening pit-membrane are fire comsect. ing threads (plasmorlesms); $n$, other threads traversing the whole thickness of the wall. ( $\times 375$.$) B, The contents of two opposed$ pits and the connecting threads of the pitmembrane. $(\times 1500$.) C, the opening of a pit and the connecting threads of the pit-nembrane riewed from the surface. $(\times 1500$.

that the protoplasts of the plant are united together by extremely fine cytoplasmic filaments, which proceed from the boundary layer of the cytoplasm and are known as plasmodesms. Such filaments are mostly confined to the pit-membrane (Fig. 104), but may also 
penetrate the whole thickness of the cell wall (Fig. 105). The existence of these connecting filaments of living substance between the protoplasts confers an organic unity on the whole body of the plant.

The members which make up the sieve vessels, or, as they are commonly called, the sieve-tubes $\left({ }^{99}\right)$, are mited by thicker strands of cytoplasm, which facilitate the transfer of substances through the tube. The transverse walls traversed by these strands of cytoplasm have been referrerl to above (p. 75) as sieve-pits, the plasmodesms of which are further perforated by mueilage strands. The whole complex of sieve-pits is known as a sieve-plate. In Angiosperms the

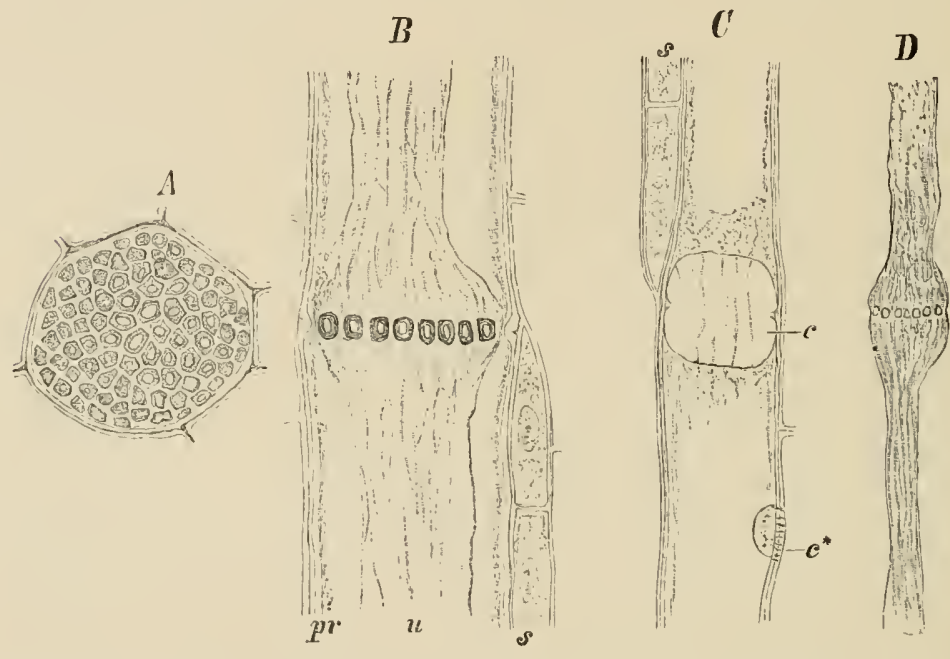

Fis. 106. - Parts of sieve-tuhes of C'ncurbita l'epo, hardened in alcohol. A, Surface view of a sievejlate; $R, C$, longitudinal sections, showing segments of sieve-tules ; $D$, contents of two sievetule segments, after treatment with sulpluric acid ; $s$, companion cells ; $u$, mucilaginous contents ; $p$, peripheral cytoplasm ; $c$, callus plate; $c^{*}$, sinall, lateral sieve-pit, with callus plate. $(\times 510$.

mueilage strands of each pit ultimately fuse to form a single strand of considerable diameter (Fig. 106). It is worthy of special note that, despite the fact that the nuelei of the sieve-tube segments disintegrate, the cytoplasm, which lines the wall, remains alive. The walls of sieve-tubes are always unlignified. Their sap cavities contain a watery, and more or less dilute, solution of albuminous substances, and small starch grains are also present in most cases. As a rule, the sieve-tubes remain funetional only through one vegetative periorl. Before their activity ceases the sieve-plates become eovered (Fig. 106 C) with highly refractive callns (p. 77 ), which interrupts the conduction of material from one member of the sieve-tube to another: If the sieve-tuhes resume their activity in the next vegeta- 
tive period the calli are dissolved. They also generally disappear from sieve-plates that have ceased to be functional.

A more complete fusion of protoplasts is found in the formation of laticiferous vessels $\left({ }^{61}\right)$. These have the same contents as latex cells (p. S0). Their occurrence, like that of latex cells, is limited to a few distinct plant families, such as the Papaveraceae, of which the Poppy (Puparer) or Celandine (Chelidonium), with its characteristic orange-coloured "sap," are familial examples, or the Compositae, of which in particular the Lettuce (Lactuca) may be cited. Latex vessels are distinguished from latex cells only by the method of their

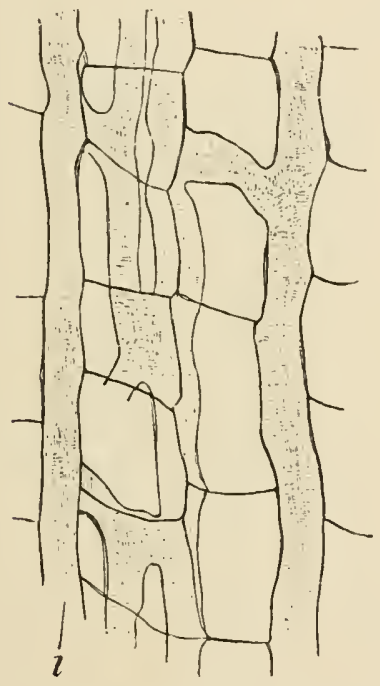

Fis. 107.-Tangential section through the periphery of the stem of Scorzonera hispanica, show. ing reticulately united latex vessels. $(\times 240$.)

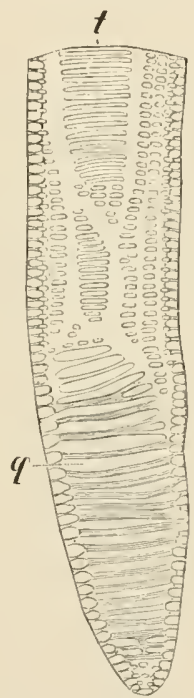

Fu. 108. - Lower third of a scalariform vessel from the rhizome of the common Bracken Fern, Pteris alquilina. t, Trans;ersely elongated pits in the lateral walls; $q$, scalariform perforations of the terminal wall. (After DE BARY, $\times$ 95.)

development, which has resulted from the fusion of rows of elongated cells, the separating transverse walls of which have become more or less completely absorbed. Such vessels as a rule possess lateral branches, which, on meeting with one another, fuse by the absorption of their end walls (Fig. 107). The nucilage tubes $\left({ }^{61}\right)$ which are found in many Monocotyledons present points of resemblance to the laticiferous vessels. Their mucilaginous sap contains albumen, starch, glucose, and tannins in addition to inorganic compounds.

A cell fusion also takes place in the formation of VESSELS or TRACHEAE, but it should not be considered as a union between living cell bodies, but merely as one between cell cavities. The mature 
vessels are dead tubes serving for water conduction. They are formed from rows of cells, the lateral walls of which are peculiarly marked by spiral or reticulate thickenings, or, as is more frequently the case, by bordered pits, while the transverse walls become swollen and more or less completely absorbed. In cases where the transverse walls are at right angles to the side walls, they usually become perforated by a single large round opening while the remains of the wall forms a thickening ring (Fig. $79 C$, Fig. $155 g$ ). When the transverse walls are oblique, they are perforated by several openings, between which portions of the wall remain, like rungs of a laclder; on this account such vessels are described as scaluariform (Fig. 108 ). According to the mode of their wall thickening, ressels are distinguished as sPIRAL, RETICULATE, or PITTED (cf. also p. 75). When the transversely elongated pits of a vessel are arranged in more or less parallel rows (Fig. 108), it is called a SCALARIFORM VESSEL. The thickening of the vessel walls is always lignified. The living contents of the cells, after the perforation of the transverse walls, become completely absorbed, and the fully formed vessels or tracheae contain only water and a limited amount of air.

There is no difference between vasiform tracheides and vessels other than that the former are single elongated cells, and the latter fused cell rows. Generally speaking, vasiform tracheides are formed in parts of plants still in process of elongation, vessels in parts where growth in length has already ceased. True vessels make their first alpearance in some of the Ferns, for instance, in the eommon Bracken (Pteris aquilina). In the Gymnosperms the small family of the Gnetaceae only are provided with vessels. In the Angiosperms vessels are only wanting, in some Magnoliaceae (Drimys, Trochodendron). V'essels are not of an unlimited length. A few plants, however, such as the Oak, and especially climbing woody plants, or Lianes, have vessels several metres long; but, as a rule, their length is not nore than a metre, and in plants the woorly portion of which conducts water only by vessels, the vessels have an average length of only ten centimetres. The length of an individual vessel is defined by the presenee of transverse walls, which are not perforated but bear bordered pits.

A similar fusion to that seen above to occur in the formation of laticiferons vessels is also met with in fungal hyphise; by an absorption of a part of the wall where two branches come into contact, their protoplasmic contents unite. A still more complete fusion is exhibited by the naked amoebae of a Myxomyecte in forming the plasmodium (1. 56). The fusion of the sexual cells in the process of fertilisation possesses special characteristies which place the process in a distinct category (p. 93).

\section{Tissues $\left({ }^{100}\right)$}

Origin of Tissues. - A continnous aggregation of cells in intinate union is caller a tissne. The origin of vegetable tissues is, in general, attributable to cell division. It is only in the Fungi and siphoneate 
that a tissue arises throngh the interweaving of tubular cells or cell filaments (Fig. 109). In such cases, where the filaments are so closely interwoven as to form a compact mass of cells, the tissue thus formed bas the same appearance as the tissues of higher plants (Fig. 110).

The mutual interdependence of the cells of a tissue is manifested both by the conjunction of their pits (Figs. 73, 77) and by the general similarity of their wall thickenings.

A very imperfect tissue formation is found in those organisms, the cells of which separate from one another at each division, but l'cmain connected by the mucilage derived from the swollen cell walls. An example of this has already been seen in the Alga Gloeocapsu polylermatica (Fig. 1). Such mions of more or less independent cells that have had a common origin may be termed cell families or cell

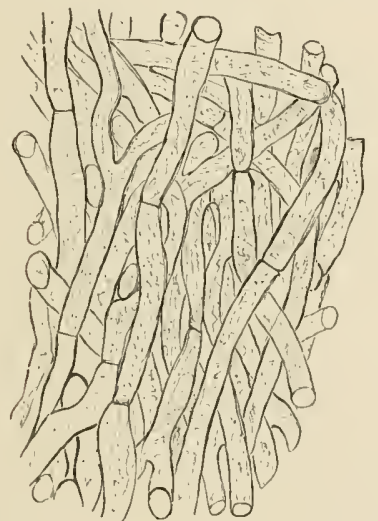

Frf. 109.-Longitudinal section of the stalk of the fructification of Boletus edulis. $(\times 300$.) colonies. The Schizophyceae, to which group Glococapse belongs, and the orders of the Volvocales and Protococcales among the Green Algae afford

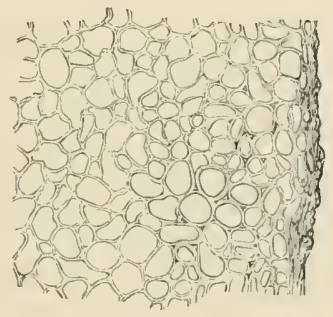

Fic. 110.-Transverse section of the sclerotium of claviceps purpurea. ( $\quad$ 300.)

numerous examples, and the descriptions in the special part shonld be consulted.

In the cell-filaments and cell-surfaces of those lower Algae in which the cells are all equivalent but are united together, the characters of a definite tissue begin to make their appearance. With the increasing number of cells composing the organism we get a contrast between base and apex and the appearance of a growing point, and also progressive division of labour among the cells.

Growing Point.-This is the place of the increase in number of embryonic cells and of the early distinction of tissues. In Thallo. phyta an apical cell occupies the growing point; this at first, as is seen in Cladophora glomerata (Fig. 6), differs little from the other cells of the filament. It assumes more and more the character of an APICAI. CELL from which all the organs of the plant take their origin; thus, in the case of Cladostephus rerticillutus (Fig. 7), the many-celled main 
axis terminates in a single conical cell which, by transverse and longitudinal rlivisions, gives rise to the cellular system of the whole plant. Its lateral branches
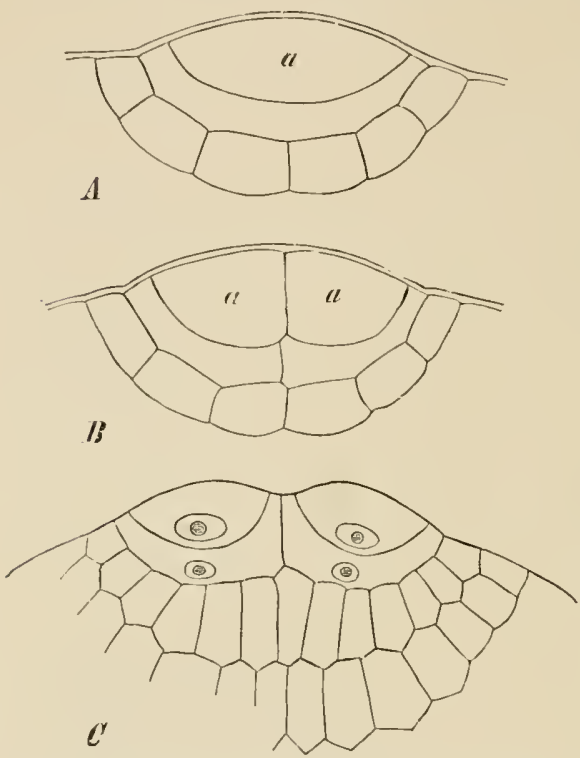

Fir. 111.-The growing point of Dictyote dichotoma, showing the dichotomous branching. $A$, lnitial cell (Afler E. DE WildemaN, $\times 500$. ) are likewise formed from similar apical cells, which develop, in regular acropetal order, from certain of the lateral cells of the parent stem, and determine the character of the branching. Flat, ribbon-like plants also, such as Dictyote dichotoma $\left({ }^{10 \mathrm{i}}\right)$ (Fig. 8), may have conical but correspondingly compressed apical cells (Fig. $111 \mathrm{~A}$ ), from which segments are cut off by concave cross walls, and become further divided by subsequent longitudinal walls. The dichotomous branching so apparent in Dictyota, and referred to on $p p .13,17$, is preceded by a longitudinal division of the apical cell into two equal adjoining cells $(B, a, a)$. By the enlargement and continuons division of these two new apical cells the now bifurcated stem becomes prolonged into two forked branches. In other ribbon-like Algae, on the other hand, and in similarly shaped Hepaticie, as in Metzgeric and Aneura (102), the apical cell is wedge-shaped (Fig. 112), and the successive segments are cut off alternately right and left by intersecting oblique walls; from these segments the whole body of the plant is derived by further division. The apparently strictly dichotomous branching of Hepaticae provided with such apical cells is in reality che to the early development of new apical cells in young segments (Fig. 112 b). In the ease of the erect radially symmetrieal stems of the Musei, most Ferns and Equisetaceae, the apical cell has generally the

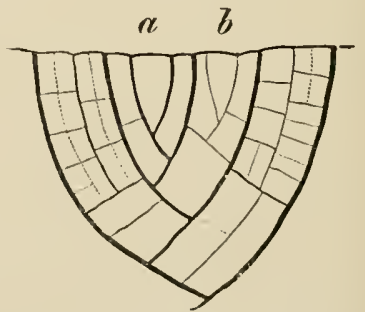

F14. 112.-Diagrammatic representa. tion of the apex of Metzgeria furcata in process of branching, viewed from the dorsal side. $a$, Apical cell of parent shoot; $b$, apical cell of daughter shoot. (After kivr, $x$ cirea 370.$)$ shape of an inverted three-sided pyramicl $\left({ }^{103}\right)$ with a convex base, and forms the apex of the vegetative cone characteristic of the more highly 
organised plants. The apical eell of the common Horse-tail (Eiquisetum arense) will selve as an example (Figs. 11:, 114). The apical cell of the main axis viewed from above (Fig. $114 A$ ) appears as an equilateral triangle, in which new walls are suceessively formed in a spiral direction, parallel to the original walls $(p)$. Each new segment thus derived is divided by a new division wall (Figs. $113,114 \mathrm{~m}$ ) into an upper and lower half; each of these halves, as is shown most clearly by an optical section just below the apieal cell (Fig. $114 \mathrm{~B}$ ), becomes again divided by a sextant wall (s) into two new cells. It is unnecessary to trace the

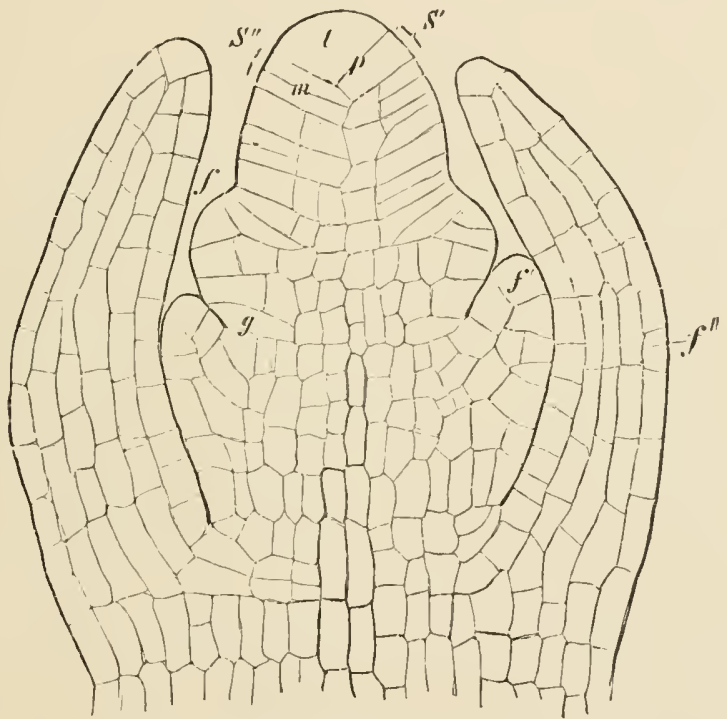

FIr. 113.-Itedian longitudinal section of the regetative cone of Equisctum uriense. Explanation in the text. $(\times 240$.

further divisions, and it will suffice to eall attention to the fact that all cell walls parallel to the outer surface of such vegetative eones or portions of plants are termed PERICLINAL WAILS, while such as meet the surface and the periclinal walls at right angles are designated ANTICLINAL; of the latter those in the plane of the axis of an organ are called RADIAL. Some distance below the apical cell of Equisetum arvense the first leaf-whor] arises from the regetative cone as a circular ridge, which grows by the formation of cell walls inelined alternately inwards and outwards in the wedge-shaped marginal cells (Fig. 113f). This is succeederl at a lower level by other and older leaf-whorls $\left(f^{\prime \prime}, f^{\prime \prime}\right)$. An initial cell $(g)$ may be distinguished in the axil of the second leafwhorl, and this is destined to become the three-sicled apical cell of a side branch. 
In the Lycopodinae, the most highly developed of the Pteridophytes, a distinct apical cell can 110 longer be recognised, while in the Phanerogams the cells of the vegetative cone are arranged as shown in the accompanying figure of Hippuris vulgaris (Fig. 115), in which the embryonic tissues are arranged in layers which, as was first noticed by SACHS (104), form confocal parabolas. The outermost layer, which covers both the vegetative cone and also the developing leaves, is distingmished as the DERMATOGEN $\left({ }^{105}\right)(d)$; the cells of the innermost cone of tissue, in which the central cylinder terminates, constitute the PLERone $(p l)$; while the layers of cells lying between the dermatogen and plerome are called the PERIBLEm $(p r)$. In the

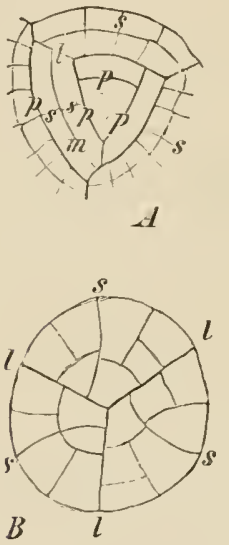

FIG. 114. - A, Apical view of the regetative cone of Equisetum arrense; $B$, optical section of the same, just below the apical cell; l, lateral walls of the segments. Further explanation in text. ( $\times$ 240.)

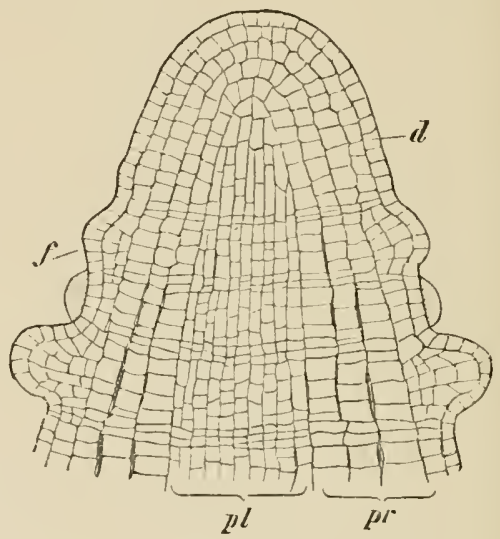

Fig. 115. - Median longitudinal section of the vegetative cone of Hipuris vulgaris. d, Dermatogen; $p r$, periblem ; $p l$, plerome ; $f$, leaf rudiment. $(\times 240$. $)$

same figure may be noticed the uniformity with which the dividing walls of the different lavers intersect at right angles. This arrangement was regarded by SACHS as characteristic of the whole plant structure. The anticlinal walls at right angles to the surface form a system of orthogonal trajectories with the periclinal walls.

While SArus regarded the insertion of new cell walls at right angles to precxisting ones as the principle of their suecession, BenTroun and EnaEra have endearoured to show that the curvature and mode of insertion of a partition wall obey the same laws as do weightless films of liquid. The cell wall tends at the moment of its origin to assume the same position as a film in a mass of soap-suds wonld under similar condition:. On the other hand, K. (itesexmagex has attempled to prove experimentally that the position of the segment walls is determinel by the two danghter cells between which it forms. The relative positions of the daughter cells in the eavity of the parent cells will, lowever, be determined by the surface tension resulting from their cohesion ( $\left.{ }^{105}\right)$. 
Trne Roots are first fomm in the Pteridophytes, and in them possess an apical cell in the shape of a three-siderl pyramid ( ${ }^{107}$ ) (Fig. $116 \mathrm{t}$ ). In addition to the segments given off by the apical cell parallel to its sides, it also gives rise to other segments (li) parallel to its base. It is from the further division of these latter cap-like segments that the ROOT-CAP is derived. In those ferns in which the root may form a terminal shoot (p. 47) the apical cell of

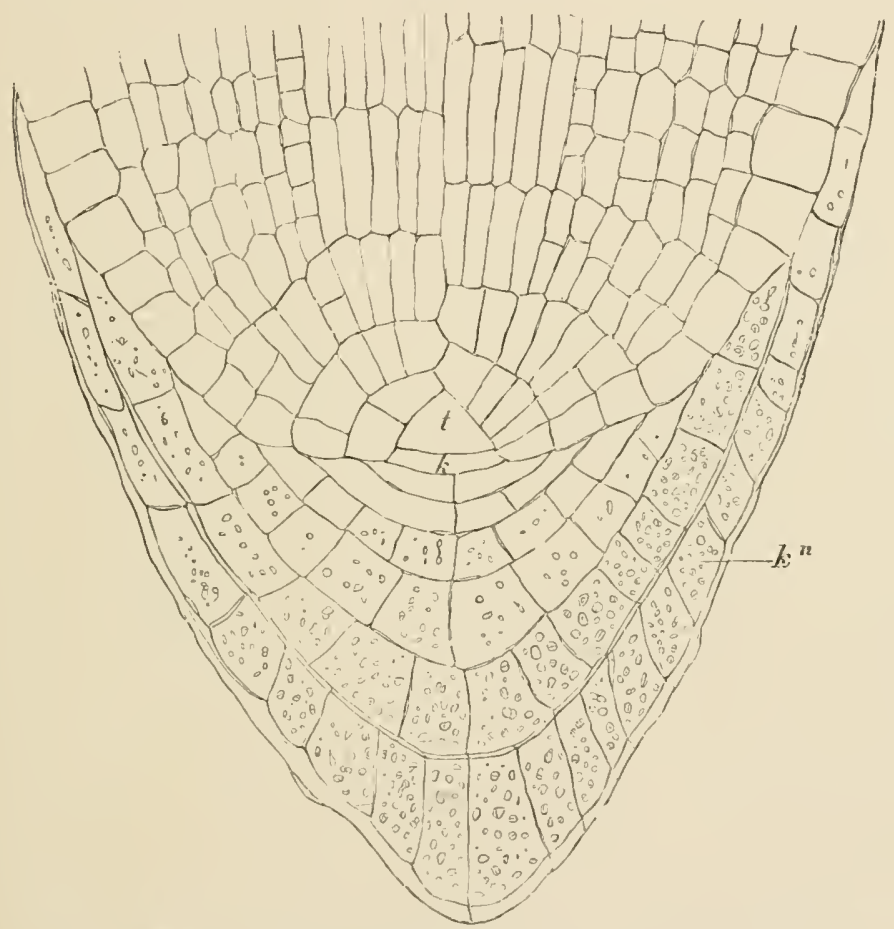

F16. 116.-Median longitulinal section of the apex of a root of Pteris creticu. $t$, Apical cell ; $k$, initial cell of root-cap; $k$, root-ean. $(\times 240$.

the root may form the apical cell of the new shoot $\left({ }^{108}\right)$. It ceases to give off segments parallel to the base, and the segments divide differently from those forming the root. In the roots, as in the stems of the Lycopodinae, no apical cells are found. In like manner the roots of Phanerogams, although exhibiting several different trpes of apical growth, follow the same law in the arrangement of their elements as the vegetative cones of the stems. It will, accordingly, be sufficient to describe a root of one of the Graminae (Fig. 117) as a representative of one of these types $\left({ }^{109}\right)$. The vegetative cone of this root differs from that of the phanerogamic stem previously 
described (Fig. 115) in the possession of a root-eap. The dermatogen $(d)$ and periblem $(p r)$ unite at the apex in a single cell-layer, outside of which lies the CALYPTROGEN $(k)$ or layer of cells from which the root-eap takes its origin. In many other roots, however, the

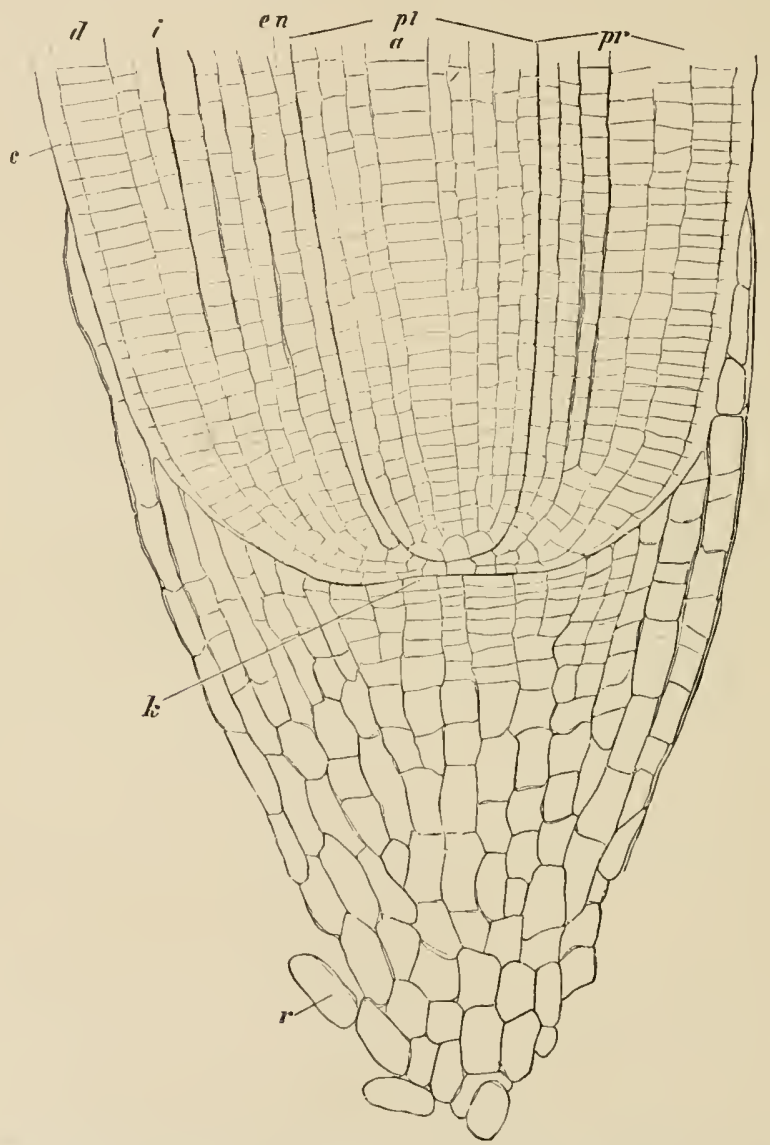

Fig. 117.-Median longitudinal section of the apex of a root of the Barley, Hordeum vulgare. $k$, Calyptrogen ; $d$, dermatogen ; $c$, its thickened wall ; $p r$, periblem ; $p l$, plerome ; $e n$, endoulernis ; $i$, intercellular air-space in process of formation; 1 , cell row destined to form a vessel; $r$, exfoliaterl cells of the root-cap. $(\times 180$.

formation of the root-eap results from the periclinal division of the dernatogen itself, which, in that case, remains distinet from the periblem. In the apices of Gymnosperms the dermatogen, periblem, and calyptrogen are not marked ont is distinet regions. In roots, as in stems, the plerome eylinder $(p l)$ almost always terminates in special initial cells. 
In stems with apical cells the RUDIMENTS OF NEW LEAVES and sHoo's are developed from single peripheral cells, or cell gromps of the vegretative cone (Fig. 113). In such cases, not only the new shoots, but even the leaves, usually begin their development with an apical cell. The apical cells of the leaves, however, soon disappear, and further growth proceeds along their whole margin.

In those fern leaves which are able to form terminal buds (p. 31) GoEbec $\left({ }^{110}\right)$ has observed the direct transition of the two-sided apical cell of the leaf tip to the three-sided pyramidal apical cell of the young shoot; this takes place by the origin of a suitably placed wall in the apieal cell of the leaf.

In a stem with no apical cells (Figs. 17, 115), the rudiments of the leaves and new shoots first appear as small protuberances, the formation of which is generally initiated by the periclinal division of a group of periblem cells; while the cells of the overlying dermatogen contimue to divide by walls at right angles to the surface. In the case of new shoots developing at some distance from the growing point of the parent stem, the cells from which they are destined to arise retain for that purpose their original embryonic character. The formation of the buds on the rapidly growing shoots of bushes and trees in the spring may be postponed, so that the rudimentary lateral shoots first appear in the axils of the eighth or even the tenth youngest leaves, and consequently at points where the differentiation of the surrounding tissue has already begun (111).

With the exception of those Pteridophytes whose roots as well as stems are dichotomously branched (cf. p. 47) the branches of all other normal roots, whether growing by means of an apical cell or not, arise in acropetal succession; the branching first begins in regions considerably removed from the growing point, where the differentiation of the tissues is already complete. Since their origin is endogenous (p. 47) the lateral roots must push through the whole outer tissues of the parent root.

Meristem.-An undifferentiated tissue, the cells of which are still capable of division, is termed embryonic tissue, or MERISTEM. The meristem of embryonic rudiments and of the growing point is called PROMERISTEI, and all meristematic tissue which ean be shown to have been derived directly from such promeristem is termed primary. A primary meristem may still retain its meristematic character in the midst of a mature tissue. Fully differentiated tissue is designated PERMANENT tissue, or somatic tissue, in contrast to meristematic tissue. At times, permanent tissue may again become capable of division, and thus give rise to a SECONDARY MERISTEM.

Kinds of Tissue.- The mature tissues of the plant may be divided into two groups, PARENCHYMa and PRosencirma, between which, however, no sharp distinction can be made. A typically developed parenchymatous tissue is one in which the thin-walled cells are equally 
expanded in all directions, and possess a layer of protoplasm lining the wall, and other cell contents. Typical prosenchymatous tissue, on the other hand, consists of thick-walled, elongated cells, either in the form of fibres or spindle-shaped cells, with interlocking, pointed ends, and with little or no protoplasmic contents. A parenchymatous tissue, in which the cells are thick-walled and elongated, resembles prosenchyma, but may be distinguished from it by the absence of pointed cell terminations, and especially by the greater abundance of protoplasn. Thin-walled prosenchyma is not, on the other hand, necessarily lacking in protoplasm, but is characterised by its pointed and interlocking cells.

General Features of Mature Tissues.-The cells in a tissue may either fit closely together (Fig. 77), leaving no openings or spaces, or so-called INTERCELLULAR SPACES may be left between the individual cells. Where cell filaments are interwoven to form a tissue, the intercellular spaces are represented by the openings left between the looselywoven filaments (Fig. 109). In tissues resulting from cell division the intercellular spaces arise subsequently, as the partition wall between two cells formed by cell division is originally a simple membrane.

Such a partition wall may nltimately split and so give rise to intercellular spaces, but this only occurs after it has been thickened. The canse of such splitting is to be found in the swelling of the primary wall consisting of pectinose material, and the tendency of the cells to assume a rounded shape. The formation of inter. cellular spaces commences, therefore, at the cell corners.

The simplest and at the same time most frequent intercellular spaces are triangular or quadrangular in outline, as seen in cross-section (Figs. $72 i, 81 i$ ). In cases where special portions of adjoining cells are in extremely energetic growth, intercellular chambers and passages, of more or less regular shape, may be formed between them. If the growth of adjoining cells is very unequal, it may lead to a complete separation of their cell walls; or the cells, or even a whole system of tissues, may be stretched and tom apart. It is by such a process that hollow stems are formed. Intercellular spaces arising from a splitting of adjoining cell walls are termed schizogkNic; those formed by tearing or dissolution of the cells themselves are called LYsigENiC INTERCELLULAR spaces. In many cases intercellular spaces that begin as schizogenic are increased in size by destruction of surrounding cells. Most intercellular spaces contain only air, although in special instances they may contain water or excreted prorlucts, such as gum, mncilage, resin, or ethereal oils, and in other still rarer cases latex. Schizogenic intercellular spaces are usually filled with air, and form the ventilating system of the plants, while the lysigenic spaces often contain either water or secretion products.

Of the schizogenic intercellular spaces, those filled with ethereal oils or resin, on account of their frequency, should be particnlarly noticel. Short cavities and longer passages, or ducts, containing ethereal oils, are to be found in the stems, 
roots, and leaves of numerous plant families. The Umbelliferae are especially rich in these, and the oil-ducts form the characteristic markings (vittae) on their fruits. The Conifer's are especially characterised by resin-ducts (Fig. $151 \mathrm{~A}, h$ ), which, even during their formation by the separation of the cell walls, seem to fill with the excretion from the cells. The enlargement of such intercellular spaces is accompanied by a division of the surrounding cells, the number of which is thus correspondingly increased. The cells themselves remain thin-walled, and in close contact laterally, but bulge out somewhat into the ducts. Lysigenic intercellular spaces, acting as receptacles for secretions, have the appearance of irregular cavities in the tissue. Where they contain oil or resin, they develop from a group of cells in which these substances appear in the form of drops. The cell group then becomes disorganised by the gradual absorption of the cell walls. In this way are formerl the receptacles filled with ethereal oils, in the Orange and Lemon. The formation of the so-called resin-galls, in the case of coniferous trees, is preceded by the formation of abuormal tissues, which afterwards become converted into resin. Such was also the origin of amber, which is the fossil resin of the Amber-fir (Picen succinifere.). The formation of gum in lysigenie gum cavities commences in the cell contents and then extends to the cell walls; either normal tissues participate in this process, as in the case of the gum-arabic of the Acacia, or abnormal tissues are first developed and then transformed into gum, as, for example, the gum on Cherry trees $\left({ }^{63}\right)$. Latex does not occur in lysigenic intercellular spaces.

The separating walls resulting from cell division are simple lamellae. In tissues which have arisen by cell division these lamcllae are comnon to the cells they separate. That part of the partition wall between two cells which stands out so distinctly in a cross-section does not consist of the original primary cell wall alone. It is made up of both the primary wall and the primary thickening layers. The former is called the MiDdLe LAviella (Figs. $72 \mathrm{~m}, 76 \mathrm{~m}$ ). In soft tissues the middle lamella, according to Devaux $\left({ }^{112}\right)$, is composed for the most part of pectic substances; in woody and corky tissnes it is also lignified. By boiling soft tissues in water, the cells may often be easily isolated, owing to the consequent swelling and dissolution of the middle lamella. In ripe fruit, an isolation of the cells frequently takes place spontaneously, through the dissolution of the middle lamella. A lignified middle lamella, on the other hand, seems able to withstand more effectually the action of oxidising agents. Consequently, it is possible, by subjecting a section of pine-wood to the action of ScHulze's MACERATINe mixture (potassimm chlorate and nitric acid), and subsequently treating with concentrated sulphuric acid, to remove all secondary and tertiary thickening layers, so that only the middle lamellae remain as a delicate network. If the macerating process be continued for a longer time, without the subsequent treatment with sulphuric acid, the middle lamellae become finally dissolved. The thickening layer will then be left free from all lignification. ScHulzE's macerating method may accordingly be employed to isolate the elements of lignified tissues. The peculiar relation of the niddle lamella towards chemical reagents gave rise at one time to the presumption of a special intercellular substance, which, like a glue, bound together the cells of a vegetable tissue. The supplementary dejosition of pectic compounds in the middle lamellae (1\%. 77 ) frequently gives rise to the formation of rod-like protuberances and excrescences, which project into the intercellular spaces, or these spaces may be filled up by the formation of gussets (Fig. $76 C$ : $m^{*}$ ). 


\section{Systems of Tissue}

A mass of tissue so united in the body of a plant as to form a higher histological unit constitutes a tissue system. In the more highly organised plants three such systems may be distinguishedthe TEGUMENTARY SYSTEM, the VASCULAR BUNDLE SYSTEM, and the FUNDAMENTAL TISSUE SYSTEM.

The tissues which make up the different tissue systems are distinguished as PRINARY and SECONDARY, according to their origin. The primary are those which are derived from the promeristem and primary meristems before growth in length has been completed; the secondary are those which owe their origin to the primary or secondary meristems after growth in length is finished.

The primary constituents of the tissue system will be considered first.

\section{A. The Primary Tissues}

The Tegumentary System.--In the Pteridophytes and Phanerogams the plant body is covered by a distinct outer layer of cells or EPIDERMIS; this is wanting in plants of the lower groups. A typically developed epidermis consists of one layer of cells (Fig. 81 e), the outer walls of which on the free surfaces of the plant are more strongly thickened. This is especially the case in all aerial parts of plants adapted for a long life, but on the more perishable parts of a plant, such as the floral leaves, or on subterranean parts, such as the roots, the cells of the epidermal layer are generally thin-walled or only slightly thickened. For such reasons the epidermis of the root was formerly termed the epiblem. Even when the external walls of the epidermal cells are considerably thickened, the side walls, at least in part, remain unthickened. The external walls are also more or less cuticularised, while their outermost layer, which is more decidedly cuticularised and capable of withstanding even the action of concentrated sulphuric acid, extends as a CUTICLE continuously over the surface of the epidermis. This cuticle appears to be always wanting from the epidermis of roots. The cuticle has its origin in the primary walls of the younger epiclermal cells, which, during the increase in size of the plant, grow in area, and at the same time are strengthened by the deposition of cutin. The cuticle of leaves in the tropics is often specially smooth and shining. It reflects a portion of the sunlight, giving rise to the sparkling appearance characteristic of tropical foliage, and serves to protect the plant from too strong insolation. The enticle frequently becomes folded, and so assumes a striated appearance (F̈ig. 124).

The remarkable blue iridescence of some leaves and fruits depends, aecording to G. Gratxer, on diltuse reflection in the onter witls of the epidermal cells. It 
is the effect of a muddy colourless medium. The opaeity in the cellulose thickening layers of the epidermal cells may possibly be due to granules of cutin in the wall. A similar influence gives rise to striated or furrowed thickenings which affect the whole thickness of the walls. A blue iridescence of the epidermis oeeurs in many shade plants though usually in a slight degree (113).

By the thickening and the cutinisation of their onter walls the mechanical rigidity of the epidermal cells is increased, and the loss of water by transpiration is lessened. Plants in dry climates, or so situated that, for any reason, transpiration from their onter surfaces must be diminished, are characterised by the greatly thickened and cuticularised walls of their epidermal cells. In some of the Gramineae, Equisetaceae, and many other plants, the cell walls of the epidermis

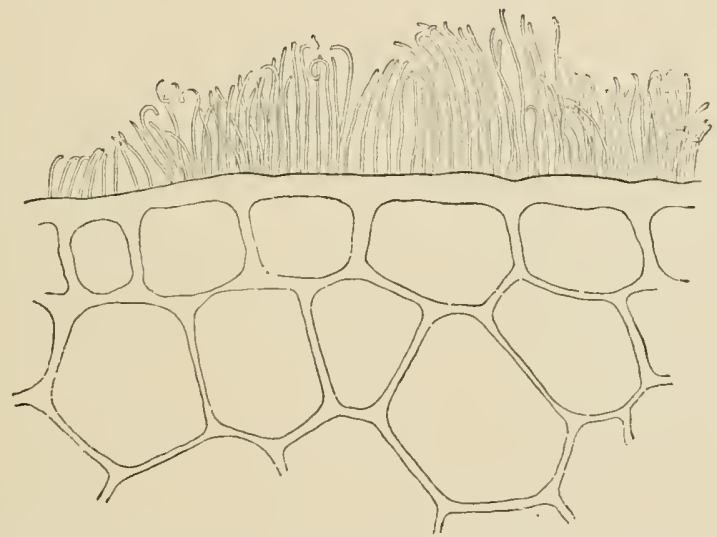

Fig. 115.--Transverse section of a node of the sugar-cane, Suecharum officinurum, showing wax incrustation in the form of small rods. $(\times 540$.

are silicified. In the Equisetaceae the impregnation with silica is so considerable that these plants are used for polishing. Heating, even to redness, does not destroy the structure of such silicified epidermal cells.

Deposits of wax are also present in the cutinised layers of the epidermis, and consequently water will flow off the epidermis without wetting it. The wax is sometimes spread over the surface of the cuticle as a wax covering. This is the case in most fruits, where, as is so noticeable on plums, it forms the so-called bloom. The wax coverings may consist of grains, small rods (Fig. 118), or crusts.

The wax deposits attain their greatest thickness on the leaves of some of the Palms; on the Peruvian Wax Palm, Ceroxylon andicola, the wax eovering is more than $5 \mathrm{~mm}$. thick. This wax as well as that obtained from the fruit of Myrica cerifera, is known as vegetalle wax, and possesses an economic value. The wax incrustations may be melted by heat; they are soluble in ether and in hot alcoliol. 
In many cases, slimy or stieky excretions are produced between the thickening layers of the epidermis and the cuticle; these press up the latter and finally burst it. Sneh exereting surfaces often oecur

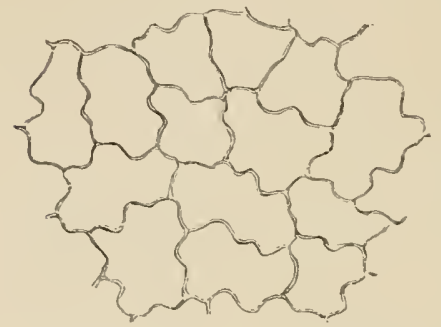

Fit. 119.-Surface view of the epidermis from the upper side of a leaf of Mereuri. wlis prevenis. $(\times 300$. on bud-scales. Sticky zones are frequently formed on stems, as in the ease of Lychnis riscuria and other Silenere, as a means of protection to the Hower's higher on the stem from undesirable visitors. Small ereeping inseets, which would otherwise rob the flowers of their honey, seem as little able to pass beyond such a stieky zone as other larger animals to surmount the rings of tar often placed around the trunks of fruit trees for a similar pro. tective purpose. Exereting epidermal surfaces form also the nectaries of flowers, which by means of their sweet secretions attract such animals, generally insects, as are instrumental in their pollination.

The cells of the epidermis are in uninterrupted contact with each other, and as a rnle have undulating side walls (Fig. 119). The protoplasm of epidermal cells generally appears to be reduced to a thin, peripheral layer, and the sap eavities filled with a colourless or coloured sap. Around their nuclei cluster the colourless rudiments of the ehronatophores, showing that, although exposed to the light, their further development into ehloroplasts may cease in cells not destined to take part in the issimilatory proeesses. Such epidermal cells with undeveloped chromatophores, besides ating as

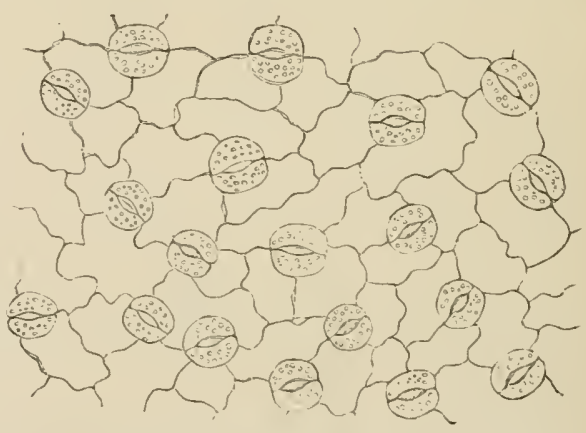

Fiv. 120.- Ejudernis with stomata from the lower surfice of the leaf of Helleborus niger. (x 120.)

an external protection, serve as water-reservoirs; their side walls, by means of folds in the unthickened parts, can expand and collapse as a bellows, according to the variations in their supply of water. In plants which grow in shade chloroplyyll is msually present in the epirlermal cells.

T'he extermal walls of the cpirdermal cells of this mper surfice of foliage leaves not uncommonly project or exhibit a lens-shaped thickening in the middle (Fig. 82); such structures are regarded by G. IHABERLANDT (114) as adaptations serving for the concentration and 
perception of light. Cells of an epidermis which is smooth on the surface may have their inner walls convex towards the interior of the leaf. In a few cases the epidermis presents arrangements which HABERLANDT has termed ocelli and regards as localised organs for the perception of light; these may be either groups of cells with smooth outer walls or single large cells with projecting outer walls and highly refractive contents.

The formation of stomata $\left({ }^{115}\right)$ in the epidermis is characteristic of all parts of the more highly developed plants which are exposed to the air. Each stoma consists of an intercellular passage perforating the epidermis and bounded by two elliptical epidermal cells, termed GUARD-CELLS (Figs. 120, 121 A). The guard-cells always contain chloroplasts, and are also characterised by their peculiarly thickened
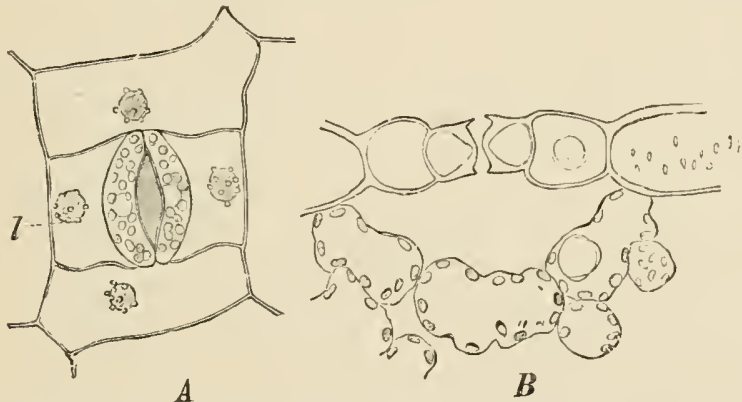

Fra. 121.-Epidermis from the under side of a leaf of Tradrscantia virginica A, In surface view : $B$, in transverse section; 7 , colourless rudiments of chromatophores surrounding the nucleus. $(\times 240$.

walls, which stand in relation to the changes of shape by which the functions of the stoma are carried out. These, as is best seen in transverse sections, form ridge-like protuberances projecting above and below from the sides of the guard-cells adjoining the air-passage (Fig. $121 \mathrm{~B}$ ). Midway between the projecting ridges, on the other hand, the walls of the guard-cells remain unthickened (Fig. 122).

The unthickened parts of the walls of the guard-cells jnt out into the pore (Figs. $121 B, 122)$, and thus facilitate its closing. In addition, the external thickened walls of the two adjacent epidermal cells become, in some cases, suddenly thin on approaching the guard-cells. By this means a hinge-like connection is formed which renders the guard-cells more or less independent of the other epidermal cells (Fig. 122). At other times the same result is accomplished by raising the stomata above the epidermis, or, more frequently, by sinking them below the less thickened epidernal walls. The elevation serves to increase the evaporation, and is on this account met with in Ferns which grow in damp situations. The depression diminishes the transpiration by creating a still atmosphere above the guard-cells. On this account it is met with in plants of dry regions (xerophytes). Frequently the epidermal cells arjoining the guard-cells are less thickened or 
lower than the other cells of the epidemis (Fig. 121). Such special epilermal cells are called smsininY ceLts, and assist the opening of the stoma.

The stomata are formed by the division of a young epidermal cell into two cells of unequal size, one of which, the smaller and more abundantly supplied with protoplasm, beeomes the stoma mother-cell; while the larger, containing less protoplasm, usually forms an ordinary epidernal cell. The stoma mother-cell beeomes elliptical in outline and divides again, by a vertical wall, into the two guard-cells, between which, by a splitting of the wall, the intercellular passage (rore) is formed. Before the formation of the definite stoma mother-cell, successive divisions of the young epidermal cell often occur; in such cases the finally developed stoma is generally surrounded by subsidiary cells.

Stomata are chiefly developed on the green parts of plants, but are sometimes found even on the coloured floral leaves. They are naturally found in greatest numbers on the leaves, as it is there that

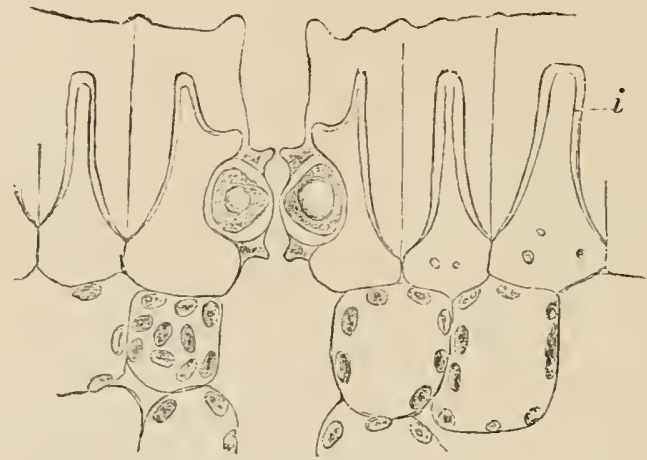

Fif. 122.-Transwerse section of the ppidermis of Alne nigricans. $i$, Inner, uncutinised thickening layer. $(\times 240$.

they are most needed to facilitate the interchange of gases in the processes of assimilation. In dorsiventral leaves the stomata oceur, for the most part, if not exclusively, on the under surface, and average about 100 to 300 to the square millimetre, although in some plants their number may reach 700 . Leaves which are alike on both sides have their stomata equally distributed on the two surfaces. Floating leares of aquatic plants have stomata only on the side exposed to the air. In some eases, as in the Oleander (Nerium Oleander), mumerous stomata are situated together in pit-like depressions of the under surfaces of the leaves. The largest stomata have been found in grasses; for instance, the stoma of wheat is $0.079 \mathrm{~mm}$. long and 0.039 $\mathrm{mm}$. broarl, and has a pore $0.038 \mathrm{~mm}$. in length by $0.007 \mathrm{~mm}$. in wikth. In the tissne directly under each stoma there is always a large intereellular space, termed the REsPIRAToir CAVITY (Fig. $121 \mathrm{~B}$ ), which is in rlirect commmnication with the other intercellular spaces extending thronghont the leaf tissue. In plants grown in abundance 
of moisture, these intereellular spaces are usually larger than in the case of plants growing in drier situations.

In contrast to the stomata, which as air-pores serve for the interchange of gases, a few plants also possess WATER-STOMATA or WATER-POREs, situated at the ends of the veins or nerves of the leaves. These pores serve as organs for the discharge of water or watery solntions. Calcium carbonate, in solution, is frequently excreted in this way, and in many species of Saxifraga it forms white scales on the margins of the leaves. Although waterpores may often be found at the apices and tips of the marginal teeth of young leaves, they seem to dry up as the leaves become more mature. The guard-cells of water-stomata nsually lose their living contents early, and thus the pas-

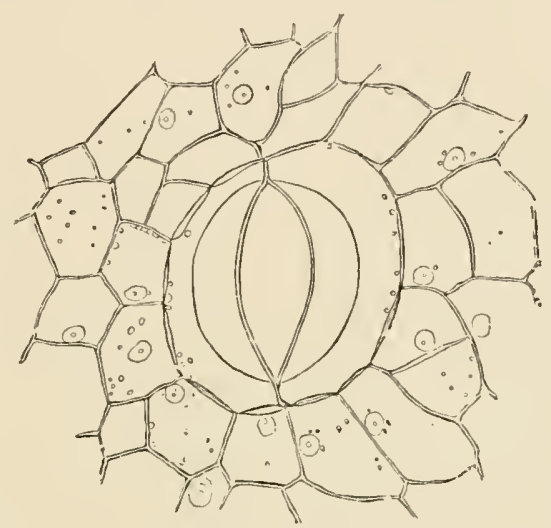

Fig. 123. - Water-pore from the margin of a leaf of Tropaeolum mujus, with sumounding epirlerunal cells. $(\times 24$ ). $)$ sage between them remains continually open. The water-stomata (Fig. 123) are always larger than the air-stomata. Although submerged leaves of aquatic plants are devoid of air-stomata, water-stomata often occur on them.

Hairs or TRICHOMES and EMERGENCES are characteristic of the tegumentary system. The cells of the hairs may retain their living

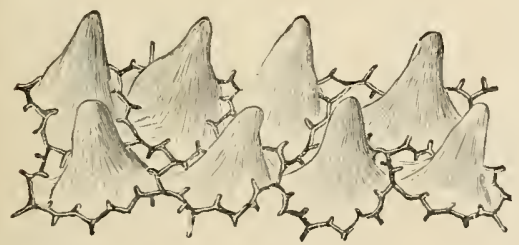

FIG. 124.--Surface of the upper epidermis of a petal of Viola tricolor, showing ridge-like projections on the lateral walls, and protruding papillae. $(x, 250$. contents, or die and become filled with air; in the latter case the hairs appear white. The simplest form of hairs are the PAPILLAE, which are merely epidermal cells, the external walls of which have protruded in a conical form. Papillae are often develojed on the petals of flowers, and are the cause of their velvety appearance (Fig. 124). Longer hairs, such as the root hairs (Fig. $173 \%$ ), are also prolongations of single epidermal cells; these are characteristic of definite regions of the root (p. 47), and only a limited portion of the onter wall of the epidermal cell protrudes as a hair. The woolly hairs found in young buds are generally similarly prolonged epidermal cells which, as a protective covering, surround the young growing tissues and 
sometimes remain on fully developed parts of plants to protect them against too rapirl evaporation and direct insolation. Hairs which have this function are usually appressed to the surface of the plant which bears them, while those which serve for flight, climbing, or defence, stand ont more or less from the surface (116). The hairs developed from some of the epidermal cells of the seed-coats of various

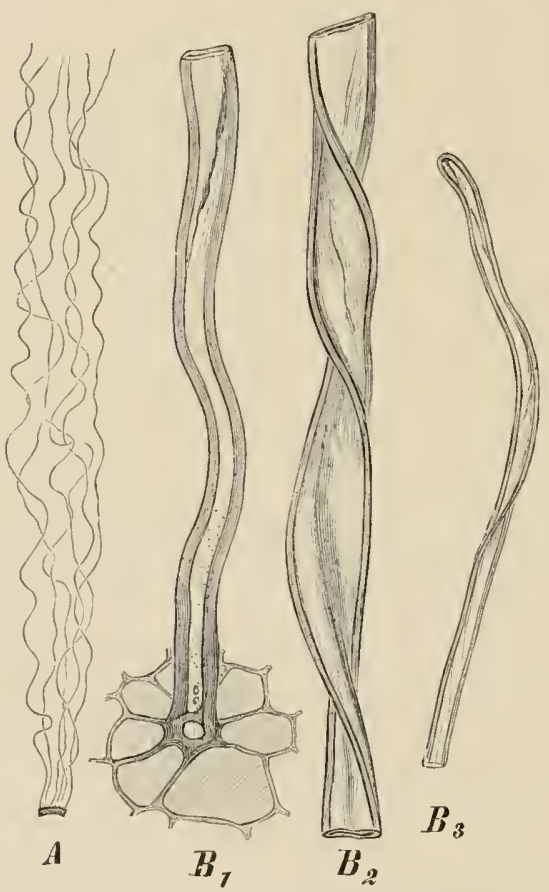

F16. 125.-Sped-liairs of the cotton, frossypium horbrreum. A, Part of serd-coat witl hairs $(\times 3)$. $B_{1}$ insertion and lower jart, $B_{2}$ middle part, and $B_{3}$ uptere part, of a liair. (x 3n0.)

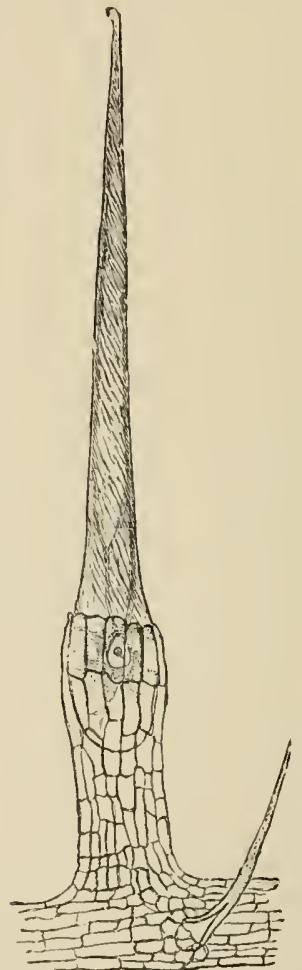

FIG. 126. - Stintring hair of Urtica dioce, with a portion of the epidermis, and, to the right, a small bristle. $(x 60$.

speeies of Gossypium attain an unusual length, and supply the cotton of commerce (Fig. 125). These cotton hairs are sometimes $6 \mathrm{~cm}$. long, and in their fully developed state contain only air; their cell walls are thicker than those of ordinary hairs, and covered with a delicate cuticle. They are usually somewhat flattened and at the same time twisted; and are wider in the middle than at either end. Only a certitin number of the epirlermal cells of the seed grow out as cotton hairs (Fig. $125 l_{B_{2}}$ ). BristLis are short, pointed hairs, in the thickened 
cell walls of which calcium carbonate or silica has been deposited (Fig. 126, below, to the right).

The stinging inalRs (Fig. 126), such as those of Nettles (Urticu) and of the Loasaceae, are special forms of bristles, and arise as prolongations of single epiclermal cells. These, however, swell in the eourse of their development, and becoming surrounded by adjoining epidermal cells present the appearance of being set in soekets; while, at the same time, by the multiplication of the cells in the tissue at their base, the whole hair beeomes elevated on a column-like protuberanee. The hair tapers towards the apex and terminates, somewhat obliquely, in a small head, just below which the wall of the hair remains unthiekened. As the wall of the hair is silicified at the end and calcified for the rest of its length, the whole hair is extremely stiff. Such hairs furnish a means of defenee against animals. The heads break off at the slightest tonch, and the hairs piercing the skin pour out their poisonous contents, which, especially in the ease of some tropical nettles, may eause severe inflammation. According to G. HaBerLandT ( ${ }^{117}$ ) this is due to the presence of a toxin of albuminous nature.

The cells surrounding the base of a hair are often arranged in a ring or in radiating lines, or are otherwise different from the surrounding epidermal cells. Such cells may be called subsidiary cells to the hairs.

UNICELLULAR HAIRs, such as we have so far considered, may terminate in well-defined heads resulting from the swelling of their tips, or their side walls may develop irregular exerescences; on the other hand, they may remain short and expanded like a balloon, or remain close to the surface of the epidermis as spindle-shaped or stellate hairs. Multickllular Hairs may be merely simple rows of similar cells, as the hairs on the stamens of Tradescuntia (Fig. 59); or their terminal cells may beeome swollen into globular heads (Fig. 127), like those on the Chinese Primrose (Primula sinensis); or an epidermis may be covered with disc-, star-, or bowl-shaped liairs (Fig. 128). Sometimes the hairs become varionsly branched, lose their living eontents, and form a silky or woolly proteetive eovering similar to that formed by micellular hairs. In special cases, as in the scale hairs of Ferns, they may even have the shape of a small leaf.

ENERGENCES, unlike hairs, are not formed solely by epidermal cells, but a number of cells, lying more or less deeply in the subepidermal tissues, also take part in their formation. Thus, for example, while only a few rows of sub-epidermal cells enter into the formation of the emergences (Fig. 129) on the margins of the stipules of the Pansy (Viola tricolor), much deeper-lying tissue participates in the development of the emergenees which, as PRICKLEs, serve in the case of Roses as a means of protection, and at the sime time are of assistanee in climbing. The thick emergenees which spring from the 
roots of the Podostemaceae, and serve to attach them to rocks, are

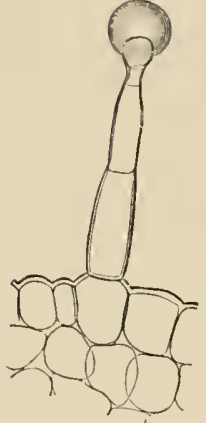

Fig. 1:7.-Glandular hair from the petiole of Primula sinensis. (After DE BARY, $\times 142$.

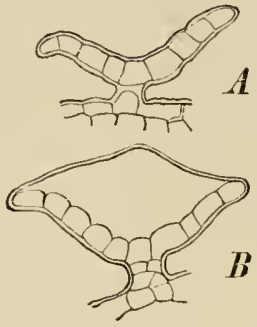

Fia. 128.-Glandular scale from the female inflorescence of the Hop, Humulus Lupulus, in vertical section. $A$, before, $B$, after the cuticle has become distended by the seeretion. In $B$ the seeretion has been removed by alcohol. (After DE BARY, $\times 142$.

parenchymatous throughout, but vasenlar bundles may be inehded within emergences, as is well shown in the club-shaped digestive glands or tentacles (Figs. 130, 198) on the leaves of the Sundew (Drosera). Some emergenees resemble in structure certain of the metamorphosed

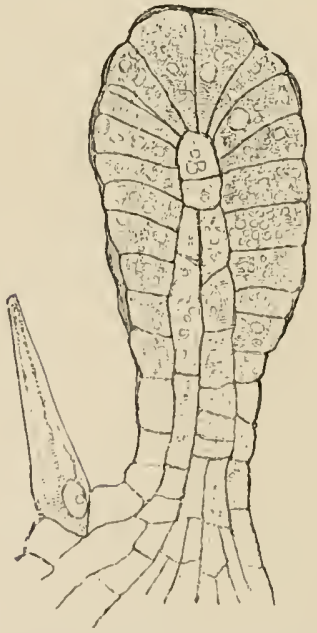

F10. 129.-Glindular colleter from a stipule of riola tricolor, showing also a unicellular hair. $(\times 240$.

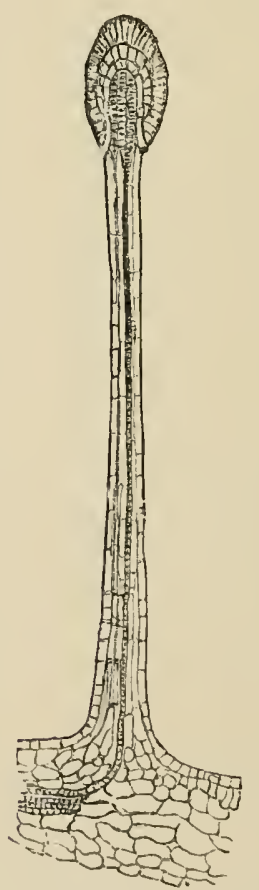

Fig. 130.-Digestive gland from Drosera rotunilifolia. $(\times 60$. $)$

members of the plant body deseribed in the preceding chapter; the 
resemblance between prickles and thorns, and between haptera and lateral roots will serve as examples. 'They are not, however, to be traced back in origin to such member's (1.51).

Both hairs and emergences frequently act as secleting organs, and are then termed GLANDS. In many cases they are concerned with the active exudation, and at times also the absorption of water. They then belong to the class of organs designated HYDATHODEs (118) by HABERLandT. Other glandular hairs excrete a resinous substanee. The hairs of Primulu sinensis (Fig. 127) are in reality such glands, in which the cuticle of the terminal globular head is pressed away from the cell wall by the resinous matter exereted from the hair, until finally the bulging cuticle is ruptured and the resinons secretion exudes. The hairs of this and other species of I'rimulu (especially $P$. obconica) are capalule of exciting inflammation in the skin of those handling them $\left({ }^{119}\right)$. Only some persous are susceptible to the effect. The similar but more complieated glandular hairs of Hops (Fig. 128) produce a secietion called LUPULIN, to which beer owes its bitter taste and distinctive aroma. The secretion is set free by the bursting of the cuticle, the latter having been previously raised up from the underlying cell wall as a continuous membrane (Fig. 128 li). Hairs and emergences with abundant protoplasmic contents occur on irritable stamens, perianth leaves, and pulvini, and, as HABERLANDT $\left({ }^{120}\right)$ showed, act as tactile papillae, hairs, or bristles in the reception of stimuli.

The mucilaginous matter produced in young buds by the mucilage papillae on COLLETERs results from the partial dissolntion of the cell wall under the euticle. After the mueilaginous secretion has becu discharged by the ultimate rupture of the cuticle, another new enticle forms over the cell wall, and the proeess is again repeated. The colleters are special forms of hairy structures, and are often developed in buds to protect the young orgaus from drying, by means of the mucilaginous modification of their cell walls. Where the dissolution of the cell wall is accompanied by secretions from the underlying cells, the colleters assume rather the character of glandular hairs. Such GLANDULAI COLLETElis are common in the winter buds of trees; in the Horsc-chestnut (Acsculus Hippocastanum), for example, the bud-scales of the winter buds are stuck together by a mixture of gum and resiu, which has exuded from colleters of this nature. The glandular hairs of the Pansy (Fig. 129) act in a similar manner. The emergences on the leaves of the Sundew (Droserc), just mentioned as digestive glands (Fig. 130), discharge glistening drops of mucilaginous matter, which accumulate on the free surface of the glands at the ends of the tentacles, through the porose entiele. Small animals are canght by means of these sticky excretions, and are afterwards digested by the plant. The neetaries also often excrete sugary solutions directly from their surfaces. In flowers these serve to attract insects, which eflect prollination, while on other parts of the plant they are known in certain cases to attract ants, which protect the nlant. The osmotieally active slibstances in the nectar are in the first instance derived by transformation of the outer cell walls, or are secreted by the cells. The presence of these substances on the surface of the neetary attracts water from the tissue beneath, and thus leads to the continued formation of the nectar. 
In some of the Pipreraceae and Begoniaceae, and in some specics of Ficus, the epidermis is eomposed of several layers; but this is a comparatively rare oceurrence. Such a many-layered epidermis results from a division of the young ejuilemal cells parallel to the external surface. The epidermis of Ficus elustica. (Fig. 83) has three layers, and serres as a reservoir for accumulating water. The eystoliths of Ficus clastica, already referred to ( 1 . 76 ), oecur in single swollen epidermal cells. A many-layered root epidermis is also met with, as in species of Aspuragus, Crinum, and Lycoris. The many-layered epidermis of the aerial roots of many Orchids, and of varions Aroids, undergoes a peenliar modifieation and forms the so-called VELAMEN liADICUX (P. 49), a parchment-like sheath surrounding the roots, and often attaining a eonsiderable thickness. The cells of this enveloping sheath are generally provided with spiral or retienlate thickenings, and lose their living contents. They then become filled with either water or air, depending upon the amount of moisture contained in the snrrounding atmosphere. These root-enrelopes absorb water like blotting-paper; when the velanen is filled with water the underlying tissues impart a greenish tint to the root; but if it eontains only air the root appears white. The epidermis of fruits, and particnlarly of seeds, exhibits a considerable variety of modifieations in its mode of thickening, and in the relations the thiekening layers bear to one another. The purpose of these modifications in the epidermis becones at once evident, when it is taken into consideration that, in addition to protecting and enelosing the internal jarts, the epidermis has often to provide for the dissemination and permanent lodgment of the fruits and seeds.

The Vascular Bundle System. - The PRIMARY VASCULAR BUNDLES extend in the form of strands throughout the body of the higher plants. In more transparent stems, such as those of Impatiens parriflora, the bundles may be clearly distinguished and their course followed. The arrangement of the bundles of leaves is apparent from the venation. In many parallel-veined leaves the bundles are easily isolated. This is often done accidentally, as when, for example, in picking a leaf of Plantain (Plantugo media) a pull is given at the same time.

Special strands of tissue serving for the transport of substances through the plant are found in the more highly differentiated Thallophyta; examples are afforded by some of the Red and Brown Seaweeds (Rhodophyceae and Phaeophyceae). In the Laminariaceae these conducting tracts contain elements which closely resemble sieve-tubes $\left({ }^{121}\right)$. 'l'he thallus of some Liverworts is traversed by a strand which resembles the nerve of a leaf. Bundles sharply limited from the surrounding tissues first appear in the Mosses; they occur commonly in the leaves, less often in the stems. A fairly simple example of this lind of conducting bundle is that of the stem of Mnium undulatum which is represented in transverse section in Fig. 172. Such bundles reach their highest differentiation in the Polytrichacea. In them the stem has a central cylinder composed of elongated cells with scanty contents, of elements lesembling sieve-tubes, and of elongated cells; the three kinrls of element serve respectively to transport water, albuminous substances, and carbohydiates (122). The arrange- 
ment of the tissue of these complicated strands is often similat to that found in the vascular bundles of more highly orgarised plants. This is a good example of a striking resemblance between structures which are analogous but have arisen independently in the course of evolution.

It is, however, in the Cormophytes, which possess roots, that a

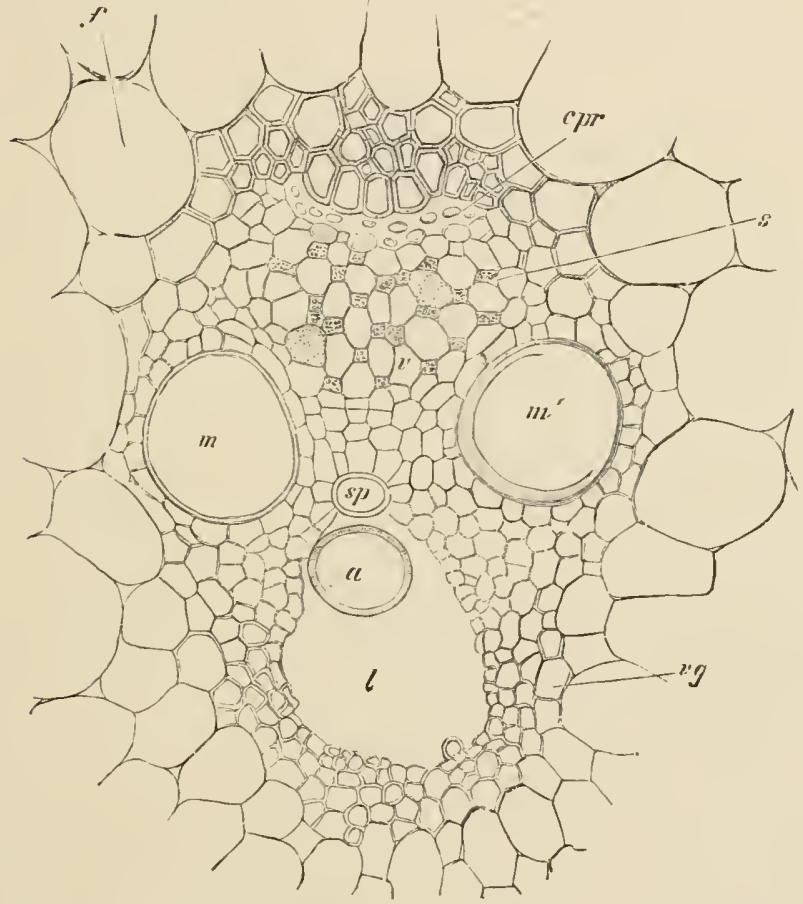

Fic. 131.-Transverse section of a vascular bundle from the internode of a stem of $Z$ ut Wais. $a$, Ring of an anular tracheide; $s p$, spiral tracheile; $m$ and $m$, vessels with bordered pits; $v$, sievetubes ; $s$, companion cells; $c p r$, compressed protophloem ; $l$, intercellular passage ; $i g$, sheatlı ; $f$, cell of fundamental tissue. $(\times 180$.

high degree of differentiation of the vascular bundles is first attained. Since the absorption of water is limited to the roots, the arrangements in the conducting tracts require to be more perfect. Two distinct components can be distinguished in these vascular bundles, the TRACHEAL or XYleir PORTION, and the SIEVE-TUBE or PHLOEM Portion. While these may form inclependent strands, they are generally united in one VASCULAR BUNDLE. Other terms often used to designate the vascular bundles are FIBRO-VASCULAR BUNDLE's and MESTOME. The rascular portion is also termed the PRIMARY WOOD, 
XYLEM or HADROME, and the sieve-tube portion the PRIMARY PHLOEM OI LEPTOME ( $\left.{ }^{123}\right)$. The distinction of the two components of the vascular bundle is most evident from transverse sections (Figs. 131, 133), with which the longitudinal section (Fig. 132) should be compared. The vascular portion contains TRACHEAE and TRACHEIDES as most essential for the fulfilment of its function of water conduction ( $a, s p$, $m$, Figs. 131, 132), or tracheides alone, and, in addition, living, elongated parenchymatous cells that may be

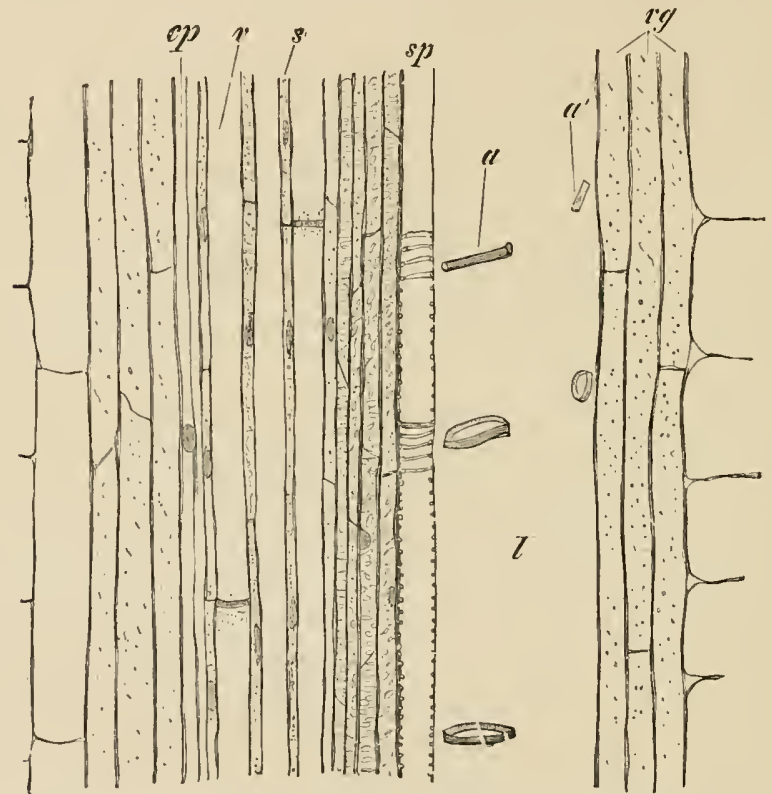

Fro. 132.-Longitudinal section of a vascular bundle from the stem of Zea Mais, a, and $a 1$, Rings of : an annular tracheicle; $r$, sieve-tubes; $s$, companion cells; $c p$, protophloem; $l$, intercellular passage; vg, sheath; $s p$, spiral tracheides. ( $x$ I $\$ 80$.

designated XYLEM or wOOD PARLNCIIYMA. In the phloem portion the most essential elements are the siEve-TUBEs $(v)$, which serve for the conveyance of albuminous matter. They are always accompanied by other living cells; either by the so-called COMPANION CLLLS (s), or in addition by elongated parenchymatous cells, or by the parenchyma alone. Companion cells only occur in the phloem of Angiosperms. They are sister cells of the cells composing the sieve-tubes, having arisen by longitudinal division from the same mother cell. The companion cells are not so large as the sieve-tubes, and may be distinguished from them by theil more abundant protoplasmic contents, and especially by the fact that they retain their nuclei, while the nuclei of the sieve-tubes soon disappear. In Monocotyledons 
(Figs. 131, 132), and in the Rammculaceae among the Dicotyledons (Fig. 133), the phloem consists solely of sieve-tulues and companion cells; in the other Dicotyledons parenchymatous elements are also present, and these are accordingly distinguished as PHLOEM PARENCHYMA; 110 companion cells are found in Gymnosperms and

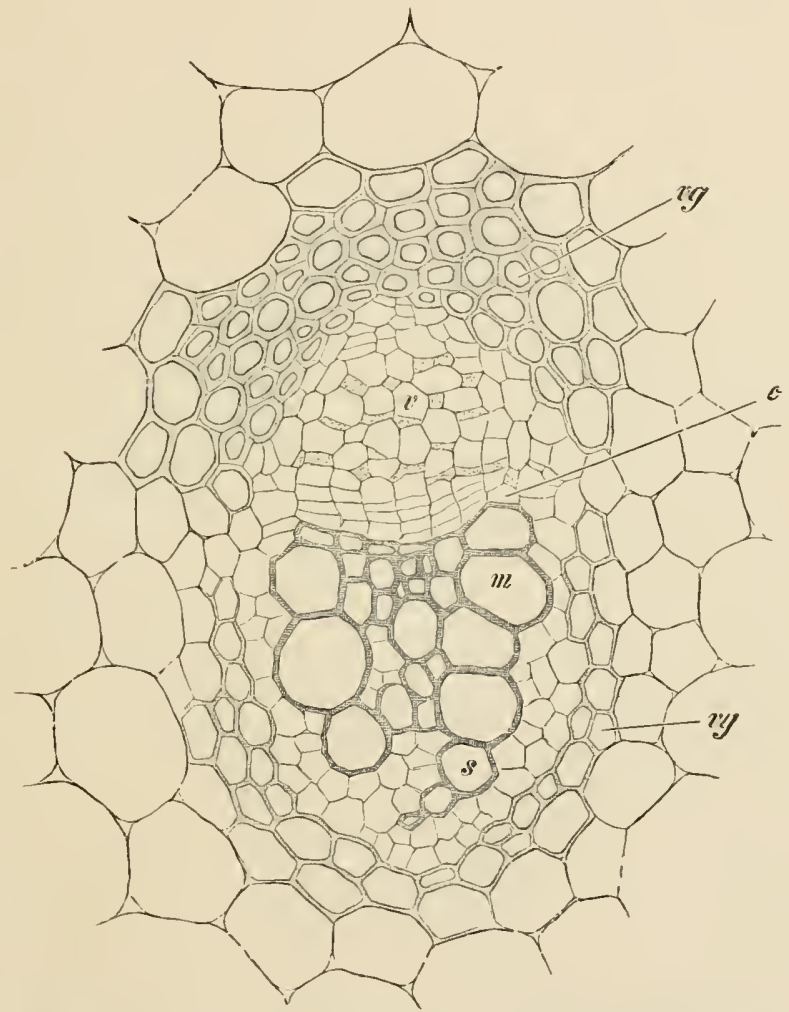

Frg. 133.-Transverse section of a vascular bundle from a stolon of Ranunculus reprns. s, Spiral tracheides; $m$, ressel with botdered pits; $c$, cambium ; $v$, sieve-tubes ; vg, sheatl. ( $\times 1 s 0$.)

Pteridophytes, and in addition to sieve-tubes the phloem contains only phloem parenchyma.

The bundles of the Phanerogams (Gymnosperms and Angiosperms) are generally COLLATERAL in structure, that is, the xylem and phloem are in contact on one side only. In stems the most usual arrangement of the two portions of a collateral bundle is that in which the xylem lies nearer the centre; in leaves the xylem portion lies nearer the upper, and the phloem portion nearer the lower surface. Closely allied to the collateral type is the bicollateral type of bundle. In 
this the xylem is accompanied by phloem both on the outside and inside. Such bicollateral bundles are characteristic of the Cucurbitaceae. The xylem and phloem of roots generally form separate strands (Fig. $134 s, v)$, and the xylem strands are differeutly oriented; while in stems the narrow vessels are nearer the centre and the wider nearer the circumference, in roots this order is exactly reversed. The xylem and phloem strands make up what is spoken of as a RADIAL bundle.

The "concentric" vasenlar bundles of the Pteridophyta (Fig. $135)$ eontain tracheides (sp), and only in exceptional cases tracheae (sc). The latter are as a rule wanting in Pteridophyta, although this group goes by the name of Vascular Cryptogams $\left({ }^{124}\right)$. The water-conducting elements exhibit scalariform thickenings, only the narrowest having spiral markings $(s p)$; they are surrounded by xylem parenchyma $(l p)$. Outside this comes a zone of tissue consisting of sieve-tubes $(c)$ and phloem parenehyma (s).

A number of vascular bundles of this kind are present in the stems of most Ferus and species of Selaginella. In Lycopodium they are fused into a single central cylinder. In the stem of Equisetaceae vasenlar bundles of collateral structurc appear.

The vascular bundles are developed from strands of meristematic tissue which are caller PROCAMBIUM STRANDS. Within each strand

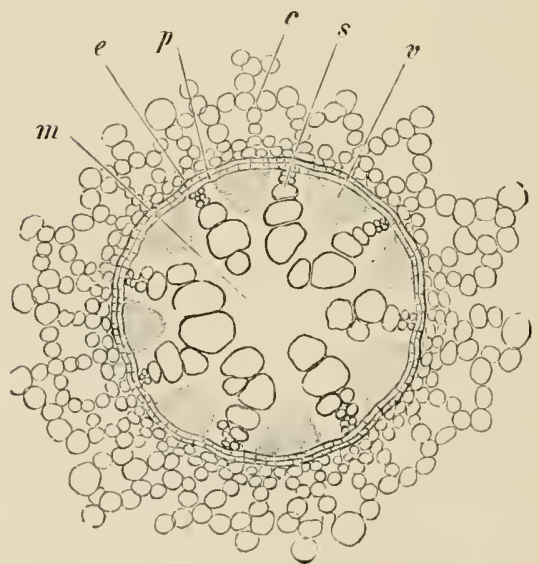

Fis. 134.-Transverse section of central portion of the root of Acorus culamus. m, Medullai ; s, xylen; $\imath$, phloem ; p, pricycle ; e, endolermis ; $r$, cortex. ( $\mathrm{x} 90$.

\section{tyledons (Fig. 133), on the contrary, have open bundles.}

In those portions of plants which are still actively growing in length, the procambium strands remain undifferentiated, except at definite points, where single rows of cells lose their meristematic condition and form narrow, annular, and spiral 
ressels, and sieve-tubes, or sieve-tubes and companion cells; the structure of all of these is of such a nature as to render their elongation possible. Such primary vascular elements are termed ProToxy LMM : while the corresponding sieve elements are in like manner designated poTupHon. The protoxylem occupies the innermost, the protophloem the ontermost side of a jrocambium strand, from which a collateral bundle is eventually formed. After the growth in length of any part of a plant ceases, the differentiation of the procambium strand into a collateral vascular

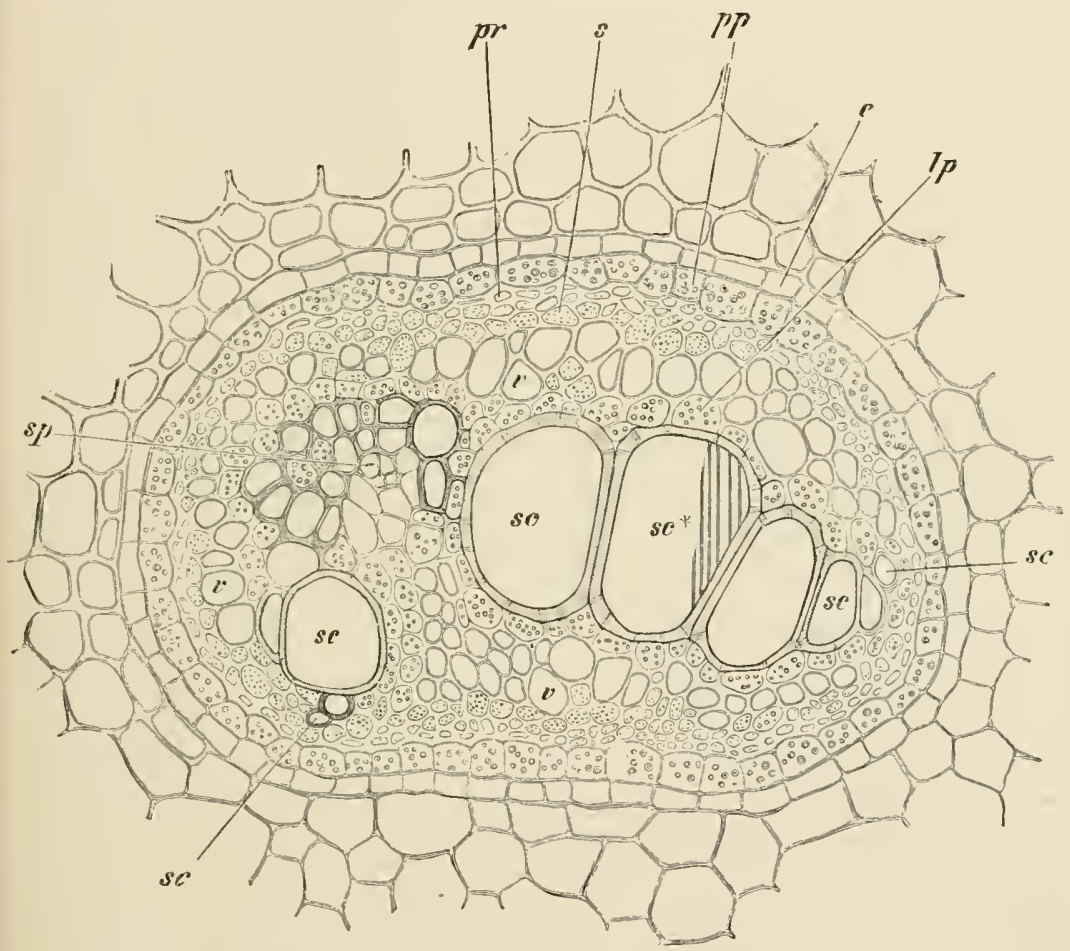

Fic. 135. - Transverse section of a concentric bundle from the petiole of pteris aruiline. sr, Sealariform ressels ; sp, protoxylem (spiral tracheirles); $s r^{*}$, part of a transverse wall showing sealariform perforations; $l p$, xyl m parenchyma ; $u$, sieve-tubes ; $m$, protophloem ; $m$, starch layer ; $e$, endodermis ; $s$, phloem parenchyma. $(\times 240$.

bundle is continued from the inner and outer sides of the strand toward the centre.

In finlly developed vascular bundles the protoxylem and protophloen cease to perform their functions. The protoxylen elements become compressed and ruptured by the tension resulting from the continued vertical growth ( $a$ and $a^{\mathrm{I}}$, Fig. 132), so that in their stead a lysigenic intercellular space is often formed (Figs. 131, 132). The protophloem elements at the same time become disorganised, and their sieve. plates closed by a covering of callus.

In accorlance with the inrerted orientation of the xylem, the protoxylem of roots is found on the onter, not or the inner side of the vasenlar strands (Fig. 134). 
The Terminations of the Vaseular Bundles.-In leaves, particularly in the foliage leaves of Angiosperms, the vascular bundles become much branched until finally they are reduced to extremely fine strands. In the leaves of Gymnosperms this branching of the bundles does not usually take place, but instead, a single vascular bundle frequently runs throughout the whole length of the leaf. The vascular bundles of the reticnlately-veined leaves of Dicotyledons illustrate the most extreme form of branching.

The minute distribution of the bundles in the leaf-lamina facilitates the regular conduction of water to all parts of the leaf-tissue, and at the same time renders easier the removal of the assimilated products. As the ramifica-

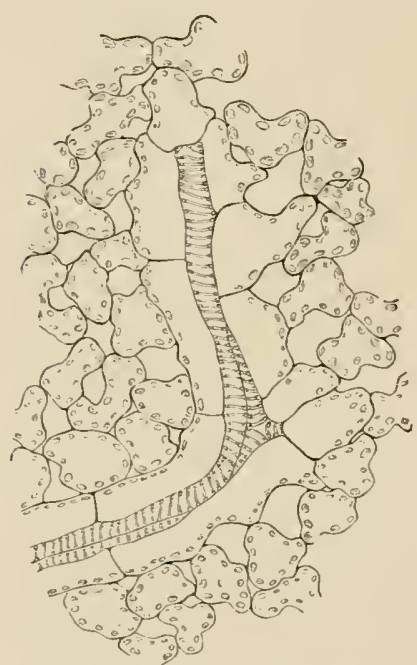

Fic. 136. - Termination of a vascular bundle in a leaf of Impatiens pariHora. $(\times 240$. The whole tissue of the lower plants, as it shows no internal differentiation, may, in a certain sense, be considered fundamental tissue. The other tissues have gradually arisen from the fundamental tissue in the course of phylogenetic development. The fundamental tissue in the higher plants is enclosed by tegumentary tissue, and traversed by the vascular bunclle system. While the tegumentary tissue protects the plant externally, and the vascular bundle system performs the office of conduction, and also of mechanically strengthening the plant, the duty of providing for the nutrition of the plant and of storing reserve food material falls chiefly to the fundamental tissue. The fundamental tissue consists, therefore, for the most part of parenchymatous cells containing chlorophyll, at least to such depth as 
the light penetrates; internally a colourless parenchyma is found. The fundamental tissue system also takes part in providing for the mechanical rigidity of plants, and in connection with this function it possesses collenchyma (Fig. 81 c) and sclerenchyma as its special mechanical tissues. The Coldenchyma (p. 76) is unlignified and very elastic, and thus fitted for stretching; it is the form of mechanical tissue suitable for those parts of plants still undergoing growth in length. The sclerenchymatous fibres, which are often unlignified but have greatly thickened walls, on the other hand, are formed after growth in length has ceased, and sclereides (p. 80) arise even later. The elongated cells of the fundamental tissue also perform a certain share of the work of conduction, and serve for the transport of carbohydrates. Secondary or waste products, resulting from chemical changes, are also deposited in special cells of the fundamental tissue. Consequently jdioblasts (p. 80 ), containing crystals or rows of crystalcontaining cells, are often met with in the fundamental tissues, together with cells, tubes, cavities, or canals containing tannin, gum, resin, ethereal oils, latex, or alkaloids. Such waste products are for the most part deposited near the surface of a plant, in order to serve as a defence against destructive anjmals, or that they may afterwards be thrown off along with the superficial tissue. Cells containing these waste products, particularly crystal cells and latex tubes, are often found, accompanying the phloem portion of the vascular bundles.

The Aroideae, Nymphaeaceae, and several other plant families possess a peculiar form of idioblast, in the so-called internal hairs, which project into the intercellular spaces of the fundamental tissue. In the wicle intercellular passages of the petioles and flower stems of the Water-Lily these idioblasts are stellate in form. Their walls are strongly thickened, and provided with short protuberances in which small crystals of calcinm oxlate are deposited.

\section{The Distribution of the Primary Tissues ( ${ }^{126}$ )}

In the body of multicellular plants a distinction between an outer small-celled and firm tissue and an inner large-celled looser tissue soon becomes apparent. The outer tissues are best adapted for protection, the inner for conduction and storage. The cells of the inner tissues accordingly become elongated for the purpose of conduction. The outer tissues in plants, which must proride independently for their own nourishment, contain chromatophores fitted for assimilation, and are correspondingly coloured, while the inner tissues remain colourless. The outer portion of the fundamental tissue thus differentiated is called the CORTEx, the inner the MEDULLA or PITH. An epidermis, distinguishable from the cortex, is found in some of the Mosses, but a sharp distinction between these tissues is first found in the more highly organised plants. 
In the Stem of a Phanerogamic plant there is an outer skin or epidermis (Fig. $138 \mathrm{~b}, e$ ) on the external surface; then follows the PRIMARY CORTEX (Figs. 137, $138 \mathrm{~A}, \mathrm{pr}$ ), and internal to this the so-called Cential CYLINDER, for which TAN TiEgheir has proposed the name STELE (column) (12i). The innermost layer of the primary cortex, which may be designated by the term PHLOEOTERNA, is for the most part not distinctly differentiated, but ean be reeognised in aerial stems of land-plants as a stareh-sheath; while in the rhizomes of land-plants and in the stems of water-plants it forms the ENDODERMIS. Differentiated as a starch-sheath (Fig. $138 \mathrm{~A}, \mathrm{~B}$, st), the phloeoterma is rendered conspicuous by the quantity of

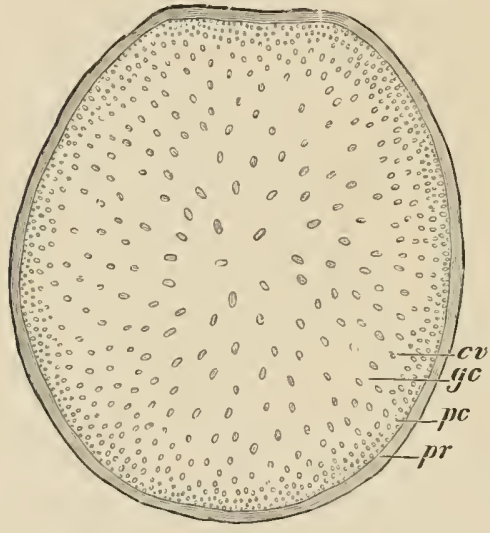

Fis. 137.-Transverse section of an internode of the stem of Zea luris. pr, Primary cortex ; pr, pericyele; $c c$, vaseular bundles; gc, fundamental tissue of the central eylinder. $(\times 2$. morable stareh contained in its cells. A starch-sheath is often present in the young shoots, while it disappears or becomes limited to certain parts of the older shoots $\left({ }^{128}\right)$. When developed as an endodermis, portions of the lateral walls of its cells become chemically altered, as a rule suberised $\left({ }^{129}\right)$. In a cross-section these suberised portions of the cell walls of the endodermis appear as dark spots (Fig. 140), but in a tangential section as a wavy band. The CENTRAL CYLINDER of the stem contains vascular bundles $(c v)$, which, in the Equisetaceae, the Gymnosperms and Dicotyledons (Fig. $138 \mathrm{~A}$ ), are arranged in a eircle, whereas in Monocotyledons

(Fig. 137) they are irregularly distributed. In all these cases the xylem portion of the vascular bundle is direeted towards the centre, and the phloem portion away from the eentre of the stem. That part of the peripheral tissue of the central cylinder lying outside of the bundles is called the PERICYCLE $(p c)$. If the bundles are arranged in a eircle (Fig. ] 38 A), that part of the central eylinder enclosed by them is the PITH or mEDULLA $(m)$ and the tissue between the different bundles the primary mEDUllary raYs. In the case of seattered bundles (Fig. 137), a distinction between medulla and medullary rays is no longer possible. Wherever there is no sharp distinction between primary cortex and central eylinder, even when the tissues are young, comparative investigation alone can determine whether a tissue belongs to the primary eortex or to the central cylinder.

Aithough the fundamental tissue of the primary cortex is mainly a chlorophyll. containing tissue, portions bordering on the epidermis frequently become converted, 
particular rows of cells provided with movable starch grains are present. The central cylinder of Phanerogams is simple, and occupies a more or less central position. In a few cases, as in the stems of Auricula and Gunnera, the central cylinder is broken $u p$ into several partial cylinders.

In Roots, the division between primary cortex and central cylinder is sharply marked by the endodermis, into which the innermost layer of the primary cortex is usually transformed (Figs. 134, 139, 140 e).

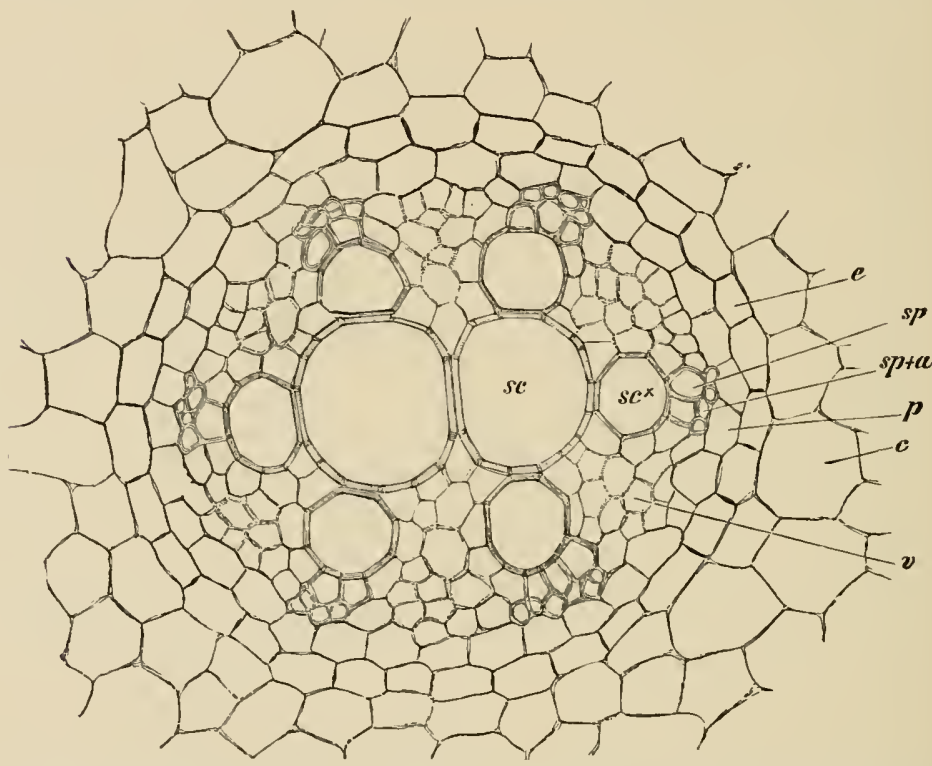

Fro. 140.-Transverse section of an adventitious root of Allium lepa. c, Primary cortex; e, endodermis; $p$, pericycle; $a$, anuular tracheides; $s p$, spiral tracheides; $s c$, and $s c^{*}$, scalariform ressels; $v$, phloem. $(\times 240$.

A close and uninterrupted contact of the endodermal cells is brought about by the chemical change which the middle strip of their lateral walls undergo. This results in a shutting off of the central cylinder from the air-containing intercellular spaces of the cortex. In the older parts of the roots, the cells of the endodermis become greatly thickened, but generally on one side only. Should thickening occur at an early stage, special endodermal cells, directly external to the xylem strands, remain unthickened and serve as TRANSFUSION CELLS (Fig. $141 f$ ).

While the root-hairs are as a rule developed from the cells of a definite region of the epidermis, they nay, in case the epidermis is throw off at an early stage, arise from the outermost cortical layer, which then assumes the functions of an epidernis. In any case the epidermis soon disappears, and the outermost cortical layer becomes more or less cuticularised and, as an ExODEnMis, takes its place 
(Fig. $139 c x$ ). Frequently some of the cells of such an exodermis remain uncutinised and serve as transfusion cells. They may be characterised by their sinaller size, and be regularly distributed between the cutinised cells. In aerial roots the epidermis usually forms a many-layered root-sheath or velamen (cf. p. 120), within which comes the exodermis.

The primary cortex of the root is composed of colourless tissue, which is usually parenchymatous. In the onter layers the cells are in close contact with one another, but intercellular spaces are present more internally. These intercellular spaces often widen into aircavities or passages. In many roots a hypoderma giving mechanical support to the epidermis or exodermis is present. The outermost layer of cells of the central cylinder (Figs. 134, $141 \mathrm{p}$ ) forms the pericycle, which is also called the pericambium; this is usually a single layer, and in rare cases is wanting. The xylem and phloem portions form separate strands (p. 124), radially disposed and alternating with each other (Figs. 134, 140). It has already been shown that the narrowest elements of the vascular strand are outermost. Roots are described as diarch, triarch, polyarch, according to the number of the vascular strands. For example, the roots of Acorus Calamus (Fig. 134) are octarch, those of Allium Cepa (Fig. 140) hexarch. The vascular strands may either.meet in the centre (Fig. 140), or they may surround a central pith (Fig. 134).

Lateral roots are developed in Pteridophytes from the innermost

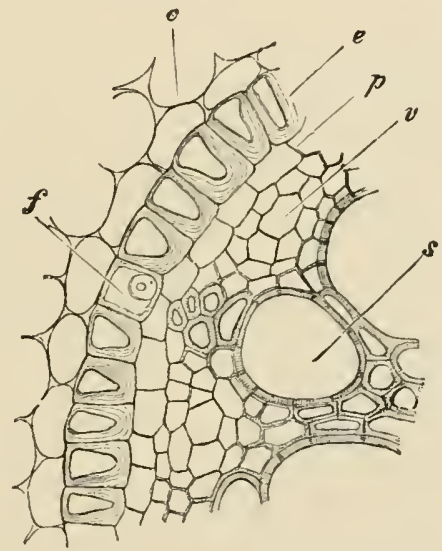

FIG. 141.- Part of a transverse section of a root of Iris Florentina. e, Endorlernis, showing cell walls thickened on one side; $f$, transfusion cell; $p$, pericycle; $v$, phloen; s, vessel of xylem; $c$, cortex. $(\times 240$.

layer of the cortex, in Phanerogams from the pericycle of the parent root. They have thus in their further development to break through the whole thickness of the primary cortex of the parent root. They are situated either directly opposite to the vascular strands of the parent root, or between the xylem and phloem strands. The number of rows of lateral roots is, therefore, as VAN TIEGHEM $\left({ }^{130}\right)$ pointed out, either equal to or double the number of vascular strands. As the strands of the vascular bundles of roots take a straight course, the lateral roots must similarly form straight rows. The distances between the rows themselves are either equal, or, when the lateral roots are situated to the right and left of each vascular strand, the rows are arranged in pairs with wider intervals between each pair.

The Leaves are composed of fundamental tissue (which is here 
termed mesophyll), bounded by an epidermis and traversed by vascular bundles. Sheaths are present around the bundles, extending to their fine terminations. The cells composing these mesophyll sheaths are as a rule elongated and not separated by intercellular spaces. Besides limiting the vascular bundles from the mesophyll, the sheaths perform the important function of conducting soluble carbohydrates from the leaf to the stem. The larger vascular bundles are usually accompanied by strands of sclerenchyma; these disappear from the finer branches. Other strands of sclerenchyma not connected with the vascular bundles may also occur in the mesophyll and contribute to the rigidity of the leaf.

The mesophyll passes into the primary cortex of the stem, while the vascular bundles are continuous with the central cylinder. Thus in the leaf, tissues corresponding to the cortex and central cylinder of the stem remain distinct from one another.

The mesophyll of the coloured FLORAL LEAVES of the Angiosperms usually consists of a somewhat loose tissue, containing intercellular spaces and traversed by vascular bundles. The laminae of many assimilating FOLIAGE LEAVES, especially of shade-loving plants, may have a similar uniform structure; but they are usually more complicated, and exhibit a difference in the structure of their upper and lower sides (Fig. 142). In such dorsiventral structures the upper epidermis (Fig. 142, ep) is succeeded by one or more layers of cylindrical parenchymatous elements elongated at right angles to the surface, and known as the PALISADE CELLS $(p l)$. These are especially rich in chlorophyll, and are often separated laterally from one another, so that the conduction of substances is limited to the direction of their longer axis. Adjoining the palisade parenchyma, and extending to the epidermis $\left(e p^{\prime \prime}\right)$ on the under surface of the leaf, is a loose tissue called the sPongY PARENCHYMa $(s p)$. In contrast to the palisade cells, the cells of the spongy parenchyma are less abundantly supplied with chlorophyll; they are also much more irregular in shape, and have large intercellular air-spaces between them. The palisade cells are elongated in the direction in which the rays of light penetrate the leaf-lamina, and by this means are particularly adapted to their special function of assimilation. The spongy parenchyma, on the other hand, is arranged to facilitate the free passage of gases, and to that end develops large intercellular spaces in direct communication with the stomata of the lower epidermis. HABERLANDT $\left({ }^{131}\right)$ has estimated that to every square millimetre of surface in a leaf of licinus communis there are, in the palisade cells, 403,200 chlorophyll granules; in the cells of the spongy parenchyma only 92,000 ; that is, 82 per cent of all the chlorophyll granules belong to the upper surface of the leaf, and only 18 per cent to the under side. The palisade cells are often arranged in groups, in which the lower ends of the cells of each group 
converge (Fig. 142). In this way several palisade cells come into direct contact with a single expauded cell $(s)$ of the spongy parenchyma, which thus functions, apparently, as a collecting cell for a group of palisade cells. The products of assimilation are passed on from the collecting cell through the spongy parenchyma, to be finally carried to the mesophyll sheath surrounding the vascular bundles. The sheaths serve as a conducting tissue towards the stem.

At the base of the lamina the tissues close together and pass into the leaf-stalk, where one is present. The dorsiventral structure becomes less marked in the petiole. The cells are mostly elongater in the length of the petiole, a modification which facilitates the conduction of food material. They are often thickened and so arranged

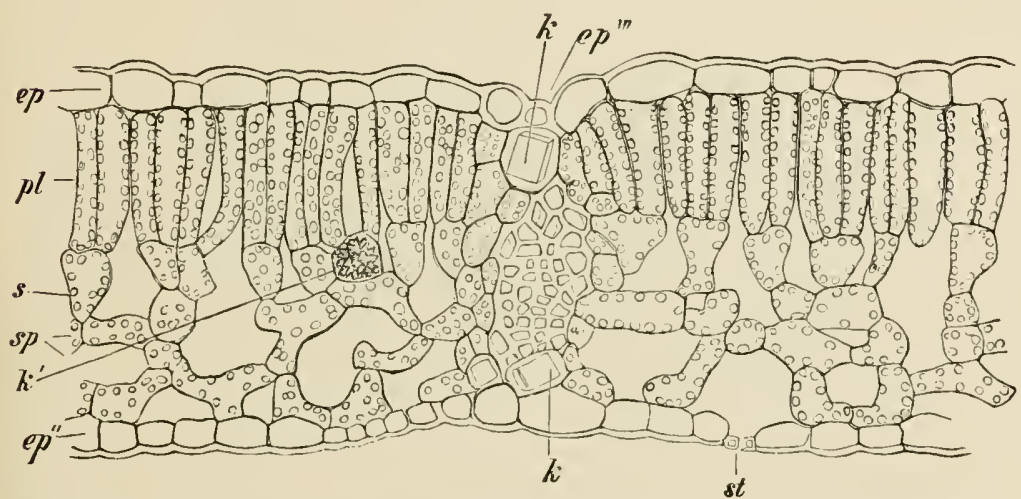

F1G. 142.-Transverse section of a leaf of Fagus syliatica. ep, Epidermis of upper surface ; $e p^{\prime \prime}$, epirermis of under surface ; $e p^{\prime \prime \prime}$, elongated epidermal cell above a vascular bundle ; $p l$, palisade parenchyma ; $s$, collecting cells; $s p$, spongy parenchyma; $k$, idioblasts witl crystals, in $k^{\prime}$ with crystal aggregate; st, stoma. ( $\times 360$.

as to meet the altered requirements for mechanical rigidity. The vascular bundles pass from the leaf-stalk into the stem and there either arrange themselves among the bundles of the central cylinder or at once fuse with some of them. In the leaf-stalks of Angiosperms the bundles usually appear arranged in a curve open above, but may form other figures. In the petioles of Ferns, the partial cylinders are accompanied, as in the stem, by sclerenchymatous fibres forming strands or plates. It is the peculiar arrangement of those brownwalled sclerenchymatous masses which forms the double eagle apparent on cross-sections of the petiole of Pteris aquilinu, from which the plant derives its specific name.

In certain families of the Dicotyledons, particularly in the Crassulaceae, the mesophyll of the leaf-lamina forms peculiar masses of tissue called the EPITHEMA between the swollen terminations of the bundles and the epidermis. The cells of the epithema are small and, for the most part, devoid of chlorophyll ; they are full of water, and joined closely together, leaving only very small interspaces, which are 
filled with water. They are internal hydathodes (cf. p. 119) and serve for the active excretion of water. Water pores (p.115) are usually situated above such epithemata. The leaf-tips of a number of aquatic Nonocotyledons show a depression into which the terminations of tracheides project. These depressions arise by the destruction of water-pores or of these together with the epidermis. They may be closed by the persisting cuticle. These apical openings serve in the same way for the excretion of water $\left({ }^{132}\right)$.

The Course of the Vascular Bundles $\left({ }^{133}\right)$.- - The bundles exhibit a definite course and arrangement within the body of a plant. It is sometimes possible, by maceration, to obtain preparations in which the course taken by the bundles may be followed. By allowing a leaf, stem, or fruit to lie in water until it has become softened and disintegrated, a skeleton formed by the more imperishable vaseular system may be obtained.

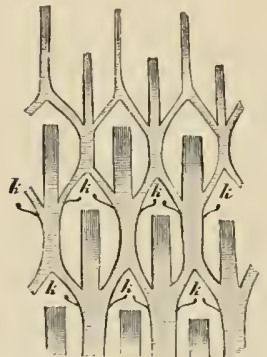

FIG. 143.-Diagram of the course of the rascular bundles in a young branch of Juniperus nana shown on the unrolled surface of the cylinder. At $k \%$ the vascular bundles passing to the axillary shoots are seen. (After GeY̌LER.)

Vaseular bundles which pass from a leaf into a stem form within the latter what are known as LEAF-TRACES. The leaf-traces may be composed of one or more vascular bundles, and are accordingly distinguished as onestrand or many-strand leaf-traces. When, as is usually the case, the vascular system of the stem is entirely composed of leaf-traces, each vascular bundle of the trace after passing downwards for some distance unites with another entering from a lower leaf. The arrangement of the bundles in a stem varies according to the distance and direction traversed before the coalescence of the bundles takes place. A relatively simple case is afforded by the young twigs of the Dwarf Juniper (Juniperus nana) (Fig. 143). The leaves are in whorls of three, the leaves of successive whorls alternating with one another. From each leaf a leaf-trace consisting of a single vascular bundle enters the stem. This divides into two about the middle of the internode below, and the divisions diverge and unite with the leaf-traees of the whorl below. The arrangement of the bundles may be shown diagrammatically by representing the bundles as if on the surface of an unrolled cylinder, so that they all appear in one plane. This is done in Fig. 143, which also shows the insertion of the vascular bundles of the axillary shoots $(k)$ on those of the parent shoot.

The arrangement of the bundles in the Yew (Tarus buccata), althongh its leaf-traces have only one bundle, is much more complicated (Fig. 144), for the bundles maintain a distinct course thronghout twelve internodes before coalescing. Each bundle at first descends in a straight direction throngh four internodes; it then curves to the 
side to give place to a newly-entering leaf-trace, with which it finally coalesces at the twelfth internode. The position of a leaf necessarily determines the point of entrance of its leaf-trace into the stem, and accordingly a diagram (Fig. 144) of the bundles of Taxus will exhibit a divergence of the leaf-traces corresponding to the $\frac{5}{13}$ divergence of the leaves. The course taken by the leaf-traces in the stem, however, is independent of the leaf position, and varies considerably in different stems, although the divergence of their leaves

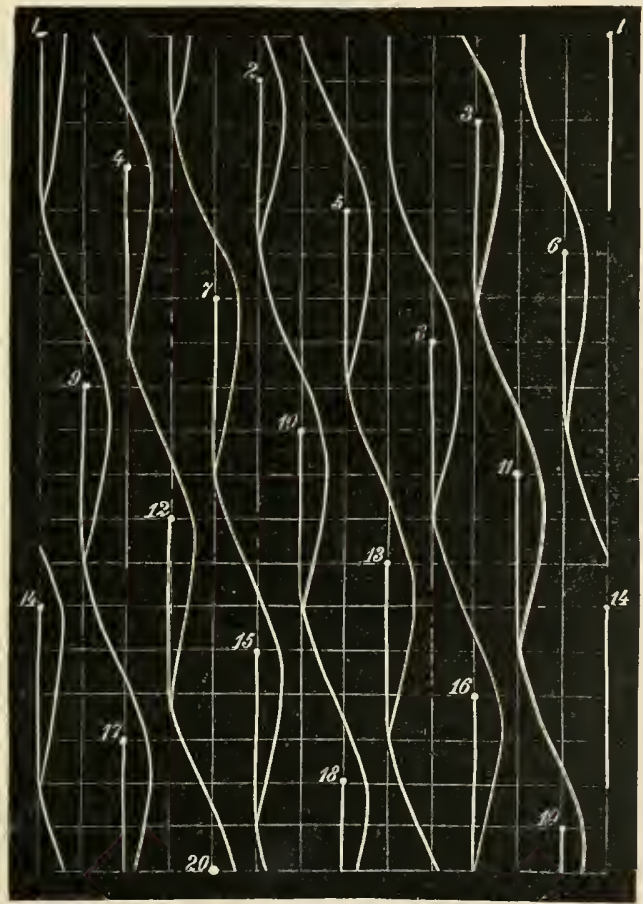

Fig. 144.-Diagram showing the course of the rascular bundles in a shoot of Taxus haccata.

may be the same. The stem of Clematis viticella affords an example of leaf traces consisting of three vascular bundles. The leaves are in whorls of two, the successive whorls alternating with one another. The median strand of each leaf-trace (Fig. $145 a d, a k, n q, t x$ ) has a free course through one internode, and at the node bclow diviıles into two arms which coalesce with the adjacent lateral strands of the leaves inserted at this node. The two lateral strands of each leaf trace (Fig. $145 b c, e f, h i, l m, o p, r s)$ also are free throughout the internode, but at the node below curve inwards and become attached to the same lateral strands as the arms of the mudian bundle of the trace. 
The traces of the axillary buds of most Gymnosperms and Dicotyledons unite to form two strands which enter the mother shoot and are inserted upon its leaf-traces (Fig. $143 \lambda_{i}$ ).

As a general rule, the leaf-trace bundles in Gymnosperms and

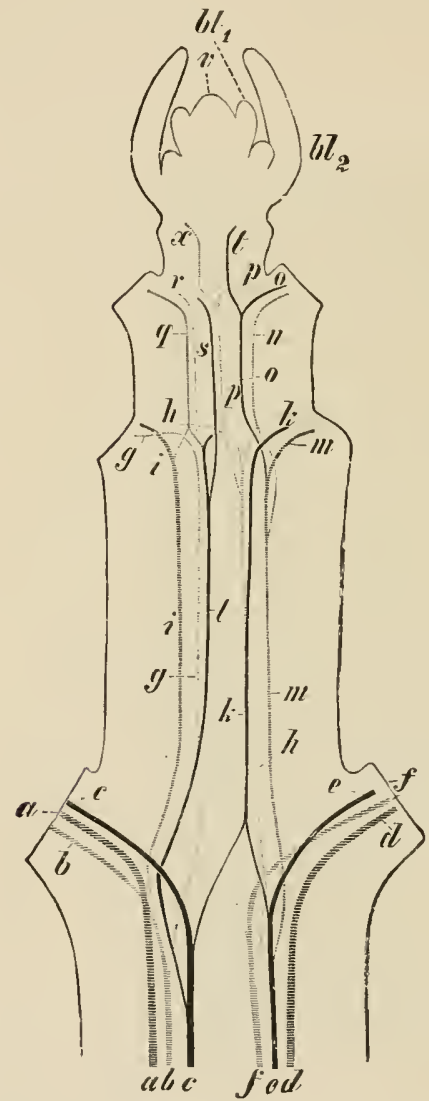

Frg. 145.-Clematis viticelle. End of a branch which has been made transparent by the removal of the superficial tissues and treatment with canstic potash. The emerging strands hase been slightly displaced by gentle pressure. The two uppermost pairs of young leaves (ll 1 , $b l^{2}$ ) are still without leaf-traces. $v$, A pical cone. (After NäGELI.)

Dicotyledons arrange themselves in a circle in the stem. There are, however, Dicotyledons in which the vascular bundles form two (Cucurbita, Phytolacca, Piper) or more circles (Amaranthus, Papaver, Thalictrum). In such cases the inner circle is nsually more or less irregular.

In the stems of Monocotyledons (Fig. 137) the vascular bundles are seattered, and without any apparent regular order.

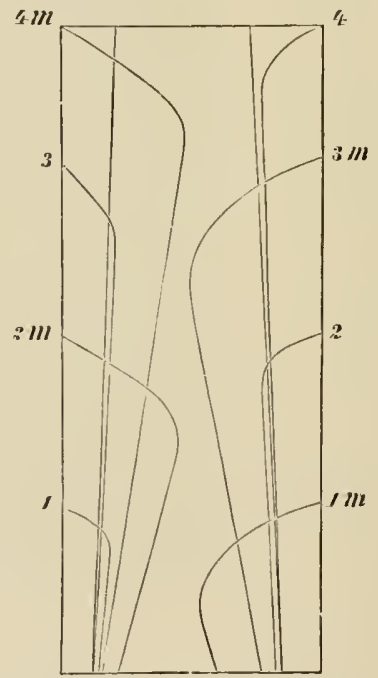

Fig. 146.- l liagram slowing the comrse of the vascular bundles of Monocotyledons of the Palm type, with alternating tworanker amplexicall leaves. The numbers indicate the sequence of the leaves ; $m$, nedian bundle. (After l)E BARr.)

Their scattered arrangement is due to the varying distances to which the bundles of the leaf-traces penetrate into the central cylinder of the stem. This results from the prolonged growth in thickness of the growing point after the first procambial strand has been laid down, 
whereby the successively formed proeambial strands are placed at different depths $\left({ }^{134}\right)$. A common arrangement of the bundles in monoeotyledonous stems is that of the so-ealled Palm type, in whieh each leaf-trace consists of the numerous bundles which pass singly into the stem from the broad leaf-base. The median bundle penetrates to the middle of the stem. The depth to which the lateral bundles penetrate lessens with their remoteness from the median bundle. In their descending course the bundles gradually curve outwards, and finally join other bundles near the peripliery of the stem. The number of internodes, therefore, through which a bundle passes before coaleseence, is variable; the median bundle, however, continues distinet for the longest distance. The deeper penetration and greater length of the median bundle $(m)$ become apparent in a median longitudinal section of such a stem (Fig. 146). The numerous bundles entering the stem from axillary shoots pursue a similarly eurved course to those entering from leaves, and end by fusing with periplieral bundles.

In addition to the leaf-trace bundles or COMNON BUNDLES which are common to both leaf and stem, there are others, ealled CAULINE BUNDLES, which belong solely to the stem, and again others, FoLIAR BUNDLEs, which on entering the stem from the leaf, at once eoalesce with other bundles and have no independent existence in the stem. The bundles of the Pteridophytes are continued as cauline bundles in the stem, and those from the leaves join on to the bundles of the stem.

The stems of some Dicotyledous (Begonia, Aralia) possess cauline bundles in addition to leaf-traces. The cauline bundles arc situated in the pith within the ring of leaf-trace bundles in the internode, and at the nodes are connected by branches with the leaf-trace bundles.

In the eentral cylinder of roots, the radially arranged strands of xylem and phloem pursue a straight course parallel to one another. The xylem and phloem strands of lateral roots are inserted upon the corresponding strands of the parent root. Those of adventitious roots are attached to the eorresponding tissues of the stem or root from which the adventitious root arises. The strands of xylem and phloem of the main root of a phanerogamic seedling (p. 168) are continuous with the leaf-trace bundles in the hypocotyl.

Inerease in Thickness by Continued Enlargement of the Primary Meristem.-The growing points of those Monocotyledons which have large stems (Palms, Pandanaceae, some Liliflorae) exhibit this feature. The growing point thus attains a considerable thiekness, and the stem has from an early period its definite cireumference. The increase in number of cells takes place in a zone lying at the periphery of the growing point $\left({ }^{135}\right)$.

Growth in Thickness of the Stem by means of the Continued Enlargement of the Fundamental Tissue.-This is often exhibited 
by Palms and Pandanaceae and leads in them to the formation of stems which may be more than 1 metre in diameter. The growth in thiekness is solely due to the eontinued expansion of the already existing cells of the fundamental tissue of the central cylinder. In this process, by the expansion of the cell lımen and inereased thiekening of the walls, the strands of selerenehymatous fibres accompanying the vasenlar bundles on their phloem sides also become greatly enlarged. In order to maintain the power of conduction of the existing vascular bundles these are reinforced by the development of new connections in the periphery of the stem $\left({ }^{136}\right)$.

Enlargement due to Continued Cell Divisions in the Fundamental Tissue.-This is seen most strikingly in the growth of the fruits of many Angiosperms. In their development from the small rudinent in the flower there may be a great increase in size, although no new meristematic tissue has been formed. The growth is due to repeated divisions in the epidermal cells and in those of the fundamental tissue. The tissue thus produced may when mature be thin-walled, or its cells may undergo various ehanges in form and in the thiekness of their walls. From small struetures such large fruits as those of the Gourds may develop in this way.

\section{B. The Secondary Tissues $\left({ }^{13 i}\right)$}

After growth in length is finished through the activity of a cambial tissue, functioning either as a primary or seeondary meristem (ef. p. 107), seeondary tissues are added to the previously existing primary tissues, or even substituted for them. Although phylogenetically considered, secondary tissues seem to have been developed first in the Pteridophytes in forms now only known in a fossil condition (Calamarieae, Sigillarieae, Lepidodendreae), they first became of general occurrence in the Phanerogams. In them the formation of secondary tissues is almost exelusively confined to the roots and stems; seeondary growth is met with in some foliar structures, but only in a slight form.

Cambium (138).-The primary and seeondary meristems, the activity of which gives rise to secondary growth, are given the name of CAmbrum. These tissues persist in a meristematic condition and undergo sneeessive divisions by walls parallel to one another, so that the cells prodnced from them are arranged in radial rows. A similar mode of division charaeterises the primary meristem in the procambial strands, which give rise to collateral vasenlar bundles, and this might also come under the term eambium. It is advisable, however, to restrict this term to meristems giving rise to secondary growth. As a rule the cambium forms new tissue-elements on both sides, but cases are not wanting in which this takes place to one side only. 
As a rule a single persisting initial layer is present in the cambium from which on one or both sides the rows of cells take their origin. In many cases in which the cambial activity is confined to one side, according to J. C. SuHoure, the original initial cells are used up in the tissue formation, and new initial cells arise from adjoining cells of the gromnd-tissue.

Growth in Thickness of the Stem in Gymnosperms and Dicotyledons. - The cambium of the open vaseular bundles of Gymnosperms and Dicotyledons, which exhibit a growth in thickness, commenees its aetivity almost direetly after the formation of the primary tissue. The primary meristem remaining between the xylem and phloem of the bundle continues its active growth as the cambium. Its cells are full of protoplasm and continue to divide by means of tangential and oecasionally radial walls. The new cells thus continuously given off from the initial cells toward the xylem and phloem sides of the bundles undergo another tangential division, or several, before attaining their definite form as elements of the xylem or phloem portions.

The vaseular bundles of Gymnosperms and Dicotyledons which undergo secondary growth are usnally arranged in a eirele. After the cambium in the bundles begins its aetivity, a zone of tangentially dividing tissue, called the INTERFASCICULAR

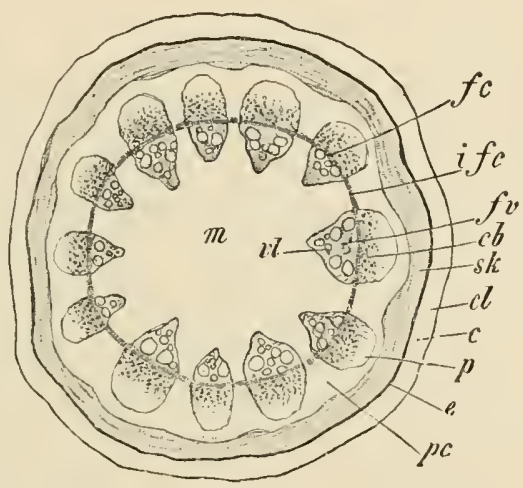

Fir. 147.-Transverse section of a stem of Aristolochia Sipho $5 \mathrm{~mm}$. in thickness. m, Medulla; $f v$, vascular bundle ; $v l$, rylem; $c h$, phloem ; $f *$, fascicular cambium; ife, interfasciculas cambium; 'p, phloen parenclyyma; pe, pericycle; $s k$, ring of sclerenchyma; $e$, starch-sheath ; $c$, primary cortex; $c l$, collenchyma in primary cortex. $(x \%$. CAmbiUn, develops in the

primary medullary lays between the original bundles, and, uniting with the cumbium in the bundles, forms a complete cambium ring. This eambium ring is thus eomposed of two distinct forms of meristematic tissue; for while the eambium of the bundles or the FASCICULAR CAMBIUN eonsists of primary meristem (p. 107), the connecting zone of interfaseicular eambium is of later development, and is consequently a secondary meristem (p. 107). A eross-section of a young stem of Aristolochia Sipho, with the eambium ring in proeess of formation, is represented in Fig. 147; in Fig. 148 a single bundle of the same cross-section, more highly magnified, shows the faseieular eambium with the interfascicular eambium to either side in a condition of active division. Within the bundle may be seen two large ressels $\left(m^{\prime \prime}\right)$, in a still incomplete state; while in the adjoining primary mecullary rays the eells which gave rise to 
the interfascicular cambium may still be plainly distinguished. All the tissue arising from the imner side of the cambium ring goes to form the secondary WOOD, while that produeed on the outside is termed seeondary BAST. The primary and secondary wood together form the wood, the primary and secondary bast the bast of the stem.

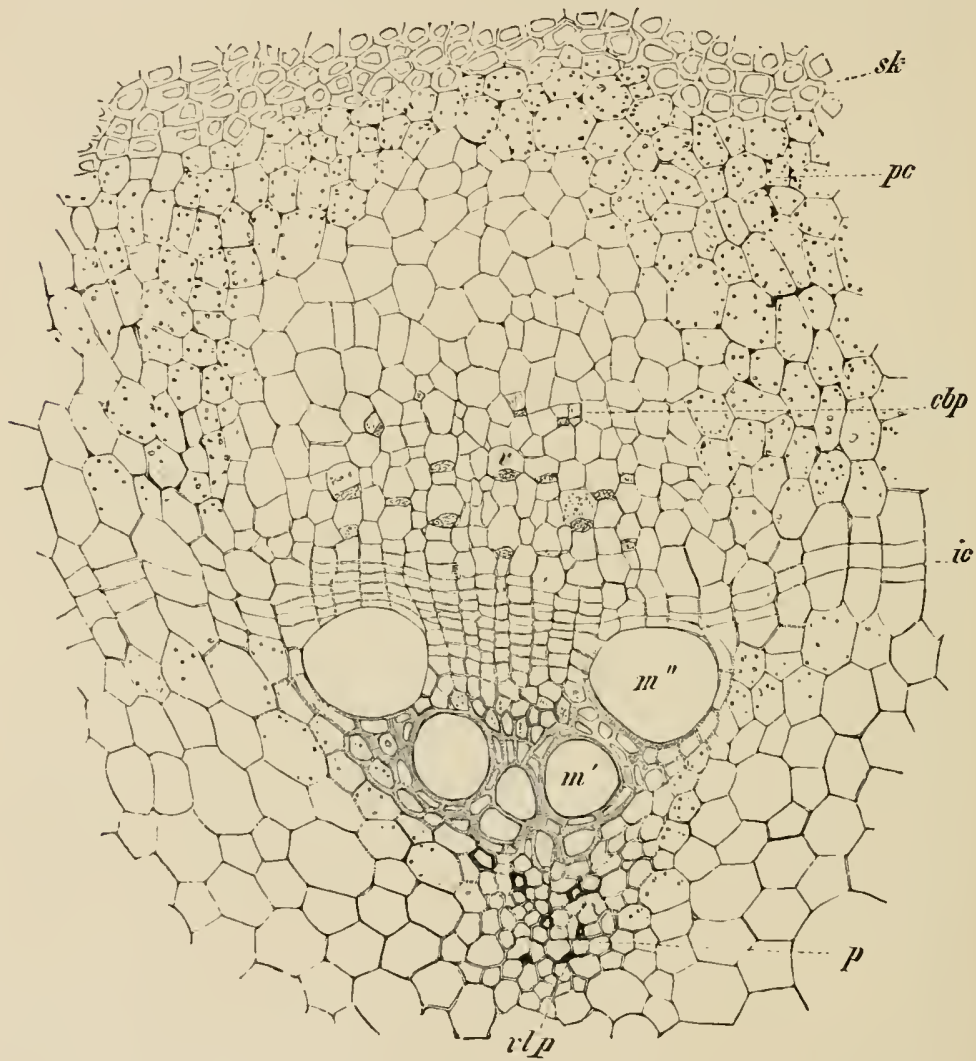

FIG. 145-Transverse section of a stem of Aristolorkia Sipho in the first year of its growth, showing a vascular bundle with eambium in active division. $p$, Vaseular parenchyma; $v p$, protoxylem; $m^{\prime}$ and $m^{\prime \prime}$, vessels with bordered pits; $i c$, interfascicular cambium in continuation with the fitscicular canbium; $v$, sieve-tubes ; $c b p$, protophloem ; $p$, pericycle ; $s k$, inner part of ring of sclerenchymatous tibres. ( $\times 130$.)

In contrast to the primary cortex (p. 128), all the tissues to the outside of the eambium may be regarded as forming secondary cortex. The vascular portions of the wood form the WOOD STRANDS, the sieve portions within the bast the BAST STRANDS. By the activity of the interfascicular cambium, the primary medullary rays are eontinued throughout both the wood and bast. As the woorl and bast strands enlarge, SECONDARY MEDULIARY RAYS are developed from the 
fascicular cambium. In one direction the secondary medullary rays terminate blindly in the wood, and in the other in the bast; the later they develop, the less deeply do they penetrate the tissues on either side of the cambium.

The primary medullary rays are therefore often distingnisher as long, the secondary as short medullary rays. The expression transverse parenchyma is also sometimes used to designate the medullary rays, which are in fact eomposed almost exclusively of parenchymatous tissue. The cells given off by the initial layer of the cambium for the formation of medullary rays do not undergo a further tangential division, as in other cases, but assume at once the character of medullary ray cells.

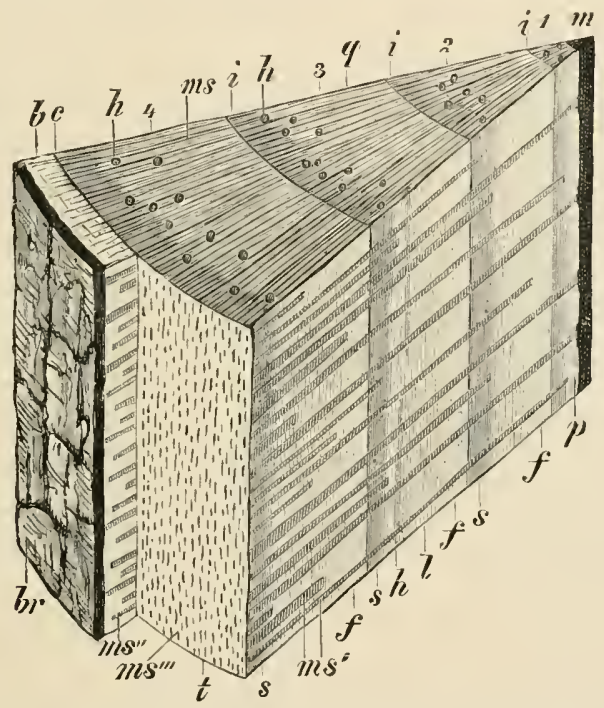

F1G. 149.-Portion of a four-year-old stem of the Pine, Pinus sylvestris, eut in winter. $q$, Transverse view; $l$, radial view; $t$, tangential view; $f$, spring wood; $s$, autumn wood ; $m$, medulla ; $p$, protoxylem ; $1,2,3,4$, the four successive annual rings of the wood ; $i$, junction of the wood of successive years; $m s^{\prime}$, $m s^{\prime \prime \prime}, m s$, medullary rays in transverse, radial, and tangential view; $m s^{\prime \prime}$, radial view of medullary rays in the bast; $c$, cambium ring; $b$, bast; $h$, resin canals ; $b r$, bark external to the first periderm layer, and formed from the primary cortex. $(\times 6$.

The cambium cells have, for the most part, the shape of right-angled prisms, of which the radial diameter is smaller than the tangential. The ends of these prisms are usually one-sided, tapering to a point, alternately on the right and left sides. The length of the cambium cells varies in different plants. Those from which medullary rays are formed are shorter than the other eambial cells. The primary vascular portions of the bundles projecting into the medulla constitute what is known as the MEDULLARY SHEATH.

Owing to climatic variations, the cambial tissue of woody plants exhibits a periodical activity which is expressed by the formation of ANNUAL RINGS of growth (Figs. 149, $151 \mathrm{~A}, 155$ ). In spring, when new shoots are being formea, wider tracheal elements are developed 
than in the following seasons (Figs. $151 \mathrm{~A}, 157$ ). For this reason a difference is perceptible between the EARLY woOD (spring wood), which is composed of large elements especially active in the conveyance of water (Fig. $151 \mathrm{f}$ ), and the LATE WOOD (autumn wood), consisting of narrow elements which impart to a stem its necessary

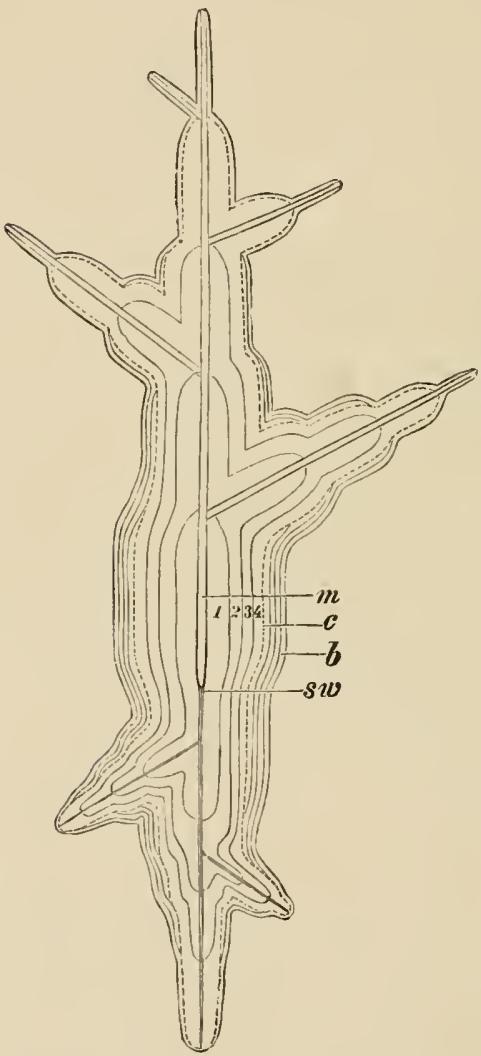

FIG. 150.-Diagram to illustrate the secondary growth in thiekness of the stem and root of a Gymnosperm or Dicotyledon. $c$, Cambium, indicated by a dotted line; $m$, pith ; $1,2,3,4$, successive almual rings of wood ; $h$, bast; sw, limit between main stem and taproot.

Althongh a cessation in the formation of woorl takes place so early, the cambium continues to form last so long as climatic conditions permit. As a rule, however, far fower elements are added to the bast than to the wood. Owing to the continued growth in length, the higher a cross-section is made of a gymnospermous or dicotyledonous the greater part of the temperate zone, the formation of wood ceases in the latter part of August until the following spring, when the larger elements of the spring wood are again developed. Owing to the contrast in the structure of the spring and the autumn wood, the limits (Fig. 149i) between successive annual rings of growth become so sharply defined as to be visible even to the naked eye, and so serve as a means of computing the age of a plant.

Under certain conditions the number of annual rings may exceed the number of years of growth, as, for instance, when MIDSUMMER GROWTH occurs, such as commonly happens in the Oak, when, after the destruction of leaves by caterpillars, a second formation of spring wood is occasioned by the new ontgrowths thus induced. In the evergreen trees of our latitude the vessels are not crowded together in the spring wood, but miformly distributed on the annual ring $\left({ }^{146}\right)$. In the wood of tropical plants the annual rings may be entirely absent. This occurs, for example, in the tropical Conifers of the genus Araucaria, which, in this respect, show a marked contrast to the Conifers of the northern zone. Any interruption of growth, such as would occur during a dry period, followed by a period of renewed activity, may occasion the formation of annual rings even in tropical plants. rigidity (Fig. $151 \mathrm{~s}$ ). Thronghout 
stem, the fewer will be the annual rings. As the diagram in Fig. 150 shows, the older rings disappear first on passing towards the apex, and in the same way the older layers of the bast are unrepresented nearer the apex. Up to a certain period, in the age of woody plants, the elements of both wood and bast exhibit a progressive increase in size.

The living elements may remain in a state of greater or less activity throughont the whole of the wood, extending even to the pith; such wood is called sPLINT wood: the Beech (Fagus sylvatica) may be quoted as an example. In other trees which form IrEART-WOOD,
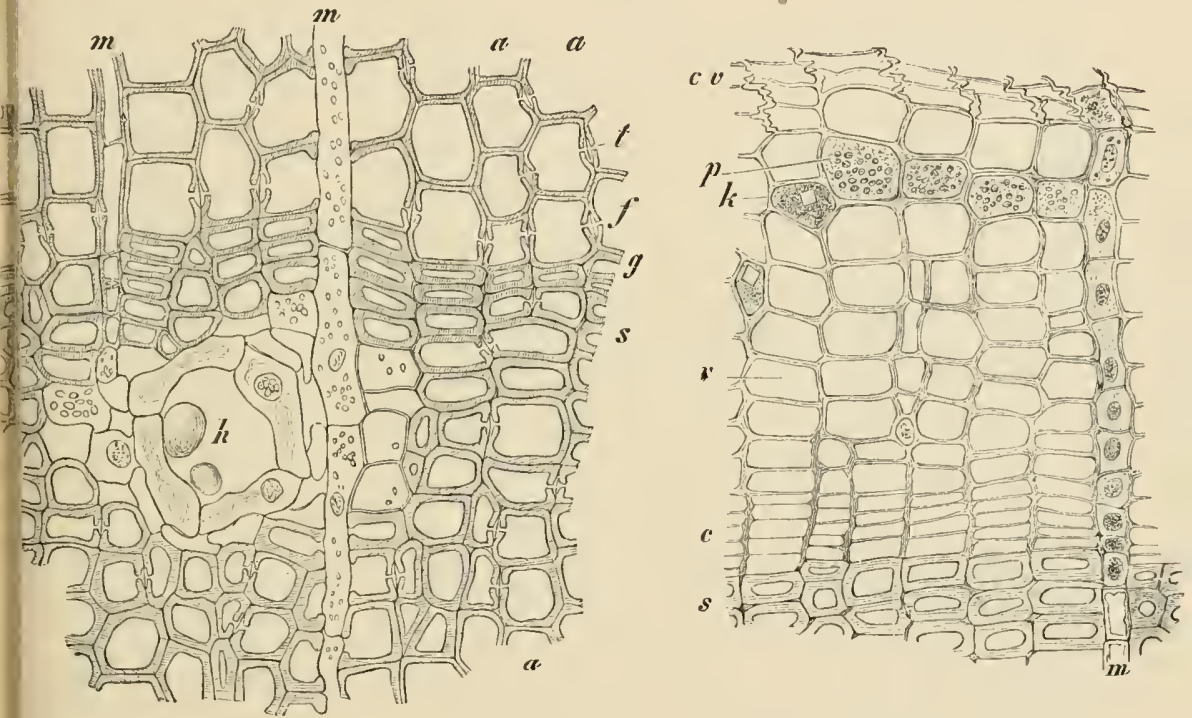

Fic. 151. $-A$, Transverse section of the wood of a Pine at the junction of two annual rings. $f$, Spring wood; $s$, autumn wood ; $t$, bordered pit; 1 , interposition of a new row of tracheides resulting from the rarlial division of a cambiun cell; $h$, resin canals; $m$, medullary rays; $g$, limit of autumn wood. ( $\times 240$.) B, Part of a transverse section of the stem of a Pille. $s$, Late wood; $c$, cambium ; $v$, sieve-tubes ; $p$, bast parenchyma ; $k$, cell of bast parenchyma containing crystal ; $c v$, sieve-tubes, compresserl and functionless; $m$, medullary ray. ( $\times 240$.

the living elements die after a certain time, so that only dead tissues are found at a certain distance from the cambium. Before the death of the living cells, they nsually produce certain substances, such as tannin and gums, which permeate the cell walls of the surrounding elements, and also partially close their cavities. The tannins impart to the dead wood a distinct colour, often very characteristic, especially when it has been transformed into wood dyes, or so-called xy Lochroure. The tamnin in the woody walls acts as a preservative against decay, while the gums close the functionless water-courses of the dead wood. The dead portion of the wood of a stem is called the HEART-WOOD or DURAMEN, in contrast to the living SAP-WOOD or ALBURNUM. Usually 
the splint or sap wood is at once distinguishable from the heart-wood by its lighter colour. In some stems, however, the heart-wood does not change its colour. In that case, as the protecting materials are generally absent, it is liable to decay, and then, as so often occurs in the Willow, the stem becomes hollow.

The sap-wood is limited, according to the kind of wood, to a larger or smaller number of the younger annual rings, and to it falls the task of water conduction.

The distinction betyreen sap- and heart-wood is sharpest where the latter is dark-coloured, as in the Oak, with its brown heart-wood, and in species of Diospyros, whose black heart-wood furnishes ebony. The darker the heart-wood, the harder and more durable it usnally is. The following may be mentioned as examples of woods which yield dyes and colouring principles-IIacmatoxylon campcchianum, L. (Campeachy wood, logwood), with a red heart-wood from which HaEMatoxyLIN is extracted ; Pterocarpus santalinus, L. fil. (red sandal-wood), from the heart-wood of which santalin is obtained ; Cacsalpinia brasiliensis, L., and C. echinata, Lam, (Brazil wood, Pernambuco wood), with a red heart-wood which supplies Brasilin; and the Alsage Orange, Maclura aurantiaca, Nutt. (yellow Brazil wood), which has a yellow heart-wood from which Morin is derived. Inorganic substances may also be deposited in the duramen; thus calcimm earbonate is found especially in the vessels of the Elm and the Beach, while amorphons silicic acid occurs in those of Teak (Tectona grandis). The closing membrane of the bordered pits in the heartwood is pushed to one side, so that the torus presses against the opening of the pit and completely closes it. According to H. MAYr ${ }^{139}$ ) resin does not penetrate the walls of wood cells under normal conditions; the wood of Conifers only becomes resinons through the impregnation of the cell walls with resin after they have become dried up through wounds or other causes. The resin-clucts of Conifers may also be closed by the formation of tyloses.

The elements of secondary growth differ in Gymnosperms and Dicotyledons. The vascular strands of Gymmosperms are composed almost exclusively of tracheides (Fig. 151 $A$ ). These are provided with bordered pits which are situated, for the most part, on their radial walls. The tracheides of the spring-wood $(f)$ have larger cavities than those formed later (s). Parenchyma is also present in the wood, though in relatively small amount; in some Abietineae resin-passages occur in it (Fig. 151 h).

Except in the Gnetaceae, true ressels are not found in the secondary growth, nor in the primary vasenlar portions of the bundles of Gymnosperms. The wood produced by the cambium consists of radial rows of tracheides, the number of which is occasionally doubled by the radial division of a cambium cell (Fig. $151 A, a)$. The tracheides are often over a millimetre long, much longer than the cambium cells from which they are developed. They attain this length by a subseouent growth, during which their growing ends become pushed in between one another. In addition to the tracheides, small amounts of wood parenchyma are also prodnced in Gymnosperms by a transverse division of the canbium cells. It is in the parenchymatous cell rows of the wood of Pines, Spruce-Firs, and Larches that the schizogenons resin-ducts are jrodueed (Fig. $151 A, h$ ). In other 
Conifers the wood parenchyma consists of simple rows of eells, which afterwards become filled with resin.

Besides tracheides $(t)$ and wood parenchyma $(h p)$, other elements take part in the composition of the secondary wood of a Dicotyledon; these are the vessels (tracheae, $g$ ), and the wood fibres $(h)$ (Fig. $154 A, B)$. The cells of the wood parenchyma are short and have abundant contents, the wood fibres are thick-walled, long cells with pointed ends. The elements with wider lumens, especially the

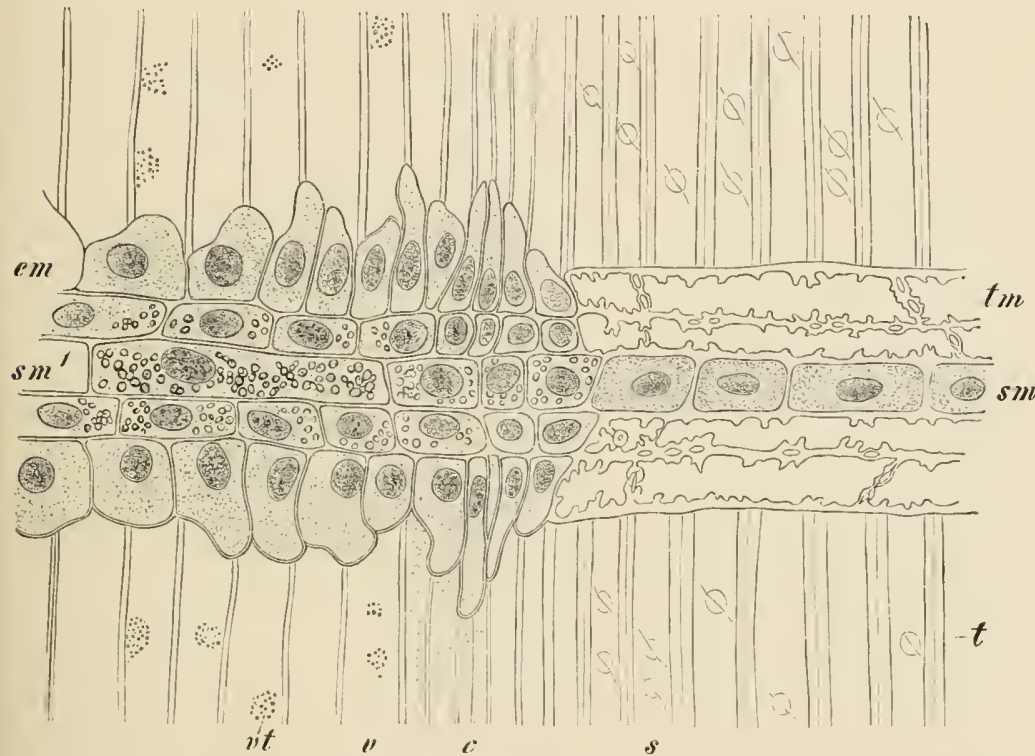

FIf. 152.-Radial section of a Pine stem, at the junction of the wood and bast. s, Autumn tracheides; $t$ bordered pits; $c$, cambium; $v$, sieve-tubes; $v t$, sieve-pits ; $t m$, tracheidal medullary ray cells; sm, medullary ray cells in the wood, containing starch; $s m^{\prime}$, the same, in the bast; em, medullary ray cells, with albuminous content. ( $\times 240$.)

vessels, are abundant in the spring wood, in which water conduction is important. The antumn wood, on the other hand, consists of narrow elements, among which the wood fibres, which contribute to the rigidity of the plant, are numerous (p. 79). On account of these differences between spring and autumn wood the annual rings are well marked (Fig. 157).

All the elements entering into the formation of the wood of Dieotyledons can be derived from the two elasses of tissue already met with in the Gymnosperms, the tracheal tissue and the parenchymatous tissue of the wood. The tracheides and vessels belong to the former class, while under the parenchymatous tissue are included the wood parenchyma, fibrons cells of greater length but with similar eontents (Fig. 154 ef), and the wood fibres.

The tracheal tissue consists of lements which lose their living contents at an 
early stage, and in their fully developed condition are in reality only dead cell cavities. In this class are included TRACHEIDEs having relatively wide lumina and large bordered pits, and ultimately also spirally thickened walls, which serve as watercarriers (Fig. $154 A, t$ ); VASCULAR TRACHEIDEs ( $g t$ ), with similar functions, but with the structure and thickening of vessels; FIBRE TRACHEIDEs ( $f t$ ), with small lumina and pointed ends, haring only small, obliquely elongated bordered pits, and, in

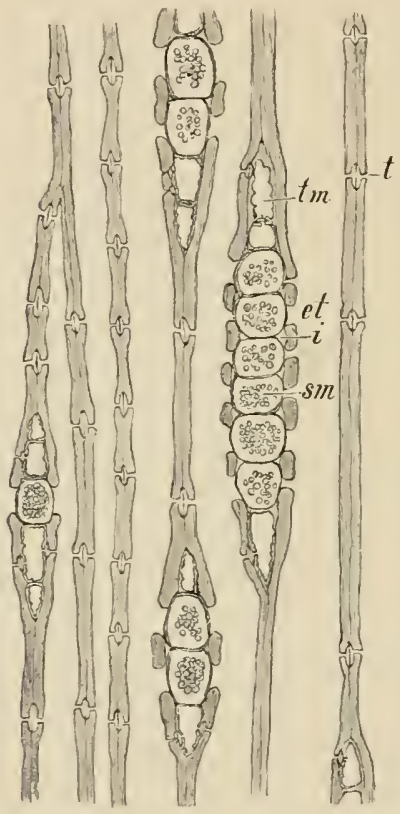

Fio. 153.-Tangential section of the autumn wood of a Pine. $t$, Bordered pit; $t m$, tracheidal medullary ray cells; sm, medullary ray cells containing starch; $c t$, pit bordered only on one side; $i$, intercellular space in the medullary ray. $(\times 240$. extreme cases, exercising merely mechanical functions; and finally TRACHEA $(g)$, formed by cell fusion, and provided with all the different forms of thickenings by which they are distinguished as annular, spiral, reticulate, or pitted ressels. All ressels function as watercarriers. If they have small lumina and iesemble tracheides, they may be distinguished as TRACHEIDAL VESSELS $(t g)$; if, as is generally the case, they have bordered pits on their lateral walls, they are usually provided with tertiary thickening layers in the form of thin, spirai bands (Fig. $158 \mathrm{~m}$ ). In the parenchymatous tissue of the wood the cells (Fig. $154 \mathrm{~B}$ ) generally retain their living contents, and never develop the true bordered pits with a torus in the closing membrane, which are so characteristic of the water-conducting elements. All tissues of this class may be best derived from wood parenchyma. The wood parenchyma is produced by transverse divisions of the cambium cells, and accordingly consists of rows of cells (hip) with transverse division walls, and others obliquely disposed, which correspond to the alternately differently pointed ends of the cambium mother cells. The cells of the wood parenchyma are provided with simple round or elliptical pits, varying in size in different kinds of wood; they generally contain starch, and some of them also take up bye-products, resulting from metabolism, i.e. from the chemical changes taking place within a plant in the processes of its nutrition and growth. The cells having the closest resemblance to those of typical wood parenchyma are the so-called FIBROUS CELLS ( $f$ ). In their contents as well as in their wall thickenings, they are similar to the cells of wood parenchyma, but each is formed directly from one entire cambium cell. In their formation, the cells of the cambium become more or less elongated and fibrous. The Libriform fIBres or wOOD FIBREs $(h)$ have a similar origin, but are even more elongated and have thicker walls, and, at the same time, narrow obliquely elongated, simple pits. Although the wood fibres may continue living, they lose their living contents in the more extremely developed forms $(h)$. They are then filled with air, and their function is merely mechanical. Under certain conditions, by later trausverse divisions, the libriform fibres may become transformed into sLPTATE woOD FIBILS (yh). The transverse septa thus formed remain thin, and form a striking contrast to the more strongly 
thickened lateral walls. While the traeheal tissues are engaged in providing for the conduetion of water, the duty of conducting and storing the products of assimilation, in particular the carboliydrates, is performed by the parenchymatous tissues of the wood. Both forms of tissue, however, aid in maintaining the rigidity of the plant body, and, in their most extreme development, furnish such elements as the fibre tracheides on the one hand, and on the other the empty wood fibres, which are only eapable of performing mechanical functions.

A
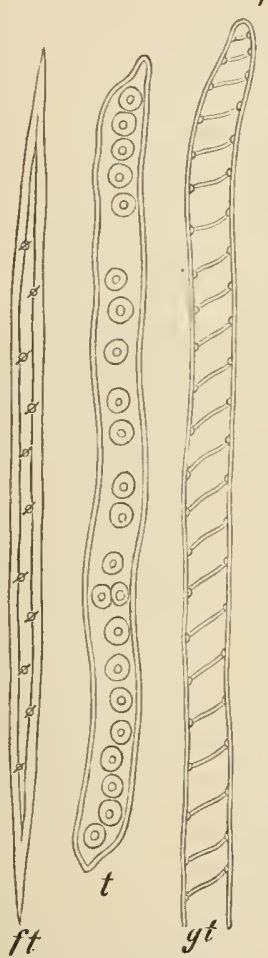
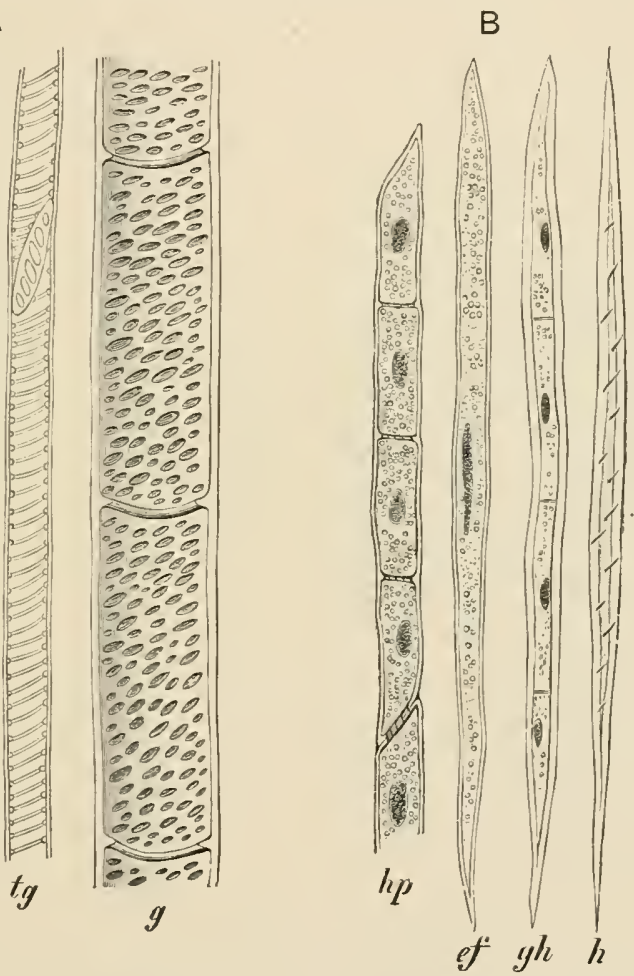

Fig. 154.-A, Elements of the tracheal tissue of the wood; diagrammatic. $B$, Elements of the parenchymatous tissue of the wood; diagrammatic. For description see text.

The wood of Dicotyledons is made np of the elements of these two classes of tissue, the tracheal and the parenehymatous, but all the different elements are not necessarily represented in any one kind of wood.

Drimys, a gents belonging to the Magnoliaceae and two genera of the related order Trochodendraceae, are the only Dicotyledous the wood of which is formed of traeheides only. These Dicotyledons elosely resemble the Conifers in structure. In numerons Leguminosae, Willows, Poplars, and species of Ficus, on the other hand, the tracheal tissues are only represented by vessels, whieh perform the task of water conduction. In the wood strands of these plants there are also present wood parenchyma and a large proportion of wood fibres. The vessels in climbing plants (lianes) are cspecially wide. 
The living elements in the wood strands always bear a distinct relation to the water-courses which they accompany, enclosing them in a more or less complete sheath. The living eells adjoining the tracheal elements are in communication with them by means of oue-sided bordered jits. When such pits occur between living cells and tracheal elements the pit cavities are absent on the side of the living cell, but present in the traeheal elements ; they differ from the true bordered pits in the absence of a torus on the pit membrane.

The Elements of the Secondary Phloem in Gymnosperms and woody Dicotyledons are sieve-tubes, or these together with companion cells, bast parenchyma with abundant cell contents, and long narrow

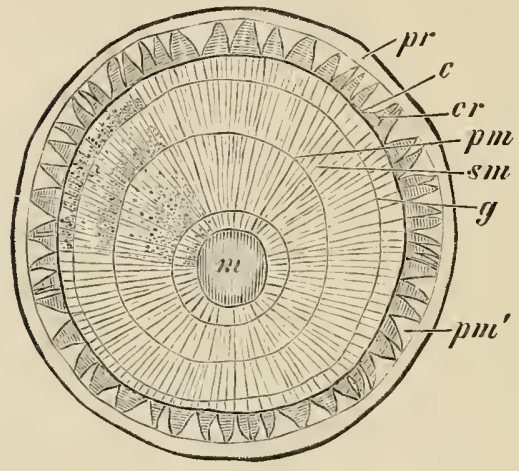

F1G. 155.-Transverse section of a stem of Tilia ulmifolia, in the fourth year of its growth. $p r$, Primary cortex ; $c$, cambium ring ; $c r$, bast ; pm primary merlullary ray ; $\mathrm{pm}^{\prime}$ expanded extremity of a primary medullary ray; sin, seconclary medullary ray ; $g$, limit of third year's wood. $(\times 6$.

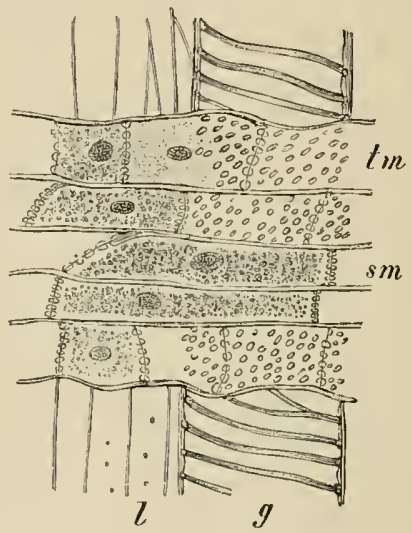

Fia. 156. - A radial section of the wood of Tiliu ulmifoliu, showing a small medullary ray. $g$, Vessel ; $l$, wood fibres ; $t m$, medullary ray cells in communication with the water-courses by means of jits; $s m$, conducting cells of the medullary ray. $(\times 240$.

bast fibres with strongly thickened walls. The sieve-tubes serve to conduct proteid materials; the companion cells, or in their absence special rows of the bast parenchyma, take up substances from the sieve-tubes; storage and conduction of carbohydrates take place in the parenchyma in which bye-products of metabolism, such as tannins and calcium oxalate, also accumulate.

As in the case of the wood, the elements of the bast may be referred to two forms of tissue, the sieve-tube and the parenchymatous. The former is represented by the sieve-tubes or by these together with compranion cells, the parenchymatous portion by the plifoem parenchyma and the bast fibres, between which there are intermediate forms of element.

In the bast strands of Gymnosperms, the phloem elements produced by the cambinm (Fig. $151 B, c$ ) consist of sieve-tubes, the parenchymatous cells of the bast parenchyma $(p$ and $k)$, and in 
certain cases, of bast fibres. These elements of the bast generally for'm alternating bands.

The Aranearieae, Taxineae, and Cupressineae lave definite, vertical rows of bast parenchyma cells which take the place of the companion eells wanting in these plants. At a certain distance from the cambium the sieve-plates become overlaid by callus. During the regetative period following their development, the sieve-tubes become empty and compressed together (Fig. $151 \mathrm{~B}, c v$ ). Less often as in the Vine the sieve-tubes remain functional for more than one year; the callus is removed when their activity is resumed. The rows of bast parenchyma cells containing albuminous substances which are found in some Conifers, undergo disorganisation at the same time as the adjacent sieve-tubes; the bast parenchyma cells which eontain stareh, on the other hand conitinue living for years, and even increase in size, while the sieve-tubes become compressed.

The elements of the phloem tissue included in the bast strands of woody Dicotyledons (Fig. 159) are represented by SIEVE-TUBES $(v)$ and COMPANION CELLS (c). Tothe parenchymatous tissues

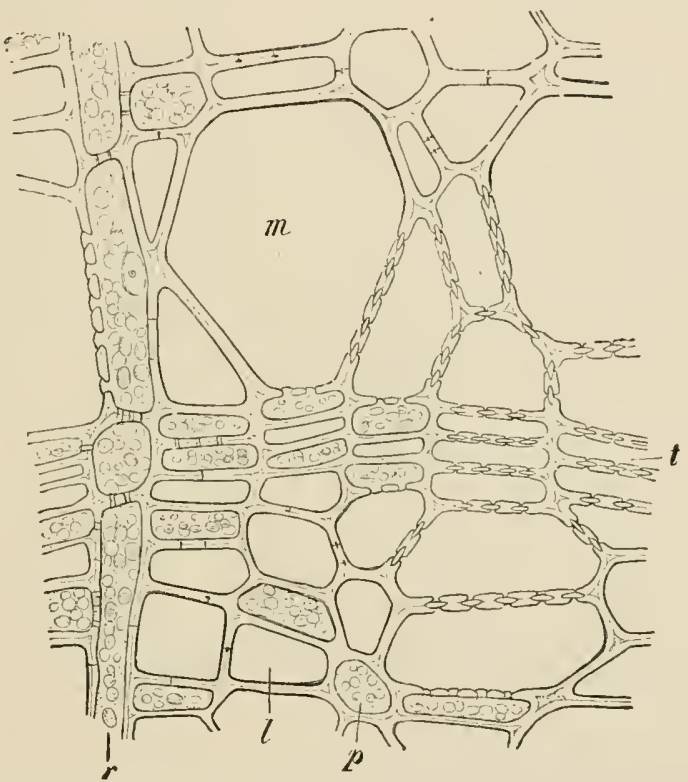

FiG. 157.-Portion of a transverse section of the woor of Tilic ulmifolia. $m$, Large pitterl vessel; $t$, tracheides; $l$, wood fibre; $r$, wood parenchyma ; $r$, medullary ray. ( $\dot{x} 540$.)

of the bast belong BAST PARENCIYMA $(p)$, BAST FIBRES $(l)$ and transitional forms between them.

The bast fibres, like the fibres of the wood, may occur in an unthickened form as F1BRous CELLS either with or without living contents, or they may be filled with stareh, or finally may become septate.

The elements of the bast of Dicotyledons frequently exlibit a great regularity in their arrangement. Thus in the Lime (Fig. 159) there is a regular alternation of sieve-tubes $(v)$ and companion cells $(c)$, bast parenchyma containing starch $(p)$ and crystals $(k)$, tangentially flattened bast parenehyma $(p)$, and then another zone of sieve-tubes. The sieve-tubes of Dicotyledons as of Gymnosperms only remain functional for a short time, after which they become empty and crushed. The companion cells, which are sister cells of the sieve-tubes, undergo the same fate. The starch-containing parenchyna, on the other hand, may remain for years 
nnaltered. The differences in the appearance of the bast of dicotyledonous trees are due to the greater or less diameter of the sieve-tubes, the presenee or absence of bast fibres, and the arrangement of the various elements.

The Medullary Rays of the Gymnosperms (Fig. $149 \mathrm{~ms}$ ) and woody Dicotyledons (Fig. $155 \mathrm{~mm}, \mathrm{sm}$ ) form radial bands, composed wholly or in part of parenchymatous elements. Their function is to supply the cambium and wood with the products formed in the leaves

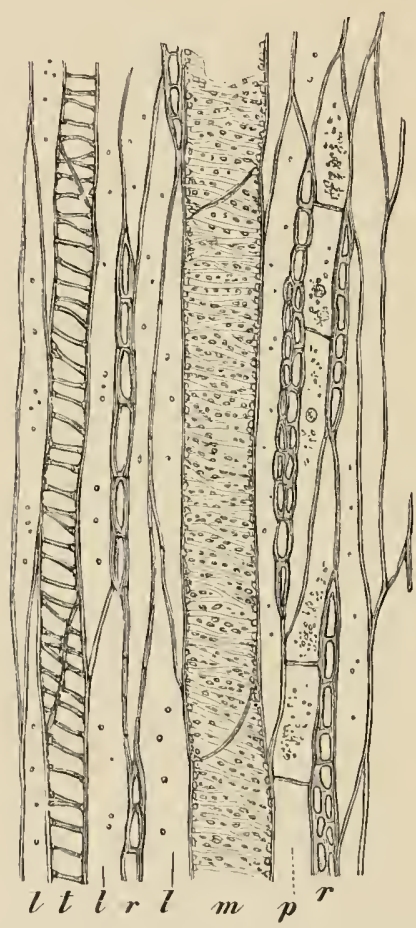

FiG. 158.- Tangential siction of the wood of Tilia ulmifolia. m, Pitted vessel ; $t$, spiral tracheirles; $p$, wood parencliyma; $l$, wood fibres ; $r$, medullary rays. $(\times 160$. $)$ between the tracheides. In other Conifers, where sueh tracheidal elements are not found in the medullary rays, hordered pits are developed in the tangential walls of the tracheides of the autumn wood, and by means of them the transfer of water in a radial direction is effected. The living cells of the medullary rays of the wood bear the same relation to the water-carriers as do the cells of the wood parenchyma, and like them are connected with the water-condueting elements by means of bordered pits on one side of the cell wall. They take up water from them and give it out again, as it may be needed to other living eells; on the other hand, 
in the spring, at the beginning of the season of growth, they press into the watercourses the products of assimilation, particularly glucose and small quantities of albuminates, in order that these substances may be transferred in the quickest way to the points of consumption. Accordingly, during the winter and in the beginning of spring, sugar and albumen may be detected in the tracheal elements $\left({ }^{(* 0}\right)$, and may then be obtained from the watery sap of "bleeding" trees, or from artificial borings or incisions, particularly in such trees as the Maple, Birch, and Hornbeam. In the rood of Dicotyledons it is usually only special rows of the medullary ray cells which stand in such close relation with the tracheal tissues. In these special rows, generally on the margins of the medullary rays, the cells are elongated vertically, and on that account have been distinguished as VERTICAI

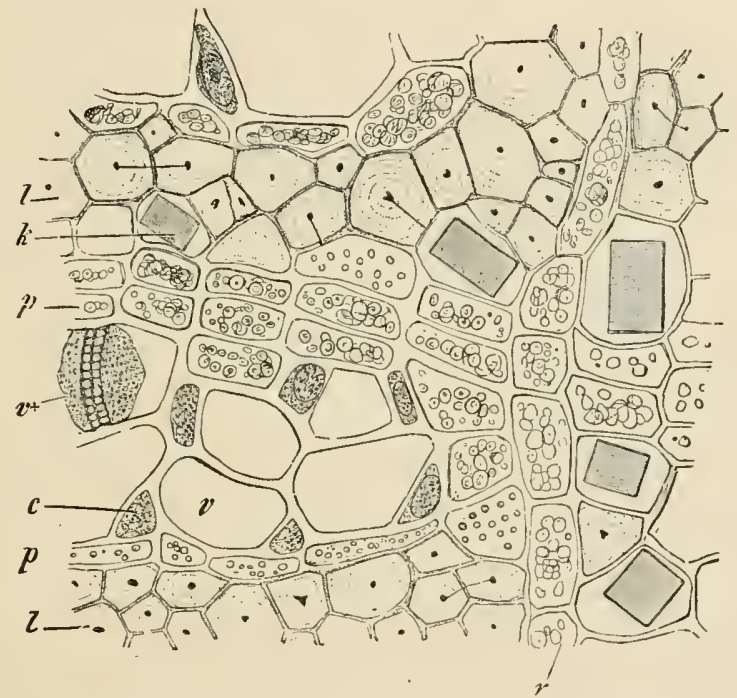

FIG. 159.-Portion of a transverse section of the bast of Tilia ulmifolia. $v$, Sieve-tubes; $v^{*}$, sieve-plate; $c$, companion cells ; $k$, cells of bast parenchyma containing erystals; $p$, bast parenchyma ; ?, bast fibres ; $r$, medullary ray. $(\times 540$.

MEDUlLARY IAAY CELLs. The other cells, or those of the middle layers of the medullary bands, on the other hand, are called HoRIZONTAL MEDULLARY RAY CELLS ; they are narrower and more elongated radially $\left({ }^{141}\right)$. These have no especial connection with the tracheal elements, but are designed for condneting and storing assinilated substances. Within the bast zone the medullary rays of Dicotyledons have a simpler structure than in the wood. It is evident, not only from the pits between the cells of the medullary rays and the bast parenchyma, but also from the similar relations in Dicotyledons between the medullary ray cells and the companion cells of the sieve-tubes, that the function of the cells of the medullary rays in the phloem is to take up substances passing down the bast sirands.

In the Pine and other Abietineae, whose bast parenchyma is devoid of cells functioning as conductors of albuminous matter, their place is taken in this respect by rows of medullary ray cells (Fig. $152 \mathrm{em}$ ). These maintain an intimate connection with the sieve-tubes 1 y means of sieve-pits. They lose their contents 
in the same manner as the sieve-tubes, and, like them, become compressed and disorganised. On the other hand, the cells of the medullary rays, which contain starch, like the similar cells of the bast parenchyma, increase in size, and continue living for years.

The width and height of the medullary rays may be more easily determined from taugential than from radial sections. In such tangential sections the medullary rays appear spindle-shaped (Figs. 153, 158). With few exceptions, as in the

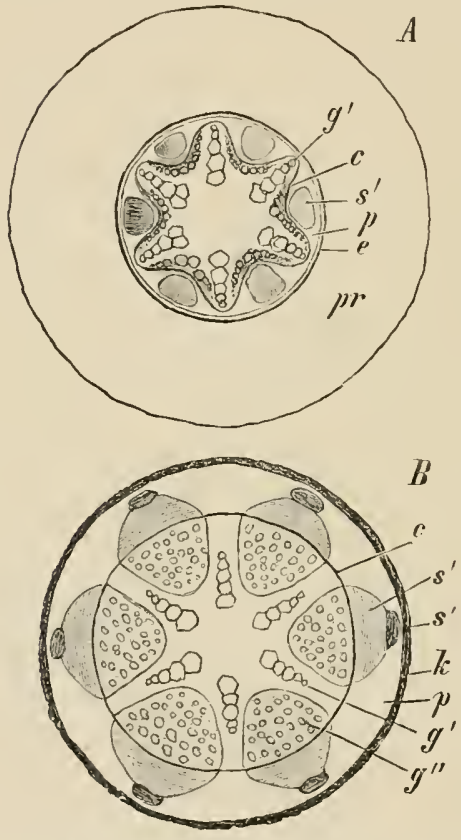

Fic. 160.-Diagrammatic representation of the growth in thickness of a dicotyledonous root. $p r$, Primary cortex; $c$, cambium ring; $g^{\prime}$, primary vascular strand; $s^{\prime}$, primary phloem strand; $p$, pericycle; $e$, endodernis; $g^{\prime \prime}$, sccondary wood ; $s^{\prime \prime}$, second. ary bast; $k$, periderm. Oak and Beech, the medullary rays are of relatively small size. The Oak, in addition to numerons small medullary rays, has other larger rays which may be as much as a millimetre broad and a decimetre high. In the Poplar, Willow, and Box the medullary rays are so small that they are scarcely visible, even with the aid of a magnifying glass. The height of the broad primary rays of many lianes, on the other hand, may be equal to that of a whole internode. Iu certain Conifers, resinpassages occur not only in the wood, but also in the broader medullary rays. These radial resin-passages are in comnunication with the vertical ducts. It is due to this fact that such a large amount of resin exudes from wounds in Pine or Fir trees.

\section{Secondary Thickening of the Root in Gymnosperms and Dicoty-} ledons.-The roors of Gymnosperms and Dicotyledons, in which the stems increase in thickness as well as those of many herbaceous Dicotyledons, show a similar GRow'TH IN THICKNess $\left({ }^{142}\right)$. When secondary growth begins in a root with its xylem and phloem strands alternating with each other (Figs. 134, $140)$, layers of cambium arise on the inside of the phloem strands by the division of the fundamental tissue; these give off wood elements towards the centre of the root, and bast towards the periphery. These cambium layers soon meet in the pericycle, just outside the xylem strands, and so form a complete cambial ring. In Fig. $160 \mathrm{~A}$, this process is diagrammatically represented. As a result of the activity of its cells the cambium ring soon loses its sinuous form and becomes circular. In front of the primary vascular strands $\left(g^{\prime}\right)$, the cambium produces medullary ray tissue, and this constitutes the broadest medullary rays which lead inwards to the strands of primary xylem (Fig. 160 b). A cross- 
section of such a root, in which the secondary growth has continued for some years, can scarcely be distinguished from a cross-section of a stem. By careful examination, however, the presence of primary xylem in the centre of the root can be discovered, and its nature thus determined. The wood of the root is also more porous than in the stem, and bears a close resemblance to spring wool. On account of this lack of differentiation in the wood, the annual rings of growth are less distinctly defined in roots than in stems.

In the root and its branches, as in the stem, the amnual zones of secondary growth become less numerous on approaching the growing points (Fig. 150).

Anomalous forms of Growth in Thickness $\left({ }^{1+3}\right)$. Extraordinary deviations from the usnal type of secondary growth are afforded by some stems and roots of Gymno-

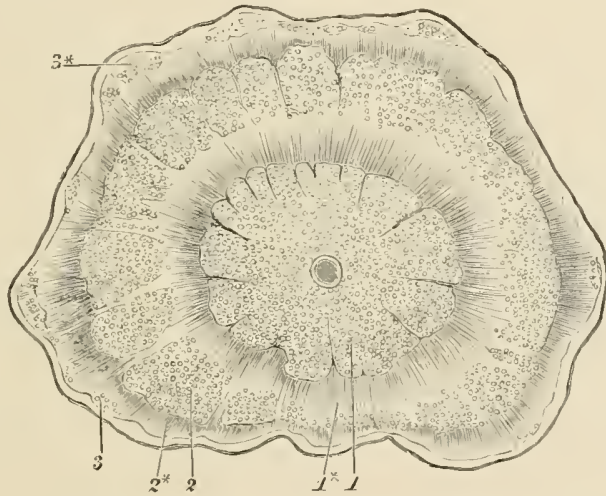

FIr: 161.--Transverse section of the stem of Aucuna altissina. 1, 2, 3, Successively formed zones of wood ; $1^{*}, 2^{*}, 3^{*}$, successively formed zones of bast. (3 11at. size.)

sperms and Dicotyledons. Anong the Gymnosperns in the Cycadaceae and eertain species of Gnetum, in the Chenopodiaceae, Amarantaceae, Nyctaginaceae, Phytolaccaceae, and other families of Dicotyledons, the cambium which has been formed in the ordinary manner soon loses its function, and a new cambium ring is developed external to the bast zone, for the most part in the pericycle, or in a tissue derived from it. This cambinm ring forms wood on the inside and bast on the outside, with the accompanying medullary rays. It then ceases to divide, and a new ring takes its place. This process is repeated, and nltimately leads to the formation of concentric rings of wood and bast, which, in cross-sections of the sugar-beet, may be distinguished with the naked eye. These concentric zones may be still more plainly seen in a cross-section of Hucuna altissima (Fig. 161), a liane belonging to the order Papilionaceae. The stem shows in this case an inner axis of wood (1) surrounded by a zone of bast $\left(1^{*}\right)$; next follows a cylinder of wood (2) and bast $\left(2^{*}\right)$, and finally a third $\left(3,3^{*}\right)$ in process of formation in the pericycle. An extraordinary appearance is exhibited by cross-sections of stems, which show several separate wood cylinders (Fig. 162). Such a structure is peculiar to various tropical lianes of the genera S.rjania and Paullinia belonging to the family 
Sapindaceae. This anomalons condition arises from the unusual position of the primary vascular bundles, which are not arranged in a circle but form a deeply lobed ring; so that, by the development of interfascicular cambium, the cambium of each lobe is united into a separate cambium ring. Each of these rings, independently of the others, then gives rise to wood and bast (Fig. 162). A very peculiar structure is exhibited by many lianes of the Bignoniaceae, the rood of which is cleft by radially projecting masses of bast (Fig. 163). The primary stem of the Bignoniaceae shows the ordinary circular arrangement of the vascular bundles. Wood and bast are at first produced from the cambium ring in the usual manner, and an inner, normal wood cylinder of AxIAL wood is formed. Such normally formed axial wood cylinders are common to many, otherwise abnormally developed lianes. The cambinm ring of the Bignoniaceae, after performing for a

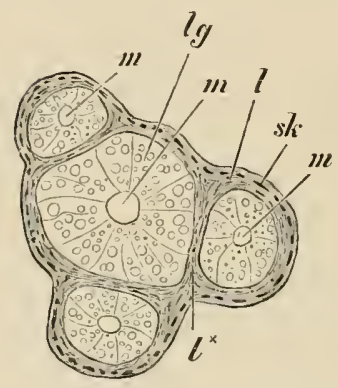

FiG. 162.-Transverse section of the stem of Serjonia Lamot. terna. sk, Part of the ruptured sclerenchymatous ring of the pericyele; $l$ and $l^{*}$, bast zones; $l g$, wood; $m$, medulla. $(\times 2$.

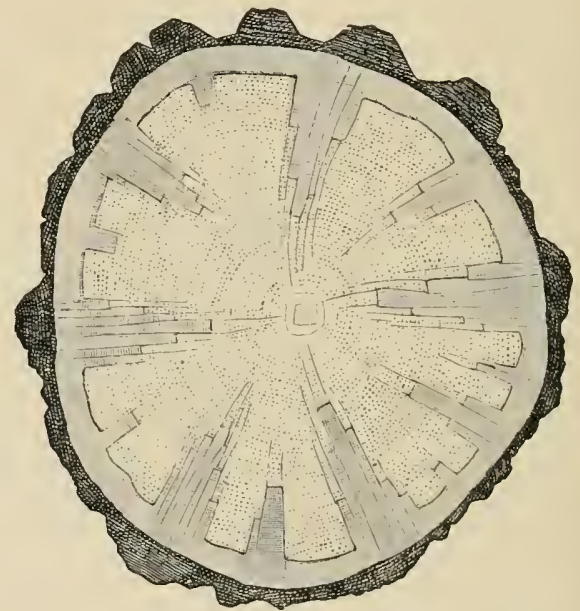

Fig. 163,-Transverse section of the stem of one of the Bignoniaceae. (Nat, size.)

time its normal functions, begins, at ccrtain points, to give off internally only a very small quantity of wood, and externally a correspondingly large amount of bast. As a result of this, deep wedges of irregularly widening bast project into the outer so-called PERIAXIAL wood (Fig. 163). The originally complete cambium becomes thereby broken into longitudinal bands, which are broader in front of the projecting wood than at the apices of the bast wedges. As the periaxial wood is always developed from the inside, and the wedges of bast from the ontside of their respective cambium bands, they extend past cach other withont forming any lateral connection.

The Formation of Knots.- The knots or streaks which add so greatly to the technical value of certain woods depend on an unusually bent or interwoven course of the elements of the wood. Their origin is duo to the stinulus of wounding, to the effects of parasites, the pressure exerted by lateral branches which are in. creasing in thickness, or to altered cambial activity. Larger knots are produced by the origin of numerous adventitious buds, especially after wounding; a finer narking by the widening of the medullary rays, which may then appear circular 
in tangential section, and influence the course of the adjacent elements of the xylem.

Secondary Growth of Monocotyledons.-There are certain monocotyledonous plant families and genera, especially Dracaena, Yucca, Aloe, and the Dioscoreaceae, in the stems of which a cambium ring is developed. As in such cases, the cambium ring generally arises in the pericycle, outside the scattered vascular bundles and from the fundamental tissue, it is a secondary meristem; it does not, as in Dicotyledons and Gymnosperms, produce continuously wood and bast in opposite directions, but, instead, only new tissue to the inner side. This later becomes differentiated into closed vascular bundles embedded in a thick-walled parenchymatous ground tissue.

The cambial ring in these cases is only active on one side $\left({ }^{138}\right)$, and its initial cells are replaced from the cells of the ground tissue on the outer side of the ring (p. 139).

At a later period the cambial ring commences to form cells to the outer side which increase the thickness of the cortex as a thin-walled, parenchymatous ground tissue (Fig. 164). When the cambium has thus become active on both sides it presents the appearance of a single initial layer. A true secondary growth in thickness of a monocotyledonous root is only known in the genus Dracaenu. The cambial ring originates not in the pericycle but in the layer of cortical cells abutting on the endodermis. Its activity resembles that of the cambium in the stem $\left({ }^{144}\right)$.

As shown in the diagram (Fig. 165) the growth in thickness of a Monocotyledon differs essentially fiom that of a Gymnosperm or Dicotyledon represented diagrammatically in Fig. 150. The stem of a Dracaena on which the diagram is based is represented as unbranched. Its primary central cylinder $(p c)$ increases in diameter as the stem grows in length, and thus forms an inverted cone. It is surrounded by the zones of secondary growth, the amount of which diminishes on passing towards the growing point. The secondary growth of the stem is continuous with that of the roots.

In other Monocotyledons which form stems that increase in thickness either by secondary growth or by cell division and progressive increase in size of primary tissues (cf. p. 137) the roots show no increase in thickness. An annual development of additional roots from the wide base of the stem takes place, as is well seen in Palms. The base of the stem of such plants may sometimes be widened out like a disc as in some species of Yucca, or show a tuberous swelling as in Nolini (Pincenectitia). The roots of such Monocotyledons often attain a considerable thickness by persistent primary growth.

Secondary Growth of Leaves $\left({ }^{1+5}\right)$ is always very slight, and is confined to a few Coniferae and Dicotyledons with evergreen leaves. The increase in thickness $i$; due to the presence of a fascicular 
cambium. This produces little or no xylem, the new elements being mostly added to the phloem. Any elements formed on the side next the xylem are water-conducting, while those adjoining the phloem

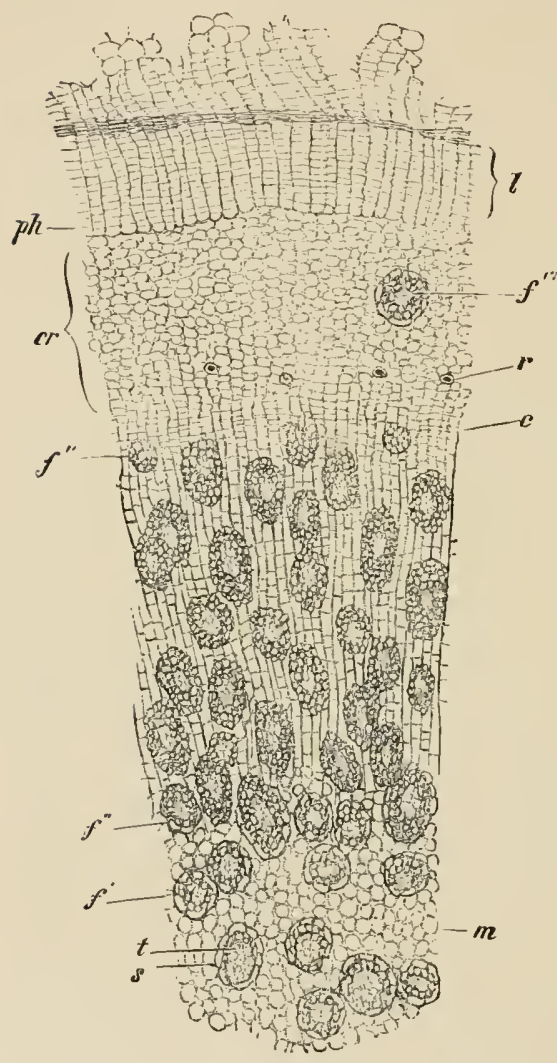

Fur. 164.-Transverse section of the stem of Cordyline (Dracaena) rubra. $f^{\prime}$, Primary vascular bundles; $f^{\prime \prime}$, secondary vascular bundles: $f^{\prime \prime \prime}$, leaf - trace bundle within the primary cortex; $m$, parenchymatons fundamental tissue; $s$, bundle-sheatl ; $t$, tracheides; r, cambium ring; $r r$, cortex, the outer portion lueing primary, the inner secondary cortex; hih, cork cambium; $l$, cork; $r$, bundles of raphides. (x 31.) mostly become sieve-tubes. The leaves of Coniferae live, according to S. Simon, about seven years, those of other evergreen plants usually no longer than two seasons $\left({ }^{146}\right)$.

Periderm $\left({ }^{14 i}\right)$. - It is very seldom that the epidermis, by the division of its own cells, is in a condition to keep pace for any length of time with theincreasing dimensions of the stem. This, however,

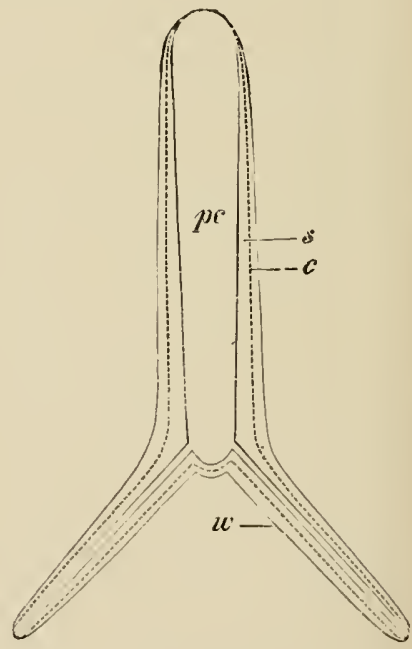

Fic. 165.-Diagram of the secondary growth of the stem and root of Dracaena. pe, Central cylinder; $s$, secondary tissue; $c$, cainbium inlicated by a dotted line; $w$, root. (Adapted from Schoutw.)

is the case in the Mistletoe (Viscum album), the number of epidermal cells of which is continually augmented by the formation of new lateral walls, and new cuticnlar layers are formed where the old cnticle becomes ruptured. On older portions of the stem, however, thickening layers form in single epidermal cells or groups of 
epidermal cells, and at the same spots similarly thickened cortical cells are developed. The epidermal cells thus cut off die, and the original epidermis is more or less completely replaced on such old regions of the stem. In the great majority of plants in which the epidermal layer persists for years it is able to meet the demands made upon it by the growth in thickness of the stem without the assistance of the underlying cortex. The stems of one of the Maples (Acer striatum), even when a foot or more in thickness and over forty years old, remain covered with a living, growing, epidernal layer. The striations to which the specific name of this plant refers are caused by a white wax exuding from splits in the outer walls. As a rule, however, the epidermis on stems which grow in thickness becomes stretehed and finally ruptured. The tissue of the primary cortex and of the bast by the expansion and division of its cells, can accommodate itself more easily than the epidermis to the increased dimensions of the stem, arising from the growth in thickness of the central cylinder. This process of accommodation is particularly noticeable in the primary medullary rays (Fig. $155 \mathrm{~mm}^{\prime}$ ) between the primary phloem. The formation of the PERIDERM generally begins during the first vegetative period, after the secondary growth has reached a certain stage. The commencement of its formation is indicated by the brown colour of the external surface of the stem, which remains green so long as the epidermis continues alive. The formation of periderm usually occurs at a later period in those plants which have a persisting epidermis; it is practically wanting only in the species of Mistletoe. The periderm is derived from a secondary meristem, termed the CORK CAMBIUM or PHELLOGEN. This phellogen may arise, in the epidermis, in a deeper layer of cells of the primary cortex, or even in the pericycle itself. The phellogen (138) is as a rule a cambium with a persisting initial layer from which cork-cells are produced to the outside and phelloderm to the inside.

The produetion of eork-cells is usually greater than that of phelloderm. If the phellogen forms only cork-cells the initial cells are often used up in the process, and are then replaced from the adjoining ground tissne (1, 139). This is found among Monocotyledons and also in some Dicotyledons, e.g. Vuleriana officinalis. The tissue formed by the phellogen to the outer side is termed pHELLEM by v. HöHNEL. Usually it consists only of cork-cells, but in eertain cases unsuberised layers of cells are formed. These are the phelloid cells of v. HöHNEL.

The young cork-cells usually have a tabular shape, fit closely together without intercellular spaces, and possess suberised, secondary, thickening layers. The cork cells usually possess brown walls. They may be thin (Fig. $164 l$ ) or thick, frequently thickened on one side (Fig. 166), and occasionally to such an extent that they are known as stone cork. Thin-walled cork-cells usually contain air; those with thickened wallis frequently have reddish-brown cell 
contents (phlobaphene) consisting mainly of tamnins and products derived from them. The cork tissue frequently shows an alternation of narrow thick-walled with thin-walled and larger cells. These layers mark annual growths. Even thin corky walls, being impermeable to water, prevent the loss of moisture by transpiration. Thicker layers of cork afford mechanical protection and hinder the invasion of the plant by parasites.

The phelloderm formed to the inner side of the phellogen in many cases, such as the Currant, attains a considerable thickness. Its cells retain their living protoplasm, and nsually contain chloroplasts. They ultimately become rounded off', so that intercellular spaces are

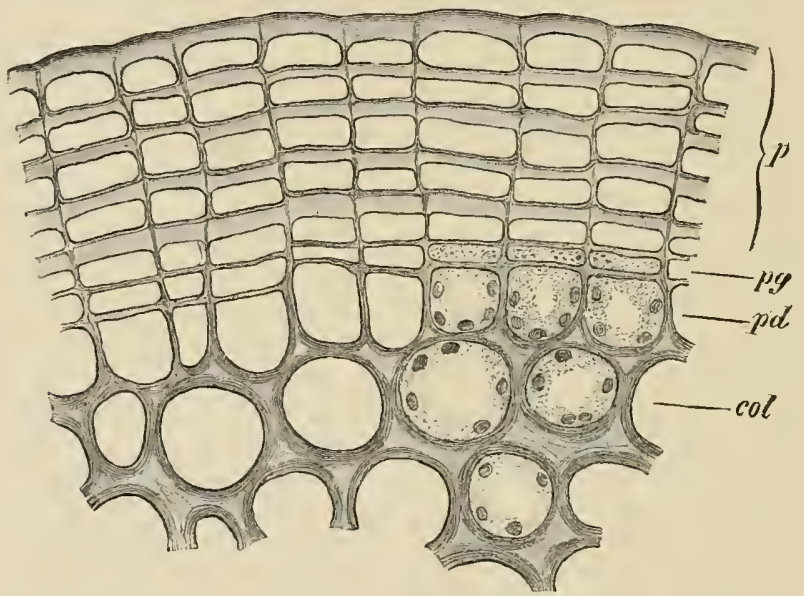

Fit. 166.-Transverse section of the outer part of a one-year-old twig of Pyrus communis made in autumn. It shows the commencement of the formation of the periderm. $p$, cork; $p g$, phellogen; $p d$, phelloderm; col, collenchyma. The cork-cells have their outer walls thickened and have brown dead contents. ( $\times 500$.)

formed between them, and serve to increase the thickness of the living cortex. The term periderm includes both cork and phelloderm.

The cork of the Cork-oak (Quercus Suber) is formed of broad layers of soft large cells, alternating with narrow layers of thinner cells, which mark the limit of the annual growth. This may be seen in bottle-corks. The first, spontaneously developed cork of the Cork-oak is stripped off, whereupon a new phellogen is formed in the deeper-lying tissuc. The cork thus produced is removed every six or eight years, and furnishes the cork of economic value.

In many cases the phellogen takes its origin in the epidermis (Fig. $166 p g$ ). This is the case in the Willow, in most l'omaceae, and in a number of other woody plants. The epidermal cells become divided into outer and inner cells, the latter of which assume the function of a phellogen. More frequently the phellogen develops from the layer of cells next adjoining the epirlermis, as, for example, in the Elder (Sambucus nigra), where it takes its origin from the outemost layer of 
collenchyma (Fig. 16 $7, p h$ ). The epidermis in this case covers the developing layer of cork.

True cork is wanting in Cryptogans, even in the Pteridophytes. When protection is required its place may be taken by the impregnation of the cell-walls with a very resistant brown substance, or by the addition of suberised lamelle to the walls $\left({ }^{1+8}\right)$.

Bark.-All tissues external to the phellogen are cut off from food supplies and consequently die. When the first cork layer has its origin deep within the stem, a BARK of considerable thickness is formed throngh the ensuing death of the peripheral tissues. If the cork layer formed by the phellogen be thin, the stem has a smooth surface, as in the Beech; if it produces thicker cork layers, the surface of the

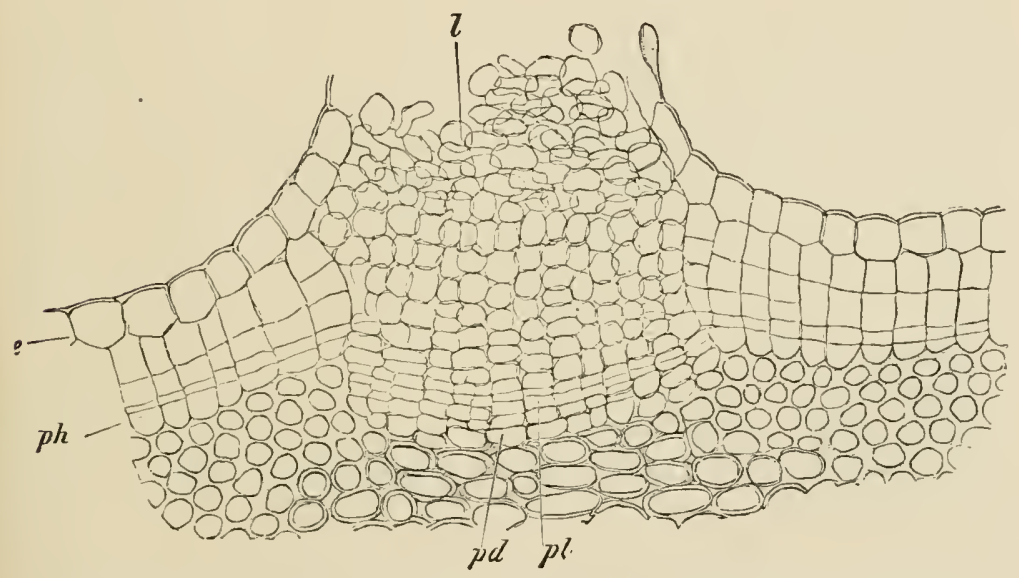

FIri. 167.-Transverse section of a lenticel of Sambucus nigra. e, Epidernis; ph, phellogen ; $l$, complementary cells; $p l$, phellogen of the lenticel; pd, phelloderm. ( $(\times 90$.

stem appears rough and full of fissures, as is the case in the Cork-oak. The primary phellogen generally ceases its activity after a short time, and another deeper-lying phellogen is formed. After a time this new phellogen discontinues its functions, and another (Fig. 168) is developed, as in the case of Quercus sessiliflora, until ultimately the phellogen comes to be formed in sccondary bast parenchyma instead of in the primary tissue. That portion of the bast cut off by the periderm loses its nutritive contents and only retains waste products. If the layers of the secondary periderm constitute only areas of the stem circumference, the bark will be thrown off in scales, as in the SCALY BARK of the Pine and Plane tree; if, on the contrary, the periderm layer's form complete concentric rings, then hollow cylinders of the cortical tissues are transformed into the so-called RINGED BARK, such as is found in the Grape-vine, Cherry, Clematis, and Honeysuckle. Bark which is not easily detached becomes cracked by the continued 
growth in thickness of the stem, and has then the furrowed appearance so characteristic of the majority of old tree-trunks. The usual brown or red colour of bark, just as in similarly coloured heart-wood,

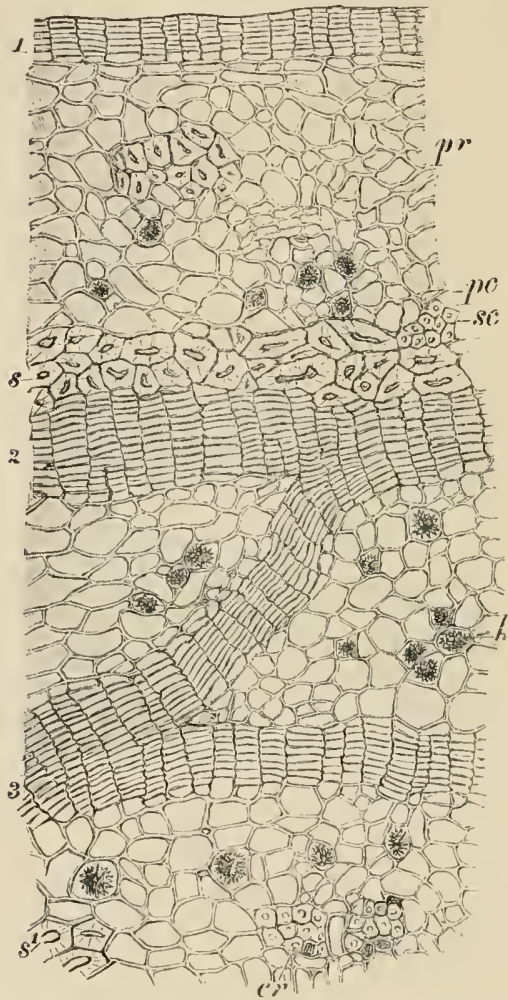

Fic: 168. - Transverse section of the periphera tissues of the stem of Quercus sessiliffora. 1,2,3, Successively formed layers of cork; $p r$, primary cortex, modifiel by subsequent growth; internally to $m$, pericycle; sc, sclerenchyuatons tibres from the ruptured ring of sclerenchy matous fibres of the pericycle; $s$, subseruently formel sclereides; $s^{\prime}$, sclereides, of secomlary growth ; er, bast fibres with accompanying crystal cells; $k$, cells with argregate crystals. All the tissue exterual to the inuermost layer of cork is dearl and discolourerl and has become transformed into bark. $(\times 225$. dermis ontwards and finally rupture it. Where the complementary
cells are only loosely united, intermediate bands or closing layers are
developed from the phellogen alternately with the layers of looser
tissne; the closing layers become eventually ruptured. The compledermis ontwards and finally rupture it. Where the complementary
cells are only loosely united, intermediate bands or closing layers are
developed from the phellogen alternately with the layers of looser
tissne; the closing layers become eventually ruptured. The compledermis ontwards and finally rupture it. Where the complementary
cells are only loosely united, intermediate bands or closing layers are
developed from the phellogen alternately with the layers of looser
tissne; the closing layers become eventually ruptured. The compledermis ontwards and finally rupture it. Where the complementary
cells are only loosely united, intermediate bands or closing layers are
developed from the phellogen alternately with the layers of looser
tissne; the closing layers become eventually ruptured. The complequalities of which is due the great resistance of bark to the action of destructive agencies. The peculiar white colour of Birch-bark is caused by the presence of betulin (bireh-resin) in the cells.

In roots which grow in thickness the phellogen usually develops in the perieycle (Fig. $160 \mathrm{~B}, \mathrm{k})$, and in consequence of this the primary cortex of the roots dies and peels off. The succeeding phellogen layers are formed in exactly the same way in the root as in the stem.

Lenticels $\left({ }^{149}\right)$. - In most woody plants, particularly in Dicotyledons, cortical pores, or LENTICELS (Fig. 167), make their appearance simultaneously with the formation of periderm. The lenticels take their origin in a phellogen layer $(p l)$ which, in the case of peripheral cork formation, almost always develops directly under the stomata. The phellogen, from which the lenticels arise, unlike the cork phellogen, does not form cork cells, but a lenticel tissue composed of COMPLEMENTARY CELLS (l) with intercellular spaces between them. On the inside, however, a phelloderm is regularly derived from the phellogen. The complementary cells press the epiis occasioned by the presence of
tannins, to the preservative 
mentary cells are as a rule not suberised, those of the closing bands are corky and lignified. The cork-forming phellogen joins the phellogen of the lenticels at its margins (Fig. 16i). In cases where the cork is more deeply seated in the inner tissue, the lenticels begin their development at a corresponding depth from the layer of phellogen. Lenticels serve to maintain the gaseons interchange between the outside air and the gases present in the intercellular spaces of the plant.

Certain aerial roots such as those of the Orchids and the respiratory roots of swamp plants possess lenticels the structure of which deviates more or less from the usual type ; these are termed pneumathodes.

Tyloses.-In the vessels of both the secondary and the primary xylem of stems and roots sac-like structures more or less completely filling the lumen may be met with. These are termed tyloses, and originate by the elosing membranes of pits between the vessel and adjoining parenchymatous eells bulging into the former, and the intrusive cell continuing to grow. The formation of tyloses may be brought about by wounding the organ; they close the vessel exposed by the wound and hinder its drying up. Such tyloses are spoken of as traumatic. But tyloses also oceur in uninjured tissues, and frequently in the heartwood (Fig. 169) where they close up the functionless vessels. They also occur in still functional vessels, but then only tend to partially

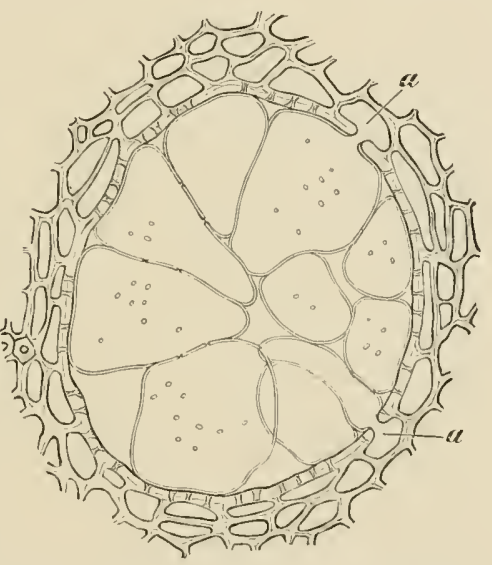

Fif: 169.-Transverse seetion of a vessel from the heart-wood of liohinia Psendacacia, closed by tyloses; at $a$, $a$, is shown the connection between the tyloses and the cells from whieh they have been formed. $(x 300$.

fill the lumen and serve for the storage of reserve-substances such as starch $\left({ }^{150}\right)$.

Absciss Layers.-The fall of the leaves of woody plants $\left({ }^{151}\right)$ is brought about by means of a layer of parenchymatous tissuc which is formed at the base of the leaf-stalk shortly before the leaf-fall. The cells of this tissue separate from one another owing to their middle lamellæ becoming mucilaginous. Within this abseiss layer all prosenchymatous elements of the petiole are greatly reduced; only the tracheal elements are lignified, and these are broken throngh when the leaf separates. The separation of the leaf results from the roumding off of the cells of the abseiss layer, and in some cases this is associated with an elongation of the cells of the onter layers. The protection of the leaf-scar is efiected in the first place by the lignifica- 
tion and suberisation of the walls of the exposed cells, and later by the formation of a layer of cork continuous with the peridern covering the stem. The ends of the tracheal elements in the scar become occluded by wound-gum or tylosis or by both; the ends of the sievetubes beeome compressed and lignified. The leaflets of compound leaves usually become separated from the rhachis by absciss layers. Herbaceous plants exhibit as a rule no definite leaf-fall. Absciss layers formed in a special way are also found at the base of the leaf-stalks in ferns, which shed their leaves. The cells covering the leaf-scar then form a protective layer by the deposition of lamellae which become suberised, and by becoming filled with certain substances $\left({ }^{152}\right)$.

Healing of Wounds $\left.{ }^{153}\right)$.- In the simplest cases among land plants the wounded cells die and become brown and dry, while the walls of the unclerlying uninjured cells become impregnated with protective substances and sometimes also protected by suberised lamellae $\left({ }^{154}\right)$. The protection of wounded surfaces takes place in this way in the Cryptogams, and when the wound is very small in Phanerogams. In the ease of larger wounds in the latter a cork-cambium, forming wound-cork, develops below the lignified cells. This cork is lignified as well as suberised $\left({ }^{155}\right)$. Suberisation of the walls of the cells immediately underlying the wound may precede the formation of cork. This oceurs in seed potatoes which are divided up before planting and left one or two days exposed to the air. On this depends their resistance to injurious influences in the soil $\left({ }^{156}\right)$. Latieiferous elements are first elosed by the coagulation of the latex at the point of wounding and below this a cell wall is formed $\left({ }^{157}\right)$. In woody plants a so-called CALLUs is formed by the active growth of the living cells borlering on the wound. These swollen growths close together over the wound, and by the suberisation of their cell walls provide a sufficient protection. Generally, however, a eork-forming phellogen arises in the periphery of the callus. In stems of Gymnosperms and Dicotyledons, wounds which extend into the wood become surrounded and finally overcapped by an outgrowth of tissue arising from the exposed cambium. While the callus tissue is still in process of gradually overgrowing the wounded surface, an outer protective covering of cork is developed; at the same time a new cambinm is formed within the callus, by the differentiation of an inner layer of cells, continuous with the eambium of the stem. When the margins of the overgrowing callus tissue ultimately meet and close together over the wound, the edges of its eambium unite and form a complete cambial layer, continuing the cambium of the stem over the surface of the wound. The wood formed by this new cambium never coalesces with the old wood which is brown and dead. Accordingly, marks ent deep enough to penetrate the wood are merely covered over by the new wood, and may afterwards be found within the stem. In like manner, the ends of severed branches may in time become so 
completely overgrown as to be eoncealed from view. The growing points of adventitions shoots often arise in such masses of callns. As the wood produced over wounds differs in structure from normal wood, it has been distinguished as CALLUS WOOD. It consists at first of almost isodiametrical cells, which are, however, eventnally followed hy more elongated cell forms. In the cherry instead of normal wood elements there are prodnced on wounding the cambium nests of thin-walled parenchymatous cells which undergo gummosis (p. 109) $\left({ }^{63}\right)$. At the base of cut-off portions of plants which are nsed as cuttings a callus formation, which according to the kind of plant is mole or less active, takes place. In extreme cases the callus forms projecting masses within which the rudiments of adventitious roots arise.

All the tissues of the wounded surface so far as they contain living cells are in this ease also capable of forming callus, but the cambium is especially concerned in it. The masses of callus formed at the two cnds of a cutting with a cut surface both above and below tend to exhibit differences in their behaviour. Thus in such cuttings of species of Populus the apical callus develops more strongly than the basal. In the basal eallus a strand of meristem is protruded from the stem cambium, which covers the exposed wood of the eutting with callus wood; in the apical callus this meristematic tissue forms a branched strand of tissue in which vessels form. Under ordinary conditions only the basal callus is capable of forming roots while the apical eallus gives rise to new shoots (158).

Regeneration.-Lost parts of the body of Fungi and Algae are often replaced, a direct regeneration thus taking place. In more highly organised plants such a proceeding is extremely rare. It oceurs most readily in embryonic organs, such as growing points, when portions have been lost, and is most often found in seedlings $\left({ }^{159}\right)$. Thus in seedling plants of Cyclamen even a severed leaf-blade has been found to be replaced $\left({ }^{160}\right)$. As a rule, however, when regeneration processes are requisite in higher plants and the necessary preformed organs are not present in a resting or latent condition, the older tissues return to the embryonic condition and give rise to new growing points of shoots. That this is a provision for the indirect replacement of lost parts is confirmed by the fact that direct regeneration is far more frequent among animals than plants.

\section{The Phylogeny of the Internal Structure}

In the section dealing with the development of form in the vegetable kingdom (p. 10) the main aspects of the origin of the external form of plants were considered. The phylogenetic differentiation in the internal structure of a plant does not altogether coineide with the progress of its external segmentation. Even unicellular plants of the Siphoneae may exhibit a high degree of external differentiation; thus the micellular Alga, Cunlerpu (Fig. 286), has developed appendares having outwardly the forms of leaf, 
stem, and root. Similarly, the Red Seaweed, Hydrolupatlum (Fig. 9), although composed almost entirely of uniform cells, bears in its external segmentation a resemblance to one of the most highly organised plants. The internal differentiation of this Alga has only advanced so far that the onter cells containing the red chloroplasts form an assimilating tissue of isodiametrical cells, while the internal colourless and more elongated cells funetion as a conducting tissue. The relatively highest degree of internal development found in the Algae is attained by the Laminariae. In their stem-like axis, which may have a considerable thickness, the external tissues frequently contain canals filled with mucilaginons matter; while internally are found rows of cells resembling sieve-tubes $\left({ }^{121}\right)$. The axes themselves
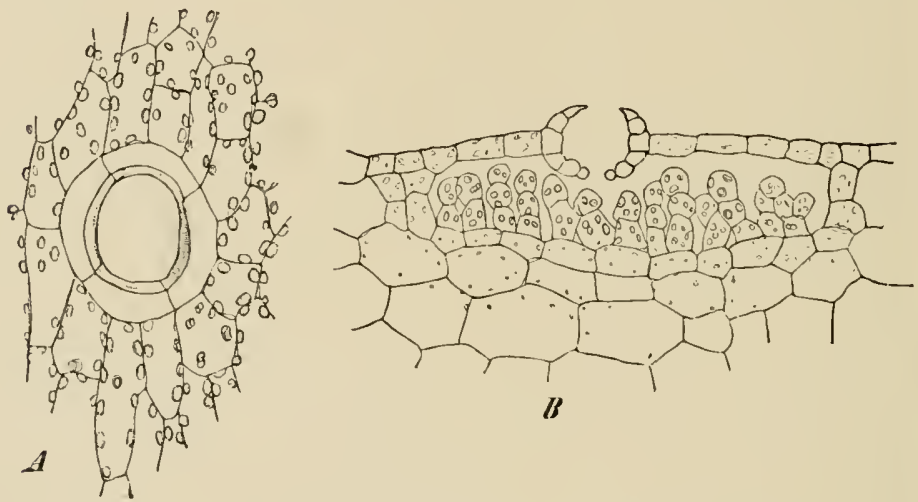

Fin. 170.- Surface view and transverse section of the thallus of Marchantia polymorpht. In $A$, an air-pore, as seen from above ; in $B$, as seen in cross-section. $(\times 240$.

grow in thickness through the continuous division of the cells of one or more of the onter eell layers. A kind of cortical tissue is formed as a result of this growth which exhibits eoncentric layers; the innermost cells gradually elongate and pass over into the so-called medulla. This secondary tissue even gives rise to sieve-tubes. In the larger Fungi internal differentiation is the result of the more or less intimate union of the intertwining hyphae. In extreme cases the hyphae forming the body of the Fungus may be so closely woven together as to give, in a cross-section, the impression of a parenchymatous tissue (Figs. 109, 110), in which, on the subsequent thickening of the cell walls, the pits in adjoining hyphae coincide. In the fructifications of many of the Hymenomycetes and Gasteromycetes, some of the longer and more swollen hyphae eontain a homogeneous or cloudy, highly refractive, and, in some instances, coloured substance, and appear, accordingly, to serve as a special tissue for the purpose of conduction. A marked alvance in the differentiation into different tissue systems is first apparent in the Bryophytes, but eren in them 
the formation of an epidermis distinct from the fundanental tissue is exceptional. In the thallus of the Marehantieae and on the spore eapsules of the Anthocerotaceae and Bryineae, the external layer of cells become more or less sharply defined from the underlying tissues. In the Marehantieae (Fig. 170) this outer layer is pierced by openings which have been termed breathing-pores, but these have a different origin from the stomata of higher plants. The air-ehamber arises as a small intercellular space between eight cells arranged in a cube which has been derived from a single peripheral eell of the thallus. The intercellular space widens into the air-chamber while the four cells above it become divided to form several tiers in order to give rise to the air-pore opening to the exterior. This when mature has the barrel-shaped appearance represented in Fig. 160 $A$ and $B\left({ }^{161}\right)$. In the Anthocerotaceac and Bryineae, on the other hand, stomata similar in structure to those of the Pteridophytes and Phanerogams are found in the onter cell layer of the spore eapsules. It wonld seem, however, that these stomata of the Bryineae are probably not homologous with those of higher plants. It

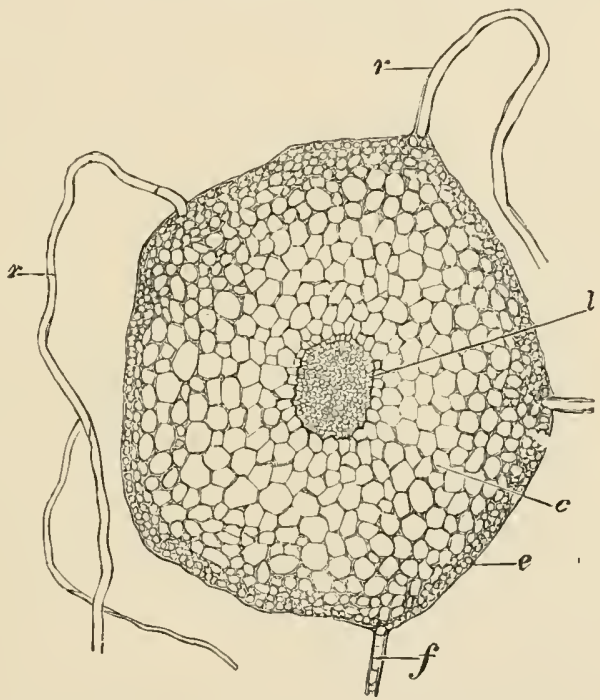

Ir. 171. - Transverse section of the stem of Mnium undulutum. $l$, Conducting-bundle; $c$, cortex ; $e$, peripheral cell layer of cortex; $f$, part of leaf; $r$, rhizoils. $(\times 90$. is more reasonable to regard them as merely analogous formations, such as from internal causes so often oceur in the evolution of organs. In the stems of many of the Bryineae there is also developed a simple form of conducting bundle (Fig. 171); and the many-layered midrib of the single-layered leaf lamina is also traversed by a conducting strand. In spite of their more advanced differentiation, the Bryophytes may still be ineluded, just as they were originally in 1813 by Auguste Pyrane De Candolle $\left({ }^{162}\right)$, in his classification of the vegetable kingdom according to the natural system, with the other lower Cryptogams in the class of CELLULAR PLANTS, as distinguished from the VASCULAR PLANTS, or Pteridophytes and Phanerogams. A separation of the tissues into the three systems of epidermal, fundamental, and vascular tissues oceurs for the first time in the vascular plants associated 
with the development of roots; while the systems themselves also exhibit widely extended division of labour.

\section{The Ontogeny of the Form and Structure of Plants}

Just as the phylogenetic development of the regetable kingdom has proceeded from the simple to the complex, every plant in its ontogeny passes through a corresponding development. The study of the ontogenetic development is termed embryology, and the commencement of the ontogenetic development is spoken of as germination.

However a plant may arise, whether from an asexually produced spore or from a fertilised egg, its first inception is always as a single cell. In unicellular, spherical, or rod-shaped organisms, such as Glococapsa polydermatica (Fig. 1) or Bacteria (Fig. 4), the whole course of development is eoneluded with the cell division which gives birth to two new independent organisms (Fig. 1). If the cell divisions be eontinuous and parallel, and the newly developed cells remain in contact, CELL FILAMents (Fig. $4 a^{*}$ ) will be formed; if the division walls have different inclinations, and are at the same time all in the same plane, CELL SURFACES are produced; and if the walls are formed in three dimensions of space, CELL MASSES are the result. Such an organism will attain but a low degree of development if all its eells have a like value. It resembles then a unieellular organism save for the fact that the cells produced by division remain united. With the distinction into BASE and APEX a plant manifests a higher degree of differentiation. A VEGETATIVE or GRowing POINT is then developed, usually at the apex (Fig. 5). This retains its embryonic nature, while the parts produeed from it attain a mature condition, a distinguishing feature of the ontogeny of plants as compared with animals (p. 4). The behaviour of growing points has been already described (p. 101), but the processes occurring in the ontogenetie development of the plant require further consideration. A qualitative difference in the embryonic tissue takes place at a short distance below the growing point. There the embryonie tissue loses its meristematic character, and becomes transformed into the differentiated body of the plant. As a general rule, in plants with an epidermis, primary cortex, and central cylinder, the epidermis is developed from the dermatogen, the primary cortex from the periblem, and the central cylinder from the plerome. This differentiation of the tissues does not take place in all cases; an already determined separation of the several tissues must not be assumed to extend to the embryonic tissue, the peculiar cell arrangement of which is due rather to physical canses. The vascular bundles must pass through the periblem in order to reach the leaves. The periblem is therefore capable of producing, not only the primary cortex, but also the vascular bundles and accompanying tissues of the central cylinder. The terms 
dermatogen, periblem, and plerome are employed merely for convenience to designate certain cell layers of the growing point, and are not to be regarded as significant of any peculiar histogenetic or tissueforming ability. The external layer from which the epilemis develops usually remains a single cell layer. The rudiments of the still undeveloped vascular bundles soon appear in the central cylinder as procambium strands; while the endodermis of roots is derived at an early stage from the innermost layer of the cortex.

The stigge of the ontogeny of the plant known as GerMINATION is specially defined in Phanerogams, where the term is limited to the further growth of the embryo already present within the seed. The embryo, enclosed within the seed, by the time

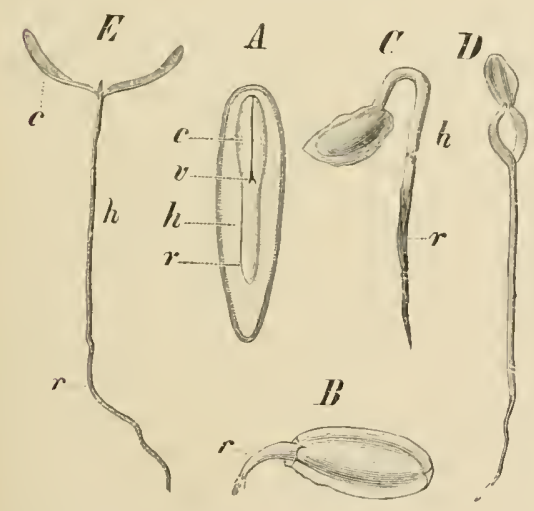

FIr. 172.-Thuju oceidentalis. A, Median Iongitudinal section through the ripe seed $(\times 5) . \quad B, C(\times 2)$; $D, E$ (nat. size), different stages of germination; $h$, hypocotyl; $c$, cotyledons ; $r$, radicle; $v$, regetative cone of stem.

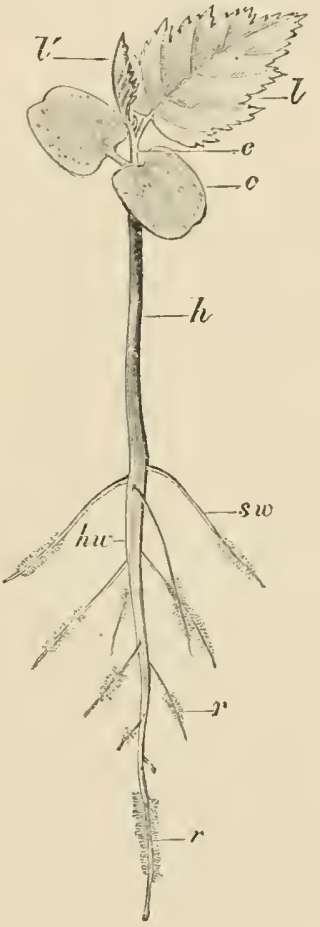

Fic. 173.--Seedling of Curpinus Lotulus. $h$, Hypocotyl ; $c$, cotylerlons ; $h w$, main root; $s w$, lateral roots ; $r$, loothairs; $e$, ejicotyl; $l, l$, foliage leaves. (Nat. size.)

the latter is shed from the parent plant generally exhibits the segmentation characteristic of Cormophytes. Protected by the hard seed-coats, it is enablerl to sustain a long period of rest. Abundant deposits of mutritive material in the embryo itself, or surrounding it, are provided for its nourishment during germination. The different segments of a phaneroganic embryo have received distinctive names; thus, as in the enubryo of the American Arbor Titae (Thuja occidentalis, Fig. 172), the stem portion $(h)$ is termed the HYPocoty $L$, the first leaves $(c)$ are the SEED LEAVES or COTYLIDONS, while the root $\left(r^{\prime}\right)$ is distinguished 
as the RADICLE: The tap-root of the fully-developed plant is formed by the prolongation of the radicle and later gives rise to lateral roots. The figure shows the germination at successive stages from the longitudinal section of a mature seed (A) to the seedling with unfolded cotylerlons (E). In Fig. 173 a germinating plantlet of the Hornbeam (Carpinus Betulus) is shown with its hypocotyl $(h)$ and two cotyledons $(c)$; its radicle has already developed into a tap-root $(h w)$ with a number of lateral roots $(s w)$. An internode and foliage

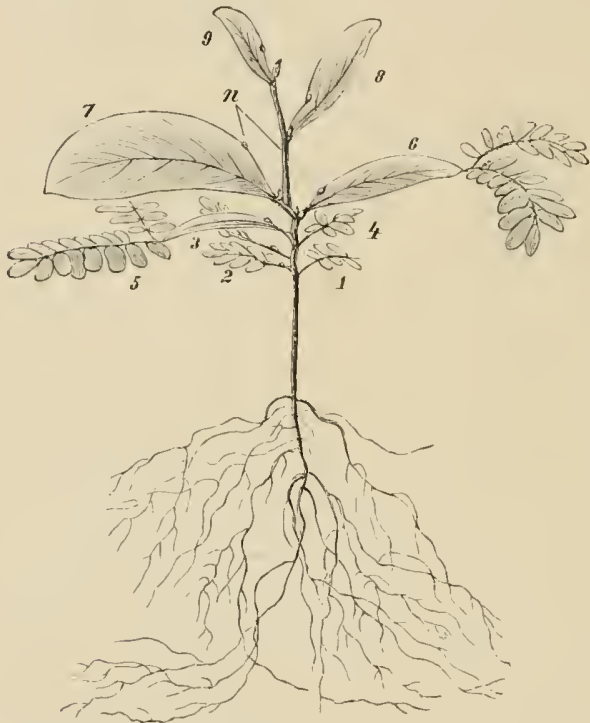

Fir: 174.-Seedling of Acacia mycuntha. The cotyledons have been thrown off, The foliage leaves $1-4$ are pinnate, the following lraves bipinnate. The petioles of leaves 5 and 6 are vertically expanded; and in the following leaves, $7,8,4$, modified as phyllodes, bearing nectaries, n. (About $\frac{1}{2}$ natural size.)

leaf $(l)$ have been produced from the vegetative cone of the stem; while the next higher internode is also distinguishable, lout has not yet elongated, and a second foliage leaf $\left(l^{\prime}\right)$ is unfolding.

A highly organised plant, which begins its development with the simplest stages and gradually advances to a ligher state of differentiation, to a certain extent repeats in its ontogeny its phylogenetic development. In the process of its ontogenetic development much has been altered, and much omitterl, so that it presents but an imperfect picture of its past history ; nevertheless, this representation is valuable, and, next to comparative methods, furnishes the most important source of our morphological knowledge. Whatever is true of the development of a plant from the embryo is also, as a rule, applicable to its further growth from the growing point, and, consequently, a knowledge of the mode of development at the growing point is of great importance in establishing homologies. The earlier a characteristic makes itself apparent in the embryo, or the nearer it is to the growing point of the old plant, so much the greater is its value in determining the general relationships existing between the different plants; the later it is exhibited in the embryo, or the farther removed it is from the growing point of the plant, the less its general value, but the greater, in proportion, its importance in defining the eharacter of a genus or species. From the fossil remains 
of former geological periods, it is safe to conclude that such Conifers as Thuju, Biotu, and the various Junipers, that now have seale-like compressed leaves, have been derived from Conifers with needleshaped leaves. This conclusion is confirmerl by the fact that on the young plants of the scaly-leaved Conifers typical needle-shaped leaves are at first developed. The modified leaf forms do not make their appearance until the so-called JUVENILE FORM bas attained a eertain age, while in some Junipers needle-shaped leaves are retained throughout their whole existence. Even still more instructive are the Australian Acacias, whose leaf-stalks become modified, as phyllodes (p. 45), to perform the functions of the reduced leaf-blades. The demonstration of such an assertion is furnished by a germinating plant of Acacia pycnantlu (Fig. 174), in which the first leaves are simply pimnate, and the succeeding leaves bipinnate. In the next leaves, although still compound, the leaf-blades are noticeably reduced, while the leaf-stalks have become somewhat expanded in a vertical direetion. At length, leaves are produced which possess only broad, flattened leaf-stalks. As many other species of this genus are provided only with bipinnate leaves, it is permissible on such phylogenetie grounds to conclude that the Australian Acacias have lost their leafblades in comparatively recent times, and have, in their stead, developed the much more resistant phyllodes as being better adapted to withstand the Australian climate. The appearance, accordingly, of the phyllodes at so late a stage in the ontogenetic development of those Acacias is in conformity with their recent origin. Lathyrus aphaca (p. 45), the leaves of which in the mature plant are transformed into tendrils, has the first leaves of the seedling provided with leaflets. It may, in like manner, be shown that in the case of plants with similarly modified leaf forms, the metamorphosis of the leaves does not take place until after the cotyledons and the first foliage leaves have been developerl, and it is then usually effected by degrees $\left({ }^{163}\right)$.

\section{Structural Deviations $\left({ }^{16 t}\right)$}

Plants, even of the same speeies, never exactly resemble each other. Every individual organism has its own peculiar charaeteristics by which it may be distinguished from every other of the same species. To a eertain extent these characters may be due to ATAVISM, or the reappearance of previous ancestral qualities. Most individual deviations belong, however, to the so-called FLUCTUATING VAIiATIONs. These oecur in all species, and may be compared to the exeursions of a pendulum to either side of its position of equilibrium. More eonsiderable departures from the normal for the speeies may be inherited. The importance of these in the origin of species was already clearly recognised by Charles Darwin. They have been ealled mutations by 
HIUGo DE Vries $\left({ }^{4}\right)$ and regarded by him as alone of value in the formation of species, in contrast to the ordinary variations which simply oscillate between plus and minus. Abrupt and striking deviations of the individual from the type of the species are called noNstrosities. When these induce a disturbance of function a diseased condition results. The canses of monstrosities may lie in the organism itself; in other cases they can be shown to stand in relation to external causes. Among EXTERnal CaUSES of VARIATIONs the influence exercised by parasites upon the devclopment of the portions of the plant is particularly striking. Éuphortia Cyparissias, when attacked by a rust fungus (Aecidium Euphorbiue), becomes sterile, remains unbranched, has shorter and broader leaves, and in its whole appearance is so changed as scarcely to be recognisable. Plant lice sometimes canse a flower to turn green, so that instead of floral leaves green foliage-like leaves appear. Another peculiar example of abnormal growths is afforded by the GALLS or CECIDIA produced on plants by Fungi, or more frequently by insects, worms, and arthropods. The effect of these formations on the normal development of the tissues of a plant is more or less disturbing, according to their position, whether it be in the embryouic substance of the growing point, in the tissnes still in course of differentiation, or finally in those already developed. The larvae of Cecidomia rosaria live in the growing points of Willow stems, and occasion a malformation of the whole shoot by the production of galls, known as "willow-roses," which are composed of modified leaves and axes. Flies (Diptera) often deposit their eggs in the tissues of partially developed leaves, in consequence of which the leaves become, according to their age when attacked, more or less swollen and tristed. After the leaves of the oak have attained their full growth they are often stung by a gall-wasp of the genus Cynips. The poison introduced by the sting, and also by the larvae hatched from the eggss deposited at the same time, occasions at first only a local swelling of the leaf tissue, which finally, however, results in the formation of round yellow or red galls on the lateral ribs on the under side of the leaf. $\Lambda$ s galls differ materially from one another according to the nature and cause of their formation, it is gencrally possible to determine the particular exciting cause to which they are due.

In the monstrosities resulting from internal canses it is also the case that the earlier they commence the more extreme do they tend to be. When the enlbryonic substance of the growing point is aflected by such an inthence altogether unexpected modifications of the usual order of growth may result. In other cases intermediate structures of more or less monstrous form result. As the embryonic substance of the growing point is of itsclf capable of producing all such forms as are peculiar to the species, instead of a flower a vegetative shoot may be developed, or the growing plant of a root may continue 
its further development as a stem. Leaves, even when somewhat advanced in growth, may under changed conditions vary their usmal charaeter, particularly within the limits of their possible metamorphosis; for example, the staminal and earpellary leaves of a flower may thus become transformed into additional perianth leaves. The later the rudiments of an organ are aeted upon by a disturbing influence, so much the less far-reaching are the modifications which are produced; thus intermediate forms between two organs may be produced which correspond more or less elosely to one or the other of them. Neither the almormal interehangeability, at times manifested between morphologically different members, nor the development of intermediate forms between them, can be considered as proof of their' phylogenetic conmection. MaLForimations ARE, accordingly, TO BH ACCEPTED AS EVIDENCE IN MORPHULOGICAL QUESTIONS ONLY IN THE RAREST CASES. When, as is only exceptionally the ease, they represent reversions, this value may be attached to them.

The study of the abnormal formations and functions of the plant is called Phyтopathology. When the pathological structures are alone in question it may be termed pathological morphology. Malformations which affect the external form are still treated by themselves as Vegetable Teratology (Pliytoteratology). Pathologieal changes in the form and contents of the vegetable cells and tissues form the subject matter of pathological plant anatomy.

The study of the aetiology of abnormal vegetable tissues shows that various external influences may give rise to them; the most important causes are the influence of wounding and of the attacks of parasites. According to Einst KüstEli abnormal cells may be characterised by their contents, the thickening of their walls, or by their nnusial size (hypertrophy); in the last case they may also show divisions which would not normally oceur. The abnormal tissue may resemble that from which it originates or deviate more or less widely from it. The tissues formed in the healing of wounds (cf. p. 162) and those of galls may be mentioned as examples. The tissues of galls are characterised more by the increase in number than by the size of their cells, which may undergo the most varions modifications. There is often a considerable accumnlation of albuminous substances and carbohydrates in these tissues. A modified part of a plant in many cases appears as if due to an arrested development. Dwarf forms and defective differentiation of tissues, with its accompranying impaiment of function, are examples of this. In all cases in which the cells of a tissue no longer present their normal properties they are liable to undergo sooner or later regressive changes leading to degeneration and necrosis. 

PAR'T I

GENERAL BOTANY

SECTION II

P H Y I OLOG Y 



\section{SEC'TION II}

\section{PHYSIOLOGY}

Physiolory is the study of life. Its ultimate object is to explain the nature of life, but at present it has to rest satisfied with describing the phenomena of life, and studying the influenee of various factors npon them. Physiology like chemistry and physics is concerned with inquiries into the causes of what takes place. It is thus distinguished from oecology (p. 6), a study which also deals with the phenomena of life; this seeks for the purpose, or, better expressed, the uses to the organism, of adaptations or of processes, and is thus a teleological rather than a cansal study. Since, however, every aspect or discipline of the science cannot be separately dealt with in a text-book, this seetion will treat of oecological as well as of physiological prol, lems. This is further justified by the fact that physiology and oecology may and often have had a useful mutual influence.

Since animals and plants are only sharply separable in their nore advanced forms, animal physiology and plant physiology must have much in common. This fact emerges the more elearly when, on the one hand, the animal physiologist concerns himself with the lower animals, and, on the other hand, the vegetable physiologist studies the processes of irritability.

In some respects the behaviour of the living plant does not differ from that of non-living bodies. In spite of the large amount of water which it contains, the plant is as a rule solid, and has the physical properties of such a body. Weight, rigidity, elasticity, conductivity for light, heat, and electricity are properties of the organism as they are of lifeless bodies. However important these properties may be to the existence and the life of the plant, they do not constitute life itself.

THE PHENOMENA OF LIFE ARE ESSENTILLX CONNECTED WITII THE Living protoplasu. No other substance exhilits even similar remarkable and varied properties, which we can compare to life. It is especially characteristic of the organism that the reaction which follows an external influence is a very complicated one. The connection between the causal influence and the effect induced by it 
is not so apparent as it is in chemical or physical processes. This depends on the part always taken by the protoplasm, so that the reaction observed is not the direct effect of an external cause, but a very indirect result.

If the free end of a flexible rod is placed horizontally, and exposed to the influence of gravity, it will bend downwards to a definite point as the result of its weight. A part of a plant will behave similarly, and if dead, as, for instance, a withered stem, will remain in the position it thus assumes. If, however, a living growing stem has been used in the experiment it will exhibit an effect of gravity which is very surprising in comparison with the purely physical effect. The growing portion of the stem curves, and by its own activity becomes erect again ; it thus moves against the force of gravity. If the experiment is made with a tap-root, this will curve vertically downwards much further than its own weight would cause it to do. A rhizome, on the other hand, will place its growing tip horizontally when it has sunk by its own weight out of the horizontal plane. In these three experiments the physical conditions are the same. The weight of the earth acts on a horizontally placed portion of a plant. The results in the three cases are as different as possible.

The explanation of this remarkable behaviour of the plant is to be sought in the fact that while, to begin with, gravity influences it as it would influence an inorganic structure-giving weight to the mass - this primary physical change then acts as what is called a stimulus. This liberates inner activities of the plant which neither quantitatively nor qualitatively have a recognisable connection with the force of gravity. Such relations become clearer if the organism is compared with a mechanism. The connection between the light pressure of the finger on the trigger of a gun and the flight of the bullet is not a simple one. The pressure first liberates a trigger; the energy thus obtained drives the hammer on to the percussion eap ; this explodes and canses the powder to explode; the gases liberated by the explosion force the projectile from the barrel. It is clear that the force of the hammer bears no relation to that of the pressure of the finger of the marksman, and there is just as little connection between the amount of force generated by the expansion of the powder and that exerted by the hammer of the gun. There are energies present, those of the trigger and powder, which are set free. Such liberations of energy, especially when they follow in order and constitute a chain of processes, are of very frequent oceurrence in the organism. They are known as phenomena of irritability, and the factor which starts them is termed the stimulus. They are found always when the specific phenomena of life are concerned.

Just as the action of a machine is only comprehensible when its construction is known, a knowledge of the external form and internal strueture of the plant is a necessary preliminary to its physiological 
study. It has been seen, however, that it is not yossible to understand the function from the structure to the same degree in the case of the plant as it is in that of a machine. This holds still more strongly for the more specific vital phenomena. While it is truc that the phenomena of life can as yet not be thoroughly explained, this does not negative the conviction that they only differ from the processes in inorganic bodies by their much greater complexity; in principle a physico-chemical explanation of vital phenomena can be attained.

The most important phenomena of life are exhibited in the following ways :-

1. An organism, which appears to us as an individual, does not consist of the same unchanged material, even when no further growth in size is taking place. While its external form remains constant, progressive changes go on internally. New substances are taken up from withont, are transformed within the plant, and are again given off from it. The organism has a METABOLIsu. Inorganic nature offers us no process analogous to this.

2. As a rule, however, metabolism does not proceed so that the absorption and giving-off of material are equal, but more is absorbed than is given off. The mass of the organism is incleased, it Grows. Growth is also known in the cases of chemical precipitates or deposits, and of crystals. In these cases it tends to proceed in such a way that no essential change of shape takes place (crystals), or that the changes in shape are accidental and irregular (precipitates). The organism, on the other hand, assumes by changes of its form quite definite shapes, which follow in regular order. It passes through a DEVELOPIENT which leads sooner or later to the production of new organisms or daughter individuals; REPRODUCTION takes place. Growth, development, and reproduction are processes highly characteristic of living beings.

3. Lastly, organisms exlibit powers of MoveneNT; they either change their positions bodily, or they bring larger or smaller parts of their borlies into other positions. Since inorganic bodies and dead organisms may exhibit movements, it is only the kind of movement and the means by which it is brought about that are characteristic of living beings.

In nature the three processes mentioned above, metabolism, development, and movement, usually go on simultancously. Metabolism without movement of the substances concerned is impossible; development is bound up with metabolic changes and with movements; and, lastly, movements cannot occur without metabolism. Nevertheless, we may for descriptive purposes consider the three processes separatcly, and thus divide Physiology into the following sections:

1. The study of metabolism or chemical physiology, which may also be termed the physiology of nutrition. 
2. The study of development or the physiology of form, ehanges of shape, and the mechanism of development.

3. The study of movement.

The full vital aetivity of the plant is only attained when a number of conditions, which may be divided into internal and external, are fulfilled. $\left({ }^{1}\right)$ The internal causes of life are connected with the protoplasm. Its structure and organisation not only determine that the ehanges which take place in the organism have a vital eharaeter, but that the organism shows speeifie differenees depending on the deseent of its protoplasm. These internal factors are only effeetive, however, by continual interaction with the external world. The environment not only provides the materials from which the body of the plant is built up, but supplies energy in the form of the vibrations of heat and light; this energy is again used in numerous processes in the life of the organism. The influences of the external world also act, as has been already pointed out, as stimuli to which the protoplasm of the plant continually reacts in the manifestations of its life. These external influences ean only be of use within definite and strictly limited ranges of intensity. The capacity of life of vegetable protoplasm is only maintained within a relatively narrow range of temperature; full vital aetivity only oceurs within still narrower limits. An excess of light is injurious to life, as is too little warmth, and it only requires a minute quantity of any poisonous substance to destroy beyond recovery the speeifie structure of the protoplasm.

The lower limit for the operation of an external factor is known as the MINIMUM, the upper limit as the MAxinum, and the particular grade of intensity of the faetor at whieh any partienlar vital phenomenon attains its highest expression is known as the opTIMUM. Minimum, optimum, and maximum, but especially the optimum, are by no means fixed points for the organism. They are changeable within certain limits, on the one hand, with the duration of action of the factor; on the other, in relation to other conditions of life. These so-ealled "cardinal points" are usually different for the various vital processes of the same plant.

The dependence of the vital phenomena on external factors can be graphically represented and made clearer by means of curves. If the intensity of the factor (degrees of temperature, intensity of light) is marked on the abscissa, and the intensity of the reaction of the plant on the ordinate, curves of the form $\mathrm{AE}$ (Fig. 175), which are known as optinum curves, are usnally obtained. The summit of this curve corresponds to the optimum.

Curves, in which the dependence of ehenical reactions, on for instance tenuperature, are represented, usually exhibit another shape (AB): they are for the most part logarithmic eurves with no indieation of an optimum. This does not express any fundamental difference between the reactions within the organism and inorganic reaetions. Probably optimum curves are always the resultants of two kinds of effect of the same factor, one accelerating, the other destructive. Thus, for instance, 
a chemical reaction in which a particular substance $\mathrm{S}$ is formed may be accelerated by temperature as is represented in the curve $\mathrm{AB}$; if, however, the substance $\mathrm{S}$ is at the same time decomposed by the rising temperature, its actual amount may be represented by the curve $\mathrm{CD}$; the effect of the rise of temperature on the chemical reaction is expressed by the curve $\mathrm{AE}$, which is the resultant of $\mathrm{CD}$ and AB. $\left({ }^{2}\right)$

The cardinal points of temperature are usually on the average much lower for the plants of cold climates than for those of temperate or tropical regions. Thus the geographical distribution of plants is in the first instance dependent on these cardinal points. The highest cardinal points are found not in tropical plants, but in certain Bacteria which can live in fermenting substances at a temperature of $70^{\circ} \mathrm{C}$.

At low temperatures in the neighbourhood of the freezing-point of water many plants are killed by being frozen. This may happen to susceptible plants at a temperature above $0^{\circ} \mathrm{C}$. and long before ice is formed in the tissues. Other plants can endure the formation of ice within these, and may be thawed from a hard, frozen condition still alive. The resistance of lower organisms to extreme cold is noteworthy. In Pictet's experiments Diatoms endured for a long time a temperature of $-200^{\circ}$ C. ; various Bacteria, according to the investigations of MACFADYEN and otlers, can support a six months' exposure to $200^{\circ}$ and even to $250^{\circ}$ of cold, produced by means of liquid air and liquid hydrogen $\left({ }^{3}\right)$.

The demands of plants on light also show much variety. Some require full

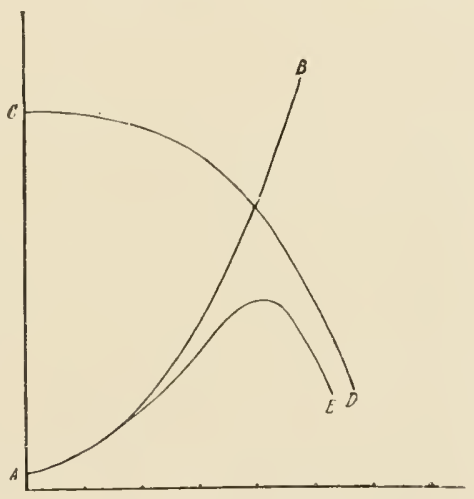

Fic. 175.--Explanation in Text. sunlight in order to thrive successfully, while others prefer the shade of woods or of caves or clefts in rocks (shade-plants).

By increase of the intensity of light any cell can be killed; in different cases the action of the light may be either mainly chemical or mainly thermal. Many Bacteria are killed even by bright daylight; on this depends the important hygienic effect of light in houses and clwelling-rooms.

The need of light not only changes from one species of plant to another, or from individual to individual, but the optinum effect of light may change for the same indivirlual as it develops. Many of the cultivated plants of the tropies, e.g. Coffee and Cocoa, require shade when young, and require to be at first protected by shade-giving trees (species of Albizzia) planted for this purpose. When older they bear or even require exposure to the full tropical sun.

In addition to the energy which the plant obtains from the rays of light and heat, numerous influences of substances in the plant's environment have to be considered. This is not the place to enumerate the elements necessary to plants, but the need of water, which is familiar to every one, may be mentioned. 


\section{Sub-Section I}

\section{METABOLISM $\left({ }^{4}\right)$}

\section{The Chemical Composition of the Plant $\left({ }^{5}\right)$}

Any consideration of the metabolie changes in the plant requires a knowledge of its chemical composition. This is studied by chemical methods.

Water and Dry Substance.-Some insight into the composition of the plant can be obtained without special means of investigation. Every one who has dried plants for a herbarium knows that the plant consists of water and clry substance. He also knows how the removal of the water influences such fundamental physical properties of the plant as its rigidity and elasticity. By means of weighing it is easy to show how large is the proportion of water in the total weight of the plant. For this purpose it is not sufficient to expose the plant to the air, for when air-dried it still retains a considerable proportion of water, which must be removed by drying in a desiccator or at a temperature of over $100^{\circ} \mathrm{C}$. It can thus be ascertained that the proportion of water is very considerable; in woody parts some 50 per cent, in juicy herbs 70-80 per cent, in sueculent plants and fruits 85-95 per cent, and in aquatic plants, especially Algae, 95-98 per cent, of the weight of the plant consists of water.

Ash. - While we ean thus distinguish by drying between the water and the dry substance of the plant, we are able by burning to distinguish between the combustible or organic material and the incombustible substance or ash. The fact that the plant leaves an ash is evident in the burning of wood or in the smoking of a cigar; the microseope further shows that even minute fragments of eell-wall or starch grains leave an ash on burning. Information as to the quantitative relations of the ash is afforded by analysis, which shows especially that the various organs of a plant differ in this respect; leaves, for example, tend to contain more than stems. It has thus been found that the dry substance of the leaves of Brassica rapa contains about 20 per eent of ash, while the stems have only 10 per cent.

The consticuents of the ash also vary according to the nature of the soil and other external influenees. On the other hand, distinct species may accumulate different quantities of mineral substances, even when exposed to the same exterual conditions.

While the majority of the more common elements occurring in the carth are found in the ash of plants, only a few elements are present in sufficient amount to be quantitatively estimated. These 
are the non-metals $\mathrm{Cl}, \mathrm{S}, \mathrm{P}, \mathrm{Si}$, and the metals $\mathrm{K}$, Na, Ca, Mg, and Fe.

Besides these the following may be met with in the ash of plants: Iodine, Bromine, Fluorine, Selenium, Tellurium, Arsenic (which may be introduced into cultivated soils with superphosphates), Antimony, Tin, Titaniun, Boron, Lithium, Kubidium, Strontium, Barium, Zinc, Copper, Silver, Mereury, Lead, Aluminium, Thallium, Chromium, Manganese, Cobalt, and Nickel.

Organic Substance.-Chemical analysis is not needed to show that the plant contains carbon in a combined form. Every burning $\log$ or match shows by its charring that it contains carbon. The examination of a piece of charcoal in which the finest structure of the wood is retained, shows further how uniformly the carbon is distributed in the plant, and how largely the substance of the plant consists of this element. Accurate weighing has shown that carbon constitutes about one-half of the dry weight of the plant. The enormous masses of coal in the earth's crust are the carbonised remains of plants that lived in earlier geological periorls; lignite and peat and also coal, when prepared by special methods, exhibit their vegetable origin by their macroscopic and microscopic structure.

On combustion of the dry plant the organic substance is changed, and passes off in the form of earbon dioxide and water, ammonia or free nitrogen. It contained the elements $\mathrm{H}, \mathrm{O}, \mathrm{N}$, and $\mathrm{C}$ chemically combined; some of the elements mentioned as occurring in the ash may also occur in organic compounds.

Source of the Materials. - There are thus only thirteen elements. found in considerable quantity in the plant. When the plant is growing their amount is continually increasing in the plant, and they must therefore be continually absorbed from without.

The mode of life of a plant affords clear indications as to the source of the materials from which it is built up. Plants are known which live wholly in the soil ; others float freely in water; others, while attached to a substratum, are eventually dependent on the air; while, lastly, others live upon the bodies of other plants or of animals (parasites).

Thus the substances which are found within the plant must have been derived from the soil, the water, the air, or from other organisms. Rarely, however, does a plant obtain all that it requires from one only of these media. The ordinary terrestrial plant sends its root down into the soil, and expands its leafy shoots in the air. Many aquatic plants have, in addition to the submerged organs, others which reach the atmosphere. Parasites also are able to absorlb substances from the atmosphere.

As a rule, only gases and liquils can enter the plant; solid substances have to be brought into solution before they can pass through the firm cell-walls. When, however, ccll-walls are absent, as 
in the Myxomycetes, the naked protoplasm is able to surround and thus to absorly solid particles.

\section{Absorption and Movement of Substances}

\section{A. Absorption of Substances into the Cell $\left({ }^{(i)}\right.$}

We may best commence our consideration of the absorption of substances with the free-living cell, and investigate in what mamner this absorbs water, solid substances, and gases.

Water.-All parts of a plant and all the parts of its individual cells are saturated with water. The cell-membrane has the water so freely divided between its minute particles that the water and the solicl substance are not distinguishable under the highest magnification. If the water is allowed to evaporate, air-filled cavities do not appear in its place, but a contraction of the cell-wall takes place. On the otler hand, the absorption of water by dry or not fully saturated cellwalls causes a swelling of the latter; this takes place with consiclerable energy, and can overcome considerable resistance. The walls of lignified cells absorb about one-third of their weight of water. The walls of some Algae and of the cells of some seed-coats and fruits consist more largely of water than of solid substance. The behaviour of the protoplasm is similar. Both wall and protoplasm are capable of swelling, and in the actively living cell are always in this condition. So long as the protoplasm is not saturated with water, it removes water from the cell-wall; owing to this, the wall which may before have been saturated becomes poorer in water, and seeks to replace the loss by taking up water from its surroundings. In this way the loss of water by the protoplasm affects the outer world by the medium of the cell-wall.

With the cell-sap it is different. This is a solution of various organic and inorganic substances in water. For simplicity we may assume that we are dealing with a solution of salts. If such a solution is enclosed by a cell-membrane, if we, for instance, fill a tube of cellnlose with the solution and fasten the ends firmly, and then this "cell" is placed in water, the salts will diffuse into the water and water will diffuse into the cell; this goes on until the same concentration is attainer at all points both within and withont the cell. A partition which is equally permealle to water and salts has no effect on the movements of diffusion which take place in every free mass of fluid; everything goes on as if the partition were not present. If this cell-membrane is replaced by one, which, while heing permeahle to both water and salts, lets the water pass throngh much more rapidly than the salts, more water will at first pass into the cell than salt passes ont; thus a pressure will arise within the cell expressed, in an increase of the volume of the cell, and in 
a stretehing of the cell-wall. Naturally this condition camnot be maintained; in the end the same result must be reached as in the former case, viz. a uniform distribution of the water and salts through the whole space. When this is attained the increase in volume of the cell is again lost. A third ease is essentially distinct: when the membrane consists of a substance which is permeable to water but impermeable to salts. If such a semi-permeable substance is employed, a condition of tension must again result, but in this ease it is permanent, since diffusion of the salts ontwards eun never take place.

In the vegetable eell itself the cell-wall is completely permeable. The layer of protoplasm applied to it, on the other hand, is more or less semi-permeable, at least so long as it is living. As a result of this there is a onc-sicled passage of water into the vacuole without any corresponding passage outwards of salts. A further result is the pressure of the cell-contents on the protoplasmic sac and through it on the cell-wall. The protoplasm becomes stretehed under this pressure (turgescence, osmotic pressure) without much resistance, but the cell-wall, by virtue of its elasticity, exerts a considerable counter-pressure. In many cases the cell-wall is stretched by the pressure some 10 per cent to 20 per cent, in extreme cases even 50 per cent, and it contracts when the pressure ceases. By the distension the cell-wall becomes more rigid, just as a thin india-rubber balloon when air is foreed into it resists ehanges of shape. The increase of rigidity of the plant, by reason of the turgor-pressure or turgescence, is very important; it is the simplest, and in many cases the only way, in which the cell becomes rigid. This is dependent naturally upon the presence of a sufficient supply of water; if a distended cell is taken from the water and allowed to give up water in the air, the streteling of the wall disappears, and with this the rigidity. The cell will wither. With a fresh supply of water the turgescent condition can be restored.

The internal pressure of the cell can be

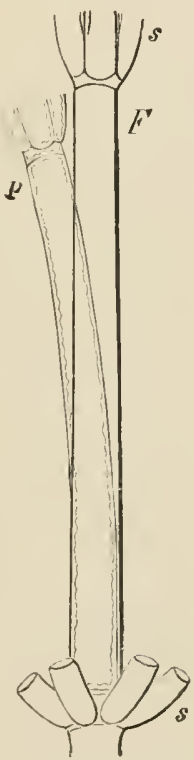

Fri: 176.-Internodal cell of Nitclla. $F$, Fresh and tur. gescent; $l$, with turgor reduced, flaccid, shorter and smaller, the protoplasm separated from the cell-walls in folds; $s s$, lateral segments. ( $x$ circa (i.) diminished in other ways than by the evaporation of the water; for instance, when the protoplasm is killed and its semi-permeable nature destroyed, or when a prick is made in the cell. In both these cases the shortening of the eell referred to above would take place (Fig. 176). The same result ean be obtained without destroying the internal 
pressure by inereasing the external pressure, so that it beeomes equal to or greater than the internal. This can be most simply done by bringing the eell into a solution instead of pure water. For simplicity we may assume that the substance in the solution is the same as that within the vacuole of the cell; in that case, if the eoncentration of the two solutions is equal, the pressure within and without the cell will be the same, and there will be no distension of the cell-wall. If, however, the external pressure is inereased, the racuole will diminish in size until the same concentration of the solution inside and ontside is attained. The protoplasm follows the diminishing vacuole, but the cell-wall is unable to do so, and there thus results a separation of the protoplasm from the wall. This is known as PLAsuloLysis (Fig. 177).
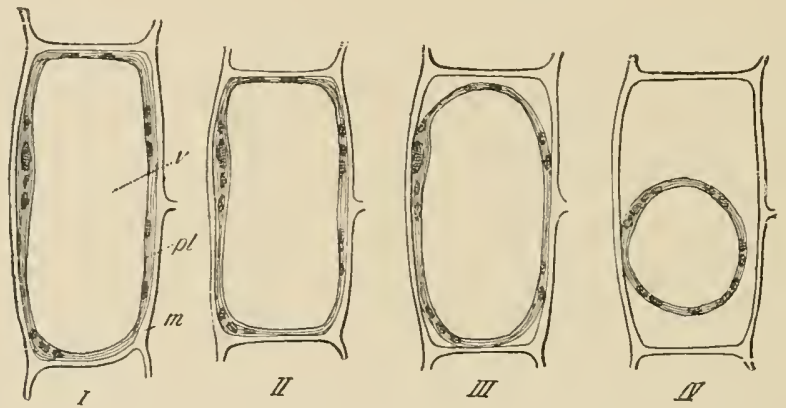

FIf, 177.-A young cell from the cortical parenchyma of the flower-stalk of Cephateria leucantha. $m$, cell-wall; $p l$, protojlasm; $v$, vacuole; $I$, in water; $I I$, in 4 per cent potassium nitrate solution; $I I I$, in 6 per ceut solution ; $I V$, in 10 per cent solution. (After DE VRIEs.)

It commences at the angles of the eell, but later the protoplasm separates entirely from the cell-wall, and lies free in the cavity as a spherical or ellipsoidal body.

What particular substance is employed to bring about plasmolysis is on the whole immaterial; it must not injure the protoplasm, and the latter must be impermeable to it. In many cells a $1-2 \%$ solution of potassium nitrate will bring abont the commencement of plasmolysis. Cells with higher osmotic pressure require a more eoneentrated solution. The effect of the solution depends entirely on the number of molecules and ions that it contains. For this reason a $1 \%$ solution of potassium nitrate corresponds to $1.7 \%$ common salt, $2.7 \%$ grape-sugar, or $5.13 \%$ of cane-sugar.

On transferenee to pure water the turgescent condition will be regained, if the protoplasm has not been injured by the solution. If the protoplasm is killed, however, it has become completely permeable, and the necessary condition for a one-sided pressure has disapleared. Fresh, living slices of the Sugar Beet and of the Beet Root when placerl in pure water allow neither the sugar nor the colouring matter to escape from the mninjured cells. If the protoplasm is killed, the sugar 
and pigment pass into the surrounding water, and as a result the slices lose their rigidity and beeome limp.

On the other hand, the internal pressure in the cells of Fungi, Bacteria, and marine plants is increased when they are placed in a less concentrated foodsolution, e.g. transferred to fresh water; this often leads to a rupture of the cell-wall.

Plasmolysis is of great scientific use since it allows us to measure by comparison the pressure within vegetable cells. If a solution of potassium nitrate of a definite percentage produces an osmotic pressure of 5 atmospheres, and this solution is just sufficient to remove the turgescence of a cell, it is clear that the cell-sap can attract water with an equivalent force and give rise to the same pressure. (That the turgescence is overcome is estimated in the case of an elastic and distended cell by the cessation of the elastic shortening.) Since a $1 \%$ solution of potassium nitrate gives rise to an osmotic pressure of $4 \frac{1}{2}$ atmospheres, the interual pressure due to turgescence can be easily ealculated in atmospheres. It amounts as a rule to not less than 5 atmospheres, but often reaches 10 and even 40 or more atmospheres (cambial cells, 25 atmospheres; nodes of grasses 40 atmospheres). The highest of these pressures far exceed the pressure of the steam in steam engines. The pressure is increased when the plants live in concentrated solutions instead of in water; for in these conditions also the cells exhibit an internal pressure. THUS the CELl is able to Regulate its osmotic pressure. The mecharical force required to stretch a wilted or plasmolysed elastic organ to its former length may also be used to give an approximate measurement of the force of turgor in the organ when turgescent.

Dissolved Substances.-If the protoplasm is really quite impermeable to the salts that have been considered above, not even traces of them can enter the cell-cavity. Practically, however, the impermeability of the protoplasm is perhaps not absolute for any substance; there are all grades, from substances that pass through the protoplasm as easily as water, to those that are almost ineapable of passing through it. Alcohol, ether, chloral hydrate, also numerous organic pigments, and, lastly, very dilute acids and alkalies diffuse with speeial rapidity.

The permeability of the protoplasm is not always the same, and may be regulated aceording to the requirements of the cell. The absorption or not of a substance is determined not by the whole protoplasm but by its external limiting layer. In the further passage of the substance, from the protoplasm into the cell-sap, the wall of the vacuole exereises a similar power of selection, which in some circumstances may differ from that of the external limiting layer. On aecount of the selection exercised by the limiting layers of the protoplasm, it is possible for the contents of the cell to be quite different chemically from the surrounding medium. The cause of the SELECTIVE POWER, by reason of which different cells ean appropriate quite distinct constituents from the same soil, is to be songht in this most important property of the limiting layers of the protoplasm.

From the same soil one plant will take up chiefly silica, another lime, a third common salt. The action of Sea-weeds in this respect is especially instructive; 
living in a medium containing some 3 per cent of common salt and but little potassium salts, these cells, nevertheless, absorb relatively little common salt, but acenmulate potassium salts together with pliosphates, nitrates, and iodine. Tho same power allows Penicillium ylaucum to llourish in a food-solution saturated with copper sulphate, since only the nutritive substances, and not the poisonous sulphate of copper, are allowed to enter the cells.

Every substance to which the limiting layers of the protoplasm are permeable must ultimately reach the same concentration in the vacnole as in the solution outside the cell. Practically it often enters in much greater amount than this. Thus, for example, only a trace of iodine is present in sea-water, but may be accumulated in such quantities in sea-weeds for these to become a source from which it is commercially obtained. The cell has not only, a selective power, but is also able to store up materials by converting them into insoluble or indiffusible forms.

A local accumulation of sugar, or of other soluble reserve materials in fruits, seeds, bulbs, or tubers, would not be possible without such transformation, for the uncontrolled osmosis would lead to a miform distribution of the diosmosing substances throughout all the eells of the plant. If the easily diffusible substance is changed in certain cells or tissues into one which does not diosmose, the diosmosing substance can flow continnonsly into these cells, and the substance into which it is transformed is stored $u p$ in the cells. This process is particularly well seen in transformation of the osmotically carried glucose into insolnble starch. Since the glucose passing into tubers and seeds is continuously transformed into the in. soluble polysaccharid starch, fresh supplies of glucose pass into these cells, and a large store of carbohydrate can be accumulated.

Gases.-There are no air-filled spaces or canals in either the cell-wall or the protoplasm by means of which gases might pass into the cell-cavity. On this account gases can only be absorbed in so far as they are soluble in the cell-wall or protoplasm, or rather in the water of imbibition which saturates these struetures. The dissolved gases behave like other dissolved substances, and diffuse into the cell.

Passage Outwards of Substances.-Substances pass out from the cell according to the same laws which govern their entrance into the cell.

\section{B. Absolip'tion of Substances in the Multicellular Plant}

\section{Translocation of Substances in the Plant}

\section{Irinciples of the Trunslocution of Substances}

It was assmmerl in the foregoing consideration of the absorption and giving up of substances, that the plant consisted of a single cell surrounded with water. The matter is not so simple when a cell is only in contact with water or with a damp substance on one sile, while the other is in contact with the air. The exchange of 
materials is still more complicated in a higher plant eomposed of many cells, the root of which is embedited in the damp soil, while the leafy shoot is expanded in the air. Not only does the possibility of exchange of substances differ essentially in the subterranean parts from that in the portions above ground, but there are all the internal cells to be considered that do not communicate directly with the environment; these have special conditions governing the exchange of substinces between them. Extensive movements of material must necessarily take place within such a plant. The principles underlying these movements, the causes of the translocation, must first be considered generally.

Transloeation of substances may either be from one cell to another, or it may go on within a limited space in the plant, such as a single cell or tube, e.g. in vessels or in intercellular spaces. The movement from cell to eell ean only take place by diffusion, and the transported substance must either be water, or a solid or gaseous substance dissolved in water. The passage from one cell to another takes piace in exactly the same manner as did diffusion into the cell from the outside. The existence of a difference in concentration between the two cells is a necessary condition; this may be due either to the protoplasm or to the cell-sap. If, for instance, the same substance is present in different degrees of concentration in the sap of two cells, and if the protoplasm is impermeable to the particular substance, water will, as a rule, diffuse from the more concentrated to the less concentrated cell-sap until the sime concentration is attained in the two. We may say that the one cell attracts water osmotically from the other. If, however, the protoplasm is permeable to the particular solution, a diffusion of the salt will also take place from the more coneentrated to the less coneentrated solution. With permeability of the protoplasm a diffusion from cell to cell is also possible when the concentration is the same, but the substances are different; a condition of equilibrium will then be reached when both substances are equally distributed between the cells. If, however, one of the substances cannot pass through the protoplasm, it will remain in the cell in which it was, anct only the other substance will be distributed equally between the two eells.

In the transport from one vaeuole to that of the neighbouring cell, which has just been considered, the substances must first pass into the protoplasm, then into the cell-wall, then again into the protoplasm, and finally into the vacuole. The cell-walls, at all events when thick, appear to offer special diffieulty in the process. On this aceomnt all thickened cell-walls are provided with thin places (pits), and the pit-membranes are traversed by fine protoplasmic threads (plasmodesms, p. 97 ). In the sieve-tubes the pit-membrane is absorbed, and thus coarser strands of protoplasm comeet the one cell with its neighbour (p. 98). Tae investigations of Brown and Escombe 
have shown that a finely perforated septum, if the perforations are a certain distance apart, offers no obstaele to diffusion. $\left({ }^{7}\right)$

Movements of diffusion may also take place within a cell if dissolved substances are not at the same concentration thronghout the cell. Movements of diffusion proceed quite slowly. The rapidity with

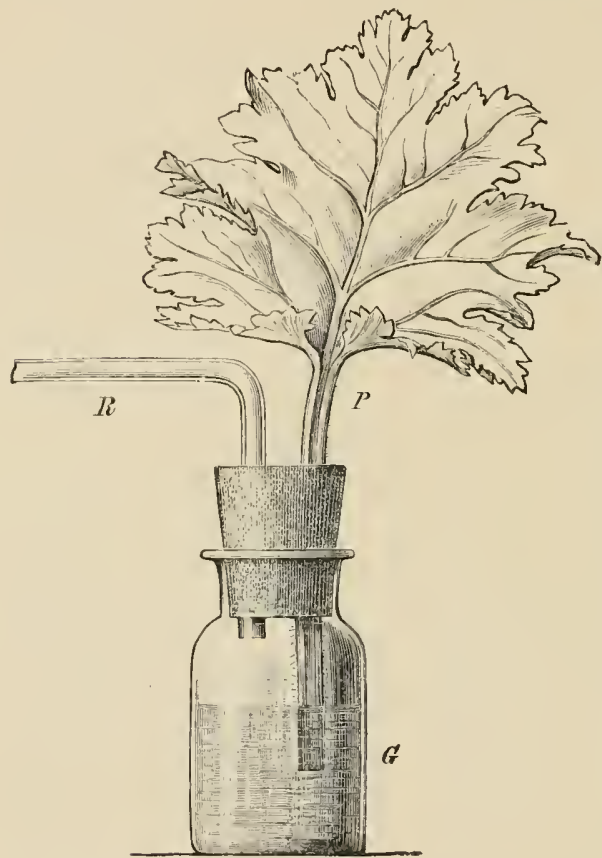

Fis, 178,-Experiment to show the direct communication of the external atmosphere with the internal tissues of plants. The glass tube $R$, and the leaf $P$, are fitted airtight in the bottle $G$; upon withdrawal of the air in the bottle by suction on the tube $R$, the external air penetrates the intercellular spaces of the leaf through the stomata and escapes in the form of small air-bubbles from the cut surface of the leaf-petiole. (From Deruer's Physiol. l'rakt.) a glass tube. That this should take place requires either a pressure from below or a pull from above. A well-known physical law teaches us that the amount of water passing throngh a capillary tube in unit time and with a given pressure is proportional to the fourth power of the radius of the tube, and inversely proportional to its length.

In the intereellular spaces gases are as a rule fomd, but sometimes they contain water and not infrequently secretions. The movements of gases may either be brought about by movements of diffusion due to differences in gaseous contents of the intercellular 
spaces, or to movement in mass due to pressure. Unequal pressure is set up by the warming or cooling of the air in the intercellular spaces, or by movement of the part of the plint leading to changes of shape. So far as movement in mass is concerned, the quantity of air passing through depends on the amount of the pressure and the diameter of the intercellular passages. Since, however, sreat variation takes place in the dimensions of most intercellular spaces from point to point in the plant, no simple law can be stated.

While the vessels form on the whole straight tracks, closed above and below, where their ends ahut on parenchymatous eells, the intercellular spaces form a highly branched system of air-cavities communicating with one another and with the external atmosphere. The communication with the ontside is effected in the first instunce by the stomata, and also by the lenticels and organs of similar function (pp. 113, 160); both diffusion and movements in mass of the gases go on througl these openings.

That the intercellular spaces were in direct communieation with each other, and also with the onter atmosphere, was rendered highly probable from anatomical investigation, and has been positively lemonstrated by physiological experiment. It is, in fact, possible to show that air foreed by moderate pressure into the intercellular passages makes its eseape through the stomata and lenticels; and conversely, air which eould enter only through the stomata and lenticels can be drawn out of the intcrcellular passages. The method of conducting this experiment ean be seen from the adjoining figure (Fig. 178).

Intercellular air-spaces are cxtensively developed in water and marsh plants, and oecupy the greater part of the floating portions of the plant. The submerged portions of water plants unprovided with stomata thus seeure a speeial internal atmosphere of their own, with which their cells maintain an active interchange of gases. This intcrnal atmosphere is in turn replenished by slow diffusion with the gases of the surrounding medium. As regards the rest of their gaseons interehange, these plants are wholly dependent on processes of difnsion, since stomata, ete, are wanting. Plants which possess these organs may also obtain gases by diosmosis if the enticle of their epidermis is permeable to gases.

Significance of the Absorbed Substances.-The materials taken into a plant may be essential, unnecessary, or harmful. In any particular ease this ean only be decided experimentally, for it would lead to erroneous conclusions to assume that all substances constantly present in a plant ar'e necessary. The necessary substances may be distinguished as food-materials.

Without nourishment and without the supply of new formative material neither growth nor development is possible, nor, indeed, without continuous nutrition can a plant maintain itself in any given stage of its development. 'The processes of life are connected with constant changes of the living substance, both transformations and excretions. Even when the supply of food ceases these proeesses continue, so that the death of the organism from starvation must 
ensue if the substances that are used up are not at least replaced in the process of nutrition.

In the following account the absorption of fool-materials will first be dealt with, and then their utilisation. Those substances which in the higher plants are obtained from the soil will be considered in the first place, and then those which are derived from the atmosphere.

\section{The Food-Materials; their Absorption and their Translocution in the Plant}

\section{(a) Water}

Without water there can be no life. THE LIVING PORTIONs of ALL ORGANISHS ARE PERMEATED WITH WATER; it is only when in this condition that their vital processes can be carried on. Protoplasm, the real physical basis of life, is, when living, of a viscous, thinly fluid consistency, and when dried either dies or becomes inactive.

Protoplasm, when in a state of inactivity, as in spores and seeds, can often endure a certain degree of desiccation for a limited time. During such periods its actual vital functions cease, and only renew their activity when water is again supplied.

With the exception of some succulent plants whieh are uninjured by the loss of nine-tenths of their water, plants as a rule have their activity impaired by the loss of water in withering, and are killed by complete desiccation. It is always to be regarded as due to some special provision or exceptional quality when entire plants, or their reproduetive bodies which have been dried, can be again brought to life by a supply of water. Thus, for example, some Algerian species of Isoctes and the Central American Selaginella lepidophylla ean withstand droughts of many months' duration, and on the first rain again burst into life and renew their growth. In like manner many Mosses, Liverworts, Lichens, and Algae growing on bare rocks, tree-trunks, etc., seem able to sustain long seasons of drought without injury. Seeds and spores, after separation from their parent plants, remain productive for a long time; seeds of Nclumbium, which had been kept dry for over oue hundred years, proved capable of germination. A similar vitality was shown by moss spores which had lain in a herbarinm fifty years. The often-repeated assertion coneerning the germination of wheat found with Egyptian mummies (" mummywheat") has, however, been shown to be erroneous. Many seeds lose their power of germination after having been kept dry for only one or a few years; others, even after a few days; and others again cannot endure drying at all. On the other hand, the seeds of some water plants (Eichhomia, etc.) germinate better after being dried for a period. It must not be forgotten that in all these instances a certain amount (about 9-14 per cent) of hygroseopic water is retained by plants even when the air is quite dry. Over the sulphuric acid of the desiccator seeds retain for weeks 6 per cent or more of their weight of water. Even drying at $110^{\circ}$, or the action of absolute alcohol, ean be borne by some spores and seeds.

Apart from permeating and energising the cells, water has other and more varied uses in plant life. It is not only indirectly indispensable for the solution and transport of the products of metabolism, 
but also directly in that its elements, hydrogen and oxygen, are made use of in the formation of organic compounds in plant nutrition. Water is also necessary for the turgidity and consequent rigidity of parenchymatous cells (p. 183); it is of use in the process of the growth of plant cells, which take it up in large quantities, and, by their consequent expansion, enlarge their volume with but little expenditure of organic substance.

\section{Absorption of Water}

Aquatic plants and the lower land plants which are but little differentiated, and also the Mosses, can absorb water by their general surface. The same is true of many aquatic Phanerogams. These (Utricularia, Ceratophyllum, $/ V_{\text {olffi }}$ ), like some Hymenophyllaceae of damp primaval forests, and the epiphytic Tillondsiu usneoides, often possess no roots.

The case of a typical land plant is different; very simple experiments show that it obtains water from the earth by means of its roots. If the soil is kept moist the plant flourishes, while separated branches wilt and ultimately die, even in a moist atmosphere. It is true that the above-ground parts are not completely impermeable to water, but the cuticle renders its entrance so difficult that even submerging the foliage does not suffice to meet the requirements of the plant for water. The root, on the other hand, is specially adapted, both by its external form and by the structure of its superficial layers, for the absorption of water. The fact that in ordinary soils the water exists in a condition of invisible and fine division, firmly held by the surface forces of the particles of the soil, renders necessary a large exposure of surface on the part of the absorbing root. This is obtained on the one hand by the high degree of branching of the root, and on the other by the development of root-hairs on the epidermis. These are developed very close together, and stand straight out all round the surface of the root; they penetrate the narrowest crevices of the soil, and fasten themselves so closely to its smallest particles as to seem actually grown to them (cf. Fig. 179). Although they have the diameter of only a medium-sized cell, and appear to the naked eye as fine, scarcely visible, glistening lines, they often attain a length of several millimetres, and greatly enlarge the absorbing surface of their parent root. According to F. ScHWARz the epidermal surface of the piliferous zone of the roots of Pisum, which has 230 root-hairs to the square millimetre, is thus increased twelvefold. The entrance of water into the plant in a given time would be correspondingly increased.

The root-hairs cover only a comparatively small zone, a short distance above the growing root-tip. Soon after they have attained their greatest length, and have come into the closest contact with the 
particles of the soil, they die off. Above this advancing zone of hairs the epidermis of the root becomes again completely divested of root-

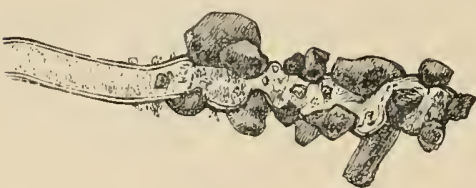

Fit. 179. - Tip of a root-hair with adhering particles of soil. ( $\times$ circa 240.$)$ hairs (Fig. 180). The older parts of roots take no share in the process of absorption. They envelop themselves with cork, increase their conclucting elements by growth in thickness, and serve exclusively for the transfer of the water absorbed by the younger portion of the roots. Even in the young roots the absorption seems principally confined to the regions covered with root-hair's, or, when no root-hairs are developed, to a corresponding zone of the epidermis of the root.

By the intimate union of the youngest roots with the soil, they are able to withdraw the minute quantity of water still adhering to the. particles of earth, even after the soil appears perfectly dry to the sight and touch. There still remains, however, a certain percentage of water, held fast in the soil, which the roots are not able to absorb. Thus, SACHS found that the water left by a Tobacco plant, which it conld not absorb, amounted in cultivated soil to 12 per cent, in loam to 8 per cent, and in coarse sand to $1 \frac{1}{2}$ per cent. Plants may even obtain a certain quantity of water from soil which is frozen hard or from a block of ice.

The alsorptive power of soil for water is due to its capacity to retain water by capillarity, so that it does not drain off. Of the soils investigated by SAr:HS, cultivated soil retained in this way 46 per cent, loam 52 per cent, and sand only 21 per cent of water.

If the development of the root system of a germinating Bean or Oak be observed, it will be found that the growing root of the embryo at onee penetrates the soil and pushes straight downwards. Lateral roots are then given off from the main axis, and, growing either horizontally or diagonally down wards, penetrate the earth in the neighbourhood of the primary root. These lateral secondary roots in turn develop other roots, which radiate in all directions from them, and so occupy and utilise the entire soil at their disposal. The lranching of the root system can proceed in this

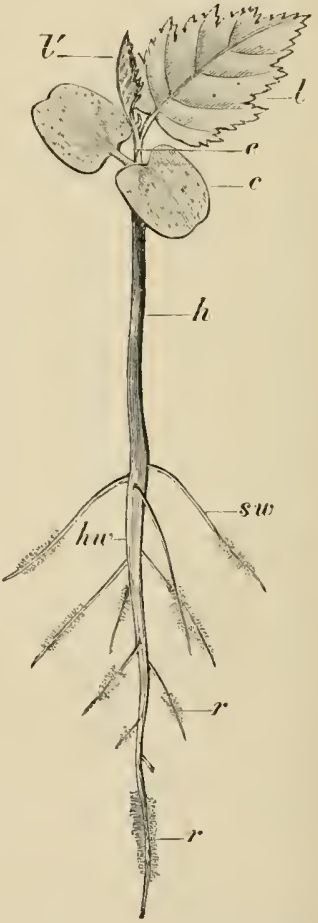

FIr, 1s0.- Seedling of Carpinus Betulus. r, Zone of roothair's near root-tip ; h, hypocotyl; $h w$, main root; sw, lateral roots; $l, l^{\prime}$, leaf; $c$, epicotyl; $c$, cotyleuons. nanner until, within the whole region oceupied by the roots of a large plant, there is not a single cubic centimetre of carth which is not penetrater and ex- 
hausted by then. The system of branches of one root system often has an astonishingly great total length.

All plants do not form a deep-growing tap-root like that of the Oak, Silver Fir, Beet, Lueerne, ete. ; some confine themselves to utilising the superficial layers of the soil by means of a thickly-branched lateral root system (Pine, Cereals). The agriculturist and forester must, accordingly, take into eonsideration the mode of branching and growth of the roots of a plant, just as much as the habit of growth of its aerial portions. Plants whieh make use of different layers of soil may he safely cultivated together in the same soil, and sweceed one another in the same ground. For similar reasons, in setting ont trees along the borders of fields, the deep-rooted Elm should be preferred to the Poplar, whose roots spread out near the surface.

Desert plants send out deeply penetrating roots, which only branch profusely on reaching depths where they find water. When grown in moderately dry soil the growth of the roots of oats is greater than when the soil is damp.

\section{Movement of Water in the Plant}

That a movement of water from the roots to the aerial parts of the plant must take place follows from the faet that water is required, both in the eonstruetion of carbohydrates and in the development of new cells in the growing regions. The plant, however, requires far more water than is needed for its construction, becanse it gives off large quantities of water in the form of vapour, and a less amount in the liquid form from its aerial portions. The former process is known as TRANSPIRATION, the latter as EXUDATION.

\section{Transpiration $\left({ }^{8}\right)$}

The vegetable cell, like every free surface of water or substance swollen with water (e.g. gelatine, mucilage), must give up water to the air so long as the latter is not completely saturated. Under eertain conditions the loss of water from some parts of plants (e.g. roots, submerged portions, shade plants), is very great. Such objeets exposed to dry air, espeeially in the sun, lose so mueh water that they become collapsed, limp, and wilted, and ultimately dried up. The leaves borne on ordinary land plants behave otherwise. At first sight no loss of water is perceptible from them; but they also wilt during a drought, whieh renders absorption of water from the soil difficult. If the supply of water to them is interrupted more suddenly, as by cutting them off, the wilting occurs more speedily. That they as a rule do not wilt when in position on the plant evidently depends on the fact that water is supplied from below in equal amount to that evaporated from above. The giving-off of water can be demonstrated by simple methods.

If a transpiring part of a plant is covered with a bell-jar that has been previously eooled, the water vapour given off from the plant will be deposited in the liquid form on the inside of the bell-jar, just as the aqueons vapour in our breath condenses on a 
cold window pane. Transpiration can be very strikingly demonstrated by the change in colour of cobalt paper ; filter-paper soaked in a solntion of cobalt-chloride has when completely dried a blue colour which changes to red on the presence of water. If a small piece of this cobalt paper is laid on a leaf and protected from the dampness of the atmosphere by a slip of glass, the change in colour to red that commences at once indicates the transpiration; conclusions as to the quantity of water given off may be drawn from the greater or less rapidity of the commencement and progress of the change in colour. It is true that exact information on this point can only be obtained by weighing experiments. These show that the loss of water rapour by a plant is usually so great as to be recorded as a common balance without great difliculty in the course of a quarter of an hour. No general statement can be made as to the amomnt of transpiration from a unit area of transpiring surface, for this depends on many external factors, c.g. temperature, light, supply of water, etc., as well as on the structure of the plant.

The process of transpiration takes place in this way: An epidermal cell exposed to the air will lose some of the imbibition water of its cell-wall by evaporation; this would go on until the cell-wall was dried by the air if a reserve of water were not obtainable from within the cell. This is in fact obtained from the protoplasm, from which the cell-wall no longer fully saturated, withdraws imbibition water, and the protoplasm in turn makes good its loss from the vacuole. Thus the movement of the water affects the interior of the cell, and brings about a concentration of the cell-sap. Thus the conditions are established for the cell to absorb water from an adjoining cell which is not itself transpiring, and the loss of water is thus conducted from the superficial cells where evaporation is taking place into the depths of the tissue. The amount of transpiration primarily depends on the permeability to water of the cell-wall; this is closely connected with the power of the wall to take up water, or the amount of imbibition. If the cell-wall is an ordinary cellulose membrane the amount of transpiration will be large; when the wall is covered with wax or cuticle, or impregnated with cuticular substance, it both absorbs and gives off little, water. Comparative investigations on suitable objects, by means of cobalt paper, show how the transpiration diminishes with the increase in thickness of the cuticular layers until it ultimately becomes practically non-existent. Corky walls behave in the same way as cuticularised layers.

In their outer covering of cork, cuticle, and wax, plants possess a protection from a too rapid loss of water. A pumpkin, with its thick cuticle and onter coating of wax, even after it lias been separated from its parent plant for months, suffers no great loss of water. A potato or an apple is similarly protected by a thin layer of cork from loss of water by evaporation. The green organs of plants, on the other hand, which must be able to get rid of the surplus water in order to secure the concentration of the nutricnt salts and to reduce their temperature, make little use of such protective coverings. On the contrary, they are provided, besides the adaptations to regulate the 
transpiration, with special eontrivances for promoting evaporation. Their great surface extension, by means of which a relatively large number of cells reach the surface, may be specially mentioned.

Transpiration is not, however, limited to the eells which are directly in contact with the atmosphere; an enormous number of internal cells can get rid of water vapour when they abut on an intercellular space. The air-filled intercellular spaces would elearly become after a short time completely saturated with water vapour were they completely closed. Communications exist, however, as we have seen, hetween the atmosphere and the intercellular spaces, the most important being the stomata. The aqueous vapour can escape by these, and thus the condition of saturation of the air in the intercellular spaces is not complete. The water vapour escaping from the stomata is readily recognised by means of cobalt paper. If pieces of this are laid at the same time on the upper and lower surface of a leaf that has stomata only on the lower side, a change of colour will take place in the cobalt paper on this side, while no appreciable giving off of water will be shown for the upper side. It is usual to distinguish stomatal and euticular transpiration, and we may thus say that only the stomatal transpiration is of importance in the typical land plant. In plants inhabiting damp localities the enticular transpiration beeomes considerable. Instead of enticular and stomatal transpiration the expressions external and internal transpiration may be used. Though the openings of the stomata (p. 114) are extremely small (the breadth of the pore being $0.0007 \mathrm{~mm}$. and less) so that neither dust nor water can pass through them into the plant, they are usually present in such enormous numbers (p. 114) and so suitably distributed that their united action compensates for their minuteness. When it is taken into consideration that a mediumsized Cabbage leaf (Brossica oleracea) is provided with about eleven million, and a Sunflower leaf with about thirteen million stomata, it is possible to estimate how greatly evaporation must be promoted by diffusion throngh these fine sieve-like perforations of the epidermis (cf. p. 213).

The stomata also afford plants a means of REGULATING EVAPORATION. The pores, which are the mouths of intereellular spaces, are surrounded by two GUARD-CELLS (p. 113). As the term guard-cell suggests, these cells have the power of elosing the pore. THE CLOSING AND OPENING OF THE STOMATA ARE ACCOMPLISHED BY CHANGES IN THE TURGIDITY OF THE GUARD-CELLS OR OF THE ADJOINING EPIDERMAL CELLS. In consequence of their peculiar wall thickenings, elasticity, and lateral attachment, a change of turgidity affects the size and shape of the guard-eells in such a way that. on diminished turgidity, they beeome flatter and elose the air-passage, while an increase of turgidity has the contrary effect and opens the pore (Fig. 81). In many plants the so-called subsidiary eells (p. 114) participate in various ways and degrees in these processes. 
The stomata are mainly present on the leaves, which are thus to be regarded as organs of transpiration (and of assimilation, p. 216). The amount of water evaporated from the leaf surfaces in the performance of their vital functions is surprising. For instance, a strong Sunflower plant, of about the height of a man, evaporates in a warm day over a litre of water. It has been estimated that an acre of Calbage plants will give off two million litres of water in four months, and an acre of Hops three to four millions. For a Birch tree with about 200,000 leaves and standing perfectly free, TON HöHNEL estimated that 500 litres of water would be lost by evaporation on a hot dry day; on an average the amount would be 60-70 litres. A hectare of Beech wood gires off on the average about 30,000 litres daily. It has been calculated that during the period of vegetation

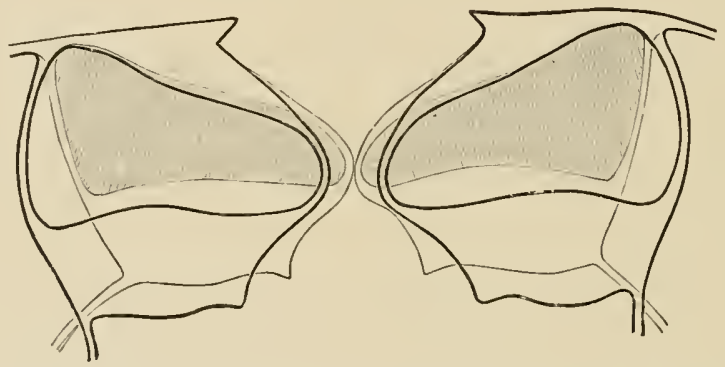

Fic. 181.-Stoma of Helleborus sp. in transverse section. The darker lines slow the shape assumed by the guard-cells when the stoma is open, the lighter lines when the stoma is closed. (After SCHWENDENER.) The cavities of the guard-cells with the stoma closed are sliader, and are distinctly smaller than when the stoma is open.

the Beech requires 75 litres and the Pine only 7 litres for every 100 grammes of leaf substance. According to DiETRICH, for every gramme of dry, solid matter produced, on the average, 250-400 grammes of water are eraporated.

It is cvident from these and similar experiments that more water is evaporated in a given time from some plants than from others. These variations are due to differences in the area of the evaporating surfaces and to structural peculiarities (the number and size of the stomata, presence of a cuticle, cork, or hairy covering, etc.). But even in the same shoot transpiration is not always uniform. This is attributable to the fact that, both from internal and external causes, not only the size of the openings of the stomata varies, but also that transpiration, just as evaporation from a surface of water, is dependent upon external conditions. Heat, as well as the dryness and motion of the air, increases transpiration for purely physical reasons; while light, for physiological reasons, also promotes it. From both physical and physiologieal causes, transpiration is more vigorous during the day than night. l'lants like Impatiens partiftora, which droop on warm days, beeome fresh again at the first aplyroach of night.

Special Contrivances for regulating the Water-supply $\left({ }^{9}\right)$. - Almost all the higher plants possess, in the power to elose their stomata, a speeial means of 
checking transpiration during a temporary insufticiency of the water-supply. In

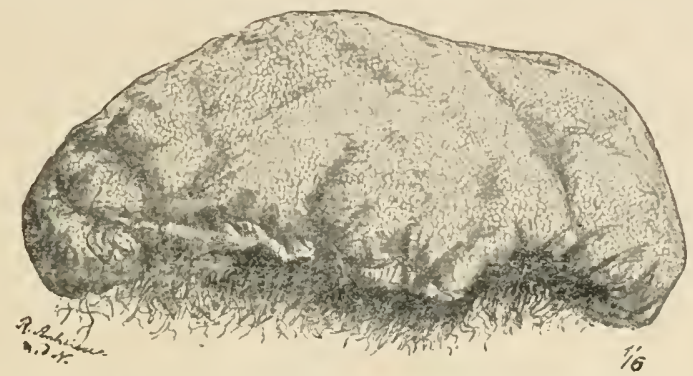

Fic. 152.-Raoulia menmillaria from New Zealand, showing the cushion-like shape of the individual plant. (From Schimper's Plant-Geogruphy.)

districts subject to droughts of weeks' or months' duration, such as deserts, rocky country, and other regions with little rainfall, only such plants can flomrish as are able either to withstand a complete drying up without injury (1. 190), or to exist for a long time on a scanty supply of water (xerophytes). This last case is only rendered possible by the extreme reduction of transpiration, or by the formation of organs in which, in times of a superfluity of water, this nlay be retained for later use.

Protection against excessive transpiration is afforded by the formation of cork or enticular coverings and in exceptional cases coverings of resin, by the reduction in the number and size of the stomata, their ocenrrence in cavities or depressions, and the nore or less complete stopping of the opening by waxy sulstances. The rolling up of the leaves, the stomatiferons surface being on the concave side, as well as the development of thick growths of hair, or of a covering of star-shaped or sealy hairs, and the assumption of a vertical position to avoid the full rays of the sun, are also measures frequently adopited to lessen transpiration. The most efficient protection, however, from too great a loss of water by transpiration is undoubtedly obtained by the reduction of the transpiring surfaces, either through a diminution in the size of the leaves or through their complete disappearance. The same result may be obtained by the erowding of the branches of the plant to form a dense cushion (Fig. 182).

The upright position of the leaves, or the substitution of expanded, perpendieularly directed leaf-stalks for the leaves (Phyllodes), particularly eharacterises the flora of Australia (Fig. 183). A

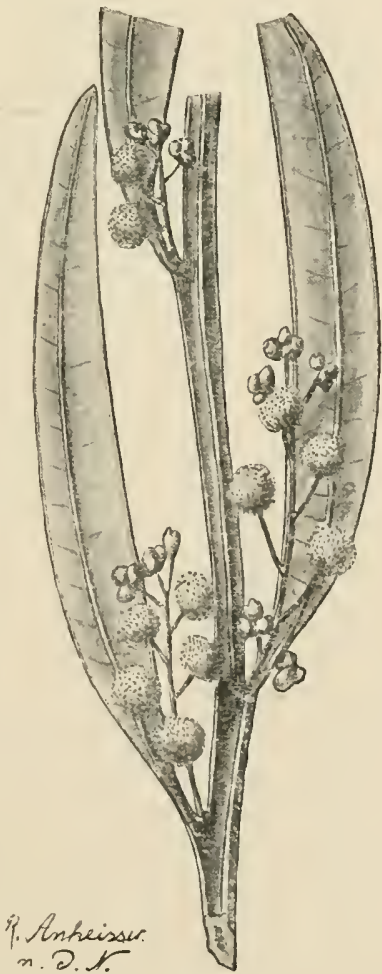

F1c, 183. - Acacia marginata, with vertically placed phyllodes. (From SCHIMPEk's l'lent-(icography.) clothing of hair, on the other hand, protects the leaves of some alpine plants 
(Edelweiss), and of some Sonth African Proteaceae. Some of the Gramineae (Stipa eapillata, Festuca alpestris, Sesleria tenuifolia, S. punetoria, etc.) roll or fold their leaf-blades, in times of dronght, by means of special hinge-like devices, into narrow tubes, the protected inner surface being formed by the side bearing the stomata (Fig. 184). Reduction of the leaves is illustrated by the desert forms of Genista and Sarothamnus, and by the Cypress-like Conifers. The New Zealand Veronica, shown in Fig. 185, closely resembles these in habit. A complete disappearance of the leaf surface takes place in most Cacti, in which also the stems become swollen and converterl into water-reservoirs. A similar development of sueculent swollen stems frequently occurs in the Euphorbiaceae
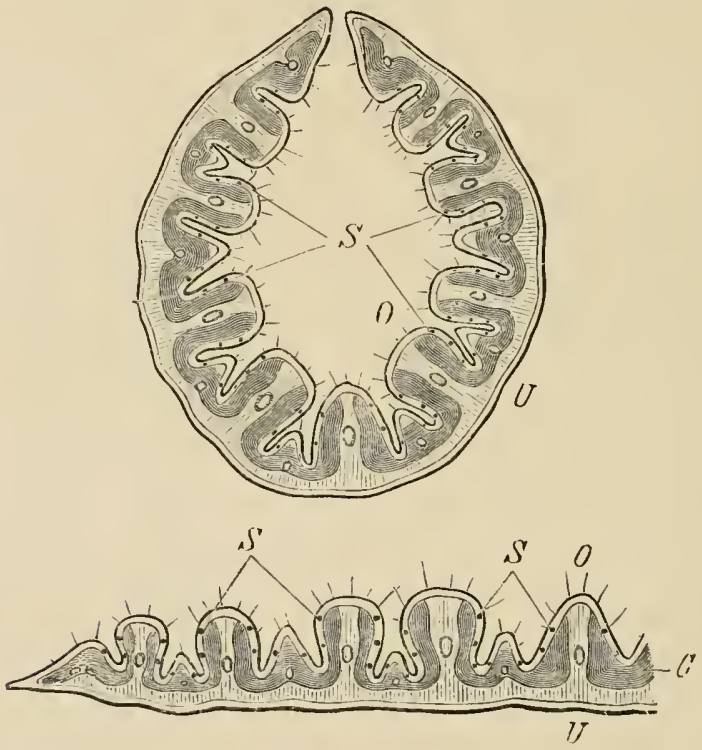

Fici. 18t.-Transierse sections of the leaf of Stipa capillata. The leaf above in the closed state, the half leaf below expanded. $U$, lower surface, without stonata; $O$, upler surface with stomata $(S)$; $C$, ehlorophyllous mesophyll. ( $\times$ 30. After KerNer vox MARiLaUN.)

(Fig. 186), in the Compositae (Kleinia articulata), Aselepiadaceae, and other plant families found in arid regions. It has been estimated that the amount of water evaporated by a Melon-Cactus is reduced by its sncenlent derelopment to $\frac{1}{1} \overline{0}$ of that given off by an equally heavy climbing plant (Aristolochia). Instead of the stem the leaves themselves may become sueculent, as in the Honse-leek and other species of Sempervivum, also in many species of Sedum, Aloe, and Agare. Both stem and leares are equally succulent in many species of Mesembryanthemum. In other plants, the parenehyma of their stem tubers (epiphytic Orehids) or of their thickened roots (Oxalideae) serve as water-reservoirs.

EptpHytes, i.c. plants which live npon others withont obtaining food-materials from them (cf. Parasites, p. 223), belong also to xerophytic plants. Some epiphytes are characterised by their arrangements for water-storage, others by their mode of absorbing water. Many epiphytic Bromeliaceae cateh the rain-water in reservoirs former by their elosely approximated leaves, and then eagerly take it 
up through the scaly hairs which cover the leaf surfaces; these are often termed cistern plants. Again, many epiphytic Orchids and Aroids collect the rain-water in a swollen sheath developed from the epidermis of the acrial root (velamen radicum, p. 120). In the case of other epiphytic Orchids, Aroids, and Ferns (Asplenium Nidus, for instance), the humus and other material, canght in receptacles formed by the leaves or aerial roots, act like a sponge in taking up and retaining water, while the absorptive roots penetrate into these moist, compost-like masses and absorb both water and nutrient substances. Nany sjecies of Frullanic (a Liverwort common on Beech trees) possess, on the other hand, special watersacs on the under surface (Fig. 376). A particularly remarkable contrivance for maintaining a constant supply of water is exhibited by the epiphytic Dischiclia Raflesiana, some of whose leaves form a deej but small-mouthed urn, into which

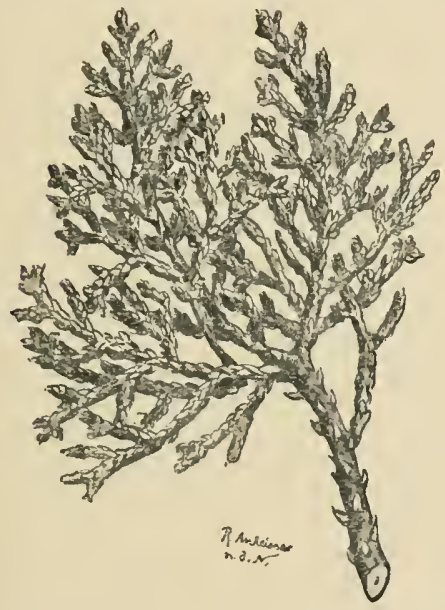

Fif. 185.-Veronica cupressoides, with the luabit of a Cypress, from New Zealand. (From Sc'HıзPER's Plant-Geography.)

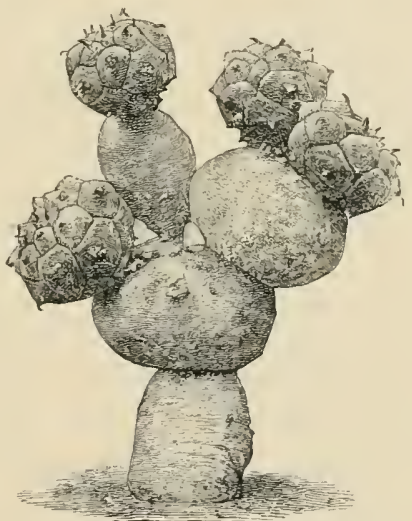

Fif. 18b. - Euphorbia globosa. The re. duced leaves may be seen on the upper globose shouts.

the branching roots grow. It would seem at first sight unnecessary that plants like the Mangrove tree, which stand with their roots entirely in water, should require protection against too rapid transpiration; but, as this tree grows in salt or brackish water, the absorption of water is made more difficult, and, further, it is necessary, as in other halophytes (Fig. 192), to reduce the amount of water absorbed, in order to prevent a too great accumulation of salt in the tissues.

In high latitudes, and also in alpine regions, where the soil remains frozen for months at a time, rendering the absorption of water by the plant difficult, arrangements, similar to those found in desert plants, are present to diminish transpiration.

lu plants living in very damp situations, on the other hand, arrangements to further transpiration are found. Of this nature are the poor development of the cuticle, the placing of the stomata on exposed projections of the epidernis, and the development of epidermal papillac, or of absorbent pigments, to eatch the rays of light. When the leaf is able, either by absorption of heat from without or by the production of heat within itself, to raise its temprature above that of 
its surroundings, transpiration is still possible even in an atmosphere saturated with aqueous vapour. In the process of exudation the plaut has further a means of giving off water even after transpiration has eompletely stopped.

\section{Exudation $\left({ }^{10}\right)$}

The discharge of water in a liquid state by direct exudation is not of so frequent occurrence as its loss by transpiration, but is found under special conditions, viz. when the plant is satmrated with water and the air is saturated with water vapour. Early in the morning, after a warm, damp but rainless night, drops of water may be observed on the tips and margins of the leaves of many of the plants

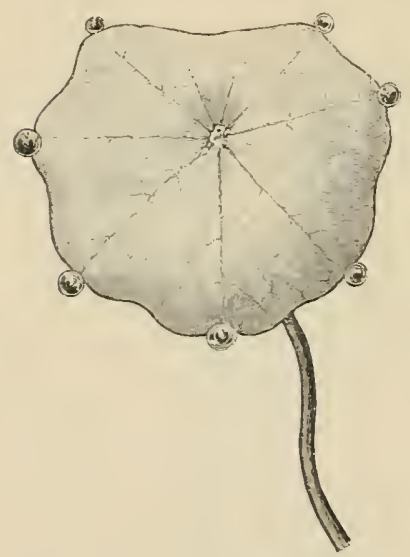

Fif. 187.-Exudation of drojs of water from a leaf ol' Tropacolum majus. of a meadow or garden. These drops gradually increase in size until they finally fall off and are again replaced by smaller drops. These are not dew-drops, although they are often mistaken for them; on the contrary, these drops of water exude from the leaves themselves. They are discharged near the apex of the leares of the Indian Corn, but in the case of Alchemilla from every leaf-tooth, and of the Nasturtium from the ends of the seven main nerves (Fig. 187). The drops disappear as the sun becomes higher and the air warmer and relatively drier, but can be induced artificially if a glass belljar be placed over the plant, or the evaporation in any way diminished. The excretion of drops from the leaves can be brought about by artificially forcing water into cut shoots. The drops are pressed out from special waterstomata (p. 115), or in other cases through the ordinary stomata, or from clefts in the epidermis (apical clefts). Sometimes they are secreted by specially constructed hairs (p. 119), and in Daturu the water is excreted through the walls of the ordinary epidermal cells. All such water-excreting organs are termed HYDATHODEs.

Such exudations of water are particularly apparent on many Aroids, and drops of water may often be seen to fall, within short intervals, from the tips of the large leaves. From the leares of Culocasia nymphacfolia the exuded drops of water are eren discharged a short distance, and 190 drons may fall in a minute from a single leaf, while ${ }_{10}^{1}$ litre may be seeted in the course of a night. Again, in unicellular plants, especially some Iloulds, the coprious exudation of water is very evident. The water in this case is pressed direetly through the cell-walls, and in some cases also, as is the ease in water plants, throngh the easily permeable enticle.

Since the excretion of water in the liquid form can occur when 
the conditions are unfavourable to transpiration, especially in submerged water plants, it may in a sense take the place of transpiration in maintaining the current from the water-absorbing organs. Its physiological significance is not, however, the same as transpiration, since the expressed water always contains salts, and sometimes also organic substances in solution. In fact the quantity of salts in water thus exuded is often so abundant that after evaporation a slight incrustation is formed on the leaves (the lime-scales on the leaves of Saxifrages). In some instances, also, the substances in solution in the water may play the main physiological part in the process as in the case of the secretions of the NECTARIES, of the DIGESTIVE GLANDS of insectivorous plants, and of the viscid STIGMATIC FLUID.

Bleeding $\left({ }^{11}\right)$. - Exudation of water may often be observed after a plant has been wounded; it is regularly seen in trees and shrubs when cut in the spring, and is especially well marked in the Vine. In shrubs cut off a short distance above the ground, the extrusion of water from the wound is readily demonstrated. In this weeping or bleeding of wounds the water comes from the vessels and tracheides, and is pressed out with considerable force (ROOT-PRESSULE).

If a long glass tube be placed on the rootstump and tightly fastened by rubber tubing, the exuded fluid will be forced up the glass tube to a considerable height. How great the force of this pressure is may be shown by attaching to the stump a manometer (Fig. 188). The column of mereury will in some cases be forced to a height of 50 or 60 , and under favourable conditions to $140 \mathrm{~cm}$. or more (in the Birch). These pressures would be sufficient to raise a column of water 6,8 ,

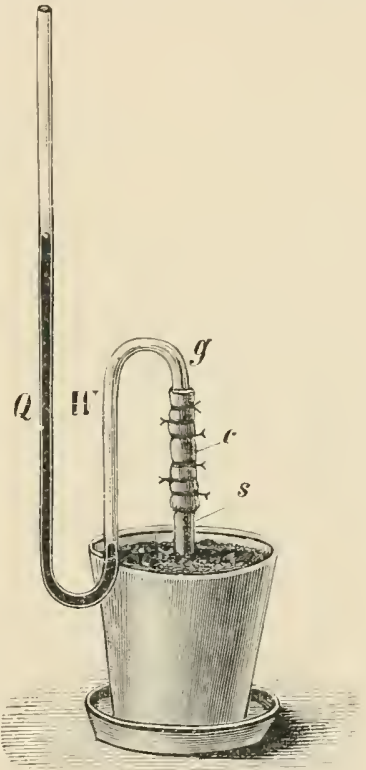

Fic. 18s. - Vigorous exudation of water as the result of root-pressure from a cut stem of Dahlia variatilis. The smoothly cut stem $s$ is joined to the glass tube $g$ by meaus of the rubber tubing $c$. The water $W^{r}$, absorbed by the roots from the soil, is pumped out of the vessels of the stem with a force sufficient to overcome the resistance of the column of mercury $Q$. and 18 metres high. The amount of water extruded is greater when the soil is kept moist and warm ; it continnes under such conditions, according to the kind of plant and its stage of development, some days or even months. The water may amount to a litre or more: up to 1 litre per day in the Vine, 5 litres in the Birch, and 10-15 litres in Palms. In parts of plants that continue bleeding for some time a certain periodicity in the amount is noticeable ; more is extruded by night than by day.

The ontflowing sap often contains, in addition to numerous salts, considerable quantities of organic substances (dissolved albuminous 
matter, asparagin, aeids, and especially carbohydrates). The amount of saccharine matter in the sap of some plants is so great that sugar may be profitably derived from it. The sap of the North American sugar maple, for example, contains $\frac{1}{3}$ per cent of sugar, and a single tree will yield 2-3 kilos. The sap of certain plants is also fermented and used as an intoxicating drink (birch wine, palm wine, pulque, a Mexiean beverage made from the sap of Agave, etc.). One inflorescence of Agave will yield 1000 litres of sap in from four to five months.

Causes of the Excretion of Water $\left({ }^{12}\right)$. - The excretion of drops of water from the intact plants is in part due to an active excretion of water from superficial cells. In other cases water is forced into the vessels, and finds a way out at the points of least resistance. In the phenomenon of bleeding, also, water is forced from parenchymatous cells into the cavities of the vessels; although this process takes place especially often in roots, it is not always absent in the cases of stems and leaves. Water may also be excreted into the cavities of intercellular spaces, e.g. in the hollow internodes and leaf-stalks of Cucurbita ; in this case, on need arising, the water may again be absorhed. The phenomenon of root-pressure may be determined or increased by the stimulus of wounding or by the processes of healing, as well as by an excess of water. This was shown by MOLISCH for the inflorescences of Palms, and in borings made in our native trees. The amount of fluid excreted from the callus tissue in the latter case was small, but was forced out even under a high pressure (up to 9 atmospheres) $\left({ }^{13}\right)$.

Thus, when fully analysed, all the phenomena described show a one-sided excretion of fluid from living cells. That this does not always result from the same cause is indicated by what was stated above, since the fluid is sometimes nearly pure water, at other times more or less concentrated sap. When the fluid contains an appreciable amount of dissolved substances, the protoplasm at the place of its excretion must have been permeable to these substances. At this point of the cell the same osmotic pressure cannot have been produced as at a spot when the protoplasm was impermeable. The resnlt is a one-sided extrusion of fluid, which may take place with a force as great as the difference between the osmotic pressures on the side with impermeable and that with permeable protoplasm. When the excretion is more highly concentrated, as for instance in nectaries, other factors come into play. The substances outside the cell (sugar), whether they have been excreted from the cell or have arisen in the cell-wall, must exert an osmotic action and withdraw water from the cell. When, however, as in the Vine, the excreted sap is almost or quite pure water, its extrusion only becomes possible by the maintenance ol a difference of concentration of the cell-sap at the different sides of the cell.

\section{Conduction of Water $\left({ }^{14}\right)$}

The water, which is partly given off in the form of vapour, especially from the leaves, and in part exudes in the fluid form from hydathodes and wounds, has, as a rule, been absorbed by the roots. It has thus to traverse a path which, even in annual plants, may amount to some metres, and in the giants of the regetable kingdom may be much nore than $100 \mathrm{~m}$.; the stems of Eucalyptus amygdalina 
are $100 \mathrm{~m}$, those of Sequoie gigunter 77-142 m. in height. Osmotic passage from cell to eell would lring about the movement of this water far too slowly to cover the loss. The movement of water for this purpose, or, as it is ealled, the TRANSPIRATION STREAM, practieally is confined to the woody portion of the vascular bundles, e.g. the wood of trees. This is shown by a classical experiment (15) represented in Fig. 189. At $Z$ in the branch $b$ all the tissues external to the slender column of wood have been removed. Since the leaves of this branch remain as fresh as those of the branch $c$, it is evident that the transpiration current must pass through the wood and not through the cortical tissues. On the other hand, when a short length of the wood is removed from a stem without at the same time unduly destroying the continuity of the bark, the leaves above the point of removal will droop as quickly as in a twig cut off from the stem. When a branch is cut off and the cut surface is placed in a solution of gelatine, which penetrates for some distance into the vessels and can then be allowed to solidify, the wood will be found to have lost its power of conducting water. This shows that the cavities of the vessels are essential for water conduction. In the living plant, however, the vessels and tracheides always contain air in addition to water, at least when transpiration is active.

In water plants and suceulents,

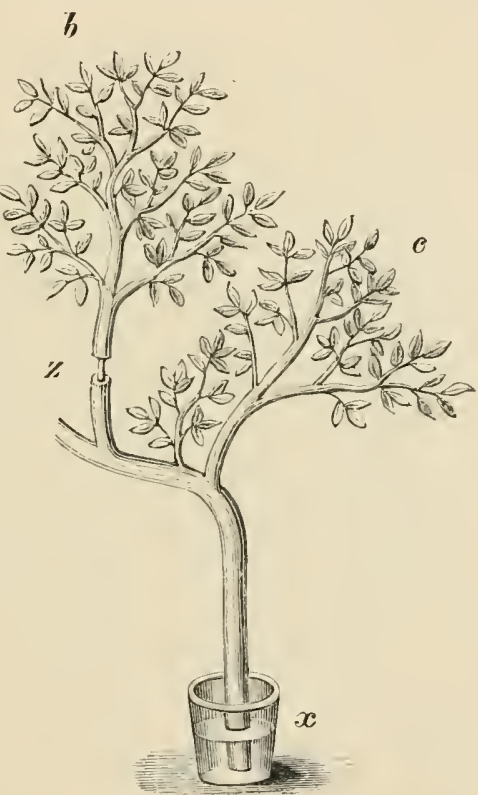

FIr. 189.-HaLEs' experiment to show the ascent of the sap in the wood. Although the cortex has been entirely removed at $z$, and the wood alone left, the leaves of the branch $b$ remain as fresh as those on the uninjured branch $c$; $x$, vessel containing water. Facsimile of the illustration in HALEs' Veyetable Stutics, $172 \%$. in which little or no transpiration takes place, the xylem is correspondingly feebly developed. On the other hand the transpiring leaf-blades have an extraordinarily rich supply of vascular bundles; these anastomose freely, so that any particular point is sure to obtain sufficient water. The illustration (Fig. 190) gives some idea of this irrigation system of a leafblade, but, since the finest bundles are only visible with the help of the microscope and are not represented, the system is even more complex. The conducting tracts in the stem leading to the leaves form, especially in trees which grow in thickness, a wonderfully effective 
conducting system. All the wood of a thickened stem does not serve this purpose; water conduction is limited to the more recently developed annual rings. When a heart-wood is formed this takes absolutely no part in the process.

There is still uncertainty as to the forces which give rise to the transpiration stream. It is natural to think of a pressure acting from

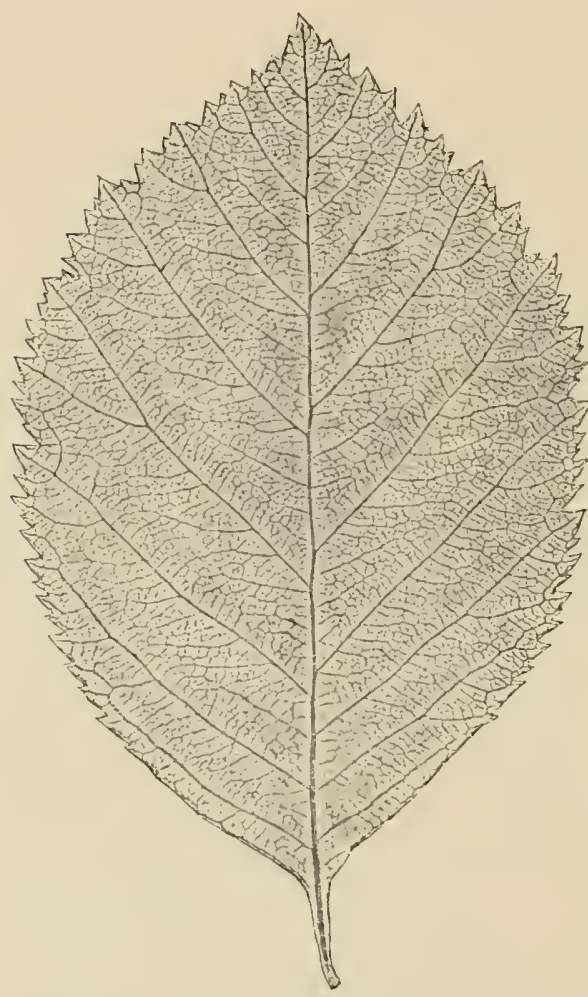

Fiti. 190. - Course of the vascular bundles (venation) in a leaf of Crutuegus. (From a photograph ; natural size.) below, or a suction from above, and to regard the former as due to root-pressure, the latter to the process of transpiration. There are, however, a number of reasons against ascribing the movement of the water to root-pressure, and whether the suction force exerted by transpiration is sufficient to continuously raise water to the summit of a high tree appears doubtful. No generally accepted solution of the much-discussed problem of the ascent of water has yet been attained.

The following points have to be consirlered as regards the root-pressure. In many plants the root-pressure actually observed is very slight or absent. Even in plants with a powerfin root-pressure the amount of water thus supplied in a given time is considerably less than that lost in transpiration. With somewhat more active transpiration, therefore, the rootpressure is not manifested in the way described above. When an actively transpiring plant is ent across above the root, no water is at first forced from the stock; but, on the other hand, if water is supplied to it the ent surface absorbs it greedily. Only after it is fully saturated does the foreing-out of water commence. In nature root-pressure thus ouly comes into play when transpiration is greatly lessened, for instance at night when the air is damp and cool. The most favourable conditions for this plienomenon occur in spring wlien, on the one hand, the wood is richest in water, and, on the otlier, the transpiring foliage is not fully developed. On wounling the xylem the sap' then oozes in drops ont of the vessels and tracheides.

That transpiration induces a suction from cell to eell has been pointed ont 
above, and it is clear that this suction will be continued from the parenchymatous cells into the ressels. This suction force ean be readily demonstrated.

A ent shoot plaeed with its lower end in water shows by remaining fresh that it is able to raise the water to its npuernost twigs. This does not fully exhibit the amount of suction foree which the shoot can exert, for if it is eonnected with a long tube filled with water it ean support a water column of 2 metres or more in height. If the end of the tube is dipped into mercury even this heavy fluid will be litted to a considerable height. Strong and otherwise minjured branehes of Conifers are able to raise the mercury to the height of the barometrie column and even higher without showing signs of wilting. The connection between the end of the shoot and the glass tube must of comrse be air-tight. Necessary conditions for such a suetion are on the one hand an air-tight closing of the water-conducting tracts such as is actually found in the plant, and on the other hand a consiclerable cohesive power of the fluid to be raised, which is also found to exist in practice. The conception is thus reached of a pull exerted by transpiration being condueted, owing to the cohesion of the water, to the tips of the roots of a plant. For this, however, the vessels wonld require to be eontinuonsly filled with water, while, in practice, columns formed alternately of air and water are found. If this held for all the water-eonducting traets it would hardly be possible to consider the "cohesion theory" (16) further. When a pull took place the air bubbles would expand, and in praetice air under diminished pressure is found in the vessels of actively transpiring branehes $\left({ }^{17}\right)$. Wheu sueh vessels are cut aeross under merenry, this is forced. for a considerable distance into the eut vessels by the force of atmospheric pressure.

Recent work has supported the eonclusion that the living elements always present in the neighbourhood of the vessels and tracheides may play a part in the raising of the water. It is not possible to form a clear conception, however, of the part the living cells play in the process.

\section{(b) The Nutrient Salts}

The mineral substances which form the ash, were at first regarded as accidental impurities of the organic substance of the plant. But every attempt to obtain a plant free from mineral substances shows that they form essential constituents of the substance.

It was first asserted by BERTHOLLET (1803), and afterwards emphasised by KARL SPRENGEL, that the mineral salts contained in plants were essential coustituents of plant food. Conclusive proof of this important fact was first obtained in 1842 by the investigations of WiegmanN and PoLstorfF $\left({ }^{18}\right)$.

This conclusion can be reached by two methods, which at the same time show whether all or only certain of the substances in the ash are necessary. The first method is to cultivate the plant in an artificial soil composed of insoluble substances such as platinum, pure carbon, pure quartz, with which the substances to be investigated can be mixed. The second method, that of WATER-CULTURE $\left({ }^{19}\right)$, is more convenient. Many plants are able to develop their root-system in water instead of in the earth. It is thus possible to add to the water the elements found in the ash in various combinations, and so 
to ascertain which elements are necessary and which superfluons. As Fig. 191, I, shows, the plant (Buckwheat) succeeds well in such a food solution if of suitable composition; it can form roots, shoots, flowers, and fruits, and increase its dry weight a hundred-fold or a thousand-fold, just as if it were growing in the soil. In distilled water on the other hand, while the plant

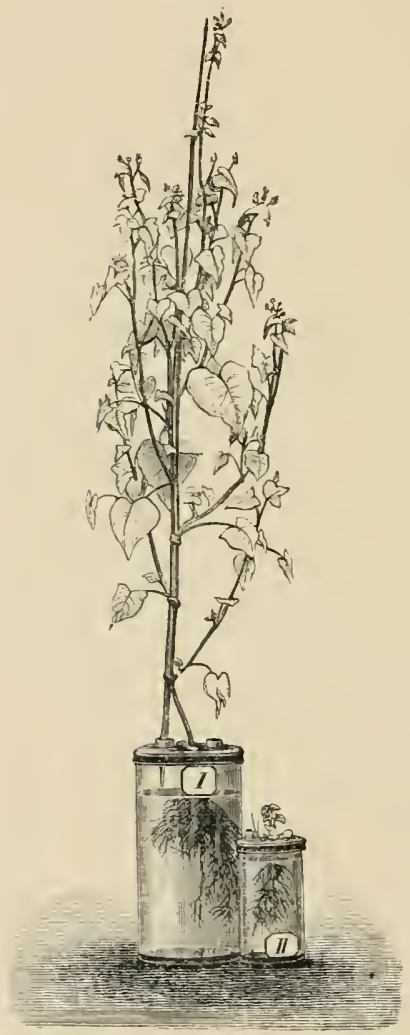

Fig. 191.-Water-cultures of Fagopyrum esculentum. I, In nutrient solution containing potassium; $I I$, in nutrient solution without potassium. Plants reduced to same scale. (After NobBE.) begins to grow normally, the growth soon ceases entirely, and only a very dwarfed plant is produced. The composition of the food solution (Sachs' solution) is: water, 1000 ; potassium nitrate, 1 ; calcium sulphate, 0.5 ; magnesium sulphate, 0.5 ; calcium phosphate, 0.5 ; iron, a trace.

From such water-cultures it results that the typical land plant succeeds satisfactorily if supplied with the elements $\mathrm{K}, \mathrm{Ca}, \mathrm{Mg}, \mathrm{Fe}$, and $\mathrm{H}, \mathrm{O}, \mathrm{S}, \mathrm{P}, \mathrm{N}$, if in addition $\mathrm{O}$ and $\mathrm{C}$ (the latter as carbondioxide) are available in the atmosphere. There are thus in all 10 elements which must be regarded as indispensable food-materials. Of these the seven which remain after excluding $\mathrm{H}, \mathrm{O}$, and $\mathrm{C}$ concern us here since the plant obtains them as nutrient salts from the soil or water. Six of these seven are found in the ash, while the nitrogen escapes on combustion in the form of rolatile compounds. That these seven elements are completely indispensable is shown by the fact that if a single one is wanting its loss cannot be made good by an excess of the others, or by the presence of a related element.

Thus, for example, potassimm cannot, as a rule, be replaced by sodium, lithium, or rubidium. Lower organisms (Algae, Bacteria, Fungi) are able to do withont $\mathrm{Ca}\left({ }^{20}\right)$. The absence of a single necessary element is shown

either by the feeble and dwarfed development of the plant (Fig. 191, II, absence of potassium) or by characteristic changes in the plant. The best known of these is the effect of absence of iron, in which ease the plant does not hecome green (ehlorosis) ( $\left.{ }^{21}\right)$.

So long as the necessary nutritive substances are provided, the form in which they are offered to the plants, as well as the proportionate strength of the nutrient solution (if not too concentrated), may vary. l'lants have the power to take up 
these snbstances in very different combinations, and are able to absorb them in other proportions than those in which they occur in the soil. In eoncentrated nutrient solutions the absorption of water is increased; conversely, in very dilute solutions it is the salts that are chiefly taken up.

More accurate consideration shows that it is not correct to speak of definite elements which are indispensable to the plant. Just as a mixture of the elements $\mathrm{H}$ and $\mathrm{O}$ is not a substitute for water, it is not sufficient to supply the plant with the elements contained in the nutrient salts either as elements or in any of their combinations. Thus metallic potassium or pure sulphur are of no use. The plant requires particular salts or, since these in part dissociate in water, particular ions. Necessary kations are $\mathrm{K}^{+}, \mathrm{Ca}^{++}, \mathrm{Mg}^{++}$, while $\mathrm{So}_{4}{ }^{-}, \mathrm{H}_{2} \mathrm{Po}_{4}{ }^{-}$and $\mathrm{No}_{3}{ }^{-}$are necessary anions. While phosphorous and sulphur can only be utilised in these combinations, the nitrogen cau also be obtained, although not always so usefully in the form of the kation $\mathrm{NH}_{4}{ }^{+}$.

The method of water-culture has not only shown the necessity for certain salts, but also that many substances which the plant usually absorbs can be done without.

This is true, for instance, of sodur, which, in combination with cHLorine, actually pre. dominates in some plants, and occasions the characteristic development of many of the succulent salt-plants (halophytes) (Fig. 192); and also of silicon, which, as siliea, is so abundantly deposited in the cell-walls of many plants-Equisetaceae, Grasses, Sedges (in the ash of Wheat-straw 70 per cent, and of Equisetaceae 70-97 per cent)-that, after combustion of their organic substances, it

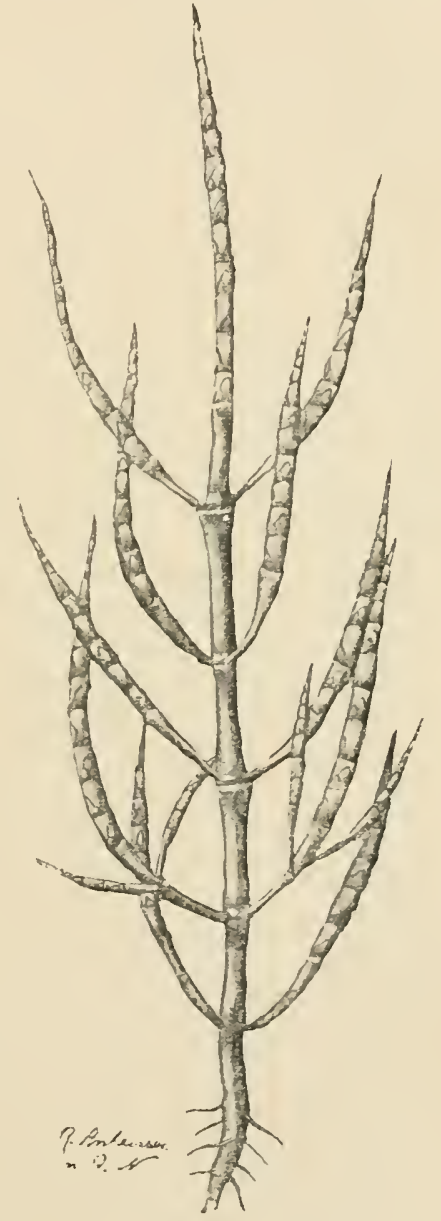

Fug. 192.-Salicornia herbacea, a characteristic halophyte. (From ScHimper's Plant-Geography.) remains as a firm siliceous skeleton, preserving the struetmre of the cell-walls. The hardness and firmuess of the cell-walls are greatly increased by these siliceous deposits; they themselves have about the degree of hardness 2, but the silicified epidermis of Equisetum has the hardness 4 (=Flnorspar), and that of the fruits of Coix $\tau$ (=Quartz). Some of the Equisetaceae are even nsed for polishing and scouring. The silicified ccll-walls of Diatoms occur as fossils, and form deposits of silickous EAnTil (Kieselguhr) in some 
geological formations; silicon is indispensable in the case of the Diatomaceae (22). Aluminum, although like silica everywhere present in the soil, is only in exceptional instanees taken up by plants (Lycopodiaceae, Lichens, Vitaceae, Legnminosae). Some species of Lycopodium contain a suffieient quantity of acetate of aluminium to render the sap useful as a mordant. The same salt is found also in Crapes. Alumininm is stored nu in masses in the cells of the leaves of American speeies of Symplocos $\left.{ }^{23}\right)$. On the other hand, although scarcely a trace of iodine ean be detected by an analysis of sea-water, it is found, nevertheless, in large quantities in seaweeds, so much so that at one time they formed the prineipal source of our supplies of this substance.

The substances which, as culture experiments show, are not indispensable for the life of the plant are, however, of use in so far as they can replace for some purposes (such as the neutralisation of free acids, etc.) essential elements of plant food. The latter are thus available for the special purposes for which they are indispensable. Thus K can be partially replaced by $\mathrm{Na}$, and Mg by Ca.

Certain other substances, althongh not indispensable, are of use in the plant economy and of advantage to growth. Thus, for example, Buckwheat flomrishes better when supplied with a chloride, and the presenee of silica is advantageous as contributing to the rigidity of the tissues. It lias also been discovered that by the presence of certain substances, in themselves of no mutritive value, the absorption of actual nutritive matter is inereased. In minimal doses poisonons substances often have a favourable effect; they lead to better utilisation of the substances at the disposal of the plant. Their effect is, however, often injurious even when diluted so as to be imperceptible to ehemical tests ; thus by such "oligo-dynamic" influence, copper sulphate, even in the proportions of $1: 25,000,000$, has a fatal effect on Spirogyra, and on Peas in a water-culture $\left({ }^{2 \dagger}\right)$.

Under natural conditions some plants absorb the nutrient salts from water as do the plants in a water-culture experiment. This is the ease in many water plants in which the whole external surface is of use in absorption. Since the salts only exist in very dilute solution in the water, the need of an extended surface for this purpose is readily understood; this in part explains the frequent occurrence of finely divided leaves in water plants. The salts dissolved in the water are not, however, sufficient for all aquatic plants; many absorb substanees from the soil underlying the water by means of their roots, and do not succeed when deprived of roots $\left({ }^{25}\right)$.

As a rule in the higher plants the salts are absorbed from the soil. The salts contained in the nutrient solution described above, or similar compounds, are eonstantly present in the water of the soil; some of them, however, in sueh small amount as only to suffice for the growth of plants for a short period. Other somrees of supply of the food-salts must exist when such growth continues. In fact, the amount of salts dissolved in the soil-water is no measure of the fertility of the soil. The soil always contains food-salts, partly in an absorbed condition, and partly in mineral form which the plant has to render aceessible. This is effected mainly by the excretion of carbonic acid from the roothairs. Many sulsstanees are much more realily soluble in water containing carbonic acid than in pure water. In spite of repeated asser- 
tions to the contrary, it is still probable that, in addition to carbonic acid, other acids or acid salts may be excreted by the root; this would render possible further absorption of mineral substances which are difficult to dissolve. Plants with marked exeretion of acids (Maize, Rye, Oats) make less demand on an already opened up good soil than do those with weaker (Wheat, Barley) or scareely noticeable exeretion of aeid (Meadow Grasses). The most marked power of decomposing mineral substances is shown by certain Lichens which live upon granite and are able to dissolve the mica $\left({ }^{26}\right)$. The solution of solid rock by the plant may most readily be shown by allowing the roots to grow against smooth polished slabs of marble; the course of the roots is indicated by the etching of the surface.

Some soils, especially those containing much clay, lime, or humus, have the property of retaining potassium and ammoninm salts, and in less degree salts of caleium and magnesium, as well as phosphates; these substances are not easily washed out of the soil but can be obtained by plants. This is spoken of as the power of absorption of the soil for the substances in question. This does not hold for all salts; thus, for instance, sulphates and nitrates are not absorbed. Absorption is completely wanting in a pure sandy soil. It is impossible to enter here into the canses of the absorption in varions cases.

Since the plant thus continnes to absorb nutrient salts from the soil, this must become poorer in the particular substances unless the loss is repaired in some way. In nature this results from the fallen and dead parts of plants returning to the soil, and the salts contained in them becoming available for further life. In agricultural praetice, however, a large proportion of the vegetation is removed in the erop, and the salts it contains are thus lost to the ground; at the most a fraction may be returned to the soil in the dung of grazing animals. The effeet of manure in inereasing growth, which has for ages been known to practical men, depends at least in part on the salts contained in it. Since, however, the amount of salts thus returned to the soil is insuffieient to meet the loss, artificial manuring is required in agricultural practice $\left({ }^{27}\right)$. The first place among manures must be given to those which contain nitrogen, potassium, and phosphorie acid. Nitrogenous substances which are used besides guano (which also eontains phosphorie acid) are Chili saltpetre, ammonium sulphate, calcium cyanamide, and calcium nitrate; the two last have recently been artificially prepared from atmospheric nitrogen. Potassium is present in the Stassfurt waste salts, of which kainite is the most important since it also contains $\mathrm{IgSO}_{4}$. As an important souree of phosphorus, the so-ealled Thomas slag may be mentioned; this substance is formed in working ores containing phosphorus, and consists of triple phosphate of ealcium. It can only be utilised by plants when in a state of very fine subdivision, as what is known as "Thomas-meal."

From what has been said it might be concluded that a soil eapable of supporting one kind of plant must be able to support any 
other species. Plant-geography $\left({ }^{28}\right)$, however, shows that the composition of the soil exerts a great influence on the distribution of plants. This depends, on the one hand, on the fact that different plants make different demands on the amount and solubility of the essential foodmaterials, and, on the other, upon the presenee in the soil of sulstanees other than the indispensable salts; the intinence of these non-essential substances is different upon different species of plants. For example, $\mathrm{CaCo}_{3}$ has a poisonous effect on some plants, and $\mathrm{NaCl}$ upon others, while other plants ean endure large doses of these substanees.

The effect of the soil upon the distribution of plants does not depend merely upon its ehemieal nature. The physical properties of soils play an important rôle. Further, a plant may be absent from a locality, which, so far as the nature of the soil is concerned, wonld be suitable, beeanse its seeds have never been bronght to the spot.

Since the plant always obtains nutrient salts from the soil in very dilute solution, the epidermal eells which absorb this will also contain only small quantities of the salts. The salts must, however, reach all jarts of the plant, and especially the foliage leaves. For this purpose diffusion would be too slow a process, and we therefore find that the nutrient salts are conveyed in the plant by the transpiration current. It is thus not merely water but a very dilute food-solution that is conducted by the vasenlar bundles, and the use of transpiration is, in the first place, to concentrate this nutrient solution and, in the second, to bring it quiekly to the proper parts of the plant. Apart from this result it wonld he difficult to understand the process of transpiration, and the plant would eertainly have found means of limiting it. When it is actually checked (cf. p. 197), we have to do with plants which grow slowly on aecount of the poor supply of salts, and also it is true of carbonie acid.

Besides water and salts dissolved gases are also taken up by the root; as a rule only oxygen is of importance. The main source of the gases absorbed by the plant is, however, the atmosphere.

When the substratum on which a plant grows contains, in addition to water and food-salts, other substances, e.g. dissolved organic substances, these may be absorbed and transported in the same way. Water-cultures show, however, that the typieal green plant at least is not dependent upon such substances. It is otherwise with fungi and other plants which resemble the fungi in their metabolism.

\section{(c) Gases}

While water and salts are, as has been seen, as a rule absorbed from the soil, the air contains sulostances which are necessary to the successful existence of the plant, and must be termed food-materials. 'These are earbon dioxide and oxygen. They are, as a rule, obtained from the atmospinere. Only submerged water plints ol,tain them from the 
water, in which case they are alosorbed in the same way as other dissolved substances.

Oxygen. - When a plant is deprived of oxygen, either by exbausting the air or by cultivation in an atmosphere of carbon dioxide, nitrogen or hydrogen growth usually ceases at once. Since oxygen is also essential to the human organism, this fact does not seem surprising (cf. also p. 241).

Carbon Dioxide. - It appears at first sight much less plausible to the laity that carbon dioxide should be indispensable to the plant, and yet this is the case. While no source of carbon is offered to the plant in a water-culture, it grows in the food solution, and accumulates carbon in the organic compounds of which it consists; the only possible conclusion is that the plant has utilised the carbon dioxide of the atmosphere. Carbon dioxicle is present in ordinary air in the proportion of 0.03 per cent. If such air is passed over a green plant exposed to bright light, it can be showil that the carbon dioxide diminishes in amount or disappeurs. Colourless parts of the plant, or organisms like the fungi which are not green, behave differently ; they absorb no carbon dioxide. If a green plant is placed in a bell-jar and supplied with air freed from carloon dioxide, its growth soon stops, and ultimately other injurious effects may be manifested; in any case increase in thy weight ceases completely. Carbon dioxide is thus an indispensable food-material, and is evidently the source from which the plant obtains its carbon. The small proportion of this gas present in the atmosphere is quite sufficient for the uutrition of plants (p. 217). A supply of organic compounds of carbon in the soil or culture solution does not enable a plant to dispense with the carbon dioxide of the air ; in any case $\mathrm{CO}_{2}$ is the best source of carbon for the green plant which we are at present considering. Neither is it sufficient to supply such a plant with carbonic acid in the soil or culture solution; it requires to be supplied directly to the leaves.

In any atiempt to distinguish the relative importance of substances utilised in plant nutrition, carbon undoubtedly ranks first. Every organic substance contains carbon, and there is no other element which could supply or take part in the formation of so many or such a variety of substances, in living organisms as in the chemical laboratory. Organic chemistry, in short, is merely the chemistry of carbon compounds. Living beings which are composed of organic substances owe the possibility of their existence prinarily to the properties of carbon.

Other Gases.-Oxygen and carbon dioxide are the only gases which are necessary to the plant. For most plants the nitrogen of the atmosphere is of no ise.

Absorption of Gases.-Carbon dioxide and oxygen in part enter the epidermal cells, and partly pass by way of the stomatil into the intercellular spaces, from which they reach the more internal tissucs. 
Gases diffuse through cell-walls more easily the richer in water these are. The ordinary cell-wall, when in a dry condition, hardly allows gases to diffuse through it; in nature, however, the cell-wall is always more or less saturated with water. The cuticle, on the other hand, has very little power of imbibing water, and places considerable difficulty in the way of any diosmotic passage of gases; it is not, however, completely impermeable.

Practically the gaseous diffusion takes place rather through the substances with which the cell-wall is impregnated than through the

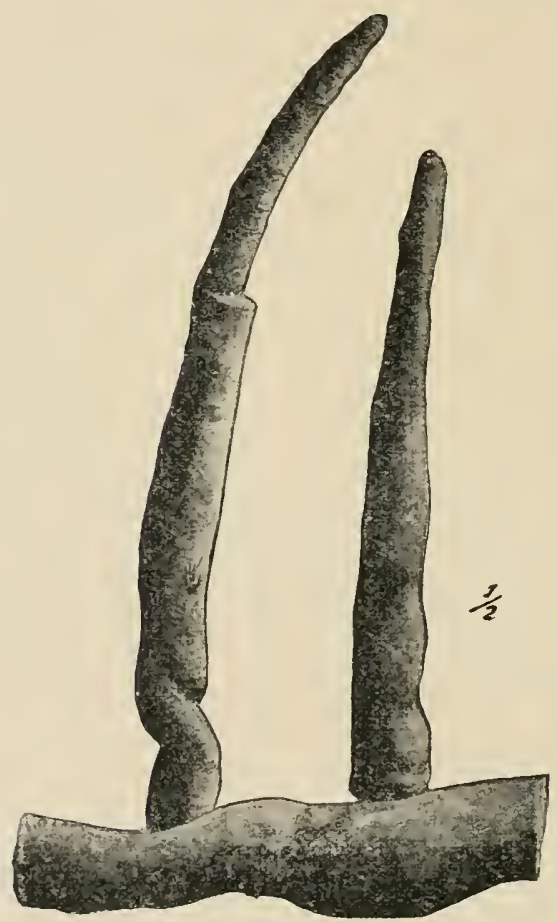

Fig. 193.-Respiratory root of Avicennia, one of the

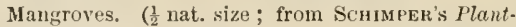
Geography.) substance of the wall itself. Since carbon dioxide is much more readily soluble in water than is oxygen, it will be evident that it will pass more rapidly through a cell-wall saturated with water than oxygen will. In all probability this holds for the cuticle as well. Since, however, the partial pressure of the oxygen in the air is relatively considerable, while that of carbon dioxide is very slight, oxygen can pass in sufficient quantity through the cuticle but not carbon dioxide; on this account we find that all organs which only require to absorb oxygen are unprovided with stomata, while organs which absorb carbon dioxide always have stomata.

In the soil as well as in the air, plants, as a rule, find so mucl oxygen that this gas is able to pass through the cuticle. Organs which live in swampy soil which is poor in oxygen forman exception to this. In marsh. plants, which stand partly in the air,

the large intercellular spaces form connecting canals through which the atmospheric oxygen without being completely used np can reach the organs growing deep in the swampy soil and cut off from other supplies of oxygen. In some cases the need of a supply of oxygen to such roots is met by specialised roots (PNEuMatophores) which project vertically from the inuddy soil (Fig. 193), and absorb oxygen from the air either through their cuticle or by special openings.

The efficiency of the stomata in gaseous exchange varies with the width to which the pores are open. The closure of the jores of the stomata, which may be 
brought about in maintaining a sufficient sulply of water, not only arrests transpiration, but also prevents the entranee of $\mathrm{CO}_{2}$ into the plant.

In spite of their enornous number, the total area of the stomatal apertures is only about 1 per cent or little more of the whole surfaee area, for eaeh individual opening is very small (about $0.0001 \mathrm{sq}$. $1 \mathrm{~mm}$. in Helianthus). Brown and Escombe have, however, shown that the minuteness of the openings, eombined with the peculiar distribution of the stomata, results in a greatly accelerated rate of diffusion. Diffusion through a number of fine apertures is much greater than throngh a single aperture of the same total area. When the small openings are placed about ten times their diameter apart, the diffusion is nearly as rapid as when no separating wall is present. The distribution of the stomata in the epidermis very nearly meets these requirements. For example, a square metre of the surface of a Catalpa leaf absorbs about two-tlirds the amount of carbonic aeid gas taken up in an equal time by the same area of potash solution freely exposed to the air $\left.{ }^{29}\right)$.

The Movement of Gases from cell to cell, or from intercellular spaces to the cells and their movement within the intercellular spaces, takes place according to the principles discussed on p. 18E.

\section{The Assimilation of the Food-Materials}

The plant grows and continues to form new organs; for these purposes it continually requires fresh supplies of food-materials. The materials of the food beeome changed after their absorption, and the substance of the plant is built up from them. They are said to have been ASSIMILATED. By assimilation is understood the transformation of a food-material into the substance of the plant. Considered generally this process of assimilation might take place without ehemical ehange of the substance that has been absorbed. As a rule, however, a chemical change is involved. Those processes of assimilation in which profound changes take place, e.g. the change from inorganic to organic compounds, are especially interesting. This is particularly the case when we are still unable to experimentally bring about the reaction outside the organism.

\section{A. Assimilation of Carbon}

\section{Assimilation of Carbon Dioxide in Green Plants}

The assimilation of carbon dioxicle by a green plant is a process of the kind referred to in which organic substance containing carbon is derived from earbon dioxide. This process is of such great importance that it is frequently spoken of without any qualification as "Assimilation." This cannot be justified, since the assimilation of carbon dioxile is only one of a number of processes of assimilation which, taken together, are characteristic of the vegetable organism.

In the assimilation of carbon dioxide, soluble earbohydrates such as grape-sugar are formed in the chloroplast under the influence of 
sunlight. If we assume that the carbonic acid gas of the atmosphere (carbon dioxide, $\mathrm{CO}_{2}$ ) becomes on its solution in the cell $\mathrm{H}_{2} \mathrm{CO}_{3}$, the formation of sugar would take place in two stages. In the first, oxygen would be given oft and formaldehyde formed,

$$
\mathrm{H}_{2} \mathrm{CO}_{3}=\mathrm{H}_{2} \mathrm{CO}+\mathrm{O}_{2}
$$

In the second stage the aldehyde is polymerised to sugar,

$$
6 \mathrm{H}_{2} \mathrm{CO}=\mathrm{C}_{6} \mathrm{H}_{12} \mathrm{O}_{6}
$$

If we start from carbon dioxide we must assume that water enters into the reaction according to the formula

$$
6 \mathrm{CO}_{2}+6 \mathrm{H}_{2} \mathrm{O}=\mathrm{C}_{6} \mathrm{H}_{12} \mathrm{O}_{6}+6 \mathrm{O}_{2}
$$

In any case, for every volume of carbon dioxide which disappears an equal volume of oxygen makes its appearance.

It has been shown by eudiometric measurements that this is the case. The oxygen given off can, however, even when it is only detected qualitatively, be used as an indicator of the decomposition of the carbonic acid. Thus, when a plant is enclosed along with phosphorus in a space free from oxygen and exposed to light, the formation of oxygen is shown by the white fumes given off from the phosphorus. Another means of drawing conchusions as to the production of oxygen by a green plant is afforded by the movements of certain Bacteria which previously lay motionless on the water. The clearest demonstration of assimilation is obtained by using certain water-plants such as Elodea or Potamogeton. If cut shoots or leaves of these plants are submerged in water and exposed to light, a brisk continuous stream of bubbles comes from the cut surface. If the gas is collected in considerable quantity in a suitable apparatus, e.g. in a test-tube (Fig. 194), it can be shown to consist not of pure oxygen but of a mixture of gases rich in oxygen; a glowing splinter bursts into flame in the gas.

The appearance of the bubbles of oxygen is explained in this way. The carbon dioxide dissolved in the water enters the green cells of the plant by diffusion and is there decomprosed. The oxyrgen giren off is much less soluble than carbon dioxide and therefore appears in the gascous form. It passes into the intercellular spaces, causing there an increase of the pressure, and this is the canse of the appearance of bubbles of gas at every wounded surface.

It was by the excretion of bubbles of oxygen that InGexHouss was first led to recognise the nutritive functions of leaves. INGENHouss himself and further Priestrey and Th. DE Saussure had established the main features of the decomposition of $\mathrm{CO}_{2}$ in the green plant by the cud of the eighteenth and beginning of the nineteenth centuries $\left({ }^{30}\right)$. This discovery is one of the most important in the progress of the natural sciences. It was by no means easy to prove that the invisible 
gaseous exchange between a plant and the atmosphere constitutes the ehief souree of its nourishment; and it reguired the courage of a firm conviction to derive the thousands of pounds of carbon accumulated in the trees of a forest from the small proportion $(0.03$ per cent) of carbon dioxide eontained in the atmosphere.

By means of the gas-bubble method it is easy to bring proof of the statement made above that only the green parts of plants, and these only in light, are able to assimilate $\mathrm{CO}_{2}$. Thus, the stream of bubbles from an Elodea which goes on briskly at a brightly lit window becomes slower as the plant is brought into the middle of the room, and ultimately ceases when the intensity of the light is still such as to allow our eyes to read. Within certain limits assimilation increases in proportion to the intensity of the light. Similar experiments may be carried out using artificial sources of light. They show that all the methods of illumination in common use may be effective in the assimilation of $\mathrm{CO}_{2}$. When, however, monochromatic light, from whatever source, is employed it is found that rays of different wave-length are by no means of equal use in assimilation. In spite of some opinion to the contrary it may be stated with certainty that red light (wavelength $\lambda=680 \mu \mu$ ) has the maximum effeet. Rays of short wavelength are less effective, but recent work appears to show that the blie rays are more active in assimilation than are the yellow or green rays.

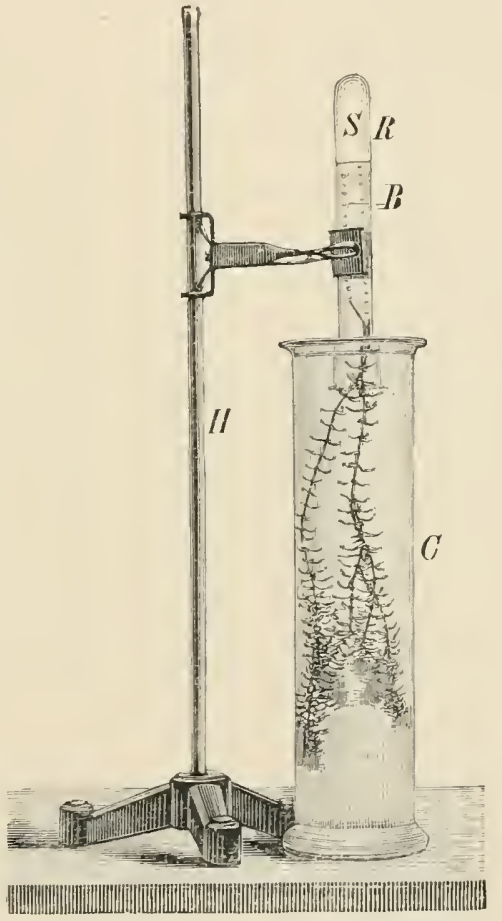

Fic. 194.-Evolution of oxygen from assimilating plants. In the glass cylinder $C$, tilled with water, are placed shoots of Elodea canadensis ; the freshly cut ends of the shoots are introduced in to the test-tube $R$, which is also full of water. The gas-bubbles $B$, rising from the cut surfaces, collect at $S . H$, stand to support the test-tube.

Since sunlight is in nature the indispensal,le factor in $\mathrm{CO}_{2}$-assimilation it becomes at once clear why certain organs of the plant, the foliage-leaves, have a Hat expanded shape. Their large surface fits them to absorb the light. If their function of $\mathrm{CO}_{2}$-assimilation is to be well performed the foliage leaves must not only have a large surface but also be thin. Practically it appears that light which has passed through one or two foliage leaves is unable to exert any further 
assimilatory effect. The leaves must, however, contain a very large number of chlorophyll grains. Their dark green colour shows that this is the case, and microscopical examination confirms this. Stems have far fewer chloroplasts than the leaves, and the roots and other subterranean organs have none at all.

Every investigation shows that organs without chlorophyll are quite umable to assimilate earbon dioxide. This holds not only for the organs of the plant but for the parts of the cell. The colourless protoplasm and the nucleus of the cell give off no oxygen when exposed to sunlight; this can readily be proved by the bacterial method (p. 214). The chloroplasts alone are the active organs in $\mathrm{CO}_{2}$ assimilation, and every member of the plant becomes, caeteris paribus, more active in assimilation the greater the number of chloroplasts it eontains. On this account THE FOLIAGE LEAF MAY BE REGARDED AS THE ORGAN OF $\mathrm{CO}_{2}$-ASSIMILATION.

In the red-leaved varieties of green plants, such as the Purple Beech and Red Cabbage, chlorophyll is developed in the same manner as in the green parent species, but it is hidden from view by a red colonring matter in the epidermis or in deeper-lying cells. In the Red Algae on the other hand the ehromatophores themselves have a red colour; after death this becomes free as a bluish-red pigment (phycoerythrin) leaving the chloroplasts green. The Brown Algae and the Diatomaceae have a brown modification of ehlorophyll (phaeophyll) which after (leath changes into elilorophyll (ef. p. 62).

In the blue-green freshwater Algae, and also in the Brown and Red Seaweeds, the maximum assinilation takes place, according to ENGELMANN, in another part of the spectrum than it does in the case of green plants. The assimilation in these Algae seems indeed to be carried on in the part of the spectrum the colour of which is complementary to their own. According to STAн the pigment of green plants composed of a yellow and a green constituent is complementary to the predominant rays of sunlight, which undergoes essential modification in its passage through the atmosplere $\left({ }^{31}\right)$.

In studying the eflect of different kinds of light upon assimilation, it is customary either to use the seprate colours of the solar speetrum, or to imitate them by means of coloured glass or coloured solutions. For such experiments it will be found convenient to make use of double-walled bell-jars filled with a solution of bichronate of potassium or of ammoniacal copper oxide. Plants grown under jars filled with the first solution, which allows only the red, orange, and yellow rays to pass througl, assimilate almost as actively as in white light. Under the jars containing the second solution, whiel readily permits the passage of the chemically active rays, assimilation is meh less active.

Very little is known with regard to the processes carried on in the chloroplasts during assimilation, and it is still by no means clear what part the green clilorophyll pigment performs. 'The pigment, which may be extracted from the protoplasm of the ehloropliyll bodies, makes up only a small part of their substance (about 0.1 per cent), and gives no reaction from which its operations nuay be inferred. The light absorbed by the chlorophyl! pigment also stands in no recognisable relation to the requirements of assimilation, for the assimilation is not proportional to the intensity of the absorption of the different lays.

The proportion of the cnergy, passing through the leaf in the form of light, 
ntilised in assimilation is, according to DETLEFsEN, only 1 per cent; according to the calculations of H. Brows, somewhat over $\frac{1}{2}$ per cent in sunlight, and over 2 per cent in difuse light. That, however, light must disappear as such in $\mathrm{CO}_{2}$ assinilation is clear, for from what other source than the energy of light conld the energy be obtained that is stored $u$, in the organic substance formed in assimilation. This potential energy of the organic substance of the plant serves to maintain the vital processes. The force exerted by our steam-engines also is to be traced to the assimilatory activity of the plants, the wood or the carbonised remains of which are burnt beneath its boiler. For in the combustion of the redueed carbon compounds to carbon dioxide the energy, which was previously required to transform carbon dioxide into the combustible materials, again becomes free.

The assimilatory activity of a chloroplast, like every vital function, is dependent on a number of internal and external factors. To the internal factors belong the presence of the pigment chlorophyll and its situation in a living chloroplast. Chlorophyll itself, separated from the plant, is as little able to decompose the carbon dioxide as is a chloroplast which for any reason has not developed the characteristic pigment (chloroplasts developed in the dark or in the absence of iron, leucoplasts of subterranean parts or of epidermal cells) or has lost it (chromoplasts). Further a chloroplast isolated from the rest of the cell cannot continue to assimilate; the protoplasm in which it is normally embedded is thus one of the internal conditions of $\mathrm{CO}_{2}$-assimilation.

Among external factors sunlight as referred to above must be mentioned first, and next the presence of carbon dioxide. Since the latter is only present in small proportion in the air, the life of plants, and with this the existence of all organisms, would nltimately cease were not fresh supplies of carbon dioxide continuously produced.

The amount of earbonic acid gas contained in the air varies at different times and places. H. Brown found that in 10,000 litres of air it was $2 \cdot 7$ to $2 \cdot 9$ litres in July, $3 \cdot 0-3 \cdot 6$ litres in the winter ; elose to the ground $12-13$ litres were present in the same volume. The average amount is abont $3 \frac{1}{3}-3 \frac{1}{2}$ litres in 10,000 litres of the atmosphere. This weighs about 7 grammes, of which $\frac{8}{11}$ is oxygen, aud only $\frac{3}{11}$ carbon. Only 2 grammes of carbon are thus contained in the 10,000 litres of air. In order therefore for a single tree having a dry weight of 5000 kilos to acquire its 2,500,000 grammes of carbou, it must deprive 12 million cubic metres of air of their carbonic acid. From the consideration of these figures, it is not strange that the discovery of Ingenhouss was unwillingly accepted, and afterwards rejected and forgotten. LIEBIG was the first in Germany to again call attention to this discovery, which to-day is accepted withont question. The immensity of the numbers just eited are not so appalling when one considers that, in spite of the small percentage of carbonie acid in the atmospliere, the actual supply of this gas is estimated at about 3000 billion kilos, in which are held 800 billion kilos of carbon. This amount would be sufficient for the vegetation of the entire earth for a long time, even if the air were not eontinually receiving new supplies of earbonic acid throngh the respiration and decomposition of organisms, throngh the combustion of wood and eoal, and through volranic activity. Au adult will exhale daily about 900 grammes $\mathrm{CO}_{2}$ (245 grammes C). The 1400 million human beings in the world 
wonld thus give back to the air 1200 million kilos of $\mathrm{CO}_{2}(340$ million kilos C). The $\mathrm{CO}_{2}$ diseharged into the air from all the chimneys on the earth is an enormons amonnt. CreDrer calculated that 460,000,000 kilos of coal are burnt annually, yielding to the atmosphere about 1,265,000 million kilogrammes of earbonic aeid gas. These somrces of $\mathrm{CO}_{2}$ are, according to BEYEnINCK, insignificant compared with the enormous amounts produced by the Bacteria of the soil in putrefactive processes. The whole carbon supply of the atmosphere is at the disposal of plants, since the $\mathrm{CO}_{2}$ becomes uniformly distributed by constant diffusion.

Submerged water-plants absorb the $\mathrm{CO}_{2}$ dissolved in water. Its amount varies considerably accorling to the temperature. $\Lambda \mathrm{t} 15^{\circ} \mathrm{C}$. a litre of water contains about as much $\mathrm{CO}_{2}$ as a litre of atmospheric air.

Artificially conducting carbonic acid through the water increases, to a certain degree, the evolution of oxygen, and the assimilatory activity. Similarly an artificial increase of earbonic acid in the air is followed by increased assimilation. According to KlieusLER assimilation in sunshine attains its maximum in air con. taining about 10 per eent of carbonic acid; with a higher percentage it begins to decrease. If the amount of carbonic acid gas be inereased three hundred times (from 0.03 per cent to 10 per cent in the atmosphere), the formation of starch is only increased 4-8 times, while an increase of the $\mathrm{CO}_{2}$ to six times the normal proportion results, according to $\mathrm{H}$. Buows, in the formation of six times as much starch $\left({ }^{32}\right)$.

Carbon monoxide (CO), though it can be utilised by certain Bacteria (Bac. oligocarboptilus), can probably not be utilised by green plants; it cannot thus replace the carbon dioxide.

The $\mathrm{CO}_{2}$-assimilation, like all vital processes, is dependent on the temperature. It begins at a temperature a little above zero, reaches its maximum at about $37^{\circ} \mathrm{C}$, and again stops at about $45^{\circ} \mathrm{C}$.

These cardinal points not only have different positions in different plants but do not remain constant for any particular plant. This is especially true of the optimum which in the course of a few hours may sink from $37^{\circ} \mathrm{C}$. to $30^{\circ} \mathrm{C}$. This fall indicates the componnd nature of the optimum curve (ef. p. 178). In bright warm weather assimilation does not reach its full possible value since the supply of carbon dioxide is then insufficient.

Other less important factors need not be considered in detail. It may be mentioned, however, that many substances can bring about a temporary, or ultimately a permanent, limitation or arrest of the assimilatory process.

Produets of the Assimilation of Carbon Dioxide.-It was assumed above that sugar was formed from the carbon dioxide, and analysis in fact shows that the amount of sugar in a foliage leaf is increased after exposure to sunlight. It is true that grape-sugar is neither always nor only shown to be present; usually other more complex carbohydrates appear. These can all, however, be traced back to hexoses like grape-sngar, and arise lyy the union of two or more molecules of hexose and the loss of the elements of water. Prominent among them are cane-sugar $\left(\mathrm{C}_{12} \mathrm{H}_{22} \mathrm{O}_{11}\right)$ and starch $\left(\mathrm{C}_{6} \mathrm{H}_{10} \mathrm{O}_{5}\right)_{n}$. The oceurrence of starch in the chloroplasts of illuminated foliage leaves is 
very common, but by no means general. When the leaves are placed in clarkness for some time the starch disappears. When on the other hand a part of the plant from which the starch has been removed is exposed to sunlight new starch grains often form in the chloroplasts in a surprisingly short time (5 minutes); these soon inerease in size and ultimately exceed in amount the substance of the chloroplast itself. Since starch is stained blue by iodine the commencement of assimilation can be readily demonstrated macroscopically (SACHs' method). Leaves which have been in the light have their green colour lemoved by means of alcohol, and are treated with a solution of iodine; they take on a blue colour. If the amount of starch is greater the colour is a deeper blue or almost black. The depth of the coloration thus aftords a certain amount of information as to the quantity of starch present. To demonstrate smaller amounts of starch the decolorised leaves are placed before staining with iodine in a solution of potash or of chloral hydrate in order to swell the starch grains. This method of demonstrating assimilation can also be nsed to show that the starch only appears in the illuminated portions of the leaf. If a stencil of opaque material from which for instance the word "Stärke" has been cut is laid on the leaf, the word "Stärke" will appear blue on a light ground, as in Fig. 195, when the leaf after being illuminated is treated with iodine.

In some plants (many Monocotyle-

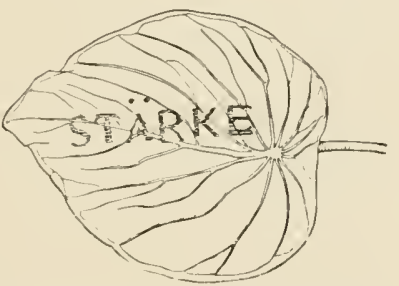

Fis. 195. - Assimilation experiment with the leaf of Ariopsis peltata (reuluced). dons) no starch is formed in the chloroplasts, but the products of assimilation pass in a dissolved state directly into the cell sap. In exceptional cases, however, starch is also formed where there is a surplus of glucose, sugar, and other substances, as, for example, in the coloured plastids of flowers and fruits. The guard-cells of the stomata and the cells of the root-eap of these Monocotyledons also contain starch. In other cases only a fraction of the product of assimilation appears as starch (in Helianthus, for example, only $\frac{1}{6}$ ) while the rest remains as sugar or is otherwise made use of. It is thus clear that the amount of starch formed cannot always be taken as a measure of the assimilation.

Starch-formation can be induced to take place in the dark by floating leaves on a sugar solution of suitable concentration. This shows that the formation of starch does not stand in direct connection with the assimilation of carbon dioxide but is only the result of the accumulation of sugar in the cell.

In some Algae neither sugar nor starch but other products of assimilation are formed.

Quantity of the Assimilate ( ${ }^{32_{x}}$ ). - If a leaf is exposed throughout 
the day to carbon dioxide and forms from this sugar or starch its weight must increase, unless other causes lead to a diminution in weight. Loss of weight may result from transpiration, from the translocation of material from the leaf, or from respiration (p. 241). The two latter eauses of loss in weight can only be approximately estimated, and the first cloes not enter into consideration if instead of the variable weight of the fresh leaf its dry weight be taken.

The inethod invented by SAcHs is as follows:-In the morning portions of leaves, usually halves, are removed; their superficial area is measured and they are then dried and weighed. In the eveuing equally large portions (the remaining halves) of the leaves which have been exposed to light throughout the day are similarly dried and weighed. The increase of weight indicates the gain to the plant by the assimilation of carbon. This is SACHs' half-leaf method. A quite distinct method of quantitatively determining the assimilation of $\mathrm{CO}_{2}$ is that of Kreusler which has been used by Giltay and Brown. A leaf still attaehed to the plant is placed in a closed eliamber through which a constant current of air jasses; the amount of $\mathrm{CO}_{2}$ removed from the air by the leaf is determined. The amount of sugar or starch which could be formed from this amount of $\mathrm{CO}_{2}$ can then be easily calculated.

The results obtained by SACHS' method do not completely agree with those obtained by the method of Kreuscer. Nevertheless it can be said that a square metre of leaf of an actively assimilating plant under optimal external conditions produces between 0.5 and 2 grammes of dry substance per hour. No fundamental difference in formation of material conld be found between tropical plants and our native plants. Considerable differences in the behaviour of distinct species were, however, found.

If one considers how many square metres of leaf-surface are aetively assimilating day after day on the surface of the earth a conception of the huge production of organic material in this largest of all chemical works will be obtained. The German wheat harvest alone contained in the yeir 1900 about 23,000 million kilogrammes of assimilates.

\section{The Gain in Carbon by Nitrifying Bacteria $\left({ }^{33}\right)$}

Certain Bacteria, which will be described in another part of this text-book, are characterised by the power of increasing their substance in a purely inorganic food-solution; they do this in the dark and without chlorophyll so long as carbonates are present. This has been exactly determined for the Nitrite- and Nitrate-bacteria, and also probably holds for the Sulphur-bacteria and for the Bacteria which oxydise methane and hydrogen.

Nothing is known at present of the products of carbon-assimilation in the Nitrifying Baeteria. For the gain in organically combined carbon is slight; in the best-growing culture of WINOGRADSKI it amounted to $26 \mathrm{mg}$. Only a quite minimal fraction of the organic 
carbon compounds which at any moment exist on the earth owes its origin to these Bacteria. The fact of their carbon-assimilation remains none the less interesting, especially since it takes place in an essentially different manner to the assimilation of the green plant. Some other source of energy must take the place that sunlight does in assimilation in a green plant to build up the organic substance; this energy is obtained by oxidation of ammonia or of nitrites (p. 245). We may thercfore term the formation of organic material in green plants PHOTOSYNTHESIS and in the Nitro-bacteria a CHEMOSYNTHESIS.

\section{The Gain in Carbon in Heterotrophic Plants}

While the gain of carbon from carbon dioxide is to be considered as the typical carbon-assimilation of plants, it is by no means the only method found in the vegetable kingdom. Since it depends-leaving the Nitro-bacteria out of account-on the presence of chlorophyll and of sumlight, it cannot come into consideration in subterranean parts of plants, in all plants that are not green and in the case of all animals. All these are in fact dependent on organically combined carbon which has been derived directly or indirectly by the assimilatory activity of green parts of plants. All organisms which in their nutrition are dependent on the activity of green plants are termed heterotrophic; the green plants and also the Nitro-bacteria are termed antotrophic. The word "auto "-trophic must not be taken too literally, for autotrophic plants also depend on other organisms. It will be seen that life is only continuously maintained on the earth by the changes in substances effected in one direction by particular organisms being balanced by the activity of other organisms. Heterotrophic organisms show by their mode of life, and especially by the situations in which they live, that they make other demands on foodmaterial than do antotrophic plants. They occur either as parasites on living plants and animals, or they live as saprophytes on dead organisms or substances derived from organisms.

The demands which heterotrophic plants make on a source of carbon can be best studied in saprophytic Bacteria and Fungi. These organisms can be cultivated on various complex substrata and conclusions can be drawn from their growth as to the nutritive value of the compounds supplied as food. The nutrient solution must as a rule contain, in addition to the indispensable mineral substances and a source of nitrogen (usually a salt of ammonia), sugar as a source of carbon. It should have a slightly acid reaction for mould-fungi and be weakly alkaline or neutral for bacteria, and is often converted into a solid medium by mixture with gelatine or agar-agar. The sugar can, in many cases, be more or less suitably replaced by other organic substances such as other carbohydrates, fats, albumen and derived substances, organic acids, etc. While these sources of carbon can 
be placed in order as regards their nutritive value for any particular organism, this cannot be done generally; there are many saprophytes which are adapted to quite peculiar conditions and use in preference, as a source of their carbon supply, compounds, which for the majority of other plants have scarcely any nutritive value (e.g. formic acid, oxalic acid).

Even the saprophytes which succeed on very varions compounds of carbon (omnivorous saprophytes) are exclusive in their selection of a substratum. Thus from ordinary tartaric acid Penicillium only utilises the dextro-rotatory form, and Bacillus subtilis only the laero-rotatory form. Aspergillus growing in a mixture of glucose and glycerine utilises the former first ("election " of nutritive materials). If the glycerine alone is given, it is completely ntilised.

The power possessed by many Fungi of utilising such organic compounds as starch, cellulose, etc., which are insoluble in water, is very remarkable; these substances can only be absorbed after a process of transformation and solution. The Fungi and Bacteria in question excrete enzymes (cf. p. 235), which have the power of rendering the substances soluble.

Saprophytes are thus characterised by the nature of their assimilatory activity; they are unable to carry out the first step in the assimilation of carbon which is effecter so easily by the green plant with the help of light. On the other hand there is probably no difference between them and antotrophic plants in the further steps of assimilation, in the construction from simple organic compounds of the more or less complex compounds which compose the body of the plant.

Among phanerogamic plants also some heterotrophic forms, that at first sight appear to be saprophytes, occur. This is the case for certain orchids which grow in humus (Neoitia, Coralliorliza, Epipogon) and for Honotropa. The absence of chlorophyll and, except for the inflorescence, the subterranean mode of life indicate the heterotrophic nature of these forms. The obvious assumption that they obtain their supply of carbon from the humus of the soil of woods is, however, very improbable. Since all these plants harbonr a fungus in their roots or rhizomes, the absorption of food material is probably due to the fungus. The flowering plants probably lead a parasitic life upon the fungi in their roots (mycorhiza; cf. p. 232).

These plants thus lead us to the consideration of PARAsites, numerous examples of which are found in the Fungi and Bacteria; parasitic forms also occur among Algae, Cyanophyceac, and the higher plants.

That these parasites, or at least many of them, absorb nutrient materials from the host upon which they live is often evident from the conclition of the litter; the host may be seriously injured and even ultimately killed by the parasite. What the particular 
substances are, that the parasite absorbs and requires for successful growth, is, however, diffieult to determine. Since frequently only organisms of a definite natural group (family, genus, species) are attacked by one species of parasite it may be assumed that the latter makes quite specific demands as to the quality or quantity of its nutriment. This assumption is supported by the faet that we are unable to cultivate most parasites apart from their hosts.

In phanerogamic parasites especially the changes in structure of the organs, which stand in relation to the morlification in their function due to parasitism, are especially evident.

From the clianges in their external appearance it is evident how far-reaching is the influence exercised by the chlorophyll. With the diminution or complete disappearance of the chlorophyll, and consequent adoption of a dependent mode o life, the development of large leaf surfaces, so especially fitted for the work of assimilation, is discontinued. The leares shrink to insignificant scales, for with the loss of their assimilatory activity the exposure of large surfaces to the light is no longer essential for nutrition. For the same reason active transpiration becomes unnecessary; the xylem portion of the vascular bundle remains weak, and secondary wood is feebly developed. In contrast to these processes of reduction resulting from a cessation of assimilation, there is the newly developed power in the case of parasites to penetrate other living organisms and to deprive them of their assimilated prodncts. In saprophytic plants, however, where the question is merely one of absorbing nourishment from organic remains, the external adaptations for taking up nourishment continue to be more like those for absorbing the mineral salts from the soil, for it then depends only upon an intimate contact with the decaying substances.

Cuscuta europea ( $\left.{ }^{3+}\right)$ (Fig. 196), a plant belonging to the family of the Convolvulaceae, may be cited as an example of a parasitic Phanerogam. Although, owing to the possession of cllorophyll, it seems to some extent to resemble normally assimilating plants, the amount of chloroplyyll present is in reality so small that it is evident that Cuseuta (Dodder) affords an example of a rery complete parasite.

The embryonic Cuscutu plantlet, coiled up in the seeds, pushes up from the ground in the spring, but even then it makes no use of its cotyledons as a means of nourishment; they always remain in an undeveloped condition (Fig. 196 at the right). Nor does any underground root-system develop from the young rootlet, which soon dies off. The seedling becomes at once drawn ont into a loug thin filament, the free end of which moves in wide circles, and so inevitably discovers any plant, available as a lost, that may be growing within its reach. In case its search for a host plant is nnsuccessful, the seedling is still able to creep' a short distance farther at the expense of the nourishing matter drawn from the other extremity of the filament, which then dies off $(t)$ as the growing extremity lengthens. If the free end, in the course of its circling movements, comes ultimately into contact with a suitable host plant, such as, for example, the stem of a Nettle or a young Willow shoot (Fig. 196 in the centre), it twines closely about it like a climbing plant. Payillose protuberances of the epidermis are developed on the side of the parasitic stem in contact with the host plant, and pierce the tissue of the host. If the conditions are favourable, these PrisHALsToria are soon followed by special organs of absorption, the Hat'storid $(H)$ (cf. p. 49). These arise from the internal tissues of the parasite, and possess, in a marked degrec, the capability of fenetrating to a considerable depth into the body 
of the host plant by means of solvent ferments and the pressure resulting from their own growth. They invade the tissues of the host, apparently without difficulty, and fasten themselves closely upon its vascular bundles, while single hypha-like filaments produced from the main part of the haustoria penetrate the soft parenchyma and absorb nourishment from the cells. A direct connection is formed

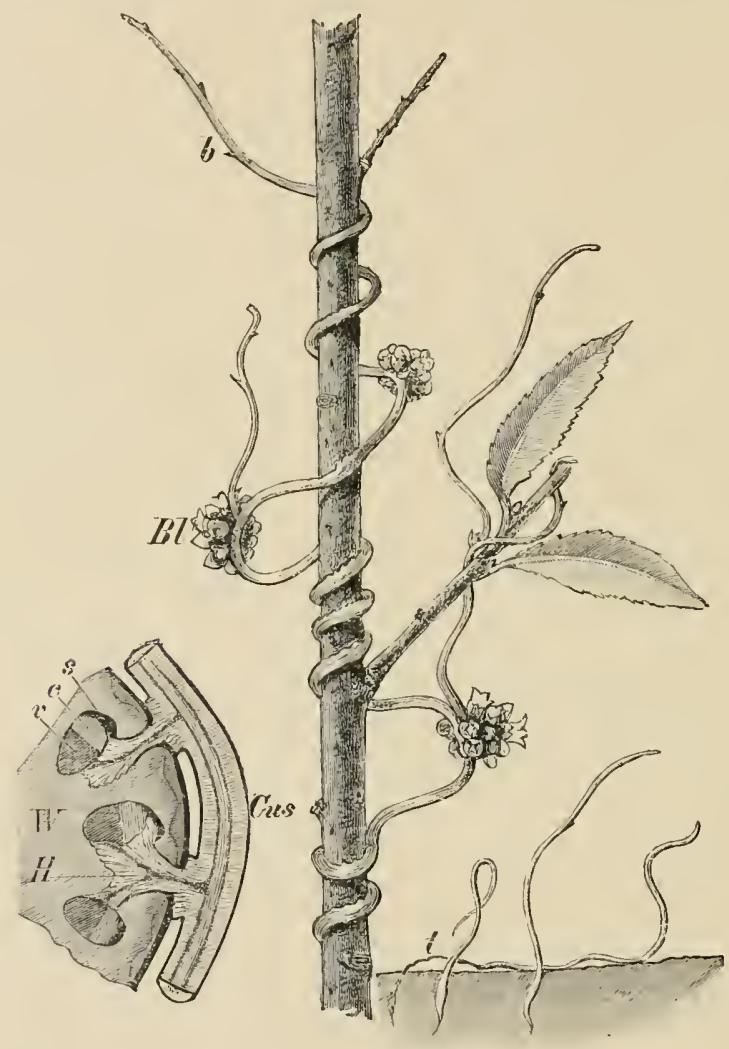

F1:, 196,-Cuscuta enropact. On the right, germinating seedlings. In the midile, a plant of Cuscuta parasitic on a Willow twig; $b$, reduced leaves ; $B l$, flower-clusters. On the left, crosssection of the host plant $\mathrm{Ir}^{r}$, showing haustoria $H$ of the jarasite Cus, penetrating the cortical parenchyma and in intimate contact with the xylem $v$ and the phloem $c$ of the rascular bundles; $s$, displaced cap of sheathing sclerenchyma.

between the xylem and phloem portions of the bundles of the host plant and the conducting system of the parasite, for in the thin-walled tissue of the haustoria there now develop, both wool and sieve-tube elements, which connect the corresponding elements of the host with those of the parasitie stem (Fig. 196 at the left). Like an actual lateral organ of the host plant, the parasite draws its transpiration water from the xylem, and its plastie nutrient matter from the phloem of its host.

The seeds of Orobanclue (Broom rape), another parasite, only germinate when in contact with the roots of the host plant; only its haustoria penetrate the roots, 
and its light yellow, reddish-brown or amethyst-colonred flower-shoot appears above the surface of the ground. Orobanche, like Cuscuta, contains a small amount of chlorophyll. Both are dreaded pests; they inflict serious damage upon cultivated plants, and are difficult to exterminate.

Many exotic parasitic plants, especially the Rafflesiaceae $\left({ }^{36}\right)$, have become so fcompletely transformed by their parasitic mode of life that they develop no

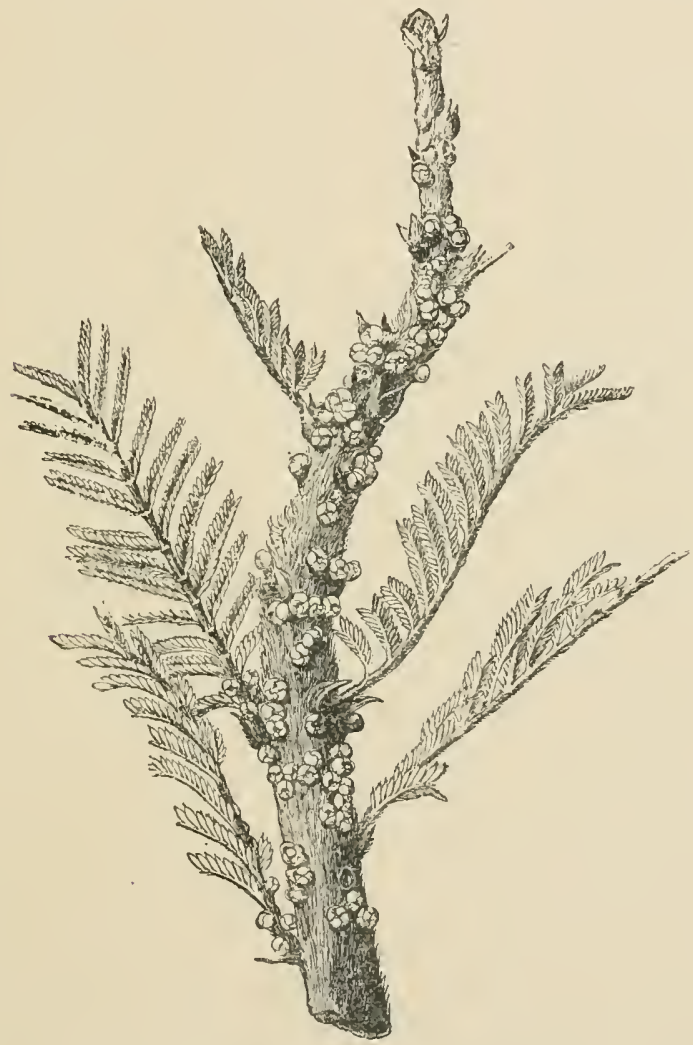

FIc. 197.-Branch of a leguminous plant from the surface of which the flowers of a parasitic plant (Pilostyles Ulei, Solms) are protruling. (From GoEber's Orgenography.)

apparent vegetative body at all; but grow altogether within their host plant, whenee they send out at intervals their extraordinary flowers. In the case of Pilostyles, a parasite which lives on some shrubby Leguminosie, the whole vegetative body is broken up into filaments of eells which penetrate the host plant like the mycelium of a fungus. The flowers alone become visible and protrude from the stems and leaf-stalks of the host plant (Fig. 197).

In contrast to these parasites, which have come to be absolutely dependent upon other plants for their nourishment, there are certain parasites whieh, to judge by external appearances, seem to be yuite independent, for they possess 
large green leaves with which they are able to assimilate vigoronsly. These will be discussed later (1. 229).

\section{B. Assinilation of Nitrogen}

Since a green plant obtains its carbon from carbon dioxide, which is only present in a very small proportion in the air, it might be assnmed that the enormous supply of nitrogen in the air would form the primary and the best source of this element of plant food. Every water enlture, however, shows clearly that atmospheric nitrogen cannot be utilised by the typical green plant. If combined nitrogen is omitted from the nutrient solution the plant will not grow.

In the food solution given above nitrogen was supplied as a nitrate, and this form is most suitable for the higher plants. But compounds of ammonia, so long as they are not injurious to the plant owing to an alkaline reaction, can also be utilised. Organic compounds of nitrogen also, such as amino-acids, acid amines, amine, ete., will serve for food, though none of them lead to such good results as are obtained with nitrates. It is still a matter of doubt to what extent nitric acid affords a useful nitrogenous food substance.

Ve are not nearly so well acquainted with the assimilation of nitric acid and of ammonia as we are with that of carbon dioxide. We do not know accurately the place in which the assimilation takes place, we know less of the contributory external conditions, and lastly, we are not clear as to the products of assimilation. Ultimately, of course, albumen is formed, a far more complex substance than a carbohydrate, containing always, besides $\mathrm{C}, \mathrm{H}$, and $\mathrm{O}$, some 15-19 per cent of $\mathrm{N}$, besides $\mathrm{S}$ and in some cases $\mathrm{P}$. The methodical study of the products of the breaking down of albumen gives some insight into the structure of the proteid molecule. This shows that in albumen a large number of amino-acids are combined with loss of water. Since the artificial synthesis of albumen, which has been practically accomplished, consists in a union of amino-acids followed by polymerisation, it is probable that in the plant also such aminoacids are first formed and then unite further. If the simplest aminoacid, glycocoll, $\mathrm{CH}_{2} \mathrm{NH}_{2} \cdot \mathrm{CO}_{2} \mathrm{H}$ (which, it is true, is not of wide occurrence in plants), is considered, it is evident that nitrogen is combined with hydrogen as the $\mathrm{NH}_{2}$ group. Nitric acid, $\mathrm{HNO}_{3}$, must therefore be rerlueed when its nitrogen is to be employed in the construetion of proteid. Since the chloroplast with the help of sunlight reduces carbon dioxides it might be assumed that it conld also effect the reduction of nitric acid. There is, however, no ground on which this hypothesis can be supported; on the contrary it can hardly be doubted that all cells, even those without chlorophyll, have the power of reducing nitric acid, and that sunlight is not necessary in the process. 
Indirectly, of course, ehlorophyll and light are of importance in the synthesis of proteids in so far as compounds containing earlon are required, and these are formed in sunlight with the help of chlorophyll. On account of their rich supply of earbohydrates the foliage leaves are specially fitted for the production of proteid, but they are not "organs of proteid formation" in the same degree as they are organs for the formation of carbohydrates. Only in a few plants (nitrateplants) ean the nitric acid be recognised in the leaves; in most plants it appears to be transformed soon after its alssorption by the root.

We know as little of the steps in the assimilation of ammonia as of those of nitric acid. Since no preliminary reduction is required, ammonia might be regarded as more readily assimilable than nitric acid ; experiment, however, lends no support to this view.

The hypothetical intermediate products between the nitrogenous compounds absorbed and the completed proteids, i.e. various aminoacids and relited substances, are present in all parts of the plant. Leucin, tyrosin, and asparagin are especially common. It can, however, rarely be determined whether these substances have been synthesised from ammonia or nitric acid or whether they have arisen by the breaking down of albumen.

While it ean be said that the typical autotrophic plant can assimilate nitrogen better as nitric acid than as ammonia, this does not hold for the majority of Fungi. Only a few of these prefer nitric aeid; as a rule ammonia is the best nitrogenous food. Some Fungi lack the power to construct the more complex substances of the plant from such simple nitrogenous compounds, or at least the latter are formed more rapidly and certainly from organic substances. Further, in these Fungi there are various types; some sueceed best with aminoacils, others with peptone, while others prefer proteid. They are all heterotrophic as regards their nitrogenous food.

The sn-called INSECTIVOROUS or CARNIVOROUS PLANTS must be referred to here $\left({ }^{37}\right)$. There are plants provided with arrangements for the eapture and retention of small animals, especially insects, and for the subsequent solution, digestion, and absorption of the captured animals by means of enzymes. All these insectivorous plants are provided with chlorophyll ; the explanation of their peculiar mode of life ean hardly be to obtain organie compounds of earbon. It is further known that they can suceed withont animal food, but the moderate supply of an animal substance has a distinetly beneficial effeet manifested in increased production of fruits and seeds. It is very probable, though by no means established, that the carnivorous habit is a means of oltaining nitrogen. Whether the nitrogen in the peat or water in which insectivorous plants often grow is insufficient in quantity, or whether its quality is not optimal must be left undetermined. It is doubtless possible that orgenically combined nitrogen is specially advantageous to these plants. This cloes not exclude the possibility 
that the insectivorons habit is related not only to the supply of nitrogen, but to that of all the untrient salts.

A great variety of contrivances for the capture of insects are male nse of by carnivorous plants. The leaves of Drosera are covered with stalk-like outgrowths ("tentacles"), the glandular extremities of which discharge a viscid acid secretion (Fig. 198; cf. IP. 118, 119). A small insect, or even a larger fly or moth, which comes in contact with any of the tentacles, is canght in the sticky secretion, and in its ineffectual struggle to free itself it only comes in contact with other glands and is even more securely held. Excited by the contact stimulus, all the other tentacles curve over and close upon the captured insect, while the leaf-blade itself becomes concave and surrounds the small prisoner more closely. The secretion is then discharged more abundantly, and now contains an acid and a peptonising ferment (1. 237). The imprisoned insect, becoming thus completely covered with the
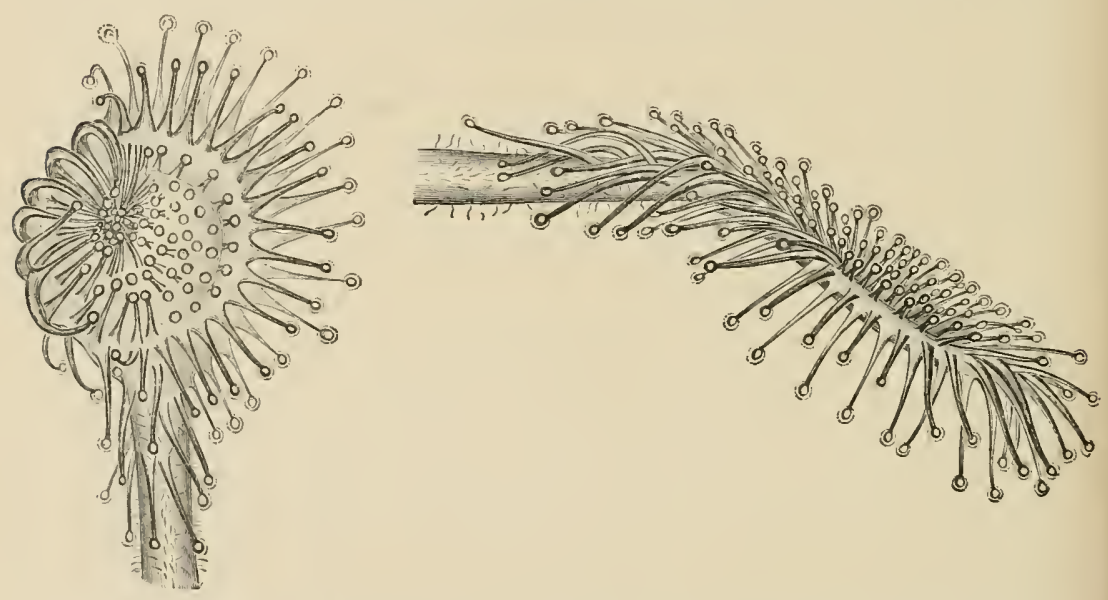

F1:. 198.-Leaves of Drosera rotundifolia. That on the left with its partly incurved tentacles is viewed from above, that on the right with expanded tentaeles from the side. (After DARW IN, enlarged.)

secretion, perishes. It is then slowly digested, and, together with the secretion itself, is absorbed by the cells of the leaf.

In Pinguienla it is the leaf-margins which fold over any small insects that may be held by the minute epidermal glands. In species of Utricularia (Fig. 47), which grow frequently in stagnant water, small green bladders (metamorphosed leaf-segments) are found on the dissected leaves. In each bladder there is a small quadrangular opening closed by an elastic valve, which only opens inwards. Small crustaceans can rearlily pass through this opening, guider to it by special outsrowths; but their egress is preventel by the trap-like action of the valve, so that in one bladder as many as ten or twelve crustaceans will often be found imprisoned at the same time. The absorption of the disorganiser animal remains scems to be performed l,y forked hairs which spring from the walls of the bladeler.

More remarkable still, and even better adapted for its pmrose, is the mechanism exhibited by some exotic insectivorous plants. In the case of Venus's fly-trap (Dioncea), growing in the peat-bogs of North Carolina, the capture of insects is 
effected by the sudden closing together of the two lialves of the leaf (Fig. 199). This action is specially due to the irritability of three bristles on the upper side of each half of the leaf (the leaf surfaces themselves are much less sensitive). Upon the death of the insect, a copions excretion of digestive sap takes place from glandular hairs on the leaf surface, followerl by the absorption of the products of the digestive solution. In the case of other well-known inseetivorous plants (Nepenthes, Cephalotus, Surracenia, Darlingtonia), the traps for the eaptnre of animal food are formed by the leaves which grow in the shape of pitchers (Figs. 46, 200). These trap-like receptacles are partially filled with a watery fluid excreted from glands on their inner surfaces. Enticed by secretions of honey to the rim of the piteher (in the case of Nepenthes), and then slipping on the extraordinarily smooth surface below the margin, or guided by the downwardly-direeted hairs, insects and other small animals fill into the fluid and are there digested by the action of ferments and acids. The larvae which Chaurnat found living in Nepenthes pitehers, may, like intestinal parasites, be enabled to live there by secreting a protective anti-ferment. In Sarracenia and

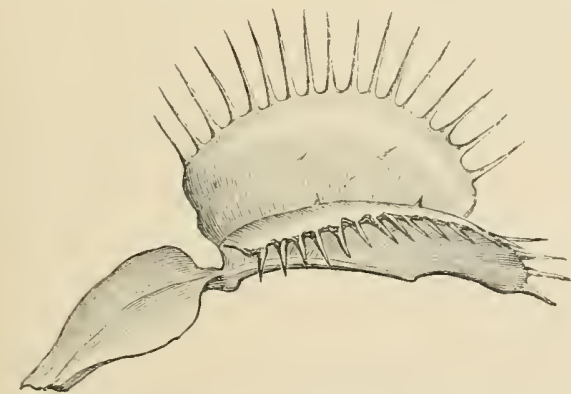

Frt. 199,-A leaf of Dioncea muscipula, slowing the sensitive bristles on jts upper surface, which, in the parts shaded, is also thickly beset with digrestive glands. (After DARWIN $\times 4$.)

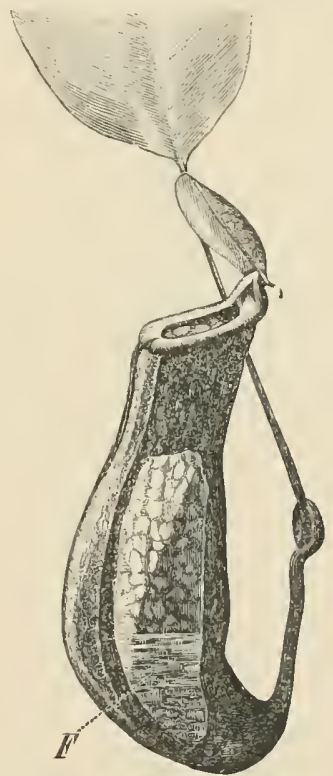

Fut, 2C0.-Pitchererl leaf of a Nepenthes. A portion of the lateral wall of the pitcher has been removed in order to show the fluid $(F)$, exereted by the leaf-glands. ( $\frac{1}{2}$ nat. size.)

Cephalotus, Goeber was mable to discover any digestive ferments; but in Cephalotus it was possible to determine that the secretions have antiseptio properties.

In relation to insectivorous plants certain phanerogamic parasites $\left({ }^{38}\right)$ may be considered which were omitted above (p. 226) since they possess green leaves and are evidently antotrophic as regards their supply of carbon. In spite of this, however, the plants only develop normally, when their root system is in connection with the roots of other plants by means of disc-shaped haustoria. They may even (as is also the case with (uscuta) enter into this relation with other individuals of the same species. Thesium, belonging to the Santalaceae, 
and the following genera of the Rhinanthacea, Phinanthus, Euphrasia Pedicularis, Bartsia, and Tozziu may be mentioned as examples of plants showing these peculiar conditions. In Tozria the parasitism is well marked in the earliest developmental stages. The Mistletoe (Viscum album), although strictly parasitic, possesses, like many of the allied foreign genera of the Loranthaceae, fairly large leaves well supplied

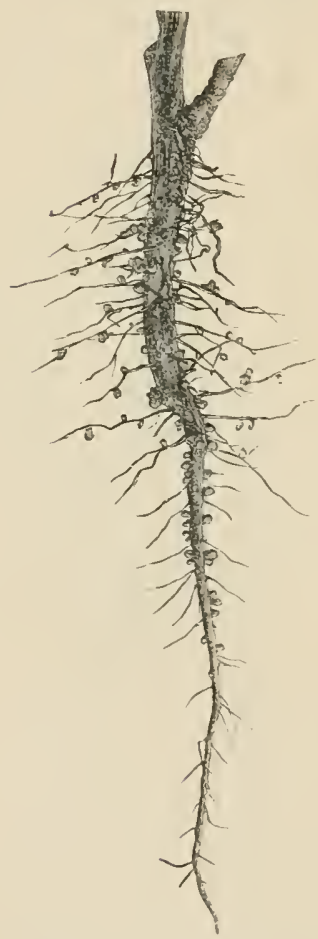

Fir. 201.-A root of Vicia Falu, with numerous root-tubercles. (Reduect.)
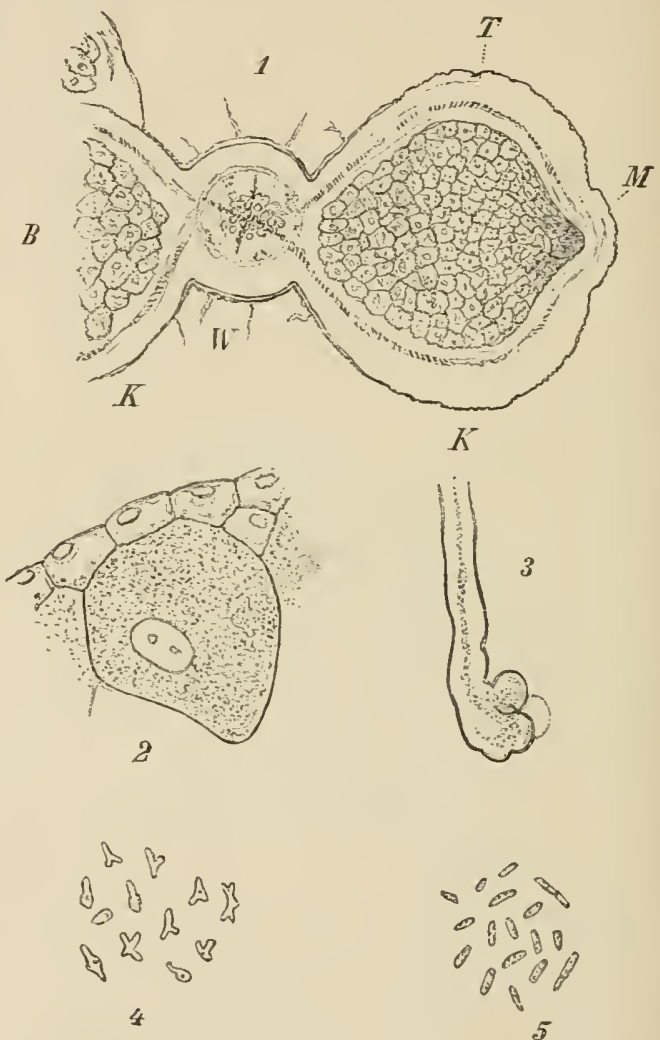

Fic. 202,-1, Joung tubercles (K) on a root (W) of Vicia Faba B, large-celled tissue filled with masses of Bacteria, 11, the "meristen " of this. T, tracheicles. ( $\times 60$.) \&, A cell of the tubercle filted with thousands of Bacteria, and besile it some un-infected cells. ( $\times 320$.$) S, An infected root.$ hair containing the "infection hypha." $(\times 320$.$) 4, Bacteri-$ oids. 5, Unaltered Bacilli. ( $\times$ 1200.)

with chlorophyll, and quite able to provide all the carbohydrates required. By its reduced root system it obtains, howerer, from the host-plant (as HeinRicheir has also shown to be probable in the case of the Rlinanthaceae) its supply of water and dissolved salts.

In contrast to these plants, which are either demonstrably or probably supplied with organically combined nitrogen, there are certain micro- 
organisms which are strikingly antotrophic as regards nitrogen, while they are heterotrophic as regards their carbon-assimilation. These organisms are able to utilise the nitrogen of the atmosphere. Their existence was first established at the end of last century by the work especially of WinogradsKi, HeLLRIEGEL and WiLFARTI ( $\left.{ }^{39}\right)$.

In the first place there are certain Bacteria, such as Clostridium Pasterriunum and related forms and Azotobucter chroococcum, which live independently in cultivated soil and in water under very various external conditions. They fix free nitrogen and thus possess a very important power both for their own success and for that of many other organisms; this property is of the greatest importance in agriculture. An increasing number of the lower Fungi have been shown by recent researches to have the same power though in less degree. In addition to these free-living forms there are micro-organisms which oceur parasitically in higher plants and have the same property. The best investigated among these are the various forms of Bucillus rudicicola, which infest the roots of Leguminosae and frequently gire rise to enormons numbers of gall-like tubercles upon them (Figs. 201, 202). The Leguminosae thus appear to differ from all other green plants in their mode of accumulating nitrogen; this was first established by Gilbert and Lawes in England and Lupitz in Germany.

The Bacteria penetrate through the root-hairs into the cortex of the roots, and there give rise to the tubereles. These tubercles become filled with a bacterial mass, consisting principally of swollen and abnormally developerl (hypertrophied) BACTERIOIDs, but in part also of Bacteria, which lave remained in their normal condition. The forner seem to be eventually partially consumed by the host plant, while the latter remain with the dead roots in the soil, to provide for future reproduction. So far as is known, we have here a case of mutual parasitism like those termed symbiosis by DE BAry. While the Bacterim lives on earbohydrates and at first also on albuminous substances supplied by the host plant, the latter profits by the power of fixing free nitrogen possessed by the Bacteria. While the Bacteria remain alive they furnish a steady supply of nitrogenous substance to the leguminous plant, and ultimately the remaining substance of the degenerated Bacterioids is absorbed. It has been ealculated that Lupins are able in this way to obtain $200 \mathrm{~kg}$. of nitrogen per hektar. When the large amount expended on nitrogenous manures (Chili-saltpetre and ammonium sulphate) is borne in mind the agricultural importance of this natural fixation of nitrogen will be evident. It has been attempted to further it by infecting fields with soil rich in the bacteria, or with pure cultures of speeially active forms ("vitragin"). If the soil in which a Leguminous plant is grown contains a sufficiency of nitrates, the plants may live at their expense; since the presence of nitrates exerts an injurious influence on Bacillus radicicola, practically no nodules are formed under such circunistances.

Besides the Leguminosae, in which order only Glaclitschia triacanthos has hitherto heen found free from nodules, Elacagnus and Almus are able, according to Nober and Hiltrer, to utilise free atmospheric nitrogen when their roots bear nodules ; these are dne to infeetion by another of the lower organisms. The same investigator's gave the experimental proof that a sjecies of Polocorpus which has 
a mycorhiza could utilise atmospheric nitrogen. It is thus not improbable, though as yet nnproved, that other mycorhizas may have a similar significance. The roots not only of the phanerogamic plants without chlorophyll, referred to on p. 222 ; but also of most green plants living in the humus soil of wonds and heaths, especially the trees, stand in close relation to Fungi $\left({ }^{40}\right)$.

The fungal hyphae are sometimes found within the root occurring in tangled groups in the cells of definite cortical layers while individual filaments extend into the soil. In other plants the hyphae invest the outer surface of the young roots with a closely woven sheath. The former is called endotrophic the latter cetotrophic mycorhiza but the extreme forms are connected by intermediate conditions. The fungi of the cndotrophic mycorhiza are in part digested by the cells of the root, and thus all the substances liberated will be available for the phanerogamic plant. This is not known in the case of ectotrophic mycorhiza. STAHL regards the significance of fungal infection of the flowering plant to lie in the active absorption of mutritive salts from the soil by the fungus. The adrantage to the fungus is obviously, at least in the cases in which it infects green plants, the provision of carbohydrates which it obtains. Whether the consurtia of Fungi and Algae which are called Lichens can be ranked here as regards their pliysiology of untrition is still doubtful.

\section{Assimllation of the other Nutrient Salts}

Sulphuric acid most nearly resembles nitrogen since it also is used in the construction of proteids which contain abont $\frac{1}{2}-1 \frac{1}{2}$ per cent of $\mathrm{S}$. It is still mucertain where and under what conditions its assimilation oecurs; we only know that a reduction of aeid radicals must take place in the process. In some plants sulphur is combined in other substances besicles proteils.

Phosphoric acid is connected with sulphurie acid in so far as it is employed in the construction of at least some proteid substances, especially the nucleo-protein of the cell-nuclei; it forms from $0.3-3$ per cent of this. In entering into the molecule of this substance the phosphoric acid, unlike sulphuric acid, is not rednced. Lecithin, which is present in all plants, also contains phosphorus, and this is also the case for phytin, which occurs especially in seeds.

The Metals. - As may be shown by the method of water-culture, potassium, caleium, magnesium, and iron are just as essential as any of the substances hitherto mentioned. It is very probable, at least for potassium and magnesium, that they take part in the eonstruction of certain compounds that are essential for the existence of the plant. Probably protoplasm contrins these elenents. Other substances also may contain them; thus, for instance, a considerable amount of magnesium has been shown to exist in chlorophyll. It was formerly believed that chlorophyll contiined iron because the chloroplasts remained yellow when iron was omitted from the food-solution, but this idea has heeome very improbahle. On the other hand it has been shown that iron is also necessary for plants that are not green, and this supports the assumption that protoplasm itself contains irom, and 
that the "chlorosis" which occurs when iron is wanting is a result of a diseased condition of the protoplasm.

Since potassium, magnesium, and iron thus pass into the substance of the plant they must be assimilated, but we know nothing of how or where this happens. The case of calcium is somewhat different; it is not invariably essential, for some Algae can succeed without it. In other plants it has a protective function, preventing the poisonous effects which result from iron, magnesium, potassium, and sodium, and also from phosphoric acid, sulphuric acid, nitric acid, and hydrochloric acid. It is, however, improbable that the indispensability of calcium in the case of the higher plants is due to this protective function.

In speaking of insectivorous plants and of certain green parasites it was mentioned that they might perhaps obtain their mineral food materials in organic compounds; nothing certain is known on this point.

The actual proportions of the more important ash constituents of some wellknown plants can be seen from the following table of ash analysis by E. WOLFF. The table also shows exactly what demands those plants make mon the soil, that is, what substance they take away from it, in addition to the nitrates which do not appear in the ash.

\begin{tabular}{|c|c|c|c|c|c|c|c|c|c|c|c|}
\hline \multirow{2}{*}{ Plants. } & \multirow{2}{*}{$\begin{array}{l}\text { Ash in } \\
100 \text { parts of } \\
\text { dry solid } \\
\text { matter. }\end{array}$} & \multicolumn{10}{|c|}{100 Parts of Ash contain } \\
\hline & & $\mathrm{K}_{2} \mathrm{O}$ & $\mathrm{Na}_{2} \mathrm{O}$ & $\mathrm{CaO}$ & $\mathbf{M g O}$ & $\mathrm{Fe}_{2} \mathrm{O}_{3}$ & $\mathrm{Mn}_{3} \mathrm{O}_{4}$ & $\mathrm{P}_{2} \mathrm{O}_{5}$ & $\mathrm{SO}_{3}$ & $\mathrm{SiO}_{2}$ & $\mathrm{Cl}$ \\
\hline Rye (grain) & $2 \cdot 09$ & $32 \cdot 10$ & 1.47 & $2 \cdot 94$ & $11 * 22$ & $1 \cdot 24$ & .. & $47 \cdot 74$ & $1 * 28$ & $1 \cdot 37$ & 048 \\
\hline Rye (straw) & $4 \cdot 46$ & 22.56 & $1 \cdot 74$ & $s \cdot 20$ & $3 \cdot 10$ & $1 \cdot 91$ & & 6.53 & $4 \div 25$ & $49 \cdot 27$ & $2 \cdot 18$ \\
\hline Pea (seeds & $2 \cdot 73$ & $43 \cdot 10$ & $0 \cdot 98$ & $4 \cdot 81$ & $7 \cdot 99$ & 0.83 & & $35 \cdot 90$ & $3 \cdot 42$ & 0.41 & $1 \cdot 59$ \\
\hline Pea (straw & $5 \cdot 13$ & $22 \cdot 90$ & $4 \cdot 07$ & 36.82 & $8 \cdot 04$ & $1 \cdot 72$ & & 8.05 & 6.26 & $6 \cdot 83$ & $5 \cdot 64$ \\
\hline Potato (tubers). & $3 \cdot 79$ & 60.06 & $2 \cdot 96$ & $2 \cdot 64$ & $4 \div 3$ & $1 \cdot 10$ & & $16 \cdot 86$ & $6 \cdot 52$ & $2 \cdot 04$ & $3 \cdot 46$ \\
\hline Grape (fruit). & $5 \cdot 19$ & $56 \cdot 20$ & 1.42 & $10 \cdot 77$ & $4 \cdot 21$ & 0.37 & & $15 \cdot 58$ & $5 \cdot 62$ & $2 \cdot 75$ & 1.52 \\
\hline Tobacco (leaves) & $17 \cdot 16$ & $29 \cdot 0 !$ & $3 \cdot 21$ & $36 \cdot 02$ & $7 \cdot 36$ & $1 \cdot 95$ & & $14 \cdot 66$ & 607 & $5 \cdot 77$ & $6 \cdot 71$ \\
\hline Cotton (fibres). & $1 \cdot 14$ & $36: 96$ & $13 \cdot 16$ & $17 \cdot 52$ & $5 \cdot 36$ & $0 \cdot 60$ & & $10 \cdot 68$ & $5 \cdot 94$ & $2 \cdot 40$ & $7 \cdot 60$ \\
\hline Spruee (wood) & 0.21 & $19 \cdot 66$ & $1 \cdot 37$ & 33.97 & $11 \cdot 27$ & $1 \cdot 42$ & 23.96 & $2 \cdot 12$ & $2 \cdot 61$ & $2 \cdot 73$ & 0.07 \\
\hline
\end{tabular}

The great difference brought out by the table in the proportions of the nore important phosphoric acid and of the less essential silica and lime contained in Rye and Pea seeds, as compared with the amonnts of the same substances in the straw, is worthy of special notice.

In the preceding table the figures do not express absolutely constant proportions, as the percentage of the constituents of the ash of plants varies according to the character of the soil; thus, the proportion of potassium in Clover varies from 9 to 50 per cent; the proportion of calcium in Oats from 4 to 38 per cent.

\section{Assinilation of WATER}

We know that water is essential to the plant. When it is taken into the plant as water without undergoing chemical change we clo not speak of its "assimilation." This is the case, for example, in the water which fills the vacuoles of cells or that which permeates the protoplasm and cell-wall. Such water can be promptly given off by evapora- 
tion; it is also able to pass from the protoplasm to the cell-sap or to the cell-wall, its place being taken by water which passes in from adjoining structures. 'This water is not a constituent of the plant in the same sense as the carbohydrates or proteids formed by assimilation are. It is different where the water is chemically combined. This necessarily takes place when carbohydrates are formed from carbon dioxide and probably in other eases also. In these cases there is the same justification for speaking of the assimilation of the water as of the assimilation of earbon dioxide.

\section{Translocation and Transformation of Assimilates}

The assimilates serve primarily for the construction of new substance of the plant and the growth of new cells. It is only rarely, however, that growth takes place where the work of assimilation is effected. Thus, the assimilation of carbon clioxide goes on mainly in fully-grown foliage leaves while the growing-points are more or less distant from the leaves. The assimilatory activity and the formation of new organs also do not coincide in time. Many plants have periods of active assimilation when but little growth is taking place and, alternating with these, periods of active growth associated with little or no assimilatory activity. Our trees lose their leaves in autumu and herbaceous plants lose all the above-ground organs. In both cases new organs of assimilation must be formed in spring before assimilation can be resumed; in the growth of these organs the plant utilises stored assimilates. Every germinating seedling also lives at first wholly at the expense of assimilates of a preceding generation. Such stored-up assimilates are termed RESERVE MATERIALs; they may be deposited where they are formed or may be carried to secondary places of deposit. Every foliage leaf which in the evening of a bright summer's day is gorged with starch is an illustration of the first condition. The second is seen in seeds where reserve materials are stored in the endosperm or the cotyledons. It is also found in vegetative organs, which may even show by their form that they are places for storage of reserve materials; examples of these are the swollen leaves of bulbs, swollen stems (e.g. potato) or swollen roots (e.g. turnip). In order that assimilates should reach these storage places they must be capable of TRANSLOCATION, and they have also to be conveyed through the plant when they are removed from the place of storage and employed in the development of new organs. Many reserve materials or assimilates occur in a solid form which does not allow them to pass from cell to cell; stareh is an example of this. Others are, it is true, soluble, but have such large molecules that they only diffuse with difficulty. For these reasons reserve substances have usually to molergo a change before they can be conveyed through the plant. 


\section{A. Mobilisation of Reserve Materials}

In the mobilisation of reserve materials we have usually a not very profound change of the nature of a hydrolysis, i.e. a splitting of the substance into smaller molecules with the absorption of water. This must be separately considered for the three main types of reserve material the carbohydrates, the fats, and the aibuminous substances.

\section{Hydrolysis of Carbohydrates}

Stareh is one of the most important reserve materials in plants. It not infrequently forms the main part of the reserve substance in seeds as well as in tubers and bullos. In the potato tuber 25 per cent and in the grain of wheat 75 per cent of the fresh weight consists of starch. It is also present in considerable amounts in the pitl, the xylem parenchyma, the medullary rays and the rind of trees. The starch has to be broken down in order to allow of its translocation. This is effected technically by treatment with acids; the grape sugar of commerce is obtained by treating potato-starch with sulphuric acid. The molecule of starch is split up into numerous molecules of dextrose according to the formula

$$
\left(\mathrm{C}_{6} \mathrm{H}_{10} \mathrm{O}_{5}\right)_{n}+n \mathrm{H}_{2} \mathrm{O}=n \mathrm{C}_{6} \mathrm{H}_{12} \mathrm{O}_{6} .
$$

In the plant this hydrolysis is effected not by means of acids but by an enzyme called diastase. The enzymes $\left({ }^{41}\right)$ are the catalysators of the organism; the name catalysators is given to substances which influence the rapidity of a chemical reaction. We are mainly concerned with the acceleration of reactions. While many inorganic catalysators influence very various chemical processes, the influence of organic catalysators is quite specific; thus diastase only acts on starch. Since the catalysator either does not enter into the reaction or at least does not do so permanently, a small amount of it is able to hydrolyse a large quantity of the substance acted on, if the products of the reaction are continually removed.

Diastase is found in many parts of the plant, especially in those which contain much starch, such as foliage leaves and germinating seeds. The amount of diastase in an organ is not constant, but is regulated according to the needs of the plant; further its action can be arrested by the formation of other enzymes (anti-enzymes). Diastase can be extracted from the organs by water or glycerine, precipitated by means of alcohol from the extract and again clissolved, without any essential change in its properties. On the other hand diastase is very susceptible to high temperatures, and is rendered permanently inactive by heating to about $75^{\circ} \mathrm{C}$. All diastatically active extracts of the plant give a proteid reaction; it is, however, 
possible that diastase may only form a relatively small proportion of such substances, and may itself not be an albuminons substance.

In the plant diastase acts on the starch grains. These are corroded under its influence; they are dissolved away from withont inwards, but this proceeds as a rule irregularly, so that the shape of the grain changes. At particular spots the diastase eats more quickly into the grain and, using pre-existing splits and canals, breaks it up into smaller portions which then dissolve further. (Fig. 203.) Outside the plant the action of diastase can best be shown on thin starch paste; on adding diastase to this the characteristic iodine reaction is lost after a few minutes or a quarter of an hour. The blue colour given at
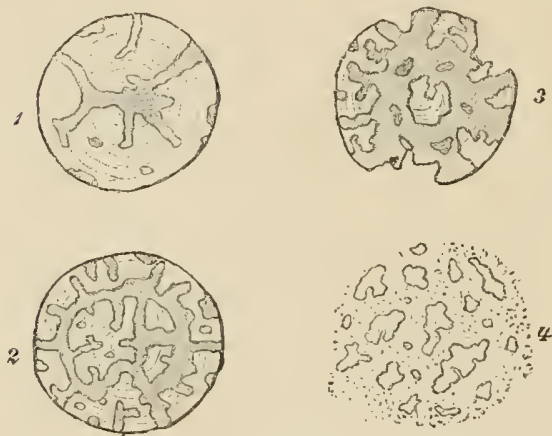

Fu: 203,-Different stages of the corrosion shown by the stareh grains of germinating Barley. first changes to a wine-red tint, and ultimately a yellow colour is given. Dextrin is an intermediate product between the starch and the dextrose.

Cellulose is also of frequent occurrence as a reserve substance. In the endosperm of many seeds the cell walls are very strongly thickened and the thickening layers are dissolved in the process of germination. Such thickened walls are beantifully shown in many palm seeds, e.g. in the Vegetable Irory Palm. The solution of the thickening is due to an enzyme, the so-called cytase, which, however, does not act on every variety of cellulose. Typical cellulose (p. 76) is not attacked by it, but only reserve cellulose, which differs in its chemical structure (p. $7 S)$. Corresponding to this difference, reserve cellulose yields on hydrolysis other products than does typical cellulose, viz. besides glueose the hexoses, mannose and galactose.

Inulin, which is found especially in Compositae and Campanulaceae, is related according to its empirical formula $\left(\mathrm{C}_{6} \mathrm{H}_{10} \mathrm{O}_{5}\right)_{n}$ with eellulose and starch, but is distinguished from these substances by always occurring in plants in the dissolved form. In spite of this it is incapable of translocation on accomnt of the size of its molecule, and is broken down on germination by an enzyme into a sugar of the formula $\mathrm{C}_{6} \mathrm{H}_{12} \mathrm{O}_{6}$. The sugar in this ease is, however, levulose.

Cane Sugar which oceurs for example in the sugar-eane and sugarbeet may be connected with inulin. It is converted by the widely spread enzyme "invertin" into equal parts of dextrose and levulose. 


\section{The Fats}

Though we are unable to manufacture the reserve carbohydrates mentioned cither from dextrose or levulose, we can understand that it is as easy for the plant to build them up as to break them down. It is much more difficult to understand in what way the plant is able to form fats (glycerine esters of various fatty acids) from carbohydrates. Fats are, as a rulc, absent from the assimilating cells; they occur on the other hand in large amount in many ripe seeds, where they are formed at the expense of carbohydrates. At germination they are decomposed by the enzyme lipase into fatty acids and glycerine. The fatty acid is capable of passing through the water-saturated cell wall more readily than the fat, but does not usually travel as such for any consiclerable distance in the plant; it is usually quickly converted into a carbohydrate. A fatty oil sometimes occurs in the succulent portions of fruits, e.g. in the oilpalm and the olive, and then does not enter again into the metabolism of the plant. Exceptionally it occurs in the wood and rind of some of our trees in winter, disappearing again in the spring; in this case it appears to be a means of protection against the cold.

\section{Albuminous Substances}

The products of the hydrolytic breaking down of albuminous substances are mainly amino-acids, the wide distribution of which in the plant has already been referred to. When seeds rich in proteid such as Ricinus, Pinus, etc. are germinating, the abundant aminoacids may be regarded as derived from the proteid. Amino-acids occurring in other situations may have arisen in the synthesis of proteids. The proteid-molecule does not prorluce at once or exclusively amino-acids; the breaking down of the very large molecule is a gradual one, in which the bodies which appear first have many properties in common with proteids; first comes albumose, then peptone, and only then amino-acils. With the latter appear hexonbases and ammonia, also products of decomposition containing sulphur and phosphorus, and generally carbohydrates also.

The breaking down of proteids takes place under the influence of enzymes which resemble the trypsin formed by the pancreas, and are therefore termed tryptic enzymes. They act best in a weakly acid solution.

The decomposition produets of albumen quiekly undergo changes in the plant $\left({ }^{42}\right)$, and therefore the mixture of nitrogenous organic compounds which one obtains from a plant kept in the dark is not ilentieal with the prodnets of the hydrolysis of albumen ontside the plaut. In the plant syntheses take place after the primary decomposition, and these lead to he formation of such substances as amides, the most widely spread of which is asparagin. These dominate in Gramineae and 
Leguminosae ( $15 \mathrm{~g}$. are present in a litre of sap from bean seedlings); they are replaced in Crueiferae and Cucmbitaceae by glntamin, while in the Coniferae a hexon-base, arginin, appears to play the same part. The syntheses proeeed still farther in light, when proteid may again be formed from the products of decomposition of albumen and from amides.

Albumen occurs in the storage places for reserve materials partly in a crystalline and partly in an amorphous form. The crystals occur free in the cytoplasm, nucleus, or in the chromatophores; in seeds they are found especially in the aleurone grains, where they are associated with globoids. The latter then contain $\mathrm{Ca}, \mathrm{Mg}$, and phosphoric acid in an organic compound (cf. p. 66).

\section{B. Transport of the Mobilised Reserve Materials}

When the reserve materials have been brought by the aid of the proper enzymes into the soluble form, or have been transformed into substances with smaller molecules, they are capable of being transported; we may speak of them as being mobilised. Their movements are governed by the general principles of translocation of substances discussed on page 186. It is especially necessary that a diffusion current should be established and maintained. This is brought about by the active growth of cells at a greater or less distance from the place of storage of the reserve material. As long as this lasts each molecule on its arrival at the place of growth is promptly transformed (e.g. sugar into stareh or cellulose), and thus room is made for the molecules that follow. A diffusion eurrent can also be artificially established where a storage structure under proper conditions is placed in relation on one side with a large amount of water. It is thus possible to bring about an emptying of seeds, bulbs, etc.

When substances have to be transported for considerable distances, the movement of diffusion since it goes on slowly, is replaced by movement in mass. Thus in spring the reserve materials depositei in the wood of our trees are carried up by the ascending current of water in these ressels; at this season the fluid in the ressels contains abunlant glueose. In the other direction a stream of mobilised reserve material can pass downwards from the foliage leaves by way of the sieve tubes. While, however, the mechanical causes of the transpiration stream are at least partially understood, so far as they depend upon the evaporation of water we do not know the forees concerned in movements in mass in the sieve-tubes.

The foliage leaves acemmulate during the day large quantities of starch (p. 219) which under favourable eonrlitions pass in a night by way of the leaf-stalk to the stem. If the sieve-tubes of one half of the petiole are cut across, the stream of earlohydrates is arrested and the eorresponling half of the leaf remains full of stareh. In stems also when these are "ringed," i.c. when a complete ring of the rind is removed, an accumulation of reserve materials is olserved at the upper 
eud of the ent; thus the substances cannot pass by means of the wool. Whether the sieve-tubes also conduct substances with large moleeules, such as proteids, without their previous decomposition, is still doubtful.

\section{Regeneration of Reseive Materials}

Sooner or later the reserve materials mobilised by the help of enzymes are again converted into substances with large molecules. This occurs at any rate at the end of their transport, whether they are again deposited as reserve materials or are employed as constructive substances. Thus, for example, glucose formed in a leaf may pass to a seed or a tuber and be there transformed into starch or celi-wall. When the transport is for a considerable distance the formation of reserve material may go on by the way and not only at the end of the journey. This is specially well seen in the case of starch. Along the routes of sugar-transport so-called transitory starch may be formed in every cell. This starch formation diminishes the concentration of the solution, and thus helps to maintain the continued motion of the diffusion current.

\section{Other Products of Metabolisir $\left({ }^{(3)}\right.$}

The chemical activity of the veretable cell is by no means limited to the production of the substances mentioned; the number of chenical compounds found to be derived from the first product of assimilation is a matter of continual surprise. Of most of them neither the manner of their formation nor their full importance in netabolism is understood. The conditions are not even fully known which are necessary for the formation and functional activity of the oradic AcIns (malic, tartaric, citric, ete.), which may in part be considered as produets of imperfect respiration, while they are produced by some Fungi to acidify the medium in which they live and render it less favourable for competing organisms. The conditions of formation and the significance of the equally widely-spread tannins are quite unknown. The function of the GLucosides is also imperfectly understood. These are compounds of sugars with a number of different substanees. They are soluble in water, and by the aetion of ferments or dilute acids are broken $u p$ into glucose and other derivative products. It is conceivable that the formation of glucosides (and tamnins) serves to locally fix substances which otherwise would readily diosmose. It might even be sugrgested that the polysaccharides, stareh and cellulose, might be regarded as glucosides of the sugars themselves. In the Amygdalaceae (Bitter Almonds, I'lum seeds), AYYGALIx is found which on fermentation yields hydroeyanic acid in addition to benzaldehyde. The Lima or Java beans (Phascolus lunatus), which of late years have been used for feeding eattle, also liberate hydrocyanic acid from a glucoside. In the wild form this may be in such quantity $(0.16$, er cent) that fatal poisoning has resulted. From a sinrilar eause Soryhum, Glycerie, and Lotus may be more or less poisonous. Glucosirles alpear in the Solanaceae as the poisonous soldNin, in the Cruciferae (mustard seeds) as MYNAIC ACID, in the bark of the Horse-chestnut as the extremely fluorescent AEsculin, in species of Digitalis as the poisonous DigrTALis, and in the cortex of Willow as "Alicis. Certain plants (Indigofere, Polygonnm tinctorium) contain IXIICAN, the glucoside of indoxyl; the latter substance is con- 
verted by oxidation into indigo. Woad (Isatis tinctoria) contains, on the other hand, the related glucoside Isatrs. Conifeis, which is present in the cambial sap of the Conifers, has recently acquired an economic value, as from it VANILLIN, the aromatic principle of vanilla, may be artificially prodnced. In this process the coniferin is decomposed, by the action of a ferment or acid, into glucose and coniferyl-alcohol, by the oxidation of which its aldehyde, vanillin, is formed.

It is as yet mnknown what part in the metabolic processes of plants is performed by the BITTEr PRINCIPLES, such as the LuPULIN of Hops, ALOIN of Aloes, ABSYNTHIN of Wormmood. There is the same uncertainty with regard to the functions of the ALKALOIDS. Since most alkaloids, STRYCHNINE, BRUCINE, VERATriNe, CONIINE, MUSCARINE, ATROPINE, QUININE, MORPHINE, CODEINE, ACONITINE, COLCHICINE, NICOTINE, PILOCARPINE, COCAINE, together with CAFFEINE (theine) and THEOBroMINE, which are closely related to uric acid, and many others are violent poisons, they furnish a certain protection to plants against destructive animals. This, however, does not preclude the possibility that they may at the same time have an important physiological significance. Thus, according to Treub, hydrocyanic acid plays the same part in the formation and transport of proteids in Pangium. edule and Phaseolus lunatus as the amides do in other plants. It must, however, be noted that alkaloids are also poisonous to the protoplasm of the plant.

The Colouming MatTers AND ETHEREAL oILs, althongh present only in small quantities, make themselves particularly noticeable to the senses of sight and smell. They probably represent only by- and end-products of metabolism and, with the exception of chlorophyll, take no further part in the vital processes of plants, except in so far as they are beneficial to the general well-being by enticing (e.g. flowers, fruits) or repelling (e.g. by warning colours) animals. Their oecological significance is accordingly much better known than their physiological functions. Jnst as the ethereal oils are frequently found in special excretory receptacles, the resins, gum-resins, and gum-nucilages, which are also excretion products, are usually deposited in canals or glandular cavities, and are often mixed with ethereal oils. Whether their formation in the particular instances is necessary for the carrying ont of the normal processes of metabolism is altogether nncertain. They are, at any rate, useful to plants when wounded, serving as a protection against evaporation and the attacks of parasites. On a square centimetre of the surface of the splint-wood of the Pine, sixty to seventy resin canals open, and the wood contains, according to MAYk, 22 kilos of resin in every cubic metre.

The significance in the economy of the plant of the so-called india-rubber (CAOUTChOdC) and GUTTA-PERCHA in the latex is still less known. In addition to these substances, there also occur in latex, resins, ethereal oils, alkaloids (in opium), leptomin, starch grains, and other carbohydrates, oil-drops, and albuminous substances. The presence of these substances, valuable as constructive material, and occasionally also of active enzymes (peptonising feruents are found in the milky juice of Ficus Carica and Carica Papaya), in the latex, gave rise to the suggestion that the latex cells and tubes function in the transport of the mutrient matter. Onr present knowlerlgc of these often caustic and poisonous saps is limited to their external utility in the economy of plant life. By their obnoxious properties they lefend plants from the attacks of enemies. Also, in the event of plants being wounded, the latex is pressed out cither by the surrounding turgescent tissue or by the tension of the clastic walls of its own cells, and forms, as it quicky coagulates in the air, an eflicient covering for the wound. In other plants, especially in trees, wound-gum serves the same purpose. (Pp. 143, 162.) 


\section{Respiration and Fermentation}

In the higher plants all the organic substance produced in assimilation is not used for eonstruction and storage purposes; a part of it is always broken down and returns to the state of inorganie compounds. The significanee of this process, whiel is usually associated with the absorption of oxygen, does not lie in the substances formed but in the liberation of energy which is essential for the life of the plant. In certain lower plants the necessary supply of energy may he obtained in other ways. Usually organic substances are absorbed from the substratum and broken down without being first assimilated. The decomposition may be effected by oxidation, reduction, or dissociation; all these processes are grouped together as fermentation. Other lower organisms can utilise the energy set free in the oxidation of certain inorganic compounds. Transitional forms oeeur between the varions methods of obtaining the necessary energy.

\section{A. Respiration}

By respiration in its typical form is understood the oxidation of organic material to carbon dioxide and water; this involves the absorption of oxygen from without (ef. p. 211). In the higher animals the process of respiration is so evident as not easily to escape notice, but the fact that plants breathe is not at once so apparent. Just as the method of the nutrition of green plants was only discovered by experiment, so it also required earefully conducted experimental investigation to demonstrate that PLANTS ALSO YUST BREATIIE IN ORDER TO LIVE; that, like animals, they take up oxygen and give off earbonic aeid. Although the question had already been thoroughly investigated by SAUssure, and by DUTRochet in the years 1822 to $183 \pi$, and its essential featmes correctly interpreted, LiEBig pronomeed the belief in the respiration of plants to be opposed to all facts, on the ground that it was positively proved that plants on the eontrary decomposed carhonic acid and gave off the oxygen. He asserted that it was an absurdity to suppose that both processes were earried on at the same time; and yet that is what oceurs.

Assimilation AND respifAtion ARE TWO DISTINCT VITAL PROCESSES CARRIED ON INDEPENTENTLY BY PLANTS. WHILE IN THE PROCESS OF ASSIMILATION GREEN PLANTS ALONE, AND ONLY IN THE LIGHT, DECOMPOSE CARBONIC ACID AND GIVE OFF OXYGEN, ALL PLANT ORGANS WITIIOUT EXCEPTION BOTH BY DAY AND BY NIGHT TAKE UP OXYGEY AND GIVE OFF CARBONIC ACID. Organie substanee, obtained by assimilation, is in turn lost by respiration. A seelling grown in the dark, so that assimilation is impossible, loses by respiration a considerable part of its organic s'lbstance, and its dry weight is considerably diminished. It has been found that during the germination of 
a grain of Indian Corn, a full half of the organic reserve material is consumed in three weeks. That green plants growing in the light aecumulate a considerable surphns of organic substance is due to the fact that the daily production of material by the assimilatory activity of the green portions is greater than the constant loss which is eansed

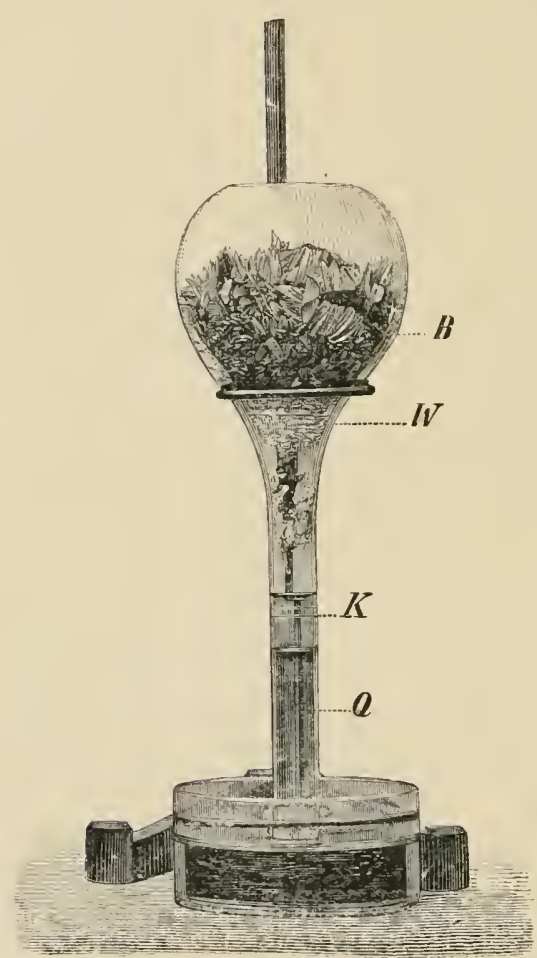

FIG. 204.-Experiment to demonstrate respiration. The inverted flask (B) is partially filled with flowers which are held in place by the plug of cotton (W). Owing to the absorption of the carbon dioxide exlaled in respiration by the solution of canstic jotash (K), the mereury (Q) rises in the neck of the flask.

heats of Compositae (B, by the respiration of all the organs. Thus, aecording to Boussingaulit's estimates, in the course of one hour's assimilation a plant of Sweet Bay will produce material sufficient to cover thirty houl's' respiration ${ }^{(44)}$. Plants produce in twenty-four hours about five to ten times their own volume of carbonic acid. In shade-plants this is usually reduced to twice the plant's volume, while the commonly cultivated Aspidistra prodnces only one-half of its own volume, and can therefore succeed even under conditions which are unfavourable to assimilation.

In order to demonstrate the existence of respiration either the absorption of oxygen or the giving off of carbon dioxide by the plant may be employed. If a handful of soaked seeds is placed at the bottom of a glass cylinder, the top of which is closed for a day by a glass plate, the oxygen in the space is used $u p$ by the germinating seeds; a candle will be extinguished if it is introduced into the cylinder. If germinating seeds or flowerheads of Compositae (B, Fig. 204) or young mushrooms are placed in a flask and prevented from falling ont when the Hask is inverted by means of a pling of cotton-wool (W), the mouth of the flask can be dipped under mereury (S) and some solntion of caustic potash (K) be introdueed above this. The carloon dioxide formed is then absorbed by the caustic potash and the mereury rises (Fig. 204). When this experiment is carried out quantitatively it is found that a fifth of the volume of air disappears, so that all the oxygen has been absorbed. 
Since, however, when no potash is present, the volume of gas is not altered by the respiration of the plants, an equal volume of carbon dioxide must be formed for each rolume of oxygen that is absorbed. If we assume that sugar is the substance respired, this nust take place according to the formula-

$$
\mathrm{C}_{6} \mathrm{H}_{12} \mathrm{O}_{6}+6 \mathrm{O}_{2}=6 \mathrm{CO}_{2}+6 \mathrm{H}_{2} \mathrm{O} \text {. }
$$

This is an exactly opposite process to the assimilation of carbon dioxide.

The rolume of air does not under all circumstances remain monanged by the respiration of the plant; the carbon dioxide produced is not always equal in volume to the oxygen which disappears. Small deviations from this ratio occur in all plants, and considerable ones, in, for instance, the germination of fatty sceds, and of the leares of certain succulent plants (Crassulaceae). This depends, on the one hand, upon other substances than carbohydrates being used in respiration, and, on the other, upon different end products than $\mathrm{CO}_{2}$ and $\mathrm{H}_{2} \mathrm{O}$ being formed.

In the germination of fatty seeds far more oxygen is absorbed than carbon dioxide is given off; this may go so far that in the first days in the dark, in spite of continual respiration, au increase in the dry weight takes place. MIost of the oxygen is used in the transformation of fats, which are poor in oxygen, into carboliydrates, and only a small proportion is used in respiration. In the Crassulaceae a large proportion of the carbohydrate is changed into organic acids in the process of respiration. The oxidation is thus incomplete; it does not lead to the formation of $\mathrm{CO}_{2}$, so that less of this gas is formed than the amount of oxygen absorbed would lead ns to expect.

This peculiar respiratory prosess which is connected with an accumulation of acids in the cell-sap, as ean be recognised by the taste, is not without oecological significance for succulent plants. Since in them gaseous exchange is difficult, they retain the carbon once it has been obtained and diminish their nced of absorbing $\mathrm{CO}_{2}$ from the atmosphere $\left({ }^{45}\right)$.

Probably other organic acids, the wide distribution of which in plants has been referred to, are products of incomplete oxidation.

It is not so casy to demonstrate the formation of water in typical respiration as it is to show the ntilisation of oxygen and the production of carbon dioxide. Quantitative estimates of the loss of dry weight and of the carbon dioxide formed show that the latter does not account completely for the former; a part of the dry substance must thus have been transformed into water.

As has been mentioned, respiration is of general occurrence in the higher plants. It not only occurs in the parts of plants which do not possess chlorophyll and are commonly used in experiments on respiration, but can be demonstrated also in cells which contain chlorophyll. In this case the respiration in the light is masked by the quantitatively greater process of assimilation; it appears only as a diminution in the products of assimilation. If the light is diminished assimilation ultimately ceases and the respiration becomes evident.

Though respiration goes on in every cell its intensity varies greatly in 
different organs and under various external conditions. Actively growing parts of plants, young Fungi, germinating seeds, flower-buds, and especially the inflorescenees of Araceae and Palms, exhibit very active respiration. In some Bacteria and Fungi this exceeds, as compared with the body-weight, the respiration of the human body. In most eases, however, especially in parts of plants composed wholly or mainly of full-grown tissues, the consumption of oxygen and production of earbon dioxide is consirlerably less than in warm-blooded animals. Among external conditions which have an important influence on the intensity of respiration the temperature and the amonnt of oxygen must be especially mentioned. An increase of temperature accelerates respiration as it does all the vital processes. The production of carbon dioxide is about doubled or trebled by a rise of $10^{\circ} \mathrm{C}$., just as other chemical processes outside the plant are. With continued rise of temperature, however, the respiration diminishes. In contrast to other like phenomena the fall in the respiratory enrve is exceedingly steep, so that the optimum and maximum almost coineide.

Respiration is eommonly spoken of as a process of combustion. Were this correct it might be expected that the amount of available oxygen would be of fundamental importance $\left({ }^{46}\right)$; in particular it might be anticipated that respiration wonld be greatly increased in pure oxygen and completely suspended in a space free from oxygen. Neither of these assumptions is true. Respiration is not markedly increased in pure oxygen and only at a pressure of 2-3 atmospheres of oxygen does an increase in the respiration become perceptible; this is soon succeeded by a decrease in the respiration indicating the approach of death. Even more striking is the fact that plants in the absence of oxygen continue to produce carbon dioxide. In this case one cannot speak of a process of combustion; the phenomenon is termed INTRAMOLECULAR RESPIRATION because the carbon dioxide which is formed owes its origin to a rearrangement of the atoms in the molecule of the sugar which serves as the material for respiration. The molecule of sugar breaks down and forms, in addition to earbon dioxide, other reduced eompounds. It may be said that this kind of respiration depends on the withdrawal of combined oxygen from one gromp of the sugar molecnle and its combination with other groups. Very often aleohol or other rerluced compounds are thus formed.

Some seeds can remain alive for many hours or days with intramolecular respiration, and some even continue to give off the same amount of carbon dioxide as in ordinary respiration. In most cases, however, the amount of $\mathrm{CO}_{2}$ rapilly diminishes. In other plants death soon occurs, probably owing to the reduced compounds acting as poisons. The value of intramolecular respiration is in these cases only slight. On the other hand it has a very great importance in eertain organisms which will be referred to later. 
It may be assumed that oxygen-respiration and intramolecular respiration are expressions of one and the same property of the plant, in other words that on withdrawal of oxygen normal respiration passes over into intramolecular respiration. If this is true, it follows that the essence of respiration does not consist in an oxidation process but in a breaking down of organic substance in which products arise that readily take up oxygen. The materials which are respired in the plant, such as carbohydrates and proteid, are not easily oxidisable at ordinary temperatures. Fats, it is true, which may also serve as material for respiration, are oxidisable, but in this case we know that they are transformed into carbohydrates before they are used for respiration by the plant. The plant must thus have at its disposal special means in order to carry on the oxidation and the preceding decompositions that are involved in respiration. It is scarcely to be don\}ted that enzymes are concerned in this, but we have at present no insight into their precise action $\left({ }^{47}\right)$.

At first sight respiration appears a contradictory process, since in it organic material which has been built up in assinilation is again broken down. If a supply of energy is required for the construction of organic material, energy will be set free on its decomposition. On this liberated energy the plant is dependent for the driving force in many of its vital phenomena. Movement of protoplasm, growth, and movements due to stimuli cease on the withdrawal of oxygen from the plant. All these vital phenomena begin again on the restoration of a supply of oxygen, if this is not too long delayed. It might have been expected that the organism would possess arrangements by the help of which the external energy of light or heat could be employed as driving power. Practically, however, it is found that the plant proceeds to store up the energy of the sun's rays in the form of potential ehemical energy, and then utilises this at need.

\section{B. Oxidation of Inorganic Material (48)}

While most plants use organic compounds, especially carbohydrates in respiration, certain Bacteria utilise other sources of energy which are more economical. Thus, the nitrite bacteria which commonly occur in the soil oxidise ammonia to nitrons acid, and the associated nitrate bacteria further oxidise the nitrous acid to nitric acid. By the help of the energy thus obtained they can then-as has already been pointed ont on p. 220 -assimilate carbon dioxide; the chemical energy takes the place for them of the sun's energy in the typical antotrophic plant. It is uncertain whether a true respiration exists in addition to this process. Probably, however, this is not the case; the whole of the assimilated nutritrive substance is thus retained, so that the working of these organisms is very economical. Since, however, only a limited amount of ammonia is available, and this is 
derived from other organisms, they cannot take the dominant place in nature which the green plants do.

The transformation of ammonia to nitric acid is of use to the higher plants for which nitric acid is the best source of nitrogen (p. 226).

With the nitro-bacteria the so-called sulphur-bacteria may be associated; these oxidise sulphuretted hydrogen to sulphuric acid, sulphur being an intermediate product, and being stored in the body of the plant. Probably some of them (Beggiatoa) are able to assinilate carbon dioxide by the help of chemical energy and without chlorophyll or light. It is doubtful whether the oxidation of ferrous to ferric oxide by the iron-bacteria is a sonrce of energy. On the other hand, the oxidation of methane and hydrogen, which has been shown to be eflected by certain bacteria, may have this significance.

\section{Ferientation.}

With the removal of oxygen intramolecular respiration begins, but this cannot supply the necessary energy to maintain life in the higher plants, althongh it may do so in lower organisms. Nany Bacteria, Fungi, and certain Algae (Characeae) are notably independent of a supply of oxygen; they succeed with slight traces of this gas, or they avoid it altogether and live in situations where oxygen is absent. Such organisms are called anaerobes or anaerobionts in contrast to the typical aerobes or aerobionts. All intermediate stages connect the two extremes. The true anaerobionts decompose large amounts of organic substances, and this decomposition, which is in principle the same as the process of intramolecular respiration, is termed FERMENTATION. As in intramolecular respiration these processes are concerned with obtaining combined oxygen. The prototype of fermentation is the alcoholic fermentation brought about by the yeast fungus. In this sugar is split up into alcohol and carbon dioxide, and the process has great technical importance in the production of beer, wine, and brandy. The chemical process is the same as that of intramolecular respiration in a green plant; in contrast to this the yeast plant obtains in the fermentation a complete substitute for respiratory activity. It is, however, only independent of oxygen when it is supplied with a suitable fermentable material (sugar). In the absence of sugar, oxygen is indispensable, and normal respiration takes place. When both sugar and oxygen are supplied, respiration and fermentation go on simultaneously; part of the sugar is transformed into $\mathrm{C}_{2} \mathrm{H}_{6} \mathrm{O}$ and $\mathrm{CO}_{2}$ and another part into $\mathrm{H}_{2} \mathrm{O}$ and $\mathrm{CO}_{2}$. Obviously, the transformation of sugar into alcohol and carbon dioxide will provide much less energy than the complete combustion to carbon dioxide and water. It is thus easy to understand that yeast utilises enormous quantities of sugar. Only about 2 per cent of the sugar in the nutrient solntion is used in the construction of the substance of the plant, i.e. is assimilated; the rest is fermented. For effecting this extensive decomposition of the sugar, yeast employs a specific enzyme (zy'mase), the existence of which was demonstrated by E. Bucuner $\left({ }^{49}\right)$. 
This feature of apparently great waste of material is found in other fermentations, in which by a rapid breaking down of carbohydrates and proteids the fermenting organisms obtain a supply of cnergy. It is impossible to draw a sharp line between those decompositions which go on without the assistance of atmospheric oxygen and those in which oxygen plays a part. We are obliged to class as fermentations all those metabolic processes by which energy is obtained, which differ from typical oxygen respiration. In this sense the oxidation of alcohol to acetic acid effected by the acetic acid bacteria and also the production of acids in the higher plants, especially in succulent plants (p. 243), would be fermentations. Lastly, the processes of denitrification and of reduction of sulphates, in which anaerobic bacteriaprobably in order to obtain oxygen-reduce nitrates to free nitrogen and sulphates to sulphuretted hydrogen, cannot be excluded from fermentations.

Many fermentations have another significance besides that of obtaining energy. The products of fermentation such as alcohol, acids, etc., are poisons; they are, as a rule, more injurions to other organisms than they are to those which produce them. On this account they are suiterl to exclude other organisms from the supply of food material. It is true that a fermentation organism in a pure culture on a definite substratum renders, by the products of its metabolism, the latter not only unsuitable to concurrent organisms but sooner or later for itself. When organic material, as is the case in nature with the remains of dead organisms, is the prey of various micro-organisms these co-operate in their action; metabolic products of one kind of micro-organism are further decomposed by others until the organic compounds are converted into inorganic or mineral substances. The final products are water, hydrogen, methane, ammonia, nitrogen, and sulphuretted hydrogen, and all of these can be oxidised or assimilated by some other organisms. It is only by this co-operation of all organisms that life is maintained on the earth and the elements again brought into circulation. If only onc type of organism existed, it would in a short time have destroyed the possibility of its own existence by its one-sided metabolism.

\section{Production of Heat and Ligint in Respiration and Fermentation}

Heat.- Since typical Respiration is a process of oxidation, it is easy to understand that it is accompanied by an evolution of heat. That this evolution of heat by plants is not perceptible is due to the fact that it is not sufficiently great, and that considerable quantities of heat are rendered latent by transpiration, so that transpiring plants are usually cooler than their ent ironment.

The spontaneous evolution of heat is easily shown experinientally, if transpira- 
tion and the loss of heat by radiation are prevented and vigorously respiring plants are selected. A quantity of germinating seeds (peas) shows under proper conditions a rise in temperature of $2^{\circ} \mathrm{C}$. The greatest sprontaneous evolution of heat manifested by plants has been observed in the inflorescences of the Araceate in which the temperature was increased by energetic respiration $10^{\circ}, 15^{\circ}$, and even $20^{\circ} \mathrm{C}$. Also in the large flower of the Fictoric regia temperatme variations of $15^{\circ} \mathrm{C}$. have been shown to be due to respiration. One gramme of the spadix of an Aroid exhales, in one hour, $n \mathrm{p}$ to 30 eubic centimetres $\mathrm{CO}_{2}$; and half of the dry substance (all the reserve sugar and starch) may be consumed in a few hours as the result of such vigorous respiration.

Specially high temperatures are obtained by cutting up living leaves in Iarge quantity and ensuring a sufficient supply of oxygen. Under these conditions MoLtscin obtained a temperature of $60^{\circ} \mathrm{C}$. The leaves naturally perished.

In the healing of wounds in plants, respiration and also the production of heat are markedly increased; the contrary is seen in conditions of starvation.

In some fermentations, e.g. alcoholic fermentation, a considerable quantity of heat is evolved. The heat of rotting manure is well known and employed in the construction of hot-beds.

In the fermentation of tohacco also a considerable rise in temperature takes place. This is still more marked when damp hay or cottonwool is piled up in large quantity and left mudisturbed; by the forma-

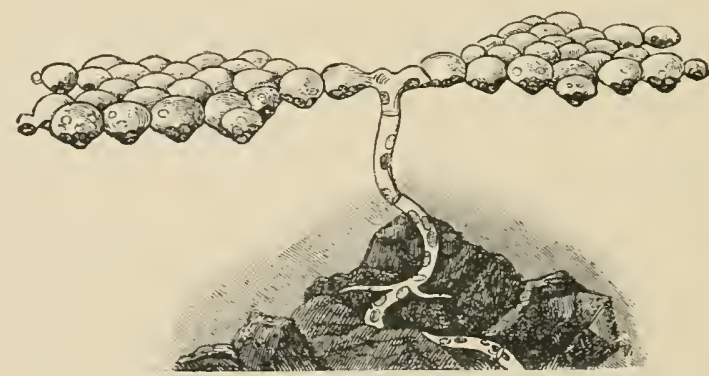

Fic, 205.-Protonema of Schistostega osmunduceu. The lens.shaperl cells concentrate the feeble light available to the habitat of the plant upon the chloroplasts. (Cf. Fig. 20ij.)

tion of easily inflammable gases, this may lead to the spontaneous combustion of the material. MıEHE has most recently investigated the spontaneons heating of hay. First by the respiratory activity of Bacillus coli the temperature is raised to $40^{\circ} \mathrm{C}$.; then a number of thermophilous Monlds and Bacteria become established, among which Biccillus culfactor raises the temperature to $70^{\circ} \mathrm{C}$. Ultimately all the organisms perish owing to the temperature to which they have given rise and the hay becomes sterile $\left({ }^{49}\right)$.

Phosphorescence $\left({ }^{50}\right)$. - Under the same conditions as those of respiration a limited number of plants, prarticularly Fungi and Bacteria, enit a phosphorescent light. The best-known phosphorescent plants are certain forms of Bacteria which occur in the sea, and the mycelium, formerly described as "Rhizomorpha," of the Fungus Armillaria mellea. $\Lambda$ s further examples of spontaneonsly lnminous Fungi 
may be cited Aguricus olearius, fount growing at the foot of olive trees in South Europe, Polyporus sulphureus and other less familiar Agaries (Ay. iyneus, noctiluec ns, Gurheri, Mycena illuminums, etc.). The phosphorescence of decaying wood is also in part, due to the growth of Fungi or Bacteria, but sometimes to an insect $\left(N_{\text {canura }}\right.$ ) which reacts in this way when disturbed. Harmless phosphorescent Bacteria (Microspira photogena, Psendomonas lueifera) occur on phosphorescent fisl or meat. According to HoLisc н Bactcrium phosphoreum (Micrococeus phosphoreus) usually occurs on meat which has been moistened with a 3 per cent solution of common salt and kept at a low temperature. The most important plants taking part in the phosphorescence seen in the sea are Pyroeystis noctilucu, belonging to the Gymnodiniaceae and certain Peridineae. Their lhosphorescence, according to observations on Ceratium tripos made by ReINkE, is bronght about by mechanical as well as by thermal and chemical stimuli.

This plosphorescence at once disappearsin an atmosphere devoid of oxygen, only to reappear on the admission of free oxygen. On this account the phosphorescent Bacteria, according to BEYEnxck, afford a delicate test for the activity of assimilation. All the

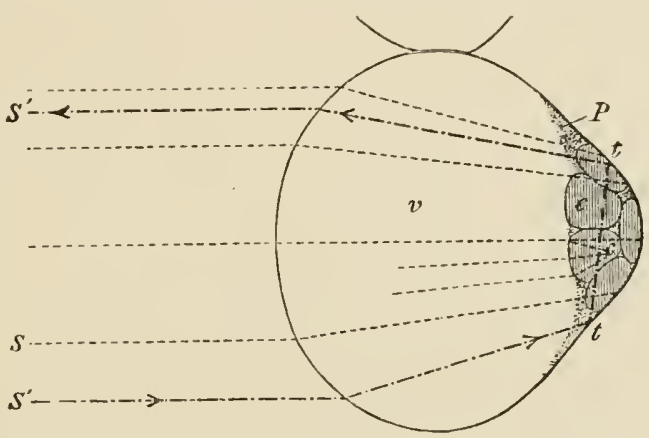

Fig. 206.-Phosphorescent cell of the protonema of Schistostega. $S^{\prime} S^{\prime}$, Path of a ray of light, which, alter passing through the chloroplasts, acquires a green tinge and is totally reflected. (Cf. Fig. 205.) ciremustances which facilitate respiration intensify phosphorescence; the converse of this is also true. According to the results of investigations concerning the phosphorescence of animals, from which that of plants does not probably differ in principle, the phospliorescence is not directly dependent upon the respiratory processes.

The so-called phosphorescence of the Moss Schistostega and of the Flagellate Chromophyton liosanoffii has nothing in common with actual phosphorescence, but is produced solely by the reflection of the daylight from peculiarly formed cells (cf. Figs. 205, 206). The phosphorescence observed in some seaweeds results, on the other hand, from the fluoreseence and opalescence of certain of their albuminons substances, or from the iridescence of their cuticular layers. The latter condition is also found in some Selaginellas.

\section{SUB-SECTION II}

\section{DEVELOPMENT}

Development accompanied by changes of form due to growth is one of the most general and striking of the vital phenomena of the plant. A mere increase in volume does not neeessarily imply growth for no one would say that a dried and shrivelled turnip grows when it swells in water. Only permanent and irreversible increase of size 
can be termed growth, and this whether the plant as a whole is gaining or losing in substance. Usually growth is associated with gain of material, but in the case of potatoes spronting in a dark cellar loss takes place by transpiration and respiration, and yet the shoots exhibit growth.

So long as a plant lives it exhibits growth if the necessary external conditions are present. If these are wanting, the plant may lead a "latent" life in which it retains the capacity for development. This latent life does not last indefinitely; even seeds, which exhibit it most completely, lose their power of development in the comrse of months or years and die. Particular organs in many plants lose their power of further development more or less completely; they become fullgrown and sooner or later perish.

In the simplest plants, such as the lower Algae, Fungi, or Bacteria, development consists merely in growth of the cell followed by eelldivision. These cases have been sufficiently dealt with in the morphological section. In more complex plants growth and division of cells are also found, but these processes appear snbordinated to the growth of the whole. In this three distinct processes can be distinguished, though they are not always separated in time. These are the stage of FORMATION OF EMBRYONIC ORGANS, that of ELONGATION, and the stage of INTERNAL DEVELOPMENT $\left({ }^{51}\right)$. These processes must be considered separately and their dependence upon a variety of factors discussed.

\section{The Embryonal Development of the Organs}

Plants, in contrast to the higher animals, continually develop new organs. These arise either from tissues retained in their embryonic condition, as at the growing point, or they have their origin in regions which have already more or less completely attained their definite form. The leaves and shoots spring directly from the tissues of the growing point; the first lateral roots, however, make their appearance at some distance from the growing point, where a perceptible differentiation of the tissues has already taken place.

Leafy shoots may also take their origin from old and fully developed tissues, which then resume an embryonic character, accompanied by an accumulation of protoplasm and renewed activity in cell division. Organs which thus arise ont of their regular order are termed ADVEnTITIOUs. As a rule, however, they develop from the growing point, either at once or after a longer or shorter period of rest.

- The manner of the Formation of New Organs at the Growing Point has already been described in the morphological portion of this hook. In the development of the embryo of the higher plants, two growing points, one of the shoot and the other of the root, are produced. A corresponding polar differentiation into base and apex also occurs in much more simply constructed plants, and even in single cells. Since 
the roots in their direction of growth react differently to light, gravity, etc., than do shoots, it might be supposed that the polarity of the embryo was determined by similar external faetors. This, however, only holds for eertain lower plants. Thus, for example, in the germination of the spores of Equisetum and of the eggs of the Fucaceae and Dictyota the direction of the first dividing wall, and therefore the positions of the base and apex of the plant, is determined by the direction of the light. Similarly an influence of gravity has been shown on the first wall formed in the fertilised egg of MLursileu $\left({ }^{52}\right)$. As a general rule, however, interual and unknown factors detemine the polarity, and even when this is primarily effected by external faetors it cannot later be altered by their influence.

On the other hand, in some simply organised Siphoneae the internal polarity is easily overcome by external influences. It is sometimes suffieient merely to rever'se the ereet thallus of Bryopsis, to convert the former apieal portion into a root-like tube which peuctrates the substratum and fastens itself to the grains of sand. It has also been positively determiner, although otherwise sueh cases are unknown among the higher plants, that the growing points of the roots of Ncottia and of certain Ferns (Platycerium Asplenium esculentum) may be converted through some inherent tendency into the vegetative cone of a stem (cf. p. 47) $\left({ }^{53}\right)$.

The symmetry of the growing point generally depends on its inherited internal nature. In some cases, bowever, it is possible by a one-sided influence of light to eonvert a radial growing point into a dorsiventral one $\left({ }^{54}\right)$. Thus, for instance, Antithamnion cruciatum, one of the Floridene, bears its successive branches decussately when grown in diffused light; when illuminated from one side these branches form in the plane at right angles to the rays of light. Other examples of dorsiventrality induced by unilateral illumination are afforded by the shoots of many Mosses, the thalli of most Liverworts, and lastly the prothalli of Ferns; these struetures in the absenee of the one-sided illumination sometimes become radial and sometimes bilateral. Thus, in Fern-prothalli and in IIurchantia the upper side is determined by the stronger illumination. While, however, on inverting prothalli the new growth adapts itself to the altered relations to light and the former upper side becomes the lower surface, in the case of the thallus of Marchantia the dorsiventrality when onee established cannot be changed.

In Adventitious Formations, on the eontrary, the influence of external forces is often very evident $\left({ }^{55}\right)$, as, for example, in the forma tion of climbing-roots, which in the Iry and other root-climbers are developed only on the shaded side of the stem. In the Alga Caulerpa the new leaf-like organs arise only on the illuminated side of the parent organ. It is, on the other hand, the foree of gravity which excites the formation of roots on the lower side of underground rhizomes, and determines that new twigs levelop, for the most part, from the upper side of the obliquely growing branehes of trees. Contact stimuili, on 
the other hand, determine the primary inception and point of development of the haustoria of Cuscutu.

MECHANI:AL INFLUENCES, probably stresses at the plices of development of lateral roots learl to the lateral roots developing only on the convex side of a curved main root (Fig. 207). Chemical STINULI have doubtless great significance in organogenesis; proceeding from foreign organisms, they determine the formation of (AALLS $\left({ }^{56}\right)$.

The development of adventitions formations is especially induced by Mutilation of plants; the same effeet may result when the organs

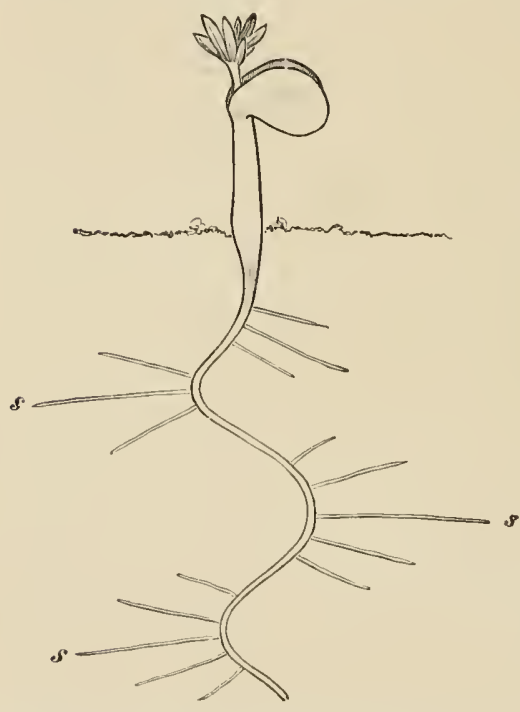

Fig. 207.-Young plant of Lupine, the main root of which has become curved. The lateral roots frave arisen on the convex faces of the curves, and aet as stays. or growing points though uninjured become functionless. New FORMATIONS are in this manner produced at points from which they would never have arisen on the iminjured plants. In the case of Pelargoniums, Willows, and many other plants, it is possible to induce the formation of roots wherever the shoots are cut. In other plants, however, there seem to be certain preferred places, such as the older nodes, from which, under the same circumstances, roots develop. In like manner new shoots will appear in the place of others that have been removed. IN THE DEVELOPMENT OF NEW FORMATIONS ON A MUTILATED PLANT THOSE VLRY ORGANS ARISE, OF WIIICH THE PLANT HAS BEEN DEPRIVED. Rootless shoots develop first of all new roots. Roots and rootstoeks deprived of their shoots form first new shoots.

While the apical and the interealary growing points are specially adapted for such regenerative processes, the same power may also be possessed by fully grown parenchymatous cells; in some plants this is very marked.

The polarity of the body of the plant is exhibited in a striking mamer in the phenomena of regeneration. Every small isolated portion of the stem or root exhibits from intermal causes (p. 253) a distinction of base and apex which was not apparent when it formed a part of the intact plant. Each portion of stem produees new shoots at its apical end (shoot pole) and new roots at its basal end (root pole). Each portion of root forms shoots at the end which was nearest to the stem and roots at the enrl directed to the root-apex. A similar 
reaction may also be found in isolated eells. If a filament of clurlophora is eut into single cells, each of them forms at its basal end a colourless rhizoid and at the apical end a green filament $\left({ }^{57}\right)$.

This contrast of base and apex does not hold in the case of foliage leaves. This depends on the faet that the regenerating leaf is not ineluded in the new formation. The latter arises as a completely new plant at the base of the leaf while the leaf itself perishes. There are further cases in which polarity is wanting or but slightly developed in stems and roots.

It is of especial interest to observe the effect of external influenees upon the position of new formations when they come into opposition to the internal disposition of the plants themselves. In this respect the behaviour of different species varies greatly. In one, the internal factors predominate, that is, the new formations apyear quite indejendently of external conditions; in another, the external influenees for the moment prevail, but the internal disposition of the plant, when thus constrained for the time being, ultimately makes itself apparent and the new formations never develop vigorously. A willow twig, planter in a reversed position, with the shoot-pole in the ground, will produce roots, and from the root-pole may even produce shoots. These, however, usmally soon die and their place is supplied by other stronger shoots arising from the shoot axis just above the roots. In soealled "weeping" trees the formation of side branches from the mper side of the hanging branches is favoured by external conditions, but the internal polarity prevents their vigorous development, and those formed soon die. In the cultivation of vines and fruit trees this peeuliarity is utilised to produce short-lived, fruitfrorlucing shoots by bending over the vines or training the branches of the trees in the cultivation of wall fruits $\left({ }^{58}\right)$.

The phenomena of regeneration have great importance in horticulture since they allow of plants being rapidly multiplied without the aid of seeds. In artificial reprodnction detached pieces of plants are made use of for the purpose of producing a fresh complete plant. In many cases this is easily done, but in others it is more difficult or even impossible. The favourite and easiest method is by means of currixas, that is, the planting of eut branches in water, sand, or earth, in which they take root (Oleander, Pelargonium, Tradescuntia, Fuchsia, IVillow, ete.). Many plants may be propagated from even a single leaf or portion of a leaf, as, for instance, is usually the ease with Begonias. In other eases the leaves, while still on the parent plant, have the power to prorluce adventitious buds, and, in this way, give rise to new plants (see Vegetative Reproduction). Even from roots or piees of roots it is also possible to propagate some few plants. An example of this is afforded by Ipecacuenha, whose roots are ent in pliees and then sown like seeds. The Dandelion possesses the same capability of developing from small portions of the root, and to this peculiarity is due the dificulty with which it is destroyed.

The polarity which is noticeable in phenomena of regeneration also influences the practice of grafting. Unlike poles of a plant may readily be induced to grow together, while like poles may only be bronght to do so with difficulty, and then do not develop vigorously. As a result of such experiments, a radial polarity has also been recognised by Vöchtrng in stem and root tissne: thus, for instance, pieces of a stem or root, inserted in a lateral incision of a similar organ, 
become united with it, if they are so placed that the side originally ontermost occupies the same relative position in the new organ, but if this position is altered no such union takes place. Such grafting experiments are of interest from another point of view. When the two portions unite and fuse no regeneration takes place. One adopts the root system of the other and conversely is adopted by this. This leads us to consicler the mutual relations of parts of the plant or what is known as CORrELATION OF GrowTH $\left({ }^{60}\right)$. This plays an important part in the normal ontogeny and leads, not only to the suppression of
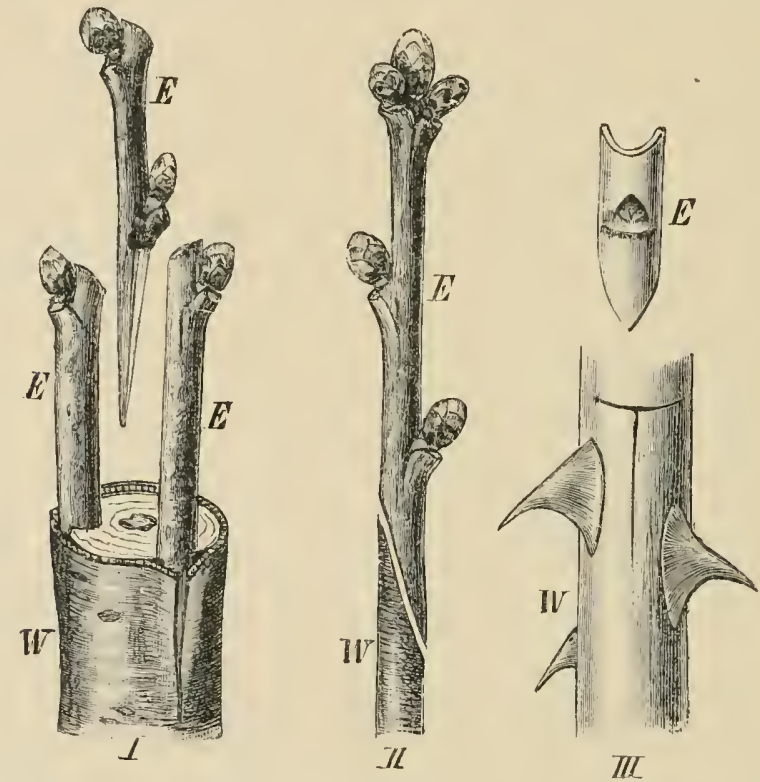

FlG. 205.-Different modes of grafting ; $I$, Crown grafting ; $I I$, splice grafting; $I I I$, bul grafting; $W$, stock; $E$, scion.

an organ that might develop, but also to the origin under certain conditions of new organs. Its influence will be frequently alluded to.

Artificial grafting, like artificial propagation, plays an important part in hortienlture. A ent off portion of a plant bearing buds, the scion, is induced to unite with another rooted plant which is called the stock.

In practice several different methods of inserting grafts are in use, but only the more important can be mentioned here. GRAFrivg is the union of a shoot with a young and approximately equally-developed wild stock. Both are eut obliquely with a clean surface, placer together, and the junction protected from the entrance of water ancl fungi by means of grafting wax (Fig. 208 II). Cleft or tonguc grafting is the insertion of weaker shoots in a strouger stock. Several shoots are uswally placed in the cut stem of the stock, care being taken that the cambial region of the different portions are in contact, and that the cortex of 
the shoots is in contact with that of the stock. In other methods of grafting, the cut end of the shoot is split longiturinally and the cut shoot is inserted in the periphery, or a graft may be inserted in the cortex or in the side of the stock. In grafting in the cortex the flatly-ent shoot is inserted in the space cut between the bark and the splint wool (Fig. 208, I). In lateral grafting, the shoot, after being cut down, is werlger into a lateral incision in the stock.

A special kind of grafting is known as BudDixa (Fig. 208, $I I I$ ). In this process a bud ("eye") and not a twig is inserted under the bark of the stock. The "eye" is left attached to a shield-shaped piece of bark, which is easily separated from the wood when the plants contain sap. The bark of the stock is opened by a T-shaped eut, the "eyc" inserted, and the whole tightly covered. Occasionally some of the wood may be detached with the shield-shaped piece of bark (budding with a woody shield). In the case of sprouting buds, the budding is marte in spring; in dormant buts, which will sprout next year, in summer.

The union is accomplished by means of a callus (p. 162), formed by both the seion and the stock. Vessels and sieve-tubes afterwards develop in the callus, and so join together the similar elements of both parts. Such an organic union is only possible between very nearly related plants: thus, for example, of the Amygdalaceae, the Plum, Peach, Almond, and Apricot may readily be grafted one upon the other; or of the Pomaceae, the Apple with the Quince ; but not the Apple with the Plum, nor (as has been asserted) with the Oak.

In spite of the physiological union between the old stock and the newly. formed growth, from a morphological standpoint they lead altogether separate and distinct existences. They may, however, exert an influence on each other ; thus anmul plants grafted on biennial or peremial stocks attain an extended period of existence. In structural character, forms of tissues, mode of secondary growth, formation of bark, etc., each maintaius its own individuality. In special cases it has been athirmed that they do mutually exert, morphologically, a morlifying effect upon each other (graft-hybrids). (Fig. 221) $\left({ }^{61}\right)$.

\section{The Phase of Elongation}

For the performance of their proper functions, the enbryonic rudiments of the organs must unfold and enlarge and assume their characteristic appearance. This subsequent enlargement of the cmbryonic organs of plants is accomplished in a peculiar and economical manner. While the organs of animals increase in sizo only by a corresponding increase of organic constructive material and by the formation of new cells rich in protoplasm, and thus require for their growth large supplies of food substance, plants attain the chief part of their enlargement by the absorption of water-that is, by the incorporation of an inorganic substance which is most alumdantly supplied to them from without, and to obtain which no internal nutritive processes arc first nccessary.

The absorption of water by living cells does not take place with the same rapidity and without interruption as in the case of porous bodies. Before the cells ean take up additional water they must enlarge by actual processes of growth. The water, penetrating the young cells by imbibition or by the force of osmotic pressure, is uniformly distributed through the protoplasm, which fills the cell; 
when the protoplasm is fully supplied with water it is accumnlated in vacuoles (Fig. 57). As the vacuoles contain also organic and inorganie substances in solution, they exert an attractive force and give rise to further absorption of water. The sap of the vacuoles would, in turn, soon be diluted and its attractive force diminished, were it not that the regulative activity of the protoplasm soon provides for a corresponding increase of the dissolved salts, so that the concentration and attractive force of the sap are continually being restored or even increased. Thus, for example, by a change of glucose into oxalic acid the osmotic pressure can be trebled. The separate vacuoles, thus enlarged, ultimately flow together into one large sap-cavity in the middle of the cell.

Osmotic pressure seems also to take an important part in the growth of the cell wall itself. Cells in which the turgor is destroyed by a decrease in the water-supply exhibit no growth of their cell walls; it is thus evident that the distension of the eell walls is pliysically essential for their surface-growth. This distension is in itself, however, by no means the cause of their growth; the internal physiological conditions of the growth of the cell walls are dependent upon the activity of the living protoplasm. Without the coneurrent action of the protoplasm, there is no growth in even the most distended cell wall; on the other hand, active growth of the cell wall may take place with the existence of only a small degree of turgor tension. A correspondence between the turgor tension of the cell walls and the amount of growtl cannot under these conditions be exprected, nor can, on the other hand, the conclusion be drawn that turgor tension is inoperative in the processes of growth. The importance of the turgor tension is variously estimated, according to whether the growth of the cell wall is regarded as resulting from the interpolation of new particles of constructive material between the already existing particles of the cell wall substance (IxTUssusceptios) or to the plastic (i.e. inelastic, not resuming its original position) expansion of the distended cell wall. In the latter case the growing membrane would continually become thinner, and require to be strengthened by the deposition of new layers upon it (Apposiriox). Both processes, which may ocenr together, probably take part in the growth of cell walls. The necessity of a certain amount of turgor, if growth is to result from plastic stretehing, is self-evident; the stretching of the wall by the internal tension, though facilitating the introduction of the new particles in growth by intussusception, is, however, not so indispensable in this case.

The assumption of a growth by intussusception is intimately related to the views leeld as to the finer (or so-called molecular) structure of organic substances. The power of swelling in water, which may even lead to complete solution, exhibited by organic substances, shows that the water of imbibition does not merely penetrate into preexisting capillary spaces, but makes a passage for itself by seprarating the solid particles from one another. It is further evident that these particles must be of mimte (molecular) size. The intimate penetration of the water is the expression of a powerful molecular attraction, which is capable of exerting an enormous force ; it is rendered possible by the peculiar molecular construction of organic substances, the cohesion of which is only gradually overcome by the water present in excess. The arrangenent of the particles has been pictured as resembling a network or a honeycomb, while the frecunent occurrence of duuble refraction as an optical property of organic substances has been explained as due to the erystalline structure and definite arrangement of the groups of molecules (micellae of NAEGELI) or to the relations of tension in a colloidal honeycomb-like system (Bürschl L). The new cellulose particles would penetrate into the cell membrane, as particles of colouring matter may be introdneed with the imbibition water into il colloil organic substance $\left({ }^{62}\right)$. 
By the growth in surface of the cell wall the volume of the cell may increase a hundredfolr or more withont any marked increase in the amount of protoplasm. The enlargement of the cell has been almost wholly produced by the increased volume of water in the sap eavity, which (to distinguish it from the "imbibition water," and "constitution water" of the plant) may be designated "distension water."

As is observed in a whole series of vital phenomena, the ratc of distension of the walls with the distension water is not uniform, but BEGINS SLOWLY, INCREASES TO A MAXIMUM RAPIDITY, AND THEN, GRADUALLY DIMINISHING, CEASES ALTOGETHER. This GRAND PERIOD of growth appears in its typical form when all external conditions are constant. It is true that occasionally very sudden changes in the rate of growth occur, due to internal and as yet unknown eauses, which disturb the regularity of the grand period of growth.

The process of elongation has so far been considered only in relation to the single coll, preparatory to the consideration of the phenomena presented by the growth of multicellular organs. This proceeds so slowly as to be, in general, imperceptible. Only some fungal hyphae and the stamcus of some Gramineae grow so rapidly that their elongation is evident, even to the naked eye. The fructification of Dictyophma grows in length to the extent of $5 \mathrm{~mm}$. per minute (A. MoLLER), and according to ASKENASY an increase in length of $1.8 \mathrm{~mm}$. a minute has been observed in the stamens of Triticum (Wheat). This approximately corresponds to the rate of movement of the minute-hand of a watch. In eomparison with these the next most rapidly growing organ known is the leaf-sheath of the Banana which shows an elongation of $1.1 \mathrm{~mm}$., and a Bamboo shoot, an increase in length of $0.75 \mathrm{~mm}$. per minute; a strong shoot of Cucurbita grows $0.1 \mathrm{~mm}$. per minute, the hyphae of Botrytis grow $0.034 \mathrm{~mm}$., while most other plants, even under favourable cireumstances, attain but a small rate of elongation $(0.005 \mathrm{~mm}$. and less per minute).

In order to measure the growth in length of a plant, it is enstomary to magnify in some way the actual elongation for more eonvenient observation. This may be effected hy means of a mieroscope, which magnifies the rate of growth enres[ondingly with the distance grown. For large objeets, the most eonvenient and usual method of determining the rate of growth is by means of an AUXA NomETEr. The prineiple of all anxanometers, however they may differ in construction, is the same, and is hased mpon the magnification of the rate of growth by means of a lever with a long and short arm. In Fig. 209, at the left, a simple form of anxanometer is shown. The threar fastened to the top of the plant to be observer is passed over the movable pnlley $(r)$, and held tant by the weight (y), which shoukl not be so heary as to exert any strain on the plant. To the pulley there is attaelied a slender pointer ( $\approx)$, which is twenty times as long as the radius of the pulley, and this inclicates on the seale $\left(S^{\prime}\right)$ the rapirlity of the growth magnified twenty-fold. 
Self-registering auxanometers are also used, especially in making extended observations. In Fig. 209, at the right, is shown one of simple construction. The radius of the wheel $(R)$ eorresponds to the long arm, and the radius of the small wheel $(r)$ to the short arm of the lever, in the preceding apparatus. Any movement of the wheel, indneed by the elongation of the shoot, and the consequent descent of the weight $(y)$, is reeorded on the revolving drum $\left(C^{\prime}\right)$ by the pointer attached to the weight $Z$, which is in turn, balanced by the counter-weight $(\mathrm{I})$. The drum is covered with smoked paper, and kept in rotation by the clockwork (I). If the drum is set so that it rotates on its axis onee erery hour, the perpendienlar distanees between the tracings on the drum will indicate the proportional hourly growth.

By this method it is easy to show that whole members of the plant

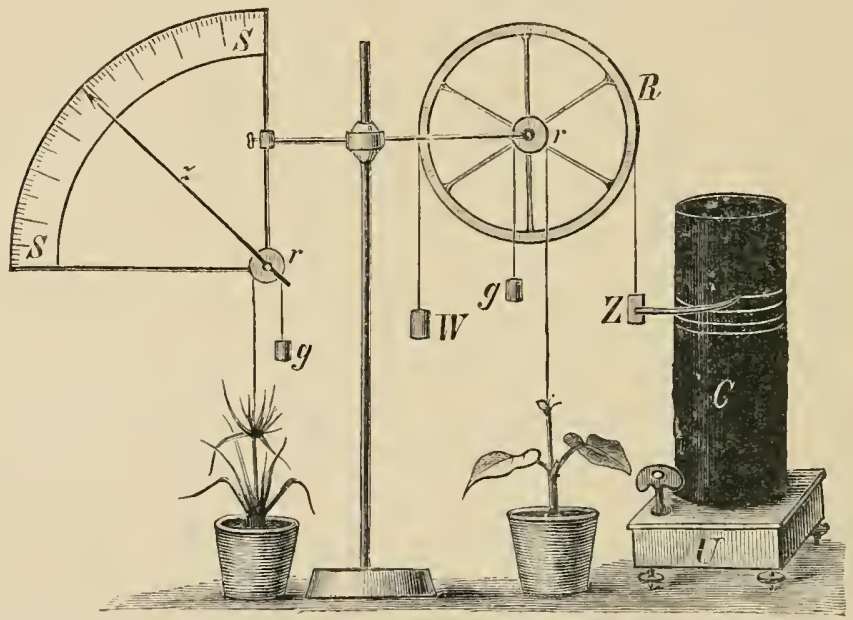

Frt. 209.- Simple and self-registering auxanometers. For description see text.

such as the shoot or root exhibit the gland perion of growth diseusserl above in relation to a single cell.

The daily growth in length of a root of Lupine, ex jressed in tenths of milimetres, was found to be :

$$
58,70,92,97,165,192,158,137,122,83,91,59,25,25,8,2,0 .
$$

For the first internorle of the stem, growing in the rlirk, the dialy growith observed was:

$$
8,9,11,12,35,43,41,50,51,52,65,54,43,37,28,18,6,2,0 .
$$

Besides the total elongation the distrilution of growth is of interest. Thus only in embryonic plants or embryouje organs are all the cells in a state of growth. At a later periorl we find elongation taking place behind the glowing point only; this at first accompanies cell division, but a little further back proceerls without this. 
Still farther from the growing point the cells are full grown. The length and position of the growing zone depends mainly on the nature of the organ, and is little affeeted by external factors. In roots it is situated at the tip and occupies a length of 5 to $10 \mathrm{~mm}$. In shoots it has generally the same situation, but extends for a length of from several centimetres to half a metre. In many shoots, especially those dirided into nodes and internodes, there are a number of zones of growth separated by filly grown zones. This is termed intercalary growth and is beautifully shown, for example, in the hanlms of grasses, where a growing zone is found at the base of each internode. At the bases of many leaves also, especially of Monocotyledons, an intercalary growing zone is found.

The distribution of growth in any member of the plant is ascertained by periodically measuring the distance between eertain natural or artificial marks.

Thus, for example, the tip of the root in Fig. 210 , I, is markerl with lines of india-ink at intervals of $1 \mathrm{~mm}$. The marks start from the growing point of the root $(0)$ just belind the root-eap. Twenty-two hours later the marks lad been separated from one another as is shown in Fig. 210, II. The elongation has been nnequal in the different zones; at the upper and lower ends of the marked region it diminishes and thus leads to the fully grown region on the one hand and the embryonal region at the tip on the other. Between these and nearer to the apieal end is a zone where the maximal growth has taken place. If the growth of one transverse zone such as that between 0 and 1 is followed on suecessive days it is found that it grows at first slowly, then rapidly and then again slowly. In other words every division of the growing 7.one exluibits the grand period of growth. The millimetre zones marked off from the apex are thus in different stages of their grand periods;

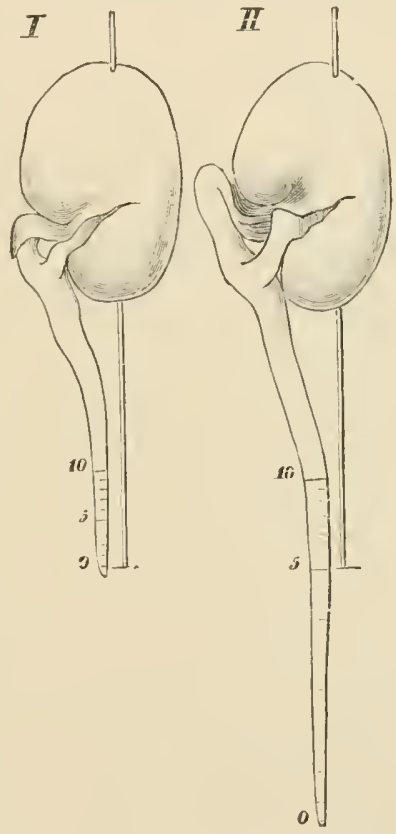

Fi:. 210.-Uiequal growth of different regions of the root-tip of trieia Futher. $I$, the root-tip divirled by marking with inlia-ink into 10 zones, pach $1 \mathrm{~mm}$. long. II, The same root after twenty-two hours: by the inequal growth of the different zones the liues lave hecome separated by nu-

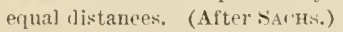

the two first are on the ascending side of the curve, 3 and 4 are at the summit, and the others are on the descending slope of the eurve. Other organs give corresponding results.

Distinet periods of growth separated by an interval of time occur, aeeording to Mryake, in the scapes of the Daudelion, the first period in relation to the developrment of the flowers, the second to that of the fruits. A similar belariour is fomm in other organs whose fumetion after a time heeomes altered (flower or fruit stalks in Limeria cymbalaria, and Araches hypoyace floral envelopes which later l,wotret the fruits and perhapis some oraries). 
From the fact that in different organs zones of different length are in a growing condition, it follows that such results as to the total growth of an organ as was described on p. 257 do not give the true rate of growth, i.e. the growth of a unit of length in unit time. Thus in the shoots of the Bamboo the growing zone is many centimetres long, while in Botrytis it is only $0.02 \mathrm{~mm}$. in length. While Bambusu shows twice as much growth per minute than Botrytis does, its rate of growth is really much less. To express the rapidity of growth it is necessary to express the elongation per minute as a percentage of the growing zone. This gives a rapidity of growth of 83 per cent. in Botrytis, and of only 1.27 per cent in Bambusa. The maximum growth observed is 220 per cent in some pollen tubes, while some shoots which are still clearly growing have a rate of only 0.5 per cent.

We can only determine the definite elongation of a part of the plant when, in addition to the rate of growth and the length of the growing region, the duration of growth is known. The size of the plant, which, as is well known, depends in various ways on external conditions and yet is a specific character, is letermined by variations in these faetors. A definite size belongs to the specifie properties of an organism just as much as the form of its leaves, etc. ; further the whole organisation of the plant is such that it involves a particular size.

Hitherto our consideration has been limited to the expansion in the longitudinal cirrection of parts laid down at the growing point. Microscopic investigation shows, however, that a growth in thickness also takes place. The diameter of the mature root or stem is greater, often considerably greater, than the same diameter immediately behind the growing point. This growth in thickness has been much less thoroughly investigated than has the growth in length, but all essential processes which we aseertained regarding the growth in length are also found in this case. In particular a well-marked grand period has been shown to exist. As has been shown on p. 138, the primary growth in thickness has to be distinguished from seconclary growth in thickness. Only the primary growth in thickness is a process of the kind we are here considering; secondary growth is due to an intercalary meristem or cambinm.

The expansion of the cells in length and breadth does not always take place uniformly and simultaneously in the whole cross section of an organ. It is nusual to find that, in growing stems for instance, the pith strives to expand more strongly than the peripheral tissues. Since no breach of continuity between the two regions is possible a state of tension (tissue tension) (iis) results. 'The pith expands the cortical tissues and these compress the pith; the actual length of the organ is the resultant of these antagonistic tendencies. If the tissnes are artificially separaterl, each assumes its own specifie length; the pith elongates and the cortex contracts and the tension disappears. 
The tissme tensions which occur generally in growing organs may be demonstrated in this way. In a sunflower shoot the pith is separated for sone distance from its connections to neighbouring tissues by means of a cork-borer. On withdrawing the cork-borer the cylinder of pith projects for some distance from the cut surface of the stem (Fig. 211,1). If a similar shoot is split longitudinally the two halves curve outwards owing to the elongation of the pith and the contraction of the epidermis. Even in the case of hollow shoots such as the stalk of the inflorescence of the Dandelion (Taraxacum) a tension exists between the outcr and inner tissues which is expressed by curvatures when the stalk is split longitudinally. (Fig. 211, 2a.) If the stalk after this treatment is placed in water the curvature increases considerably. (Fig. $211,2 b$.

Tissue tensions also oceur in leares and roots. The tensions need not be in the longitudinal direction alone ; there are also transverse tensions. Thus, for example, the rind of trees which increase in thickness by secondary growth is considerably stretehed in the tangential direction. On being separated from the wood it therefore contracts.

The tissue tensions gradually arise at some distance from the growing point when the expansion of cells is commencing and, as a rule, they again clisappear in the fully-grown zone, though they persist in the case of some organs. They are of great importance for the rigidity of growing tissues; they inerease the rigidity given by the turgescence of the individual cells. 'The tissue tension presents a certain resemblance to the turgescence of the cell ; this is most evident in the typical stem. Just as the cell-sap distends the cell-wall by its osmotic pressure, the expanding pith stretches the cortical tissues. In-

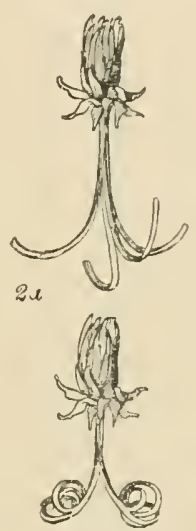

$2 b$

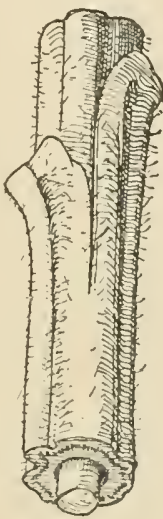

1

Fit: 211. - 1. Shoot of Ilelianthus anmuns with the leaves removed and the pith separated from the peripheral tissues by neans of a cork-borer. 2. Stalk of the inflorescence of Taraxacum, split longitudinally by two incisions at right angles to one another. u, Jist after splitting. $b$, After immersion in water. creased resistance to deformation and increased rigidity result from the stretching of the cortex, just as they do in the cell from the stretching of the wall.

The tissue tension ceases as all the cells attain the permanent mean length dietated by the size of the organ. Sometimes, however, certain cells after attaining their greatest length exhibit a considerable contraction associated with an alteration in shape. This occurs often in roots $\left({ }^{64}\right)$ when the tissues of the cortex and of the central portion are thrown into folds by the contraction of the tissue that lies between them. The significance of this contraction of roots, which may lead to a shortening of the fully-grown structure by 10-70 per cent, is very great. Thus, it is due to it that the leaves of many "rosette plants," in spite of the continued growth in length 
of the stem, remain always appressed to the soil. It determines and regulates the penetration of many tubers and bulbs to a definite depth in the soil. It increases the fixation of the plant in the soil, since greater stability results from tense than from slack roots.

External Influences upon Growth.-External factors often take an active part in the process of elongation, either as retarding or accelerating influenees. Growth being itself a vital aetion, it is affected by any stimulus acting upon the protoplasm; on the other hand, as it is also a physical function, it is modified by purely physieal influences. Growth is particularly dependent upon temperature, light, moisture, the supply of oxygen and other substances. It is also influenced by pressures and tensions and by injuries.

The INFLUENCE OF TEMPERATURE is manifested by the complete cessation of growth at a temperature less than $0^{\circ}$ or higher than $40^{\circ}-50^{\circ}$. Between the MINIMUM and MAXIMUm temperatures, at which growth ceases, there lies an optinum temperature (p. 178), at which the rate of growth is greatest. This optimum temperature usually lies between $22^{\circ}$ and $37^{\circ} \mathrm{C}$. The three CARDINAL POINTS of TEMPERATURE here given include a wide range, as they vary for different species and even for individual plants of the same species or for different developmental stages of the same individual and for their several vital processes. In tropical plants the minimum temperature may be as high as $+10^{\circ} \mathrm{C}$., while those of higher latitudes, where the first plants of spring often grow through a covering of snow, as well as those of the higher Alps and polar regions, grow vigorously at a temperature but little above zero. Many of our spring plants show that the opening of their flowers ean take place at a lower temperature than the unfolding of the foliage leaves. In like manner, the optimmm and maximum temperatures show great variation in different species of plants. The optimum does not usually lie in the middle between the minimum and maximum, but is nearer the maximum. (On the dependence of the cardinal points on external conditions ef. p. 178.)

The INFLUENCE OF LIGHT makes itself felt in a different manner from changes of temperature. Light as a general rule retards growth. This is apparent from observations on stems and roots grown in the dark, and is also true in regard to the growth of leaves, if the disturljing effects resulting from long-continued darkness be disregarderl. Too great an intensity of light causes a cessation of the growth of an organ, while feeble illumination or darkness increases it in most organs accustomed to light. Thus, in the diminished light of a wood leaves are often larger than in full daylight.

$\Lambda$ s a rule, therefore, the growth of plants is greater in the night than in the day, provided that the growth is not arrested at night hy too low a temporature.

The effect of darkness upon the growth of plants is, however, differently manifester according to its duration, whether it be con- 
tinuous or interrupted, as in the changes of night and day. Longcontinued darkness produces an ahnormal growth, in that the normal correlation between different organs is disturbed; the growth of certain organs is unduly favomred, and of others greatly retarded. 'The stems of Dicotyledons, in such cases, become unusually elongated, also soft and white in colomr. The leaf-blades are small and of a bright yellow colour, and remain for a long time folded in the bucl (Fig. 212, E). A plant grown under such conditions is spoken of as ETIULATED $\left({ }^{65}\right)$.

The elongation of certain organs and simulaneous recuction of others has an oecological significance in nature in the case of seedlings and rhizomes which are growing in the dark. The parts which are finctional only in the light remain at first undeveloped, and the construction material for them and especially for the chlorophyll is economised. The great elongation of the other organs which is mainly dependent on an accumulation of water, brings the prarts that need it as soon as jossille into light.

Etiolation does not occur in all plants as in the tylical Dicotyledon. The stems, for instance, of certain Cucti are much shorter when grown in the dark than in the light, and their flattened shoots remain cylindrical. Similarly, the leaves of varieties of the Beet (Beta) grow as large, or even larger, in the dark than in the light; this is also true, under conditions favourable to nutrition, of the leaves of other plants. In some Monocotyledous, narrow but very long leaves are developed.

Just as the rays of light of different wavelength were found to be of different value in the process of assimilation, so growtl is by no meins equal in differently coloured light. It is to the strongly refractive so-called chemical rays that the influence of light on growth is due; the red-yellow end of the spectrun acts upon many plants in the same manner as dirkness.

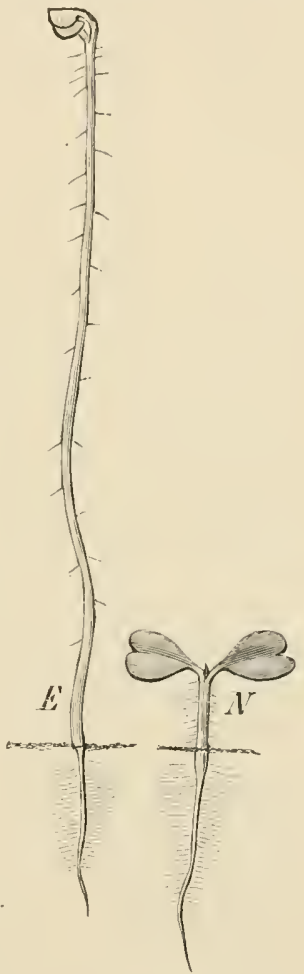

Fir. 212.-Two seedlings of Sinupis albu of eqnal age; $E$, grown in the dark, etiolated ; $N$, grown in or. dinary daylight, nornal. The roots bear root-hairs.

Ralium and the Riontgen rays tend to arrest the processes of growth and development ( $\left.{ }^{\circ 6}\right)$.

Since elongation is essentially due to the introduction of water, the significance of the water supply to a growing plant is obvious. Growth often ceases when there is not sufficient water in the soil. Even a dimimution in the moistness of the air may arrest growth by increasing transpiration. Some plants, however, can store water, and are therefore more indeuendent of its direct alssorption. They grow 
at the expense of the stored water and can often withdraw the water from older portions so that these wither while growth goes on at the apex.

Plants in damp, situations are usnally larger than those grown in dry places, and in faet may differ from them in their whole habit and mode of growth. Direct contact with water seems frequently to exert a special influence upon the external form of plants. Amphibious plants, that is such as are capable of living both upon land and in water, often assmue in water an entirely different form from that whieh they jossess in air. This variation of form is particularly manifested in the leaves, which, so long as they grow in water, are frequently linear and sessile or finely dissected, while in the air their leaf-blades are mueh broader and providerl with petioles (cf. Fig. 37). The leaf-stalks and internodes also often exhibit a very different form in air and water, and undergo the same abnormal elougation as in darkness. This is espeeially notieeable in submerged water plants, whose organs must be brought to the surface of the water (young stems and leaf-stalk of Trape natuns, stem of Hippuris, leaf-stalk of Nymphuea, Nuphur, Hydrocharis). Such jlants are enabled by this power of elongating their stems or leaf-stalks to adapt themselves to the depth of the water, remaining short in shallow water and becoming very long in deep water $\left({ }^{67}\right)$.

The great importance of free oxyGEN has already been alluded to (1) 211). Without gaseous or dissolved oxygen in its immediate enviroument the growth of a plant entirely ceases, at least in the ease of aerobionts. Variations in the proportion of oxygen in the air also influence growth.

Among chemcal strmuli the poisons $\left(^{68}\right)$ must first be mentioned; these are substances which in very dilute solutions arrest growth and ultimately life. It is a striking fact that mauy of them when in extrense dilution lave a stimulating effect on growth. Chemieal stimuli due to other substances play a large part in the germination of many seeds, spores, and pollen grains, and in the development of fruits. Some pollen grains only germinate when they obtain traces of substances which are present on the stigma. Many prarasitie fungi and also parasitic phanerogams (Orobanche, Lathrea) are stimulated to develop by unknown substances 1roceeding from their hosts. In Algae and Fungi high coucentration of some foodmaterials may give rise to striking changes in form $\left({ }^{69}\right)$.

The many influences which occur in symbiotic or parasitic association of organisms are probably, when analysed, of a chemieal nature. Hypertrophies or new formations (galls) result from them (cf. 11). 170, 252).

Growth may also be strongly modified by coriLLations. It can ouly be mentioned that the unfolding of one axillary bud in a Phanerogan may linder the growth of many others; if, however, the dominant shoot is removed the arrested buds proceed to grow farther. Other internal conditions in which correlations certainly play a part may modify the form of the plant. For example, in shouts, an elongation of the internodes and a reduction of leaves, such as is seen in etiolated plants, may result from the development of flowers or the transition to a twining habit of growth. We shall searcely gro wrong in considering the determining inlluences in these cases also as of the nature of ehemical stimuli.

Mechanical Influences. - Prussure and traction exert a prely meehanical influenee upon growth, and also aet as stimuli upon it. Exterual pressure at first retards growth; it then, however, according to l'FeFFli, stimulates the protoplasm and occasions the distension of the elastic cell walls, and frequently also an increase of turgor. $\Lambda$ s a consequence of this increased turgor, the counter- 
resistance to the external pressure is intensified. If the resistance of the body exerting the pressure eannot be overcome, the liasticity of the cell walls renders possible a most intinate contact with it; thus, for instance, roots and roothairs which penetrate a narrow cavity fill it so eompletely that they seem to have been poured into it in a fluid state. It would be natural to suppose that the effect of such a tractive force as a pull would accelerate growth in length by aiding and maintaining turgor expransion. But the regulative control exereiserl by the protoplasm over the processes of growth is snch that mechanical strain, as Hegulin has shown, first acts upon growth to retard it, but then eauses an acceleration of even 20 per ecut $\left({ }^{70}\right)$.

\section{The Internal Construction of Organs}

The interual development of an organ commences close behind the growing point and lasts for a longer or shorter time. While hairs are frequently very rapidly fully developed the definite form and structure of the internal tissues is often only completed after the phase of elongation is ended. When secondary growth in thickness takes place there is no termination to the internal development. The development of the "permanent tissues" from the primary and secondary meristems has been described in the morphologieal section. Here it is only necessary to reeall the fact that the following processes are concerned; in the first place the formation of cells by cell-clivision which takes place in the embryonic tissues and at the commencement of elongation; following on this the separation of cells which gives rise to intercellular spaces; the independent growth of the individual cells; thickening and chemical changes of the cell-walls; modifications (and eventually in some cases the complete disappearance) of the cellcontents; and lastly fusions of cells (cf. p. 97).

All the tissues cannot be referred to the primary growing points ; many arise from the cambium, though this does not involve any essential distinction from urimary tissues; other tissues are formed in processes of regeneration $\left(^{i 1}\right)$. Iu the ease of regeneration (1).252), full-grown parenclinuatous cells which normally have ceased to be eapable of growth may take part; they may give rise to ahmost all the tissues which are produced by the growing point. Thus, for exanple, when the conducting tracts are interupted, new vessels, which restore the connection, may be formed from the parenchyma. It is true that the separated or interrupted tissues are not always formed again, but substitutionary tissues may be developed. Thus, as a rule, the epidernis is replaced by cork and only exceptionally is a true epidemis with stomata developer. On the callus which is so frequently formed in regeneration of. $p$. 162.

In the arrangement of the tissues the same symmetry, which is apparent in the external form of the organs of the plant, is seen; the construction of the organs is thus radial, bilateral, or dorsiventral. When it is possible to experimentally modify the external symmetry the internal structure is modified at the same time. A close connection exists between external form and internal structure, and every change 
of the former as the result of external factors expresses itself also in the internal structure.

Space will only allow of a short reference to the two factors of light and moisture. Shade-leares $\left({ }^{72}\right)$ exhibit a quite diflerent structure to the leaves of the same species developed in full sunlight. They are thinner, their palisade cells narrow from above downwards leaving wide intercellular spaces, and further, form only a single layer, while several layers may be present in leaves exprosed to full light. In etiolated plants the tissues are little differentiated and thickened cells are wanting. The tissues of water-plants $\left({ }^{73}\right)$ are similarly developed; thickenel cells are wanting in the stem, and the vascular bundles are also reduced, while the leaves reall in structure the shade-leaves. With a limited water-suply or with increased transpiration, on the other hand, the vascular bundles are strongly developed, and arrangements appear in the epidermis which have been considered among the means of proteetion against excessive transpiration.

Many of these changes due to external factors can be most shortly characterised by terming them "purposive" reactions. The plant forms those tissues which are most useful to it under the particular conditions.

At suitable places in this section and in the morphological section of this work, the most important facts regarding the function of tissues have been given. It must be mentioned here that G. HaberLanot has clissified and named the tissues on the basis of their respective functions. All tissues with the same function are grouped by him in a tissue-system. (The tissue-systems of this physiological anatomy are thus something different from the tissue-systems as considered on p. 110.) Physiological anatomy is often able to show that these systems correspond to the needs of the plint, both in the structure of the elements of the tissue and in their arrangement. This will be shown here fully for the mechanical tissue-system, and only indicated in the case of the other tissues.

\section{A. The Mechanicha 'Tissue-Systeim $\left({ }^{7 \pm}\right)$}

Without a certain amount of rigidity the definite form which is essential to the performance of their functions in most plants would be inconceivable. In isolated cells and in growing tissues this rigidity is attained by turgor and tissue tensions. Since, however, turgor and tissne tensions are destroyed by an extreme loss of water, leading to the wilting of the plant, they do not alone confer the necessary rigidity upon plants. We therefore find special tissues, known as the STEREOME, which have a purely mechanical funetion.

How great are the demands made npon the stability of plants will be at onee appurent from a consideration of a liye hanlm; althongh it is conposed of hundreds of thonsinels of small chamber's or cells, and has a height of 1500 1mm., it is at its base scarecly 3 mun. in diancter. The thin stems of reeds reach a height of $3000 \mathrm{~mm}$. with a base of only $15 \mathrm{~mm}$. diameter. The height of the reed exceeds by two hundreel 
times, and that of the rye haulm by five hundred times, the cliameter of the base. In addition, moreover, to the great clisproportion between the height and dimeter of plants, they often support a heavy weight at the summit; the Rye straw must sustain the burden of its ear of grain, the slender Palm the heavy and wind-swayed leaves (which in speeies of liaphia have a length of $15 \mathrm{~m}$. and a corresponding brealth), while at times the weight of the bmeles of fruit has also to be eonsidered.

In plants, however, the rigid immobility of a buikling is not required, and they possess instead a wonderful degree of ELAsticuTY. The rye straw bends before the wind, but only to return to its original position when the force of the wind has been expended. The meehanical equipment of plant bodies is peenliar to themselves, but perfectly adapted to their neerls. The firm but at the same time elastie material which plants produce, is put to the most varied uses by mankind; the wood forms an easily worked yet sufficiently durable building material, and the bast fibres are used in the numufacture of thread and corlage. The sclerenchymatous elements of these tissues are the main mechanical elements of the plant; the collenchyma also plays an important part.

Selerenchyma.-The firm thick walls of sclerenchymatous cells and fibres are not infrequently further hardened by deposits of mineral substances. The resistance which these forms of tissue offer when the attempt is made to cut, tear, or break them affords sufficient evidence of their hardness, tenacity, and rigidity. Moreover, Souwendener has been able to determine their mechanical value by means of exact physieal experiments and investigations. According to such estimates, the sustaining strength of sclerenchymatous fibres is, within the limits of their elasticity, in general equal to the best wrought iron or hammered steel, while at the same time their ductility is ten or fifteen times as great as that of iron. It is true that soon after exceeding its linit of elasticity the stereome of the plint becomes ruptured, while the modulus of rigidity for iron is not reached until the load is increased threefold. It is, however, of value for the needs of the plant that its limit of elasticity extends almost to the limit of its rigidity.

Collenchyma.-The sclerenchyma corresponds to the bony skeleton of the animal body. Its elements are no longer in a condition which allows of growth, and it cannot be employed in parts of the plant which are still actively elongating. Where such parts of the plant require special strengthening in addition to that given by the tensions of cells and tissues, this is obtained by means of collenchyma (pp. 75 , 127). This tissue in spite of the large amonnt of water contained in it, possesses considerable resistance against tearing. At the sanıe time it can yield to the growth of surrounding tissues since it is itself capable of active growth. The collenchyma may be said to represent the cartilaginous tissue of the plant.

Just as the mechanieal tissues of the internal framework of plants exhibit the physical properties most essential for their purpose, their arrangement, as ScHWENDENER showed, will also be fomd equally 
well adapted to the varions ends in view, according as they may. be required to withstand the strain of flexure, traction, or pressure.

To withstand bending, and to olfer the utmost possible resistance to it, a peripheral disposition of the rigid meehanical tissue is the most favourable.
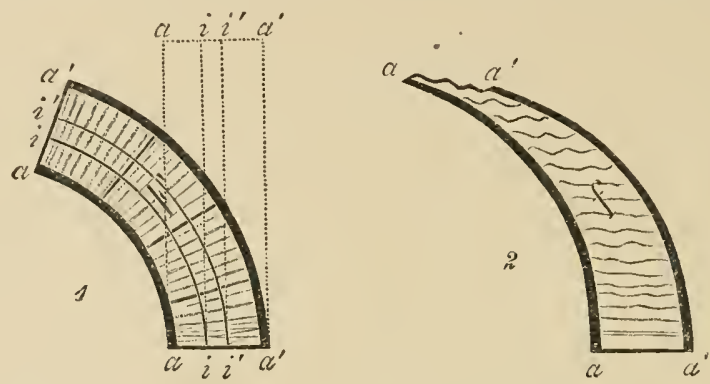

Fit: 213. - l. Longitulinal section of an elastic cyliuder, before benting (dotted outline) and after benling (lieavy outline). After bending the convex sirle $(a)$ is stretched and the concave sjult (a) compressed. F, Connecting tissue,

2. When the connecting tissue $(f)$ is not sufficiently tirm, the bands of stereone $(a, a)$ eurve independently and remain unaltered in lengtl.

When a straight rod (Fig. 213) is bent, the convex side elongates and the eoneave sicle contracts, that is, the outer edges $\left(a, a\right.$ and $\left.a^{\prime}, a^{\prime}\right)$ are exposed to the greatest variations in length, while, nearer the centre $\left(i, i\right.$ and $\left.i^{\prime}, i^{\prime}\right)$ the deflection and consequent variations in length are less. Accordingly, if the sulporting skeleton of a plant stem be placed near the centre $\left(i, i^{\prime}\right)$, a considerable degrce of curva-

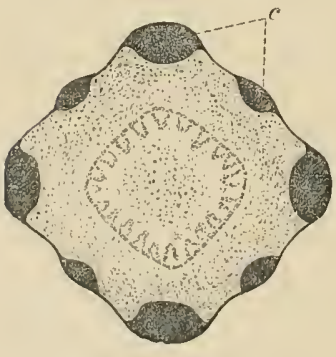

1

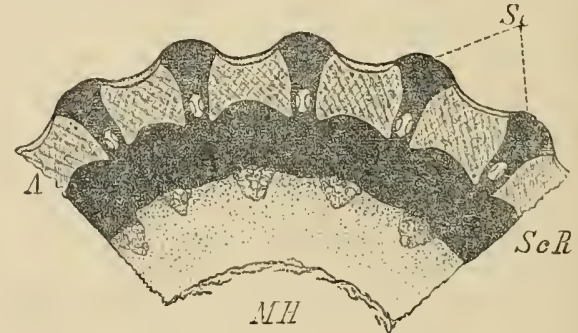

2

Fis. 214.-Rigidity ngainst bending. 1. Transierse section of a youngtwig of sumbucus; $c$, collenchyma. 2. l'ut of the transverse section of a Jauln of grass (Molinie coerule $(t)$; sic, ribs of selerenchyma; sic $R$, selerencliynatous ring conneting them laterally; $A$, green assinilatory tissue; $M H$, jith-eavity.

ture is possible with but little flexure of the nechanical tissue. Nearer the periphery this would be subject to greater strain, and so offer a greater resistance to the delleeting force. It is essential that the girder-like arrangement of the stereone should be held torgether by a conneeting tissue which is at onee resistant and elastic. In the absenee of such comnecting tissue, the place of which in hollow members may, however, be taken by firm tangential connection of the 
mechanical tissues, the individual ribs of stereome are easily bent (Fig. 213, 2). In erect stems and flower-stalks where rigidity is an essential requirement, the - mechanical tissue is situaterl at the periphery, and often takes the form of projecting ridges (Fig. 213, 1, 2).

In roots, and in many rhizomes and stolons, which must pusls between impeding obstacles, the skeletal system is central, where, without interfering with the bending, it can more effectually sustain strain upon the longitudinal rigidity of the organ by being thus massed together (Fig. 215). The stereome is more highly developed in those roots which mainly serve to attach the plant to the substratum than in those the chief duty of which is to absorly food material.

Where, however, pressure must be guarded against (as in Plum-stones, and in Hazel-nuts and Walnuts), and also in some subterrunean or submerged [larts of plants, the mechani-

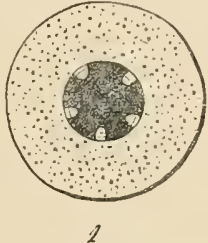

Fir. 215. - Mechanical tissue of roots. 1, Centrally placer to resist longiturinal pulling strains ; 2 , a prop root with a peripheral layer of mechanical tissue $(P)$ to resist lateral pressnre, in arldition to the central strand.

eal resistance is maintained by an arching mass of sclerotic cells or selerenchymatous fibres.

Stems of trees which have to support heavy and frequently large crowns must, like pillars, be construeted to withstand the longitudinal pressure as well as the bending.

Leaf-blades must be strengthened not only against bending forees, but against tearing of their expanded surface by the action of wind or eurrents of water. The former requirement is met by the vascular bundles which often project as ribs on the lower surface, and by girder-like arrangements of the stereome (Thorminm tenax, Fig. 216, 1). Protection against tearing forces is mainly afforded by the firmness of the margin of the leaf; this is partly attained by the vascular bundles forming marginal arches or rumning parallel to the margin, in part by special marginal
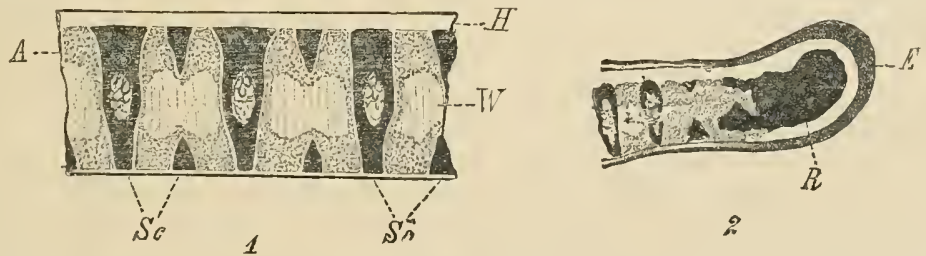

Fig. 216. -Leaf of Phormium tcuar. 1. Transverse section; sc, plates and strands of sclerenchyma; $A$, green assimilatory parenchyma ; $I I$, hypolerma serving for water-storage; $W$, colourless mesophyll (internal water-storage tissue). 2. Edge of the same leaf; $E$, thick brown epirlermis; $R$, marginal strand of sclerenchyma fibres.

strands of stereome (Fig. 216, 2). Where, as in the Banana, both these means of 1notection are wanting, the lamina is regularly and easily torn by the wind (1\%. 35).

Since, as las already been pointed out, the resistance of the meehanieal elements to tlexure is greater the firther they are removed from the centre of an organ, it will be readily seen that, while a fottened, ontspread organ, can be easily bent, its fower of resisting a deflecting force would be increased if it were folderl or rolled 
togrether. In accordance with this prineiple many leaves become plaited or rolled (Fig. 217), and so acquire a sufficient rigidity
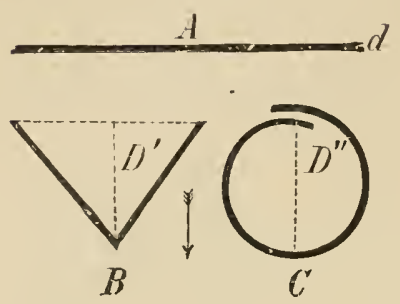

FI0. 21 $\bar{i}$ - Ditgrammatic transverse sections, to show method of securing rigidity by folding and rolling. In the ontspread organ $A$, to withstand a pressure acting in the direction of the arrow, only the thickness $d$ is available, but in the folled organ $l$ the thickness $D^{\prime}$, and in the rolled organ $C^{\prime}$ the thickness $D^{\prime \prime}$. without the assistance of any specially developed mechanical tissues.

In addition to the rigidity of the individual organs of the plant, their arrangement and position are of importance for the stability of the whole organism. The lateral branches, which are normally arranged as symmetrically as possible, may be forcenl by bending them npwards or downwards to take on an elliptical cross-section. In Conifers the "white wood," which offers greater resistance to stretching forces, and the "led wood," which, being denser, offers greater resistance to compression; are formed on the sides which are respectively stretched or compressed $\left({ }^{75}\right)$. The roots of many tropical trees are so eccentrically constructed as to form relatively thin plank-like buttresses to the trunk.

\section{B. Other Systems of Tissue (i5)}

In considering physiological anatomy the nature of the mechanical tissue-system can be most readily understood since its elements are differentiated in a very one-sided manner, and for the most part perform the single function of giving strength. There are, however, exceptions. In the wood of Conifers the water-conducting elements or at least the tracheides of the autumn wood also serve as stereome ; in the wood of Dicotyledonous trees typical sclerenchyma cells oceasionally serve for storage.

A "main function" is often not so clearly recognisable in the other tissue-systems distinguished by HABERLANDT ; the tissnes are suited to perform several functions, and are therefore not so sharply differentiated. In spite of this we may distinguish after HABERLANDT the following systems, meristematic tissues, tegumentary system, absorption system, assimilatory system, conducting system, storage system, rentilation system, and also excretory and secretory tissues. The functions of these systems are sufficiently characterised by their respective names; their arrangement ean only be referred to in some examples. The assimilatory system consists of cells containing ehlorophyll. Since these can only perform their function in sunlight, we find them developed only in ahove-ground organs, especially in the leaves, which are the special organs of assimilation. IIere the assimilatory cells occupy the whole space from the one epiclermis to the other, thongh their slape is different on the npper and lower sides of the leaf; the palisiule cells are adlapted to light of greater intensity, the cells of the spongy parenchyma to 
light of lower intensity. Assimilatory parenchyma is also found in the stem, but is naturally limited to the peripheral regions where sufficient light can be obtained. Sinee the stereome also tencls to oceupy the most peripheral position possible, the available space is often dividerl between these two tissues. Stereome is also present in the leaf, usually in relation to the vaseular bundles; where it is present it renders the development of assimilatory tissne impossible.

The assimilatory tissue leads by gradnal transitions to the storage tissue, which ean oecurpy any available situation not requirerl for other tissues. Thus in the stem the storage tissue may have a central position and in roots be peripheral.

It is characteristic of the conducting tissues that the tracheal elements which serve for water-conduction are associated in the vasenlar bundle with the sieve tubes which serve for the conduction of organic substances. Comparison of the distribution of vessels in the leaf-blarle and in the stem shows elearly that only conduetion takes place in the stem, while water is given off from the leaves. (Cf. p. 203.)

\section{Periodicity}

The development and growth of the organism does not proceed with constant and uniform activity. In the simplest organisms cell-division tends to follow on a certain amonnt of growth. In this way two elementary organisms result, each of which proceeds to develop in the same way as the parent organism. Growth and division thus sneceed one another in regnlar periodicity. In plants which have a growing point the latter not only grows on uniformly, but from time to time forms lateral ont-growths or branches. The more complex the organism is, the more obvious are periodic changes in its development; these sometimes arise from more or less recognisable external causes and in other cases from purely internal changes. One of the most striking of the periodic phenomena is that exhibited by some plants in which after a time part of the organism dies away, leaving usualiy only a small portion alive; from this the further development proceeds. Not less remarkable is the fact that the development is often arrested for weeks, months, or longer periods withont the eapacity of development being destroyed. 'The three states of rest, activity, and death are in the highest degree characteristic of the organism.

A resting condition or a condition of rigor results if the necessary factors for growth are not present; this has already been referrerl to. On the other hand we see a periodic arrest of growth in many tropical trees which is evidently not determined hy external factors or at most is connected very indircetly with such factors. Although the temperature and water-supply remain contimously favourable, the leaf formation does not proceed continuously, but is 
interrupted by resting periods ; in the course of the year several periods of expansion of shoots may occur. Periodic activities are also seen in our native trees, the growth of the shoots of which generally commenees in the spring while the leaves are shed in antumn. In this ease at first sight we are inclined to recognise a direct result of the cold winter season. That this is not the case is shown by further consideration and some observations. The rise of temperature in spring is doubtless the canse of the commencement of growth, but the canse of the preceding cessation of growth does not lie in the lower temperature. The unfolding of the lcaves of many trees ceases eompletely in May or June. Further, our trees, when transferred to a tropical elimate, frequently exhibit a periodicity similar to the native plants of the new locality. It must thus be assumerl that they possess a periodicity depending on internal causes, and that they become adapted to the seasonal changes in countries where these oecur; with us the resting period is the winter while in other countries it occurs in the dry period. This does not hold for all plants, however. In our climate there are some herbs, such as Senecio vulgaris, which continue to grow throughout the whole year if the external conditions permit, and in the tropics plants which grow continuously also occur.

The Oak, Beech, Apple, and Pear retain their resting period in the sub-tropieal climate of Madeira, while under uniformly favourable conditions in the mountain regions of Java the periodieity may be disturbed in partienlar individuals. This even oceurs in the several branches of the same tree, which may then bear leafy and leafless boughs at the same time (Oaks, Magnolias, Fruit and Almond trees, together with some endemie speeies). Other trees again gradually accustom themselves to the new eonditions, as the Peaeh, for instance, which in Ceylon has become an evergreen tree. The Peach is stated to produce flowers and fruit throughout the entire year; while the Cherry, like many other trees of the temperate zone, ceases altogetlier to bear flower's in tropieal climates.

The resting period may be more or less shortened by a premature provision of favourable conditions for growth; previous exposure to frost, dryness, darkness, to ether-vapour, or to a suitable rise of temperature may favour this by yroviding preliminary steps. The awakening from the resting stage does not sueceed equally well at every period. The best time naturally is shortly before the normal resumption of vital activity, but a period shortly after the resting condition has been assumed is nearly as good. In the intervening period of complete rest attempts to induce the plant to resume its activities are usually fruitless. These facts must be consiclered in the foreing of plants, and just as much so the circumstance that the temperature optima for various developmental processes in the plant differ $\left({ }^{76}\right)$.

In the case of seeds and spores it is much more apparent than in the case of winter buds that the resting period depends on internal causes. These organs are eut off from their water supply, and nltimatoly shed as a result of the vital processes of the plant. Many of them, even when favourable conditions of growth are supplied, are umable to germinate at once; but require first to undergo a long periol of rest. Periorlic phenomena are also frequently met with 
during active growth. Thus, for example, the rate of growth changes with the alternation of day and night. This will be readily understood from what has been said previously. What is much more striking is that the periodicity continues where the external factors have become uniform. This is termed an after effect of the cause and we shall meet with it in other cases also. Another example of this is the behaviour of our native trees when transplanted to Madeira; they maintain their old periodicity although they conld grow continuously throughout the year.

Besides the daily periodicity in growth in length, periodic modifications in the forms of stem and leaf are met with, which are not only quantitative but qualitative; foliage leaves alternate with scale-leaves or bracts, leafy shoots alternate with rhizomes, etc. In these phenomena we have again to do with correlation of growth which was considered on p. 25t. The production of a certain quantity of foliage exerts an influence on the further rudiments arising at the growing point and causes them to develop into scale-leaves, bud-scales, etc. If the foliage leaves are removed in the early summer, foliage leaves instead of scale-leaves are formed from the rudimentary leaves at the apex. In a corresponding way the removal of the leafy shoots frequently acts on the subterranean rhizome and causes it to grow above ground and to form foliage leaves instead of scale-leaves $\left({ }^{78}\right)$. The existence or rather the functioning of one organ thus forces another which is potentially similar to develop in a different way.

Lastly, we have to consider the periodic alternation expressed in the duration of life of the plant, as a whole. There are plants, such as Stellaria media and Senecio vulgaris, which in a few weeks go through their whole development from the germination of the seed to the ripening of their seeds. Since each seed can germinate at once, sereral generations may be developed within the year. The individual plant dies on producing a certain number of seeds, but the seeds ensure the maintenance of the type of plant. Many armual plants are similar thongh their life is more closely connected with the seasons of the year. With these may be placed other plants which only fruit once (monocarpic) but in which seed-formation is preceded by two or many years of purely vegetative growth, with or without resting periods. Probably in all these cases the derelopment of fruit is the cause of the death of the vegetative organs, for their life can be considerably prolonged by preventing seed-formation. In contrast to these plants, others, such as our native trees, fruit repeatedly, the existence of the individual not being terminated by seed-formation. All perennial types exhibit another periodicity besides that due to the seasons. A tree in its first year when it is a seedling has less intensity of growth than many annual plants; the intensity of growth increases gradually and its growth in length, its growth in thickness, and even the elementary organs of the wood continue to increase in size until 
a maximum is attained. With the same natural necessity the aseending branch of the eurve proeeeds until finally terminated by the death of the tree after the latter has for many years produced seeds to continue the species. Long before the whole inclividual perishes, however, single parts of it have died. Thus, the leaves have been shed after persisting for one or several years. In some cases whole branches are shed, though often they perish without being thrown off and gradually break up while still attached to the plant. All the older tissues of the stem also die; the peripheral tissues are transformed into bark and either fall off or form a protective covering to the parts within. In the centre the wood is transformed into heart-wood in which the remaining living elements clie. In an old tree only the growing points, whether apical or intercalary, and the youngest tissues derived from them remain alive. Thus we see that every eell which lias lost its embryonic charneter dies after a longer or shorter time, if it does not nnder special conditions become again embryonic.

The duration of life of a tree though in prineiple unlimited is determined by external conditions. An end comes to its existence owing to the attacks of parasites and other enemies, the effect of wind, or espeeially to disturbanees in its nutrition.

The longevity of trees having an historical interest is naturally best known and most celebrated, although, no doubt, the age of many other trees, still living, dates lack far beyond historieal times. The celebrated Lime of Nenstadt in Wurtemberg is nearly 700 years old. Another Lime $25 \cdot 7 \mathrm{~m}$. in eircumference had 815 annual rings, and the age of a Yew in Braburn (Kent) whieh is $18 \mathrm{~m}$. in eircmmference is estimated at 2880 years. A stem of a Sequoia in the Berlin museum has, witlı 1360 annual rings, a diameter of $4.7 \mathrm{~m}$., from which an ilea can be formed of the age of those trees which have attained a diameter of $16 \mathrm{~m}$. An Adunsonic at Cape Verde, whose stem is $8-9 \mathrm{n}$. in diameter, and a Water Cypress (Texodium mexieanum) near Oaxaca, Mexieo, are also well-known examples of old trees. Of an equally astonishing age must have been the celebrated Dragon tree of Orotava, which was overturned in a storm in 1868 , and afterwards destroyed by fire. The lower plants also may attain a great age; the apically growing mosses of the calcified Gymnostomum clumps, and the stems of the Sphagnaceae, metre-deep in a peat-bog, must eertainly continue to live for nany centuries $\left({ }^{79}\right)$.

\section{Reproduction}

Some trees attain, as we have seen, a great age and are in principle capable of unlimited life. After a certain maximum in their development has been reached, however, the new shoots formed anmully beeome smaller, obviously because the exchange of material between the roots and shoots becomes increasingly difficult. Ultimately the tree clies owing to this or other causes. If new roots can be induced to form near to the growing points the intensity of the growth of the shoots is maintained and under these conditions no limit can be placed to the growth. 'This experiment camnot be earried out in the ease of every tree since all do not form roots readily; it is, how- 
ever, easily done with the Willows, when branches are used as cuttings. What is here artificially induced takes place in other ways in nature. Many rhizomes coutinue to grow at their ends in the ground, form new roots at some distance from the apex and so persist, while the older portions die away. Strictly speaking we are not dealing here with ordinary growth but with the simplest kind of reproduction involving the production of new living units consisting of root and shoot. When in addition to the straightforward growth of the apex a rhizome also exhibits branching, increase in number of individuals is associated with this reproduction; from one living unit several are produced.

Reproduction in lower plants, which exhibit no differentiation, is effected by each cell division. Since, however, cell division occurs when the amount of protoplasm las doubled, reproduction is in this case identical with the new formation of protoplasm. Only those forms of reproduction require special consideration in which special organs are formed (reproductive organs, gerns) which separate from the parent plant and, at the expense of a supply of reserve material, commence a new life. In this way young organisms originate which then repeat the development of the parent organism, its gradnal increase in strength and its later decay. Often these reproductive organs have the further duty of carrying the organism over a period of cold or drought; they thus constitute a resting stage. With favourable conditions their growth recommences, they germinate.

The conditions of the outer world make the still further demand upon reproduction, that from it a multiplication of the species should result. As the germs after separation from the mother plant do not always find the conditions necessary for their development, and so for the most part perish, the extinction of the whole species would soon result if a plant produced but a single germ. In reproduction care is taken for the multiplication of the individual in an almost spendthrift manner. The number of germs produced is a hundred, a thousand, or even millions of times that of the parents. Inummerable spores are producel by a single mushroom, or by a large fern. Besser has estimated the number of seeds produced anuually ly a Poplar tree at about 28 millions.

REJUVENATION, SEPARATIUN, and IIULTIPLICATION of the individual are accordingly the essential requisites of reproduction. It is also important that the germs should be distributed as widely as possible.

These requirements are fulfilled by plants in the most varied manner. Each great division of the vegetable kingdom has adopted its own special method; ant each family and genus, or even the different species, are characterised by some peculiar feature of their manner of reproduction. Systematic botany is, indeed, essentially based upon differences in the development of the reproductive organs and in their functions.

Numerous and varied as the processes of reproduction in the 
vegetable kingdom are, they are in reality but modifications of two different and distinct modes of reproduction.

The simpler of these, ol VHAETATIVE REPRODUCTION, consists in the formation of cells or cell-bodies which, after their sepalration from the parent plant withont undergoing any further change, either germinate at once, or develop into new orgamisms after a period of rest. This mode of reproduction is distinguished as MONOGENETIC, VEGETATIVE, Or ASEXUAL reproduction.

In SEXUAL REPRODUCTION, the second of the two modes of reproduction, two kinds of reproductive cells, each of which carries the characters of the organism producing it, are first formed, but neither is directly capable of furthel development, and both perish in a very short time, unless opportunity is given for their fusion with each other. Not until the one cell has fused with the other cell does the product acquire the capacity of development and growth. This mode of reproduction is termed sExUAL or DIGENETIC reproduction.

\section{A. Veghtative Reproduction}

Vegetative reproduction is wide-spread in the vegctable kingdom; it is completely wanting only in a few plants, such as in many Conifers and some Palms. We shall here exclude from consideration all phenomena of regeneration. Reproduction and increase in number of individuals by means of multicellular bodies (shoots, gemmae) may on purely external grounds be distinguished from a reproduction by single cells (spores, unicellular gemmae).

Multiplication by Multicellular Vegetative Bodies (Budding) often consists merely in the separation of lateral sloots, or in the division of a single plant into several.

In this way the lateral shoots of $A \approx o l l a$, through the death and disrnption of the older parts of the parent axis, beeome separated from one another and continue their growth as independent plants ; similarly, separate plants originate from the vegetative body of the Duekweed (Lemua).

Nultiplication by stolons, rhizomes. and tubers results in a similar formation of independently existing plants. As may be seen in the Strawberry, the Bugle (Ajuga reptans) and numerous other plants, the shoots prodneed from many of the axillary bnds of the widely outstretehed stolons take root and form new plants. In eases where the rumners themselves eventually die, the parent plant beeomes finally surrounded by a colony of entirely independent plants. Instead of forming runners, the single tuber may divide (Corydalis soliclet), and in this way give rise to two, four, or more new tubers. New bulbs are produced in the leaf-axils of the seales of bulls, while brood buds (bulbils, gemmae) are frequently developed on aerial vegetative organs.

Bulbils are found on the inflorescence in the place of the flowers in many species of Allium, in the grass Poo bullifera, and also in Polygomum viviparum. In Litium bulbiferum, Dentaria bulbifora, ete., the bulbs in the axils of the leaves are specially construeted with a view to detrehnent from the parent plant (lig. 22). Their swollen leaves contain reserve food material, and frequently develop roots before 
falling from the plant. In Ranunculus Fitariu the roots of the axillary burts are full of reserve food material, and resemble grains of corn. When the plant dies the bulbils remain on the ground, and have given rise to the fable of slowers of grain. Bulbils or gemmae are met with also among the Ilosses, Liverworts, and Ferns. The winter buds or hibernacula of many water plants (Hydrocharis, Ctrieularie, Lemna, ete.) have a peculiar biological significance. They are forned in the antumn, and sink to the bottom of the water; in the succeding spring they rise to the surface and form new plants.

By vegetative multiplication higher plants can aunually give rise to indiriduals which are strong and eapable of flowering and fruiting. The seedlings of such plants, on the other hand, often require to grow for several years before the capacity of sexual reproduction is attained (bulbous plants, Hol, ete.).

In addition to the instances just eited, in which the vegetative reproductive bodies take their origin from points where lateral shoots are normally formed, they may also appear in places where no shoots are normally developed. Thus the adventitions formations often found on leaves, particularly on the leaf-blades, serve

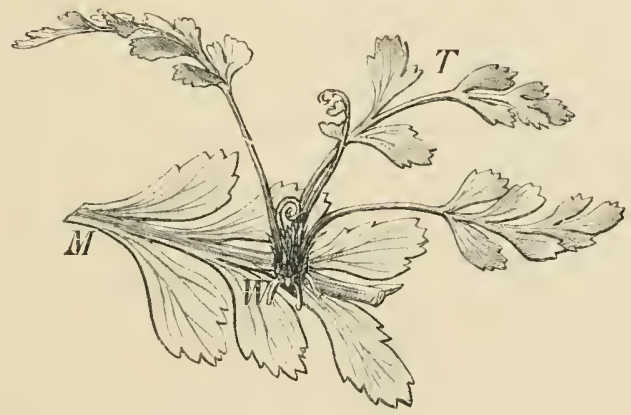

Fig. 21s-Asglenium Fabianum. A young plant $(T)$, with leaves and roots $(W)$, has sprung from the leaf $(M)$ of the older plant.

the purpose of reproduction. Just as the leaves of Begonia, Drosera, ete, after they have been ent off, are able to give rise to new plants, in other cases the leaves possess this power while still growing on the parent plant. Some ferns afford specially characteristic examples of this (Asplenium decussatum, $A$. Fabianum, $A$. bulbiferum, $A$. viviparnm); adventitions buds are produced on their laminae, developing into small rooted plants (Fig. 218). The adventitious buds of Cystopteris bnlbifera take the form of bulbils with snall swollen leaves. Adventitious plantlets are frequently formed also on the leaves of Cardamine pratensis, and Cardamine amara manifests a sinilar tendeney. One of the best-known examples of such adventitious formations is afforled by the leaves of the tropical Bryophyllum, in the marginal indentations of which the brood plantlets develop when the leaf is separated from the plant or wounded. Gemmae are abundantly produced on the thallus of many Hepaticae (Marchantia, Lunularia), and by their continuous growth the gemma cups (Figs. 371, 372) are always kept well filled.

Vegetative Multiplication by Single Cells (Spores). - As in the case of multicellular vegetative bodies, multiplication can be effected also through the separation of single cells. Strictly speaking, this manner of multiplication actually takes place whenever a division of 
the vegetative body occurs in unieellular Bacteria, Fungi, and Algae. Cells which serve the purpose of regetative reproduction, and have a special form and method of development (spores, conidia, swarmspores, gemmae), are first met with in the higher Cryptogams. They are frequently formed in special organs or receptacles (sporangia, conidiophores, fruit bodies).

\section{b. Sexual Reproduction}

Sexual reproduction is also wide spread in the regetable kingdom, and is wanting only in such lowly organised groups as the Bacteria and Cyanophyceae and in some Algae and Fungi.

In its typical form two distinet cells, which are distinguished as the female or egg-cell and the male or sperm-cell, give rise after their fusion to a new plant. Neither the egg-cell nor the sperm-cell can be strictly regarded as a reproductive organ, since neither by itself is capable of further development. Only when the egg-cell has been fertilised, i.e. has united with the sperm-cell, is a structure which subserves reproduction produced.

Sexual reproduction is met with in the vegetable kingdom in very different forms; the extremes are very distinct but are connected by many intermediate forms. Only a few can be mentioned here (cf. the special part). In the lowest grade we find two completely similar motile cells (gametes); these are evidently to be phylogenetically derived from swarm-spores, but are distinguished from them by undergoing further development only after fusion (certain Brown and Green Algae). At a slightly ligher stage one of the two gametes is distinguished by its size and by losing the power of movement earlier than the other one; it is the female gamete, and when at rest is songht out and fertilised by the male gamete. At a further stage this egg-eell bas completely lost the power of movement; it remains in its mother-cell the oogoniun, where it is reached by the male cell (spermatozoid), which enters by an opening in the wall of the oogonium (Oedogonium, Chara). Essentially similar relations hold for all Bryophyta and Pteridophyta, only in them instead of unicellular oogonia we meet with arehegonia. The archegonium is an organ which forms the egg-cell enclosed within an investment of cells which ultimately opens at at definite place.

In all these cases fertilisation takes place in water. The egrgcells excrete certain substances by means of which spermatozoids are attracted. Among Thallophyta there are also forms in which motile sperm-cells are wanting and the approximation of the sexual cells is a result of growth. Either both cells grow equally towards one another (cf. e.g. Conjugata, Zygomycetes in the special part) or the male cell only grows to reach the female cell (cf. Saprolegnieae, 
Peronosporeae, certain Aseonycetes). In both cases the separating wall is ultimately absorbed and the contents of the male cell passes into the female cell and fuses with the latter.

In the most highly developed plants, the Phanerogams, the male eell, which is here usually reduced to a nuclens, is also brought into relation to the egg-cell by a process of growtl.

The egg-cell is within the orule, and this is enclosed by the orary, and the sperm-eell is formed in the pollen-grain. The pollen-grain has to be bronght to the tip of the carpel (stigma); this proeess is known as pollination. There it forms a tubular ontgrowth, the pollentube, which grows down the whole length of the style, enters the ovule, and ultimately liberates the sperm-cells at its tip. In some Phanerogams the pollen-grains and the ovules are formed in distinet male and female flowers; these may either be borne on the one plant or on distinct individuals. In any case a transference of the pollen to the stigma is necessary, and this is never eflected actively by the plant, but by external means of transport.

It will be seen in the description of the Phanerogams that currents of air and water, as well as eertain animals which frequent flowers, are employer for the purpose of etfeeting pollination.

Where the male and female organs are present in the same flower, i.e. in hermaphrodite flowers, it might be assumed that no speeial arrangements would be necessary to bring the pollen to the stigma. More accurate investigation has, however, shown that such adaptations exist in abundance and are often of the most detailed nature. They do not, it is true, ain directly at the conveyance of the pollen to the stigma of the same flower; often they render such SELF-POLLINATION impossible, and effeet Cross-POLLINATION, i.e. the converance of pollen to the stigma of another flower on the same plant or on another individual.

The produet of fusion of the egg and sperm-eell surrounds itself, as a rule, with a cell-wall. In the lower plants an oospore or zygospore is thus formed which germinates, usually after first undergoing a period of rest. In the higher plants growth and cell-division take plaee forthwith; an embryo is produced which in Bryophyta and Pteridophyta continues its further development, while in the Phanerogams it soon enters on a periorl of rest. Before this, however, a number of stimuli hare proceeded from the development of the embryo; these are especially complex in the Angiosperms. The ovule in which the embryo is enclosed commences to grow ; it enlarges and assumes a characteristic structure. It has developed into the seed, and this as a rule is liberated from the ovary and, after a resting period, germinates. The ovary also grows actively after fertilisation and develops into the fruit The variety in fruits cannot be entered upon in this place. 
These formative processes of growth in the ovules, ovary, and ultimately also in other parts of the flower, are to be regarded as phenomena of correlation. When fertilisation does not take place, all those changes which lead to the development of a ripe fruit from the flower do not usually oceur. Instead another eorrelative influence arises which leads to the easting off of the now useless organ as a whole. Some few plants, especially snch as have been long cultivated, are to some extent an exception to this. In nearly all varieties of the Banana, in the seedless Orange, and in the sultana raisin, no embryo is formed, but in spite of this the fruits develop. The stimulus to this development ean proceed either from the mere pollination of the stigma or from the fertilisation of the ovules, which then sooner or later cease to develop withont arresting the development of the fruit. In some cases, however, "barren" fruits develop wholly without the stimulus of pollination (parthenocarpic fruits of the Fig, Cneumber, and certain species of Apple and Pear ; also the seeds of Cyeads) $\left({ }^{80}\right)$.

Influences which affect parts at a distance also proeed from the pollen-grains and pollen-tubes on the stigma. Thus after the stigma of an orehid is pollinated the stigma and the gynosteminm swell, and the perianth is promptly arrested in its growth and withers. As FrrTixg showed, this influence proceeds from soluble organie substances which withstand heating, and ean be readily separated from the mass of ungerminated pollen.

Whether a simple spore or a complex embryo is the result of fertilisation it is always distinguished from the cells which gave rise to it by exhibiting nuclei which contain the diploid number of chromosomes (p. 94). On this account a reduction division which restores the normal number of chromosomes is sooner or later the necessary sequel to fertilisation.

\section{The Conditions of Repronuction ( ${ }^{81}$ )}

It has been already pointed out that the most simple form of reproduction, such as the division into two of an algal cell or the multiplication of a branched plant by dying off of the older portions connecting the branches, is nothing more than a process of growth. The formation of complicated reproductive organs on the other hand is a process which is fundamentally different from purely vegetative growth. Thus the question arises, under what conditions does vegetative growth and under what conditions the formation of reproductive organs respectively take place? Since these problems have as yet been relatively little studied, it is not easy to give a general answer to this question. We must, therefore, confine ourselves to making clear some of the essential facts by means of suitable examples. In other words, we must show that the regular succession of stages met with in nature, and constituting the characteristic course of development of a species concluding with reproduction, can be deliberately modified. The typical development is only one of many possibilities.

The fungi belonging to the genns Suprolegnice have a non-septate branched mycelium without chlorophyll. They oceur commonly in nature on dead insects 
which have fallen into water, and their thallus first grows through the body of the insect. After a time however it grows ont and forms a radiating growth around the insect. The end of each of the radiating hyphae becomes as a rule ent off by a septum, and its contents diride up into numerous swarm-spores; these emerge, move about, and finally germinate to give rise in another place to a new individual of Saprolegnia. Later eggs and sperm-cells are formed on the older plant and, at least in some species, the former only develop after being fertilised. Witl the production of fertilised eggs the activity of the Saprolegnia plant tends to cease ; it gradually perishes.

G. KLEBs has shown that it is possible to completely change this course of development of Saprolegnia; KLEBs has sueceeded in direeting the development in the following ways among others:-

1. The mycelium can continue for the whole year to grow vegetatively when supplied continually with fresh and suitable nutritice material.

2. Such a well-nourished mycelium on being trausferred to pure water proceeds completely and at once to form sporangia.

3. In solutions of leucin $(0.1 \%)$ and haemoglobin $(0.1 \%)$ at first a strong growth flevelops and then sexual organs are formed. Swarm-spores are not formed; they appear, however, after the sexual organs, when a more dilute solution $(0.01 \%)$ of haemoglobin is employed.

It is thus clear that quite definite conditions exist for vegetative growth, others for the formation of sexual organs, and yet others for the appearance of asexual reproduction.

In Phanerogams the question of the causes of the development of flower's is of special interest. Observations in nature and experimental work show that in this case also sexual reproduction is not absolutely essential to the maintenance of the species, and that the formation of flowers only takes place under quite definite conditions. The results which KuEBs obtained with Sempervivum Funkii can be sumariserl thus :-

1. With active carbon-assimilation in bright light and rapid absorption of water and nutrient salts, the plant continues to grow purely regetatively.

2. With active earbon-assimilation in bright light, but with limitation of the absorption of water and salts, the development of flowers takes place.

3. With a moderate absorption of water and nutrient salts it depends on the intensity of the illumination whether vegetative growth or the production of flowers takes place. With weaker intensity of light, and when blue light is used, only growth takes place; with stronger illumination or with rell light flowering oceurs.

There are thus a number of observations and experinents which enable us to see that light, temperature, and supply of nutrient salts are of significance in determining flower formation.

The importance of light in the formation of flowers is shown by the well-known fact that the Iry only flowers when growing in a well illuminated situation and not in the shade of woods, although it grows well in the latter habitat. Voes'Huxc's experiments on Mimulus Tilingii gave the same result. At a certain low intensity of light, which is quite adequate for vegetative growth, this plant produces no flowers. This effect of diminished light becomes evident even when the floral shoots have been formed; the rudiments of the flowers in the axils of the bracts are arrested in their development, and axillary buds which would otherwise remain dormant grow out as leafy shoots. There is a return to the vegetative condition. KLEss has made corresponding experiments with Fermica 
Chrmacdrys, and he states that in all plants which do not contain any great amount of reserve materials a riminution of light leads to the snplression of flowerformation. He regards the carbon-assimilation resulting from the illumination as the primary cause of this influence on the development of flowers. At a certain intensity of light, which is insufficient for the development of normal flowers, eleistogamous flowers are prodneed.

Temperature also obviously plays a part. A continuous high temperature hinders flowering. Thus plants of our climate eventually become vegetative in the tropics (Cherry, ef. 1.272), and native perennial plants, such as the Beet or Foxglove, can be prevented from flowering in their second year if they are kept warn and allowed to grow on during the winter. In this way KLEBs snceeded in keeping the Beet in a purely vegetative state for several years. Clechomo and Scmpervivum. also, if their winter rest is prevented, grow vegetatively for years.

Lastly, the nutrient salts have to be considered. By removing the supply of salts, seedlings can often be converted into dwarf starved plants in which, after a few minute foliage leaves have been formed, the development of flowers begins at once. Experiments of MoEbIus have shown that Grasses and Borago flower better if the supply of salts is limited than if well manured. The increase of fertility which results from ront-pruning in fruit trees may dejend upon a limitation of the absorption of nutrient salts. That, however, all nutrient salts do not act in the same way has been pointed ont by BerEcke, who showed both from the literature and from his own experiments that nitrogenous food led to a diminution and phosphorous to an increase in the development of flowers.

\section{The Sirnificance of Sexual Reproduction}

The significance of sexual reproduction is not at once evident. Many plants occur in nature or under cultivation without being sexually reproduced, and succeed with vegetative reproduction only.

Lower plants which have not attained to sexnal reproduction liave already been referred to. Of higher plants which no longer produce descendants sexnally the cultivated Bananas, some Dioscoreaceae, some forms of Vine, Oranges, and Strawberry may be mentioned. The Garlic, which forms small bulbils in place of flowers, the White Lily, and Ranumeulus Ficaria, which has root-tubers, only rarely produce fertile seeds if allowed to form their vegetative organs of reproduction. Under certain conditions, as for instance on eut inflorescences, seeds may be producerl, though as a rule these plants are multiplied entirely vegetatively. No degeneration such as was formerly held to be unavoidably associated with purely vegetative multiplication is to be observer in these cases.

If thus the monogenic reproduction suflices to maintain the species digenic reproduction must serve some further purpose not effected by the former. Otherwise it would be inconceivable why digenic reproduction had arisen, and why the arrangements to effect it are far more complicated and less certain than in the case of vegetative reproduction.

Were the Algae and Fungi alone taken into consideration it might be supposed that sexual reproduction led to the formation of specially resistant germs which could endure a longer period of rest under unfarourable conditions - as a matter of fact the zygospores and oospores are much more resistant than the swarm-spores and conidia. 
But even in the Pteridophyta this relation is inverted, for the fertilised egg-cell requires to develop forthwith, or else it perishes, while the asexual spores can endure a long resting period.

It is the rule in digenic reproduction that the sexual cells are individnally incapable of development; this takes place only after the sexnal cells have united. Thus onc use of fertilisation lies in the removal of an arrest of growth, thongh it cannot be said that this was its original and essential significance. It is much more probable that the sexual cells have gradually lost the capacity of independent development since in this way the possibility of fusion was increased. If every sexual cell commenced to grow at once, this wonld in most cases take place before fusion with another sexual cell conld be effected.

This assumption is supported by the behaviour of some Algae, in which the sexual cells can often germinate independently; the egg-cells especially may develop without fertilisation. From the analogy with similar cases in the animal kingdom this phenomenon has been termed parthenogenesis. In the primitive Algae parthenogenesis is possible, because in them the incapacity of development of the egg-cell has either not been acquired or is easily removed under special conditions. Thus for example in the Alga Protosiphon parthenogenetic development is induced by a high temperature, and the same liapyens in the case of the ova of some lower animals (Echinoderms) on treatment with certain chemical substances. It may perhaps be assumed that in the cases in which development only takes place after fertilisation the stimulus to development is given by some substance contained in the sperm-cell.

Among the higher plants also phenomena to which the name parthenogenesis $\left({ }^{82}\right)$ has been applied occur. Thus the egg.cells of some Compositae, and also of Alchemilla, Thutietrum purpuraseens, Wiekstroemia indica, Fieus hirta, and Narsilea Drummondii develop withont previous fertilisation. These cases are distinguished from those just described by the egg-cells in question having retained the number of chromosomes characteristic of vegetative eells. They are diploid cells (p. 94) and not fitted for fertilisation. Strasburger terms these cases apogamy, and distinguishes them from parthenogenesis. WINKLER speaks of somatic parthenogenesis in contrast to the true or generative parthenogenesis of haploid eggs (c.. p. 96).

A number of cases of aprogamy (loss of sexuality) are naturally groupecl here. In the first instance there are those in which an embryo is developed from a tell of the embryo-sac other than the egg-cell, for instance from synergidae, antipodal cells, or from other nuclei of the embryo-sac. Further there are eases in which the embryo arises from the nucellus or from the inner integument, projects into the embryo-sac, and assumes the form of an embryo. Here also we are dealing with a purely vegetative reproduction which only resembles the sexual rejroduction in the place where it occurs. This development of "adventitious embryos" is as a rule associated with polyembryony, i.e. the development of numerous embryos in seerl (Funkiza ovata [Fig. 219], Enonymus latifolia, Citrus aurantium, Nothoscordon fratruns, Caelebogyne ilicifolia, etc).

The egg-cell previonsly existing in the embryo-sae is able to continne its development after fertilisation, but is usually prevented from so doing by the adventitions embryos. The seeds in such rases no longer contain the products of sexual reproduction, but have become organs of regetative multiplication. The adven- 
titions germs in the polyembryonic seed are, however, so far dependent upon sexual reprortnction, that for the most part they only attain their development in eases where pollination has previously taken place; bnt in Caelebogyne, one of the Australian Euphorbiaceae, of which usually only female specimens are fonnd in cultivation, and in Balanophore clongate and Elatostema acuminatum according to Treub, and Bal. ylobosa according to Lor'sr, the adventitions germs develop without the stimulus of fertilisation. These plants accordingly afford examples of a well-marked loss of sexuality.

This is the place also to mention the Ferns $\left({ }^{83}\right)$ in which the development of the embryo frequently does not proceed from the fertilised egg-cell. In Lastraca
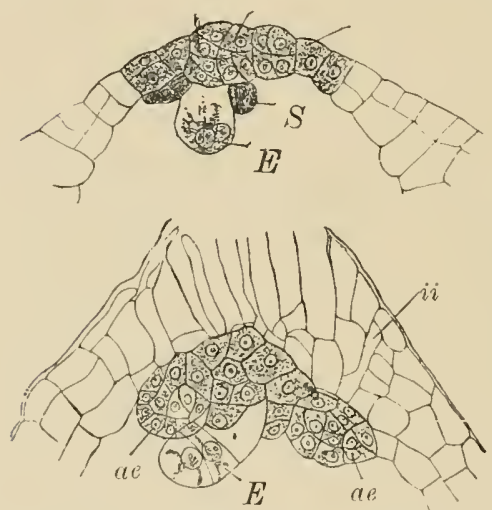

F1G. 219.- Vegetative formation of embryos in Funkice ovata (Hosta coerulen); $n$, nucellus witl cells in process of forming the rudiments (ac) of the adventitious embryos; $S$, synergidae; $E$, egg-cells, in the lower figure developing into an embryo; $i i$, inner integument. pseudo-mas polydactyla two ordinary prothallial cells fuse to give rise to the sporophyte. In Athyrium filix focmine clarissima, Jones, a prothallial cell with a diploid nuclens develops directly into the embryo without any process of fusion; in Nephrodium molle the same takes place with a laploid cell. In Athyrium filix fomine clarissima, Bolton, and in Harsilea Drummondii the sporophytes develop without fertilisation from diploid egg-cells. In many other eases, which are not confined to cultivated forms, the process of apogamous development has still to be studied in detail.

In Ferns, and occasionally also in Phancrogams, a pogamy is found associated with apospory, i.c. the absence of spores; the prothallus or the embryosac in these cases arise from ordinary regetative cells of the sporophyte.

$\mathrm{V}$ e thus arrive at the conclusion that the essential of sexial reproduction cammot consist in the removal of the arrest to development of the sexual cells. This leads us to consider THE FUSION OF THE SUBSTANCE OF THE TWO CELLS AND THE MINGLING OF PATERNAL AND MATERNAL CHARACTERS WIICH FOLLOWS FROM THIS. This brings ont the chief distinction between the two modes of reproduction; the vegetatively produced progeny are due to $n$ such mingling of characters. The complex of charaeter's in vegetative multiplication does not differ as a rule from that in the parent form. As a matter of fact, we obtain by vegetative multiplication all the varieties and races of our cultivated plants, even when these do not eome true from sexually produced seed.

It is of course not exeludel that the vegetative descendauts like the parent plant or its purts may undergo variation. From a bud of a tree a branch with new characters (ditfering in form or colour) may arise by what is known as It1)-VARATIOx; on such an altered branch years after, a complete or partial reversion to the ancestral eharacters may take place (atavism). In the same way variations may 
arise in vegetative multiplication, as may happen, aceording to BEYERIXCK, even in Bacteria which reproduce only by division into two $\left(^{8 t}\right)$.

In contrast to the regetative progreny the sexually produced descendants, as a rule, cannot completely resemble the mother plant, but must combine the characters of both parents. The more these differ from each other, the more striking will be the visible effect of fertilisation. Since, however, the individuals of a species frequently differ but slightly to our observation, the effect of the mingling of character's may be hardly noticeable in a typical case of fertilisation. Fortunately it is often possible to combine sexually inaividuals of distinct races, varieties, species and even genera, and the progeny resulting from such hybrid unions exhibits in the clearest way the mixture of characters of the two organisms (see below).

The faet already mentioned that many arrangements in the flowers of the higher plants lead to a erossing being effected supports this assumption of the significance of fertilisation. While it is quite possible that the egg-and sperm-cells of the same flower may differ from one another in their hereditary properties, it is probable tlat the sexual cells of distinct flowers will exhibit larger differences. It is of great interest that plants exist in which self-pollination does not result in the development of seeds since in extreme cases the pollen is incapable of growth on the stigma of the same flower (self-sterile flowers). Thus, for example, the flowers of Corydelis cara and Sccale cornutum are self-sterile. In certain orchids this goes so far as to result in injurious effects of the jollen on the stigma, or the stigma on the pollen when eross-pollination has not taken place. In other cases (e.g. in some Papilionaceae) the failure to set seed after self-pollination depends on the pollen being able to grow only on a stigma whieh has been rubbed. While this is not a case of actual self-sterility, the adaptations of the flower are such that the growth of the pollen will usually take place only after the visit of an insect; a visiting insect will, however, as a rule bring pollen from another flower.

\section{Hybrids}

The mnion of two sexual cells is, as a rule, only possible when they are derived from individuals of the same species; it is only then that they fuse together in the act of sexual reproduction. Occasionally, however, the sexual cells of different varieties, species, or even genera have been shown to be able to unite and produce descendants capable of development. Such a mion is termed Hrbridisition, and its products HYBRIDS.

By the demonstration of the possibility of hybridisation, the sexuality of plants, for a long time doubted, was iudisputably proven. With this object in view, and following the work of FAlrchiLD, in 1717 , hybrids were raised in great numbers by KöLREUTER as early as $\left.1761{ }^{85}\right)$. It also demonstrated that the real purpose of sexual union was the eombiuation of the properties of both parents, for transitional forms are found among hybrids which in many characteristics resemble the male and in others the female ancestor (hetero- 
dynamic hybrids), or they may show an equal combination of the characters of both (homodynamic hybrids, e.g. Nicotiana rustica o $x$ Nic. paniculate of). Less frequently it happens that the hybrid resembles one ancestor almost exclusively. Thus, certain hybrids of the Strawberry resemble the male parent only. In such a case the attributes of the other ancestor remain latent, and maty appear regularly or quite unexpectedly, through atavism (1). 284), in later generations.

The mingling of characters is often complete. Had one speeies simple leaves and the other compound, their hybrid would have leaves more or less eleft; or were the flowers of one parent species red and those of the other yellow, the hybrid frequently bore flowers with red and yellow markings (mosaie hybrids), or which were orange-coloured. If an early blooming form were crossed witl a late bloomer, the hybrid would flower at a time intermediate between the two.

A large number of spontaneous hybrids have been found which have arisen naturally from jlants with a special tenleney to hybridisation. Tluat such natural hybrids do not ocenr oftener is dne to the lack of an opportune time or space for their development, and also to the fact that in the case of pollination of flowers with different kinds of pollen, that of their own speeies seems as a rule more effectual in effecting fertilisation.

The investigations of Gregor Mendel, DE Vries, Corress, Tschermak, and others, have greatly inereased our knowledge of the laws governing the inheritance of different eharacters of plants. To final conclusions are yet attained, however, sinee even in regard to linited portions of the problem new features are still becoming apprarent $\left({ }^{86}\right)$.

In the crossing of elosely relaterl forms (rarieties or nearly related speeies), Mendel's laws (called after their first disenverer, Gregor JoH. MEnder [1866]) are found to hold. These laws, the most generally applicable of whieh is that of the segregation of characters, were independently rediscovered by be Vriss, Confens, and Tschersak. An example will give the best idea of these laws. If a redflowered Mirabilis julapa be erossed with a white-flowered individual one obtains a generation of hybrids with uniformly rose-coloured flowers. If these are fertilised from one another a seeond generation is obtained, but the individuals of this are not uniformly coloured; in addition to rose-eoloured plants pure redflowered and white-flowered plants oecur in the proportion per cent of $50: 25: 25$, i.c. in the ratio $2: 1: 1$. When fertilised from one another the pure red-flowered plants produce a red-flowered progeny and the white-flowered plants also breed true; they have returued to the pure parent forms. The $50 \%$ of rose-colomred plants again splits in the next generation, and like the former generation yields $25 \%$ pure resl, $25 \%$ pure white, and $50 \%$ rose-coloured plants. The proportion of hybrid plants thus continually becomes lessened by the return to the red and white types; in the eighth gencration only $0.75 \%$ of hybrids remain, and this small remainder continues to split further on breoding. These results are theoretieally explained by assuming that the sexual cells of the rose-flowered hybrids are not themselves of hybrid nature, but are already segregated into pure red and pure white sexual elements. In the process of fertilisation the mion prodneing a hybrid, red $\times$ white (white $\times$ red, red $\times$ white) will oceur twiee is frecuently as the union red $\times$ red or white $x$ white which grive rise to pure forms. This is illustrated in the acempanying diagram in which the dark circles represent the red sexual elenents.

The characters in which the parents difler do not, however, always blend so 
that the hybrid exhibits an intermediate character. More nsually the hybrids completely resemble in this respeet either the paternal or maternal parent, the character of the one parent being dominant in the hybrid while the other remains latent (Law of dominant charaeters). This is the case for example in hybrids
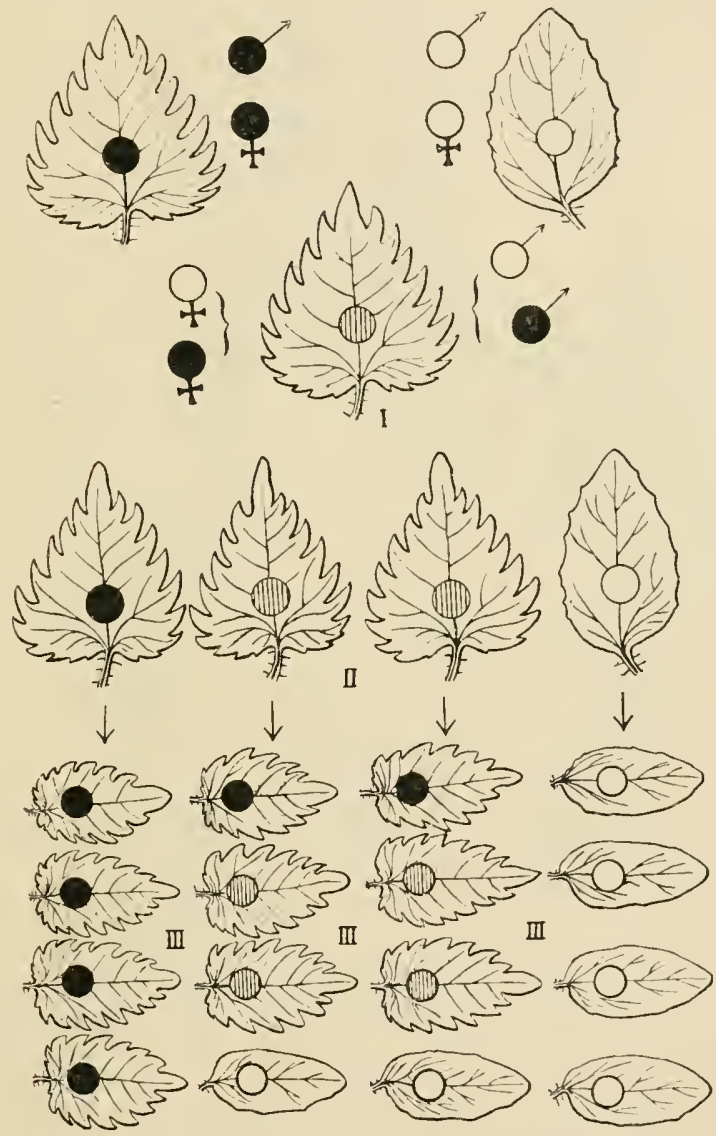

Fig. 220.-Hybridisation of Urtice pilulifere (to the lef't, ahove) with $U$. Dodurti (to the right). 1, First generation which, though hylrid, shows the dominant leaf-form of $U$. pilulifera. Its sexual cells, in which a separation of the ehasacter oecurs, give rise in generation II to a pure and constant pilulifera, a pue Dodarti, and two hybrids. In generation III the pure forms to the right and lelt are constant, the hybrids in the entre show further splitting of characters.

between L'rtica pilulifera with serrate leaves and $U$. Dudarti (Fig. 220). The hybricls have all serrate leaves like $U$. piluliferc, so that in the second generation the proportion of serrate-leaved to entire-leaved individuals is per cent $75: 25$ $(3: 1)$. Only $50 \%$ of the serratc-leaved individuals are, however, of hybrid nature and continue to show a similar plitting of characters in the next generation; $25 \%$ have become pure $U$. pilulifera. It is impossible to prediet whieh charaeters 


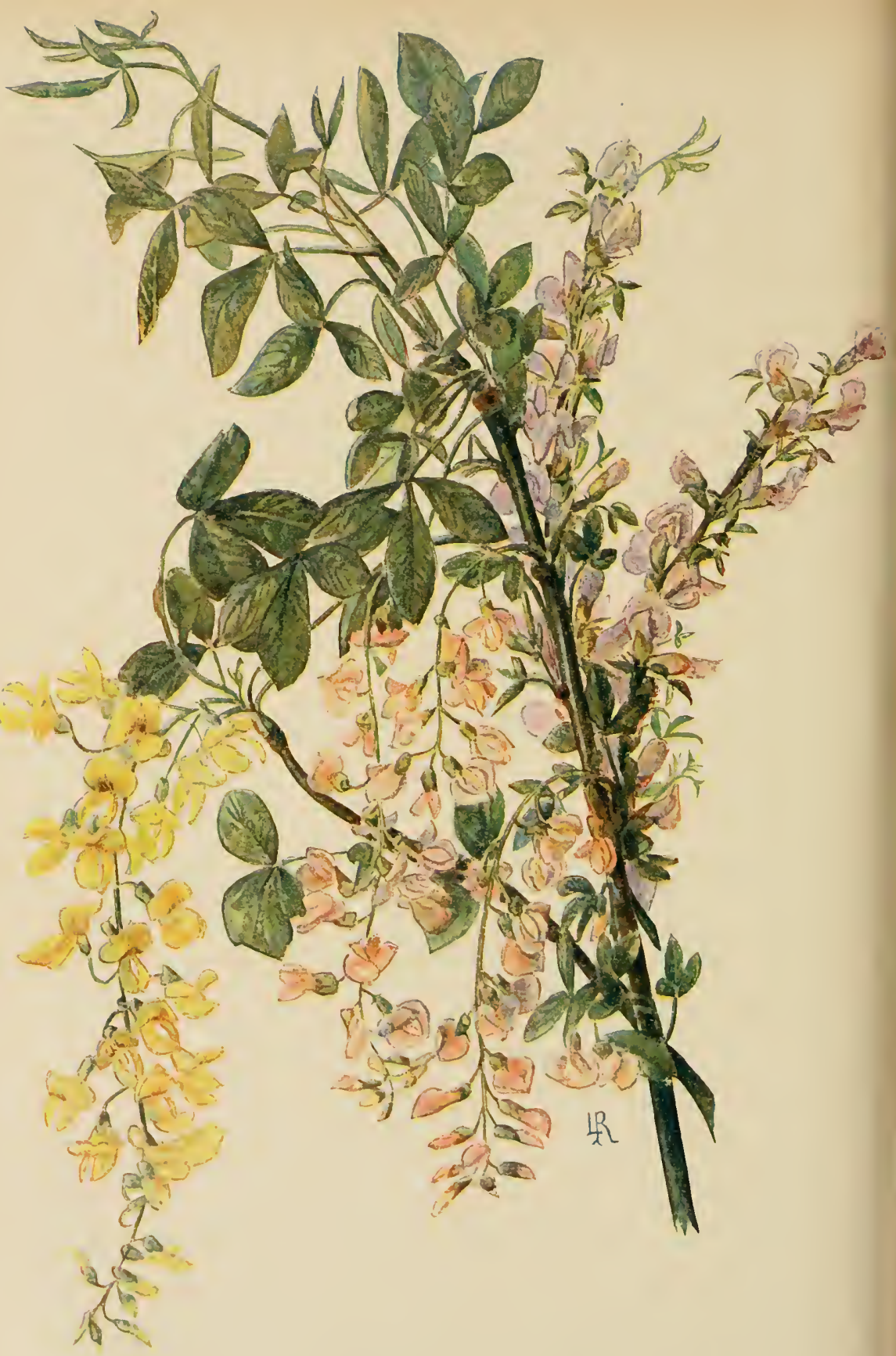

FIG. 221.-Laburnum Adumi, Poit (Cytisus Ademi, Iort) with atavistic branches showing the characters of the two parental forms, Luburmum vulgare to the left and Cytisus purpureus to the riglit. 
will prevail in any eross, and the question ean only be settled by experiment; usually the phylogenetically younger character appears to be dominant.

When the parents differ in two characters instead of only one, monofybrids instead of dihybrids result. It then appears that the several elaracters are independently transmitted and distributed in the descendants (autonomy of characters). Thus new combinations of characters may eome about, a fact of great inplortance in plint-breeding. From the crossing of peas with yellow, wrinkled seeds, and those with green, smooth seeds, among other possible combiuations of the characters the new ones yellow-smooth and green-wrinkled alpear. Many characters, however, tend to remain associaterl together (coupled characters).

It is not possible to enter in this place into the complicated phenomena of the production and segregation of clihybrids and polyhybrids.

In crossing some races quite new characters frequently appear in the hybrids. Thus in crossing a white-flowererl with a yellow-flowered Nirabilis there may result, besides white-flowered and yellow-flowererl deseendants, others with rose-, rerl-, red-white, yellow-white, rose-red, and rose-white coloured or striped flowers. Since these newly appearing eharacters each in turn obey the Mendelian laws it is assumed that they were latent in the parents, and that the latter belonged to what are ealled eryptomerous races.

The IIendelian laws hold also in the animal kingdom and for the human race, but only for the crossing of nearly related forms. Thus crosses between negroes and negro-albinos follow Mendelian laws, while those between negroes and whites do not.

The nore closely allied the parent plants, the more readily, as a rule, may lyybrids between them be produced. Many families seem to incline naturally to hybridisation (Solanaceae, Caryophyllaceae, Iridaceae, etc.); others again develop lyybrids only oeeasionally or not at all (Papilionaceae, Convolvulaceae, Coniferae, ete.). Even in the same family the related genera and species exhibit great differenees in the readiness with which they may be erossed. The Grape-rine, and also the Willow are easily crossed with other species of their own genus, and the same is also true of the different sprecies of Dianthus, while the speeies of Silene cross with each other only with difficnlty. Species hybrids are easily prodneed from species of Nicotiana, of T'erbuscum, and of Geum; on the other hand, it is very difficult to cross different species of Solanum, Linaria, or Potentilla. The hybridisation, liowever, of nearly allied forms is often impossible-the Apple with the Pear, for instance-althongh the Peach and Almond may be crossed, and also the species of even the different genera Lychnis and Silene, Rholodendron and Aselea, Aegilops and Tritieum, Secale and Triticum (Rrurau), Zea and Éuchleene (Zea eanina results from a eross between Z. mais o and Euchlaena mexicane o ), each aceording to their "sexual affinity."

Derivative Hybios arise when hybrids are crossed with one another, or with one of the original parent forms. In this way it has been possible to unite six speeies of Willow in one hybrid, and in the case of the Grape-vine eren more speeies have been combined. It is only in rare cases, however, that the form of the hybrid remains constant in the suceeding generations. These exhibit more frequently a tendeney to revert to one of the original ancestral forms.

In addition to their inherited qualities HyBRIDs ExHIBIT NEW IECULIARITIES not derived from their parent forms. These are a MODIFIED FERTILITY, GREAT TENIENCY TO VARIATION, and often a 
MORE LUXURIANT GROWTH. The fertility is often so enfeebled that the hybrids either do not flower (Phododendion, Epritobinm), or are sterile and do not reproduce themselves sexually. This enfeeblement of the sexuality inereases the more remote is the relationship of the ancestral forms. Other hybrids snch as those of Salix and Hicrucium remain fertile.

The tendency to variability is often greatly enhanced in hybrids, especially in those arising from the hybridisation of different varieties of the same species (ef. p. 289).

Hybrids, particularly those from nearly related parents, frequently produce more vigorous vegetative organs, they bloom earlier, longer, and more profusely than the uncrossed plants, while at the same time the flowers are larger, more brilliant, and exhibit a tendency to become donble. The luxuriance of growth and the increased tendency to produce varieties displayed by the hybrits have made the whole subject of hybridisation one of great practical as well as theoretical importance.

As WINkLER has shown, intermediate forms can also be produced under favourable cireumstances by vegetative union (grafting). The graft-hybrids ( ${ }^{\left({ }_{i}\right)}$ letween the Nightshade and the Tomato artificially produced by WinkLen leave hardly any doubt that certain intermediate forms of uncertain origin in cultivation are of similar nature. Thus Cytisus Allami (Fig. 221) is an intermediate form between Cytisus laburnum and C. pmpureus. Another example is afforded by the intermediate forms between Hespilns germanica and Crutuegus monogyna, known as Bronveaux hybrids. These plants are peculiar in often reproducing the parent forms by bud-variation (Fig. 221). The actual conditions under which graft-hybrids arise are not fully known. It is, however, at least doubtful whether a fusion of two cells gives the starting point for the hybrid form.

\section{Variation and Mutation ("s)}

The laws which govern hybridisation nutst also hold for the fertilisation between two individuals of the same species when these exhilit differences in their hereditary characters. In this way descendants are produced, characterised by a combination of paternal and maternal characters; fertilisation thus gives rise to new forms. These, it is true, will not persist if their properties are not useful, or if on erossing with other individuals of the species their characters do not prevail.

The differences between the individnals of a pure species and the individuals obtained by in-breeding from a plant need not, when aceurately observed, be so slight as is commonly supposed. The deviations from the type which are olserved can be placed in two eategories; we distinguish the fluctuating variations from mutations. 
Fluctuating variations are quantitative deviations from a mean type which ean be eounted, weigherl, or measured. They appear to be determined by the external conditions of growth which similarly fluctuate around a mean value, and they can be to a certain degree fixed or even increased by careful selection. Thus, for instanee, the amount of sugar in the sugar-beets has been considerably increased by selection. On selection ceasing this artificially maintained variation disappears, and this would be the case in nature. In contrast to these fluctuating variations the mutations are larger or smaller deviations from the type which suddenly, not gradually, appear from unknown causes, and possess inheritable characters. Such mutations have been most thoroughly studied by DE VRIES in Oenothere Lamarckiuna. Typical examples are also afforded by many forms which have spontaneously appeared in gardens, and have proved the starting point for valuable cultivated forms. Examples are Chelidonium luciniatum, which arose in 1590 in a Heidelberg garden, and C'apsella Heegeri, Solms, which appeared at Landan.

It is hardly a matter of doubt that new sub-species (petites especes, of which Jordan has described over 200 in Draba verna) have arisen by such sudden mutations. More distinct species may develop from these, partly by the oecurrence of further mutations, and partly by the dying out of the intermediate forms and the persistence of the extreme forms. Since those organisms which do not possess sexual reprodiction are also differentiated into genera and species, the occurrence of mutations cannot be eonfined to digenie reproduction. Bud-variations have also been frequently observed to arise (cp. p. 284).

\section{Sub-SeCTION ${ }^{\circ}$ III.}

\section{Movement}

Phenomena of movements are met with in the living plant not less generally than those of metabolism and development. Metabolism is associated with a continual movement of the raw food-materials, which are absorbed, and of the elaborated assimilates and excreted sulbstances. These movements cannot be directly observed, but are not less certainly established; they have already been dealt with. In addition there exist a number of visible alterations of position exhibited either by the whole plant or by its several organs; these movements are, it is true, often very slow but sometimes are quite sudden.

\section{Survey of the Various Kinds of Movement}

Protoplasis itself is capable of different movements. Naked protoplasmic bodies almost always show slow movements resulting in 
a gradual change of position; but cells enclosed by cell walls possess also the power of INDEPENDENT LOCOMOTION, often indeed to a considerable extent. Multicellular plants, however, as a mle ultimately attach themselves, by means of roots or other organs, to the place of germination, and so lose for ever their power of locomotion, exeept in so far as it results from growth. A gradual change in position due to growth is apparent in plants, the rhizomes and stems of which are continually growing forward. Thus the growing point of the giant Eucalyptus tree of Australia is moved from close to the soil to a height of $100 \mathrm{~m}$. The tip of a rhizome may move more slowly, but perhaps in the conrse of centuries, even further. In addition to these movements, occasioned by a growth in length, plants firmly established in the soil possess also the power of ehanging the position and direction of their organs by means of curvature. Not only mequal growth but other processes also take part in these changes of form. In this way the organs are lorought into positions necessary or advantageous for the performance of their functions. By this means, for example, the stems are directed upwards, the roots downwards; the upper sides of the leaves turned towards the light, climbing plants and tendrils twined about a support, and the stems of seedlings so bent that they break through the soil without injury to the young leaves.

\section{A. Loconotion}

In a fuller consideration of changes of position we can leave on one side the carriage forward in a straight line by means of growth of the growing point since this has been dealt with in the chapter on development. We thus confine ourselves to the protoplasmic movements among which the AMOEBOID MOVEuENT, the CILIARY MOVEMENT, and the MOVEMENT OF PROTOPLASM IN CELLS WITII CELL-WALLS may be distinguished.

The ereeping movements of naked protoplasts, such as are shown by an amoeba or plasmodium, in the protrusion, from one or more sides, of protuberances which ultimately draw after them, the whole protoplasmie body, or are themselves again drawn in, are distingnished as AMOEBOID MOVEMENTs. These movements resemble, externally, the motion of a drop of some viscid fluid on a surface to which it does not adbere, and are chiefly due to surface tension, which the protoplasm can at different points increase or diminish by means of its quality of irritability.

By means of irregular changes of surface-tension similar amoeboid movements are also exhibited by dropss of Iifeless fluids, such as drops of oil in soap solution, drops of an oily emulsion in water, or drops of mercury in 20 per cent solution of potassium nitrate in contact with erystals of potassium bichromate.

In the sivmming Movements bY MEANs of chliA, on the con- 
trary, the whole protoplasmic boly is not involved, but it possesses special organs of motion in the form of whip-like FLAFELLA or CILIA. These may be one, two, four, or more in number, and arranged in various ways (Figs. 97, 98). They extend through the cell wall when this is present and move very rapidly in the water, imparting considerable velocity to the protoplast, often giving it at the same time a rotary movement. The minute swarm-spores of Fuligo vuriuns traverse $1 \mathrm{~mm}$. (sixty times their own length) in a second, those of Ulva, $0.15 \mathrm{~mm}$, while others move more slowly. The Vibrio of Cholera, one of the most rapilly moving bacteria, takes 22 seconds to traverse a millimetre.

Although plants which are firmly attached and stationary exhibit no such locomotory movements, the protoplasm within their cells does possess a power of movement. Such internal protoplasmic movements are especially active in the non-cellulaw Siploneae, and in non-septate Fungi, in the elongated internodal cells of the Characene, in the hairs of many plants, as well as in the leaf-cells of some aquatic plants (cf. p. 58).

In these movements the outermost layer of protoplasm in contact with the cellwall remains at rest; the movement cannot thus be compared to that of an amoeba enclosed in a cell. The movement continues when the rrotoplasm has been detached from the cell-wall. Its cause must be looked for in surface tensious betwcen the protoplasm and the cell-sap.

The continuance and activity of such protoplasmic movements, the existence of which was first observed by Corte in 1772, and later rediscovered by TrisVIRANu's in 1807, are dependent on factors which, in general, support and promote the vital activity; the presence of free oxygen in aerobionts and proper conditions of temperature seem to be particularly favourable to them. That the movements in Nitella continued for weeks in the absence of oxygen is cxplained by the power the Characeae possess of becoming facultative anaerobes. Those Bacteria which are obligate anaerobes lose their power of notion in the presence of oxygen. On the other hand aerolic Bacteria which lose their motility in the absence of oxygen become motile again on the supply of oxygen being restored (ef. p. 214). From the study of sections in the cells of which emrents had been induced in the protoplasm, by the injuries sustained in their preparation and by other abnormal conditions, grave

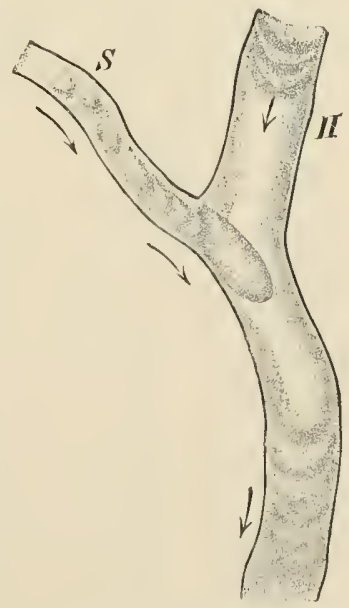

F1c. 222.-Sitreaming protoplasm in the hyphas of Rhizopus nigrieans. (After J. C. ArtuUr.) errors have arisen concerning the existence of such protoplasmic movements in cells, in which under normal conditions they cannot be observed. The presence of protoplasmic currents in a cell may, in fact, indicate cither an energetic vital activity, or, on the other hand, be mercly a symptom of a pathological or, at least, of an excited condition of the protoplasm. 
A peculiar mode of protoplasmic movement, which may be termed streadivg, occurs in the non-septate mycelium of some Fungi. In it the whole mass of protoplasm, with its included vacuoles, streams towards the end of the liypha, only the limiting layer remaining at rest. After a longer or shorter interval a similar streaming movement commenees in the opposite direction (cf. Fig. 222). Teisetz observed the same type of movement in the mycelimm of Ascophanus carncus, where the protoplasmic stream, with its racuoles, makes its way through the pores of the perforated transverse septa. In this latter case it was established that the direction of streaming was determined by local differences in the supply of water. It is hardly doubtful that we have here to do with a normal vital phenomenon $\left({ }^{89}\right)$.

Diatoms and Desmids exhibit quite a different class of movements. The Diatoms glide along, nsually in a line with their longitudinal axis, and change the direction of their morements by oseillatory motions. From the manner in which small particles in their neighbourhood are set in motion, it is conclued that there exists a current of protoplasm, which bursts through the raplie ; this, according to $O$. MULLEr, is the cullse of the movement $\left({ }^{90}\right)$. The cells of
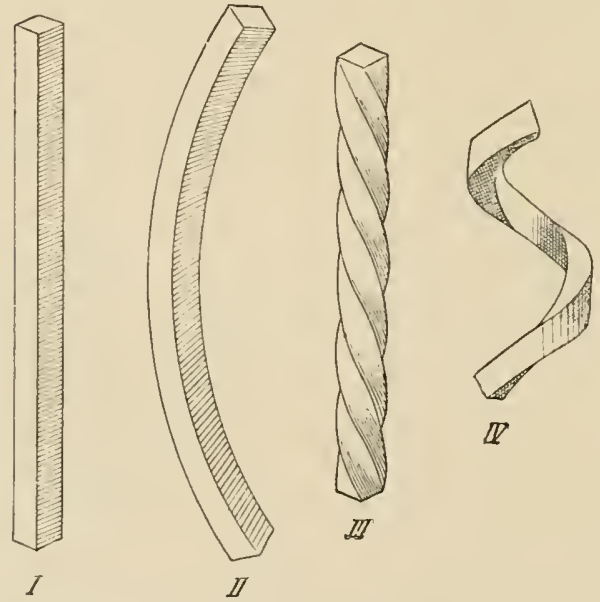
selves to the substratum by mucilaginous exeretions, and effect their peculiar morements by loeal fluctuations in the mneilaginous layer. The advaneing movements of the filamentous Oseillarieae and Spirulinae take place, aceording to Corress, in a mucilaginous sheath, but their mechanism is as little understood as that of the slow movements of spiregyru.

\section{B. Curvatures}

The sorts of curvature which may take place in the organs of attached plants are illustrated by Figr. 223. A four-angled prism is of equal length along each of its angles. If it is bent in one plane the angles of the concuve side must become markedly shorter than those of the convex side. An elongation of one side or a shortening of the other side or simultaneous lengthening of one side and shortening of the opposite side must lead to curvature. W'hen in this proeess of bending the column remains in one plane, it is spoken of simply as a curvature. When, however, it passes out of the one plane so that the bending follows a line oblique to the longitudinal axis it is spirally wound $(\mathrm{IV})$. Lastly, when the columm renains as a whole straight but its angles follow spiral lines, it is termed twister. The 
torsion comes about by a difference in length between the middle line and the angles; all the latter are of equal length.

Ways in which Curvatures are produced. - In the production of enrvatures we are always concerned, as has just been shown, with changes in the dimensions of an organ dne to unequal lengthening or shortening. In bringing about these changes in dimension the following means are employed by the plant.

1. Growth; this can only lead to elongation.

2. Osmotic pressure. This can effect an elongation or a shortening according as it is inereased or diminished.

3 Viriations in the amount of water in the cell-wall or in dead cells. These also can effeet either elongation or shortening.

Aecording to the means employed in altering the dimensions, the curvatures of plants may be divided. into Gliowti-CUlivatulies, VARIATION MOVEMENTS DEPENDING ON TURGESCLNCE and HYGROSCUPIC Movknents. Since growth and osmotic pressure are vital phenomena, i.e. are essentially influenced by the living protoplasm, they will be treated below along with the locomotory movements which are dependent on the living substance of the plant. The hygroscopic movements on the other haud are not vital phenomena; they oceur in dying or dead organs and are exclusively brought about by external factors. The protoplasm only plays a part in these movements in that it has led to such a construction of the organs that changes in the amomnt of water present produce curvatures and not a simple ebange in length.

\section{Hygroscopic Movements}

Two quite distinct types of movement are included in the lyygroscopic movements. In the first, which are termed miBibition MECHANISus ( ${ }^{91}$ ), the cell-walls increase in size on swelling or contract on shrinking.

The swelling or shrinking depends on the fact that the water of im!jbition is not contained in cavities like those in a porous borly (such as a sponge or a piece of plaster of Paris) that contain the capillauly water, but in being absorbed has to force apart the minute particles of the cell-wall. Conversely these particles approach one another again when the iubibition-water evaporates. When on different sides of an organ there are mequally well-developed layers, or layers that swell with unequal rapidity, or when opposite layers differ in the direction of their greatest extension on swelling, curvatures must take place every time the organ is moistened or dries. 'Thongh here we are dealing with purely physical phenomena, they may possess great importance for the plant. 
The rupture of ripe seel-vessels, as well as their dehiscence by the opening of special apertures (Poparcr, Lychnis, Antimhinum, ete.) is a consequence of the unequal contraction of the cell-walls due to desiceation. At the same time, by the sudden relaxation of the tension, the seeds are often shot ont to a great distance (Tricoecae, Geranium, ete.). In eertain fruits not only eurvatures but torsions are produeed as the result of changes in the amount of water they contain, e.y. Erodium gruinum (Fig. 221), Stipa pennata, Avena sterilis; by means of these, in conjunction with their stiff barb-like hairs, the seerls bury themselves in the earth.

The opening or elosing of the moss sporogonium is, in like manner, due to the hygroseopic movements of the teeth of the peristome surrounding the mouth of the capsule. In the ease of the Equisetaceae the outer walls of the spores themselves take the form of four arms, which, like elaters, are capable of active movements; by means of these numbers of spores beeome massed together

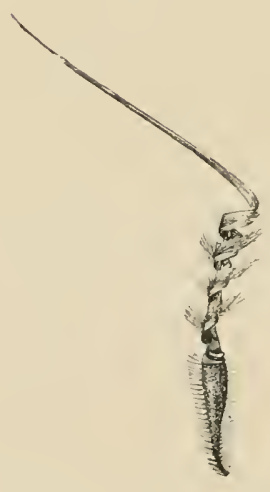

4
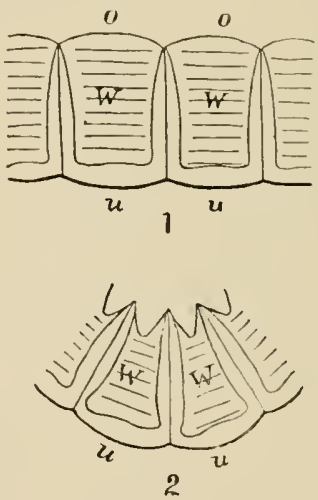

Fig. 225.-Diagram of a cohesion curvature. 1. Culls in original position. 2. After partial evaproration of the water filling them (w) ; the nuyer cell-wall (u) is curved in, while the lower $(u)$ retains its original length.
FIc. 224.-Partial fruit of Erolium gruinum. $\mathrm{A}$, in the dry condition, cuiled ; $L$, moist and elongated.

before germinating, and the isolation of the dioecions protlallia prevented (Fig. $408 \mathrm{E})$.

Similar movements of no nse are also met with, thus dead branehes of Conifers exhibit the most beantiful hygroseopie movements.

In orler to call forth imbibition movements the actnal presenee of liquid water is not neessary, for the cell-walls have the $1^{10}$ wer of absorbing moisture from the air. They are hygroseopie, and are nserl to estimate the hmidity of the air in hygrometers and weather-glasses.

S'TEINBRINCK and KAMERLING have distinguished the mechanisms which depend on the cohesive power of water from those depending 
on imbibition. The combsion Mechanisms (92) were previously confounded with the latter, from which they differ in that, even during the movement, the cell-walls remain saturated with water. It is the lumen of the cell which diminishes in size when the loss of water, on which the movement depends, occurs. The cohesive force of the diminishing amount of water tends to pull the thinner walls of the cell inwards after it ( 1 ig. 225 ), and thus to approximate other walls, which are strongly thickened and exhibit a definite arrangement. In this way an energetic shortening of the specialised tissue is brought about which leads to alteration of form or to the deliscence of spaces enclosed by the tissue. The walls of anthers and of the sporangia of the higher eryptogams aflord examples of such a method of dehiscence. The movements of the pappus of most, and the involucre of some, Compositae, are effected in the same way.

Mechanisms dependent on imbibition and on cohesion may cooperate in the movements of some plants.

\section{Movements in the Actively Living Plant}

These movements are to some extent dependent on the factors which we have recognised as general conditions of life. They are most active at an optimal temperature and humidity and sometimes also intensity of light. On overstepping the minimum or the maximum for these factors a loss of motility or a condition of rigor results. Thus we speak of cold-, heat-, darkness-, or drought-rigor, etc. This condition can be removed by a return of the favomable conditions, but if it lasts long enough will ultimately lead to death. In some cases it is sufficient that these general conditions of life should be present, butin others the movement only results on the application of a special stimulus. We have, therefore, autonomic movements and induced or stimulus movements to study.

\section{A. Autononir: Movenexts}

The creeping movements of plasmodia and amocbae, the swimming movements of swarm-spores and gametes and the protoplasmic streaming in cells are frequently, though not always, antonomic. That is to say we cannot refer the start of the movement to one or several external factors. When these movements are purely autonomic they usually tend to be without definite direction. The plasmodia move without object, the swimming movements and the circulatory movements alternate contimully, and only the current of the rotating protoplasm exhibits a definite direction.

Thus also the growth of the shoot or root in a straight line (with the characteristic grand poriod of growth, dependent as has been shown wholly on internal causes) is an autonomic movement. A 
number of growth curvatures or nutations are associated with this growth, and it might almost be said that there is harlly such a thing as growth in a straight line. The tips of the organs describe extraorclinarily irregular curves in space ; they cxhibit "circumnutations," as was discovered by DARwin. While these curvatures are usually so slight as not to be perceptible withont the aid of special methods, cases exist in which organs exhibit very conspicuous, striking, and regular autonomic growth eurvatures.

The unfolding of most leaf and flower buds, for eximple, is a nutation movement which is induced by the more vigorous growth of the upper side of the young leaves (epinasty). The same unequal growth manifests itself most noticeably in the umrolled leaves of Ferns and many Cycadeae (hyponasty). The stems of many seedlings are, on their emergence from the seeds, strongly curved, and this aids them in breaking through the soil. By the nutation of the shoots of Quinario a curvature is produced which continuously advances with the increased growth; so that, by means of its hooked extremity, a shoot is better enabled to seek ont and cling to a support.

When the unequal growth is not confined to one side, but occurs alternately on diflerent sides of an organ, the nutatious which result seem even more remarkable. Such movements are particularly apparent in the flower-stalk of an Onion, which, although finally ereet, in a lalf-grown state often curves over so that its tip tunches the ground. This extreme curvature is not, lowever, of long duration, and the Hlower-stalk soon becomes erect again and bends in another direction. Thin and greatly elongaterl organs (e.y. tendrils) must, from purely physical reasons, quickly respond to the eflects of unequal growtl.

It the line of greatest growth advances in a definite direction around the stem, the apex of the latter will exhibit sinilar rotatory movenents (RIVurvixg NUTATION). This form of nntation is characteristic of the tendrils and shoots of elimbing plants, and facilitates their coming in contact with a support. The socalled IEVOLVING NUTATION GF TWINING l'LAN's is not, however, an AURUNOMIC MOVEMENT, and will be considered later with the pratonic movements (1. 312).

Besides these mutations which result from growth autonomic variation movements are also met with, though less commonly. They are almost confined to foliage leaves, and indeed to those which have pulvini at the base of the petiole and of its further ramifications. P'nlvini oceur especially in Leguminosae and Oxalideae, also in Marsilet, and are charactcrised by a structure which fits with their particular function.

In the ordinary parenchymatous eell the cell-wall, owing to its growth in thickness, ceases to be stretehed; on plasmolysis it therefore does not in full-grown cells contract in the same degrce as it cloes in growing cells (p. 256, Fig. 177). Conversely on an increase of the internal pressure the wall only becomes slightly stretehed. In some cases, however, and the pulvinus is an cxample, the cell-wills even in their fully-grown state are considerably distender by the osmotic pressure. This is shown not only by their behavionr on plasmolysis, but also by the persistence of marked tissue-tensions. 
A pulvinus of one of the Legmninosae, such as the Kidney Bean, has the vascular bundle and the sclerenchyma, which are peripherally arranged in the leafstalk, united to form a central and easily bent strand; this is surrounded by a thick zone of parenehyna (Fig. 226, 3). If from a pulvimus isolated by two transverse sections the middle sheet of tissue is cut out (Fig. 226, 1) the bulging of the cortical parenchyma both above and below shows the considerable tension. On splitting the portion of the pulvinus longitudinally as in Fig. 226, 2, the tendency towards expansion of the parenchyma, especially of its mirldle layers, is very elearly shown.

It will now be readily seen that an increase in turgescence on all sicles will inerease the tension between the vaseular bundle and the parenchyma and thus inerease the rigiclity of the pulvinus. On the other hand, an inerease of turgescence on one side or a climimution

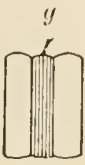

1

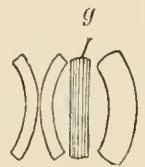

2

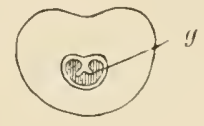

3

EIG. 226.-Pulvinus of Phaseolus (after SACHs). 1, Layer cut longitudinally from the midale of the pulvinus; 2 , the same cut up ; 3 , transverse section. $g$, Vascular bundle. on the other side, or the occurrence of both these changes together, will cause a lengthening of the one side and a shortening of the other side which naturally curves the pulvinus. The vasenlar bundle is passively bent, and undergoes no alteration in length. The passive movement of the part of the leaf attached to the pulvinus is due to the curvature of the pulvinus.

A remarkable example of this form of movenent is furnished by the small lateral leaflets of Desmodium gyrans, and still more strikingly by Oxalis hedysaroides. In a moist, warm atmosphere $\left(22^{\circ}-25^{\circ}\right)$ these leaflets make circling movements which are of such rapidity that the tips describe a complete circle in 1-3 minutes; in the ease of the leaflets of Oxalis a path of $\frac{1}{2}-1 \frac{1}{2} \mathrm{~cm}$. is traversed in one or a few seconds. Variations in illumination do not disturb these movements. The antonomie variation movements of Trifolium and of the WoodSorrel take place, on the contrary, only in darkness. Thus the terminal leaflets of Trifolium, pratense exhibit oscillatory movements in the dark with an amplitude which may exceed $120^{\circ}$, and are regularly repeated in periods of $2-4$ hours; but on exposure to light the leaflets cease their oscillations and assume a fixed light position. In a less striking form similar antonomic variation movements are exhibited by all leaves provided with pulvini.

\section{b. Paratonic Movements (Stmulus Movements)}

The induced or paratonie movements are of much greater interest to the physiologist; in these an external factor aets as a stimulus and starts the movement. By means of these movements freely motile organisms seek ont the situations in which they find the optimal eonditions 
for life, and the organs of plants first assume such positions in air, or water, or in the earth as are necessary for the performance of their vital functions. A green plant which spread its roots over the surface and unfolded its leaves below ground could not exist, even though all its members possessed the best anatomical structure. Seeds are not always deposited in the soil with the embryonal stem directed upwards and the racliele downwards, so that their different organs can, merely by direct growth, attain at once their proper position. A gardener does not take the tronble to ascertain, in sowing seed, if the end which produces the root is directed downwards or the stem end upwards; he knows that in any position the roots grow into the ground and the stems push themselves above the surface. Plants must accordingly have in themselves the power of placing their organs in the positions best adapted to the conditions of their environment. This is only possible, however, when the externally operative forces and substances can so influence the growth of a plant that it is constrained to take certain definite directions.

The same external influences excite lifferent organisms or different parts of a plant, and even the same structure in different stages of its development, to assume different positions. Thus, for instance, the young plasmodia of Myxomycetes avoid the light, while swarm-spores of Algae move towards the light. The motile spheres of l'olrox seek a less intensity of light wher they contain egg-eells than when they are in a purely vegetative stage. The stem grows towards the light, the root away from the light; both grow in the direetion of the rays of light. The leaves on the other hand place themselves with their surfaces at right angles to the rays of light falling on them.

These examples only indicate a few of the modes of reaction of the organism. In the particular description of the stimulus movements it will always be necessary to make clear what is the determining stimulus. Light, heat, gravity, contact, material and mechanieal influences of the most varied kind can serve as stimuli. It has to be earefully determined whether the movement is one of locomotion or merely a curvature; the former is termed taxis, the latter tropism or nastic movement. We speak of tropism when the organ takes up a resting position definitely related to the direction of the effective stimulus. Nastic movements on the other hand are curvatures which bring about a particular position in relation to the plant and not to the direction of the stimulus.

In the following account the tactie and tropic movements which lead to a definite orientation of the plant in space will be grouped together. The other movements will be termed niastic.

The condition of reeeptiveness to stimuli in the plant is common to all irritable movements and inleed all irritable phenomena. The stimulus must give rise to definite changes in the plant, the protoplasm must react to these changes in such a way that the eharacteristic externally visible reaction ultimately takesplace. Between 
this result and the reception of the stimulus there donbtless intervene many and complieated proeesses whieh are at present but little understood. The places where the stimulus is received and pereeived are termed sense organs or, better, organs of perception. The power of perception or of sensation in the plant ean be spoken of withont implying any subjeetive perception, will, or thonght, as in the complieated human psychology. This is mfortmately sometimes done by modern sensational writers. There is reason to distinguish organs of perception, especially when it can be shown that the place where a stimulus is received is separater in spaee from the part where the movement is effected. In snch a case a conduction of the stimulus must take place $\left({ }^{93}\right)$.

\section{Directive Movements (Movements of Orientation)}

Whether the directive movements are expressed in free changes of position or in curvatures, we have to distinguish orthotropous (parallelotropous) and plagiotropous organs. The former place themselves in the direction of the stimulus and approach the source of the stimulus (positive reaction) or move away from it (negative reaction). Plagiotropous organs place themselves at right angles to the direction of the stimulus (diatropic organs) or obliquely to its direction (klinotropic organs). The mode of reaction of any particular organ may be changed by external or internal factors. The movements of orientation are distinguished as phototropic, geotropic, etc., and as phototactic, geotactic, etc., according to the stimulus bringing them about.

\section{(a) Stimulus of Light}

Phototaxis ( $\left.{ }^{94}\right)$. Phototactic movements may be hest observed when a glass vessel containing water in which are Volvocineae, Chlamydomonadinae, or swarm-spores of Algae is exposed to one-sided illumination from a window. After a short time the uniform green tint of the water disappears since the motile organisms have all aceumulated at the better-illuminated side of the vessel. If the latter is turned through an angle of $180^{\circ}$ the Algae lasten to the sirle which is now illuminated. If, however, a stronger light, such as direct sunlight, is allowed to fall on the vessel the same organisms which have reacted till now positively become negatively phototactie and swim away from the source of light.

The ehange from a positive to a negative reaetion involves the passing through an indifferent stage in whieh no tactic movement results. This stage of indiflerence does not lic at the same intensity of the light for all the individnals of a species. Exceptionally also changes in the reaction of siugle inclividuals oecur, the causes of which are only partially recognisable. In some organisus, such as the plasmotia of Myxomyeetes, we find a negative reaction even to a light of low intensity. There are also colourless organisms which have a positive phototactic reaction.

In the ease of many swarm-spores and some Volvoeineae phototaxis has the effect of eausing when light falls from one sile, a rotation of the organism, bringing it into 
the direction of the rays of light; it then proceeds straight on in this direetion (topic reaction). In other cases a quite different mode of reaction is observed (phobic reaction); the organism bounds back when its movements have brought it into a region of the medium where it is exposed to a distinetly different intensity
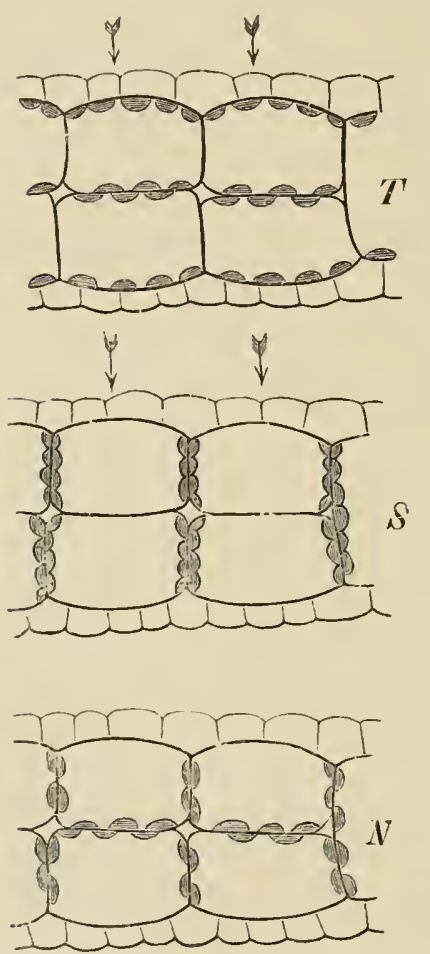

Fia. 227.-Varying positions taken by the chloropliyll grains in the cells of Lemna trisulcu in illumination of differ. ent intensity. $T$, in diffuse daylight; $S$, in direct sunlight; $N$, at night. The arrows inclieate the direction of the light. (After Stant.) of light. No rotation of the organism takes place in this case.

A very striking example of phototaxis is afforded by the chloroplasts within the cell $\left({ }^{95}\right)$. These movements have the result of bringing the chlorophyll grain into such a position that it can obtain an optimal amount of light. This object is sometimes attained by rotation of the chloroplast, and sometimes by its movement to another position in the cell.

In the eylindrical cells of the filamentous Alga Mesocarpus, the elloroplasts, in the form of a single plate suspended length-wise in each cell, turn upon their longitudinal axes according to the direction and intensity of the light. In light of moderate intensity, they place themselves transversely to the source of light, so that they are fully illuminated (transverse position); when, on the other liand, they are exposed to direct sunlight, the chlorophyll plates are so turned that their edges are directed towards the source of light (profile position).

In the leaves of mosses and of the higher plants and feru prothalli a similar protection of the chloroplasts against too intense liglit, and their direct exposure, on the other hand, to moderate illumination, is accomplished, where they are of a different form and nore numerous, by their different disposition relatively to the cell-walls. In moderate light the ehlorophyll bodies are erowded along the walls, which are at right angles to the direetion of the rays of light (Fig. 227 T). They quickly pass over to the walls parallel to the rays of light, however, as soon as the light becomes too intense, and so retreat as far as possible from its action (Fig. $227 \mathrm{~S}$ ). In darkness or in weak light the elloroplasts group themselves in still a third way (Fig. $227 \mathrm{~N}$ ), the advantage of which is not altogetler elear.

The form of the elilorolliyll grains thenselves undergoes noditication during ehanges in their illumination; in moderate light they beeme flattened, while in light of greater intensity they are smaller and thieker. As a special mode of protee tion against too iu tense light, the ehloroplasts of the Siphoneae and Diatomeae (and the same thing is observed in many plants) become balled together in separate elumps. 
In eorrespondence with the changes in the position of the chloroplasts, the colonring of green organs naturally becomes modified. In direct sunshine they aplear lighter, in diffused light a darker green. The attention of SAr'Hs was first ealled to the phenomena of the movements of the elloroplasts by the aecidental observation that the shadow of a themometer was rejuresented in dark green on a leaf otherwise direetly illuminated by the sun.

\section{Phototropism (Heliotropism) ${ }^{(96}$ )}

A good opportunity for the observation of heliotropic phenomena is afforded by ordinary window-plants. The stems of such plants do not grow ereet as in the open air, but are inclined towards the window, and the leaves are all tulned towards the light. The leaf-stalks and stems are accordingly ORTHUTROPIC and POSITIVELY PHOTOTROPIC. In contrast with these organs the leafblades take up a position at right angles to the rays of light in order to receive as much light as possible. They are IIAPHOTOTROPI, Or TRANSTERSELY HELIOTROPIC, in the strictest sense (Fig. 228). If among the plants there should be one with aerial roots, Chlorophytum for instance, an example of NEGATIVE PHOTOTROPISM will be affordeci, as the aerial roots will be found to grow away from the window and turn towards the room. In lig. 228 the phototropic curvatures which take place in a water culture of a seedling of the White Mustard are represented.

For more exact investigation of phototropic movements it is necessary to be able to control

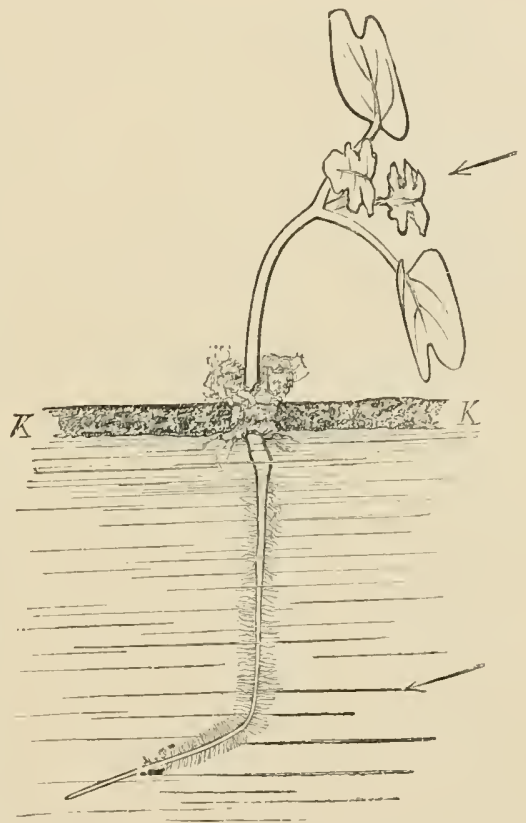

Fri, 228. -A seedling of the Whitu Mnstard in a water eulture which has first been illuminated from all sides and then from one side only. The stem is turned towards the light, the root away from it, while the leaf lyades are expranded at right angles to the ineident light. $K K$, Sheet of cork to whicl the seelling is attached. more accurately the soluree and direction of the light. This can be best accomplished by placing the plants in a room or box, lighted from only one side by means of a narrow opening or by an artificial light. It then becomes apparent that the direction of the incident rays of light determines the phototropic position; every alteration in the direction of the rays produces 
a change in the position of the phototropic organs. The apical ends of many positively heliotropic organs will be found to take up the same direction as that of the rays of light.

The exactuess with which this is done is illustrated by an experiment made with Pilobolus crystallinus (Fig. 229). The sporangiophores of this Fungus are quickly produced on moist horse or cow dung. They are positively phototropic, and turn their black sporangia towards the source of light. When ripe these sporangia are shot away from the plant, and will be found thickly elustered abont the centre of the glass covering a small aperture through which alone the light

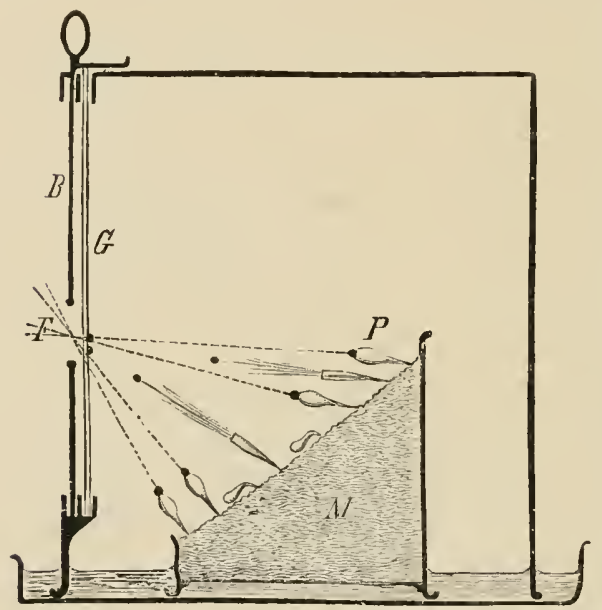

Fig. 229.--Pilobolus crystullinus $(P)$, abjeeting its sporangia towarls the light. $(i$, sheet of glass; $B$, opraque case with a circular opening at $F$; $M$, vessel containing horse-dung. (Cf. description in text.)

has been admitted; a proof that the sporangiophores were ail previonsly pointed exactly in that direction.

Upon closer investigation of the manner in which the POSITIVE PHOTOTROPIC CURVATURE of an organ is accomplished, it is found THAT THE SIDE TURNED TOWARDS THE LIGHT GROWS MORE SLOWLY, THE SIDE AWAY FROM THE LIGHT MORE RAPIDLY TIIAN WHEN ILLUMINATED FROM ALL SIDES. This may be readily shown by previously marking with Indian ink regular intervals from one to two millimetres apart on the opposite sides of the organ. After the eurvature has taken place the intervals between the marks will be found to be much farther apart on the shaded side than on the side turned to the light. As compared with the elongation under normal conditions of growth, the marks on the illuminated side have remainerl nearer together, while those on the shaded sicle have drawn farther apart; that is, the growth in the case of a positive heliotropic curvature has been retarded on the illuminated side anil promoted on the shaded side. It also becomes evident, from observation of the ink-marks, THAT CURVATURE TAKRS PLACE ONLY IN THE PORTIONS OF STELS STILL IN PROCESS OF GROWTH, AND THAT THE CURVATURE IS AS A RULE GREATEST WHERE THE GROWTH IS MOST VIGOROUS.

It was formerly believerl that the increased growth of the shaled side was prodneerl by the leginning of etiolation, and that the diminisher growth on the illminateil side was dur to the retarling effeet which light exerts upon growth in length 
(1. 262). Other phototropic phenomena were found to be at varianee with this explanation of phototropism. Unicellular perfeetly transplarent fungal hyphe are also subjeet to positive eurvature, although in this instance there ean he no shaded side; on the contrary, the side of a hypha turned away from the light is especially illuminated on aecount of the refraetion of the light rays. The faet, too, that negative curvatures also take place renders it evident that phototropism cannot be due to one-sided etiolation; for in negative phototropism the side most directly illuminated is the one that grows more rapidly, although the retarding effect of light on the normal growth in length of negatively phototropie organs is equally operative (roots, rhizomorplia).

It is evident from these eonsiderations that it is not the difference in the intensity of the light which causes the heliotropic curvatures, but the direction in which the most intense light rays enter the organs. LIGHT ACTS AS A MOTORY STIMULUS WHEN IT PENETRATES AN ORGAN IN ANY OTHER DIRECTION THAN THAT WHICII CORRESPONDS WITH THE position of IiEliotropic Equilibriun. Only one-sided illumination can thus cause curvature in a plant. If without altering the direction or the intensity of the illumination the plant is kept in constant rotation, around a vertical axis, by means of clock-work, the phototropie stimuli acting on the different sides neutralise one another and no curvature takes place. This apparatus is known as a kLiNostat.

The phototropic enrvatures are most strongly produced, just as in the ease of the heliotactic novenents of freely moving swarm-spores, by the blue and riolet rays, while red and yellow light exerts only a mueh shighter influence. When a plant receives on one side red light, and on the other side blue light, it turns towards the latter, althongh the red light is of greater importance for its earbon assimilation.

Sensibility to phototropic influenees is jrevalent throughout the vegetable kingdom. Even organs like many roots, whieh are never under ordinary cireumstances exposed to the light, often exhibit phototropie irritability. Positive phototropisin is the rule with aerial vegetative axes. Negative phototropism is much less frequent; it is observed in aerial roots, and sometimes also in climbing roots (Ivy, Ficus stipulate, Begoniu sccundens), in the hylocotyl of germinating Mistletoe, in many, but not all, earth roots (Sinapis, Helianthus), in tendrils (chiefly in those with attaeling dises), and in the stems of some elimbers. By means of their negative heliotropic eharacter, the organs for elimbing and attachment, and the primary root of the Mistletoe, turn from the light towarls, and are pressed firmly against, their darker supports.

Negative phototropic curvatures are oceasionally produced, not in the region of most rapid growth, but in the older and more slowly growing portions of the stem. The stems of Tropecolum majus, for example, exhibit positive plototropic curvatures in the region of their greatest elongation, but lower down the stems, where their growth is less rapid, become negatively phototropic.

Tiansverse PHototropisu is confined almost solely to leaves and leaf-like assimilatory organs, such as Fern prothallia and the thalli of Liverworts and Algae. In hese organs transverse phototropism, in conformity with its great utility for assimilation, predominates over 
all other motory stimuli. Such organs become placed at right angles to the brightest rays of light to which they are exposed during their development; in the full-grown condition they assume what is known as a fixed light-position.

In too bright light the transverse position of the leares becomes changed to a position more or less in a line with the direction of the more intense light rays. In assuming a more perpendicular position to avoid the direct rays of the mid-day sum, the leaf-blades of Lactuca Scariole and the North American Sitphium laciniatum necessarily take, according to STAll, the direction of north and south, and so are often referred to as compass plaxts. The foliage leaf has thus, like the chloroplast of Nesocarpus, the power of assuming either a profile or a full-face position, and thus regnlating the amount of light received.

A number of foliage leaves possess pulvini at the base of the petiole, and also at the bases of secondary and tertiary branchings; by the aid of these variation movements are effected. In this way these leaves are able to change their position throughout life, and at any moment to assume the position which affords them the optimal supply of light. They do not have a fixed light-position determined by the strongest illumination during their development, but they sometimes expose their edges and sometimes their surface to the light.

The phototropic character of organs, and depending on this the specific position of the organs of the plant, may change through the activity of external influences, and also at different stages of their development and growth. The flower-stalks of Linaria cymbalaria are at first positively phototropic. After pollination, however, they become negatively phototropic, and as they elongate they push their fruits into the crevices of the walls and rocks on which the plant grows (p. 259). The intensity of the illumination has a great influence, since plants which in subdned light are positively phototropic exbibit negative phototropism when the illumination is excessive. Between the two reactions a nentral condition exists. The adjustments to the environment dependent on the intensity of light, and the search for an optimal intensity of light connected with this (cf. the plototactic swarm-spores, p. 301), are evidently of great use to the plant.

Heliotropic sensibility is markedly increased when traces of coal-gas, carbonmonoxide, etc., are present as impurities in the atmosphere. This is so strikingly the case that conchisions as to the degree of impurity ean be drawn from the heliotropic deflection exhibited by susceptible plants (Peas, Vicia calcarata, etc.) $\left({ }^{97}\right)$.

Localisation of Phototropie Perception ( $\left.{ }^{98}\right)$. - Often the stimulus of light is received at the same place that the movement is effected. In certain leaves, however, the lamina is able to perceive a phototropic stimulus without being able to carry out the corresponding movement; this takes place only after the stimulus has been conducted to the leaf-stalk. It is true that the leaf-stallk can also react to direct stimulation, but as a rule the dominant impulse 
proceeds from the lamina. Still more striking relations are met with in the seedlings of certain Grasses; in some Paniceae only the tip of the so-called cotyledon can be phototropically stimulated, and only the hypocotyledonary segment of the stem, separated by some distance from the tip of the cotyledon, is capable of curvature. In this case there is a well-marked distinction betwcen a perceptive organ and a motile organ; the similarity to corresponding phenomena in the animal kingdom is very striking. There is an essential difference, however, in the method of transmission of the stimulus. For not only are "norves" completely wanting in the plant, but the stimulus is conveyed from. cell to cell; as FITTING showed, this does not only take place in a direct line, but also "round the corner."

There is no doubt that the perception of light by the plant is elosely connected with photochenical processes (98a). As to how the plant perceives the direction of the light we are, however, ignorant. HABErLANDT attempted to show that the structure of the epidermal cells brought about an unequal illumiuation of their inner walls. When the rays of light fell vertically, the middle of the wall would be most brightly illuminated. When any other distribution of light was brought about the plant made a phototropic movement. The projection outwards of the outer walls of these cells ( 1.112 ), or thickenings in these walls (p. 70), act as convex lenses, and increase the difference in the illumination between the centre and periphery of the inner walls of the cells. This hypothesis is still open to considerable doubt.

\section{(b) The Stimulus of Gravity ( $\left.{ }^{99}\right)$}

Geotropism.-It is a matter of experience that the stems of a fir-wood or of a palm avenue are all vertical, and therefore parallel to one another; the branches and leaves of those trees, on the other hand, take other positions. If, instead of a tree, we consider a seedling, for example of the Maize, we find that, at any rate to begin with, the organs stand in the vertical line. At the same time we here observe more readily than in the case of a tree the totally different hehaviour of the roots and the stem. If we bring the seedling from its natural position and lay it horizontally we find that a curvature takes place in both organs; the root curves downwards, and the shoot of the seedling upwards. Since these curvatures are not effected at the region where the root passes into the shoot, but in the neighbourhood of the apices of the two organs, a region of variable length remains horizontal, and only the two ends of the plant are bronght by the curvature back into their natural directions, and continue to grow in them. 'That this vertical growth of the main root and main stem is due to gravity is apparent from direct observation, which shows that these organs are similarly oriented all over the globe, and lie in the direction of radii of the eartl. The only force acting everywhere in the direction of the earth's radius that we know of is gravity. Not, however, as a result of this line of thought, but from 
the experiments of Kxicht (1806), was this knowledge introduced into our science. KNIGHT's experiments rest on the following consideration. It is evident that gravity can only cause the root to grow downwards, and the stem to grow upwards, if the seed is at rest and remains in the same relative position to the attractive force of the earth. From this KingHT conjectured "that this influence could be removed by the constant and rapid change of pasition of the germinating seed, and that we should further be able to exert an opposite effect by means of centrifugal force."

He therefore fastened a number of germinating seeds in all possible positions at the periphery of a wheel, so that the root on emerging would grow outwards, inwards, or to the side, and he caused the wheel to rotate round a horizontal axis. Since this rotation was rery rapid, not only was the one-sided action of gravity excluded, but at the same time a considerable centrifugal force was prodnced, which in its turn influenced the seedlings. The result of the experiment was that all the roots grew radially away from, and all the shoots radially towards the centre of the wheel. Thus the centrifugal force determined the orientation of the seedlings as gravity does normally.

In another experiment KNIGHT allowed gravity and centrifugal force to act simultaneously but in different directions on the seedlings. The plants were fastened on a horizontal dise which rotated round a vertical axis. When the distance of the plants from the centre and the rapidity of rotation were so adjusted that the mechanical effects of the centrifugal force and of gravity were equal, the roots grew outwards and downwards at an angle of $45^{\circ}$ and the stem inwards and upwards at the same angle. As the rapidity of rotation increased the axis of the seedlings took a position approximating more to the horizontal. It results from these experiments that the plant does not discriminate between gravity and centrifugal force, and that the one can be replaced by the other. Both these forces have this in common that they impart to bodies an acceleration of mass.

An essential addition to the fundamental researches of KivighT was given much later (1874) by the experiments of SACHS. In these the plants were rotaterl round a horizontal axis as in KNIGHT's first experiment, but the rotation was slow, taking ten to twenty minutes to effect one complete rotation. This is so slow that no appreciable centrifugal force is developed. Since, however, by the continual rotation any one-sided influence of gravity is eliminated, the roots and shoots grow indifferently in the directions which they had at the beginning of the experiment. In this experiment SAcHs employed the KLINOSTAT (p. 305), which is so arranged that its axis of rotation can be horizontal as well as vertical.

The property of plints to take a definite position under the influence of terrestrial gravity is termed GEOTRoPISII. It has been 
seen that there are not only orthotropous organs which place themselves in the direetion of gravity, and grow positively geotropically (downwards) or negatively geotropically (upwarls), but also plagiotropous organs which take up a horizontal or oblique position. The positions assumed by the lateral organs are also - though as a rule not exclusively-determined by gravity.

All vertically upward growing organs, whether stems, leaves (Liliiflorae), tlower-stalks, parts of flowers, or roots (such as the respiratory roots of Avicennia (Fig. 193), Palms, etc.), are negatively geotropic. When such negatively geotropic organs are forced out of their upright position, they assume it again if still canable of growth. As in phototropisin, GEOTROPIC CLRVATURE RESLLTS FROM THE IXCREASED (IROWTH OF OXE SIDE AND THE IETARDED GROWTH OF THE OPPOSITE SIIE, and the region of greatest growth is, in general, also that of the greatest curvature. In negatively geotropic organs, growth is acceleraterl on the side towarls the earth; on the upper side it is retarded. In eonsequence of the unequal growth thus induced, the erection of the free-growing extremity is effecterl. After the upright position is again attained, the one-sided growth ceases and the organ continues to grow in an upward direction.

The process of negative geotropic movement is dependent: (1) upon the vigour of the existing growth ; (2) upon the sensibility of the organ; (3) upon the fact that the stimulus of gravity is most energetic when the apex of the orthotropic organ is removed about $90^{\circ}$ from the vertical; the more nearly the zone eapable of curvature aprroaches this position, the stronger is the motory stimulus; deviations from this optimal position of stimulation do not result in such striking differences in reaction as are caused by even very small $\left(\frac{1}{2}^{\circ}\right)$ deviations from the vertical; $(4)$ and also upon the fact that after a stimulus has ceaserl to act npon a plant, the induced stimulation continues to produce so-called AFTER EFFECT:

These considerations determine the actual course of the directive movement of geotropism, which, as will be seen from the adjoining figure (Fig. 230), does not consist merely of a simple, continuous curvature. The numbers 1-16 show, diagrammatically, different stages in the geotropic

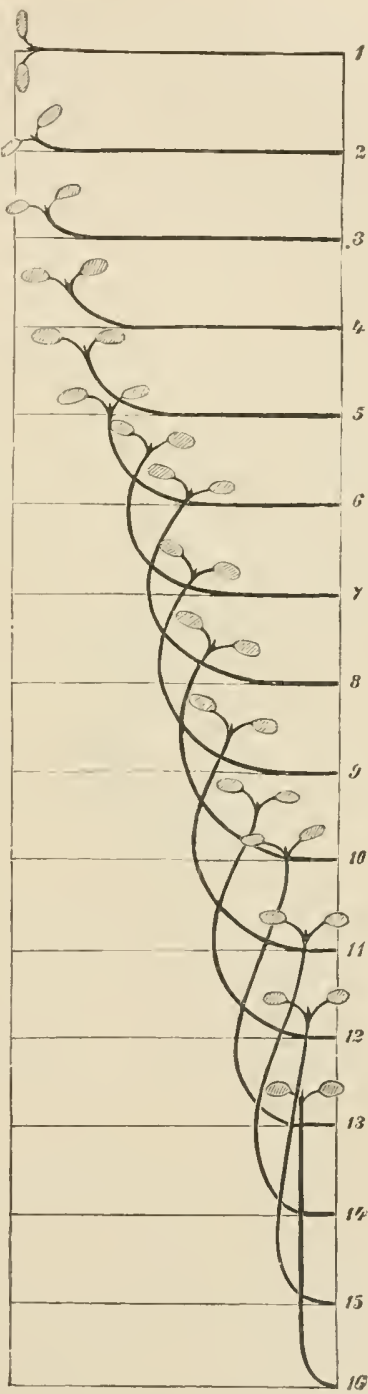

Fir. 230.-1)ifferent stages in the process of geotropic movement. The figures 1-16 insicate suecessive stages in the geotropic curvature of a semlling grown in semi-darkness : at 1 , placed horizontally; at 16 , vertical. For description of intermerliate strues see text. (Dia. grammatic.) 
erection of a seedling growing in semi-darkness and placed in a horizontal position (No. 1). The growth in the stem of the seedling is strongest just below the cotyledons, and gradually decreases towards the base. The curvature begins accordingly close to the cotyledons, and proceeds gradually down the stem until it reaches the lower, no longer elongating, portions. Through the downward movement of the curvature, and partly also owing to the after-effect of the original stimulus, the apical extremity becomes bent ont of the perpendicular (No. 7 ), and in this ray a curvature in the opposite direction takes place. For two reasons this excessive eurvature must again diminish. In the first place every curved part of a plant, whatever the cause of the currature has been, tends to straighten (antotropism). This is shown when a geotropically curved shoot is rotated on a klinostat. This autotropic tendency is naturally only effective when geotropism does not oppose it. In the case in question, however, after the excessive curvature another geotropic stimulus in the opposite direction to the first combines with the autotrolism. The final result is thus always sooner or later a complete straightening of the stem.

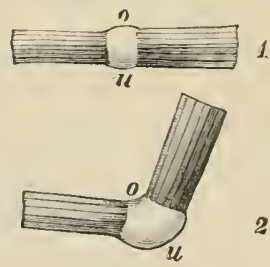

Ftc. 231.-Geotropic erection of a grass-hanlm by the curvature of a node. 1, Placed horizontally, both sides $(u, 0)$ of the node being of equal lenstli; 2, the under side (u) lengthened, the upper side $(0)$ somewhat shortened; as a result of the curvature the grass-haulu has been raised through an angle of $75^{\circ}$.

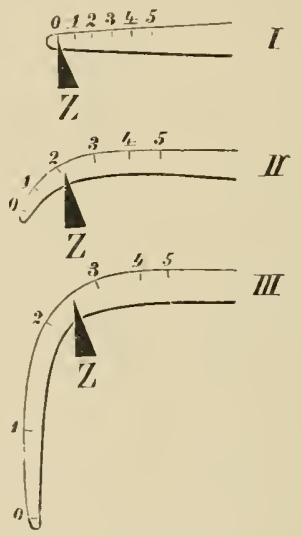

Flc. 232.-Geotrolic currature of the roots of a seedling of Tiria Fabr. I, Placed horizontally; $I I$, after seven hours: $I I I$, after twenty-three hours; $Z$, a fixed index. (After SAchs.)

In some eases negatively geotropie curvatures may take place in full-grown shoots, i.e. in such as no longer exhibit growth in length when not geotropically stimulated. Thus in woody stems and branches the growth in length of the cambium of the lower side may bring the organ into the erect frosition as a result of geotropism. The greater the resistance of the frarts which have to be passirely bent the more slow and incomplete will this response be. The so-called nodes of grasses which in reality are leaf-cushions, can also be stimulated by geotropism to further growtl. If the stimulus acts on all sides, as when the node is horizontally placed and rotated on the klinostat, all the parenchymatous cells exhibit a nniform elongation. If the node is simply placed horizontally the growth is limited to the lower side while the upper side is passively compressed (Fig. 231). By means of such curvatures in one or several nodes grass haulms laid by the wind and rain are again brought into the erect position.

Positive geotropisin is exhibited in tap-loots, in many aerial roots, and in the leaf-sheaths of the cotyledons of sone Liliaceane and in the rhizome of Fueca. All these organs, when placer in any other position, assume a straight downward 
direction and afterwards maintain it. Formerly, it was believed that this resulted solely from their weight ant the pliancy of their tissues. It is now known that this is not the case, and that positively geotropic, like negatively geotropic, movements are possible only throngh growth. The power of a downward curving root-tip to penetrate mercury (specifically much the heavier), and to overcome the resistant pressure, nuch greater than its own weight, proves conclusively that positive heliotropism is a manifestation of a vital process. Positive geotropic curvature is due to the fact that THE GROWTH OF AN ORGAN IN LENGTH IS PRONOTED ON THE LPPER SIDE, AND RETARDES, EVEN MORF, STROXGLT, ON THE SIDE TURAED Towalins tile Fartu. Fig. 232 represents the course of the geotropic eursature in a root.

Most lateral branches and roots of the first order are plagiogeotropic, while branches and roots of a ligher order stand ont from their parent organ in all directions. THESE ORgaNs ARE ONLY IN A POSITIOY OF EQU1LIBRIUM WHEN THEIR LOXGITUDIXAL AXES FORM A DEFINITE ANGLE WITI THE LINE OF THE ACTION OF GRAVITY. If forced from their normal inclination they return to it by curving. A special instance of plagiogeotropism is exhibited by strictly horizontal organs, such as rhizomes and stolons, which, once they have attained their proper depth, show a strictly ThaNSVElise GEOTROPISM (diageotropism). Should the proper depth not be attained the plant teuds towards it by upwardly or downwardly directed movements, and then takes on the horizontal growth. The oblique position naturally assumed by many organs is in part the result of other influences.

A special form of geotropic orientation is manifested by dorsiventral organs, e.g. foliage leaves, zygomorphic flowers. All such dorsirentral organs, just as radial organs that are diageotropic, form a definite angle with the direetion of gravity, but are only in equilibrium when the dorsal side is uppermost. In the orientation of dorsiventral organs not merely simple curvatures but torsions are concernerl.

The rotation of the ovaries of many Orchidaceae, of the flowers of the Lobeliaceae, of the leal-stalks on all hanging or oblique branches, of the originally reversed leaves (with the palisade parenchyma on the under side) of the Alstroemeriae, and of Allium ursinum, all afford familiar examples of torsion legularly occurring in the process of orientation $\left({ }^{100}\right)$.

The foliage leaves which possess pulvini must be specially mentioned again among dorsiventral organs since they eall change their position by geotropic variation movements in the fully-grown state.

As in the case of phototropism, an alteration of the relation of the organ of the plant to the geotropic stimulus may be brought about by internal or external influences. It is very common to find a change of the geotropic position during the development of the shoots of plants with rhizomes and aiso of flowers and fruits. In this way the fruits of Trifolium subterraneum and of Arachis hypogaea become buried in the soil. Of external influences may be mentioned the cutting off of the supply of air, inducing a want of oxygen which causes some roots and rhizomes to become negatively geotropic. Temperature also modifies the position of the main and lateral axes of some plants. Thus the stems of many of our spring plants lie prostrate while the temperature is low, but become erect as a result of their geotropism at a higher temparature. The influence of light modifies especially the geotropism of rhizomes and of lateral roots. 
While phototropism is increased by impure air (p. 306), geotropism is, as a rule, weakened by this influence.

The discoverer of geotropism, KNIGIT, attempted to explain the geotropic movements on purely mechanical lines; this did not seem diffienlt, especially for positively geotropic organs. He regarded them as simply following the attractive foree of gravity till a condition of rest is attained. Later HoFMEISTER advaneed similar views. The correet assumption that we are concerned with complicated stimulus mechanisms in which terrestrial gravity only plays the part of the liberating factor dlepends on the work especially of DUTRociIET, Frank, and SAcHs. Even the one fact that the root can carry out its geotropic enrvature against the resistance of merenry is sufficient to eall in question every purely meehanical explanation.

Only in recent times has the attempt been made to determine what is the primary effect of gravity in the plant (100a). F. NoLL first elahorated the idea that there must be some bodies in the cells of greater speeific gravity than the surrounding protoplasm, and capable under the influence of gravity of exerting a one-sided pressure on the protoplasm; on this taking place the protoplism directs the processes of growth in accordance with the direction of the force of gravity. NËMEC and HaberLANDT then suggested that these specifieally heavier bodies might be found in eertain stareh grains which show relatively rapid movements of falling in the cells. They found such starch grains in the pericycle of the stem (p. 129) and in the cells of the rooteap. They assume that the stimulus of gravity can only affeet directly portions of the plant provided with such starch grains, but that it may be conducted from these points to others. As a matter of fact the attempt had previonsly been made to show that only the tip of the root ean receive the gravitational stimulus. Even at the present time this question is not deeided, and not a few investigators assume that all cells - thongh in various degrees-are geotropically sensitive. The hypothesis of NEMEC and HABERLANDT, though there is much in its favour, is not fully established.

Twining Plants $\left({ }^{101}\right)$, which are found in the most various families of plants, have shoots which require to grow erect but are unable to support their own weight. The erect stems of other plants, which often secure their own rigidity only by great expenditure of assimilated material (in xylem and selerenchyma), are marle use of by stem-elimbers as supports, on which to spreal ont their assimilatory organs in the free air and light. The ntilisation of a support produced by the assimilatory activity of other plants is a peculiarity they possess in common with other climbers, such as tendril- and rootclimbers. Unlike them, however, the stem-climbers accomplish their purpose, not hy the help of lateril clinging organs, but by the capacity of their main stems to twine abont a support. The first internodes of young stem-elimbers, as developed from the subtermen 
organs which contain the reserve food material, as a rule stand ereet. With further growth the free end curves energetically to one side and assumes a more or less oblique or horizontal position. At the same time the inclined apex begins to revolve in circles like the hand of a watch. This movement continues from the time of its inception as long as the growth of the shoot lasts, and as a rule takes place in a definite direc-

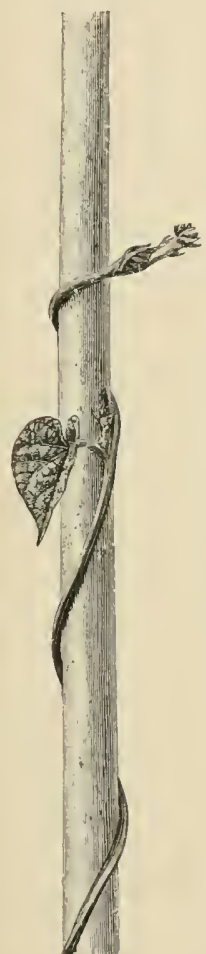

I

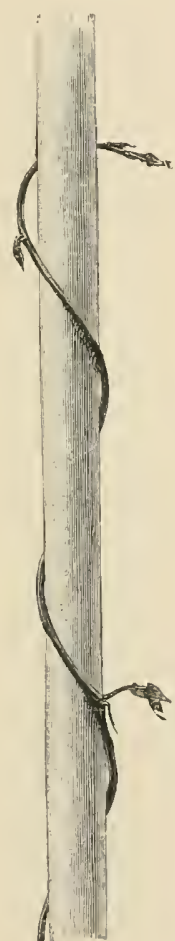

II

FIf. 233.-1, Sinistrurse shoot of Pharbitis. II, Dextrorse shoot of Myrsiplyllum. asparagoifles.

tion. In the majority of twining plants the cireling movement as seen from above is in the direction opposite to that of the hands of a watch (towards the left as we commonly express it). The Hop and the Honeysuckle twine to the right, in the direction of the hands of a watch. In Boviea volubilis and Loasa luteritio a rotation alternately to the right and left has been observed. The plants that circle to the left are also left-handed climbers, i.e. the spiral which their stems form (Fig. $233 \mathrm{I}$ ) mounts from the left to the right and, as seen from above, against the direction of the hands of a watch. Similarly the plants that eirele to

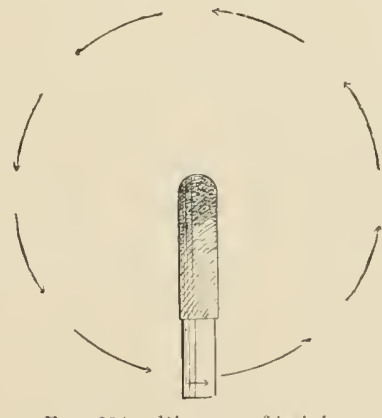

FIG. 234.-1)iagram of twining.

the right are also right-handed twiners (Fig. 233 II). There is thus an intimate connection between the cireling movement and the twining.

The revolving movement ean be made clearer by construeting a simple model. Fasten a stiff-walled rubber tube at its base to an ereet post, stick in its free end a piece of lead pencil which is sufficiently heary to bring the tuhe into a horizontal position, and guide the point of the prencil in a cirenlar direction opposite to that of the hands of a wateh (Fig. 23.). If a colonred line is marked longitudinally on the prencil it will be seen that this line during the revolving movement rotates 
parallel to itself round the axis of the pencil. If at the commencement of the revolving movement it was at the lower side of the pencil, it will be fonnd after a quarter of the circle has been moved through to be on the left side (as seen from the ontside), and after half the circle has been traversed to be on the npper side. The rotation of the line thins proceeds (as seen from the outside) in the direction of the hands of a watch and thus in the opposite direction to the revolving movement. If, however, the rotating movement of the pencil, as the revolving movement proceeds, is hindered by loolding the end of the pencil, a torsion will arise at the lower portion of the rubber tube. If after a time the end of the pencil is liberated it undergoes the rotation that has been prevented, and with this the torsion again disappears. If we now mark with Indian ink an angle of the horizontal terminal portion of the shoot of Calysteyia, this line will be seen like tho line in the model to move in the direction of the hands of a watch as the rerolving norement of the shoot proceeds. When the end of the shoot has completed a revolving movement against the hands of the watch of $360^{\circ}$, the line has also moved through $360^{\circ}$ in the direction of the hands of the wateh. In other words, after a complete circular movement everything is as before and there is no torsion in the vertical portion of the shoot.

The levolving movement was for long regarded as a purely autonomic movement resulting from internal causes. In practice it is found that it only occurs under the influence of gravity and ceases completely on the klinostat. Some authors regard it as a geotropic movement. NoLl has arrived at the following view. In this case it is not an upper or lower side that is hindered in growth by terrestrial grarity, but a lateral flank; in the sinistrorse plants it is the right side (the apex being looked at from above) which grows more strongly than the oprosite side. This "lateral geotropic" reaction does not occur in the whole shoot of the twining plant; on the contrary it is linited to the transition region between the erect portion and the horizontal portion of the end of the shoot. The part that has become erect is simply negatively geotropic, the horizontal portion is diageotropic. If now the right flank of the curved portion of the shoot is accelerated in its growth by gravity the horizontal end will begin to move in a circle. In doing this, however, it must, in order to avoid a basal torsion, rotate around its axis, and thus another angle will be brought to occupy the right flank. The geotropic acceleration of growth will thus involve the several angles of the stem as they successively come to occupy the right tlank.

This view of the influence of gravity is not, lowerer, accepted on all sides. PFEFFER, for instance, regards the revolving movement as an antonomic movement, and only regards gravity as having the significance of a general condition of the movement, such as heat, water, light, etc., are.

The commencement of the revolving movement does not by itself determine a twining movement. This only begins when the shoot meets a more or less vertical and not too thick support. This is enclosed in loose and at first very horizontal spirals which gradually become more ereet and steeper. The straightening results from negative geotropism and leads under otherwise favourable conditions when the support is subsequently removed to a complete obliteration of the spiral coils, the straightened stem appearing twisted. If the support is not removed it leads to tightening of the spiral and increased pressure on the support. The twining movement thus 
comes about by the revolving movement together with negative geotropism. The support plays a part in that it prevents the other. wise inevitable straightening. It must stand more or less vertically, because otherwise it would not be continually grasped by the overhanging tip of the shoot; this is so since the support does not influence the shoot as is the case where tendrils are concerned (p. 318). The twining is further assisted by the shoots of the twining plant having to begin with elongated internodes while the leaves remain small. In this respect these shoots resemble those of etiolated plants; the delayed unfolding of the leaves allows of the regular circling of the tip which might otherwise be interfered with by the leaves encountering the support. The firm hold on the support is frequently increased by the roughness of the surface of the stem owing to hairs, prickles, ridges, etc. Torsions also, the canses of which cannot be entered into liere, have a similar effect.

A detailed analysis of the process of trining is unfortunately still wanting, and all investigators do not agree that twining is due only to rerolving movement and negative geotropism. Thus Sehwendener (1881) holds that in addition to these factors a "grasping movement" is necessary. The point of the twining shoot will from time to time come in contact with the support, and by the tensious which will thus result the curvatures become "permanent" coils.

Geotaxis.-In some lower organisms an influence of gravity on changes of position has been shown to exist. This fact ean only be mentioned here.

\section{(c) Chemical Stimuli}

In the same way as light and gravity, heat and electricity, when their action is one-sided, may bring about directive movements of the plant. Since, however, these movements play 110 great part in nature they need not be further considered. Those directive morements which are brought about by the nnequal distribution of dissolved or gaseous substances in the neighbourhood of the plant are of much greater importance; these movements are termed chemotactic and chemotropic.

Chemotrorisu $\left({ }^{102}\right)$. In the ease of Fungi and of pollen-tubes chemotropic movements have been demonstrated which bring the organism into a certain concentration of particular substances; this concentration is the optimal one. With the same organism and the same stimulating substance these morements are sometimes positive and sometimes negative; positive when they lead towards a higher concentration of the substance, and negative in the converse case. In the casc of pollen-tubes sugar is the chief substance that acts as a stimulus; in fungi, in addition to sugar, peptone, asparagin, compounds of ammonia and phosphates. There are also substances such as free acids which always have a rejellent influence even in extremely weak concentration. Chemotropic irritability has also been rlemonstrated 
in roots, though it cannot be said that it plays an important rôle in their life.

In the examples of chemotropism given above the stimulating substances were solid substances in solntion. When on the other hand the plant is induced to perform directive movements by the mequal distribution in a space of aqueous vapour or gases, a distinct name has been required, though no distinction of principle can be drawn. Irritable movements caused by differences in moisture are termed hydrotropic $\left({ }^{103}\right)$, while those brought about by gaseous differences are termed aerotropic ${ }^{(104)}$. Aerotropism has been proved for pollen tubes, roots, and shoots, and hydrotropism for roots and moulds. Thus loots are positively hydrotropic and seek out the damper spots in the soil by reason of this irritability. The sporangiophores of the Mucorineae are negatively hydrotropic and thus grow out from the substratum. These reactions may be so energetic as to overcome other (e.g. geotropic) stimuli.

Chemotaxis plays the same part in the case of freely motile organisms or organs as does chemotropism in those that are attached. Here also chemotaxis in the narrower sense may be distinguisher from hydrotaxis and aerotaxis. Aerotaxis determined by oxygen is found in the case of Bacteria; on this account these organisms have been used to demonstrate the assimilation of carbon dioxide (p. 214). A positive hydrotaxis is shown by the plasmodia of Myxomycetes, and this passes into negative hydrotaxis at the time of spore-formation. The chemotaxis of Bacteria and spermatozoids $\left({ }^{105}\right)$ is especially wellknown owing to PFEFFER's fundamental investigations; this leads to the Bacteria seeking out favourable nutrient substances and to the spermatozoid seeking out the egg-cell.

The spermatozoids of the Ferns are attracted by malic acicl or matates to the neck of the archegonium; in the case of the spermatozoids of Lyenporium, ritrie acid, in Mosses, cane sugar solution, and in the Marchantieae proteid substances are the respective attractive substances. Often extremely minnte quantities of the substance will bring about active irritable movements; thns even a $0.001 \% \mathrm{soln}$ tion of malic acicl will attract the mumerous spermatozoids of a Feru swimming in pure water.

In part these tactic irritable morements are brought about by the organism, when it has reached the area of diffusion of the specific stimulating substance, at once turning so that its long axis is in the direction of diffnsion; it then, according to the special ciremustances, swims either to or from the centre of diffusion. Often, however, as oceurs, for instance, in the aceumulation of Bacteria at a partienlar spot, no such rotation and arrangement in the line of diffusion takes place. The organisms move about in the fluid without object, but hasten back when their movements have carried them beyond a certain concentration of the stimulating substance (phobic reaction, ef. p. 302).

We may perhaps comnect with ehemotaxis the movements which have been observerl in nnclei ant protoplasts after wounding (trammotaxis). 


\section{(d) Mechanical Stimuli}

Thigmotropism ( $\left.{ }^{106}\right)$. A curvature inwards on one-sided contact is found especially in climbing plants which seek by such grasping morements to encircle the touching body and utilise it as a support. The arrangement thus resembles what was seen in the case of twining plants, but the movements are not in any sense geotropic. In the case of tendril-climbers, the attachment to the support is effected, not by the main axis of the plant, but by lateral organs of various morphological character. These may either maintain, at the same time, their normal character and functions (as foliage leaves, shoots, or inflorescences), or, as is usually the case, become moctified and as typical tendrils serve solely as climbing organs. According to FitTung, contact with a solid body quickly induces an increase in the growth of the opposite side of the organ, and this, without any retardation of growth on the touched side, leads to a sharp curvature of the tendril which coils it about the support. The more slender the tendrils and the stronger their growth, the more easily and quickly this process occurs. Through the tendency of the curvature to press the tendrils more and more firmly against the support, deep impressions are often made by them upon yielding bodies, soft stems, etc.

According to PFfFFre's investigations, it is of great importance to the tendrils in the performance of their functions that they are not induced to coil by every touch, but only through CONTACT WITI THE UNEVEN SURFACE OF SOLID BODIES. Rain-drops consequently never act as a contact stimulus; and even the shock of a continued fall of mercury produces no stimulation, while a fibre of cotton-wool weighing $0.00025 \mathrm{mgr}$. is sufficient to stimulate the tendril. Probably the arrangements described on p. 74 (Figs. 74, 75) favour the reception of such weak stimuli.

In the more typically developed tendrils the curvature does not remain restricted to the portions directly subjected to the action of the contact stimulus. Apart from the fact that, in the act of coiling, new portions of the tendrils are being continually brought into contact with the suplort and so acted upon by the stinulus, the stimulation to curvature is also transferred to the portions of the tendril not in contact with the support. Through the action of the propagated stimulus, not only is the free apex of the tendril turned more quickly arond the sulport, but a tendency to curvature is imparted to the portion of the tendril between the support and the parent shoot. As this intervening part is extended between two fixed points, this tendeney canses it to coil spirally, like a corkscrew. With the spiral coiling, a torsion is produced, and since, on aceount of the fixed position of the two end points, it camnot be exerted in one direction only, the spiral, for furely mechanical reasons, coils partly to the left and partly to the right. PorNers of reverisal $(x)$ thus occur in the windings which, in equal numbers to the right and to the left, equalise the torsion (Fig. 235). By the spiral coiling of the tendrils the parent-stem is not only drawn closer to the 
support, but the tendrils themselves acquire greater elasticity and are enabled to withstand the injurious effects of a sudden shock.

Advantageous changes also take place in the anatomieal structure of the tendrils after they are fastened to the supports. The young tendrils, during their rapid elongation, which under favourable conditions may amount to 90 per cent of their length, exhibit active nutations, and thus the probability of their finding a support is enhanced. During this time they remain soft and flexible, while the turgor rigidity of their apices is maintained only by collenchyma. In this condition they are easily ruptured, and have but little sustaining eapacity. As soon, however, as a sulport is grasped, the coiled-up portion of the tendril thickens and hardens, while the other part lignifies and becomes so strengthened by sclerenchymatous formations that the tendril can

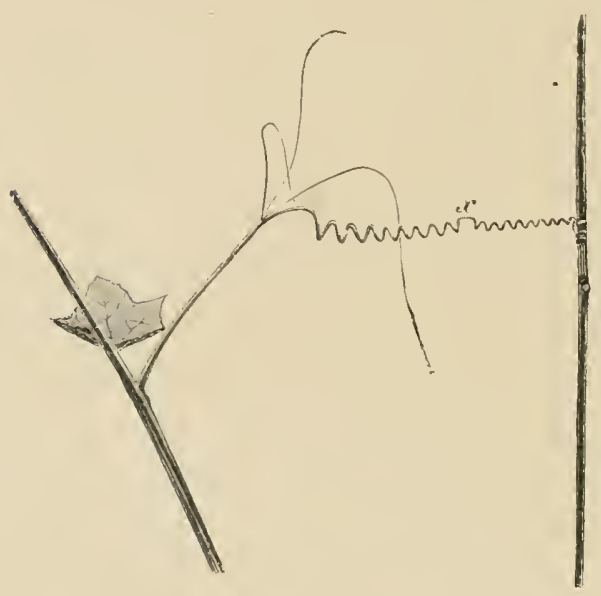

Fig. 235.-- Portion of a stem of Sicyosunulutus,with tendril; $x$, point of reversal in the coiling of the tendril. finally sustain a strain of many pounds. When the tendrils do not find a support they usually dry up and fall oft, but in some cases they first coil themselves into a spiral.

The tendrils of many plants (Cobaer, Eicremocaryus, Cissus) are irritable and eapable of curving on all sides; others (tendrils of Cucurbitaceae and others with hooked tips) are, aceording to Fitring, sensitive on all sides but only curve when the under side is tonched; if the upper surface is at the same time stimulated, curvature is arrested. In some cases the tendrilsquickly grasp) the support (Pussiftora, sicyos, Bryonic); while in other tendrils the supports are very slowly grasped (S'milax, litis).

'lendril-climbers are not, like twining plants, restrieted to nearly vertical supports, althongh, on account of the manner in which the tendrils coil, they can grasp only slender supports. A few tendril-chimbers are even able to attach themselves to smooth walls. Their tendrils are then negatively heliotropic, and provided at their apices with small cushion-like outgrowths, which may either develop indepentently on the young tendrils, or are first called forth by contact irritation. Through their sticky excretions these eushions become fastened to the wall and then grow into disc-like suckers, the cells of which come into such close contact with the supporting wall that it is easier to break the lignified tendrils than to seprarate the holdfasts from the wall. Fig. 236 represents the tendrils of Quincerin (Amprlopsis) Veitchii. The suckers ocenr on its young tendrils in the form of knobs. In Quineria quinquefolia and Qu. radicantissima the suckers are only produced as the result of contact, and the tendrils of these plants are able also to grasp thin supprorts.

Sometimes, as in the calse of Lophospermum seamens (Fig. 237), the leaf-stalks, although bearing normal leaf-blades, become irritable to contact stimuli and function as tendrils. Of leaf-stalks which thus act as tencirils, good examples are 
afforded by Tropacolum, Maurandia, Solanum jasminoides, Nepenthes, ete. The subsequent modifications oecurring in more perfectly developed tendrils are not noticeable in the ease of petiolar tendrils, although the coiling portion of the leafstalk of Solanum jasminoides does become strongly thickened and lignified; while the leaf-blades of clematis, by remaining small for a time, enhance the tendril-like character of their leaf-stalks, and by bending backwards also assist in maintaining the initial contaet with a support. At other times the midribs of the leaf-blades themselves become prolonged, and assume the funetion of tendrils (Gloriosa, Littonia, Flagellaria). In many species of Fumario and Corydalis, in

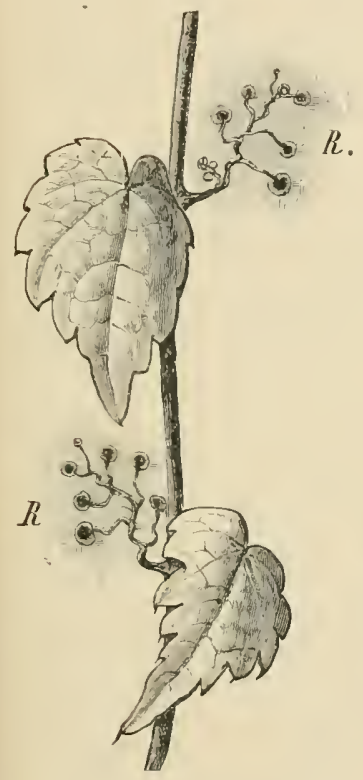

Fuc: 236.-Portion of a climbing shoot of Ampelopsis Veitchii. The tendrils $(R)$ have fastened themselves to a smooth wall by means of holdfasts. addition to the leaf-stalks, even the stalks of the leaflets twine around slender supports, while the parasitic shoots of Cuscute (Fig. 196) are adapted for both twining and climbing. In many tropieal plants axillary shoots are transformed into tendrillike climbing hooks. Climbing parts of the thallns oceur in some Thallophyta (Florideac) $\left({ }^{107}\right)$.

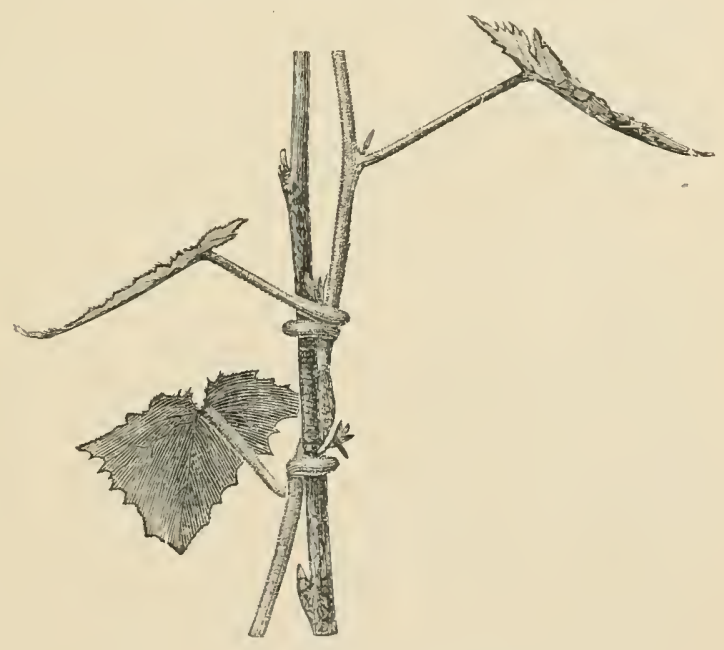

FIG. 237.-Luphospermum seandens climbing hy means of its tendril-like petioles.

Turgarutaxis has been observed in some lower organisms (Chlamylomonas Chromatiun $/$ eissii) and in some spermatozoids (Fucus). The phenomenon is so rare that its mere mention will be sufficient.

\section{Nastic Movements}

In the tropistic and tactic movements of irritability, the direction of the stimulus stands in direct relation to the direction of the movement; the nastic movements on the other hand are either brought about by diffuse stimuli with no definite direction or are not influenced by the direction of the stimulus. The direction of the movement 
always depends on the reacting organ and not on the environment, the movements are not movements of orientation sueh as those we have hitherto considered.

Typical nastic movenents of variation are show by stomata; the structural relations of these determines the opening or closing of the pore by changes in the curvature of the guard-cells bronght about by variations in their turgescence. It is frequently assmmed that the closing on loss of water, and the opening on illumination are purely mechanical results. Loss of water will have as its direct result a diminntion of the osmotic jressure, and illumination will increase the pressure by increasing the production of assimilates. It cannot, however, be doubted that in addition to purely physical inlluences true stimulus-movements also take place. Thus light and some other fuctor's also may act as stimuli directing the production of osmotic substances by the protoplasm in particular directions.

As in the ease of the stomata, so also in other nastic movements, light and heat (photonasty, thermonasty, nyetinasty), chemical substances (chemonasty), and sometimes also vibrations (seismonasty) may play the part of stimuli. Often the movement of a particular organ results from several of these stimuli in the sime or in different ways.

\section{(a) Nyetinastic Movements $\left({ }^{108}\right)$}

Many foliage leaves and floral leaves assume different positions by day and by night. According as the change from the one position to the other is brought about by variations in the intensity of light, in the temperature, or in both factors at onee, we distinguish between photonasty, thermonasty, and nyctinasty. The movements are earried out partly as growth-movements, partly as variation-movements.

Growth-movements due to rariations in temperature are found especially in flowers, e.g. Crocus, Tulip, Ornithogalum, Colchicum, and Adonis. These flowers on a rise of temperature exhibit a sudden and limited acceleration of the growth of the inner side of their periantlleaves or petals. The flowers consequently open. On the other hand they elose on a fall in the temperature.

The flowers of the Tulip and Crocns are esprecially sensitive to changes of temperature. Closed flowers bronght from the cold into a warm room open in a short time; with a difference of temperature of from $15^{\circ}-20^{\circ}$ they open in four to live minutes. Sensitive flowers of the Crocus react to a diflerence of $\frac{1}{2}^{\circ} \mathrm{C}$; ; those of the Tulip to $2^{\circ} \cdot 3^{\circ} \mathrm{C}$.

In a similar fashion other flowers (Nympluen, Cacti) and also the flower heads of Compositae (Fig. 238) open on illumination and close on darkening. The night-flowering plants snch as Silene noctiflorw and Cereus grundifturus behave in an opposite manner.

The significance of these movements must lie in only exposing the sexual organs when insect-visits may be ixpeterl; at other times they are protected against injury by rough weather, especially ly rain. 
Many foliage leaves also exhibit nyctinastic movements which are usually inftuenced more by light than by temperature. In some cases (e.y. in Chenopodiaceae, Caryophyllaceae, Balsamineae, and some Compositae) these movements are entirely growth-movements as in the floral leaves; in the Leguminosae, Oxalideae, and other plants provided with pulvini, variation movements are found. The former are naturally of short duration and cease when the leaves are full grown. The latter, however, continue for a long period. In the movements of variation an increase
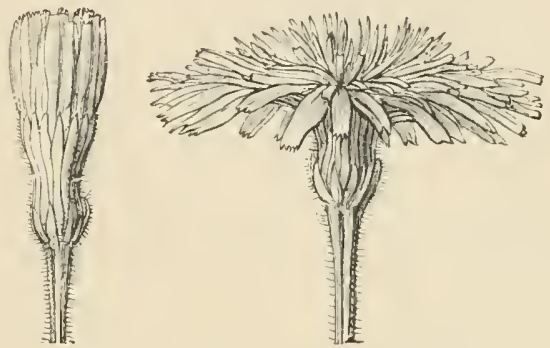

Fig. 235.-Flower-hearl of Leontudon hustilis, closed when kept in darkness, open when illuminated. (From Detwer's Physiol. Prat.) of turgor probably takes place in darkness in both halves of the pulvinus but more weakly or slowly on the concave side. The night- or sleep-position is always characterized by the vertical position of the laminae, the leaf-stalk or the pnlvinus curving either upwards or downwards; the laminae themselves have thus either their under or upper faces turned outwards. In the day-
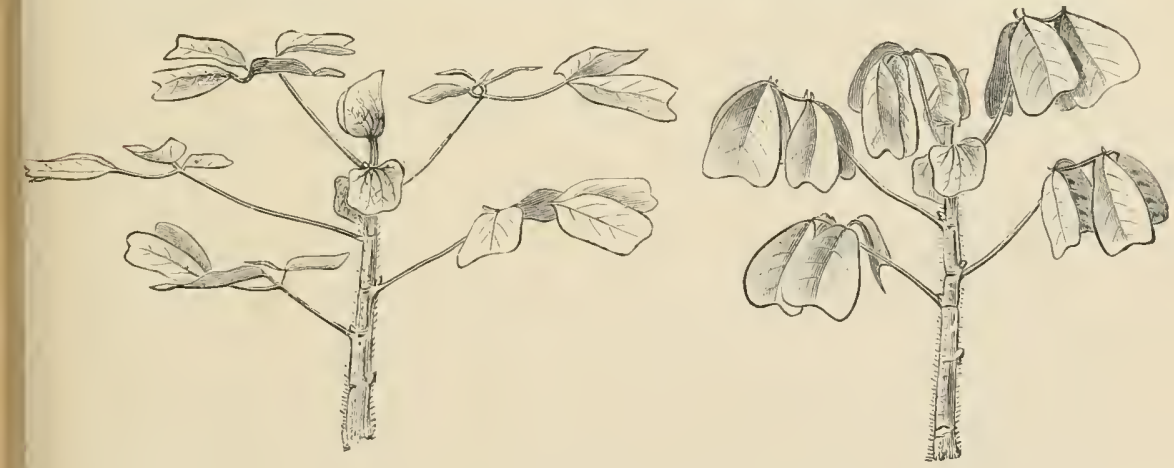

Fia. 239.-Amicic zygomeris, showing diurnal and nocturnal position of leaves.

position the surfaces stand horizontally or at right angles to the incident light (p. 306) (Fig. 239).

That these phenomena are not due to phototropism is shown by the day-position being assumed whether the under or the upper sile is more strongly lighted or when the illumination is equal. The same holds tor the effect of darkness.

The signiticance of the rertical position assumed by foliage leaves at night is regarded by STAHL as consisting in the diminution of the formation of dew and the consequent favouring of transpiratıon.

Excessively high temperature or illumination causes the leaves to depart from 
the ustal day-position and to assume a different one; this is either externally similar to the night-position or is diametrically opposite to this. Thus the leaflets of Robinio are bent downwards at night, in diffused daylight they are spread out flat, while in the hot mid-day sunlight they stand vertical. This so-called diurnalsleep is only found in leaves with pulvini and is brought about in a different way to the evening change of position ; there is no increase of turgescence but a condition of flaccidity.

When a plant has earried out regular nyetinastic movements for a long period under the influence of the alternation of day and night, the periodic movements continue for some days in constant light or constant darkness. In some plants it is possible to bring about experimentally a shorter or longer period of change than the usual one of twenty-four hours; this new periodicity also shows an after effect.

\section{(b) Chemonasty (109)}

Chemonasty bears the same relation to chemotropism as photonasty does to phototropism. From whatever side a chemical stimulus (such as the vapour of ether, chloroform, or ammonia) acts on a sensitive tendril the same side of the latter always becomes concave; this is the side which is especially sensitive to thigmotropic stimulation.

These chemonastic curvatures of tendrils are evidently of no use to the plants. Thus natural selection cannot have played a part in bringing about these properties of tendrils. The same is the case for the nastic movements of tendrils which take place on wounding and on rise of temperature (traumatonasty, thermonasty). On the other hand chemonastic movements play an important part in some insectivorous plants.

Very striking chemonastic movements are exhibited by the tentacles of Drosera (Fig. 19S). On chemical stimulation these curve so that their upper sides become concave and the glandular heads are thus brought towards the centre of the circular leaf. Such substances as albumen, phosphates, etc., which Drosera can use as food, serve as stimuli (p. 228); so also can indifferent and even poisonous substances. Often minimal traces of these substances (e.g. $0.0004 \mathrm{mgr}$. of ammonium phosphate) suffice to bring abont the irritable movement; when the stimulus is applied to the summit of the tentacle it leads to the curvature at the base of the latter. There is thus in this case as in certain phototropic curvatures, but even more clearly than in these, a separation between the organ of pereeption which receives the stimulus and the motile organ that effeets the movement. The stimulus received by the head of the tentacle must be conducted to the base of the latter.

The enrature resulting from growth may be carried out in the same way as in tendrils. Further the tentacles of hrosere in common with tencirils can exhibit thigmonastic and thermonastic leactions. Donbtless, however, their eliemonastic irritability is the main and most important one. Chemical stimuli are concened in the movements of other in sectivorons plants, e.g. Dionaca (p. 228) and Pinguicula. 


\section{(e) Seismonasty $\left({ }^{110}\right)$}

In Dionace the two halves of the leaf-blade (p. 228) close together not only as a result of ehemical stimuli but also owing to a mechanical stimulus. In eontrast to the thigmotropic movements of tendrils or of Drosera resulting from contact with solid bodies, in the case under consideration every disturbance resulting from a meehanieal shoek acts as a stimulus; the movement can thus be brought about by raindrops. These movements are termed seismonastic.

The most faniliar example of this irritability to mechanical stimuli is furnished by Mimose pudica, a tropical leguminous shrubby plant, which owes its name of
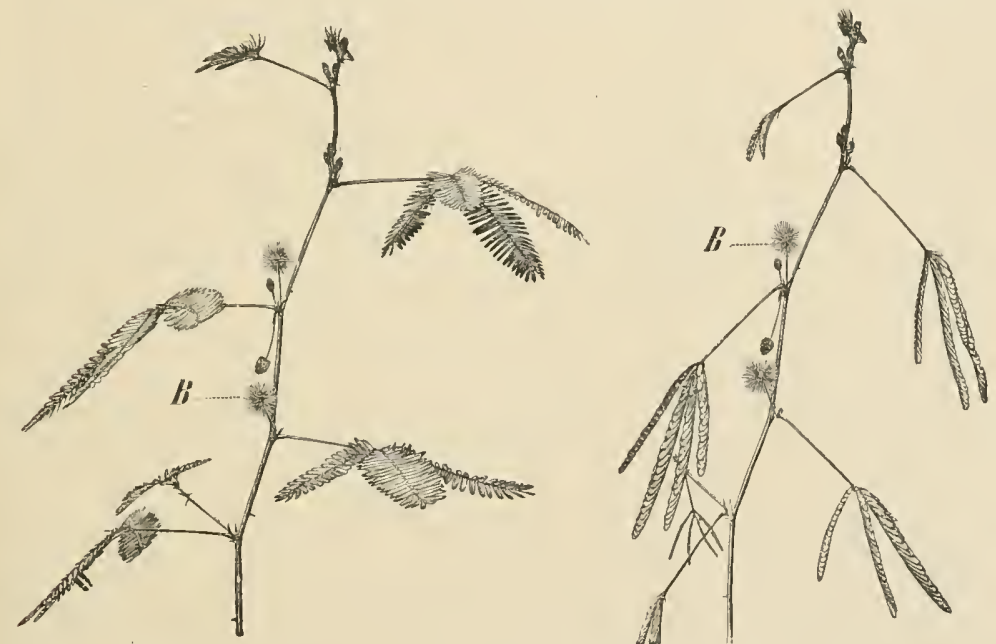

Fic. 240.-Mimose puitee, with leaves in normal, diurnal position; to the right, in the position assumed on stimulation ; $B$, inflorescences.

sensitive plant to its extreme sensitiveness to contact. The leaves of this plant are doubly compound (Fig. 240). The four secondary leaf-stalks, to which closely erowded leaflets are attached left and right, are articulated by well-developed pulvini with the primary leaf-stalks; while they, in turn, as well as the leaflets, are similarly provided with motile organs. Thus all these different parts are capable of independent novement, and the appearance of the entire leaf becomes, in consequence, greatly modified. In their unirritated, light position (Fig. 240, on the left) the leaf-stalk is directed obliquely upwards, while the seeondary petioles with their leaflets are extended almost in one plane. Upon any vibration of the leaf, in favourable conditions of temperature $\left(25^{\circ}-30^{\circ} \mathrm{C}\right.$.) and moisture, all its parts perform rapid movements. The leaflets fold together, and, at the same time, move forward, the secondary petioles lay themselves laterally together, while the primary leaf-stalk sinks downwards (Fig. 240, on the right). Leaves thus affected, if left undisturbed, soon resume their former position.

The behaviour of the leaves is still more remarkable when only a few of the 
leaflets are acted upon by the stimulus. This is easily demonstrated by holding a burning match near the leaflets of one of the pinnae. The leaflets directly affected by the flame fold quickly upwards, and this morement is performed suecessirely by each pair of leaflets of the pinua until the articulation with the primary leafstalk is reachel. The stimulation is then convered to the other pinnae, the leaflets of which go through the same movement in the reverse order; finally, the secondary petioles themselves draw together. Suddenly, when the whole process seems apparently finished, the main leaf-stalk in turn makes a domnward morement. From this leaf the stimulus is able to travel still farther through the stem, and it may thus induce morement in leares $50 \mathrm{~cm}$. distant.

In this case we are dealing with a wound-stimulus which has farreaching effects. On otherwise disturbing the plant we also find a conduction of the stimulus which, it is true, is not so extensive.

The processes in the conduction of the stimnlns are not fully known, but it is probable that they are effected differently in the case of wounding and of shock. After wounding the conduction may take flace with a rapidity of about $10 \mathrm{~cm}$. in a second $\left.{ }^{111}\right)$.

The position of a disturbed leaf is externally similar to its sleep- or nirgt-position, but the conditions of tension in the pulvinus which lead to the two positions differ. The seismonastic, like the sleep-position, is cansed by rariations in turgor, but depends on a diminution of the osmotic pressure and a flaccid condition of the half of the pulvinus that becomes concave. This condition can be most clearly recognised in the initable under sile of the main pulvinus of the leaf; it is connected with an escape of liquid from the cells into the adjoining intercellular spaces.

Many Leguminosae and Oxalideac are similar but less irritable. Thns Fobinia psirudacacia and Oxalis ucetosella exhibit slight morements on strong mechanical stimuli.

The state of rigor sometimes occurring in motilc organs may also be best observed in Minosu, for, although so sensitive to the action of external influences, it does not exhibit its irritable morements at all times. Whenerer the temperature of the surrounding air falls below a certain level $\left(15^{\circ}\right)$, no morements take place, and the whole plant passes into a condition known as COLD rigor, while, on the other hand, at a temperature of about 40, HE.LT RIGOI occurs. DROLGHT RIGOR is induced, just before withering, by an insufticient supply of water, and a DAR RIGor by a prolonged retention in darkness. In a racumm, or on exposure to hydrogen and other gases-chloroform vapour, coal gas, ete.-movement also ceases partly on account of insufficient oxygen, and partly from the actual poisonous action of the gases themselves. If the state of rigor is not continued too long, the original irritability will again return on the restoration of normal conditions (112).

The rariation morements exhibited by the staminal leaves of some Berberidaceae (Berberis, Hhoniu) and Compositae, especially beautifully by Cintaurea umerican, bear a certain relation to those of foliage leaves. The bow-shaped filaments of the stamens of the Conupsitae straighten upon meehanical irritation. As they frermently contract 10-20 por cent of their longth, the style becomes extended loyond the anther-tube (Fig. 241). The reduction in the length of the filaments is acempranied by a moderate increase in their thickness, lue to the elastic contraction of the cell-walls, and the consergnent expulsion of water into the intercellular spaces. The stanens of Berbris and Mahonie are only sensitive to contact on the inner side near the base, and as their contraction oceurs only on the inner side, the anthers are thus brought into contact with the stigma. Examples of rariation movements 
of earpellary leaves may be seen in the flowers of Wimulus, Strobilanthes (Foldfussiu), Inatynia, Turcnire, and other plants. The two lobes of the styles of these flowers fold together when irritated. The stigmas of Mimulus and Turcniu open again shortly unless aetive pollen has been denosited, when they remain in the elosed condition.

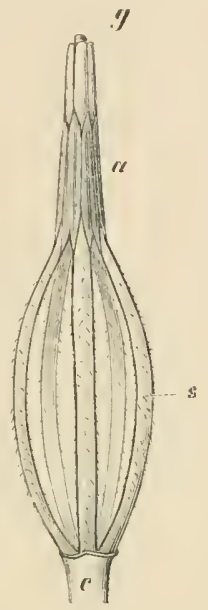

A

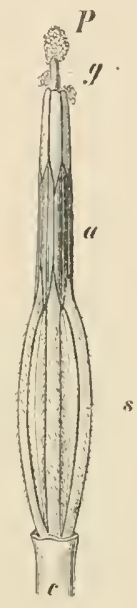

b

Fis. 241.-A single Hower of Centarere jaced with perianth removed. A, Stamens in normal position : $B$, stamens contracted; $c$, lower part of tubular jeriantls; $s$, stamens ; $a$, antlertube; g, style; I', pollen. (Aften PFEFfer, enlarged.)

It appears that irritability to shock is mainly seen in organs which are capable of movements of variation, while irritalility to contact is associaterl with growth movements. Dioncte perhaps forms an exception since its seismonastic movements are possibly brought about by growth. There are also plants the sensibility of which is intermediate between irritability to shock and irritalility to contact. 



\section{PAR'T' II \\ SPECIAT, BOTANY}

SECTION I

CRYPTOGAMS 



\section{SPECIAL BO'TANY}

Special Botany is eoncerned with the special morphology and physiology of plants. While it is the provinee of general botany to investigate the structure and vital processes of the whole vegetable kingdom, it is the task of special botany to interpret the structure and vital processes of its separate divisions. The aim of general morphology is to determine the phylogenetic derivation of the external and internal segmentation of plants, and to refer their numerous structural peculiarities to the primitive forms from which they have arisen. The purpose of special morphology, on the other hand, is to traee the development which has been reaehed in the different divisions of the plant kingdom, to understand the form of individual plants, and to trace the connection between one form and another. Thus the methods of special morphology are also phylogenetie, and furnish the hasis for a NATURAL SYSTEM of elassification of regetable organisms, based upon their actual relationships. Such a system must necessarily he very imperfect, as it is not possible to determine, directly, the phylogenetic connection of different plants, but only to infer their relationships indirectly from morphological comparisons.

Such a natural system, founded on the actual relationship existing between different plants, stands in direet opposition to the ARTIFICIAI SYSTEM, to which has never been attributed more than a practical value in grouping the plants in such a manner that they could easily be determined and elassified. Of all the earlier artificial systems, the sexual system proposed by LiNvaus in the year 1735 is the only one which need be considered.

LINxaUs, in establishing his classification, utilised cliaracteristies which referred exclusively to the sexual organs, and on this basis distinguished twenty-four classes of plants. In the last or twenty-fourth class he included all snch plants as were devoid of any visible sexnal organs, and termed them collectively CryptogaMs. Of the Cryptogams there were at that time but comparatively few forms known, and the complicated methods of reproduction of this now large class were absolutely unknown. In contrast to the Cryptogams, the other twenty-three classes were distinguished as Phaxeroguss or plants whose flowers with their sexual organs eould be easily seen. LINN.eus divided the Phanerogams, according to the distribution of the sexes in their flowers, into such as possessed hermaphrodite flowers (Classes 
I.-XX.), and those in which the flowers were unisexual (XXI.-XXIII.). Plants with hermaphrodite flowers he again divided into three gromps: those with free stamens (II.-IV.), which he further distinguished according to the number, mode of insertion, and relative length of the stamens; those with stamens nnited with each other (XVI.-XIX.); and those in which the stamens were mited with the pistil (XX.). Each of the twenty-four classes was similarly subdivided into orders. While some of the classes and orders thus constituted represent naturally related groups, although by the method of their arrangement in the artificial system they are isolated and widely removed from their proper position, they include, for the most part, plants which plyylogenetically are very far apart.

LINNAUS himself (1738) felt the necessity of establishing natural families in which the plants should be arranged according to their. "relationships." So long, however, as the belief in the immutalility of species prevailed, the adoption of a system of classification expressive of relationship and fanily could have no more than a hypothetical meaning, and merely indicated a supposed agreement between plants having similar exterual forms. A true basis for a natural system of elassification of organisms was first afforded by the theory of evolution.

The system adopted as the basis of the following deseription and systematic arrangement of plants is the natural system of ALEXANDER Braun, as modified and further perfeeted by Eichler, ENGLer, I'ETTSTEIN, and others.

According to this system, we have to distinguish between CryptoGAMS as the lower division, and PHANEROGAms as the higher division of the plant kingdom.

\section{SECTION I}

\section{CRYPTOGAMS}

The Cryptogams include an extraordinary variety of the most different plant forms, ranging from unicellular organisms to plants exhibiting segmentation into stem, leaf, and root. The Cryptogams, howerer, are collectively distinguished from Phanerogams by the mode of their dissemination by srores, in contrast to that of the Phanerogams, which is effeeted by SELDs; spores are formed also by Phanerogams, but they are not the immediate eause of the origin and development of new individuals. Seeds are multicellular bodies, within which is included the multicellular rudiment or Eumpyo of it plant; while spores, which, in the case of the Cryptogams, become separaterl from the mother plant, and give rise to a new and independent organism, are unieellular struetures. Cryptogams could 
therefore be termed SPORE PLANTS, and Phanerogams SEED PLANTS or Spermaphytes; although previous usage and custom would recommend adherence to the older ternis.

The Cryptogams are divided into the following main groups:-

I. The 'ThallopHyta, embracing a great variety of plants whose vegetative portion may consist of one or many cells in the form of a more or less branched thallus. Reproduction is both sexual and asexual, but there is usually no definite succession of the two morles of reproduction.

II. The Archegonfatas exhibit a regular alternation of two generations in their life-history. The asexual generation forms spores, and is called the SPorophyte. From the spore the sexual generation or GAnEтоннуте develops; this bears sexual organs of characteristic coustruction, the male organs being called antheridia, and the female organs archegonia. From the egg-cell contained in the latter, after fertilisation, the sporoplyte again arises. The Archegoniatae are divided into

1. The BRyophyta, which include forms with a leaf-like thallus, as well as colmophytic forms, with evident segmentation into stems and leaves. The Bryophytes possess no true roots, and their conducting bundles, when present, are of the simplest structure. The sporophyte is a stalked or unstalked eapsule, which lives semiparasitically on the sexual plant.

2. The Pteridophyta have small thalloid gametophytes; the sporophytes exhibit a segmentation into stems, leaves, and roots, and also possess true vascular bundles; they thus resemble the Phanerogams in structure.

The Thallophytes and Bryopliytes are also characterised as Cellular Plants, in contrast to the Pteridophytes or Vascular Cryptogams, which, together with the Phanerogams, are colleetively designated Vaseular Plants. Bryophyta and Pteridophyta must be regarded as having had a common origin from the higher Algae, the development of the two groups having been on different lines.

\section{THALLOPHYTA}

It was formerly customary to divide the Thallophyta into Algae, Fungi, and Lichens. The Algae are Thallophytes which possess chromatophores with pigments, particularly chlorophyll; they are, therefore, capable of assimilating and providing inclependently for their own nutrition. The Fungi, on the other hand, are colourless and have a saprophytic or parasitic mode of life. Such a methor of classification, however, although possessing a physiological valne, has no phylogenetic significance, as it does not express the natural relationships between the various groups. In the lichens (Lichenes), which were formerly regarded is simple organisms, the thallus affords an instance of a symbiosis of Algae 
and Fungi. From a strictly systematic standpoint, the Fungi and Algae composing the Lichens should be classified separately, each in their own class; but the Lichens, among themselves, exhibit such a similarity in structure and mode of life, that a better conception of their characteristic peenliarities is obtained by their treatment as a distinet class in comnection with the Fungi.

The phylogenetic connections of the fourteen classes into which the Thallophyta are divided are expressed, so far as is possible, in the following scheme:-

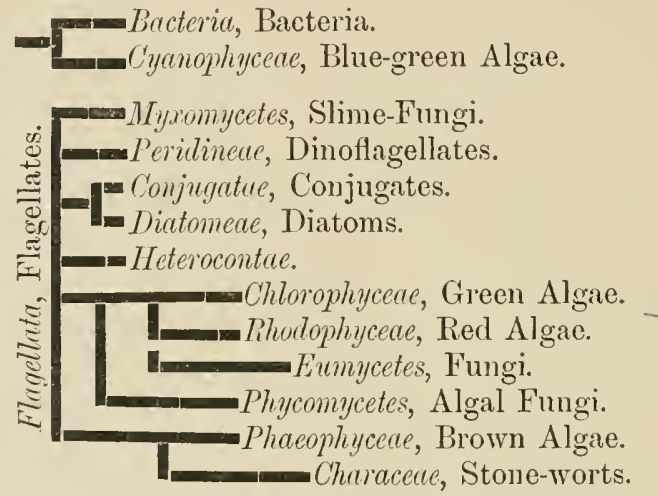

The Bacteria and Cyanophyceae are among the most simply organised Thallophyta; they are closely connected and are often grouped together as the Schizophyta. They oceupy an isolater position in contrast to the remaining simple Thallophytes, which with greater or less probability may be derived from the Flagellatae. The Flagellatae used to be (and frequently still are) plaeed with the lowest animals. As a matter of fact they combine plant and animal eharacteristies, and may also be regarded as the starting-point of the lower animals. The Myxomycetes may also have sprung from them as a group of colourless saprophytes. The Peridineae are a further-developed branch of the Flagellatae. The simplest forms among the Hetcrocontae, the Green Algae, and the Phaeophyceae connect directly with the Flagellata; on the other hand a direct connection of the latter with the Conjugatae and Diatomeae (which together form the Zygophyeeae), while probable, is not shown in existing forms.

The Pliycomycetes have branched off from the main series of the Chlorophyceae. The origin of the Red Algae and the Eumycetes, which appear to have sprung from a common stock, is still in doubt. The Characcae ocenpy a quite isolated and rery advanced position, and have been usually regarded as the most highly developed of the Green Algac; they rather appear to be comneeted in important characters with the Brown Algae.

The Thallophytes are commonly multiplied and distributed by asexually produced spores, the mode of development of which differs in the several groups. In many cases the spores arise by a process of cell division within certain cells, which are known as sporangia; 
in other cases they arise by modification and separation of cells of the thallus or by a process of cell-budding. When the spores possess cilia and are able to move actively in the water, they are known as swarm-spores (zoospores); when they do not bear cilia they are termed aplanospores. In the latter case the spores if distributed by water may be naked, or they nay be provided with a cell-wall and suited for distribution in the air.

Sexnal reprodnction is also of wide-spread occurrence. It consists, in the simplest cases, in the production of a single cell, the ZYGOSPORE or ZYGOTE, by the mion or conjugation of two similarly formed sexual cells or gametes (IsogAly). The organs in which the gametes are formed are termed gametangia; planogametes are provided with cilia while aplanogametes are non-ciliated. In many of the more highly developed forms, however, the gametes are differentiated as small, usually ciliated, male cells or sperMatozons, and as larger non-ciliated female cells, the egg-cells or oospHeres. The spermatozoids are formed in ANTHERIDIA, the oospheres in OOGONIA. As a result of the fusion of an egg-cell and a spermatozoid, an OOSPORE is produced (OOGAMY). It must be assumed that the sexual cells have been derived in the phylogeny of plants from asexual spores, and that asexnal multiplication has taken origin from simple cell division. The gametangia, oogonia, antheridia, and sporangia of the Thallophyta are homologons structures. The sexual reproduction has originated independently in several distinct groups.

While the reprorluction of some.Thallophyta is exclusively asexual, and of other's exclusively sexual, in many other's both forms of reproduction occur. In the latter ase this may occur on the one plant, or separate successive generations may be distinguishable. Generally speaking, there is, however, no regular sucession of asexual and sexual generations in Thallophytes, the mode of reproduction being to a great extent under the influence of external conditions $\left({ }^{1}\right)$. Only in some Brown Sea-weeds, in the Red Sea-rveeds, and some Fungi is there an alternation of a sexual generation (gametophyte) with an asexual (sporophyte), such as is foum? in all Bryophytes and Pteridophytes.

In the union of the two sexual cells the fusion nuclens obtains the donble number of chromosomes; it becomes DIPLord while the sexual celis always have IAPLOID melei. A reDuction Drvision of the diploid nucleus to the haploid must thus occm in the course of the ontogenetic development. In most cases this happens on the germination of the zygospore or oospore. In some Brown Algae with an alternation of generations and similarly in all archegoniate plants a diploid sporophyte is first developed from the remmating oospore and the rednction division takes place in the asexnal sporangia which the sporophyte bears. From the haploid spores of these sporangria, haploirl gametophytes in turn develop. 


\section{Cluass I}

\section{Bacteria $\left({ }^{2}\right)$}

Bacteria are unicellular or filamentous organisms of very simple construetion. Chlorophyll is wanting in them, and their mode of life is consequently a parasitic or saprophytic one. A large number of speeies exist distributed over the whole earth, in water, in the soil, in the atmosphere, or in the bodies of dead or living plants and animals. They are often termed Fission-Fungi, or Schizomyeetes, since the multiplication of the micellular forms takes place by a division into two and the separation of the segments. This mode of multiplication is also found in other unicellular plants.

The cells of the Bacteria are surrounded by a thin membrane, and contain a protoplasmic body, which is usually colourless, and can be made to contraet away from the membrane by plasmolysis. The protoplasm mily contain one or more racuoles. One or several gramular structures are also present in the protoplast; these so-called chromatin bodies may be deeply coloured by stains, and have been regarded as nuclei by various authors. Sinee, as yet, undoubted karyokinetic division has not been observed in these bodies, the presence of nuclei in the bacterial cell eannot he regarded as certainly established.

For the most part the Bacteria are extraordinarily minute organisms, and probably include the smallest known living beings. The spherical cells of the smallest forms are only $0.0008 \mathrm{~mm}$. in diameter; the rod-shaped cells of the tubercle bacillus are only $0.0015-0.004 \mathrm{~mm}$. long, while the transverse diameter of most species is about $0.001 \mathrm{~mm}$.

The simplest form of Fission-Fungi is represented by minute spherical cells, coccI. Forms consisting of rod-shaped cells are designated BACTERIUM or BACILLUs. Rod-shaped forms with a slight spiral curvature are ealled vibrio, and those more strongly curved SPIRILLuM. Straight filamentous forms are termed LEPTOTHRIX, spirally wound filaments, sPIROCHAETE. In the highest stage of their development the Fission-Fungi consist of cell filaments exhibiting false branching. The unicellular cocei, rod-shaped forms, and vibrios may also remain mited in chains after the cell-division. Frequently the cell-membranes undergo a mucilaginous swelling, the cells or cell-rows being embedded in the gelatinous mass. This stage of derelopment is termed zOOGLOEA.

Many Bacteria are motile. Their independent movements are due to the viluration and contraction of fine protoplasmie cilia. These flagella, according to $A$. Fischer, are either distrihuted over the whole surface of the cells (peritrichons) (e.g. Pucillus sultilis, Fig. 244, a, $l$; Bucillus typhi, Fig. 242, c; Bucillus tetuni, Fig. 247, e), or they spring 
from a single point either as a single flagellum (monotrichous) or as a group (lophotrichous). A single, polar flagellum occurs in Vibrio cholercte (Fig. 242, a); a polar terminal tuft of flagella in Spiritlum undulu (Fig. 242, b, d); a lateral tuft in the swarm-spores of Cladothrix (Fig. 243). The ciliary tufts may become so closely intertwined as to present the appearance of a single thick flagellum. The cilia are never drawn within the body of the cell, but undergo dissolution before the formation of spores takes place, or under unfavourable conclitions (Fig. 242,e).

Multiplication of the individual is accomplished regetatively by the active division or fission of the cells; the preservation and dis-

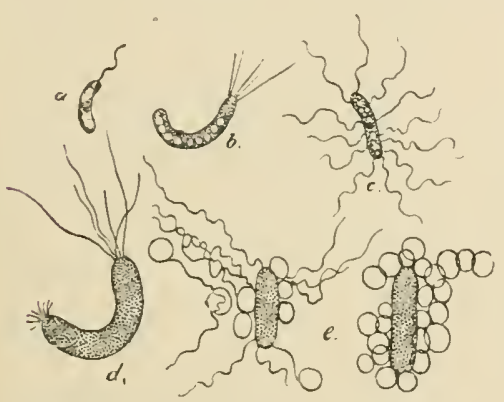

Fir: 242.-Tyjes of arrangement of flagella. $\imath_{\text {, }}$ Vibrio cholene; $b, d$, spirillum undula; $d$, develoment of a new bunch of eilia in division; c, Bacillus typhi; e, Becillus subtilis. (After A. Fischer, $\times 2250$.)

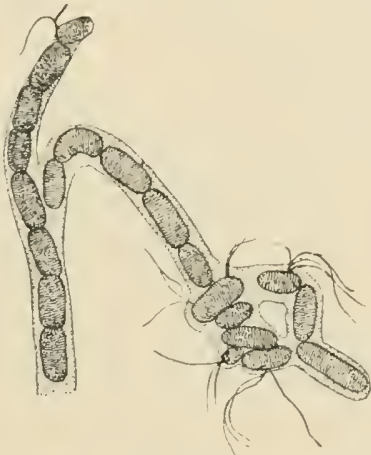

FIG. 243,-Clarlothrix elichotome Formation of swarm cells fron the cells of the tilament. (After A. Fischer, $\times$ 1000.)

tribution of the species by the asexual formation of resting spores. These arise as endospores (Figs. 244, c, 246,e,f) in the middle or at one end of a cell by the imner portion of the protoplasm separating itself from the peripheral, and surrounding itself with a thick membrane. The membrane of the mother cell becomes swollen and disintegrated when the spore is ripe. Spores are not found in all species.

Bacillus subtilis, the Hay bacillus (Fig. 214), which appears as a rule in the decoction obtained by boiling hay in water, will afford an example of the lifehistory of a Bacterium. The spores of this species, which withstand the effect of the boiling water, produce on germination rod-slaped swarming cells with cilia on all sides; these divide and may remain connected in short chains. At the surface of the fluid these swarming cells change into non-motile cells withont cilia, which livide up, giving rise to long intertwined chains of cells. These arc associated together in the pellicle covering the surface (zoogloea stage). Spore formation occurs when the nutritive substances in the fluid are exlatusted.

Although the cycle of forms passed through in the life-history of a Bacterimm is a very simple one, the individual species, which can often be barely distinguished by morphological characters, show great variety in their nretabolic processes and in their mode of life. The majority of Bacteria require oxygen for 
their respiration, and are therefore aerobic ; many can, however, develop without

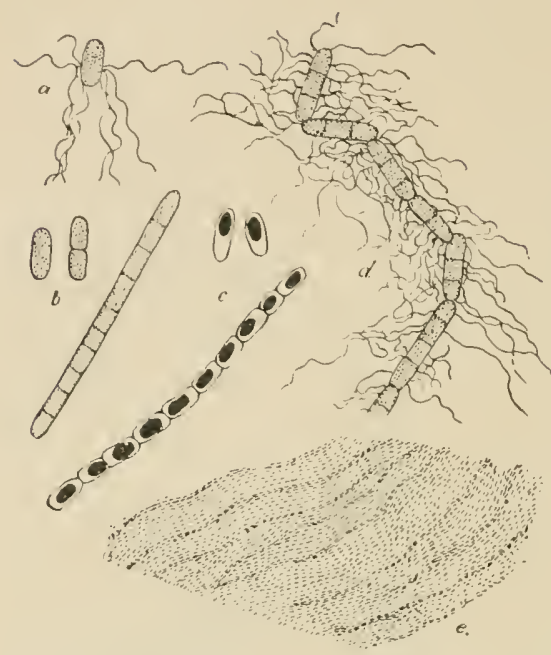

Fu: 244.-Decillus subtilis, $a, d$, Motile cells and chain of cells; $b$, non-motile cells and chains of cells; c, spores from the zoogloea, $c$. (From $\mathrm{A}$.

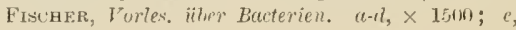
$\times 250$.

water, and consists of falsely branching delicate filaments attached to Algae, stones, and woodwork, and forning a slimy coating over them; the filanents are composed of rod-shaped cells. Rejuroduction is effected by ciliated swarn-cells, which originate by division from cells of the filament and are set free by the swelling of the sheath (Fig. 243). The swarm-cells come to rest after a time aud grow into new filaments.

Another very common form is Crenothrix Külnione, which consists of unbranched filaments attached to the substratum, but easily lroken. It often forms masses in the carities of water- fires, blocking them up and renlering the water undrinkable. The reproduction of crenothrix is effected hy small, rouml, nonmotile cells, which arise by subelivision of the cells of a filament enclosed by its sheath.

The numerous kincls of Sulphur Bacteria, of which Beysiatoc allur is the most widely distributed, are found in stilplunrons springs and at the bottom of pools where sulphuretted hydrogen is being formed by decomposition of organic this gas, while some sprecies, e.y. the butyric acid bacterium and the tetanus bacillus, are strictly anaerobic and only succeed in the absence of oxygen. Some bacteria siderable lieat; this is the explanation of the spontaneous heating of damphay, dung, tobacco, and cottouwool. In such substrata Bacillus calfuctor develops; it is adapted to live at ligh temperatures (above $40^{\circ}$ ) and is still motile at over $70^{\circ} \mathrm{C}$. (ef. 1. 248).

Saprophytic and parasitic species are distinguished, though a sharp' separation is often impossible. In cultures the parasitic forms can be made to lead a saprophytic life on suitable substrata.

To the saprophytic Bactcria belong in the first place the forms which inhabit water. The widely distributed Cladothrix dichotone is morphologically the highest among these. It is found in staguant

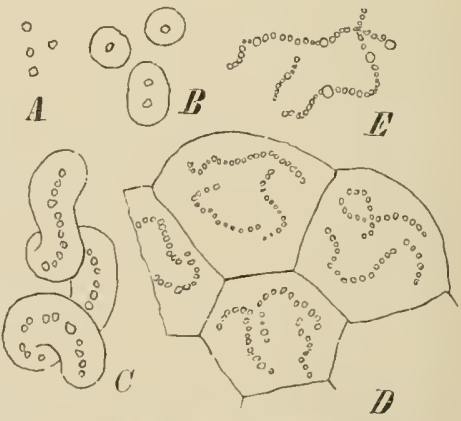

Fin. 245.,-streptorucens mesenterioides. A, Isolated cells without gelatinous sheath; $B, C$, formation of cliaiu of cells with selatinous shratlı; $D$, portion of mature zooglota ; $E$, formation of isolated cells in the lilaments of the zooglocit. (After VAN TIEOHEM, $\times 520$.) produce by their respiration con. 
material. These Bacteria oxidise sulphuretted hydrogen into sulphur, and store the latter substance in the form of rounded granules within their cells, ultimately oxidising it to sulphuric acid.

Leptothrix ochracea, the so-called Iron-Bacterimm, oxidises oxide of iron to the hydrated oxide of iron which it accumulates in the sheatls of its filaments. It occurs in ditches and swampy places in meadows.

The zymogenous or fermentation Bacteria and the saprogenons or decomposition Bacteria are other saprophytic forms. The former oxidise or ferment carbolyylrates. The latter decompose nitrogenons animal or vegetable substances (albumen, meat, etc.) with the liberation of ill-smelling gases.

Thus streptococus (Leuconostoc) mesenteriouldes (Fig. 245) canses fermentation of beet-sugar. It forms large mucilaginous masses like frog-s prawn, the bead-like lows of cells leing surrounded by a gelatinous investment. The acetic acid bacteria (Fig. $246 a, b, c)$ oxidise alcohol to acetic acid. The transformation of

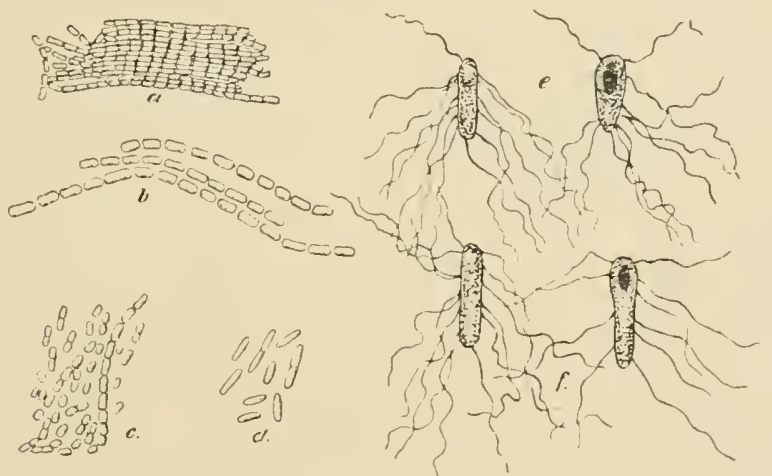

Fjg. 24b. - Bacteria of fermentation. (t-c, Vinegar bacteria ; a, Barillus aceti; $\circlearrowright$, Bac. Pustcurianus : e, Bai. Kutzingianus; 1 , Bar. acidi lactici, lactic acid bacillus; e, Clostritium butyricum, butyric acid bacillus; $f$, Plectridium paludosum, fermentation bacterium from marsh water. (From A. Fischer, Forles, iiher Bueterien, $\times 100$ f.)

sugar into lactic acid is brought about by the rod-like cells of Bacizlus aciali lactici (Fig. $246, d$ ). Clostridium butyricum (Fig. $246, e$ ) forms butyric aeid from various carbohydrates in the absence of oxygen, while certain marsh Bacteria (Fig. 246, $f$ ) in the absence of oxygen form marsh-gas and hydrogen from cellulose. Bacillus valguris is the most common cause of decomposition of meat, albumen, etc.

The Purple Bacteria, which develop in water with decomposing organic matter in the absence of oxygen and the presence of light, contain, accorting to IIoLiscH $\left(^{3}\right)$, a green and a red pigment (bacterio-chlorin and bacterio-purpurin). Other bacteria secrete pigments in their cells or around them. The latter is the case with Bacillus mocliyiosus, the ellipsoid peritrichons rod-shaped cells of which form fuchsin-red eolonies on milk or bread, and so have given rise to the miracle of the bleeding Host.

The photogenic bacteria produce within their cells a substance which becomes phosphorescent on oxidation. The most widely spread of these phosphorescent bacteria is Bacterium phosphoreum, which occurs on meat.

The parasitic baeteria inhabit woth animals and plants. The best known forms which cause diseases of plants (bacterioses) are Pseudomonas Hyacinthi, giving rise 
to a rot of Hyaciuths; Bacitlus phytophthorus, which attacks the potato ; and Bucillus Oleac, which gives rise to the Canker of the Olive Tree $\left({ }^{+}\right)$.

The numerous pathogenic Bacteria are the most important causes of infectious

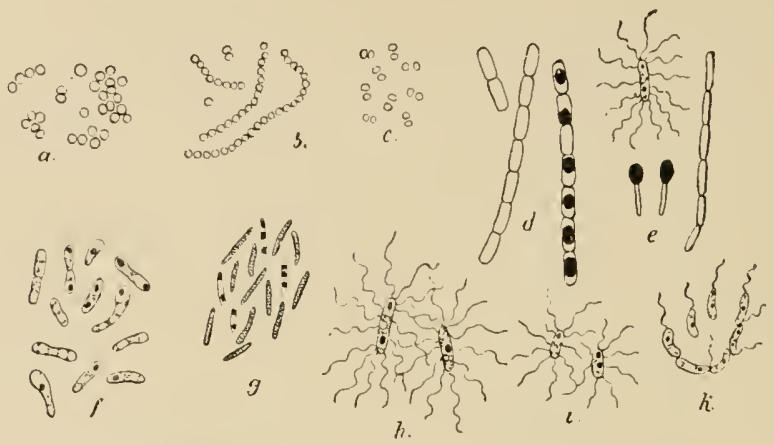

FIG. 247.--Pathogenic Bacteria. a, Pus cocci; $b$, erysijelas cocei ; $e$, gonorrhoea cocei ; $d$, splenic fever bacilli; $e$, tetams bacilli; $f$, diphtheria bacilli ; $g$, tubercle lacilli ; $h$, typhoid bacilli $i$, colon bacilli; $k$, cholera bacilli. (From A. Fischer, Vorles, über Bacterien, $x$ abont 1500.)

diseases. Their injurious influence on the tissues and blood of men and animals is brought about by the excretion of poisonous substances, to which the name toxins has been given. The following forms may be mentioned. Stapleylococcus
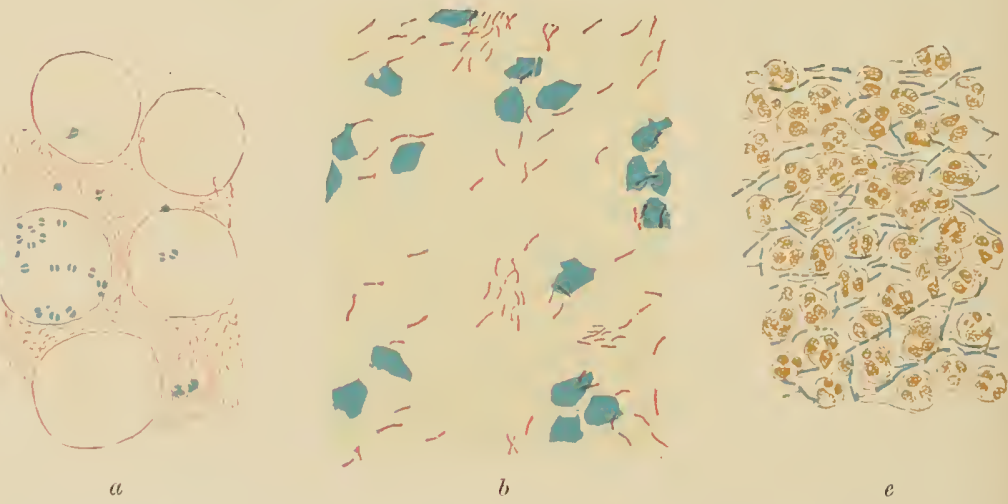

Fif, 248,-Staiced preparations from Ziegler's Text-hook of Putholon!. a, Gonocoeci in the gonorrhoeal discharge, mucus and prs corpuscles with cocci (methylene blue and easin), $\times 700$; $b$, tubercle bacilli in sputum of phthisis (fuchsin and methylene blue), $\times 400 ; c$, splenic fever bacilli in the pustule of the disuase (methylene blue and vesurin), $\times 3.50$. (From A. Fischrr, ITorles. ̈̈̈ber Dorterien.)

pyoycnes (Fig. 247, a), the cocei of which form irregular or racemose masses, is the most common cause of suppuration, while Streptococeus myogenes (Fig. 247, $)$, with cocci united in cliains, occurs in erysipelas and other suppurative lesions. Hicrococeus (Diplococcus) gonorrhoeae (Figs. 247, c, 248, a) lias somewhat flattened cocci arrangerl in pair's, and causes gonorrhoea. Bacillus anthravis (Figs. 247, d, $248, c)$ was found by $\mathrm{R}$. Kon in the blood and organs of animals suffering from 
splenie fever. The relatively large rou-shaped cells may be nnited in short chains; they form endospores in cultures in the same way as the Hay bacillus. Bacillus tetani (Fig. 217,e) oceurs in the soil, and is the canse of tetanus. Its straight rol-shaped cells are eiliated, and grow only in the wound itself; their spores are formed in the swollen end. Bacillus influenzae, short, slender rods; Bacillus pestis, small, stout, non-motile rods. LöFFLER's Bacillus diphtheriae (Fig. 217, $f$ ) consists of small rod-shaped cells sometimes thickened at one end. Ko'H's Baeillus tubereulosis (Figs. 247, $g, 248, b$ ), which is found in all tuberculous lesions and secretions, and in the sputum, is a slencler, slightly curved rod; branched forms also occur. It is non-motile and does not form spores. For these reasons it is grouped with some other species in a speeial family, the Mycobacteriaceae $\left(^{5}\right)$. Typhoid fever is cansed by the eiliated cells of Becillus typhi (Fig. 247, h) ; Beceillus eoli (Fig. 247, i), the colon bacillus, which is as a rule harmless and always oecurs in the hmman intestine, elosely resembles the typhoid bacillus. The comma bacillus of Asiatic cholera, Fibrio cholerce (Fig. 247, $h$ ), was discovered by R. Косн. It oceurs in the intestine as short curved rods with a single polar flagellmm, and sometimes in longer ehains of spirally wound cells. spirochaete obermeieri, which eonsists of long, thin, spirally wound filaments, without flagella, but capable of motion,
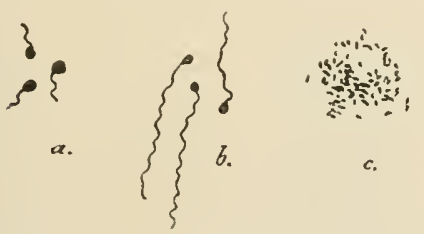

F1G. 249.-Nitrifying bacteria, afte1. Winogradsky. a, Nitrosomones europaea, from Zurieh; 1, Nitrosomonas juconensis, from Java; c, Nitrobuter, from Queto. (Fron Fischer, Iorles. viber Bacterion, $\times$ 1000.)

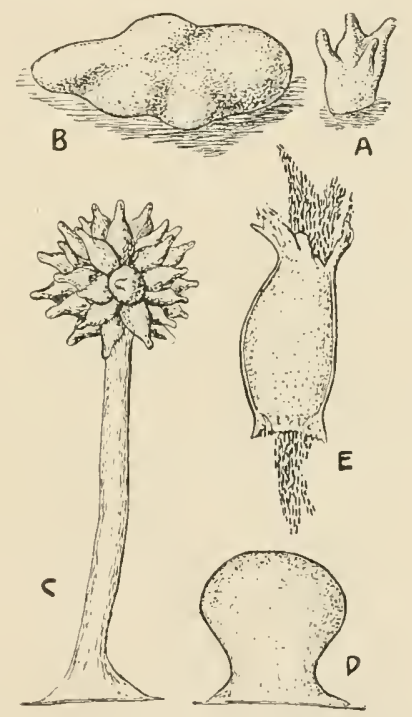

Fia. 250.-A, Myxococcus digitatus, bright red fructification oceuring on dung ( $\times 120)$. L, Polyangium primigenium, red fructification on dos's dung $(x+0)$. C; thondromyces apiculatus, orange fructification on antelope's ilung. $D$, Young fructification $(\times 45)$. $E$, Single eyst germinating $(\times 200)$. ( $A, B$, after QUEHL; ('-E, after ThaXTER.)

oceurs in the blood during the attacks of relapsing fever, of which it is the cause.

Besides the above injurious parasites there are others which are nore or less harmless occurring on the mucous membranes, in the mouth (Fig. 4), or the intestine. Sareince ventriculi, which occurs as packets of cocci in the stomach and intestine of man, will serve as an example of these.

The Bacteria ineluded under the names Bacillus (likisobium), raticicola and Brac. Beyerinekii necur in the root-tubereles of Legminosae, and, like certain other Baeteria found in the soil (Clostridium Pasteurianum, Azotobater chroococeum), ant in the sea, are capable of utilising free nitrogen in their metabolism. The denitrifying Bacteria which occur in the soil and in the sea decompose nitrates and nitrites, and liberate free nitrogen. 
In addition to saprophytic and parasitic Bacteria, there are some which, though possessing no chlorophyll, obtain their food from inorganic compounds only. These are the Nitrite Bacteria, (Nitrosomonas), and the Nitrate Baeteria (Nitrobacter), which live in the soil. The former oxidises ammonia to nitrous aeid, and the latter oxidises the nitrous to nitric aeid. They both obtain their earbon from earbonie aeid, and thus derive their food independently of any organic foodsupply (Fig. 2\$9, cf. p. 245).

The Myxobacteriaceae $\left({ }^{6}\right)$ are a rery peculiar family of Baeteria, our aceurate knowledge of which is in the first instance due to Thax'Er. They nearly all live saprophytieally on the dung of animals, and in habit resemble the Myxomyeetes (cf. p. 342). In the vegetative stage they appear as swarms of rol-shaped Bacteria eonneeted together by the gelatinous substance secreted by the eells, and exhibit slow ereeping movements. Ultimately they form fructifieations that are usually brightly coloured; these have the form either of definitely limited masses of spores or of eysts containing within a firm membrane the numerous bacterial spores. The eysts are unstalked, or are raised singly or in groups on a stalk, formed, like the wall of the eyst, of the lardened gelatinous material (Fig. 250).

\section{Class II}

\section{Cyanophyceae, Blue-green Algae (7)}

The Cyanophyceae are simply organised unicellular or filamentous Thallophytes of a bluish-green colour; the cells or filaments are frequently united into colonies by the gelatinous swelling of the cell walls. The numerous species, which are distributed over the earth,
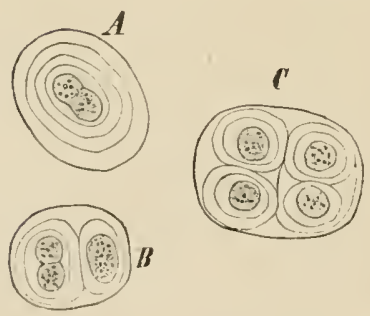

Fic. 251,-Glococipse polyilermuticu. $A, \ln$ process of division; $l$, to the left, shortly after dirision; C, a later stage. $(\times 540)$
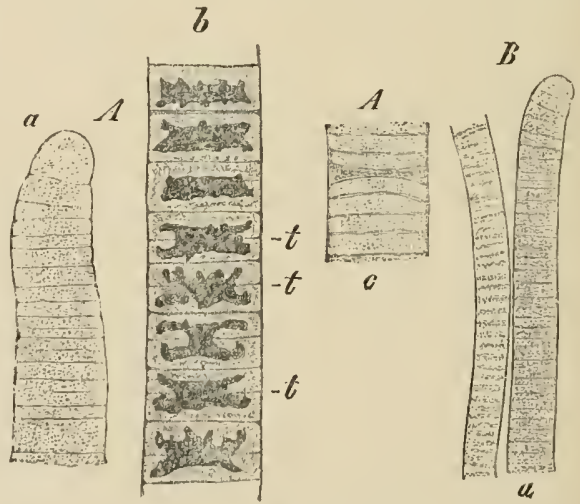

Frs. 252.-A, Oscilleriu princeps: $a$, terminal portion of a filament; $b$ and $c$, portions from the midlle of a tilament properly lixed and stained; $t$, cells in division ( $\times 10$ sil). B, Oseillaria Froltichii $(\times 540)$.

live in water, or form gelatinous or filamentous growths on damp soil, damp rocks, or the bark of trees.

The protoplast of eaeh eell possesses a peripheral chrumatophore of the form of a hollow eylinder or hollow sphere; in addition to ehlorophyll this eoutans a 
blue-green pigment (phycocyan) from which the name of the class is derived. The 1roduct of assimilation is glycogen. The centre of the cell is occupied by the colourless central body, which corresponds to a nueleus and contains chromosomelike structures. As definite inclusions of the cells may be mentioned the cyanophycin granules, which are of proteir nature and are situated within the chromatophore. Chitin has been shown to be present in the cell wall.

Reproduction is exclusively vegetative by cell division. In many forms resting spores are formed by the enlargement of single cells, the walls of which beeome greatly thickened (Fig. 253). Resting nuclei are present in these spores.

Just as the Bacteria are designated Fission-Fungi (Schizomycetes), the Bluegreen Algae may be termed Fission-Algae (Schizophyceze), since the reproduction of both depends on fission. The two groups would form the class of fission plants Schizophyta. The Bacteria and the Cyanophyceae have much in common, but the cilia and endospores of the former are unknown in the latter group. According to the observations of Pnilipps, which, however, require confirmation, some of the Cyanolhyceae which exhibit movements possess cilia.

The simplest Cyanopliyceae consist of spherical cells; this is the case with species of Chroococcus. In Glococapse (Fig. 251), found on damp rocks and walls, the cells remain connected together after division into a gelatinous mass, forming a multicellular colony.

The species of Oscillaria, which occur everywhere in water or on damp soil, are the simplest of the filamentous forms. The filament, which is usually provicled with a thick sheath, consists of similar flattened cells (Fig. 252). It can separate into pieces (hormogonia), which become free owing to the pressure of the sheath, and grow into new filaments. In other filamentous Cyanophyceae specially modified cells with their contents degenerated

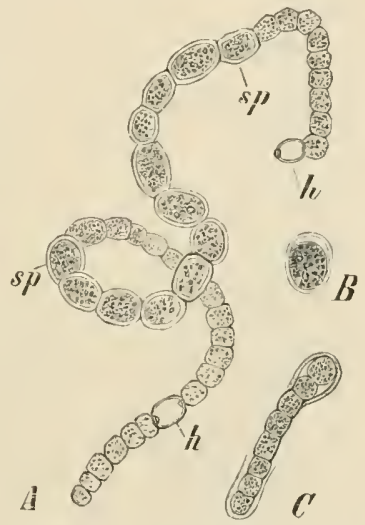

EIG. 253.-Nostoc Linckii. A species that floats freely in water. $A$, Filament with two lieterocysts $(h)$ and a large number of spores $(s p) ; B$, isolated spore beginning to germinate ; $C$, young filament developed from spore. (After BORNET, $\times$ 650.) occur in the filament. The significance of these HETERocrsts is not yet clear. The species of Nostoc (Fig. 253), whose bead-like filaments are united by the swelling of the cell walls into more or less spherical gelatinous colonies living on damp soil or in water, afford an example of this.

Some Cyanophyceae take part with the Fungi in the formation of Liehens. Some speeies also are endophytic and inhabit cavities in other ylants, e.y. Anabaenc in dzolla, Nostoc in some Liverworts, in Lemne, and in the roots of Cyeas and the stem of Gunnera.

\section{Class III}

\section{Flagellata (Flagellates) (", 9$)$}

The Flagellata are a group of anicellular, aquatic organisms exhibiting a wide range of form; they combine animal and vegetable chajacteristics, and may he 
regarded as the starting-point on the one side of unieellular Thallophytes, on the other of the Protozoa.

The protoplast exhibits contrictile or amoeboid movements, and is limited by a denser protoplasmic layer and not by a definite eell wall. One or more cilia (flagella) are present as motile organs. The protoplist contains a

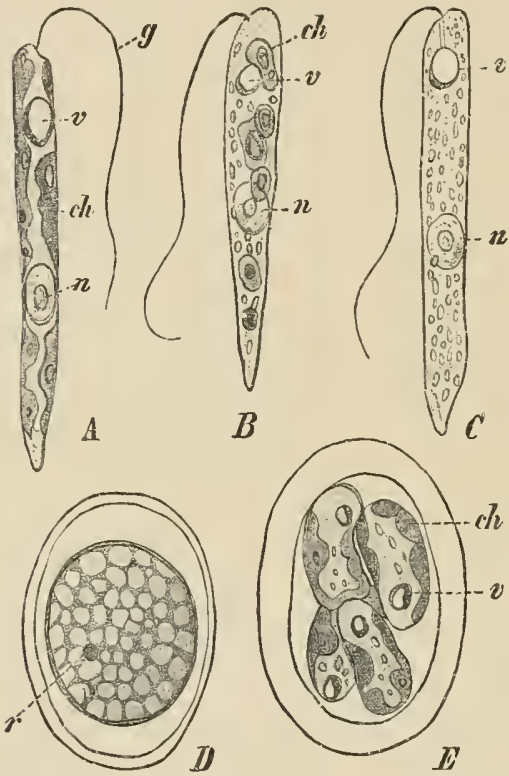

Fir. 254. - Fuglena gracilis. A, Form with green chromatophores $(c h) ; n$, nuclens ; $v$, vacuole and rel eye-spot; $g$, flagellum. $B$, Hemi-saprophytic lorm with small green chromatophores. C, Colourless saprophytic form occurring in nutrient solution in absence of light. $D$, Resting cyst ol the form $C$; $r$, red eye-spot. $E$, Germination of the resting cyst of the form $A$ by division into four daughter cells which later escape. (After Zumistein ; $A, C, \times 630 ; E, \times 650 ; D, F, \times 1$ C00.) nueleus, a pulsating vaeuole, and in many speeies well-formed green, yellow, or brownish-yellow ehromato. phores. A red eye-spot is frequently present. Other forms are colourless and live saprophytically; many are also able to take np solid particles as food.

Most representatives of the group live as naked, free cells; otliers form more or less complicated cell-colonies held together by mucilage, or they possess peculiar stalked or unstalked firm investments.

Sexual reproduction is wanting. Inltiplication takes plaee by longitudinal division, and in many speeies thick-walled resting spores or cysts are produced.

Englene (Fig. 254) may be taken as an example. The species live in water containing organic substanees and often appear in large numbers. By varying the uutritive conditions eolonrless forms with reduced chromatophores are obtained $\left({ }^{10}\right)$.

\section{Ciass IV}

\section{Myxomycetes (Slime-Fungi)}

The Myxomycetes form an independent group of lower Thallophytes; in certain respects they occupy an intermediate position between plants and animals, and have in consequence also been termed Myeetozoa or Fungus-animals. They are represented by numerous species, and are widlely distributed over the whole earth. In their vegetative condition the Slime-Fungi consist of naked masses of protoplasm, the PLASMODIA, containing numerous small nuelei but ntterly devoicl of chlorophyll. Glycogen occurs as a reserve substance, while starch is not fomd. The plasmodia (p. 54) are fomnd most frequently in woods, "tpon soil rich in humus, upon fallen leaves, and in deeaying wood. 'They creep about on the substrati, changing their form at the same time, and thrust out processes or psendopodia, whieh may in 
turn coalesce. At the period of spore-formation the plasmodimm creeps ont from the substratum towards the light and air, and, after coming to rest, is converted into a single or into numerous and closely contignons fructifications, according to the gems. On the periphery of each fructification an outer envelope or PERIDIUs is former; while internally the contents of the fructification separate into spores, each of which is provided with a nucleus, and enclosed by an onter wall. In many genera, part of the internal protoplasm within the SPORANGIUM or spore-receptacle is ntiliser in the formation of a CAPILlitiun (Fig. 255, $\mathrm{i}$ ), consisting of isolated or reticulately united threads or tubes. Upon the maturity of the spores, the peridium of the sporangium becomes ruptured, the eapillitium expands (Fig. $255, B)$, and the spores are dispersed by the wind, aicled by the hygroscopic movements of the capillitium. In the case
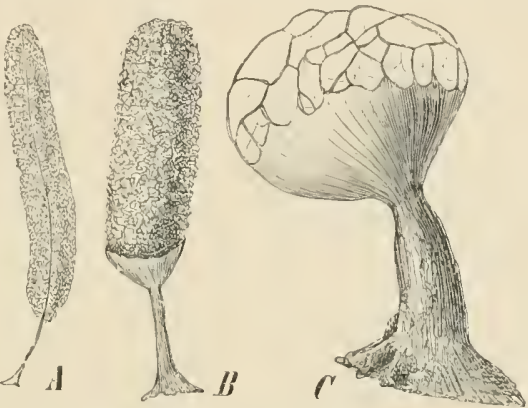

Frs. 255.- Ripe fruetifications, after rischarge of the spores. A, Stemonitis fuse $(\times 10) ; B$, drayria punicea ( $\times 12) ; C$, Cribraria rufat $(\times 32)$.

of the genus Ceratiomyra, the process is somewhat simplified, as the fructification is not enveloped by a peridium, and the spores are produced at the extremities of short stalks.

The germination of the spores (ef. Fig. 58, Choulrioderme) takes place in water or on a wet substratum. The spore-wall is ruptured and left empty by the eseaping protoplast. After dereloping a flagellum or crluus as an organ of motion, the protoplast swins about in the water, being converted into a swA RM-sPonis (Fig. 58, $e-y)$ which resembles a Flagellate, with a cell-nucleus in its anterior or ciliated end, and a contractile vacuole in the posterior end of its body. Even within the spore a division may take place, so that two swarm-spores are liberated. In some species the swarm-spores can increase in number by fission. Eventually the cilimm is drawn in, and the swarm-spore hecomes transformed into a MrxaMoEBA; these have the eapacity of multiplication by division. In conditions unfavourable for their development they suriound themselves with walls, and as microcysts pass into a state of rest, from which, under favomrable conditions, they again emerge as swarm-spores. Ultimately a number of the myxamuebae aproach close together (Fig. 58, l) and coalesce, forming small plasmodia (Fig. 58, m), which in turn fuse with others into larger plasmodia, but no fusion of nuclei is associated with this. The amoebae and plasmodia feed upon nutritive particles which they absorb, and exhibit active streaming movements of the protoplasm. After some days the plasnodium becomes converted into the fructification.

According to the investigations of JAIN and KrïzLIN ( $\left.{ }^{12}\right)$ a conjugation in pairs of the nuclei (kaygogamy) takes place in the young sporangia, ant the nnpaired nuclei clegenerate. This nuclear fusion ean be regarded as a sexual process. The diploid nuclei, shortly befon 3 the delimitation of the spores, undergo a leterotypic division in which the number of chromosomes is reduced to the half number. 
Each haploil nuclens thus formed becomes the nuclens of a spore. In Cerationyxu on the other haul a large proportion of the nuclei degenerate after the reduction division, and the spores may include a degenerating unelens as well as the normal one. From the latter by two successive divisions four nuclei are formed and are present in the ripe spore. Another division occurs on germination, so that ultimately eight swarm-spores are produced from each spore.

In the structure of their swarm-spores and myxamoebae the Myxomycetes slow their derivation from organisms of the nature of the Flagellata.

Very large plasmodia, often over a foot in breadth, of a bright yellow colour and creamy consistency, are formed by Fuligo rarians (Acthatium septicum), and as the "flowers of tan" are often found in summer on moist tan hark. If exposed
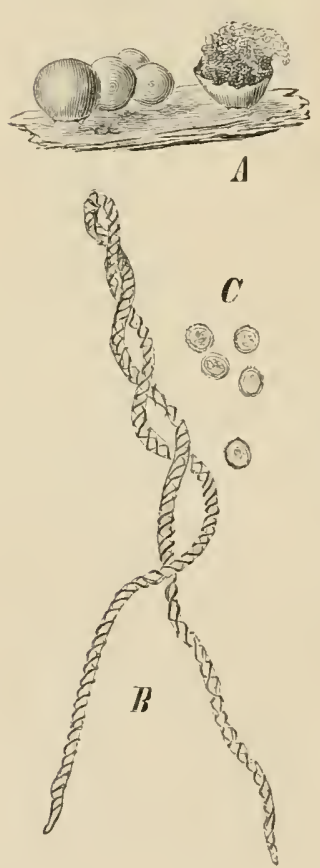
to desiccation, the plasmodia of this Myxomycete pass into a resting state, and become converted into spherical or strand-like scLEIoTiA, from whicls a plasmodium is again produced

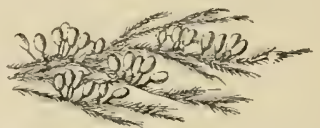

FIs. 257. - Leocarpus fregitis. Groups of sporangia upom a Moss. (Nat. size.) on a further supply of water. Finally, the whole plasmodium becomes transformed into a dry enshion or cake-shaped fructification of a white, yellowish, or brown colour. The fructification, in this instance, is enveloped by an outer calcareous crust or rind, and is subrivided by numerous internal septa. It encloses numerous dark violet-coloured spores, and is traversed by a filamentous capillitium, in which are dispersed irregularly-shaped vesicles containing granules of calcium carbonate. A fructification of this nature, or so-called aethalium, consists, therefore, of a number of sporangia combined together, while in most of the Myxomycetes the sporaugia are simple and formed singly.

The structure and nature of the sporangia afford the most convenient means of distinguisling the different genera. The usually brown or yellow sporangia are spherical, oval, or eylindrical, stalked (Figs. 255, 257) or not stalked (Fig. 256). They usually open by the rupture of the mper portion of the sporangium Fit. 25\%. - Trichie vario. A, walls, the lower portion persisting as a cup (Figs. 255, Closed and upen sporangia $B, 256, A$ ). In Cribruria (Fig. 255, C) the upper part $(\times b)$; $B$, a tibre of the ca- of the wall of the sporangimn, which contains no pillitiun $(\times 2411) ; C$, spores
$(\times 240)$.

In Slemonitis (Fig. 255, A) the whole peridiun falls to pieces, and the capillitimn is attached to a columella, which forms a continuation of the stalk.

Plasmodiophora Brossicac $\left({ }^{13}\right)$, one of the few parasitic Myxomycetes, causes tuberous swellings on the lateral roots of various species of Brossiec. Its unltinueleate myxamocbae oceur in numbers in the cells of the hypertrophied parenchyma of these swellings; after the contents of the lost-cell have heen exhansted they fuse into plasmorlia, and these, after repeater nuclear divisions, 
give rise to the numerons spores, which are set free by the disorganisation of the plant. According to Prowazek the plasmodium first divides into uninucleate cells which then conjugate in pairs to give rise to the spores; the muclei before the fusion have undergone a reduction division. The spores germinate like those of Chondrioderma, and the myxamoebae penetrate the roots of a young Cabbageplant. The formation of true sporangia, however, does not take place, and this Slime-Fungus represents a more simply organised or, in consequence of its parasitic mode of life, a degenerate Myxomycete.

According to the observations of Pinor various Myxomycetes, among them Plasmodiophora, only develop in the presence of definite Bacteria, which serve as food for the IIyxomycete $\left({ }^{14}\right)$.

\section{Clasis T}

\section{Peridineae $\left({ }^{8,15}\right)$}

The Peridineae or Dinoflagellata are connecter as an independert and furtlier developed group with certain Flagellata (Cryptomonarlinae). They oecur as unicelhular, free-swimming organisms in fresh water, but for the most part in the sea, where, together with the Diatomeac, they constitute an important coustituent of the phyto-plankton. Their cells are characterised by the possession of two long cilia or flagella which spring from the middle of the ventral surface in a longitudinal furrow: one of the cilia is directed backwards, the other is thrown into curves and lies in a transverse furrow (Fig. 258, $A, g f$ ). The protoplast contains a nucleus, vacuoles of different sorts, and numerous brownishyellow chromatophores; the latter contain a mixture of several special pigments (red. dish-brown pliycopyrrin, red peridinin, and yellowish-green chlorophyllin). Oil is usually
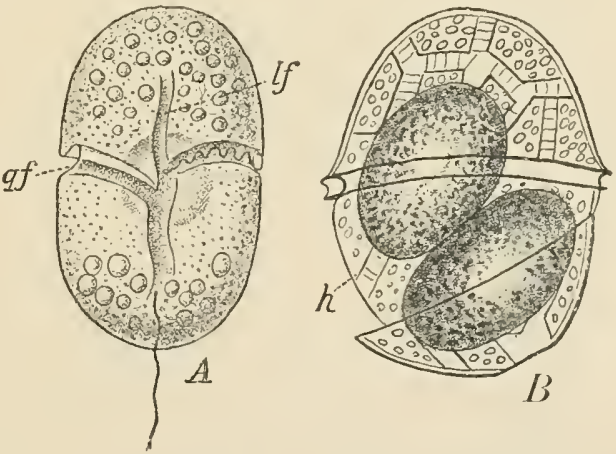

FIs. 258.-A, Gymnorlinium rhumboides : lf, longitudinal groove; gf, transverse groove. D, Peritinium tululatum: $h$, wall. ( $A$, After Schütт ; $l$, after KLebs ; from OLtManNs' Algue.) formed as the product of as-

similation. While the Gymnodineae (Fig. 258, A) lave either naked cells or cells limited by a uniformly thickened cellulose wall, the typical Perirlineae have a wall composed of cellulose formed of polygonal plates; these are usually delicately sculptured and perforated with pores. The transverse furrow is formed by one girdle-shaped plate.

In many Peridineae of the plankton the plates bear special wing-like explansions (Fig. 259) or the cells have long horn-like processes. These adilitations enable the organisms to remain floating in the water $\left.{ }^{16}\right)$.

In some Peridineae the chromatophores are only represented by colourless lencoplasts. Such species liv: either as saprophytes or in the same way as animals. Crymnodinium hyalinum is a colourless, naked, fresh-water form, the 
protoplast of which for the purpose of absorbing nourishment loses its cilia and assumes the form of an amoeba; in this condition it encloses and rigests small Algae $\left({ }^{1} \bar{i}\right)$.

Some marine Peridineae (e.g. Ceratium tripos, Peridinium dixergens) are phosphorescent, and play a considerable part in the phosphorescence of the sea $\left({ }^{91}\right)$.
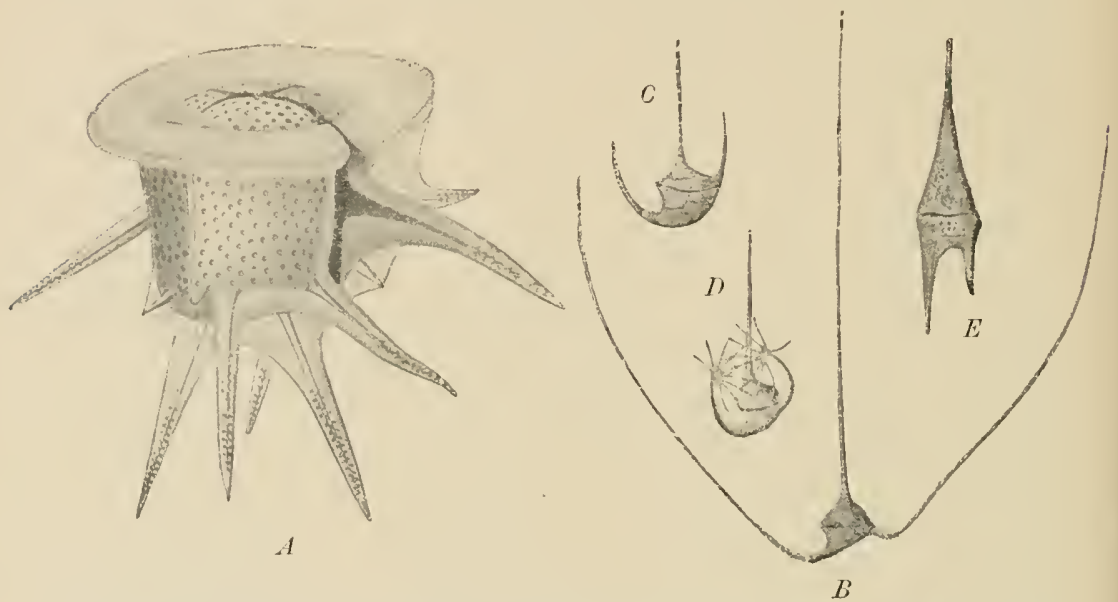

Fir. 250.-Peridineae of the plankton. A, Ceratocorys horrida rar. rfricand, Indian Ocean $(\times 250)$; $B$, Ceratium tripos intermelium var, aequatorialis, Indian Ocean $(\times 62) ; C$, Ceratium tripos gihberum, and $I$, Ceratium palmatum, Atlantic Ocean ( $\times 62) ; E$, reratium furra, Atlantic Ocean $(\times 125)$. (After' G. KARsten.)

Reproduction is by cell-division and also by means of swarm-spores. In the latter case the protoplast escapes from the membrane and either shortly forms a new wall or divides into several swarm-cells (Fig. 258, B). Thick-walled resting cells (cysts) also occur. ZEDE1:BAUER has recently observed a process of sexual

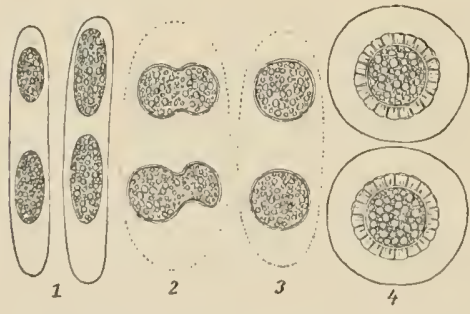

Frc. 260).-. Spirotacnia condensate. 1, (i) nju. gating colls rach divided into two daughter rells ; 2,3 , stages of conjugation : 4 , mature zygotes. (After Aroner; from OltuanN' Algoc.) Diatomeae, with whieh they might be united in the group of the Zygophyceae, since the two classes show essential agreement in their mode of sexual reproduction. This eonsists in the conjugation of plasts escaping from two similar cells to form a zygote) in Ceratium $\left({ }^{18}\right)$.

\section{Class Ti}

\section{Conjugatae $\left({ }^{8,} 19\right)$}

This class of green freshwater Algae includes mnicellular and simply filamentous forms, and is clearly listinct from that of the Chlorophyceae. The Conjugatae are most nearly related to the

reproduction (the conjugation of proto- 
two equivalent gametes to form a zygote or zygospore. Asexiral reproduction by means of swarm-spores is wanting in both classes, and since the gametes also are umprovided with cilia these forms are also classed as Acontae. The cells of the Conjugatae, which increase in number by cell-division, are uninuclear, and differ from those of the Diatoms in having a cell wall which is not silicified and in the presence of large green chloroplasts of complicated structure.

1. The Mesotaeniaceae, the simplest of the unicellular Conjugatae, inclnde only a few genera. They are distinguished from the following order by the cell wall of the shortly cylindrical cells not being formed of two halves. The mode of conjugation pre. sents some differences. In Spirotuenia (Fig. 260) the protoplasts of the conjugating cells first divide and the daughter cells unite in prairs to form the zygotes; in Mcsotucnium and Cylindrocystis the protoplasts conjugate without a preliminary cell-division. Similar differences are shown by the Diatomeae. The zygote on germination divides into four new individuals.

2. The Desmidiaceae are unicellular or their cells are united in rows; they are of great beauty and, like the Diatoms, exhibit a great variety of form. Their cells
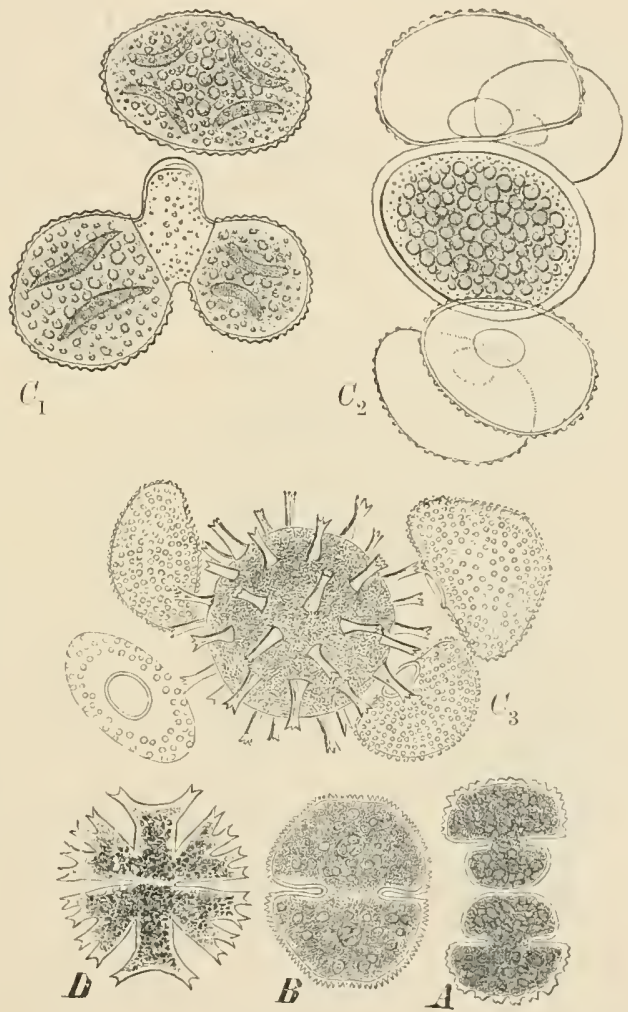

Flt: 2til.-A, c'usmutium coelatum, diviling. B, C, Cosmarium botrytis. $C_{1}$, two cells at right angles preparing for conjuration--the lower cell shows the conjugation canal ; $C_{2}^{2}$, gametes fused into the young zygote: $C_{3}$, mature zygote; D, Micresterias crux melitensis. (After RaLrs; $C_{1}, I_{2}$, alter DE BARY.) are comprosed of two symmetri-

cal halves, separated, as a rule, from each other by a constriction. Each half contains a large, radiate chromatophore or a chromatophore composed of a number of plates. Within the ebromatophores are disposed several pyrenoids, while the unclens lies in the centre of the cell in the constriction. The cells themselves display a great diversity of form and external configuration, being sonetimes rounded (e.y. Cosnarium, Fig. 261, A, B), sometimes stellate (Micrusterias, Fig. 261, $D)$. The cell walls, which, as in the Diatoms, consist of separate halves, are frequently beset with wart. or horn-like protuberances and often prorided with 
pores. In some genera there is no eonstriction between the two halves of the cell. This is the case, for instanee, in the crescent-shaped Closterium moniliferum (Fig. $262, F^{7}$ ), whose two chromatophores consist of six elongated plates, united in the long axis of the plant, while in each end of the eell there is a small vacuole containing minute erystals of gypsum in constant motion. Mlany Desmids are
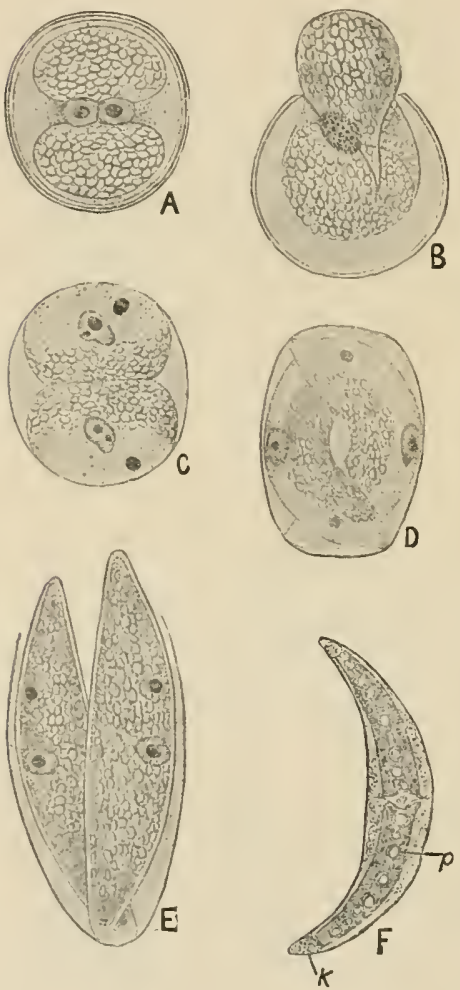

F13. 262.-Closterium, A, Zygote before ger mination showing the two nuclei not yet united; $B$, germinating zygote with the nuclei united; $C$, division into two cells aach containing one larger and one smaller uuclens; $M$, further state of germination E; young flants escilying from the cell. nembrane; $F$, Closterium monitifermm, mature plant. (A-E after KLEBAHN.)

eharacterised by heliotactic movements; they protrude fine mueilaginous threads through the cell walls at their ends; by means of these they ean push themselves along, and take up a position in a line with the direction of the incident rays of light.

Iultiplication is effected by ceil division. This is accomplished by the formation of a partition wall across the middle of the cell after the nuclear division is completed. Each daughter cell eventu. ally attains the size and form of the mother cell, by the outgrowth of a new half on the side towards the new division wall (Fig. 261, A).

In conjugation two cells approacli each other, and surronud themselves with a mucilaginous envelope. Their eell walls rupture at the constriction, and parting iu half allow the protoplasts to eseape; these then unite to form a zygospore. The zygospores frequently present a very characteristic appearanee, as their walls are often beset with spines (Fig. 261, C). The four empty eell halves may be seen elose to the spore. In some Desmidiaceae the conjngating cells nndergo a preliminary division, the daughter cells uniting in pairs.

The two sexual nuclei in the zygote do not fuse until germination of the latter is about to commence. The resulting nucleus then undergoes division into four nuelei, two large and two small. Only two cells are formed from the zygote, each of which has thus two nuclei of different sizes; the smaller nuclei disappear. The production of two cells on germination thus appears to be derived from the division into four cells seen in Mesotaenium,

and to stand to the latter as a rerluced form.

3. Zygnemaceae.-In this family, all of which are filamentous in character, the genus sproyyra, with its numerous speeies, is the best known. It is commonly found in standing water, forming unattached masses of tangled green filaments. The filaments exhibit no distinction of base and apex, and are composer of simple rows of cells, whieh rary in length in different species. 
Growth results from the division and elongation of the cells in one direction only. Each cell las a large nuclens and one or several spiral green band-like chromatophores (Fig. 263, C). The cells of Zyymema contain two star-shaperl ehromatophores.

Cosudgatios, in the case of spiroygre, is precederl by the development of converging lateral processes from the cells of adjacent filaments. When two processes from opposite cells meet (Fig. 263, 1 ), their walls become absorbed at the point of contact, and the whole protoplasmic contents of one cell, after contracting from the eell wall, passes through the eanal which is thus formed into the opposite cell. The protoplasm and nuclei of the conjugating protoplasts then fuse together while the chloroplasts do not unite, but those of the entering protoplast disorganise. The resulting cell forms the zygospore invested with a
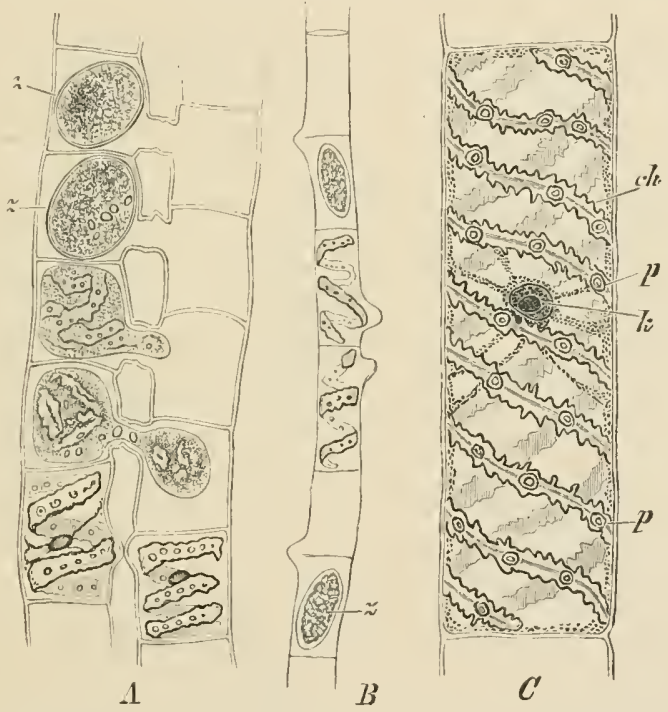

Fin. 263.-A, Conjugation of Spirogyra quinina $(\times 240)$. B, Spirogyra longate $(\times 150) ; z$, zygospore.

$C$, Cell of spirogyra jugalis ; $k$, nueleus ; ch, chromatophores ; $p$, pyrenoid. ( $\times 256$.

thick wall, and filled with fatty substances and reddish-brown mucilage-splieres, This form of conjugation, which is the one exhibited by most sprecies, is described as sealariform (Fig. 263, $A$ ), as distinct from the lateral conjugation of some species, in which two adjacent cells of the same filament conjugate by the development of coalescing processes, which are formed near their transverse wall (Fig. 26:3, D). In some genera the zygote is formed midway in the conjugation tube.

The conjugation nucleus of the young zygospore gives rise, according to ChMLelewsix, to four by two suecessive divisions. According to Kalistes this is to be regarded as a reduction division $\left({ }^{20}\right)$. On germination the zygote grows into a tubular cell, from which by cell division the filament is derived. 


\section{Class VII}

\section{Diatomeae (Diatoms) $(8,21)$}

The Diatomeae (Bacillariaceae) constitute a very large class of unicellular Algae. They occur, usually associated together in large numbers, in both fresh and salt water, and also on damp soil.

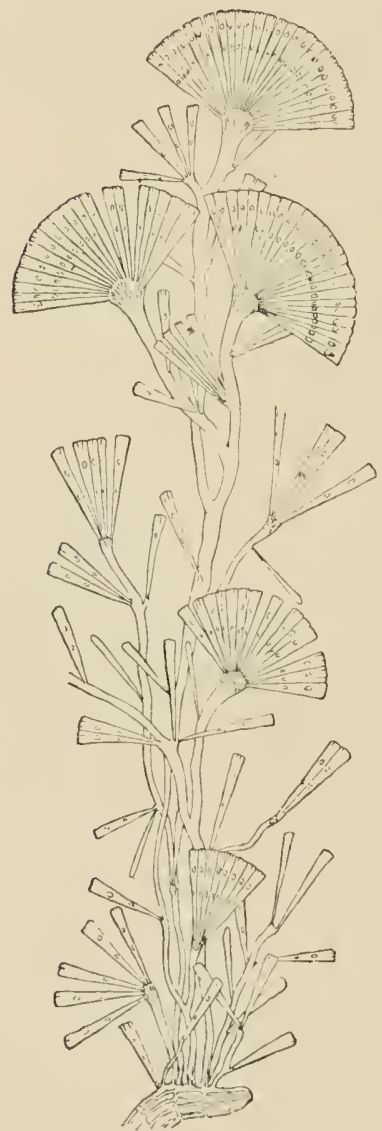

Fir: 2bt.-Licmophora flabellata. Colony of biatoms with brancled grelatinous stalks. (Alter SurTi, from, GoEBEL's Uryenoyraphie.)

The cells are either solitary or for'm colonies ; they are free-floating, or are attached by means of gelatiaous stalks, excreted by the cells themselves (Fig. 264). Sometimes the cells remain connected and form bands or zigzag chains, or, on the other hand, they are at-

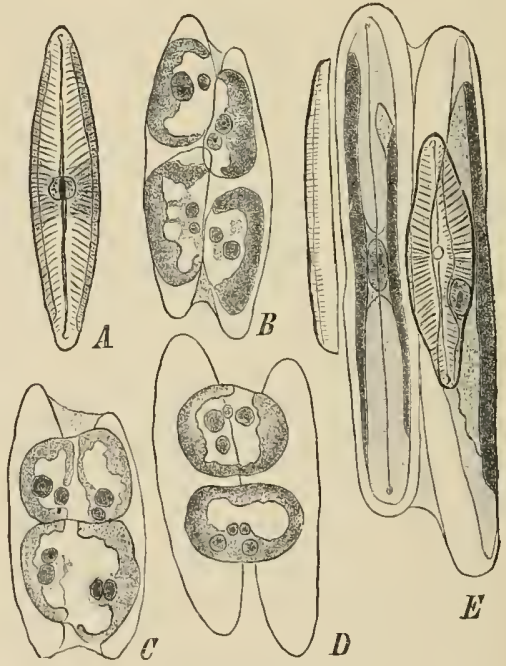

F14. 265.-Formation of auxospores in Navicula viridula. A, Cell seen from the valve side. 13 , Two cells lying alongside one another; their contents have divided into two daughter cells, each of which possesses two nuclei. C, 1), Conjugation in pairs of the daugliter cells to form the auxospores, which at filst contain four nuclei. H, The two full-grown anrospores; the two larger nuclei in each have fused into one, the two smaller one's have disintegrated. (After liarsten, $\times 50 \%$.)

tached and enclosed in grelatinous tnbes, while in the case of the marine genus Schizonemu they lie embedded in large numbers in a 
gelatinous branching thallus, often over 1 dcm. in size. The cells also display a great diversity of shape; while generally bilaterally symmetrical, they may be circulir or elliptical, rod- or wedge-shaped, curved or straight. The structure of their cell walls is especially characteristic; it is composed of two halves or VALVEs, one of which overlaps the other like the lid of a box (Fig. 3, B). The cells thus present two altogether different riews, according to the position in which they are observed, whether from the rirdene (Fig. 3, $B$ ) or VALVE SIDE (Fig. 3, A). The two valves are so strongly impregnated with silica, that, even when subjected to intense heat, they remain as a siliceous skeleton, retaining the original form and markings of the cell walls. The walls of the cells, particularly on the valve side, are often ornamented with numerous fine, transverse markings or ribs, and also with small protuberances and pits. They are often perforated by open pores which serve to give exit to the gelatinous secretion.

The cell has always a central nucleus and one (Fig. 3) or two to four (Fig. 265) large, or numerous smaller chromatophores (Fig. 267) embedded in its parietal protoplasm. These chromatophores are flat, frequently lobed, and of a brownish-yellow colour. Pyrenoids are often present. Globules of a fatty oil are also included in the cell contents, and take the place of starch as an assimilation product.

The Diatomeae multiply vegetatively by longitudinal division which always takes place in one direction. In this process the two valves are first pushed apart from one another by the increasing protoplasmic contents of the mother cell, which then divides longitudinally in such a direction that each of the two new cells retains one valve of the mother cell. After the division of the protoplasm of the mother cell is accomplished, each daughter cell forms, on its naked side, a new valve fitting into the old one. The two valves of a cell are therefore of clifferent ages. In consequence of this peculiar manner of division, as the walls of the cells are silicified and incapable of distension, the daughter cells become successively smaller and smaller, until finally, after becoming reduced to a definite minimum size, they undergo transformation into AUxospores. The auxospores are usually two or three times larger than the cells from which they arise, and by their further development they re-establish the original size of the cells.

According to the structure of the cell walls and the mode of reproduction the Diatomeae are subdivided into the two orders of the Penmatae and the Centricae.

Order 1. Diatomeae Pennatae. - In shape these are elongated, elliptical, or boat-shaped, but may be wedge-shaped anrl zygomorphic; the valves have their sculpturing pinnate (Figs. 264, 265). In many of the Penuatae (Fig. 3) a longitudinal line corresponding to an opening in the cell walls, and exhibiting swollen nodules at both extremiices and in the middle, is distinguishable in the surface of the valves. Forms provided with such a median suture or laAPHE are 
characterised by peculiar creeping movements, resulting from the streaning protoplasm in the longitudinal slit of the raphe.

The formation of the anxospores, which correspond to the zygospores of the Conjugatae, is accomplished in various ways. The process in Navicula (Fig. 265), Pleurosigmo, etc., may be compared with the zygospore formation of Spirotacnice; two cells lay themselves side by side, the protoplast of each undergoes division into two, and the resulting cells emerge from the valves of the cell wall and conjugate in pairs. By division of the nucleus each gamete was provided with a larger and a smaller nnclens; in the auxospores the two large nuclei fuse, while the two suall nuclei disintegrate.

In Surirclla and Cocconeis (Fig. 266) the conjugating cells do not undergo division, but unite directly with one another. The nuclei, however, divicle; in

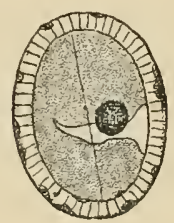

1
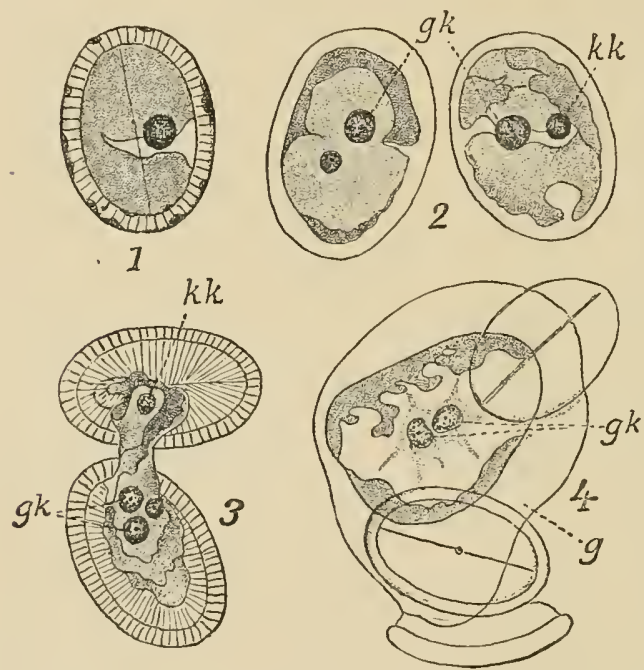

FIr. 2036-Cocconeïs placentula. 1, Vegetative cell; 2, pair of cells before conjugation; 3,4 , cells in process of eonjugation. $g k$, Large nucleus; $k k$, small nucleus; $g$, gelatinous substance. (After Kaksté, from OLTMANs' Algie.) a division, but the resulting muclei again fuse. In Rhabdonemu areutum the process is similar, but the second nuclear division does not oecur.

Ihabdonema adriatien goes a step further; the nucleus divides, but one of the daughter nuclei is extruded from the protoplast. The undivided mother cell develops into the auxospore.

Many Diatoms oceur in places where decomposing substances are present in abundance. Such species can assume a saprophytic mode of lile, their chromatophores beconing eolourless and reduced in size. It has been shown that some colomless sprecies of Nitzsehia which oceur in the sea are cxclusively dependent on organic substances for food, the reduction of their chromatophores and jigment being complete $\left({ }^{22}\right)$.

Naricule ostrcuria is a Diatom occurring in the oyster-beds of the French coast, which serves as food for the oysters; its protoplasm contains a sky-blue pigment 
ealled marennin. This pigment is the canse of a green coloration of the oysters in which the marennin nndergoes alteration and is accmmnlated (2i).

Order 2. Diatomeae Centricae.-In these the valves are symmetrical abont

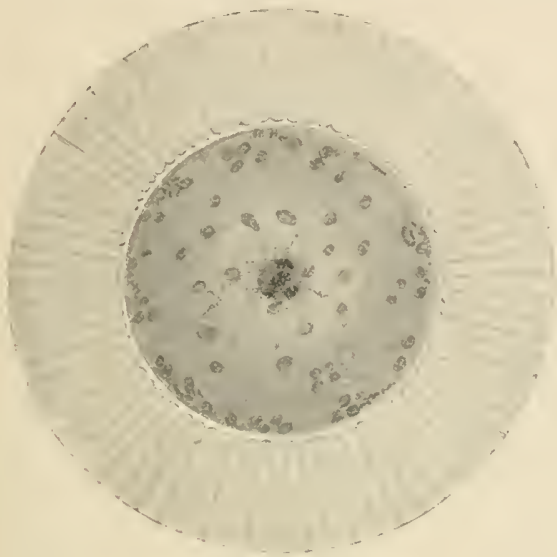

Fic. 267.-Plenktunielle sol. Atlantic Ocean. A discslaped plankton diatom with a hollow floating wing arising from the girlle sile. The protoplast contains a nucleus and numerous chromatophores. ( $\times$ 32. After G. Kanstex.)

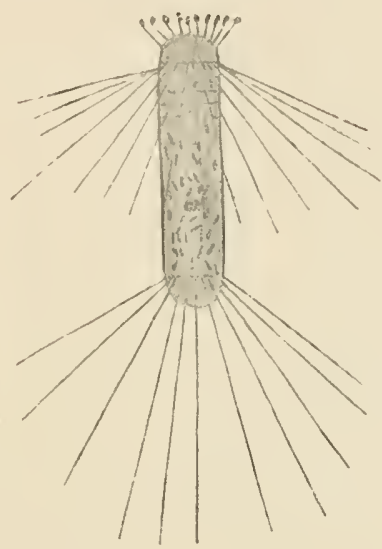

Fit. 26s. - Corethron whliviae. A plankton diatom of the Antarctic Ucean with bristle hairs and prehensile bristles. ( $x$ 100. After (i. Kanstex.)

a centre, and have the sculpturing radially or concentrically arranged. The great majority of the forms of this order are marine, and play a large part in the composition of the jlankton $\left.{ }^{16}\right)$. The plankton diatoms are luovided with special

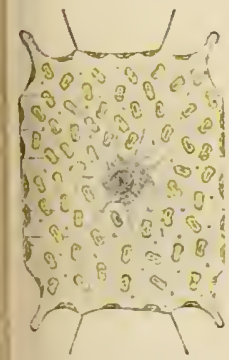

A

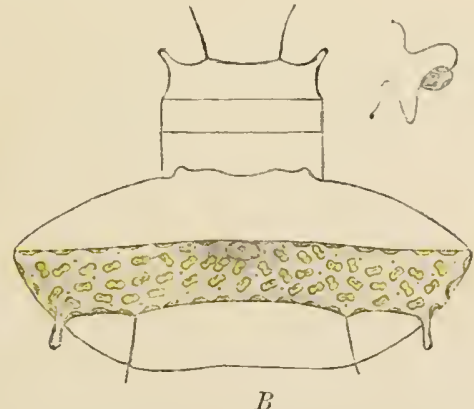

B
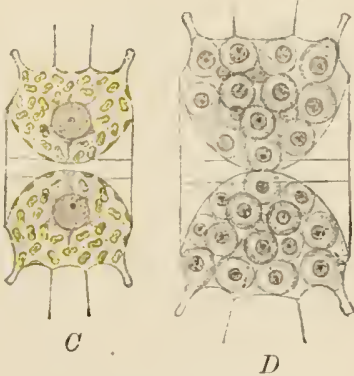

D

Fiv. 269.-Biddulphia moliliensis. A, View from the girdle side; $B$, Auxospore formation; $c$, cell divided into two sporangia preparatory to the formation of microspores; $D$, spore formation in the sporangia: $E$, swimming microspore. $(A-D \times 22 \mathrm{~s}, E \times 570$. After P. Berfex.)

arrangements for floating, horn-like projections or wings of the cell wall snch as are seen in Figs. 267 and 268.

The auxospore formation in the Centrieae does not take place by the conjugation of two gametes but by the protop asmic body of a cell becoming free from the cell walls and increasing in size; the enlarged cell is first smronnded by a weakly 
silicified membrane (perizonium), and in this the new valves are formed (Fig. $269, B)$.

The Centricae further differ from the Pennatae by possessing a special method of reproduction by means of so-called microspores; the formation of these has been accurately followed by BERGEx in Biddulphia mobiliensis. A cell first divides into two daughter cells or sporangia, the contents of which round off and by repeated division form many (32) microspores. These emerge as naked swarm-spores, each provided with two long cilia with knob-like thickenings at the tip (Fig. 269, $C-E)$. These swarm-spores appear to behave as gametes, for KArstes observed in preserved material of Corethron valdiviae that the nicrospores conjugated in pairs to form zygotes. The zygote increased in size and divided into two cells. Each daughter cell had at first two nuclei, one of which later disappeared; it grew gradually into a mature individual of Corethron. The whole process may be compared with that described above in Closterium among the Desmidiaceae $\left({ }^{24}\right)$. The ciliated gametes or microspores indicate a phylogenetic relation of the Diatomeae to the Peridineae and Flagellatae.

Diatoms oceur also as fossils. Their silicified valves form a large part of the deposits of siliceous EAITH (Kieselguhr, mountain meal, etc.), and in this form they are ntilised in the mannfacture of dynamite.

On accomnt of the extreme fineness of the markings of their ralves, it is customary to employ certain species of Diatoms as test objects for trying the leuses of microscopes. Pleurosigma angulatum is commonly used for this purpose.

\section{Class VIII}

\section{Heterocontae $\left({ }^{s}\right)$}

In the Heterocontue a number of genera of green $\mathrm{Algae}$ are included which were formerly placed in the Chlorophyceae but are now separated as an independent class.

At the base of the class may be placed

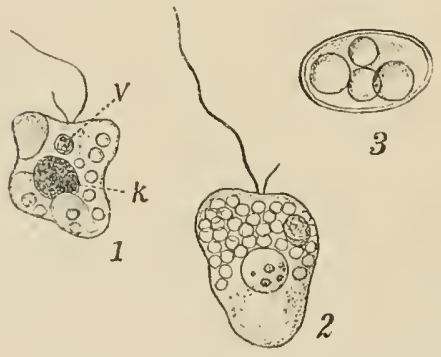

Fic: 270.-Chloramoeba heteromorjha: $i$, vacuole; 7 ; nucleus ; 3 , a resting cell. (Aftir Bunins, from OLtuansis' Alyue.) such true Flagellata as Chloramocba heteromorplue (Fig. 270), which lives in fresh water. The naked, amoeboid cell contains a nucleus and 2-6 yellowish-green chloroplasts; at the anterior end, just ontside a vacuole, two cilia are situated whieh are of very unequal leugth. It is this last feature which gives the name to the group. Chloramoebc is one of those low green organisms which become colourless and lose the power of independent nutrition when cultivated in a nutritive solution in the dark. Thick-walled resting cells also oceur.

Anong the higher Heterocontae characterised by the presence of pectin in the cell wall the genus Conforve which is widely spread in fresh water must he mentioned (Fig. 271). The plant consists of simple unbranched filanents the cells of which have peculiarly constructed walls; the wall consists of two parts separaterl by an oblique anmular split at the middle part of the cell. On cell division a new portion, H-shaped in longitudinal section, is interealated. The characteristics of the group and the resemblance to Chloramoche are seen in the 
yellowish-green, oil-forming cltloroplasts, and the formation of zoospores with eilia of unequal lengths (in many Confervae the zoospores have only a single ciliunı). In acklition to zoospores thick-walled aplanospores arise by the separation by the cells of the filament.

The majority of the Heterocontae have uninucleate, only occasionally bi-nucleate cells. But there are some genera with multinucleate cells in the class, c.g.
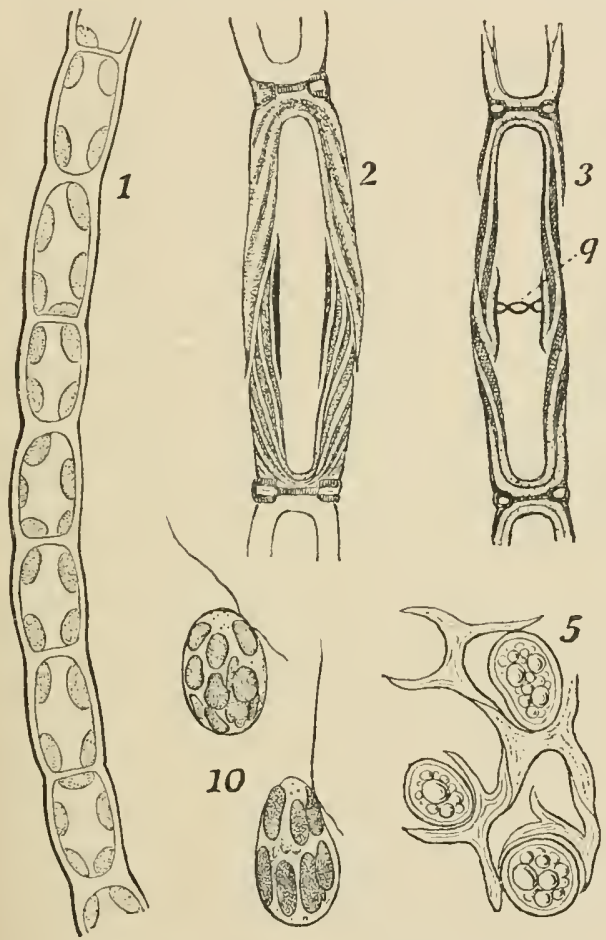

Opliocytium and Sciadium. On this account, with some reservation, Oltmanss also places here botrydizm granulatum (Fig. 272), which was formerly iucluded in the siphoneae. This Alga is cosmopolitan and grows on damp clayey soil, where it

FIG. 271.-Conferva lumbyeina. 1, Filament; 2,3 , formation of transverse wall $(q)$ in cell division ; 5 , formation of aplanospores by breaking down of the filament; 10 , Zoospores with cilia of unequal length. (After GAY $(1,5)$, Bohlin $(\because, 8)$, Luther (10). From Oltmanns' Algue.)

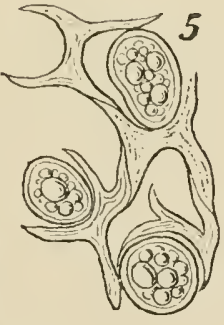

40

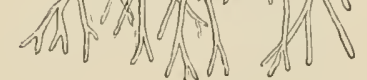

F1:. 272.-A, b, Botrydium gianu. lutum. A, The whole plant; $B$, swarm-spore. $(A \times 2 s$; $I+540$.

forms groups of green, balloon-shaped vesicles about $2 \mathrm{~mm}$. in size. These are attached to the soil by branched colourless rhizoids. The whole plant corresponds to a single multinucleate cell ; its protoplasm contains numerous green chloroplasts. The zoospores, produced in large numbers by the division of the contents, escape by an opening at the sumuit. Each has a single cilium and contains two chloroplasts. After swarming the spore surrounds itself with a wall and grows into one of the balloon-shaped plants $\left({ }^{1}\right)$.

In some genera, gametes rescmbling the zoospores but conjugating in pairs have been observed. 


\section{Class IX}

\section{Chlorophyceae $\left({ }^{8,25,26}\right)$}

When the green Conjugatae and Heterocontae are separated there remains the large natural group of the Chlorophyceae, including several series of genera. The majority of these Algae live in fresh water or in damp situations, but a large number are found in the sea. Their characteristic chloroplasts are of a pure green colour, frequently contain pyrenoids, and nearly always form starch. The asexual swarm-spores are pear-shaped, and in typical forms possess two or four cilia of equal length (on this account the group is sometimes termer Isocontae) and a curved or bowl-shaped chloroplast. In some genera the swarm-spores are replaced by non-motile aplanospores, and in certain of the more advanced genera (Oedogonium, Vaucheria) the swarm-spores are of more complicated structure, but can be derived from the typical simple form.

Of the five orders included in the Chlorophyceae the Volvocales stands nearest to the Flagellata and, as is also the case with the Protococcales, include unicellular and colonial forms. The Ulotrichales and Siphonocladiales are filamentous; in the former the filaments are composed of uninucleate, in the latter of large multinucleate cells. The filaments are simple in the lower forms, but branched in the more advanced oncs. The thallus of the Siphonales is formed of a
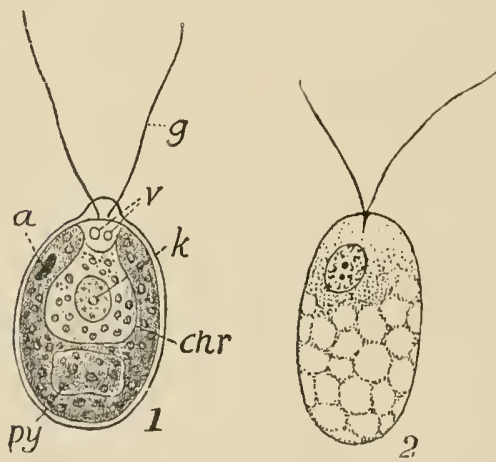

Fic. 273. - 1. Chlamigelomennas angulost. (After 1)LL.) $q$, cilia ; $r$, vacuob; $h$, nucleus; rler, clirouatopluores; py, pyreroid. 2. I'olytoma uiellu (after DANoranD); $a$, rye-spot. (From OLIMANx's' Algre.) single multinucleate cell.

In all the orders sexual reproduction is usnally effected by the conjugation of gametes which resemble the zoospores. In all the groups, except the Protococcales, isogamy is replaced by oogamy in the higher forms.

Order 1. Volvocales. - Typical representatives of this order are characterised by the eilia being retained by their cells in the vegetative stage ; the plants are therefore motile. Each eell has a nucleus and a ehloroplast. The Volvocales thus resemble the Flagellatil, some forms of which, sneh as Polyblepharis, might, on the ground of their cell structure be placed in the former gron], bnt differ by the absence of a cell wall and of sexual reprodnction.

Chlamydomonus (Fig. 273) and Hecmatococens (Fig. 274) are widely distributed forns consisting of free-swimming cells $\left({ }^{27}\right)$. In the former the cell membrane is closely applied to the protoplast, at the anterior end of whieh two cilia and a red 
eye-spot are situater ; in the latter genns the membrane is separated from the

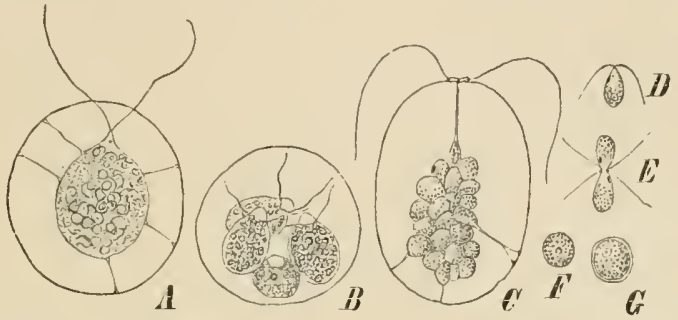

Fis. 274.-A, D, Hacmatococeus plurialis $(\times 360)$; $A$, swarming cell ; $I$, formation of swaru-spores. C.f, Haematococess Biitschlii; C', formation of gametes $(\times 400) ; D$, gamete; E, conjugation of two gametes ; $F, f$, zygotes ( $\times$ sori). (C-G, after Blochmann.)

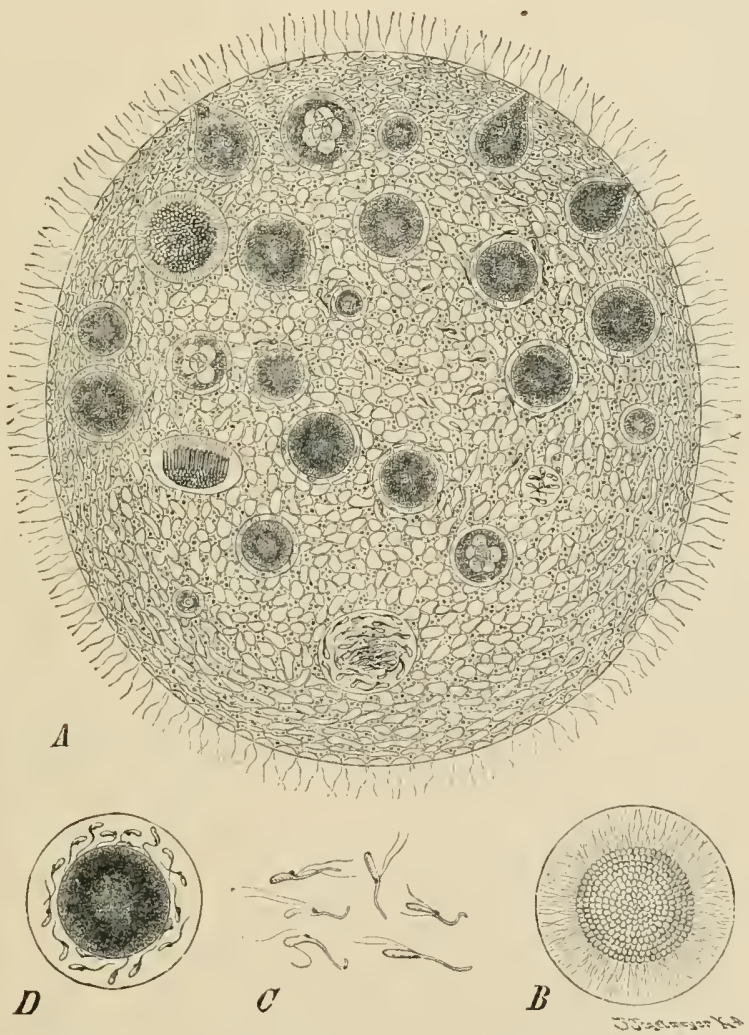

F1r. 275.-Volvox glohator. A, Colony showing various stages of derelopment of ova and spermatozoids $(\times 165)$. $\quad I$, Bundle of spermatozoisls formed by division from a singl cell $(\times 530), C$, spermatozoids $(\times 530), D$, Egg-cell surroundexl by spermatozoids in the mucilaginous membrane ( $x$ 26is). (After F, Cous.)

protoplast by a gelatinons layer except at the anterior end. IItematococus 
plurialis occurs commonly in puddles of rain-water, and, like Chlamydomonas nivalis, which gives rise to "red-snow" and occurs on snow in the Alps, etc., is characterised by the presence of a red pignent (liaematochrome) in the cells. Reproduction is both asexual, by swarm-spores, 2-8-16 of which are formed in a mother cell and are set free by rupture of the membrane, and sexual ; the sexnal reproduction is by conjugation of similar, small, biciliate gametes formed in large numbers (to 64) in a mother cell, and uniting in pairs by their anterior ends to form a zygote. In Chlamydomonas coccifere, according to Goroschanisin $\left({ }^{28}\right)$, there is in contrast to the other species a marker differentiation in the sexual cells. Single cells become transformed into large, non-ciliaterl, female gametes or egg-cells; others divide and each gives rise to 16 small, biciliate male gametes. The transition to oogany thus occurs in this group even among the isolated unicellular forms.

Polytoma uvelle, which resembles Chlamydomonas in structure, is a colourless and saprophytic form (Fig. 273, 2).

The biciliate cells of Pandorina, Eulorina, Folvox, etc., are united in colonies or coenobia. In $I^{r}$ olvox ${ }^{(29}$ ) (Fig. 284), which may be regarded as the highest form in the order, the free-swimming colonies have the shape of a hollow sphere. The component protoplasts are connected by fine processes, so that the organism must be regarded as constituting a single individual. The sexual cells are differentiated into ova and spermatozoids. The egg-cells arise by the enlargement of single cells

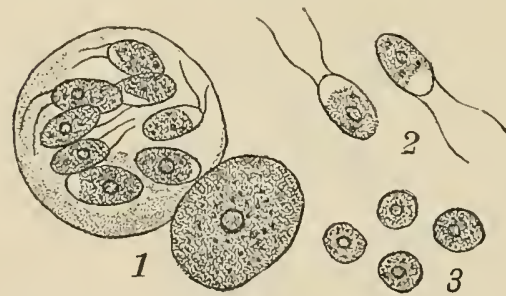

Fir. 276.-Chlorococcum (Chlorosphaera) limicola. 1, Vegetative cell and cell divided into 8 zoospores; 2, free zoospores; 3, zoospores after they have formed cell walls. (After BEYERINck, from Oltmanns' Algae.) of the colony; they are large, green, non-motile cells surrounded by a mucilaginous wall. The small spermatozoids are clongated bodies of a bright jellow colour, provided with two cilia attached laterally below the colourless anterior end ; they arise by the division of a cell of the colony into numerous daughter cells. After fusing with a spermatozoid within the cavity of the colony the egg-cell is transformed into the thickwalled, resting oospore. The vegetative reproduction of Folvox takes place hy the division of single cells of the colony to form a new danghter colony ; this corresponds to the formation of swarm-spores in other genera. Eudorina is also oogamous.

Order 2. Protococcales.-These are unicellular green Algae, or their cells are united in colonies of various form; the vegetative cells have no cilia, and the cell or colony is consequently non-motile. Usually each cell contains a nucleus and only one chloroplast. Reproduction is by means of zoospores, in place of which in many genera non-ciliated aplanospores are found. Sexual reproduction, when present, takes the form of conjugation of similar gametes.

The simplest forms belong to the genera Chlorocoecum and Chlorellec $\left.{ }^{30,}{ }^{31}\right)$. The cells of the former are splherical, and oceur in fresh water and also on dlanp' substrata; they frequently take part in the composition of Lichen thalli. Asexual reproduction is by the production from a cell of a number of biciliate zoospores (liig. 276); under certain conditions these are reflaced by aplanospores without cilia. Chlorella vulyaris (Fig. $27 \%$ ) is a wide-spreal Alga, the small cells of which often live symbiotically in the protoplasts of lower animals (Infusoriac, IIydra, 
Spongilla, l'lanariae); it is multiplied only by division of the cells into 2, 4 , or 8 aplanospores which surround themselves with a wall and grow to the full size.

The simplest type of cell-colony, consisting of four cells, is found in the genus
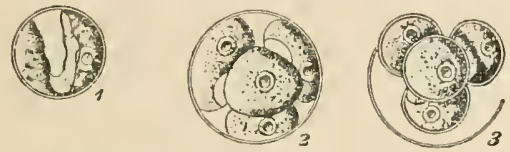

Scenedesmus ( $\left.{ }^{32}\right)$, whieh is widely spread in fresh water, and connects on to Chlorella. The commonest form, Sc. acutus, has spindle-shaped cells, while the colonies of s'c. coudutus are distinguished by four long horn-like pro-
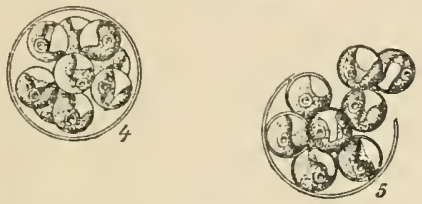
longations of the cell wall (Fig. 278). In reproduction each cell divides in the direction of its length into four daughter-cells, which on escaping from the parent cell form a new colony. More complicated cell colonies are met with in Pediastrum ( ${ }^{33}$ ) (Fig. 279), in which each cell-family forms a freeswimming plate, composed internally

FIє. 277.-Chlorclla vulgaris. 1, Cell ; 2, 8, division into four aplanospores ; 4,5 , division into eight aplanospores. (After Gristzesco.)

of polygonal cells, while on the margin it consists of cells more or less acutely crenated. The formation of asexual swarm-spores is effected in Pedicstrum by the division of the contents of a cell into a number (in the case of the species illustrated, $P$. granulatum, into 16 ) of naked swarm-spores, each with two cilia. The swarm-spores, on eseaping through the ruptured cell wall (Fig. 279, $A, b$ ), are enclosed in a common envelope. After first moring vigorously about within this envelope, they eventually collect together and form a new cell-family. Pediastrum also prossesses a sexual mode of reproduction. The gametes are all of equal size,

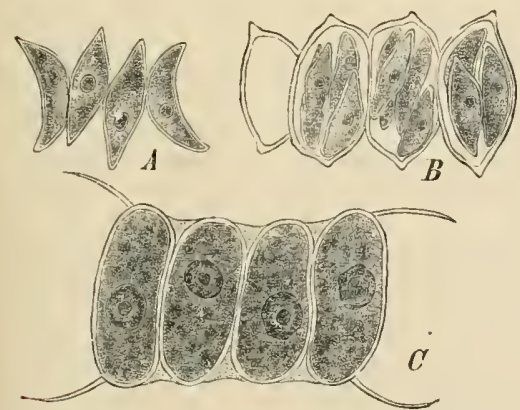

Fia. 278. - A, Scenerlesmus acutus. $b$, the same, undergoing division; C', Sconedesmus caudatus. (After SENs, $\times$ 1000.)

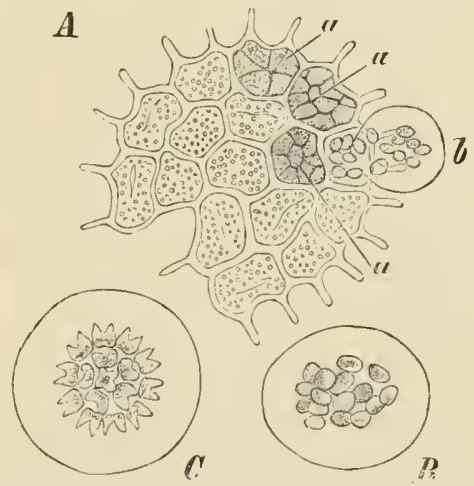

Frr. 279.-Peliastinu granulatum. A, An olil cell-family : $a$, cells containing spores ; $b$, spores in process of extrusion (the other cells have already discharged their spores); B, cell-family shortly after extrusion of the spores; $C$, cell-family $4 \frac{1}{2}$ hours later. (After At. BRALN, $\times 300$.

and except that they are smaller and are produced in greater numbers, arc similar to the swarm-spores. They move freely about in the water, and in conjugating fuse in pairs to form zygotes. The further development of the zygotes into cellfamilies is not yet fully known.

The life-history of the Water-1,et (Hydrodictyon utriculatum $(1,34)$ is essentially similar. It is one of the most beautiful of the free-floating, fresh-water Algae, the 
hollow eylindrical colonies being formed of elongated cells united together to form a many-meshed net.

Order 3. Ulotrichales. - The Ulotrichales exhibit, as compared with the miecllular green Algae, an adrance in the exterual segmentation of the thallus. It is always multicellular, and, in most of the genera, consists of simple or branched filaments. The filaments are either attached by a colourless basal cell to the substratum (Fig. 281, A) or float free. The thallus of the marine genus $T$ r $r^{\circ} \alpha$ (Ulv $\alpha$ lactuca, SEA LETTUCE) has the form of a large, leaf-like eell surfaee, and is two layers of cells thick (Fig. 5, young plant). In Enteromorplea (Fig. 280) the thallus is ribbon-shaped, either cylindrical or flattened; when young it is two-layered, but later it becomes hollow, the wall thins consisting of one layer of cells. Although the majority of the Ulotrichales live in fresh or salt water, a few aerial forms

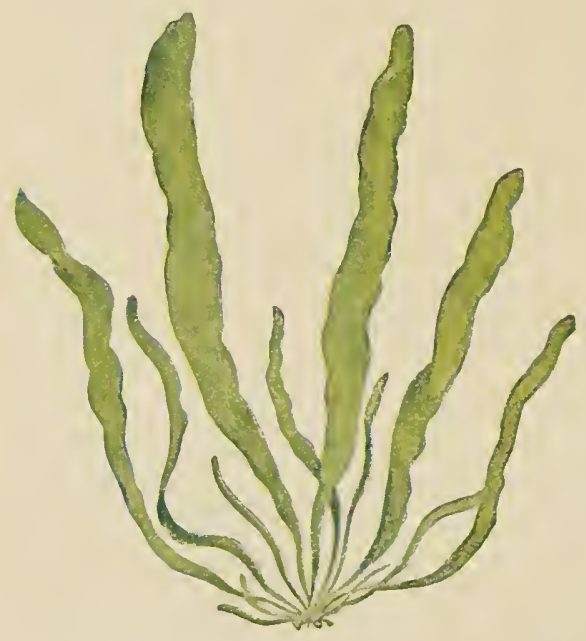

Fif. 2s0.-Enteromorphe compressa. (12 nat. size.) (Chroolepideae) grow on stones, trunks of trees, and, in the tropics, on leaves. To this family belongs Trentepolilia (or Chroolepus) Jolithus, often found growing on stoues in mountainous regions. The ecll filaments of this speeies appear red on account of the haematochrome they contain and possess a riolet-like odour.

The eells have always only one nueleus and also a single cliloroplast.

The asexual reproduction is accomplished by the formation of eiliated swarm-spores. Sexual reproduction is effeeted either by the fusion of planogametes, or the sexual eells are differentiated as non-motile egg-eells and motile spermatozoids.

Ulothrix anuata ( ${ }^{(35}$ ) (Fig. 281, A) is one of the eommonest filamentous Algae. The filaments of Ulothrix exhibit no pronouneed a pieal growth ;

they are unbranched, attached by a rinizoid eell, and consist of rows of short cells; each cell contains a band-shaped chloroplast. The asexmal reproduction is effected by means of swarm-spores, which have four eilia $(C)$, and are forned singly or by division in any cell of the filament. The swarm-spores eseape throngh a lateral opening $(B)$ formed by absorption of the cell wall, and, after swarming, give rise to new filaments. The sexual swarm-cells, or planogametes, are formed in a similar manner by the division of the cells, but in muel greater numbers. They are also smaller, and possess only two cilia $(E)$. In other respects they resemble the swarm-spores, and possess a red eye-spot and one ehromatophore. liy the conjugation of the planogametes in pairs, zygotes $(F-H)$ are produced, which, after drawing in their eilia, round themselves off and become invested with a cell wall. Ulothrix is dioecious, for gametes derived from the same filament do not fuse, but only those of distinct origin. After a shorter or longer period of rest the zygotes are converted into unicellular germ plants $(J)$, and give rise to several swarm-spores $(K)$, which in turn grow out into new filaments. Under some conditions the jlanoganetes can give rise to new ylants parthenogenetically without conjugating. 
Further, the filaments can, in addition to the swarm-spores with four cilia described above, produce others of smaller size (miero-zoospores) which resemble the gametes. These possess four or two cilia, and as a rule die if the temperature of the medium is above $10^{\circ}$; below this temperature they come to rest after a few days and proceed to germinate slowly. This Alga is thus of interest from the incomplete sexual differentiation exhibited by its gametes.

The genera Oedoyonium (36) and Bulbochacte may be quoted as examples of oogamons Ulotrichales. While the thallus of the latter is branched, the numerous species of Oedogonium consist of unbranched filaments, each cellof which possesses one nucleus and a single parietal chromatophore composed of numerous united bands. The asexnal swarnspores of Oedogonium are unusually large, and have a circlet of cilia around their kinoplasmic, colourless, anterior extremity (Fig. 282, $B$ ). In this case the swarm-spores are formed singly, from the whole contents of any single celi of the filament $(A)$, and escape by the rupture of the cell wall. After becoming attached by the colourless end they germinate, giving rise to a new filanent. For the purpose of sexual reproduction, on the other hand, special cells become swollen and differentiated into barrel-shaped oogonia. A single large egg-cell with a colourless receptive spot is formerl in each oogonium by the contraction of its protoplasm, while the wall of the oogonium becomes perforated by an opening at a point opposite the receptive spot of the egg. At the same time, other, generally shorter, cells of the same or another filament become

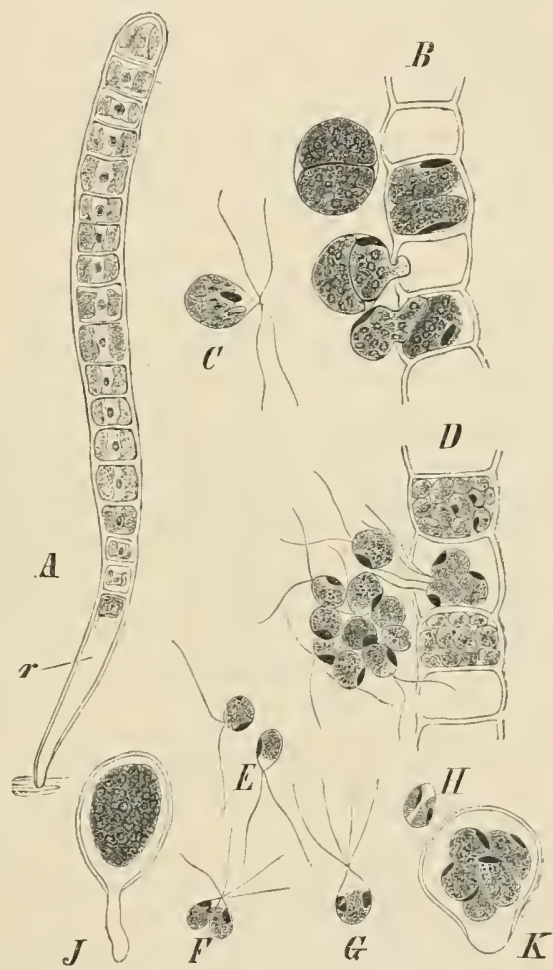

Fr. 's1.-Uluthrix zonute. A, Young filameut with rhizoid cell $r(\times 300)$; $r$, portion of filament with escaping swarm-spores; $C$, single swarm-spore; $D$, formation aul escape of gametes; $E$, gametes; $F, f_{r}$, conjugation of two gametes: $H, z y$ zote ; $J$, zyote after period of rest; $K$, zygote after division into swarmi-sporis. (After IODEL-PORT. $\quad B-K \times 48 \%$.) converted into antheridia. Each antheridium usually gives rise to two spermatozoids. The spermatozoids are smaller than the asexnal swarm-spores, but have a similar circlet of cilia. They penetrate the opening in the oogonium and fuse with the egg-cell, which then becomes transformed into a large, firm-walled oospore. On the germination of the oospore its contents become diviled into four swarmspores, each of which gives rise to a new cell filament. In the adjoining figure (Fig. 283) a germinating oospore of Bulbochacte with four swarm-spores is represented.

In some species of Ocdogonum the process of sexual reproduction is morc 
complicated, and the spermatozoids are produced in so-called DWAFF MALS. These are short filaments (Fig. 282, C, a) consisting of but few cells, and are developed from asexual swarm-s]ores (ANDrospores) which, after swarming, attach themselves to the female filaments, or even to the oogonia. In the ulper cells of the dwarf male filaments thus derived from the androspores, spermatozoids are proinced which are set free by the opening of a eap-like hid (Fig. 282, D, $\alpha$ ).

The genus Colcochucte $\left({ }^{37}\right)$ is also oogamous. The long colourless neck of the flask-shaped oogonimm opens at the tip to allow of the entranee of the spermatozoid. The spherical oospore increases in size and becomes surrounded by a single lajer of psendo-prarenchymatous tissne derived from filaments that spring from the stalk cell of the oogonium and neighbouring cells. In this way a fruit-like body is formed. On germination the oospore undergoes a reduction division and livides

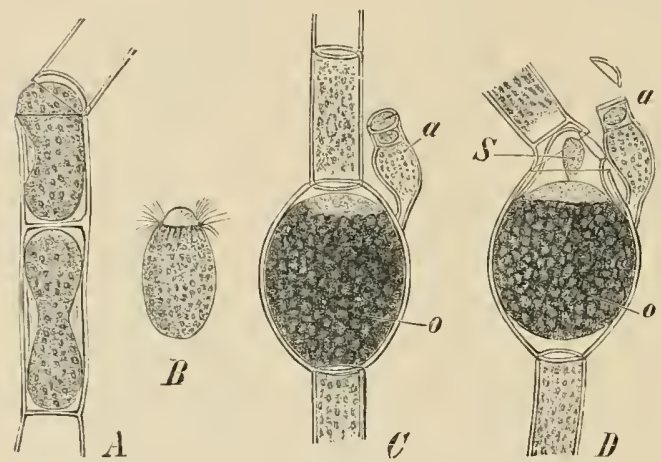

FIr. 28:- $-A, L$, Oerlogunium: $A$, escaping swarm-spores ; $B$, free swarm-sport. $\quad €, D$, Oeclognnium ciliutum: $C$, before fertilisation; $D$, in process of fertilisation; 0 , oogonia; $a$, dwarf males; s, spermatozoid. (Attri Provisherm, $\times 350$. )

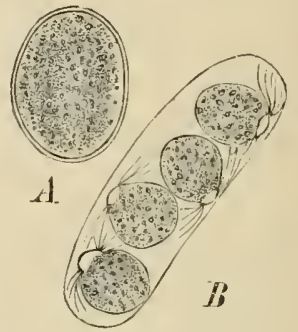

Frg. 2s3.--Bulbechate intermedia. A, Oospore; 3 , formation of four swarm. spores in the germinating oospore. (After PrisgsIIEIM, $\times 250$.

into 16-32 wedge-shaped cells, then breaks up and liberates a swarm-spore from each cell.

Order 4. Siphonocladiales. - The Algae of this order are filamentous and nsually branched; they are distinguished from the Ulotrichales by their large multinucleate cells, the chloroplasts of which are either solitary, large and reticn. lately formed, or appear as numerous small discs.

The genus Cladophora, numcrous species of which oceur in the sea and in fresh water, is one of the most important representatives of the order. Cl. glomerata (Fig. 281) is one of the eommonest Algae in streams, often attaining the lengtlo of a foot. It is attached by rlizoid-like cells, and consists of branched filaments with typical apical growth which some other representatives of the order do not show. The structure of the cells is represented in Fig. 60. Branching takes place from the uplerends of the eells ly the fornation of a protrusion which is ent off as the first cell of the brumch. Asexual reproduction is by means of biciliate zoospores (Fig. 284), which arise in numbers from the upler cells of the filaments, and escape from these sporangia by a lateral opening in the wall. The sexual reproduction is isogamous as in Elothrix.

Only in the genus Sphacroplea las the sexual reproduction become oogamons. S. anmulina consists of simple filinents and oceurs in fresh water.

Many forms ocenr in the sea (c.y. Siphonocladus), and some liave a lighly 
complicated thallus, which is always, however, formed of branched filaments; by ealcareous incrustation some forms come to resemble coral. Acetabularia mediter. ranea $\left({ }^{38}\right)$ (Fig. 285) will serve as an example of such ealcareons Algae. The thin stalk of the thallus is attaehed by means of rhizoids, while the mmbrella-like dise consists of closely mited tubular outgrowths, each of which is to be regarded as a gametangium. The contents of the latter do not form the biciliate gametes

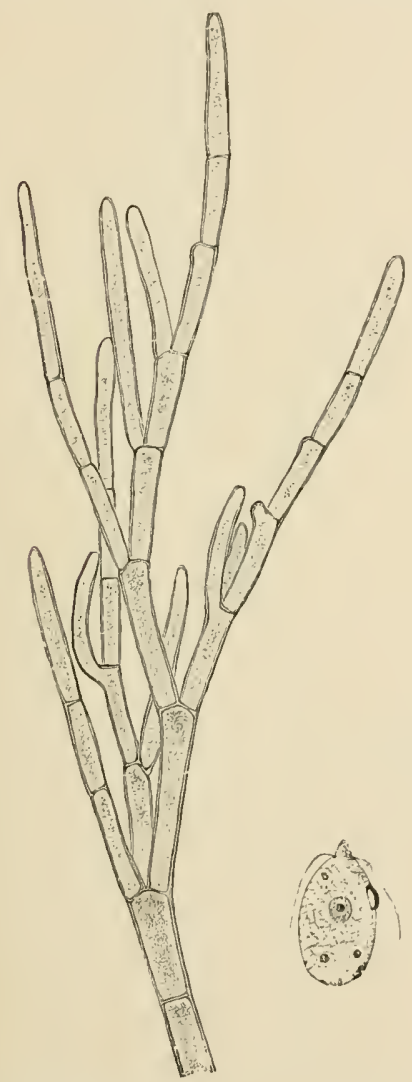

F1a. 284.- Portion of Cladiophoraglomerata. ( $\times 4$ s.) To the right a swarm-spore. ( $\times 1000$.) directly, but first divide into a large number of firn-walled cysts. These remain in the resting condition thronghont the winter, and then give rise to numerous gametes which conjugate in pairs. The zygotes germinate promptly and grow into new plants.

Order 5. Siphonales. - The Siphoneae are distinguished from the preeeding grouls of Algae by the structure of their thallus, which, althougl more or less jrofusely branched, is not

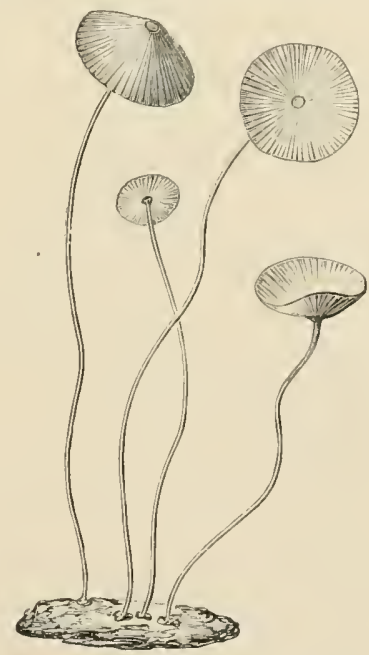

Fic. 255.-Acetabularia meriterranea. (Nat. size.)

at first divided by transverse septa. The cell wall thus encloses a continuous protoplasmic borly in which numerous nuclei and small green chloroplasts are embedder. The same type of thallus is also met with in the Phycomycetes or Algal Fungi.

The majority of the Siphoneae inhalit the sea, and on account of the complicated segmentation of their thallus, afford one of the most interesting types of algal development. The genus Caulerpe (39), represented by many speeies inhabiting the warmer water of the ocean, has a creeping main axis. Increasing in length by apical growth, the stem-like portion of the thallus gives off from its under surface profusely branched colourless rhizoids, while, from its upper side, 
it produces green thalloid segnents, whieh vary in shape in the different species. In Canlerpa prolifera (Fig. 286), which occurs in the Mediterrancan, these ontgrowths are leaf-like and are frequently iroliferous. In other species they are pinnately lohed or branched. The whole thallus, horever branched and segmented it may be, encloses but one cell-cavity, which is, however, often traversed by a network of cross-supports or trabeculae. Starch-forming lencoplasts are present in the colonrless parts of the thallus.

The genus Bryopsis $\left(^{\left({ }^{\prime \prime}\right)}\right.$, on the other hanr, has a delicate, pinnately brancherl thallus. The thallus of Halimeda, the species of which oceur in the warmer seas,

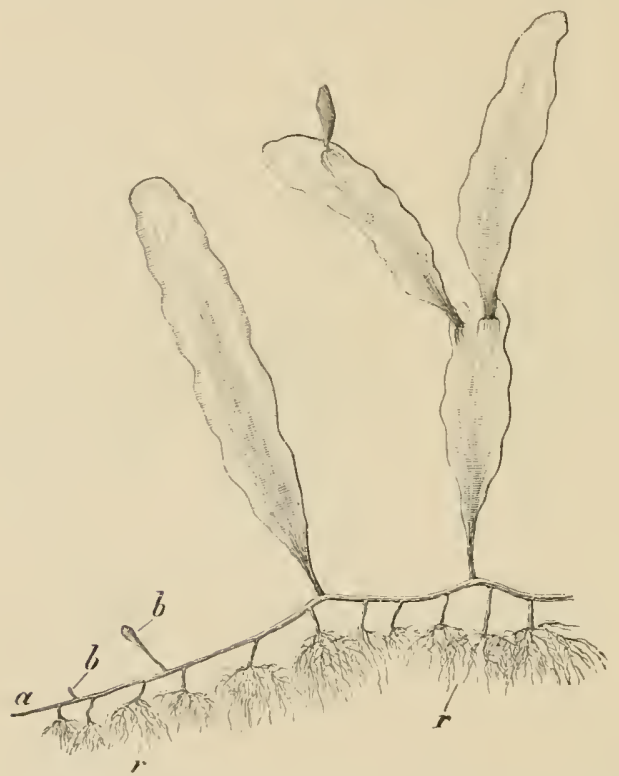

FIg. 280. - Caulerpa prolifera. The shaded lines on the thallus leaves indicate the currents of protoplasinie movement; $a$, growing apex of the thallus axis; $b, b$, young thallus lobes; $r$, thizoirls. ( $\frac{1}{2}$ nat. size.)

trenties of lateral branches by means of tianterse is composed of flattened segments, and resembles an $O_{p}$ untia on a small scale. by incrustation with lime it attains a liard, coral-like texture. The segments are formed of branched tubular filaments.

In Bryopsis the biciliate, pear-shaped, conjugating gametes are differentiated into $\mathrm{n}$ larger female cell with a green chromatophore and a smaller male cell, three times smaller than the female and with a single yellow chromatophore; in Vancheria and Dichotomosiphon oogamous reproduction is well marked $\left(^{41}\right)$. The latter Algae occur in fresh water or on damp soil. The thallus consists of a single branched, filamentous cell attacherl to the substratum by means of colourless rhizoids (Fig. 2st, D).

The swarm-spores of $V^{r}$ aucheria, which differ from those of the other Siphonales, are developed in special sporangia, cut off from the swollen extremities of lateral branches by means of transverse walls (Fig. 2si). The whole contents of such a sporangium become converted into a single, green swarm-spore. The wall of the sporangium then ruptures at the apex, and the swarm-spore, rotating on its longitudinal axis, forees its way through the opening. The swarnsprore is so large as to be visible to the naked eye, and contains numerous nuclei embedded in a peripheral layer of colourless protoplasm. It is entirely surrounded with a fringe of cilia, which protrucle in pairs, one pair opposite each nuclens. Morphologieally the swarm-sjores of Itucheria correspond to the eollective, individual zoospores of an ordinary sporangium.

The sexual reproduction of Iraucheria is not effeeted, like that of the other Siphoneae, hy the conjugation of motile gametes, from which, howerer, as the earlier form of repoduction, it may be considered to have been derived. The oogonia and antheridia first appear as small protuherances, which grow out into 


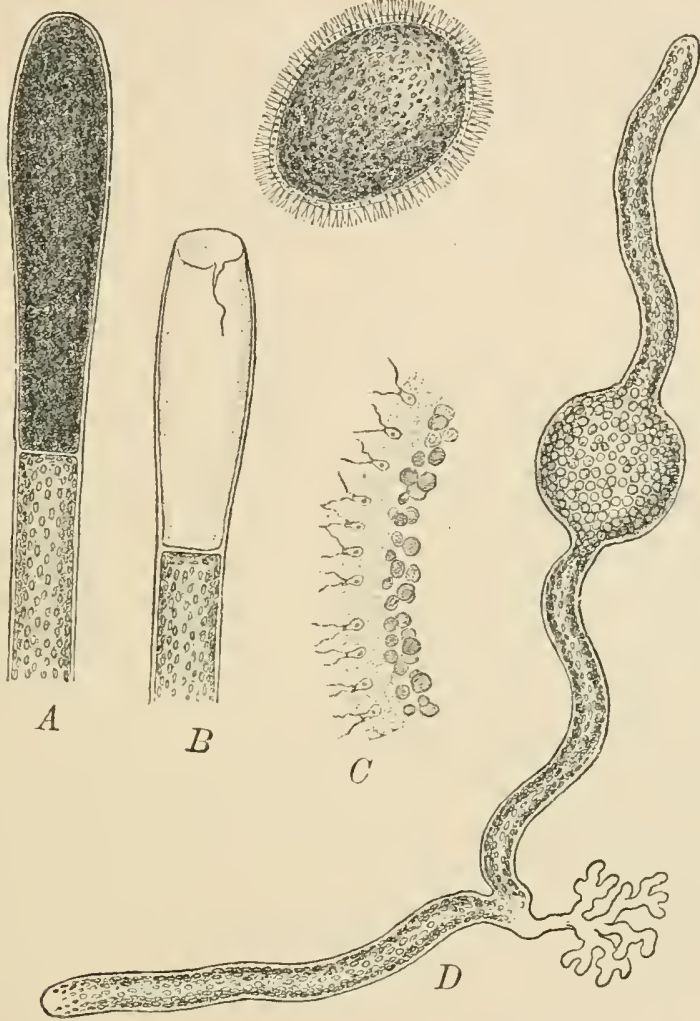

Fio, 2si.-Vaucheria sessilis. A, Young sporangiun. D, \%oospore with the sporangium from which it has escaped. $C, A$ portion of the peripheral zone of a zoosjore. $D$, A youmg jlant with rhizoids developed from a zoospore. ( $A, L$, after Götz; $D$, after stachs ; from OLTMANмs' Algae. C, after Strasburger.)

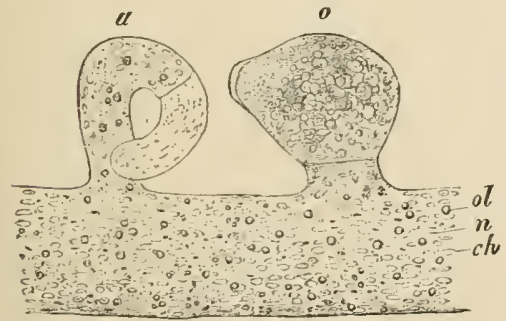

F1f, 2s8,-I'aucheria sessilis. Portion of a filament with an oogonium, $o$; antheridium, $a$; $r$, chro. matophores; n, cell nuclei; ol, oil globules. $(\times 240$. short lateral branches, and become separated by means of septa from the rest of the thallus (Fig. 2SS, o, a). At first, according to OLTMANXs and HEIDINGER, the rudiment of an oogonium contains numerousnuclei, of whieh all but one, the nuclens of the future ego-cell, retreat again into the main filament before the formation of the septum. In its mature condition the oogonium has on one side a beak-like projeetion containing only eolourless protoplasm. The oogonimm opens at this place, the oosphere rounding itself off. The antheridia, which are also multinuclear, are more or less coiled $(\alpha)$, and open at the tip to set free their nucil- 
aginous contents, which break up into a number of swarming spermatozoids. The spermatozoids are very small, and have a single nueleus and two eilia inserted on one side. They colleet around the receptive spot of the egg-cell, into which one spermatozoid finally penetrates. After the egg-eell has been fertilised by the fusion of its nucleus with that of the spermatozoid, it becomes invested with a wall and converted into a resting oospore. On germination the oospore grows into a filamentous thallus.

\section{Class $\mathrm{X}$}

\section{Phaeophyceae (Brown Algae) (\$, 25, 42)}

The Plaaeophyceae, like the Chlorophyceae, can be derived from unicellular Flagellata, and in particular from the Chrysomonadinae which possess yellow chromatophores. They attain a higher grade of organisation in their vegetative organs than do the Green Algae.

With the exception of a very few fresh-water species, the Phaeophyceae are only found in salt water. They attain their highest development in the colder waters of the ocean. They show great diversity in the form and structure of their vegetative body. The simplest representatives of this class (e.g. the genus Ectocarpus) have a filamentous thallus consisting of a branched or unbranched row of simple cells. Some Phaeophyceae, again, have a cylindrical, copiously branched, multicellular thallus (e.g. Cludostephus), whose main axes are thickly beset with short multicellular branches (Fig. 7); while in other cases the multicellular thallus is ribbon-shaped and dichotomonsly branched (e.g. Dictyota, Fig. 8). Growth in length in both of these forms ensues from the division of a large apical cell (Figs. 7 and 111). Other species, again, are characterised by discshaperl or globose thalli.

The Laminariaceae and Fucaceae include the most highly developed forms of the Phacophyceae. To the first family belongs the genus Laminuria found in the seas of northern latitudes. The large, stalked thallus of the Laminarias resembles an immense leaf; it is attached to the substratum by means of branched, root-like holdfasts, developed from the base of the stalk.

In Lamincria dryitata and L. Cloustoni (Fig. 290), a zone at the base of the falmately divided, leaf-like expansion of the thallus retains its meristematic character, and by its interealary growth prodnces in autunn and winter a new lamina on the perenuial stalk. The older lamina becomes pushed up and gradually lies, while a new one takes its place and beeomes in turn palmately divided by longitudinal slits. The large size of their thalli is also characteristie of the Laminarias; L. succherina (North Sea), for instanee, Ias an undivided, but annually renewed lanina, frequently $3 \mathrm{~m}$. long and a stalk more than $1 \mathrm{~cm}$. thiek.

The greatest dimensions attained by any of the Phacopliyceae are exhibited by certain of the Antaretic Laminariacede. Of these, Mfecrocystis pyriferce (Fig. 289) is noted for its gigantic size; the thallus grows attached to the sea-bottom at a depth 
The cells of the Phaeophyceae have usually but one nucleus. They contain a larger or smaller number of simple or lobed, disc-shaped

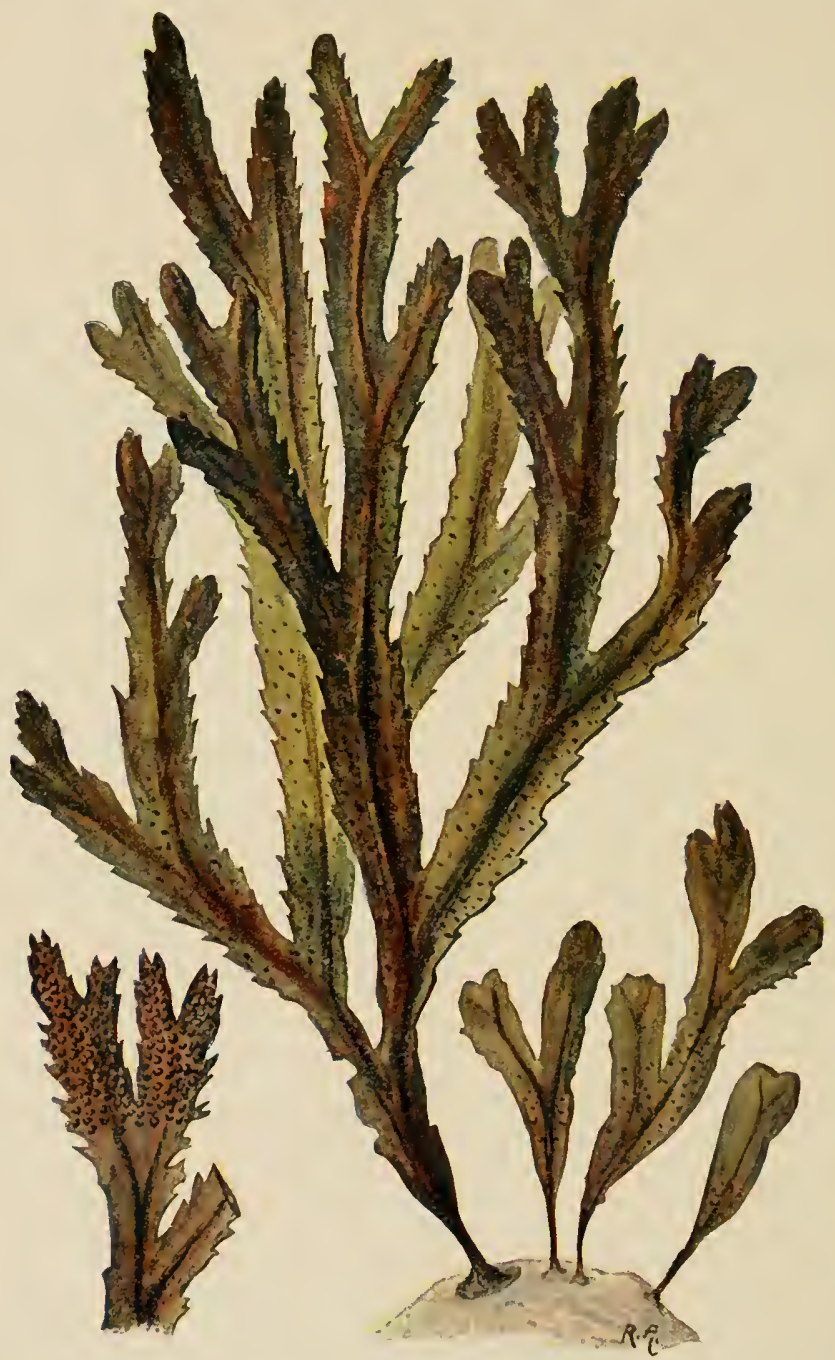

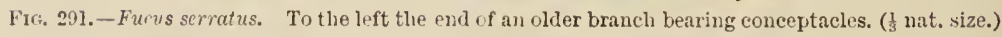

chromatophores, which contain a brown pigment (phaeophyll, p. $62)$, giving to the algae a yellowish-brown or dark-brown colour. Numerous grains of a semi-fluid substance, to which the name fucosan has been given, appear as the product of assimilation. 
This substance appears to be a carbohydrate, and, according to Hansteen ( ${ }^{45}$ ), originates in the ehromatophores. Among the more highly developed forms the thallus exhibits a highly differentiated anatomieal structure. The onter cell layers, as a rule, function as an assimilatory tissue, the inner eells as storage reservoirs. In the Laminariaceae and Fucaceae structures closely resembling the sievetubes of the cormophytes oceur, and possibly conduct albuminous substanees $\left({ }^{46}\right)$.

Two orders of Phaeophyceae may be distinguished. The Phaeosporeae are vegetatively reproduced by means of zoospores and sexually by ciliated gametes; they thus resemble Ulothrix among the Green Algae. The Cyclosporeae show a marked differentiation of their sexual cells into large, naked, nonmotile, spherical oospheres and small, ciliated spermatozoids; sorne forms are also asexually reproduced by means of naked, non-motile spores.

\section{Order 1. Phaeosporeae ( $\left.{ }^{47}\right)$}

In this order are included the Laminarias, as well as the majority of the other Phaeophyceae. Asexnal multiplication is effected by means of swarm-spores, which are produced in large numbers in simple (unilocular) sporangia; they have a red eye-spot, a chromatopliore, and two LATEIALLY IXsEnTED cilia (Fig. 292), one directed forwards and the other backwards. Only this asexual reproduction is yet known in the Laminariaceae.

In addition to unilocular sporangia, multilocular sporangia are produced in the Phaeosporeac (Fig. 293). Each cell of the multilocular sporaugium produces a single swarm-spore, rarely several. The conjugation of these swarm-spores has heen observed in some genera. On this acconnt these swarmspores must be termed planogametes, and the corre-

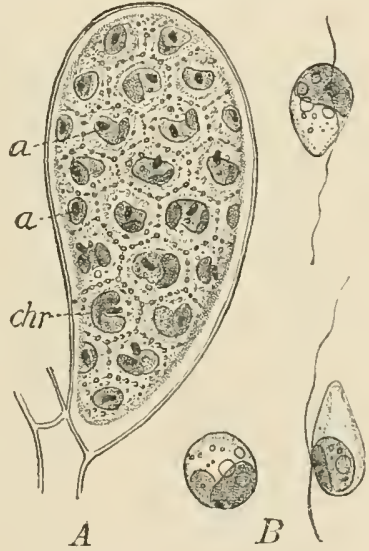

FIt. 292.-A, Pleurocladia lacustris. Unilocular sporangium with it: contents divided tip into the zoospores; $a$, eye-slot; $c h r$, chromatophore. (After KLEВАнх.) $B$, Chordi filum. Zoo. spores. (After Reinke.) (From OLtMANN'Algie.)

sponding sporangia gametangia. The degree of sexual differentiation varies, and in some cases the swarm-spores produced in multilocular sporangia can germinate without conjugating, as was seen to occur in Clothrix among the Chlorophyceae.

Ectucarpus siticulosus (Fig. 291) will serve as an example of the mode of conjugation of gamctes produced from multilocular gametangia. The gametes are similar in form, but their different behaviour allows of their distinction into male and female which are formed in distinet gametangia, borne on the same, or different plants. The female gamete becomes attached to a substratum, and numerons male gametes gather around it (Fig. 294, 1). Ultimately a male gametc fuses with the female to form a zygote (Fig. 294, 2-9). This contains after the fusion a single nuclens, but two chromatophores, and soon hecomes attached and surrounded by a cell wall; it grov:s into a new plant.

In other l'hacophyceae the distinction between the two kinds of gannetes is 
expressed in their shape and size. The Cutleriaceae affort a particnlarly good transition from isogamy to oogany and a differentiation of the gametangia into antheridia and oogonia (Fig. 295) $\left({ }^{(8)}\right)$.

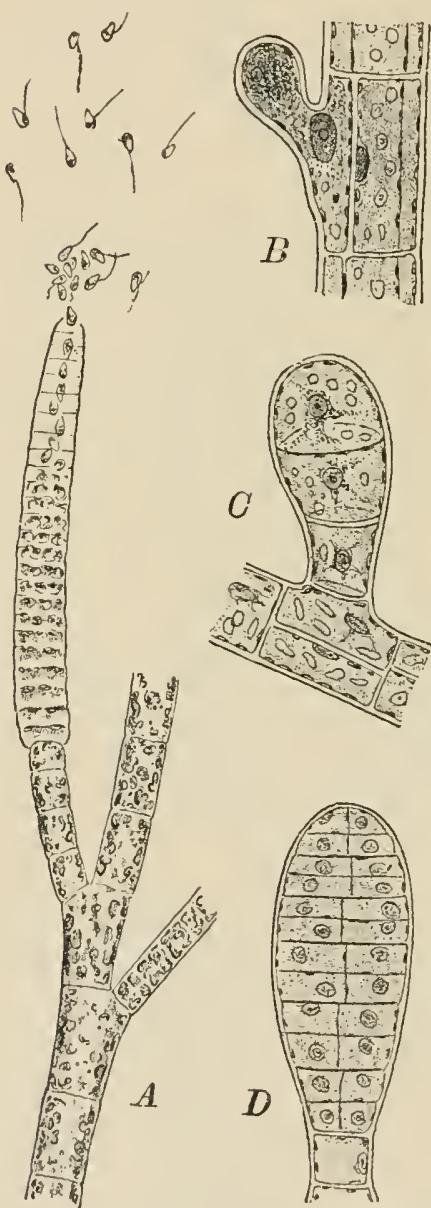

Fivi. 2!3.-A, Ectocarpus silu'ulnsus. Phrrilocular sporangium liberating its contents (after

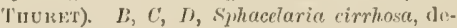
velopment of the plurilocular sporangium (after Reiske), (From Oltwasis' Algoe.)

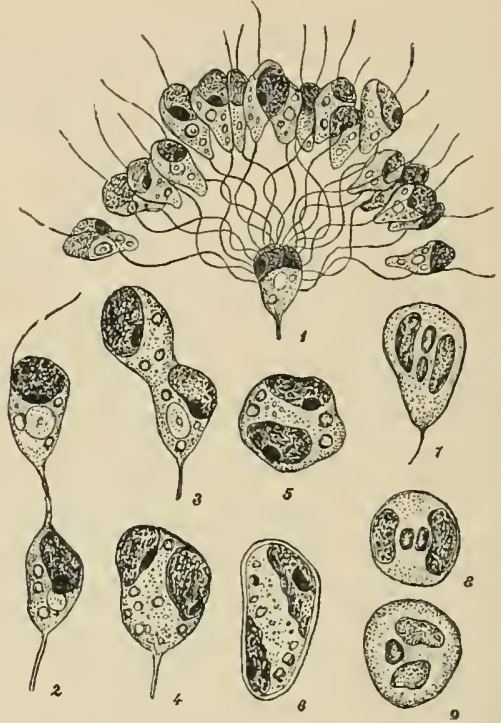

F1t. 294.-Ectocarmus siliculosus. 1, Female gamete surrounded by a number of male gametes; seen from the side. 2-5, Stages in the fusion of gametes. 6, Zygote after 24 hours. 7.9 , Fusion of the nuclei in conjugation, as seen in fixed and stainerl material ( $1-5$, after Berthold ; $6-9$, after (ItTyanNs.)
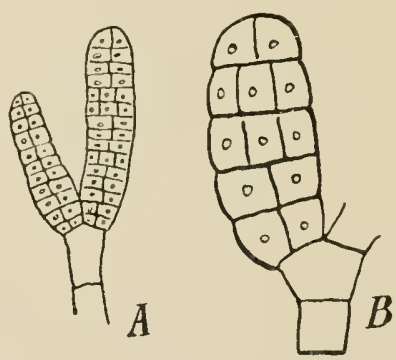

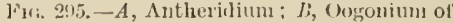
Cutloria multiflde. (After RE1నke, $\times 410$.

\section{Order 2. Cyclosporeae $(49,50)$}

Family 1. Dictyotaceae.-Only a small number of forms belong to this family. The fan-slaped I'atina paconiu, which occurs in the Mediterranean, and 
Dictyota dichotome, with a forked ribbon-shaped thallus, which is widely spread in the European seas (Fig. 8), are examples. They are distinguished from the Fucaceae by bearing asexual and sexual organs on distinct individuals. The spores are formed as in the Red Algae in sporangia; usually there are four spores (tetraspores), less commonly eight. They have no cell walls and are unprovided with cilia and must be termed aplanospores (Fig. 296, 1). The oogonia and antheridia in Dictyotu are grouped in sori (Fig. 296 2, 3), and arise from adjacent cortical cells, each of which divides into a stalk cell and the oogonium (or antheridium). The peripheral cells of the antheridial group remain sterile and form a kind of indusium. Each oogonium forms a single rninueleate oosphere, the antheridia
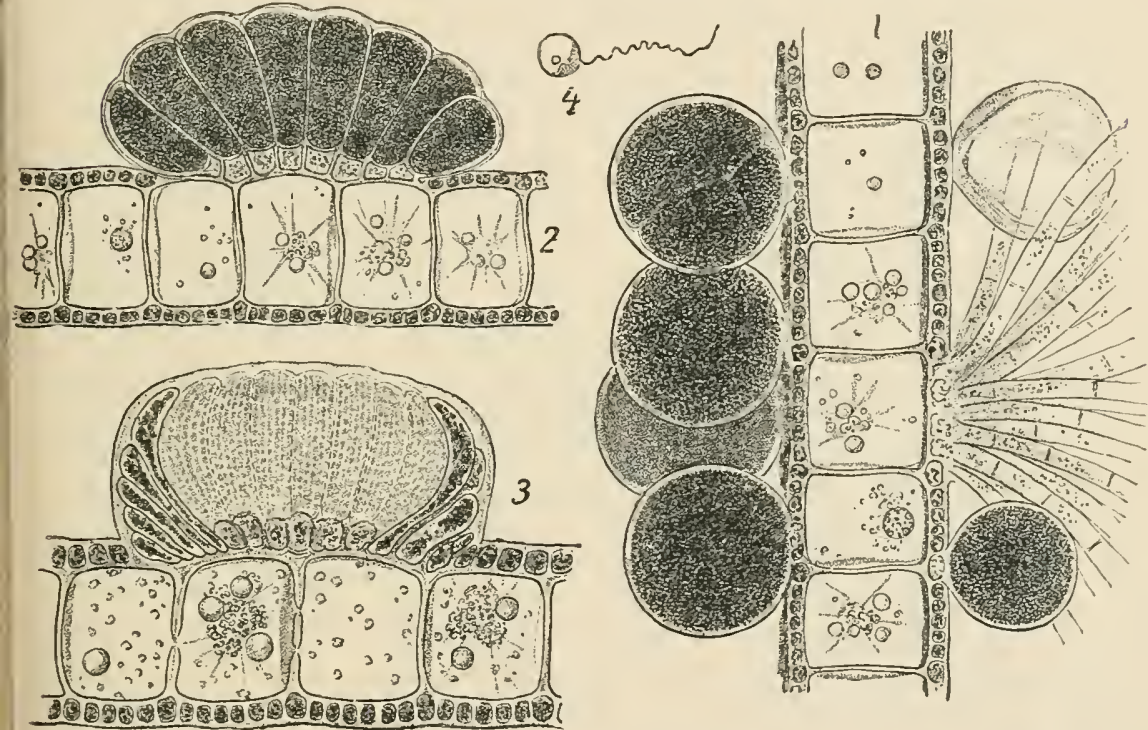

FiG. 206.-Dictyota dichotome. Transverse sections of the thallus. 1, With tetrasporangia; 2, with a group of oogonia; 3, with a group of antheridia (after THureT). 4, Spermatozoid (after Wit.liass). (From Oltmans' Algue.)

become septate, resembling the plurilocular gametangia, and each cell gives rise to a spermatozoid. This, in contrast to the spermatozoids of other Brown Algae, has a single long eilium inserted laterally.

Dictyote is dioeeious. The male and female plants arise from the asexually produced tetraspores; from the fertilised ovum plants which bear tetraspores are developed. In the tetrad division in the sporangia the number of chromosomes beemes rerluced from 32 to 16 , and the reduced number is maintained in all the nuclei of the sexual plants, the donble number being again attained in fertilisation. There is thus (in contrast to the condition of things in the Phaeosporeae) a true alteruation of generations. The sexual generation (gametophyte) and the asexual generation (sporophyte) do not, however, show diflerences in structure as is the case in the Bryophyta and Pteridophyta.

Family 2. Fucaceae $\left.{ }^{51}\right)$.-Asexual reproduetion is wanting in this order, while sexual reproduction is distinetly oogamous. The oogonia and antherilia of Fucus 
are formed in special flask-shaped depressions termed concEPTACIEs, which are crowded together below the surface in the swollen tips of the dichotom-

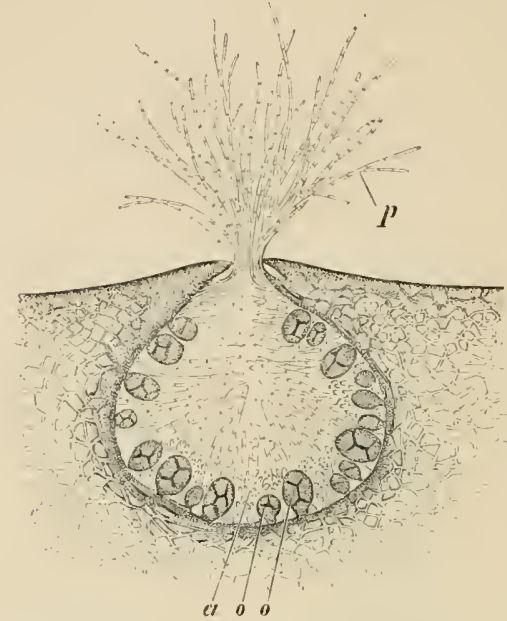

Fis, 297. - Fucus platycarpus. Monoecious coneeptacle with oogonia of different ages $(o)$, ant clusters of antheridia $(a)$; ${ }^{\prime}$, paraplyyses. (After THuREт, $\times$ cirea 25.)

lateral cilia of mequal length and a rer! eye-spot. The oogonia (Figs. 297, o, 298)
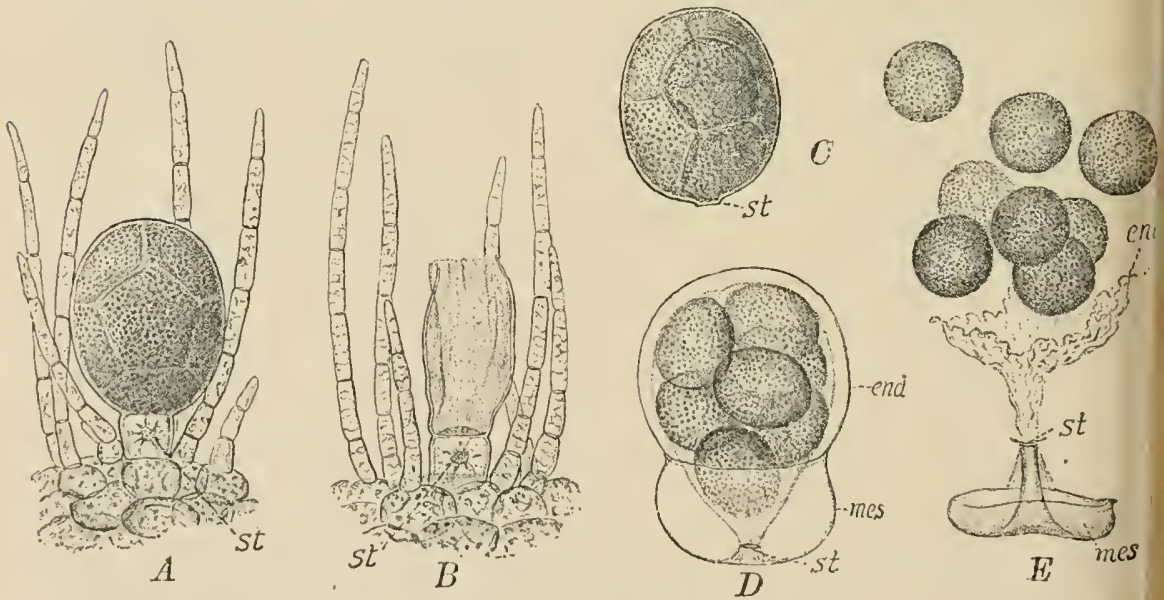

Frr. 29:S, -A, Oogronium, the contents of which have divired into the pight egrg-cells, $I$, Oogonium, from which the contents (C) have bren extrufled. D, E, Liberation of the eiglit eggrecells. st, stalk-erll; mes, millle, and end, immer layers of the oogonial cell wall. (After THuRET. From Otimsaxss' Algue.)

are nearly spherical, and are borne on a short stalk consisting of a single cell. 
They are of a yellowish-brown eolour, and enclose eight spherieal egg-cells which are formed by the division of the oogonium mother cell and are separated by delicate cell walls. The eggs are enclosed within a thin membrane when ejected from the oogonium (Fig. 29S, $B, C$ ). This membranons envelope deliquesees at one end and, turning partly insile out, sets free the eggs $(D, E)$. . The spermatozoids then gather round the eggs in such numbers that by the energy of their movements they often set them in rotation (Fig. 299, 5). After an egg has been

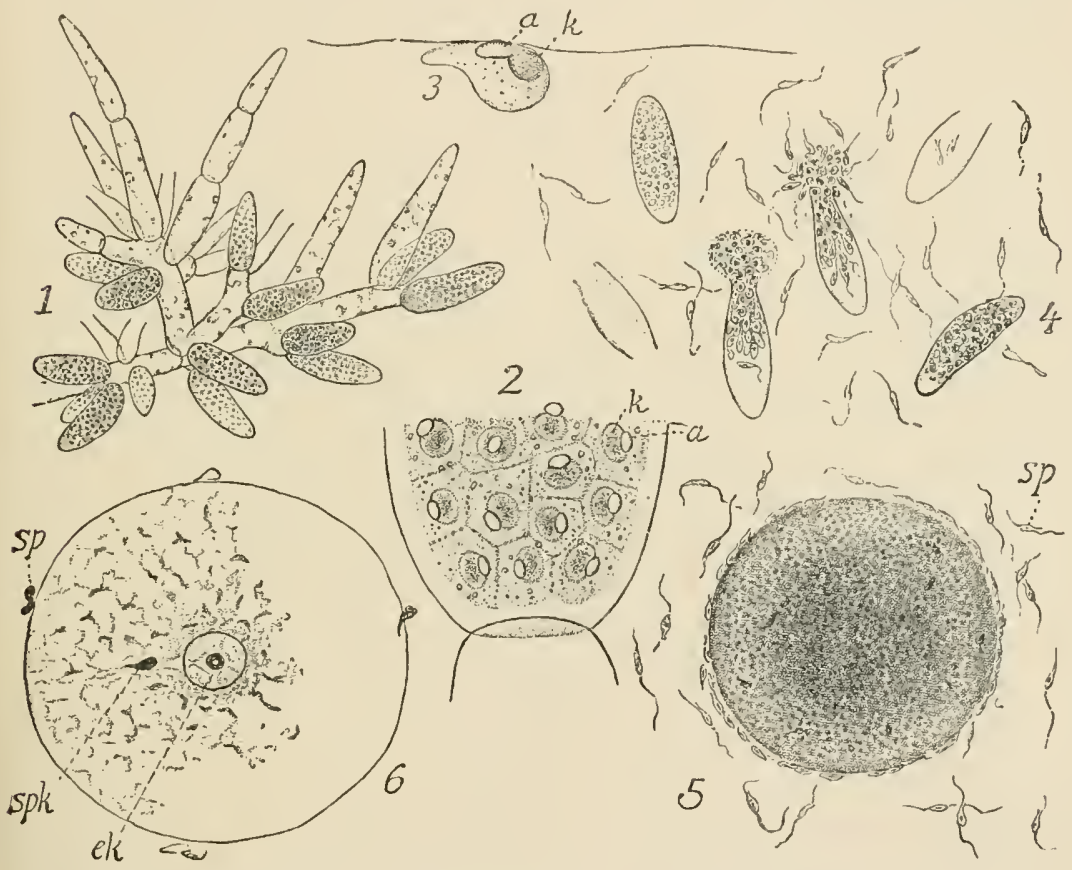

FIt. 299.-Fucus. 1, Group of antlerilia. 2, Purt of an antheridium showing developing sjermatozoids. 3, Spermatozoid: a, ere-spot; $k$, nuclens. \&, Isolated antheridia liberating the spermatozoirls. 5, Oosphere surrounded by spermatozoids. 6, section throngl a fertilised

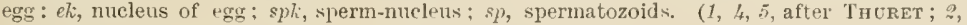
8 , after Guignard; $f$, after Farmer. From Oltuinns' Algae.)

fertilised by the entrance of one of the spermatozoids (Fig. 299, 6) it becomes invested with a eell wall, attaches itself to the substratum, and gives rise by division to a new plant.

In the ease of other Fueaceae which produce four, two, or eren only one egg in their oogonia, the nueleus of each oogonium, according to OLTMAxs, nevertheless first divides into eight daughter nuelei, of whieh, however, only the proper number give rise to eggs capable of undergoing fertilisation. The other rednced eggs, ineapable of fertilisation, degenerate.

Since the Fueaceae have no asexual spore-formation the alternation of generations characteristic of Dictyote is wanting in them. The thallns of Fucus, developed from the fertilised ormm, has diploid unelei. Reduction takes place in the first two divisions within the oogonium and antheridium, so that four haploid 
nuclei result. In the oogonium one further division, and in the antheridium four take place before the sexnal cells are produced. Thus in Fucus, in contrast to Dictyota, only a very short haploid stage can be recognised.

Economic Uses. - The dried stalks of Laminaria digitata and $L$. Cloustoni are used as dilating agents in surgery. Ionrse is obtained from the ash (varec, kelly) of varions Laminariaceae and Fucaceae, and formerly soda was similarly obtained. Many Laminarias are rich in MANATE (e.g. Laminaria saccharina), and are used in its production, and also as an article of food by the Chinese and Japanese.

\section{Class XI}

\section{Rhodophyceae (Red Algae) $\left(^{8,25,52}\right)$}

The Rhodophyceae or Florideae constitute an independent group of the higher Algite, the phylogenetic origin of which is perhaps to

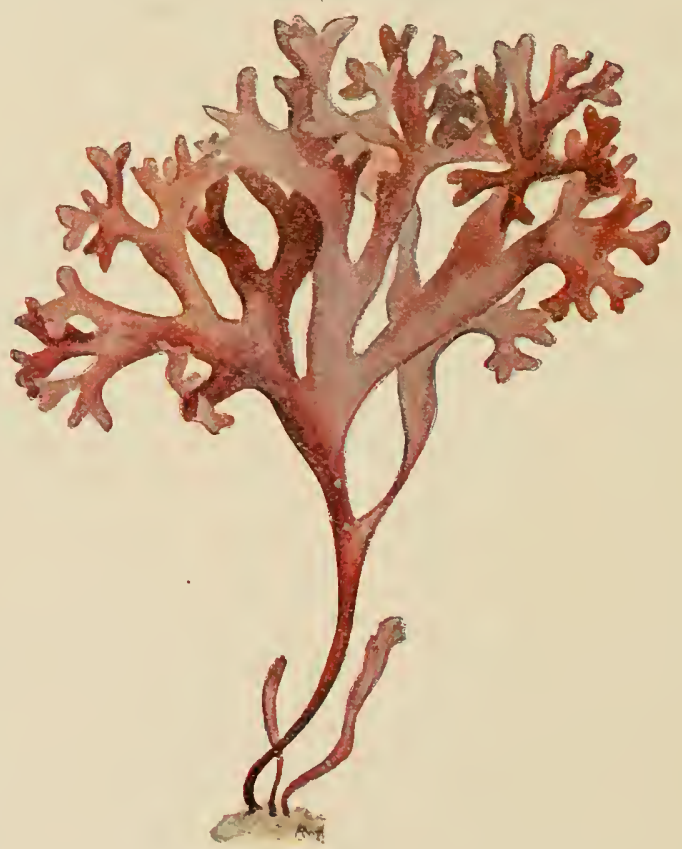

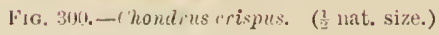

be sought mong the higher Green Algae. They are almost exclusively marine, and specially characterise the lowest algal region on the coasts of all oceans. A few genera (e.g. Brtrachospermum, Lemune grow in fresh-water streams.

The thallus of the Red Algae exhibits a great variety of forms. The simplest forms are represented by branched filaments consist- 
ing of single rows of cells (e.g. Callithammion). In other cases the branched filamentous thallus appears multicellular in cross-section. In many other forms the thallus is flattened and ribbon-like (e.g. Chonlrus crispus, Fig. 300; Gigartina mamillosa, Fig. 301); while in other species it consists of expanded cell surfaces attached to a substratum. All the Florideae are attached at the base by neans of rhizoidal filaments or discoid holdfasts. One of the more complicated forms is Delesseriu sanguinea (IIydrolapathum) (Fig. 9), which occul's on the coasts of the Atlantic. The leaf-like thallus which springs from an attaching disc is providerl with mid ribs and lateral ribs. In the antumn the wing-like expansions of the thallus are lost, but the main ribs persist and give rise to new leaf-like branches in the succeeding spring. The thalli of the Corallinaceae, whieh have the form of branched filaments or of flattened or tuberculate incrustations, are especially eharacterised by their corallike appearance, owing to the large amount of calcium carbonate deposited in their cell walls. The calcareous Florideae are chiefly found on coasts exposed to a strong surf, especially in the tropics.

The Rhodophyceae are usually red or violet; sometimes, however, they have a dark purple or reddish-brown colour. Their chromatophores, which are flat, discoid, oval, or irregular-shaped bodies and closely crowderl to-

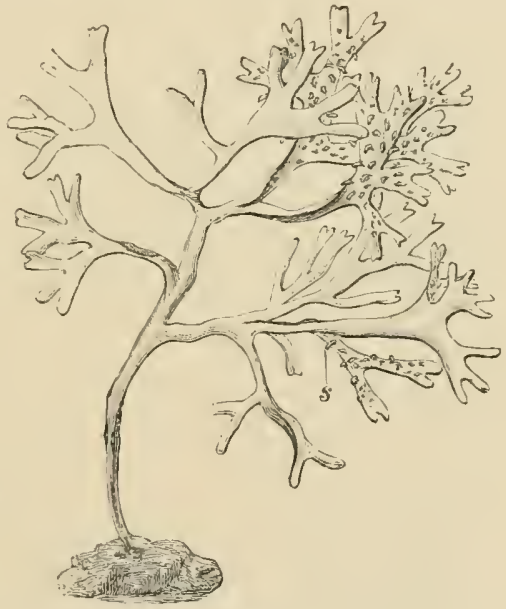

Fir. 3on.-Gigarlina mamilloso. s, Wart-shaped eystrocarps. (3 11at. size.) gether in large numbers in the cells, contain a red pigment, PHYCoERYTHRIs, which completely masks the chlorophyll and appears to be chemically combined with it (p.62). True starch is never formed as a product of assimilation, its place being taken by other substances, very frequently, for example, by Floridean starch, in the form of spherical stratified grains which stain red with iodine. Oil-drops also occur. The cells may contain one or several nuclei.

Reproduction is effected either asexually by means of spores, or sexually by the fertilisation of female organs by male cells.

The asexual spores are non-motile; they have no cilia and are simply naked, splherical cells. They are prolucer, usually, in groul's of four, by the division of a mother cell or sporangium. The sporangia themselves are nearly spherical or oval bodies seated on the thatloid filaments or cubedded in the thalius. The spores escape by a transverse rupture of the wall of the sporangium.- In con- 
sequence of their nsmal formation in fours, the spores of the Florideae are termed TETRASPOAFs (Fig. 302). They are analogous to the swarm-spores of other Algae ;

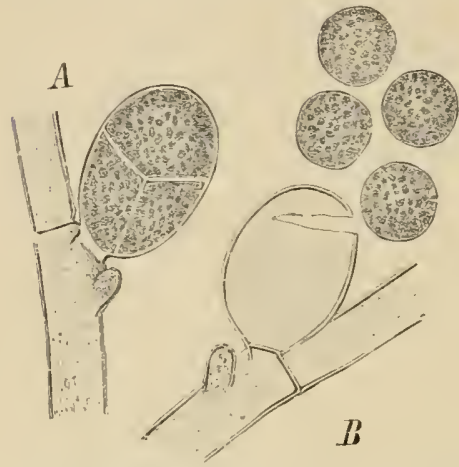

Fir. 322. - Callithamnion rorymbosum. A, Closerl sporangium; $B$, empty sporanginm with four extruderl tetraspores. (After Thiret.) similar spores are found also in the Dictyotaceae among the brown Algae.

In the construction of the sexual organs, particularly the female, the lihodophyceae differ widely from the other Algrae. Batrachospermum moniliforme, a freshwater form, may serve as an example to illustrate the mode of their formation. This Alga possesses a brownish thallus, enreloped in nucilage, and consisting of verticillately branclied filaments. The sexual organs aplear in the autumn on the branching whorls seated on closely crowded. short, radiating branches.

The antheridia, also known as spermatangia (Fig. 303, $A$ ), are produced, usually in prairs, at the ends of the radiating branches. Each antheridium ennsists of a single thin-waljed cell, in which the whole of the protoplasm, as is the rule in all Rhodophyceae, is consumed in the formation of one minucleate spEnMATIrn; according to some anthors

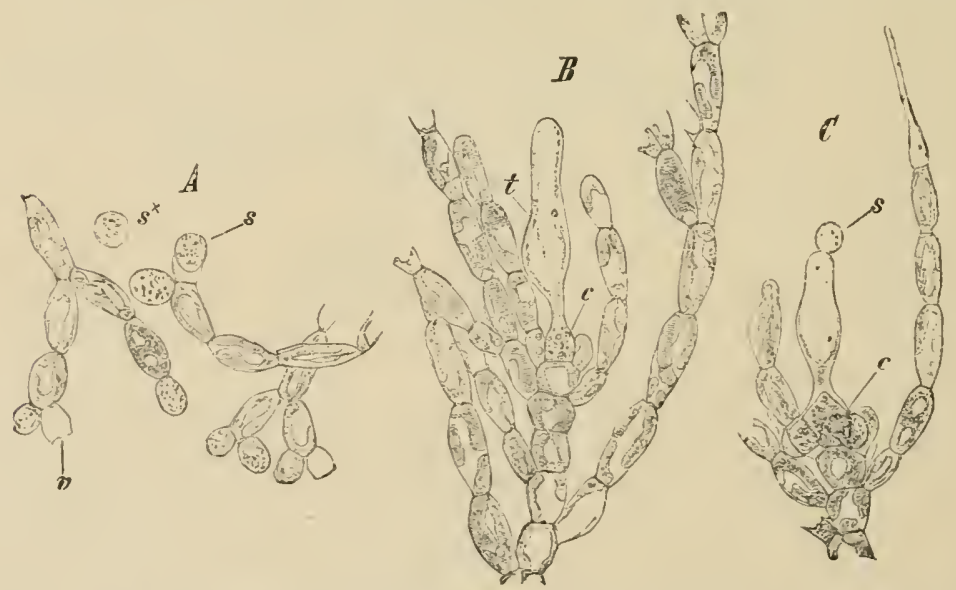

Frs. 303. - Datsachospermun monilifurme. A, Male branch with antheridia, inolated by lressure; $s^{+}$, a slermatimu; $s$, a sprermatinm escaping from au antheridinm; $v$, an empty intlseridium. $b$, female branch with an unfertiliserl carpogonjum; $c$, basal jortion ; $t$, trichogyne of carpoconium, $f$; fenale brauch with fertilised carpogonium; $s$, the spermatimn after the fusion of its contents with the trichongue: c, fertile filauents fereloping from the bastl portion of the earpoxnnium. ( $x+540$.

the nneleus of the spermatiun divicles into two. The spermatia are nearly spherical, and are invested with a thin onter membranc or cell wall. They are non-motile, mulike the ciliater spermatozoirls of the other Algae, and liave therefore receiver a distinctive name. In eonsequenee of their incapacity 
for indejendent movement, they must he earried passively by the water to the female organs, which are sitnated near the antheridia at the ends of other branches. The female organ is called a cinpugovium (Fig. 303, B), and consists of an elongated cell with a basal, flask-sluaped portion (c) prolonged into a filament, termed the Tlichogrex $(t)$. The basal portion contains the nucleus of the egg and the chromatophores, while the trichogyne functions as a receptive organ for the spermatia, one or two of which fuse with it, and the contents, eseaping through the spermatium wall, pass into the earpogonium. The sperm nueleus passes dow the trichogyne and fuses with the nuelens of the egg-cell. The fertihserl egg, which becomes limited from the trichogyne by a wall, does not become converted direetly into an oospore, lut, as a result of fertilisation, numerons branehing sporogenous filaments grow ont from the sides of the ventral portion of the carpogonium. At the same time, by the development of outgrowths from eells at the base of the carpogonium an envelope is formed about the sporogenous filaments. The whole product of fertilisation, inchuding the surrounching envelope, constitutes the fructification, and is termed a CrsToCARP. The profusely-branched sporogenous filaments become swollen at the tips and give rise to spherical, uninucleate spores known as CARPospores, which are eventually set free from the envelope. In the ease of Batrachospermum the carpospores produce a filamentous protonema, the terminal cells of which give rise to asexual unicellular spores. These spores serve only for the multiplieation of the protonema. Uitimately, however, one of the lateral branches of the protonema develops into the sexually differentiated filamentous thallus. The production of spores by the protonema is analogous to the formation of tetraspores by other Florideae.

The formation of the anthericlia $\left({ }^{53}\right)$ as well as the frequently complicated cystocarps and earpospore exhibits various types in the Florideae, but in all eases, aceording to OLTMANss, the carpospores are deseended from the fertilised egg-cell. There are thus two generations distinguishable in the life-history of the Florideae, the sexual (gametophyte), which bears the egg-cells and the spermatia, and the asexual generation (sporophyte), derived from the fertilised egg-cell; the latter generation, which produces the earpospores, remains in comection with the parent plant. This type of alternation of generations is comparable with that found in Mlosses and Ferns. The produetion of tetraspores is an asexual mode of rejroduction of the sexual generation and preedes the formation of the sexulal organs.

Dudiesnayce cocinea, which is found on the warmer eoasts of Furope, has a branched, cylindrical thallus and will serve as an example of the more eomplicated mode of origin of the spore-bearing generation (Fig. 304). The earlogonial branches consist of about seven cells, the terminal one bearing a rery long trichogyne. After fertilisation the earpogonial eell grows out into a filament, which elongates and becomes branched. This filament fuses with a number of speeial eells, eharacterised by their abundant contents, the aUxiLiary celds. The first of these lie in the carlogonial branch itself, the others in adjoining lateral branches. All the nuclei of the sporogenous filament are derived by division from that of the fertilised egg-cell. The snccessive fusions with auxiliary cells do not involve nuclear fusions, but simply serve to nourish the sporogenous filament. A second and third sporogenons filament may arise from the earpogonial eell. Two ontgrowths now arise from each of the swollen eells of the sporogenous filament whieh fused with auxiliary eells. By further division of these ontgrow ths the splherieal masses of carpospores, which subsequeutly become free, are derived (Fig. 304, E). 
Harveyclla mirabitis ( $\left.{ }^{54}\right)$, one of the Florideae oceurring in the North Sea, is of

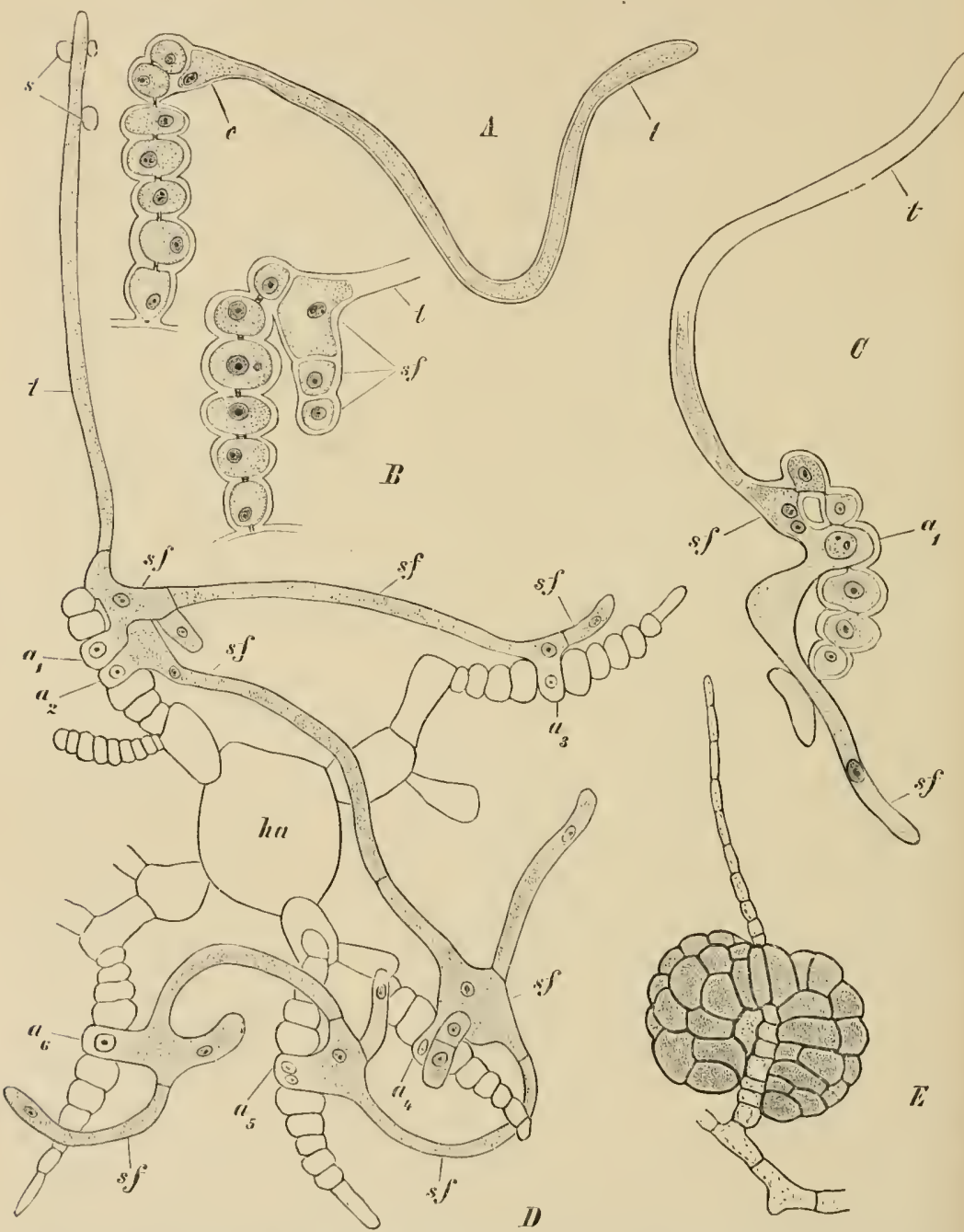

Fur. 304.-Dulresnaya rorcinea. A, Caspogonial branch ; c, carpogonium ; $t$, trichogyne. $\quad B$, (ar ringronium after fertilisation. grown out into the sporogenous tilament (sf). $C$, fusion of the? s]orogenons filament with the first anxiliary cell $\left({ }^{\prime} t_{1}\right)$. D, branching of the filament and fusion with six aluxiliary cells $\left(r_{1}-{ }^{-(1} f_{6}\right)$; the cells $\alpha_{3}-\alpha_{6}$ are borne on branches originating from the axis het (diagrammatic). Es, Ripe elnster of carpospores originating from one brancl. ( $f-D$, after (Oltmanss; $k$, after Bornet. A.C, $\times$ about $500 ; D, \times 250 ; E, 300$. )

special interest. It grows as a parasite on another red seaweed, Rhorlomela subfusen, on which it appears in the form of a sinall white cushion-like growth. 
As a result of its parasitic mode of life the formation of chromatophores has been entirely suppressed, and thus this plant behaves like a true Fungus.

Economic Uses.-Gigartina mamillose (Fig. 301), with peg-like cystocarps 2-5 mm. in length, and Chondrus crispres (Fig. 300), with oval cystocarps about $2 \mathrm{~mm}$. long, sunk in the thallus, tetraspores in groups on the terminal segments of the thallus. Both forms occur in the North Sea as purplish-red or purplislybrown Algae; when dried they have a light yellow colour, and furnish the official CAlragheEs, "Irish Moss," used in the preparation of jelly. AGAli-Agali, which is used for a similar purpose, is obtained from various Florideae ; Sphacrococcus (Gracilaria) lichenoides supplies the Agar of Ceylou (also enlled fiucus amylaceus), Euchcuma spinosum, the Agar of Java and Madagascar. Species of Gelidium the Agar of Japan.

\section{CLASS XII}

\section{Phycomycetes $(55,56,57)$}

In the nature both of their thallus and sexual organs the Phyconycetes exhibit a close connection with the Siphoneae. The phylogenetic origin of most of the Phycomycetes must be sought in this group, thongh certain forms point to a relationship with other Green Algae (eg. Basidiobolus with the Conjugatae). They can only for the present be regarded as a definite class, pending their scparation into several series derived from distinct classes of Algae.

The thallus consists of extensively branched tubular threads in which, as is the case in Vaucheria, transverse septa only form in comnection with the reproductive organs. The continuous protoplasmic mass contains numbers of very small nuclei, but chromatophores are entirely wanting in these colourless organisms. The whole thallus of a Fungus is spoken of as the mycelium, the individual filaments as hyphae. In the Phycomycetes the hyphae are non-septate, their division into distinct cells only taking place in a few cases. The plants are either saprophytes occurring on the putrefying remains of animals or plants in water or on decaying organic substances exposed to air, or they live parasitically in the tissues of higher plants or on insects.

Asexual reproduction is effected by means of spores. These are formed in the majority of the gencra within sporangia, the protoplasm of which splits into the numerous spores. The latter escape in the genera which live in water as ciliated swarm-spores (Fig. 306); in the forms which are exposed to the air the spores are enclosed by a cell wall (Fig. 313). The conidia, which are sometimes found together with sporangia, in other cases alone, are also adapted for clispersal in air. They arise by a process of budding and abstriction from the ends of certain hyphae which are usually raised above the substratum as special conidiophores.

The sexual organs of the Phycomycetes are in many ways 
peculiar, and the two groups of the Oomycetes and the Zygomycetes are distinguished according to their nature, In the Oomycetes, which stand nearer to the Green Algae, oogonia and antheridia are found; the contents of the latter enter the oogonium by means of a tubular outgrowth, and after fertilisation oospores are formed. In Monoblepharis alone are free spermatozoids found. The sexual organs of the Zygomycetes are alike, and on conjugation a zygospore is produced. They are usually multinucleate and thus are morphologically comparable to a whole gametangium of an isogamous Alga.

Multinucleate gametangia, oogonia, and antheridia, which fuse directly with one another, without the separation and escape of the individual gametes, are generally termed CoExocametes.

\section{Order 1. Oomycetes}

1. Only in the small family of the Monoblepharideae $\left({ }^{58}\right)$ are free ciliated spermatozoids liberited from the antheridia. In the other Oomycetes the multinucleate contents of the antheridium do not divide into separate spermatozoids,
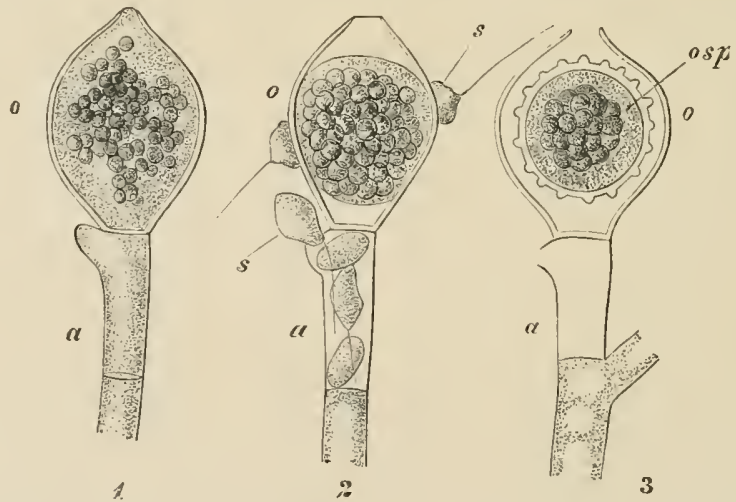

Frc. 305. - Ionnble pharis sphaerice. End of filaneut with terminal oogonium (v) and an antheridium (11): 1 , before the formation of the egg-cells and spermatozoids; 2, sjermatozoids (s) escaping and anjroaching the opening of tle oogonium ; $3,0 \mathrm{sp}$, ripe oospore, and an empty antheridium. (Aiter Corne, $\times$ son.)

but are directly introduced into the egg-cell by means of an ontgrowth of the antlerirlium.

The sprecies of Honoblcpharis live in water upon deeaying remains of plants. Asexual reproduction is effected by means of swarm-spores, formed in large numbers in sporangia. The oogonium, which is usually terminal, contains only a single egg-cell (Fig. 305). The antherilia, which resemble the sporangia, liberate a number of uniciliate spermatozoids. On a spermatozoid reaching the egroech through an oprening in the tip of the oogonimm an oosporc is formed. A spinous cell wall forms aronurl the oospore.

2. The Saprolegniaceae $\left({ }^{59}\right)$, which comect on to the preceding fanily, live like them saprophytically on the surfacc of decaying plants and insects and even on 
living fishes. Asexual propagation is oflected by elub-shaped sporangia (Fig. 306) which produce numerous bieiliate swarm-sjores. The sexual organs develop on oller branehes of the myeelium (Fig. $307, a$ ). The oogonia give rise to a larger (as many as 50) or smaller number of egg-cells, rarely only to a single one. At first the oogonium contains numerous nuclei, most of which, however, degenerate; the remaining nuelei divide once mitotieally into rlanghter nuelei, of whieh some again degenerate, while round the re. maining nuclei the oospheres become rlelimited. The egg-eells are always uninneleate. The tubular antheridia, with a number of nuclei that undergoone mitotic division, aplly themselves to the oogonia and seml fertilising tubes to the eggreells. Onemale nucleus enters the egg-eell and fuses with its nueleus (Fig. 308). The oospore

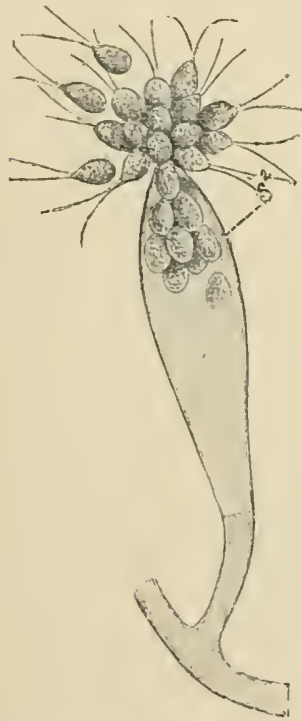

Fic, 30t, - Saprolegnia wixta. The biciliate zoospores, $s^{2}$, are escaping from the sporangium.

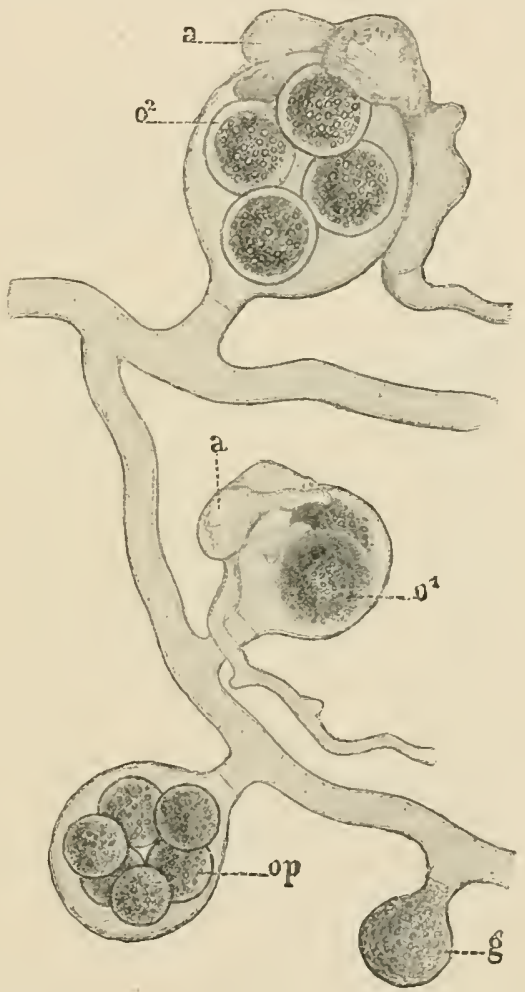

Firi. 307.-Saprolegnia mixta. Hyplae bearing the sexnal organs; $a$, antheridium whieh has sent a fertilisation tube into the oogonium; ol, egg-cell ; $r^{2}$, oospore enclosed in a cell wall ; op, parthogenetic oospores; $y$, young oogonium. (After G. Kilebs.)

after fertilisation aequires a thick wall. In some forms belonging to this family and to the Peronosporeae the formation of antheridia is oecasionally or eonstantly suppressed; the oospores develop parthenogenetieally without being fertilised (Fig. 307).

3. The Chytridiaceae $\left({ }^{60}\right)$ are mieroscopically small Fungi parasitic on aquatic or land plants and in some cases on animals. The non-septate myeelium is feebly reveloped, and is frequently redueed to a single sae-shaped eell inhabiting a cell of the host. Asexual multiplication is effeeted by means of swarm-spores provided with one or two eilia. In the simplest forms the entire cell becomes eonverted 
into the sporanginm. Orpidium Brassicae (Fig. 309), which is parasitic in the tissues of the base of the stem of young caljbage plants and brings about their death, may be taken as an example. The sporangia in this case have a long neck from which the swarm-spores escape. Thick-walled sporangia which undergo a resting period are also frequently found in the Cliytridiaceae.

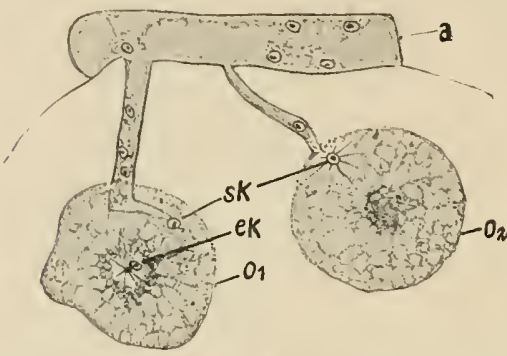

Fir. 3ns.-Achlya polyandre. The fertilisation of two egg-cells, o, of an oogonium by two tubes from the antherifium $a ; c k$, nncleus of the eggcell; sli, sperm-nucleus; in $O_{2}$ the section has not prassed through the egg-nuelens. (After 'Trow.)

Sexual reproduction is only found in some of the genera, in the form of fusion of an antheridimn with an oogonium and the production of an oospore. The systematic position of the Chytridiaceae among the Phycomycetes is still doubtful; the simplest forms appear to have origrinated in part from Flagellatae and partly from Protococcaceae.

4. The Peronosporeae $\left({ }^{61}\right)$ arc parasitic Fungi whose mycelium penetrates the tissues of the higher plants, and is frequently the cause of death. In damp climates certain species occasion epiclenic discases in cultivated plants. Thus, the mycelium of Phytophthora infestans, the fungus which causes the Potato disease, lives in the intercellular spaces of the leaves and tubers of the Potato plant, and by penetrating the cells with its short haustoria leads to the discoloration and death of the foliage and tubers. Sexual reproductive organs have not as yet been observed in this species. Asexual, oval sporangia are formed on long branching sporangiophores which grow ont of the stomata, particularly from those on the mider side of the leaves (Fig. 310), ancl appear to the naked eye as a white mould. The sporangia, at first terminal, are cut off by transverse walls from the ends of the branches of the sporangiophore, by the subsequent growth of which they become pushed to one side, and so appear to be inserted laterally. Before any division of their contents has taken place, the sprorangia (B) fall off and are clisseminated by the wind; in

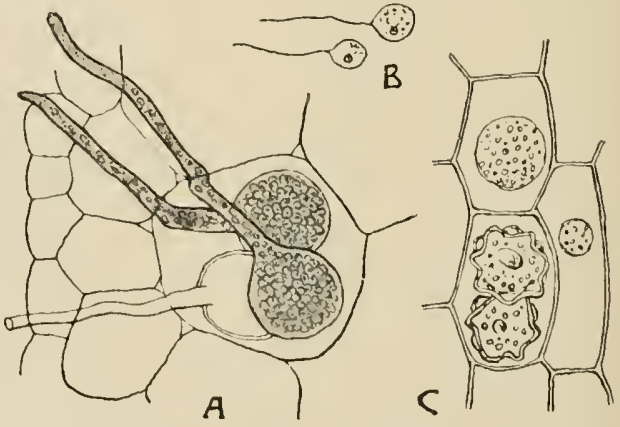

Fici, 309.-Olpidium Brassicae. A, Three zoosporangia, the contents of one of which has eseaped $(\times 16$ ill). B, Zoospores ( $\times$ 5201). (', Resting; sporangia ( $\times$ 520). (After WORONIN.)

this way the epidemic becomes widespread. The development of swarm-spores in sporangia is effected only in water, and is eonsequently possible only in wet weather. In this process the contents of the sporangimm divide into several biciliate swarm-spores $(C, D)$. Each of these spores after escaping from the sporangim gives rise to a mycelium, which penetrates the tissnes of a leaf. The sporangium may also germinate directly withont undergoing division and 
forming swarm-spores. $\Lambda$ similar transformation of sporangia into coniclia is also found in other Peronosporcae as a result of thcir transition from an aquatic to a terrestrial mode of life.

Plasmopara viticola, an extremely clestructive parasite, also froduces copiously branched sporangiophores and occasions the "False Nildew" of the leaves and fruit of the Grape-vine. Albugo candida (=Cystopus condidus), another very common species, occurs on Cruciferae, in particular on Cepselle burse pastoris, causing white swellings on the stems. In this speeies the sporangia are formed in long chains on the branches of the mycelium nuder the epidermis of the host plant, and produce in water numerons swarm-spores.

The sexnal organs of the Peronosporeae resemble those of the genus Vucheria (Fig. 288). They arise within the host plant-the oogonia as spherical swellings of the ends of certain hyphae, the antheridia as tube-like outgrowths arising as a rule just below the oogonia. Both are cut off by transverse walls and are multinucleate (Fig. 311). The several species exhibit interesting differences as regards the nuclear changes. In Peronospora parasitica, Albugo candielce, and $A$. Lepigoni, Pythium, Plasmogare, and Selerospore, a single large central egg-cell or oosphere becomes differentiated in the protoplasm of the oogonium; this contains a single inucleus in a central position, while the remaining nuelei pass into the peripheral layer of protoplasm (periplasm). The antheridium now seuds a process into the oogonium, which at its apex opens into the oosphere and allows a single male nucleus to prass into the latter (Fig. $311,2)$. The oosphere then becomes surrounded with a cell wall (Fig. $311,3)$, and nuclear fusion takes

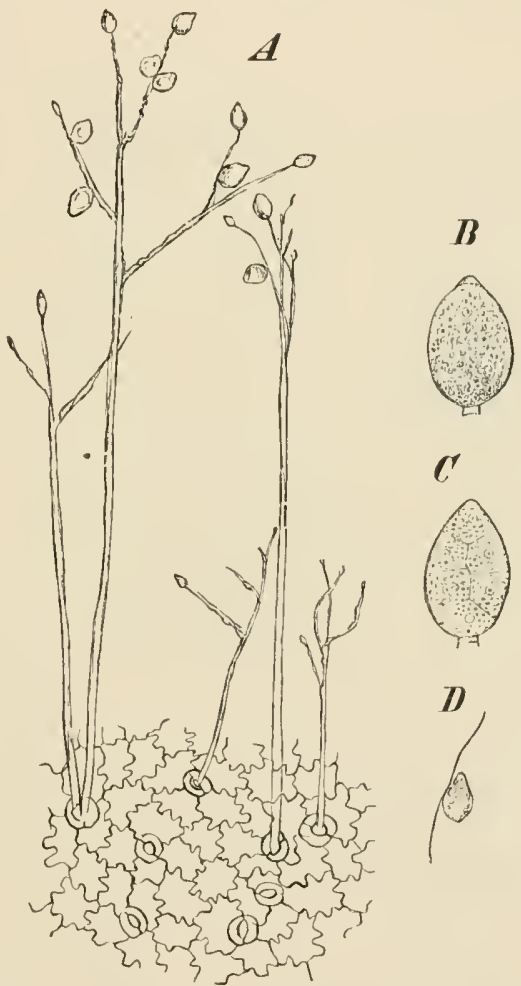

Fre. 310.-A, Surface view of the epidermis of a potato leaf, with sporangiophores of I'hytnphthore infestans projecting from the stomata $(\times 90) ; n$, a ripe sporangium ; $C$, another in process of division; $D$, a swarm-spore. $(B \cdot D \times 540$. place, while the periplasm is utilised in forming the outer membrane of the slore (episporium). In Peronospora parasitica the rije oospore has a single nucleus, in Albugo it becomes multinucleate as a result of nuclear division. In Albugo Lliti and $A$. portulacae there is also a central oosphere surrounded by periplasm, but the oosphere contains numerous nuclei, which fuse in pairs with a number of male nuclei entering from the antherilium. A multiuncleate oospore thus arises from the componnd egr-cell. The behaviour of these two species can be regarded as primitive, the nuinucleate oospheres of the first-named forms having been derived 
from the multinncleate condition. Albugo trugopoyonis occupies an intermediate position in that its oosjhere is at first multinucleate, hut later contains only one female nuelens, the others having degenerated. The superthons nuclei in the oogonia and antheridia may be regarded as the nnclei of gametes which have become functionless, and are comparable with the superfluous egg-nuclei of certain Fucaceac. The oospores either produce a mycelium directly or give rise to swarnı-spores.

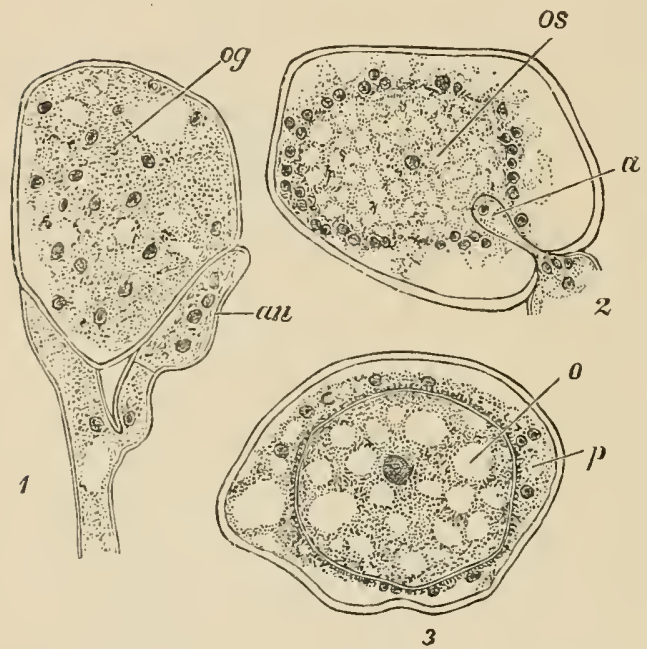

F1: 311.-Fertilisation of the Peronosporeae. 1, Peronospora parasiticu. Young multinucleate oogonium $(\circ g)$ and antlerjlium (in). Q Albugo candide. Ongonium with the central minucleate ouspliere and the fertilising tube $(a)$ of the antheridium which introduces the male nucleus. S. The same. Fertilisecl egg-cell (o) surrounded by the periplasm ( $p$ ). (After W.AtER. $\times$ ti6u.

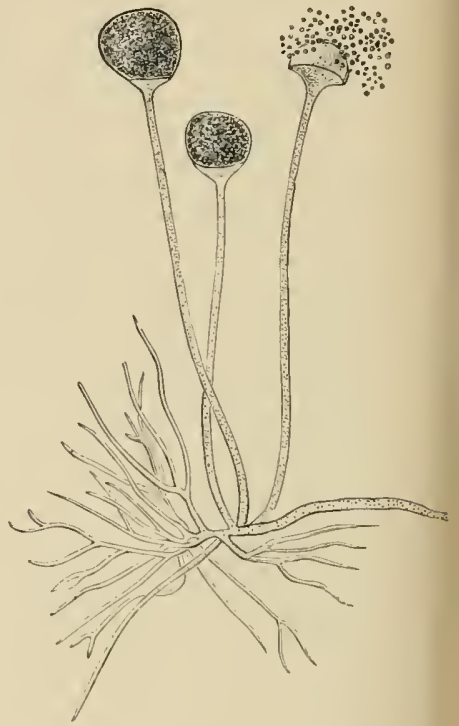

Fig. 312.-Lihizopus nigrieans (= Muror stolonifer). Portion of the nycelium with three sporangia ; that to the right is shedding its spores and slows the persistent hemispherical columella. ( $\times$ 38.)

\section{Order 2. Zygomycetes}

1. The Mucorineae ${ }^{\left({ }^{62}\right)}$ comprise a number of the most eommon Monld Fungi. They are terrestrial and saprophytic, and are fond shiefly on decaying vegetable and animal substances. Asexnal reproduction is effected by non-motile, wallerl spores, which either have the form of conidia or arise endogenonsly in sporangia. Sexual reproduction consists in the formation of zygospores, as a result of the conjugation of two equivalent coenogametes.

One of the most widely distribnted species is Mucor Hucelo, frequently fonul forming white fur-like growths of mould on damp brear, preserved fruits, dung, ete. Mucor stolmifer (= Rhizopus nigricans), with a brown mycelium, oceurs on similar substrati. The spherical sporangia are horne on the end of thick, erect branehes of the mycelium (Fig. 312). From the aprex of each sporangiophore a single spherical sporangium is ent ofl by a transverse wall, which protrucles into the cavity of the sjoringium and forms a columelta (Fig. 313, 1, e). The contents of the sloranginn becone divided by repeated cleavages into numerous spores. 
These escape by the swelling of a substance which lies between the spores and the bursting of the sporangial wall. In Pilobolus, which oceurs commonly on dung, the sporangium is forcibly cast off from the turgid sporangiophore which bursts at the columella. According to HARPER the spores of Pilubolus are binucleate, while those of Sporadinia (Fig. 314) are multimucleate.
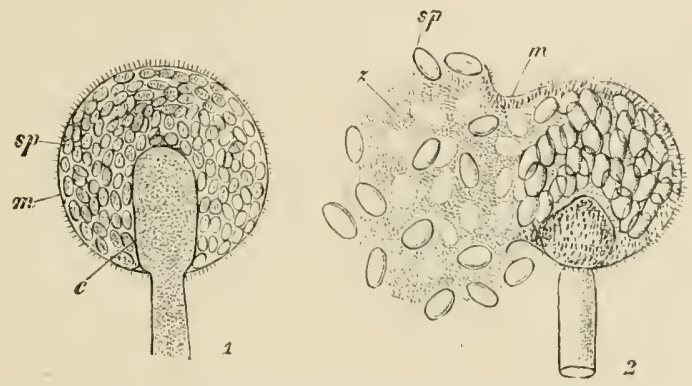

Fur, 313.-1, Mucor Muredo. A sporangium in optical longitudinal section ; $r$, (olumella ; $m$, wall of sporangium; sp. spores. 2, Mucor mucilagineus. A sporangium sheduling its spores; the wall $(m)$ is ruptured, and the muciaginous substance between the spores $(z)$ is greatly swollen. (After BRefeld, $1 \times 225,2 \times 300$, from v. TAYel, Pilze.)

Under certain conditions, instead of asexual sporangia, organs of sexual reproduction are produced. The hyphae of the mycelium then give rise to lateral, club. shaped branches. When the tips of two such branches come into contact, a conjugating cell or coenogamete is cut off from each by a transverse wall (Fig. 315). The two gametes thereupon coalesce, and fuse into a zYGOSPORE, the outer wall of which is covered with warty protuberances. As regards the behaviour of the nuclei in the process of conjugation, only some facts for sporodinia are known. According to Lendener, a larger sexnal nucleus is differentiated in each of the multinneleate gametes. The two sexual muclei fuse in the centre of the zygospore, while the numer ons small peripheral nnelei take no part in the process. They still divide, however, and probably play a part in the formation of the wall of the zygospore. After a period of rest the zygospore germinates, developing a germtube, which may at once bear a sporangium (Fig. 315, 5).

BLAKESLEE's ( $\left.{ }^{63}\right)$ demonstration of the dioecions (heterothallic) nature of the

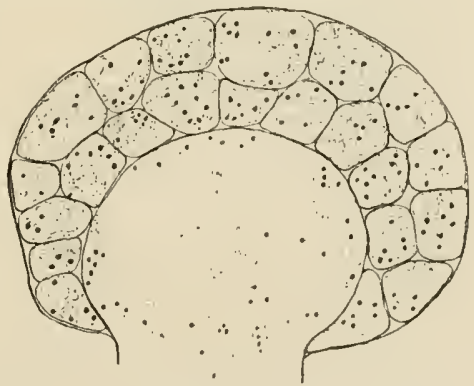

Fu. 314.-, Spmodinia grandis. Median section of a ripe sprorangium. The spores are multinucleate. (After H.IRPER, $\times 4.25$.)

mycelium of most Mucorineae, for example Wucor Mucedo and lihizoms niyricens, is of great interest. The formation of zygospores only takes place when male and female mycelia come in contact. In other Incorineae (homothallic, e.g. Sporodinia grandis) the two conjugating gametes may arise on the same mycelium. Exception. ally in heterothallic species, snch as l'hycomyces nitens, a homothallic mycelinm may appear. This arises from a zycosprore, the germ-tube of which has not, as is the rule, formed a sporangium at once. 
Within the group of the Zygomyeetes a reduction of sexnality can be seen. Thus, in the case of certain Mucorineae, although the conjugating hyphae meet in pairs, no fusion takes place, and their terminal eells become converted directly into spores, which are termed Azrguspores. In other forms again, hyphae producing azygospores are developed, bnt remain solitary, and do not, as in the preceding ease, come into eontact with similar hyphae. There are also many

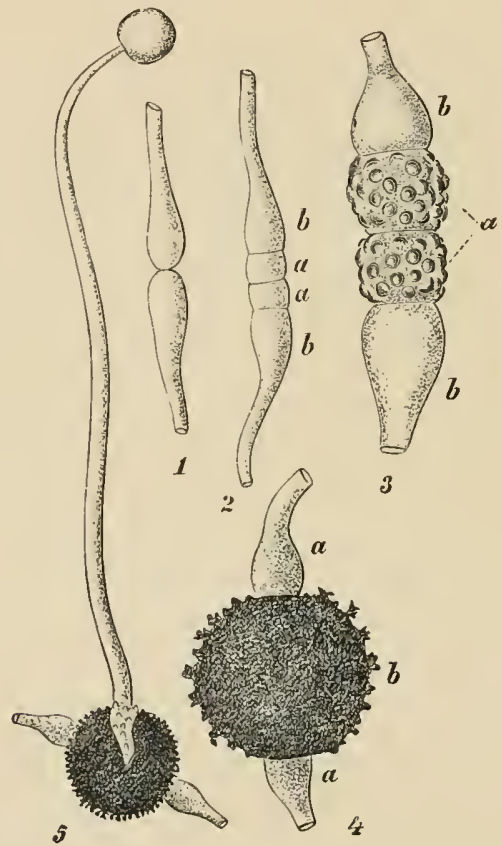

Fic. 315.-Mucor Mucedo. Different stages in the formation and germination of the zygospore. 1, Two conjugating branches in contact; :, sejtation of the conjugating cells $(a)$ from the suspensors $(b)$; 3 , more advanced stage, the conjugating cells $(\alpha)$ are still distinct from one another: the warty thickenings of their walls have commenced to form; 4 , ripe zygospore (II) between the suspensor's (u); 5 , germinating zygospore with a germ-tube bearing a sporangium. (After BREFELD, $14 \times 225,5 \times$ cirea tio, from v. TAvei, I'ilzo.) speeies in which the formation of zygospores is infrequent.

Both the size and number of spores produeed in the sporangia of Hucor Drucelo are subject to variation. The sporangia of the genus Thamnidium are, on the other hand, regularly dimorphic, and a large sporangium containing many sprores is formed at the end of the main axis of the sporangiophore, while numerons small sporangia, having but few

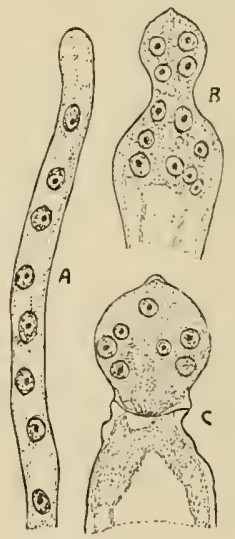

Fic. 316.-Empusa muscae. A, Hypha from the body of a fly, $B$, Young conidiophore arising from the mycelium and projecting from the body of the insect. $C$, Formation of the conirlium into which the numerous nuclei have passerl from the condioflhore. (After OLive, $\times 549$.)

spores (sporangioles), are produced by its verticillately branehing lateral axes. The sporangia my at times develop only a single spore, as the result of certain eonditions of food-suplly, and in this way assume the character of conidia. This dimorphism is cven more complete in the tropical genus Choanephora. In this case, in addition to large sporangia, conidia are produced on special conidiophores. There are, finally, Zygomycetes (e.g. Chactocladium) whose only 
asexual spores are conidia. In this one group, therefore, all transitional forms, from many-spored sporangia to unicellular conidia, are represented.

2. The Entomophthorineae $\left({ }^{64}\right)$ is a small group of Fungi which mostly live parasitically in the bodies of insects and caterpillars. The multinucleate mycelinm remains non-septate or later becomes divided intocells. Asexnal multiplication is effected by means of conidia which contain one or numerous nuclei. These arise siugly at the ends of branches of the mycelinm and when ripe are forcibiy abjected. Sexual reproduction is by means of zygospores; in place of which azygospores frequently arise.

The best-known example is Empuse muscue (Fig. 316), which is parasitic on house-flies. The conidia, which are multinucleate, form a white halo around the body of the dead fly which has been killed by the fungus. This is particularly well seen when the dead fly is adhering to the glass of a window.

3. Basidiobolaceae $\left.{ }^{65}\right)$. - Basidiobolus ranarum, a saprophytic Fungus growing on the excrement of Frogs, must be separated from the preceding gronp. Each of the cells of its septate mycelium contains one large nucleus. The conidia, which arise singly on the ends of the conidiophores and are abjected when ripe, are minucleate. The mode of origin of the zygospores is peculiar. Two adjoining cells conjugate after they have put out beak-shaped processes which are cut off as transitory cells. In the zygospore the two sexual nuclei give rise to four, of which two disorganise while the other two fuse. Both in this procedure and in the muclear structure there are evident resemblances to the Conjugatae (Spirogyra).

\section{Class XIII}

\section{Eumycetes $(55,56)$}

When the Phycomycetes are excluded there remain two great groups of Fungi, the Ascomyeetes and the Basidiomycetes, regarding the classification and phylogeny of which there is still much uncertainty. The attempt has been made to derive them from the Phycomycetes. Not only is the construction of the thallus against this, but the strueture of the sexual organs and the development of the fruit in the Ascomycetes indicate on the other hand a remarkable relationship with the Red Algae. The Uredincae or Rusts, one of the simplest orders of Basidiomyeetes, appear to connect the latter group with the Ascomycetes.

The saprophytic or parasitic thallus of the Eumycetes is, like that of the Phycomycetes, composed of fine, richly branched filaments or hyphae which together form the mycelium. The hyphae are, however, in this case septate, consisting of rows of cells. The cellmembrane, which contains ehitin, is usually thin. In the colourless protoplasm there are usually numerous minute nuelei (Fig. 61), while in other cases each cell has a pair of nuclei or only a single nucleus. Chromatophores are wanting and true starch is never formed; the place of the latter is taken by glyeogen, often in considerable quantity, and by fat globules. The hyphae of a mycelium are, as a rule, either isolated or only loosely interwoven; they spread 
throngh the substratum in all directions in their search for organic nourishment. In many of the higher Fungi, however, the profusely branching hyphae form compact masses of tissue. Where the filaments in such cases are in intimate contact and divided into short cells, an apparently parenchymatons tissue or PSEUDO-PARENCHYMA is produced. Such compact masses of hyphal tissue are formed by some species of Fungi when their mycelia, in passing into a vegetative resting stage, become converted into SCLEROTIA, tuberons or strandlike, firm, psendo-parenchymatous bodies, which germinate under certain conditions (Fig. 110). In the fructifications the byphae are also nearly always aggregated into a more or less compact tissue (Fig. 109).

The two sub-classes are distinguished by their respective methods of asexual spore-formation. The ASCUs is characteristic of all Ascomycetes; it is a club-shaped sporangium within which a definite number of spores (usually 8 ) is formed in a peculiar way by free cell formation (Fig. 317). The Basidiomycetes have in place of the ascus a BASIDIUM of varying shape. It may either be four-celled or a unicellular tubular structure from which the spores are abstricted by a process of budding in definite numbers, usually four (Figs. 333, 334, $343)$.

\section{Sub-Class I.-Ascomycetes $(55,56,66,67)$}

The Ascomycetes in their typical forms possess sexual organs, the oogonia, which here go by the name of ascogonia or, as in the Red Algae, of carpogonia, and antheridia. The sexual organs have been accurately investigated in relatively few forms; a number of distinct types are found.

1. In the Laboulbeniaceae (Fig. 332) the carpogonium with its trichogyne, and the antheridia which produce spermatia, show a striking correspondence with the structures of the same name in the Red Algae.

2. The Ascomycetes which enter into the composition of Lichens (Figs. 360, 361) approach most closely the preceding group. The carpogonium is here a spirally wound filament of cells terminating in a trichogyne. The spermatia are formed in special flask-shaped depressions of the thallus, the spermogonia. Similar reproductive orgauls occur in some Ascomycetes (e.g. Polystigma) which do not form parts of Lichens.

3. Pyronemu (72) (Fig. 326) and related genera, Ascodesmis (= Bioudiera Cluatssen) (72), Monascus (is), Aspergillus $\left({ }^{70}\right)$, exhibit a distinct type. A multinucleate carpogonium which is provicled with a trichogyne is fertiliserl by a multinncleate antheridium, the two structures being thus coenogametes. Lathea $\left({ }^{73}\right)$, the carpogonium 
of which bears, however, a multicellular trichogyne, may be placed here.

4. In the Erysipheae (Fig. 318) a uninucleate antheridium unites directly with a unimucleate oogonium.

It remains for future research to determine whether these types are to be derived from a single one or whether they indieate a polyphyletic origin for the Ascomycetes.

In many genera the sexual organs are present, but no fertilisation of the carpogonium takes place, and in some groups of Ascomycetes they are more or less completely reduced.

The carpogonium does not give rise to a resting oospore, but remains in comnection with the parent plant; from it ascogenous hyphae or eell-filaments grow out, branch, and ultimately form at the ends of branches the asci. The ascogenous hyphae and asci proceeding from a carpogonium, or in some cases from a group of carpogonia, form a fruit-body or fructification. In the formation of this, vegetative hyphae, derived from the mycelium of the parent plant, and sharply distinct from the ascogenous hyphae, take part. The sterile hyphae grow between and invest the aseogenous filaments. The mycelium which produces the sexual organs represents the sexual generation (gametophyte); the system of hyphae proceeding from the carpogonium and ending in the asci corresponds to the asexual generation (sporophyte). In this type of alternation of generations there is a remarkable agreement between the Ascomycetes and the Red Algae.

Within or on the surface of the fructifications of some groups of the Ascomycetes the asei stand parallel to one another in a layer ealled the hymenium, and between them as a rule are paraphyses borne on the sterile system of hyphae of the frutification.

In some orders of Ascomycetes the sexulal organs and the fructifications are completely wanting, probably owing to reduction. The asei then arise directly from the myceliun.

The Ascus ( ${ }^{67}$ ) originates from a single cell ; this to start with contains two nuclei, derived from the precerling fertilisation, which fuse, and the resulting nucleus by repeated division gives rise to eight nuclei. By a process of free cell-formation the spores become limited by cell walls in the way shown in Fig. 97 (Figs. 317,327 ). In contrast to the formation of spores in the sporangia of Phyeomyeetes the cytoplasm of the ascus is not completely used up in the formation of the ascospores. The spores isually form a longitudinal row, embedded in the remaining epiplasm, which contains glycogen, and are ultimately ejected from the ruptured apex of the ascus by the swelling of this. The spores are adapted for dispersion in the air.

The behaviour of the sexual nuclei in and after fertilisation of the carpogonium is only accurately known in a few cases. For some Ascomyectes (Pyromeme and Monascus) it has recently been shown that the sexual nuclei do not fuse in the carpogonium, but lay themselves side by side. In the ascogenous hyphae the 
pairs of muclei divide conjugately, and only in the young ascus do two nuclei, the

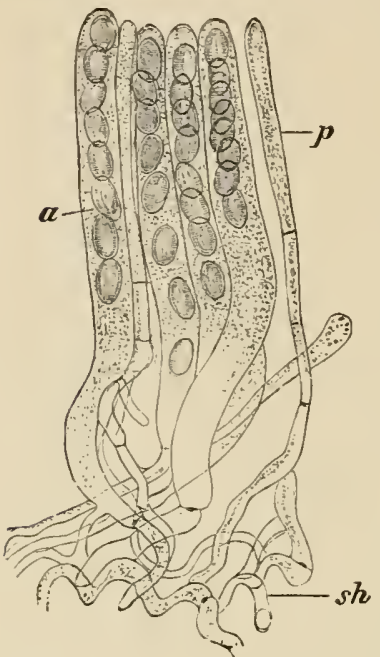

FIG. 317.-Portion of the hymeninm of Morchella esculenta. a, Asci ; $P$, paraphyses; sh, subhymenial tissue. $(\times 240$.

To these orders must be added the Exoasci, in which the asci
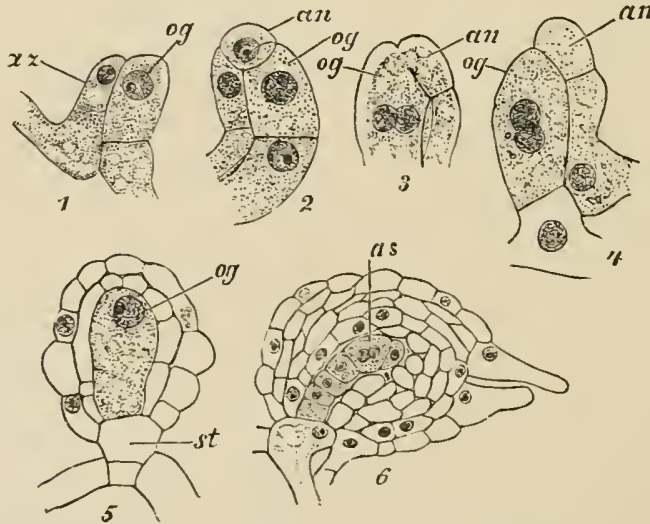
descendants respectively of a male and a female sexual nucleus, fuse together. Thus the conjugation of the sexual nuclei is here delayed from the carpogonium to the derelopment of the ascus.

So far as the results yet obtained allow of a conclusion being drawn, the reduction division in the Ascomyeetes happens just after the fusion of the two nuclei in the ascus.

In the life-listory of the Ascomycetes an asexual reproduction by means of conidia often precedes the development of the fructification. The conidia are spores provided with a cell wall which are budded off from the tips of simple or branched hyphae, the conidiophores (Fig. 320).

According to the construction of the fructification we may distinguish in the first place the orders of the Erysipheae, Plectascineae, and Pyrenomycetineae, with closed or vase-shaped fruit-hodies (perithecium), the Discomycetes with an open fructification (apothecium), and the Tuberaceae with a fructification that is at first open but becomes completely closed. 
fructification, and the very simple Sacharomycetes or Yeast-Fungi. These two groups can be regarled as extremely reduced Ascomycetes. The Laboulbeniacene in which the asci are enclosed in small perithecia occupy an isolated position.

\section{Order 1. Erysipheae (Mildew Fungi) $\left({ }^{55},{ }^{69}\right)$.}

The small spherical peritlecia have a closed investment (peridium) which ultimately opens irregularly and liberates the ascospores. The asei stand

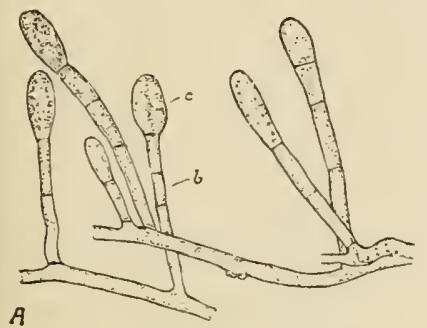

$B$
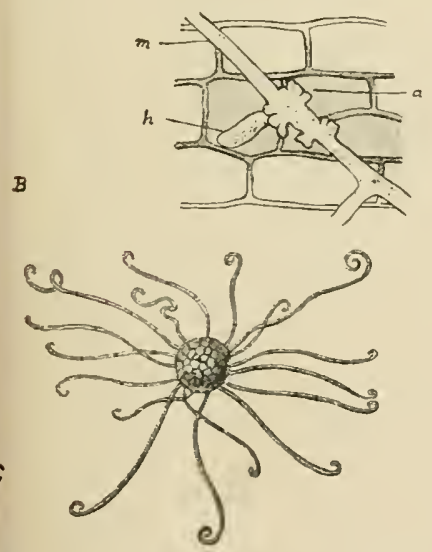

Fit: 319.-Uneinule necator. A, Conidia! stage ; $c$, conidium; $b$, conidiophore. $B$, Hypha which has formed a disc of attachment $(\alpha)$ and lias sent a haustorium $(h)$ into an epidermal cell. $C$, Perithecium with a]pendages. (From SoRAUER, LINDAU, anrl Rer. Hanth. d. Pfanzenkrankiheiten, ii. p. 194. 1!mit.) singly or in a group in the centre of the fruit.

The Erysipheae live as epiphytic parasites whose mycelium, somewliat resembling a cobweb, and ramifying in all directions over the surface, particularly the leaves, of higher plants, sends out haustoria which penetrate the epidermis of the liost. In some cases the mycelium also inhabits the intercellular spaces of the leaf. The ripe ascus fructifications (perithecia) are small black bodies provided with peculiar appendages. In the simplest forms (e.g. in the genus Sphacrotheca) the spheroid perithecium encloses only a single ascus with eight spores.

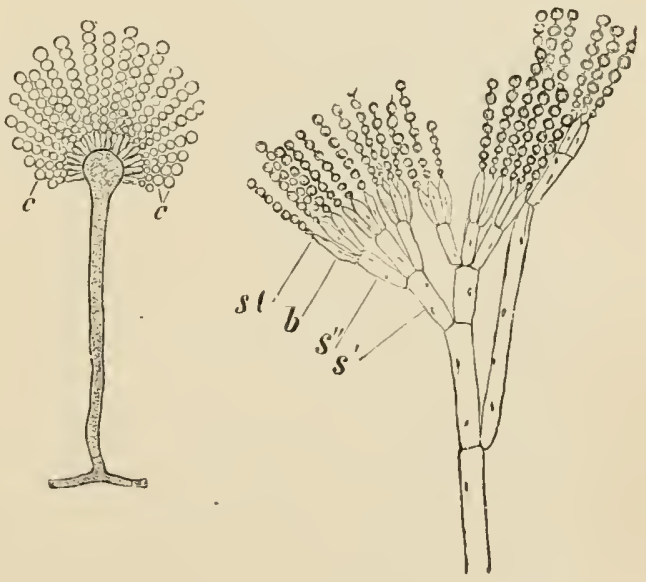

F1i. 320.-Conidiophores of Aspergillus herbariorum (to the left) and Penicillium crustacem (to the right).

It is enveloped by a covering of sterile hyphae, forming a sheathing layer, two to three cells deep. The genera Erysiphe and Thcinula, on the other hand, develop several asci in each perithecium, and in Phyllactinia 12 to 25 asci are present. Since all the eight nuclei are not utilised in spore formation the number of spores in each ascus is usually 4 or ouly 2 . The perithecia are irregularly ruptured at their apices and the spores are thus set free. As HARPE ${ }^{\circ}$ has shown, the first rudiment of the perithecium consists of an oogonium and an antheridiun. These are uninucleate cells, separated from the mycelium by partition walls, and stand close 
together. The male nucleus passes into the oogonium by an opening which forms in the cell walls (Fig. 318, 1-4). After fertilisation the oogonium is surrounded by investing filaments which spring from its stalk-cell or from that of the antheridium (5), and the oogonium itself becomes converted into a multicellular structure (6). In Sphacrotheca the ascus containing eight sprores arises from the binucleate penultimate cell, while in Erysiphe and Phyllactinia this cell exclusively or mainly prodnces ascogenous hyphae which in turn give rise to the numerons asci. Before entering upon the formation of perithecia, the Mildew Fungi multiply by means of conidia abstricted in chains from special, erect hypliae, from the tip downwards. These are distributed by the wind. The Nildew Fungus of the Grape-vine oceurs on the leaves and berries in America and has alpeared in Europe since 1845. This fungus, known as Oidium Tuckeri, is the conidial form of Uneinula necator ( $=U$. spiralis), the small perithecia of which have a plyendages spirally rolled at their free ends and are only rarely found (Fig. 319).

\section{Order 2. Plectascineae.}

The spherical perithecia have a closed peridium; the asci are irregularly arranged within this.

1. Aspergillaceae $\left({ }^{70}\right)$. Fructification small; not subterranean. Here belong two of the most conmon Mould Fungi, Aspergillus (Eurotium) herborionum and Penieillium erustaceum, which live saprophytically on organic substances. Both multiply extensively by means of conidia before they begin to form perithecia.

In the case of Aspergillus hrbarionum, the conidia are abstricted in chains from a number of sterigmata arranged radially on the spherical, swollen ends of the conidiophores (Fig. 320). The conidiophores are closely crowded together, and constitute a white mould, afterwarls turning to a blue-green, frequently found on damp regetables, fruit, bread, etc. Some species of Aspcrgillus are pathogenic in man and other mammals; thus $A$. fumigatus, which lives in fermenting heaps of hay at a temperature of $40^{\circ} \mathrm{C}$, , causes mycosis of the external ear, the throat, and the lungs.

In Penicillium crustaceum, another widespread blue-green mould, the erect tonidiophores (Fig. 320) are verticillately brancherl. The spherical perithecia of Aspergillus and Penicillium are produced later on the mycelimm, but only rarely occur in the latter genus. Their structure is more complicated than in the Erysipheae. They develop from the sexnal organs consisting of an antheridium and a carpogonium provided with a trichogyne. The walls of the asci and the surrounding prendo-prarenchyma disappear in the ripe fruetifieation which opens irregularly by the rupture of the peripheral layer.

2. The Elaphomycetaceae liave subterranean, trufle-like fructifications, the peridium of which is sharply marked off from the powdery mass of spores derived from the ascorenous hyphae.

Elaphomyces gronulutus (Boletus cervinus), the yellowish-brown fructifications of which are of the size of a walnut and have a bitter taste, ocen's commonly in woods in Enrope. It is used in veterinary medicine.

3. The Terfeziaceae are distinguished from the preceding group by the peridium of the fructification not forming a sharply distinet layer. Species of Terfezia with edible trufle-like fructifications ocenr in the Mediterranean region.

\section{Order 3. Pyrenomycetes}

The Pyrenomycetes comprise an exceclingly varied group of Fungi, some of which are prarasitic upon dificrent portions of plants, and others are sapropliytic 
upon decaying wood, dung, ete., while a few genera oceur as parasites upon the larvae of insects. The flask-shajed fructifications or perithecia are characteristic of this order. The peritheeia are open at the top, and are covered inside, at the base, with a hymenial layer of asei and hair-like paraphyses (Fig. 321). The litteral walls are coated with similar hyphal hairs, the periplyyses. The ascospores escape from the perithecia through the aperture.

The simplest Pyrenomycetes possess free perithecia (Fig. 321) which are usually small and of a dark colour, and grow singly on the inconspicuons nycelimm (e.y. Nectria, Sphecria, and Podospora). In other cases the perithecia are in groups

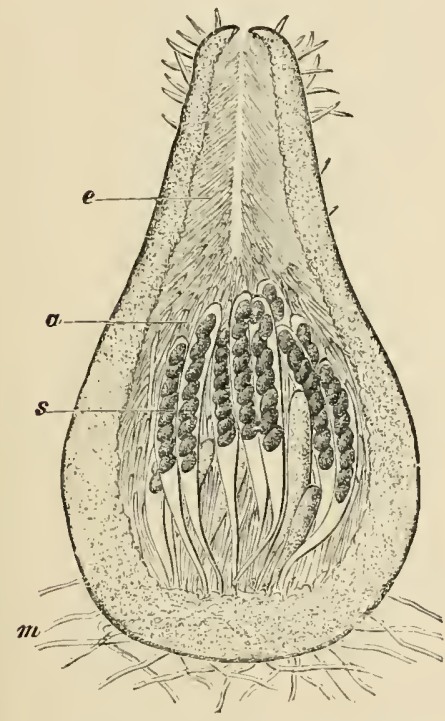

F16. 321.-Perithecium of l'odospora fimiserte in longiturlinal section. $s$, Asci; $a$, paraphyses ; $e$ periphyses ; $m$, inycekial hyphae. (After v. TAVEL, $\times 90$.) embelded in a cushion- or elub-shaped, sometimes branching, mass of compact mycelial hyphae having a pseudo-parenchymatons structure. Such a fructification is known as a stromi.

In the life-history of most Pyrenomy. cetes the formation of prerithecia is precerled by the production of various aecessory fructifieations, particularly of conidia, which are abstricted in different ways,

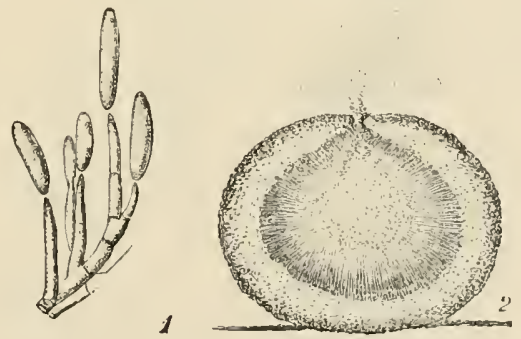

Fir. 322.-1, Conirliophore abstricting conidia, from a pycnidium of Cryptospore hypodermia. (After Brefeld, $\times 300$. ) 2, Pyenifliun of Strilieria olulucens in rertieal section. (After TULASNE, $\times$ 70.)

either directly from the hyphae or from special conidiophores, and assist in disseminating the fungus. The conidiophores are frequently united in distinct, conidial fructifications. A special form of such fruetifications are the PYCNIDI produced by many genera. They are small spherical or flask-shaped boulies which give rise to branched hyphal filaments from the apices of which conidia, in this case termed prCNospores or pycNocunilia, are abstricted (Fig. 322, 1, 2). The structure of the pyenidia and yycnospores corresponds to that of the spermogonia and spermatia of the Lichens, and they may in part at least be regarded as malc orgalls.

Clariceps murpuree, the lungus of Ergot, is important on account of its official value. It is parasitic in the young ovaries of different members of the Gramineae, particularly of Rye. The ovaries are infected in early summer by the ascospores. The myeclium soon begins to form ('onirlia, which are abstricted in small elusters from short laceral conidiophores (Fig. $323, A$ ). At the same time a sweet fluid is extruded. This so-called moser-DEW is eagerly sought by 
inseets, and the conidia embedded in it are thus earried to the ovaries of other plants. The conidial form of this Fungus was formerly regarded as a distinet
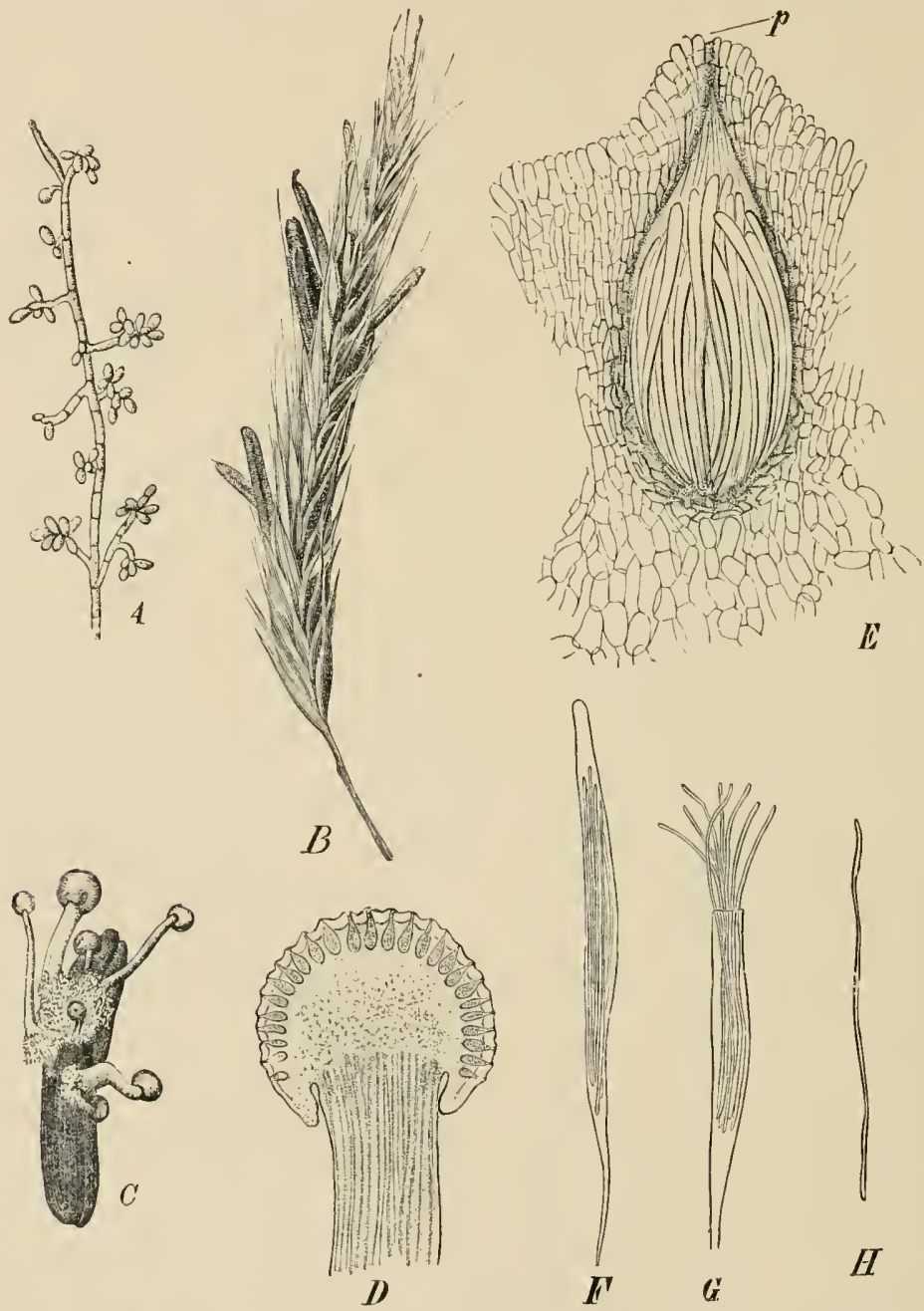

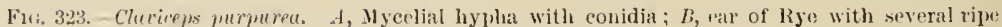
sclerotia; $\ell$, a selerotium with stromata; $D$, longitudinal section of a fructification showing numerous perithecia; $F$, a single peritlecium, more highly matnified; $F$, ascus witl eight liliform spores; $G$, a rupiturerl ascus with eseaping spores; $H$, a single spore. (At after BREFELD; C-II after TULASNE ; $B$ pliotographel from natme. OFFICLA and l'orsoxols.)

genus under the name of Sphacelice segetum. After the completion of this form of fructification, and the absorption of the tissue of the ovary by the mycelium, a selerotiun is eventually formed in the place of the ovary from the hyphae of the 
mycelium by their intimate nnion, especially at the periphery, into a compract mass of psendo-parenchyma (Fig. 110). These elongated dark-violet screrotra, which project in the form of slightly curved bodies from the ears of corn, are known as Ergot, SECAle CORxutu M (Fig. 323, $B$ ). The selerotia, copiously supplied with reserve material (fat), eventually fall to the ground, where they pass the winter, and germinate in the following spring when the Rye is again in flower. They give rise to bundles of hyphae which produee long, stalked, rose-colourer globular heads $(C)$. Over the surface of the latter are distributed numerous sunken peritheeia $(D, E)$. Each perithecium contains a number of asei with eight long, filiform ascospores, which are ejected and carried by the wind to the inflorescences of the grass.

Nectric ditissima $\left(^{71}\right)$ is a very injurious parasitic fungus which inhabits the cortex of various trees and causes the canker of fruit trees. It is propagated in summer by means of slightly eurved, fusiform, multicellular condia, and in winter and spring forms small red peritheeia which are elosely crowded together.

OFFICIAL. - Ergot is the selerotium of Claviceps purpurea.

\section{Order 4. Discomycetes $\left({ }^{72}\right)$}

The Diseomycetes are distinguished from the other orders by their ofen apothecia, which bear the hymenium, consisting of asci and paraphyses, freely exposed on their upper surface (Fig. 325). The different gromps exhibit great diversity as regards the manner of development of their finctifications.

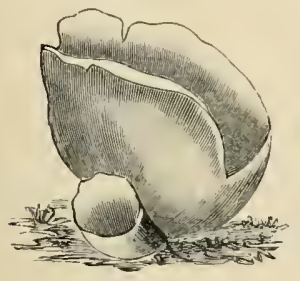

FIi, 324.- l'ezizu aurantiaro. (After Krouвнolz, nat. size.)

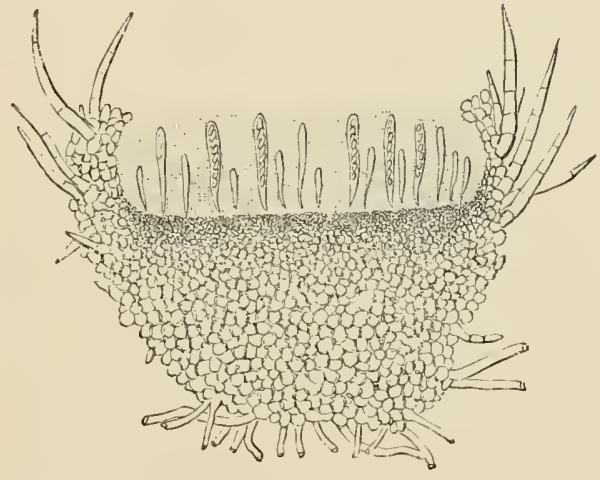

Fu: 325.-Lachneu pulcherrima. Aplotheciun ruytured, showing old and young asci between the paraphyses. (After WoronIN, from v. TAVEL)

The great majority of the Disconycetes, of which the genus Peziza may serve as a type, grow on living or deacl regetable substances, especially upon decaying wood, but sometimes also on humns soil. They produce sancer-or cup-shaped fructificatious of a fleshy or leathery consistency, and usually of small dimensions. One of the largest forms, Pcziza aurantiaca (Fig. 324), lias irregularly bowl-shaped fructifications, which may be seven centimetres broad and of a bright orange-red colour, while in most of the other species they are grey or brown. Such cupshaped fructifications are termed APOTHECIA. 
The development of the apotheeium ma be described for Pyromema eonfluens, in which it was first thoronghly investigated by R. HARPFi. The fruit-body of this speeies is about $1 \mathrm{~mm}$, across, and of a yellow or reddish colour; it often oceurs on spots where fires have been kindled in wooks. The earpogonia are especially large in this species, and several usually take part in the formation of each a pothecium (Fig. 326, A). The carpogonium or ascogonium consists of the spherical, multinncleate oogonium, on the apex of which a multinucleate eurved cell, the trichogyue, is situated. The cylindrieal, multinueleate anthericlium arises from a neighbouring hypha; its apex comes into opren communieation with
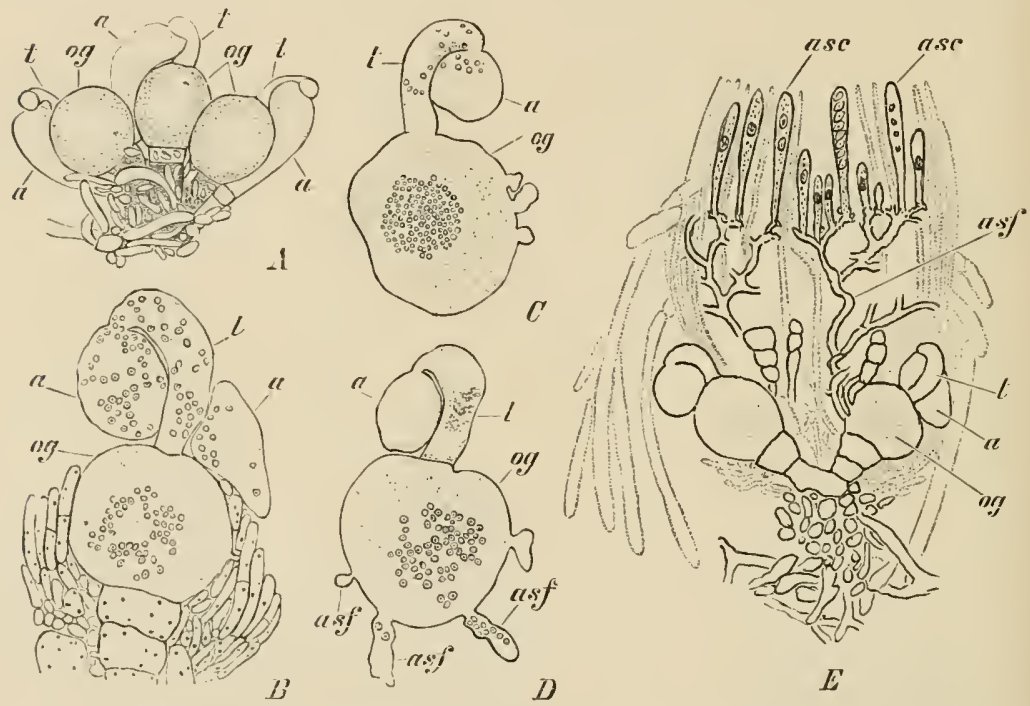

F1: 326.-l'yronemaconfluens. A, Rudinent of an apothecium, consisting of three ongronia (og), with trichogynes $(t)$ and three antherichia $(a)$. B, Fusion of the antheridiun and the tij, of the trichogyne. $C$, The basal wall of the trichoggne having been absorbed, the male and female nuclei are grouped in the centre of the oogonium. D, separation of the oogoniun from the trichogyne by means of a new partition wall. Formation of the ascogenous filaments (usf). $F$, Longitudinal section through a young ajothecium. asc, Asci. (After R. HARPEk. A, $E$ $\times$ about $150, B-D \times$ about 300 .)

the tip of the trichogyne by the breaking down of the intervening walls. The male nuelei first wander into the triehogyne cell, ant then, by the breaking down of the hasal wall of the latter, into the oogonium. The egg-cell then becomes linited from the trielıgyne by a new cell wall and sends ont ascogenous filaments containing the conjugated nuelei. These filaments branch and ultimately terminate in asci $(\mathrm{E})$, while the sterile hyphae and the paraphyses of the fructifieation are derived from hyphae arising beneath the carpogonium. Accorling to HARper the male anr female nuelei fuse in pairs with one another in the earjogonium. Mlore recent investigations by CLAUssex show that they only place themselves side by side, and in the aseogenous hyphae divide conjugately, but renain distinet from one another. The fusion of a descendant of a male nueleus with the descemlant of a female nueleus does not take place till the development of the ascus. 
A reduetion in sexuality has ocemred in many Discomyeetes. Thus Lachened stercorea develops an ascogonimu as Pyromema loes, hut with a 5- to 6-celled trichogyne; an antheridimm is still present, but the male inclei only enter the trichogyne and are functionless. They do not reach the ascogonimn, the unclei in which fuse in pairs, after which the ascogenous hyphate are formed $\left({ }^{73}\right)$. In Ifamaria granulata no trichogyne is formed and antheridia are completely wanting; the nuclei of the ascogonium fuse in pairs $\left({ }^{7+}\right)$. Lastly, in Mumarice rutiluns no sexual organs are formed, but fusion of nuclei takes place in the complex of hyphae, from which the ascogenous hyphae arise $\left({ }^{75}\right)$.

The asci clevelop in various ways at the ends of ascogenons liyphae. As a rule the end of the ascogenous hyphae when about to form an asens becones curved

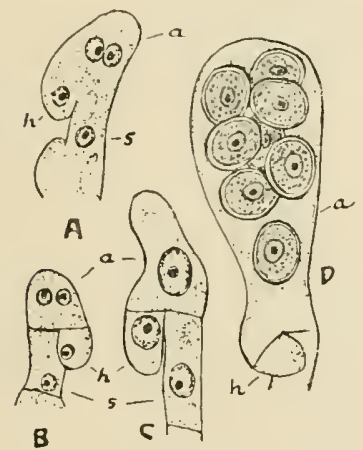

Fu. 327.-Development of the Ascus. A-C, P'yroneme ronfuens. (After HARPER, D, Young ascus of Bemliera with eight spores. (After Cuarseser). Explanation in text.

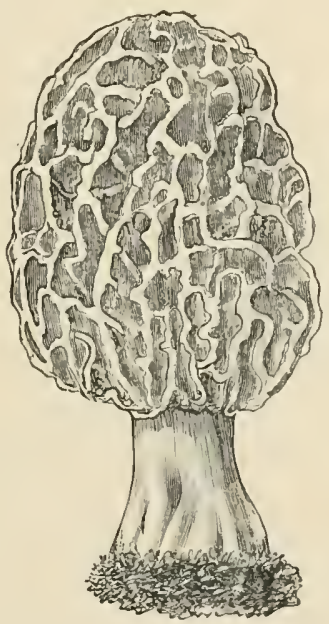

Fit, 32s.-Morrlelle rementu.

(

into a hook-like shaje (Fig. 327,1 ). The two nuclei of the young asens (ut) lie near to the bend, and on the formation of transverse walls are selarated from the uninucleate terminal cell $(h)$ and the stalk-cell $(s)$, which also has a single nucleus. The two nuclei of the young asens fuse $(C)$, and the resulting nucleus gives rise by rejeated division to the nuclei of the eight aseospores $(D)$.

The highest development is exhibited by the peculiar fruetifications of the Helvellaceae, whose mycelium grows in the humus soil of woorls. In the genus Morelella (Fig 328), the fructifieations consist of a thick erect stalk, bearing it club-shaped or more or less spherical cap or filens, which bears the hymenimm, with its eight-sprored asci, on the reticulately indented exterior surface (Fic. 315). The Morchellas are edible ( $\left.{ }^{76}\right)$, in particular $M$. esculenta and $M$. conica. The former has a yellowish-brown cap, ovately spherical in shape, and attains a height of $12 \mathrm{~cm}$. ; the eap of the latter is conical and dark brown, and it reaches a height of $20 \mathrm{~cm}$. Gyromitra esculenta, with dark brown caj and white stalk, and others are also edible. In their external appearance the fructifications of these highly developed Discomycetes greatly resemble those of the Basidionycetes. 


\section{Order 5. Tuberaceae (Truffles) $\left.{ }^{78}\right)$}

The Tuberaceae or Truftle Fungi are saproplyytic Ascomycetes whose mycelium oceurs in humus soil, particularly in woods. The asens fructifications familiar under the name of truffies are underground tuberous bodies, consisting of a
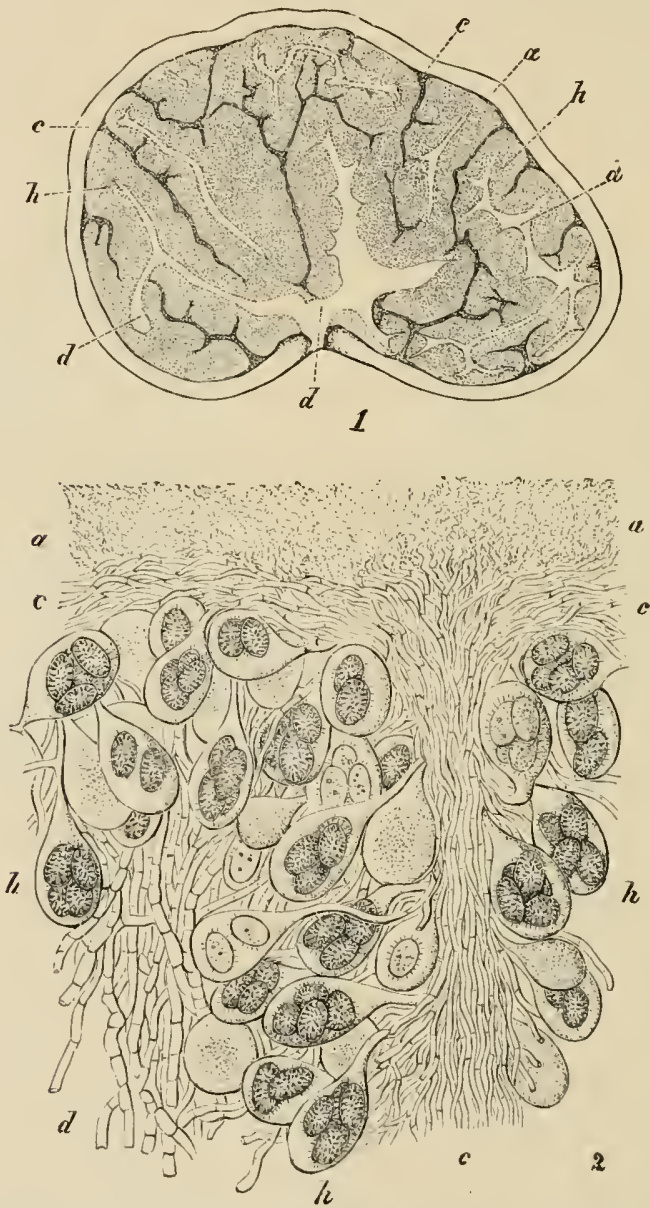

Fuc. 329. - Tuler rufum. 1, A fructification in vertical section $(\times 5) ; \alpha$, the cortex; $d$, air-containing . tissue; $c$, flark veins of complact liyphae; $h$, ascogenous tissue: 2 , a portion of the hymenium ( $\times$ itio). (After TulasNe, from $r$. Tatel.)

thick, investing layer, with passages opening to the exterior; the walls of these are lined with the hymeuium compend of club-shaped asci (Fig. 329). The asei contain only a small number of spores; in the case of the true truftles (Tuber) they are usually only four in number, and generally have a spinous or reticulately 
thickened epispore. They are set free in the soil by the breaking down of the asei and of the wall of the fructification.

The fructifications of many of the Tuberaceae are edible $\left({ }^{76}\right)$, and have an aromatic odour and taste. They are, for the most part, obtained from France and Italy. of the edible varieties, the most important are the so-called black truflles belonging to the genus T'uber, viz. T'uber brumale, melanosporum (Perigord Truftle), cestivum, mesentericum. The fructifications of these species have a warty cortex of a black, reddish-brown, or dark brown colour. The white truffle, Choiromyecs meandriformis, the external surface of which is pale brown, is also edible.

The fructifications when very young are open as in the Discomycetes. The Truflles seem most nearly related to the Helvellaeeae.

\section{Order 6. Exoasci $\left({ }^{9} 9\right)$}

The most important genus of this group of Ascomycctes is Taphrina (ineluding Eroascus), the species of which are parasitic on various trees. They develop in part annully beneath the cuticle of the leaves, eausing discolorations of these organs; their myeelium lersists during the winter in the tissue of the host, so that a constant recurrence of the disease takes place. The presence of the mycelium in the tissues of the infected part canses the abnormally profuse development of branches known as WITCHES'-BRooms. Taphrine Carpini produces theabnormal growths oceurring on the Hornbeam; Taphrina Cerasi those on Cherry trees. Taphrina deformans attacks the leaves of the Peach and causes them to curl. Taphrina Pruni is parasitic in the young ovaries of many species of Prunus, and produces the malformation of the fruit known as "Bladder Plums," containing a cavity, the so-called "pocket," in the place of the stone; the mycelium persists through the winter in the branches. In the formation of asci, the copiously-branched mycelium ramifies between the epidermis and cutiele of the infected part. The individual cells of the myeelium become greatly swollen and grow in to club-shaped tubes, which burst through the euticle and, after cutting off a basal stalk-cell, are usually converted

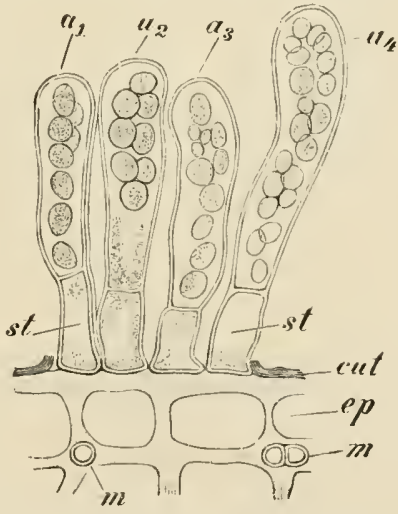

Fif. 330.-Taphrinc Pruni. Transverse section throngh the eyidermis of an infected plum. Four ripe asci, $a_{1}, a_{2}$ with eight spores, $a_{3} a_{4}$ with yeast. like conidia abstricted from the spores; st, stalk-cells of the asei ; $m$, filaments of the mycelium cut transversely ; cut, cuticle ; $e p$, ejiilermis. (After SALEBECK, $x$ ti00.)

into asci with eight spores (Fig. 330). As in other Asconncetes the young ascus has two nuclei which fuse, and the resulting nucleus undergoes three divisions to give the nuelei of the eight spores. The numerous asei are closely crowded together.

The spores, which bud in water or sugar solntion, frequently germinate whilc still enclosed within the asci ( $F$ ig. $330, \alpha_{3}, \alpha_{4}$ ), and give rise by buclding to yeastlike conidia, e.g. in Taphrina Pruni.

The Exoasci are perhaps to be regarded as reduced $\Lambda$ scomyeetes, in which the sexual organs liave become comple ely suppressed. 


\section{Order 7. Saccharomyeetes (Yeast-Fungi) $\left({ }^{80}\right)$}

The beer, alcohol, and wine yeasts included in the genus Sackaromyces are simple unicellular Fungi which assume the form of splherical, oval, or cylindrieal

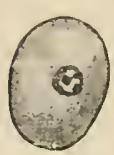

A

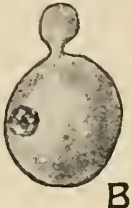

B
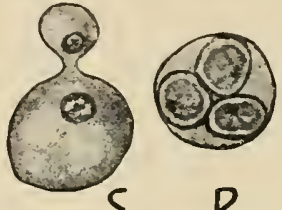

D

Frr. 331.-Sacheromyces revevisine. A, yeast-cell; $B, C$, yetst-cell budding; $D$, ascus with four spores. (After Guilliermoxd, $\times 1125$. conidia eontaining a single nucleus. They increase in number by budding (Fig. 331). No mycelium is formed, though sometimes the cells remain for a time united in chains. With free access of oxygen and at a suitable temperature yeasts form asei when the mutrient substratum is exhausted; the asci externally resemble the conidia but contain a few spores. In some yeasts a conjugation of two cells accompanied by a nuclear fusion has been observed. In Saccharomyccs Lulwigii the four spores in the ascus germinate and fuse in pairs by means of a narrow conjugationtube; the latter elongates into a germ-tube from which yeast-cells are abstricted. In the ginger-beer jeast (Zyyosecchoromyes) and in Schizosacharomyecs the yeast-cells conjugate by means of long tubes before spore-formation. These nuelear fusions possibly correspond to those in the young asci of other Ascomycetes.

Physiologically these Fungi are remarkable for their power of exciting, by means of an enzyme (zymase), the fermentation of saecharine solutions, alcohol and carbon dioxide being prodnced. The beer yeast (Saccharomyces cerevisiae) is only known in the eultivaterl form; the wine yeast ( $S$. cllipsoideus), on the other liand, occurs regularly in the soil of vincyarels in the spore-form; the latter is therefore always present on the grapes and need not be added to the grape-juice. Other genera, in some of which a myechium is developed, belong to this orler.

No evidence is at present forthcoming to show that the Yeasts

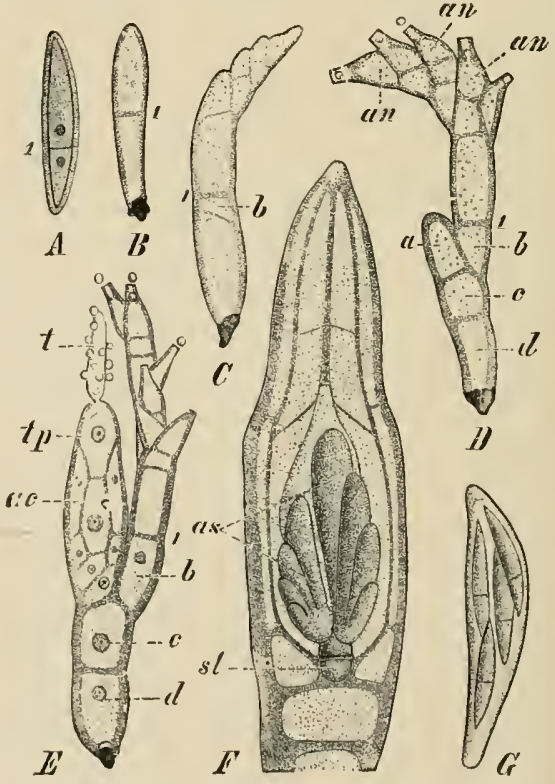

FIt. 332..-Stiqmatomynes fiecri. Description in text. $A$, sprore; $B-F$, successive derplopmentill stages, $D$, with spermatia escetyjug from the antleridia $a n ; E$, with antheridia abose and the lateral finale organ; $F$, lerithecium with developing asci ; $(\dot{r}$, ijpe ascus. (After Tнахтен.) are to be regarded as developmental forms of other Fungi. In various menluers of the Exoasci, and Ustilngineae, however, yeast-like conidia which reprodnee by bulding are known. Possibly the Saceharomycetes are reduced Ascomycetes, or they may represent an indepenlent group of very simple Funcri. 


\section{Order 8. Laboulbeniaceae $\left.{ }^{(8)}\right)$}

The Laboulbeniaceae are a group of minute Fungi occupying an isolated position; our knowledge of them is largely due to the work of Thuxtwi. Their thallus consists of two to a number of cells, and is attached to the body of the insect, most commonly a beetle, on which it is parasitic by mears of a pointed process of the lowest cell inserted into the clitinous integmuent of the insect or by means of rhizoids which penetrate more deeply. Stignatomyces Bacri which occurs on house-flies in Europe may be taken as an example. The bicellular spore (Fig. 332, $A$ ), which has a mucilaginous outer eoat, becomes attached ly its lower end $(B)$, and divisions occur in both cells $(C)$. From the upper cell an appendage is developed bearing a number of unicellular, flask-shaperl anthericlia $(D, a n)$ from which naked spherical spermatia without cilia are shed. The lower cell divides into four $(D, a, b, c, d)$, and the cell $a$ projects and gives rise to the multicellular female organ. The true egg-cell ( $E$, ac), which is caller the carpogonium, is surrounded by a layer of cells. Above the carpogonium cone two cells $\left(E, t_{p}, t\right)$ the "lpler of which is the freely projecting trichogyne or recentive organ for the spermatia. The behaviour of the nuclei has not yet been followed, but probably a fusion of male and female unclei takes place in the carpogonium. The latter becomes divided into three cells, of which the uppermost disappears, the lowest $(F, s t)$ remains sterile, while from the middle cell the asci grow out. Each ascus $(G)$ prorluces four spindle-shaped, bicellular spores. The sinilarity of the sexual organs to those of the Fiorideae and of the lichen-forming Ascomycetes is of great interest.

\section{Sub-Class II._-Basidiomycetes (55, 56, 82, 83,84$)$}

The Basidiomycetes no longer possess sexual organs; only in the Uredineae or Rust-fungi are structures found which can be regarded as persisting though functionless male organs, and cells which appear to correspond to the carpogonia of Ascomycetes. In place of asci, basidia are present which produce by a process of budding in most cases four basidiospores. The basidia agree with the asci in containing when young two nuclei, which fuse with one another. The reduction division appears to follow on this nuclear fusion ol karyogamy. The resulting nucleus undergoes two divisions, and the four resulting nuclei pass into the spores which are budding off (Fig. 333) $\left.{ }^{83}\right)$. A mycelimm with uninucleate cells develops from the spore.

The basidia present three distinet types. In the orders Urerlineae and Aurcularieae the upper portion of the basidium is rivided by transverse walls into four cells; each cell bears on a thin stalk (sterigma), arising near the upper end, a single spore (Fig. 334, A). In the Tremellineae, on the other hand, the basidium is divided by longitudinal walls into four cells, each of which continues into a long tubular sterigma (Fig. $334, b$ ). The basidium in the Hymenomycetes and Gasteromycetes is unicellular, and bears as a rule four 
spores at the summit; these may be sessile or situated on sterigmata (Figs. 333, 343).

The Ustilagineae are of interest since in one family of these fungi the basidia are divided, while in the other they are undivided. The number of spores prorluced is not a definite one but often very large.

The basidia may be regarded as a special form of conidiophore, since it is usual to give the name conidia to spores arising in the fungi by budding from a cell.

In addition to conidiophores differentiated as basidia, the Basidiomycetes produce other forms of conidia as accessory fructifications in many species. The origin of asexual spores by the rounding off of hyphal cells and their developing

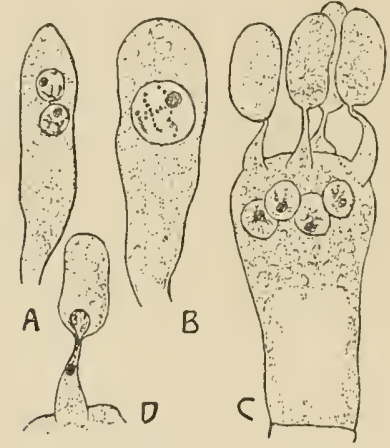

Fir. 333.-Armillaria mellert. A, young basidium with the two primary nuclei; $B$, after fusion of the two nuclei. Hypholomarmenticulatum, $C$, a basidium before the four nuclei derived from the secondary nuclens of the basillium have passer into the four basidiospores; 1 , passage of a meleus through the sterigma into the basiriospore. (After RuHLAND.)
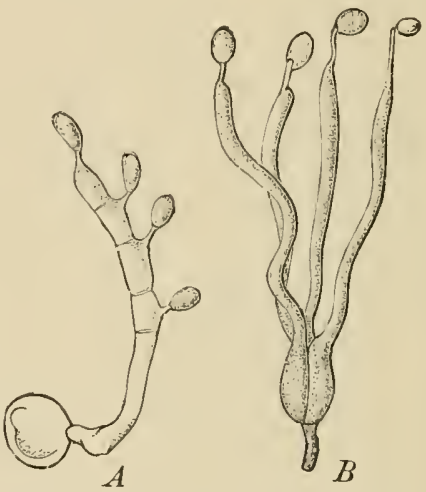

FIr. 334. - Basidia. A, of a Uredineons fungus (Eulophyllum Euphorbiue silrerticcie) (after Triasne). $D$, Of one of the Tremellineae (Tremella lutesens) (after Brefeld ). ( $\times 450$. From $v$. Tavel, Jilze.)

a thick wall and ultimate separation, is different from that of conidia (chlamyro spores aecording to BrEFFLD). These appear in the Ustilagineae as the smutspores, and as the rust-spores in the Urerlineae. In these groups the hasidia arise directly from sprores of this kind (Figs. 334, A, 336). In other Basidiomycetes, if a few simple forms are disregarded, the hasidia are always borne npon or within more or less complicated fructifications. The layer in which the basidia are associated together is termer the hymenimm. These fruetifieations correspond to those of the $\Lambda$ senmyertes, but no sexual process is enucerned in their origin.

\section{Order 1. Ustilagineae (Smut-Fungi) $\left({ }^{85}\right)$}

The Ustilagineae are prirasites, and their myeelimn is found ramifying in higher 1) lants, usually in definite organs, either in the leaves and stems, or in the fruit or stamens. The Gramineae in partieular serve as host plants; certain species of 
Ustilagineae are in a high degree injurions to cereals, and yrodnce in the inflorescences of Oats, Barley, Wheat, Nillet, and Maize the disease known as Snut.

The myceliun ultimately produces resting-spores by the formation of additional transverse walls, and by the rivision of its profusely branched hyphae into short swollen cells (Fig. 335, $A$ ). The cells become rounded oft and converted into spores, within a gelatinous envelope, which, however, eventually disalprears. The spores then become invested with a new, thick wall. In this way the mycelium is transformed into a dark brown or black mass of spores. These smut-spores, brand-spores, or resting-spores are seattered by the wind, and germinate only after an interval of rest, jroducing the basidia in the succeeding spring; the formation of these is eharacteristically different in the two families of the Ustilaginaceae and the
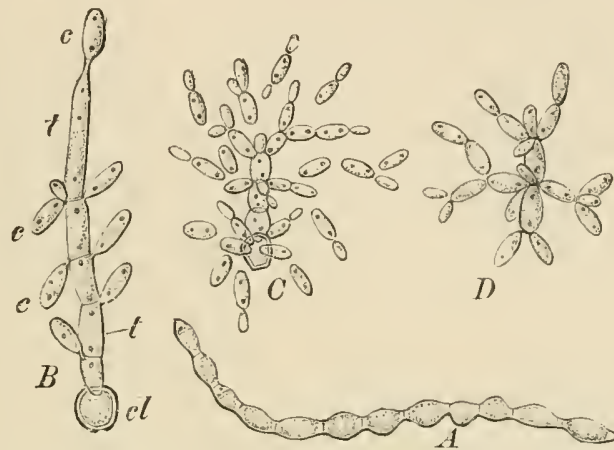

Fri. 335.-A, Ustilago wivarea. Myeelial liyplat in process of forning smut-spores $(\times 400)$. B-D, Ustileys srgrtum: $D$, germinating smut-spore (cl), cultivated in nutriput solution; $t$, transversely septate basidimn with lateral and terminal hasidiospores (conidia) $(*)(\times 450)$; $c$, germinatinn smut-spore lying in the nutrient solution surounderl by abstricted conidia, which are multiplying by burding $(\times 200) ; D$, an aggregation of budding conidia $(\times 3511)$. (After Brefeld, from v. Tavel, Pilzo.)

Tilletiaceae.

The most important genus of the Ustilaginaceae is L'stilago. I'st. Avence,

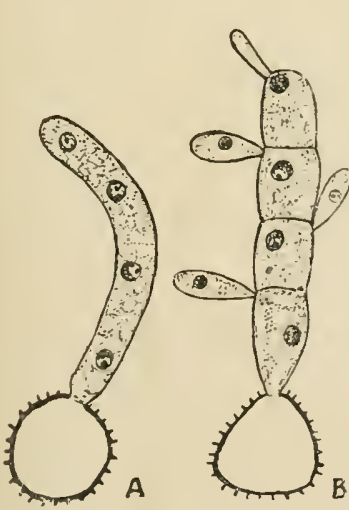

$I^{r}$. Hordei, and $U$. Tritici segetum, which were formerly united as $l$. Carbo, canse the "smut" or" "brand" of Oats, Barley, and Wheat. The mycelimm penetrates the ovary, and forms dark brown, clustlike masses of escaping resting-sporer. $T$. Muyclis produces on the stalks, leaves, and inflorescences of the Maize tmmour-like swellings filled with bramispores in the form of a black powder. Other species live on the leaves of different grasses; while $t$. violacea $(=U$. antherarum) occurs in the anthers of various Carophyllaceae (e.\%. Itychnis, Suponarior), and fills the pollen-sacs with hrand-s wres.

The brand-spores of Istilago fall to the ground, and after a periorl of rest give rise, on germinating, to a sliort tube (promycelium) which becomes divided by three or four transverse walls (Fig.

Frr: 336. - Estilago Subosiae. A, $336, B)$, and, functioning as a basidiun, produces young basidium with four muclei ovate basidio-spores or conidia (sporidia), both formed on germination of the laterally from the upler ends of the intermerliate resting spore; $B$, spore-formation cells, and also from the tip of the terminal cell. on the 4-celled basidium. (After HARPER.)

When abundantly supplied with nourishment, as when eultivated in a nutrient solution, conidia are continuously abstricted in laıge numbers (Fig. 335, C), and then multiply 
further by budding; cell-fusions or union of uuclei frequently oceur as a preliminary $(C, D)$. After the food-supply of the substratum is exhausted, the conidia grow out into mycelial hyphae. The formation of the conidia in the damp manured soil of the grain fields is accomplished during a saprophytic mode of existence, but the hyphal filaments which are eventually produced become parasitic, and penetrate the young seedlings as far as the apical cone where the inflorescence takes its origin. The mycelinm continues its development in the inflorescence, and ultimately terminates its existence by the production of brandspores. To conidia are formed on the host plant itself.

In addition to the infection of young plants, either resting-spores or the conidia resulting from their germination may be carried to the stigmas of the grass-flewers and germinating there produce a mycelium which penetrates to the young seeds and passes the winter in the embryo-plants. Snch infection of the flowers may

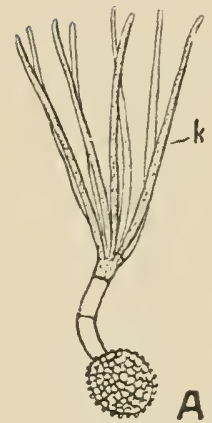

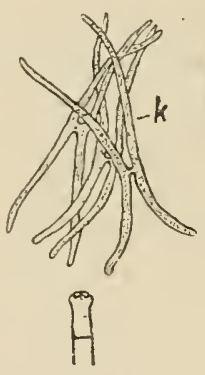

B

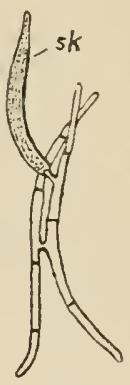

$\mathbf{S}$

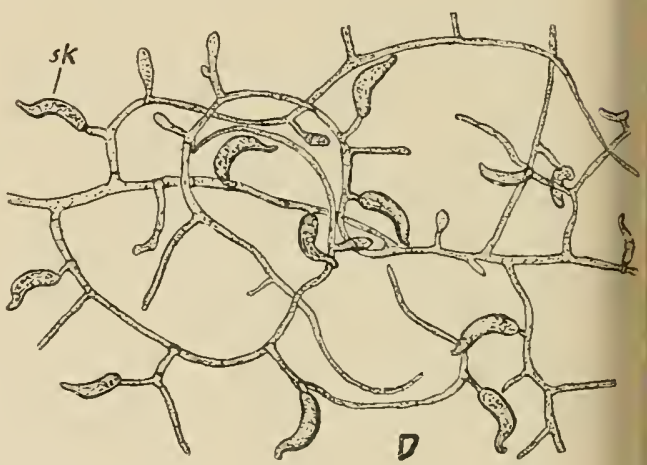

Frr. 337.-Tilletiu Tritici. A, the basidium developed from the brand-spore bearing at the end four pairs of spores $k(\times 3 n 0) ; B$, the dispersion of the spores which bave fused in pairs $(\times 250) ; C$, one of the paired spores germinating and bearing a sickle-shaped conidium $s k$ ( $\times 400)$. D, Mycelium with sickle-shaped conidia ( $\times 350)$. (After Brefeld.)

alone take place as in L'stilugo Tritici, U. Hordei, and U. antherurum, or the seedling may more often be infected as in $U$. Avenae, $U$. Sorghi, $U$. Panici miliacei, $U$. Crameri. The Smut of Maize can infect all parts of the plant while in a young state anct the disease is limited to the infected spots.

The life-history of the Tilletiaceae is similar to that of the Ustilaginaccae. The best-known species are Tilletiu Tritici $(=T$. Caries) and Tilletia Inevis, the fungi of the stink-brand of wheat. The resting-spores fill the apparently healthy grains and smell like decayed fish. In the first-naned species the resting-spores are reticulately thickened; those of $T$. laeris, on the other hand, are smooth-walled. Unlike the Ustilaginaceae, the germ-tube gives rise only at its apex to filiform basirtiosprores, which are disposed in a whorl, ancl consist of four to twelve spores (Fig. 337,A). The basidiospores also exhibit the jeculiarity that they coalesce with one another in pairs in an $\mathrm{H}$-form. Such cell fusions also occur between germinating conidia of the Ustilagineae, but are not aceompanied by nuclear fusions. The filiform spores germinate readily, and produce sickle-shaped conidia at the apex of the germ-tubes (Fig. 3:37,C). When abundantly supplied with food nuaterial, the germ-tubes grow into large mycelia, from which such sickle-shaped conidia are so abundantly abstricted that they have the appearance of a growth of mould $(I D)$. 
Thus Tillctia, unlike Ustilugo, produces conidia of two forms; but in other particular's the development of both gronps is the same.

The young resting-spores and the cells of the mycelium from which they are produced contain each two nuclei which fuse with one another as the spore becomes

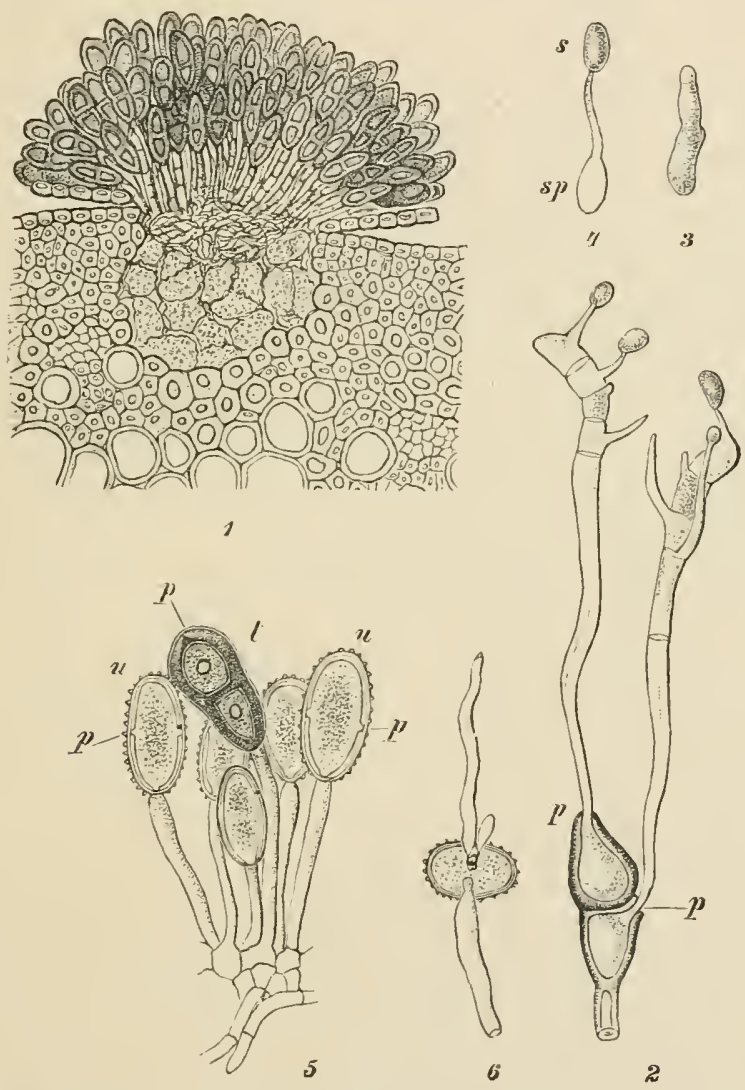

Fig. 33s.-l'uceinia grum inis. 1, Transverse-section through a grass-haulm witl group of teleutospores; 2 , germinatin telentospore with two basidia; 3, veretative, 4 , fructifying rerminating basidiospore: the latter has formed a'secondary spore, not having been able to infect a host plant: 5 , a portion of a group of uredospores $(u)$ and teleutospores $(t) ; p$, the germ-spores; $r$, germinating uredospore. (1, 2, 3, 4, after TULASNE; 5,6 , after DE BARY ; $1 \times 150,2 \times$ eirca $230,3,4 \times 370,5 \times 300,6 \times 340$, from $v$. TAvel, Pilze.)

mature. The cells of the basidia, and the basidiospores are all uninucleate, only the secondary conidia of Tilletia being again binucleate.

\section{Order 2. Uredineae (Rust-Fungi) (46-89)}

The mycelium of the Uredineae lives parasitically in the intercellular spaces of the tissues of the ligher plants, especially in the leaves, and gives rise to the 
widely-s lread diseases known as Rnsts. Their more varied sprore-formation is a distinguishing feature as contrasted with the Ustilagineae.

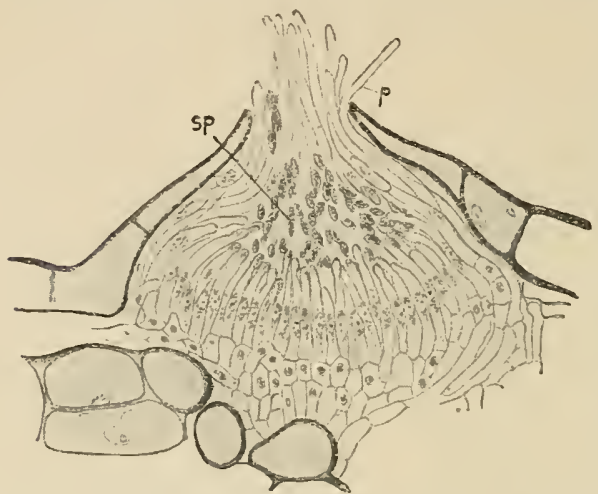

Fr:, 33!. - Gymnosporengium rlacariceforme. A spermogonium rupturing the epidermis of a leaf of Crataegus; $s p$, s]ermatia ; $p$, sterile paraphyses. (After Bı.Ack.s. )

As in the latter order, the basidia are not produced directly on the mycelium but on the germination of a special type of spore, TELEUTOSPoliEs or winter spores, which are characteristic of all Uredineae. The telentospores arise in small clnsters beneath the epidernis of the diseased leaf from the ends of hyphae; frequently two or more form a short ehain. They are thick-walled resting-spores and persist through the winter (Fig. $338,1,5 t)$. The group of spores usually bursts through the epidermis. At first the spores, like the cells of the myeelinm which bears them, have two muclei, lunt the nuclei fuse before the spore is ripe.

In the germination of the telentospore a BAsnofu (promycelium) grows from

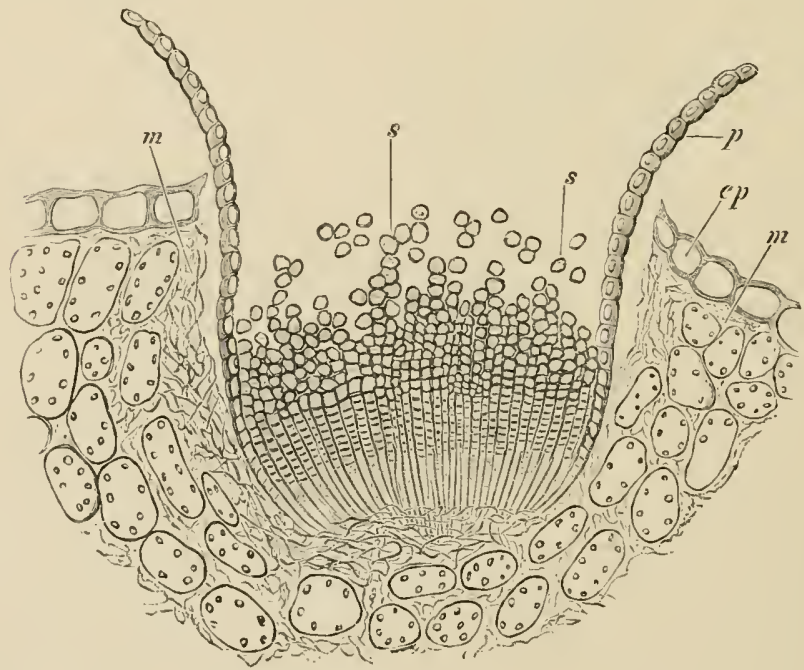

Fr: 340.-1'urrinia grominis. Aecidium on Berberis 'ulgaris : ep, epidernis of lower surface of leaf ; $m$, intercellular mycelium ; $p$, peridium ; $\times$, chains of spores. ( $\times 112$.

each cell (Fig. 338,2 ) ; it hecomes dividerl by a transverse septa into a row of four cells from each of which a sterigma bearing a single minneleated BAsIDIOSPORE (sporidiun) is produced. The sporidia are dispersed by the wind and germinate in the spring on the leaves of host plants (which may be of the same or different 
species from the one on which the teleutospores were prorluced), giving rise to an intercellular mycelium, all the cells of which are uninucleate. From this mycelimm organs of two kinds arise, spermogonia on the nuper surface of the leaf and aecirlia on the lower surface.

The speniogoria (Fig. 339) are flask-shaped structures, the base of which is covered with the projecting ends of hyphae; from these are abstricted spermatia, each of which has a single nnclens. Morphologically they are completely comparable to the similarly named male sexual organs of some Ascomycetes; among the Basidiomycetes they persist only in the Urcdineae, and even in them are no longer functional and may be completely wanting. In mutrient solutions the spermatia may put ont short germ-tubes, but are not capable of infecting the liost plant.

The AECrDIA (Fig. 340) are eup-shaped fructifications, which when young are elosed, but later open; from the ends of the hyphae numerons closely associated chains of spores are abstricted. As a rule the enveloping layer or peridium of the aecidium is formed of thick-walled cells corres]onding to the sterilised peripheral rows of spores. In Phragmidium violaceum, which oecurs on Blackberry leaves and has been fnlly investigated by BLACKuAN $\left({ }^{87}\right)$, the hyphae beneath the epidermis when about to give rise to an aecidium first ent off a sterile cell, which midergoes no further development, from their ends (Fig. 341, A). The cell below this increases in size; it has at first only a single nuclens, but becomes bintcleate by the passage of a nuclens into it from an adjoining mycelial cell. The two nuclei do not fuse. The binucleate cell mudergoes successive divisions into a chain of spore-mother-cells, each of which has a pair of nuclei; and from each spore-mother-cell an npper binncleate aecidiospore and a sterile intercalary cell, which is also binucleate but soon slurivels np, are derived by a transverse division $(B, C)$.

According to Christuras $\left({ }^{87}\right)$ the development of the aecidiospores in Phragmidium speciosum (Fig. 342), which is parasitic on Post, proceeds somewhat differently. Here also the ends of the hyphae $(A)$ divide into a terminal sterile cell and a lower fertile cell $(E)$, but the fertile cells fuse in pairs with one another, the mper prortions of the separating walls breaking down $(C)$. The two muclei lie side by side and divide simultaneously (conjugate division). Two of the danghternuelei remain in the lower part aud two pass to the npper portion of the rlividing cell, and this upper portion is separated by a transverse wall as the first sporemother-cell $(D)$. In other respects the formation of the aecidiospores proceeds as described above. A peridium is not formed in Phragmidinm.

The ripe, binucleate aecidiospores (Fig. $311, D$ ) are shed and infect a new host plant. Each spore gives rise to an intereellular mycelinm which soon proceds in the summer to bear uneDosponss or summer spores. These appear in small eircular or linear groups and arise singly from the enlarging terminal cells of the liyphae (Fig. 338, 5, 6). They have two nuclei like all the cells of the mycelium developed from the aecidiosporc. They serve commonly to ensure the spread of the fungus in the summer. Later, either in the same or in distinet sori the telentospores are formed, and in these the fusion of the two melei to a single one takes place; such a fusion as a rule is found to take place in the young basidium.

The two types of cell fusion in the formation of the aecidium are also known in other Uredineae, and must be regarded as replacing a formerly cxisting mothod of fertilisation. If we attempt to derive the Uredineae from the Ascomyeetes the spermatia must be regarded as now functionless male cells, and the so-called fertile cells in the young aecidium as corresponding to earpogonia. Extending the comparison further the mycelium proceeding from the aecirliospore in the Urerlineae and the uredospores and teleniospores borne on it, together with the basidia, 
formed by the latter, would together correspond to the asexnal generation (sporophyte) of the Ascomycetes. The basidiospores would thus correspond to the ascospores, while the mycelium proceeding from the basidiospores and ending in the production of aecidia would be eqnivalent to the sexual generation (gametophyte).

The three forms of spore borne by the sporophyte show, according to CuIistman, a certain agreement in their development from the "basal cell" from which they arise; they may thus be regarded as morjhologically equivalent.

The life-history of the Rust-fungi is thus

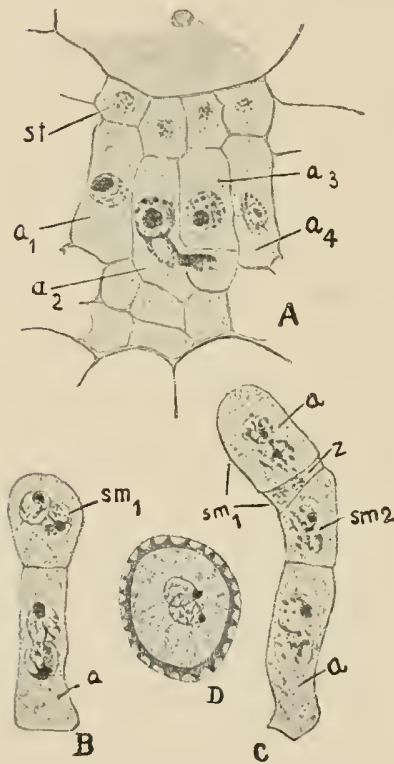

FIG. 341.-Phragmidium violaceum, $A$, portion of a young aecidium; st, sterile cell; $a$, fertile cells; at $a_{2}$ the passage of a nueleus from the acljoining cell is seen ; $B$, formation of the first spore-motlier-cell sin, from the basal cell $t$ of one of the rows of spores ; $C$, a further stage in which from $s m_{1}$ the firstaecidiospore $(a)$ and the intercalary cell $(z)$ have arisen; $s m_{2}$, the second spore-mother. cell ; $D$, ripe aecidiospore. (Alter BI.A(KMAx.) a complicated one. The several forms of spore may appear in the course of the year on the one host, such Uredineae being termed autoecions. On the other hand, the spermogonia and aecidia may occur on one sprecies of host plant, and the uredospores and telentospores on another, often mrelated, plant. In these heteroecious species there is thus an alternation of host plants. There are also pleophagous heteroecions Uredineae in which the aecidia or the uredo- and telentospores appear on a number of distinct host plants $\left({ }^{88}\right)$.

An example of an heteroecions Rust-fungus is afforded by Puccinia graminis, the rust of wheat. It develops its uredospores and telentospores on all the green parts of Gramineae, especially of Rye, Wheat, Barley, and Oats. The aecidia and spermogonia of this species are fonnd on the leaves of the Barberry (Berberis vulyaris). In the spring the hibernating double telentospores give rise to transversely septate basidia, from which the four basidiospores are abstricted (Fig. 338, 2). These are scattered by the wind, and if they fall on the leaves of the Barberry they germinate at once. The germ-tube penetrates the cuticle, and there forms a myceiim which gives rise to spermogonia on the upper side of the leaf and to accidia on the under side (Fig. 340). This form of the fungus is known as Accidium Berberidis. On the rupture of the peridium the reddish-yellow aecidiospores are conveyed by the wind to the hamlms and leaves of grasses, upon which alone they can germinate. The mycelium thus developed produces at first uredospores (Fig. 338, 5). They are micellular, studded with warty protuberances, and provided with four equatorially disposed germ-pores. In consequence of the reddish-yellow fat globules contained in the protoplasm of the spores, the fructification forms red markings (formerly termed Uredo lincoris) on the epidermis of the lost plant. The nredospores are capable of germinating at once on the wheat, and thus the rust disease is quickly spread. 'Towards the end of the summer the same mycelimm produces the dark brown, thick-walled telentospores (Fig. 338, 1), which in this species are always double, 
being united in pairs. Each telentospore is provided with one germ-pore and on germination in the succeding year the cycle is begun afresh. The mycelium of the Uredo-form may hibcruate in winter wheat, and thus the rust may appear in the spring without the previous formation of basidiospores or of aecidia $\left({ }^{89}\right)$.

In heteroecions species the true relation of the varions types of spore can only be made out by means of culture experiments. So long as the connection of the different forms was not known it was enstomary to designate each by a special generic name-the Uredo-forms as Uralo; the aecidia according to their structure as Accilium, Rocstelin, Peridermium, etc. The generic name is now determined by

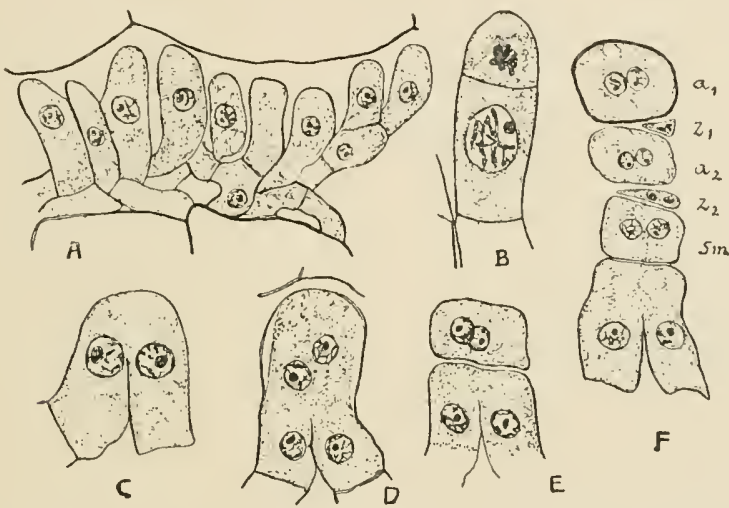

FIG. 342.-Phragmidium speciosum. A, the first rudiment of all aecilium beneath the ejidermis of a leaf of Rese; $B$, the division of the end-cell of a hypha into the upper, transitory, sterile cell and the lower fertile cell ; $C$, conjugation of two adjoining fertile cells ; $D$, later stage in which the first nuclear division is completed ; $E$, abstriction of the first aecicliospore mother-cell ; $F$, chain of aecidiospores $\left(a_{1}, a_{2}\right)$ separated by intercalary cells $\left(z_{1}, z_{2}\right)$; sm, the last-formed sporemother-cell still undivided. (After Christman.)

the character of the telentospores, since they exhibit the most cliaracteristic distiuctions.

All Uredineac do not exhibit so complicated a course of development as Puccinic yraminis. Rust-fungi which produce all the forms of spore are termed en-forms; those withont euredospores, opsis-forms; those without aecidia, brachy-forms ; those without aecidia and uredospores, micro-forms; and lastly, those without aecidia, spermogonia, and uredospores, but with repeated formation of telentospores before basidia are formed, are termed lepto-forms.

In those Uredineae which no longer possess aecidia and spermogonia, the cells of the vegetative mycelium arising from the basidiospore are nninucleate, but subsequently, before the formation of the teleutospores, binucleate cells are found. The binncleate condition is attained, as has already been shown, for sereral species, in the preparation for the development of the first uredospores or, when these are wanting, for the first telentospores. It results fron the conjugation of two cells, as has already been described for the developing aecidium. This suprorts the homology of the three kinds of spore.

\section{Order 3. Auricularieae}

The basidia, as in the case of the Uredineae, are transversely septate, with four 
spores. Only a few forms are included in this order. Among the most familiar

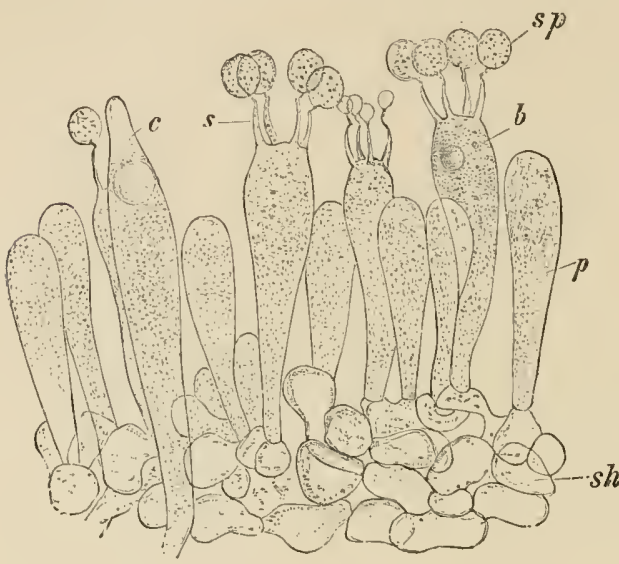

Fir. 343.- linssula rubra. Portion of the hymenium. sh, Sub-lıymenial layer ; $b$, basidia ; $s$, sterigmata ; sp, spores ; 2, paraphyses ; $c$, a cystid. ( $(\times 540$.) is Auricularia sembucina (Judas's ear), found on old Elder stems. It has gelatin. ous, dark brown fructifieations, which are shell-shaped and bear on their imner sides the basidial hynenium.

\section{Order 4. Tremellineae}

The basidia are longitudinally divided (Fig. 334, $B)$. The hymeninm is situated on the upper surface of the frnctifications, which are generally gelatinous and irregularly lobed or folded. The few genera included in this order are saprophytic on decaying wood and tree-trunks, on the surface of which the fruetifieations are produced.

\section{Order 5. Hymenomycetes $\left({ }^{76,84}\right)$}

The basidia are undivided, and bear four spores at the apices of slender sterigmata (Fig. $343, s p$ ). In the simplest forms these basidia spring directly from the myeelium, but in the great majority of eases fructifications are produced, which bear definite hymenial layers, composed, in addition to the basidia, of paraphyses (Fig. 343, p), and also of sterile cystids (c) or club-shaped tubes eharacterised ly their larger diameter and more strongly thickened wall.

Most of the Hymenomyeetes develop their jrofuselylranched white mycelium in the limmus soil of forests, in decaying wood, or ondying tree. trunks, and produce fructifieations, commonly known as toadstools, motruding from the substratum. The myeelinm of the forms vegetating in the soil spreads farther and fartler, and lying in the centre as it ex-

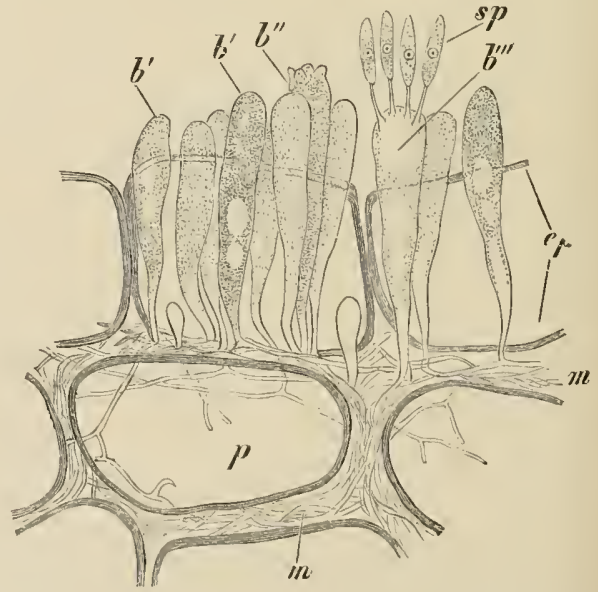

Fra, 344. - Kxobasidium Toceinii. Transverse suction through thr peripluery of a stem of Farininm; $e p$, 'pidermis; $p$, cortical pas'enclyyua; $m$, myceliat hyphae; $b^{\prime}$, frotruling hasillia without sterigmata; $b^{\prime \prime}$, with rudimentary sterignata; $7{ }^{\prime \prime \prime}$, with four spores. (After WokoniN, $\times 620$.) hansts the food material of the substratmo, oenpies eontinually widning con- 
centric zones. In eonsequence of this mode of growth, where the development has been undisturbed, the fruetifications, which appear in autumn, form the soealled fairy rings. A few Hymenomycetes are parasitic, and regetate in the bark or wood of trees.

The Hymenomycetes are further elassified according to the increasing complexity exhibited in the structure of their basidial fructifications.

1. In the Exobasidiineae no distinctive fructifications are formed, and the basidia spring in irregular groups direetly from the myeelium. Exobusidium Tuecinii may be taken as a type of this form. The mycelium of this fungus, whieh is widely spread in Europe, is parasitie in the Ericaceae, especially on species of Tatcinium; it eauses hypertrophy of the infected prarts. The basidia are formed in groups nuder the epidermis, which they finally rupture (Fig. 344). In this genus, as in many others,

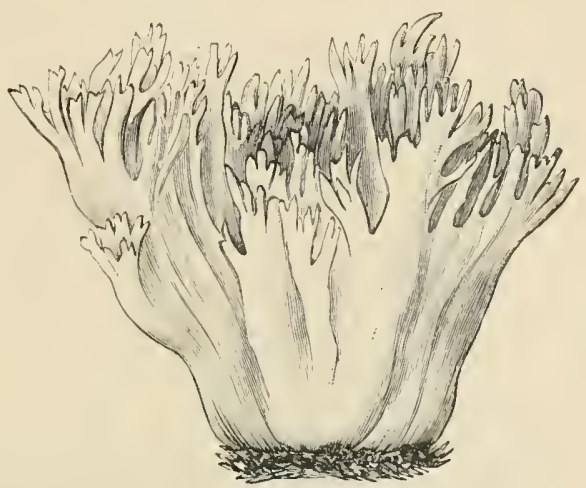

Fi1. 345.-Clararia botrytis. (Nat. size.) aecessory fruetifieations are developerI, and spindle-shaped conidia are abstrieted from the inyeelium on the surface of the host plant, before the formation of the basidia.

2. In the group of the Thelephoreae, distinctive fructifieations of a simple type are found. They form on the trunks of trees either flat, leathery incrustations bearing the hymenium on their smooth uper surfaces; or the flat fruetifications

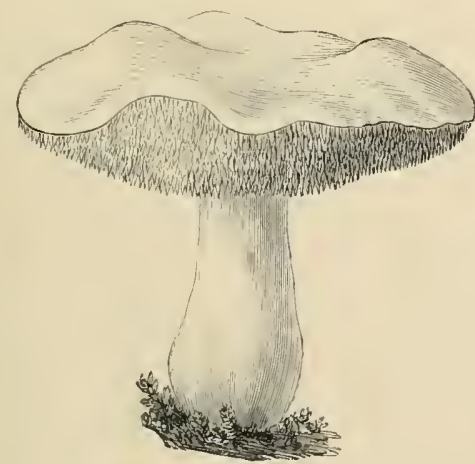

FIG. 346.-Hydnum reptendum. (Reduced.) beeome raised above the substratum and form bracket-like projections, which frequently show an imbricated arraugement, and bear the hymenium on the under side (e.\%. Stereum hirsutum, common on the stems of deciduous trees).

3. The fructifications of the Clavarieae form erect whitish or yellow-colonred bodies, either fleshy and elub-shaped or more or less brauched, in a coral-like fashion. The larger, profusely branched forms of this group are highly esteemed for their edible qualities; in prartieular, Clavaria flare, whose fleshy, yellowcoloured fructifications are often ten centimetres high, also Clavaria botrytis (Fig. 345), which has a pale red colour. Sparassis crispe, which grows in sandy soil in Pine woods, has fructifications lalf a metre in diameter, with compressed, leaf-like branches.

4. The Hydneae have fructifications with spinous projections over which the hymenium exteuds. In the sim oler forms the fructifications have the allearanee of incrustations, with spinous outgrowths projecting from the upper surface; in 
other cases they have a stalk, bearing an umbrella-like expansion, from the under side of which the ontgrow ths depend. The latter form is exhibited by the edible fungi Hyinum imbrieatum, which has a brown pileus $15 \mathrm{~cm}$. wide, with dark scales on the upper surface, and Hydnum repandum (Fig. 346), with a yellowish pileus.

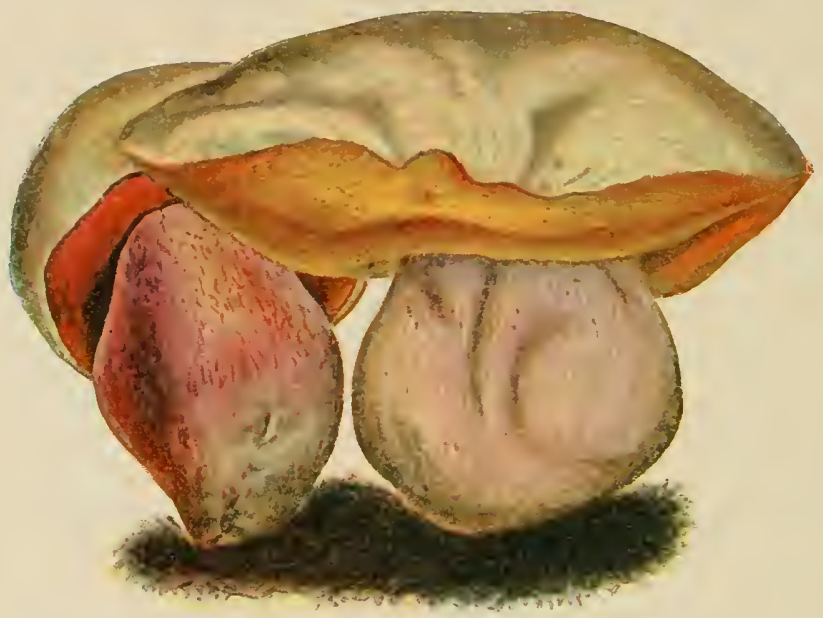

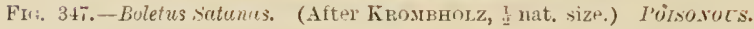

5. In the Polyporeae, a group containing numerous species, the stalked or sessile and bracket-shaped fructifications are indented on the under side with litlike depressions, or deep winding passages, or covered with a layer of tubes, closely

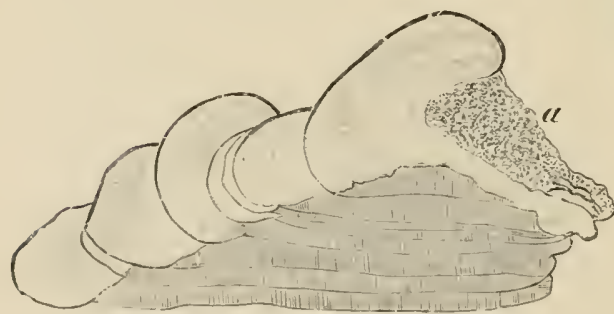

Fu. 345,-Polyporus iyniurins. Suction through an oll fructitieation, showing anumal zones of growth; $a$, point of nttachment. (lis nit. sizr.)

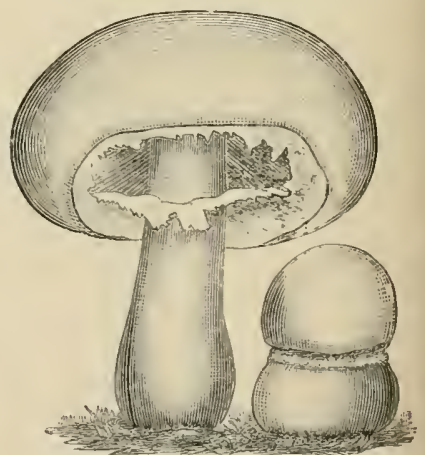

Fis: 3t!,-Poulliotu rempestris (= Agaricus campestris). Mlushrom. To the right a young fructitication. (Rorlucerl.)

fitted together and lined by the hymenium. To this family belongs the genus Eoletus, occurring on the soil of woods, which has a large, thick-stalked pileus, covered on the under side with a layer of narrow dependent tubes. Although many sprecies of this genus are edible (e.y. Ji. cllulis), others are excerlingly 
poisonous, in partieular I3. Saturas (Fig. 34t). The stalk of the latter fungus is a yellow to reddish-purple, or has red reticulate markings, while the pileus, whieh may be $20 \mathrm{em}$. wide, is yellowish-brown on its upper surface, but on the under side is at first blood-red, becoming later orange-red. Of the numerous species of the genus Polyporus, P. fomentarius, Touch-rood, is used in medieine. Its myeelium is parasitic in deeiduous trees, espeeially the Beech, and produces large, bracket or hoof-shaped, perennial fruetifications, $30 \mathrm{~cm}$. wide and $15 \mathrm{~cm}$. thiek. They have a hard, grey external surface, but inside are composed of softer, more loosely woven hyphae, and were formerly used for tinder. The narrow tubes of the hymenium are disposed on the under side of the fruetitications in successive aunual layers. $I$. iymiurius (Fig. 348), which is often found on Willows, and has a similar strueture, has a rusty-brown colonr, and furnishes, since it is much harder, a poorer quality of tinder. Polyporus offieinalis, with an irregularly tuberous white fructification, occurs on Larches in South Enrope; it contains a bitter resinous substance and is also used in medicine.

Many parasitic Polyporeae are highly injurious to the trees attacked by them; thus Heterobasidion an. nosum often causes the death of Pines and Spruce Firs. Mcrulius lacrymans $\left({ }^{90}\right)$ is an exceedingly dangerous saprophytie species only rarely found wild in roods, but attacking and destroying the timber of damp houses, esprecially eoniferous wood. The mycelium of this fungus forms large, white, felted masses with firmer branched strands which serve to conduct water and food sub-

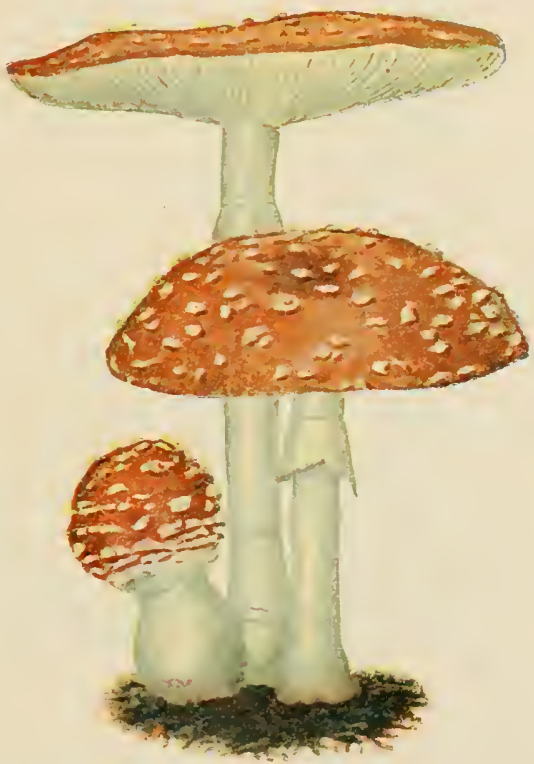

FIc.350.-Amanitu muscario. (1 nat. size.) Porsovocs. stances. It gives rise to outspread, irregularly shaped, pitted fructifications of an ochre or rusty-brown colour, and covered with a hymenial layer. Good ventilation of the infected spaee and dryness are the best remedial measures.

6. The Agaricineae, which inelude the greatest number of species, have stalked fructifieations, commonly known as IIushrooms and Toadstools. The under side of the pileus bears a number of radially disposed lamellae or gills which are covered with the basidia-produeing hymenium. In the early stages of their formation the fructifications consist of nearly spherical masses of interworen hyphae, in which the stalk and pileus soon become differentiated. The rudiments of the stalk and pileus are at first enclosed in a loosely woven envelore, the roLvA. In the course of the further development and elongation of the stalk the volva is ruptured, and its torn remnants form a ring or sheath at the base of the stalk, and in many cases (as in the "Fly Mnshroom," Amanita muscaria) are still traceable in the white seales conspicuons on the red surface of the pileus (Fig. 350). In addition to the rolva many Agaricineae develop a so-called resum, consisting of a thin membrane 
of hyphal tissue which extends in young fructifications from the stalk to the margin of the pileus, but is afterwards ruptured, and remains as a ring of tissue encireling the stalk (Fig. 349).

Nany of the Mnshrooms found growing in the woods and fields are highly esteemed as articles of food.

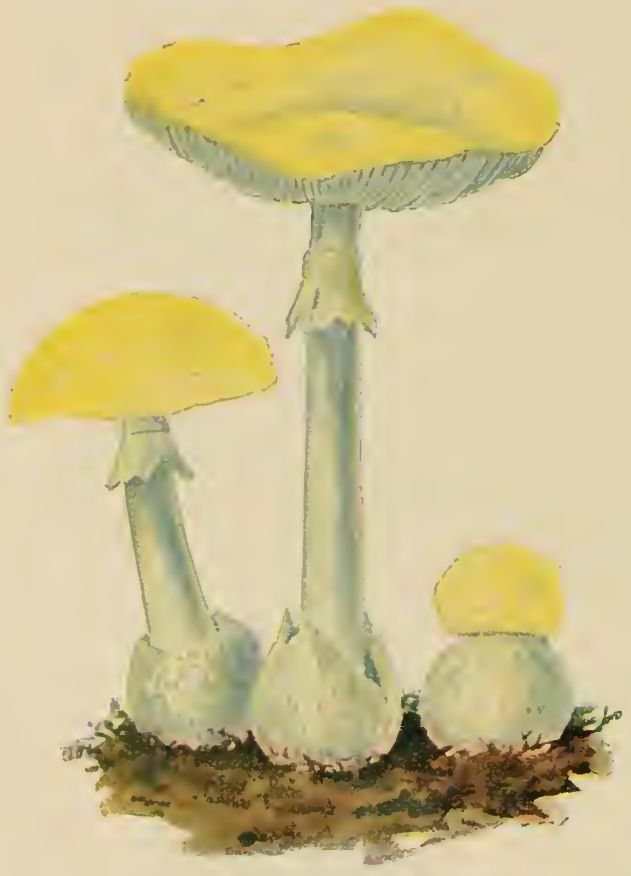

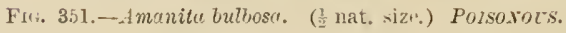
Of edible speeies the following may be named: the common Field - Mushroom, now extensively eultirated, Psalliote campestris (Fig. 349), with whitish pileus and lanellae at first white, then turning flesh-eolomr, and finally beeoming eliocolate-colonred; Cantharcllus cibarius, having an orangecoloured pileus; Lactarius deliciosus, which has a reddish-yellow pileus and contains a similarly colonred milky juice in speeial hyphal tubes; Lepiota procera, whose white pileus is flecked with brown seales; $A$ manita caesurec with an orange pileus bearing a few white scales and yellow lamellae. The brownish frnetifications of Amillaria mellea are also edible. This species is a very injurious parasite, especially in Pine woods; its mycelinm is characterised by the produetion of photogenie substanees which eause the infected wood to appear phosphorescent in the dark $\left({ }^{91}\right)$. The mycelium forms as a resting stage blackish branched strands (rhizomorphs) beneath the bark or between the roots of the host jlauts.

Of the poisonous Agaricineae the following are best known: Amanita muscaria (Fig. 350), with white lamellae; Amanita bulbosa (Fig. 351), often confounded with the Mushroom, with whitish or yellowish pileus and the stalk swollen at the base; Russuin cmetica, with a red pilens and white lamellae; Lactarius torminosus. having a shaggy, yellow or reddish-brown fileus and white milky juice.

Prozites gomgylophora, fonnd in South Brazil, is of special biological interests According to $\Lambda$. Mör.LE⿺, this species is regularly enltivated in the nests of the leaf-rutting ants. Its myeelium produees spherieal swellings at the ends of the hyphae, which become filled with protoplasm, the so-called liohl-rabi heads, and serve the ants as food material. The ants prevent the development of the accessory conidial fruetifieations peculiar to this fungus, and thus continually maintain the nyeelium in their nests in its regetative condition. The fructifieations, which rarely occur in the nests, resemble those of Amanitu muscariu, with which Rozites 
is nearly allied. According to HoLtermax, the mycelim of Agaricus rajub is cultivated in their nests by termites in tropical Asia ( $\left.{ }^{92}\right)$.

Ecoxomic Uses. - Polyporus fomenturius (Fuxgrs chirurgortin). Pulyporus ofjucinalis (=Boletus larivis) gives Agaricus ALPT's, Agaricinum, and Acidum Agaricinum.

\section{Order 6. Gasteromycetes $\left({ }^{76}\right)$}

The Gasteromycetes are distinguished from the Hymenomycetes by their closed fructificatious, which open only after the spores are ripe, by the rupture of the outer hyphal cortex or PEIDIrM. The spores are formed within the fructifications in an inner mass of tissue terned the GLEBA; it contains numerous chambers, which are either filled with loosely interwoven hyphae with lateral branches terminating in basidia, or their walls are lined with a basidial hymeniuns.
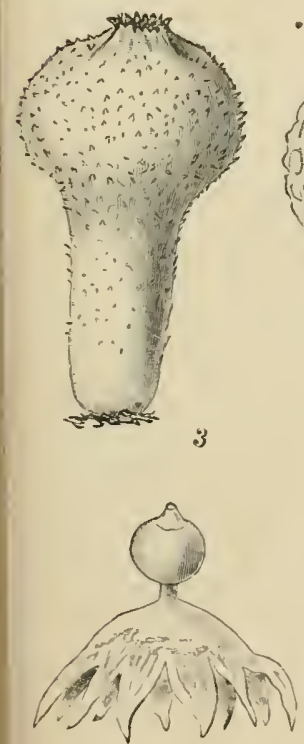

4
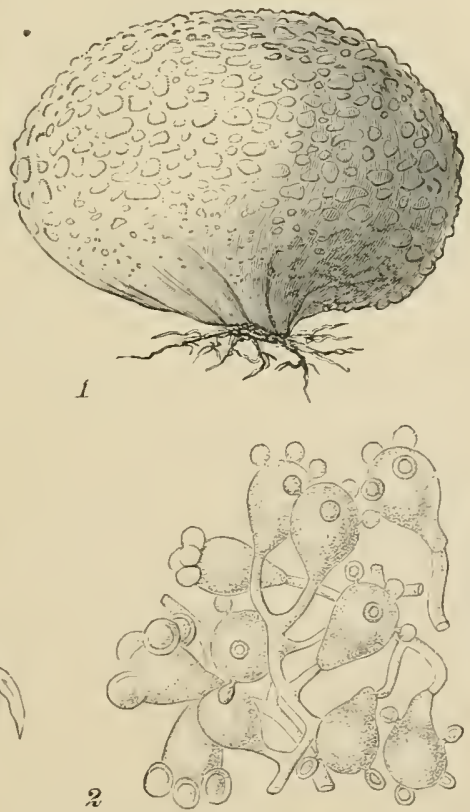

FIr, 35\%.-1, scleroderma vulgare, fructitication; 2 , basidlia of same. (After Tulasne.) 3, Lyeoperdon gemmatum ; 4 , Geaster granulnsus. ( $1,3,4$, nat. size ; 2 enlargerl.)

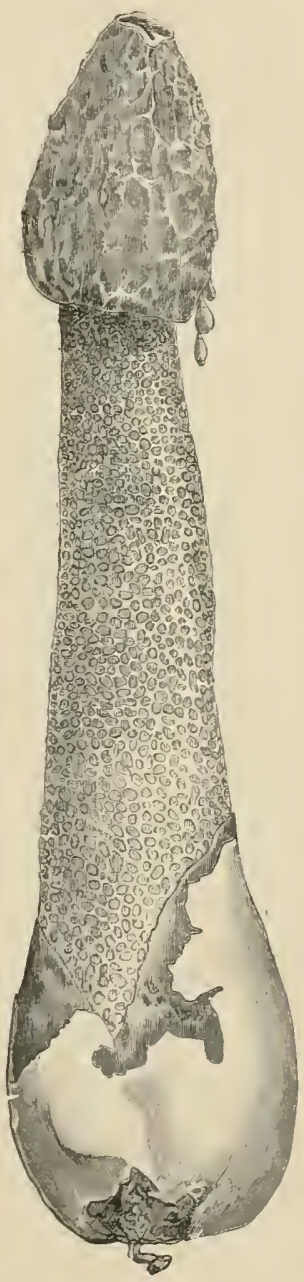

Fir, 353.-Phallus impulicus. (After Kroniholz, $\frac{1}{2}$ nat. size.)

The Gasteromycetes are saprophytes, and derelop their mycelium in the humus soil of woods and meadows. Their fructifications, like those of the Hymenomycetes, are raised above the surface of the substratum, except in the group of the Hymenogastreae, which possesses subterrantan, tuberous fructifications resembling those of the Tnberaceae. 
The fructifications of Seleroderma vulyare (Fig. 352, 1) have a comparatively simple structure. They are nearly spherical, usually about $5 \mathrm{~cm}$. thick, and have a thick, light brown, leathery peridium which finally becomes crackerl and rupturerl at the anex. The gleba is black when ripe, and contains numerous chambers filled with interwoven hyplae which produce lateral, pear-shaped basidia with four sessile spores (Fig. 352, 2). This species, which is considered poisonous, is sometimes mistaken for one of the Trufle Fungi.

The genera Boriste and Lyeoperdon (Fig. 352, 3) (Puflballs) have also spherical frnctifications, which are at first white and later of a brown colour. In the lastnamed genus they are also stalked, and in the case of Lycoperdon Boriste may even become half a metre in diameter. The peridium is formed of two layers; the onter separates at matnrity, while the inner dehisces at the summit. The hymenial layer of basidia, in the fungi of this group, lines the eliambers of the gleba. The chambers are also provided with a fibrous capillitiun consisting of brown, thickwalled, branched hyplaae which spring from the walls, and aid in distributing the spores. The fructifications are edible while still young and white. When mature they contain urea which is not elsewhere found in plants.

In the related genus Geaster (Earth-star) (Fig. 352, 4) the peridia of the nearly spherical fructifications are also composed of two envelopes. When the dry fruit dehises, the onter envelope splits into several stellate segments and the inner layer of the peridium becomes perforated by an apical opening.

The highest development of the fructifications is exhibited by the Phalloideae $\left({ }^{93}\right)$, of which Phallus impudieus (Stink-horn) is a well-known example. This fungus is ustually regarded as poisonons. It was formerly employed in a salve as a renedy for gout. Its fructification recalls that of the discomycetous Morchelle, but it has quite a difierent mamner of development. A fructification of this species of Pliallus is about $15 \mathrm{~cm}$. high. It has a thick, lollow stalk of a white colour and is perforated with pores or chambers. Surmounting the stalk is a bellshaped pileus covered with a brownish-green gleba which, when ripe, is converted into a slimy mass (Fig. 353). When young the fruetification forms a white, eggshaped body, and is wholly enveloped by a double-walled peridium with an intermediate gelatinons layer. Within the penLmin (also termed volva) the hyphal tissue becomes differentiater into the axial stalk and the bell-shaped pileus, carrying the gleba in the form of a mass of hyllial tissue, which contains the chambers and basidial hymenium. At maturity the stalk becomes enormously elongated, and pushing through the ruptured peridium raises the pilens with the adhering gleba high above it. The gleba then deliquesces into a dropping, sliny mass, which enits a carrion-like stench serving to attract carrion-flies, by whose agency the spores embedded in it are disseminated.

\section{Class XIV}

\section{Lichenes (Lichens) $\left({ }^{55,}, 94-1010\right)$}

The Lichens are symliotic organisms; they consist of higher Fungi, chietly the Ascomycetes, more rarely Basidiomycetes, and unicellular or filamentous Algae (Cyanophyceae or Chlotophyceae), living in intimate connection, and together forming a componnd thallus or ('onsontium. Strictly speaking, both Fungi and Algae should be classified in their respective orders; but the Lichens exhibit among 
themselres such an agreement in their structure and mode of life, and have been so evolved as consortia, that it is more convenient to treat them as a separate class.

In the formation of the thatlus the algal cells become enveloped by the mycelium of the fungus in a felted tissue of hyphie (Fig. 354). The fungus derives its nourishment saprophytically from the organic matter produced by the assimilating alga; it can also send haustoria into the algal cells, and so exhaust their contents $\left({ }^{95}\right)$. The alga, on the contrary, derives a definite advantage from its consoltism with the fungus, receiving from it inorganic substances and water, and possibly organic substances also. From the symbiosis entered into by a Lichen fungus with an alga, a dual organism results with a distinctive thallus, of which the form (influenced by the mode of nutrition of the independently assimilating alga) differs greatly from that of other non-symbiotic Eunycetes.

The thalli of the Lichens exhibit a great variety of forms.

The simplest Lichens are the FILAMENTOUs, with a thallus consisting of algal filaments interworen with fungal hyphae. An example of such a filamentous form is presented by Ephebe pubescens, which is found growing on damp rocks, forming a blackish layer.

Another group is formed by the GELATIxous Lichens, whose thallus, usually foliaceous, is of a gelatinous nature. The algae inhabiting the thalli of the gelatinous Lichens belong to the families of the Chroococcaceae and Nostocaceae, whose cell walls are swollen, forming a gelatinous mass traversed by the hyphae of the fungus. The genus Collema is a European example of this group.

In both the filamentous and gelatinous Lichens the algae and the fungal hyphae are uniformly distributed through the thallus, which is then said to be unstratified or HoMOIOMEROUS.

The other Lichens have stratified or HeTERonerous thalli. The enclosed algae are usually termed GoNIDIA. They are arranged in a definite GONIDIAL IAYER, covered, externally, by a CORTICAL LAIER, devoid of algal cells and consisting of a psendo-parenchyma of closely woven hyphae (Fig. 354). It is customary to distinguish the three following forms of heteromerous Lichens. Crustaceous LiCHexs, in which the thallus has the form of an incrustation adhering closely to a substratum of rocks or to the soil, which the hyphae to a certain extent penetrate. FolidCEOUs LiCHeNs (Fig. 355), whose flattened, leaf-like, lobed, or deeply-cleft thallus is attached more loosely to the substratum by means of rhizoid-like hyphae (rhizines), springing either from the middle only or irregularly from the whole under surface. Fruticose Lichens (Fig. 356) have a filamentous or ribbon-like thallus branched in a shrub-like manner and attached at the base. They are either erect or pendulous, or may sometimes lie free on the surface of the substratum.

In nature the germinating spores of the Lichen Fungi appear to 
be capable of continuing their further development only when they are enabled to enter into symbiosis with the proper gonidia. For a few genera of Lichens, however, it has been determined that the fungi sometimes exist in nature without the presence of the algae; it has been shown that the tropical Lichen Cora paronic (Fig. 362), whose fungus belongs to the order Hymenomycetes, may produce fructifications even when deprived of its alga; these have a form resembling those of the fungal genus Thelephora. Small thalli have also been successfully grown from the spores of certain Lichenforming Ascomycetes, cultivated withont algae and supplied with a proper nutrient solution.

Many Lichens are able to multiply in a purely vegetative manner,

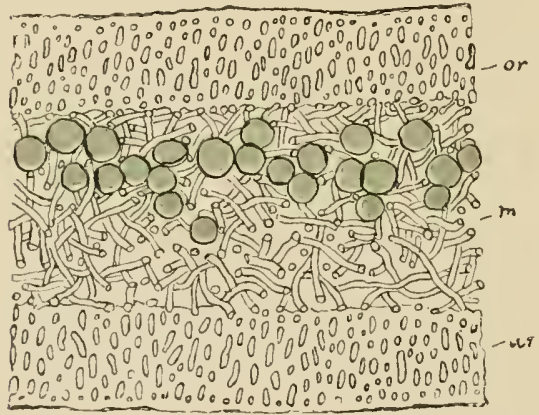

Fr: 35t.-Cetraria islanlica. Transverse section through the thallus; or, cortical layer of upper surface; $t r$, of the lower surface; $m$, medullary layer containing the green cells of the Alga, Chlorococcum humirola. $(\times 272$. by means of loosened pieces of the thallus, which continue their growth and attach themselves to the sub-

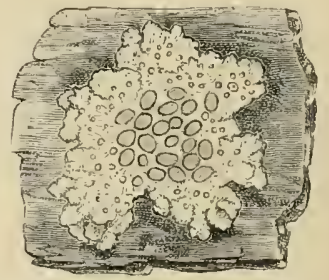

Flt: 355.-Xanthoria parietina on a piece of bark. (Nat, size.)

stratum with new rhizines. The majority of the heteromerous Lichens possess in the formation of sorEDIA another means of regetative multiplication. In this process, small groups of dividing gonidia become closely entwined with mycelial hyphae and form small isolated bodies which, on the rupture of the thallus, are scattered in great numbers by the wind and give rise to new Lichens.

The fructifications of the Lichens are produced by the fungi, not by the algae, which are purely vegetative.

The numerons Liehenacids which are wanting only in the gelatinous Lichens are products of metabolism peeuliar to the group. Their production is due to the mutual chenical influence of the alga and fungus. They are deposited on the surface of the hyphae in the form of erystals or gramnles. Their supposed use as a protection against suails appears, aecording to KopF, not to hold generally ${ }^{96}$ ).

\section{Ascolichenes}

Only a few genera of Liehens have flask-shaped perithecia, the fungus belonging to Pyrenomyectes (Endocarpon, Verrucaria). Most genera produce, as 
the aseus-fruit of their fungus, eupular or discoid apothecia, sessile or somewhat sunk in the thallus. In structure they resemble those of the Pezizeae, and bear on their ulper side an hymenium of asci and paraphyses. One of the commonest speeies of fructicose Lichens belonging to this group is I'snea barbata, the Beard Lichen, frequently oceurring on trees and having large fringed apothecia (Fig. 356). liamalina fraxinee which has a broal ribbon-shaped branched thallus and grows on trees, and the numerons species of Roccelle found on the rocks of warmer coasts, have similar apotheeia. Cetrarie islandica, Iceland Moss (Fig. 357), occupies an intermediate position between the fruticose and foliaceous Lichens. It has a divided, foliaceous but partially ereet thallus, which is of a light bluishgreen or brown colour, whitish on the under side, and bears the apothecia obliquely on its margin. This Lichen is found in mountainous regions and in the northern part of the Northern Hemisphere. Xanthoric parictine (Fig. 355) may be

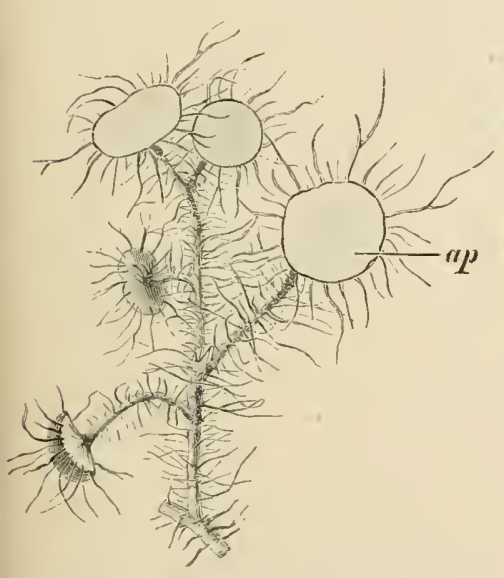

FLt, 356.-Usncu berbate. ap, Apothecium. (Nat. size.)

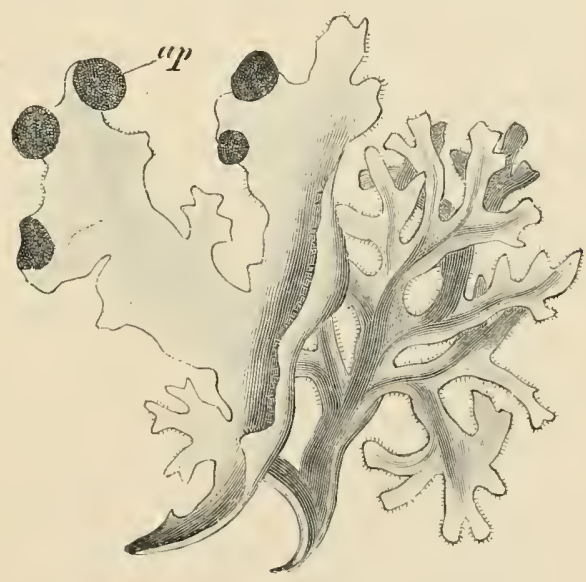

Fur, 357.-Cetraria islundicu. ap, Apothecium, (Nat. size.) OFFlCLA $L$.

taken as an example of one of the commonest of the foliaceous Lichens. The thallus is orange-yellow in colour, and bears numerous apothecia on its central portions. Graphis scripta is a well-known example of the crustaceous Lichens ; its greyishwhite thallns oceurs on the bark of trees, particularly of the Beech, on whose surface the apothecia are disposed as narrow, black furrows resembling writing.

A peeuliar mode of development is exlibited by the genus Cladonü $\left({ }^{97}\right)$, whose primary thallus consists of small horizontal scales attached directly to the ground, from which rises an erect portion, the PODETIUM, of varying form and structure in the different species. In some eases the podetia are stalked and funnel-shaped, hearing on the margin or on outgrowths from it knob-like apothecia, which in C. pyxidata are brown, in C. cocciferce (Fig. 358) bright red. In other species the erect podetia are slender and cylindrical, simple or forked; in C. rangiferina, Reindeer Moss, which has a world-wide distribution, particularly in the tundras of the North, the podetia are finely branched (Fig. 359), and bear the small brown apothecia at the ends of the branches. The primary thallus of this species soon disappears.

The ascus-fuetifications (apotheeia or perithecia) of the Lichens originate, as 
Sranl and, more recently, liavr (98) have shown, from carlogonia or female sexual organs which are frequently present in larse numbers on young lobes of

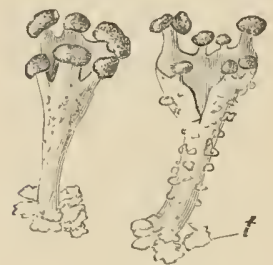

Fic, 358, - clatonia coccifera. $t$, scales of primary thallus. (Nat. size.)

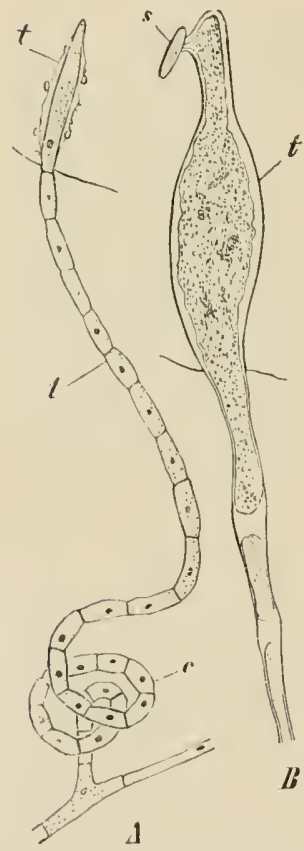

Fıc, 360.-Collemu crispum. A, carpuguniun (r) witl, its trichogyine $(i)(>405)$. li, a)ex of the trichogyne with the sirmatium (s) attachris ( $\times 1125)$. (Aiter E. BAUR.)

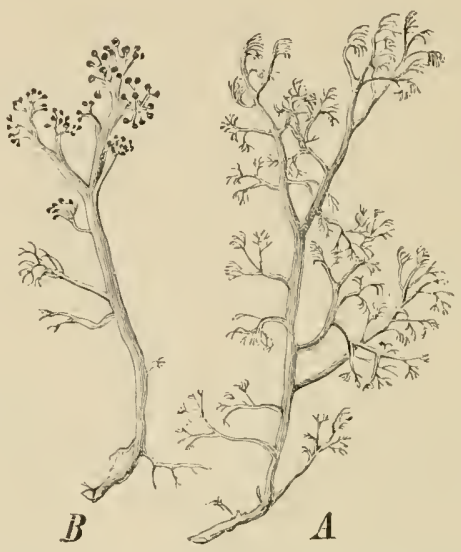

Fu. 359--Clatoniu rengiferinu. A, sterile ; $D$, with ascens-fruits at the ends of the branclies. (Nat. size.)

the thallns. The (arpogoninu (Fig. 360) is here a multieellular filament, the lower part of whieh is sjirally coiled, while it continues alove into a trichogyne composed of elongated cells and projecting from the surface of the thallus. All 
the cells are uninucleate and communicate with one another by means of pits. Those of the lower part of the filament contain abundant protoplasm. A part from their multicellular nature these structures recall the carpogonia found in the Florideae. The spermatia which originate in spermogonia (Fig. 361) are presumably the male sexual cells. The spermatia develop in different ways $\left({ }^{99}\right)$. In some cases the inner wall of the spermogonium is liner with simple or brancher hyplual branches from the ends of which the slermatia are abstricted (Peltigere, Purmeliu). In other cases the spermogonimm is at first filled with a hyphal tissue in which cavities are formed later and the spermatia arise on very sniall and thin stalks from the cells lining the cavities (Anaptychia, Physcia, Stieta). The spermatia, embedderl in a slimy mass, are shed from the spermogonium and conjugate with the adhesive tip of the trichogyne (Fig. 360, B). After conjugation the spermatia appear empty and their nucleus has disappeared. When this has taken place the cells of the trichogyne collapse, while the cells of the coiled carpogronimm swell, undergo divisions, and form the ascogonium. From the latter the ascogenous hyphae which bear the asci are produced. The vegetative hyphae composing the fruetification and the paraphyses originate from hyphae which arise below the carpogonium. The fructification may arise from one or from several carpogonia. The behaviour of the sexual unclei requires further investigation. Such carpogonia have been shown to give rise to the fructifications in a large number of genera. In other genera (Peltigere, Solcrinct) they are reduced and the trichogyne is wanting, and the reproduction is apoganous. Spermogonia are as a rule not found in these cases, or are, as in the case of Tephromium, elearly degenerating structures. It has been shown by A. MöLLER $\left({ }^{99}\right)$ that the spermatia of Lichens can germinate and produce a nycelium; but this is not inconsistent with their primitively sexual nature.

\section{Basidiolichenes (Hymenolichenes) $\left({ }^{100}\right)$}

The Hymenolichenes are represented by Cora paronia, of which the genera Dictyonema and Laulated are only special growth forms. This Lichen is widely spread in the tropies growing on the soil or on trees. The fungus of this Lichen belongs to the fanily Thelephoreae (P. 411); its flat, lobed, and often imbricated fructifications are also found entirely devoid of Algae. In symbiosis with the unicelhular Alga Cleroococeus, it forms the fructifications of Coraparonia (Fig. 362), resembling those of the Thelephoras with a channelled, basidial hymenium on the nnder side. Associated symbiotically, on the other hand, with filaments of the blue-frreen Alga Seytonema, if the Fungus preponderates, it produces the bracket-like Lichens of the Dictyouewa form, found projecting from the branches of trees with a semicireular or nearly circular thallus, having the hymenium on the under side. When

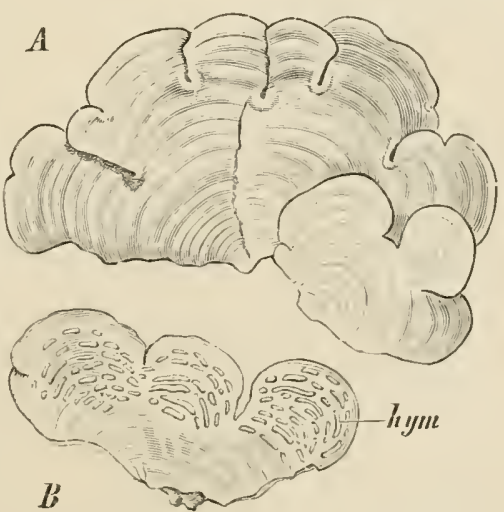

Fu, 312.-Cora naroniu. A, viewerl from above; $B$, flom below; hym, lymenium. (Nat. size.)

the shape of the thallus is determined by the Alga, a Lichen of the Laudatea 
form occurs as felted patches of fine filaments on the bark of trees, with the hymenium on the parts of the thallns, which are turned away from the light.

OFFICLAL. - The only representative of the Liehens is Cetraria islandica (Lichen isliandicus). Sticta putmonacea is also used in domestie medicine.

The Manna Lichen (Leconora esculcnta) is a erustaceous Liehen that often covers the ground to a depth of $15 \mathrm{~cm}$. in the Steppes and Deserts of Southerm Russia, Asia Minor, and North Africa. The thallus falls into pieces the size of a pea, and is thus readily spread by the wind; it is used by the Tartars who prepare earth-bread from it. Gyrophora csculenta is eaten in Jajan. Clalonia ranyiferina is important as affording food for the Reindeer.

Some speeies particularly rich in Liehen acids are used in the preparation of the pigments orseille and litmus; there are in the first place species of liocecla (especially $R$. Montagnei, $R$. tinctoria, $R$. fuciformis, and $R$. phycopsis) which are collected on the coasts of the warmer oceans, and the crustaceous lichen, Ochrolechen tartarea, in North Europe and America.

\section{Class XV}

\section{Characeae (Stoneworts) $(s, 101)$}

The Characeae or Charophyta form a gromp of highly organised green Thallopliytes sharply isolated from both simpler and higher forms. Their origin must be looked for in the Chlorophyeeae, but the complicater strneture of their sexual organs does not allow of any immediate connection with the oogamons Green Algae. On the other hand in some characters they show some approach to the Brown Algae, from which they difler in the pure green colour of the chromatophores. They cannot be regarded as leading towards the Bryophyta although their karyokinetic nuclear division exhibits a great agreement with that of the Archegoniatre.

The Characeae grow in fresh or brackish water, attached to the bottom and covering extended areas with a mass of vegetation. Their regular construction and habit is characteristic. In some species their cylindrical main axes are over a foot in length, and are composed of long internodes alternating with short nodes, from which short, cylindrical branches are given off in regular whorls with a similar structure, but of limited growth (Fig. 363). The lateral axes are either unbranched or give rise at their nodes to verticillate ontgrowths of a second order. From the axil of one of the side branches of each whorl a lateral axis resembling the main axis is produced. The attachment to the substratum is effected by means of colourless branched rhizoids springing from the nodes at the base of the axes.

Both the main and lateral axes grow in length by means of an apieal cell, from which other eells are suceessively ent ofl by the formation of transverse walls. Each of these cells is again divided by a transverse wall into two cells, from the lower of which a long internodal cell develops without further division; while the upper, by continued division, gives rise to a dise of nodal cells, the lateral axes, and also, in the lower portion of the main axis, to the rhizoids. In the genus Nitella the long internorles remain naked, but in the gemus Chara they become enveloped by a cortical layer eonsisting of longitudinal rows of cells which develop at the nodes from the basal cells of the lateral axes. A corresponding 
construetion is only found among other Thallophyta in certain Brown Algae (e.g. Spermatochnus).

Each cell contains one normal muclens derived from a karyokinetic division. As a result of the fragmentation of its original nuclens, however, eaeh internodal cell is provided with a number of nuelei which lie embedded in an inner and actively moving layer of parietal protoplasm. Numerous round chloroplasts are found in the internodal cells.

Asexual reproduction by means of swarm. spores or other spores is unrepresented in the Characeae. Sexual reproduction, on the other hand, is provided for by the production of eggcells and spermatozoids. The female organs are ovate. They are visible to the naked eye; and, like the spherical red-coloured anthericlia, are inserted on the nodes of the lateral axes. With the exception of a few dioecious species, the Characene are monoecions. The fertilised eggcell develops into an oospore in the germination of which, as we are forced to assume, the reduction-division of the diploid fusionnucleus takes place. The Characeae thus exhibit no alteration of haploid and diploid generations but a succession of haploir gametophytes.

The male organs (Fig. $364, a$ ) are developed from a mother-eell that first becomes divided into eight cells. Each octant by two tangential walls gives rise to three cells. In this way are derived the eight external tabular cells of the wall, the cavities of which are incompletely partitioned by septa extending in from the cell wall; the eight middle cells form the manubria and become elongated; the eight

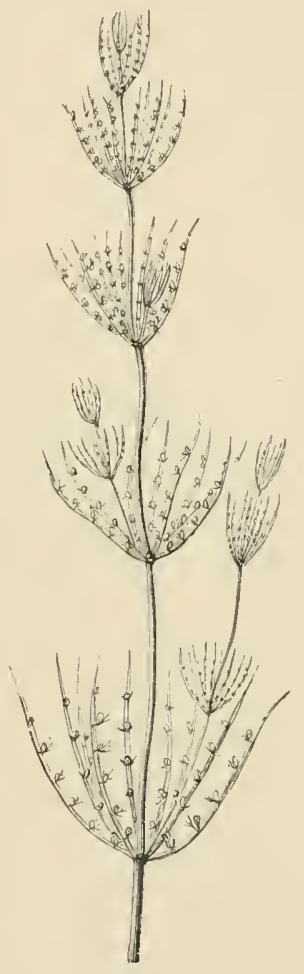

Fif: 363,-Chara fragilis. End of main slioot. (Nat. size.) innermost cells assume a spherical form as the primary head-cells. Owing to the rapid surface growth of the eight shield cells a cavity is formed within the male organ into which the manubria bearing the head-cells project. The latter form 3-6 secondary head-cells and from each of these arise 3-5 long unbranched spermatogenous filaments. These are composed of dise-shaped cells from each of which a spirally wound spermatozoid with two eilia is liberated (Fig. 99, A). The spermatogenous filaments or antheridia may be compared morphologically to the plurilocular gametangia of the Brown Algae. These, as in Stilophore for instance, may consist of simple rows of cells and be grouped together in sori. The male organ of the Characene, which as a whole is commonly spoken of as an antheridium, thus contains 
eight gromps of endogenously-formed antheridia and must on this account be termed an antheridiophore.

The female organ (Fig. 364, ob) consists of in oogonium which contains a single egg-cell with numerons oil-drops and starch grains. To begin with the oogonium projects freely, but later becomes surrounded by five spirally wound cells. These cells end in the corona, between the cells of which the spermatozoids make their way in

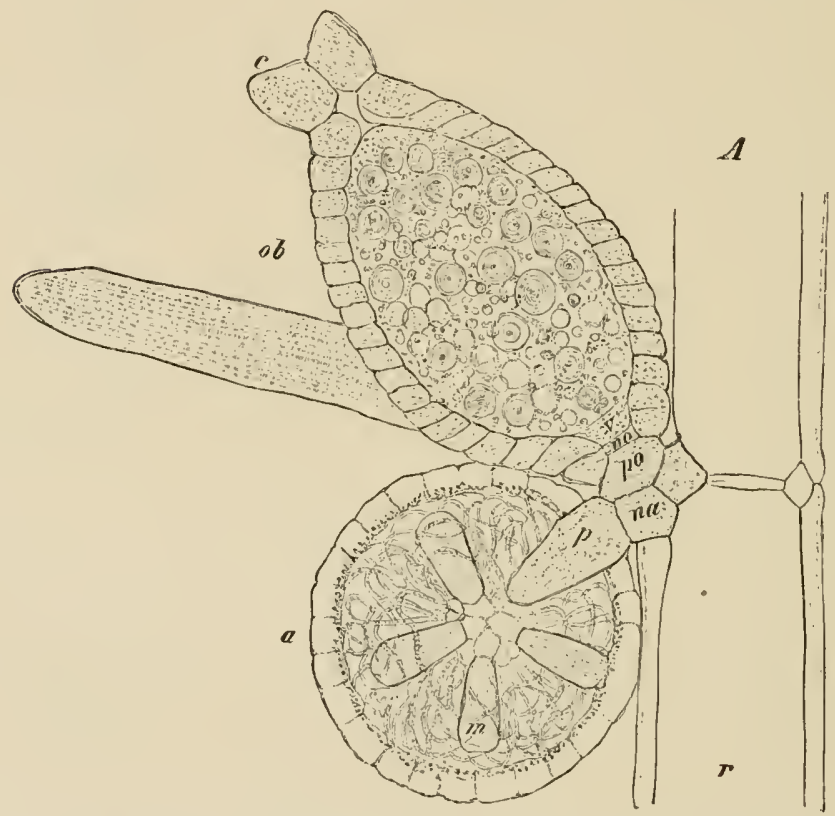

Fis: 364.-Chare fregilis. A, median longitudinal suetion throngh a lateral axis $r$, and the sexual organs which it bears $(x(0)$; a, anthericlium borne on the basal nodal eell na, by the stalk cell $f$; $m$, manubrium; ob, an oogonium; no, nodal r.ell ; po, the stalk-cell; $v$, pirotal cell (Wendungszelle); e, the crown. $\quad b$, a lateral axis bearing axes of the third order $(\times 6) ; a$, antheridium; o, oogonitum.

fertilisation. At the base of the oogonium there are small cells (Wendungszellen) cut off from the cell-forming oogonial rudiment; in Chrra there is one, in Nitelle three such cells. These divisions correspond to the first divisions in the mother-cell of the male organ. The female organ may thus be reganded as an oogoniophore reduced to a single oogoninm.

The coge, after fertilisation, now converted into an oospore, becomes invested with a thick eolourless wall. The inner walls of the tubes hecome thickened and encrusted with a deposit of caleium carbonate, while the external walls of the tules, soon after the fruit has been shed, lecome disintergated.

The oospore, on germination, gives rise first to a simple, filamentons row of 
eells, the proembryo. From the first node of the procmbryo rhizoids are produced, while at the second nocle there arise, together with a few simple lateral axes, one or more main axes, which finally develop into a full-grown plant.

Chara crimite, only female plants of which occm in Emrope, is remarkable in that the egg-cells develop parthenogenetically (i.e. without being fertilised) into oosjores. These, omitting the reduction division, give rise to jurely female sexual plants.

The formation of tuber-like bodies (bulbils, starch-stars) on the lower frart of the axes is charaeteristic of some spreeies of the Characeae. These tubers, which are densely filled with stareh and serve as hibernating organs of vegetative reprodnetion, are either modified noles with much-shortened branch whorls (c.g. in Tolypellopsis stelligera, when they are star-shajed), or correspond to modified rhizoids (e.g. the spherical, white bulbils of Charce aspera).

\section{BRYOPHYTA (MOSSES AND LIVERWORTS) $(102,103,104)$}

The Bryophyta or Muscineae comprise two classes, the Heputicae or Liverworts, and the Musci or Mosses. They are distingnished from the Thallophyta by the characteristic structure of their sexual organs, ANTHERIDIA and AICHEGONIA, which are similar to those of the Pteridophyta. The Bryophyta and Pteridophyta are accordingly in contrast to the Thallophyta, referred to collectively as Archegoniutue.

The Bryophyta as well as the Pteridophytes multiply also asexually by means of spores provided with cell walls and adapted for dissemination through the air. These two modes of reproduction, sexual and asexual, occur in regular alternation, and are confined to sharply distinct generations: a sexual (gametophyte), provided with sexual organs, and an asexual (sporophyte), which produces spores. The sexulal generation arises from the spore; the ascxual from the fertilised egg. The number of chromosomes in the nuclei of the sporophyte is twice as great as in the nuclei of the gametophyte. The double number is acquired in the fusion of the sexual nuclei, while the reduction to one-half takes place in the division of the spore-mother-cells. This REGULAR ALTHRNATION OF GeNerations is characteristic of all Archegoniatae. While in the Bryophyta the plant is the haploid generation, in the Pteridoplyta the plant is diploid.

In the development of the slixual aneration, the miccllular spore on germinating ruptures its outer coat or ExINE, and gives rise to a germ-tube. In the case of the Hepaticae, the formation of the plant at once commences, but in most of the Musci a branched, filamentons PROTONEMA is first produced, composed of cells containing chlorophyll. (Fig. 365, $\%$ ). The green, filamentous protonema gives rise to branched, colourless rhizoids $(r)$, which penetrate the substratum. The Moss-PLANTS arise from londs developed on the protonema at the base of the branches.

Protoncma and Moss-plant, in spite of the difference in appearance 
between them, together represent the sexual generation. Many Liverworts possess a thallus consisting of dichotomously branching

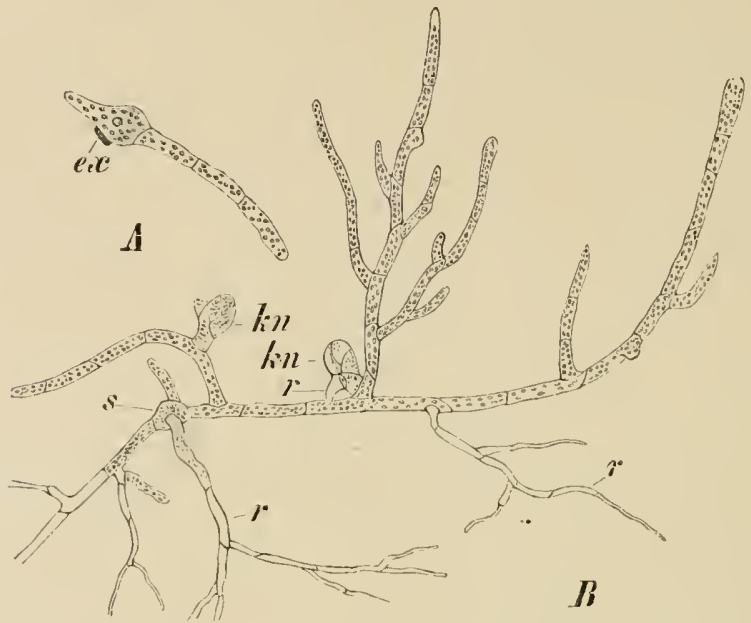

Fif. 365.-Funaria hygromerrica. A, germinating spore ; ex, exine ; $D$, protonema ; $k n$, buds ; $r$, rhizoitls ; $s$, spore. (After Mluler-Thurgat ; magnitiel.)

lobes, which is attached to the substratum at its base or on the under side by means of rhizoids, thus repeating the vegetative structure of many Algae (Fig. 369). In the higher Hepaticae, on the other hand,

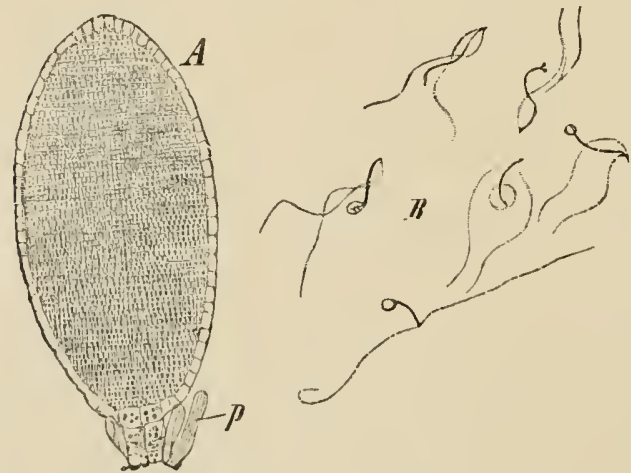

F16. 366.-Marchentia polymorpha. A, nearly ripe antheridinm in optical section; $p$, parapliyses. $B$, spermatozoids fixei with 1 jer cent perosuic acil. $(A \times 90, \mathrm{~B} \times 600$. and in all the Musei, there exists a distinct differentiation into stem and leaves (Figs. 375, 381). Rhizoids spring from the lower part of the stem. True roots are wanting in the Bryophytes, which thus do not attain a higher grade of organisation than the differentiated thallus already met with among the Brown Algae, for example in Sargassum. The stems and leaves of Mosses are also anatomically of a simple structure; if eonducting strands are present, they are composed merely of simple elongated cells. The sexual organs (antheridia and arehegonia) are 
produced on the adult, sexual generation; in the thalloid forms, on the dorsal side of the thallus; in the cormophy tie forms, at the apex of the stem or its branches.

The ANTHERIDIA (Figs. 366, 367) or male sexualorgans are stalked, ellipsoidal, spherical, or club-shaped, with thin walls formed of one layer of cells and enclosing numerous small, enbical cells, each of which beeomes divided diagonally, but without the formation of a cell wall,
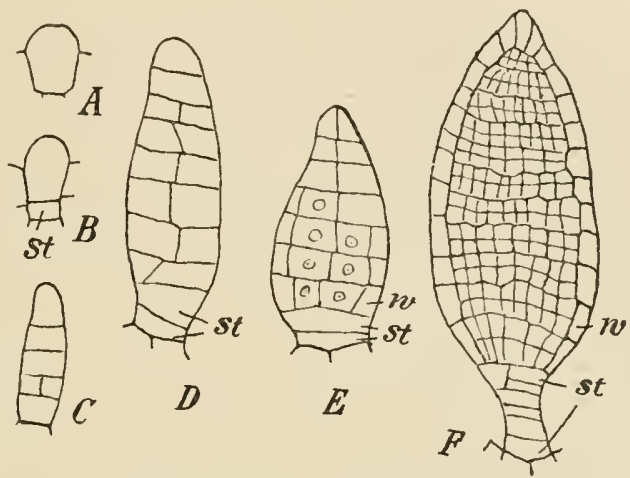

Fici, 367.-Development of the antherilium in Fegutella conice, one of the Marchantiaceae. A, unicellular stage. $B$, the stalk-cell (st) cut off. $C, D$, antheridium diviled into a row of eells which in turu are dividing by longitudinal walls. E, cutting off of the layer of cells to form the wall (w). $F$, advanced stage of levelopment. $(A-E \times 400$; $F \times 220$; after BolletER.)

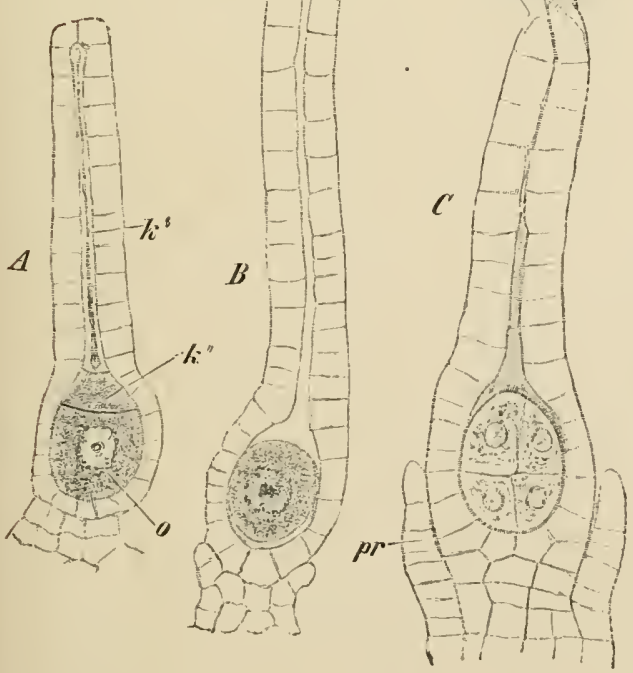

Fu. 3is.-Marchantia polymorpha. A, young, $B$, mature archegonium; $C$, fertiliserl archegoniım, ı. ith dividing egr-cell; $k^{\prime}$, neck-canal-cell ; $k^{\prime \prime}$, ventral-canal-cell ; 0 , egg-cell ; $p r$, pseudo-periantlı. ( $\times$ 540.) into two spermatozoid mother-cells (105). At maturity the spermatozoid mother-cells separate and are ejected from the antheridium, which ruptures at the apex. By the dissolution of the enveloping walls of the mother-cells the spermatozoids are set free as short, slightly twisted filaments, bearing two long cilia elose to the anterior end.

The ARCIEGONIA (Fig. 368) are flaskshaped bodies, sessile or shortly stalked, sometimes also somewhat sunk in the tissue, and consist of a dilated ventral portion and a neck. The ventral portion encloses a large central cell, the contents of which shortly before maturity divide 
into the egg-cell (Fig. $368, d, 0$ ) and the ventral-canal-cell $\left(k^{\prime \prime}\right)$. The latter is situated at the base of the neck, just below a central l'ow of neek-canal-cells $\left(k^{\prime}\right)$. On the maturity of the archegonium, the ventral- and neck-canal-cells become mucilaginous and disorganised. If water is present, the eells at the apex of the neck separate $(B)$ and the mucilaginous matter is discharged, and exerts through the diffusion of certain of its constituents in the water (proteid substances in Marchintia, cane-sugar in the case of Mosses $\left({ }^{106}\right)$ ) an attractive stimulus on the spermatozoids. The spermatozoids, thus directed toward the neck of the archegonium, traverse it as far as the egg, into which one spermatozoid penetrates. The water necessary for the process of fertilisation is supplied by rain or dew. After fertilisation has been accomplished, the egg-eell divides and gives rise directly to an embryo $(C)$, without first, as is usually the case in oospores, undergoing a period of rest.

Antheridlia and archegonia are developed by cell-rlivision from single superficial eerls of the thallns, and are homologous organs; their homology is supported by the occurrence of structures intermediate in nature. The rentral-eanal-cell and the canal-cells thus correspond to gametes which have becone fumctionless.

The behaviour of the sexual melei requires further investigation. Aceording to the observations of W. and C. VAN LeEvwex-ReisnvaA on Pulytriclum and Mnium it alpears that in the last division of each spermatogenons cell to give rise to two spermatozoids the nuclens is halved in such a way that each daughternuclens shows only half the haploid number of chromosomes; this is not a reduction division. The mother-cell of the ovmm of Polytrichum aljears to behave in the same way. The two daughter-cells by again fusing form the eyg-cell, and this is then fertilised by two spermatozoids of the half-value $\left({ }^{107}\right)$.

By the division of the fertilised egg (Fig. 367,C) a multicellular embryo is formed, which, by its further development, gives rise to the second or ASEXUAL GENERATION, represented by the SPOROGONIUM or the stalked Hoss CAPSULE. The sporogonium, in most cases, consists of a round or oval capsular receptacle, in whose internal tissue numerons unicellular spores are produced. In both the Bryophytes and Pteridophytes the spores are formed in TETRADs by the twice-repeated division of the spore-mother-cells, which previously have separated from one another and become rounded off. The spore eapsule has usually a shorter or longer stalk, of which the basal portion, or foot, remains in the distended venter of the arehegonium, and, in consequence of the overgrowth of the underlying tissue, has the appearance of being sunk in it. Although the sporogonium constitutes a listinet asexual generation, it continues throughout its existence united with the sexual generation, and, like a semi-parasitic plant, draws from it the nourishment necessary for its development.

There are diffeulties in the way of the phylogenetic deriration of the Bryophyta form any definite gromp of $A$ lgae. between the bryophytes on the one hand, and the higher Green Algae and Characeas on the other, no transitional forms are 
known. Horphological comparison points rather to a connection between the Bryophyta and the Brown Algae, the mnltilocnlar ganetangia of which (in some genera already differentiated into oogonia and antheridia) may be regarder as homologons struetures leading to the arehegonia and antheridia of the Archegoniatae. Thus the antleridium of the lower Liverworts (Ricceaceae, Marchantiaceae) shows a cellular eonstruction in agreement with that of the gametangia of Brown Algae (cf. Figs. 366, 367, and Figs. 293, 295); it is distinguished by the possession of a sterile, protective layer of eells forming the wall, and the differentiation of this can be regarded as an adaptation to a terrestrial mode of existence. Further, among the Brown Algae, in Dictyota, there is an alternation of generations agreeing with that of Bryophyta, thongh the gametophyte and sporophyte are similar in their regetative strueture. The tetrasporangia of the sporophyte of Dictyota correspond to the spore-nother-cells of the sporophyte of the Bryophyte; their endogenons position in the latter nay be related to the influence of a terrestrial mode of life. While the form of the gametophyte in the thalloid Liverworts shows many points in common with the thallus of certain Brown Algae, the sporophyte of the Bryophyta froceeds early to the development of its spores, and ceases growth withont a division into vegetative organs. It thus becomes essentially dilierent from the gametophyte with whieh it is by origin homologons (108).

The two very distinct classes of Bryophytes may be briefly characterised as follows :-

1. Hepaticue (Liverworts).-The sexual generation, with poorly developed and generally not distinctly differentiated protonema, is either a dichotomously divided thallus or is developed as a leafy and, with few exceptions, dorsiventral shoot. In the majority of Hepaticac, in aldition to spores, the capsule produces also elaters, sterile cells which, in their typical development, become greatly elongated and provided with spiral thickenings (Fig. 372, F). They conduct nourishment to the developing sporogenous cells, and at maturity, after the opening of the capsule, serve to separate and scatter the spores. Only in one order, Anthocerotaceae, does the capsule have a columelli, or an axial mass of sterile cells, which also conduct the metabolic products to the developing spores.

2. Musci (Mosses), - The protonema of the sexnal generation is usually well developed and distinctly defined, and the moss plant is always segmented into stem and leaves. The leaves are arranged spirally in polysymmetrical, less frequently in hisymmetrical, rows. The capsule is always withont elaters, but, except in one genus, it always possesses a columella.

\section{Class I}

\section{Hepaticae (Liverworts) $\left(^{10 !}\right.$ )}

The Hepaticae are divided, according to the structure of the sporogonium and the segmenuation exhibited by the sexual generation, into four orders: the licciacene, Mrerehantiucene, and Anthocerotuceae, 
comprising exclusively thalloid forms, the Jungermunniaceae, including both thalloid and dorsiventral foliose forms, and in the group of the Haplomitricae, radially constructed foliose forms.

\section{Order 1. Ricciaceae $\left({ }^{110}\right)$}

Of all the Hepaticae, this order exhibits the simplest structure. The genus Iiccia belongs to this order; its dichotomously-lobed or eleft thallus forms small rosettes, and grows on damp or marshy soil. Riccic natans is found floating, like Duckweed, on the surface of stagnant water. Riccic fluitans, on the other hand, lives wholly submerged, and has narrow, more profusely branehing, thalloid segments (Fig. $369, A$ ). These two aquatic species can, however, grow on marshy soil,

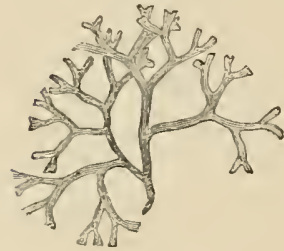

$A$

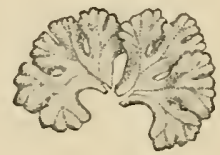

B

FIG. 369.-A, Fiveie fluitens; submerged floating form. $B$, Ricciu natuns; land form. (Nat. size. $B$, after Goebel.) side of the thallus. From the fertilised egg-cell is developed a spherieal sporogonium which has no stalk. The wall of the sporogonium consists of a single layer of eells; it beeomes disorganised during the ripening of the spores, which are eventually set free by the rupture and disintegration of the venter and the surrounding cells of the thallus.

\section{Order 2. Marchantiaceae (111)}

The Liverworts included in this order are much more highly organised, and in many genera they have a deeidedly complieated strueture. Narchantia polymorpha, found growing on damp soil, may serve as an example. It forms a flat, deeplylobed, diehotomously-branched thallus, about two eentimetres wide, and having an inconspicuous midrib (Fig. 371, A, Fig. 372, $A$ ). From the under side of the thallus spring unicellular rhizoids, some of whieh have smooth walls and serve mainly to attach the thallus, while others have conical thickenings projecting into the cell. eavity; these peg-rhizoids serve for water conduetion. The thallus is provided also with ventral seales, eonsisting of a single layer of cells. The dorsiventrality of the thallus is further shown by its complicated anatomical structure. With the naked eye it may be seen that the upper surface of the thallus is divided into small rlombic areas. Each area is perforaterl by a central air-pore leading into a corresponding air chamber immediately below (Fig. 170, $A, B$, and p. 165). The lateral walls of the air chambers determine the configuration of the rhombie areas. The air-pore in the rooting wall of each chamber is in the form of a sliort canal, bounded by a wall formed of several tiers of cells, each tier comprising four cells. Numerous slort filaments, consisting of rows of nearly splherical cells containing chlorophyll 
grains, project from the floor of the air chambers and perform the functions of assimilating tissue. Chlorophyll grains are found also in the walls and roof of the chambers, but ouly in small numbers. The intensity of the illumination exereises a great influence on the formation of air chambers; when the illumination is very weak they may not occur at all (112). The epidermis on the under side of the thallus is formed of one layer of cells. The tissne below the air-chamber layer is devoid of chlorophyll, and consists of large parenchymatons cells, which serve as storage cells.

Small cu[-shaped outgrowths, with toothed margins, the gemmiferons receptacles or gemma-cujs, are generally found situated on the upper surface of the thallus over the midribs (Fig. $371, \zeta$ ). These contain a number of stalked gemmae, flat, biscuitshaped bodies of a green colour. The gemmae arise by the protrusion and repeated
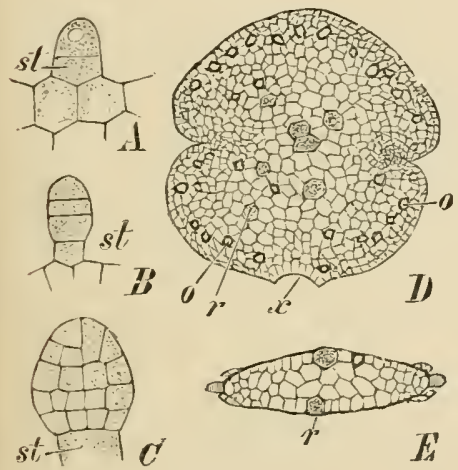

Fig. 370.- Marchantic polymoryhe. A-C, successive stages in the formation of a gemma : st, stalk-cell ; $D$, surface riew ; $E$, transverse section of a gemma; $x$, point of attachment to stalk ; 0 , oil cells: $r$, colourless ceils with granular contents, from which the rhizoids will develop. (After Kxy, $A-C \times 275 ; D-E \times 65$. )

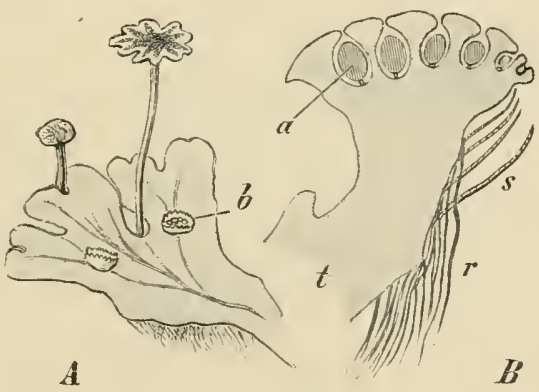

Fic. 371.- Marchentia polymorphe. A, a male plant, with antheridiophores and gemma-cups $b$ (nat. size); $B$, section of young antheridiophore; $a$, antheridia; $t$, thallus; $s$, rentral scales; $r$, rhizoids. (Sonewhat magnified.)

division of a single epidermal cell (Fig. 370); at maturity they become detached from the stalk (at $x$, Fig. $370, D$ ). They are provided with two growing points, one at each of the marginal constrictions, from which their further development into new plants proceeds. On cross-section $(E)$ they are seen to be composed of several layers of cells; some of the cells are filled with oil globules $(D, 0)$, while from other colourless cells rhizoids develop. Cells containing oil are also present in the mature thallus, and are of frequent occurrence in all the Hepaticae. By means of the abundantly developed gemmae Marchartia is enabled to multiply vegetatively to an enomous extent.

The sexnal organs, antheridia and archegonia, are borne on special erect branches of the thallus. The reproductive branches, which are contracted below into a stalk, expand above into a profusely-branched uper portion. In this species, which is dioecious, the antheridia and archegonia develop on different plants. The branches producing the male organs terminate in lobed discs, which bear the antheridia on their upper sides in flask-shaped dejressions, each containing an antheridium (Fig. $371, B$ ). The depressions, into each of which a narrow canal 
leads, are separated from each other by tissue provided with air chambers. (The structure of the antheridia and spermatozoids is illustrated by Fig. 366 and the accompanying description.)

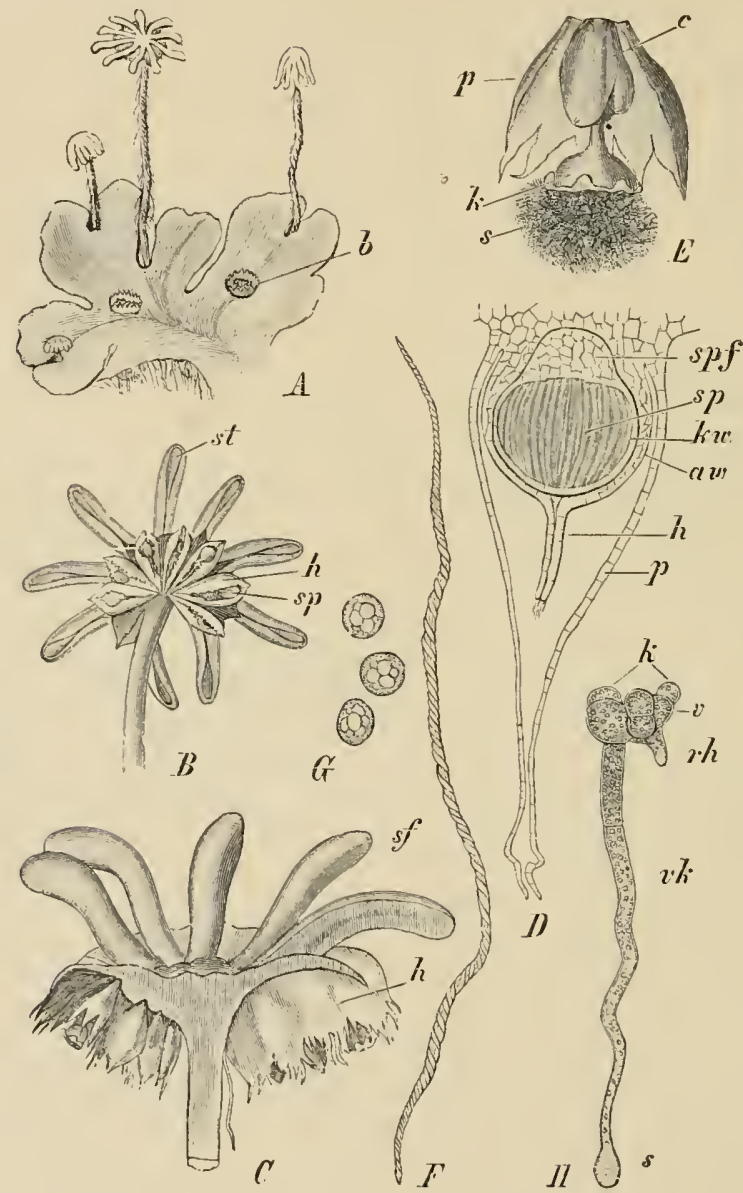

Fig. 372. - Harchantia polymorpha. A, a female plant, with four arehegoniopliores of different ages; $b$, gemma-cups (nat. size). $B$, under side of receptacle; st, rays; $h$, sheath; $s p$, sporogonium $(\times 3)$. $c$, half of a receptacle, divided longitudinaly $(\times 5) . \quad D$, longitulinal section of a young sporogonium; spf, the foot; sp, sporogenous tissue; $k w$, wall of capsule; $a u$, wall, and $h$, neck, of archegonitum; $p$, pseudo-periantl $(\times 70)$. E, ruptured sporogonium; $k$, capsule; $s$, spores and elaters; $p$, pseudo-perianth; $c$, archegonial wall $(\times 10) . F$, an elater. $G$, ripe spores (×315). H, serninating spore $(s) ; 2 \%$, germ tube; $k$, germ-disc, with the apical cell $r$ and rhizoid $r h(\times 100)$. (C, E, after BischorF; $B, D, F \cdot I$, after hisr.)

The female branches terminate each in a nine-rayed disc (Fig. 372, A). The ulpuer surface of the disc, between the rays, becomes displaced in the process of growth, and, as the arehegonia are borne on these portions, they seem to arise from 
the under sicle of the dise. The archegonia are disposed in raclial rows between the rays, each row leing surrounded by a toothed lamella or sheath (Fig. 372, $B, C, h$; for structure of the arehegonia see Fig. 368 and description).

The fertilised egg-cell gives rise to a multicellular embryo (Fig. 368, C), am! this, by further division and progressive diflerentiation, develops into a stalked oral spologoxidr. The capsule of the sporogonimm is provider with a wall consisting of one layer of eells except at the apex, where it is two-layered ; the cell-walls. have thickenei banils. The capsule ruptures at the apex to let free the spherical spores. The Elaters, or elongateri, spirally thickened cells formed in the capsules, between the spores, by the prolongation of lefinite cells, are characteristic of the Marehantiaceae and most of the Liverworts, except the Rieciaceae. The elaters are discharged from the ruptured eapsnle, together with the spores, and assist in their dispersion in the same way as the capillitim of the 1 yyxomycetes (Fig. 372, E, F', C). The ripe cajsule, before the elongation of the stalk, remains enclosed in the arehegonimm wall $(D, \alpha w)$, which, for a time, keeps paee in its growth with that of the capsule. As the stalk elongates, the arehegonim wall or ealyptra is broken through and remains behind, as a sheath, at the bave of the sprorogonium $(E, c)$. The capsule is surrounded also by the pseudo-perianth, an open sac-like envelope which grows, before fertilisation, ont of the short stalk of the archegonium (Fig. 368, C, pr ; Fig. 372, D, $k, p$ ).

Marchantio was formerly nsed in the treatment of diseases of the liver; this fact explains the origin of the name Liverwort.

\section{Order 3. Anthocerotaceae (113)}

The few forms ineluded in this peculiar and isolated order have an irregular, disc-shaped thallus, which is firmly anchorer to the soil by means of rlizoids. The cells of the thallus contain, in contrast to those of other Bryophyta, a single large chloroplast. The antheridia arise singly or in groups of two to four, by the division of a eell lying below the epidermis; they remain enelosed in cavilies beneath the upper surface of the thalhus intil maturity. The origin of the antheridia thus clitiers from what is the case in all nther Archegoniatae in being endogenous; a superfieial eell divides into an onter segment, forming the roof of the cavity, and an inner one, which beeomes the mother-eell of the antheridia. The archegonia are sunk in the npler surface of the thallns; after fertilisation they become covered over by a many-layered wall formed by the overarching growth of the arljoining tissue. This enveloping wall is afterwards ruptured by the elongating capsule, and forms a sheath at its base.

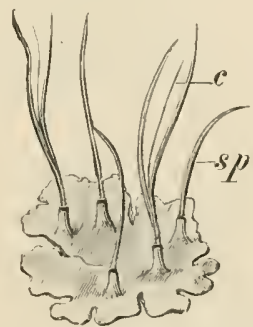

Fir. 3,3. - Inthoreras luevis. sp, sporogonium; $c$, columella. (Nat. size.) The sporogonium consists of a swollen foot and a long, pod-shaped eapsule; it has no stalk. The superficial cells of the foot grow out into rhizoid-like papillae. The capsule splits longitudinally into two valves, and has a central hair-like columella formed of a few rows of sterile cells (Fig. 373). The columella does not extend to the apex of the capsule, lut is surmounterl by a narrow layer of sporogenous cells. Elaters also oceur; they are multicellular, variously shaped, and often forked. The sporogonis, milike those of all other Hepraticae, do not ripen simultaneously throughout their whole length, but from the tips downwards, and continue to elongate by basal growth after emerging from the archegonia. 
The wall of the sporogonium jossesses stomat, which do not oeeur in other Liverworts; chlorophyll is present in its eells.

On the under side of the thallus, slit-like openings, formed by the separation of the cells, lead into cavities filled with mueilage. Nostoc filaments penetrate into these eavities, and develop into enlophytie colonies (114).

\section{Order 4. Jungermanniaceae}

These are usually small forms whieh grow on the gronnd or on trec-trunks, and in the tropies on the surface of living leaves. In the simplest forms of this order the thallus is lroadly lobed, similar to that of Marehantia (e.g. Pcllice cpiphlyglla, frequently found on damp gromnd) ; or, like that of Riccia fluitans, it is nurrow and ribbon-shaped, and at the same time profusely branched (e.g. Metzgcria furcate, Fig. 112). In the other forms, again, the broar, deeply. Jobed thallus has an erident nidrib, and its margins, as in the ease of Blasia pusilla (Fig. 374), exlibit an incipient segmentation into leat'-like members. The majority of Jungermanniaceae, however, slow a lis-

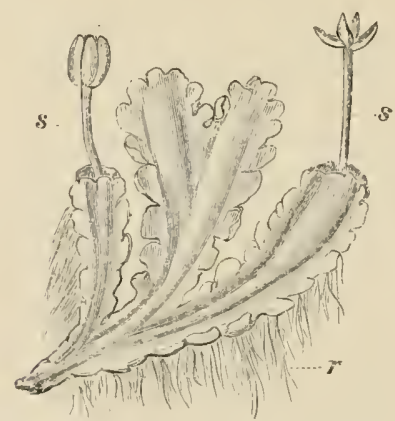

Fro. 3个4.-Dlasia pusillu. s, sporogonimm; r, rhizoids. $(\times 2$.

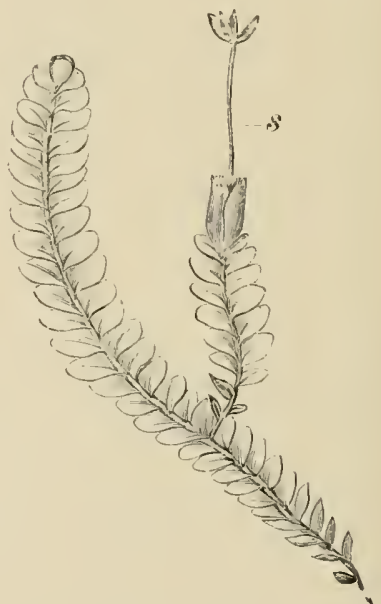

Fui, 375.-Plagiochila asplenioides. \&, sporogonium. (Nat. size.)

tinct segmentation into a prostrate or aseenling, dorsiventral stem and leaves. The latter eonsist of one layer of eells without a midrib, and are inserted with obliquely directed laminae in two rows on each flank of the stem. Some speeies $(c . y$. Frullania Tamarisci, a delieately branehed Liverwort of a brownisl colour oceurring on rocks and tree-trunks) have alio a ventral row of small seale-like leaves or ampligastria ( $\mathrm{Hig} .376, a$ ). The dorsal leaves are frequently divided into an npler and lower lobe. In speeies growing in dry plaees, like Frullania Tumarisci, the lower lobe may be modified into a sae, and serves as a eapillary water-reservoir. The leaves regularly overlaj each other; they are then said to be succubous, when the posterior edges of the leaves are overlapred by the anterior edges of those next below (Frullumiu, Fig. 376), or incubons, if the posterior edges of the leaves overlap, the anterior edges of the leaves next below (Pingioelila, Kig. 375).

The long-stalked sporogonium is also elaracteristis of this order ; it is already fully developer before it is pusher through the ajex of the arehegonial wall hy 
the elongating stalk. It has a spherical capsule which on rupturing splits into four valves (Figs. 374, 375). No colmmella is formed in the capsule; but in addition to speres it always produces elaters, which, by their movenents while drying, scatter the spores. The stalk of the capsule is delicate. The wall of the capsule (usually two or several cells thick) consists of cells with aumular or baurllike thickenings, or the walls are uniformly thickened with the exception of the outermost walls. Dehiscence is dependent on the cohesive power of the water in these cells causing the outer walls to bulge into the cavity.

According to the position of the sexual organs and sporogonimn the Jungermanniaceae are divided into two groups. 1. In the Analiogynae the a pex is not used np in the formation of the arehegonia, and the sporogonia are situated on the dorsal surfice and are smrounded by a sheath-like ontgrowth of the thallus forming an involucre. To this gronp, belong the thalloid forms (Pelliu, Wetzgeria) and others showing $\mathrm{a}^{*}$ transition to the frondose forms (Blasic). 2. In the Akrogynae, on the other hand, the archegonia and

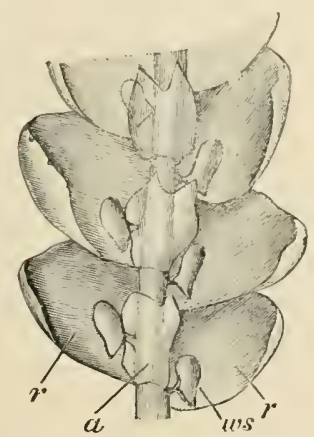

Fifi, 376.-Part of a slioot of Frullaniu Tamarisci, seen from below. $r$, Dorsal leaves with the lower lobes $(u s)$ modified as water-sacs; $u$, amphigastriun. ( $x$ 36.)

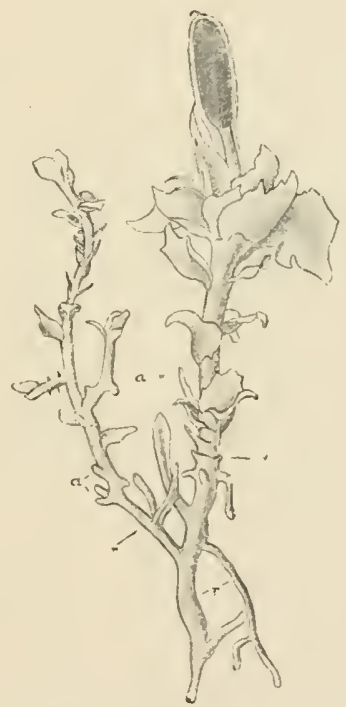

Fro. 377.-Haplomitrium Hookrri. a, Origin of a new shoot; $r$, rhizome ; $o$, lower limit of the aerial shoot. (After GotTische.)

the sporogonimm stand at the end of the main stem or of a branch and are surrounded by a perianth formed of modified leaves. To this gronj belong the dorsiventral leafy forms, e.g. Plagiochila (Fig. 375), Frullainia, and Jungermannia, a genus with numerous species. 3. The Haplomitrieae (115) hold an isolated position but appear to exhibit the closest connection with the Anakrogyna. This order contains only two genera, Calobryum, occurring in the tropics, and Huplomitrinm. The single species of the latter genus, Ir. Hookeri (Fig. 37T), oceurs in Europe, and possibly is a survival of preglacial Liverworts. The Calobryaceae differ from all other Liverworts in the radial construetion of their shoot, which bears three rows of leaves. The sexual organs form termiral groups in Calobryum, in Haplomitrium they occur between the upper leaves. 


\section{Cluass II}

\section{Musci (Mosses) $\left.{ }^{116}\right)$}

The profusely branehed protonema of the Mosses appears to the naked eye as a felted growth of fine, green filaments (Fig. 365). The young moss plants are developed on the protonema as small buds which arise as protrusions of cells of the filament, usually from the basal eell of one of the branehes. The protrusion is cut off by a transverse septum, and after the separation of one or two stalk-cells the three-sided pyramidal apieal cell of the moss plant is delimited in the enlarged terminal cell (11i). The moss plants are always differentiated into stem and leaf. The Mosses may be readily distinguished from the foliose Jungermanniaceae by the spiral arrangement of their small leaves, which are rarely arranged in two rows. In Mosses which have prostrate stems, the leaves, although arranged spirally, frequently assume a somewhat outspread position, and all face one way, so that in such cases a distinetion between an upper and a lower side is manifested, but in a manner different from that of the Liverworts.

The stes of the Moss Plant is formed of cells which beeone gradually smaller and thicker-walled towards the periphery. In the stems of many genera (e.g. Mnium, Fig. 171) there is found a central, axial strand consisting of elongated, conducting eells with narrow lumina. These strands are not as lighly differentiated as the vascular bundles of Pteridopluytes. They are wanting in the Sphagnaceae or Borg-mosses which grow in swampy places. The stems of the Spliagnaceae show a peculiar develojment of the outer cortical layers. The eells in these layers are devoid of protoplasm, and are in communication witl each other and the atmosphere by means of large, open pores; to secure rigidity, they are also provided with spirally thickened walls. They have a remarkable power of eapillary absorption, and serve as reservoirs for storing and conducting water.

The LEAvEs of the true Hosses have, as a rule, a very simple strueture. They consist usually of a single layer of prolygonal cells containing chloroplasts (Fig. 62 and Fig. 103, Funaria), and are generally novided with a median conducting bundle of elongater cells. The leaves of the Bog Mlosses (Sphagnaceae) have no bundles, and instead are supplied with eapillary cells for the absorption and storage of water. These eells are devoid of protoplasm, and are similar to those in the periphery of the stem, but larger and more elongated; their walls, which are jerforated, are strengthened by transverse thickening bands. Between them are other elongated, reticnlately united cells eontaining chloroplasts. A similar differentiation of the leaf-eells occurs in a few other Mosses (c.g. Lencobryum vulgare).

A nore complieated structure of the leaves resulting from their aclaptation to the absorption of water is exhibited by Polytrichnm eommune. In this Moss the leaves develop on their upper surface nmmerous, eruwded, rertical lamellae, one cell thick; these contain chloropliyll and serve as an assimilatory tissue, while the spraces between the lamellae serve as reservoirs for the storage of water. In a 
Iry atmosphere the leaves fold together, and thus protect the delieate lamellae from excessive transpiration $\left({ }^{118}\right)$.

The numzorns (Fig. 383), each of which consists of a branched filament of cells, spring from the base of the stem. In structure they resemble the protonema, into which they sometimes become converted, and then can give rise to new Moss plants.

The SEXUAL ORGAxs are always borme in groups at the apjees either of the main axes or of small, lateral branches, surrounded ly their upper leaves; each group with its involucral leaves constituting
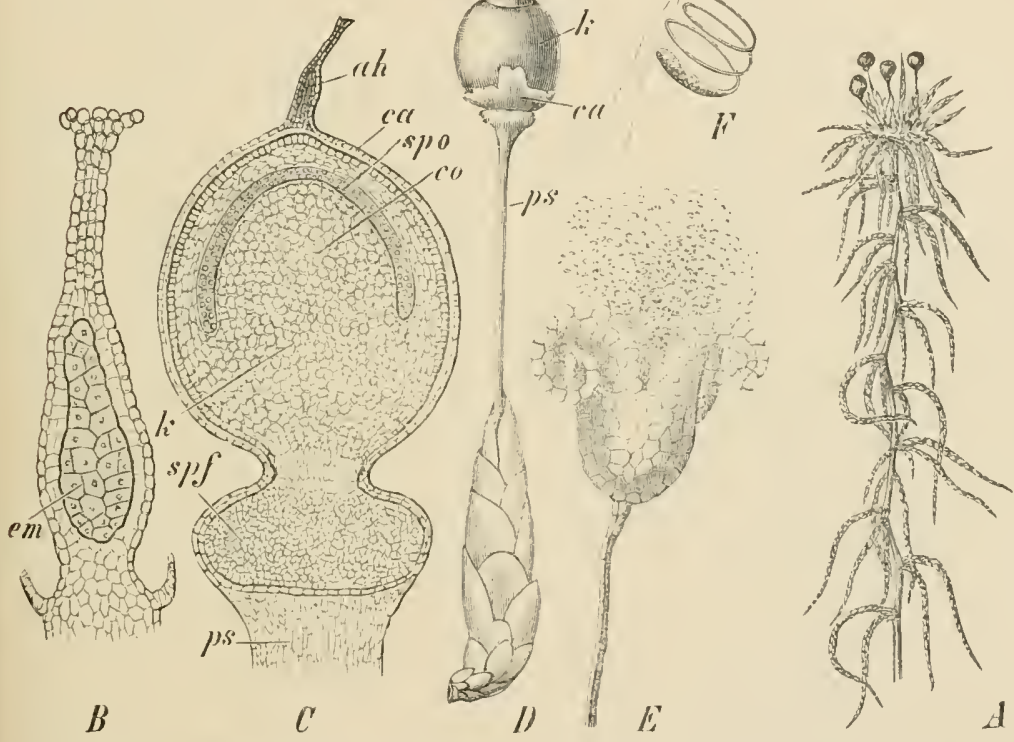

Fri. 378.-Finhegum fumbiulum: A, A slont with four ripe sporogonia. Sphugnum acutifolium: $B$, Archegonium with the multicellular embryo of the sporogonium em; $C$, a young sporogonium in longitudinal section ; $p s$, pseurlopodium ; $c a$, archegonial wall or calyptra ; $\alpha h$, neck of archegoniun ; spf, foot of sporogonium; $k$, capsille; co, columella ; spo, spore-sac with spores; $E$, ruptured antherislium with escaping spermatozoids; $F$, single spermatozoid, highly magnitiel. Sphagnum squerrosum: $D$, A lateral shoot witl a terminal sporogonimn; cu, ruptured calyptra; $d$, operculum. (Atter W. P. Scmmper; $A$, nat. size; the other figures matrnified.)

a receptacle. The antheridial and archegonial receptacles are sometimes inappropriately referred to as moss flowers, but they have nothing in common with the true flowers of vascular plants; the involucral leaves, which frequently have a distinctive structure, are also known as the PERichaETium (Fig. 383). Between the sexual organs there are usually present a number of multicellular hairs or paraphyses. The moss plants may be monoecions, in which ease both kinds of sexulal organs are boune on the same plant either in the same or different receptacles; or dioecions, and then the antheridia and 
archegonia arise on different plants. The archegonia and antheridia of Mosses differ in their development from those of other Archegoniatae

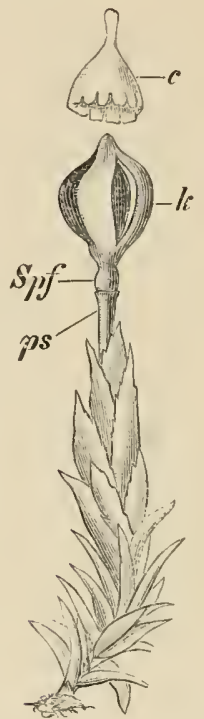

Fı. 37:.-Andreaca petrophilu. ps, Psendopodiun ;

Silf, fout; $k$, capsule : $e$, caly, tra. ( $\times 12$.

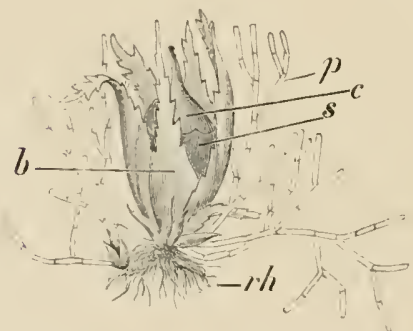

Fris. 3s\%.-Diphemerum serratum. p, Protonema ; b) foliage-Ieaf; $s$, sporogonium; $c$, calyptra; rh, rhizoids. (Alter W. P. SOHIMER, $\times$ 200.)

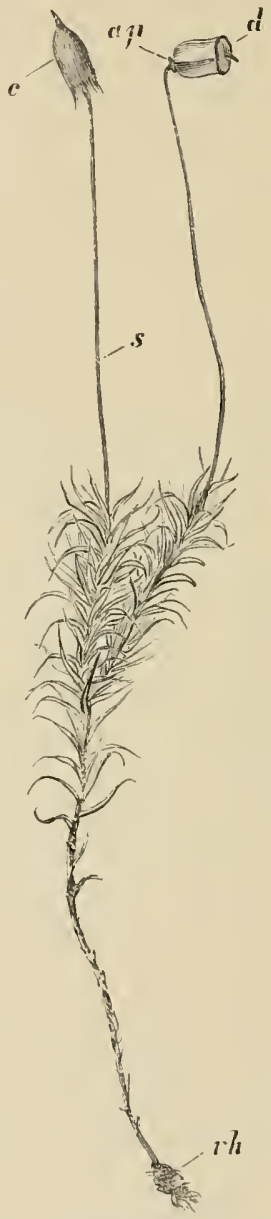

Fir, 3s].-l'olytrichum commune. th, Rhi. zoids; $s$, seta ; c, calyptra ; ap, apophysis ; 17, operculum. (Nat. size.)

by being formed by the segmentation of a two- or three-sided apieal cell.

The sporogoniun of the Mosses $\left({ }^{119}\right)$ develops a capsule with an axial columeuta consisting of sterile tissue (Fig. 385). The spore-sac surromends the columella, which accumulates food material and water for the developing spores. Elaters are never formed. In the young 
sporogonium ontside the spore-sac, a well-developed assimilating tissue is present; this is bounded by water-storage tissue and an epidermis. In most Mosses stomata are found on the lower part of the eapsule. Distinctive variations in the mode of development and structure of the capsules are exhibited by the four orders of the Musei: Sphagnucue, Andreneateue, Phascaceue, and Bryinae. The Sphagnaceae and Andreaeaceae are nearest to the Liverworts.

\section{Order 1. Sphagnaceae $\left({ }^{120}\right)$}

The order of the Sphagnaceae, or Bog Hosses, includes only a single genus, sphagnum, eontaining many species. The bog Mosses grow in swanipy places, and form large tussocks saturated with water. 'The upper extremities of the stems eontinne their growth from year to year, while the lower portions dic away and become eventually converted into peat. Of the numerous lateral

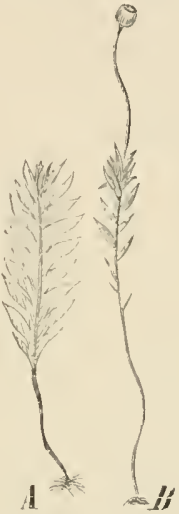

Fuc. 352.-Srhistostega nsmunlacer. $A$, sterile; $L$, fertíle plant. $(\times 5$. branches arising from each of the shoots, some grow upwards and form the apieal tufts or heads at the summits of the stems ; others, whieh are more elongated and

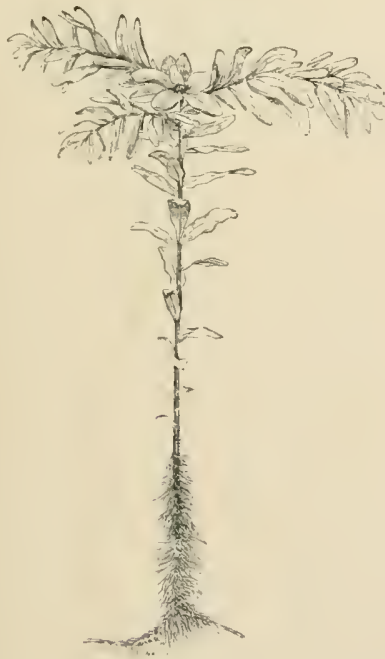

Fici, 383.-1Inium uninlatum. Orthotropons sloot terminating in a male receptacle surrounded by involucral leaves. The lateral shoots are plagiotropous. (After GOEBEI.)

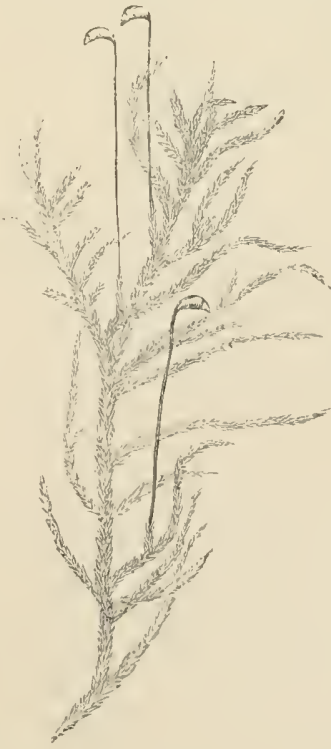

Fis. 384.-Hypnum purum. (Nat. size.)

flagelliform in shape, turn downwarls and envelop the lower portions of the stem (Fig. 378,4 ). Every your one branch below the apex develops as strongly as the 
mother sloot, so that the stem thins becomes falsely bifureated. By the gradual death of the stem from below upwards the danghter shoots become sejarated from it, and form independent plants. Speeial branches of the tufted heads are distinguishable by their different structure and colom; ; on these the sexual organs are prodnced. The male branches give rise, near the leaves, to spherical stalked antheridia, which open at the apices by means of valves; these bend back and set free the spirally twisted spermatozoids (Fig. $378, E, F$ ). The archegonia are borne at the tips of the female branches. The sporogonium develops a slort stalk with an expanded foot $(B, C)$, but remains for a time enclosed by the archegonial wall or ealyptra. Uyon the rupture of the archegonimm, the calyptra persists, as in the Hepaticae, at the base of the sporogonium. The eapsule is spherical and has a dome-shaped columella, whieh in turn is overarehed by a hemispherieal spore-sac (spo); it opens by the removal of an opereulum. The ripe sporogoniun, like that of Andreneu, is borne npon a prolongation of the stem axis, the pisendopodimm, which is expanded at the top to receive the foot of the stalk. Of the peeuliar structure of the leaves and stem cortex a deseription lias already been given above. The protonema of the Spliagnaceae is in some respeets preculiar. Only a short filament is formed on the germination of the spore, the protonema broadening ont almost at once into a flat structure on which the young moss plants anise.

\section{Order 2. Andreaeaceae}

The Andreaeaceae comprise only the one genus, Arblrcuet, small, brownish caespitose Mosses growing on roeks. The sporogonimm is also terminal in this order. The capsule, at first provided with a calyptra, splits into four longitudinal valves (sehizocarpous), which remain mited at the base and apex (Fig. 379). The stalk is short, and is explanded at the hase into a foot $(S p f)$, which in turn is borne on a pseudopodium $(p s)$, a stalk-like prolongation of the stem resulting from its elongation after the fertilisation of the arehegonimn.

\section{Order 3. Phascaceae}

To the Pliascaceae (Cleistocarpae) helong small Mlosses with few leaves growing on the soil; they retain their filamentous protonemata until the eapsules are ripe, and have the simplest structure of all the Mosses (Fig. 380). The eapsule is terminal and has only a short stalk; it is protected loy a calyptra. It does not open with a lid, but the spores are set free l,y the decay of its walls.

\section{Order 4. Bryinae $\left({ }^{121}\right)$}

In this order (termed also Stegocarpae), which inchudes the great majority of all the true Mlosses, the noss fruit attains its most complicated structure. The rifue spolicionitm, dereloped from the fertilised egg, consists of a long stalk, the SETA (Fig. 381, s), with a Foor at its base, sunk in the tissue of the mother plant, and of a CAPStLE, which in its young stages is surmounted by a hood or CALYPTLA. The calyptra is thrown off before the spores are ripe. It consists of one or two layers of elongated tells, ant origrinally formed part of the wall of the arehegoninm which, at first, enclosed the embryo, growing in size as it grew, mutil, finally ruptured by the elongation of the seta, it was carried ny as a cal', covering the eapisule. In the Liverworts the calyntra is, on the eontrary, always piercen by the elongating sporogoniun, and forms a sheath at its base. The upper part of the seta, where it joins the eapsule, is termed the Aropursis. In Mrnium (Fing. 
387, A, up) it is searcely distinguishable, but in Polytrichum commune it has the form of a swollen ring-like protuberance (Fig. 351, $a p$ ), while in species of Splachnum it dilates into a large collar-like structure of a yellow or red colour. The ulprer jart of the eapsule becomes converted into a lid or opereulum which is sometimes drawn out into a projecting tip. At the margin of the operenlum a narrow zone of epidermal cells termed the ring or asiuns becomes specially differentiated. The cells of the anmulus contain mueilage, and by their expmsion at maturity assist in throwing ofl the lid. In inost stegocarpons Mosses the

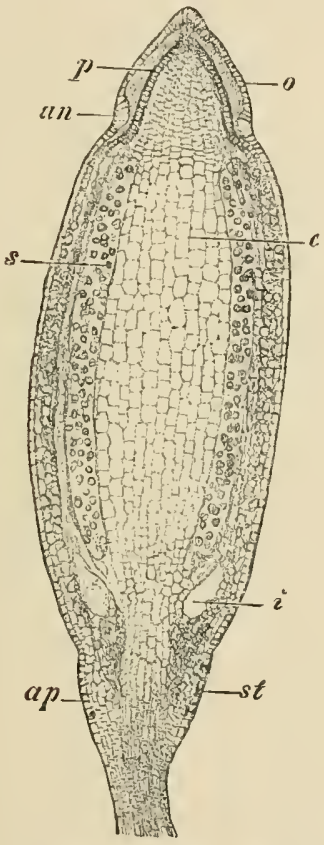

Fic. 385.-Mnium hornum. Median longi. tudinal section of a lialf-ripe sporogonimu. o, Operculum; 1 , peristome; c, colunella ; $s$, spore-sac containing the spores; $i$, airspace; " $p$, apophysis; ; st, stomata. $(\times 18$.

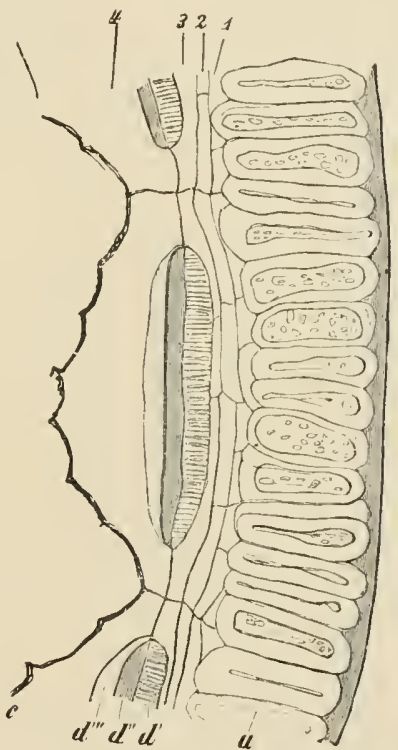

Fin. 3si,-Mnium hornum. Transierse section through the wall of the capsule in the region of the ring. $\alpha$, Cells of the ring ; $1-4$, sucees. sive cell layers with the tlickened masses of the peristome, $d^{\prime \prime}, d^{\prime \prime} ; d^{\prime \prime \prime}$, transierse projecting ribs; ", the coalesced cilia. ( $x$ 240$.

mouth of the deliseed capsule bear's a fringe, the PElistume, consisting usually of tooth-like appendages.

The jeristome of Unium homum (Fig. 387), which will serve as an example, is double; the onter peristonle is formed of 16 pointed, transversely striped teetl inserted on the inner margin of the wall of the capsule. The immer peristome lies just within the onter, and consists of cilia-like appendages, which are ribbed on the inner side and thus alpear transversely striped; they coalesce at their base into a continuous membrane. Two eilia of the inner leristome are always situated between each two teeth of the onter row.

The teeth and cilia of the perstome are formed in this instance of thickened portions of the opposite walls of a single layer of cells next to the operenlum (Fig. 
356), the teeth from portions of the external wall, and the cilia from portions of the internal walls of the same layer. On the opening of the capsule the $\mathrm{m}$ thickened portions of this layer break away and the teeth and cilia split aprart. The transversely ribbed markings on their surface indicate the position of the former transverse walls.

The structure of the peristome varies greatly within the Bryinae. By its peculiar form and hygroscopic novements the peristome causes a gradual dissemination of the spores from the capsule.

Tariations in the form of the capsule, peristome, operculum, and calyptra afford the most important means of distinguishing the different genera. The Bryinae are divided into two sub-orders, according to the position of the archegonia or of the sporogonia developed from them.

(a) Eryinae acrocurpae.-The arehegonia, and consequently the sporogonia, are terminal on the main axis. Mnium undulatum (Fig. 383) and hormum, Poly-
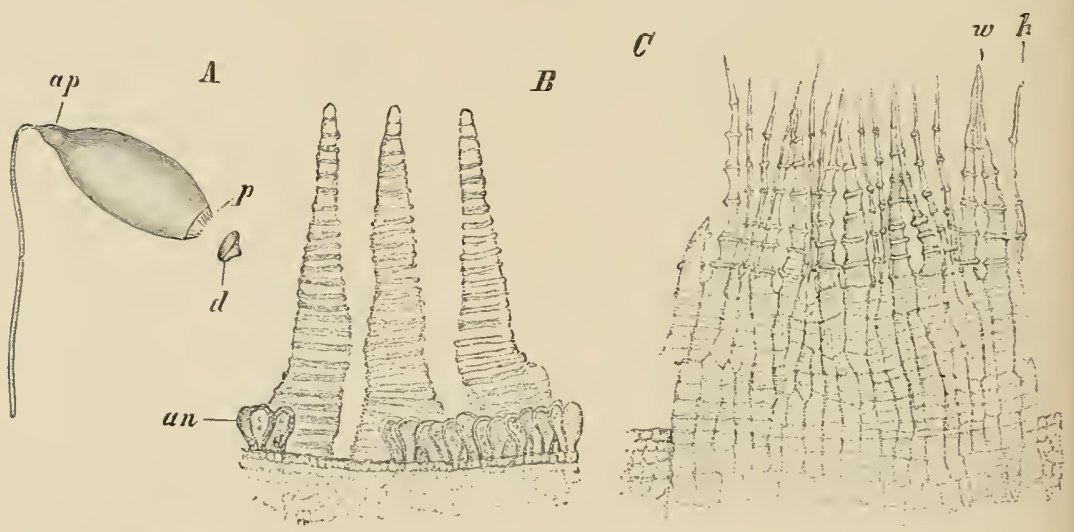

Fig. 3s..-Mnium hornum. A, Capsule with upper yortion of seta; $a p$, apopliysis; $p$, peristome: d, the separated operculum. B, Three teeth of the onter peristome seen from the ontsirle; $a n$, annulus. $C$, inner peristome seen from the inside; $v$, broader cilia; $h$, narrower cilia, $(A \times 4 ; B, C \times B 0$.

trichum commune (Fig. 3S1), and Funaria hygrometrice are common examples. S'chistostcye osmumlace, a moss living in caves, has fertile shoots, which have spirally irranged leaves and bear stalked calsules devoid of peristomes, and also other shoots that are sterile, with two rows of leaves (Fig. 382, $A, B$ ). The protonema of this species is peculiarly constructed and gives out an emerald phosphorescent light. (Cf. Figs. 205, 206.)

(b) Bryinae pleurocarpae. - The growth of the main axis is mnlimited, and the archesonia with their sporogonia arise on short, lateral branches (Fig. 384). In this group are included numerous, usually profusely-branched species of large Mosses belonging to the genera Hytucominom, Neckera, and Hymmum, which are anong the most conspicuous mosses of our woods, and also the submerged Water Noss, Fontinalis untipyretica.

\section{PTERIDOPHYTA (VASCULAR CRYPTOGAMS) (103, 12:)}

The Pterirlophytes include the Ferns, Water-Ferns, Horse-tails, and 
Club Mosses, and represent the most highly developed Cryptogams. In the development of the plants forming this gromp, as in the Bryopliyta, a distinct alternation of generations is exhibited. The first generation, the sexnal, bears the antheridia and arehegonia; the second, the asexual, develops from the fertilised egg and produces asexmal, unicellular spores. On germination the spores in turn give rise to a sexmal generation.

The haploid SEXUAL GENERATION is termed the PROTHALLIUM Or GAMETOPHYTE. It never reaches any great size, being at most a few centimetres in diameter; in some
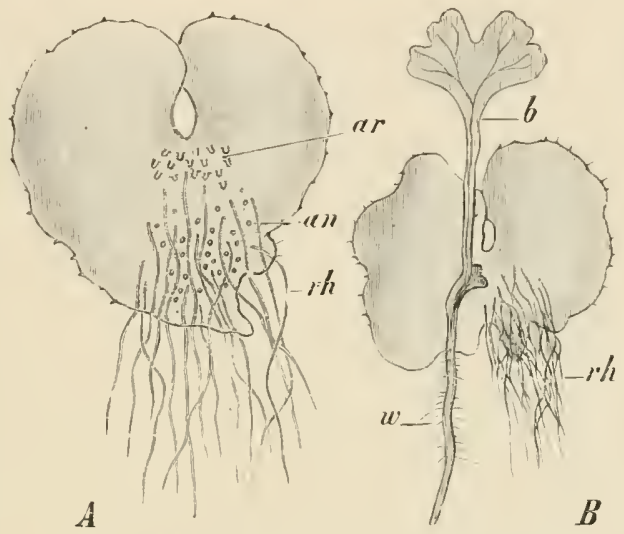

Frs. 38s.-Aspidium filix mas. A, Prothallium seen from below; $a r$, arclegonia ; an, antheridia ; $r h$, rhizoids; $B$, prothallium with young Fern attached to it by its foot; $b$, the tirst leaf; $w$, the primary root. ( $\times$ circa 8 .) forms it resembles in appearance a simple, thalloid Liverwort; it then consists of a small green thallus, attached to the soil by rhizoids springing from the under sicle

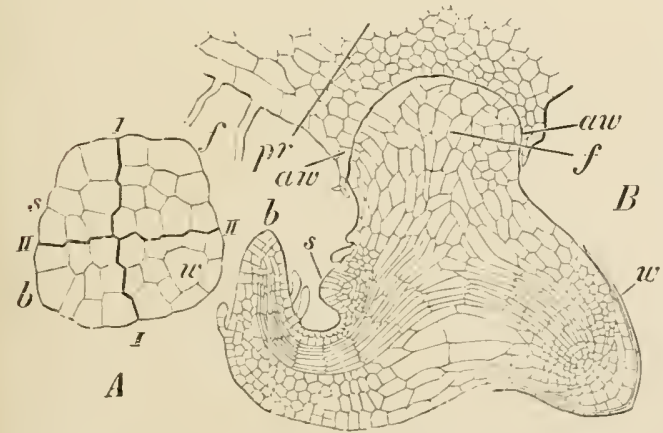

F10. 359.-A, Pter is serrulute, embryo freed from the archegonium, in longiturliual seetion (after KiexıTZ-GerLofF): 1, basal wall; $I l$, transverse wall dividing the egg-cell into duadrants ; rudiment of the foot $f$, of the stem $s$, of the first leaf $b$, of the root $w ; B$, section of a further-dpveloped embryo of Pteris antilina (after HOFuElster); $f$, foot still embedderl in the enlarged renter of the archegonium aw; $p r$, prothallium. (Mlagnitieri.)

(Fig. $388, A$ ). At other times the prothallinm is branched and filamentous; sometimes it is a tuberons, colourless mass of tissue, partially or wholly buried in the ground, and leading a saprophytic existence, while in certain other divisions of the Pteridophyta it indergoes reduction and remains more or less completely enclosed within the spore. On the prothallia arise the sexual organs, antheridia (Figs. 393, 400), producing numerous ciliate, usually spiral spermatozoids, and archegonia (Figs. 394, 401), in each of which is a single egg-cell. As in the Mosses the presence of water is necessary for fertilisation. The 
spermatozoids are induced to direet their motion toward the archegonia by the excretion from the latter of a substance which diffuses into

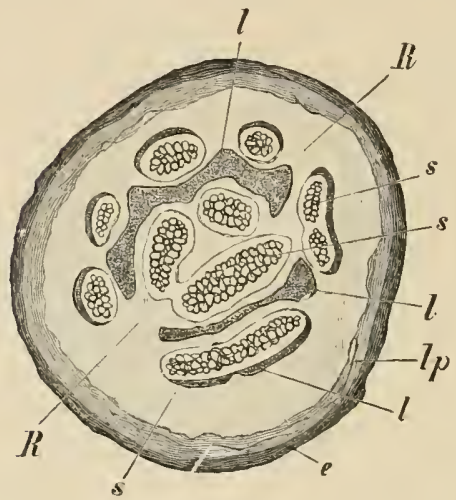

Fig. 390.-Transverse section of the rhizome of I'teris anuilina. s, Concentric vascular yeripheral bumdles; $l$, selerenchymatons plates: l? zone of sclerenchymatons tihres; li, cortex ; e, epidermis. $(\times 7$.

the surrounding water. In Ferns, Salvinia, Equisetum, Selaginella, and Isoetes, this substance is malic acid or one of its salts, while in Lycoporlium it is citric acid or its salts $\left({ }^{123}\right)$.

After the fertilisation of the eggeell by a spermatozoid there is developed from it, as in the Bryophyta, the diploid asexual generation; this is the cormophytic fernplant.

The asexual generation or sporophyte is represented by a plant possessing a highly differentiated internal strueture, and externally segmented into stem, leaves, and roots. In the majority of Ptericlophytes (Ferns, Equicetum), the fertilised egg-cell, while still in the arehegonium, surrounds itself with a cell-wall and undergoes division, first

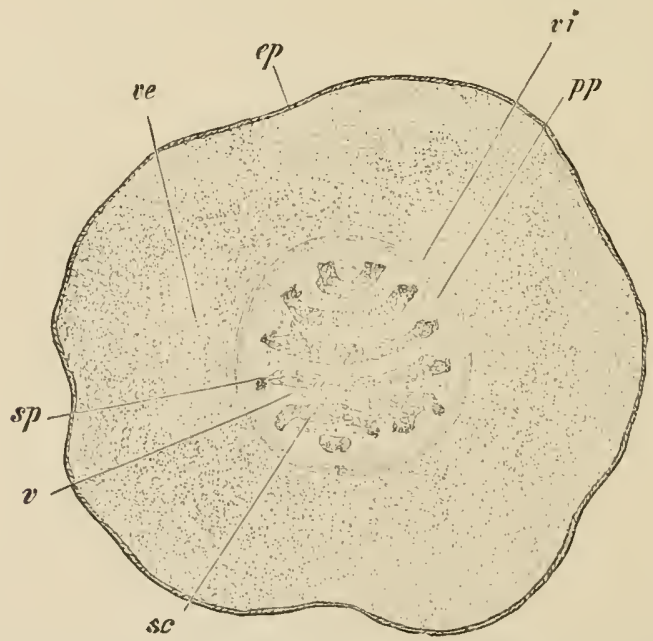

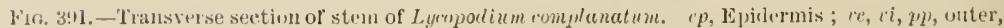
inner, and innermost parts of the pintry cortex, surrounling the central eylinder formed by the coalescence of roncentrie bundles: sc, sciluriform tracheiles; sp, amular anul spiral trabliciles ; $i$, phlowin. $(\times 26$.

into two cells, Jy the formation of a triusverse or bisal wall, and then into oetants by two walls at right angles to each other and to 
the basal wall. By the further division of these eight cells a small mass of tissue is formed, and from this are developed the stem apex, the first leaf, the primary root, and an organ peculiar to the Pteridophytes, the so-called roo' (Fig. 389, f). The foot is a mass of tissme, by means of which the young embryo remains attached to the parent prothallium aud absorbs nourishment from it, until, by the development of its own roots and leaves, it is able to nomrish itself independently. The prothallium then usually dies. The stem developed from the embryonic rudiment may be either simple or bifureated, erect or prostrate; it branches without reference to the leaves, which are arranged spirally or in whorls, or occupy a dorsiventral position. Instead of rhizoids, as in the Bryophyta, true roots are produced, as in the Phanerogams (cf. Fig. 116). The leaves also correspond in structure with those of the Phanerogams. Stems, leaves, and root are traversed by well-differentiated vascular bundles, and the Pteridophytes are, in consequence, designated Vascular Cryptogams. The bundles of the great majority of Pteridophytes are as a rule constructed on the concentric type (cf. Fig. 390 and Fig. 135). Secondary growth in thickness, resulting from the activity of a special cambium, occurs only oceasionally in existing forms, but it was eharacteristic of the stems of certain extinct groups of Pteridophytes.

The sPOREs are produced vegetatively in special receptacles termed SPORANGIA, which oceur on the asexual generation, either on the leares, or less frequently on the stems in the axils of the leaves. The leaves which bear the sporangia are termed sporopirtus. The sporangium consists of a wall enclosing the sporogenous tissue, the cells of which, becoming rounded off and separated from each other as spore-mother-cells, give rise each by a reduction-division to four tetrahedral spores (spore-tetrads). The cells of the innermost layer of the sporangial wall are rich in protoplasm, and constitute the TAPETUM. This layer persists in the Lycopodineae, but in the case of the Ferns and Equisetineae the walls of the tapetal layer become dissolved. In the course of the clevelopment of the sporangium the tapetal cells then wander in between the spore-mother-cells, so that the spores eventually lie embedded in a mucilaginous protoplasmic mass, the PERIPLASM, from which they derive nourishment. The wall of the mature sporanginm is formed of one or a number of layers of cells. 'The unicellular spores have cell-walls composed of several layers.

The spores of the majority of the Pteridophytes are of one kind, and give rise on germination to a prothallium, which produces both antheridia and archegonia. In certain cases, however, the prothallia are dioecious. This separation of the sexes extends in some groups even to the spores, which, as IACrospores (megaspores), developed in MAcrosPoRANGIA (megasporangia), give rise only to female prothallia; or as Microspores, which are produced in MICROSPORAKG1A, develop similarly only male prothallia. In accord- 
ance with this difference in the spores, a distinction may be made between the HOMOSPOROUS and HETEROSPOROUS forms of the same group) but this distinction has no systematic value in defining the different groups themselves, as it has arisen independently in several groups.

The correspondence in the structure of their antheridia, arehegonia, and spore-mother-cells is in favour of a relationship between the Bryopizyta and the Pteridophyta. Thongh both groups may have had their origin from a common group of Algae, an independence in the further course of development must be assumed in the two cases. Especially, it is impossible to derive the sporophyte of the Pteridophyta from the sporophyte or sporogoninm of the Moss. While the latter without attaining any regetative complexity comes to an end early with spore-formation, the Fern sporophyte develops into a massive embryo within the archegonial venter, and this becomes differentiated into stem, leaf, and root. The vascular bundles appear as quite new structures, the possession of which enables the sporophyte to proceed to the development of a large complicated and sometimes tree-like terrestrial plant ; this contrasts with the Bryophyta, where, owing to the simple cellular structure and the absence of special water-condncting channels, no great size can be reached. The plant only proceeds at a late stage to the prodnction of spores. The spore-mother-eells are formed endogenously in special parts of the leaf; these are indeed called "sporangia," but are not homologous with the sporangia of Thallophyta. On this account it wonld seem advisable to use a new term for the so-called sporangia of Pteridophyta (sporothecae). The spore-mother-cells, which may be most closely comparel with the tetrasporangia of Brown Algae, correspond rather than the sporothecae to the sporangia of Thallopliyta.

The gametophyte of the Vascular Cryptogams closes its development early by the formation of sexual organs. The typical fern-prothalius hardly surpasses the youth-form of a thallus, while in the Bryophyta, on the other liand, the sexual generation exhibits a progressive development $\left({ }^{108}\right)$.

\section{The existing Pteridophyta are classified as follows:-}

1. Filicinae-Ferms. Stem simple or branched, with welldeveloped, alternate, often deeply divided or compound leaves called fronds. Sporangia either on the under side of the sporophylls, united in sori or free, or enclosed in special segments of the leaves.

Sub-Class 1. Filicinue ensporungutue.-Ripe sporangia with firm wall composed of several layers of cells. Homosporous.

Sub-Class 2. Filicinue leptosporungiutue. - Ripe sporangia with walls one layer thick.

Order 1. Filices.-Ferns, in the narrower sense. Homosporons. Order 2. Hydropteridene.-Water-Ferns. Heterosporons.

2. Equisetinae.-Horse-tails. Stem simple or verticillately branched, with whorled, scale-like leaves forming a united sheath at each norle. Sporophylls peltate, bearing a number of sporangia on the under side, and aggregated into in cone at the apex of each fertile shoot. 
Order 1. Eifuisetuceue.-Horse-tails. Homosporous.

3. Lycoporlinue.-Cluh Mosses. Stems elongated, dichotomously branched, either forked or forning a sympodium, with leaves, in many eases greatly reduced, or submerged, shortened, and tuberous with awl-shaped leaves. Sporangia arising singly in the form of firm-walled capsules either from the stem in the leaf-axils, or from the leaf-base. Tapetal cells persistent.

Orler 1. Lycopuliuceac.-C Club Mosses. Homosporous.

Order 2. Selaginellaceue.-Heterosporous.

Oriler 3. Isoetaceuc.-Heterosporous.

There are also various fossil groups, some of which are included in the above divisions, while some form independent classes.

\section{Class $\mathrm{I}$}

\section{Filicinae (Ferns) ${ }^{\left({ }^{124}\right)}$}

The great majority of existing Pteridophytes belong to the Ferns, taking the group in a wide sense. Two sub-classes are distinguished aceording to the strueture of the sporangia. The Ensporangiate Ferns are characterised by sporangia, the thiek wall of which consists of a number of layers of cells. They open by a transverse split. The Leptosporangiate Ferns on the other hand have sporangia which when mature have their wall formed of one layer of cells. Stipules, which are found at the base of the frond in the former group, are wanting in the Leptosporangiatae. Differences also exist in the prothallus and in the strueture of the sexual organs.

While in earlier geological periods the Eusporangiatae were abundantly represented, they now include only two families, each with a few genera. 'They appear to represent the more ancient type of Ferns and to stand nearest to the forms from which both Filicinae and Lyeopodinae have been derived. Along with them even in palaeozoie times we have the Lejtosporangiatae, from which the Hydropterideae have branched off as a small group of aquatic or marsh-growing Ferns. In the Hydropterileae only among Ferns the spores are diflerentiated into microspores and macrospores.

\section{Sub-Class I. Eusporangiatae}

\section{Order 1. Ophioglossaceae $\left({ }^{125}\right)$}

European examples of this order are aftorded by Ophioglossum vulyutum, Adeler ' Tongue (Fig. 392, B) and Botrychium, Moonwort (Fig. 392, A). Both have a short stem, from which only a single leaf unfolds each year. The leaves in both cases are provided with leaf-sheatls. In ophioglossum the leaf is tongue-shaped, in Botrychium it is pinnate. These leaves hear on their npper side a fertile 
segment arising near the uprer end of the leaf-stalk. This fertile segment in Ophinglussum is simple and cylindrical, with the sporangia sumk in two rows; in Botrychium it is pinnately branched in the upper part, and thickly beset on the imer sile with large nearly spherical sporangia.

Onr knowledge of the pecnliar monoecious prothalli of the Oplnioglossaceae is largely dne to Brichmass; they are long-lived, subteranean, saprophytic,
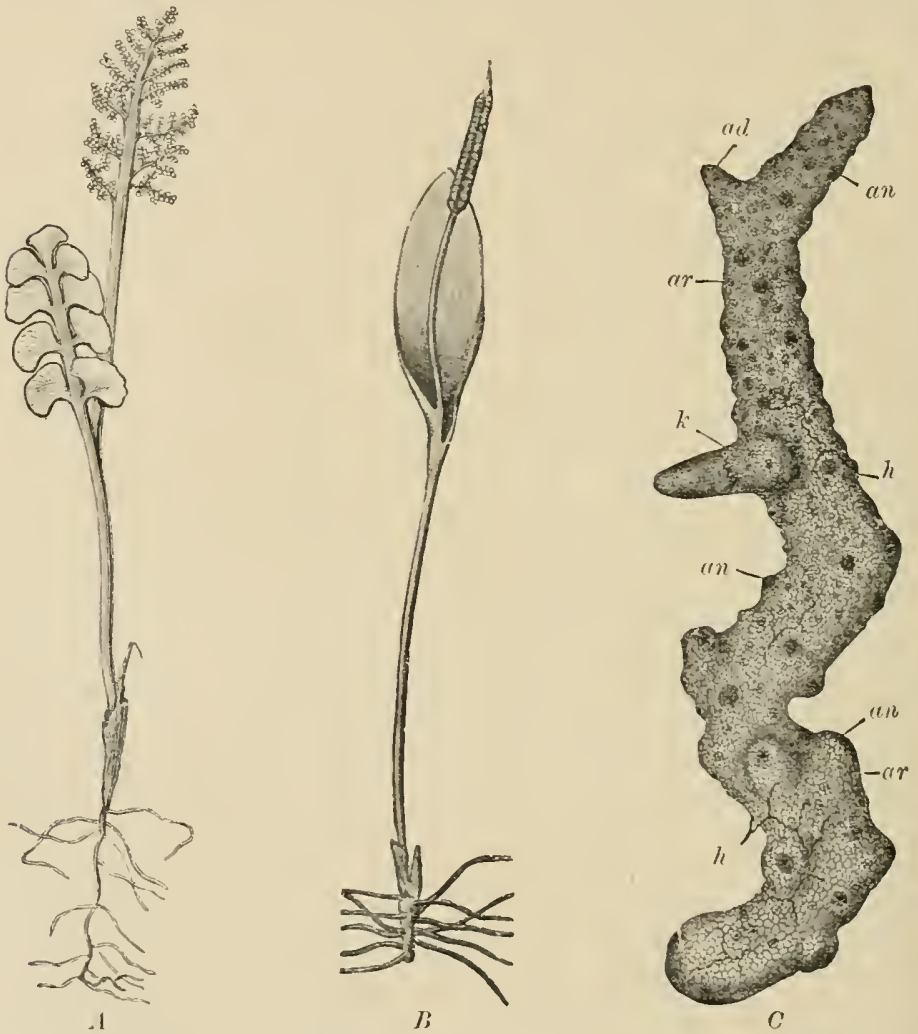

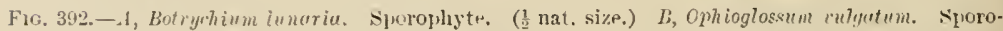
phyte showing the bud for the sncreeding year. (i nat. size.) C; Ophioglossum rulgotum. Prothallus. an, antheridia; ar, archegonia; $k$, young plant with the first ront; arl, adventitious branch; $h$, fungal hyphae. ( $\times 15$; alter Bruchusx.)

tuberous borlies without chlorophyll but inhabited by a mycorhizal fungus. In Ophioglossum (Fig. 392, C) they are cylindrical and radially symmetrical, simple or branched; in Botrychium they are oval or lieart-shaped and dorsirentral. The antherilia (Fig. 393) and arehegonia (Fig. 394) are sunk in the tissne of the prothallis. The antheridium encloses a large spherieal mass of spermatozoid mother-cells which are set free when mature by the swelling of the contents and the breaking down of one of the central cells of the wall. The spermatozoids have a spirally wound body and numerous cilia; a small resicle is adherent to the spernatozoid (Fig. 393, E). The antherilia originate from single superficial cells 
(Fig. $393, A-C$ ), as to also the archegonia (Fig. 394, $A-C$ ). The slightly projecting neck of the latter opens after the neek-canal-cell has swollen and disintegrated; the oosphere $(o)$ remains in the sunken venter. In many speeies the embryo leads a subterranean existence for several years. The primary root is first formed and soon projects from the archegonium (Fig. 392, C, $h$ ); later the first leaf and the apieal cell of the stem are differentiated. In some species of Botrychium the embryo torms an elongated multicellular suspensor at the end of which the proper embryonic mass is formed $\left(^{126}\right)$. In this an agreement with the Lycoprodinae is evident (ef. Fig. 412 and Fig. 417).

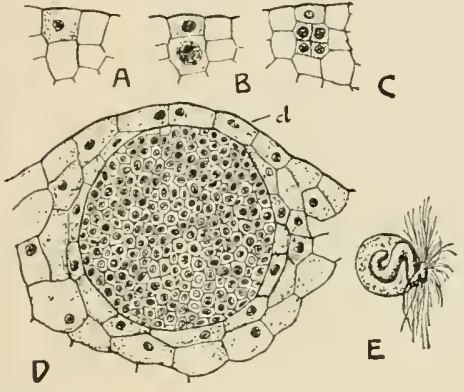

Fig. 393.-Ophioglossum inlgatum. A-1; stages in the development of the antheridium from a superticial cell; the upper cell iu $C$ gives rise to the cover-cells, the lower to the mother-cells of the suermatozoids. $D$, Antheridium not yet opened; $d$, cover-cells. $E$, Spermatozoids. (After Brtchмass.)

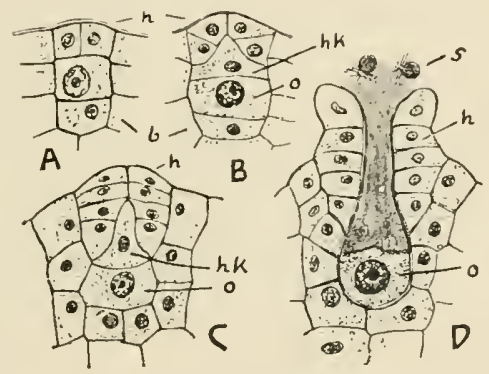

Fig. 394. - Ophioylossun vulyatum. A-C', Development of archegonjum ; $D$, mature opened archegonium with two spermatozoids $(s)$ in front of the opening; $h$, neck-cells ; $h k$, neckcanal-cells; $o$, egg-cell; $b$, basal cell. (After BRT'HMANX.)

\section{Order 2. Marattiaceae}

This order includes a number of stately tropical Ferns with thickened tuberous stems and usually very large leaves provided with two stipules at the base. The sporangia are situated in groups (sori) on the under surface of the leaves, and are either free (Angiopteris), or united to form an oral capsule-like body, the ehambers of which are the sporangia. The prothallium in contrast to that of the Ophioglossaceae is a green, heart-shaped thallus, resembling that of a Liverwort and growing on the surface of the soil. It is sometimes dichotomously branclied. The sexual organs resemble those of the preceding order but are developed on the lower surface of the prothallus. An endophytic fungus occurs in the eells of the prothallus $\left({ }^{127}\right)$.

\section{Sub-Class II. Leptosporangiatae}

\section{Order 1. Filices}

The Filices, or Ferns, in the narrower sense of the word, comprise a large number of genera with numerous species, being widely distributed in all parts of the world. They attain their highest development in the tropies. The TreeFerns (Cyathea, Alsophila, ete.), which include the largest representatives of the order, occur in tropical eounties, and characterise the special family of the Cyatheaceae. The stem of a Tree-Fern (Fig. 395) is woody and unbranehed: it 
bears at the apex a rosette of pinnately compound leaves or fronds, which are produced in suecession from the terminal bud, and leave, when dead, a large leaf sear on the trunk. The stem is attached to the soil by means of numerous adrentitions roots. The majority of Ferns, however, are herbaceons, and possess a creeping rhizome, terminating usually in a rosette of pinnate or deeply divided leaves. Such a habit and growth are illustrated by the common Fern Aspidium filix

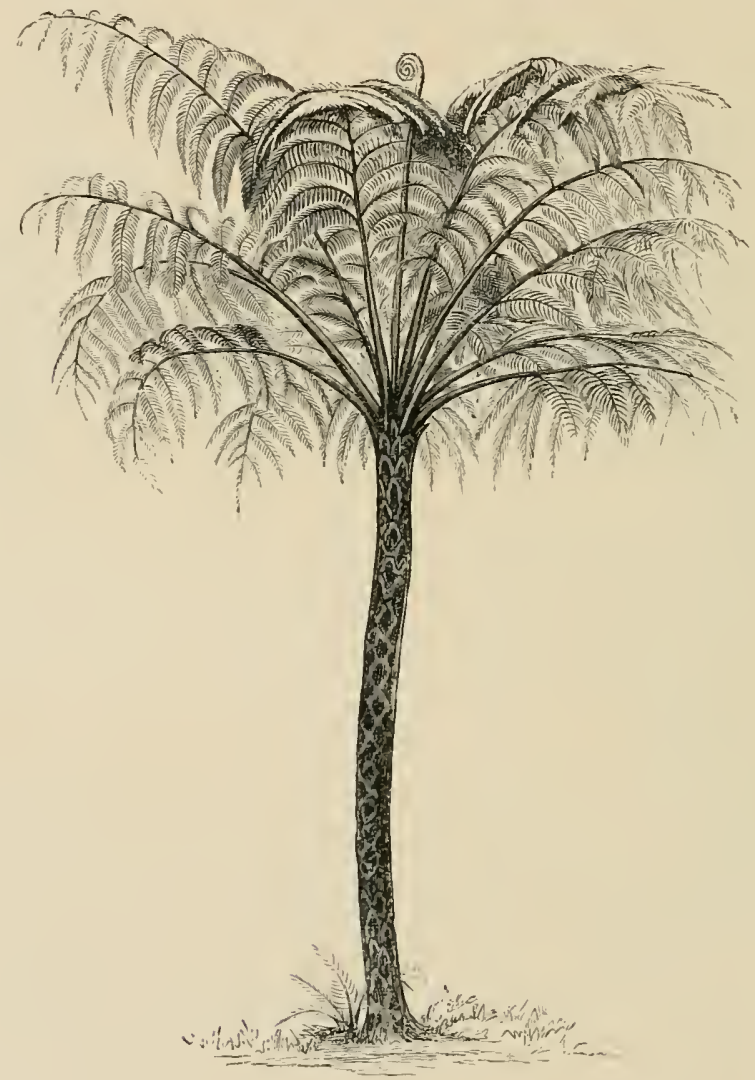

Fu, 345,-Alsophilu crinitu. A Tree-Fern growing in Ceylon (Reduced.)

mas, the rhizome of which is official (Fig. 396). When young, the leares of this Fern are coiled at the tips (Fig. 396, 1, a), a peculiarity common to the Ferns as a whole, and to the Water-Ferns. Unlike the leaves of Planerogans, those of the Ferns continue to grow at the apex mutil their full size is attained. The leaves of the common Polypulium vulgare are pinnate, and spring singly from the upper side of the creeping branched rhizome. In other cases the leaves may be simple and undivided, as in the Hart's-Tongne Fern, Scolopendrium vulyare (Fig. 397). In the tropies many herbaceons Ferns grow as epiphytes on forest trees.

Pcculiar brownish scales (paleae, ramenta), often fringed and consisting of a 


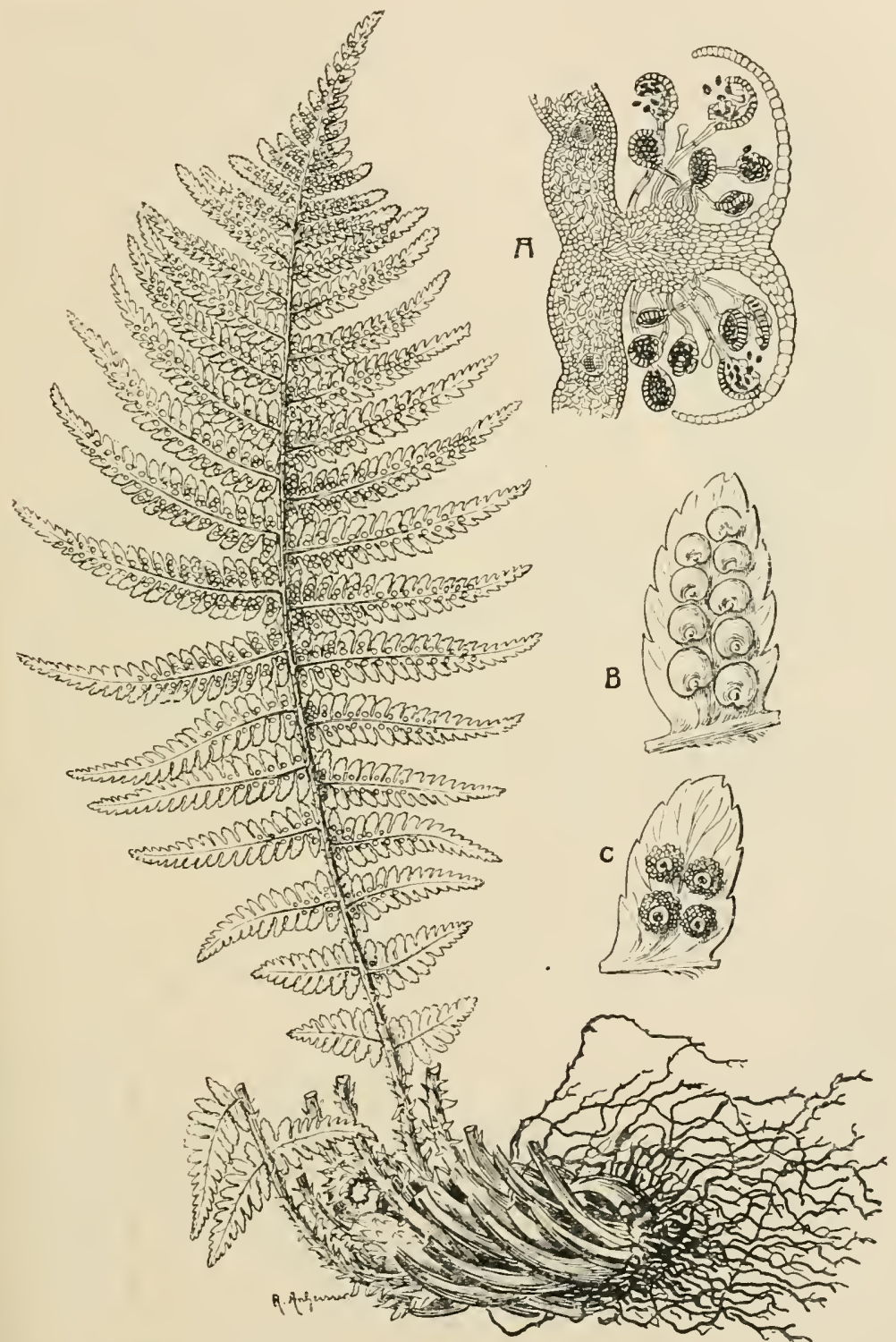

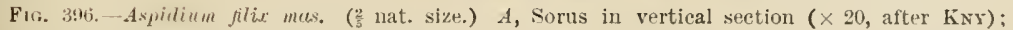
$B$, pinna with young sori still eovered by the indusia; $C$, somewhat older sori with withered indusia. (Slightly masnifieil.) OFFICIAL.

single layer of cells, invest the stems, jetioles, and sometimes also the leaves of most Ferns. 
The sporangia are generally produced in large numbers, on the under side of the leaves. The sporophylls, as a rule, resemble the sterile, foliage leaves. In a

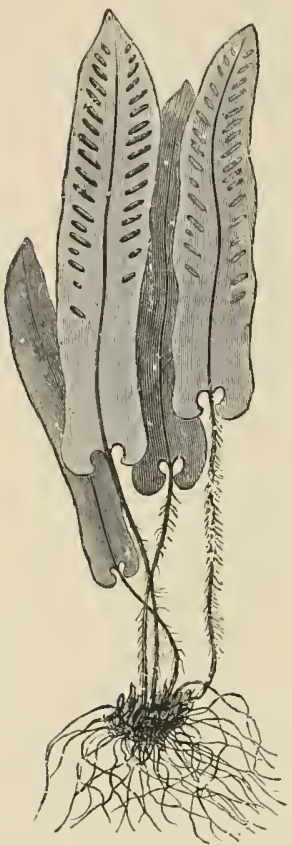

Fig. 397.-Scolopendrium v'ul-gaie. ( $\frac{1}{4}$ nat. size.) few genera a pronounced heterophylly is exhibited: thus, in the Ostrich Fern, Struthiopteris yermanica (Onocleo Struthiopteris), the dark brown sporophylls are snaller and less profusely branched, standing in groups in the centre of a rosette of large foliage leaves.

In the different families, differences in the mode of development, as well as in the form, josition, and structure of the sPolid NGIA are manifested.

The sporangia of the Polypodiaceae, in which family the most familiar and largest number of species are comprised, are united in groups or soRI on the nnder side of the leaves. They are borne on a cushion-like jrojection of tissue termed the RECEPTACLE (Fig. 396, A), and in many species are covered by a protective membrane, the INDUsiun, which is an ontgrowth of the tissue of the leaf (Fig. 396, $B, C$ ). Each sporangium arises by the division of a single epidermal cell, and eonsists, when ripe (Fig. 398), of a eapsule attached to the receptacle by a slender multicellular stalk, containing a large number of spores. The wall of the capsule is formed of a single layer of cells. A row of cells with strongly thickened radial and inner walls, extending from the stalk over the dorsal side and top to the middle of the ventral side of the capsule, are speeially developed as a ring or ANNULUs, by means of which the dehiscence of the sporangium is effected. This type of annulus is characteristic of the Poly. podiaceae.

On drying of the wall of the sporangium the cohesion of the remaining water in the cells of the annulus draws in the thin outer walls of these cells; this causes the annulus to shorten and determines the dehiscence of the sporanginm by a transverse slit
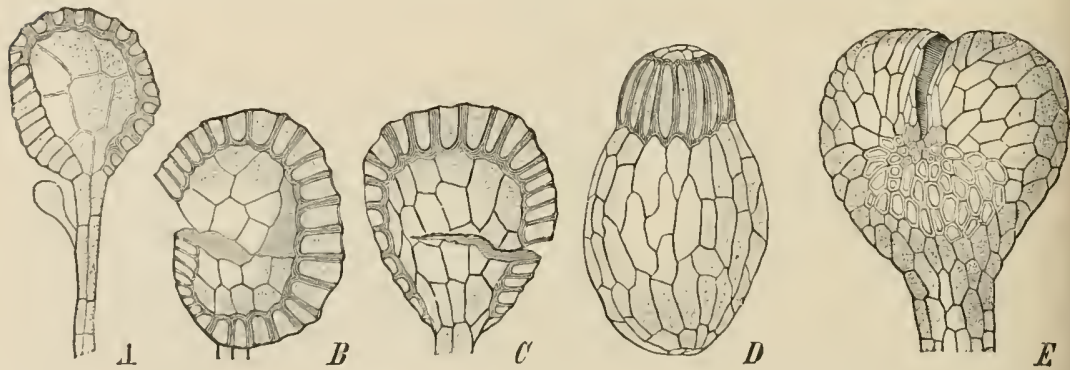

Fir. 398.-Sporangia. A, Aspilinm filir mes ; there is a glandular hair at the base; $B$ and $C$, Alsuphilu urmetu, seen from the two sides; $D$, Aneimia crudutu; E; Osmuntu regulis. (A-D $\times 70$ orig. ; $E \times 4$ II, after LijkssEn.)

between the broar terminal cells of the ammulns. When the pull exerted by the cohesive power of the water suddenly gives way, the annulus returns by its 
own elastieity to its original position, thins effecting the dispersal of the spores. The sporangium remains open owing to the drying and contraction of the thin cell walls $\left.{ }^{128}\right)$.

The form and insertion of the sori, the shape of the indusiun when present, or its absenee, all constitnte important criteria for distingnishing the different genera. The sori of Scolopendrium are linear, and covered with a lip-shaped indusium consisting of one cell-layer. They are so disposed in pairs on different sides of every two snccessive nerves, that they appear to have a donble indusinm opening in the middle. In the genus Aspidium, on the other hand, each sorus is orbicular in form and covered by a peltate or reniform indusinm attached to the

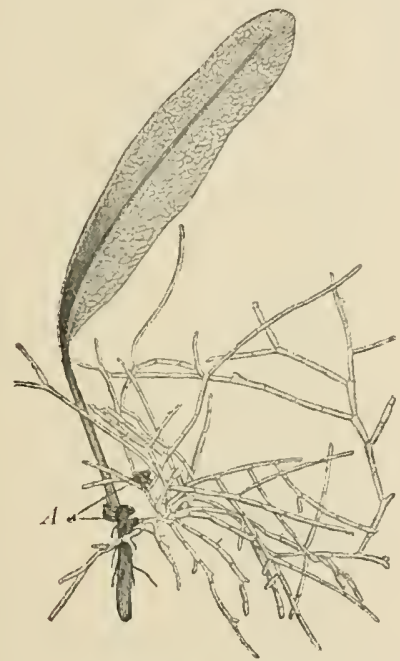

FIG. 399.-Trichomunes rigilum. Portion of a prothallus with an archegoniophore (A) to which a young plant is still attached. (After GoEBEL.) apex of the placenta; a glandular hair is frequently present on the stalk of the sporangium. The sori of Polypodium vulgare are also orbicular, but they have no indusia. In the common Bracken, Pteris aquitina, the sporangia
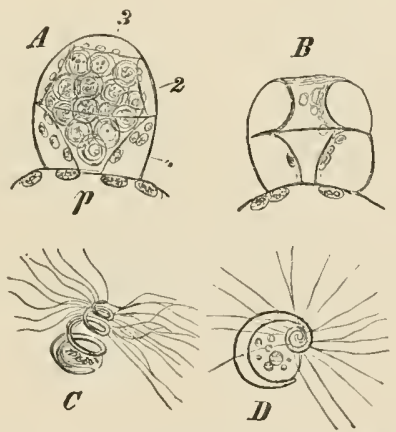

Fig. 400. - Polyporlium vulgure. A, Mature, $B$, discharged antheridium; $p$, prothallium cell ; 1 and 2 , ring-shaped cells ; 3 , lid-cell ; $C, D$, spermatozoids. $(A, B \times 240 ; C, D$ $\times 540$.)

form a continuous line along the entire margin of the leaf, which folds over and covers them.

Besides the Polypodiaceae the Ferns inclnde other families, mainly represented in the tropics, the sporangia of which differ in the construction of the annulus and in the mechanism of their dehiscence. The sporangia of the Cyatheaceae, to which family belong principally the Tree-Ferus, are characterised by a complete annulns exteuding obliqnely over the apex of the capsule (Fig. 398, $B, C$ ). The Hymenophyllaceae, often growing as epiphytes on Tree-Ferns, have also sporangia, with a complete, obliqne, or horizontal annulus. The sporangia of the Schizaeaceae, on the other hand, have an apical annnlus (Fig. 398, D), while in the Osmundaceae, of which the Royal Feru, Osmunda regalis, is a familiar example, the annulns is represented merely by a group of thick-walled cells just below the apex of the sporangium (Fig. 398, E).

All the members of the Filices are homosprorons. The Prothaldium has usnally the form of a flat, heart-shaped thallns (Fig. 398), bearing the antheridia and archegonia on the under side. In certain Hymenophyllaeeae (Trichomanes) the 
prothallium is filiform and branched, resembling in structure the protonema of the Mosses, and producing the antheridia and archegonia on lateral branches (Fig. 399).

The ANTHERIDIA and ARCHFgoxia $\left({ }^{12 y}\right)$ are similarly constructed in nearly all Leptosporangiatae, and present differences from those of the Eusporangiate Ferns ; those of Polypodium vulgare (Figs. 400,401) may serve as a type. The antheridia are spherical projecting bodies (Fig. $400, A, p$ ), arising on young prothallia by the septation and further division of papilla-like protrusions from single superficial cells. When mature, each antheridium consists of a central cellular cavity, filled with spermatozoid mother-cells, and enclosed by a wall formed of two ring-shaped cells $(A, 1,2)$ and a lid-cell $(3)$. The spermatozoid mother-cells are produced by the division of the central cell. They are discharged from the antheridium by the pressure exerted by the swollen ring cells, and the consequent rupturing of the lid-cell. Each mother-cell thus ejected liberates a spirally coilerl spermatozoid. The anterior extremity of the spermatozoid is beset with numerous cilia, while attached to its posterior eud is a small vesicle which contains a number of gramles,

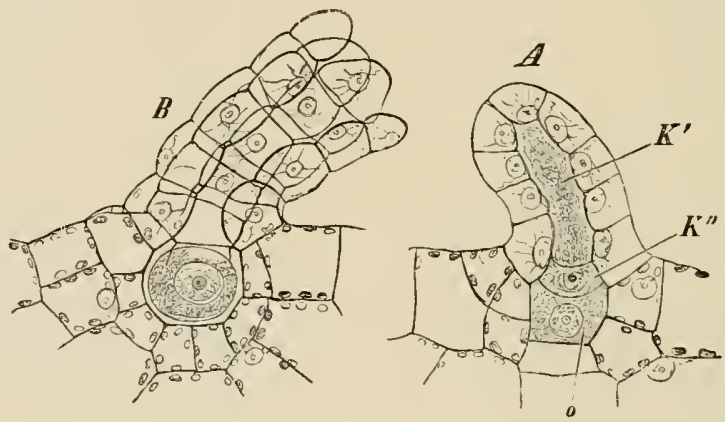

Fig. 401.-Polyporliun vulgare. A, Toung archegonium not yet open; $K^{r}$, neck-canal-cell ;

$K^{\prime \prime}$, ventral-canal-cell; o, egg-cell; $B$, niature archegonium, open. $(\times 240$.

and represents the unused remnant of the contents of the mother-cell (Fig. 400 , $D, C$; Fig. 99, $B$ ).

The archegonia arise from the many-layered median portion of older prothallia. They are developed from a single superficial cell, and consist of a ventral portion, embedded in the prothallium, and a neck portion. The neck, which projects above the surface of the prothallimm, consists of a wall composed of a single layer of cells made up of four cell rows (Fig. $401, A, B$ ) ; it encloses the elongated neckeanal-cell. The ventral portion contains the large egg-cell and the ventral-canalcell immediately above it. As the archegonium matures, the canal-cells become disorganised, and fill the canal with a strongly refractive mucilaginous substance. This swells on the admission of water, and, rupturing the neck at the apex, is discharged from the archegonimm, which is now ready for fertilisation. Thr development of the embryo is representerl in Fig. 389.

In certain ferms the sporoplyyte may originate on the prothallus by a process of budrling or rlirect vegetative growth; the sexual organs are not formed or take no part in the production of the plant (apogamy). Conversely the prothallus may arise directly, without the intervention of sjores, from the tissues of the leaf (ajospory) (130).

OrFirtal.,-Aspridium, filix mus, Filix mas. 
The long silky brown lairs from the base of the leaf-stalks of varions TreeFerns, especially Cibotium Barometz, and other species of this genus, in the East Indies and the Pacific Islands, are used as a styptic (Penawar, Djambi, Pulu).

\section{Order 2. Hydropterideae (Water-Ferns) (131)}

The Water-Ferns include only a few genera, which are more or less aquatic in habit, growing either in water or marshy places. They are all heterosporous. The macro- and microsporangia do not develop, like those of the Filices, on the under side of the leaves, but are enclosed in special receptacles at their base, constituting sporangial fructifications or sporocarps. The wall of the sporangium, which consists of a single layer of cells, has no annulus.

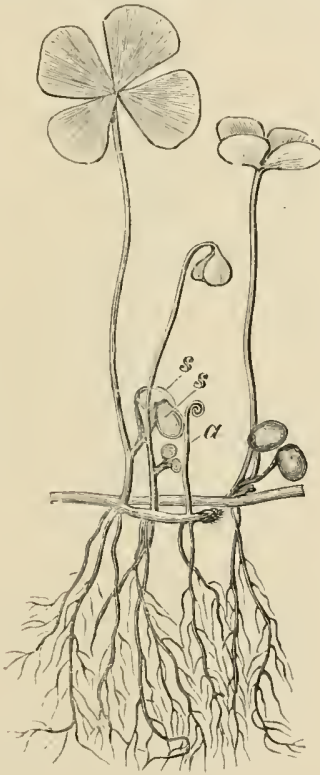

A

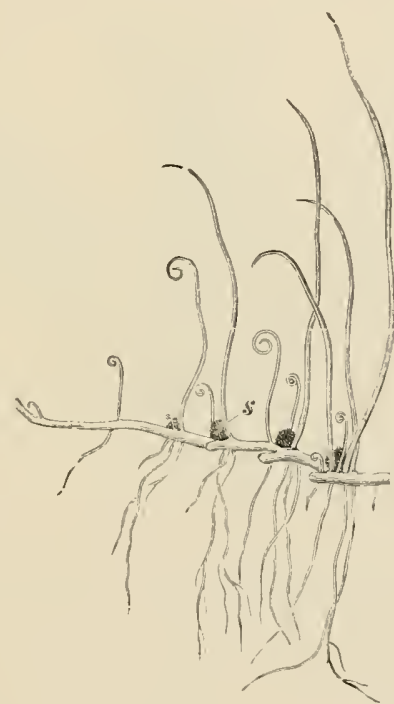

li

F14, 402.-A, Mursilu qualrifoliutu. ", Young leaf; s, sporocarps. B, Pilulutiuglubuliferu. s, spornearp. (After Bischoff, rerluced.)

The Water-Ferns are divided into two families: Marsitiaceac, incInding three genera, and Salviniaccae, with two genera.

To the Marsiliaceae belongs the genus Marsitia, of which the European $M$. quad ifoliate (Fig. 402, A) may be taken as an example. This species grows in marshy meadows, and has a slender, creeping, branched axis, bearing at intervals single leaves. Each leaf has a long erect petiole, sumounted by a compound lamina composed of two pairs of leaflets inserted in close proximity. The stalked oval sporocarps $(s)$ are formed in pairs above the base of the leaf-stalk, or in other species they are more numerous. Each of them corresponds in development to the quadripinnate sterile lamina, but is not divided into pinnæ. The joung leaves, as in the Filices, are circinate. 
Pilutaria also grows in hogs and marshes. $P$. globulifere is found in Britain. It differs from Marsilia in its simple linear leaves, at the base of which occur the spherical sporocarps, which arise singly from the base of each sterile leaf-segment; the sporocarp corresponds to a segment of the leaf (Fig. 402, B).

The Salviniaceae contains only free-floating aquatic plants belonging to the two genera Salvinia and $A \approx o l l \alpha$. In Solvinia natans, as representative of the first genus, the sparingly-branched stem gives rise to three leaves at each node. The two upper leaves of each whorl are oval in shape, and developed as floating foliage leaves; the third, on the other hand, is submerged, and consists of a number of pendent, filamentous segments which are densely covered with hairs, and assume the functions of the missing roots. The sporocarps have an entirely different mode of development from those of the Ilarsiliaceae; they are spherical, and are borne in small groups on the submerged leaves at the base of the filamentous segments (Fig. 403, $A$ ). The sporangia are produced within the sporocarp from a column-like

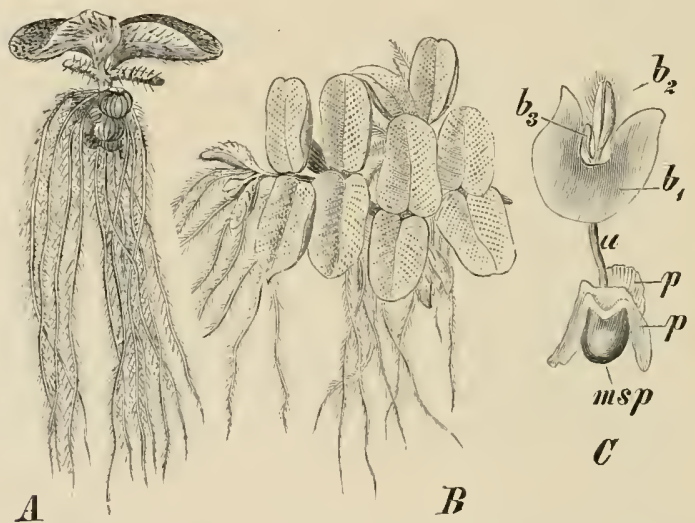

Fin. 403.-Salvinia nutuns. A, Suen from the side; $B$, from above (after Brscuoff, reduced). $C$, An embryonic 1,lant; $m s p$, macrosyore; $p$, prothallium; $a$, stem; $b_{1}, b_{2}, b_{3}$, the first three leates ; $b^{l}$, the so-called sentiform leaf. (After Pringsheis, $\times 15$.)

receptacle, which corresponds in origin to a modified leaf-segment. The envelope of the sporocarp is equivalent to an indusium; it arises as a new growth in the form of an anuular wall, which is at first cup-shaped, but ultimately closes orer the receptacle and its sorus of sporangia.

The second genus, Azollo, is ehiefly tropical, represented by small floating plants, profusely branehed, and beset with two-ranked closely crowded leaves. Each leaf consists of two lobes, of which the upper floats on the surface of the water, while the lower is submerged, and assists in the absorption of water. A small cavity enclosed within the upuer lobe, with a narrow orifice opening outwards, is always inhabited by filaments of Vostoc. From the fact that luairs grow out of the walls of the cavity between the algal filaments, the existence of a symbiotic relation between the two plants would seen to be indicated. Azolla, unlike Salvinici, possesses long, slender roots developed from the umler side of the stem. The sprorocarps are nearly spherical, and produced usually in pairs on the under side of the first leaf of some of the lateral branches.

In the structure of the sporangia and spores, and in the development of the prothallia, the Hydroptrideae dilfer in some respeets from the Filices. These differ- 
ences may be best understood on reference to Salvinia natans $\left({ }^{132}\right)$ as an example. The sporocarps contain either numerous nicrosporangia or a smaller number of macrosporangia (Fig. 404, $A$, mo, mi). In structure both forms of sporangia resemble the sporangia of the Leptosporangiate Ferns; they are stalkerl, and have, when mature, a thin wall of one cell-layer, but no amulns $(I, D)$. The MrclisPoRANGlA enclose a large number of microspores, which, as a result of their development in tetrads from the mother-cells, are disposed in grolips of four $(C)$, and embedded in a hardened frothy mass filling the cavity of the sporangimn. This frothy interstitial substance is rerived from the tapetal cells, which gradually lose their individuality and wander in between the spore mother-cells.

The microspores germinate within the microsporangium, which does not open ; each germinating microspore puts ont a short tubular male frothallinm, which pierces the sporangial wall. The antleridia are developed in this by successive divisions (Fig. 405). Each antheridium produces four spermatozoids, which are
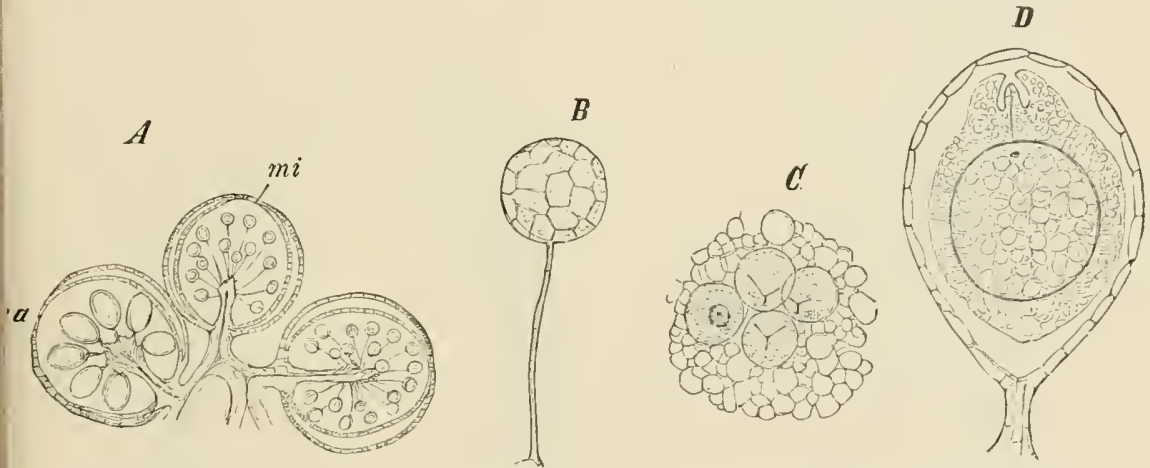

F1f. 404.-Salviniu natans. A, Three sporocarps in median longitudinat section; ma, maerosporocarp ; mi, microsporocarp $(\times 8)$; $B$, a microsporangium $(\times 55)$; $C$, portion of the content of a microsporangium, showing four microspores embedked in the frothy interstitial substance $(\times 250) ; D$, a macrosporangium and maerosjore in merlian longitulinal section $(\times 55)$.

set free by the rupture of the cell walls. Aithough the whole male prothallium is thus greatly reunced, it nevertheless exhibits in its structure a resemblance to the prothallia of the Filices.

The viacrospolidisid are larger than the microsporangia, but their walls consist similarly of one cell-layer (Fig. 404, D). Each nacrosporangium prodnces only a single large macrospore, which develops at the cxpense of the numerous spores originally formed. The macrospore is densely filled with large angnlar proteid grains, oil globules, and starch grains; at its aprex the protoplasm is denser and contains the nuclens; the membrane of the spore is covered by a dense brown exinium, which in turn is enclosed in a thick frothy envelope, the perinium, investing the whole spore and corresponding to the interstitial substance of the microspores, and like this formed from the dissolution of the tapetal cells. The macrospore remains within the sporangium, which is eventually set free from the mother plant and floats on the surface of the water. On the germination of the macrospore, a small-celled female prothallium is formed by the division of the denser protoplasm at the apex, while the large underlying cell does not take part in the division, but from its reserv. material provides the developing prothallium with nomishment. The spore wall splits into three valves, the sporangial wall is 
ruptured, and the green prothallium protrules as a small saddle-shajed body. On it three archegonia are prodnced, but only the fertilised egg-cell of one of them develops into an embryo, whose foot, remaining for a time sunk in the venter of the archegonium, finally ruptures it (Fig. 406). The first leaf of the germ plant is shield-shaperl (Fig. 403,C), and floats on the surface of the water.

The development of Azolla $\left(^{(33)}\right.$ proceeds in a similar manner, but the sporangia and spores exhibit a number of distinctive peculiarities. The micro- and macro-

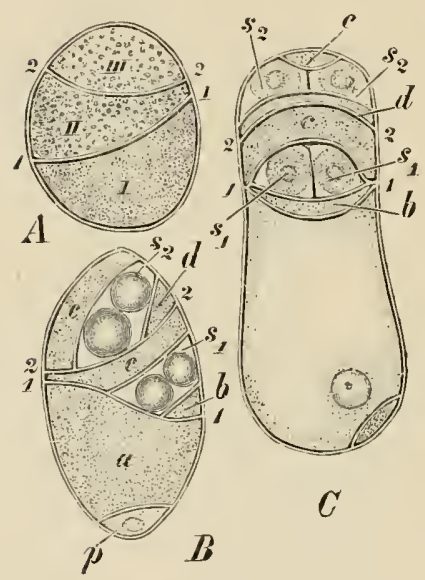

Fí. 405.-Sulviniu nutuns. Development of the male prothallium. $A$, livision of the microspore into three cells $I-I I I(\times 860) ; B$, lateral view ; $C$, rentral view of mature prothallium ( $x$ 640 ). Cell $I$ has divided into the prothallium cells $a$ and $p$; cell $I I$, into the sterile cells $b, r$, and the two cells $s_{1}$, each of which has formed two sperma. tozoid mother-enls ; cell $I I$, into the sterile cells $d, e$, and the two cells so. The cells $s_{1} s_{1}$ and $s_{2} s_{2}$ represent two antheridia; the cells $b, c, d, e$, their wall-cells. (After BelaJEFF.)

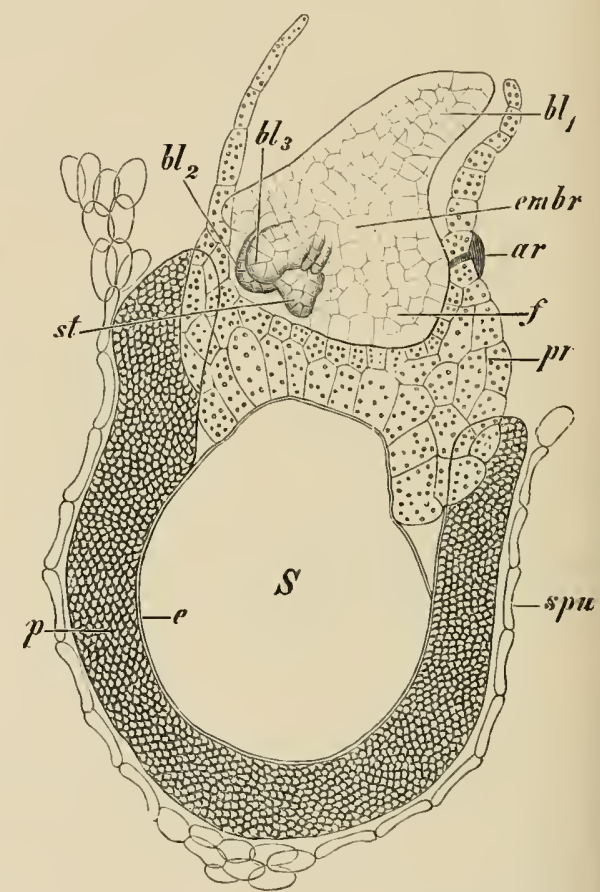

FIf. 4106. - Selviniu nutens. Embryo in longitudinal section; $p r$, prothallium; $S$, spore-cell ; $e$, exinium; $p$, perinium; spu, sporangial wall; $u r$, arelıgonium; embr, embryo; $f$, foot; $b l_{3}, b l_{3}, b l_{3}$, the first three leares; st, apex of stem, (After Prixosherm, $\times 100$.)

sporocarpss at first develop alike, in each a single macrosporangimm is laid down surrounded by the tubular indusium, and from the stalk of the macrosporangium the macrosporangia grow out. In the nicrosporocarp only the microsporangia develop; in the macrosporocarp, on the other hand, only the macrosporangimm becomes mature. The numerous spores of the microsporangia are aggregated into several nearly splierical balls or massulae, formed from the interstitial substance derived from the protoplasm of the tapetal cells. Each massula, enclosing a number of spores, is beset externally with barbed, hook-like outgrowths of the interstitial snbstance (glochidia). On the rupture of the sporangia the massulae are set free in the water, and are carried to the macrospores, to which they become attached. In the macrosporangium 32 macrospores are developed but only one comes to maturity ; 
in the course of its development it supplants all the other sporogenous eells, and finally the sporangial wall itself becomes flattened against the inner wall of the sporocarp, frequently undergoing at the same time partial dissolution. The macrospore is enveloped by a spongy perinium whose outer surface exhibits numerous depressions and protuberances prolonged into filaments. At the apex of the spore the perinium expands into three pear-shaped appendages. The massulae become attached to the perinium. The wall of the sporocarp is ruptured at its lower portion, the apical portion remainiug attached to the spore in the form of an ampulla-likecovering. The formation of the prothallia is effected in essentially the same way as in Salvinia, except that only one antheridium with eight spernatozoids arises on each of the small male prothallia protruding from a massula.

The sporocarps of the Narsiliaceae have a more complicated structure : those of Pilularia glolulifera are divided into four ehambers, each with a single sorus; in Marsilia they enclose numerous sori (14-18) disposed in two rows. The sori in both genera contain both nicro- and macrosporangia. These arise as in all other forms from superficial cells and come to lie in cavities by the npgrowth of the surrounding tissue.

In the case of the Marsiliaceae the prothallia are even more redueed than those of the Salviniaceae, but otherwise their mode of development is very similar. Each of the minute female prothallia formed at the apices of the macrospores prorluces a single archegonium. An apogamous formation of the embryo has been shown to occur iu a nmmber of Australian species of Marsilia belonging to the group Drummondii $\left({ }^{134}\right)$.

\section{Class II}

\section{Equisetinae (Horse-tails) ( ${ }^{135}$ )}

The Equisetinae include only the one genus Equisetum, eomprising 20 species, found widely distributed over the whole world. Developed partly as land, partly as swamp plants, they may always be distinguished by the characteristic strncture and habit of the asexwal generation. They have a branching, moderground rhizome on which arise erect, aerial hauhs, usually of annual growth. The rhizome of the conmon Horse-tail, Equisetum arense, revelops also short tuber-like branches which serve as reservoirs of reserve

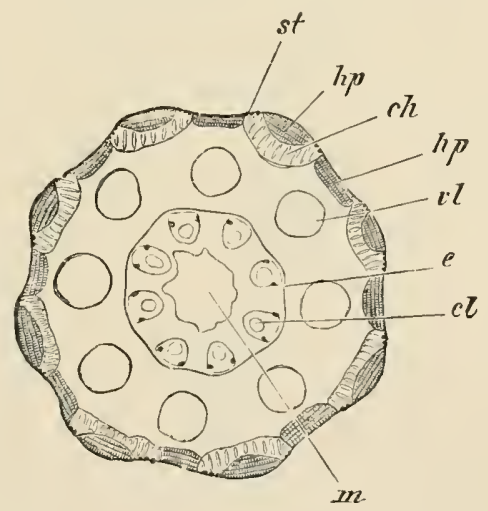

Fig. 407.-Equisetum remensc. Transverse section through the stem. $m$, Lysigenic merlullary cavity ; $r$, endodermis ; $r l$, carinal canals in the collateral bundles; $\%$, vallecular cavities; $h p$, sclerenchymatous straucls in the furrows and ridges; ch, tisisue of the primary cortex containing (hloroplyyll ; st, rows of stomata. $(\times 11$. material and hibernating organs (Fig. 408).

The aerial haulms remain either simple, or they give rise to branch whorls, and these in turn to whorls of a higher order. All the axes are formed of elongated internodes; they have a central pith-eavity and a peripheral series of snaller air channels. The collateral vascular bundles form a single circle, as seen in transverse section (Fig. 40\%).

At each node is borne a whorl of scale-leaves pointed at the tips, and united below into a sheath elosely enveloping the buse of the internocle. The lateral 
branches are developed in the axils of the scale leaves, lut not having space to

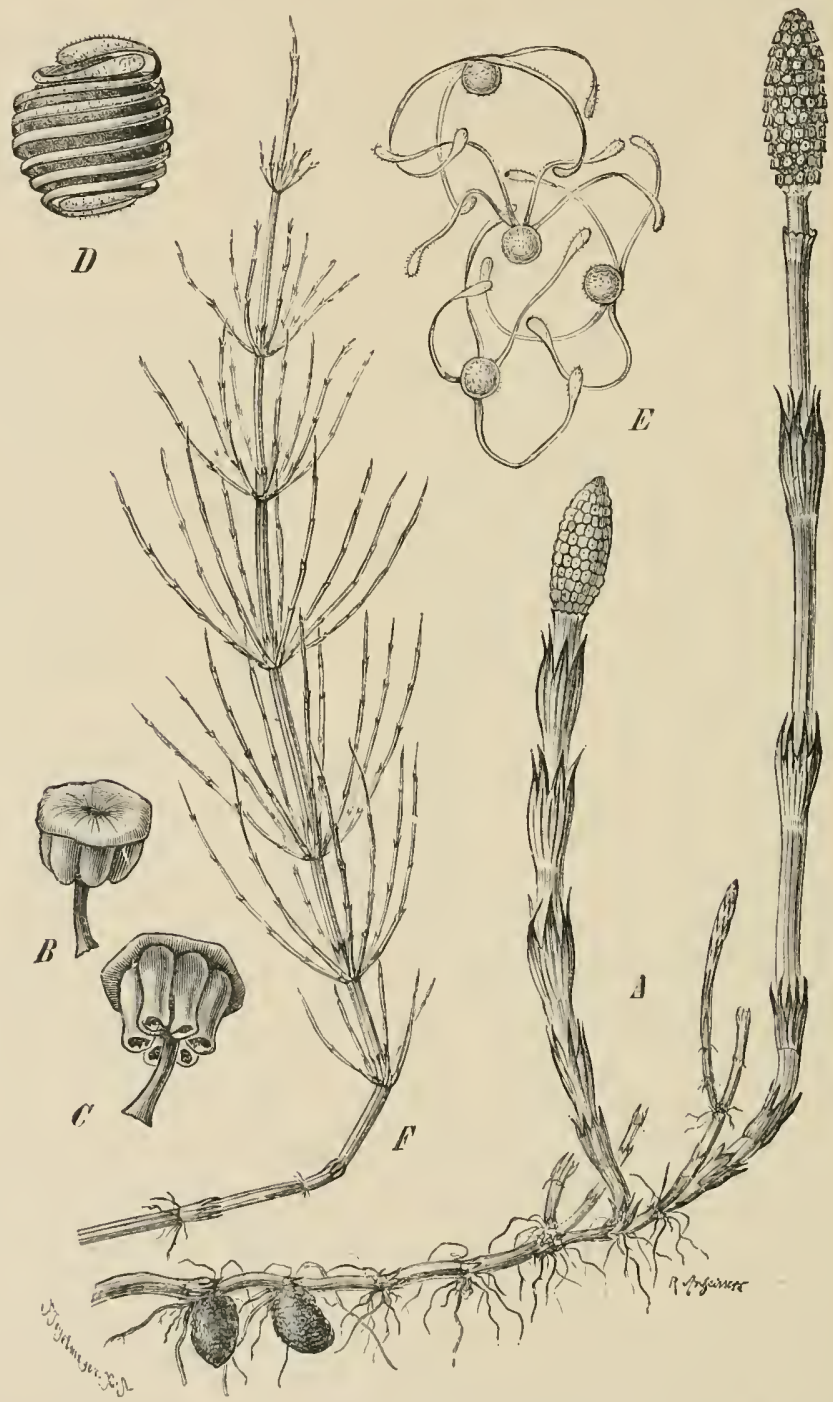

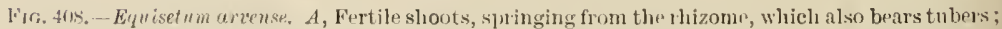
1he vegetative shoots lave not yet unfollec. F, Sterile vegetative shoot. $\quad$;, $C$, Sporophylls lmaring sporangia, which in $C$ have opened. I), sporf showing the two spiral bands of the perinium. F, Dry spores showing thr expander] spiral bands. ( $A, F, \frac{x}{2}$ nat. size. $B, C, D, F$, enlarged.)

grow upwards they fieree the narrow sheath. As a result of the rerluction of the leaf laminae, the haulms themselves assume the function of assimilation, 
and for that jurpose their cortical tissue under the epidermis is provided with ehlorophyll.

The spoliaxgia are borne on specially-shaped leaves or sporophylls. The sporophylls are developed in whorls, but are closely aggregated at the tips of the erect fertile shoots into a cone (Fig. 408), which is sometimes spoken of as a flower, from the correspondence in its structure to the male flower of the Conifers. The lowest whorl is sterile, and forms a collar-like protuberance. The sporophylls (Fig. $408, B, C)$ are stalked and have a peltate expansion, on the under side of which are borne the (5-10) sac-like sporangia. In the young sporangium the sporogenous tissue is surrounded by a wall consisting of several cell layer's, but eventually the tapetal cells of the inner layer become disorganised, and their protoplasm penetrates between the developing spores. At maturity the wall of the sporangium consists
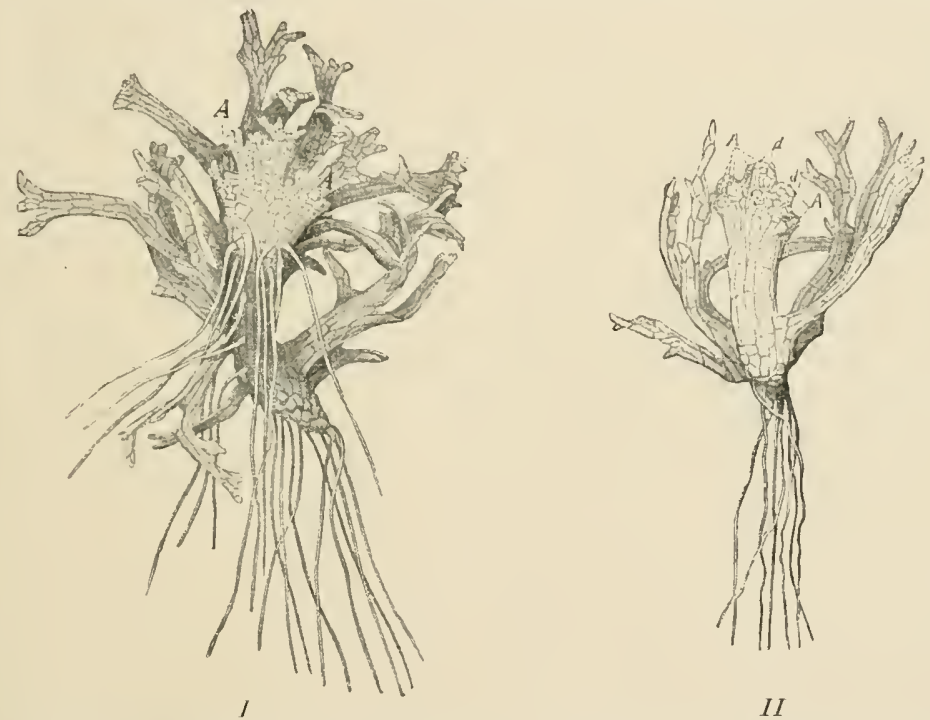

FIG. 409.-Eyuistum pratense. I, Female prothallium from the under surface, showing the archegonia $(A)$. II, Male prothallium with antheridia $(A)$; $d$, cover cells of antheridia. $(I \times 17$, $I I \times 12$. After GoebeL.)

only of the ontermost of the original layers, the cells of which are provided with annular and spiral thickenings ; the sporangia thus resemble the homologous pollensacs of Phanerogams. The dehiscence is determined by the cohesive force of the diminishing amount of water in the cells of the onter layer and the contraction of the thin parts of the cell walls on drying $\left({ }^{3 i b}\right)$. The sporangia split longitudinally, and set free a large number of green spores, which are nearly spherical in shape, and have peculiarly constructed walls. In addition to the intine and exine, the spores are overlaid with a perinium cleposited by the protoplasm of the tapetal cells, and consisting of two spiral bands which are attached to the sjores only at their point of intersection (Fig. 408, D). On drying, the spiral bands loosen and become uncoiled; when moistened they close again alound the spore. By means of their hygroscopic movements they serve to hook together the spores, and in this way assure the close proximity of the inisexual prothallia which the latter produce (Fig. 408, $E$ ). 
In certain species some of the aerial hauhms always remain sterile, branching profnsely, while others which produce the terminal eones either do not branch at all, or only at a later stage, and then sparingly. This distinction between the sterile and fertile laulms is most marked in Equisetum arrense and Equisetum Telmateja, in both of which the fertile shoots are entirely unbranched, and terminate in a single cone (Fig. 408). Resembling in their mode of life a parasite upon the rhizome, they are otherwise distinguished from the regetative haulms by their lack of chlorophyll and their light yellow colour.

Equisetum giganteum, growing in Sonth America, is the tallest species of the genus; its branched hanlms, snpported by neighbouring plants, attain a height of over twelve metres, and are abont two cm. in diameter.

The spores are all of one kind, and on germination give rise to thalloid Pliothallis which are generally dioecious (Fig. 409). The female prothallia are larger than the male, aud, branching profusely, are prolonged into erect rufled lobes at whose base the archegonia are produced. In structure the archegonia resemble those of the Ferns, but the upper cells of the four longitudinal rows of cells constituting the neck are more elongated and, on opening, curve strougly outwards. The first leares of the embryo are arranged in a whorl and encircle the apex of the stem. The growth of the embryo is effected by the division of a threesided a fical cell (Figs. 113, 114).

The onter epidermal walls of the stem are more or less strongly impregnated with silica. In Equisetum hiemule, and to a less degree in Equisetum arrense, the silicification of the external walls is carried to such an extent that they are used for scouring metal utensils and for polishing wood.

Poisonous substances are formed in some species of Equisetum, and hay with which the shoots are mixed is injurious to cattle.

\section{CIAASS III}

\section{Lycopodinae (Club Mosses)}

To the Lyeopodinae belong, as their most important genera, Lycopodium, Selaginella, and Isoetes. They are distinguished from the other Pteridophyta, by their general habit and the mode of their sporangial development.

The dichotomous branching of the stem (Figs. 18, 19) and root and the simple form of the leaves are characteristic of the sporophyte. The two first-named genera have elongated stems and small leaves; lsoctes on the other hand has a tuberous stem and long awl-shaped leaves. Unlike the fertile leaves of the Filicinae and Equisetinae, which always bear numerous sporangia, the sporophylls of the Iycopodinae produce the sporangia singly, at the base of the leaves or in their axils. Althongh in many cases scarcely distinguishable from the sterile leaves, the sporophylls are frequently distinctively shaperl, and, like those of Eiquisetum, aggregated at the ends of the fertile shoots into terminal spike-like cones or Howers. Compared with the leaves, the sporangia are lelatively large and have a firm wall of a number of layers of cells. The innermost layer of the 
sporangial wall, the tapetal layer, is not absorbed. The sporangia have 110 annulus. Except in the case of Isoctes, the spores of which become free by the decay of the sporangial wall, they dehisce by longitudinal slits, which divide the sporangia into two valves; the slits ocenr where rows of cells of the wall have remained thin $\left({ }^{136}\right)$. The sporangia of Lycopodium are homosporous; those of Selaginella and Isoetes are heterosporous. The heterosporous forms produce only greatly modified and reduced prothallia; in the genus Lycopolium, on the other hand, the prothallia are well developed, and show certain resemblances to those of the Ophioglossaceae.

The Lycopodiaceae and the Selaginellaceac agree in the segmentation of the embryo, which in both is characterised by possessing a suspensor, and in the structure of the spermatozoids, which are bi-ciliate. The Isoetaceae on the other liand have multiciliate spermatozoids and the embryo las no snspensor. On these grounds the two sub-classes of Lycopodiaccac biciliatae and Lycopodiacear plariciliatae may be distinguished.

\section{Order 1. Lycopodiaceae $\left({ }^{13 i}\right)$}

The uumerous, widely distributed species of the genus Lycopodium (Club Moss) are for the most part terrestrial plants ; in the tropics many epiphytic forms also oceur. In Lycopolium claratum, one of the commonest species, the stem, which is thickly covered with small, all-shaped leaves, creeps along the ground; it branches dichotomously, and gives rise to ascending lateral branches, while from the under side spring the dichotomonsly branched roots (Fig. 410). The cone-like Howers, consisting of the closely aggregated sporophylls, are situated in groups of two or more at the ends of the forked erect shoots. The sjorophylls are not like the sterile leaves in shape; they are broader and more prolonged at the tip ; each bears a large reniform sporanginm on the upper side at the base. The sporangium opens into two valves by a transverse slit, and lets free numerous minute spores (Fig. $410, I$ ). Lycopodium Sclago differs in habit from the other species; its bifureately branched stens are all erect, and the fertile are not distinet from the vegetative regions of the shoots.

The spores of the Lycopodiums are all of one kind, and in consequence of their formation in tetrads are of a tetrahedral though sonewhat rounded shape. The exine is covered with a reticulate thickening (Fig. $410, J, K$ ).

The prothallia developed from the spores show a remarkable variety in the gronp. The prothallia of Lycopodium elevatum (Fig. $410, A, B$ ) and the closcly related $L$. cnnotinum are small white tuberous structures, which live as subterranean saprophytes. At first top-shaped, they bccome converted by the continued marginal growth into cup-shaped lobed bodies, which may attain a size of two.centimetres. Long rhizoids spring from the lower surface, while the npper surface bears unnerous antheridia and archegonia. In L. complanutum (Fig. 411) the subterranean prothalli are turnip-shaped, in $L$. Selago ronnded or elongated and cylindrical. The prothalli of the latter may be developed on the surface of the soil, in which case they are green. In the case of $L$. inundatum, the prothalli of which are found on damp peaty soil, and in the tropical $L$. cernuum, with erect profusely branched shoots, the prot'ialli are proor in chlorophyll and are attached to the soil by rhizoids; they have the form of small, half-buried, enshion-like 
masses of tissue, which give rise to green aerial thalloid lobes. The archegonia oceur at the base of these lobes, the antheridia also on their surface. The Lycopod prothalli have fungal filaments forming a myeorhiza in their peripheral tissne.

The protliallia are all monoecions. The antheridia are somewhat sunk in the tissue (Fig. $110, C$ ) and enclose numerous spermatozoid mother-eells, in which

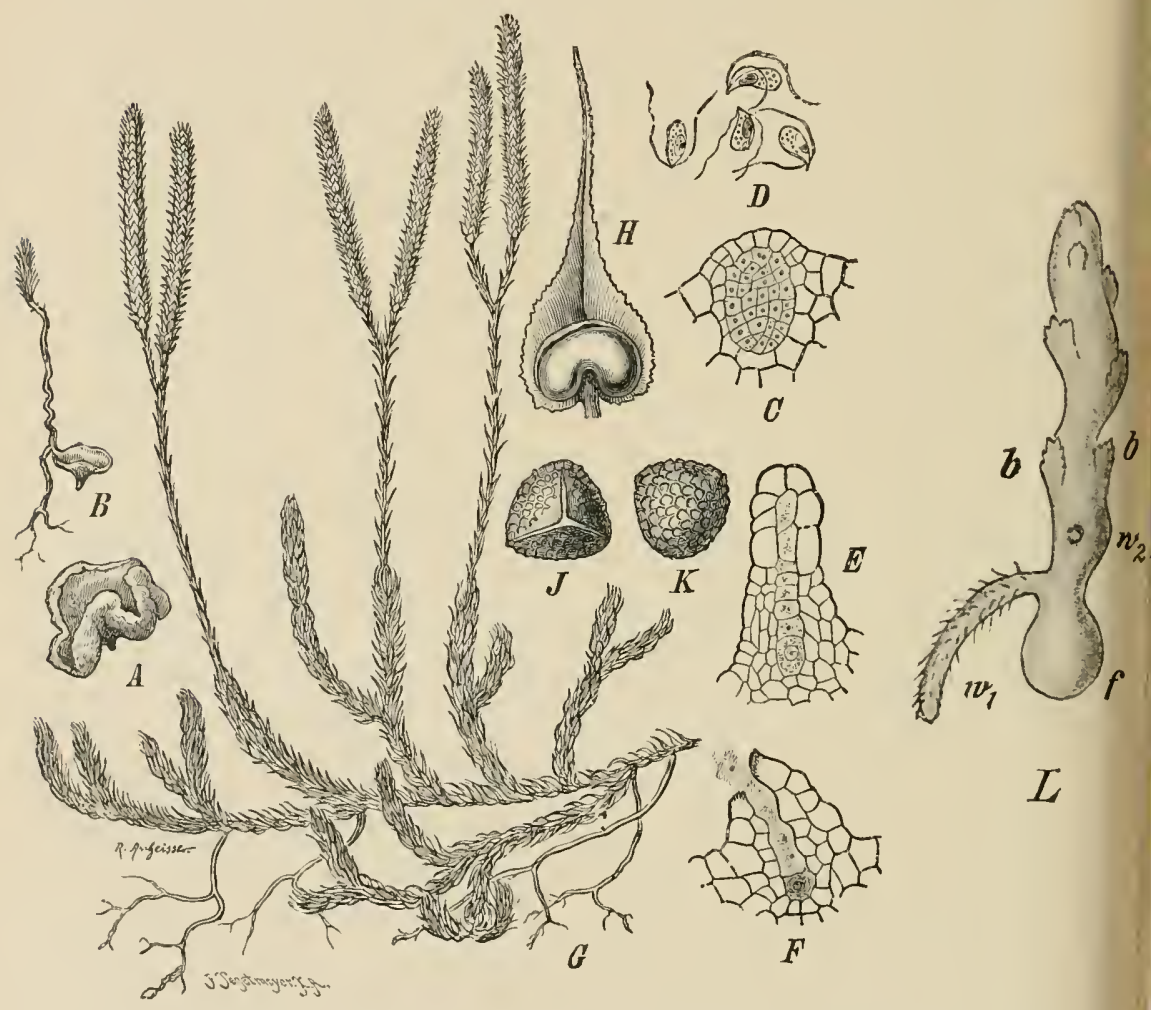

Fig. 410.-Lyeopolium clucufum. A, Old protlullus. $B$, Prothallus with young plant attached. $C$, Antheridium in vertical section. $D$, Sperinatozoins. $E$, Young areinegouium, the neck

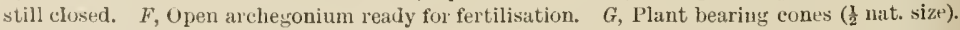
$H$, Nporophyll with an opened sporangium. $J, K$, Spores from two points of view. $L$, a young subterranean sporeling still withont chloropliyll; $f$, foot; $u$, root; $b$ seale-leaves. ( $A-F$ and $L_{\text {, after BrCumann.) }}$

small oval spernatozoids, with two cilia attached below the apex, are formed. The arehegonia (Fig. $410, E, F$ ) are eonstructed like those of the Ferns, but have a shorter neek, whose nuper cells beeome disorgunised on opening. The number of neck-canal-cells differ's in the varions sprecies $(1,3,5$, or $6-10)$.

The embryo (Figr. 112) renains during its development enclosed in the prothallus. It has a sphlerieal, in $L$. complenatum club-shaped and irregular, loot which serves as an alsorbent organ for the sporeling. Beneath the foot the young shoot forms; the first leaves are scale-like, and from the basal portion of 
the shoot the first root develops. The suspensor is situated between the shoot and the foot; it serves as the first absorbent and nourishing organ of the embryo.

The spores of Lycopodium clavatum and other species are sometimes used in pliarmacy.

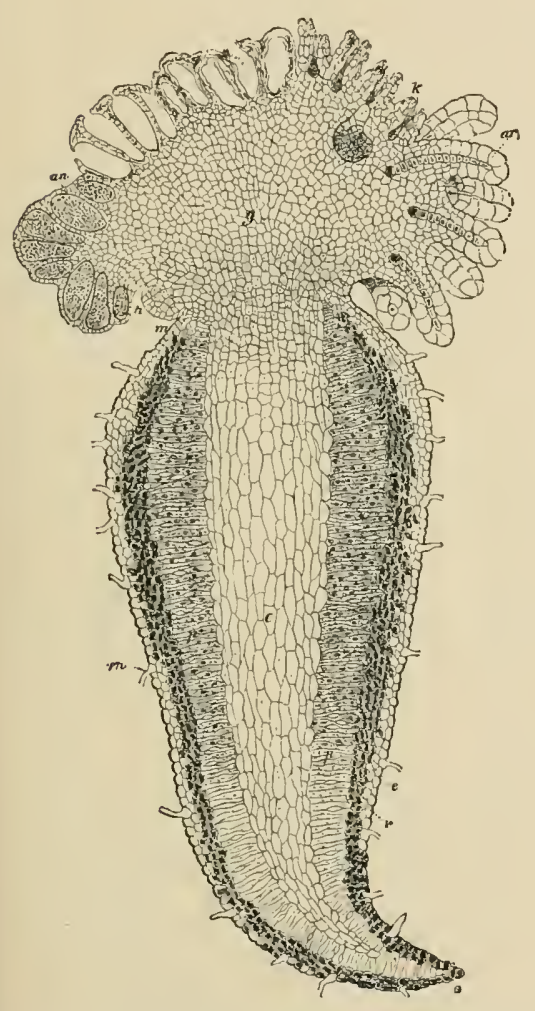

FyG. 411.-Lyeopordium eomplenatum. Protlallus with antheridia ( $(u t)$, areliegonia ( $(u)$, and a young embryo (k). (After Bruchuann, $\times 26$. )

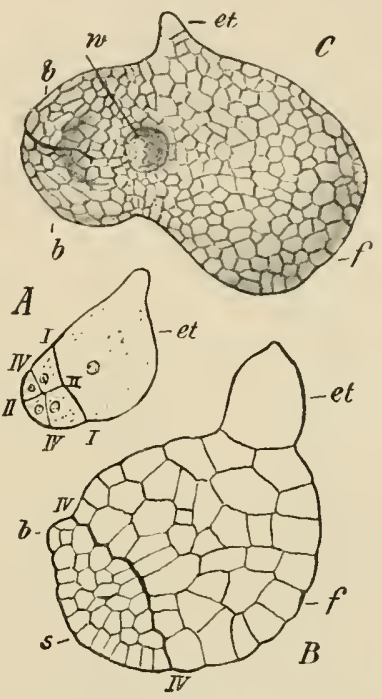

Fig. 412.--Development of the embryo in Lycoportium complanatum. A, Embryo showing the first divisions; the basal wall $I$ separates the suspensor (ct) from the body of the embryo; the transversal walls $I I$ and $I I I$ (the latter being in the plane of the section) together with the transverse wall $I V$ give rise to two tiers of four cells; the tier next the suspensor gives rise to the foot, the terminal tier forms the shoot. (x 112.) $B$, Embryo of meilium age; $s$, apex of stem ; $b$, rudiment of leaf ; $f$, foot. ( $\times$ 112.) C, Embryo shortly before breaking out of the protballus; $b b$, the two first leaves covering the apex of the stem; $w$, the tirst rout. $(\times 40$.) (After BRU(HanN.)

\section{Order 2. Selaginellaceae $\left({ }^{138}\right)$}

To this order belongs the genus Selaginella, represented by numerous and for the most part tropical species. They have, as a rule, profusely forked, ereeping, and sympodially branched stems, but occasionally erect, branched stems; some form moss-like beds of vegetation; others, clinbing on arljacent plants, possess stems several metres long. In general the Selaginellas are similar in habit to the Lycopodiums. They have small, scale-like leaves which usually exhibit a dorsiventral arrangement, such as is shown, for example, in the alpine Selaginella helvetice (Fig. 413), the stem of which bears two row's of small dorsal or upper 
leaves, and opposite to them two rows of larger, ventral or inder leaves. The development of a small, membranous ligule at the base of the leaves, on their dorsal side, is characteristic of the Selaginellas. The rhizophores $\left({ }^{139}\right)$ are organs that are peculiar to the plants of this order; they are cylindrical, leafless, shoot-like structures, which arise exogenously, usually in pairs, from the stem at a bifurcation (cf. p. 51). At their ends a number of endogenons roots are produced, but the rhizophores are able, when the normal shoots are cut lrack, to continue their growth as shoots of ordinary construction. Even below the first leaves of the seedling plant short rhizophores are formed, from which the first roots arise

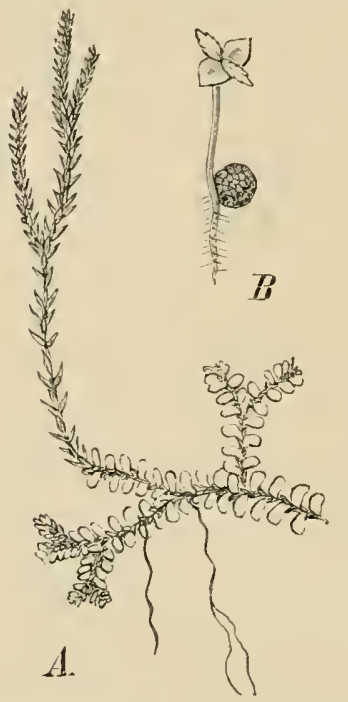

Fis: 413.-...A, Selieginelle helecticu (from nature, nat. size). $B$, Selaginellit dentirulutue, embryonic plant with macrospore still attached. (After Bischогғ, magnitied.)

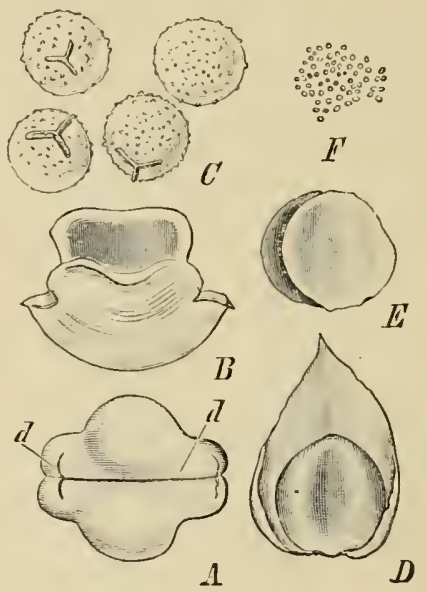

Fic. 414. - Selaginella helectim. A, Macrosporangium from above showing the line of dehiscence $(d)$. $B$, opened, seen from the side; the four nacrospores, $C$, have been ejected. $D$, microsporangium in the axil of its sporophyll. $E$, the same, opened. $F$, microspores. ( about 15.)

endogenonsly. In many species of Selaginella the ejiclermal assimilatory cells of the leaves possess, as in Anthoceros, ouly one large chloroplast $\left({ }^{140}\right)$.

The eones or flowers are terminal, simple or branched, radially symmetrical, or less commonly dorsiventral. Each sporophyll subtends only one sporangium, which springs from the stem above the leaf-axil. The same spike bears both macrosporangia and nicrosporangia. Each maerosporanginn (Fig. 414, $A-C$ ) contains only four macrospores, which are produced by the growth and division of a single spore-mother-cell; all the other mother-cells originally developed ultimatcly disaplear. On account of the increasing size of the spores the spherical macrosporangia become nodular. Opening, which is due to a coliesionmechanism, occurs along definite lines of dehiscence, the wall splitting into two valves, which curre back from a boat-shaped basal portion. The spores are ejecterl hy the pressure of the contracting boat-shaped part and the valves. Numerous spores are formed in the flattened mierosporangia. The morle of 
dehisence is similar in these also, but the boat-shaped portion of the wall is smaller, the valves extending to the base.

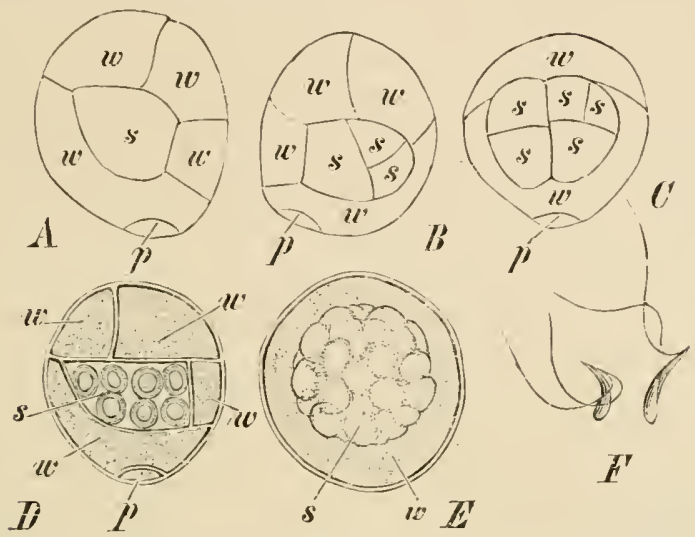

FIG, 415.-A.E, Scluginelle stolonifiru, successive stages in the germination of a microspore: $p$, prothallial cell; $w$, wall-cells of antheridium; $s$, sperriatogenous cells; $A, B$, $D$, lateral, $C$, dorsal view. In $E$ the prothallial cell is not visibie, the disorganised wall-cells enclose the spermatozoid mother-cells; $F$, spermatozoids of Selaginella euspidutu. (After BELAJEFF, A. $E \times 640, F \times 780$.)

The microspores begin their development while still enclosed within the sporangiun. The spore first divicles into a small lenticular vegetative cell, which
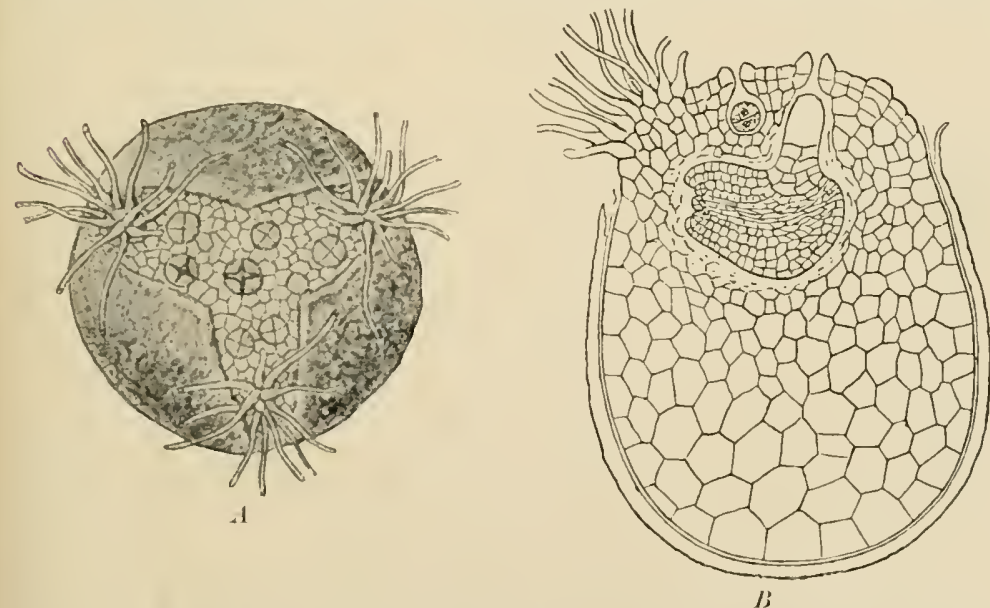

Fis. 416,-Selaginelle, Martensii. A, Ruyturel uracrospore seen from above showing the prothallus with three groups of rhizoirls and several archegonia. $(\times 11 \%)$ b, Longitudinal section of the prothallus showing two archegonia in which embryos are developing. $(\times 112$.) (After BRI'HMANN.)

corresponds to the rhizoid cell of Salvinia, and into a large cell, which divides successively into eight sterile prothallial or wall cells and two or four central 
spermatogenous cells (Fig. 415, A). By the further division of the central cells, which represent a single antheridium, numerous spermatozoid mother-cells are formed $(B-D)$. The peripheral cells then break down and give rise to a mucilaginous substance, in which is embedded the central mass of spermatozoid mother-cells $(E)$. The small prothallial cell $(p)$, however, persists. The whole male prothallium is up to this stage still enclosed by the wall of the microspore. This ultimately ruptures, and the mother-cells are set free and liberate the clubshaped spermatozoids. Each of these has two long cilia at its pointed end.

The macrospores in some species similarly begin their development within the sporangia. After the division of the nucleus - which lies in the peripheral cytoplasm at the apex-into daughter-nuclei and their distribution in the apical cytoplasm, the formation of cell walls begins. In this way, progressing from apex to base, the spore becomes filled by a process of multicellular formation, witl

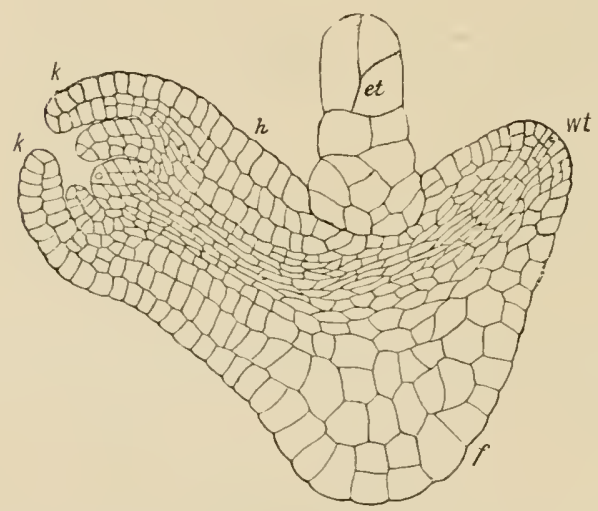

FIG. 417.-Seleginelle Martensii. Embryo before becoming free from the prothallus in longitudinal section; $f$, foot; wt, rhizophore; et, suspensor; $k$, cotyledons with their ligules. ( $\times 150$, after BRu(hyaxw. $)$

large prothallial cells. At the same time, and proceeding in the same direction, there begins a further division of these cells into smaller cells. In some species the apical diso of tissue is formed first, and is separated by a thickened wall or diaphragm from the rest of the cavity of the spore; cellformation occurs in this later. In the tissue at the apex, consisting of small cells, the rudiments of a few arehegonia appear, often even before the formation of the prothallium has been completed. The archegonia are usually not formed until the spores have been discharged from the sporangium.

The wall of the spore eventually bursts at the apex, and the prothallium becomes partially protruded; it forms a number of rhizoids on three projections of its tissue. The fertilisation of one or two archegonia, which then takes place, is followed directly by the segmentation of the fertilised egg-cells and the formation of the embryos (Fig. 416.)

The embryogeny of Selayinelle recalls that of Lycopodium. The egg-cell is divided by the formation of a trausverse wall into two cells; the upper and larger ecll increases considerably in size, and gives rise, by the division of its lower portion, to a suspensor, while the lower cell, by repeated division, develops into an embryo, the segmentation of which according to Bruchmann follows several distinct types. While in S. Martensii, S. spinulosa, S. helretice, and other species the first rhizophore comes between the suspensor and the foot (Fig. 417), it arises in S'. Poulteri and S. Kraussiana beneath the suspensor and foot, as it does in Lycopodium. The stem apex, with the first pair of leaves, eventually grows mpwards, and the root also extends beyond the macrospore. As the foot still remains in the frothallium the young plant continues united to the spore, and 
presents the appearance of a phanerogamic seedling with the seed still attacherl (Fig. $413, E$ ).

\section{Order 3. Isoetaceae $\left({ }^{141}\right)$}

The isolated genus Isoctes must be regarded as a persistent branch of an ancient group of plants, which in earlier geological periorls was more richly represented. It also exhibits some affinities with the eusporangiate Ferns. The species of Isoetes are peremnial plants, growing either on damp soil or submerged in water. The stem is short and tuberous, rarely dichotomously branched, terminating below in a tuft of dichotomously branching roots, and above in a thick rosette of long, stiff, awl-shaped leaves (Fig. 418). The stem is characterised by a sccondary

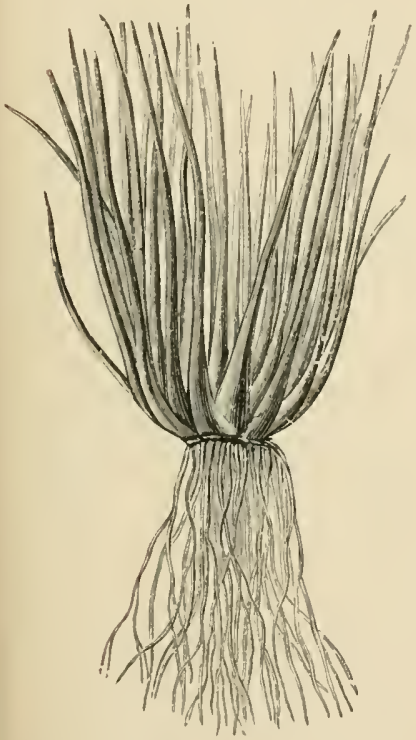

Fif. 418.-Isoctes lacustris. (1 $\frac{1}{2}$ nat. size.) growth in thickness by means of a cambium; this produces to the outer side cortex (without phloem) and to the inner side secondary xylem. The leares are traversed longitudinally by

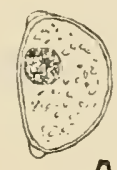

A

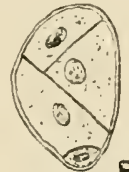

8
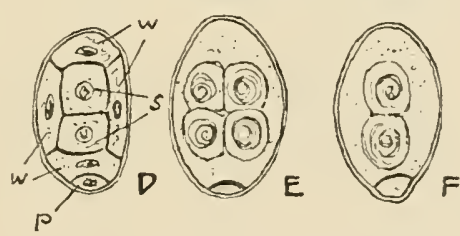

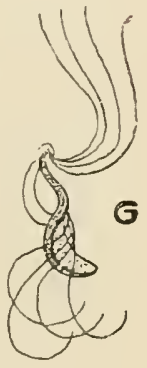

FIG. 419. - A-F, Isoetes setucert $(\times 640)$. A, microspore spen from the sirle. $B$ - $D$, segmentation of the spore; $p$, protliallial cell; $w$, the four cells of the wall; s, spermatogenous cells. $E$, the four spermatozoid mother-cells are surrounded by the disorganised cells of the wall; surface view. $F$, the same in side view. $G$, Isuetes Malinierniunn, slermatozoid. (X Fs?. After BeLAJEFF.)

four air-passages, and expand at the base into a broad sheath. On the inner side of the leaves, above their point of insertion, is an elongated pit, the forea, containing a large sessile sporangium. A ligule, in the form of a triangular membrane, is inserted above the forea. Isoetes thus differs greatly in habit from the other genera, but resembles Selaginella in the development of a ligule.

The macrosporangia are situated on the outer leaves of the rosette ; the microsporangia on the inner. Both are traversed by transverse plates of tissue or trabeculæ, and are in this way imperfectly divided into a series of chambers. The spores are set free by the decay of the sporangial walls.

The development of the sexual generation is accomplished in the same way as in Selaginella. The reduced male prothallinm (Fig. 419) arises similarly within the spore, by the formation of a small, lenticular, vegetative cell $(p)$, and a larger cell, the rudiment of a single antheridium. The larger cell divides further into 
four sterite peripheral cells, which completely enclose two central spermatogenous. cells. From each of the latter arise, in turn, two spermatozoid mother-cells, four in all, each of which, when liberated by the rupture of the spore wall, gives rise to a single, spirally coiled, multiciliate spernatozoid. The female prothallium (Fig. 420) just as in Sclaginella, also remains enclosed within the macrospore, and is ineapable of independent growth. It shows similarly an approach to the

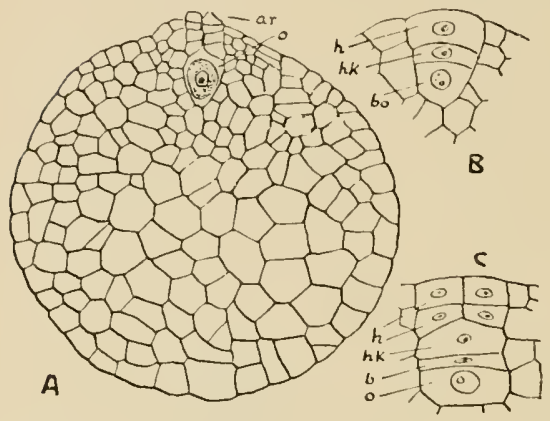

Fin. 420.-Isnetes erhinospore. A, Female prothallium ; ur, archegonium; 0 , egg-cell. $B, C$, development of the archegonium from a superticial cell ; $h$, neck. cells; $h k$, neck canal-cell; $b$, ventral canal-cell ; o, egg-cell. (After Campbelt, $\times$ 250.)

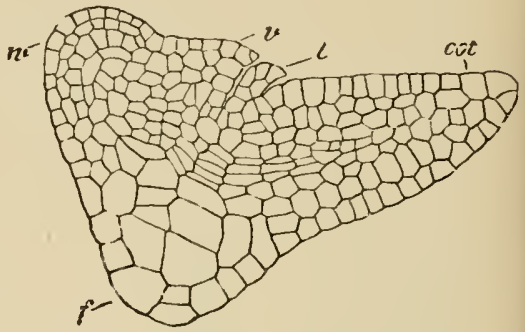

Fic. 421. - Isoctes echinosport. Embryo before breaking ont from the prothallus iu longitudinal section. cot, cotyledon; $l$, ligule: $r$, sheath at the base of the cotyledon in the axil of wlich the apex of the stem arises; $v$, root; $f$, foot. $(\times 200$. After CAMPBEI.L.)

Conifers, in that the nucleus first divides into unnerous, parietal daughter-nuclei before the gradual formation of the cell walls, which takes place from the apex of the spore to the base. As a result of this process the whole spore becomes filled with a prothallium, at the apex of which the archegonia are developed. The embryo has no suspensor and thus differs from other Lycopodinae.

\section{The Fossil Cryptogams $\left({ }^{142}\right)$}

The remains of cryptogamic plants of former geological periorls afford no evidence as to the phylogenetic relations of the classes of Thallophyta and Bryophyta. Intermerliate forms between Algae and Archegoniatae, are, as yet, unknown. On the other hand Phytopalacontology lias made us acquainted with interesting, long-extinct types of Pteridophytes, which serve to complete the classification of the existing Ferns, Horse-tails, and Club-mosses, and in part afford a transition from the Ferns to the Gymnosperms.

I. The great majority of Thallophytes are, on accomt of their delicate structure, not adapted to be preserved in the fossil condition. The absence of remains of many classes of Thallophytes is therefore no ground for concluding that they did not exist in earlier periods. Even in the Silurian rocks remains of Algae are found, though they do not permit of their relationship being deternined. The remains of calcareous Algae belonging to the Siphonales are, owing to their good jreservation, among the best known; of these, forms are known from the Tertiary strata back to the Silurian, while the Corallineae, which are calcareous Red Seaweeds appear from the upper Jurassic onwards. Among micellular Algae the Diatomaceae, which have a silieified cell wall, are well preserved. The fossil forms 
frequently helong to existing genera, and occur from the Jurassic onwards, especially in the Cretaceous and Tertiary strata, often forning thick layers of Kieselguhr (diatomaceous earth). From Tertiary times onwarls Characeae are abundant, and oceasional remains are fouml as far back as the Uper Cretaceons. Nost of the existing groups of Algae are only to be distinguished with ecrtainty from Tertiary strata onwards.

Bacteria must have played their part in causing the decomposition of organic substances from very early times; they can be distinguished in regetable remains from Carboniferous rocks. The Phycomycetes, Eumycetes, and probably the Myxomycetes also, were present in Carboniferous times; Ascomycetes living on leaves and stems are found from the Carboniferous onwards in all strata. Remains. of existing genera of Lichens aplear in the Tertiary rocks.

II. Bryophyta.-Most of the exanuples of this groul, which is rarely met with in the fossil condition, come from the Tertiary strata and resemble existing genera closely. Only isolated examples of Liverworts and Mosses occur in the older rocks back to the Carboniferons.

III. The Pteridophyta extend back to Silurian times, but were most highly developed in the Carboniferous period, when they formed the main mass of the land vegetation. With the adrent of Gymnosperms, and later of Angiosperms, their relative importance in this respect diminislied.

1. The class of the Equisetinae represented at present by the single genus Equisctum, which can be traced back to the Triassic period, was much better developed in Palaeozoic times. The large order Calamarieae consisted of plants resembling the Horse-tails in general habit, but in some cases attaining the size of trees 30 metres high ; the hollow stem bore whorls of branches at the nodes, was covered with a periderm, and unclerwent secondary thickening. The leares (Anmularia) stood in alternating whorls; their form was uarrowly lanceolate and at their bases they united into a sheath. In the most ancient type, Archafocalamites, they were dichotomously divided. The cones or tlowers (Calamostachys) had in some the same structure as those of Equisetum; in most cases they were more complicated, whorls of scale-leaves alternating with the sporophylls. At least some of the Calamarieae were heterosporous.

2. The Lycopodinae were also abundantly represented in Palaeozoic times, especially by the two great extinct orders, the Sigillarieae and the Lepidodendreae. The Sigillarieap, found from the Culn onwards, are most numerous in the Carboniferous yeriod, and persist with one species in the Bunter Sandstone. They were stately trees, with but little-branched, pillar-like stems, which grew in thickness. They had long narrow leaves, which when they fell off left longitudinal rows of hexagonal leaf-scars on the surface of the stem. Long-stalked, cone-like flowers. were borne on the stem; only one kind of spore was contained in the sporangia which were borne singly on the sporophylls.

The Lepidodendreae extend from the Lower Devonian to the Rothliegende, but are also best developed in the Carboniferous period. They were tree-like plants attaining a height of some 30 metres with dichotomonsly branched stems which grew in thiekness. The leaves, which attained a length of $15 \mathrm{~cm}$. , were spirally arranged and seated on rhombic leaf-cushions. The cone-like flowers (Lepidostrobus) were borne on the ends of branches or sprang from the stem itself; each sporophyll bore a single sporangium, which contained either macrospores or microspores.

The leaves of Sigillaria and Lepidodendreae are characterised by the possession of a ligule springing from the uppor portion of the leaf-base.

Smaller Lycopodiaceae, the predecessors of the existing species of Lycopodium, 
were already present in the Carboniferous flora, while Isoctes is only known witl certainty from the lower Cretaceous strata.

The discovery of seed-like structures borne by some of the palaeozoic Lycopodinae (Leprilocarpon, Miadesmia) is of special interest. In them the macrosporangium was surrounded by an integument leaving only a narrow slitlike opening; the sporophyll also took part in enclosing the sporangium. Only one macrospore attained full development. As in Isoetes the prothallium remained within the spore. The macrospores were produced on sporopliylls resembling those of Lepidostrobus. Probably pollination occured while the sporangia was still attached to the parent plant from which later the macrosporophyll, together with its sporangium, separated as a whole.

3. The suall class of the Sphenophyllinae occupies an intermediate position between Lycopodinae and Equisetinae. These three classes appear to have had a common origin, and may be grouped together as the Lycopsidae in contrast to the Pteropsidae which include the Filicinae and the Pteridospermae.

The Splienophyllinae were represented by two genera in palaeozoic times. Cheirostrobus from the Lower Carboniferons had complex cones of similar strneture to those of the Calamarieae, but approacher Lepidodendron in anatomical structme. The species of sphenophyllum which liver from the Devonian to the Permian periods were herbaceons land-plants with elongated internodes. The stems, which underwent secondary growth in thickness, bore superposed whorls of wedge-shaped or dichotomonsly divided leaves. The spike-like cones resembled somewhat those of Equisetum ; each sporophyll bore one to four homosporons sporangia.

Among existing Pteridophyta the Psilotaceae, which were formerly placed in the Lycopodinae, are apprarently most nearly related to the Sphenophyllinae. They include two gencra Psitolum with two tropical species, and Tmesipteris with one species in Australasia.

4. The class of Filicinae was richly represented in palacozoic times, for instance in the Carboniferous period, by the Marattiaceae and by the extinct family of the Botryopterideae.

The Hydropterideae are known with certainty from the Tertiary rocks, but Salvinio and Marsilic can be traced back to the Chalk.

So far as our knowledge goes the Eqnisetinae, Splrenopliyllinae, and Lycoporlinae are loranches of the Pteridophyte stock which have mulergone no further develofment in the direction of the more highly organised plants. From the Filicinae on the other hand the first seed-plants had arisen even in palaeozoic times. A comnecting gronp below the Ferns on the one hand, and the primitive Gymnosperms (Corlaiteae, Cycadaceac) on the other, is provirled by the extinct class of the Pteridospermae (1+3) to which for eximple Lyyinodemiron and Neuropteris belong. These plants, which have only in recent times become accurately known, formed a rery important constitnent of the Carboniferous flora. In the general aplearance of their vegutative organs they resembled Furns; their stems underwent secondary thickening. They were heterosporons; the macrosporangia lad a similar structure to those of the Cycadeac and must therefore be termed seeds. They were borne, as were the microsporangia upon fronds that scarcely differed from vegetative leaves. The sporophylls were thus not yet arranged as in the Cycadeae in cone-like flowers. 


\section{PAR'T II \\ SPECIAL BOTANY}

SECTION II

PHA NEROG A M I A 



\title{
SECTION II
}

\author{
PHANEROGA II A
}

The Transition from the Cryptogams to the Phanerogams.-The old names, Cryptogams and Phanerogams, are here retained partly on historical grounds and also becanse there are no better and equally short terms for the two great grades of the vegetable kingdom. The sharp distinetion which formerly appeared to exist between the two groups has, however, as our knowledge has advanced, become less marked. The Phanerogams appear as a continuous development from heterosporons Vascular Cryptogams. The recognition of this is owing, in the first place, to the work of W. Hofukister ( ${ }^{1}$ ).

It has been seen (p. 425) that the existence of an alternation of generations is an essential eharacter, common to both Bryophytes and Pteridophytes; the life-history exhibits a regnlar alternation of a sexual with an asexual generation. While in the Bryophyta only the sexual generation attains an independent existence, in the Vascular Cryptogams this stage appears as the inconspicnons prothallium. The asexnal generation, on the other hand, which in the Moss was represented by the sporogonium dependent thronghont its life on the sexual plant, becomes physiologically independent in the Pteridophyta. In them it appears as the eouspicuous plant, the Fern or Horsetail, and bears leaves, on some of which (the sporophylls) the sporangia develop. A shoot bearing a number of sporophylls, and frequently with other leaves forming an onter investment, is known as a FLower. Thus Equisetum (Fig. 408, p. 460) affords a good example of a flower of simple eonstrnction, in which the sporophylls are all alike.

The appearance of heterospory ( $\rho .446)$ marks a most important advance; the sexual differentiation, which in homosporous forms did not appear until the sexual generation (prothallimm, gametophyte) is evilent in the asexual plant (sporophyte). The sporophyte produces male sporangia (the microsporangia) and female maerosporangia. The function of the sexual generation is limited to the production of the male or female sexnal organs, and it undergoes still further reduction. In the germination of the mierospores only a single, vegetative pro- 
thallium-cell is to be recognised, the remainder of the small prothallium representing one or more antheridia. The female prothallinm, which in Saliniu still becomes green and emerges from the macrospore, in Selaginella and Isoetes has lost the power of independent nutrition. The prothallium begins its development while still within the macrosporangium of the parent plant, and the macrospore, after being set free, only opens in order to allow of the access of the spermatozoids to the archegonia.

Thus within the series of Vaseular Cryptogams a reduetion of the sexual generation can easily be traced; this reduction is carried further in those Phanerogams which stand nearest to the Cryptogams $\left({ }^{2}\right)$.

The MACROSPoRE, which in the Phanerogams is termed the EMBRYO-SAC, remains enelosed in the MACROSPORANGIUM or OVULE.

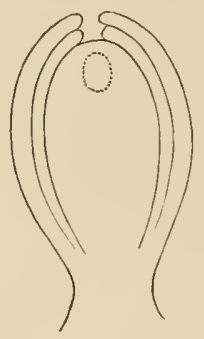

1

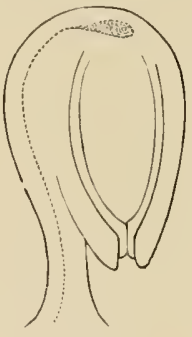

l

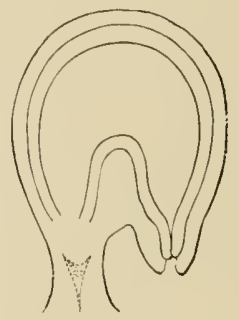

0

Fif, 422,-A, Atropons ; $B$, anatropous ; $C$. campylotropous orules.

(Diagramnatic and magnified.)

The latter consists of the Nucellus, from the base of which (the CHALAZA) one or two INTEGUMENTS arise; these grow up as tubular investments of the nueellus and only leave a small passage, the MrCROPYLE, leading to the tip of the latter. The ovule is attached to the MACRO-SPOROPHYLL or CARPEL by a stalk or FUNICULUS, which is often very short. The region to which one or more ovules are attached is called the PLACENTA. If the nucellus forms the direet continuation of the funiculus the ovule is termed straight or ATROPOUs. More frequently the funiculus is sharply curved just below the chalaza, so that the ovnle is bent baek alongsile its stalk (ANATROPOUS ovule). The line of junction of the funiculus with the outer integument is still recognisable in the ripe seed, and is termed the RAPHE. Lastly the ovule itself may be eurved, in which case it is spoken of as CAMPYLOTROPOUS. The three types are diagrammatically represented in Fig. 422 A-C.

As a rule only one embryo-sae is containerl in an ovule. In the same way as the four macrospores originate by the tetrad division in the macrosporangium of Selaginelle, in the macrosporangium (ovule) of 
the Phanerogams there is usually a single embryo-sac mother-cell which divides into four daughter-cells; three of these do not develop further, while the fourth becomes the embryo-sac. The formation of the PROTHALLIUN (or HNDOSIERM) and of the AR(HEGONIA (OI EGG-CELLS) differs in the several classes of Phanerogams. The fertilised ovum grows into the embryo while still enclosed within the macrospore and at the expense of the parent plant. When the embryo has reached a certain stage in its development, which is different and characteristie in different plants, its growth is arrested, and after the separation from the parent plant it undergoes a period of rest. It is still surrounded $b_{y} y$ the other portions of the macrosporangium, viz. the prothallium or endosperm, the mucellus (if this still persists), and the seed coat formed from the integuments. THE COMPLETE STRUCTURE DERIVED FRON THE OVULE IS TERMED A SEED, AND THE FURTHEI IDEVELOPHENT OF THE UNOPENED MACROSPORANGIUM TO FOKM A SEED is Characteristic of ali PHanerogans. As seed-plants or Spermaphyta the latter may be eontrasted with the seedless Cryptogams.

An account of the male sexual generation of the Phanerogams must now be given for comparison with the above short sketch of the development of the female generation.

The microsporis of the Spermaphyta are called PoLLen-Grains. They are formed in large numbers within the MICROSPORANGIA or POLLEN-SACS, which are borne singly or in numbers on the MICROsPOROPHYLLS or sTAMENS. The part of the stamen which bears the pollen-sacs is usually clearly distinguishable and is called the ANTHER.

The development of the pollen-sae (Fig. 423) commences with divisions parallel to the surface taking place in cells of the hypodermal layer; this separites the cells of the primary archesporium from an outer layer of cells. The latter give rise to three layers of cells the outermost of which is the fibrons layer, the innermost the tapetum, while the intervening layer is later crushed. The archesporium after' undergoing a number of divisions forms the pollen-mother-cells, each of which divides as in Pteridophytes into four danghter-cells (cf. Fig. 102). These are the pollen-grains, and are spherical or ellipsoidal in shape and provided with a cell wall; an external cntinised layer (the ExINE), and an inner cellulose layer, rich in pectic substances (the INTINE), can be distinguished in the wall.

While the male sexual cells of all archegoniate plants are dependent on water for their conveyance to the female organs, the transport of the pollen-grains to the egg-cells is brought about in Seed-plants by means of the wind or by animals. However far the reduction of the male prothallium has proceeded-and even in the case of the heterosporous Pteridophyta only a single sterile cell was present-two constituent parts are always distinguishable in the germinating pollengrain ; these are a VEGETATIVE CELL which grows out as the POLLENTUBE, and an ANTIIERIDIAL MOTHER-CELL which ultimately gives rise 
to two GENERATIVE CELLS. The pollen-tube, the wall of which is continuons with the intine of the pollen-grain, ruptures the exine and penetrates, owing to its chemotropic irritability, into the tissue of the macrosporangium (ef. p. 279). The antheridial mother-cell passes into the pollen-tube and sooner or later gives rise to two generative eells which reach the embryo-sac and egg-cell by passing along the pollen-tube. The name Siphonogams has been applied to the seed-plants on account of the common eharacter of the group afforded by the formation of a pollen-tube.

The results reached by the above survey may be summarised by
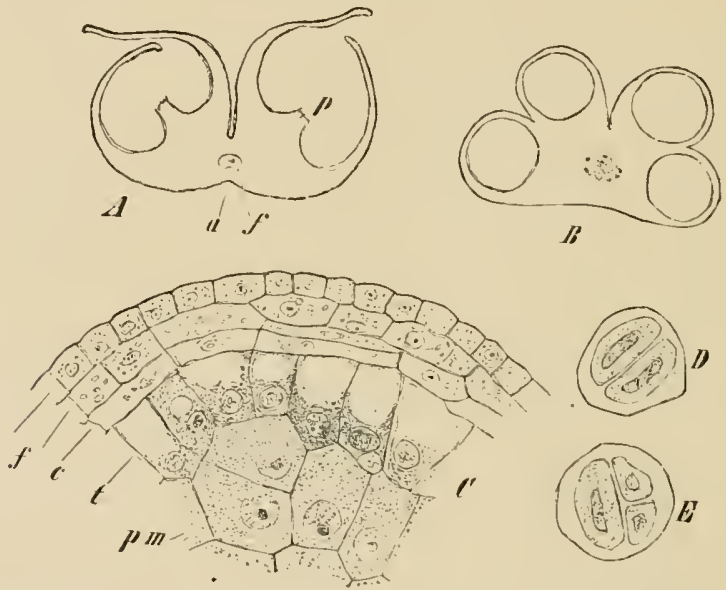

FIf. 423.-Hemerocall is fulva. A, Trunsverse section of an almost ripe anther, showing the loculi ruptured in cutting; $p$, partition wall betweell the loculi ; $a$, groove in connective; $f$, vascular bundle $(\times 14) ; B$, transverse section of young anther $(\times 28) ; C$, part of transverse section of a pollen-sac ; $m$, pollen-mother-cells ; $t$, tapetal layer, later undergoing dissolution ; $r$, inteymediate parietal layer, becoming ultimately compressed and disorganised; $f$, larietal layer of eventually fibrous cells; $e$, ejidermis $(\times 240) ; D$ and $E$, pollen-mother-cells after division $(\times 240)$.

saying that the Phanerogams continue the series of the Arehegoniatae and agree with the latter in exhibiting an alternation of generations. While the asexual generation becomes more complex in form and more highly organised, there is a corresponding reduction of the sexual gencration. The fenale sexual generation is enelosed throughout its whole development in the asexual plant, and only lecomes separated from the latter in the seed, which further contains as the cmbryo the commencement of the succeeding asexual generation. The exhanstive investigations made of recent years into the phenomena of the reduction division (cf. p. 84) in the spore-mother-eells of archegoniates and l'hanerogams have resulted in a confirmation of the limits of the two generations in the latter $\left({ }^{2 a}\right)$. 'The number of chromosomes ehar- 


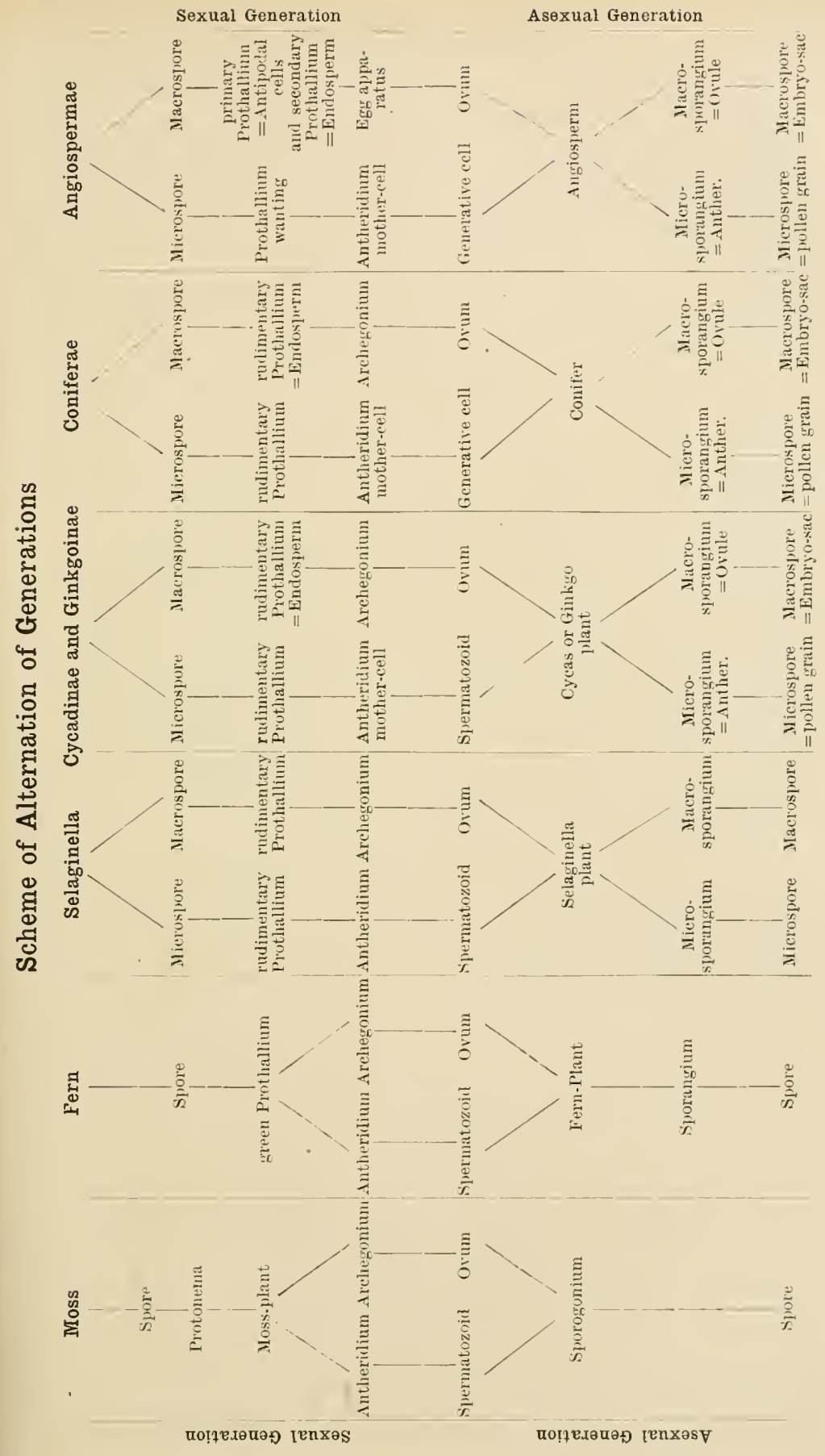


acteristic of any plant is diminished to one-half, during the divisions that lead to the origin of the sexual generation, and the full number of chromosomes is not again attained until fertilisation takes place. The asexual generation has always the double number, the sexual generation the single number of chromosomes. 'The gametophyte is haploid, the sporophyte diploid (ef. p. 95).

The Spermaphyta are divided into two classes $\left({ }^{3}\right)$ which differ in their whole construction: (1) the Gymnosperms, with naked seeds; (2) the Angiosperms, with seeds enclosed in an ovary.

The names of these classes indicate the nature of one of the most important differences between them. THE CARPELS of THE ANGIOSPERMS FORM A CLOSED CAVITY, THE OVARY, WITHIN WHICI THE OVUles DEVEloP. SUCH AN OVARY IS WANTING IN TIIE GYMNOSPERIS, THE OYULES OF WHICH ARE BORNE FREELY EXPUSED ON TIE MACROSPOROPHYLLS OR CARPLLS.

The Gymnosperms are the phylogenetically older group. Their construction is simpler and in the relations of their sexual generation they comnect directly with the heterosporous Archegoniatae; they might indeed be perhaps best treated as belonging to this group.

The Angiosperms exhibit a much wider range in their morphological and anatomical structure. The course of their life-history differs considerably from that of the Gymnosperms, and without the intermediate links supplied by the latter group, the correspondence with the life-history of the Archegoniatae would not be so clearly recognisable.

These conclusions are confirmed by the evidence afforded by Palaeobotany. Gymnosperms or forms resembling them are found along with what appear to be intermediate forms between the Gymnosperms and the Pteridophyta in the fossiliferous rocks of the Devonian, Carboniferous, and Permian formations. The Angiosperms are, on the other hand, first known from the Cretaceons formation.

\section{Morphology and Oecology of the Phanerogamic Flower and of its Sexual Generation}

\section{The Phanerogamic Flower $\left(^{4}\right)$}

The distinction between the gymnospermic and angiospermic plants is briefly and well expressed by the statement that the seeds of the Gymnosperms are exposed while those of the Angiosperms are enclosed. Only an accurate examination of the floral features, especially of the structure, equipment, and development of the scxual generation in the two cases will enable us to form a correct judgment on the differences between these two great classes of Phanerogams.

The flowers of the Gymnosperms are all misexual and diclinous. 
The macrosporophylls form the female, the microsporophylls the male flowers. The two sexes are found either on the same individnal (Monoecrous), or each plant bears either male or female flowers (bIoEcious). Leaves forming an envelope around the group of sporophylls are only found in a few flowers of the Gymnospermae. (Gnetaceae).

The MALE FLOWERS are shoots of limited length, the axis of which bears the closely crowded and usually spirally arranged sporophylls. The scales which invested the flower in the bud often persist at the base of the axis (Fig. 424). The microsporangia are borne on the
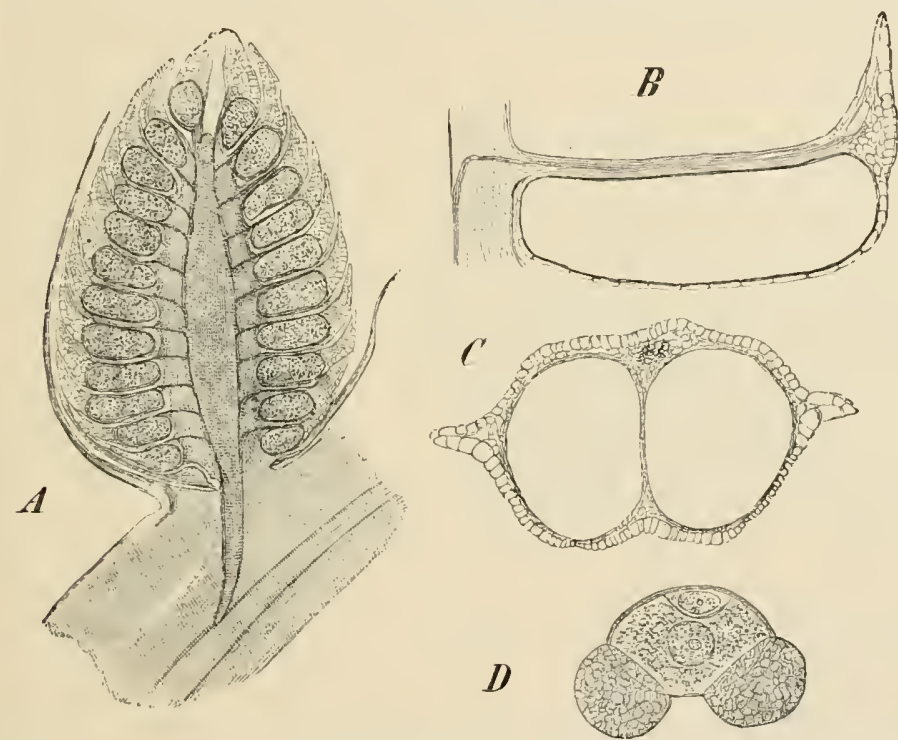

Fro. 424.-Pinus montana. $A$, Longitudinal section of a ripe male flower $(\times 10)$, $B$, Longitudinal section of a single stamen $(\times 20)$. $\quad C$, Transverse section of a $\operatorname{stamen}(\times 2 i)$. $\quad D$, a ripe pollengrain of Pinus silvestris $(X 400)$.

lower surface of the sporophylls, two or more being present on each. Their opening is determined as in the sporangia of the Pteridophyta by the peculiar construction of the outer layer of cells of the wall (exothecium). The pollen-grains are spherical, and are frequently provided with two sacs filled with air which increase their buoyancy and assist in their distribution by the wind (Fig. 424). On germination the outer firm layer of the wall of the pollen grain (exine) is completely lost, being fractured by the increase in size of the protoplasmic body (cf. Fig. $459 \mathrm{D}$ ).

In many Gymuosperms the fEMALE FLowers or cones resemble the male flowers in being composed of an axis bearing numerons spirally arranged sporophylls. In other cases they differ from this 
type in various ways, which will be described in the special part below.

In Angiosperms, on the other hand, a union of the two sexes in the one flower, which is thus HERMAPHRODITE, and the investment of the flower by coloured leaves (differing in appearance from the foliage leaves), forming a PERIANTH, is the rule (Figs. 425, 426). In contrast to the UNISEXUAL or DICLINOUS flower with the sporophylls arranged spirally on an elongated axis, which is characteristic of the Gymnosperms, the perianth leaves and sporophylls in the Angiosperms are usually borne in whorls on a greatly shortened axis. THE ARRANGEMENT OF THE FLORAL LEAVES IN WHORLS, THE COLOURED PERIANTH, AND THE HERMAPHRODITE NATURE OF THE FLOWERS ARE THUS CHARACTERISTIC OF ANGIOSPERMS, although these features do not

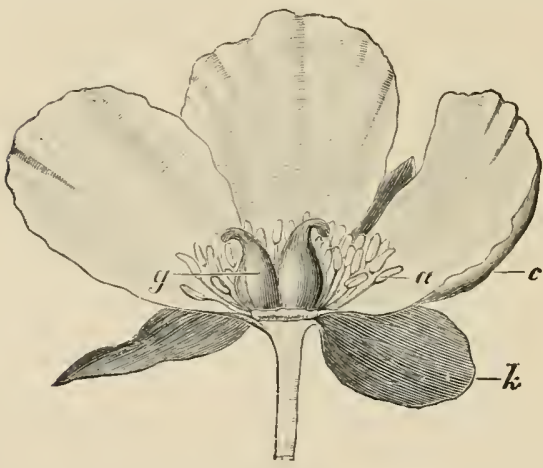

Fı. 425.-Flower of Pueonia peregrina, in longitudinal section. $k$ and $c$, Perianth; $"$, androecium; $g$, gynaeceum. (를. size.) apply without exceptions to all angiospermic flowers. These differences depend on the important factor of the NEANS OF POLLINATION.

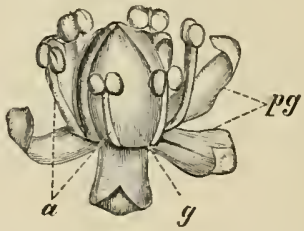

Fia. 426.-Flower of Acorus Culumus. $p g$, perigone; $\mu$, androecium; $g$, gynaeceurn. (Enlarged. After ENOLER.)

When, as is the case with the Gymnosperms and the catkinate flowers of Angiosperms, this function is performed by the wind, the elongation of the axis and the absence of an investment of leaves around the female receptive organ are advantageous. When, on the other hand, pollination is effected by insects or birds, the conspicuousness given l,y the presence of a perianth and other attractions, such as scent or sweet-tasting substances, are necessary. The form of the flower, the arrangement of the sporophylls in it, and the place at which nectar is secreted must be adapted to the visiting insects (cf. p. 493, weology of the flower). It is to this that the variety of form and colour exhibited in the flowers of Angiosperms must be ascribed.

The moncecions and dicecions conditions whieh are the rule in the gymnospermie flower also occur in $\Lambda$ ngiosperms; they are, howerer, much less common than the hermaphrodite condition. The association of hemaphrodite and unisexual flowers on the same plant leads in certain $A$ ugiosperms to what is known as polygumy. When hermaphroditc and misexual flowers are distributed on distinet individuals 
we have andro- or gyno-dicecism; when on the same individual andro- or gynomonœecism.

The perianth (Figs. 425, 426) consists of two whorls of members: these may be similar in form and colour, when the name PERIGONE is given to them, or may be differentiated into an outer green CALYX and an inner whorl of coloured leaves, the COROLLA. In every complete flower two whorls of stamens or microsporophylls come next within the perianth, and within these again a whorl of carpels or macrosporophylls. The whorls alternate regularly with one another. The stamens collectively form the ANDROECIUM, the carpels the GYNAECEUM $\left({ }^{5}\right)$.

Each stamen consists of a cylindrical stalk or FILAMENT and of the ANTHER; the latter is formed of two THECAE or pairs of pollen-sacs joined by the continuation of the filament, the CONNECTIVE (Fig. 427). According to whether the thecae are turned inwards, i.e. towards the whorl of carpels, or outwards, the anther is described as INTRORSE or ExTRORsE. The opening of the ripe theca depends as a rule

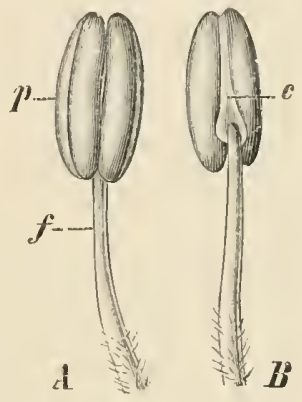

FIG. 427.- $A$ and $B$, Anterior and posterior view of a stamen of Hyoscyrmus niger; $f$, the filament ; $p$, auther ; $r$, connective (magnified). (except in the Ericaceae) on the peculiar construction of the hypodermal layer of the wall of the pollen-sac. This is called the fibrous layer or ENDothecium. On the other hand, in the Gymno. sperms (excluding Ginkgo, cf. p. 530), as in the Ferns, the dehiscence

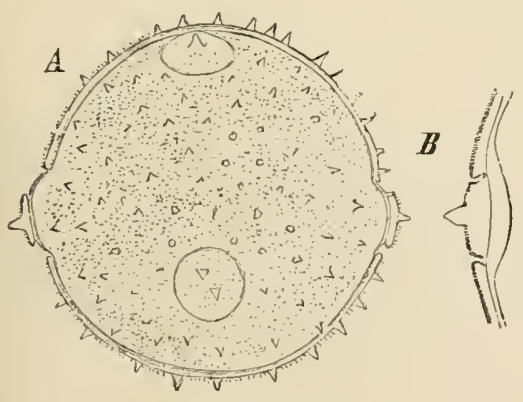

Fig. 42S-A, Pollen-grain of C'ueurbita Pepo $(\times 240)$; $B$, section of pollen-grain of Cucurbita verrucose, showing one of the lid-like areas through which the pollen-tubes protrude $(x 5+1)$.

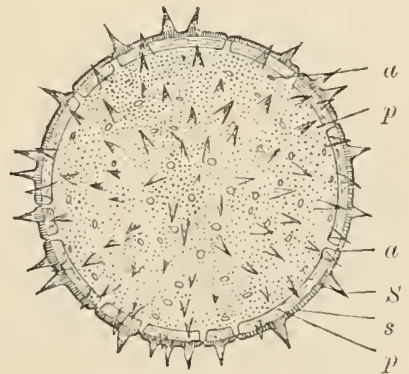

FIG. 429.-Pollen-grain of Mralca silvestris, $S$, Spinous projections of the exine; $s$, vertically striated layer of the exine; $p$, the same seen from above; $\alpha$, places of exit of pollen-tubes. (After A. Merer.)

is effected by means of the external layer of cells (exothecium). As a rule the septum between the two pollen-sacs breaks down, so that they are both openec by the one split in the wall. The microspores in anemophilous plants are smooth, dry, and light, and 
adapted for distribution by the wind. In entomophilous flowers, on the other hand, the exine is frequently sticky or provided with spiny projections, and the pollen-grains are thus enabled to attach

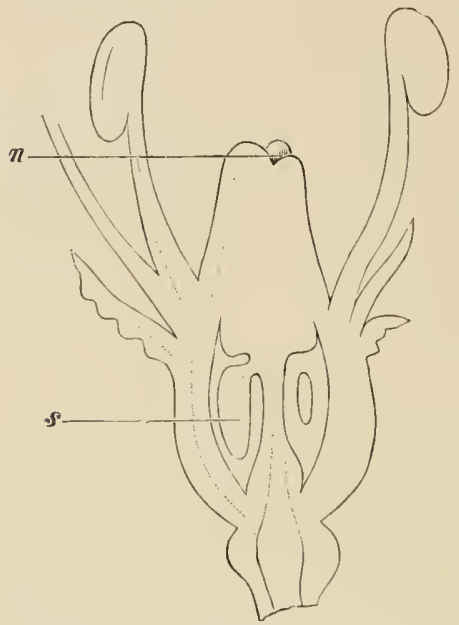

Fı. 430.-Srembueus nigro. Longitudinal section of flower. $s$, Ovule; $n$, stigma. (After TSCHNCH-OSTERLE.) themselves better to the bodies of the insect visitors. They also differ from the pollen-grains of the Gymnosperms in having more or less numerous spots in the wall prepared beforehand for the emission of the pollen-tube (Figs. 428, 429). Various modifications of the androecium result from

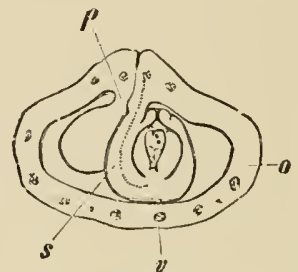

Fis. 431.-Transverse section of an ovary of Delphinium Ajacis, showing ovule placed horizontally. $s$, Ovule; $p$, placenta ; 0 , wall of ovary ; $v$, vascular bundles. $(\times 18$.

the cohesion and branching of the stamens, and will be described in the special part. Sterile stamens which do not produce fertile pollen are termed STAMINODES.

The flower is terminated above by the GrNaEckum (Fig. 430).
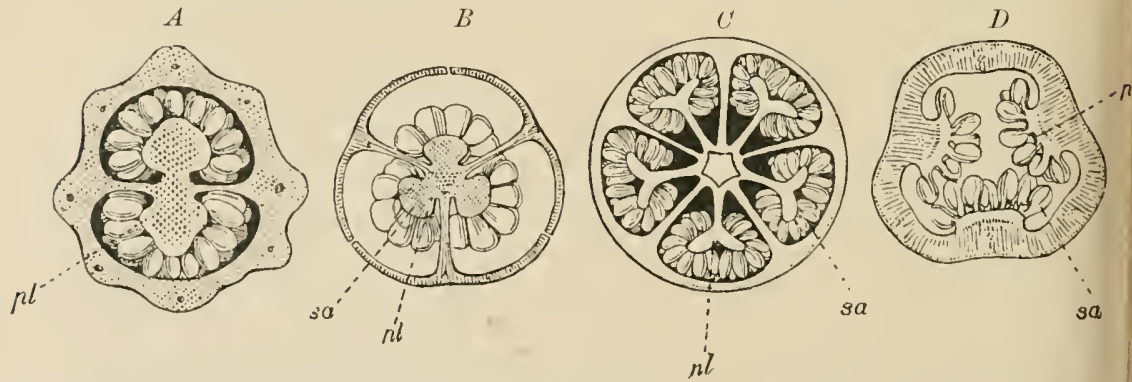

Fuc. 432.-Transwerse sections of ovaries. A, Lobetia; B, Diaynsia; C, lhotodendron;

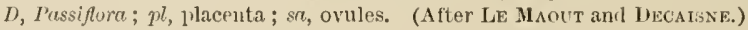

The CARPELS composing this may remain free and each give rise to a separate fruit (APOCARPUUS GYNAECLUM), or they mite together to form the ovary (sYNCARPous GYNAECEUM). The carpels, as a rule, bear the ovules on their margins, on more or less evident outgrowths 
which are termed Pracentas (Fig. $431 \%$ ). In apocarpons gynaecea the ovules are thus borne on the united margins of the carpels, each margin bearing a row of ovules (Fig. $431 \mathrm{~s}$ ). This is termed the VENTRAL SUTURE, while the midrib of the carpel forms the DORSAL SUTURE. In syncarpous ovaries the ovules are similarly borne on the margins of the coherent carpels. The placentation is termed PARIETAL when the placentas form projections from the inner surface of the wall of the ovary (Fig. $432 \mathrm{D}$ ). If the margins of the carpels project farther into the ovary, and divide its cavity into chambers or loculi, the placentas are correspondingly altered in position, and the placentation becomes AXILE (Fig. 432 B). In contrast to such TRUE SEPTA, formed of the marginal portions of the carpels, those that arise as ontgrowths of the surface or sutures of the carpels, as in the Crnciferae, are called FALSE SEPTA. By the upgrowth of the floral axis in the

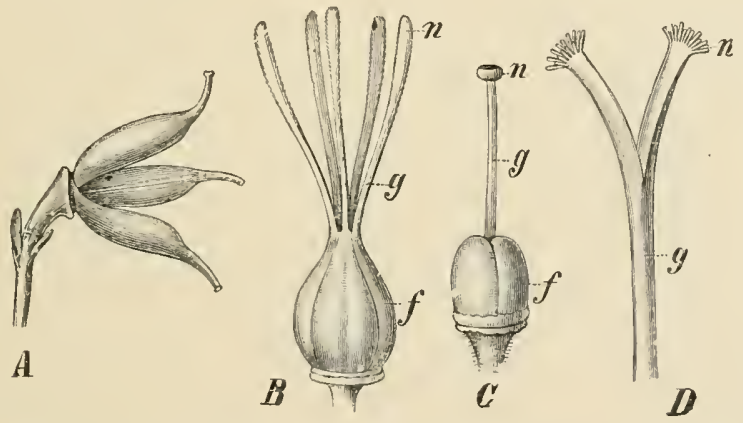

FiG. 433.-Different forms of gynaecea. A, Of Aconitum Napellus; $B$, of Linum usitatissimum; $C$, of Nicotiann rustica; $D$, style and stigma of Achilleu Millefolium; $f$, ovary; $y$, style; $n$, stignia. (After BERG and Sснмid, magnified.)

centre of the ovary what is known as FREE CENTRAL PLACENTATION comes about. The projecting axis cannot be sharply distinguished from the tissue of the carpels. The septa, which were originally present, are arrested at an early stage of development or completely disappear, so that the ovules are borne on the central axis covered with carpellary tissne and enclosed in a wall formed by the outer portions of the carpels.

Each carpel is usually prolonged above into a stalk-like STYLE terminating in a variously shaped sTigMa. The stigma serves as the receptive apparatus for the pollen, and in relation to this is often papillate or moist and sticky (Fig. 433 I)). When the gynaeceum is completely syncarpons, it has only one style and stigma. In Fig. 433 an apocarpons $(A)$ and a syncarpous gynacceum $(C)$ are represented, together with one in which the carpels are coherent below to form the ovary while the styles are free $\left(l^{\prime}\right)$.

The position of THE OVUles Within THE ovaRY may be erect, 
pendulous, horizontal, or oblique to the longer axis (Figs. 434, 435). In anatropous ovules the raphe is said to be ventral when it is turned towards the ventral side of the carpel, and dorsal if towards the dorsal side of the carpel.

The differences in the form of the floral axis, which involve changes

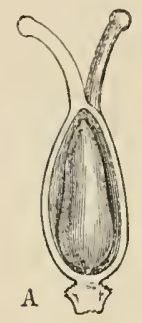

Fig. 434.-Ovaries containing basal ovules shown in longitudinal section. A, Fayopyrun esculentum (atropous); B, Armeria meritime (anatropous). (After DU. CHARTRE. $\times 20$.

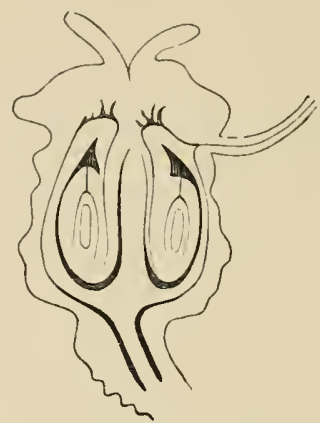

Fra. 435. - Ovary of Conium maculutum with pendulous ovules, in longitudinal section. Raphe ventral. (After Tschirch-Osterle.)

in the position of the gynaeceum, lead to differences in the form of the flower itself. Some of the commonest cases are diagrammatically represented in Fig. $436 A-C$. The summit of the floral axis is usually thicker than the stalk-like portion below; it is often widened out and projecting, or it may be depressed and form a cavity. If the whorls of members of the flower are situated above one another on a simple, conical axis THE GYNAECEUM FORMS THE UPPERMOST WHORL

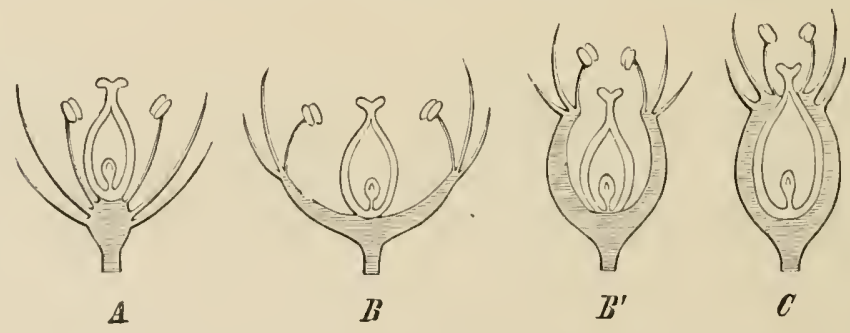

Fin. 436.-Diagram of $(A)$ liy pogynous, $\left(B, B^{\prime}\right)$ perigynous, and $(C)$ ejigynous flowers.

AND IS SPOKEN OF AS SUPEIRIOR, WHILE THE FLOWER IS TERMED HYPOrynous (Figs. 437,438). If, liowever, the end of the axis is expanded into a flat or cup-shaped receptacle (hypanthium), an interval thus separating the androecium and gynaeceum, the flower is termed P'RIGYNous (Fig. 438,2). When the concave floral axis, the margin of which bears the androecium, becomes adherent to the gynaeceum, 
the latter is said to be INFERIOR while the flower is described as EPIGY NOUS (Fig. 438, 3).

The regions of the axis, or of other parts of the flower which excrete a sugary solution to attract the pollinating animal visitors, are ealled NECTARIEs. Their biological importance is considerable.
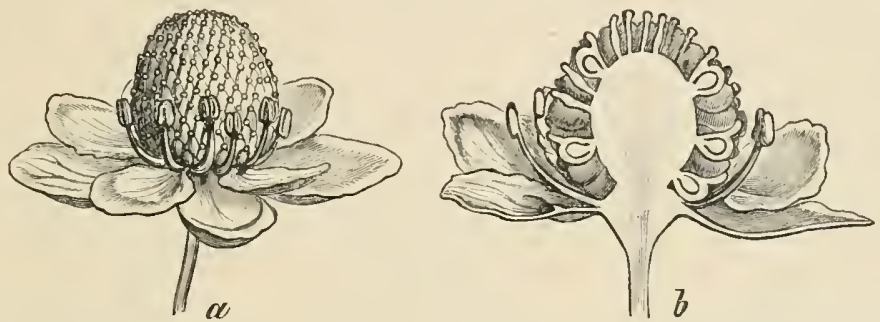

Fr6. 437.-Hypogynous flower of Ranunculus sceleratus, with numerous superior ovaries born upon a club-shaped receptacle. (After BAlLLon, magnified.)

In a typical angiospermie flower the organs are thus arranged in five alternating whorls, of which two comprise the perianth, two the androecium, while the gynaeceum consists of one whorl. The flower is PENTACYCLIC. The number of members is either the same in each whorl (e.g. three in a typieal Monocotyledon flower, or five in a typical Dicotyledon flower), or an inerease or deerease in the number takes
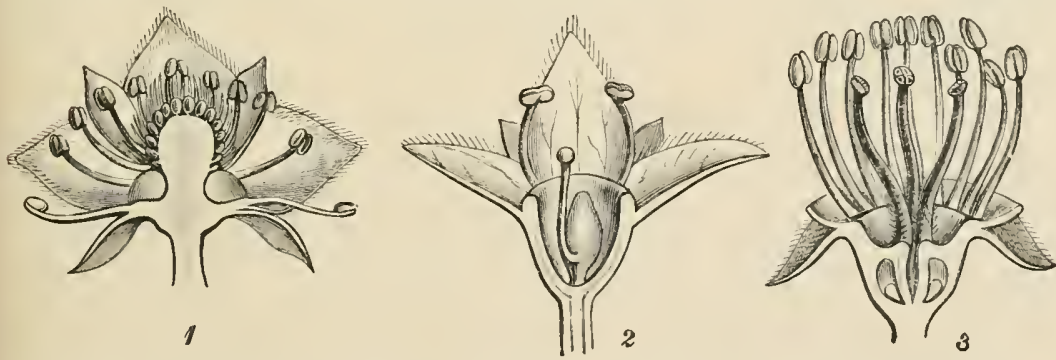

FIG. 438.-Different flowers belonging to the family Rosaceae, cut through longitudinally. 1, Potentilla pulustris, hyposynous ; 2, Alchemilla alpina, perigynous ; 3, Pyrus Malus, epigynous. (After Focke in Nut. Iflunzen-fitmilien, magnified.)

place. This is especially the ease with the whorls composing the androecium and gynaeceum.

Some of the more frequent deriations from the floral structure described above may be referred to here. Variation in the number of whorls is common. A diminution in the number may result from the absence of one kind of sexual organ in diclinons tiowers (e.g. Myristica), or from the absence of one of the two whorls composing the androecium or perianth (Compositae). Flowers in which the androecinm consists of only one whorl are terned HAPLOSTEMONOUs, those with two whorls of stamens DIPLOSTEMoxous. On the other hand, the number of whorls 
may be increased, and this may affect the androecium (Rosa), the gynaecenm (Punice granatum), or the perianth (Haycnia abyssinica). Another simple modifieation concerns the position of the whorls. The outer whorl of the androecinm, in Erica, for instance, does not alternate with the segments of the eorolla but the stamens stand directly above the latter. Snch an androeeium is distinguished as OBDIPLOSTEMoNous from the ordinary DIPLOSTEMoNous type.

Variations in floral symmetry are more important both biologically and with regard to the general habit of the flower. Those flowers which ean be divided into similar halves by more than two planes passing through the axis are termed RADIALIY SYMMETRICAL or ACTINOMORPHIC (Fig. $439 \mathrm{~A}$ ). When a symmetrical division ean only be made by two snch planes of section the flower is BISYMMETRICAL or bilateral (e.g. Dicentra, belonging to the Fumariaceae). From the originally radial type the DORSIVENTRAL (MONO-SYMMETRICAL, ZYGOMORPHIC) and the ASYM. METRICAL types ean be derived by the uneqnal size of some of the members or

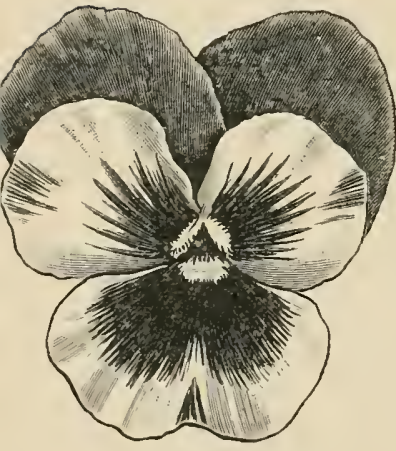

B

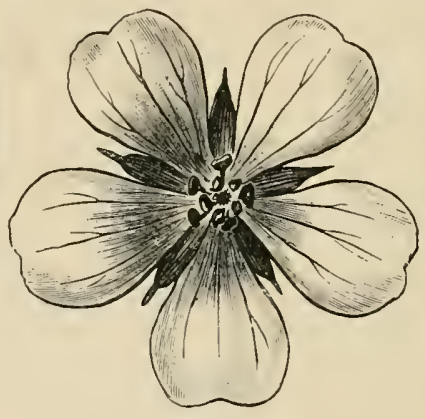

4

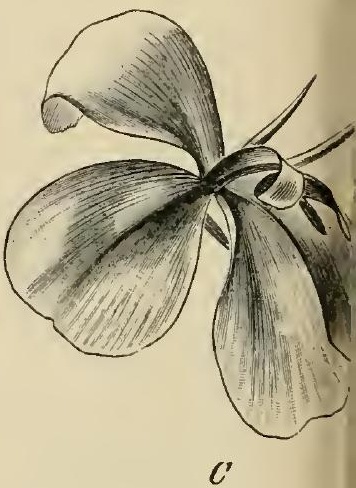

$C^{\prime}$

Fia. 439.-A, Actinomorphic flower of Geranium senguineum. L, Zygomorphic flower of Violu tricolor. C, Asymmetrical flower of Canna inilica.

their displacement or suppression (Fig. $439 B, C$; cf. p. 16. In zygomorphic flowers there is only one plane of symmetry by which the fiower can be divided into corresponding halves; while in asymmetrical flowers no such plane of symmetry exists. Dorsiventraf flowers tend to take up a partieular position in relation to the directive foree of gravity and exhibit a high degree of adaptation to insect pollination. According to whether the plane of symmetry coincides with the MEDIAN PLANE of the flower (i.c. the plane passing through the axis of the flower and the main axis), forms an acute angle with the median plane, or is at right angles to it, lowers are distinguished as MEDIANLY DolsivexTral (Fig. $440 \mathrm{~A}$ ), obleqeh Dolisiventlat (Fig. $440 \mathrm{~B}$ ), or transversely dolsiventral respectively (Fig. $440 \mathrm{C}$ ). Radially symmetrical monstrosities of normally zygomorphic flowers are termed reLOHIC.

If a diagram of the arrangement of the members as they are seen in a crosssection of an oprened flower-bud is constructed (ef. p. 16) and so oriented that the transverse seetion of the axis of the infloresence stands above, that of the bract below, the ground plan of the flower, what is known as a FLORAL DIAGRAM is obtained. The accompanying floral diagram (Fig. 441) is that of a monocotyledonous flower with five whorls of members. A FLolial formula gives a short expression for the 
members of a flower as shown in the floral diagram. Denoting the ealyx by $k$, the corolla by $\mathrm{C}$ (if the periantl forms a perigone it is denoted by $\mathrm{P}$ ), the androecium by $\Lambda$, and the gynaeceum by $G$, the number of members in each case is placed after the latter. Thus the floral formula of the monocotyledonous Hower represented in Fig. 441 would be, $\mathrm{P} 3+3, \mathrm{~A} 3+3, \mathrm{G} 3$. When there is a large number of members in a whorl the symbol $\infty$ is used denoting that the number is large or indefinite. Such a formula may be further made to denote the cohesion of the members of a whorl by enclosing the proper number within brackets, and by
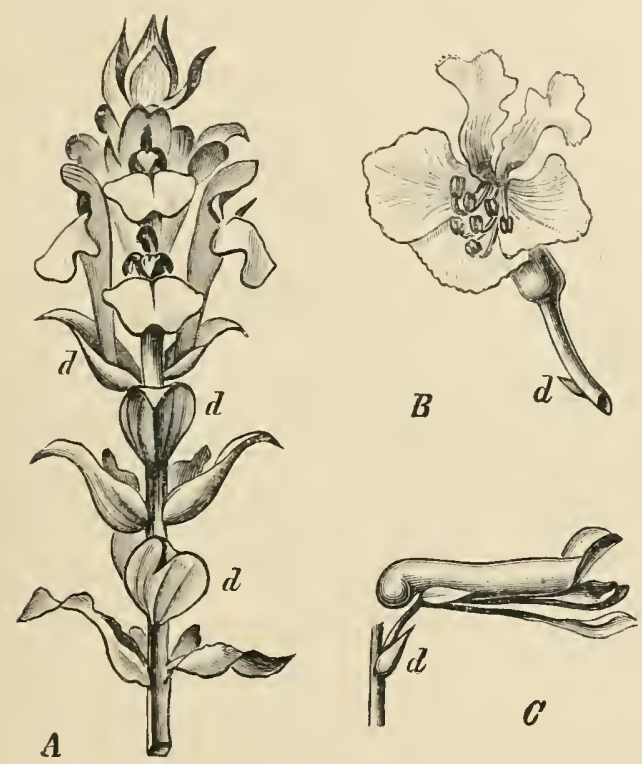

Fig. 440.-Flowers of, A, Soutellaria alpina, medianly zygromorphic (dorsiventral); $B$, Aesculus hippocustanum, obliquely zygomorphic (dorsiventral); $C$, Corydulis luteu, transversely zygomorphic (dorsiventral); $l$, bracts. placing a horizontal line below or above the number of the carpels the superior or inferior position of the ovary is expressed. By placing an arrow before the formula the dorsiventrality of the Hower may be indicated, and by varying the direction of the arrow it can be made clear whether the dorsiventrality ismedian, oblique, or transverse. The formula for the Lily given above and

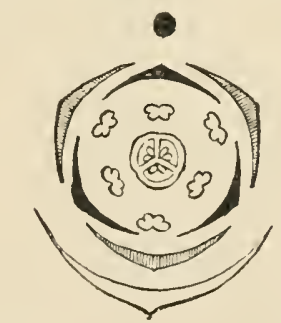

F1i, 441.-Diagram of a penta. cyelic flower (Lilium).

for a number of other flowers would thus take the following forms :-

Lily. $\mathrm{P} 3+3, \mathrm{~A} 3+3, \mathrm{G}(3)$.

Buttercup. K $5, \mathrm{C} 5, \mathrm{~A}_{\infty}, \mathrm{G}_{\infty}$.

Laburnum. $\downarrow \mathrm{K} 5, \mathrm{C} 5, \mathrm{~A}(5+\overline{5}), \mathrm{G} 1$.

Hemlock. K 5, C 5, A 5, G (2).

Artemisia. K $0, \mathrm{C}(5), \mathrm{A}(5), \mathrm{G} \overline{(2)}$.

Inflorescence. - In many Angiosperms the single flowers are borne in large numbers on special branch systems which differ in a number of respects from the vegetative branch systems, and are termed INFLOREsCENCEs. In inflorescences, as in the vegetative region (cf. p. 20), branches usually arise only from the leaf-axils, the subtending leaf being termed a BrACT. Leaves borne on the axis of the flower itself are known as BRACrEoLEs. Bracts and bracteoles may be classed together as mRACTEAL LEAVEs (Fig. 442). The MeUian plane passes through the axis and 
the middle line of the bract. The bracteoles, and the branches produced from their axillary buds, may lie in this median plane, when they are said to have a MEDIAN POSITION, or more commonly they stand right and left of it, and their position is described as Transverse (Fig. 442).

According to the relative development of the main and lateral axes in an inflorescence a distinction is made between RACEMOSE inflorescences, in which the main axes are strongly developed and exceed their lateral shoots, and CrMosE inflorescences in which the lateral axes are more strongly developed and overtop the main axis. The former may be also termed monopodia in contrast to the

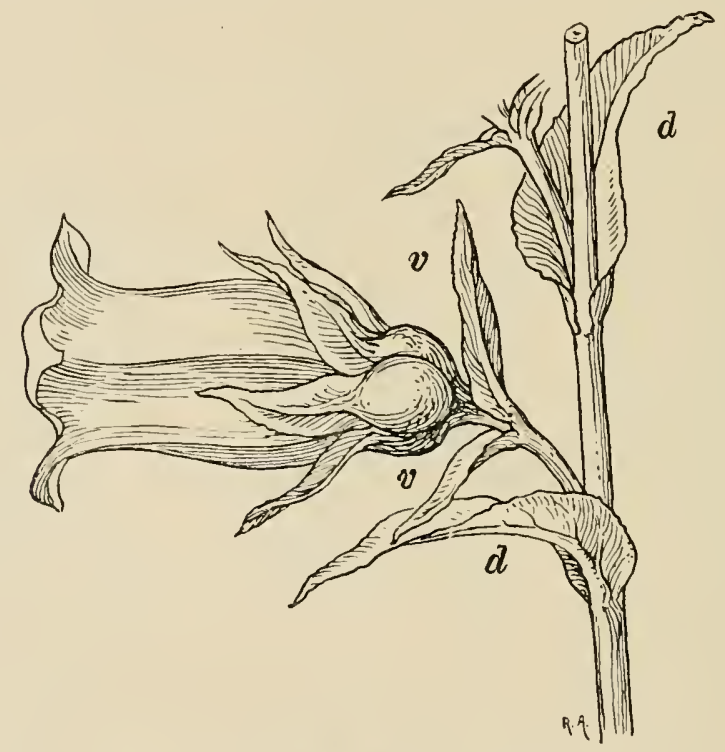

Fro. 442.-Flower of Crimpanula medium with bract (il) and bracteoles (i).

symponfal or eymose type (cf. p, 17). The more frequent kinds of inflorescence are enmmerated below.

\section{Racemose Inflorescences.}

(a) Lateral axes unbranched.

1. RACEME; stalked flowers borne on an elongated main axis (Figs. $443 A, 444$ ).

2. SPIKE; flowers sessile on an elongated main axis (Figs. $443 \quad B, 445$ ). $\Lambda$ spike in which the axis is thickened and succulent is termed a sPADIx; a spike which, after flowering or after the fruits have ripened, falls ofl as a whole, is a CATkin (Fig. 446).

3. UMBLL; flowers stalked, on a shortened main axis (Figs. $443 C, 447$ ).

4. Cajitulum or hFad ; flowers sessile, on a sliortened main axis (Fig. $443 \mathrm{D}$ ). (b) lateral axes branched.

5. PANICLE; a main axis bearing racemes laterally (Figs. $443 \mathrm{E}, 448$ ).

6. Compouni umbla ; an umbel bearing small umbels in place of the single flowers (Fig. $443 \mathrm{~F}$ ). 


\section{Cymose Inflorescences.}

(a) The relatively main axis bearing more than two lateral branches; Pleionhasium.

(b) Each relatively main axis bears two lateral branches; Dichasium (Figs. $449 E, 450$ ).
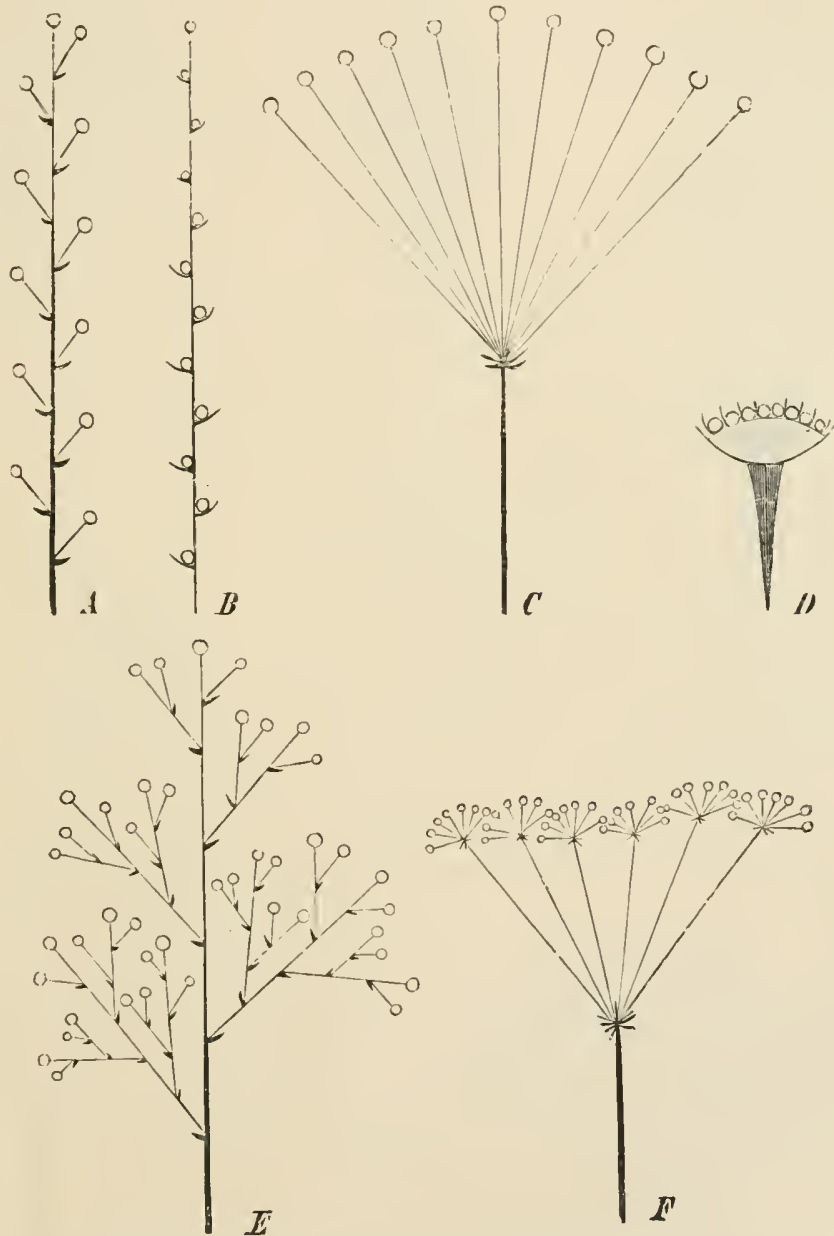

F1G. 443.-Diagrams of racemose inflorescences. $A$, Raceme, $B$, Spike, $C$, Unbel. $D$, Capitulum. E, Panicle. $F$, Compound umbel.

(c) Each relatively main axis bears one lateral branch; Moxocilasiv

1. The snccessive lateral axes all fall in the median plane.

(a) all the branches arise on the same side; Drepanium (Fig. $449 \mathrm{C}, D$ ).

( $\beta$ ) branches alternately right and left; Rhipidus (Fig. $449 \mathrm{~A}, B$; Fig. 773 , Iris). 


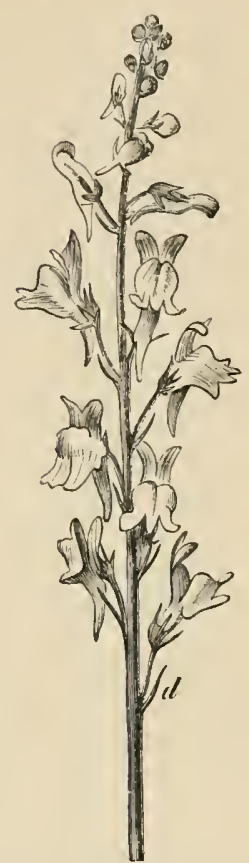

Fro. 44.-Raceme of Linuric striutu. $d$, Bracts.

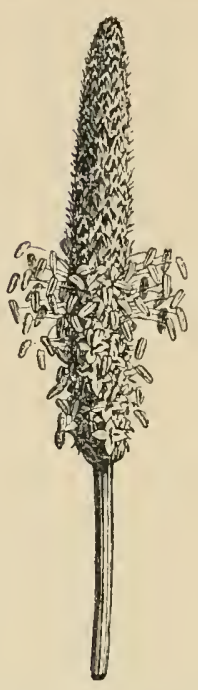

Fig. 445.-Spike of Pluntugo lanceolutic. (After DUCHARTRE.)
(After Du-

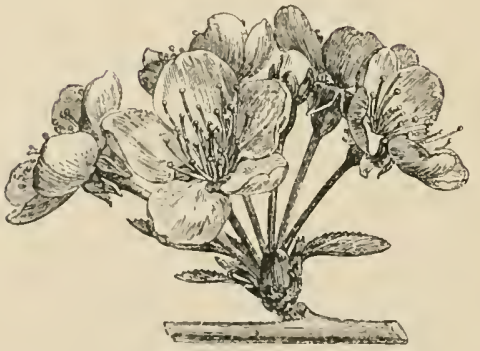

Fic: 447,-Unbel of the Cherry. (After loverartirk)

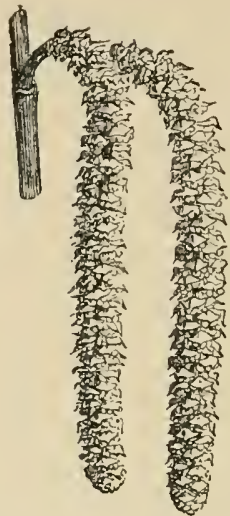

Fig. 446. - Catkin of Corylus americana. (After DUCIIARTE.)

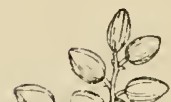

QDine (1) 0100 e(1) 3 , i 210
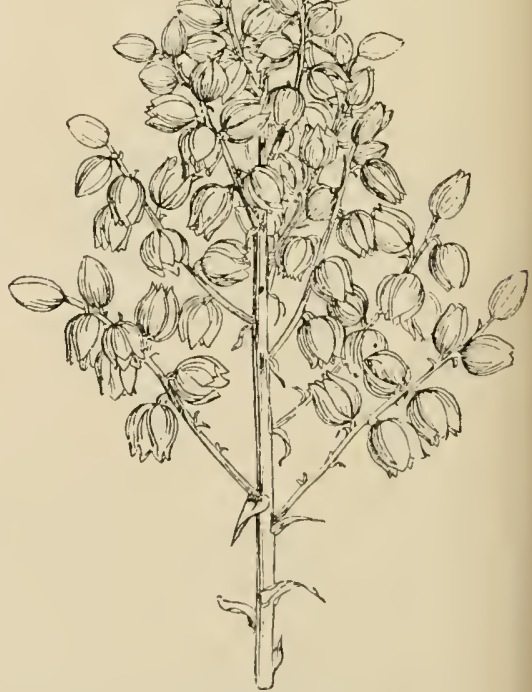

H'r. 448, - Panicle of Yuecre filumentuse. (Rerluced.) 
2. The lateral axes are transverse to the relatively main axis; their arrangement ean thus only be shown in ground plan.

(a) lateral axes always falling on the same side of the relatively main axis ; Bostryx (Fig. $449 \mathrm{~F}^{\prime}$ ).
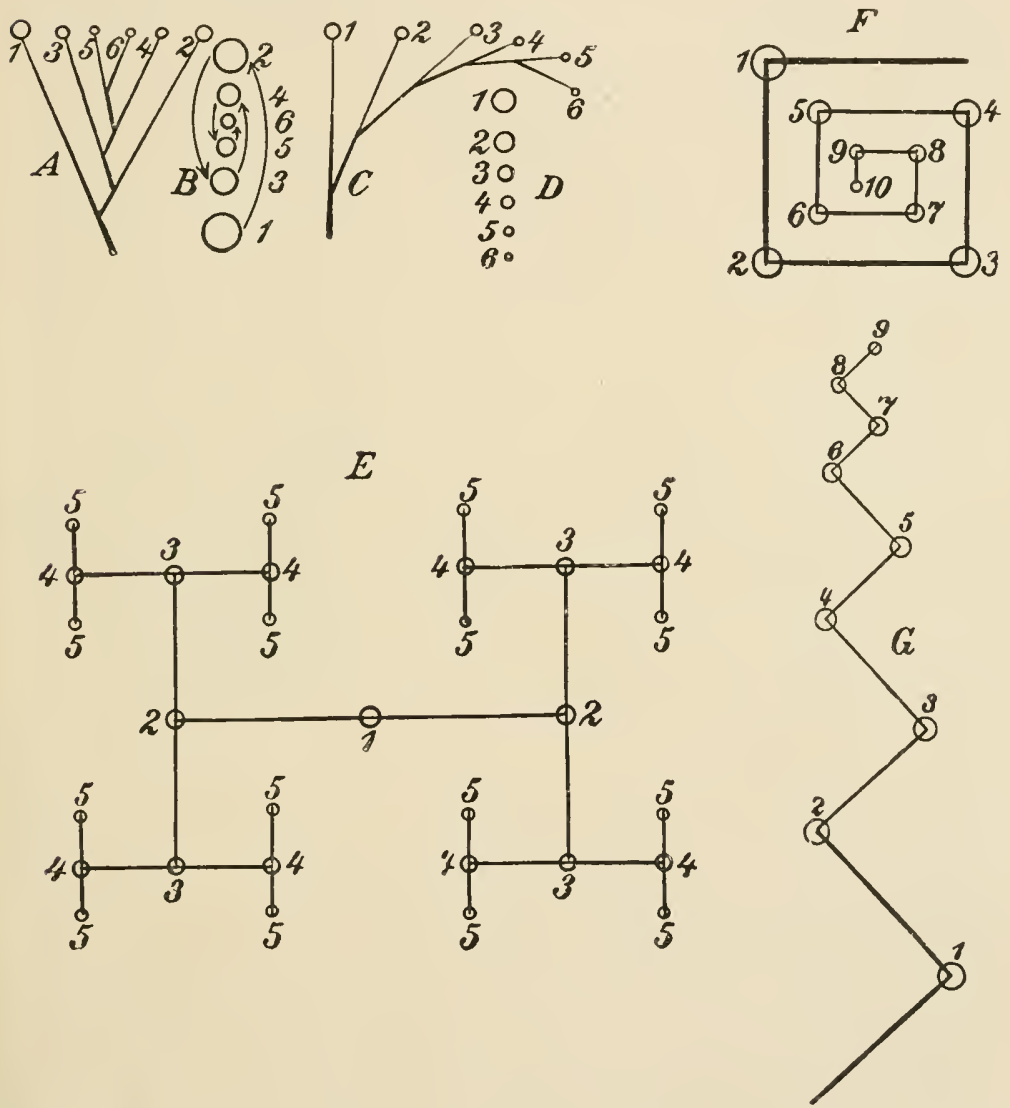

Frs. 449.-A, Rhipidium from the side; $B$, shipidium in ground plan; $C$, drepaninm from the side; $D$, ground plan of drepanium; $E$, ground plan of dichasiun ; $F$, ground plan of bostryx : $G$, ground plan of eincinnus. 1-10, successive, relatively main axes. ( $A-D$, after EICHLER.)

( $\beta$ ) lateral axes falling alternately on opposite sides of the relatively main axis ; Cincinnus (Fig. $449 \mathrm{~F}$; Fig. 451, a double cincinmus).

\section{Floral-œeology}

Many differences in the structure of flowers and in the arrangement of their organs which would otherwise be doubtful, are explained when brought into relation to the functions performed by the flower. 
All flowers have the function of producing progeny sexually; the methorls leading to this common end are, however, very various. In contrast to the Bryophyta and Pteridophyta in which the union of the

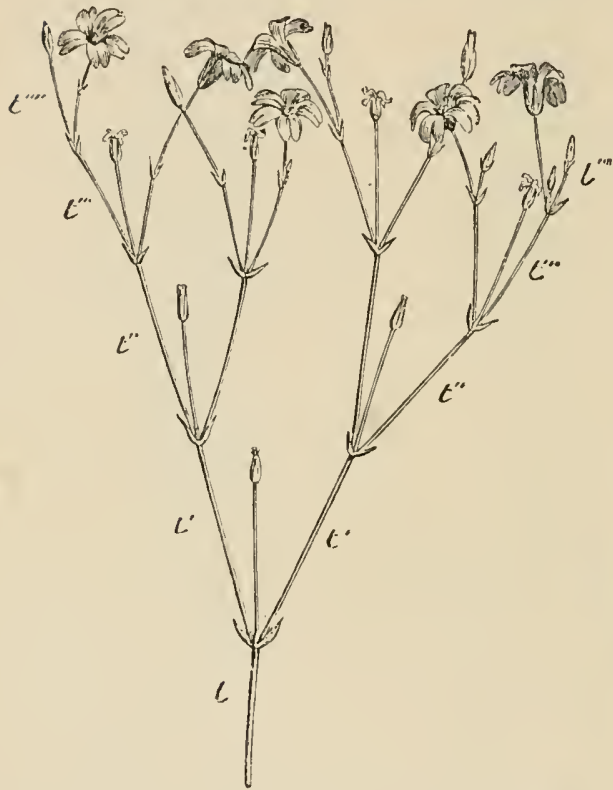

Fig. 450.-Cymose inflorescence (dichasium) of Cerastium collinum $t$ - $t^{\prime \prime \prime \prime}$, successive axes. (After Duchartre.) sexual cells is effected by the aid of water, the Phanerogams, which do not separate a motile male gamete, and have the egg-cells permanently enclosed in the tissues of the parent plant, are forced to adopt other methods. Arrangements to convey the microspores, enclosing the

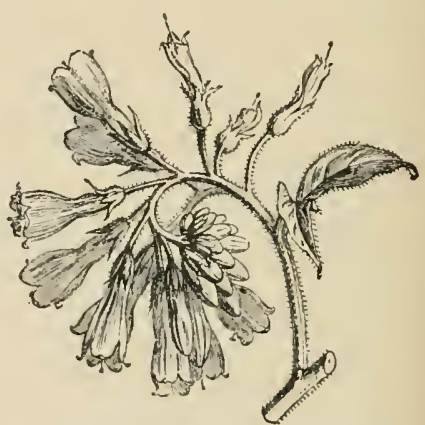

FIG. 451.-Scorpioid eyme of Synnhytum asperrimum. (After DUChaRTRE.)

male sexual cell, to the macrospores, enclosed in the macrosporangia and containing the egg-cells, become necessary.

A large number of Phanerogams make use of the wind to convey the microspores, i.e. the pollen, to its destiuation. Examples are all the Conifers, and also the majority of our native deciduous trees such as the Elm, Oak, Beech, Hornbeam, and further our Grasses and cereals. Simple as the relations in this case appear to be, varions necessary preliminaries are required for successfully effecting this method of pollination.

It is espeeially necessary that such anemophilous plants shonld produce a very large quantity of pollen, sinee laturally only a small fraction of what is slied will reach its destination. Thus at the season when our coniferous woods are in flower large quantities of pollen fall to the ground constituting what is known as sulphurshowers. When steh forests stand in the vicinity of lakes or of the sea-eoast the pollen thus sled may form an essential part of the fool of the aquatic famma.

Anemophilous plants exhilit some eharacters in eonmon which stand in definite relation to wind-pollination. The male infloreseence has usually the form of a longer or shorter eatkin which bears a large number of niero-sporophylls; these 
are so oriented that after the sporangia have opened the pollen can be readily carried away by the wind. Examples are the catkins of the Oak, Birch, Alder, Hazel, and Walnut; the eatkins of the last (Fig. 516) are especially long. The male flowers of the Coniferae, the shedding of the pollen of which has been investigated by GoEBEL, are similar. The pollen grains also have characteristic features. They are light and smooth, and in some Conifers are even provided with two winglike sacs (Fig. $424 \mathrm{D}$ ) which enable them to remain suspended longer in the air. Some Urticaceae (P'ilea, Urtica) scatter the pollen on the opcning of the elastically stretched wall of the pollen-sac as a light clond of dust.

The female flowers are nsually not brightly coloured and do not develop nectaries. The stigmas, which catch the pollen, are strongly developed and pro. vided with long feathery hairs, or thcir form is brush-like, pinnate or elongated, and filamentons. In many Gymnosperms (e.g. Taxus) the macrosporangium excretes a drop of fluid in which the pollen-grains are canght; on drying up of the drop the jollen is drawn down on to the tip of the nucellus. In other cases the pollen grains glide down between the carpellary scales of the cones till they reach the moist micropyles of the ovules and adhere to them.

Lastly, the time of flowering is not without imjortance. The Elm flowers in February and March long before its leaves develop, and the same holds for the Hazel, Poplar, and Alder. In the Walnut, Oak, Beech, and Birch the flowers open when the first leaves are unfolding and flowering is over before the foliage is fully expanded. Were this not so, much of the pollen would be intercepted by the foliage leaves and even more pollen would need to be prodnced than has to be done to ensure fertilisation. In the Conifers the foliage presents less difficulty, but here the female cones are borne at the summit of the tree (Abies) or ligh up (Pivec), while the male flowers are developed on lower branches. The pollen grains are shed in warm dry weatler, and carried up in the sunshine by ascending currents of air till they reach their destination on the female cones situated high above the male flowers.

Only a small number of Phanerogams make use of the agency of water for effecting their pollination, and are, on that account, temed HyDropHILOUs PLANTs.

The pollen of the submerged Zoster $\alpha$ exhibits certain peculiarities, distinctly referable to the necessity of effecting fertilisation under water. It does not form round grains, but in their place elongated thread-like filanents devoid of an exine, which, as they have the same specific weight as the surrounding water, are easily set in motion by the slightest currents, and are thus bronght into contact with the stigmas. Species of Halophila which live in tropical seas behave in a similar fashion. In the case of the submerged water plants, Fullisicrio, Elodea, Irydrilla, and Enalus, the pollination is accomplished on the surface of the water. Thus, for example, the male flowers of Tallisneria, after separating from the prarent plant, rise to the surface of the water, where tliey open and float like little boats to the female flowers; these, by the elongation of their spirally coiled flower-stalks, ascend, at the same time, to the surface of the water, only to become again submerged after fertilisation.

'The great majority of Phanerogams are dependent npon animals, especially on insects, for the transference of their pollen. Plants pollinated by the aid of insects are termed entomophilous. Since the discovery of the relations between flowers and insects by KoNraI) SPRENGLL, investigations into floral-cecology have been so actively carried on that one thinks first on this small department of the whole 
subject when floral biology is mentioned. The literature upon it is proportionately large.

What influence on floral construction can rightly be ascribed to entomophily ?

The Gymnosperms must be excluded from consideration as purely anemoplihilons plants. What other explanation than as an attraction apparatus in relation to the world of insects in search of food can be given of the brightly coloured, i.e. not green, leares around the flower, such as the perigonial leares, petals, bracts, or spathes? A striking example is afforded by an orchard in flower with its gleaming colours contrasting in the sunlight with the general green. What explanation of the strong scent, increasing towards evening, of Lonicera, Philadelphus, etc. can be given except that it serves as an attraction to night-flying insects, such as Hawk-moths, which are led by the scent to find their food? How could the existence of nectaries, and the excretion by the plant of an important reserve food substance be accounted for, if the guests which greedily consume it were not indispensable to the flowers? How, lastly, could the construction of a dorsiventral flower, such as that of Salvia or of Orchis, be understood if we did not relate it to the insects which visit the flower in search of nectar, and in doing so effect pollination? The mutual adaptations between the form of flowers and the bodies of insects are so numerous, and the experimental fact that plants removed from their native country, though growing healthily, remain sterile owing to the lack of the pollinating insects to which they are adapted, is so well established, that no doubt can be entertained on the mutual adaptations of flowers and insects. Usually the position of the nectaries is such that the hairy body of the visiting insect unust carry away pollen from the flower; often the pollen will be deposited on special regious of the insect's body and on auother flower being risited will be deposited on the stigma. It is of importance that the pollen of such entomophilous plants differs from that of the anemophilous flowers described above. Pollen grains provided with spiny projections, or with a rongh or sticky surface, are characteristic of entomophilous plants; the grains may remain united in tetrads or in larger masses representing the contents of a whole pollen sac (Orchis, Asclepias). The pollen itself forms a valuable nitrogenous food for some insects such as Bees; these form "bee-bread" from it.

In addition to the stimulus of hunger, plants utilise the reproductive instinct of insects for securing their pollination. Not a few plants (Stapelia, Aristolochia, and members of the Araccae), by the nnnatural colour of their flowers, combined with a strong carrion-like stench, induce carrion-flics to visit them and deposit their eggs; in so doing they effect, at the same time, the pollination of the flowers. In the well-known lollow, pear-shaped inflorescences of the Fig (Ficus cariea, Fig. 532) there occur, in addition to long-styled female flowers that produce seeds, similar gall-flowers with short styles. In each of the latter a single egg is laid by the Gall-wasp (Blastophoya), which in effecting this pollinates the fertile flowers with pollen carried from the male inflorescence (the Caprificus). The large white flowers of Fuceu (Fig. 452) are exclusirely pollinated by the Yncca moth (Pronuba). The moth escajes from the pupa in the soil at the tine of flowering of Fucc $\alpha$ and introduces its eggs into the ovary by way of the style; in doing this it carries pollen to the stigma. The larvae of the moth consume a proportion of the ovules in the ovary, but without the ageney of the moth no sceds will be developed, as is shown by the sterility of the plant in cultivation.

Orxituophis plays a much less important part than entomophily; the birdvisitors are confiner to the American Humming Birds and the Honey Birds of the 
Old Worlel. A specially remarkable case of adaptation of this kind is afforded hy Strelit:ic reginae, which is often cultivated in greenhouses (Fig. 453). Its three outer perianth segments $(t)$ are of a bright orange colour; the large azme-blue labellum $(p)$ corresponds to one of the inner perianth leaves, while the other two $(p)$ remain inconspicuous and roof over the prassage lcarling to the nectary. The stamens (st) and the style (y) lie in a groove, the margins of which readily separate, formed by the labellum, while the stigma $(q)$ projects freely. 'The similarly coloured and showy bird (Nectarinia afra) flies first to the stigma and tonches it, then secures pollen from the stamens which it will deposit on the stigna of the flower next visited.

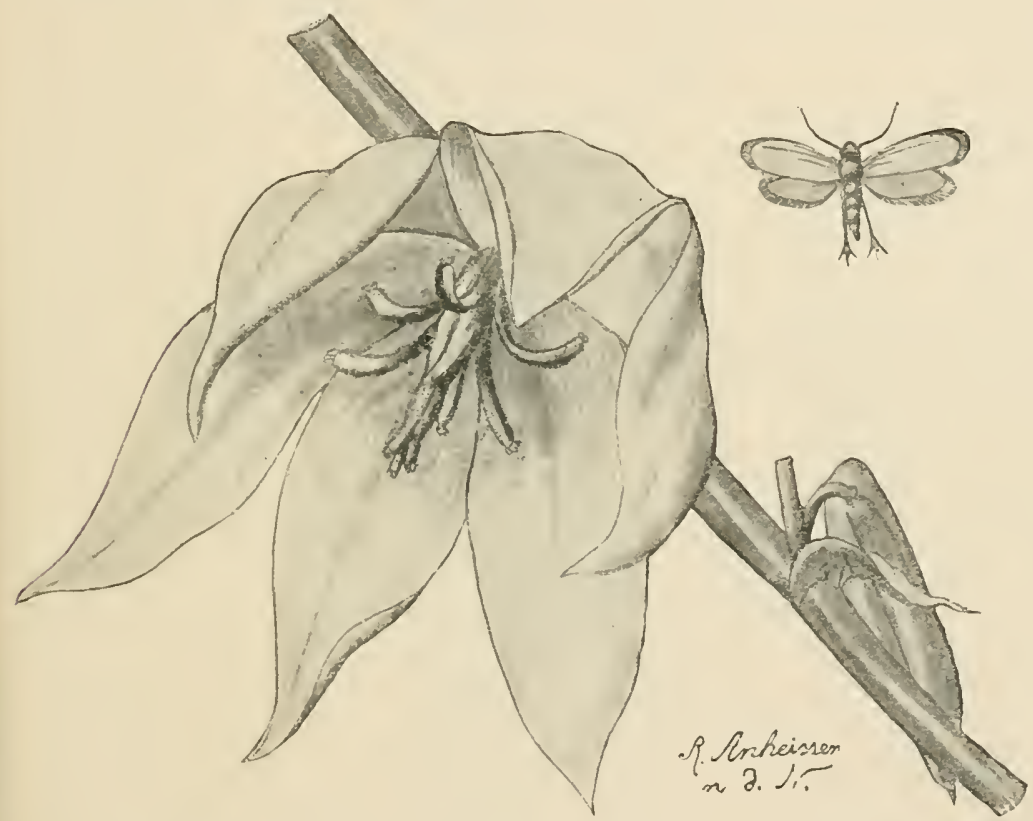

Fia. 452.-Flower of Yucen filnmentusa and the Pronuba moth. (From Schimper, Plant Grogmony.)

The structure of the pendulous inflorescence of Margravic is just as remarkable (Fig. 45t); in this the bracts form receptacles containing the nectar. Numerous insects fly around these nectaries, and the darting Humming-birds, either in pursuit of the insects or themselves in scarch of nectar, get dusted with prollen from the flowers, which face downwards, and carry it to other flowers.

Besides these orxiтholmilous plants there are a few visiterl by Bats ('Hiropterophilous); thus the dicecious Paudanaceous plant Freycinctic of the Malayan Archipelago is pollinated by a Flying For (Pteropus), which eats the inner bracts.

Pollination in some cases is effected by means of snails (M.ILAcopHutors plaxts). To their instrumentality the flower's of Callo pralustris, Chrysosplenium, and also the half-buriet llowers of the well-known Aspidistra owe their pollination. 
It would seem remarkahle that such manifold and various adaptations for the conveyance of pollen exist while the majority of

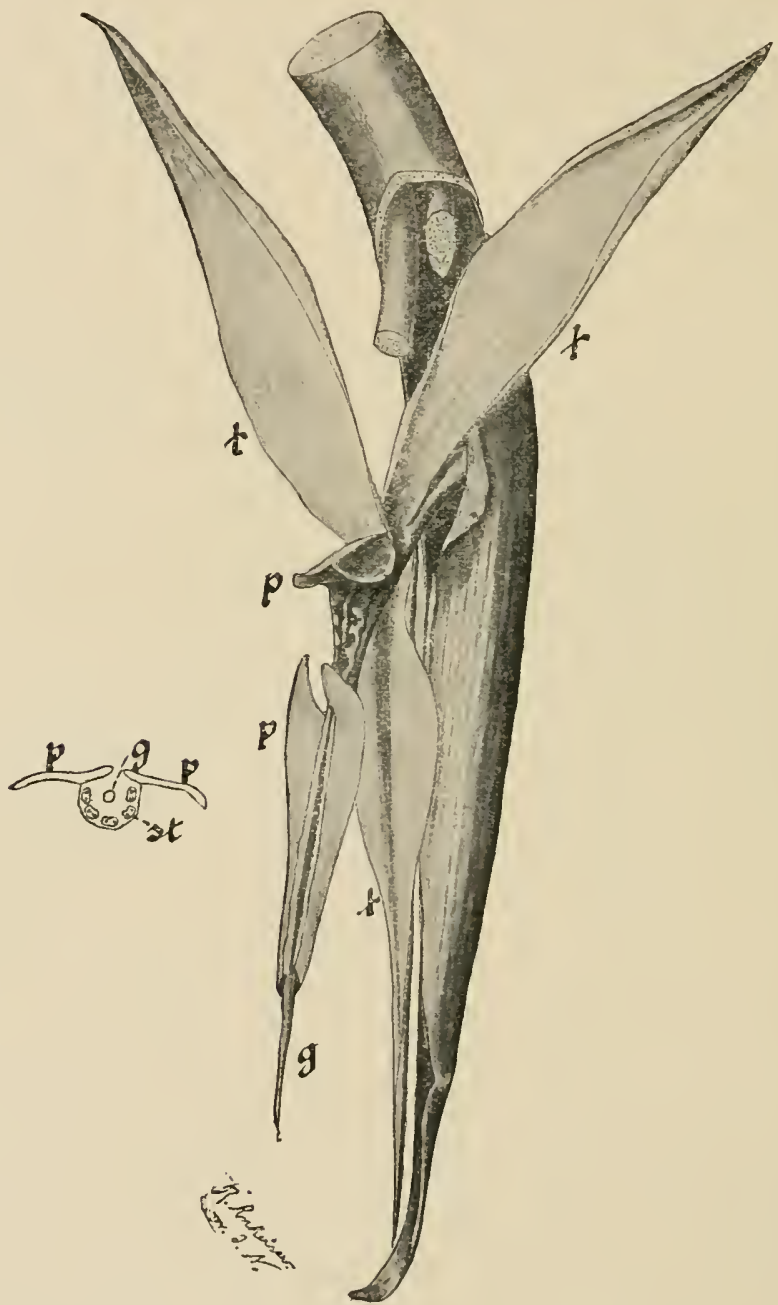

Fia. 453.-Ornithophilous flower of sfrelitziu reginae and a cross-section of its large labellum $(p)$; $t$ outer, and $p$ inner perianth leaves ; $y$, style and stigma; st, stamens. (From scmuper, Plunt Goography.)

angiospermic plants have hermaphrodite flowers; it is known, however, that the pollination of a flower with its own pollen may result in 
a poorer yield of seed (liye) or be without result (self-sterility in Cytisus Labumum, Lobelia fulgens, Corydulis Cava, some Cruciferae, etc.). It may even have a directly injurions influence, as in certain orchids in which the application of the flower's own pollen canses the flower to die. In certain plants in addition to the large CHASMOGAnOUs flowers, pollinated by wind or insects, small inconspicuous flowers oceur which never open and only serve for self-fertilisation; these CLEISTOGANous flowers $\left({ }^{7}\right)$ afford a further means of propagating the plant, while the

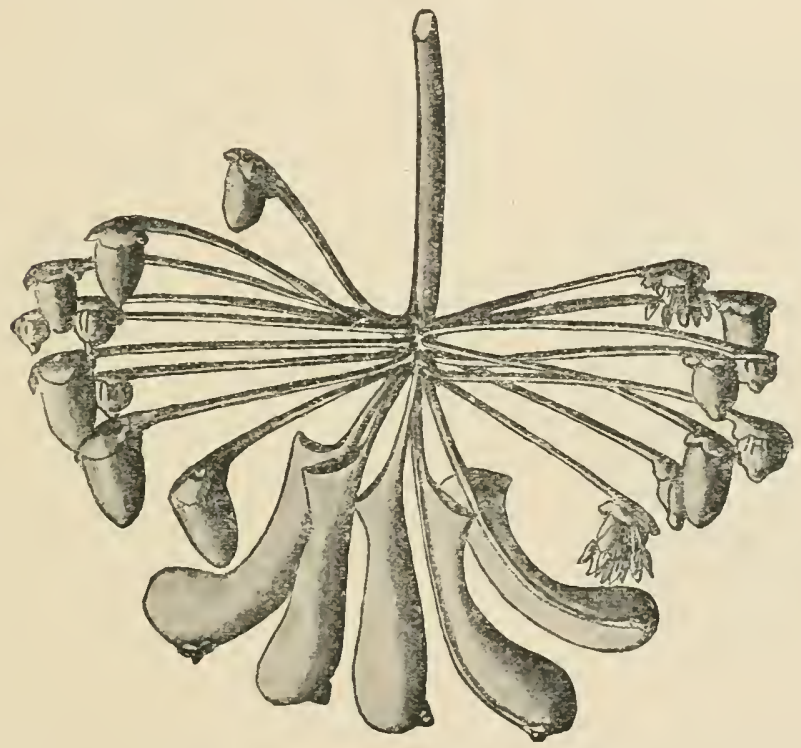

FIG. 454.-Inflorescence of AIergrevia umbellutu adapted for pollination by IImmming-birds. (From Somyper, Plunt Geography.)

plants have the opportunity of oceasional eross-pollination owing to the presence of the large chasmogamous flowers.

Cleistogamous flowers are the result of an arrested development, though their sexual organs become mature. The pollen-sacs usually lack the mechanism for opening, so that the pollen-tubes have to grow through the wall of the anther to reach the stigma. The occurrence of cleistogamous flowers is in all cases traceable to insufficient nutrition, whether due to lack of mineral food-materials or to insufficient light. Since seed is regularly set by these flowers, the plants bearing them can succeed even when chasmogamous flowers are not developed. Cleistogamy is of frequent or regular occurrence in species of Tmpatiens, Fiolu, Lamium, and Stellariu, in Specularic perfoliate, Juncus bufonius, etc. Polycarpon tetraphylhum has only cleistogamous flowers.

On the other hand there are many and varions conditions which 
render the self-fertilisation of hermaphrodite Howers completely impossible. It is obrious that diocism completely prerents self-fertilisation, and that monocism at least hinders the pollination of the flowers with pollen from the same plant. A similar result is brought abont when the two kinds of sexual organs of a hermaphrodite flower mature at different times. This very frequent condition is known as DICHOGAMY.

There are obrionsly two possible cases of dichogany. Either the stamens mature first and the pollen is shed before the stigmas of the same flower are receptive;

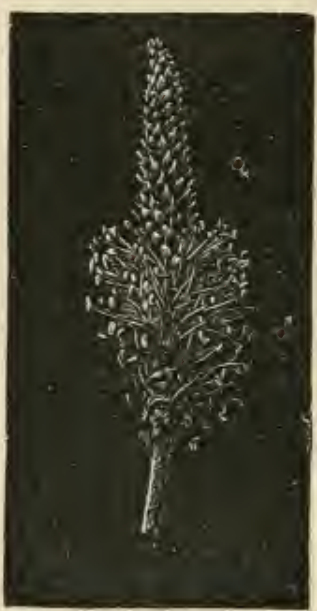

FIG. 455.--Inflorescence of Plantago media with protogynous flowers. The upper, still closed flowers (१) have protruding styles; the lower ( $\delta$ ) lave lost their styles, and disclose their elongated stamens. the plant is known as protaxnRous (proterandrons, androgynous). On the other liand the style with its stigma may ripen first, before the pollen is ready to be shed; the plant is reotogracs (proterogynons, gynandrous).

Protaxdry, the earlier maturing of the male sexual organs, is the more frequent form of dichogamy. It occurs in the flowers of the Geraniaceae, Campanulaceae, Comprositae, Lobeliaeeae, Umbelliferae, Malvaceae, etc. The anthers, in this case, open and diseharge their pollen at a time when the stigmas of the same flowers are still imperfeetly developed and not ready for pollination. Aceordingly. PROTANDROL' FLOWERS CAN ONLY BE FERTILISIII BY THE POLLEX OF YOUNGER FLOWERS.

In the less frequent protograr the female sexual organs are ready for fertilisation before the pollen of the same flowers is ripe, and the stigma is usually pollinated and withered before the pollen is shed; so that the PROTOGYNOUS FLOWERS MUST BE FERTILISED BY THE POLLEx OF OLDER FLOWERS (Anthoxanthum adoratum, Luzula pilosa, Serophularia nodosa, Avistolochia clematitis, Helleborus, Magnolia, Plantago, Fig. 455).

A still more eomplieated method of effecting cross-fertilisation, because involving also morpho-

logical and anatomical differenees of structure, results from Hetenostrur, or the peenliarity of some speeies of plants of producing stigmas and anthers which vary in height in different individnals of the same species. In contrast to the unlimiter possibility of crossing in other hermaphrodite flowers, there is here a limitation to eertain classes of indiriduals of the species. A good example of heterostyled tlowers is afforded hy the Chinese Primrose (Fig. 456). This plant has two forms of flowers, long-styled $(L)$ and short-styled $(K)$, while the positions of the stignas and anthers in the two kinds of flowers are exactly reversed. The pollen grains of the short-styled flowers, moreover, are larger, and the stigmatic papillae shorter, than in those with the longer styles $(p, P$, and $n, x)$. The purpose of such norphologieal and anatomical differences existing letween flowers of the same slrecies was first muderstood after they were discovered by DArwis to be a contrivance for cross-pollination. Fertilisation is most suceessful in sueh eases when the pollination of the stigmas is effected by the pollen of antlers eorrespondingly situated. By such a "legitimate" fertilisation, more and better seeds are 
produced than by "illegitimatc" fertilisation, and in some cases (Linum perenne,
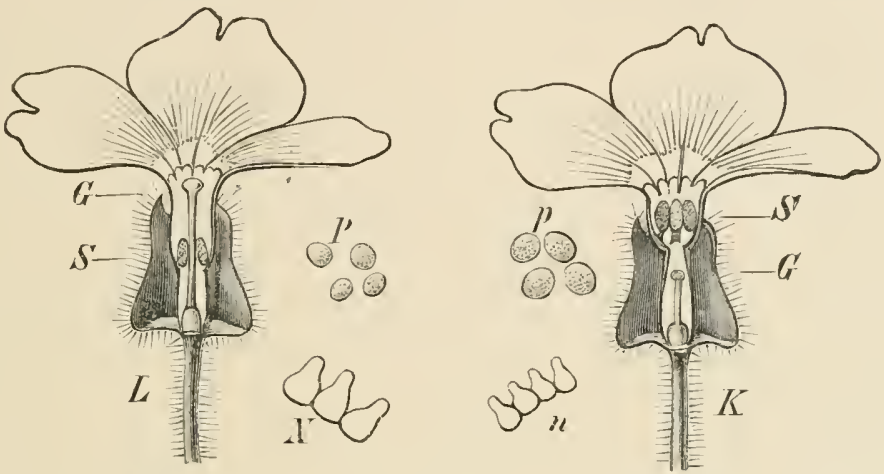

Fig. 456,-Primulu sinensis: two leterostyled flowers from different plants. $L$, Long-styled, $K$, short-styled flowers; $G$, style; $S$, anthers ; $P$, pollen-grains, and $N$, stigmatie papillae of the long-styled form; $p$ and $n$, pollen-grains and stigmatic papillae of the short-styled form. $(P, N, p, n, \times I 10$.

Fagopyrum csculentum) legitimate fertilisation alone is productive. Legitimate fertilisation is rendered more certain by the fact that insects in visiting the flowers touch correspondiugly placed sexual organs with the same portions of their body. The flowers of Primroses have styles of two different lengths (DIMORPHIC HETEROSTYLY); the same peculiarity is exhibited hy Pulmonaria, Hottonia, Fagopyrum, Linum. There are also flowers with Trimorphic HETEIOSTYLY (Lythrum salicaria, and some species of Oxalis) in which there are two circles of stamens and three variations in the height of the stigmas and anthers.

In a great number of flowers selfpollination is made mechanically impossible, as their own pollen is prevented by the respective positions of the sexual organs from coming in contact with the stigna (HERCogaMY). In the Iris, for example, the anthers are sheltered under the branched petaloid style. The conveyance of pollen from the older to the younger flowers is effected in Aristolochice by small insects. The flowers at first stand upright with a widely-opened month (Fig. 457 I), and in this condition

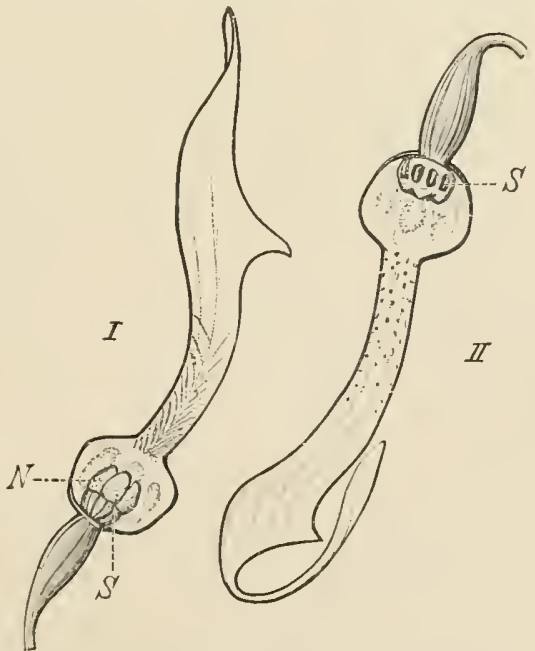

Frg. 45T.- Flowers of Aristulorhia clemutitis cut through longitudinally. I, Young tlower in which the stigma $(N)$ is recejtive and the stamens (S) lave not yet openeri ; II, Older hower with the stamens opened, the stigma withered, ant the hairs on the corolla drierl up. ( $\times$ 2.)

the insects can easily push past the downwardly directed hairs clothing the tubular portion of the corolla and reach the dilated portion below. Their 
exit is, however, prevented by the hairs mil the stigma has withered and the anthers have shed their pollen. When this has taken place (Fig. $457 I I$ ) the hairs dry up, and the insects covered with pollen ean make their way ont and convey the pollen to the receptive stigmas of younger flowers. In the Orchidaceae and Aselepiadaceae (Fig. 686) self-pollination is rendered impossible both by the nature of the pollen masses and by their position. A complicated form of structural contrivance, by means of which eross-pollination is seenred, may be seen in a flower of Salvia pratensis (Fig. 458). The anthers of this flower are concealed in the upper lip of the corolla, from which the style, with its bilobed stigma, projects. When the humble-bee visits the flower in search of honey, it must first with its proboscis push out of the way the small plate $(s)$, formed of two sterile anther halves grown together. These are situated at the ends of the short arms of the connectives (c), which are so elongated that they night easily be mistaken for the

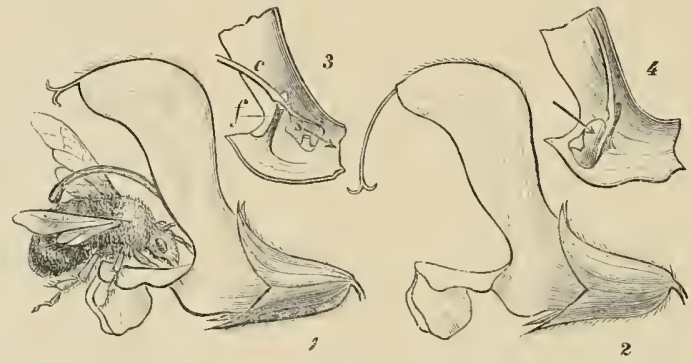

F16. 458.-Pollination of Salvia prutensis. 1, Flower visited by a lumble-bee, showing the projection of the curverl connective from the helmet-shaped upper lip, and the deposition of the pollen on the back of the humble-bee; 2, oliker flower, with connective drawn back, and elongated style; 4 , the staninal apparatus at rest, with connective enclosed within the upper lip; 3 , the same, when disturbed by the entrance of the proboscis of the bee in the direction of the arrow ; $f$, filament ; $c$, comnective ; $s$, the obstructing half of the anther.

filaments $(f)$ of the stamens. The fertile anther-halves are situated at the other ends of the connectives, and are thus brought in contact with the hairy back of the humble-bee when it pushes against the plate at the short ends of the lever-like connectives. The pollen thus attached to the bee will be brushed off its back by the forked stigma borne on the elongated style of an older flower (Fig. 458, 2).

\section{Development of the Sexual Generation in the Phanerogams}

Having become acquainted with the various adaptations by which the union of the sexual products, in the Phanerogams, is made possible, we have to follow the course of development in the macrospores and microspores leading to the formation of the sexual products and the method by which the union of these is effected.

In the Gymnosjerms $\left({ }^{8}\right)$ a prothallium consisting of a few cells is formed on the germination of the microspore. This lies within the large cell, which will later give rise to the pollen-tube, closely applied to the cell wall. The prothallimm is comprosed of from 1 to 3 eells. The first-formed cells (Fig. $459 A-C, v$ ) correspond to the vegetative eells of the prothallium. The spermatogenons eell $(s p)$, which is cut off after these, divides later into the mother-cell of the anthericlinm and a 
sterile sister-cell $(s)$ adjoining the vegretative cells (Fig. $459 \mathrm{~L}, D$ ). It is by the A

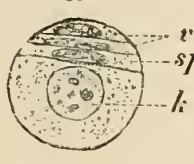

C

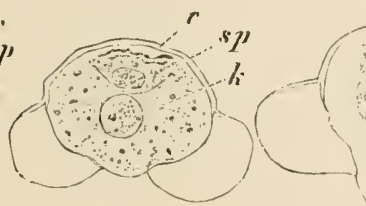

1)

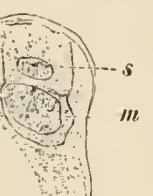

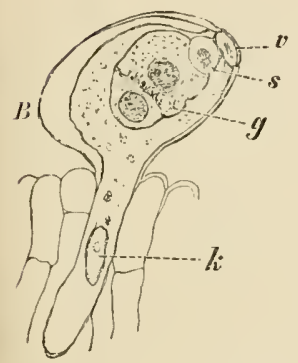

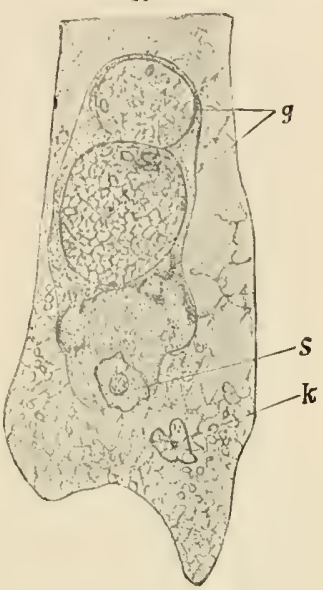

Ftg. 459.-A-E, Pollen-grains of Gymnosperms and stages in the development of the pollen-tube. $A$, Pollen-grain of Ginkgo biluba still enclosed in the sporangium ( $\times 360$ ). $B$, Pollen-grain of Larix europcea germinating on the tip of the nucellus $(\times 160)$. C, D, Pinus Laricio (after Coulter and Chanberlain ; $\times 300$ ). E, Pinus strobus (after 11. C. Ferguson ; $\times 270$ ). Tip of a pollentube which has reacherl two-thirds of the way to the archegonium. $v$, Vegetative, prothallial cell ; $s p$, slermatogenous cell which gives rise to the antheridial mother-cell $(m)$ and its sterile sister-cell (s); !, the two generative cells derived by the division of the antheridial mother-cell. They are of unequal size and enclosed in the same mass of protoplasm; $k$, nucleus of the pollen-tube.

breaking down of this latter cell that the antheridial mother-cell becomes free to pass into the pollen-tube. On this taking place, or while the latter cell is still in

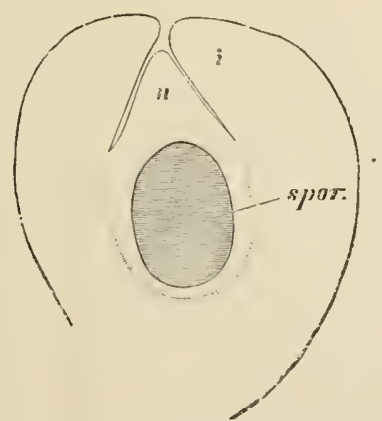

FiG. 460.-Ceratozamia longifolia. Longitudinal section through a young orule, showing the nucellus ( $n$ ), including a large group of sporogenous cells (syor.) and the integument (i). (After T'ReuB. $\times 33$.)

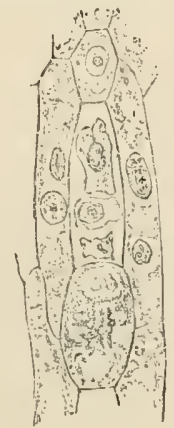

Fig. 461.-Taxus baccata. Longitudinal section through the sporogenous tissue, showing an embryo-sac mother-cell which has undergone the tetrad division; three of the facul. tative macrospores are degenerating, while the fourth is undergoing further development. $(\times 250$.

its original position, it divides into two danghter-cells $(g)$; these are the genera- 
tive cells or the male sexual cells. These are of very different form in the various orders of Gymnosperms. The simpler development in the Coniferae, which was known earlier, may first be followed.

The Abietineae have two generative nnclei of unequal size in the one protoplasmie body; only the larger nuelens whieh goes first is fertile (Fig. $459 \mathrm{E}$ ). Taxus has only one generative cell, its sister-cell being greatly reduced. Two equal generative cells are normally present in the Cupressineae. In Araucaria numerous nnclei develop in the pollen-tube ; this case requires more aecurate investigation.

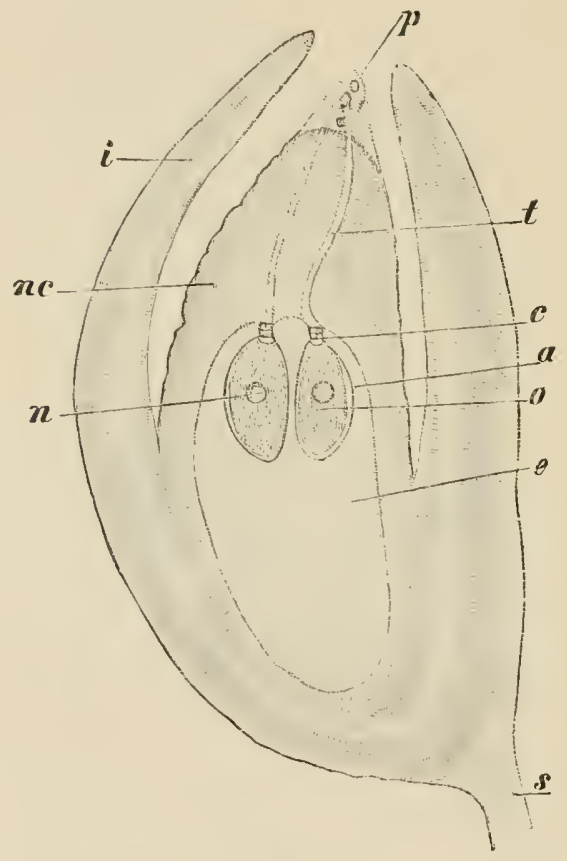

F16. 462.- Jedian Iongiturinal section of an orule of licere exretor, e, Embryo-sac filled with the prothallium; $u$, archegonimu showing ventral $(o)$ and neck portion $(r) ; n$, nucleus of egg-cell ; nc, nucellus; $\dot{p}$, pollen-grains; $t$, pollen-tube ; $i$, integument ; $s$, seerl-wing. $(\times 9$. small ventral eanul-ecll is eut off from the egg-cell shortly before fertilisation. lertilisation takes place by the entrance into the ornm of one of the generative cells, the development of which has already been followed; this enters from the pollentube, which penetrates between the eells of the archegonial neek. The nucleus of fertilised orum results from the fusion of the male and female sexual nuclei (Fig. 415), and the protoplasm is in part derived from the male cell. The development of the embryo linom the lertilised ovum presents great diflerenees in the several orders and even genera, and the following deseription applies to the species of l'inus. (Fig. 463.)

By two successive divisions of the nuclens four muclei are formed which pass to 
the base of the egg-cell, where they arrange themselves in one plane and undergo a further division. Cell walls are formed between the eight nuclei of this eightcelled pro-embryo. The cells form two tiers, those of the upper tier being in open communication with the carity of the orum. The four upper cells then undergo another division $(F)$ and this is followed by a similar division of the four lower
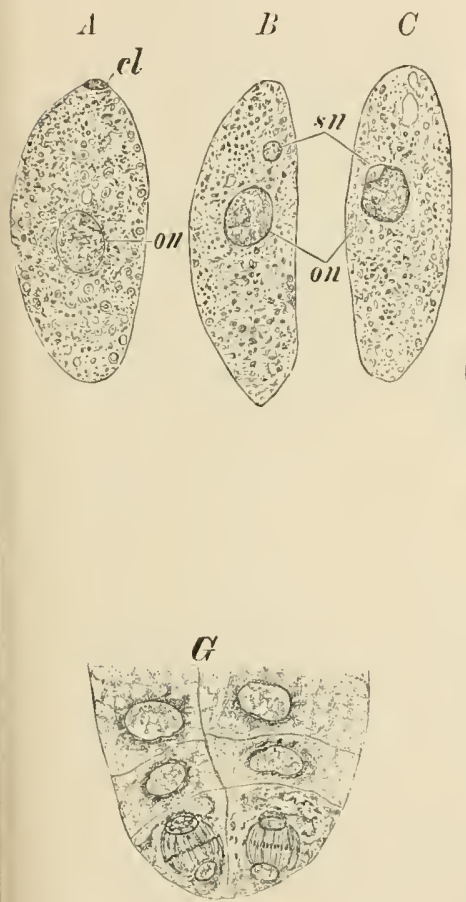

D

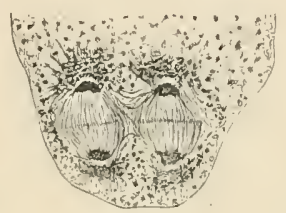

$k_{1}$
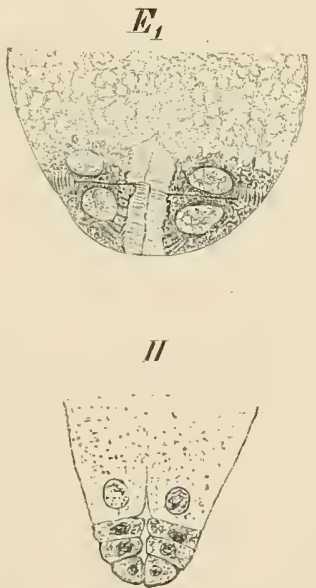

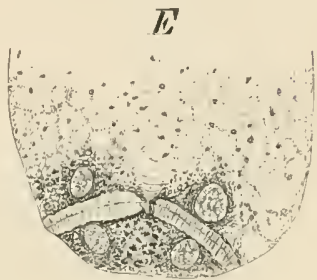

$T$

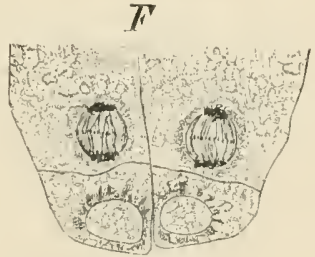

I

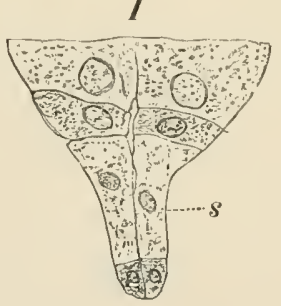

F2G. 463.-Ficea exelsu (A-C). Pinus levicio (D-I). A, Mature ovun with its nucleus (on) and the ventral-canal-cell $(c l) ; B$, the male nucleus $(s n)$ within the ovun; $C$, fusion of the male and female nuclei; $D$, the four nuclei produced by division of the nuclens of the embryo have passed to the lower end of the ovum and are there in process of further division (only two of the nuclei are visible in the section); $E, E_{1}$ between the eight nuclei, first transverse and then longitudiual walls are formed-the four upper nuclei remain in connection with the upper part of the fertilisert orum, the lower nuclei are enclosed in independent cells ; $F$, further division of the nuclei of the upper series; $G$, the cells of the lower tier have divirled; $H$, four tiers of nuclei are present, those of the upper tier not being separated from the general cavity of the eggcell ; $I$, the elougation of the middle tier of four cells to form the suspensor (s) has commenced. $(A-C \times 55$, after MYAKE; D.G $\times 200$, after KLLDAHL; $I, I \times 10 t$, after Coulter and CuAMBerlain.)

cclls $(G)$. The Pro-EMBryo thus consists of four tiers, each containing four cells, the cells of the upper tier being continuons with the remaining portion of the ovm. In the further development of the three lower tier's the middle tier elongates to form the suspexson $(I s)$ pushing the terminal tier from which the embryo will arise into the tissue of the protha'lium or endosperm; the cells of the latter are filled with nutritive reserve material. 


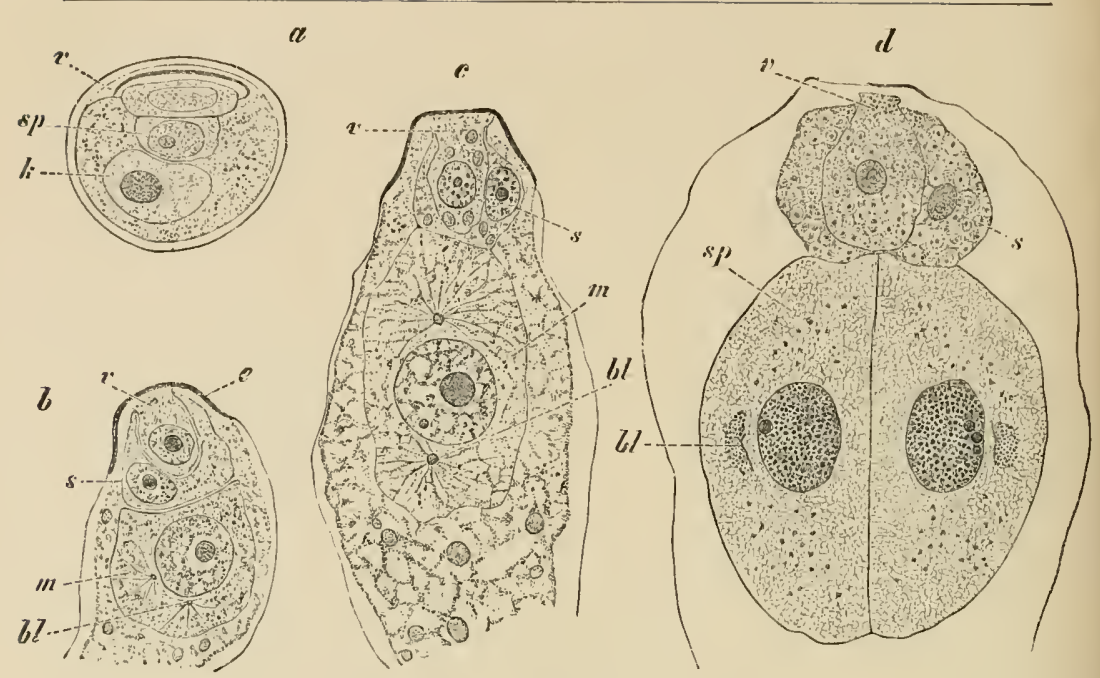

FIG, 464.-Formation of spermatozoids in Zumü floridunu. $u$, Mature pollen-grain ( $x$ s00); $v$, vegetative prothallial cell-the dark streak at its base indicates the position of anotiter crushed cell; $k$, nueleus of the pollen-tube; $s p$, spermatogenous cell, $b, c, d$, stagcs in the development of the antheridium $(b, c \times 400 ; a \times 200) ; v$, persisting vegetative cell growing into the sterile sister-cell of the antheridjum $(s)$; $m$, mother-cell of the antherisium, i.e.mothercell of the spermatozoids; $e$, exine. In the mother-cell the large blepharoplasts $(b l)$ which form the cilia are visible; in $b$ and $e$ they are star-shaped, while in $d$ they are comprosed of small granules, which will form the cilimm-forming spiral band. Starch-grains are present in the pollen-tube, and in $e$ they are appearing in the vegetative cell and the sister-cell, both of which in $d$ are packerl with starch. In $d$ the two spermatozoids $(s p)$ derived from the mother-cell are seen divisled from one another by a wall. (After H. J. Webrer.)

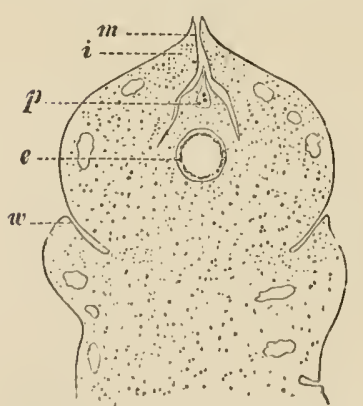

lis: 465.-Longitudinal section of a young macrosporangium of Ginligo bilulu. $m$, Mierolyle; $i$, integument ; $p$, pollen-chamler ; $e$, embryo-sac ; $w$, outgrowth of sporopliyll, The possession of a well-developed pollen-chamber points to the relationship with the Cyculactae. ( $\times 35$. After Coulter and Chambrilan.)
In other genera a separation of the four rows of cells takes place, and each bears a young embryo. As a rule, however, only a single embryo eontinues its development in eaeh macrospore although several archegonia may have been fertilised. The embryo consists of a main root or RADICLE directed towards the micropyle, an axis, the InPocotyL,

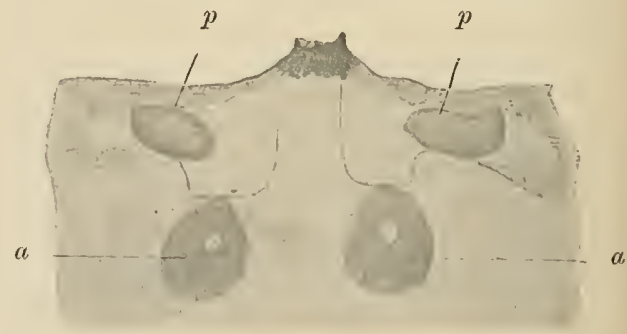

Fia. 466.- Ginkgo bilubu. Apex of the nucellus with the pollen-tubes $(p)$ projecting into the archegonial clamber. $(\iota$, archegonia. ( $\times 27$. After IIIRAse.) 
a whorl of from two to several corYLEnoss, and the pUMULE or but of the future shoot.

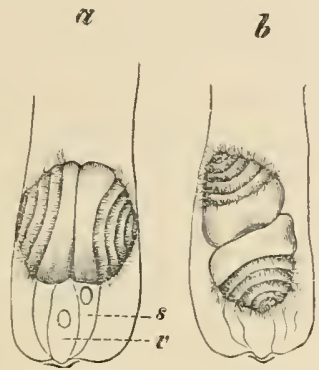

Fig. 467.-Upper end of the pollen-tube of Zumiu furitana, showing the vegetative prothallial cell $(v)$, the sterile sister-cell $(s)$, and the two spermatozoids. $a$, Before movement of the spermatozoids has commenced; $b$, after the beginning of ciliary motion; the prothallial cell is broken down and the separation of the two spermatozoicls is taking place. ( $x$ circa 75 . After H. J. WEBBER.)

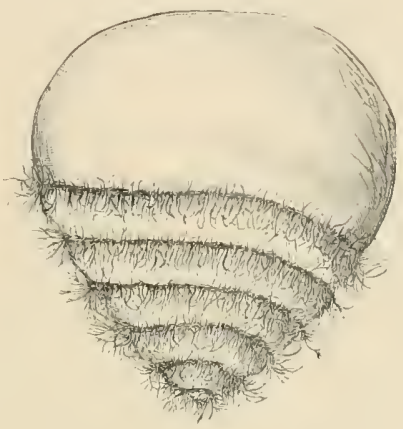

Fif. 468.-Zumia floriduna. Mature, freeswimming spermatozoid. $(\times 150$. After H. J. WEBBER.)

The development of the sexual generation in the Cycadaceae and Ginkyo $\left(^{9}\right)$ differs in a number of respects from the Coniferae. The differences indicate that the group is more closely connected with the Pteridophyta, and their nature will be evident from a deseription of Zamia floridana, which las been fully investigated by Webrer.

The female cones of $Z$ amia bear numerous sporophylls, the hexagonal shield-shaped terminal expansions of which fit closely together. Each sporophyll bears a pair of macrosporangia. The macrosporangium consists of the nucellus and an integument (cf. Fig. 460). The micropyle forms an open canal above the tip of the nucellus. At the period during which the male cones are shedding their pollen, the macrosporophylls become slightly separated from one another so that the wind-borne pollen-grains can readily enter. A more or less extensive cavity (pollexCHAMBER ; Fig. $465, p$ ) has by this time been formed at the apex of the nucellus, while the disintegrated cells, together prer haps with fluid excreted from the surrounding eells of the mucellus, have given rise to a sticky mass which fills the micropylar canal and forms a drop at its entrance. The pollen-grains reach this drop

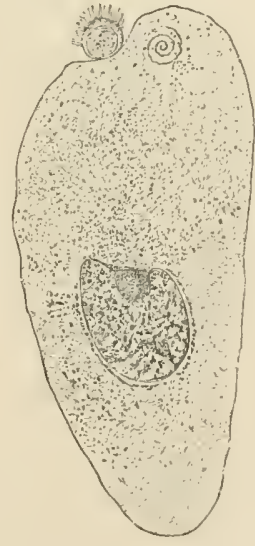

Fig. 469.-Zimia floridum. An ovum inmediately after the fusion of the nucleus of a spermatozoid with the fenale nucleus has taken place. The ciliary band of the spermatozoid remains in the upper portion of the protoplasm of the ovum. A second spermatozoil has attempted to enter the ovum. ( $\times$ 18. After H. J. WEBHER.) and, with the gradual drying up of the fluid, are drawn through the micropylar canal into the pollen-chamber. During the development of the pollen-tube (Figr. 
$461)$ and the formation of the motile spermatozoids, which have been found in all the Cycads yet investigated and in Ginkgo (Figs. 467, 468), the embryo-sac filled with the prothallial tissue is increasing in size within the nucellus. As it crushes the tissue of the upper portion of the nucellus it approaches the base of the pollen-chamber. At the alex of the embryo-sac are found the archegonia, ustally four in number, and separated from one another by some layers of cells. Each archegonim has a

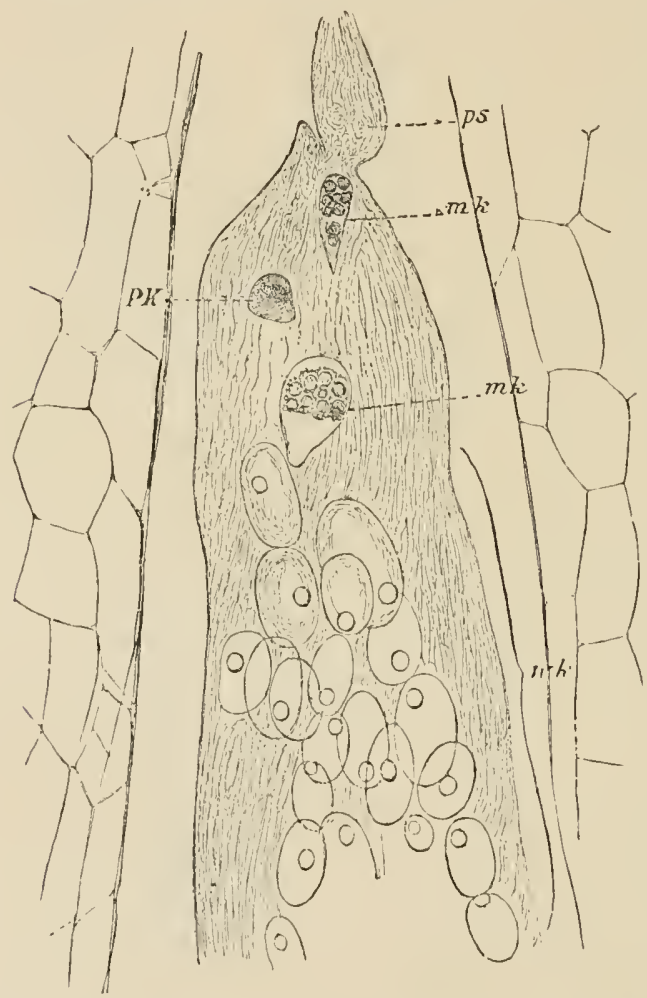

HIs. 470.-Apex of the embryo-sac of Gnetum liumphirnum sliortly before the development of the fenale cells; $w \%$, female nuclei ; $m k$, male nuclei ; $P K$, pollen-tube nuclei ; $p s$, pollentube. $(x 500)$ of a suspensor. It ultimately possesses a pair of large cotylerlons, a well-developed plumule between these and a relatively short hypocotyl.

The development of the sexual generation and the fertilisation in Ginkigo bilobe, the only known sprecies of the genus, is very similar to what has been described for Zamia. The possession of a well-developed pollen-chamber indicates the relationship to Cycals. The fertilised ovum becomes lilled with a continuous tissue and forms the embryo at the end farthest from the mieropyle. This grows out and penetrates the endosperm, but there is no clear distinction into suspensor and embryo. 
The last order of Gymmosperms, the Gnetineae ( ${ }^{(0)}$ ), exhibit a peeuliar and isolated course of development. The mierospores in their development and germination show no essential diflerences from those of other fymnosperms; the separation of the generative cells is, however, less clear and sometimes wanting. The macrospores show more marked peculiarities. The macrospores of Ephedre and Welwitschio have well-rleveloped prothallia; in the latter plant the arehegonia

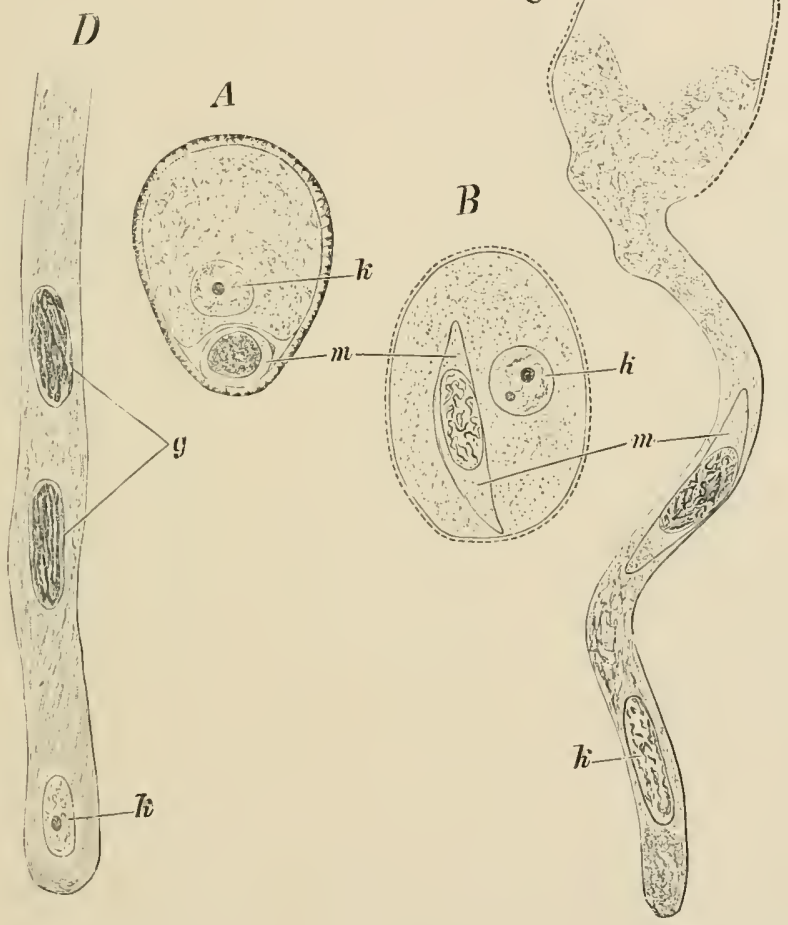

F19. 471.-Pollen-grain of Lilium Martrgon and its germination. $\quad k$, Vegetative nucleus of the pollen.grain ; $m$, anthericlial mother-cell ; $g$, generative melei. ( $\times 400$.

are reduced to elongated cells penetrating the tissue of the nucellus. Since, however, more than one nueleus may be present in these cells, further investigation into their function and significance is needed. In Gnctum, on the other hand, either no prethallium is formed but the embryo-sac becomes filled with protoplasm in which are numerous nuelei, or a prothallium is developed in the lower portion of the embryo-sae while the upper portion contains protoplasm with free nuclei. Each of the two generative cells from the pollen-tube fuses with a female nucleus. Of all the fertilised cells resulting from the penetration of a number of pollentubes to the embryo-sae only one develops into an embryo (Fig. 470). 
The micnospones of Angiosperms ("1) before they are shed from the pollen-sac form an antheridial mother-cell (Fig. $471 \mathrm{~m}$ ) which is elearly delimited from the large pollen-tube cell, but is not enelosed by a cell wall. When the pollen-grain germinates on the stigma the antheridial cell passes into the pollen-tube, and its nucleus sooner or later divides into two generative nuelei which lie free in the protoplasm within the pollen-tube. They are of an elongated oval or ellipsoidal sliape and pass one after another down the pollen-tube. The nucleus of the pollentube $(k)$ is usually visible in the neighbourlood of the generative nuclei. The absence of the small prothallial cells, and of a sterile sister-cell of the antheridium,

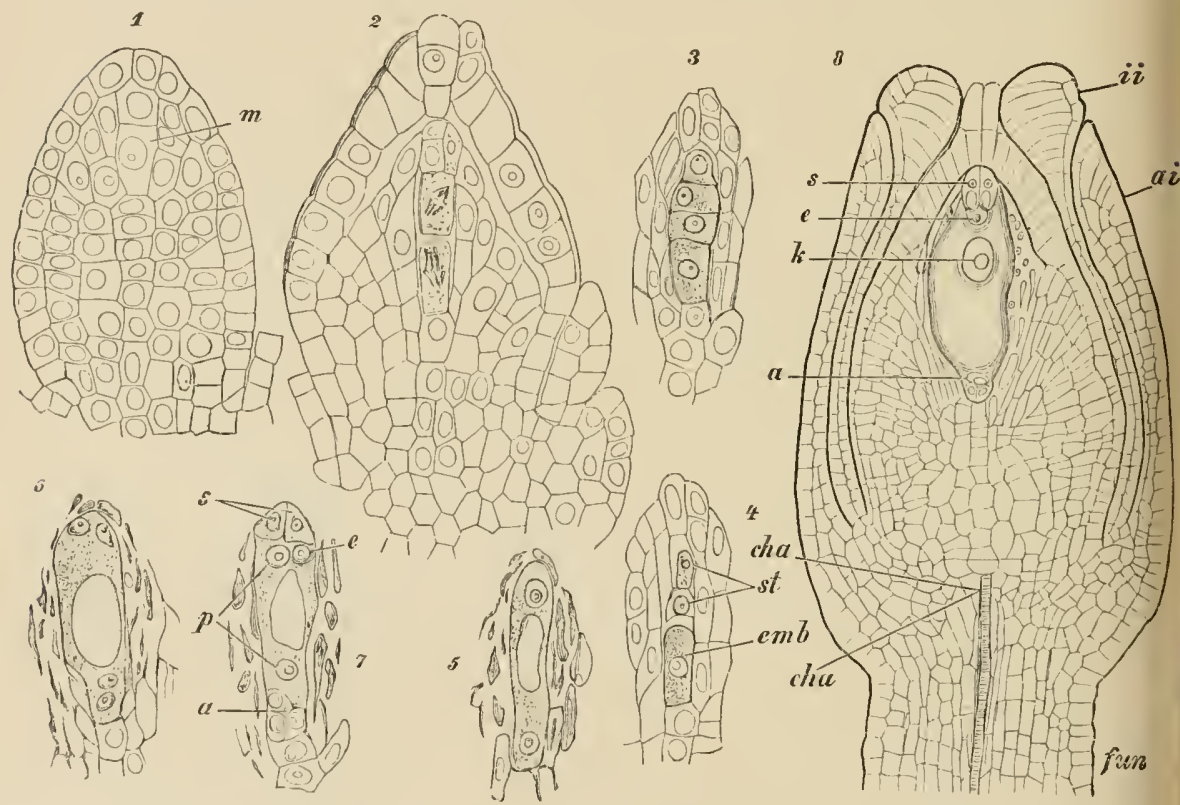

Fio. 472.-Development of the embryo-sac in Polygonum divaricatum. $m$, Mother-cell of the embryo-sac; $e m b$, embryo.sac; st, sterile sister-cells; $e$, egg-cell; $s$, synergidae ; $r$, polarnuclei ; $a$, antipodal cells; $k$, secondary nucleus of the embryo-sac; cha, chalaza; $m i$, mieropyle; $a i, i i$, outer and inner integuments; fun, funicnlus. $(I-7 \times 320, \delta \times 135$.

as well as the absence of a cell wall from the mother-cell of the antheridium, and lastly the presence of naked generative nuelei instear of gencrative cells in the pollen-tube, are points in which the Angiosperms differ from Gymnosperms. The resluction of the male prothallium has thus gone so far that only the indispensably necessary parts remain.

The characteristic differences which the Angiosperms show from the general course of development of the maCrospoliaxigium in the Gymnosperms commenee with the eell divisions in the single, functional, maerospore mother-cell resulting from the tetrad division (Fig. 472, 5). The "primary NUCLeUs of the embryosac" divides and the daughter-nuclei sequrate from one another. They divide twice in succession so that eight nuclei are present. After this, cell-formation commences around these nuelei (Fig. 472, 6-8). lioth at the upper or microlylar end of the 
embryo-sac and at the lower end three naked cells are thus formed. The two remaining "POLAR NUCLEI" move towards one another in the middle of the embryo-sac, and fuse to form the "sEconDari nucleus of the embryo-sac." The three cells at the lower end are called the ANTIPODAL CELLS; they correspond to the vegetative prothallial cells, which in Gymnosperms and in Gnetum fill the cavity of the embryo-sac. The three cells at the micropylar end coustitute the EGG-APPARATUS. Two of them are similar and are termed the syaErgids, whils

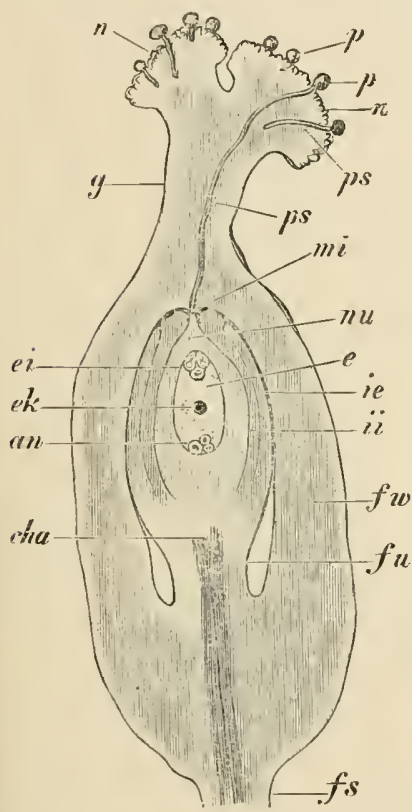

Fig. 473.-Ovary of Polygonum Convolvulus during fertilisation. $f s$, Stalklike base of ovary ; $f u$, funiculus; cha, chalaza ; $n u$, nucellus ; mi, micropyle; $i$, inner, $i e$, outer integument; $e$, embryo-sac; ek, nucleus of embryosac ; ei, egg-apparatus ; an, antiporlal cells ; $g$, style; $n$, stigna; $p$, pollen. grains; $p s$, pollen-tubes. $(\times 48$.

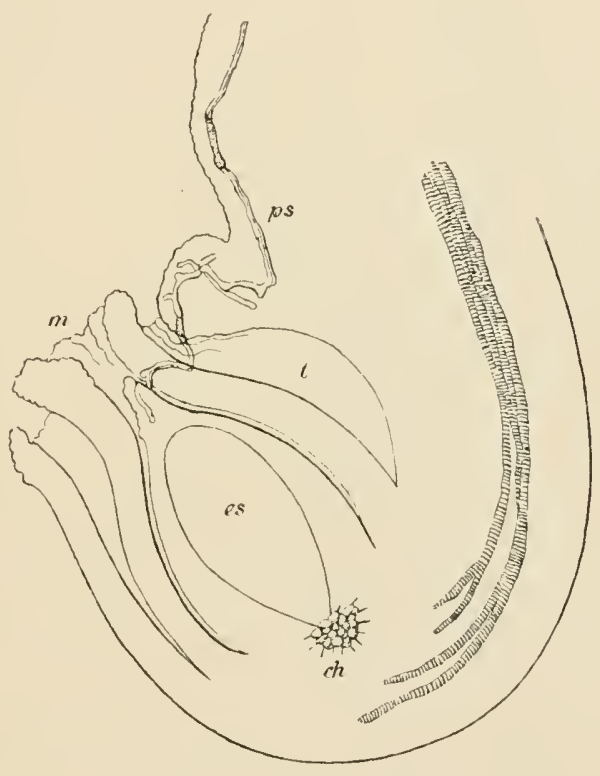

Fio. 474.-Ovule of Ulmus perlunculata. es, Embryosac ; $m$, micropyle; $c h$, chalaza ; $t$, pocket-like space between the integuments. The pollen-tube, $p$, pene. trates directly through the two integuments and reaches the apex of the nucellus. (After Nawascuns.)

the third, which projects farther into the cavity, is the EGG-CELL or ovUs itself. The synergidae assist in the passage of the contents of the pollen-tube into the embryo-sac. Here also the process of reduction has gone as far as possible; in place of the more or less numerous archegonia of the gymnospermons macrospore only a single egg-cell is present. The significance of the synergidae is difficult to determine unless they are regarded as archegonia which have become sterile.

The microspores, which cannot reach the macrospore directly, germinate on the stigma (Fig. 474). The pollen-tube penetrates for the length of the style, and as a rule the tip enters the micropyle of an ovmle and so reaches the apex of the nucellns. Of late years a number of exceptions to this usual course have become 
known. Treus first showed in Casuarina that the pollen-tube entered the ovule by way of the chalaza, and thus reached the peenliar sporogenous tissue, whieh in this ease develops a number of maerospores or embryo-sacs. CHAlAzogamy, as this mode of fertilisation is termed in contrast to PorogAmy, has no special systematic significanee, since it is found to oceur in mumerous plants. Nawaschis espeeially has established an almost eomplete series of forms whieh exhibit parallel transition from ehalazogamy to porogamy (Casuarinaeeae, Jnglandaceae, Betnlaceae, Umaceae) (Figs. 473-475). WETTSTEIN has more recently supported this view and sought to explain it on biologieal grounds. That higher series of Angiosperms sometimes

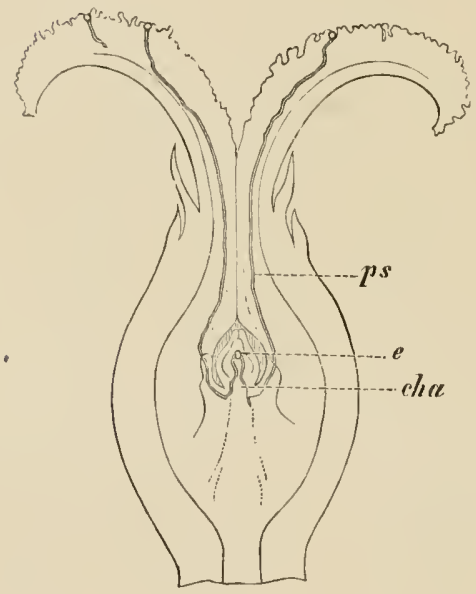

Fid. 475.-Longitudinal seetion of an ovary of Juglans regia to show the ehalazogamy. $p s$, Pollen-tube ; e, embryo-sac ; cha, ehalaza. (Somewliat diagrammatic. $\times 6$.)

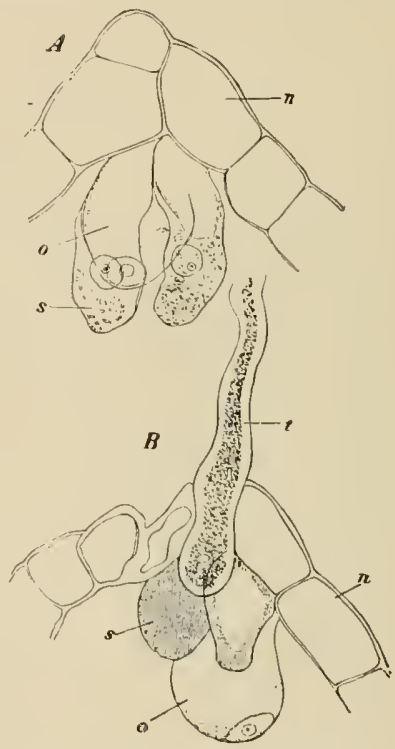

F10. 476.-Funkia ovatu. Apex of nueellus, showing part of embryo-sac and eggalyaratus. $A$, Before, $B$, during fertilisa. tion ; 0 , egg-eell ; $s$, synergidr ; $t$, pollentube; $n$, nucellus. $(\times 390$.

revert to chalazogamy is to be compared with the loss of other eharaeters in angiospermie flowers, and does not by itself diseredit the developmental series reeognised above.

When the pollen-tube, containing the two generative eells, has reaehed the embryo-sae, its eontents eseape and pass by way of one of the synergidx to the ovmm; the corresponding synergida then dies. One of the two generative nuelei fuses with the nuclens of the ovmm, which then beeomes surrounded by a eellulose wall. The seeond generative uneleus passes the ovmm and unites with the large seeonlary nueleus of the embryo-sae to form the Exwosperm Nucheus (Figs. 476-478). lioth the male nuelei are often spirally enrved like a corkserew, and Nawascuin, who first demonstrated the behaviour of the second generative nucleus, eompares them to the spermatozoids of the l'teridophyta. The further development usually commences by the division of the endosperm nuclens, from which a 
large number of nuelei lying in the protoplasm lining the wall of the embryo-sae are derived. The endosperm arises by the formation of cell walls around these nuelei and their proper surrounding protoplasm, and by the inerease in number of the cells thus formed (Fig. 96) to produce a massive tissue.

The distinctive feature of the development of the endosperm in Angiosperms from the prothallus of Gymmosperms lies in the interruption which ocenrs in the process in the case of the endosperm. In the embryo-sae, when ready for fertilisation, only an indication of the prothallus exists in the vegetative, antipodal cells. The true formation of the endosperm is dependent on the further development of the

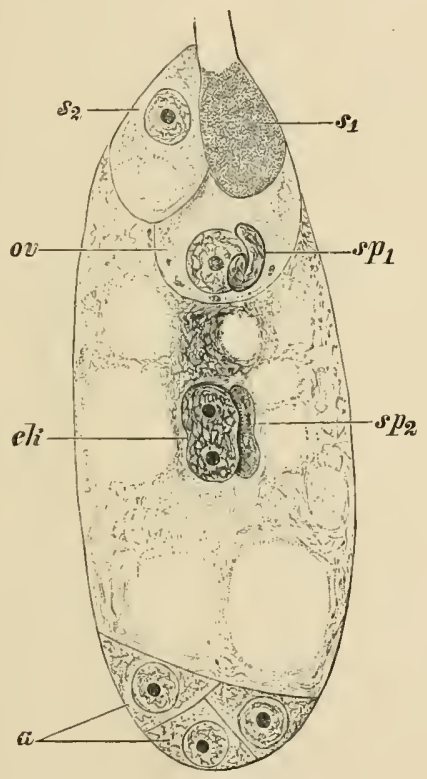

F16. 477.-Fertilisition of Lilium Martagon. One of the male nuclei is close to the nucleus of the orum, the other is in contact with the nuclei of the embryo-sac. (Diagrammatic.)

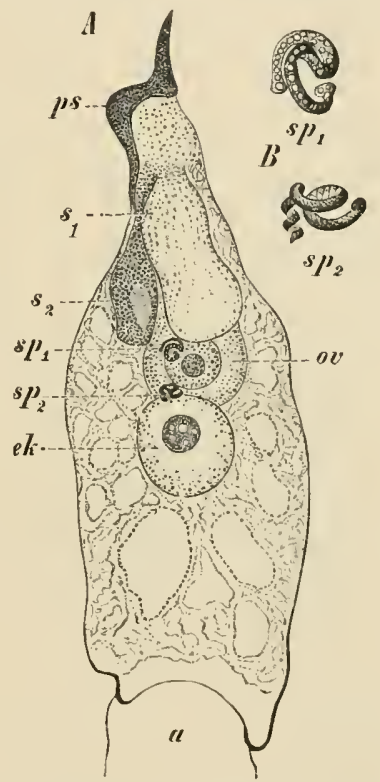

Fig. 478. - A, Embryo-sae of Helianthus annu (after NAwaschis). B, The male nuelei more highly magnified. $p s$, Pollentube ; $s_{1}, s_{2}$, synergidie ; $s p_{1}, s_{2}$, male nuclei ; $o v$, egg.cell; ek, nucleus of embryo-sac ; $a$, antipodal cells.

embryo-sac, and waste of material is thus guarded against. The starting-point of this endosperm-formation is given by the seeondary nuclens of the embryo-sac, which needs to be stimnlated by fusion with the second generative nucleus (1ra) to form the endosperm nucleus, before it enters on active division.

From the fertilised ormm enclosed within its cell wall a PRO-EMBryo consisting of a row of eells is first developed; the end cell of this row gives rise to the greater part of the EMBryo. The rest of the pro-embryo forms the suspexson. Between the embryo and suspensor is a cell known as the uypopursis, which takes a small part in the formation of the lower end of the embryo. The segmentation of the embryo presents differenees aceording to whether the plant belongs to the Monocutyledons or Dieotyledons. iN THE LATTER TWO COTYLENONS ARE ForMEI AT THE END OF THE gRoWING EMBRY (Fig. 479), AND THE GROWING POINT OF 
THE SHOOT ORIGINATES AT THE BASE OF THE DEPRESSION BETWEEN THEM. MoNocotrleDoNs, ON THE OTHER HAND, HAVE A SINGLE LARGE TERMINAL COTYLEDON, THE GROWING POINT BEING SITUATED LATERALLY (Fig. 479 A). In both cases the root is formed from the end of the embryo which is directed towards the micropyle; its limits can be readily traced in older embryos, and it can be seen that a few cells are derived from the hypophysis adjoining the embryonic cell. After fertilisation a considerable accmulation of reserve materials is necessa' $y$ in the embryo-sac both for the development of the embryo and for its future nse. It is thus of importance that a means of transfer of these materials should exist. In the simplest cases the endosperm simply enlarges, crushing the surrounding tissues of the nucellus; often the antipodal cells, which are the structures which lie nearest to the chalaza, are entrusted with the function of nourishing the embryo-sac. They then increase in number and sometimes undergo considerable further development. Other portions of the embryo-sac may grow out as long haustoria which sometimes emerge from the micropyle and sometimes
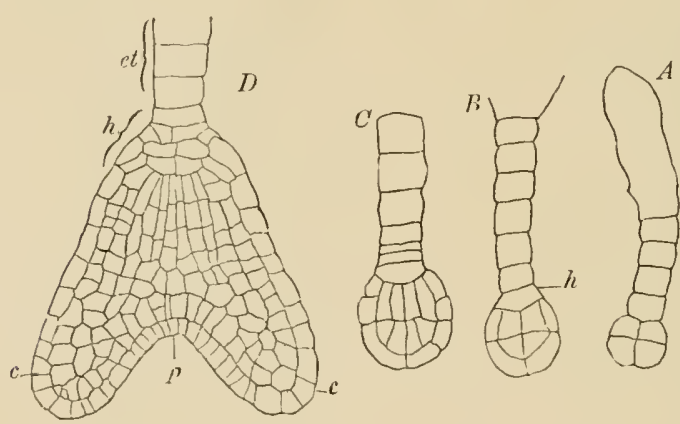

Fig. 479.-Stages in the development of the embryo of Citpsella burso pastoris $(A-D)$. $h$, Hypophysis ; et, suspensor; $c$ cotyledons ; $p$, plumule. (After Hanstein, magnified.)

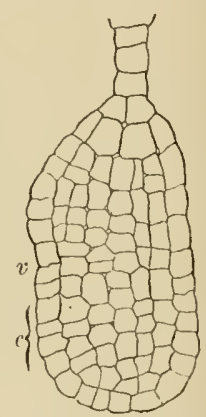

Fig. 479 A.-Young embryo of Alisma Plantago. $c$, Cotyledon ; $v$, growing point. (After Hanstein, magnified.)

penetrate the tissue beneath the chalaza. In some cases (Utricularia) a special store of reserve material is laid up for transference to the macrospore.

The phenomenon of APOGAMY (11a), which has recently been accurately investigated in several Angiosperms, must be considered here (cf. p. 283). Thorough investigation of the embryology has shown that in these cases we have to do with aprogamy and not, as was first assumed, with parthenogenesis. The reduction in number of the chromosomes $(\Gamma .86)$ is omitted in the development of the embryosac, all the nuclei of which have the vegetative number of chromosomes; they are diploid vegetative nuclei, not haploid generative, and the egg-cell is apogamous and not parthenogenetic. The fact that the loss of sexuality is particularly shown in polymorphic genera such as Alchemilla, Hieracium, Taraxacum, Thalictrum, is explained by STrasbURger as resulting from the excessive mutation which has occurred; in time this, together with continuous crossing of the mutations in varions directions originating from the same species, wonld lead to a considerable weakening of the sexuality, and from this the apogamous reproduction would follow. On the other hand there are extraordinarily polymorphic genera such as Jiose and Rubus which lave only sexual reproduction. According to the investigations of Ostenfeli) and Rosenberg, the genus Hieracium is of special interest, since the 
formation of the embryo within the ovule may commence in very various ways. In most a tetrar formation accompanied by a reduction division takes place, but only some of these ovules are found to have a normal embryo-sac capable of fertilisation ; as a rule this is displaced by a vegetative cell which derelops into an aposporous embryo-sac. In exceptional cases apogamons embryo-sacs are formed. Thus in Hieraeium apoganty and apospory are found in addition to the normal mode of development of the embryo as a result of fertilisation (cf. p. 283). It is noteworthy that these plants of Hieracium in the course of generations may, after a larger or smaller number of apogamous or aposporous embryos have been produced, give rise to descendants which exhibit normal fertilisation.

\section{The Seed}

The entire structure developed from the ovmle after fertilisation is termed the SEED. Every seed consists of the more or less developed EMBRYo developed from the fertilised ovum, the ENDOSPERM surrounding the embryo, and the protective seed-coat. The seed-coat always is derived from the integument or integuments; their cells, by the thickening, suberisation, and lignification of the walls give rise to an effective organ of protection for the dormant young plant within. A special development of the epidermis of the seed into mucilage cells is of frequent occurrence (Quince, Linum, many Cruciferae, species of Plantago, Cuphea, Cobuea, etc.). The mucilage serves as a first means of fixation in the soil and also retains water which is necessary for germination. Such other features of the surface as hairs, prickles, etc., have usually the former function, if they do not stand in relation to the distribution of the seed.

Points of morphological importance in the sced-coat have been referred to in considering the ovule; MICROPYLE, HILUM (=place of attachment to the funicle), and RAPHE. From what was said above (p. 476) it follows that the micropyle and hilum will lie at opposite poles of the seed when the ovule is atropous (Fig. 473). In seeds derived from anatropous ovules (i.e. those in which the funicle lies along one side of the ovule, which is bent round at the chalaza) the hilum and micropyle are close together (Fig. 474). Only seeds of this kind possess a raphe connecting the hilum and chalazal region. Campylotropous ovules develop into seeds resembling those derived from anatropous ovules.

In some cases the function of the seed-coat is modified owing to the protection of the seed or seeds being undertaken by the pericarp; the innermost layers of the latter are developed as sclerotic cells and form the stone of the drupe (cf. p. 520). In snch cases (e.g. Almond, Cherry-Laurel, Cerasus, Piper, etc.), since any special development of the seed-coat is umecessary, it tends to become reduced; its cells do not thicken or modify their walls and the varions layers become simply compressed.

The nutritive tissue in the seeds is developed, as a rule in the case of Gymnosperms, by the time of fertilisation and constitutes the 
prothallium (=endosperm). This fills the embryo-sae and nourishes the embryos, which grow down into it. The surrounding tissue of the nucellus becomes crushed so that the embryo-sae extends to the seedcoat. The cells of the endosperm are packed with reserve materials (starch, fat, proteid) and these are utilised in the further development of the embryo which takes place on germination, usually after a period of rest.

The nutritive tissue in the Angiosperms arises on the other hand after the egg-eell has been fertilised. It is derived from the secondary nucleus of the embryo-sac derived by the fusion of the two polar nuclei. This is stimulated to division after fusion with the second generative nucleus. The nuclei derived by this process of division are distributed in the protoplasm which lines the wall of the embryo-sac, and when a large number has been formed the protoplasm divides to form

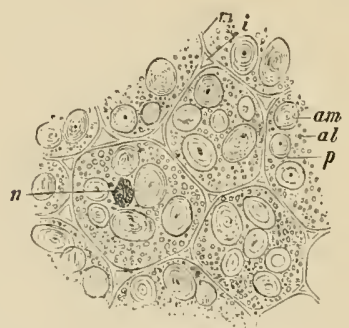

FIG. 4S0.-Part of section through one of the cotyledons of the Pea, showing cells with reserve material. $\iota m$, Stareh grains; $k l$, aleurone grains; $p$, jrotoplasm; $n$, nucleus. $(\times 160$.)

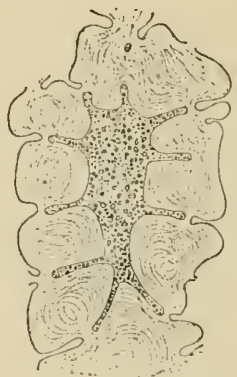

Fra. 4s1.-Cell from the endosperm of Phytelephus mucrocurpu, with reserve cellulose. $(\times 225$.

numerous cells. These by further division fill the whole embryo-sac with the tissue of the endosperm.

Gnetum is the only Gymnosperm in which the process resembles that in Angiosperms. In it after one or more free egg-nuelei has been fertilised the remaining nuclei increase in number and hy a process of free-ccll-formation give rise to the tissue of the endosperm which fills the embryo-sac.

In Angiosperms also the endosperm as a rule compresses the remains of the nucellus. Reserve materials such as starch, fatty oil, and aleurone grains are accumulated in the endosperm cells (Figs. 69, $70, p .67)$; in other cases the greatly thickened walls form a store of reserve-cellulose (Fig. 481). In a few cases, as in Piperaceae, Scitamineae, ete., the nucellus persists and also serves as a nutritive tissue; it is then termed perisperm (Fig. 482). In very many cases, however, not only is the nucellus absorbed by the endosperm, but the latter is completely displaced by the embryo. The reserve materials are then stored $u$ in the cotyledons or in the whole body of the embryo. 
Lastly, a structure known as the ArILLUs must be mentioned, which usually stands in relation to the distribution of the seeds. It

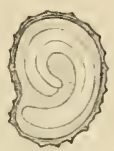

1

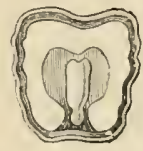

$B$
F1a. 482.-A, Seed of Iyoscyremus niger, slowing the dicotyledonous embryo embedded in the endosperm ; $B$, seed of Elettaria Curdamomum, enveloped by a thin aril; the white, mealy perisperm next to the seed-coat encloses an oleaginous emlosperm (sharled), in which the monocotyledonons embryo lics embedded. (After BERG and ScussidT, )
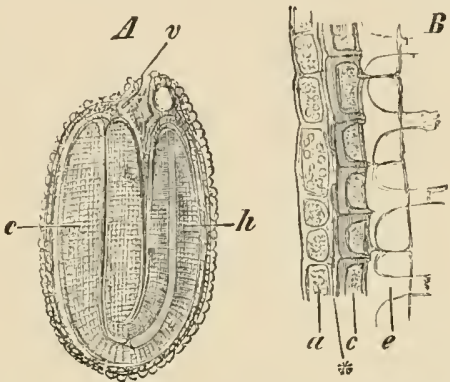

FIf. 483.-Capsrllu burse prestoris. A, Longitudinal section of a ripe seel; $h$, hypocotyl; $c$, cotyledons; $v$, vascular bundle of the funicle $(x 26) ; b$, longituclinal section of the seed-coat after treatment witl water; $e$, the swollen epidermis; $c$, brown, strongly thickened layer; *, compressed layer of cells; $a$, the single persisting layer of endosperm cells containing aleurone grains $(\times 250)$.

arises as a succulent and usually brightly coloured outgrowth from the funicle. It grows up around the ovule and ultimately comes to invest the seed more or less completely (Fig. 485). An outgrowth
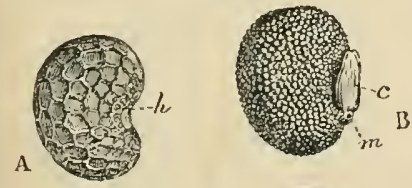

C
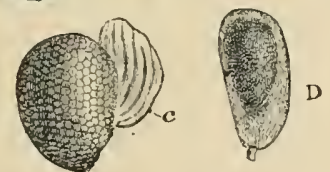

F10. 484.-A, Seed of Papuever Rhoras; $h$, the hilum ; $B$, seed of Corydalis veluro. loura; $m$, micropyle ; $c$, caruncula ; $C$, seed of Chelidonium majus'; $D$, seed of Nymphara albe with its arillus. (After Duchartre.)
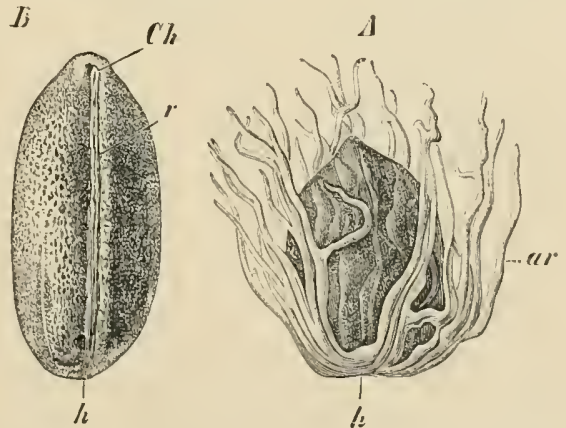

Fig. 485.-A, Myristicn frogrens, seed from which the? arillus (ar) is partly detached $P$, Myristicu argenter, seed after removal of the arillus; $(h$, chalaza; $r$, raphe; $h$, hilum. (After WARBuRs. 3 nat. size.)

in the neighbourhood of the micropyle, which is found in the Euphorbiaceae, is termed a CARUNCULA (Fig. 484).

The effect of fertilisation is not only seen in the macrosporangia but extends to the macrosporophylls or carpels. The structures of 
very various form which are formed from the carpels (often together with the persistent calyx and the floral axis) are called rruiTs, and serve primarily to protect the developing seeds. In Gymnosperms where the ovules are borne freely exposed on the carpels no fruits in the striet sense can exist, since no ovary is present. Thus in Cycas, Ginligo, Laxus, Podocarpus, Gnetum, and. Ephedra we can only speak of seeds and not of fruits. When, however, the carpels after fertilisation close together as in the cones of some Gymnosperms and the berrylike cones of Juniperus, a structure analogous to the angiospermic fruit is formed, and the term fruit may be used.

The Fruit ( $\left.{ }^{12}\right)$. - A great variety in the development of the fruit in Angiosperms night be anticipated from the range in structure of the gynaeceum described above. The product of the individual earpels associated in such apocarpous gynaecea as those of the Rosaceae will here be termed PARTIAL FRUITS or FRUITLETS, while
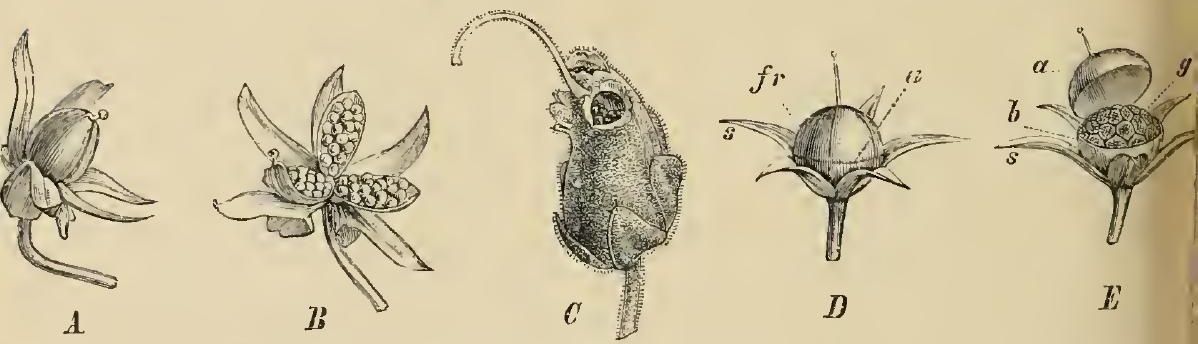

Frs. 486.-Modes of dehiscence of capsular fruits. A, B, Capsule of Viola tricolor before and after the dehiscence; C, poricidal capsule of Antirrhinum majus (magnificd); $D, E$, lyxidium of Anagullis arvensis before and after dehiscence.

the product of the whole gynaeceum will be spoken of as the FRUIT. The hollowed-out or projecting floral axis bearing the carpels may be included in the fruit. In the case of fruits resulting from synearpous gynaecea the further development of the wall of the ovary as the PERICARP has to be especially considered. The outermost, middle, and innermost layers of this are distinguished as EXOCARP, MULSOCARP, and ENDOCARP respectively. Aceording to the nature of the periearp the forms of fruit may be classified as follows:-

1. A fruit with a dry pericarp, which opens when ripe, is termed a CAPSUle (Fig. 486). When dehiscence takes place by a separation of the earpels along their lines of union the capsnle is SEPTICIDAL; when the separate loculi open by means of a longitudinal split, it is termed LOCULICIDAL, and when definite circumseribed openings are formed, it is termed poricidal. As special types of frequent occurrence may be mentioned: The roLLICLE, which is a capsule developed from a single carpel and opening by separation of the ventral suture, e.g. Aconitum napellus (Fig. 563): The I.EgUme or 
pod, which differs from the follicle in dehiscing by both ventral and dorsal situres, e.g. Cytisus Luburnum (Fig. 646): The siliQuA consists of two earpels and typically dehisces at maturity by their separation from a false septum lying in the plane of the sutures. The fruit of the Cruciferae, e.g. Cheiranthus Cheiri (Fig. 582), is of this
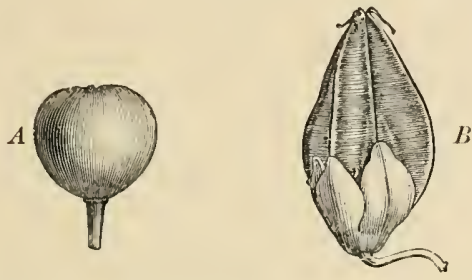

FIG. 487.-Dry indehiscent fruits. A, Nut of Fumaria officinalis $(\times 6)$. I , Achene of Fayopyrum esculentum ( $\times$ 2). (After Duchartre.)

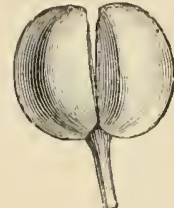

Fic. 488.-Schizocarp of Galium mollugo. (After Duchartre, $\times 6$.

nature. The Pyxidiun opens by the removal of a lid, e.g. Anagallis (Fig. 486 D, E).

2. DRY INDEHISCENT Fruits have a dry pericarp which does not open at maturity. Those with a hard periearp are termed NUTS.

An indeliseeut fruit containing one seed, the eoat of whieh is adherent to the leathery periearp, is known as a caryorsis (e.g. Grasses). When the seed is

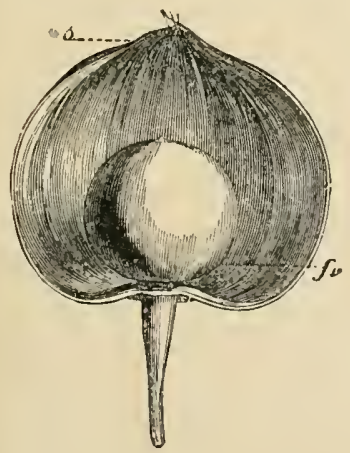

Fia. 459.-Fruit of l'hysulis alkelengi, consisting of the persistent calyx $s$, surrounding the berry $f r$, derived from the ovary. (After Duchartre..)
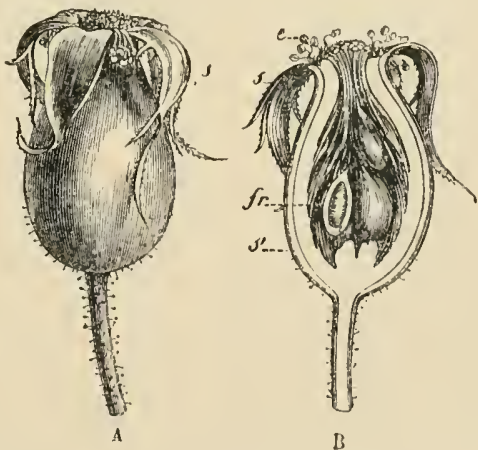

Fia. 490.-Fruit of Rosa albu, consisting of the flesliy hollowed axis $s^{\prime}$, the persistent sepals $s$, and the carpels $f r$. The stamens $e$ have witheres. (After DUChaRTRE.)

distinct from the pericarp, as in the Compositae, Polygonaceae, etc., it is termed an ACHENE (Fig. 487).

3. When a dry fruit, consisting of several carpels, separates at maturity into its partial frrits without the latter opening, it is termed a schizocanP (e.g. Umbelliferae, Malva, Galium, Fig. 488). 
4. A BERRY is a fruit in which all the layers of the pericarp become succulent, as in Vuccinium, Vitis, etc.; when at complete matnrity the succulent tissue dries up a DRY BERRY results (Capsicum). In a few cases berries may be dehiscent, as in Myristica and some Cucurbitaceae.

5. In the DRUPE the pericarp is differentiated into a succulent exocarp and a hard endocarp. Prunus Cerasus (Fig. 631), and Juglens regia (Fig. 516), are familiar examples.

Fruits which do not originate from the ovary alone are found in Rose (Fig. 490), in which the succulent receptacle protects the partial fruits and still bears
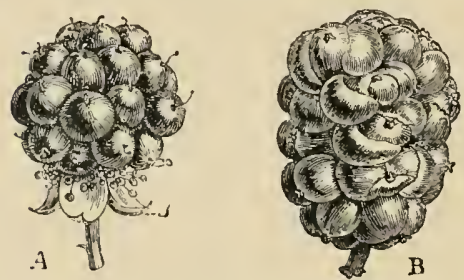

Fic. 491.-A, Merocarpic fruit of Rußus fruticosus, consisting of a number of drupes; $B$, intlorescence of Nlulberry (Morus nigru) bearing a number of small drupes. (After DUCHARTRE.)

The above enumeration of the most important and frequentiy recurring forms of fruit is in no sense cxhanstive. It shonld be added that the varions forms are only to be understood when regarded from an oecological point of view. The form and other peculiarities of the fruit must be considered in relation to the distribntion of the seeds.

\section{Distribution of Seeds $\left({ }^{13}\right)$}

The most important means by which plants compete with others living under the same conditions is to produce as many seeds as possible. With the number of descendants the probability that some at least will succeed is increased. The number of seeds by itself would, however, be of little avail if all the seeds remained in the place of their origin. Thus good arrangements for the distribution of the seeds are of the greatest importance and the form and construction of fruits and seeds exhibit the great influence of this factor.

The same agents are available in the distribution of seeds as in the conveyance of pollen-currents of air and water, animals, and in addition human traffic. A distinction must be made, however, between the conveyance of pollen and of seeds, in that while a pollen grain is extremely small and weighs very little, seeds contain a certain amount of rescrve materials and are thus larger and heavier. In spite of this the transport of seeds by the wind is the main means of their dispersal. 
Often the suitability of seeds for wind-dispersal is due simply to their minute size and their lightness; thus millions of seeds are produced in a capsule of Stanhopen, and the weight of a seed of Dendrobium antennatum has been deternined by BECCARI to be about $\frac{1}{20}$ milligramme. The strongly hygroscopic pericarp and the elater-like hair's assist in dividing up the mass of seeds so that the latter are isolated, and this favonrs dispersal by the wind. Thus these orehids play a part as epiplyytes in damp tropical forests only equalled by Ferns, the spores of which are as light. A much more common arrangement is found in heavier seeds when the volume is increased and a large surface is offered to the wind. Either the whole surface of the seed bears longer or shorter hairs as in the Willow (Fig. 529), Poplar (Fig. 530), and Cotton (Fig. 597), or a longer tuft of hairs is borne at one end as in the Asclepiadaceae and Apocynaceae (Strophanthus, Fig. 683), many Gesneriaceae and Bromeliaceae and the fuits of Typhaceae, Eriophorum (Fig. 745) and Anemone (Fig. 560). The same use is served by the crown of hairs (pappus) which is developed at the upper end of one-seeded fruits such as those of Valerianaceae (Fig. 717) and Compositae (Figs. 731, 737), especially when it has

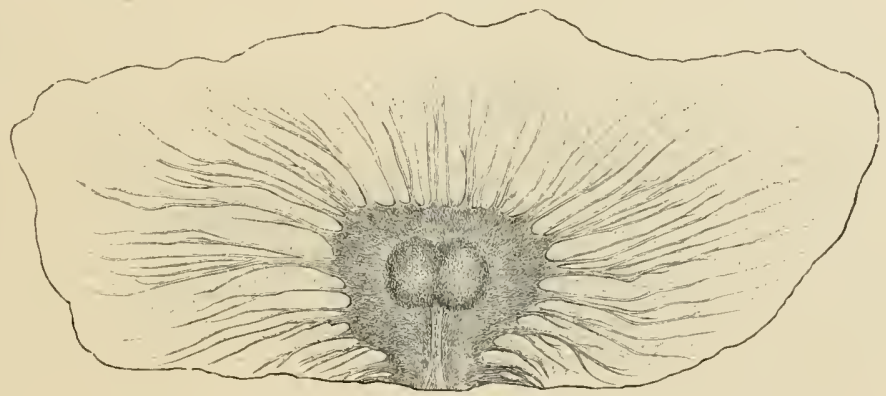

FIa. 492.-Winged seed of Pithecoctenium echinutum. (Nat. size.)

a parachute-like form due to the later elongation of the upper end of the fruit as in Taraxacum (Fig. 732), Tragopogon, etc. An equally frequent arrangement in other families of plants is the development of a flat wing formed of a thin and light menbrane. This in our Firs (Fig. 509) and Pines (Fig. 510) is split off from the ovuliferous scale, while in Rhododendron, Bignoniaceae, some Cucurbitaceae (Zunonia), and in the Rubiaceae (Cinchone, Fig. 711) it develops on each seed within the ovary. In no ease is it more perfect than in Pithccoctenium echinatum (Fig. 492) when the delicate silky wing leads to the falling seed assuming an almost horizontal position and being carried far even by a slight breeze.

Other parts of the flower or fruit may be developed as wings, espeeially when one-seeded fruits (or schizocarps) are concerned. Examples of this are afforded by the sepals of the Dipterocarpaccae (either two, which are then much larger than the others, or all five as in Dryobalanops), the large bract of the inflorescence of the Lime (Fig. 599), the bract and bracteoles of Carpinus (Fig. 521) and more commonly the wall of the ovary as in Betula (Fig. 519), Alnus (Fig. 517), Ulmus (Fig. 531), Polygonaceae (Fig. 547), Aeer (Fig. 616), Fruxinus (Fig. 675), ete. Aceording to Dingler the fall in ail as compared with that in a vacuum in the first second is six times slower in the ease of the fruits of Cynare Scolymus provided with scaly hairs; in Pinus sylvesuris the fall is seven times and in Pithccocteninu thirty tines slower. 
The distribution of seeds and fruits by ocean currents is important for many plants. The strand-flora of the Malayan Archipelago, for example, consists, according to Schimper's investigations, exchsively of plants with floating fruits or seeds the adaptations of which correspond more or less to those of the Coco-nut which is distributed everywhere on tropical coasts. A thick exoearp consisting of a coarsely fibrous tissue renders the fruit buoyant and protects the brittle and stony endocarp from being broken against the rocks and stones of the shore. A very similar structure is exhibited by species of Barringtonia, Cerbera Odollam (Fig. 493), Terminalia catappa, Nipa fruticans, and many smaller plants belonging to the shrubby and herbaceous vegetation of the dunes and strand. Others have large air-spaces in the pericarp or seed-coat, which being protected from the entrance

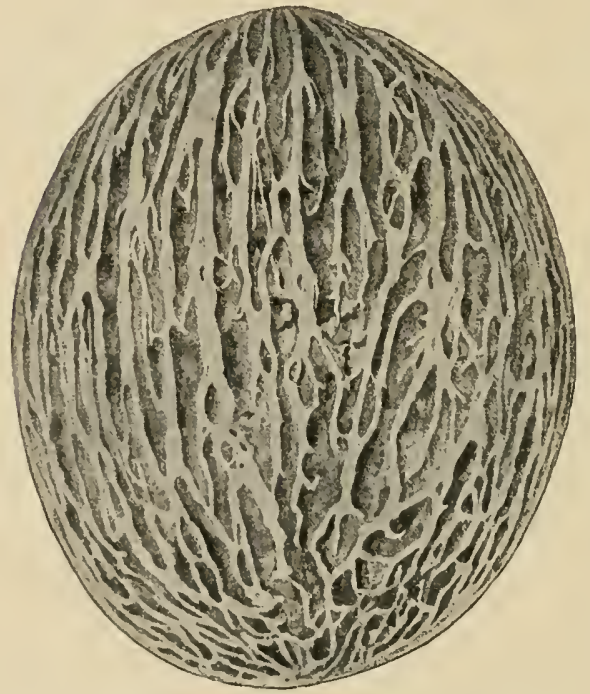

FIG. 493.-Fruit of Certera Odollum, from the drift. The succulent endocarp is wanting, so that the buoyant tissue traversed by coarse tibrous strands is exposed. (After SCHMPER.) of water, serve as swimmingbladders. In all cases the capacity of floating for a long time is a condition of the dis. tribution of the seeds and the suceess of the species.

The distribution of fruits and seeds by means of animals depends as a rule upon the succulent and attractive fruits serving as food for birds, the undigested seeds being shed. A familiar example is alforded by the Elder (Sambucus nigra), the black fruits of which are eaten by various birds in summer. There are many such cases and for some seeds the passage throngh the intestine of the animal appears to be a necessary preliminary to germination. The development of an arillus (cf. p. 517) is in many cases an adaptation to distribute the seed by means of animals. The arillns of Taxus with its bright red colour surrounds the single seed, which is not poisonous and is greedily eaten by blackbirds; the red fruits of Euonymus when they open expose fonr seeds with bright red arilli, which are eaten by chaffinches. The Nutmeg is distributed over the islands about the Moluccas by a large pigeon which is attracted by the bright red arillus around the black seed which is exposed on the dehiscence of the fruit. In a similar way our Mistletoe in winter, when little other food can be obtained, is eaten by blackbirds and other birds; when the birds elean their beaks the seeds remain attached to the branches by reason of the viseid substance aromd them and are able to germinate in this position. Since germination does not occur in other situations the viseid fruits of this plant are indispensable to its success.

The spread of plants with hooked fruits, etc., such as Galium aparine, speeies of Luppu, Budens, Xanthium, etc., by means of the fur of quadrupeds, the general 
distribution of water-plants from one pond to another by aquatic birds, and the distribution of the Hazel-nut, ete., by means of squirrels do not require detailed deseription.

It is a matter of general knowledge that man by his commerce and industry has exerted great inlluence on the distribution of food-plants and other plants of economic value. With these the seeds of many weeds have been unintentionally distributed over the inhabited earth, a fact that conld be illnstrated by numerons examples.

The active movements of plants by which their seeds or spores are forcibly ejected, whether these movements are due to cohesion, turgescence, or are hygroscopic, have been already discussed (cf. p. 296).

\section{Germination}

Seeds which have escaped the varions risks of distribution require to be soon covered with soil. Small seeds readily find shelter in cracks or depressions of the soil and become fixed there owing to special properties of their surface. Larger seeds are sufficiently covered by fallen leaves. The fruitlets of Erodium and other Geraniaceae, of Avenu sterilis, species of Stipa and other Gramineae penetrate the soil by the aid of their hygroseopic enrvatures; the presence on their surface of backwardly directed hairs prevents their losing the position reached. The burial of the fruits of Arachis hypogaea, Trifolium subterraneum and Okenia hypoguea is brought about by the growth of their positively geotropie stalks, while negative heliotropism determines the insertion of the fruits of Linaria cymbalaric into the crevices of the walls on which the plant lives.

When the seeds find sufficient moisture they swell considerably. With this they lose some of their resistance to such dangers as extremes of temperature and dessication; their former resistance was due to the small proportion of water they contained. The next step is the rupture of the seed-coat, which is effected by the emerging root, less frequently, as in some Monocotyledons, by the cotyledon. The root at once bends downwards geotropically and by means of its roothairs, which are especially long and numerous at the junction of the root and hypocotyl, fastens the seedling in the soil. Meanwhile the hypocotyl grows and gradually emerges from the seed-coat, while the cotyledons as a rule remain for a time enclosed in the latter and absorb the remainder of the reserve material (Fig. 494 a). This process leads to the hypocotyl becoming more and more strongly curved and the tension resulting from its further growth withdraws the cotyledons from the seed-coat. The seedling then becomes erect, the leaves are expanded and can assimilate, and thus its independent life commences.

This most frequent type of germination is characterised by the eotyledons being expanded a'sove ground and is termed EPIGEAL. It is nearly always found in the case of small seeds. Further details 
cannot be given, but it may be mentioned that the germination of most Grmuosperms is epigeal, but that the number of cotyledons may amount to 6-10 (Pinus).

HYPOGEAL germination is for the most part found in large-seeded Dicotyledons, the cotyledons of which contain the stored reserve

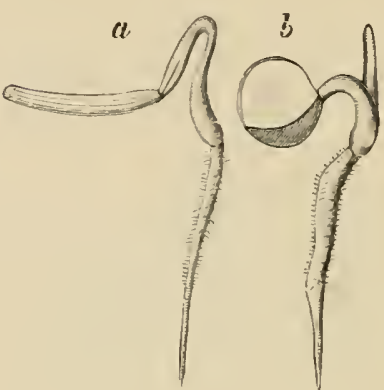

Fic, 494. - Seedlings, $a$, of Scorzonere humilis; $b$, of Iris pseulecurus. (After liLEPS.)

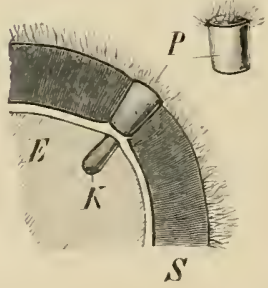

Fig. 495. - Section tlurongh the npper part of the fruit of Aerncomia sclerocarpa. S, The hard shell; $P$, the plug which is pushed out of the shell by the germinating embryo, $K$; $E$, endosperm. (After l'ritzer.)

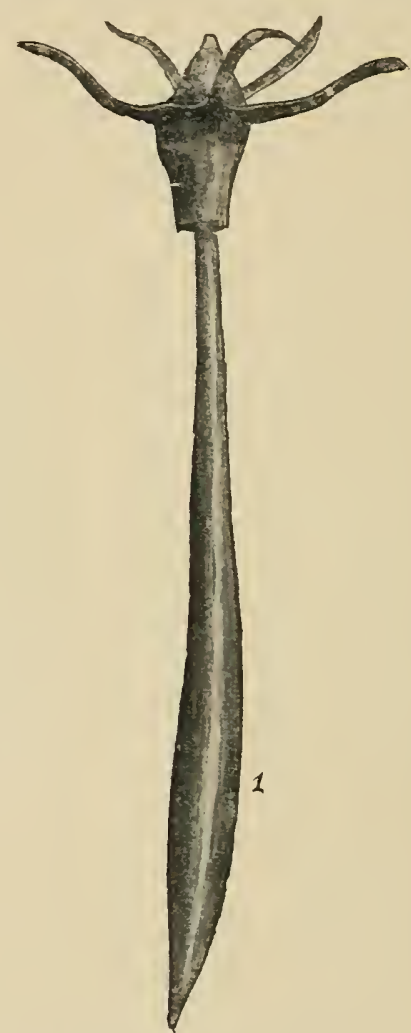

Fir. 496, - Kandelia Thedii. The massive root of the seedling (1) has broken out of the fruit. When the Ilant separates from the fruit the ront will become inserted into the muddy soil. (After Scmistren's Plent-Geograplly.)

materials (e.g. Vicin fubo, Pisum, Aesculus, Juglens, ete.). It is characterised by the cotylerlons remaining enclosed in the seed-coat after the root has penetrated into the soil ; the epicotyledonary stem emerges from between the cotyledons, becomes erect and bears the later leaves in the usual way. While there is a sharp morphological distinction between the two types of germination, the difference is of little systematic value; within the Papilionaceae many intermediate conditions 
are found, and in the genus Phaseolus, $P h$. vulgaris is epigeal and $P h$. multiflorus hypogeal.

The germination of monocotyledonous sceds differs from the cases described above in that after the main root has emerged-sometimes before this - the sheathing base of the larger or smaller cotyledon emerges from the seed. Its tip remains either for a time or permanently in the seed, and serves as an absorbent organ to convey the reserve materials stored in the endosperm to the seedling. The first leaf of the latter soon emerges from the sheathing base of the cotyledon (Fig. 494). Individual peculiarities cannot be described here, but it may be mentioned that very hard seed-coats are often provided with special arrangements to enable the root to escape. Thus in the coco-nut three openings are present, one corresponding to each earpel. The opening behind which the tip of the root of the single embryo is situated, is covered by a very thin layer, while the two other openings are firmly closed. The hard stony seed-coat of another Palm (Acrocomia sclerocarpa) (Fig. 495) has a loosely fastened plug opposite the tip of the root. In the whole family of the Scitamineae there is a limited thinner region of the hard seed-coat above the root-tip of the embryo, which is lifted up as a sort of lid on germination.

The so-called "viviparous" plants show peculiar arrangements which can only be briefly mentioned here. Vivipary $\left({ }^{15}\right)$ is found exclusively in the inhabitants of tropical mangrove-swamps and is to be regarded as an oecological adaptation to the conditions of life. The one-seeded fruits germinate while still attached to the parent plant, i.e. the pericarp is ruptured by the radicle of the embryo which first grows from the micropylar end of the seed. The hypocotyl which thus becomes free may attain the length of over 1 metre in Rhizophora. This swells somewhat in the lower part, and the embryo thus hangs by its absorbent cotyledons which remain in the seed, until it separates from the plant owing to its own weight, and, falling vertically, sticks into the soft mud. The various genera of Rhizophoraceae (Figs. 496, 653) and the biologically similar Avicennia, Aegiceres, and Carapes show various degrees of vivipary. One of the smallest examples from the family of the Rhizoploraceae is represented in Fig. 496.

\section{SPECIAL PART $\left({ }^{16}\right)$}

\section{Arrangement of Classes, Orders, and Families}

It has been mentioned in the introductory portion of this section, and again in speaking of the floral relations and the developmental history of the sexual generation, that the Gymmosperms are phylogenetically more ancient than the Angiosperms. For this reason the Gymnosperms are placed first. The long-disputed question as to whether the Monocotyledons or Dicotyledons are the more primitive is perhaps settled by the durivation of the Monocotyledons from the Polycarpicae among the Dicotyledons; these exhibit features of agree- 
ment with Monocotyledons in floral construction, anatomical structure, and in morphological characters. On this account the Monocotyledons will be placed after the Dicotyledons in the following systematic arrangement.

Any direct transition from Gymnosperms to Monocotyledons is thus out of the question while a relation of dicotyledonous plants to Gymnosperms is not excluded. The best solution of this problem at present is that of rON WETTSTEIN who derives the simplest angiospermic flowers from a gymnospermous inflorescence. If the systematic arrangement of the Dicotyledonsis based on this idea the most simply constructed flowers would be those with one whorl of perianth segments and borne in catkins. This assumption is supported by developmental evidence. Thus the Casuarinaceae, Juglandaceae, Betulaceae, Ulmaceae, etc., will be placed at the beginning of the system, and to them will be connected the other families with a simple perianth which are grouped together as Monochlamydeae. To these in turn may be connected the Dialypetalac, the flowers of which have both calyx and corolla. The forms with a gamopetalous corolla are separated as the Sympetalae, and the other Monochlamydeae and Dialypetalae contrasted with them as Choripetalae; the forms without perianth are grouped with the Choripetalae. Since within the Monochlamydeae various lines lead from forms with a simple perianth to those with a pentacyclic structure, any arrangement in a simple ascending series is impossible. Various parallel series lead from simple to highly organised floral structure, and similarly numerous parallel series are found in the Dialypetalae. Thus the natural or phylogenetic relationships can only be exhibited in an incomplete fashion in the following arrangement $\left({ }^{11 i}\right)$.

\section{Class I. Gymnospermae}

1. Cycadinae: Fam. Cyeadaceae.

2. Ginkgoinac: Fam. Ginkgoaceae.

3. Coniferae: Fam. Taxaceae, Pinaceae.

4. Anctinae: Fam. Gnetaceae.

\section{Class II. Angiospermae}

Sub-Class 1. Dicotylae

Series 1. Choripetalae

A. Monochlamydcac

1. Verticillatce : Fam. Casmarinaceae.

2. Fuglantiflorae: Fam. Iuglandaceae. Myricaceac.

3. Quereiflorae: Fam. Betulaceac. Cupuliferae.

4. Saliciflorae: Fam. Salicaceae.

5. Urticinae: Fam. Ulmaceae. Moraceac. Cannabinaceac. Urticaceae.

6. Loranthiflorce : Fam. Santalacear, Loranthaceae, Balanophoraceae. 
7. Piprerinae: Fam. Piperaceae.

8. Hamamelidinae: Fam. Hamamelidaceae. Platanaceae.

9. Tricocce: Fam. Euphorbiaceae. Buxaceae.

10. Centrospermae: Fam. Polygonaceae. Chenopodiacea. Caryophyllaceae. Cactaceae.

\section{Dialypetaleae}

11. Polycarpicae: Fam. Nympliacaceae. Ceratophyllaceac. Rannnerilaceae. Magnoliaceae. Anonaceae. Myristicaceae. Menispermaceae. Berberidaceae. Lauraceae. Cephalotaceae. Sarraceniaceae. Nepenthaceac. Droseraceae. Aristolochiaceae. Rafflesiaceae.

12. Rhoeadinae: Fam. Papaveraceae. Cruciferae. Capparidaceae. Resedaceae.

13. Cistiflorae: Fam. Cistaccae. Violaceae. Ternstroemiaceae. Guttiferac. Dipterocarpaceae.

14. Columniferae: Fam. Malvaceae. Tiliaceae. Sterculiaceac.

15. Gruinales : Fam. Geraniaceae. Tropaeolaceae. Oxalidaceae. Linaccae. Balsaminaceae. Erythroxylaceae. Zygophyllaceae. Rutaceae. Simarubaceae. Burseraceae. Polygalaceae.

16. Sapindinae: Fam. Anacardiaceae. Aquifoliaceae. Celastraccae. Aceraceac. Sapindaceae. Hippocastanaceae.

17. Frongulinae: Fam. Rliamnaceae. Vitaceae.

18. Saxifraginae: Fam. Crassulaceae. Saxifragaceae.

19. Rositlorac: Fam. Rosaceae.

20. Leguminosae: Fam. Mimosaceae. Caesalpiniaceae. Papilionaceae.

21. Passiflorinae: Fam. Passifloraceae. Caricaceae. Begoniaceae.

22. Thymelaeinae: Fam. Thymelaeaceae. Elaeagnaceae.

23. Myrtiflorae: Fam. Lythraceae. Melastomaceae. Onagraceae. Halorrhagidaceae. Rhizophoraceae. Combretaceae. Myrtaceae. Punicaccae.

24. Umbelliflorae: Fam. Cornaceae. Araliaceae. Umbelliferac.

(a) Pentacyelieae.

Series 2. Sympetalae

1. Ericinae: Fam. Ericaceac. Pirolaceae.

2. Diospyrinae: Fam. Sapotaceae. Ebenaceae. Styracaceac.

3. Primulinae: Fam. Primulaceae.

( $\beta$ ) Tetracyclicae.

4. Contortae: Fan. Oleaceae. Loganiaceae. Gentianaceae. Apocynaceae. Asclepiadaceae.

5. Tubiflorae: Fam. Convolvulaceac. Polemoniaceae. Hydrophyllaceae. Boraginaceae. Verbenaceae. Labiatae.

6. Personatre: Fam. Solanaceae. Scrophulariaceac. Orobanchaceae. Bignoniaceae. Gesneriaceae. Lentibulariaceae. Acanthaceae. Plantaginaceae.

7. Rubiinae: Fam. Rubiaceae. Caprifoliaceae. Valerianaceae.

8. Campanulinae: Fam. Campanulaceae. Lobeliaceae. Cucurbitaceae.

9. Aggregatce: Fam. Dipsacaceae. Compositae.

\section{Sub-Class 2. Monocotylae}

1. Helobice: Fam. Alismaceae. Juncaginaceae. Potamogetonaceae. Naiadaceac. Hydrocharitaceae.

2. Glumiflorce : Fam. Cyperaceae. Gramineae.

3. Spadiciforae: Fam. Typlaseae. Sparganiaceae. Pandanaceae. Palmae. Araceae. Lemnaceae. 
Cycas is a native of Asia ; Hacrozumie and Bowcnia of Anstralia. Encephalartos and stangerio are African, while America has the genera Dioon, Ceratoanict, Zamia, and Licrocyces.

The stem, which undergoes secondary growth in thickness, is as a rule unbranched and bears large, pinnate foliage leaves. These, which are of

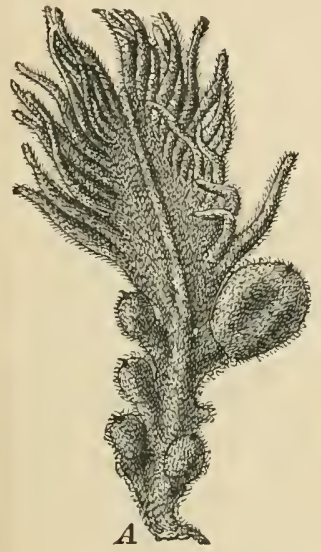

Fia. 498. - Carpel of Cyeas revolute. (After SAcHs, re. duced,) firm leathery texture and persist for a number of years, alternate with smaller scale-leaves and form a large terminal crown. The surface of the cylindrical or tuberons stem is clothed with the scalc-leaves and the bases of the old foliage leaves. Mucilage ducts are present in all parts of the plant. 'The vascular bundles are eollateral but their xylem consists of tracheides only.

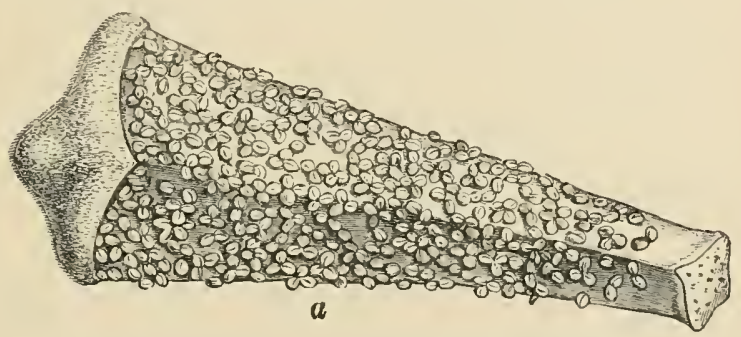

FIG. 449.-Stamen of Cycas circinalis, from below. (After Richard.)

The Cycadaceae are dioecious. Fig. 497 represents a female plant of Cycas recolute, in which the growing point forms alternate zones of foliage leaves and macrosporophylls. When young the foliage leaves are rolled up circinately as in the Ferns. One of the sporophylls is represented in detail in Fig. 498. It shows the pinnate form of the foliage leaf, but is densely covered with hairs, and chlorophyll is wanting. Towards the base two to eight macrosporangia are borne on the margins. It is evident that each female plant of Cycus which has reached the flowering condition exhibits a regular succession of flowering and vegetative periods. The flower represented by the group of sporophylls is always grown through by the further development of the apex which does not branch. The male plant of Cycas

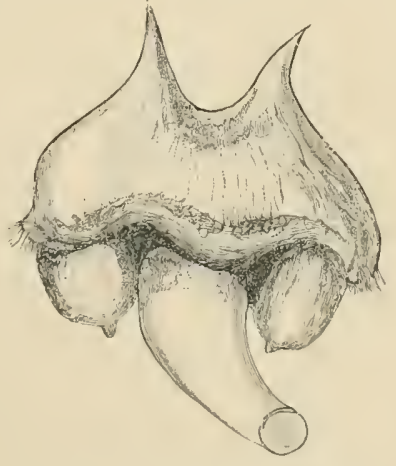

Fig. 500,--Ceratozumia robusta. Maerosporophyll with two macrosporangia. (After Gotbei.) and of the other Cycarlaceac bear their sporophylls in terminal cones often of great size, while the further growth of the plant is effeeted 
by a lateral bud which continues the direction of growth of the sympodial axis, displacing the cone to one side.

The cones consist of numerous sporophylls arranged spirally on the axis. The microsporophylls bear large numbers of microsporangia on the lower surface (Fig. 499). The macrosporophylls of the conebearing Cycadaceae are considerably modified as compared with Cycus, and each bears two marginal macrosporangia (Fig. 500); only in Stangeria are the macrosporangia situated on the lower surface. For the developmental history of. p. 507.

\section{Order 2. Ginkgoinae}

The single representative of the Family of the Ginkgoaceae whieh forms this order is Ginkyo bilobo. This tree comes from Japan but is often seen in cultivation in Europe. The long-stalked leaves are divided diehotomously into two or more

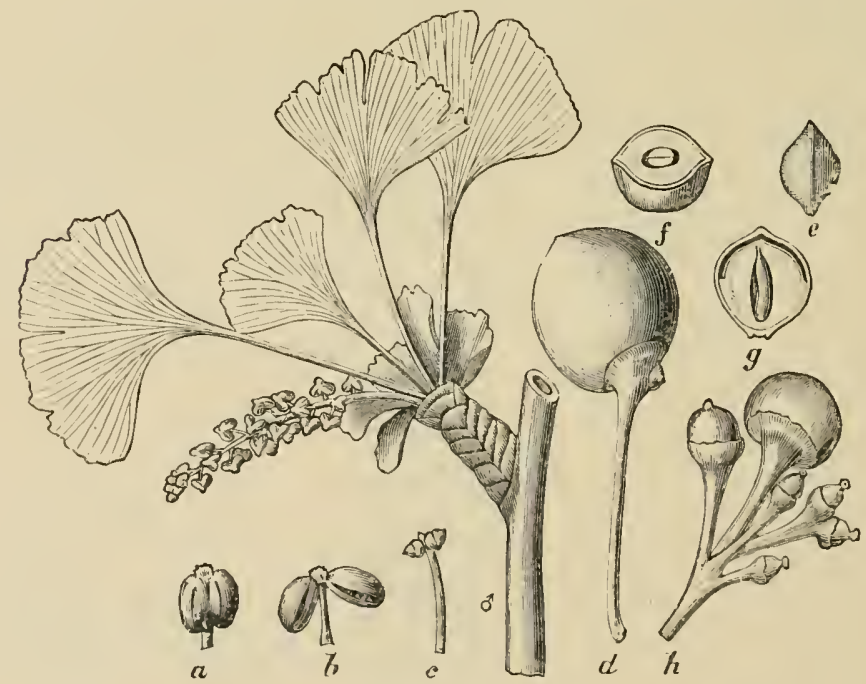

Fui. 501.-Ginligo bilobu. Male branch with flower; the leaves are not yet full growu. $a, b$, Stamens; $e$, fenale Hower; $d$, fruit; $e$, stone of same; $f$, stone in eross section; $g$, in longitulinal section showing the embryo; $h$, female flower with an exceptionally large number of ovules borne on separate stall:s. (Male flower and $c$, nat. size; $d$, slightly reclucel; the other ligures magnifiel. After RicuARD; a-d after EıcuLEK.)

lobes and are shed annully. The flowers are dioecious. The numerons stamens are situated on an elongated axis whieh bears no enveloping leaves. Mierosporangia with an "endothecium" (ef. 1) 483). Macrosporangia in pairs at the summit of short shoots; sporophylls reduced to a collar-like ontgrowth around the base of the sporangrim (Fig. 501). Developmental history cf. p. 508. 


\section{Order 3. Coniferae $\left({ }^{19}\right)$}

The Coniferae include conspicuous trees or shrubs with woody stems. The possession of small, undivided, firm leaves, flat or needleshaped, and usually lasting for several seasons, is a common character of the plants of the order; they are thus for the most part evergreen. All Conifers are profusely branched, and a distinction into long and short shoots is usually evident. In many cases the direction and rapidity of growth of the main axis differs from that of the lateral branches. This is especially seen in young individuals; old trees are often more irregular in outline.

The absence of vessels from the xylem of young plants and from the secondary wood is an anatomical characteristic (cf. p. 144). Their place is taken by large tracheides with peculiar bordered pits on the radial walls; these form a very uniform wood. The majority of the Coniferae have resin abundantly present in all the parts of the plant.

The Coniferae in contrast to the Cycadinae are mostly inhabitants of temperate regions, and are among the trees which approach nearest to the polar regions. Within the tropics they are mostly confined to moluntains.

The Coniferae are divided into two families on account of differences in the floral structure.

The Taxaceae have female flowers with one or fow macrosporangia ; the latter are nsually provided with an arillus. The flowers are usually not definite cones. Mostly dioecious.

The Pinaceae on the other hand have a number of ovules in each female flower, the latter being a cone with numerous sporophylls borne on an axis. Arillus not present; usually monoecions.

Family Taxaceae. - The plants belonging to this family are gronped in a number of small genera distributed in the southern hemisphere. The most important genus is Podocarpus, the mumerous species of which are widely distributed in temperate East Asia and in Australia and New Zealand, and also occur as stately trees on the mountains of the Asiatic tropics. The female flowers are small shoots, the sporophylls of which are swollen and succulent; one or two sporophylls bear at the summit a single anatropous ovule surrounded by a fleshy arillns. The male flowers, which are borne on the same or on distinct individuals, are small cones consisting of numerons sporophylls attached to a short erect axis. Each sporophyll bears two microsporangia on the lower surface; the microspores are provided with distended wings.

Taxus baccata is the only European representative of the family. The Yew, which is now for the most part artifieially introduced, had formerly a wide distribution as an evergreen undergrowth in our native woods (Figs. 502, 503). Isolated examples of large size occur in North and Central Germany, and it occurs as a more important constitnent of the vegetation in Switzerland, e.g. on the steep slopes at Uetli. The Yew tree attains a height of $10 \mathrm{~m}$. All the branches are shoots of unlimited growth. The leaves stand on all sides of the ascending main shoots, but in two rows on the horizontally expanded lateral branches. They are 
narrow, flat leaves and persist for several years. The tree is dioecious ; the flowers are situated on the lower surface of the twigs and arise in the axils of the leaves of the preceding year. The male flowers are invested at the base by a number of scale-leares and contain some 10 peltate stamens, each of which bears 5-9 pollen-sacs. The mode of opening of the sporangia is peeuliar. The onter wall splits at the base and along the side of each pollen-sac, so that the whole stamen
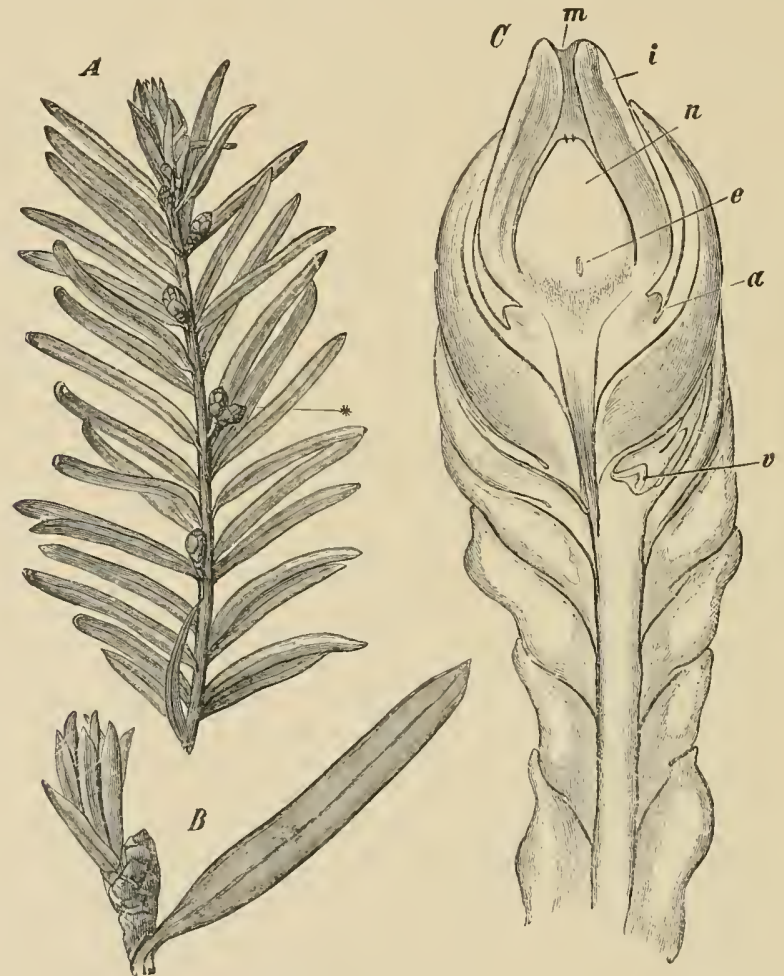

Fin. 502,-Truxt baccatu. A, branch with female flowers; *, two ovules on the same shoot (nat. size); $B$, leaf with axillary, fertile shoot $(\times 2) ; C$, median longitudinal section of a primary and seconclary shoot; $v$, vegetative cone of the primary shoot; $u$, rudiment of the aril; $e$, rudiment of the embryo-sac; $n$, meellus; $i$, integument; $m$, micropyle $(\times 48)$. Porsosocs.

resembles an umbrella turned inside ont; the pollen remains for a time in the pocket-like depressions, from which it is removed by the wind. The female flower usually develops singly as a secondary, axillary shoot of the nppermost scale leaf of a primary shoot; the apex of the latter is deplacet to the side and does not develop further. Each flower consists of a single, atropous orule with one integument. The frop of fluid excreted from the micropyle of many Gymuo. sperms is especially well shown liy the Yew. As the seed develops, a fleshy arilhus springs from its base and surrounds the mature seed like a bright red cup. The foliage and seed are poisonous, but the aril, which induees birds to distribute the seed, is harmless. 
Family Pinaceae.-This family includes the most important Coniferae, and on gronnds of differences in leaf arrangement and in the position of the orules is diriderl into two sub-families. The forms with the leaves opposite or in whorls are included in the Cupressineae; they also have the orules erect. Cupressus, Thuja, Juniperus, and Turodium are representative genera; the habit of Taxodium is peenliar. All the forms with alternate leaves are included in the Abietineae, and, almost without exception, they also possess

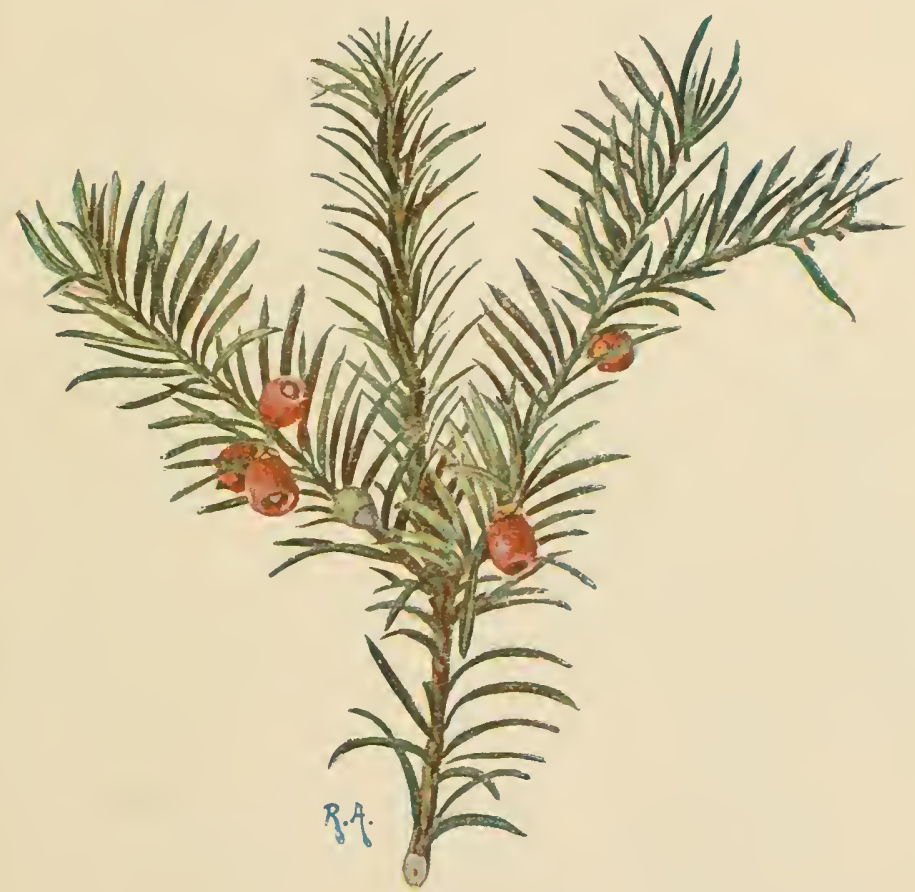

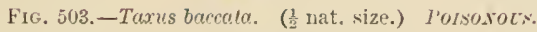

inverted ovnles. The genera Aruncuric and Agathis-Sequoin and Sciadopitys-Abies, Picen, Larix, and Pinus, may be distributed in three distinct groups which may be named Arancarieae, Sequoieae, and Abietineae, in the narrow sense.

Sub-family Cupressineae. - Some of the Cupressineae have needle-slaped leares in whorls (Juniper, Fig. 501) ; others have decussately arranged, seale-like leaves (Thuja, Juniperus subina, Fig. 505). The former type is to be regarded as the more primitive, for the seedlings of Thuja have ncedle-shaped leaves, and individual branches of scale-leaved forms of Juniperus revert to the needle-shajed leaves in whorls of three. The short slioots of Taxodium have two ranks of leaves and are shed as a whole. 
The Cupressinae, with the exception of Juniperus, are monoecious. The male flowers of Juniperus communis stand in the leaf axils. At their base are a number of small scale-leaves (Fig. 506, $A, \alpha$ ), above which come several whorls of peltate sporophylls $(e)$ bearing $2-4$ mierosporangia $(d)$ on the lower surface. The sporangia open by a vertical slit parallel to the long axis of the sporophyll. The female Howers occupy a corresponding position. The scale-leaves at the base (Fig. 506, $B$ ) are succeeded by a whorl of carpels $(C, b)$, each of which bears a single upright ovule in a median position (e). After fertilisation a succulent parenchymatous growth mainly of the basal portions of the sporophylls raises the seeds and presses them together, without, however, obliterating the central space altogether. The three

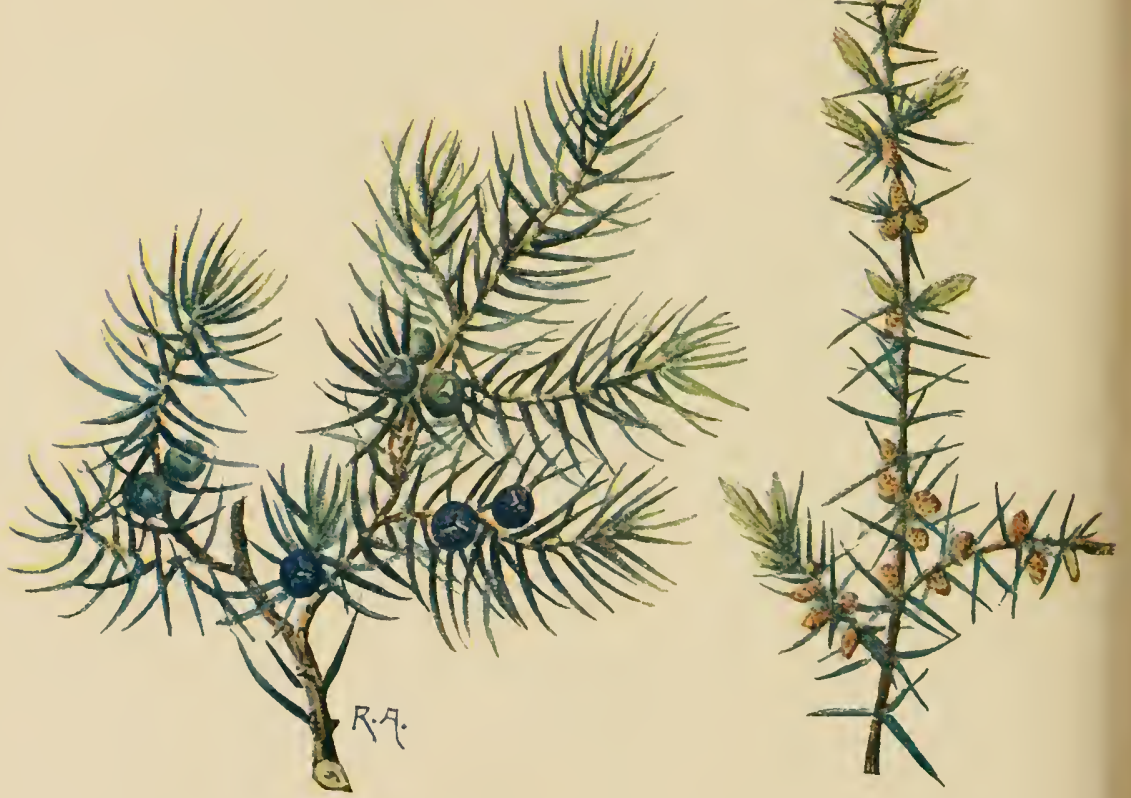

F16. 504.-Juniperus communis. Twigs bearing fruits and male flowers. (

carpels become completely colierent above the sceds, but the place of union is still indicated by the scar at the apex of the ripe fruit; the tip of each carpel is a little back from the corresponding angle of the suture. The fruit takes two years to ripen. The sueculenee of the earpels gives the fruit the appearance of a berry. Juniperus is the only genus of the Cupressineae with such fruits ; the others, sueh as C'upressus, Thuja, Traxodium, have cones.

Juniperus communis, Juniper, is a shrub or small tree distributed over the northcrn hemisplere. J. Sabina, a prostrate shrub of the Alps and other momtains of central and southern Europe. The Cypress (Cupressus sempervirens) in the Mediterranean region. Tuxodium distichum is a deciduous tree, forming extended swampy woods on the north coast of the Gulf of Mexico from Florida to Galveston. T. mexicamm is evergreen and is widely distributed on the highlands 
of Mexico; very large specimens occur such as the giant tree of Tule, which at a

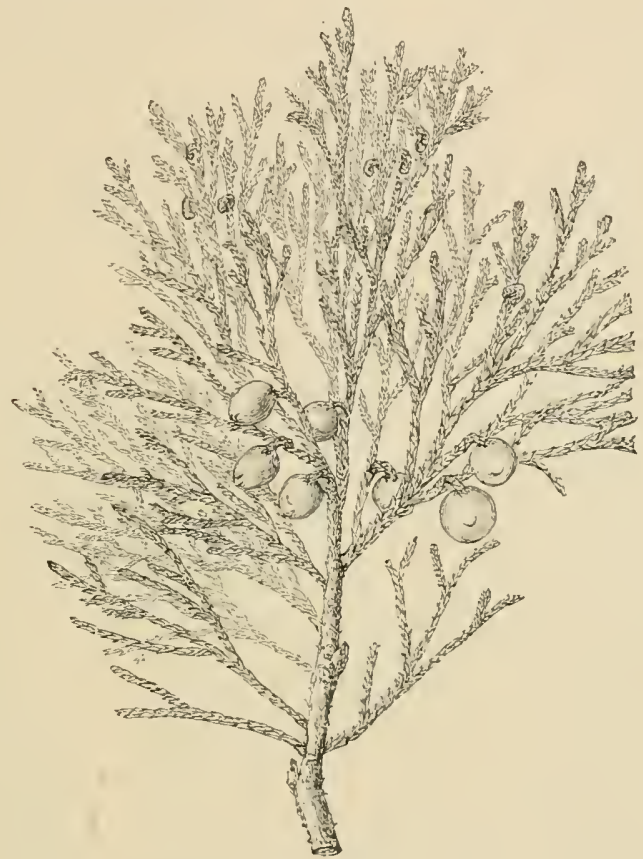

FIG, 505, - Juniperus Sabina: branch with fruit. PoIsovot's.

height of $40 \mathrm{~m}$. was $30 \mathrm{~m}$. in circumference, and was estimated by rox HuMBOLDT to be 4000 years old.
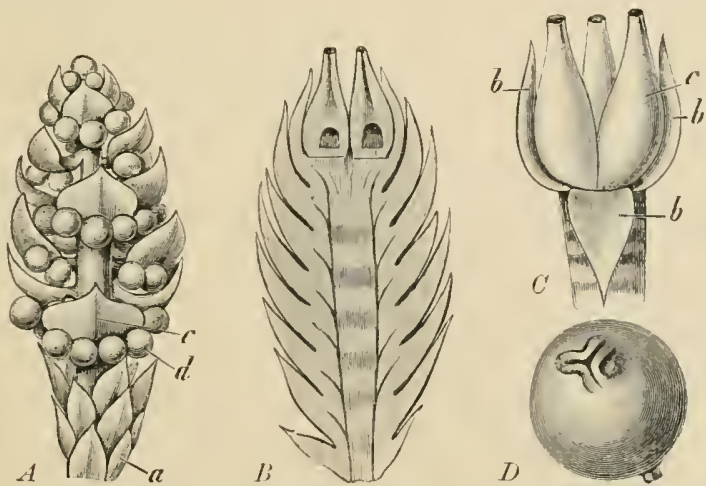

Fif. 506.-Juniferus communis. A, Male flower; $B$, fertile shoot with female flower; $C$, female flower with one scale bent out of place; D, fruit. UFFICI.L. (After BERG and ScHsidt, all magnified.)

Sub-family Abietineae.-The floral structure of the Abietineae may be described 
in the first place. The male flowers (cf. Fig. 424, p. 481) consist of an axis bearing scale-leaves at the base, and, above this, numerous stamens; the pollen-sacs

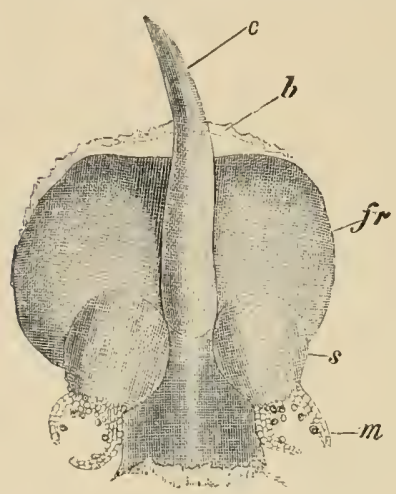

Fig. 507.-Pinus silcestris. Ovuliferons scale $(f r)$ bearing two orules $s$ and the keel $c$. The bract-scale $b$ is visible behind. The free margin of the integument of the ovule forms two prolongations $(m) . \quad(x 7$.

not sharply marked off from the scale.) The condition of affairs in Sequoic and Seiadopitys is similar, but the outgrowth is more definitely defined; each seale bears 4-9 anatropons ovules. In the Abietineae proper the limits of the two scales are still more markerl. The two anatropous ovules are borne on an inner scale, which, at its base, is continuous with the scale of the cone. THE OUTER SCALE Is CALLEI THE PRACT SCALE, THE INNER, THE OVULIFEROUS SCALE (Figs. 50 The ovuliferons scale is the more strongly developed and it is the part that becomes lignified and affords jrotection to the ovnles. Even at the period of flowering the bract scale is usually concealed by the ovuliferous scale and only to be detected on close inspection. In other forms, however (e.g. Abics bracteate, A. pectinata, Fig. 508, B, Pseudotsuga Douglusii, (tc.), the bract scales even in the older cone project prominently between the ovuliferous scales.

The view here followed, that the oruliferous scale is a placental outgrowth of the bract-scale bearing the macrosporangia, and that its increase in size can be 
tracel in the series of the Arancarieae and Abietineae, is that suplorted by SAcHs, Eichler, and Goebel. Attention must be drawn, however, to an alternative view supported by Strasberger and Celakovsky among others. According to this the ovuliferous scale corresponds to the coherent bracteoles of an axillary shoot borne in the axil of the bract scale. The cone itself would thus not correspond to a single flower bearing a number of sporophylls, but to a system of shoots, i.e. it would be an inflorescence.

Most important Genera and Species.-Agutlis (Dammara) is distributed in

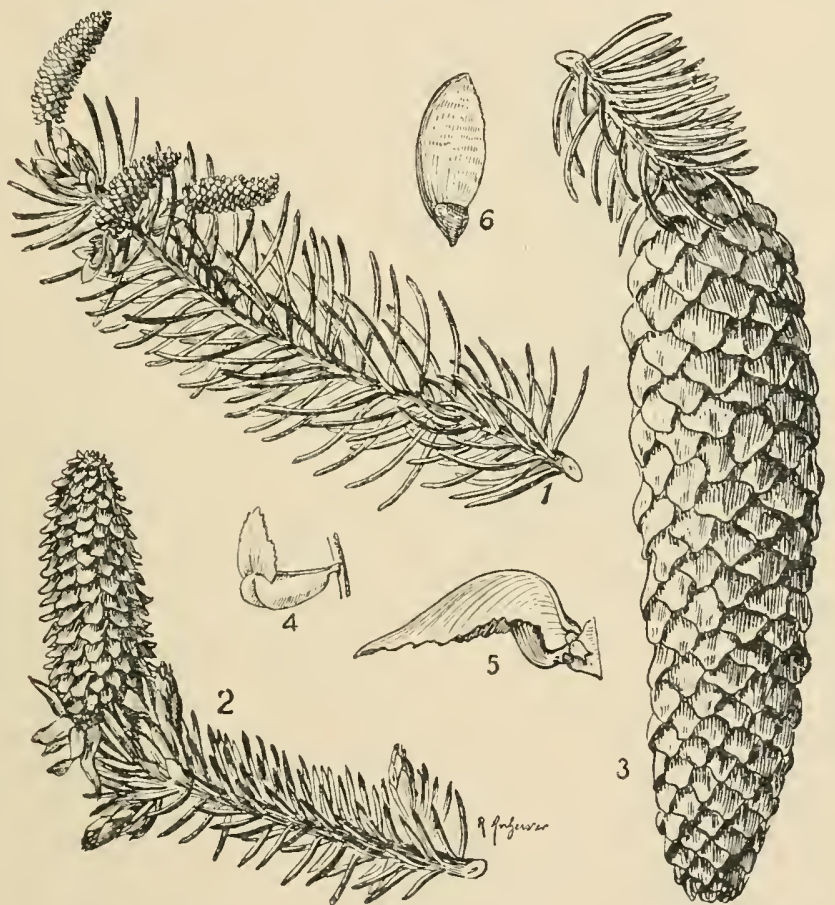

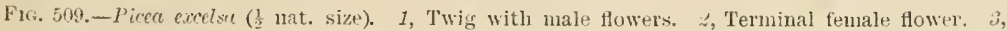
Pendulous cone. 4, Microporophyll. i, Macrosporophyll: the uract-scale is coveres by the large, bent-back, ovuliferons scale; an ovule is visible at the base of the oruliferous seale. 6 , Ripe seerl with the wing formed by a detacher portion of the ovuliferous scale. ( $\times$ 4-6.)

the Malayan Archipelago and extends to New Zealand; $A$. australis and $A$. Dammare yield Kanri Copal but no Dammar Resin; Arcuecerie bresiliana and $A$. imbricata are stately, S. American, forest trees; A. excelsa, A. Cookii, and other species with very linited distribution are extensively cultivated as ornamental trees. The genus Sequoir includes the most gigantic trees known; specimens of $S$. gigentec from the Californian Sierra Nevada attain a height of $100 \mathrm{~m}$. and a diameter of $12 \mathrm{~m}$; the main locality of these trees has recently been injured by fire.

The Silver Fir (Alics pectinath, Fig. 508) is a native of the mountains of the middle and south of Europe. It bears only long shoots. The flat, needle-like 


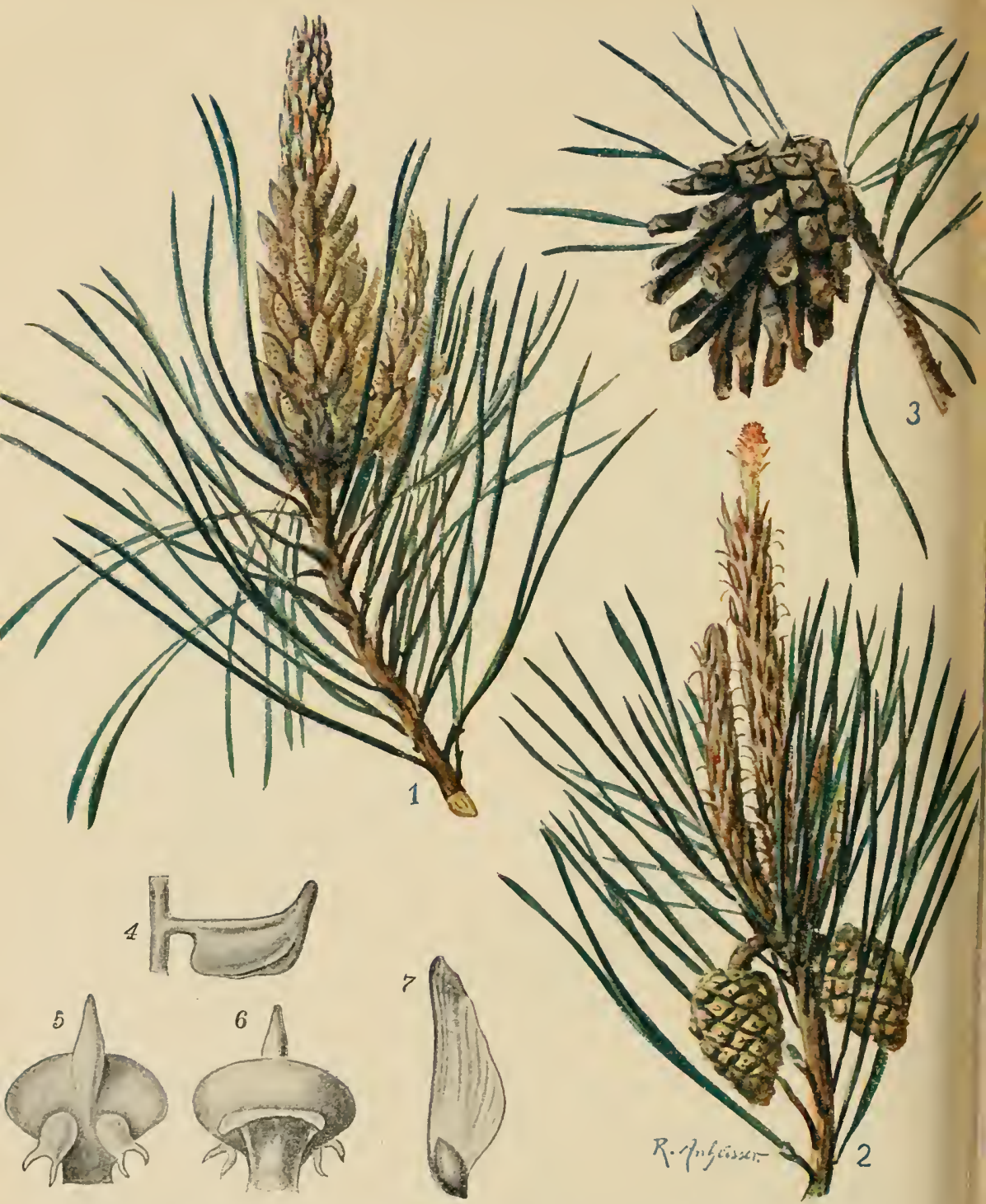

Flc. 510.-Pinus silvestris ( $\frac{2}{3}$ nat. size). 1, shoot of unlinited growtl bearing short shoots; at the top the shoot of the current year. At the base of the latter are numerons male flowers each in the place of a short shoot, and nearer the tip brown scale-leaves, in the axil of each of which is a short shoot. 2, Similar branch bearing a young female flower at the summit of the shoot of the current year, in place of a branch of unlimiterl growth. Two dependent green cones are borne on the shoot of the preceding year. 8, Cone of the year before last, opened to allow of the eseape of the seerls. 4, A microsporophyll. 5, Maerosporopliyll from the adaxial side showing the ovmliferous scale with thr two ovules at the base. 6 , Macrosporophyll from the abaxial side slowing the small bract-scale below the large ovuliferous seale. $\gamma$, Ripe seed with its wing derived from the superfieial layers of the oruliferous scate. $(\times 4-5$.$) OrFICIAL.$ 
leaves, marked below by two white lines and emarginate at the tip, are borne on all sides of the axis, but are twisted into a horizontal position on the branches illuminated from above. The male flowers stand in the leaf-axils on the under side or on the flanks of the shoot, and grow downwards so that the pollen-sacs are directed upwards. The wall of the sporangium opens by an obliquely longitudinal split, which gapes widely and allows the winged microspores to eseape. The female flowers arise from the npper side of a branch and are directed vertically upwards. The bract-scales are longer than the broad, ovuliferous scales. The fertilised cones retain the upright position, and when ripe the scales separate from the axis and so set the seeds free from the plant. The development of the seeds takes a year. Abies Nordmanniana from the Caucasns, A. pinsapo from Spain, A. concolor, A. balsamea, and A. nolitis from N. America are in cultivation.

Picca cxcclsa, the Fir (Fig. 509), is a fine tree of lyramidal shape; it has no short shoots, and the long shoots bear on all sides pointed, quadrangular, needle-shaped leaves, which on horizontal or pendulous branclies stand more or less erect. Nale flowers as a rule on shoots of the previous year; on flowering they become twisted into an erect position. The two pollen-sacs open by a longitudinal slit. Female flowers terminal on the shoots of the previous year usually near the summit of the tree. They stand erect at the time of Howering. The ripe cones are pendulous and, after setting the seeds free from between the scales, fall in pieces. The development of the seeds is completed in one year. The male and female flowers occur on the same individnal. Picen orientalis from Asia Minor and Picca alba from N. America are frequently cultivated.

Laria europaca, the Lareh, is one of the few deciduous Conifers and replaces its foliage annually. There is a differentiation into long and short shoots. The former bear the narrow linear leaves on all sides and continue the branching of the pyramidal tree, the lower branches of which often droop downwards. The short shoots arise in the axils of the leaves of the long shoots of the preceding year, and bear a rosette of $30-40$ leaves which are somewhat shorter but resemble those of the lons shoots. The flowers occur in a position corresponding to that of the short shoots. The male flowers are bent downwards when fully developed, and the opening of the upwardly directed pollen-sacs occurs as in Abies. The erect female cones produce seed in the same year.

The most arivanced diflerentiation of the vegetative organs is found in the genus Pinus; P. silvestris, the Scotch Fir, will serve as an example (Fig. 510). Toung seedlings in the first or second year have long shoots bearing needle-shaped leaves. On older plants this type of foliage is lost; the needles are replaced by colourless, membranons scale-leaves in the axils of which stand the short shoots. These have 2 -in other species 3 or 5 -needle-shaped foliage leaves. The latter are about $5 \mathrm{~cm}$. in length, their flat surfaces are turned to face one another, and the outer or lower surface is convex. The growing points of the short shoots soon become functionless unless stimulated to activity by the death of the apical bud. The male flowers appear in large numbers at the base of the long shoots of the current year and stand in place of the short shoots. One or several female flowers arise at the tip of similar long shoots, and each corresponds in josition to a shoot of unlimited growth. At the time of flowering they are erect, but are bent downwards after pollination. The seeds ripen in the second year, and are set free by the separation of the scales of the cone, which till then have been closely pressed together. The cones subsequently are shed (Fig. 510). Pinus montana, a dwarf Pine occurring on mountains; $P$. pinea, $P$. cembra, with edible seeds; $P$. laricio, 
Corsican Pine from Austria; P. Pinaster, Maritime Pine from the Mediterranean region; $P$. taeda, $P$. Strobus, Weymouth Pine, $P$. Lambertiana from N. America.

Cedrus.-Cedars from the forests on Atlas and Lebanon. Cultivated.

Porsorous.-Juniperus Sabina, Taxus baecata.

OFFICIAL. - Pinus sylvestris and other species produce OLEUM TEREBINTHINAE and Resina; Abies balsamea supplies terfinthisa Canadensis ; P.palustris and $P$. taed $\alpha$ yield Thus AMERICANtM ; $P$. excels $\alpha$ yields PIX BURGUNDICA ; $P$. sylvestris, etc., PIX LIQUIDA; P. pumilio, OLEUAI PIN1; Jumiperus oxyeedrus and other species yield OLEUM CADINUM; Juniperus communis, OLEUM JUNIPERI.

\section{Order 4. Gnetinae $\left({ }^{20}\right)$}

The only Family in this order is that of the Gnetaceae, to which only three genera belong: Ephedra (Fig. 511), leafless shrubs of warm

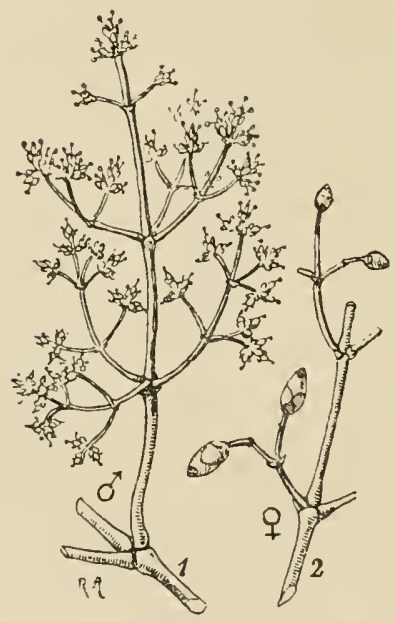

Fic. 511.-Epheulra altissima. 1, Habit of a male inflorescence. 2 , An inflorescence with umripe fruits. ( 2 nat. size.) dry regions of the northern hemisphere; IV elwitschia mirabilis, a monotypic plant from the deserts of South-West Africa; the widely expanded summit of the stem bears after the cotyledons only a single pair of leares, which are $1 \mathrm{~m}$. in length and continue to grow at their bases; Gnetum (Fig. 512), tropical trees or climbers with pairs of broad, reticulately veined leaves. These genera, while differing widely in appearance, agree in possessing opposite leaves (in Ephedra reduced to scales), in the development of ressels in the secondary wood, the absence of resin canals, and in the presence of a perianth to the flowers which are usually dioecious (Fig. 513).

These points of agreement with both Gymnosperms and Angiosperms make the group in many ways an intermediate one between the two classes. Insects risit the flowers of $I T$ cluitschice and Gnetum. The development of the sexual generation (cf. p. 509) in the three genera is as various as their external habit.

\section{Fossil Gymnosperms $\left({ }^{21}\right)$}

In contrast to what was seen to be the case for the Pteridophyta, Gymnosperms have not yet been detected in Cambrian and Silurian strata. They appear first in the Devonian, but are sparingly representerl and first form an important constituent of the flora in the Carboniferous. From the Cycadofilices, which possessed stems with secondary thickening and fern-like foliage and had been hitherto regarded as Pteridophyta, OLIVEr and ScoTT $\left({ }^{21_{2}}\right)$ have recently separated the Pteridospermeae ; 


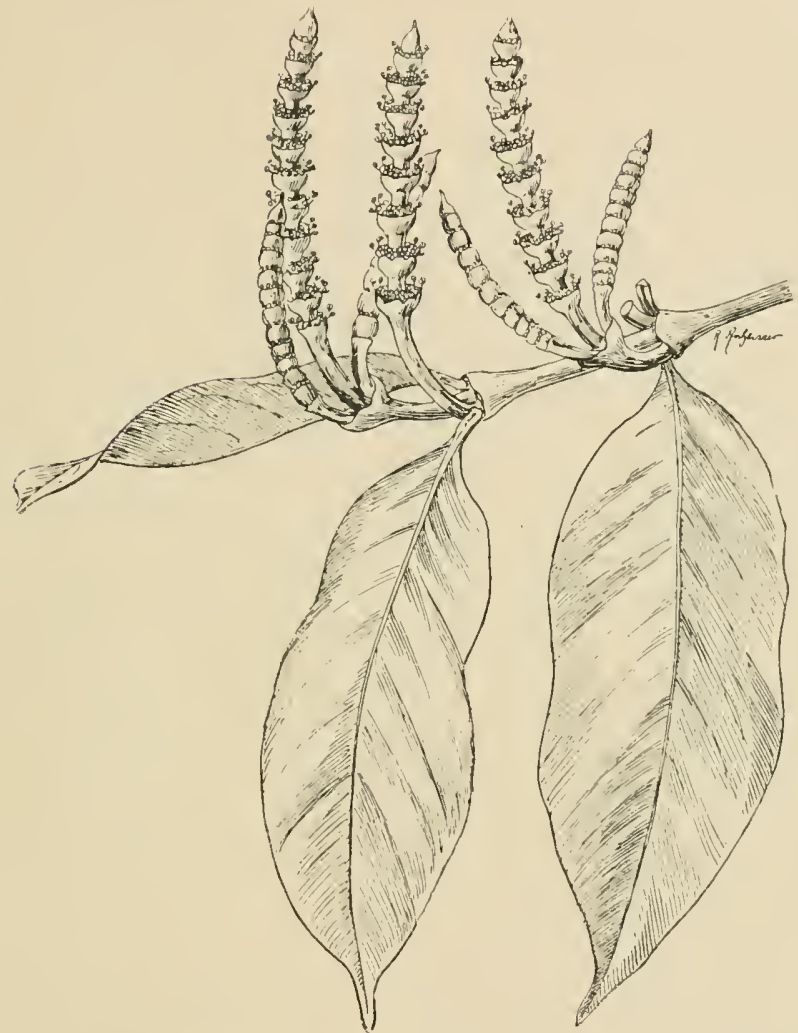

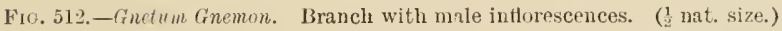
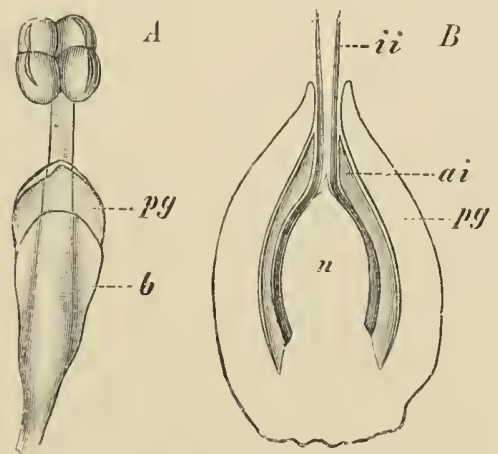

Frr. 513. - A, Elhedru altissime. Male fower, $\times 16 ; p y$, perigone; $b$, leaf. D; Gnetum Gnemon, longitulinal section of a female flower ( $\times 32$; after LotsY $)$; nucellus; $i i$, immer, and ai, outer integuments ; $p y$, integument-like investment or perianth. 
these may be briefly characterised as fern-like spermaphyta. They have shown that the seeds of Lagcnostoma Lomaxi, Will, belong to Lyginodendron, one of the Cycadofilices with fern-like foliage, and that this plant must therefore be placed in the Pteridospermeac. It is highly probable from the further work of Scort ( $\left.{ }^{21 b}\right)$ that the whole of the Lyginopterideae and the Medulloseae must be placed in this group. The structure of the seed of Lagenostoma, the best known example of the new order, resembles that of Cycas, but, instead of the single thick integument of the latter, had a cupular investment to the seed, on the outside of the integument. In all Pteridospermeae the macrosporophylls resembled the vegetative leaves almost exactly. The same is the case for the microsporophylls, and their sporangia can hardly be distinguished from those of certain Ferns. In the structure of the stems and leaves the Pteridospermeae are intermediate between Ferns and Gymnosperms but nearer to the former group.

Cordaitcs is a peculiar type confined to the Palaeozoic rocks. Owing to the excellence of the preservation of their remains the morphology of the Cordaiteac is as well known as that of the existing Gymnosperms. They were lofty trees with linear or broad and lobed leaves. Their flowers differ considerably from those of recent Gymnosperms. An important fact as bearing on the phylogeny of the group is the presence of a male prothallus as a small multicellular body. The ovules and seeds show great structural agreenent with those of the Cycadaceae. With the exception of some less common fossils (Cyeadites, Dieranophyllum), which may be placed witl the Ginkgoineae, Cordaites is the most richly represented type of Gymnosperm found in the Carboniferous rocks. Undoubted Cycadophyta make their ajpearance in the lower Rothliegende. In later strata the genus Walchia, of uncertain affinity, appears; the regetative organs, which alone are known, recall the lowest Coniferae (Araucariaceae). In the upper Rothliegende undoubted Ginkgoaceae (Baiera) nake their appearance, with another type referred to the Coniferae (Ullmannia).

The Cordaiteae disappear in the lower mesozoic strata. The Gymnosperm flora can be followed through the Trias, in which it consisted of extinct types of Cycadophyta, Ginkgoineae, and Coniferae (Toltzia, in the Bunter Sandstone), to the Jurassic period. In the latter it attained a great development in that both the Ginkgoineae and the Cycadineae attained their maxinum development.

SCOTT $\left({ }^{21 c}\right)$ has recently given an accomnt of the appearance and the high degree of organisation attained by the mesozoic Cycadophyta, from the knowledge obtained by Wieland's stndy of the abundant material found in North America. The name Cycadcoidea proposed by the American author is synonymous with Bennettites; fruits derived from the hermaphrodite flowers were already imperfectly known from European strata under the latter name. The short and sometimes branched stems resembled recent Cycads in their appearance and foliage and bore flowers which were hermaphrodite and $12 \mathrm{~cm}$. in length. A hundred or more spirally arranged perianth leares surrounded a whorl of 18-20 microsporophylls, which were united at the base to form a decp cup in the centre of which the gynaecerm arose (Fig. 514). The jinnate microsporophylls, $10 \mathrm{~cm}$. in length, resemble the leaves of Ferns, and the microsporangia resemble the sporangia of the Marattiaceae. The gynaeceum consists of numcrous, long-stalked, atrolous ovules which are surrounded and separated by scale-leaves: the microsporophylls, liowever, open freely on the exterior. The ripe seeds contained a highly developel dicotyledonous embryo and had no endosperm. They were protected and enclosed by the closely crowded outer ends of the scale-leaves. Just as the palaeozoic Pteridosperns combine 
the eharacters of Ferns and Gymnosperms, the flowers of the mesozoic Bennettites or Cycaleoile show a combination of characters of Angiosperms, Gymnosperms, and Ferns.

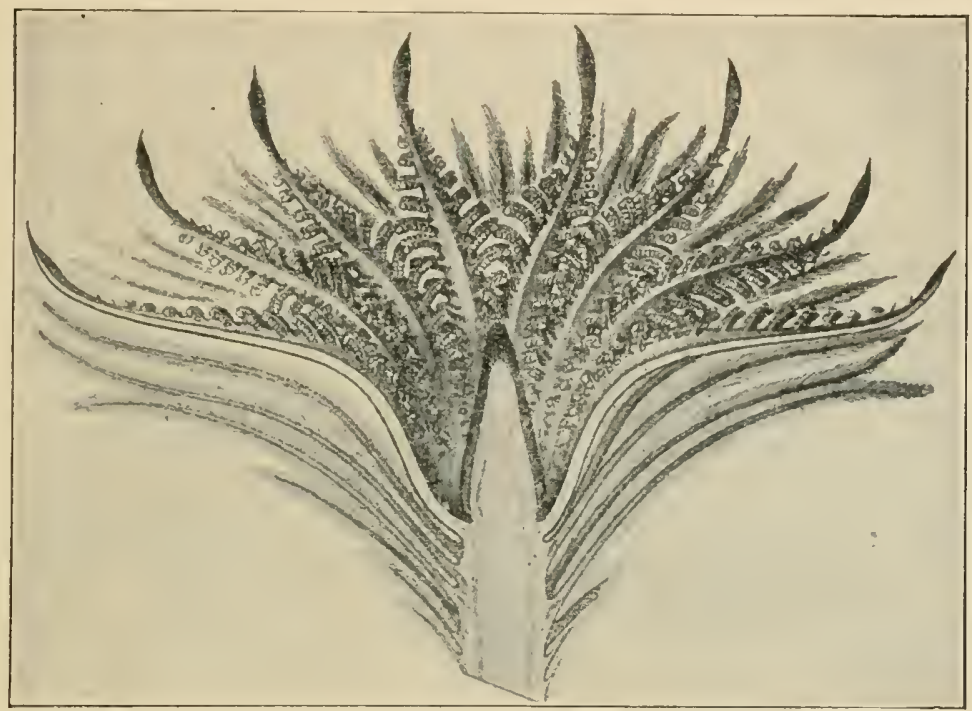

FIG. 514 A.-Reconstruction of the longitudinal section of the flower of Cycadeoidea ingens. (From ScotT after Wieland.)

True Arancarieae also appear in the Jurassic; on this account, as well as on account of their organisation, this group may be regarded as the oldest of the existing Coniferae. In the Wealden Cycadineae and Ginkgoineae along with some Coniferae were dominant anoug the Gymnosperms. On passing to the Cretaceous strata the ancient types are found to be reduced, while the Coniferae become more numerous. Among the latter existing genera appear (Dammara, Sequoia, Pinus, Cedrus, Abies, Callitris, etc.). The Taxaceae also appear to be represented, but the remains are of uncertain affinity.

The Tertiary Gymnosperms belong entirely to existing types and for the most part to existing species. The Coniferae are rominant; the Ginkgoineae are represented only by Ginkgo biloba, but this occurred in Europe along with other species now limited to Eastern Asia or North America (Cryptomeria japonica, Taxodium distichum, T'. heterophyllum, Sequoia gigantea, s'. sempervirens,

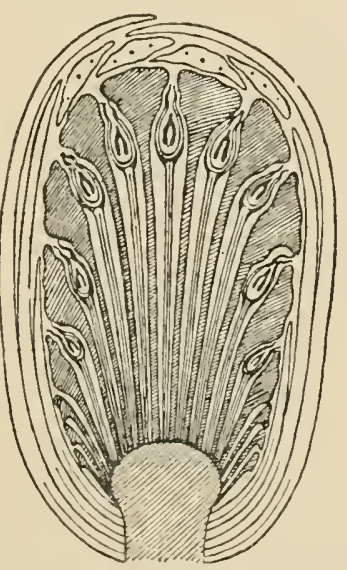

FIG. $51+$ B. - Longritudinal section of a fruit of Bennettites Gibson. iunus. (After ScotT.)

Pinus Strubus, ctc.). One Cycadaccous plant (Enteqluelertos) is also known. 


\section{Class II. Angiospermae}

\section{Sub-Class I}

\section{Dicotylae $(16,17)$}

The Dicotyledons with few exceptions possess a pair of seedleaves; these on germination either expand as green assimilating leaves or remain within the seed-coat and supply the seedling with the reserve materials stored in their cells. The growing point of the

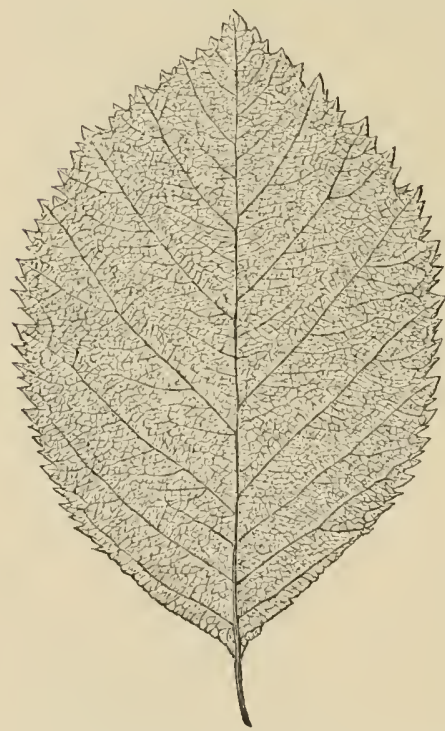

Fir. 515.--Leaf of Cratcegus with reticulate venation. (? nat. size.) stem, lying between the cotyledons, grows into the shoot of the seedling. The main root of the embryo has meanwhile penetrated into the soil ; as a rule it persists as a tap-root and gives rise to a regularly branched root-system.

The stem has a circle of open vascular bundles, while the root on transverse section shows a regularly alternating arrangement of the xylem and phloem-groups. The meristem situated in the vascular bundles of the stem, or to the inner side of the phloem in the root, soon becomes completed across the mednllary rays and forms a complete, meristematic ring. By means of this cambinm a regular growth in thickness of the stem and root takes place (cf. Fig. 147, p. 139).

The typical form of leaf found among Dicotyledons is provided with a longer or shorter petiole, and often has a pair of stipules developed from the leaf-base; a leaf-sheath is usually absent. The lamina may be simple or compound; the latter condition is always the result of branching during the dovelopmont of the leaf. The margin of the leaf presents considerable variety. The venation is as a rule reticulate (Fig. 515).

The flowers of Dicotyledons (of. p. 489) exbibit a wide range in their appearance and construction. Most frequently they can be derived from a type with five whorls of five members; increase and decrease of the number both of the whorls and the members are met with. The Dicotyledons are divided into the two series of the Choripetulue (with free perianth segments) and the Sympetalue (with the petals coherent). A series of forms without a corolla are included in the 
Choripetalae and contrasted as Monochlamydeae with the Dialypetulue, which have a perianth of two whorls (ef. p. 526).

\section{Series I. Choripetalae}

\section{A. MoNOCHLAMYDhAE \\ Order 1. Verticillatae}

Single Family, Casuarinaceae $\left({ }^{22}\right)$. Highly branched trees, inhabiting the seashore and mountains of Australia and Sonth-East Asia. Young shoots with an Equisetum-like habit. Anemophilous. Male flowers in whorls; each has a single stamen and a perianth of two leaves. Female flowers chalazoganic (ef. p. 512); in lateral inflorescences; ovary of two carpels; no perianth. Winged indehiscent fruits enclosed by the lignified bracteoles.

The following orders 2-5 agree in the unisexuality and anemophily of their very simple flowers. They include various transitional forms from chalazogamy to porogamy.

\section{Order 2. Juglandiflorae}

Aromatic woody plants, with anemophilous, unisexual flowers in catkinate spikes, sometimes containing very few flower's. Ovary bicarpellary and unilocular with a single, basal, erect, atropous ovule. Fruit, a drupe. Seed without endosperm.

Family 1. Juglandaceae $\left({ }^{23}\right)$.- - Conspicuous, monoecious trees of the northern hemisphere with imparipinnate, aromatic leaves arranged alternately. Stipules wanting. Male catkins springing from the leaf-axils of twigs of the preceding year; female flowers in terminal spikes containing more or less numerous flowers. Ovary inferior.

The Walnut, Jugluns regice (Fig. 516), is the best-known representative of the family. It is endemic in Western Asia and the eastern portion of the Mediterranean region, but the tree is in cultiration throughout Europe. In spring the axillary buds of the previons season produce long, thick, pendulous eatkins bearing numerous flower's. Each of the latter has 3 to 5 perianth segments, and these together with the two bracteoles are adherent to the bract and surround the numerous stamens, which face towards the tip of the inflorescence. The female flowers in smaller numbers are borne at the summit of the young shoots. The two carpels terminate in large, feathery, diverging stigmas. The perigone is adherent to the bract and bracteoles and reaches to the summit of the inferior ovary. The single loculus encloses an atropus, basal ovule. Fruit, a crupe. The exocarp contains abundant tannin. The liard endocarp is divided into two valves in the plane of the dorsal sutures of the coherent carpels, the limits of which are indicated by the partial septum at the lowe part of the fruit. Within the stome is the embryo, enclosed in a thin seed-coat. The large cotyledons, which contain oil, 
are lobed in correspondence with the false septa that project from the inner surface of the orary. Endosperm wanting. Other species of Juglans and Carya yield edible seeds and valuable timbers.

Family 2. Myricaceae.-Myrica gale is a dioecions shrub with entire leaves found on moors. Some American forms yield wax derived from the fruits.

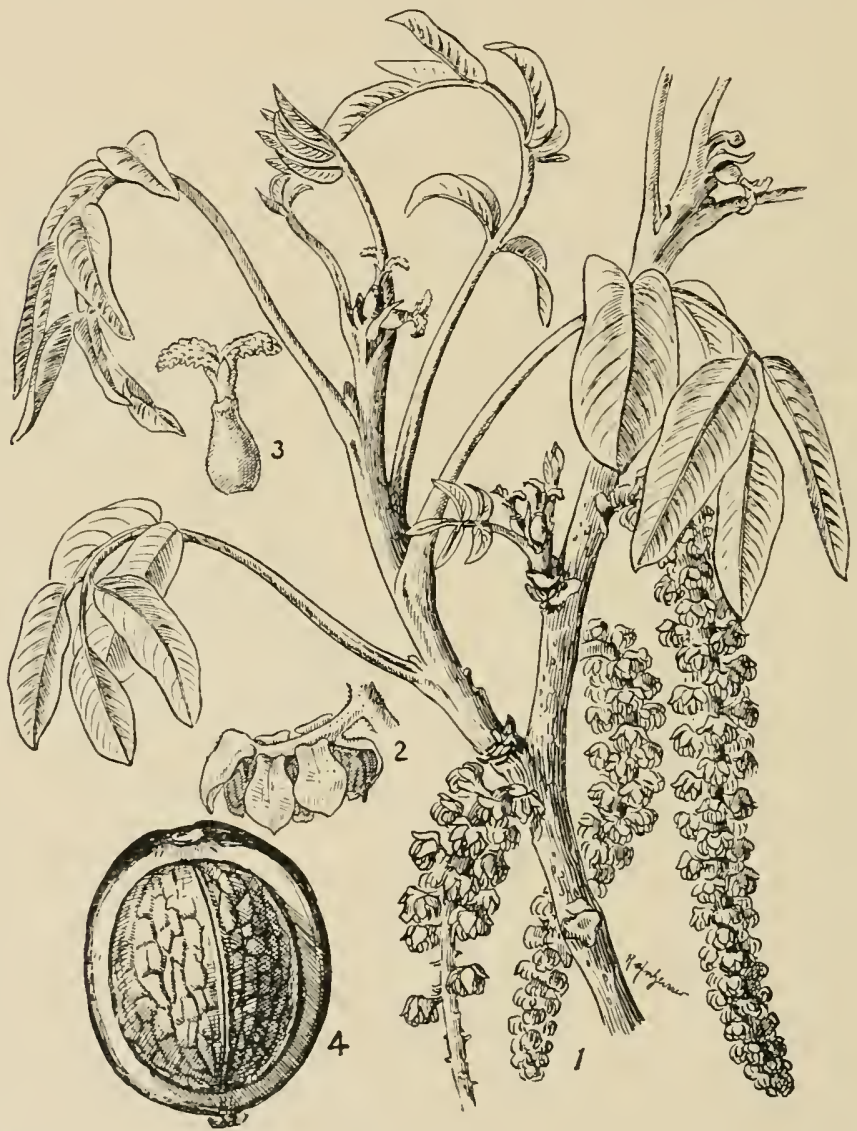

Fic. 516.-Jugluns regiu. 1, Branch with young leaves, male eatkins and at the tip female flowers.

8, Male flower. 8, Female flower. 4, Fruit with the outer layer of the pericary in part

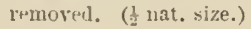

\section{Order 3. Querciflorae}

Trees or shrubs usually with entire leaves and deciduous stipules. Monoccious. Male flowers in catkins. Ovary inferior; ovules pendulous. Fruit, a one-seerled nut. Endosperm wanting. Anemophilous. This order includes most of our important forest-trees. 
Fanily 1. Betulaceae. - Male flowers adherent to the bracts; in catkins.

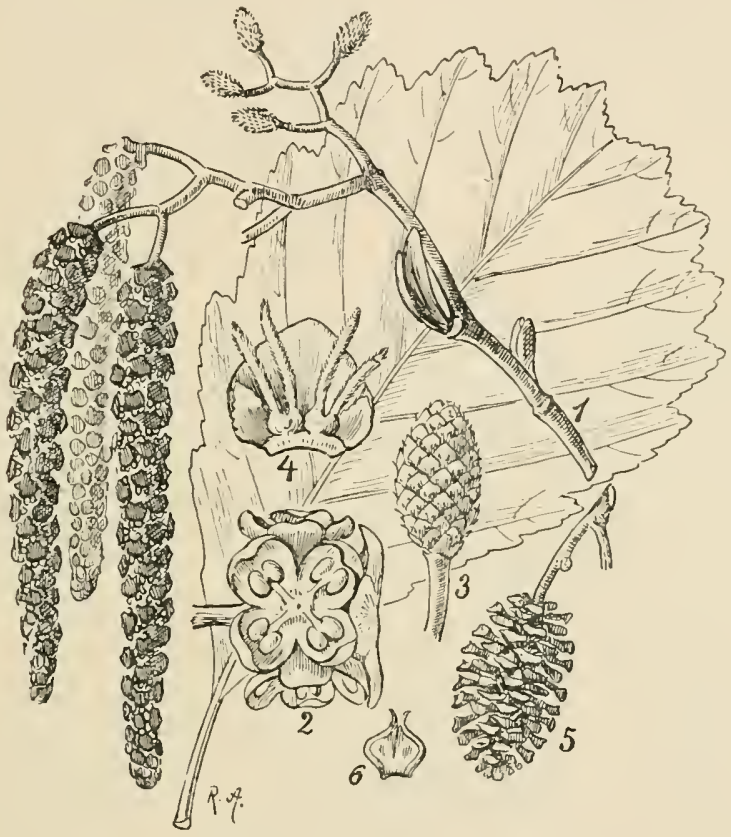

Fit. 517.-Alnus ylutinose. 1, Flowering branch bearing the suall, erect female catkins anct the pendulous male catkins. 2, A bract-scale with male flowers. 3, Female eatkins. 4, Fenale Hower. 5 , Catkin in fruiting condition. 6 , Fruit. ( 1 and the leaf, $\frac{3}{1}$ nat. size ; $8-6$, enlarged.)

Female flowers in catkins. Ovary bilocular, with two long stigmas; a single, pendulons ovule in each loculus. Mainly distributed in the northern hemisphere.

Most mportant Genera.-Alnus glutinosa, the Alder, is a prominent tree of damp woorls, and is also distributer in swamps and by the banks of streams (Fig. 517). The leares are bluntly obovate. The infloreseences are already evident in the autumn as stalked catkins, the male long and pendulous, the female erect and short. Male flowers P4, A4; a dichasium of three flowers adherent to each bract (Fig. 518). The female flowers are in pairs, their bracteoles adhering to the bract to form the fivelobed, persistent, woody scale of the cone. Almus incane is distinguished by its leaves being grey and hairy below. Betule verrucosa (Fig. 519), the Birch, has a white bark and long-stalked, triangular leaves. When young, all the parts are covered with numerous glandular hairs which give the plant an aromatic, resinous odour. The male inflorescences are formed
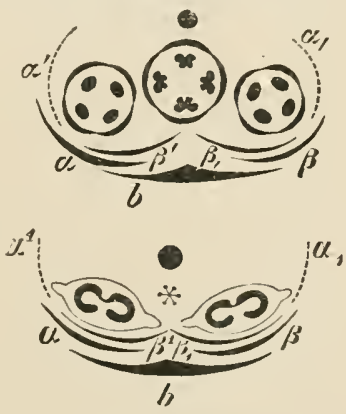

Fu, 518.-Aluus glutinose. Liagrams of Fig. 517, 2and 4. Bract $b$; bracteoles $\alpha \beta, \alpha^{\prime} \beta^{\prime}, \alpha, \beta$. (After Eichler.) in the autumn of the previous year, singly or a few together, at the tip of shoots 
of unlimitel growth. Flowers $\mathrm{P} 2, \mathrm{~A} 2$; in dichasia of three, adherent to the bract. Anthers deeply bifid (Fig. 519, 3, 4; Fig. 520). Female inflorescences solitary, at the apex of sulall, short shoots of the current year. Flowers in dichasia of three in relation to each three-lobed scale; the latter is composed of the bract and the two adherent bracteoles. Fruits borne on pendulous catkins; winged. After the fruits are shed the seales of the eatkin separate. Carpinus Betulus, the Hornbeam (Fig. 521), is an important forest-tree. The intlorescences appear in spring, the male, from axillary buds of the previous

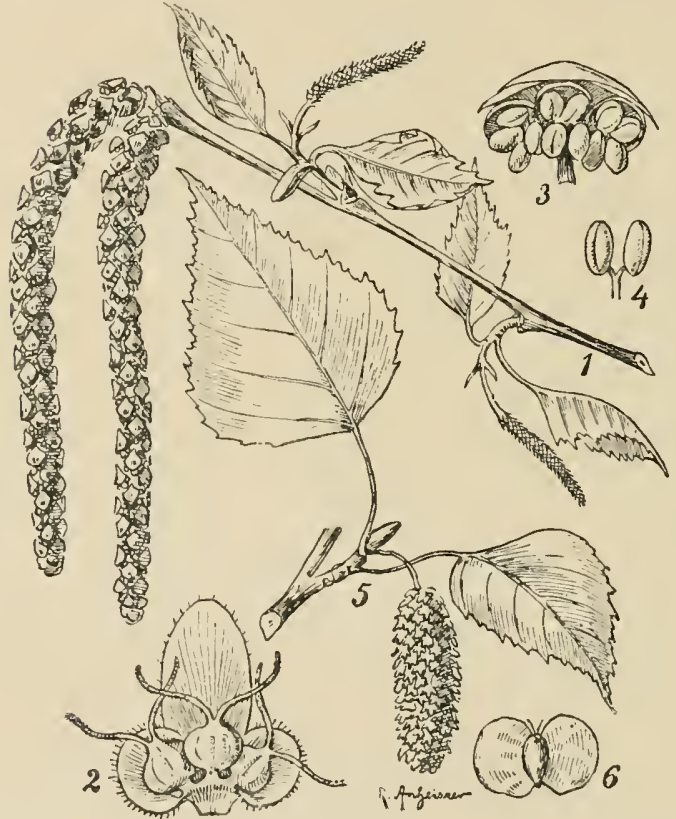

Fic. 519.-Detula verrucosa. 1, Branch with terminal male catkins anil female catkins on small lateral branches. 2 , Female flower. 3 , Male flower. 4, Stamen. 5, A catkin in fruit. 6, Fruit. ( 1 and $\delta$, 8 Hat. size ; 2.4 and 6 , enlarged.) year, either want leaves or are accompanied by one or two, the female are usually terminal. The bract of the male catkin bears $4-10$ stamens, bifid to the base, but without bracteoles or perigone. Two female flowers in relation to each bract; each flower with its special bract and pair of bracteoles. The three latter unite to form a

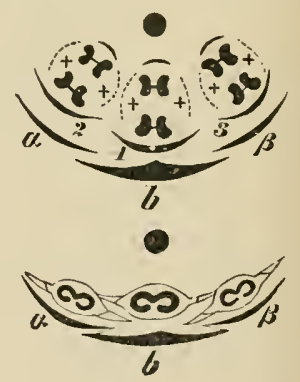

FIG. 520.- Detule verrucose. Diagrams from Fig. 519, 3 and 2. $b$, bract; $\alpha \beta$, bracteoles. (After Eichler.)

threc-lobed involucre which serves as an aid to distribution of the fruit by the wind. Corylns avellana, the Hazel (Fig. 522), develops its inflorescences in the preceding year. The male catkins are freely exposed during the winter, while the female remain enelosed by the bud-scales, and only protrucle their long red stignas between the seales at the actual time of flowering. The male flower has no perianth but has a pair of bracteoles which are adherent to the bract, as are the four deejly bifid stamens (Fig. 523). In the short female eatkins a two-flowered dichasium is present in the axil of each bract as in Carpinus; the fringed involuere also is derived from the colscrent bracteoles and sprecial bract of each flower (Fig. 523). Corylus tululose fion southern Europe.

Family 2. Cupuliferae.-Inflorescences in the leaf axils, as a 
rule of shoots of the current year. Flowers with perianth. Ovary trilocular, with three stigmas; two, pendulous, anatropous ovules in each loculus. One or more female flowers are enclosed in a CUPULE formed of coherent bracteoles, which only reaches full development around the fruit. Another interpretation of the cupule is that it

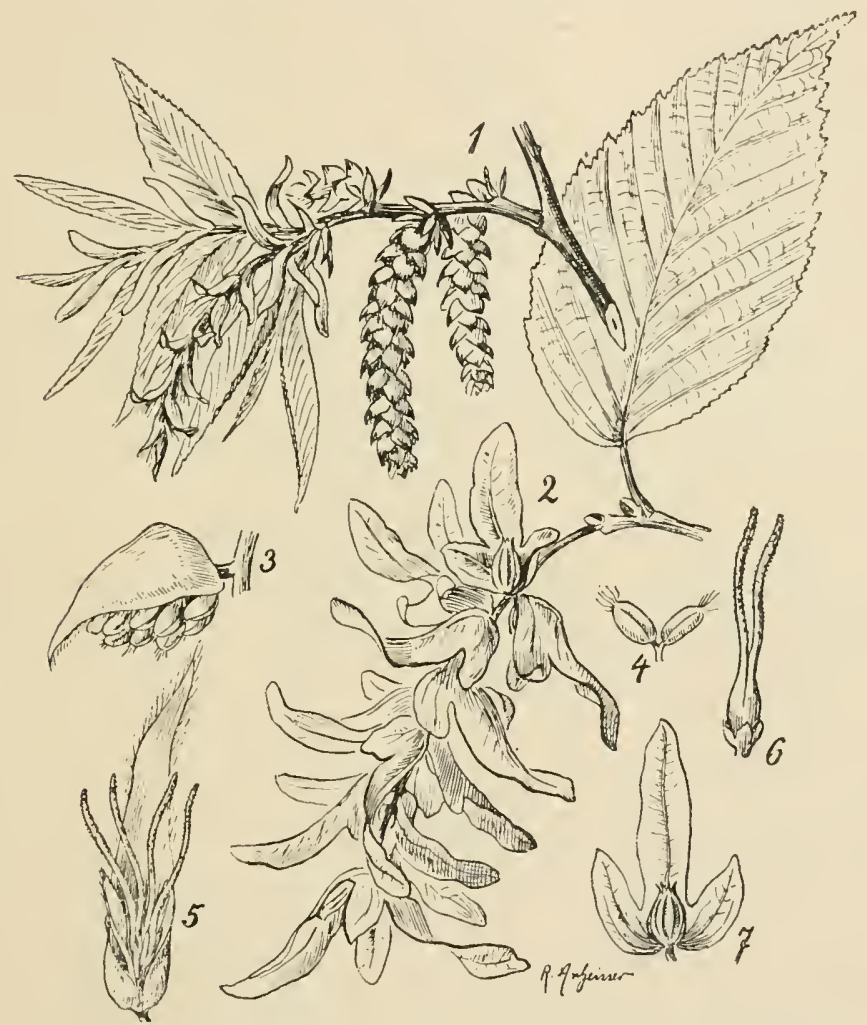

Fig. 521.-Carpinus betulus. 1, Branch with male catkins projecting from the buds of the freceding year and female catkins on the growth of the current year. 2, Female catkin in fruit. 3, Male flower. 4, stamen. 5, Bract with two female flowers. 6 , Fenale flower. 7 , Frujt. $\left(1,2,7, \frac{8}{3}\right.$ 1)at. size ; $3-6$ enlarged. $)$

corresponds to an outgrowth of the axis bearing numerous reduced leaves (Fig. 524).

Distributed ehiefly in the temperate zones of the northern hemisphere, also in tropieal $\Lambda$ sia, and one genus (Nothofatusu) ${ }^{(24)}$ in New Zealand, the southern point of S. America, and S. Australia.

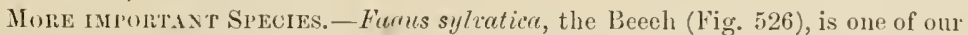
most important deeiduous trees. The leaf is entire, elliptieal, shortly stalked, and, esprecially when young, covered with fine hairs. Leaves two-ranked, 
Inflorescences on shoots of the current season. Male inflorescences lateral,

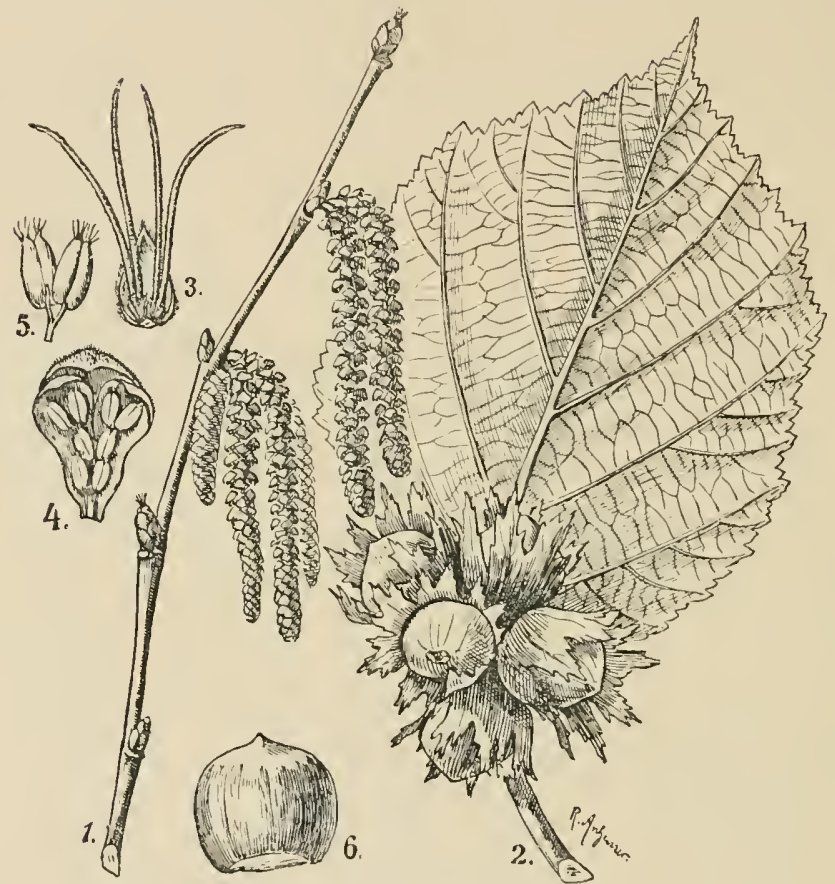

Frr, 522,-Curylusurellenu. 1, Braneh with male and female catkins. 2, Gronp of fruits. B, Brat with two female flowers. 4, Male flower. 5, Stamen. 6. Fruit removed from the cupnle. $\left(1,2,6, \frac{1}{2}\right.$ nat. size ; $8-5$ enlarged. $)$

capitate and pendulons ; flower with an oblique, bell-shaped perianth and usmally
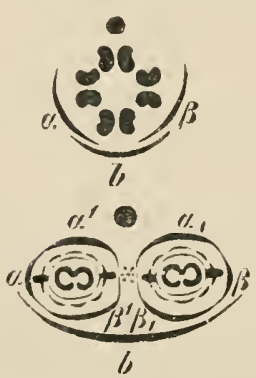

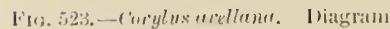
of Fig. 522, 3 and $/ 4$. 1, bract. a $\beta, \alpha^{\prime} \beta^{\prime} \alpha, \beta$, brartules. (Alter Ji(Hแ⿰к.)

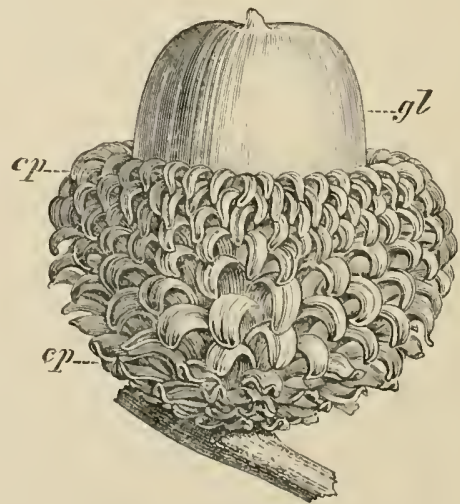

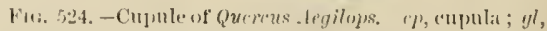
fruit. (After llochantre.) 


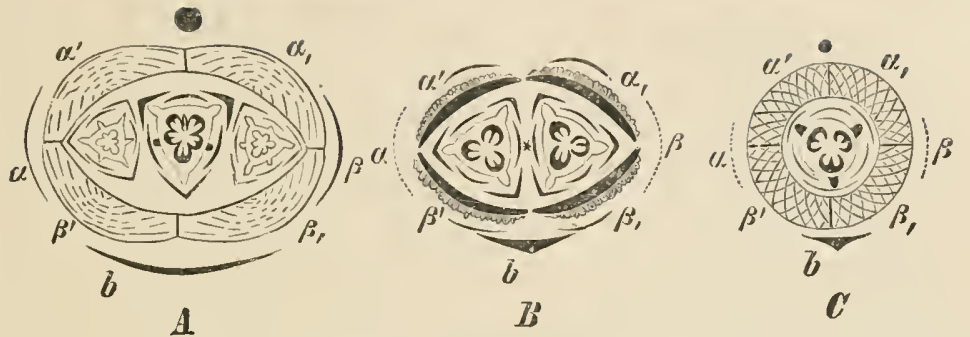

Fia. 525.-Diagranns of the female dichasia of : A, Fustencu vulyuris ; $B$, Fagus syleaticu ; $C$, diagram of the single flower of 'Qxercus pedunculutu. $b$, Bract; $\alpha \beta$, bracteoles; $\alpha, \beta, \alpha^{\prime} \beta^{\prime}$, bracteoles of the secondary flowers altherent to the cupule. (After Eichler.)

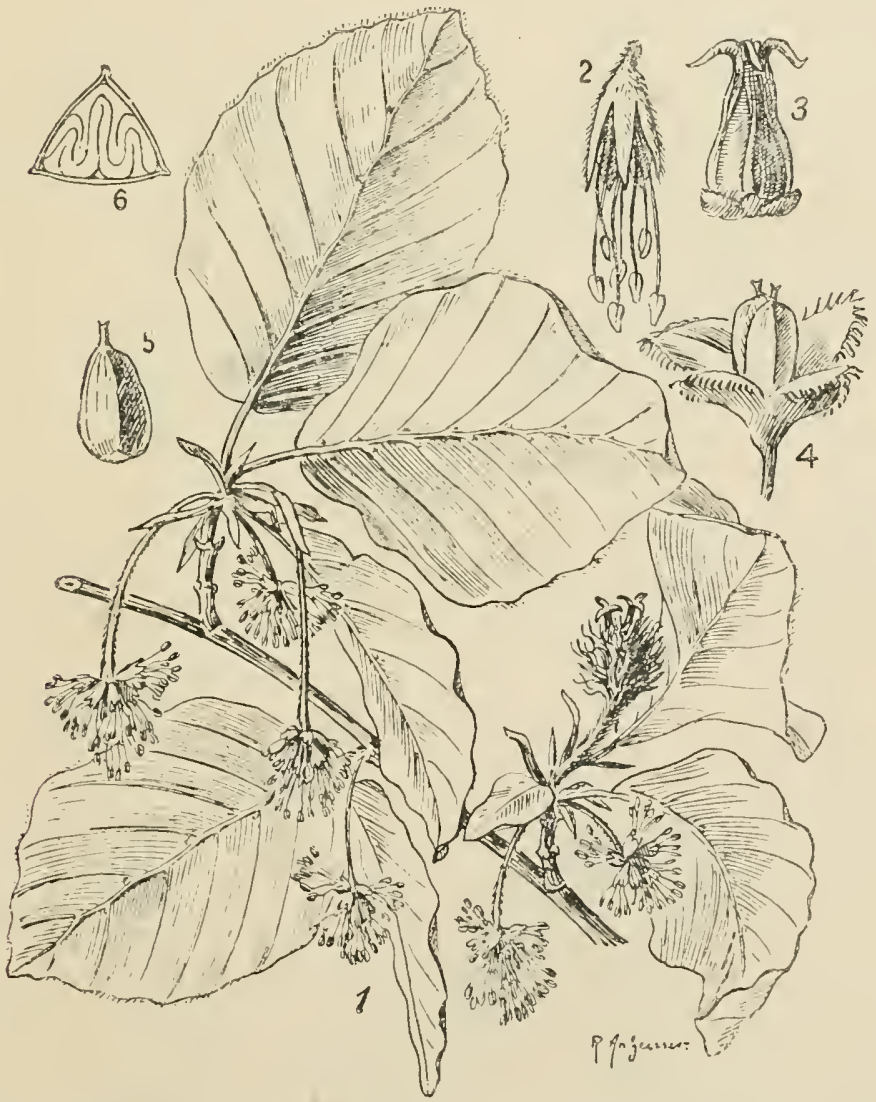

F1G. 326.-Fugus sylvaticu. (3 nat. size,) 1, Branch with male and female inflorescences. 2, Male flower. 3, Female fower. 4, Open cupule with two fruits. 5 , Fruit. 6, Transverse section of a fruit showing the folidim cotyledons of the embryo. (3, 3. f, enlargerl.) 


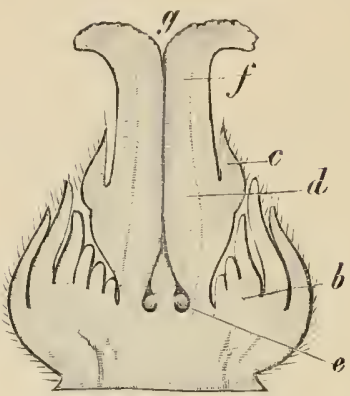

Fic. 527.-Quereus peluneulutu, longitudinal section of the female flower. $b$, The young eufule; $e$, ovule; $d$, ovary ; $e$, perigone: $f$, style; $g$, stigma. (After BER; and Sснмірт, magnified.)
8-12 stanens. Female inflorescences terminal, eapitate and ereet; Howers in twoHowered diehasia. The enpule surrounds both flowers (Fig. 525, B), and eompletely envelops the triangular, nut-like fruits; at maturity it opens by splitting into four valves. The surface is covered with numerous, blunt prickles.

Castanea vulgaris, the edible Chestnut, is a native of the Mediterranean region. The inflorescences on shoots of the current year bear in some eases only male flowers, in others female flowers at the base and male flowers above. Flowers gronped in dichasia. Female dichasia three-flowered (Fig. 525, $A$ ), so that three nuts come to be enclosed within the spiny enpule, which

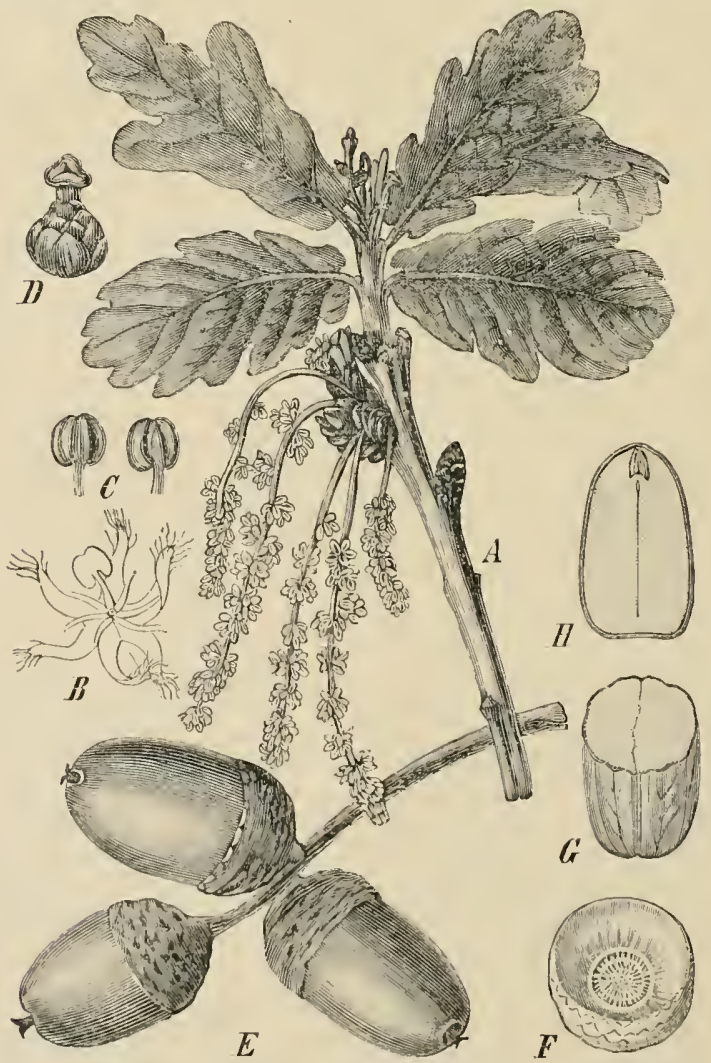

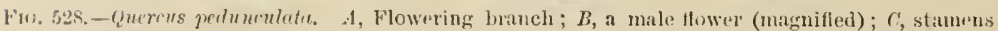
(magritierl); I), a female Ilower (ntagnitied); $E$, infructescence : $F$, cujule; $F \cdot I I$, sced. 
splits into four valves. The Oaks, Quereus peoluneulate (ligss. 527, 528) and Quercus sessiliflore, are the largest deciduons trees of Europrean woods. Leaves oval, margins sinuately lobed; those of $Q$. sessitiflore with longer stalks. The pendulous male inflorescences spring at the time that the new foliage is expanding from axillary bnds of the shoot of the preceding year or from the lowest buds of the shoot of the eurrent year ; flowers solitary, consisting of a perianth of 5-7 segments and 6-12 short stamens. Female inflorescences erect, few-flowered, in the axils of the npper leaves of the sloot of the current year. Flowers solitary; in Q. peduneulate with long stalks, in $Q$. sessitiftoru sessile. Each flower is invested by a cupule (Fig. 525, C), which is at first inconspicnous, but is fully developed on the ripe fruit.

The Beeeh yields firewood, tar, and pyroligneous acid; the Oak provides a valuable timber, a bark containing tamnin used in tanning, and cork from the Cork-oak.

OFFICIAL. - The GALLS produced on the young twigs of Quereus infectoric as a result of puneture by the Gall-was], Cynips tinctorio ; Tamnic Acirl is obtained from these.

\section{Order 4. Saliciflorae}

Family Salicaceae.-Trees and shrubs with simple, alternate, stipulate leaves. Flowers in dioecious catkins, usually developed before the leaves. Both male and female flowers are naked and stand in the axils of bracts. More or less developed scale-like development of the disc or floral receptacle. Ovary of two carpels, unilocular. Fruit, a capsule containing numerous, parietal seeds. Seeds without endosperm; seed-coat with a tuft of hairs.

This family is mainly represented in the north temperate zone. Sulix, Willow, and Populus, Poplar, are the only genera. Salix has ereet catkins and is adapted for pollination

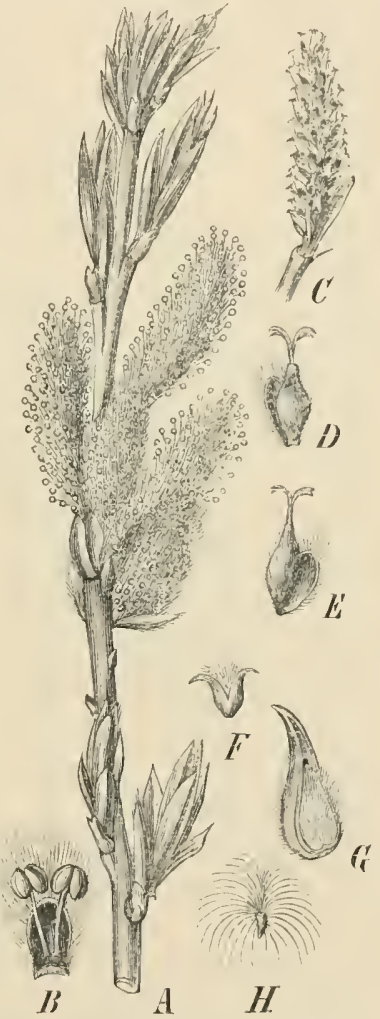

Fig. 529. - Salix viminulis. A, Flower ing male twig (nat. size); $b$, male flower with subtendingr bract (magnified); $C$, female inflorescence; $D-E$, female flowers (magnified); $F$, fruit (nat. size); $G$, the same magnitied; $H$, seed (magnified). by inseets; in relation to this, neetar is secreted by small scales at the base of the flower. Male flowers seented, pollen sticky. The number of stamens varies from 2 to 5 in the different species. Braets entire (Fig. 529). Willows oeenr commonly by the banks of streams where their shortly stalked, narrowly lanceolate leaves grive them a charaeteristic appearance. Some species are among the more abundant plants of high northern latitudes; they have subtermean, ereeping stems, only the young shoots projecting from the soil. Populus has anemophilous 
flowers ; dise enp-shaped ; no secretion of nectar. The long-stalket eircular leaves of the Poplars give them a different habit from the Willows. Flowers similar to those of Salix but with dividerl bracts. Catkins pendulons (Fig. 530).

Official. - Salicin is obtained from the bark of species of Salix and Populus.

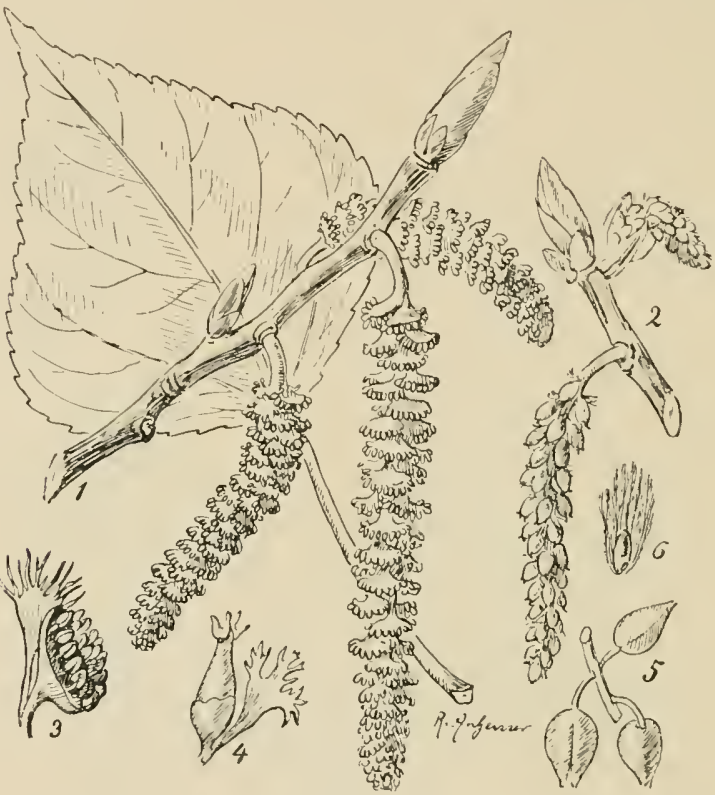

Fir. 530.- Populus nigru. 1, Hale inflorescence. 2, Female inflorescence. 8, Male flower.

4, Female flower. 5, Fruit. 6, Seed. (1, 2, $\frac{3}{4}$ nat. size; 3-6, enlarged.)

\section{Order 5. Urticinae}

Herbaceous or woody plants with small, inconspicuous flowers closely aggregated in the inflorescence. Mainly anemophilous. Perianth simple, sepaloid. Stamens equal in number to the leaves of the perigone and superposed on the latter. Ovary superior, composed of one or two carpels, usually unilocular, and containing a single ovule. Fruit, a nut or drupe. Seeds usually containing endosperm.

Family 1. Ulmaceae. - Trees or shrubs with simple, asymmetrical leaves borne in two rows. The pinnate venation, the lairy surface, the serrate margin of the leaf and the cadncons stipules are characteristic. Flowers in clusters in the axils of leaves of the previons year, hermaphrodite, or unisexual by suppression of the male or female organs. P'erigone of $4-6$ leaves, with a corresponding number of stamens situated oflosite to them. Stanens straight in the bud. Unilocular ovary eomposed of two earjels with one pendulous ovule. The family is widely listributed. 
Ulmus campestris (Fig. 531), the Elm, is a common Enroprean tree. The arrangement of the leaves on the sides of the twigs in two rows and the corresponding branching leads to the leaf-surface exposed on each lateral branch making a definite angle with the main branch and composing the regular convex crown of foliage exhibited by older examples. The tree flowers in February and the fruits

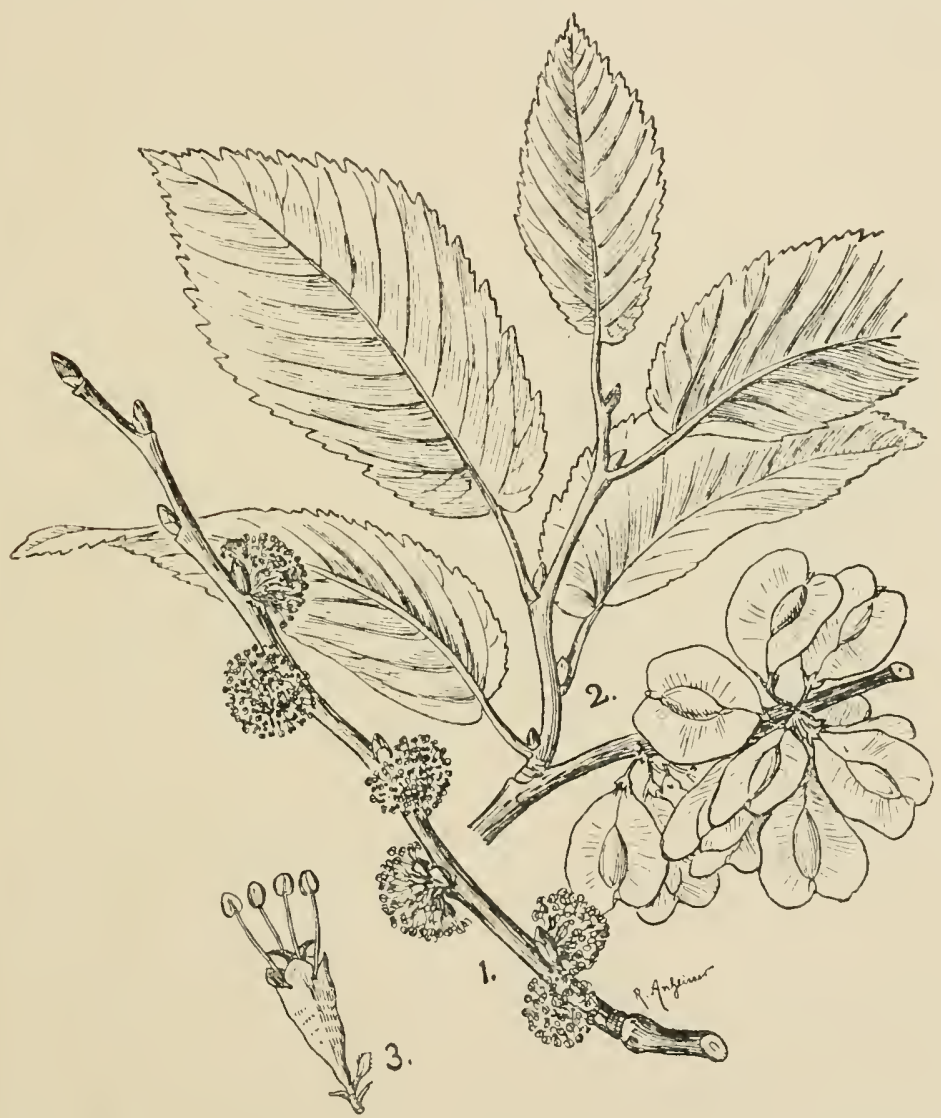

Fu: 531.--llmus cempestris (2 nat, size). 1, Branch witl flowers. 2, Branch with fruits. 8 , Single flower, enlarged.

ripen before the leaves expand. The fruits are broadly winged and adapted to he carried by the wind. U. montena, U. effusa are closely related forms. Several species of Celtis, in which the fruit is a drupe, are in cultivation.

Family 2. Moraceae $\left({ }^{25}\right)$. - The majority are trees or shrubs with abundant latex. Leaves alternate, stipules caducous. Flowers unisexual in globulat or dise-snaper inflorescences; mostly tetramerous, Stamens opposite the leaves of the perigone. Ovary bicarpellary. 
unilocular, with one pendulous anatropous ovule. Widely distributed family.

Important Representatives. - In addition to the Mulberry trees, of which Morus alba is eultivated for the rearing of Silk-worms and M. niyra (Fig. 491, B) as a fruit-tree, the genus Ficus deserves special mention. The speeies occurring farthest north is the Common Fig (Ficus carica, Fig. 532), which is endemic to the Mediterranean region, and has heen long enltivated. It is a low tree with palmately incised leaves and stipules, which form a cap-like protection to the bud. The inflorescences are lollow, pitcher-shaped structures with a narrow opening. The flower's are borne closely crowded together on the inner surface. The flat, dise-shajed inflorescences of Dorstenia which bear the flowers on the npper surface are in many respects corresponding structures $\left({ }^{26}\right)$. The pollination of the Fig is

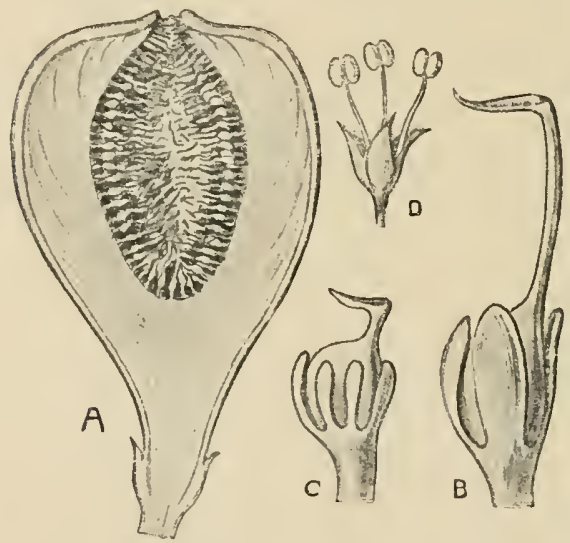

Fic. 532.-Ficus carice. A, Longitudinal section of an inflorescence. $B$, Fertile flower. $C$, Gall-flower. $D$, Male flower. ( $D-D$, enlarged; $D$, after KERnER; $B, C$, after Solms-Lal'bach.) soil, and it is no longer dependent on the scanty food supply obtainable in the epiphytic position. The host-plant is gradnally strangled, additional roots are sent down to the soil and thicken into pillar-like supports, and ultimately a small wood capable of sheltering an entire village is developed from the single small seedling. The latex of Ficus clastica is obtained from the tree by making incisions in the bark, and serves as one souree of india-rubber. Castilloa elasticu is another important rubber-tree of Central America. The gigantie infloreseences of species of Artocarpus when in fruit are eaten raw or cooked and form the Brcadfruit of the Tropics.

The species of Cecropia are Amcrican mymecophilous trees $\left({ }^{27}\right)$. The ant-plant theory propounded and established by FuITz NÜLLEI and Schimpre is based largely ou Cecropia arlenopus, a common tree of tropical America. This harbours a species of ant in the hollow internorles of the stem and also bears albuminous "MüLLEn's borlies" on the leaf-hases; these are utilised as food by the ants. Acoording to the hypothesis advancel these provisions of honse-room and food to a war-like species of ant are adaptations to enable the plant to withstand the attacks of leaf-eutting ants. The latter cut out picees from the leaves and carry them to 
their nests, where they are knearled up into a mass npon which the fungal cultures are made; this fungus is the sole fool of these ants. While the fucts observed by BELT and MöLLER are well established, their connection with the protection afforded by the ants in the stem has become donbtful. Various observers have shown that Cecropia can exist quite well without the defendingr ants, that the leaf-cutting ants are less injurious than other animals and insects, and lastly, that those more injurious forms are left unmolested by the defensive ants. The formation of M ḦLLER's bodies must thus have some other explanation. Similar structures ocenr in other plants and remind one of the extra-floral neetaries.

OFFICIAL. - The fruits of Ficus carica.

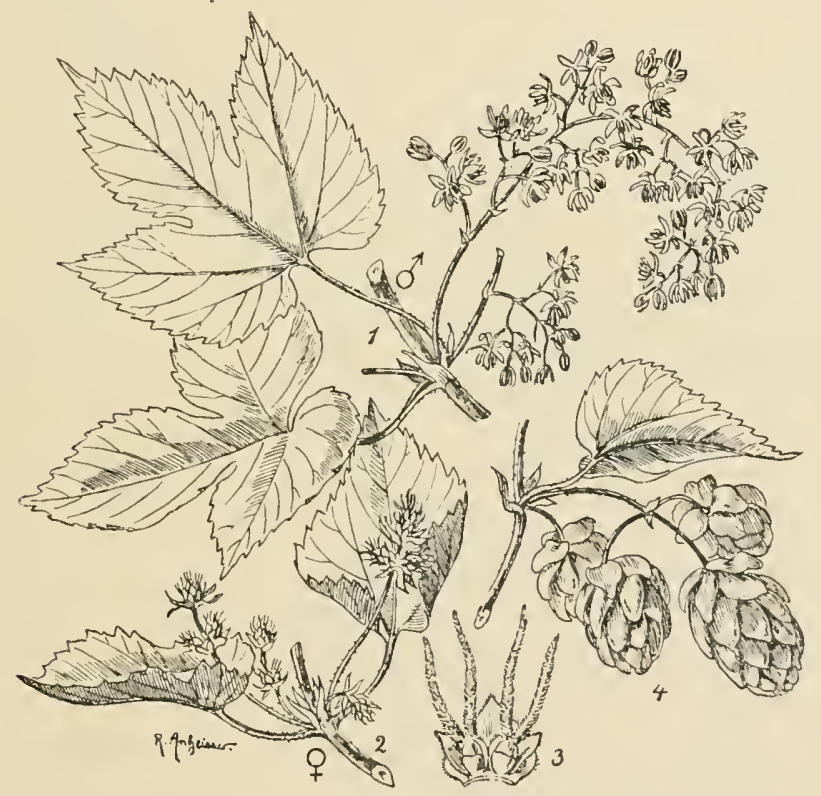

Fig. 533.-Humulus lıpulus. 1, Male inflorescence. 2, Female inflorescence. 3, Two female flowers in the axil of a bract. 4, Cone-like inflorescences in fruit. (1 uat. size.)

Family 3. Cannabinaceae.-Annual or perennial herbs without latex, with palmately veined leaves and free, persistent stipules. Dioecious. Male flowers pentamerous; stamens straight in the bud. The male inflorescences are dichasia, the eentral branch capable of further growth. The female flowers have a slightly developed, cntire perianth. Ovary bicarpellary, with two large feathery stigmas; unilocular, with a pendnlons, anatropous orule. Anemophilons. Fruit, nut-like. Embryo curved.

Genera.-Humulus lupulus, the Hopr, is a native of central Europe; it has a perennial rhizonse, which annully prodnees a crop of twining shoots (Fig. 533). The stem and opposite leaves bear eoarse hairs, and the former hears hooked priekles which jrevent it slipping down the support. The branches of the female inflorescence are catkin-like, the scales being formed of the pairs of stipules belonging to bracts, the laminae of which are suppressed. The axillary shoot of 
the bract is also suppressed, but each stipule has two flowers in its axil ; each flower is enclosed by its own bract. These bracts project beyond the stipules when the inflorescence is mature, and give the latter its cone-like appearance. Upon them are developed the glandular hairs on account of which the Hop is eultivated.

Comabis sativa, Indian Hemp, is an annual herb with palmately divider, hairy leaves, which are opposite below and alternate in the upper portion of the shoot. The female inflorescence resembles that of the Hop, but the central shoot, which in that plant is suppressed, grows out in the Hemp to a leafy shoot. Only a single flower is present in the axil of each bract. The same process is repeated in the axil of each leaf of the leafy middle shoot, so that the whole female inflorescence is a repeatedly branched structure. The plant is utilised in Europe for its bast fibres, which are from one to several centimetres long $\left({ }^{28}\right)$. The glandular hairs which cover all parts of the female inflorescenee seerete a sticky resinous substance which is used medicinally. In the East it is used in the prepraration of a narcotic ealled Hasehiseh.

OfFicial.-Cannabis sative provides cannabis indroa. Humulus lumulus provides LUPULUS and LUPULINUM.

Fanily 4. Urticaceae.-Perennial herbs or less commonly shrubs. Leaves simple, stipulate. Flowers unisexual by suppression of parts, as a rule bimerous. $\mathrm{P} 2+2, \mathrm{~A} 2+2$. Stamens inflexed in the bud, and scattering the pollen when they suddenly straighten. Ovary consisting of a single earpel, unilocular, with a basal, atropous ovule. Perianth of the female flower adherent. Flowers in dichasia, or crowded in dorsiventral infloreseences. Anemophilous. Widely spread in the tropics.

$\Lambda$ number of the Urticaceae are characterised by the possession of stinging hairs (ef. Fig. 126), e.g. the common Stinging Nettles, Urtica dioice and U. urens, and the dangerous tropical species of Laportea. Some provide important fibres, especially Bochmeria nive from which hamie fibre is obtained, and of less value, Urtica connobine, and our native species of Urtice.

\section{Order 6. Loranthiflorae}

Woody plants (only the Balanophoraceae are herbaceous) with opposite or alternate leaves and frequently with entomophilous flowers. Ovary inferior, uni. locular, compound of 1-3 earpels.

Family 1. Santalaceae $\left({ }^{29}\right)$. - Green plants growing in the soil and partially parasitic on the roots of other plants from which their haustoria obtain nutrient materials. In Britain, Thesium.

OFFICIAL. - Santalum album, the wood of which when distilled yields oLEuM SANTALI. The wood is also of economic value.

Family 2. Loranthaceae $\left({ }^{30}\right)$. - Leafy semi-parasitic shrubs, living on the branches of trees. They are most abuudant in the tropies, and, for instance in South Anerica, adil to the beanty of the forest by their brightly coloured flowers.

Lorcenthus curopreus, on Oaks in Enrope. In Britain V'iscum album (Fig. 534), the Mistletoe, oceurs as an evergreen parasite on a number of trees. It has opposite, obovate leaves. Stem swollen at the nodes. The ineonspicuons flowers open in early spring; they are dichinous and dioecious, usually himerous, and are borne in two- to five-flowered dichasia. The white berries ripen during the winter (December to Nareh) and are eaten by birls. By means of a viseid layer of the pericarp they allhere, together with the seeds, to branches against which the birds rub their 
beaks. The root on germination forms an expanded, attaching dise. From the centre of this a sucker, which has no root-cap, penetrates the rind of the branch as far as the wood. From the base of this sucker lateral roots arise, which grow in the rind, giving off secondary suckers. $\Lambda$ s the wood of the host grows in thickness year by year, the tips of the suckers become embedded in the new wood. Their tips become converted into permanent tissue, while further growth in length is effected by a zone corresponding in position to the cambium of the host ylant. Species of Struthantus and Phthirusa from Venezuela have caoutchouc in their fruits in place of the layers of viscin present in Fiseum ( $\left.{ }^{30 a}\right)$.

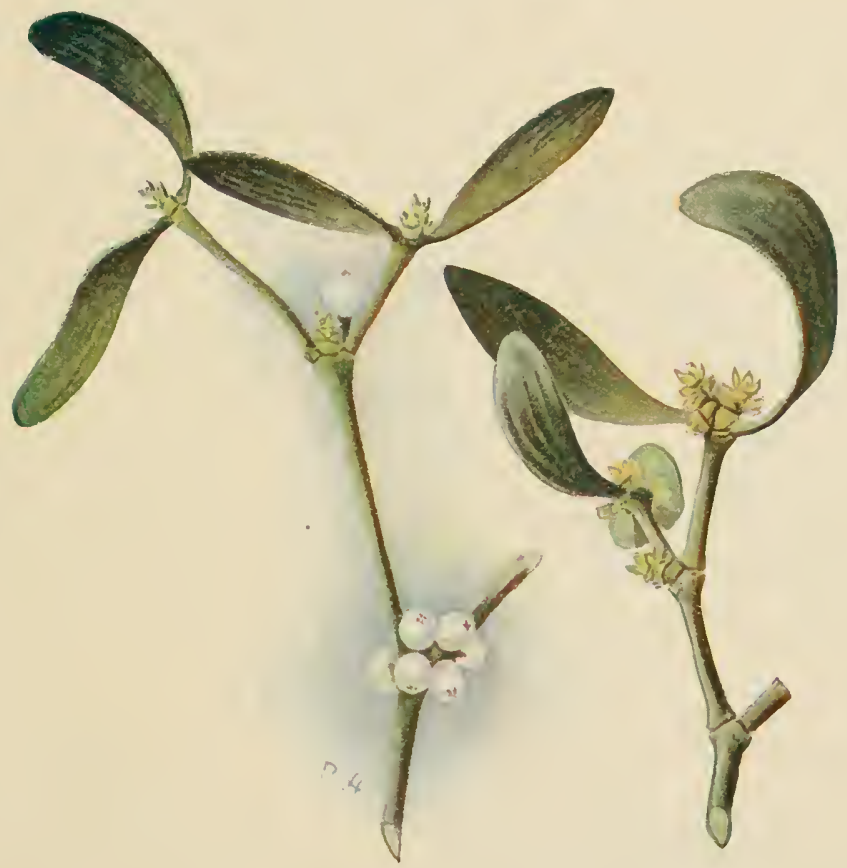

Fig. 534.-T"iscum album. With Howers and fruits. ( $\frac{1}{2}$ nat. size.)

Family 3. Balanophoraceae $\left({ }^{31}\right)$. Total parasites, without green leaves. Natives of the tropics of both hemisplieres. Species of Balenophora and of other genera are apogamous.

\section{Order 7. Piperinae}

The single Family of the Piperaceae contains a few tropical genera. Flowers as a rule unisexual and without perianth, associated in spikes; typically trimerous but usually reduced. Ovary unilocular, ovule solitary, basal and atropous. Fruit drupe-like. The embryo is embedded in a small end sperm surrounded by a well-developed perisperm. The vascular bundles are scattered in the cross-section 


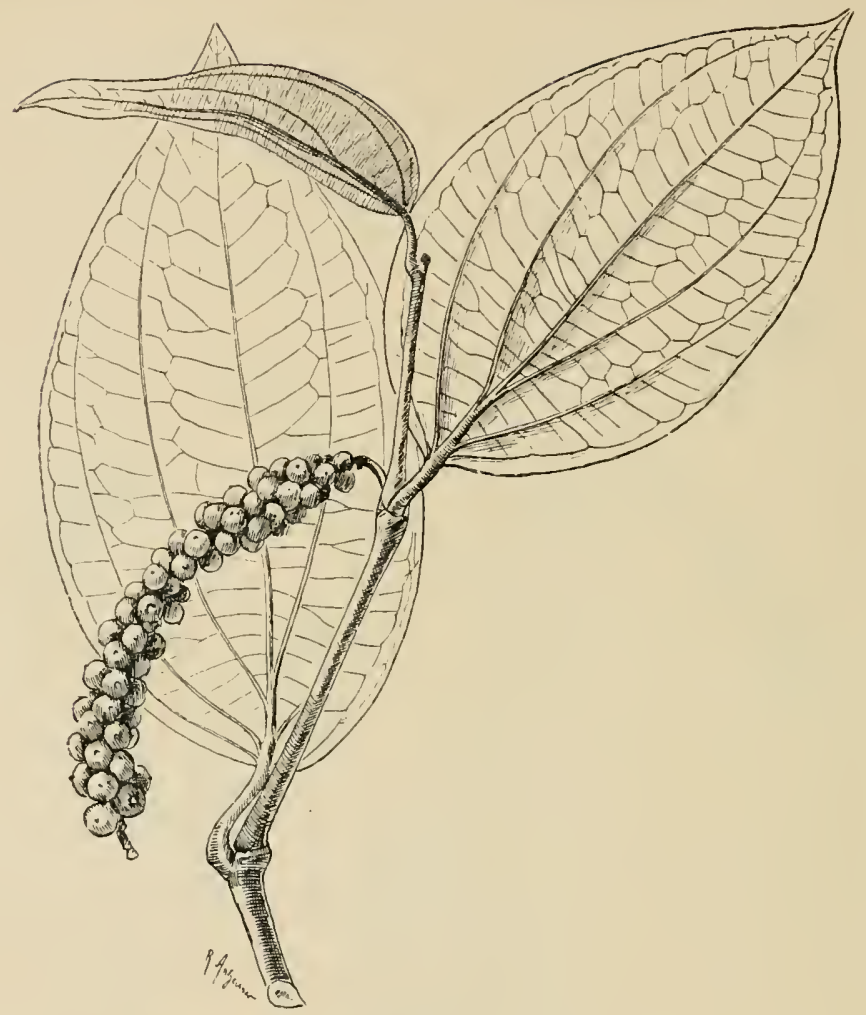

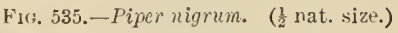
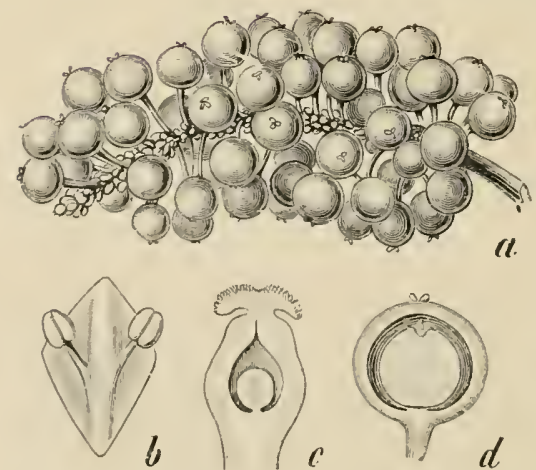

Fis: 536.- Piper cubelic. ", Infructescence; $b$, a male flower; $c$, a fenale flower in longitudinal section; $d$, fruit in longitulinal section. OFF. ('IAL. (After BERf and SchMIDT.) of the stem resembling the arrangementin Monocotyledons, but with secondary thickening.

The gemus Piper includes a large number of shrubby plants of primaeval forests. Piper niyrum, from which the Peppers are derived, is the most important representative. This is a root-climber, native to the Malayan region, but now enltivated throughont the tropies (Fig. 535). The muripe fruits provide black pepper, while white peprer is obtained from the ripe fruits after removal of the outer layers of the periearp. The genus Peperomic has hermaphrodite flowers. 
Piper eubebe (Fig. 536). The latter is a native of Java and is distinguished by the stalk-like base of the fruit from that of the Black Pepper. It provides CUBEBAE FIUCTUS.

The orders $8-10$ constitute parallel series leading from the simplest flowers to the Dialypetalae, but are not directly connected with one another.

\section{Order 8. Hamamelidinae}

Woody plants, with stipnlate leaves. Flowers as a rule inconspicuons, without perianth and anemophilous. Conspienous, entomophilous, Howers with a simple, or more rarely donble, jerianth also occur. A transitional order leading to the Dialypetalae; formerly placed with the Saxifraginae.

Family 1. Hamamelidaceae. - Woody plants of the tropies and sub-tropic:. Liquidamber styracifluc is a common tree in North American forests. Flower's monoecious in heads: male flowers aletalons, Altingia excelsa in the mountain forests of West Java; female flowers with a periauth and a bilocular ovary.

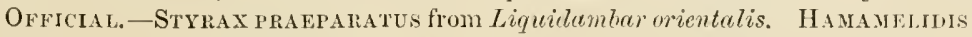
COLTEX and Folda from Hamamelis virginiana.

Family 2. Platanaceae.-Stately trees with alternate, three- to five-loberl leaves and large stipules. Elower's diclinons, monoecious, in small splherical hearls, three or four of which are borne at some distance from one another on pendulons stalks. Male flowers with three to four stamens; female flowers with four free carpels. Perianth inconspicuous. Natives of Western Asia and North America.

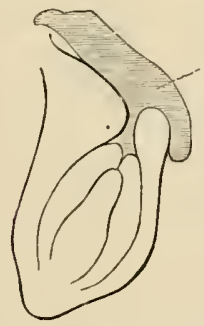

Fis. 537.-()vule of Euphorbiu dioice showing the obturator. (After Pax in Engler-Prantl.)

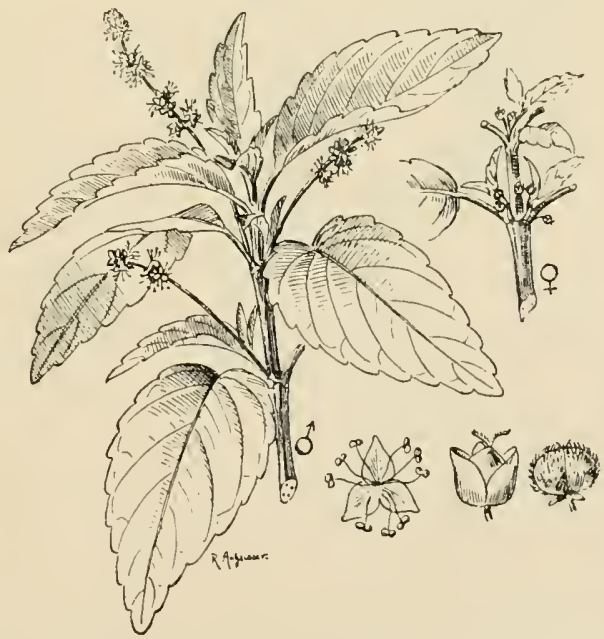

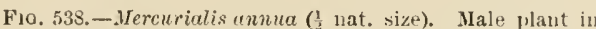
flower and single male flower. Portion of a female plant. single female flower and fruit. Porsovors.

Platumus orientalis and $I$. occulentalis are commonly planted as shade trees by the sides of streets.

\section{Order 9. Tricoccae $\left({ }^{32}\right)$}

The large Family of the Euphorbiaceae which belongs to this order is of much greater importance than the small family which is 
here placed along with it. The plants belonging to the Euphorbiaceae are of very diverse halit. The order includes herbs, shrubs, leatless succulent plants, trees with normal foliage, and others with scale leaves and assimilating phylloclades. The plants agree, however, in possessing unisexual, actinomorphic flowers, with a simple perianth or with no trace of the latter. Androecium diplostemonous or stamens numerous. The female flowers are especially characterised by

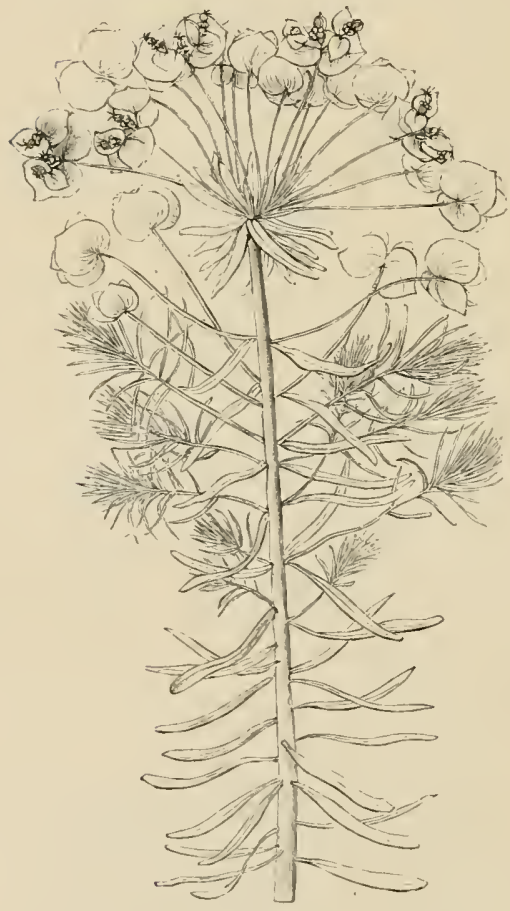

Fu, 539.-Enphortiu (ypurissiens (a nat. size). Porsonac's.

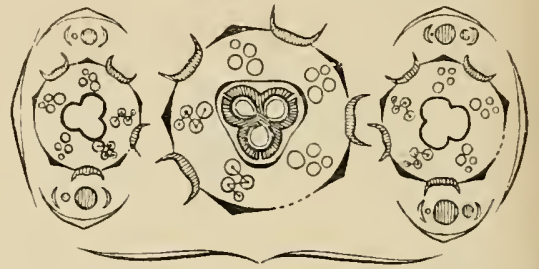

Fig. 540.-Diagram of a dichasial branch of Euplior. hive, with three cyathia, only the middle one of which has a fertile female flower. (After Eıcнi.fr.)

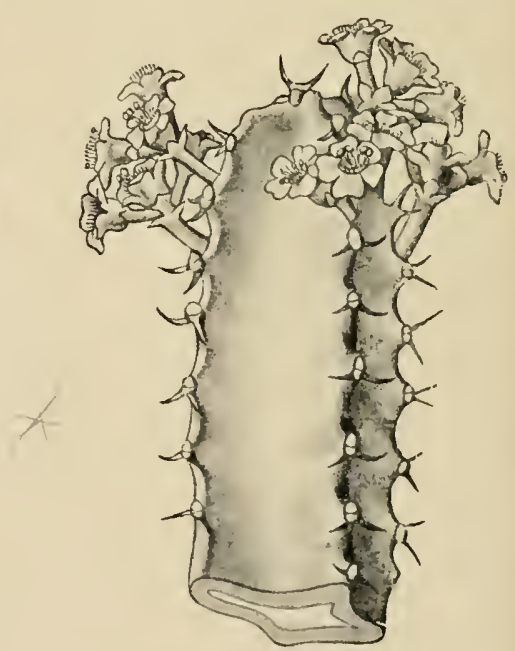

Fu, 541.-Euphorbia resiniferr. (Nat, size. After BERg and Scminit.)

the superior, trilocular ovary formed of three carpels; in each loculus are one or two pendulous ovules with a ventral raphe, and the micropyle directed upwards and outwards.

The micropyle is covered by a placental ontgrowth called the obturator (Fig. 537); this assists in condueting and nourishing the pollen-tube, and disappears after fertilisation. The existence of the obturator on the orule may be regarded, as marking a transition from the clalazogamic to the porogamic fertilisation. The (ARUNCULA, which is formed from the outer integument (Fig. $542 \mathrm{D}$ ), persists on 
the other hand in the seed ; the separation of the later from the placenta is assisted by it.

The fruit is a capsule, the outer walls of which contract clastically away from a central column, and thus open the loculi.

The plants of this family are distributed over the whole earth. IMrortant GENERA. - Many Euphorbiaceae are dioecious or monoecious, and have flowers of relatively simple construction. Thus Mecurialis (Fig. 538), two species of which oceur in Britain, is characterised by its bicarpellary ovary. Croton is a tropical genus including valuable official plants, $C$. Eleuteria and $C$. Tiglium; the male Howers have a double, the female flowers a single perianth. In the Sjurges
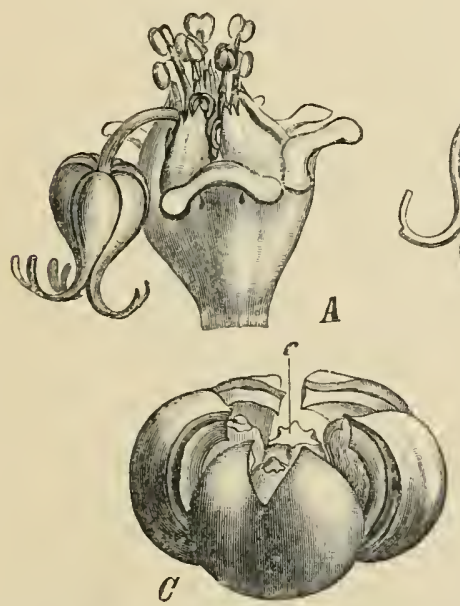
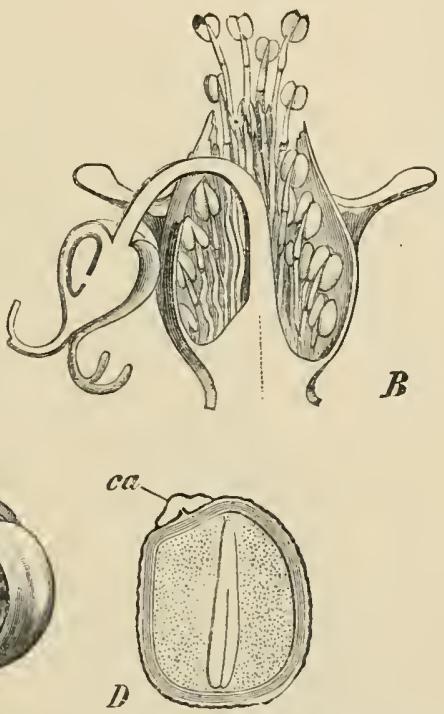

Fia. 542.-Euphortia Lathyris. A, Cyathium $(\times 5), \quad B$, Cyathium cut through longitudinally $(\times \quad$ ). $C$, Fruit after dehiscence showing the central columm (c). D, Seed in longitudinal section showing the embrgo embedded in the endosperm; cu, caruncula $(X 4)$. ( $A$ - $D$ after BAILLON.)

(Euphorbia), of which there are several British species, a number of the extremely simply constructed flowers are grouped in a complicated inflorescence terned a Cyathium (Figs. 539-542). This consists of a naked, terninal, female flower, borne on a long bent stalk surrounded by a number of groups of male flowers. Each of the latter is stalked and consists of a single stanen, the limit between which and the flower-stalk is distinguishable. In some cases the female flower and each male flower are provider with a small perianth. The whole cyathium, which is an inflorescence, is always enclosed by five involucral bracts; alternating with these are four nectar-secreting glands, the presence of which increases the likeness between the cyathium and a flower. The fifth gland is wanting, and the inverted female flower hangs dow in the gap left. Between the groups of male flowers which stand opposite to the braets (Fig. 540), are branched hairs which are visible when the eyathium is cut through longitudinally (Fig. $542 \mathrm{~B}$ ). The cyathia 
are usually groured in diehasia, and these in turn form an umbellate infloreseenee, with three to many branches. It often happens that the female flower is only derelopet in some of the eyathia, remaining rudimentary in the others. Many speeies of Euphorlio, especially the African species, are succulent-stemmed plants - resembling Cucti in general appearance (ef. Fig. 541).

Euphorbic, like many but not all the other plants of the fanily, contains a

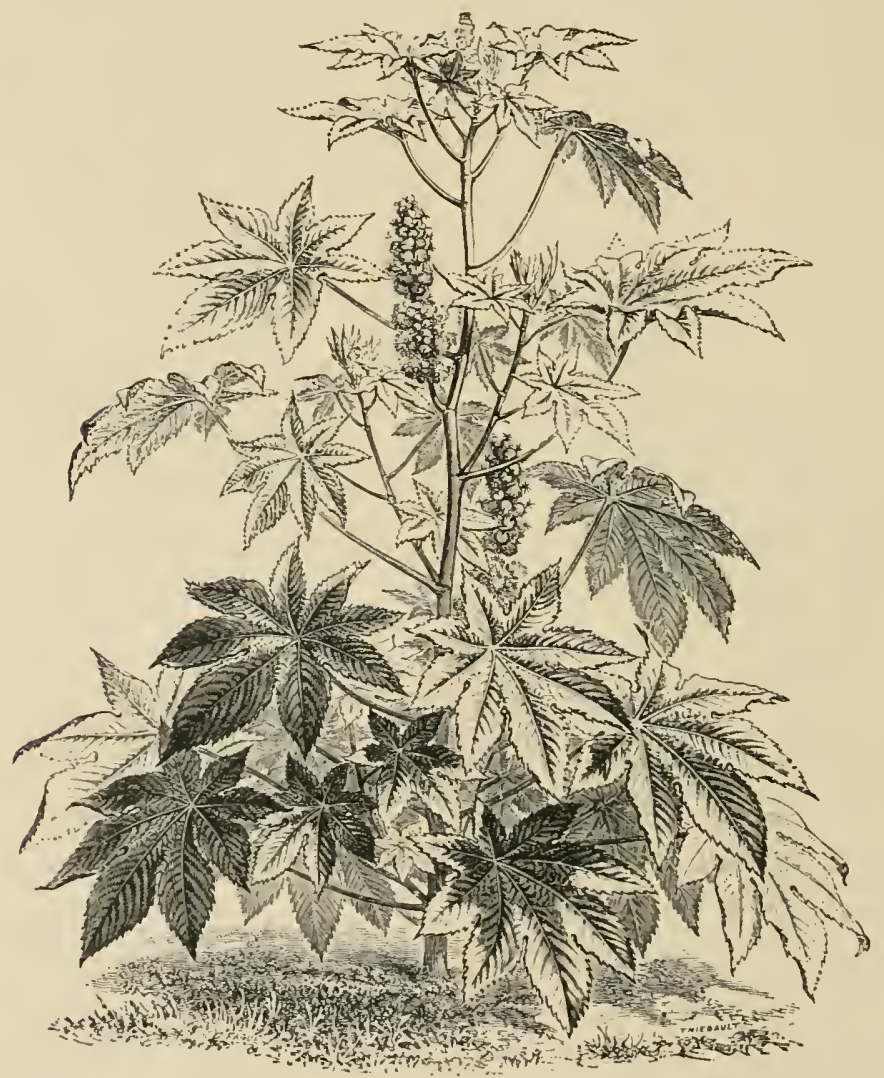

Fit, 543.- Ricinus communis, greatly reducel. (After BaILLOx.) I'olsovot's and OFFICIA.

milky juice, which is secreted in non-septate latex-tubes. This jnice, which in many eases is poisonous, exudes wherever the plant is wounded.

An important constituent of the latex of species of Hevec (H. Sicberi, diseolor, rigidifolia, paucifolia, lutea, yuyanensis, Spruceana) is caovrchovc. As Para Rubber obtained in the tropies of Sonth America, especially in the $\Lambda$ mazon Region, this affords ahout one half of the total rubber supply. In addition IIonihot Glaziovii, another Sonth American plant of this order, which yields Ceara Rubber, must be mentioned. A nearly related plant, Munihot utilissima, provides in its tuberous roots a very important food in the tropies. The stareh obtained from 
these roots forms mandioc or cassava meal, the finest varictics of which, as tapioca or Brazilian arrowroot, are of commercial importance. The shrub, which is a native of Brazil, is now enltirated thronghout the tropies.

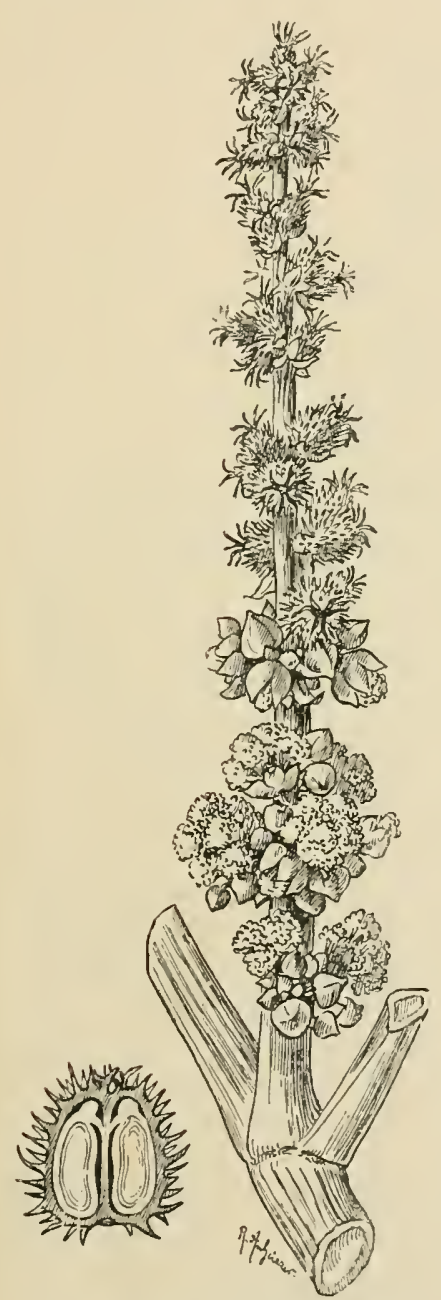

Fir. 544.-Riciuss rommunis. Inflorescence ( $\frac{\mathrm{I}}{\mathrm{s}}$ nat. size); young fruit eut through longiturinally. OFFICIAL.
Ricinus Communis (Fig. 543) is a tall shrub of tropical Africa. In our climate it is annually killed by the frost. The hollow stem bears large palnately diviled leaves. The terminal inflorescences (Fig. 544) are overtopled by vegetative lateral

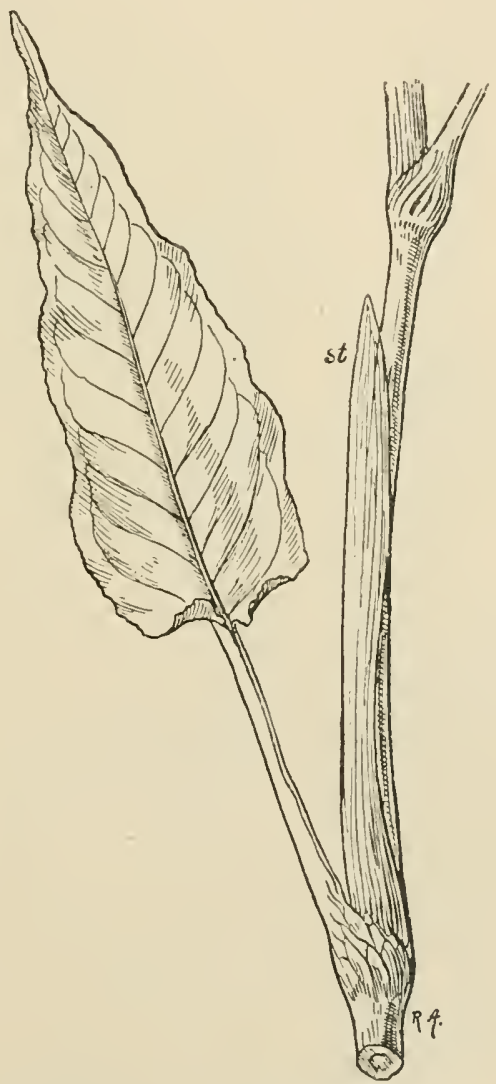

F16. 545.-Leaf of I'olygonum rmplexicunle show-

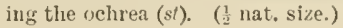

branches. The male flowers, situated towards the base, have a membranons calyx of $4-5$ sepals, enclosing the lianched stamens; the end of cach branch bears a theea The female flowers, nearer the sunmit of the inflorescenee, have 3-5 sepals and a large triprartite ovary. The latter is covered with warty prickles, and bears 
three large, bifid, red stigmas. In each loculus of the fruit is a mottled seed with a whitish caruncula.

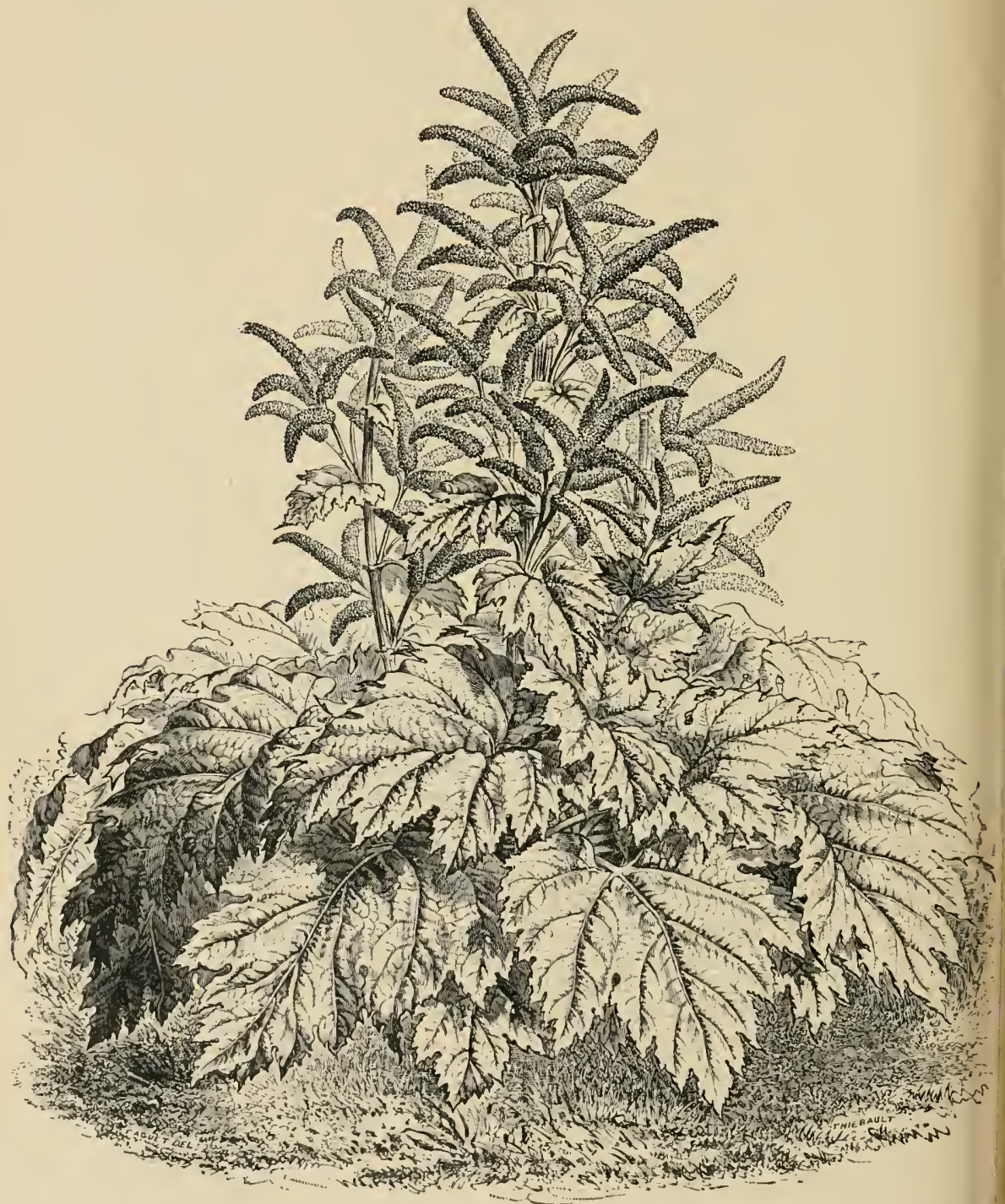

Fro. 546.--Rheum oficinule, greatly reducerl. (After BaILlon.)

OrFicial.-Croton Eleuteria (Bahamas) yields cascanılLA. C. tiglium (East Indies), oleun chotonis. Oleum lidCini, Castor Oil, is obtained from Ricinus Conmunis. 
Fumily 2. Buxaceae. Characterised by a loculicidal eapsule, and a dorsal raphe to the seed. Buxus sempervirens, the Box, is a poisonous evergreen shrub with very elose wood, native of Southern and Western Europe. In the axils of snali, decussate bracts stand capitate inflorescences, consisting of a terminal, trimerous female flowcr, and a number of tetramerous male flowers.

\section{Order 10. Centrospermae}

Herbs, less commonly small woody plants. Flowers with few exceptions hermaphrodite and tri- or penta-merous. Perianth and androecium consisting of onc or two whorls. Sometimes numerous stamens. Ovary superior, milocular, with a single basal ovule or with a free central placenta bearing a number of ovules with very long funicles.
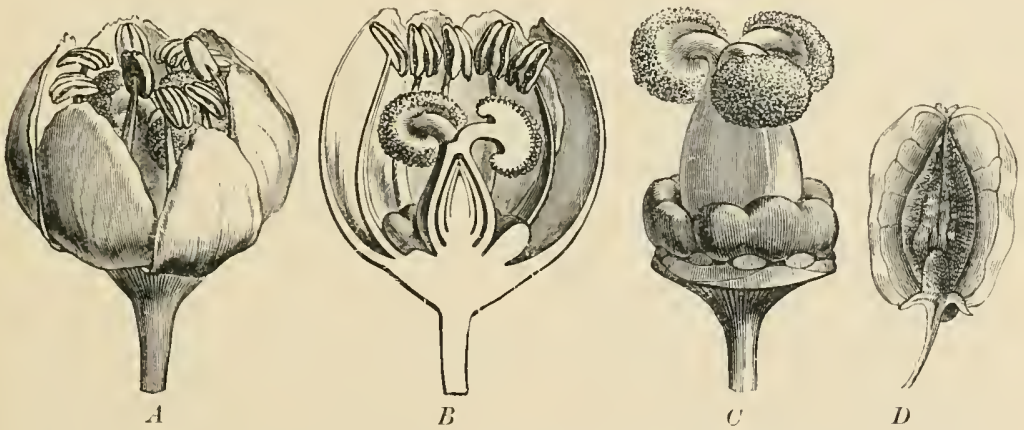

FIG. 54t.-Liheum uffirinale. A, Flower; $B$, the same cut through longitudinally; $r$, gynaecenm with dise. Rheum compectum: $D$, fruit. (After Lürssex, mannitiel.)

Family 1. Polygonaceae.-For the most part perennial herbs, with hollow stems swollen at the nodes, and alternate, simple leaves. The membranous stipules of the latter are coherent to form a sheath or OCHREA protecting the terminal bud; when broken through by the growth of the stem, this remains as a tubular sheath around the lower part of the internode (Fig. 545). The hermaphrodite flower is typically trimerous, but a larger number of members sometimes occurs in the perigone or the androecium. Ovary superior, formed of three earpels, unilocular, with a single, basal atropous ovule. Fruit in nearly all cases a triangular nutlet.

Mainly natives of the $\mathrm{N}$. Temperate zone.

Genera.- Rheum, Rhubarb. This is an East Asiatic genus, with large, radical leaves and a large,.spreading, paniculate inflorescence (Fig. 546). Leaves simple, cordate-reniform, with palmate venation, sonetimes more or less lobed. The flower has a perigone of two similar whrrts, and two whorls of stamens, the outer whorl being double by chorisis; $\mathrm{P} 3+3, \mathrm{~A} 6+3, \mathrm{G}$ (3). Nectar for visiting insects is secreted by the large scales of the disc. The triangular ovary becomes winged as 
it derelops into the fruit (Fig. 547). Speeies of Rheum are cultivated as ornamental plants and as vegetables. Rumex acetos $\left({ }^{33}\right)$, Sorrel, with sagittate leaves. The structure of the flowers of the hermaphrodite species of Rumex is similar to that of Pheum, but the inner whorl of stamens is wanting. The species of Polygonum have

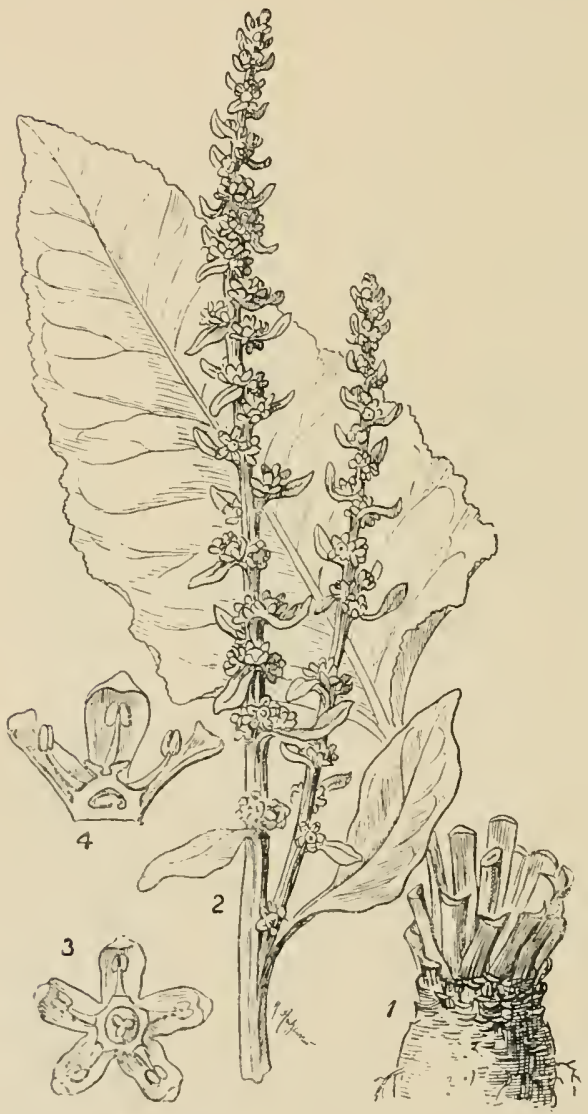

Fifi. 548.- Jietce vulgaris. 1. U1per portion of the root with the rosette of leaves, the blades of which are cut ofl. (Greatly reducerl.) 2, Branch of the inflorescence ( $\frac{1}{2}$ nat. size). 3, Single flower. 4, Flower cut throngh longitudinally ( 3 and / ("ularged).
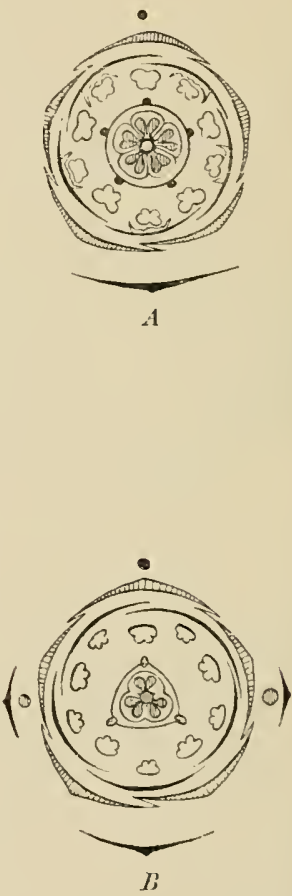

FIt. 549.- lliagrams of the Caryophyllaceae. A, Viscrevia, septa present in the lower lart of the ovary; $B$, Silene, septa absent. (Atter Ercuter )

a perigone eonsisting of five coloned leaves and a rarying number of stmens. The triangular fruits of Fagopyrum csculentum form Bnekwheat (Fig. 487).

OrFI'IAL.-The Rhizome of Rheum officinale, Rh. palmatum, and prohably other species yields ranx riner.

Family 2. Chenopodiaceae.-Perennial or anmual herbs, rarely small woorly plants, with alternate leaves. Flowers typically 
pentamerons, with a single wholl in both perigone and androecium; P 5. A 5, G $(2-5)$. Redueed, unisexual flowers are not infrequent. The uniloeular ovary eontains a basal, eampylotropus ovule. Fruit, a nut. Seed with a curved embryo bent around the perisperm.

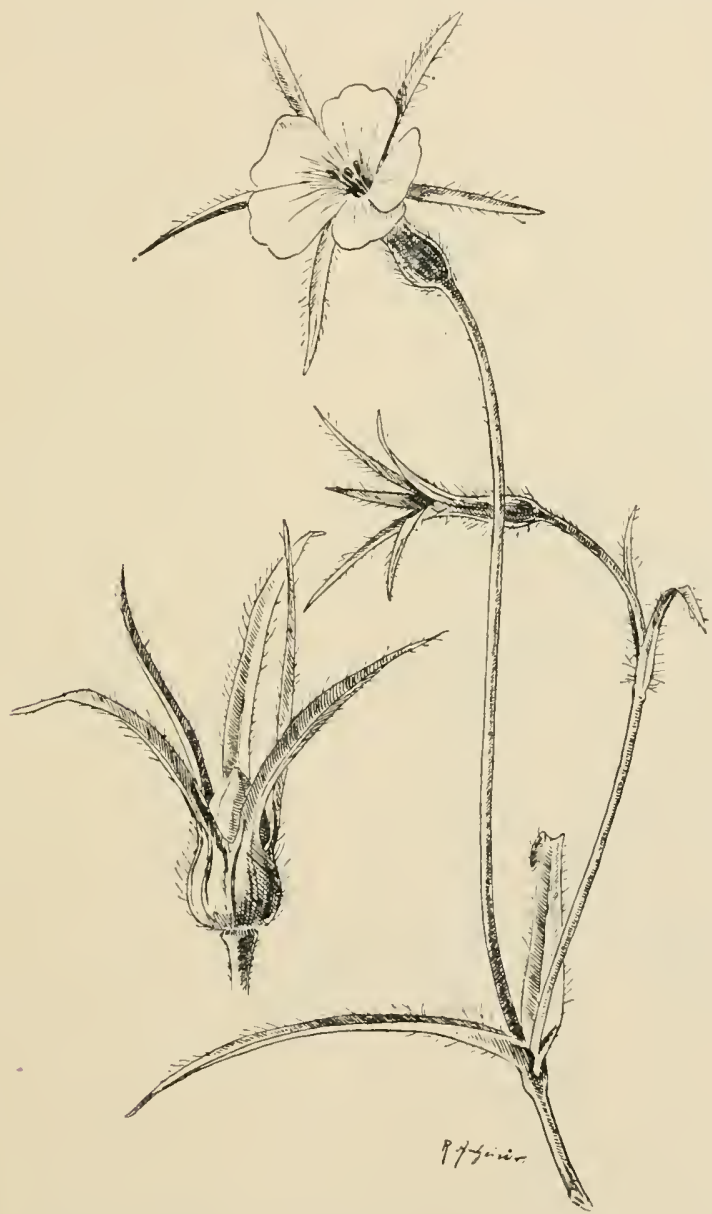

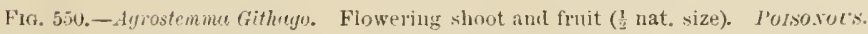

Many of the Chenopodiaceae are strand plants or occur on soils containing a large amount of salt, such as the great A siatic salt steples and deserts $\left({ }^{34}\right)$. The Spinach (Śpinacia oleracea) and the Summer Spinach ( $S$. glabra) are used as vegetables. The Sugar Beet (Beta vulyaris, var. rapa) (Fig. 548) is a plant of great economic importance. It is a biennial plaut, and in the first season forms a thick, swollen root bearing a bud consisting of a number of thick-stalkerl, entire, succulent, and often crisperl leaves. From this rosette of leaves there springs in the second season 
a highly branched panicle, bearing the inconspicuous greenish flowers. Ovary formed of three carpels. At the end of the first season the root contains cane-sugar as a reserve material, which at this stage is extracted from the plant. By constant selection the percentage of sugar is raised from $7-8 \%$ to an average of $14 \%$; it nuay, however, reach $21-26 \%\left({ }^{35}\right)$. The original form of the Sugar Beet is Beta patula.

Chenopodium and Atriplex are

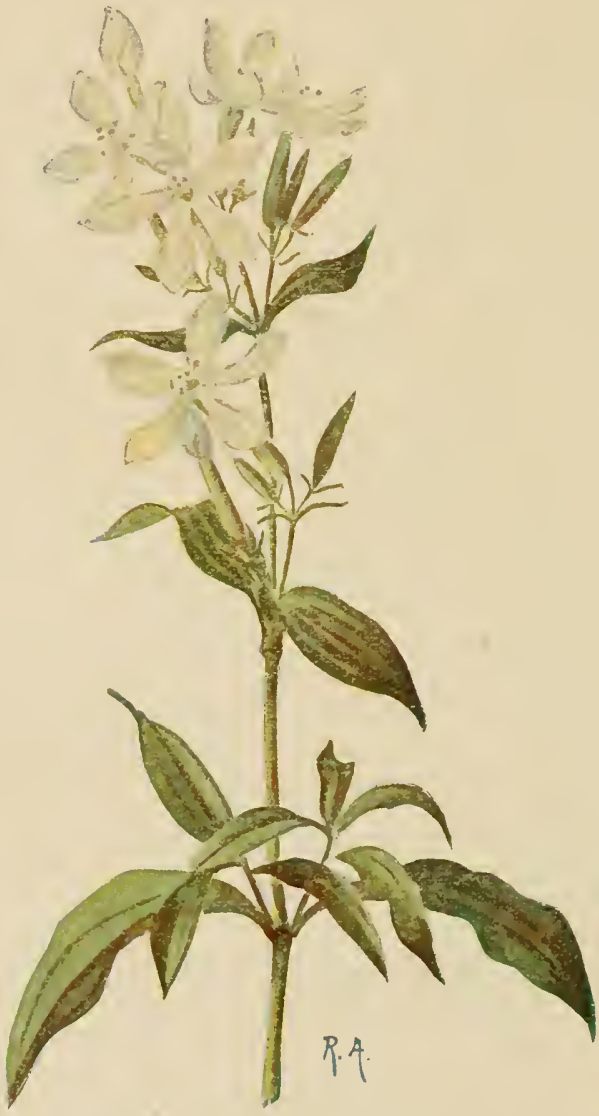

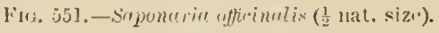
l'olsonots common weeds near luman dwellings.

\section{Family 3. Caryophyl-} laceae. - Annual or perennial herbs, very rarely shrubs, with simple, liuear, usually opposite leaves; flowers typically pentamerous, witl calyx and corolla. Two whorls of stamens, obdiplostemonous. ['nilocular or incompletely septate ovary. K5, C5, $\mathrm{A} 5+5, \mathrm{G}(5)$. Fruit, a capsule. Seeds numerous, embryo curved around the floury perisperm. In reduced forms the fruit is mut-like (Figs. 549-551).

The family is distributed over the whole earth.

Sub-Fanilies Axi Gexelia. -1. Alsineae-Calyx prolysepalous; petals with short claws; fruit, a capsule. Cerastium, Speryule, with pentamerous Howers; Stellaria and Arenaria with tri-carpellary ovary.

2. Perouychicae. Calyx polysepalous; corolla wanting or ineonspieuous; fruit nutlike. Selerenthus, Herizicria. 3. Silenere. Calyx gamosejalous; petals with long claws, fruit a capsule. Lychnis and Ayrostemun with five carpels, Silene with three, Dianthus and Saponctia with two.

Cerustium and Stellaric have white flowers and bifid petals, and are conspicuons, early-flowering forms. Species of Diunthus, Pinks, have frequently attractire colours and scent, and oceur in dry sunny situations. Ayrostemma Githago (Fig. 550), Corn-cockle, is a hairy plant with pink Howers; it is a common weerl in corn-fields. Since its sceds are poisonous, their mixture with the grain may have serions results. S'aponarice officinalis oceurs especially by the banks of streanı ; it 
is a lierb attaining the height of a metre, with opposite, loroad leaves and rosecoloured flowers. The saponin contained in all parts of the plaut remers it [oisonous (Fig. 551).

Family 4. Aizoaceae ( $\left.{ }^{17}\right)$. Perennial herbs or small shrubs, usually with succulent leaves. Flowers herma] a poly petalous corolla derived from modified stamens. Stamens numerous. Carpels $2-\infty$; united to form a superior or inferior, septate ovary. Fruit a capsule.

Xerophytic plants of lot countries. Mesembryanthemum; a large genus, especially in A frica.

Family 5. Cactaceae $\left.{ }^{36}\right)$.-For the most part leafless plants.with succulentstems, natives of America. In size they range from very small to gigantic forns. Flowers hermaphrodite, actinomorplic, less commonly dorsiventral. Perianth of many members, spirally arranged and showing a gradual transition from the calyx to the corolla. Stamens and carpels numerous. Oraly inferior, unilocular, with numerous parietal placentas. Ovules with long stalks. Fruit, a berry, the succulent tissue being largely derived from the stalks of the seeds.

Peireskia and some species of Opuntic possess leaves. Other species of Opuntia have flattened branches. Cereus, Echinocactus, with longitudinal ridges on the stem ; Mammillaria has free projections (mamilhae). The numerous groups of spines on the shoots, ribs, or separate mamillae corre. spond to axillary shoots, the subtending leaves of which are re-

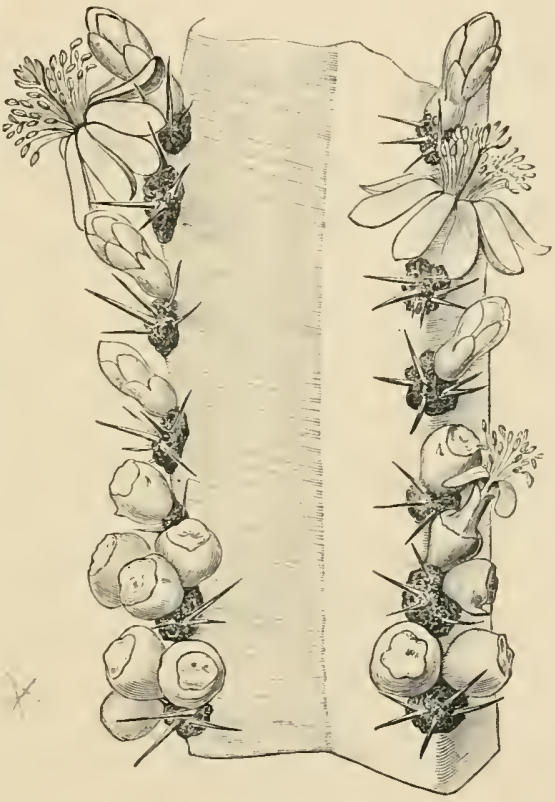

Fis. 552. - Cereus geometrizuns. Two of the ribs or ridges of a five-ribbed stem bearing flowers and fruits ( $\begin{aligned} & 3 \\ & 1\end{aligned}$ nat. size). duced, while the leaves of the expanded axis of the axillary shoot are metanorphosed into spines (Fig. 552).

Cactaceac form a dominant constituent of the regetation in the dry soutl. western regions of the United States and in Mcxico. They are also widely distributed in the West Indies and Sonth America. A similar habit is found in some Euphorbiaccae and Asclepiadacea living under corresponding climatic conclitions. There are numerous epiphytic Cactaceae, especially species of lihipsulis, Epiphyllum: and Phyllocactus, which clothe the branches of trees and atlect the general aspect of the regetation.

Opuntia ficus indica has become naturalised in the Mlediterranean region. The fruits of this species and of others of the grenus are edible, and the plants are cultivated as fruit-trees. Some Cactaceae, such as Anhalonium, contain highly poisonous alkaloids and saponine. The Cochineal insect is grown upon species of Opuntia and Nopalea ( $N$, coccinellifera). 


\section{B. Dialypetalae}

Flowers with a green calyx and a coloured eorolla.

\section{Order 11. Polyearpicae}

This large order includes a number of families of very different general appearance but exhibiting as common characters a superior gynaeceum with the carpels free from one another, and a spiral

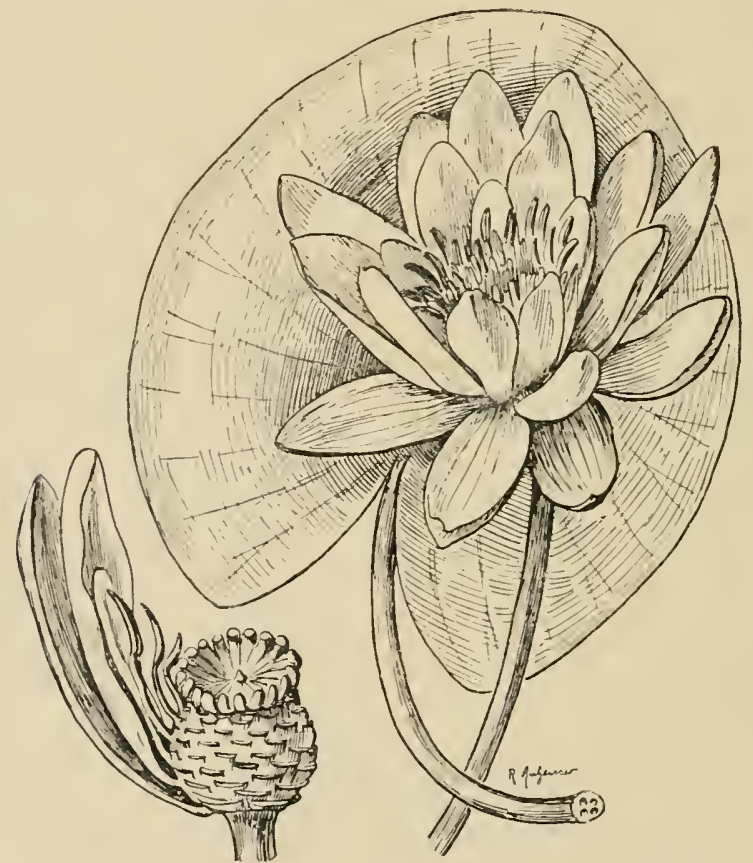

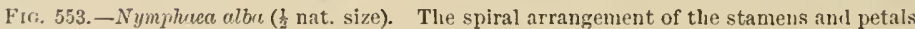
is shown by their insertions on the ovary to the left.

arrangement of the members of the flower. The tendency to considerable increase in the number of stamens stands in relation to this.

It is, however, to be notel that by no means all the plants of the families united in this order exhibit the above characters in the same degree. The characteristic features may indeed be completely wanting, though the existence of intermediate forms leaves no donbt that the genera in question must be elassed here.

Family 1. Nymphaeaceae ( $\left.{ }^{37}\right)$. - Aquatie plants with submerged or floating leaves, the latter often of very large size; when both types of leaf are present 
there is more or less marked heterophylly. Flowers hermaplirodite, with calyx anl corolla. The whorls consist of three (rarely), four or more numerous members. Carpels sometimes free. Parts of the flower often spirally arrauged (Figs. 553-555). Latex.

Nymphace alba, the White Water Lily (Fig. 553), has large floating leaves and white flowers, protected by firm green sepals. Within the corolla comes the zone

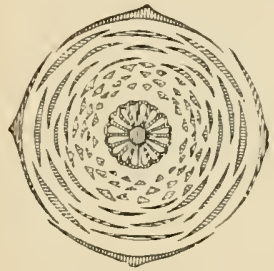

Fig. 554.-Nymphuea. Floral diagram.

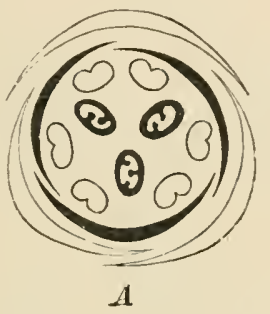

Fig. 555.-A, Floral diagram. B, Fruit of Cabomba aquatice showing two carpels developed as partial fruits. (After BAILLON. $\times 4$.)

of numerons stamens and the inferior ovary composed of numerous, coherent carpels. The spiral arrangement of the members of the perianth and androecinm is seen by the scars of their insertion when they are removed from the inferior ovary (Fig. 553), and in the floral diagram (Fig. 554). In Nuphar the ovary is superior and the small petals bear nectaries; the conspicuous calyx renders the flower attractive. In the American genus Cubomba the flowers are trimerous and the pistil is apocarpous. The finely divided, submerged leaves differ in appearance

A

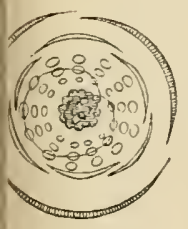

B

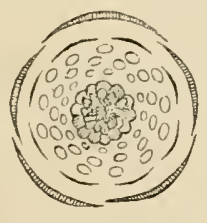

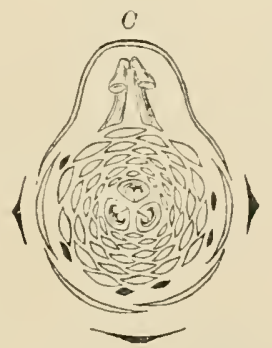

D

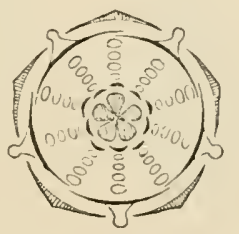

$E$

Fig. 556.-Floral diagrams of Rannnculaceae. A, Anemone nemorosa. D, Adonis autumnalis.

C, Aconitum nupellus. D, Aquilegiı vulgaris. E, Cimicifugr raremosu. (After Eichler.)

from the entire, floating leaves. The carpels are also free in Nelumbium, both the leaves and flowers of which are raised above the surface of the water. I retorit regic from the Amazon, and Eurycle ferox from tropical Asia, have gigantic floating leaves; they are often cultivated in Botanic Gardens.

The family of the Ceratophyllaceae $\left.{ }^{(34}\right)$ with the single genus Ceratophyllum may be placed here. The plants, which often occur in masses, are submerged aquatics.

Family 2. Ranunculaceae $\left({ }^{39}\right)$.- Herbs or rarely woody plants 
with alternate, exstipulate leaves. Flowers hermaphrodite, the members in many cases arranged spirally. Perianth either forming a simple perigone or differentiated into calyx and eorolla. Stamens indefinite. Pollen-grains with at least three places of exit for the pollen-tubes. Carpels three to indefinite, borne on the convex receptacle, and forming an apocarpous, superior ovary. Ovules,
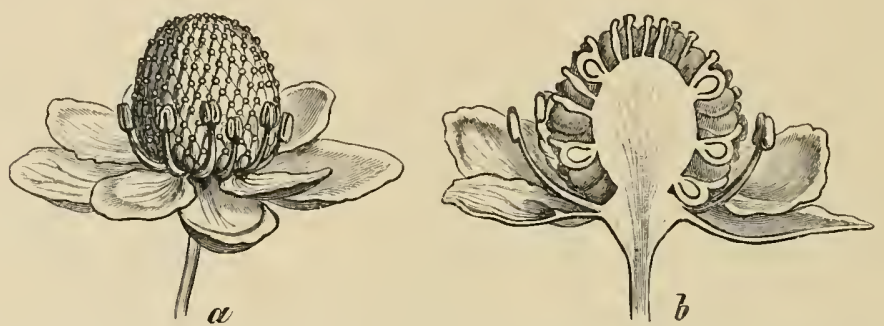

Fı, 557.-Flower of Rununculus scelerutus; $b$, the same, cut through longitudinally ; magnitied. (After BALLON.)

borne on the ventral suture, singly or in numbers. The partial fruits are follicles, achenes, or berries. Seed with a small embryo enclosed within the large, oily endosperm.

This family is mainly distributed in the northern hemisphere; some genera are widely distributed.

Important Genera. - Many of our eommonest meadow and woodland plants

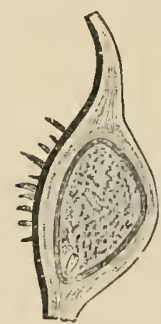

Fia. 558.-Ronunculus arvensis. (arpel in longitudiual section. (After BAlLLON, enlarged.) belong to this order. They are all in greater or less degree poisonous. Numerous speeies of Ranuncutus, eharacterised by the usually yellow flowers, convex receptacle, and fruit composed of numerous free achenes, oceur in Britain. The petals have a neetary at the base. Leaves palmately divided more or less deeply. Ir. seeleratus is very poisonous (Figs. 557, 559). R. arvensis with large, spiny achenes or mutlets (Fig. 558). The aquatie speeies of Ranunculus, belonging to the section Batrachium, are often heterophyllons (Fig. 37, p. 36), the floating leaves serving to snlyort the flowers above the surface of the water.

Spreeies of Anemone are also widely distributed in Emrope. A. nemorosa ocenrs commonly in woods and is one of our early spring flowers. It has a horizontal, subterranean rhizome, which terminates in a flower, the further growth of the plant being carried on by a lateral shoot. Perianth simple, petaloid. All spreeies of Anemone have at a greater or less distance from the perianth a whorl of, usually, three leaves forming an involuere (Fig. 560). In $A$. hepatice this stands just below the perimth and thus resembles a ealyx. All the species are to some extent poisonous, especially $A$. Pulsatille. Many are valued and are cultivated in quintity during winter, especially on the Riviera, to supply the market with ent flowers. The plants of the genus Clematis are mostly woody and chifler from other Ranuneulaceae in having opposite leaves. Many speeies are cultivated 


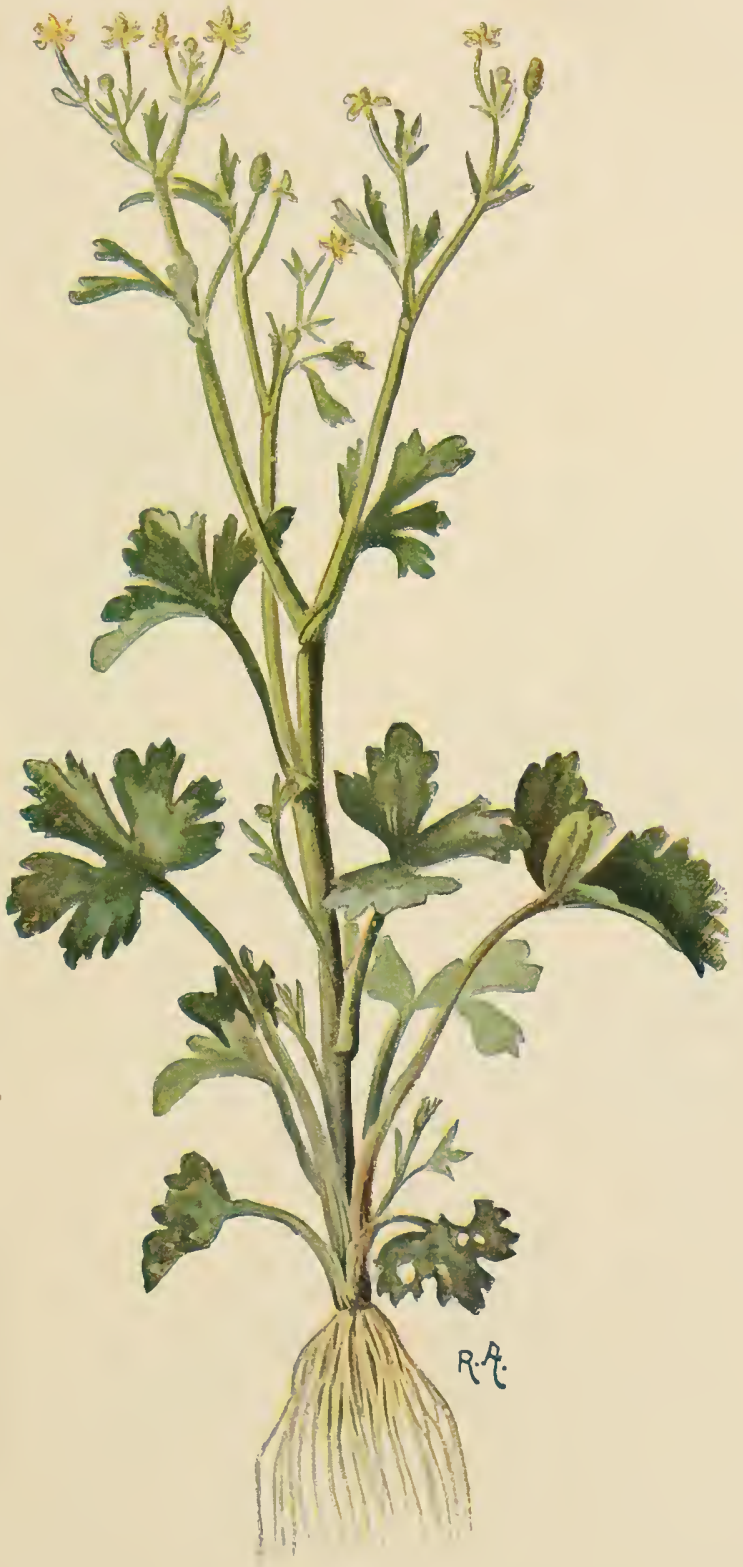

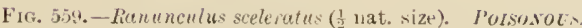




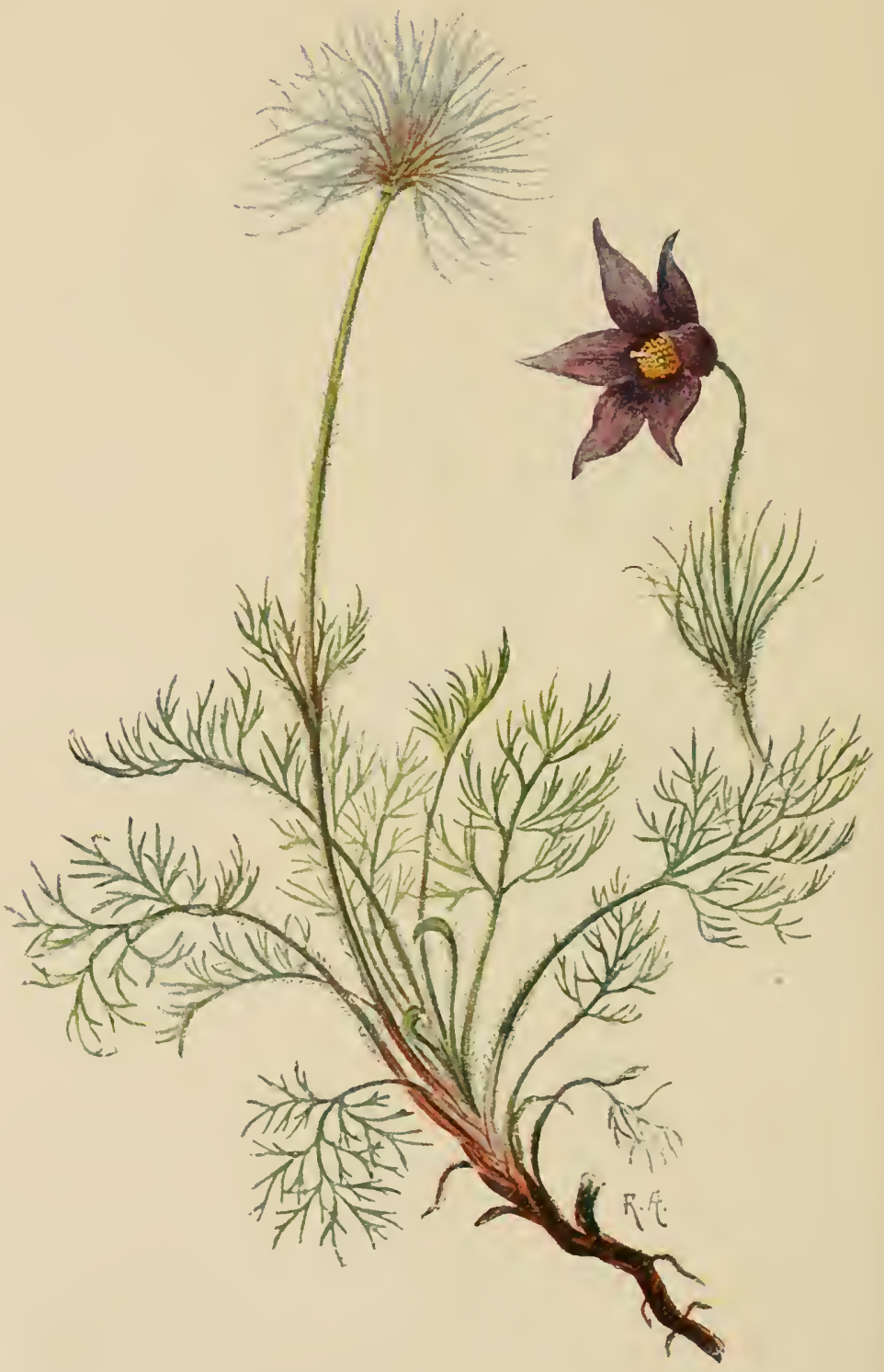

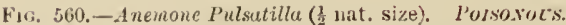


C. vitalba is one of our few native lianes. The aehenes of the species of Clematis and of many kinds of Anemone are provided with hairy or feathery appendages, which facilitate their distribution by the wind. The floral axis in the Mouse-tail (Myosurus) is greatly elongated and the spiral arrangement of the small achenes upon it is very evident. Thalictrum has large, showy stamens, and the perianth

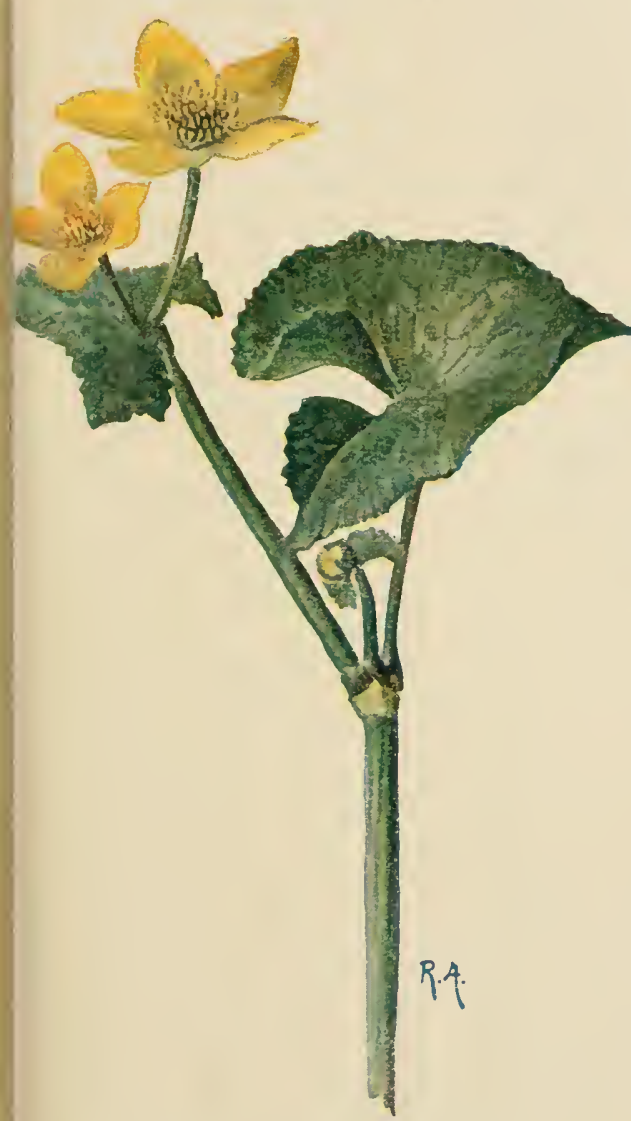

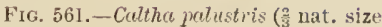
POISOTOC: is readily shed (on apogany in this genus, ef. p. 514). Caltha mulustris, the Marsh Marigold (Fig. 561), is one of the most eonspicuous spring flowers in damp meadows. Perianth simple, bright yellow. Leaves cordate or reniform, short-stalked, with erect sheathing base. Frnit com-

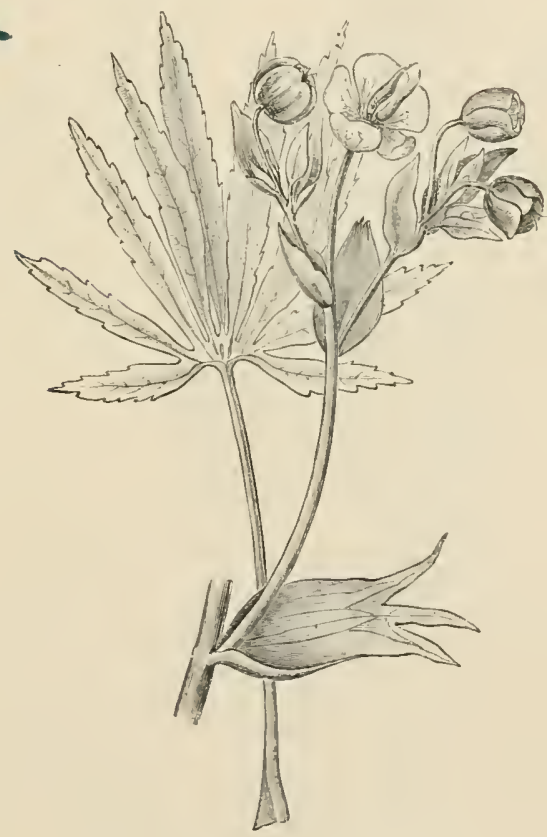

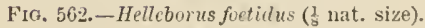
Polsoxous.

posed of follicles. Helleborus fuetidus (Fig. 562) has firm palnately divided leaves. The prominent infloreseence bears in Jaunary or February greenish flowers which stand in the axils of the broadly sheathing, three-toothed bracts, and are spirally construeted throughout. The five large sepals persist until the fruit is ripe. The petals, which are usually thirteen in number, have the form of tubular, two-lipped nectaries. Numerous stamens. Carpels $3-5$, developing into follicles. Helleburus niger, from the south-eastern Alps, flowers in autumn and winter and is commonly cultivated. Helleborus viridis. All three 
speeies are poisonous. The Monkshood (Aconitum napellus) (Figs. 563, 564) is a

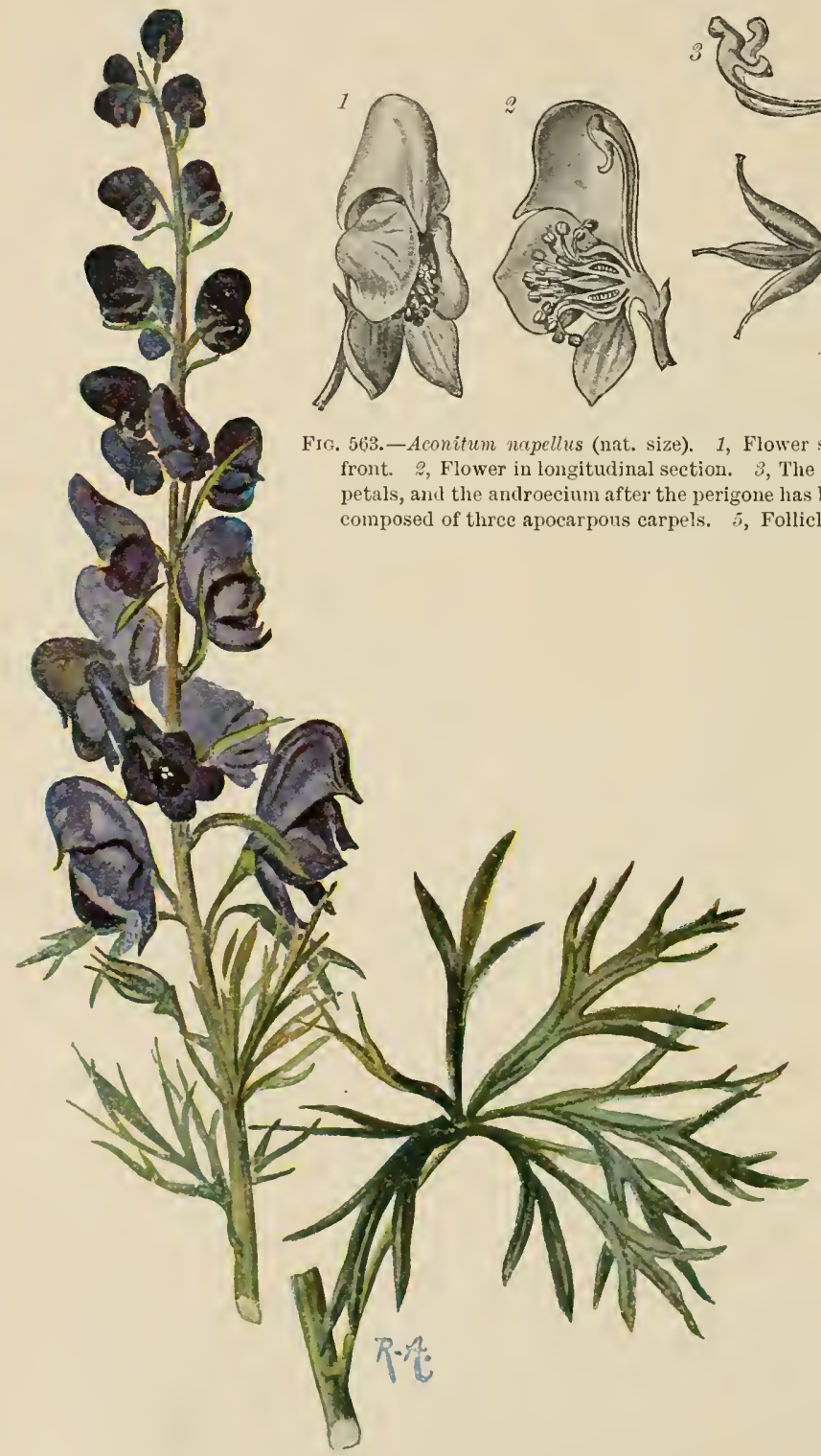

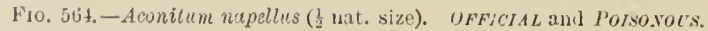

stately perennial herb with underground tubers and occurs most commonly in 
alpine meadows. The leaves are prantely divided, the segments being in turn pinnately lobed and widened towards the tip. Inflorescence a dense raceme, re. . in forced by lateral intlorescences standing in the axils of the upper leaves. Flowers zygomorphic. One of the five, dark-blue sepals is helmet-shaper, and protects two long-stalked, tubular, two-lipped nectaries, which correspond to petals. The remaining petals are wanting $01^{\circ}$ are rednced to inconspicnons, narrow structures. Aconitum Lycoctonum (Fig. 565) has smaller, yellow flowers of similar construction. A. Stocikianum and $A$. vuriegutum resemble $A$. napellus, but are more brightly coloured. All the species are poisonous. Aquilegia, Delphinium, and Pueonia are

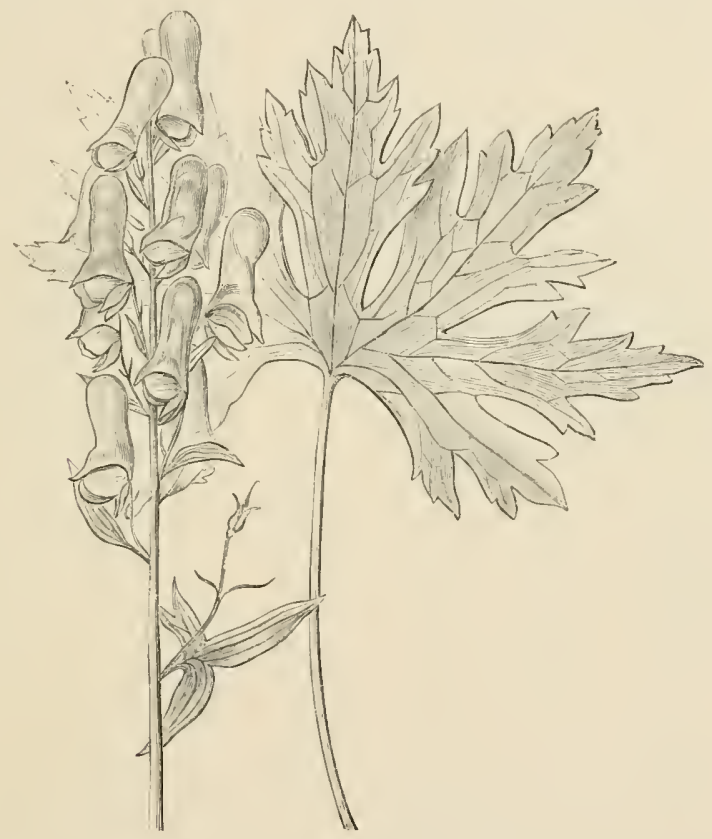

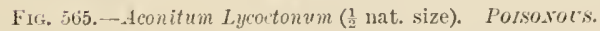

favourite ornamental plants with showy flowers. In Actuea and Hydrastis the fruit is a berry.

OfFiclal.-Acoxiti liablx is obtained from Aconitum napellus. Staphis-

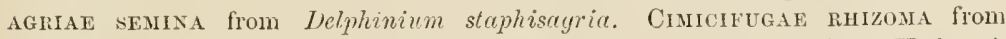
Cimicifuga racemosce. Hrvliastis RHzona from the North American Hyelrastis Canadensis (Fig. 566), a perenuial herb which sends its subaerial shoots up from the subterranean rhizome; the base of the shoot has keeled scale-leaves in two ranks. The flowers are solitary and terminate the shoots, each of which bears two foliage leaves. The simple, white perianth falls when the flower opens. The androecium and the apocarjous gynaceum consist of numerous members. The fruit consists of numerous, small berries, each of which includes $1-2$ seeds. The alkaloid нурfastrix is obtained from the rhizome.

Family 3. Magnoliaceae $\left({ }^{40}\right)$. - Woody plants from tropical and temperate America and Asia. The leaves are alternate and usually provided with stipules, 
which protect the structures in the bud. Flowers and fruit as in the Ranunculaceae, but the pollen-grains have only one place of exit for the pollen-tube. Oilcells in stem and leaf. Species of Magnolia are largely cultivated on account of their showy flowers. Liriodendron (Tulip tree), N. America.

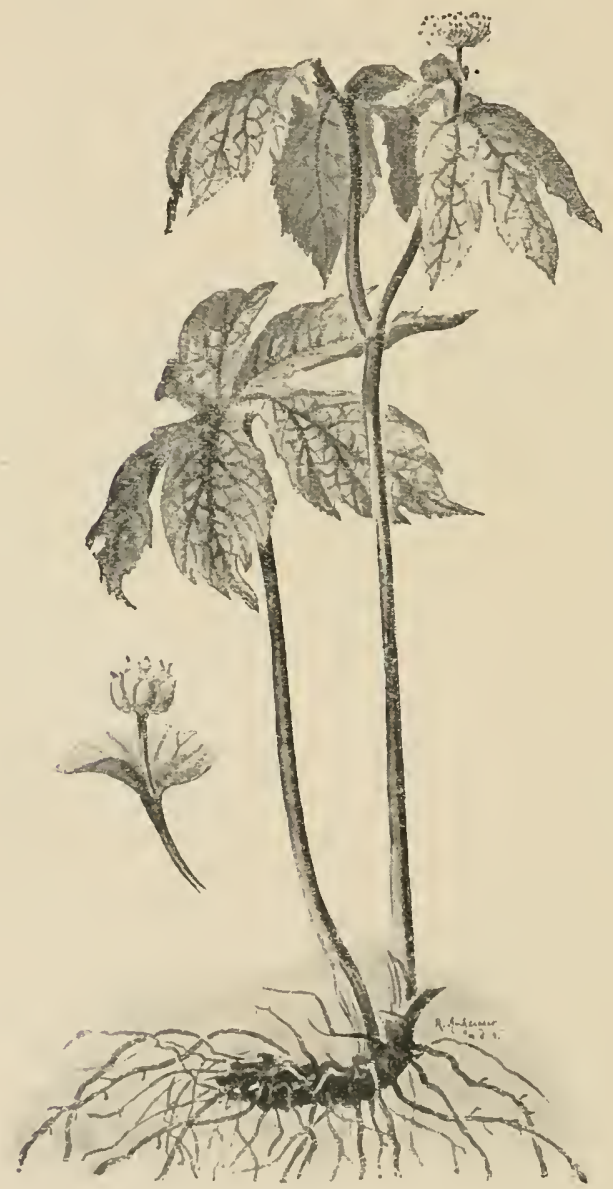

Fıg. 566, - Hydrustis canudensis (1 nat. si\%r). The apocarpous fruit to the left. OFF/CIAI

OFFICIAL. - ANISI STLLLATI Fructe's, Star-anise, is obtained from Illicium anisatum (China). The fruits of Illicium religiosum (Japan) are poisonous.

Family 4. Anonaceae.Woody plants of tropical Asia and America, lis, $\mathrm{C} 3+3$, in other respect. like the preceding families. Seeds with ruminated endosperm. Species of Anona yield succulent fruits. A perfume is obtained from Canange odorata.

Family 5. Myristicaceae $\left({ }^{41}\right)$. - Tropical, woody plants. Dioecious. $M y$. ristica fragrans (Figs. 567 , 568). The male and female flowers are similar in appearance and resemble those of the Lily of the Valley: perianth simple, trimerous. Nale flower witl a central column around which 3-15 adherent anthers are arranged. Female flower with one ovule enclosed by the single carpel. Fruit berrylike, with coarse flesh, but dehiscent. Seed with rmminater endosperm and arillus.

Official. - Mrristica, Nintmeg. The seed of $M y$ risticu fragrans divested of its testa.

Family 6. Berberidaceae. -Flowers formed of a varying number of trimerous whorls. Carpel always solitary. $\mathrm{K} 3+3, \mathrm{C} 3+3, \mathrm{~A} 3+3, \mathrm{G} \mathbf{1}$. In Bcrbcris vulgaris the leaves on the shoots of unlimited growtl are transformed into spines; the short shoots bear sinple leaves and tcrminate in racemes of flowers. The stamens are irritable to contact (ef. 1) 321). With the exception of the genus Berberis the family is confined to the north temperate zone.

OfFicial. - Podorimlit rinzoma obtained from Podophyllum poltatum 


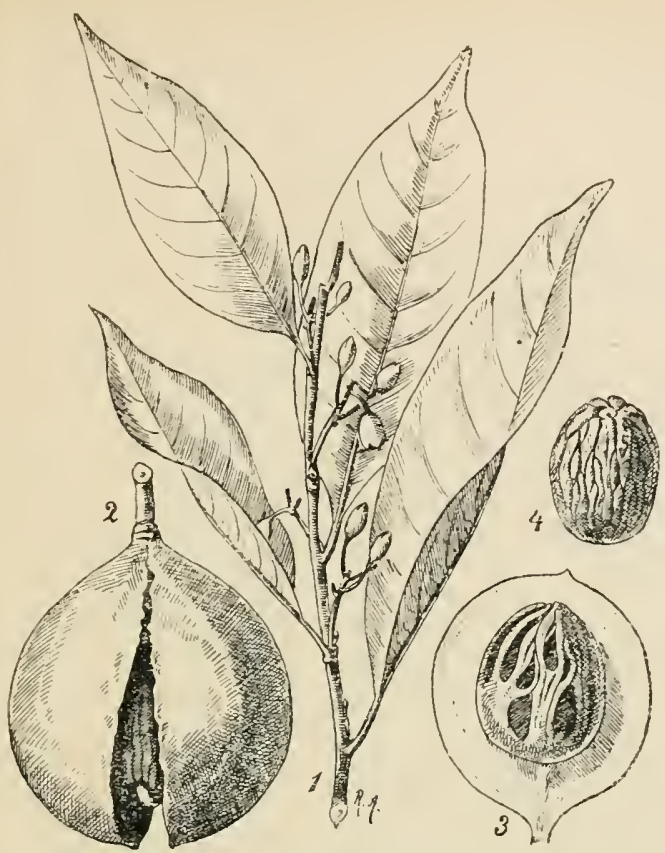

F10. 567.-Myristire fregrans. 1, Twig with male flowers (1) nat, size). 2, Ripe pendulous fruit opening. 3 , Fruit after removal of one-half of the pericarp, showing the dark brows seed surrounderl by the ruptured arillus. ', Kernel freerl from the seerl-coat. OFFICI.t.

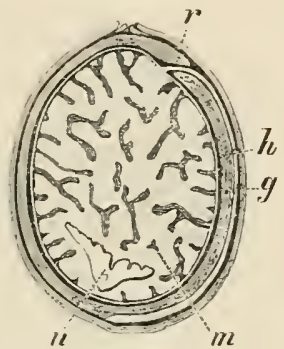

Fici, 568, - Myristice fregruns, seer?, cut through longitudinally; $g$, aril; $h$, outer integument, inter. rupted at $r$ by the raphe ; m, ruminated endosperm; $n$, embryo (nat, size). ()FFICIAL. (After BERF: and ScHмiDт.)

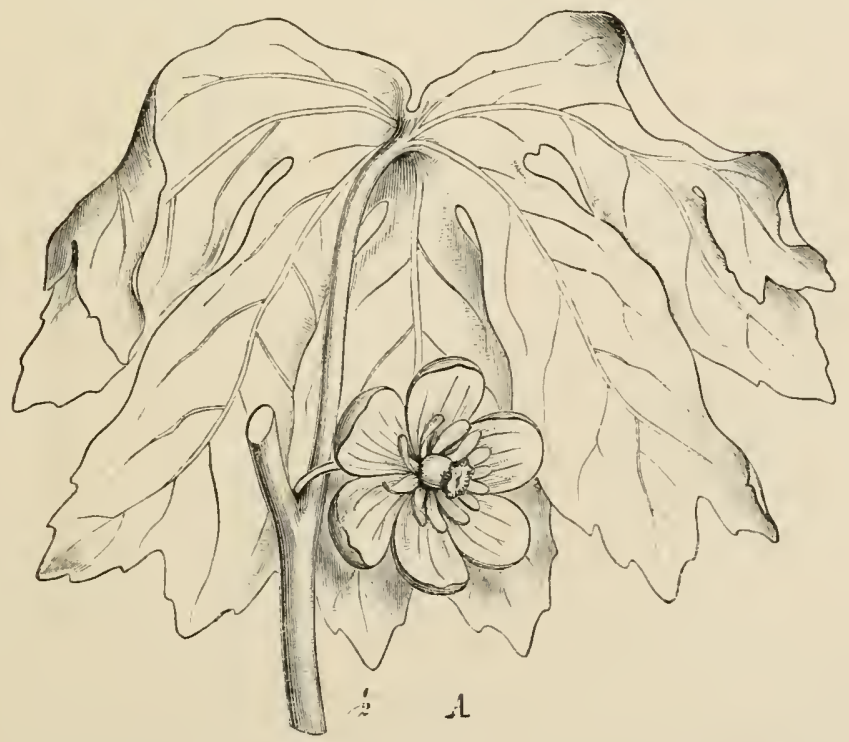

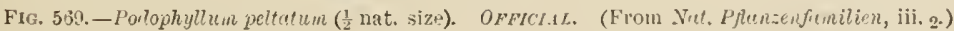




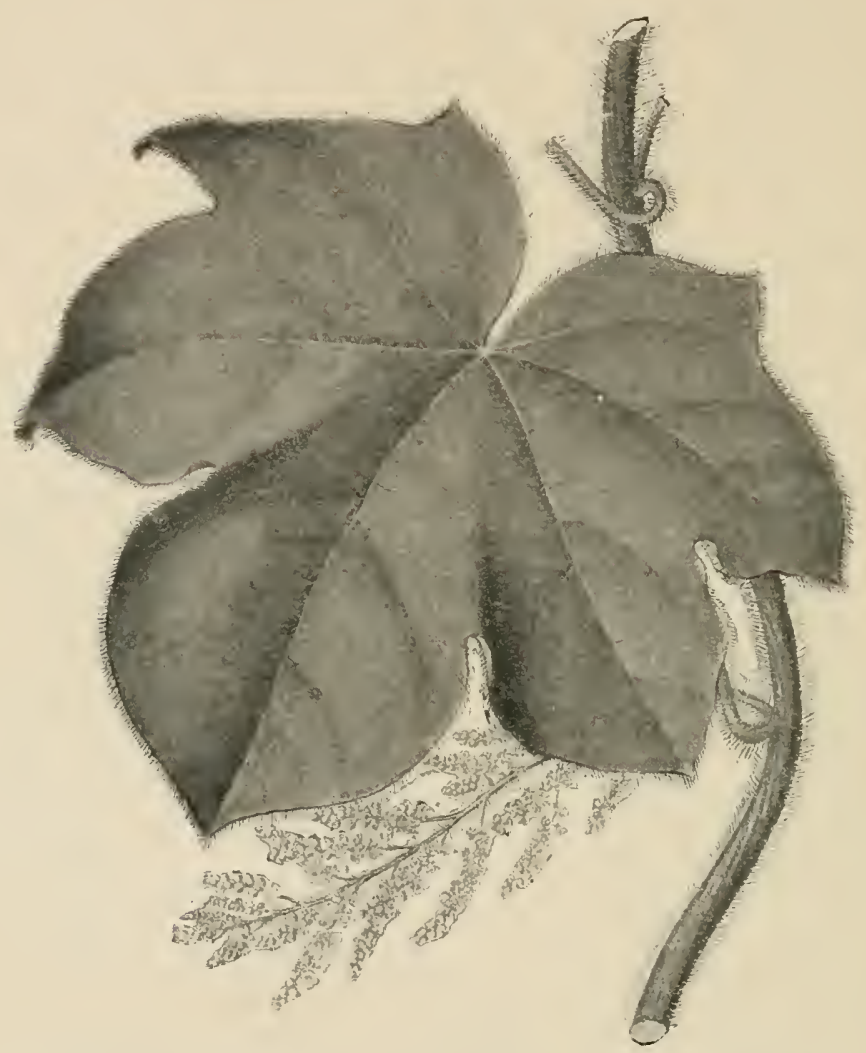

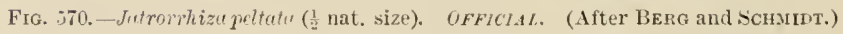

(Fig. 569), a Torth American, herbaceous plant with large, palmately divided leaves and a terminal flower.

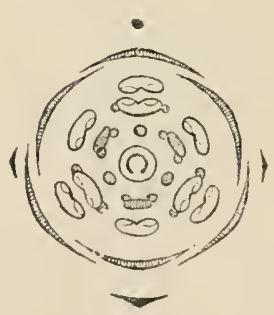

Fic. 571.-Floral tliagrum of P'ersect. (After Eichiter.)

Fanily 7 . Menispermaceae. - Similar to the preceding family but G3. For the most part tropical, climbing plants.

OFFICIAL-CALUMIBAE IADIX obtained from Jatrorrhisa palmate (Fig. 570) from l'ortuguese East Africa.

Family 8. Lauraceae.-Aromatic trees or shrubs with entire leathery leaves, which usually persist for sereral seasons. Only Sassafras (Fig. 572), which has three-lobed leaves as well as simple ones, sheds its foliage annually. No stipules. Flowers ineonspicuous, borne in panicle-like inflorescences. They are actinomorphic 
and composed of trimerous whorls. Androecium of four whorls, some of which frequently consist of staminodes or are wanting. Anthers opening by valves. Filaments sometimes bearing glands. Carpels 3, coherent to form an unilocular ovary with one, pendulous ovule.

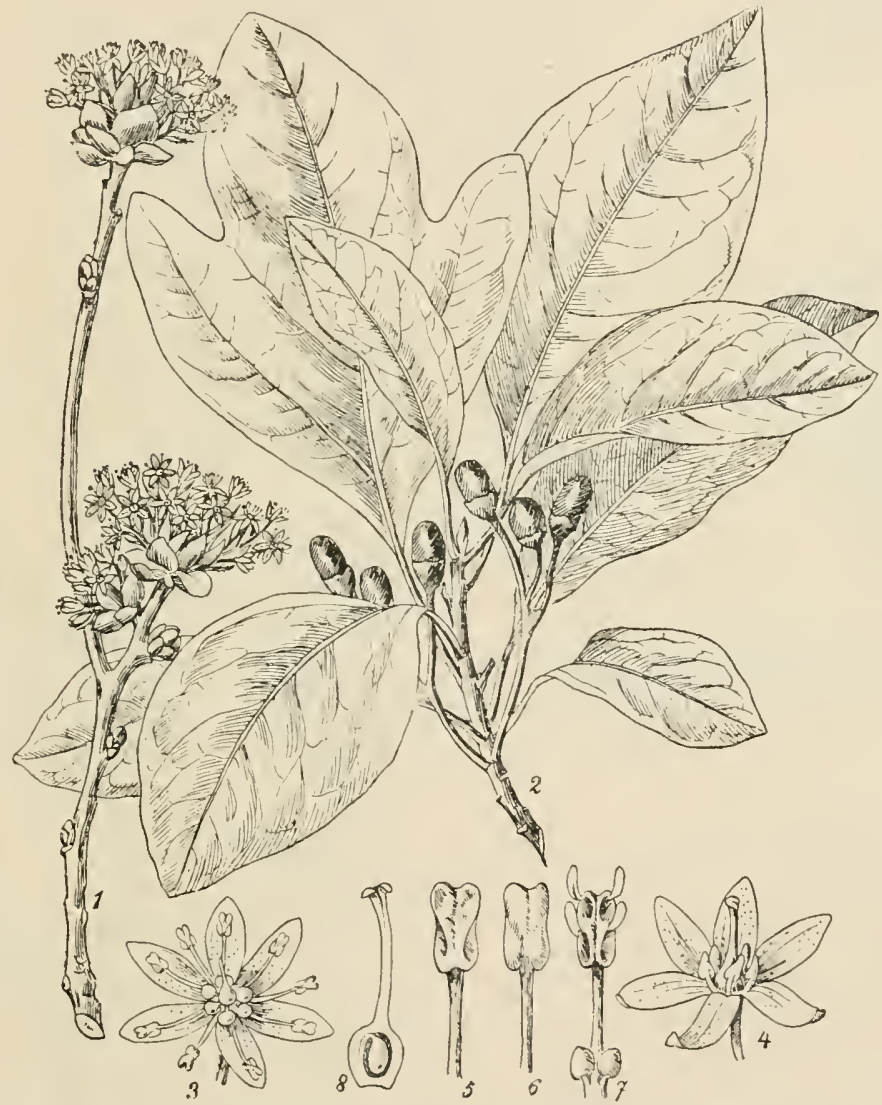

F10. 5i2.-Siessufres offirinale. (1 nat. size. After BERG and ScHмIDT.) 1, Male inflorescences on a still leafless branch. 2, Fruits on a ieafy shoot. 3, Male flower. 4, Female flower. 5, 6, Closed stamens of the two outer whorls. $\%$, Opened stamen of the innernost whorl. 8 , Ovary showing the style and the ovule. OFFICIAL.

Fruit, a berry or drupe. Endosperm wanting. Floral formula, P $3+3$, $\mathrm{A} 3+3+3+3, \mathrm{G} 3$.

The family is distributed especially in the tropies and sub-tropies.

Inportant Genera axd Species ( $\left.{ }^{+2}\right)$. - Laurus nobilis, the Laurel, is a dioecious, evergreen tree of the Mediterranean region, which was well known in the early period of the Grecian cirilisation ; it is frequently grown in cool green- 


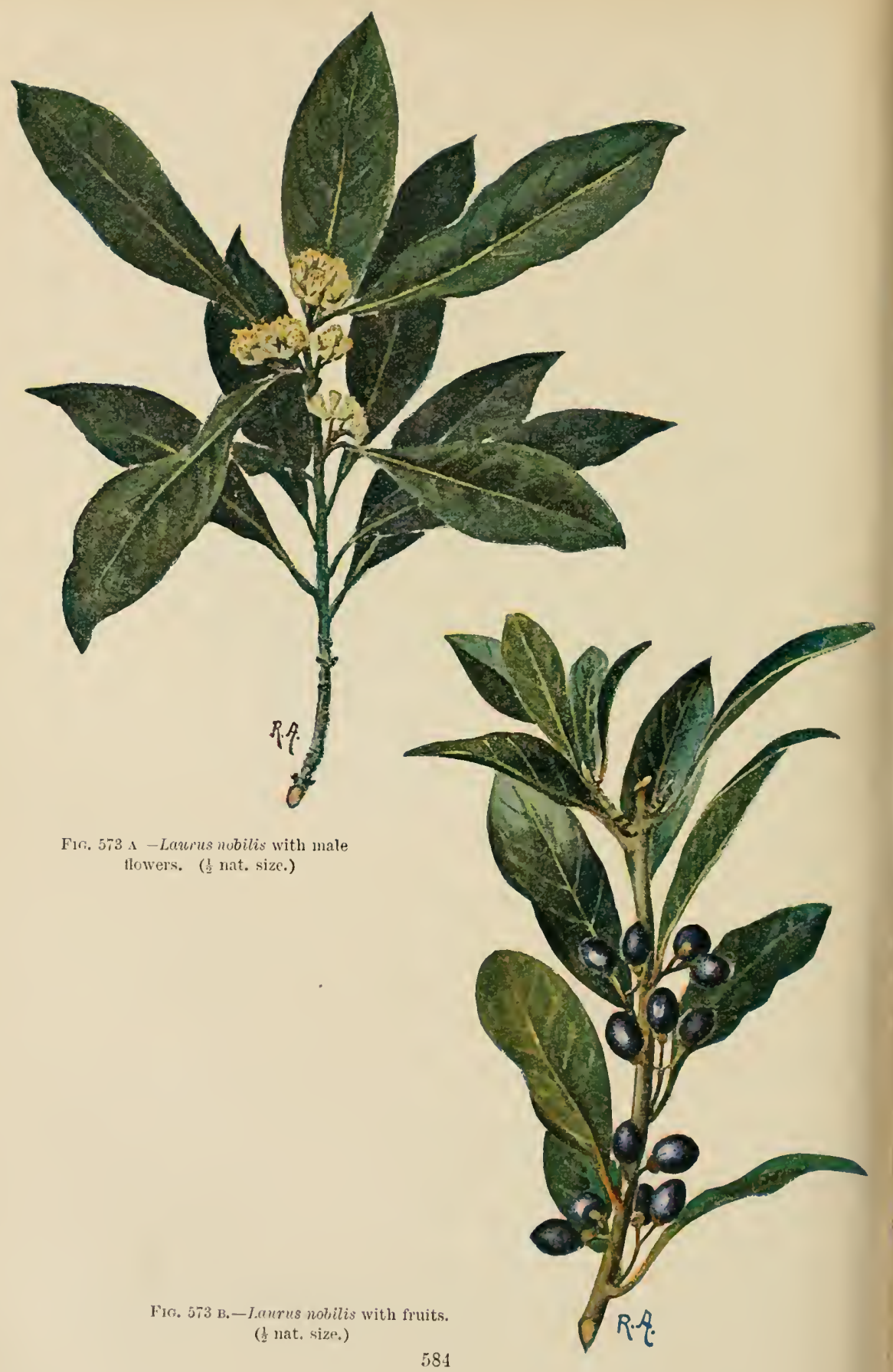


houses (Fig. 573). Large plantations are grown at the Lake of Garda, where the oil is extracted, and here the trees ripen their oval, blackish-blne drupes in October. The widening of the floral axis just below the insertion of the fruit is characteristic. The genus Cinnumomum includes a number of economically important trees such as the Camphor tree from Japan and China (Fig. 574) and the Cinnamon tree from China and Ceylon. The latter is a stately erergreen with smooth, leathery leaves and inconspicuous, greenish flowers in axillary inflorescences. Persea yratissime

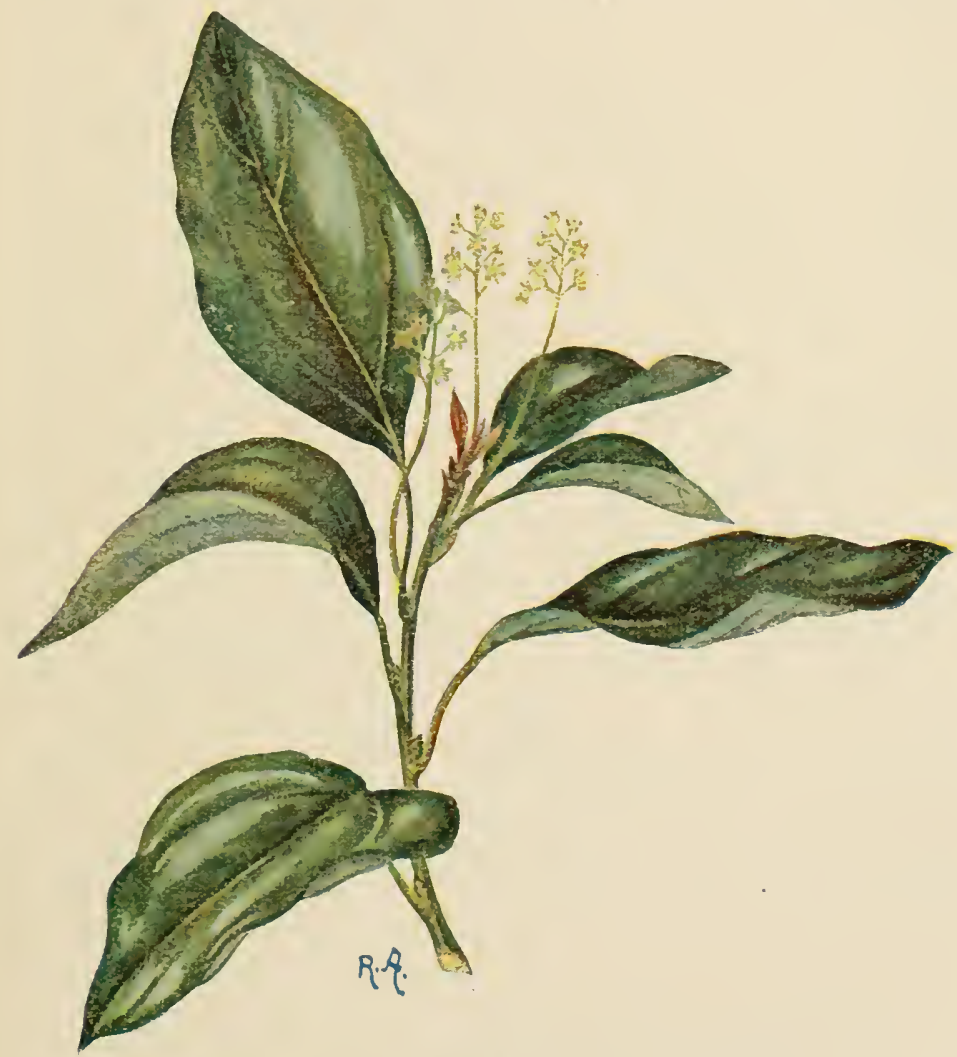

Fig. 574.-Cinnamomum Cimphora (3 nat. size). OFFICIAL.

(Fig. 571) is a native of tropical Mexico, and is frequently cultivated as a fruit tree in the tropics. Its fruit is known as the Avocado Pear. Species of Cassytha, the only genus of the family including herbaceons species, occur throughout the tropies as parasites resembling Cuscuta.

OfFicial.-CAMPHORA, Camphor, is obtained from Cimamomum Camphora. CiNNAMOMI CORTEX and OLEUM CINNAMOMI from Cinnamomum zeylanicum. Sassafras radix from Sassafras officinale, a dioecious, North American tree.

Family 9. Cephalotaceae $\left({ }^{17}\right)$. - Herbs with pitcher-leaves which capture insects in addition to ordinary leaves. Hermaphrodite, hexamerous flowers with a 
perianth of one whorl and an apocarpous pistil. Cephalotus follicularis, a monotypic species from West Australia.

Family 10. Sarraceniaceae $\left({ }^{43}\right)$.- Piteher-shaped leaves; flowers pentamerons Saracenia Darlingtonia. North Ameriean swamp and moor-plants.

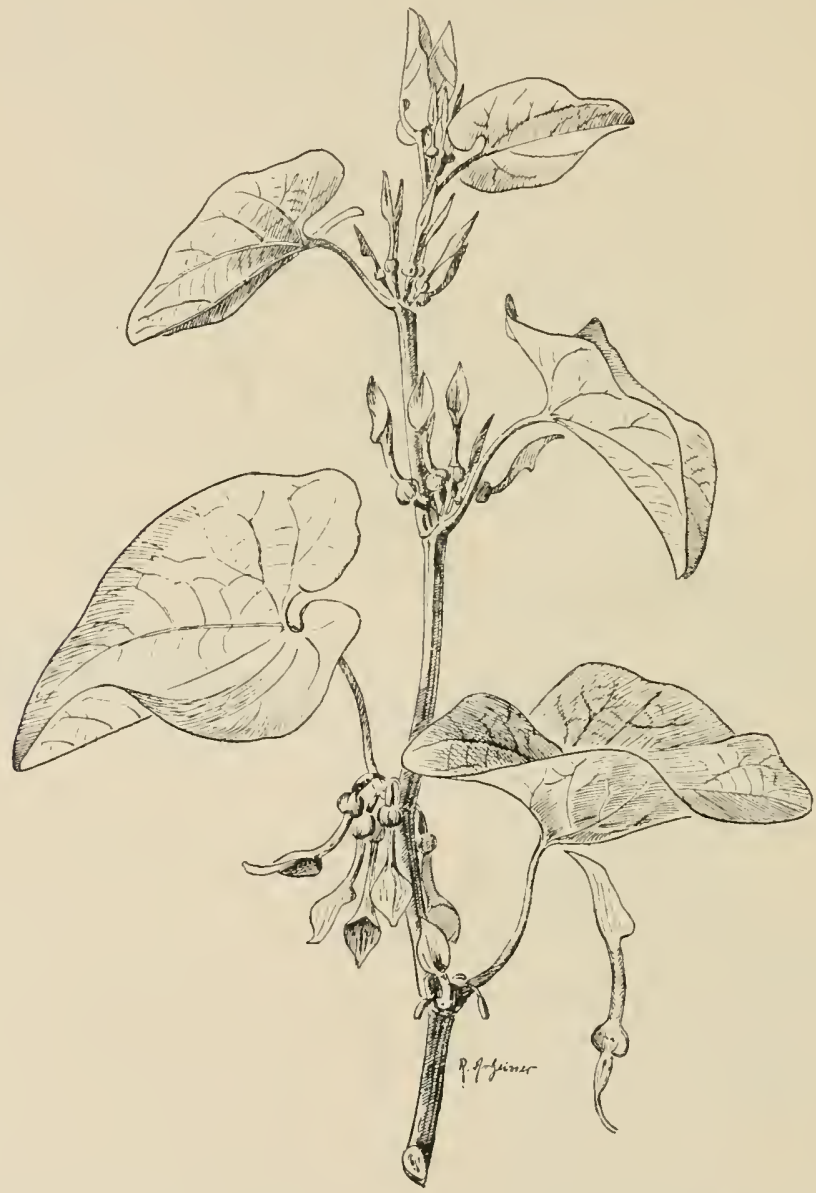

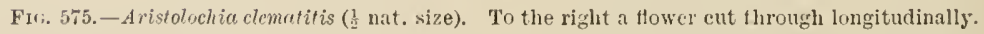

Fanily 11. Nepenthaceae.-Climbing, divecious, pitcher-plants of tropical A sia (Fig. 46). Flowers tetramerous. Only genus Nepenthes.

liamily 12. Droseraceae $\left({ }^{H}\right)$. - I Ierbaceous rosette plants with glandular hairs on the leaves for the capture of insects. These plants may best be placed here, although their relationship to the three preceding families is doubtful. Drosera, Sun-dew; a number of species occur on heaths and moors in this country. Drosophyllum lusitanicum, Spain and l'ortugal. Dionace, North American Fly-catcher. 
Aldroxcenda vesiculose is a European water-plant that also occurs in India and Australia.

(For further information on insectivorons plants ef. p. 228. )

Family 13. Aristolochiaceae.-The Aristolochiaceae may be associated with the Polycarpicae on account of the numerical rclations of the floral organs in spite of their inferior ovary ; their flowers are often zygomorphic and they thus present analogies with the Rannenlaceae. Herbs and twining slurubs with simple cordate leares. Flowers with a simple, gamophyllous perianth. Androeceum and gynaecenm united to form a gynostemimm. P $3, \mathrm{~A} 6+6 \mathrm{G}(6)$ ovary inferior, septate. Fruit a capsule. Distributed over the whole earth, but mainly in Soutli Anerica.

Aseran Europeum with actinomorphie flowers ocenrs in Britain. Aristoloctice elematitis (Fig. 575) with zygomorphic, protogynous flowers (for prollination ef. 1. 501) are erect herbs with large alternate leaves. Numerous solitary flowers in the leaf-axils.

Family 14. Rafflesiaceae $\left({ }^{45}\right)$. - Parasites with vegetative organs reduced to hansteria; without ellorophyll. Flowers often very large (Rafflesia). Tropical. Rufflesir Amoldi. (Sumatra) has the largest known flowers, attaining a diameter of $1 \mathrm{nil}$.

\section{Order 12. Rhoeadinae}

Herbs, or more rarely shrubs, with alternate, exstipulate leaves. Flowers hermaphrodite, cyclic; whorls usually bimerous. Ovary superior, unilocular. Placentas on the united margins of the carpels, projecting more or less into the cavity. Stigmas commisural, i.e. situated immediately over the sutures. Dehiscence of the fruit by separation of the middle portions of the earpels from the persistent placentas.

Family 1. Papaveraceae.-Herbs with milky juice. Leaves usually pinnately lobed. Flowers actinomorphic. Floral formula, K 2, C $2+2$, $A \approx G(2)$ or $\infty$. Seeds with abundant endosperm.

The number of the stamens, and usually their position, is indefinite. In the genera Chelidonium, Gluucium, Escholt:ia, there are two carpels; in Pupacer, Argemone, and Meconopsis the number is greater (15-16) (Fig. 576$)$.

Mainly in the northern hemisphere outside the troyics.

Importaxt Native Genera.-Chelidonium mujus, Celandine, has yellow latex and a bicarpellary ovary. A number of species of Escholtsiu, Aryemone, and Paperer are cultivated as ornamental plants. Pupecer Phoces, the Poply (Fig. 577 ), is a common weed in coln-fields or dry meadows. The leaves are narrow and pimnately divided. The whole plant is covered with coarse, bristly hairs. The bent position of the flower-bud is characteristic of many Papareraceae. Ultimately the flower becomes erect as it opens; the two sepals forming the calyx are thrown off, and the four, large, wrinkled petals, forming the corolla, expand. Priparer somniferum, which is of oriental origin, has abundant white latex. The plant has a glaucons bloom and, except on the flower-stalks, which bear a few bristly hairs, is glabrous. Leaves sessile, margin irregularly serrate or lobed. Petals violet or white with a dark patch at the base. Orary unilocular, incompletely septate by 
the projection inwards of the numerons plaeentas. Fruit ripens erect on the peduncle. In Papaver the separation of the central portion of each carpel from the placentas at dehiscence is limited to the tips of the carpels. These bend ontwards just below the flat stigmatic expansion, and the kidneyshaped seeds are thrown out of the small openings when the capsule, borme on its long stalk, is moved by the wind.

OFFICLAL. - Papaver somniferum, the Opium Poppy, yields PAPAVERIS CAPSULAE and OPIUM. Paparer lihoeas yields RHOEADOs PETALA.

Family 2. Fumariaceae.Glabrous herbs, without milky juice, with bipinnate or tripinnate leaves. Flowers binerous throughout; the number of whorls in the corolla is doubled. Floral formula, $\mathrm{K} 2, \mathrm{C} 2+2, \mathrm{~A} 2$, $G(2)$. The outer petals, or one of them, bear spurs. In the latter case the flower is transversely zygomorphic (Figs. 578, 579). The inner whorl of stamens is suppressed. The stamens of the outer whorl are each tripartite, consisting of a central anther with two thecae and two lateral anthers each with a single theca borne on a common filament. In Hypecoum the lateral branehes join in pairs, and apparently form the

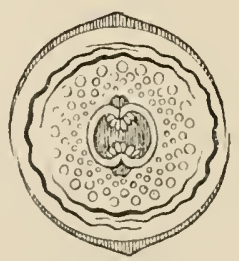

Fio. 570 . --Floral diagram of Glaurinin. (After Еıснцкк.)

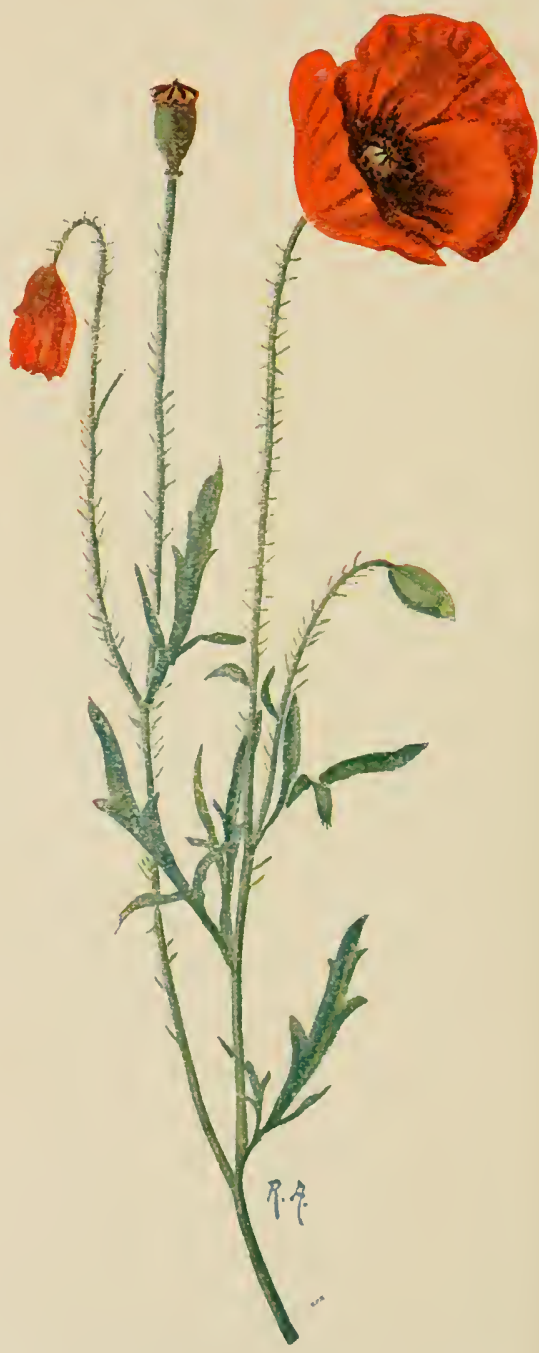

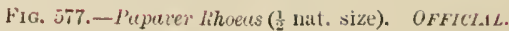

inner staminal whorl, the position of which they occupy. The transversely zygomorphic flowers of the Fumariaceae with only one spur afford the only example of this type of symmetry. The fruits of Fumaria are nutlets, those of Corydalis 
and Dicentra are capsules. Dicentra spectabilis, which is frequently cultirateri, has a bisymmetrical corolla with two spurs. Seeds with endosperm.

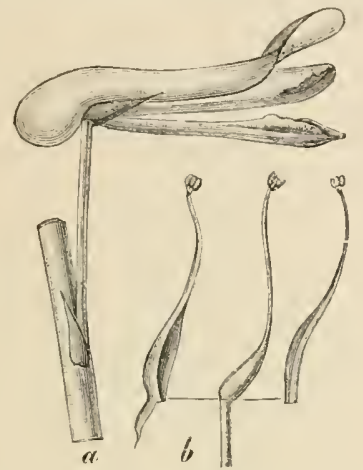

Fif. 5is. - Corydulis wuret. a, Part of axis of raceme with a Hower; $b$, style and stamens. ( $\times 2$.)

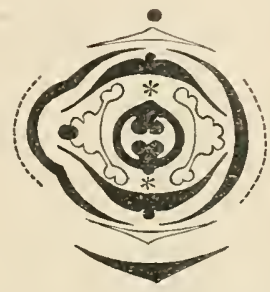

Fic. 579.-Floral diagram of curystalis mer. (After Eichler.) At the base of the stamen stanching above the spur is a nectary.

Family 3. Crueiferae $\left(^{+6}\right)$. - Annual, biennial, or peremnial herbs withont milky juice. Inflorescence racemose, usually without bracts or bracteoles. Flowers actinomorphic, always lateral, composed of bimerous whorls. Floral formula, K $2+2, \mathrm{C} 2+2, \mathrm{~A} 2+4, \mathrm{G}(2)$. The outer whorl of sepals stands in the median plane; the forr

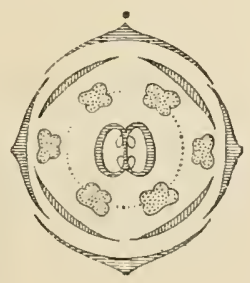

Fig 580.-Cruciferae. Floral diagram (Brossicu).

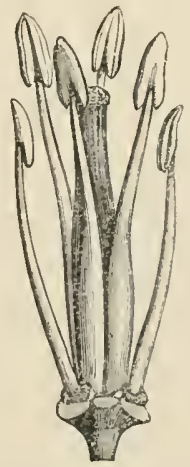

FIa, 5s1.-Cardamine mutensis. Flower with perianth remover. (After Barllox, $\times 4$.)

petals alternate with the sepals. The two outer stamens are shorter than the four inner ones which stand in the median plane. The latter correspond to two stamens branched to the base. The carpels form a superior, usnally pod-like, ovary, which is divided into two chambers by a false septum stretching between the parietal placentas. The fruit opens by the separation from below npwards of the main 
portion of each carpel, leaving the seeds attached by their stalks to the central portion formed by the placentas together with the false septum. Rarely the fruit is indeliscent. Embryo curved. Endo-
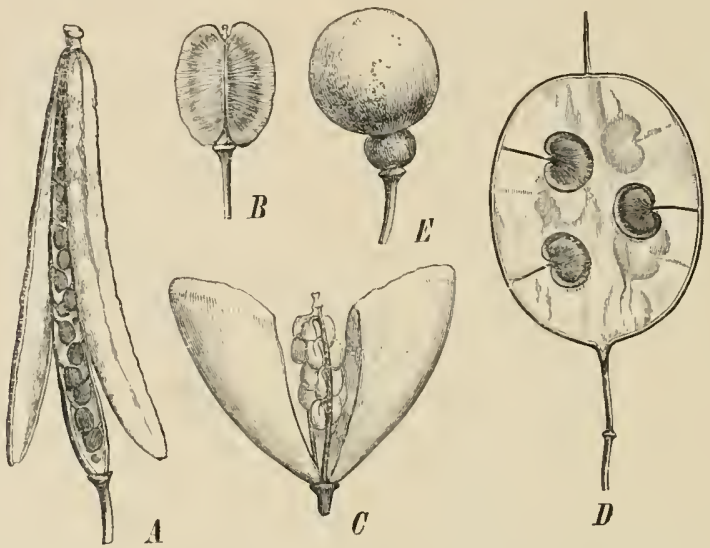

Fio. 582.- Cruciferons fruits. A, Cheiranthus cheiri; $B$, Lepiulium sutivum; $C$, Capsella bursa pastoris; D, Lunariu biennis, showing the septum after the carpels have fallen away. $F$, Crumbe muritime. (After BAILION.)

sperm wanting or reduced to a single layer of cells coherent with the seed coat (Figs. 580-586).

Distribution, in the northern hemisphere, especially in the IIediterranean region.

The form of the fruit and the position of the embryo in the seed are nsed in

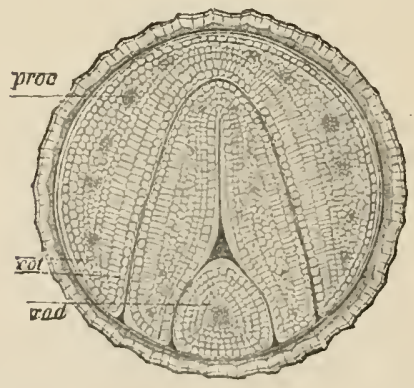

Fia. 583.-Transverse scetion of the seed of Brussica niyra. red, radicle; cot, cotyledons ; proc, vascular bundles. (After IInt.ter.)

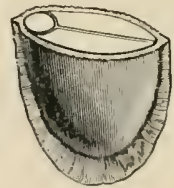

1

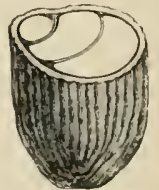

$\boldsymbol{B}$

Fig. 584, - Seeds of Cruciferate cut across to show the radicle and cotyledons. $A$, Cheiranthuscheiri $(\times 8)$; B, sisymlrium alliaria $(\times 7)$. (After Barlıox.)

the subdivision of this extremely uniform family. This general classification, which dates from the time of Lixisal's, will be used here, but reference must be made to the more recent, natural division of the family, founded on eharaeters afforded by a number of organs, which is given in the Natuirlichen P'flenzenfamilien by Prostr. 
Linsaeus distinguished the Siliquosue, in which the fruit is a siliqua, from the Siliculosce, in which it is a short silicula. The Siliquosae are further divided into Siliquosae dehiscentes, with the usual type of siliqua, and Sitiquosac lomentacae, in which the siliqua breaks transversely into one-seeded joints. The Siliculosae are

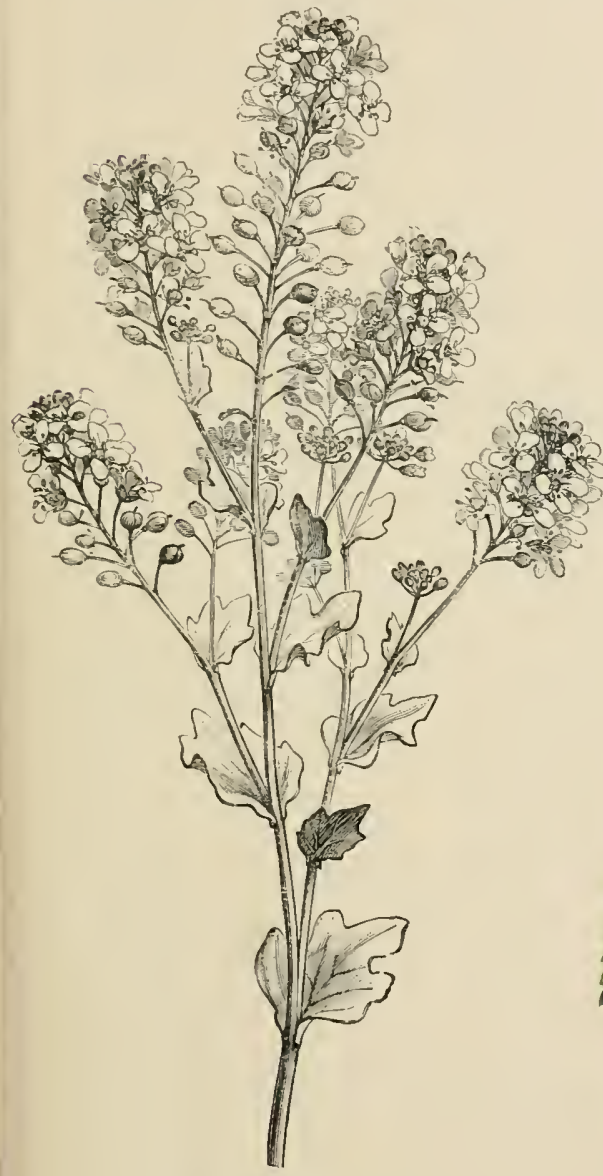

Fis. 5S5.-Cochlcaria officinalis. (After Baillon.

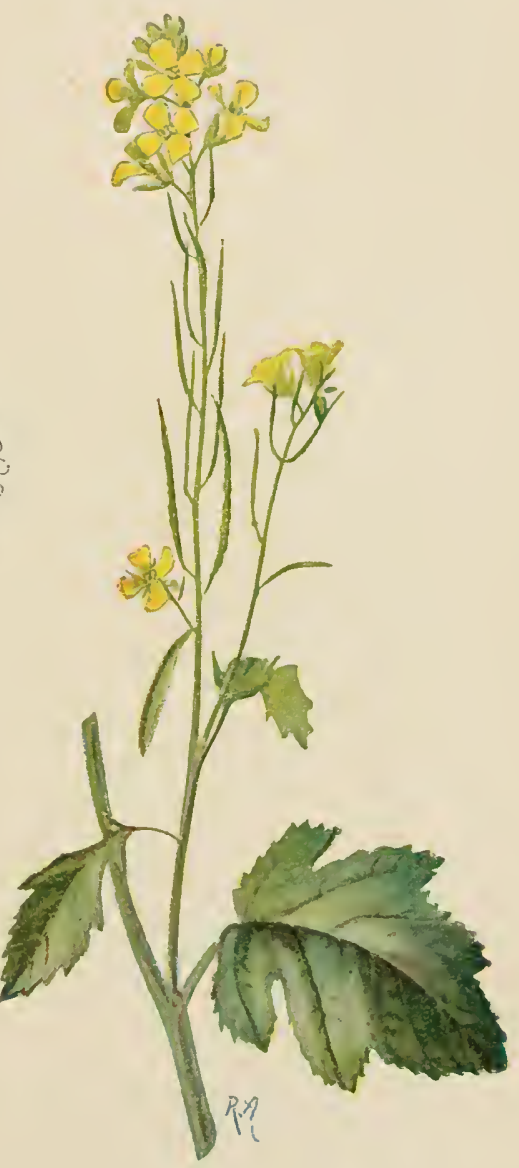

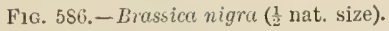
OFFICIAL.

also diviled into siliculosuc dehiscentes and Siliculosae nucamentaceae with indehiscent fruits. The Siliculosae debiscentes were later divided by A. P. DE CANDolde into the $S$ latiseptae with a broad septum and the $S$. angustiseptac in which the septum is narrow.

The number of species and their abundance make the Cruciferae one of our most important, native families of flowering plants. Their brightly coloured, mostly yellow flowers render them conspicnous in various situations and at all 
periods of the year. The nectaries, which are borne on the receptacle at the base of the stamens, also show that the flowers are entomophilous. The family iucludes a number of economic plants.

1. Siliquosae dehiseentes: Cheiranthus Cheiri, the Wallflower (Figs. 582, A, 584, A). Matthiole, the Stock. Numerous species of Brassica have been long in cultivation; $B$. oleracea, the Wild Cabbage, in its various forms-(a) sylrestris, which occurs on the coasts of Northern Europe and is to be regarded as the wild form ; (b) acephala, Borceole or Kale ; (c) gonglyodes, Turnip-rooted Cabbage ;

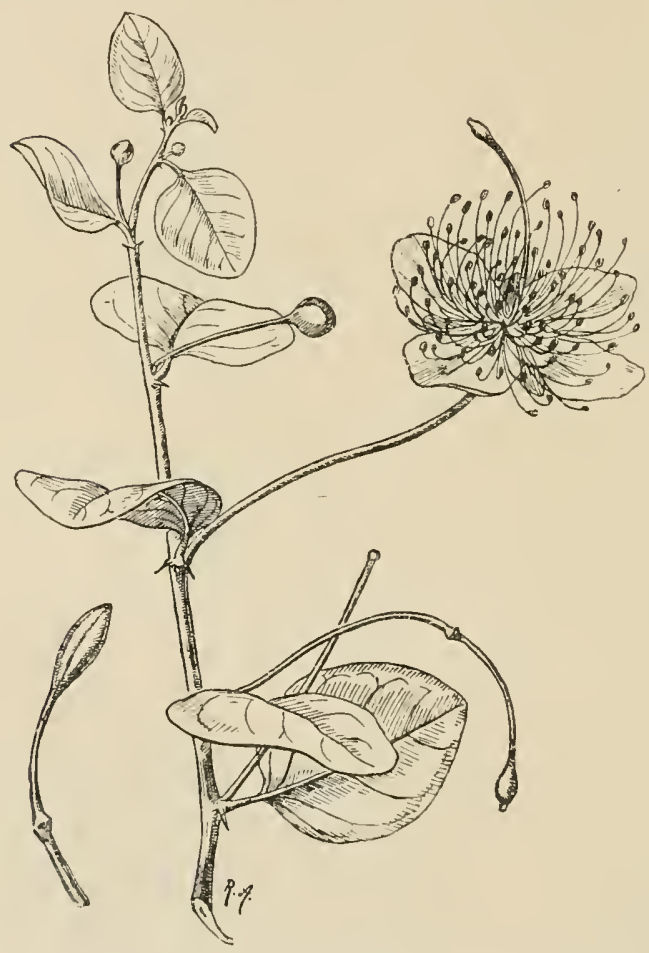

F1\%. 587.-Capparis spinosu. Floweriug branch and a young fruit borne on the gynophore. (l nat. size.)

(d) yemmifera, Brussels Sprouts; (e) sabauda, Saroys ; $(f)$ copritata, the Cabbage; $(g)$ Botrytis, Cauiiflower and Broccoli. Brassica campestris, with the cultivated forms- $-(a)$ anmua, (b) aleifera, (e) rapifera. Brassica napus, the Turnip- (a) annue, (b) oleifere, (c) napibrassica. Brassica nigre, Black Mustard (Figs. 583-586), an anmual plant derived from the eastern Mediterranean region, was cultivated even in ancient times. The radical leaves are long. stalked and lyrate with rounded terminal lobes; on ascending the copiously branched stem they become lanceolate and gradually smaller. The plant is glabrous except for some bristly hairs on the upper surface of the leaf. Inflorescence a raceme; the bright yellow flowers stand out from the main axis, while the developing fruits are erect and applied to the axis. The mature fruits have a short beak; the slightly convex valves are keeled and traversed by a well-marked midril. Seeds spherical. Sinapis alba, White Mustard, is a hairy plant, distinguishable from the Black Mustard by the long broadly-beaked fruits, the valves of which bear coarse bristly hairs. The fruits project from the axis of the inflorescence. The seeds are yellowish-white and twice as large as those of Brassica niyra. Anastatica hierochuntica, Rose of Jericho, is an ammal desert plant of $N$. $\Lambda$ frica characteriserl by the hydroseopic movements of its branches.

2. Siliquosac lomentaceae: Crambe (Fig. 582, E), with the lower portion of the siliqua sterile, and Calitc are thick-leaver, strand plants. liaphanus sativus, the Radish. 
3. Siliculosae dehistentes latiseptae: Vesicaria, Aubrictia, Iraba, Lunaria (Fig. 582, D). Cochlearia officinalis, Seurvy Grass (Fig. 585), is a glabrous, biemial herb which germinates in summer, forming a large rosette of stalked, eordate leaves, persists over winter, and early in the suceeding summer produces a low, copiously branched inflorescence of white flowers. The rosette of radical leaves has disalpeared by the time the fruit is ripe.

4. Siliculosae dehiscentes angustiseptae: Thluspi, Iberis with somewhat zygomorphic flowers, Capsella (Fig. 582, C).

5. Siliculosae nueamentaeeae : Isatis tinctoria, Woad.

Official. - Sinapis a lbae Semina, from Sinapis alba; Sinapis nigrae semina, from Brassica nigra. AnMoraciae radix, from Cochlearic Armoracie.

Family 4. Capparidaceae.-Herbs or shrubs with simple or palmately-divided leaves, often stipulate. Flowers as in the Cruciferae, $\mathrm{K} 4, \mathrm{C} 4, \mathrm{~A} 2+2, \mathrm{G}(2)$; they difler by the intercalation of a gynophore raising the ovary high above the level of the other parts of the flower, and by the branching of the stamens (or some of them) giving rise to an indefinite number (Fig. 587). Fruit nsually a berry, in other cases a capsule or drupe. Seeds without endosperm. Distributed in the tropies and sub-tropics.

Capparis spinosa is a small shrub occurring on rocky ground in the Mediterranean region. The leaves are simple with short, recurved, spiny stipules. The actinomorphie flowers are axillary and solitary; the androecium by chorisis consists of numerous members. The fruit is a berry which reaches the size of a plum and contains numerous seeds. Capers are prejared from the young flower buds.

Family 5. Resedaceae.-Herbs with alternate leaves and zygonorphic flowers forming a dense raceme. Mainly Mediterranean. The sexual organs are borne on a gynophore or disc. K $5-8, \mathrm{C} 5-8, \mathrm{~A} \infty, \mathrm{G}(2-6)$. The ovary is unilocular and open above, or the carpels are free. Reseda odorata, Mignonette. $R$. luter, $R$. luteolu, British.

\section{Order 13. Cistiflorae}

The plants belonging to this order are characterised by their usually regular, pentamerous flowers; the stamens are increased in number by chorisis, or when the separation of the branches is incomplete they form distinct bundles; the superior ovary is usually trimerous.

Family 1. Cistaceae.-Perennial herbs or shrubs of the northern hemisphere, with opposite, simple, stipulate leaves. Pentamerous, regular flowers, with numerous stamens and three to five carpels united to form a unilocular or multilocular ovary with a single style. In Britain the Rock Rose (Helianthemum vulyare); the prostrate stem bears small elliptical, sessile leaves and racemes of bright yellow flowers (Figs. 588, 589). Many species of Cistus are characteristic shrubs of the type of vegetation of the Mediterranean region, known as the Maquis.

Family 2. Violaceae.-Herbs, shrubs, or trees distributed in all zones usually with dorsiventral flowers with only five stamens. Ovary unilocular with a simple style. There are a number of species of $V$ iole in Britain. The flowers have the anterior petal prolonged backwards as a spur, into which two nectur-secreting processes of the two anterior stamens project (Figs. 59C, 591). Many linds of Violet have, in addition to these conspicuons flower's adapted to insect pollination, inconspicuous, cleisto- 


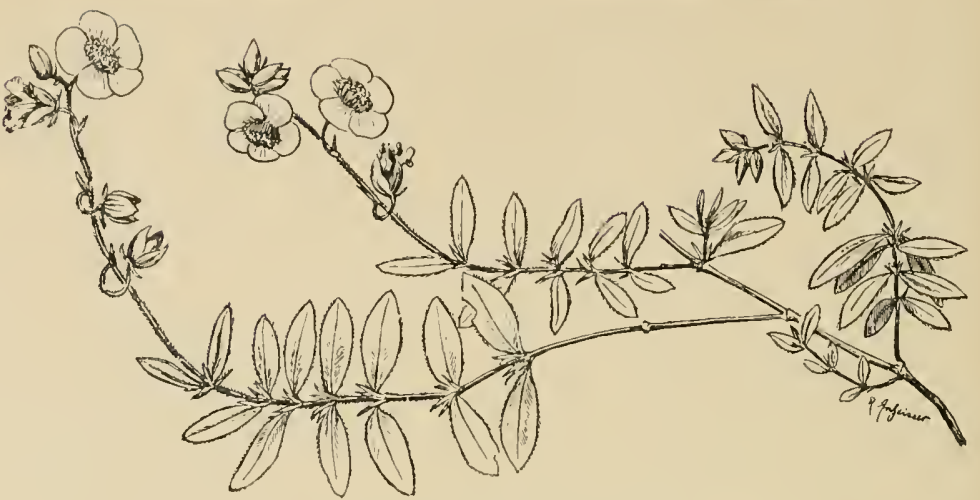

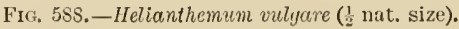

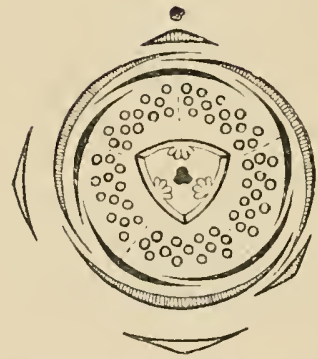

FIG. 58\%,- Floral diagram of Heliunthemun vulgare. (Cistaceae.) (Eichler.)

gamons flowers which are self-fertilised (ef. p. 499). Viole tricolor, the Wild Pansy, has large pinnately - divided stipules hardly smaller than the leaf-blade itself.

Family 3. Tern. strömiaceae. - Tropical and snb-tropical. Herbs, shrubs, or trees, with alternate, simple, leathery leaves. Flowers regular; aestivation imbricate ; sometimes with indistinet separation of ealyx and eorolla. Stamens numerous. Ovary sepitate. Theee chinensis (lig. 592) is a small evergreen tree or slırub, native to sonthern

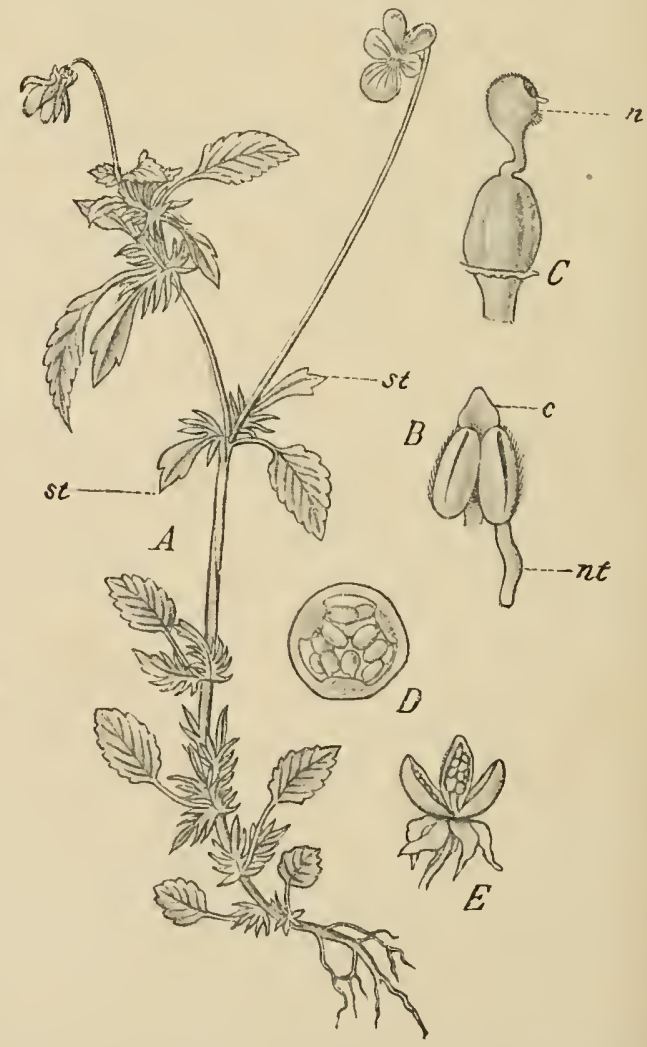

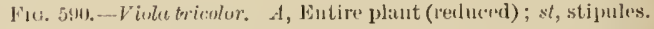
B, A stanen, enlarged; $c$, connective; $u t$, nectary. C, Gynae. ceum, enlarged; $n$, stigrua. $D$, Transverse section of ovary. E, lruit (nat, size). 
China. The young leaves and tips of the shoots yield TEA after heing fermented and dried. The tea-plant is cnltivated on an extensive scale in China, Japan, and many tropical colonies. CAFFELNE is obtained from thea chinensis, Thea japonica, the Camellia, is a favomite ornamental shrub.

Family 4, Guttiferae.-Herbs, shrubs, or trees with olposite, simple, entire leaves. Flower's sometines diclinous. Stamens in bundles. Schizogenous intercellular spaces containing secretions in all parts of the plant. In Britain Hyperieum, with a number of species; stamens in three or five bundles (Fig. 593). Oil glands apparent as trans-

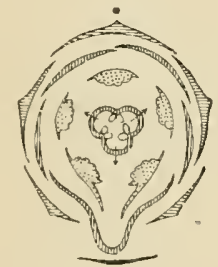

Frc. 591.-Floral diagram of violu.

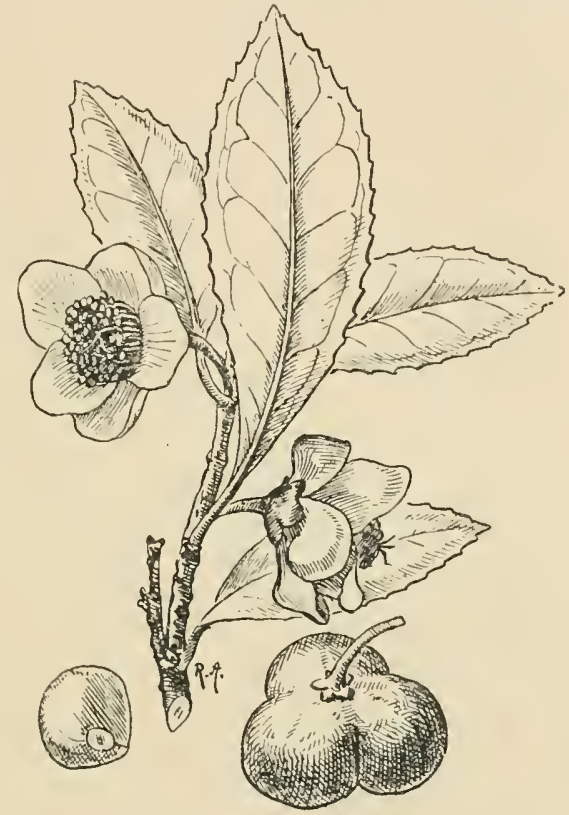

Fic, 592,-Thea chinensis, Flowering shoot ( $\frac{2}{3}$ nat. size); fruit and seed.

lucent spots in the leaf-blade. Garcinic Nangostrma, the Mangosteen, is one of the most esteemed fruit-trees of the Asiatic tropics.

OFfICraL. - Gureinic Hanburyi is a tree of Farther India, with thick leathery leaves and diclinons flowers. The male flowers have numerous stamens seated on a short globular receptacle; the female flowers have an ovary composed of three to several carpels surmounted by a broadly peltate stigma. The red contents of the secretory organs, which exudes on wounding the plant, provides when iried, cambogra, Gamboge.

Family 5. Dipterocarpaceae. -Inhalitants of tropical A sia. Contain secretory reservoirs.
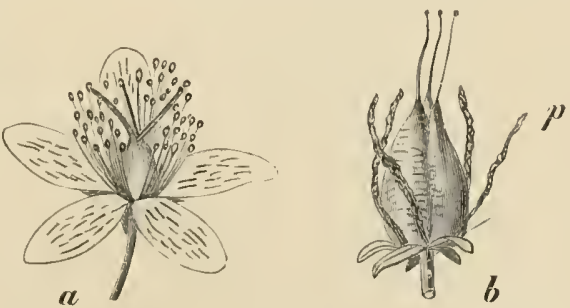

Fig. 593.-Hyperirum tetropterum. a, Flower, somewhat magnifiel ; b, fruit; $p$, the dried, persistent petals. ( $\times$ 2.)

Characterised by the great enlargement of some or all the sepals after fertilisation. Dryobalanops Camphora, yields Borneo camphor. Dammar $\left({ }^{47}\right)$ is obtained from Shorea Wiesneri. 


\section{Order 14. Columniferae}

The essential character of this order is afforded by the androecium of the regularly pentamerous, actinomorphic, hermaphrodite flowers. One of the two whorls of stamens, usually the onter one, is suppressed or only represented by staminodes, while the other whorl

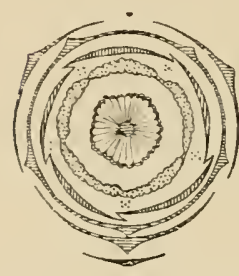

FIc. 594.-Mlalvaceae. Floral diagram (Malva). has undergone a greater or less increase in the number of its members by chorisis. The branching is frequently accompanied by cohesion of the filaments. The carpels also sometimes exhibit an increase in number as a result of branching. The superior ovary is then divided into a corresponding number of loculi.

Family 1. Malvaceae.-Herbs or shrubs, frequently with palmately-lobed, stipulate leares which in the young condition often have a velvety covering of stellate hairs. Flowers with an epicalyx, a gamosepalous calyx, and a corolla which is usually of considerable size and attractively coloured, and is contorted in the bud. Protandrous. Stamens united into a tube around the ovary; the free ends of the stamens, each of which bears a single reniform theca, project from the margin of the staminal tube. Pollen-grains with

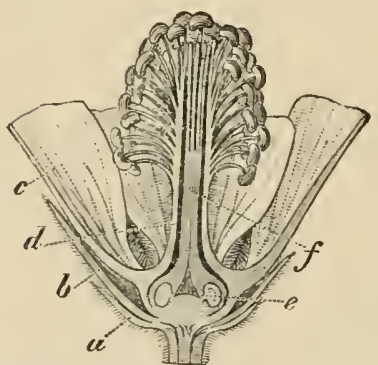

Fin. 595-Flower of Althara offirinalis, cut through longitudinally. $u$, Outer; $b$, inner calyx; $c$, petals; $r$, androecinm ; $f$, pistil ; $e$, ovule (magnifierl). (After Berr and SснмIDT.)

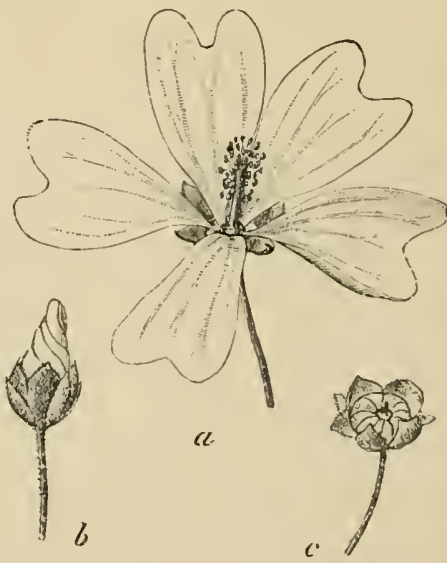

FIG. 590.-Malva silvestris, a, Flower; $b$, flower-bud ; $e$, fruit (nat. size).

spiny exine (ef. Fig. 429). Carpels usually numerous. Fruit a schizocarp or a capsule (Figs. 594-597).

Generally distributed, especially in the tropics.

Inportant Sub-families and Genera. - 1. Malveae. - Schizocarps composed of numerous carpels, arranged in a circle. Malva, with a number of British species 
(Hig. 196). P'eremnial herbs, with long-stalked, palmately-veined leaves. Flowers solitary or in small eymose inflorescences, in the axils of leaves. Three, free segments of the epicalyx. Petals usually rose-coloured, deeply notehed. In Althece the whole plant is clother with stellate hairs giving it a soft velvety. appearance. Epicalyx of $6-9$ segments united at the base.

2. Hibiscree.-Fruit, a capsnle usually formed of five carpels with a correspond-

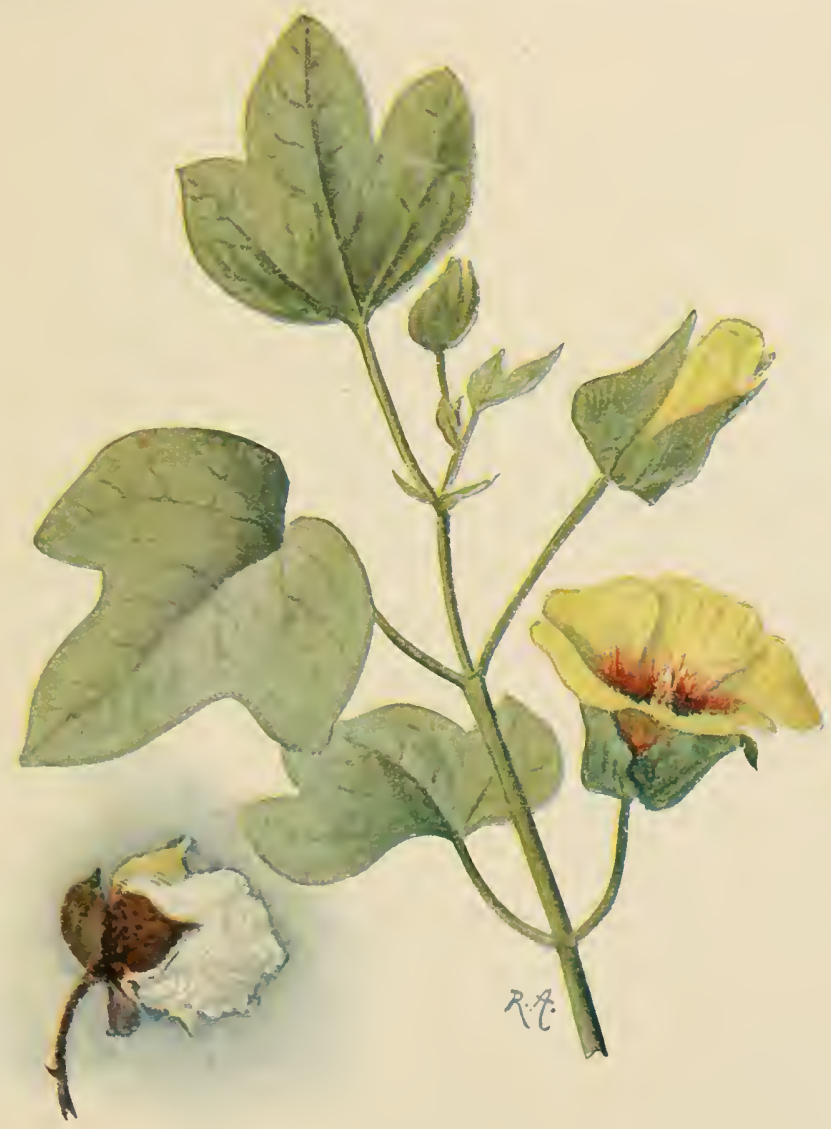

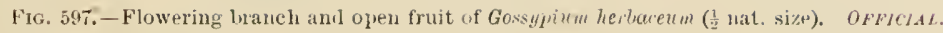

ing number of loeuli. Hibiscus is frequently cultivated as an ornamental plant. Gossypium, shrubs with three- to five-lobed leaves with long stalks. Flowers with a large epicalyx of three segments, which completely covers the ealyx. Fruit of three to five carpels, loculieidal. Seed covered witl long hairs which aid in its dispersion by the wind. When stripred from the seeds and cleaned these hairs form cotton wool. The most important species of Cotton are G. berbadense, G. arborcum, G. herbaceum (Fig. 597).

OFFICIAL. - Gossypium berbadense and other speeies yield gossyrium. 
Family 2. Tiliaceae.-For the most part trees or shrubs, less commonly herbs, with simple, stalked leaves provided with deciduous stipules. Calyx polysepalous. Estivation of calyx and corolla valvate. Stamens completely frec from one another with introrse anthers. A $5+5$, or only the inuer whorl is present and has nsually midergone branching (Fig. 598). Ovary with two to many loculi, and one to many ovules in each loculus. Style simple.

llost of the senera are tropical. The herbaceous species of Corchores vield Jute.

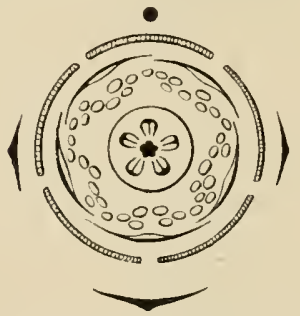

Fic. 598.-Tiliaceas. Floral diagram (Tiliet). (After Eichler.)

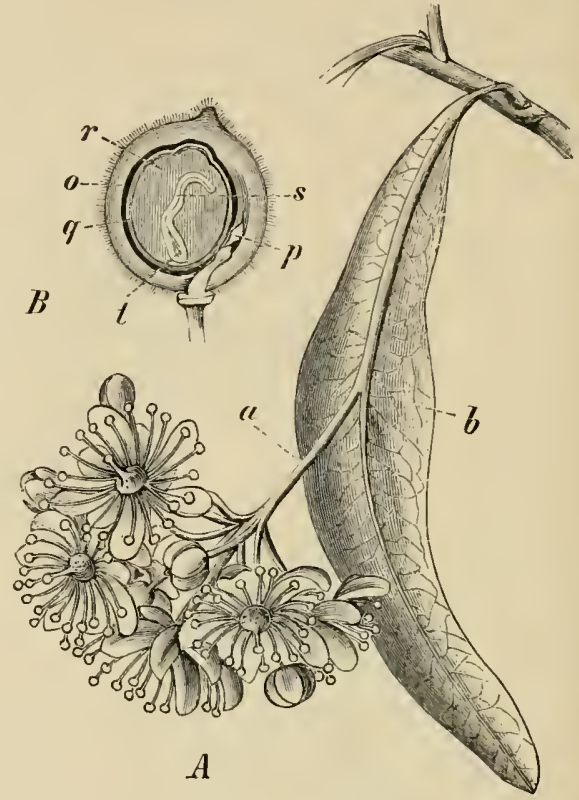

Fig. 599.-Tiliu ulmifuliu. A, Inflorescence (a), with bract; $b$, (nat. size). $B$, Longitndinal section of fruit (magnified); v, pericarl); $p$, atrophied dissepiment and ovule; $q$, seed ; $i$, endosperm ; $s$, embryo ; $t$, its radicle. (After BERG and Schuid,.)

In Britain two species of Filia, Lime, occur. These are stately trees with two-ranked, petiolate leaves, the stipules of which are soon shed. The leaves, which have a serrate margin, are asymmetrical. The inflorescence (Fig. 599, $A$ )

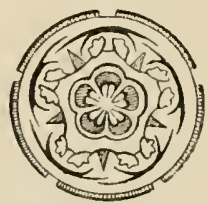

Fig. 600 $\rightarrow$ terculiacear.

Floral diagram. (Theo-

bromu.) (After Eis HI.ER.) is coherent with a braet for half its length; this serves as a wing in the distribution of the fruit. A second lract at the base protcets the axillary bud, which will expand in the suceeeding scason. Below the terminal Hower are three small bracteoles; the lowest of these is sterile while the two upyer ones have single flowers in their axils. Each of these flowers has a pair of bracteo'es which serve as the subtenting leaves for further branching. The umbel-like inflorescence of the Lime is thus composed of dichasia; Tilia platyphyllos las $3-7, T$. parvifolia 11 or inore flowers in the intlorescence. The hairy ovary has two ovules in each of its five loculi. The fruit only contains one seed (Figr. $599, E$ ).

Family 3. Stereuliaceae.-Tropical herbs, shrubs, or trees, with 
simple leaves and deciduous stipules. Flowers with a gamosepalous calyx. Corolla twisted in the bud. Stamens coherent to form a tube; the antisepalons stamens are staminodial, the antipetalous stamens are often increased in number. Anthers extrorse.

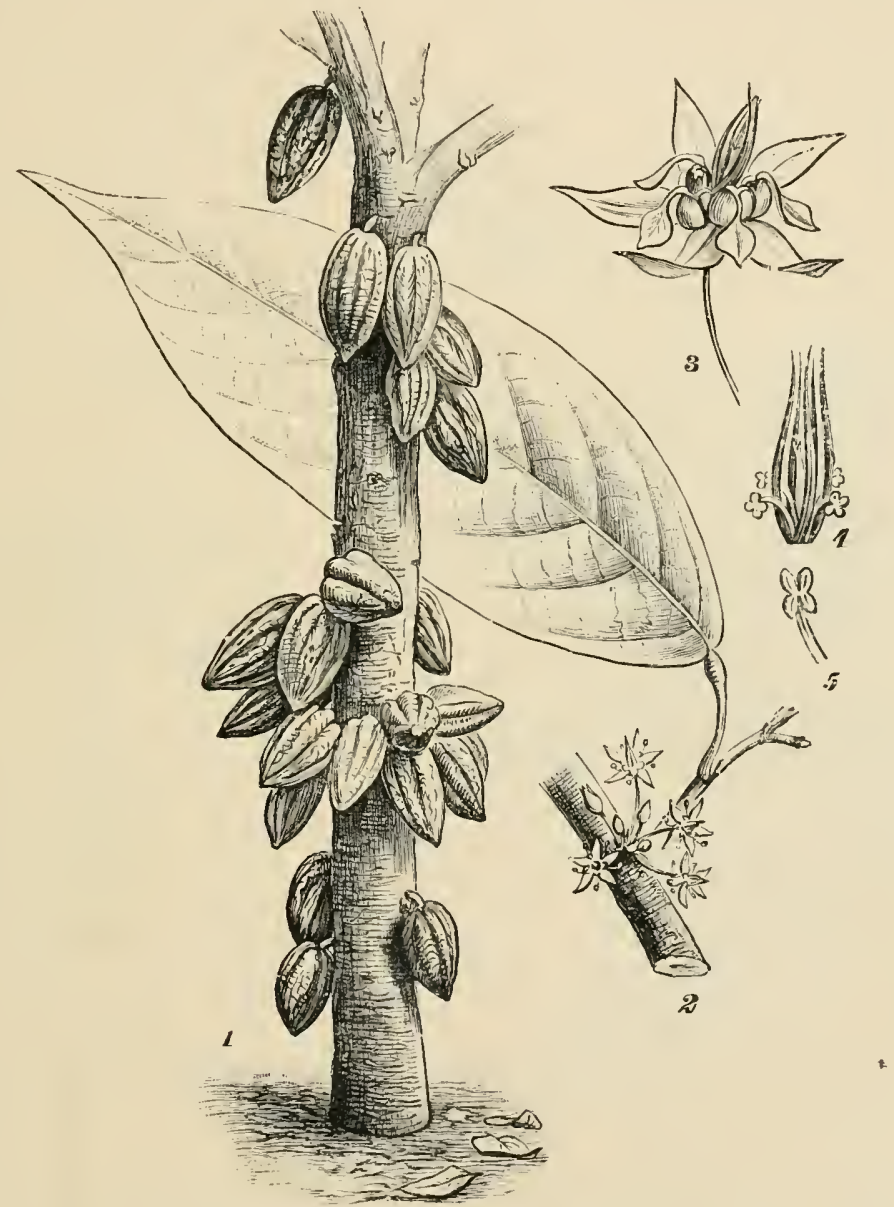

Fit. 601.-Theobromu caeru. 1, stem bearing fruits. \&, Flowering branch. 3, Flower. 4, Circle of stamens. i, Stamens from anterior sidp. (3) 4, about nat. size; 5, enlarged ; 1 , g, freatly redneed.) OFFICIAL.

Importast Gexera. - The most important plant is the Cocoa tree (Theobromu Cacao $\left({ }^{48}\right)$, Figs. 600,601). It is a native of tropical Central and South America, but has long been cultivated. The increasing demand has led to its being grown with more or less success in many tropical colonics. It is a low tree with short. stalked, firm, brittle, simple leaves of large sizc, oval shape, and dark green colour. 
The young leaves are of a bright red colonr, and, as in many tropical trees, hang limply dowurards. The flowers are borne on the main stem or the older branches, and arise from dormant axillary buds (CAVLIFLORY). Each petal is bulged out at the base, "narrows considerably above this, and ends in an expanded tip. The form of the reddish flowers is thus somewhat urn-shaped with five radiating points. The pentalocular ovary lias numerous ovules in each loculus. As the fruit develops, the soft tissue of the septa extends between the single seeds; the ripe fruit is thus unilocular and many-seeded. The seed-coat is filled by the embryo, which has two large, folded, brittle cotyledons. Cola acuminata and $C$. vera, natives of tropical Africa, yield the Kola nuts which are used in medicine.

OFFICIAL. - Theolrome Cacoo, from which OLEUM THEOBRonatis is obtained.

\section{Order 15. Gruinales}

The flowers of the majority of the plants belonging to this order are hermaphrodite, pentamerous, and rarlially symmetrical, with a superior, septate ovary. K 5, C 5, A $5+5, G(5)$. When the flowers are zygomorphic they frequently exhibit reduction. Stamens coherent at the base, obdiplostemonous or haplostemon-

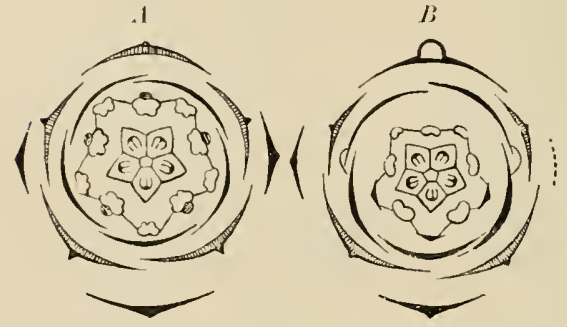

Fif. 602.-Floral diagrams of Geraniaceae. A, Gernenium pratense; B, Pelargonium zonale. (After Eıchuer.)

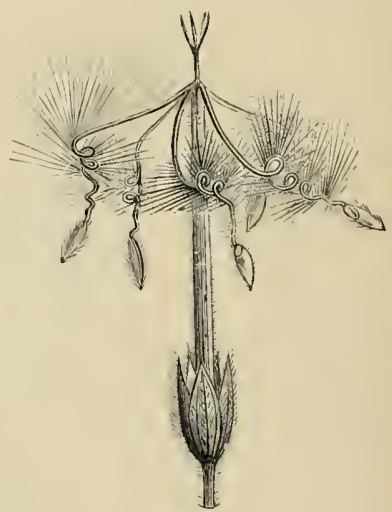

F16. 1003.-- Fruit of Pelargonium inquinens, $\times 3$. (After BAlLLON.)

ous. Nectaries to the outer side of the stamens or as an annular dise within the stamens. Ovules, usually pendulons; micropyle directed upwards.

Family 1. Geraniaceae.-Herbs or small slirubs witl, as a rule, aiternate, stalked, palmately veined leaves. Flowers conspicuous, solitary in the leaf axils or forming cymose or nmbellate inflorescences. They are usually actinomorihic; in Peluryonizum zygomorplic and provisled with a spur. Stamens 10 or 5 . Two ovules in each loculus. When ripe the five beaked carpels separate from a central columu, and either open to liberate the secds, or remain elosed and by the hygroscopic movenents of the awn-like portion bury the seed in the soil (Figs. 602, 603. Cf. Fig. 224, p. 296). Distributed over the whole earth.

Geranium with ten stanens and Erodium with five fertile and five sterile stamens oceur in Britain. Numerous species of Peluryonitum from the Cape are 
cultivated as ornamental plants; the peculiar seent of the vegetative organs is due to the ethereal oil secreted by the glandnlar hairs.

Family 2. Tropaeolaceae.-Tropaeolum majus, Indian Cress, climbs by hel' of the petioles. Flowers zygomorphie, spmrred, with 8 stamens and 3 earjels. Fruit, a eapsule. Leaves peltate (cf. Fig. 187). The genus is native in the Anrles from Mexico to Clili.

Family 3. Oxalidaceae. - Leaves compound, in some species irritable to mechanical stimuli (Biophytum. Oxalis acetosella, Wood Sorrel, ef. pr. 299, 324). Mainly in S. Afriea and S. America.

Fanily 4. Linaceae.-Herbs or shrubs with alternate, narrow, entire leaves. Distributed in nearly all regions of the earth. Flowers aetinomorphic. Stamens coherent at the base ; those opposite the petals developed as staminodes. Ovary 5-locular,

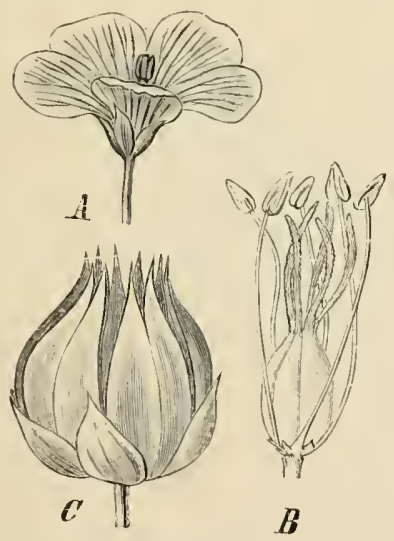

Fıg. 604.-Iinum usitatissimum. At, Flower; $B$, androecim and gynaeceum; $\ell$, capsule after dehiscence. (A, nat. siz" ; $B, C$, FICIAL.

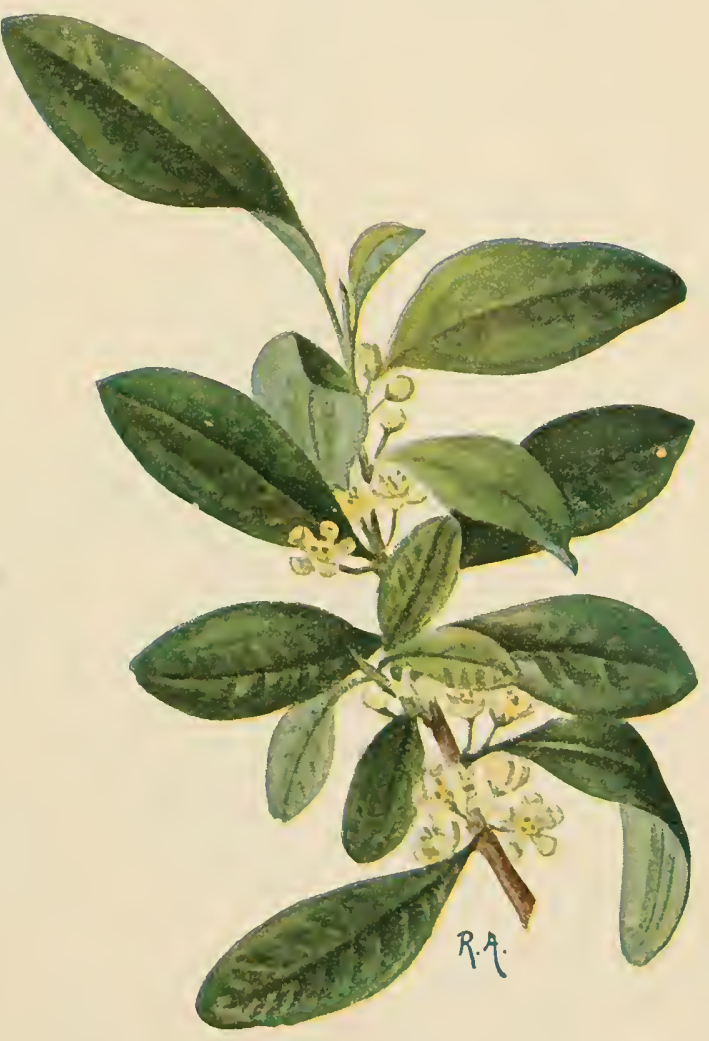

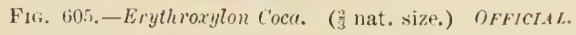

each loculus incompletely divided by a false septum; in each chamber is one pendulous ovule. Fruit a capsule (Fig. 604, $A-C$ ). Linum usitatissimum, Flax, has long been in eultivation. It is an annual, and bears numerous blue flowers, which last only a short time, in racemose cincinni. The flower has five free styles. The stem bears numerons small, narrow leaves. The bast-fibres after proper preparation are woven into linen. The seeds yield oil.

OFFICIAL. - LINUM, the seeds of Linum usitatissimum.

Family 5. Balsaminaceae. - Inceulent herbs, with translueent stems, sometimes swollen at the nodes, and simple leaves. Flowers zygomorphic with five 
free stamens. Capsule deliseing elastically.

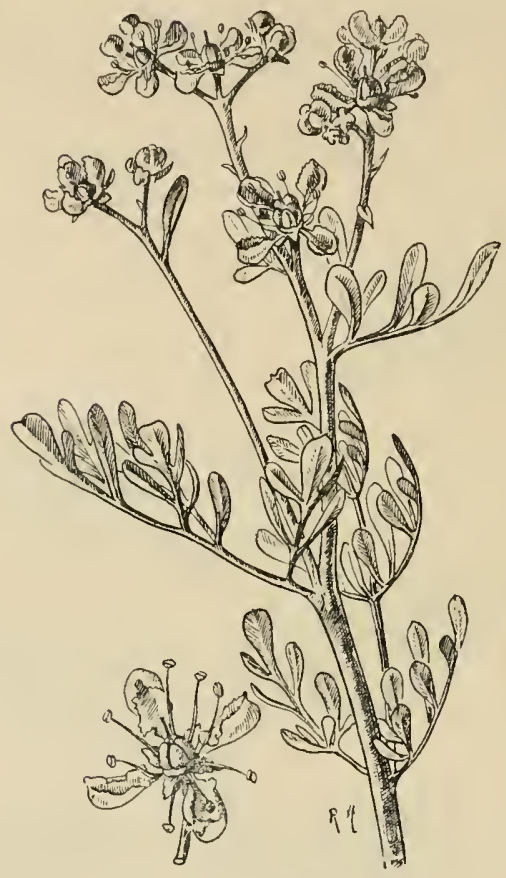

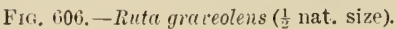

Impatiens noli tangere, I. parviftora, and I. Balsamina. Regarding the oceurrence of cleistogamons flowers in Impatiens, ef. p. 499. Mainly distributed in the tropics of the old world.

Family 6. Erythroxylaceae. -Erthroxylon Coce is a small Peruvian shrub, with entire, simple leaves and axillary groups of small, white flowers. Petals with appendages. Stamens 16, united at the base into a tube, G (3), but only one loeulus of the ovary is fertile. Fruit, a oneseeded drupe (Fig. 605). The family is especially abundant in equatorial Ameriea.

OFFICIAL. - From É. Coca

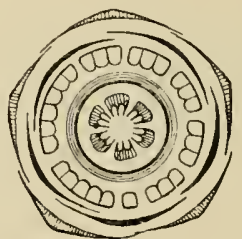

Fic. 607.-Floral diagram of Citrus vulgaris. (After ErchLER.)
COCAE FoLIA, whieh yield COCAINA, are obtained.

Family 7 . Zygophyllaceae. - Typically pentamerous Hower with an intrastaminal dise.

OFFIOIA L. - Guincum officinale, a West Indian tree with opposite, paripinnate leaves. Ovary biearpellary, biloenlar. Fruit winged. It yields GUIACI LIGNUM and GUIACI IRESINA.

\section{Fanily 8. Rutaceae.}

For the most part slirubs or trees, rarely herbs, witl alternate, pinuate leaves. Flowers usllally actinomorphie, tetramerous or jentimerous with a large

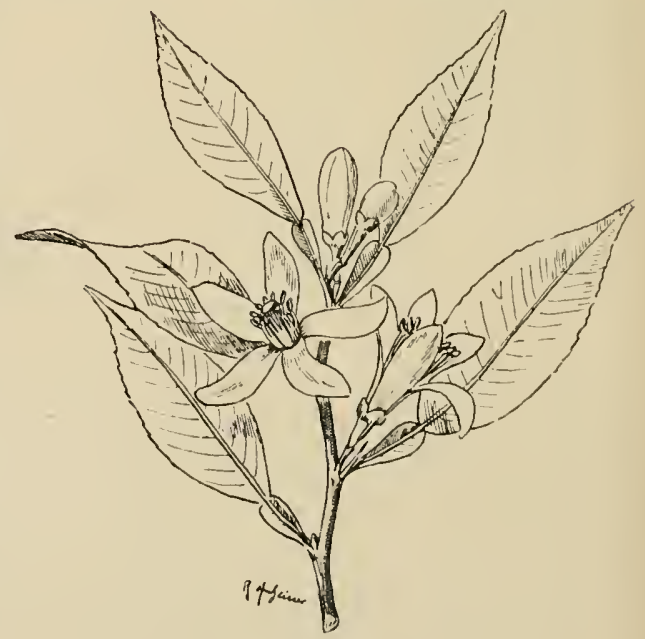

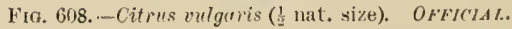


intrastaminal disc. Oil-containing eavities in all the members. Distributed in the warmer zones of all regions.

Impoltant Geneia.-Ruta graveolens (Fig. 606), the Rue, is a somewhat shrubby plant with pinnately divided leaves. The teminal flowers of the dichasial inflorescences are pentamerous in robust examples; all the other flowers

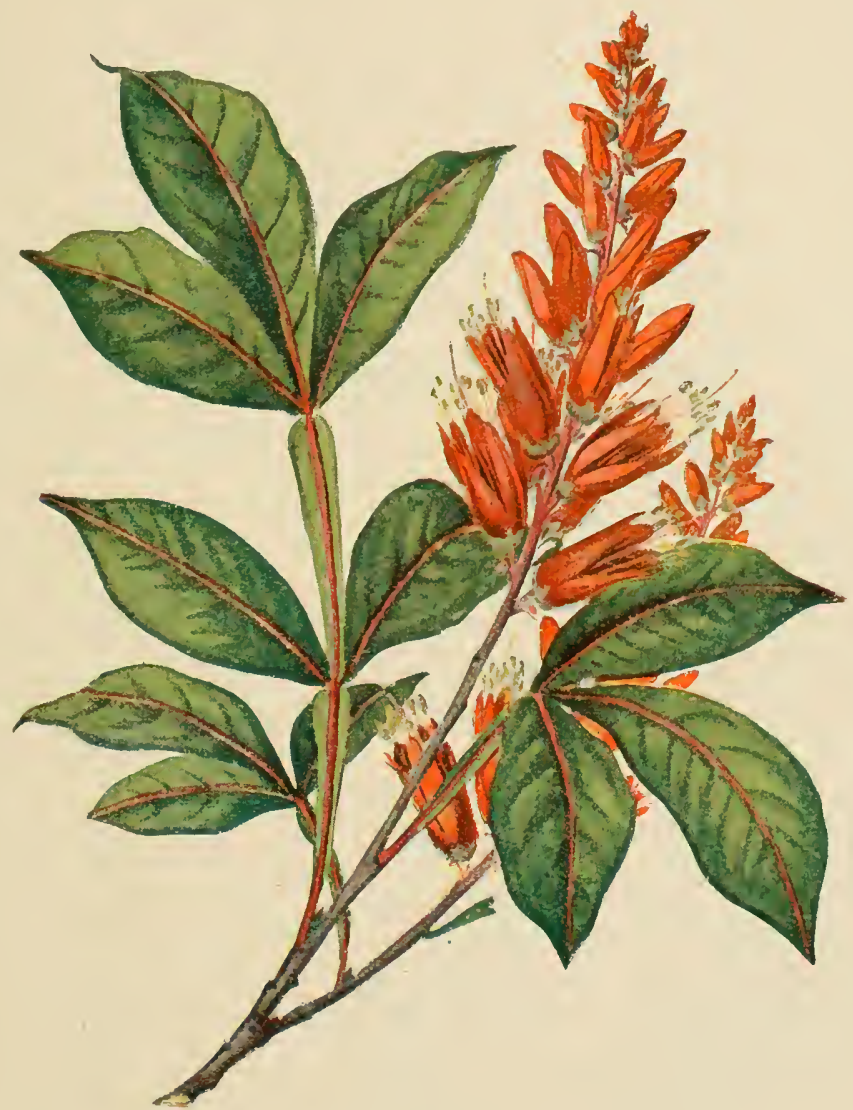

Flf. 609.-Quessia amure. (Nat. size. After Berg and Schmot.) OFFICIAL.

are tetramerous. Dictamnus Fraxinclla has panicles of conspicnous, dorsiventral Howers; the carpels are free in their upper portions. The important genus Citrus. ( ${ }^{49}$ ) has peeuliarly constructed flowers (Figs. 607, 608). The numerous stamens are mnited in bundles and arranged in a single whorl. The number of carpels is also increased. The fruit is a berry; the succulent portion is formed of large cells with abundant cell-sap which project into and fill up the loculi of the ovary. The seeds have usual'y several embryos. (Cf. p. 283.) The leaves of many species are simple and provided with more or less winged petioles. Other 
speeies have trifoliate leaves and the articulation at the base of the lamina shows that the apparently simple leaves correspond to imparipinnate leaves, of whieh only the terminal leaflet is developed. The thorns at the base of the leaf are derived by modification of the first leaves of the axillary bud. Citrus is originally an East Asiatic genus; a number of speeies inhabit the warmer valleys of the Himalayas. All the inportant cultivated forms have been obtained from the Chinese. Citrus dccumana, the Shaddock, is tropical ; $C$. medica is the form which was known to the Greeks in the expeditions of Alexander as the Mledian apple. It is now widely spreal and has a number of varieties of which Citrus (medica) Limonum is the Lemon. This tree was introduced into the Nediterranean region in the third or fourth eentury. Citrus (medica) Bajoura has thick-skinned fruits from which eitron is obtained. Citrus Aurontium oecurs in two distinet forms, C. (Auruntium) vulgaris and $C$. (Aurantium) sinensis. The latter is a rariety of the Bitter Orange tree of apparently Chinese origin, and already comes more or less true to seed (ef. Apogamy,

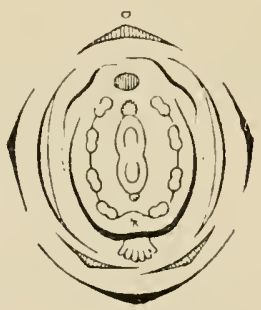

Fig 610, - Floral diagram of f'olygula myrtifolia. (After EIcHLER.)
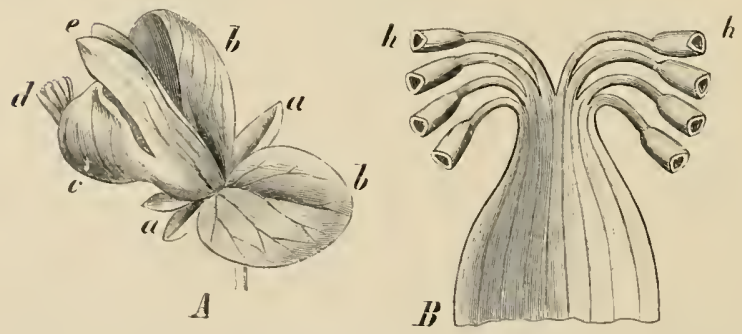

Fic, 611. - I'vlygulu senegu. A, FloweI; 4 , small; $b$, large sepals $c$, keel; $e$, lateral sepals; $l$, androeciun. $B$, androteium; $h$, anther: (nagnified). (After Herga and Schuidt.) (IFFIClal.

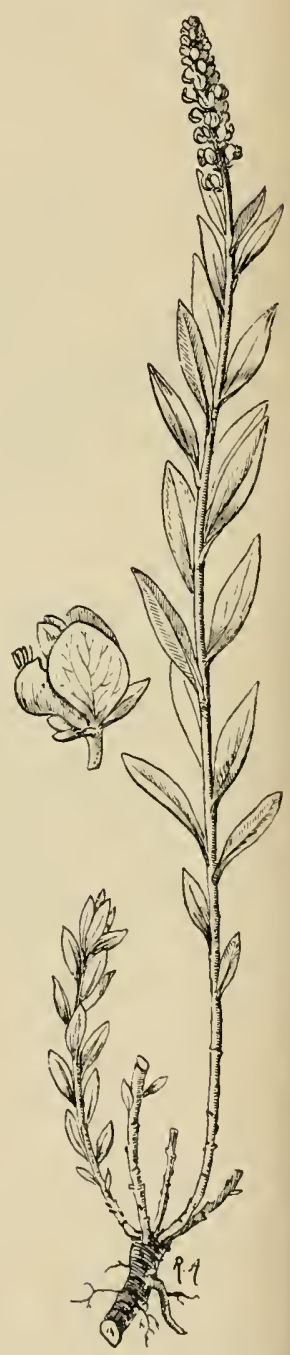

FiG. 612.-P'olygula Scnegin (4 nat. size.) OFFICIAI.

1. 283). The name Orange, which is introduced into many languages and is derived from the Sanserit word Nagarunga, points to the ancient cultivation of the plant in India. The name was first applied to the Bitter-fruited Orange, which found its way west much earlier that the sweet variety, and was sub- 
sequently applied to the latter. Citrus nobilis, the Mandarin, is also of Chinese origin.

OfFicial.-Citrus Aurantium, var. Bigaralia, yields auranti cortex

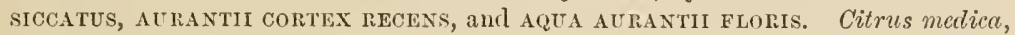
var. limonum, gives LIMONIS CORTEX, and LIMONIS sUCCUS. BUCHU FOLIA are obtained from Barosma betuline. Cespaliate contex from Cusparia felrifuga. JABORANdi folia from Pilocarpus jaborandi, a tree-like shrub with large, imparipinnate leaves, native of Eastern Brazil.

Family 9. Simarubaceae. - K 5, C 5, A 5 +5, G5. Carpels free. No oil glands. Contain bitter principles. Distributed in all tropical countries-especially American.

OFFicial. - Quassiae Lignu y from Pierasma execlsa (West Indies) and Quassia amara (Surinam). The latter (Fig. 609) is a small tree with beatiful leaves and showy flowers.

Family 10. Burseraceae.-Woody plants with resin passages. Fruit, a drupe. Tropical. Commiphora abyssinica and C. Schimperi are trees found in Arabian East $\Lambda$ frica. Boswellice Carteri and B. Bhau Dajianae are small trees $\left({ }^{50}\right)$ from the same region which yield OLIBANUM. Canarium.

Official. - Mrrena, Myrrh, from Balsamodendron Myrrha and other species.

Family 11. Polygalaceae.-Herbs or shrubs with small simple leaves and dorsiventral flowers. K5, C3, A (8), G(2). The two lateral sepals are petaloid. Three petals, the lowest of which forms a keel. Stamens 8 , coherent into a tube. Anthers opening by pores. Ovary bilocular, formed of two carpels; a single ovule in each loculus (Figs. 610-612). The Polygalaceae are widely distributed and are wanting only in New Zealand, Polynesia, and in Arctic America and Asia. Polygala chamaebuxus is a small shrubby plant occurring in the Alps. P. vulyaris and P. amara oecur in Britain.

Official. - Polygale Senega (North Anerica) yields Senteate Radix.

\section{Order 16. Sapindinae}

This order includes trees and shrubs of very different appearance, with cylic flowers. The latter exhibit reduction in the perianth, androecium, and gynaecenm.

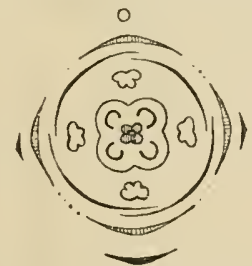

Fis. 613.-Floral diagram of Ilex rquifolium. (After Eichler.)

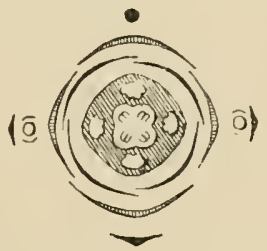

Fif. 614.-Floral diagram of Euonymus curopuer. (After Eichler.)

One or two ovules are contained in each chamber of the ovary; when the ovules are erect the raphe is ventral, when they are pendulons it is dorsal.

Family 1. Anacardiaceae.-Distributed in the tropies and warm temperate regions. Ovary of 1-3 carpels. Fruit usually a one-seeded drupe. Schizogenous resin lassages. Mangifera indiea ${ }^{51}$ ) an important fruit tree of the tropies. Species of Rhus yield japan lacquer. R. toxicodendron, a North American climbing 
shrub, is extremely poisonous. Speeies of Pistacic (Mediterranean region) have pinnate leaves. $P$. vere is eultivated on aecount of its drupaeeous fruits ealled Pistachio nuts.

Family 2. Aquifoliaceae.-Ilex aquifolinm, the Holly, is an evergreen shrub or tree of Western Europe (Fig. 613). Flower tetramerous throughont. In each beulus of the ovary is a pendulous ovule. I. paraguariensis in extra-tropical South Anerica yields Paragnay Tea or Matè. Centre of distribution in Central and Southern America.

Family 3. Celastraceae.-Euonymus europaca, the Spindle tree (Figs. 614, 615),

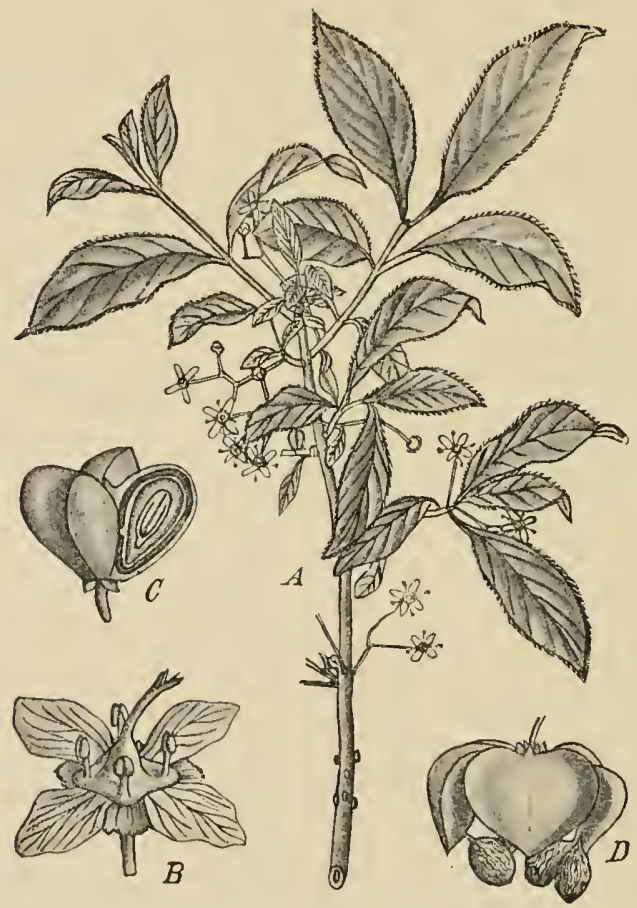

Fin. 615.-Euonymus europrut. A, Flowering branch (reduced); $B$, a flower (magnified) ; $r, D$, the fruit (nat. size), (B-D, after Engler-Prantl.) Polsonots.

is a British shrub with ineonspienons tetramerous flowers. The stamens are inserted at the margin of a large dise; two ovules in each loculus. In autumn the bright red arillus of the seeds, which hang by their stalks from the opened pale red eapsule, makes the fruit conspicuous. The family is generally distributed.

Family 4. Aceraceae. -Trees with opposite leaves. The flowers show a tendeney to beeome unisexual by abortion of stamens or earpels. Dise intra- or extra-staminal. Carpels two. Fruit, a winged sehizoearp (Fig. 616). Family of boreal origin. In Britain Aeer campestre and A.pseudoplutanus. The characteristis lobed outine and palmate nervation of the leaves, as a rule, enable the genus to be readily recognised. 
Family 5. Sapindaceae.-Tropical trees or shrubs usually with obliquely zygomorphic flowers with an extra-staminal disc.

The crushed seeds of Paullinia cupana, a liane of tropical Brazil, yields GUARANA.

Family 6. Hippocastanaceae.-Closely related to the Sapindaceae. Acsculus,

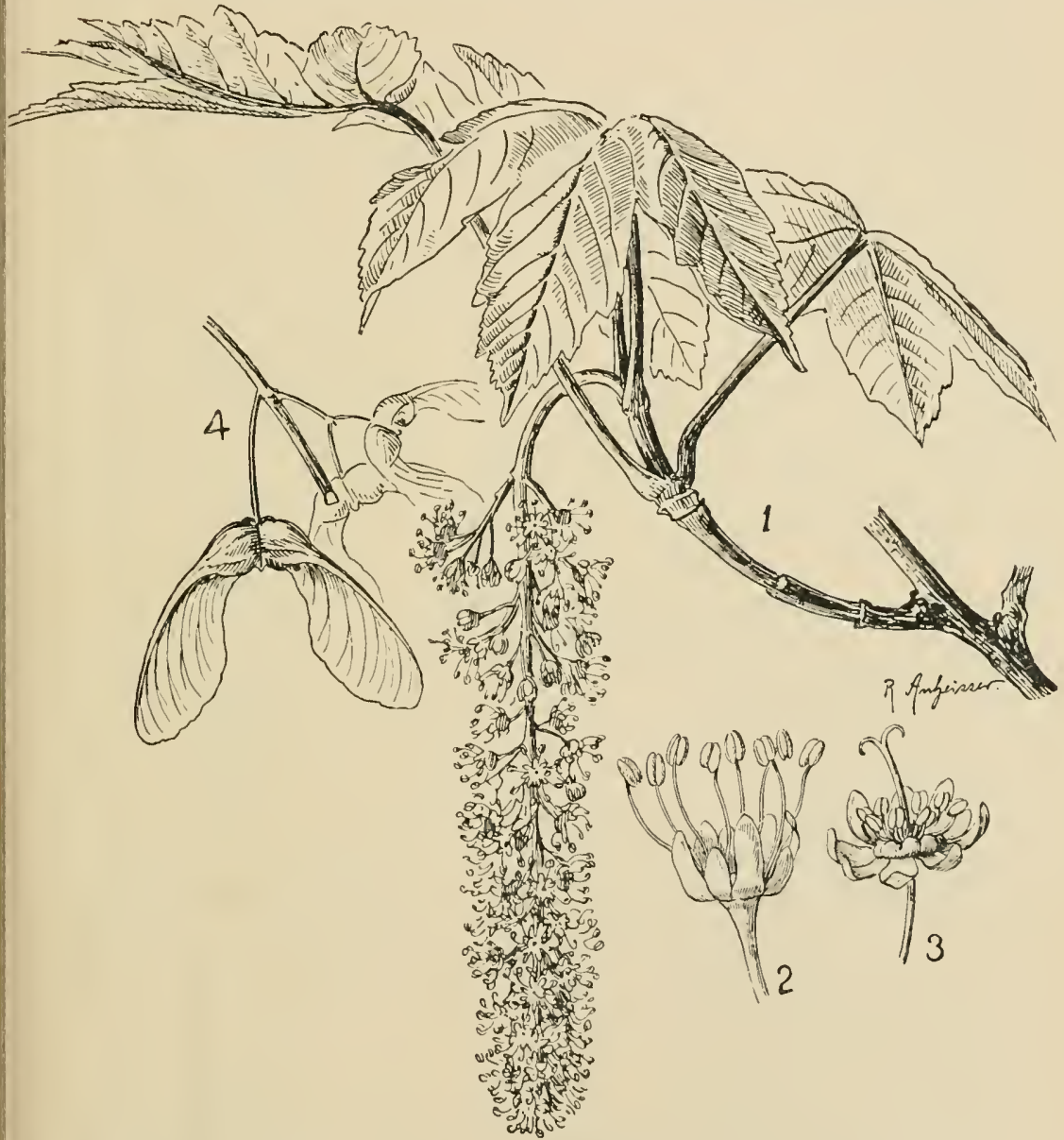

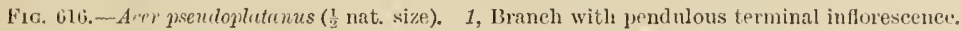
2, Male flower. \&, Female flower. 4, Fruit. (2 and 3 enlarged.)

Horse-chestnut. Aesc. Hippocustanum, the White Horse-chestuut, is a tree of hilly regious of the eastern Mediterrancan (Fig. 440, B). Aesc. poriu, the Red Horse-chestuut, is a native of the mountains of the Atlantic side of North America. Both are commonly cultivated. The family is distributed in the North temperate zone. 


\section{Order 17. Frangulinae}

Shrubs or trees with inconspieuous, aetinomorphic, tetramerous or pentamerous Howers. There is only one whorl of stamens, which are
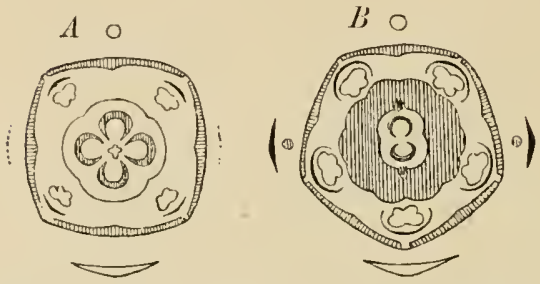

FIG. 617.-Floral diagrams of A, Rhumnus cuthartica (represented as hermaphrodite) and $B, R h$. Frangula. (After Eichler.)

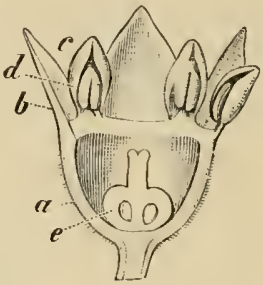

Fig. 618.-Rhamnus Frangulu. Flower eut through longitudinally. $a$, Receptacle; $b$, ealyx ; $c$, petal ; $d$, a stamen; $c$, pistil (magnified). (After BERO and SCHMıтT.)

antipetalous. Flowers hypogynous or perigynous. Ovary composed

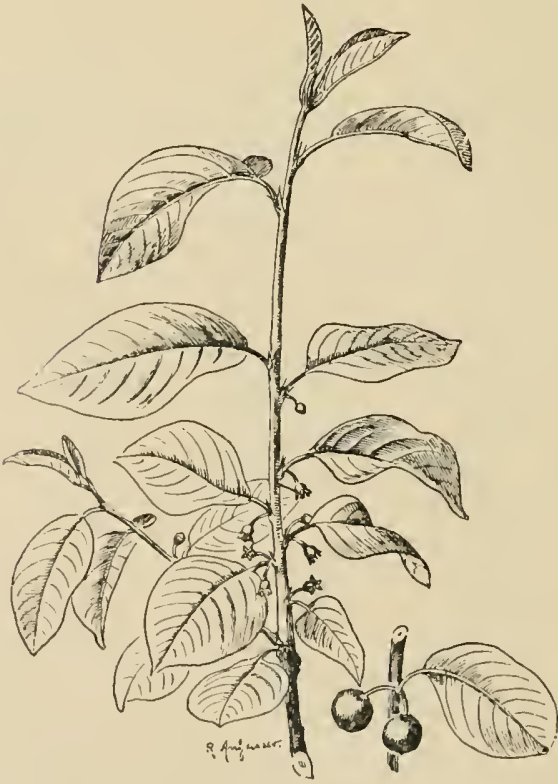

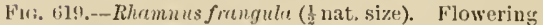
branch and portion of a branch bearing fruits.

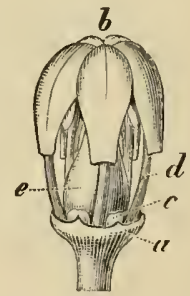

F1G. 620.-Vitis vinifere. Onening flower. $u$, Calyx; b, corolla ; $e$, lise ; d, stamens ; $e$, ovary (magnified). (After Beraand Schump.)

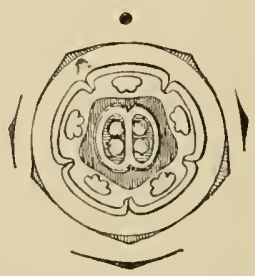

Fıci, fi2l.-Floral diagram of Ampelopsis heieraceu. (After Euchusi.)

of two to four carpels with one or two erect ovules in each loenlus. Jise intrastaminal. 
Family 1. Rhamnaceae.-The only native genus of this family, which is distributed in the tropies, is Phammus.

Rh. Frangula (Figs. 617 B, 619), the Berry-bearing Alder, is a shrub with alternate, entire leaves provided with small stipnles. The flowers are solitary or in gronps in the axils of the leaves; pentamerous, with two carpels. The floral receptacle forms a cup-shaped dise. Two (less commonly three) carpels; stigna undivided. Fruit, a drupe with two or three seeds. The wood was formerly used as a source of charcoal for the manufacture of gunpowder. Fih. catharticus has nsually spiny branches bearing opposite leaves with serrate margins. Flowers tetramerons throughont (Fig. $617 \mathrm{~A}$ ), dioecions by suppression of stamens or carpels; female flower with four free styles and a four-seeded drupe. Seeds with a dorsal furrow. Colletic spinosa and $C$. cruciata are leatless South American shrubs; the thorns of the former are cylindrical, those of the latter flattened laterally.

OFFICIAL. - Rhumnus purshiames yields CASCARA SAGRADA Or RHAMYI PTRSHIANI CORTEX.

Family 2. Vitaceae.-Shrulby plants climbing by means of tendrils; leaves palmately lobed or divided. Flowers hypogynous. Ovary composed of $2-4$ carpels and with a corresponding number of loculi. 'Two ovules in each loculus. Disc often consisting' of separate glands (Figs. 620, 621). An almost exclusively tropical and subtropical family.

Important Genera. - Vitis, climbing shrubs of the northern hemisphere. Vitis vinfera, the Grape Vine, is a cultivated plant with numerons races and varieties. The tendrils correspond to shoots and stand opposite to the leaves; they are at first terminal, but become displaced to one side by the development of the axillary shoot. The wlole shoot is thus a sympodium. The original relation between the tendrils and the axillary shoots, which are both reeognisable at the growing point, eannot be completely followed in the ontogeny. The inflorescence is a panicle taking the place of a tendril ; intermediate forms between inflorescenees and tendrils are of frequent oceurrence. Calyx only represented by a small rim; Corolla thrown off when the flower opens. Currants are the seedless fruits of $l$ ritis vinifera, var. apyrena. Species of Quinaria distributed in North Ameriea and Asia go by the name of Wrild Vines; some of them have tendrils with adhesive dise (Fig. 29 and P. 318). Cissus is a large, exclusively tropical genus.

OfFictal.-Uvae, Raisins from Vitis vinifera.

\section{Order 18. Saxifraginae}

Herbs or woody plants of very diverse habit, with actinomorphic, pentamerous flowers. Androecium usually obdiplostemonous. Carpels 2-5, free or coherent. Flowers hypogynous, perigynons, or epigynous.

The family of the Podostemonaceae ( $\left.{ }^{52}\right)$ may be included in this order. The vegetative and reproductive organs of these plants are peculiarly modified in relation to their mode of life, anc the situations they occupy in the most rapir currents and waterfalls of rivers and streams in the tropics. 
Family 1. Crassulaceae. - Succulent $\left({ }^{53}\right)$ herbs or under-shrubs with cymose infiorescenees. Flowers hermaphrodite, with calyx and corolla consisting of a variable number of members. Obdiplostemonous or haplostemonous. Carpels free (Fig. 622), flower hypogynous or perigynous. Seale-like neetaries at the base of the carpels.
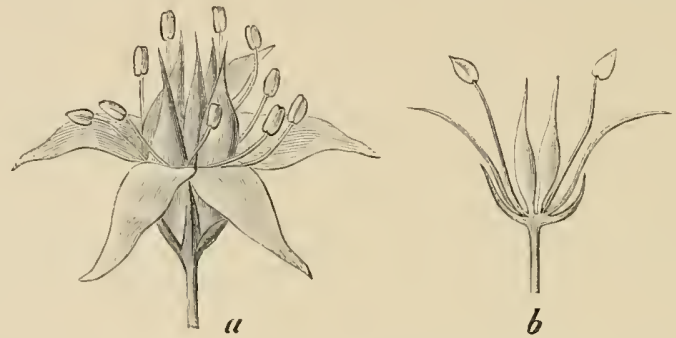

Frg. 622.-Srim Tomephium. $a$, Flower; $b$, flower in longitudinal section. $(x 4$.

Fruit a capsule containing numerous seeds with a small amount of endosperm. Mainly found in the old world.

More Important Genera. - Sedum with pentamerous flowers; there are a number of British species. Semperivum, Howers with from six to an indefinite number of nembers in the whorls; $S$. tectorum. Bryophyllum with tetramerous

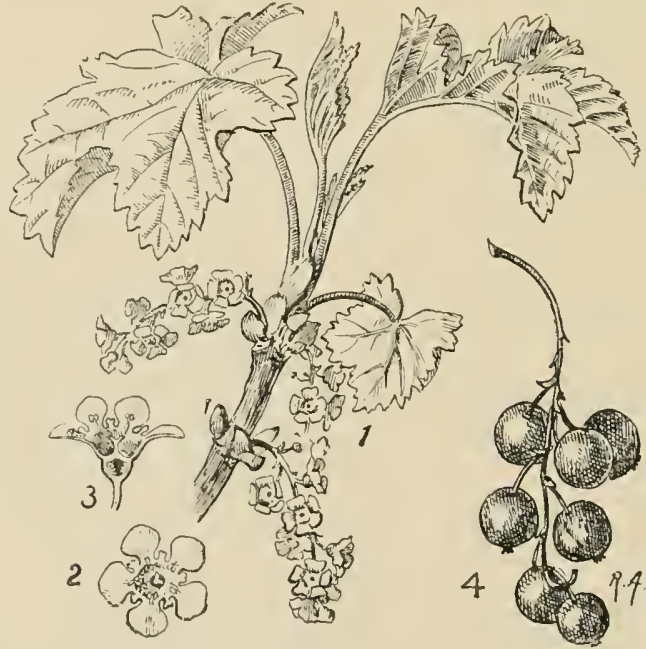

FIs. 623.-Ribes rubrum. ( $\frac{2}{3}$ nat. size.)

llowers, noteworthy on acemnt of the abundant formation of buls in the indentations of the margin of the leaf. Crossuld.

Family 2. Saxifragaceae $\left({ }^{54}\right)$. - - Herbs or woody plants with alternate leaves. Flowers hermaphrodite, obdiplostemonous, tetramerous or pentamerous, perigynous or epigynous. Carpels usually 
two ; ovary uni- or bi-locular. Fruit a capsule or a berry containing an indefinite number of albuminous seeds.

Inportant Geneka. - Saxifragr, Saxifrage, small herbaceons plants which are especially numerons on crags and rocky ground in mountainous districts. They liave a rosette of radical leaves (cf. p. 15, chalk glands) and bear numerous pentamerous flowers grouped in varions types of inflorescence. The two partially inferior carpels are distinet from one another above. Purnassia palustris is common on wet moors, pentamerous flower with 4 carpels. Ovary unilocular, placentation parietal. One whorl of stamens modified into jalmately divided staminodes, which serve as nectaries. The species of Ribes have an inferior ovary which develops into a berry, and on this account are commonly eultivated. li. rubrum (Fig. 623), Red Currant, $R$. nigrum, Black Currant, R. grossularia, Gooseberry. Other Saxifragaceae are favourite ornamental plants, e.g. Ritbes aureum and $R$. sanguineum, Hydrangea, Philadelphus, and Deutia.

\section{Order 19. Rosiflorae}

Family Rosaceae $\left.{ }^{55}\right)$.- - This is the only family in the order. Herbs, shruls, and trees with alternate, stipulate leaves, showing considerable differences in form and habit. Distributed thronghout the world. Flowers nearly always actinomorphic, with the members in whorls. K 5, C 5. Stamens usnally numerous. Flowers perigynous or epigynous; one to many free carpels borne on the expanderl, convex, or hollowed floral axis. In the epigynous flowers only the styles are free. The floral axis in many cases takes part in the construction of the fruit. Seeds usually without endosperm.

The apocarpous pistil and numerons stamens are characteristic of the Rosaceat (Fig. 624). Both these features are also found in the Ranmuculaceae or generally in the Polycarpicae, but the floral members are there spirally arranged while in the Rosaceae they are in whorls. The latter are further distinguished by the peculiar development of the fioral axis (Fig. 625). In many cases the increase in number of members of the androecium and gynaeceum proceeds from an intercalary zone of the hollowed floral axis, and continues for a considerable period. The introduction of new members is determined by the spatial relations, so that differences in the numbers of members are found in individuals of the same species.

The family is divided into a number of sub-lanilies.

(a) Spiraece. Typically pentamerous flowers, other numbers of members in the whorl are less frequent. Carpels free or united, each containing two or more ovules. Fruits usually dehiscent. Floral axis expanded as a more or less flat dise. The genus Spircaed has inflorescences bearing numerons flowers; many species are cultivated as ornamental shrubs (Fig. 624 E). Quillaja Saponaria (Fig. 626), from Chili, is an evergreen tree with shortly stalked, alternate, leathery leaves and terminal dichasia usually consisting of three flowers. The flower has a five-toothed, nectar-secreting disc projecting above the large sepals. Five of the stamens stand at the projecting angles of the dise opposite the sepals; the other five are inserted opposite the petals at the inner margin of the dise. Petals narrow, white. Ovary superior. Only the middle flower of the dichasium is hermaplurodite and fertile, the lateral flowers are male and have a reduced gynaeceum. Fruit star-shaped, 
composed of partial fruits. Each earpel dehisces by splitting into two valves. Seeds winged.

(b) Pomeae.-These are distinguished from the other Rosaceae by their inferior
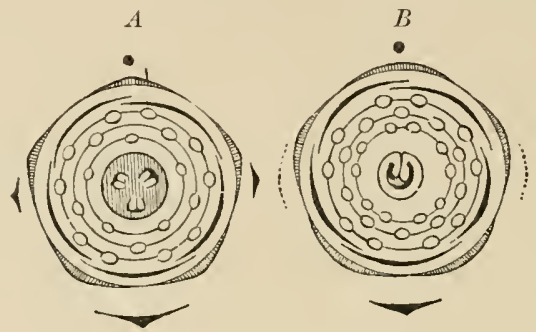

C

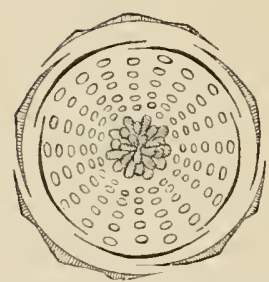

L

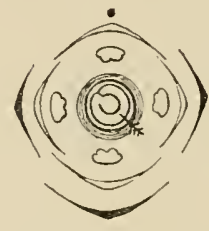

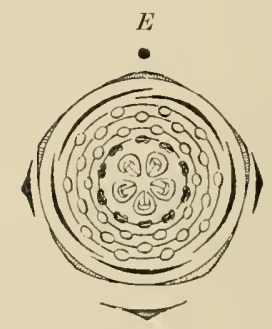

FıG. 624.-Floral diagrams of Rosaceae. A, Sortus dumestiea; B, Prunus Pudus; C, Rosa tomentusa: D, Sanguisorbu officinalis; E, Spiruea hypericifolit. (After Eıchler.)

ovary, which usually consists of five carpels bound together by the hollow floral receptacle so that only the styles are free. Each carpel contains one to many ovules. The fruit resembles a berry, the floral receptacle becoming succulent. The boundaries of the separate loculi are formed of parchment-like or stony tissue,
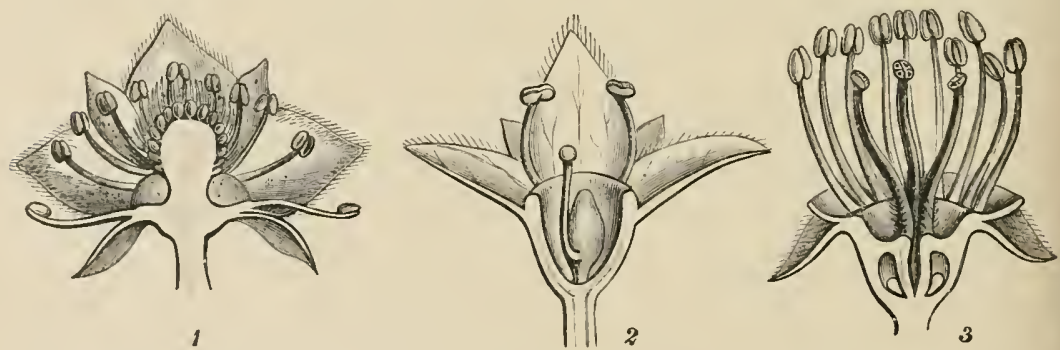

Fic. 625,-Rosaceae. Three flowers ent through longitulinally to show different furms of the receptacle. 1, Potentilla palustris: 2, Alchemille alpina; 3, I'yrus malus. (After Focke in Nutiirl. I'fanzenfumilien.)

The seeds are exalbuminous and enclose a well-developed embryo with fleshy cotyledons. Pyrus malus, Apple (Fig. 625, 3; Fig. 627), and I'. communis, the Pear, are important and long-cultivated fruit trees, of which numerous varieties are grown. Cydonic vulyaris, the Quince, has large, solitary, rose-coloured flowcrs. The fruits are in shape like an apple or pear, coverel with fine woolly hairs and with a pleasant 
scent, though not edible when uncooked. In Vespilus germanica, the Medlar, the fruit has an apical depression smrounded by the remains of the calyx. The evergreen Eriobotrya japonica, is commonly planted in the Mediterranean region; fruits contain several large seeds, and are sucenlent, having an acid flavour, Sorbus (Pyrus) aucuparia, the Rowan. Cratcergus (Mespilus) oxyeantha, the Hawthorn, in hedges or planted as an ornamental tree.

(c) Roscue. - Floral axis concave, pitcher-shaped, with one to many free carpels, each of which encloses 1-2 ovules. The partial fruits are unt-like, and are enclosed by the hollowed floral axis. Rose with numerous species, varieties, and cultivated forms, which have been for long valned on account of their form, colour,

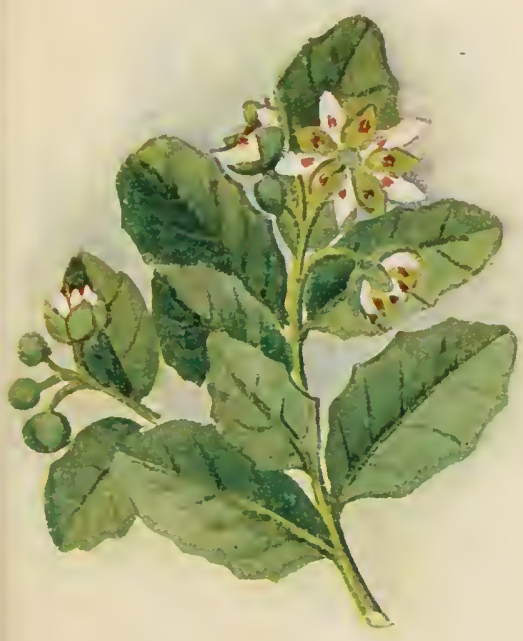

Fia. 626.-Quillaja Saponario. ( $\stackrel{+}{s}$ nat. size. After A. Meyer and Schumayx.)

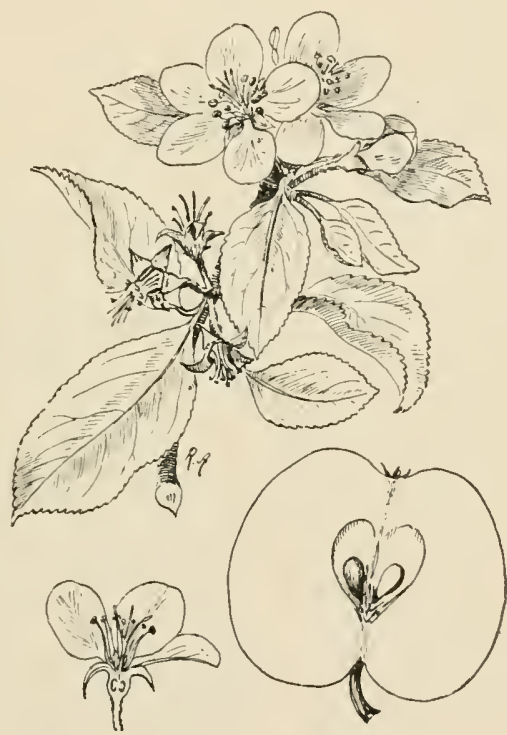

FìG. 6:\%. - Pyrus mulus, Flowering shoot, single flower, and fruit in longitudinal

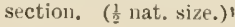

and scent (Fig. 62t C). The Horal receptacle becomes succulent. Shrubs, sometimes straggling climbers, with unequally pinnate leaves, the large stipules of which are adherent to the base of the leaf-stalk, and brightly coloured, conspicuons flowers. Sepals, inserted on the margin of the receptacle, leafy and pinnately divided (cf. Fig. 490). The double flowers result from the petaloid development of many of the stamens. Agrimonia and Hagenia abyssinica have a dry cup-shaped receptacle. Hagenia $\left({ }^{55 a}\right)$ is a dioecious tree with unequally pimnate leares, the adherent stipules of which render the petiole winged and channelled. Inflorescence a copiously branched panicle. Each flower has two bracteoles and an epicalyx. The flowers are unisexual by suppression of the male and female organs respectively. The corolla later falls off and the sepals become inrolled, while the epicalyx enlarges. The two free carpels have each a single ovule. Fruit one-seeded (Figs. 628, 629). Alchemille has no petals; the lack of a conspicuous corolla may perhaps stand in relation to the apogamous derelopment of the embryo ( ${ }^{1}$ a) 
(Fig. 625, 2). Sanyuisorba officinalis has polygamous flowers, without epicalyx or corolla, aggregated in heads. Flowers tetramerous with 1-2 carpels (Fig. $624 D$ ).
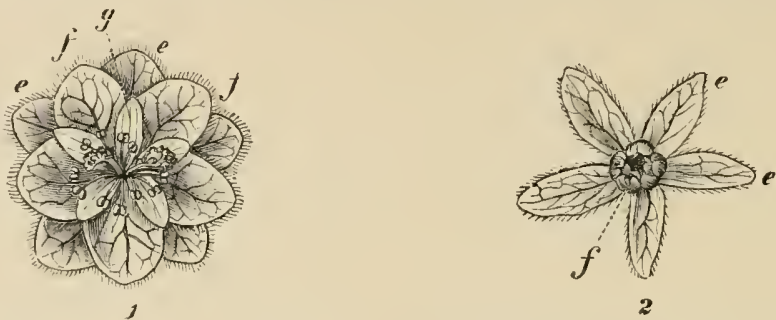

FIs. 62s, - Hagenia abyssinica. 1, Female flower; $e$, epicalyx ; $f$, calyx; $g$, corolla $(\times 4)$; 2 , fruit (nat. size), with enlarged epicalyx. (After Berg and Schumt.) OFFICIAl..

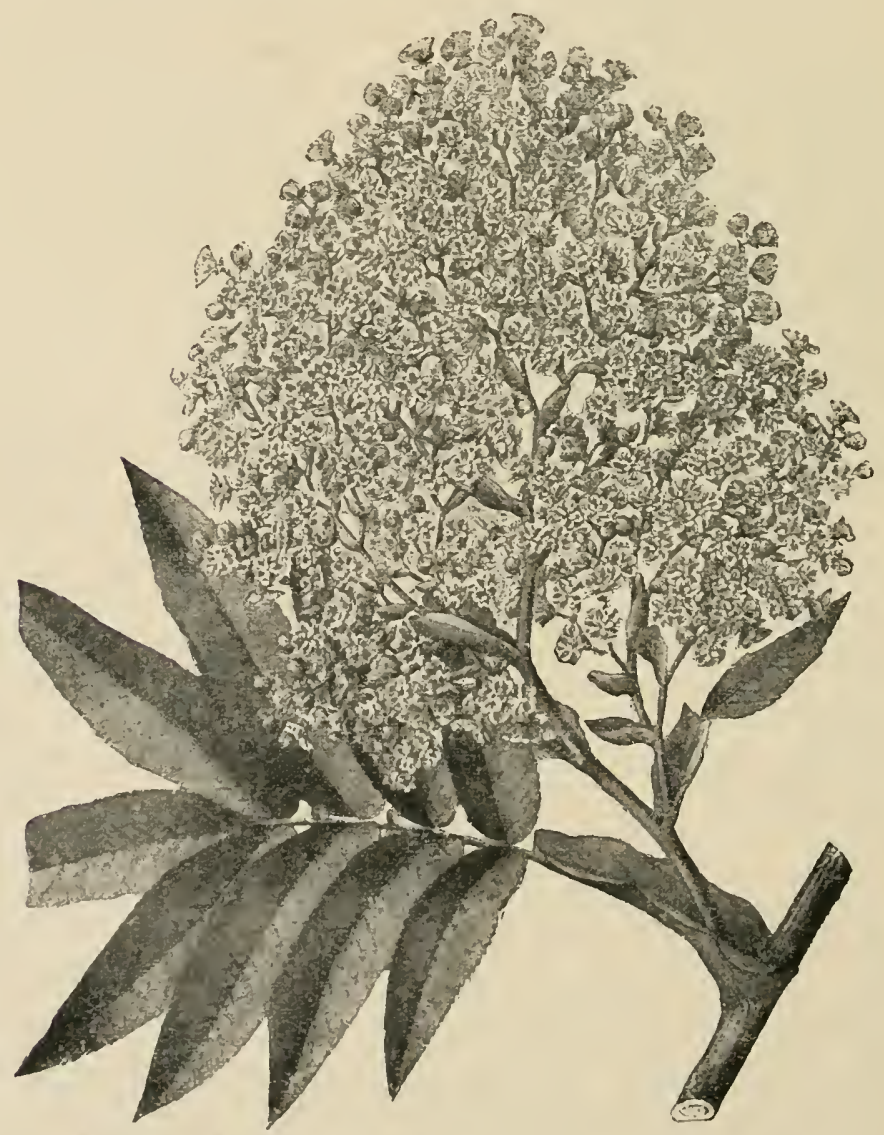

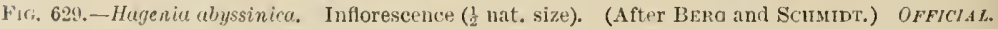


(d) Potentillecte.-Floral receptacle plate-shaped, flat or convex and bearing numerous free carpels which develop into nutlets, drupes, or berries. Each carpel with one ovule. Epicalyx often present. Potentill with a number of British species (Fig. 625, 1). Geum and Dryus lave hairy carpels which elongate in fruit and are distributed by the wind. The latter genus includes arctic and alpine forms. Fragraria, Strawberry, with small achenes situated on the succulent, enlarged, floral receptacle. Rubus, Blackberry, has numerous species, mostly scrambling shrubs with recurved prickles. Leaves trifoliate. $R$. idcueus, the Raspberry, is one of the few species which are not straggling climbers (Fig. 630). The small drupes are closely crowded on the convex receptacle, only slightly con nected with one another. The withered style is for a long time visible on the partial fruits. R. fruticosus.

(c) Pruncae.--Flower perigynous, with a single carlel seated on the cup-shajed

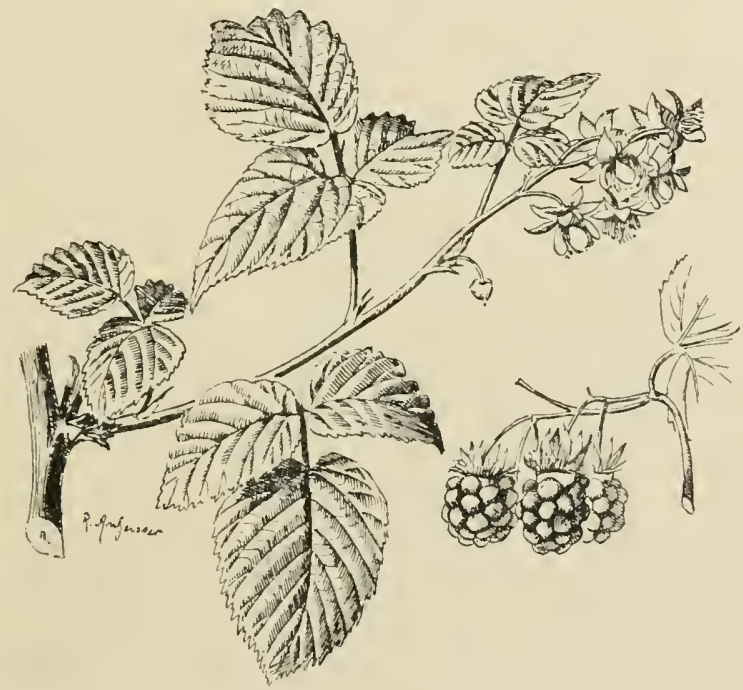

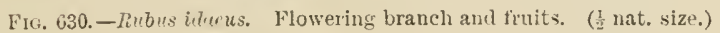

receptacle (Fig. 624 $L$ ). Orules two. Fruit, a one-seeded drupe. The group includes a number of important fruit trees. Prunus cercusus, the Wild Cherry (Fig. 631) ; $P$. avium, Gean ; $P$. domestica, the Plum; $P$. armeniace, the Apricot, and $P$. persict, the Peach, are of Chinese origin ; $P$. Amygdulus, the Almond, from the eastern Mediterranean region. The two last-named species have hairy fruits. The succulent mesocarp of the Alnond dries up as the fruit ripens, and ruptures, setting the stony endocarp free.

$\left(f^{\prime}\right)$ Chrysobalaneae.-Frequently with dorsirentral flowers. A single carpel.

Porsoxous. - The seeds of many Rosaceae contain amygdalin, but usually not in such amount as to be poisonous, owing to the resulting hydrocyanic acid, when eaten fresh in small quantity; this is, however, often the case with the residum left after the seeds, e.y. of bitter almonds, have been crushed. The leaves of the Cherry Laurel (Prunus laurocert sus) may also give rise to toxic effects.

OfFicial.-Rosae gallicaE PeTALA from eultivated plants of Rosa yalliea; 
OLEUM FOSAF and AQUA ROSAE from Rose damaseenc. AMYGDAla DUlCis and amygdala amalia from Prumus amygdalus. Prunum from Prumus domesticus. Prexi virginianae contex from Prunus serotinc. Latrocerasi folia from Prunus laurocerasus. Cr'sso from Hagenia abyssinica. Qullialat cortex from Quillaja Saponario.

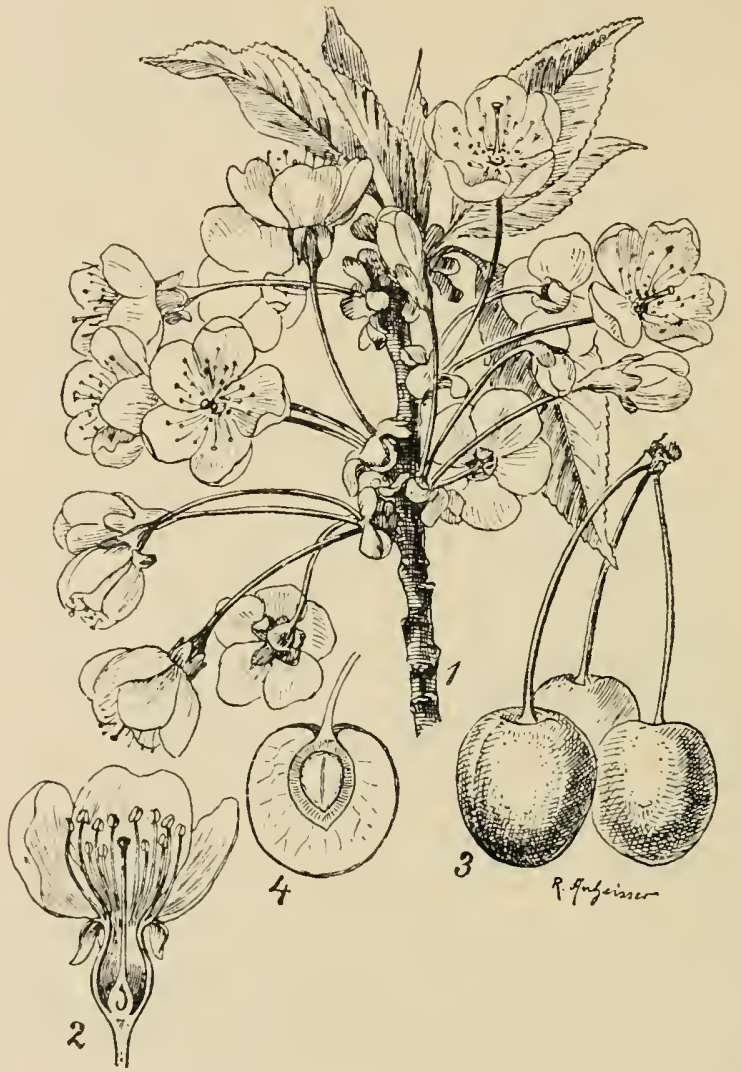

Fig. 631.-P Punus cercusus ( $\frac{2}{3}$ nat. size). 1, Flowering shoot ; 2 , Hower eut in two (slightly enlarged); 3 , fruits ; 4 fruit cut tlurough longitudinally.

\section{Order 20. Leguminosae}

The common characteristic of all Leguminosae is aftorded by the pistil. This is always formed of a single carpel, the ventral suture of which is directed to the dorsal side of the flower (Figs. 632, 635, 641). It is unilocular, and bears the ovules in one or two rows on the ventral suture. The fruit is usually a pod (legume), which dehisces by splitting along both the ventral and dorsal sutures (Fig. 646). Nearly 


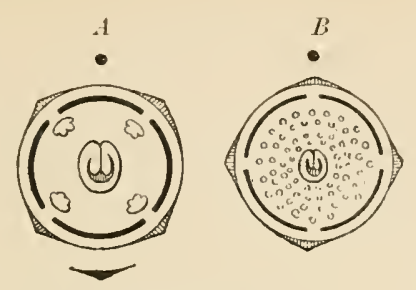

Frg. 632.-Floral diagrams of Mimosaceae. A, Mimosa pudica; B, Acucia lophanthu. (After Eichler.)

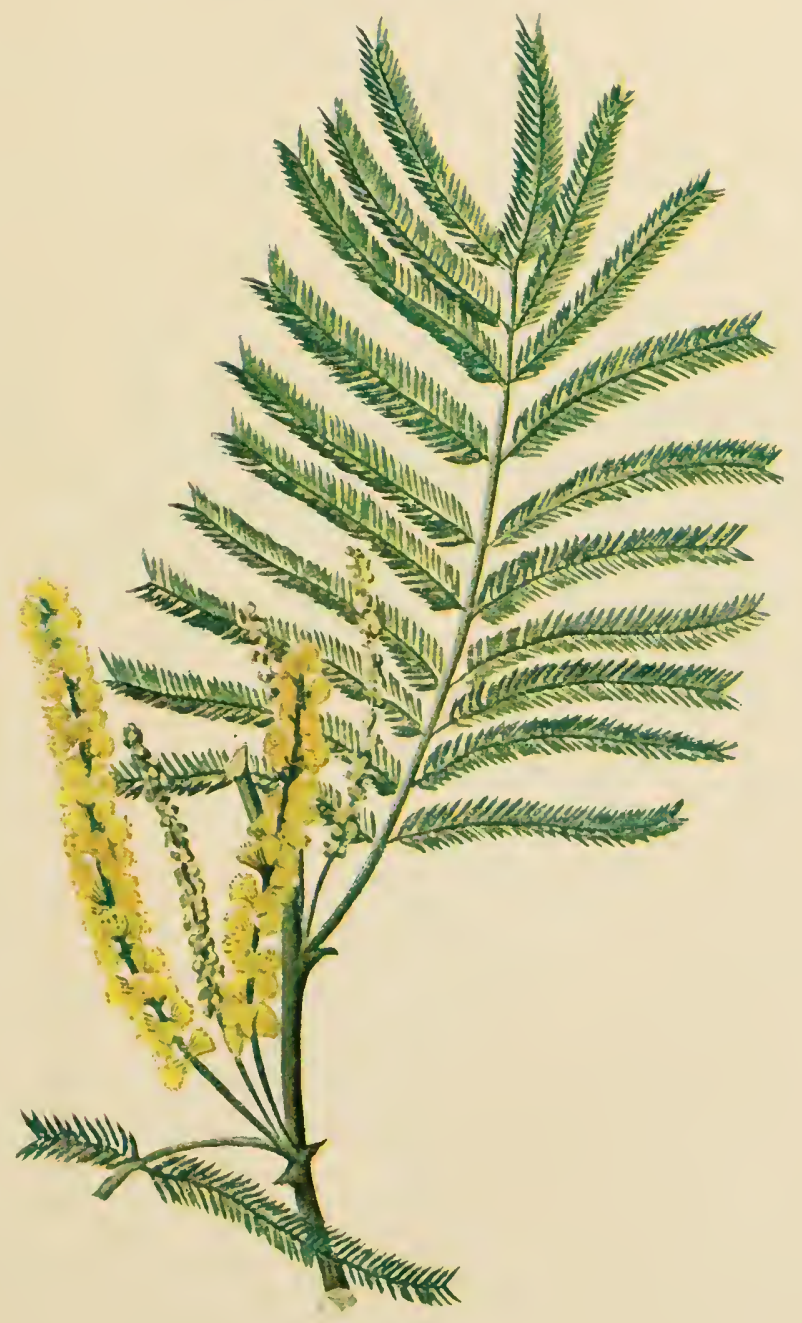

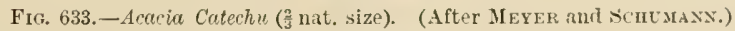


all Leguminosae have alternate, compound, stipulate leaves. Many are provided with pulvini (Figs. 239, 240), which effect variation movements of the leares and leaflets.

Family 1. Mimosaceae.-Trees, and erect or climbing, shrubby plants with bipinnate leaves. Flowers actinomorphic, pentamerous or tetramerous. Estivation of sepals and petals valvate. Stamens free, numerous, or equal or double in number to the petals. The colour of the flower is due to the length and number of the stamens, the corolla being as a rule inconspicuous. The pollen grains are often united in tetrads or in larger numbers. The flowers are grouped in spikes or heads. Embryo straight in the seed.

Impontaxt Gexera.--There are no representatives native to Europe of this family, which is abundant in the tropics. The Sensitive Plant (Mimosa pudicu)

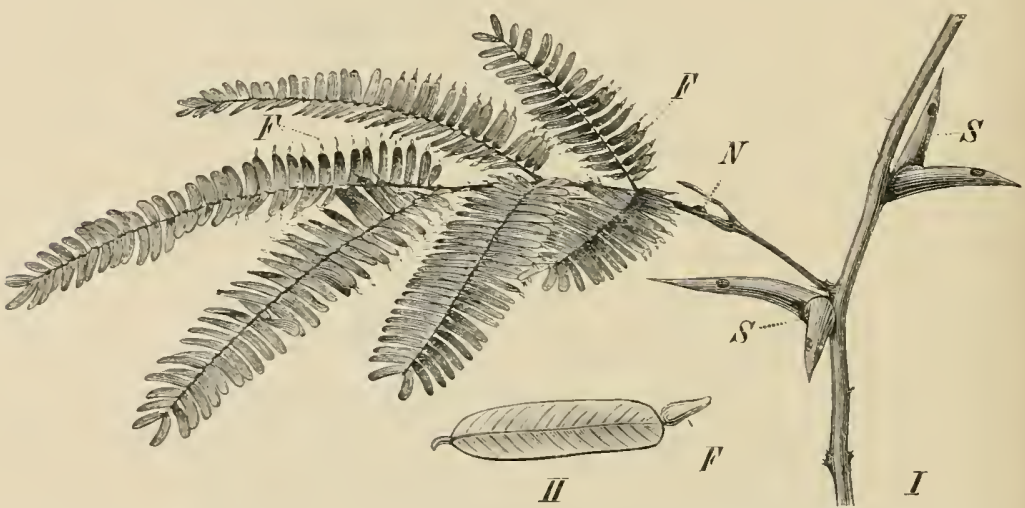

FIG. 634.-Acacir sphaterocephulı. I, Leat and part of etem; $s$, hollow thorns in which the ants live; $F$, food bodies at the apices of the lower pinnules; $N$, nectary on the petiole. (Reduced.) $I I$, single pinmule with fool-body, $F$. (Somewhat enlarged.)

(Fig. 240) oecurs as a weed throughout the tropics and exhibits great irritability to contact (ef. p. 323). Numerous species of the gemus Acacia are distributed through the tropics and sub-tropies of the old and new worlds; some are in cultivation in the Nediterranean region. The Australian forms of the genus are frequently charaeterised by possessing phyllodes (Figs. 174, 183), the rertical position of which contributes to the peculiar habit of the Australian forests. Only the seerllings of these speeies have a few bipinnate leaves which constantly succeed the cotyledons. Some American species of Acacia are inhabited by ants (Fig. 634) which live in the large stipular thorus and obtain food from Belt's food-bodies at the tips of the pimmles. A nutual symbiosis is as little demonstrated as in the ease of Cecropiu alenopus (cf. p. 556). Many species of Acacia are of considerable economie value owing to the presence of gums and tanuins in the cortex or in the heart-wood. A. catcchu (Fig. 633) and $A$. sumce are East Indian trees from which Catechu is obtained.

OFFICIAL - By the disorganisation of the parenchyma of the stem of Acacin 


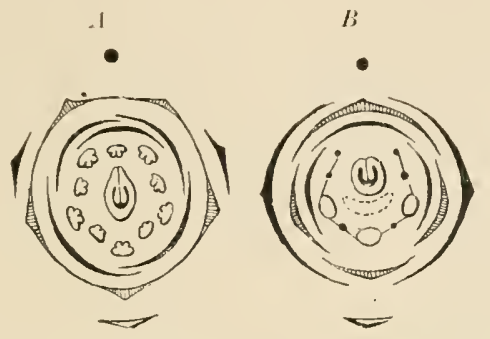

FIG. 635. -Floral diagrams of Caesalpiniaceae. A, Cercis siliquustrum; $D, T$, (After Eichler.)

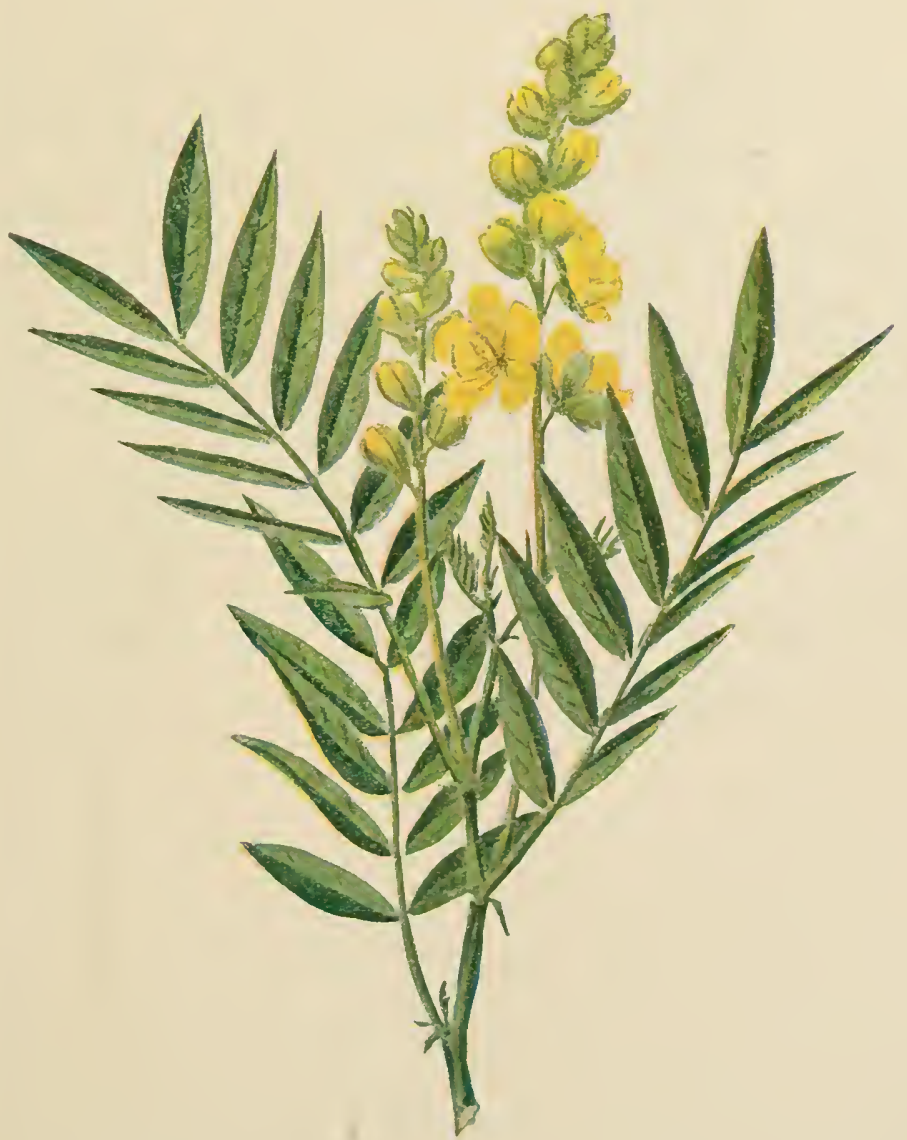

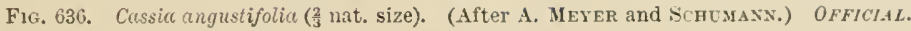


senegal (Soudan and Senegambia) and of other species, ACACIAE GUMM is obtained. This exudes from wounds as a thick fluid and hardens in the air.

Family 2. Caesalpiniaceae.-Trees or shrubs with pinnate or bipinnate leaves. Flowers usually somewhat dorsiventral. Corolla with ascending imbricate aestivation (Fig. 635) or wanting. Typical

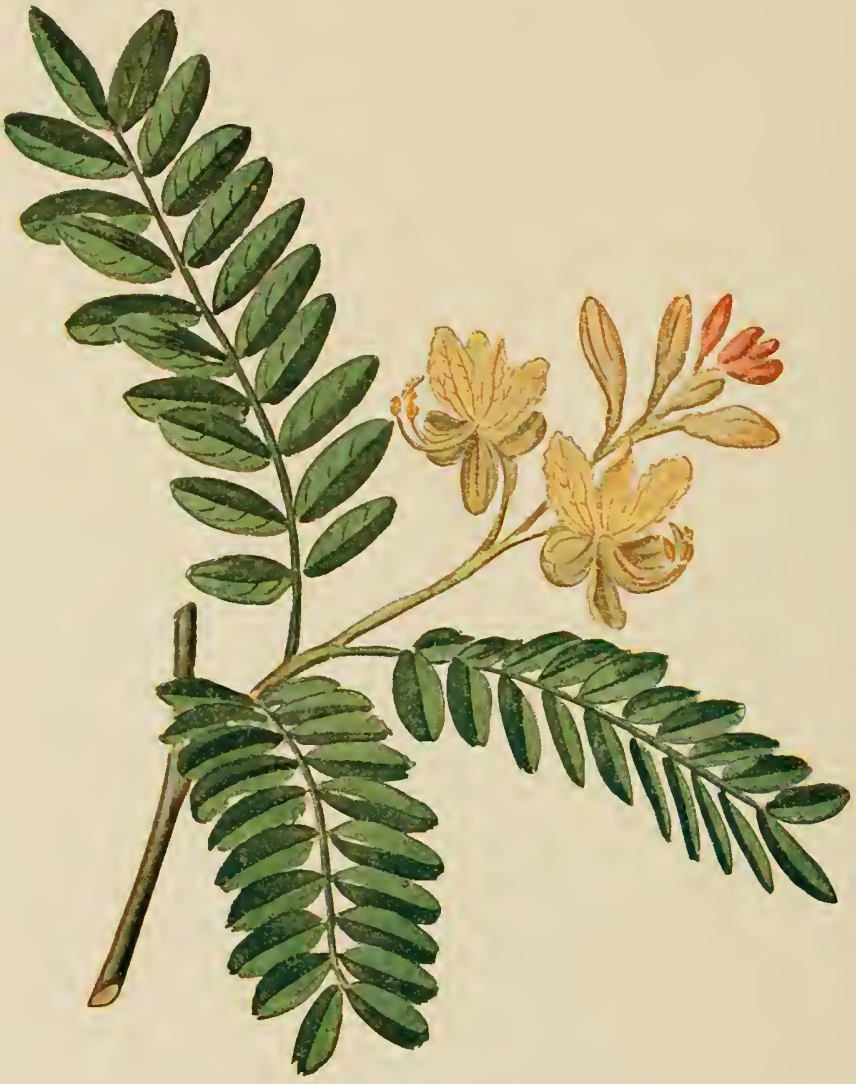

Fic. 637.-Tumarindus indiea (t nat. size). (After A. Meyer and Schumann.) OFFlcial.

floral formula: K 5, C 5, A $5+5$, G 1 . The number of petals and stamens is often incomplete. Embryo straight.

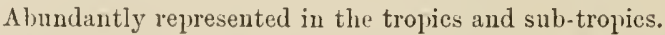

Impolitant Genera. - Characteristic examples of the Caesalpiniaceae arc afforded by the flowers of Cassir. In the sub-group Senna, to which C. angustifolia belongs, the sepals and petals are both five in number and free (Fig. 636). The lower overlapping petals are somewhat larger than the upper ones. Of the ten stamens the three npper ones are short and sterile, while the other seren, thic 
filaments of which are curved and convex below, diminish in length from above dowwards. The anthers open by means of terminal pores. The pod is compressed and broad and flat. The flowers are borne in racemes in the axils of the leaves of the shrub, which is about a metre high. The bright green, equally pinnate leaves have small stipules at the base (Fig. 636). Tamaindus indica

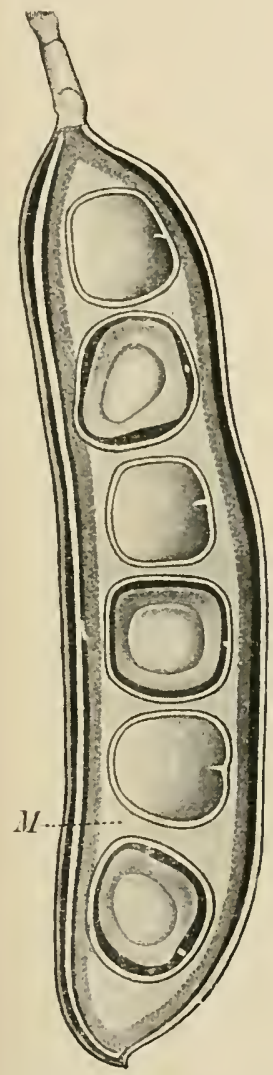

F1G. 63.s. - Temarinulus indica. Fruit in longitudinal section. $M$, the fleshy mesocarp. (After BERG and SCHMIDT.) OFFI'IAL.

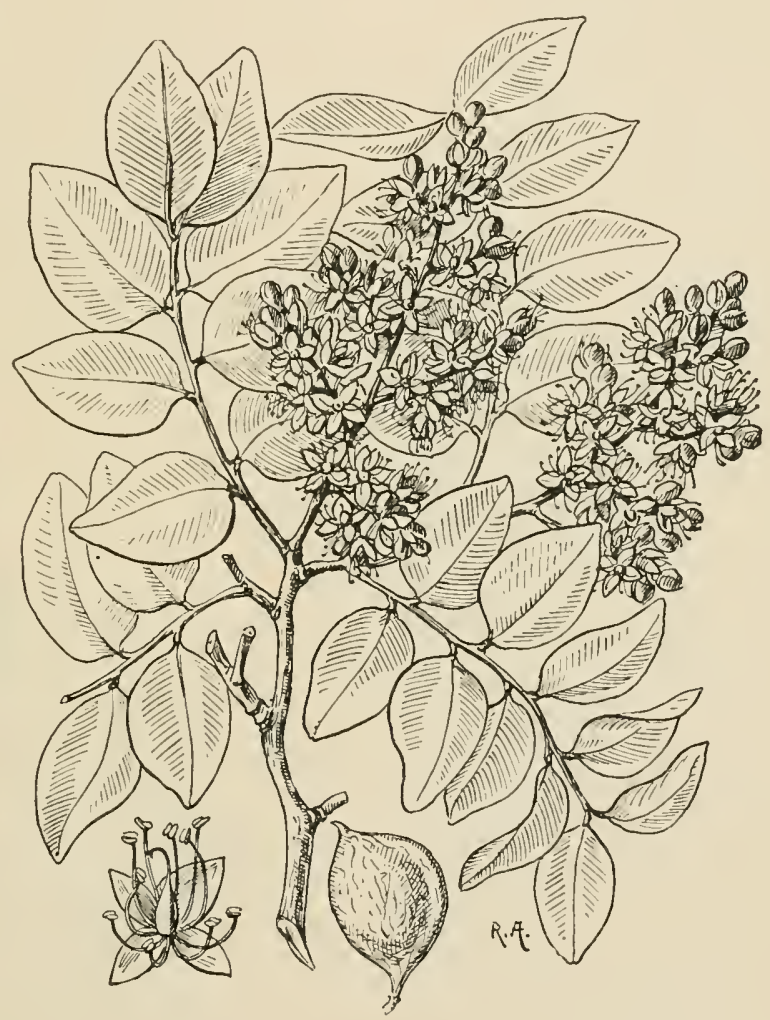

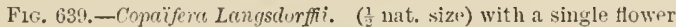
(nat. size) aut the fruit (rerlucel).

(Fig. 637) is a handsome tree, native to tropical Africa, but now planted throughout the tropics. Its broadly spreading crown of light foliage makes it a favourite shade-tree. The racemes of flowers are terminal on lateral twigs bearing equally pinnate lcaves. The individual flowers are markedly zygomorphic (Fig. $635 \mathrm{~B}$ ). The bract and two bracteoles are soon shed. The four sepals have a somewhat cruciform arrangement. The three red-veined, yellowish-white petals stand erect. The three stamens are coherent at the base and lie close to the easily movable 


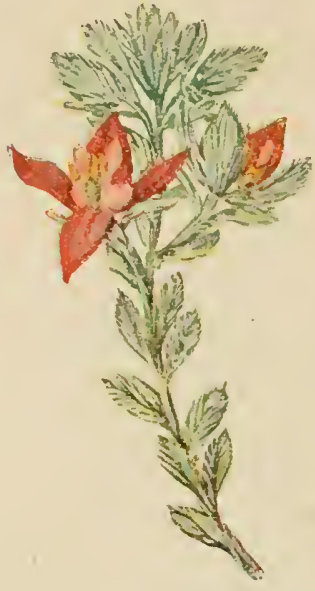

FIc. 640.- Hrumeria triandra (t nat. size). (After A. MEYer and ScHUMANN.) OFFI(IAL.

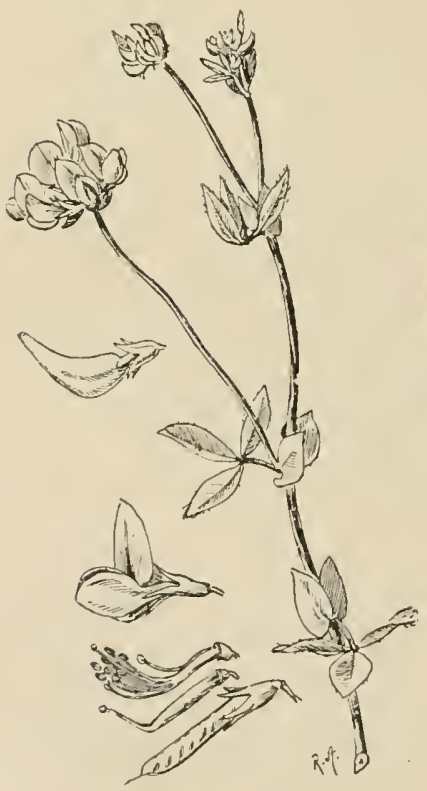

Fig. 642. - Lotus comiculates (1 nat. size). Flowerinc shoot; flowtr, keel, stamens. Carpel (nat. size) and fruit

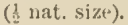

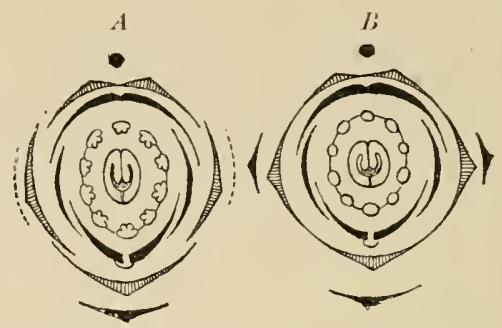

Fif. 641.-Floral diagrams of Papilionaceae.

A. I'iciu Fube; B, Cytisus Laburnum. (After EICHLER.)

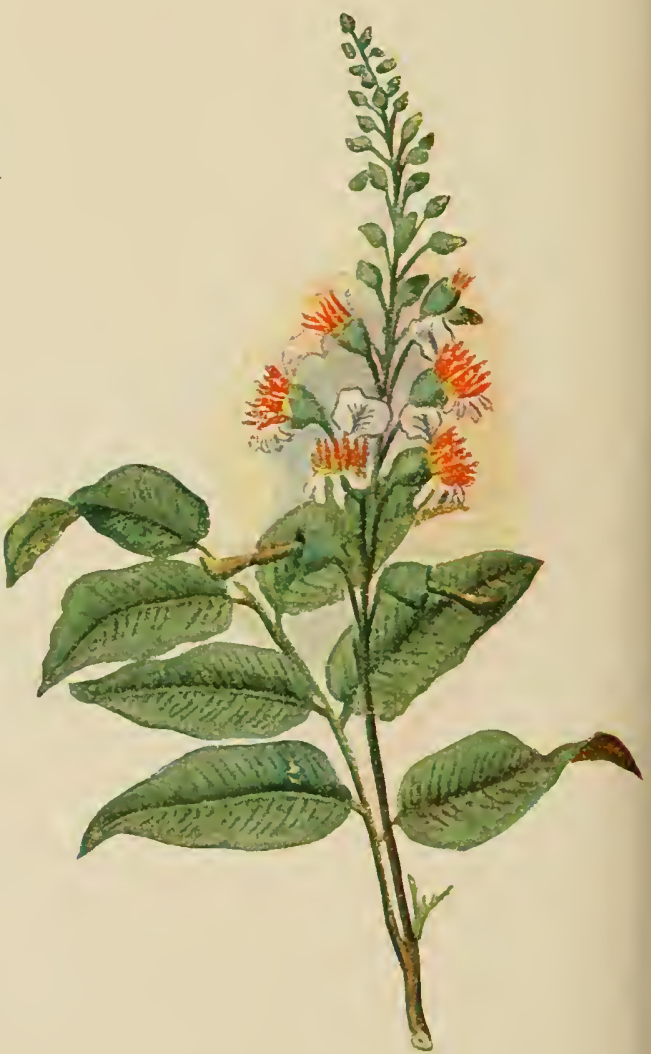

Fig. 643.-Myrorylun l'ereirce (3̊nat. size). (After Bero and S'IMIDT.) OFFICLAL. 
eurred carlel, so that the anthers and stigma froject together. The fruit is peculiar. The pericarp is differentiated into an outer brittle exocarp, a succulent mesoear 1 , and a firm endocarp consisting of stone-cells investing the more or less numerous seeds individually (Fig. 638). The almost imperceptibly dorsiventral flowers of Copoiffera (Fig. 639) have no corolla; the four sepals are sueceeded by 8-10 free stamens. The fruit is one-seeded but opens when ripe. The seed is invested on one side by a sueculent, irregularly limited arillus. None of the Caesalpiniaceae are British. Cercis siliquestrum from the Mediterranean region, which bears its flowers on the old woody stems (eauliflorous) (Fig. $635 \mathrm{~A}$ ), and Gleditschic triacanthos (N. Am.) are sometimes cultivated as ornamental plants in gardens and Ceratonic siliqure in the cool greenhouse.

Official. - Sexpa ixdica, the pimnae of Cassic angustifolia ('Trop. East Africa and Arabia, eultivated at Tinnevelly in Southern India) ; SENNA ALEXANDirna from $C$. acutifolia; C'essia. fistuta (Trop. Am.) yields CASSIAE PULTA; CopAIPA is obtained from Copaiffere

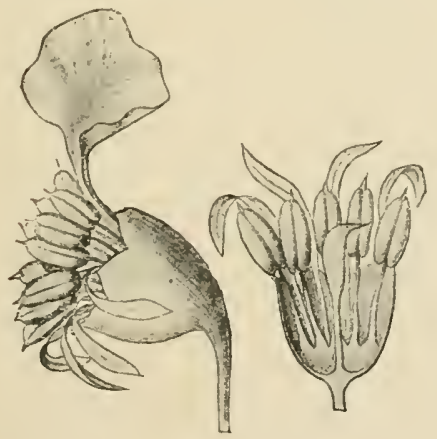

Fr. 644.-Myroxylun I'ereire. Ses Text. (En-

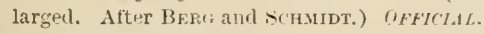

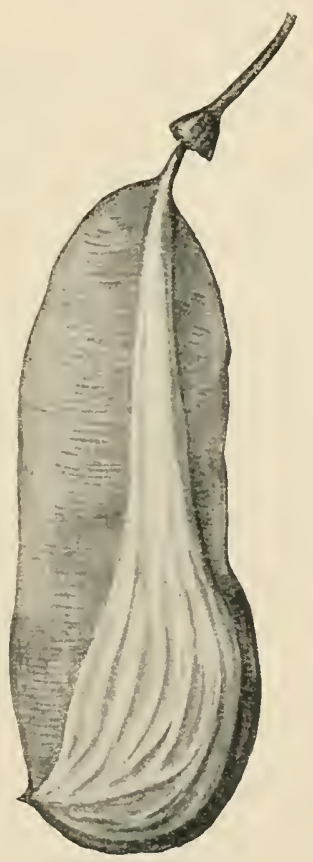

Fig. 645.-Fruit of . Iyroxylun l'ereirm (z) nat. size). OFFICIAL.

Langsdorfi and other species; TAMAlindes from the sticculent mesocarl, of Tamarindus indice; HAEMATOXYL1 LIGNUI, the heart-wood of Haematoxylun

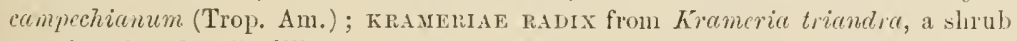
growing in the Cordilleras. Flowers atypical; the sepals brightly eoloured within; the corolla small. Three stamens opening by fores at the summit. Fruit spherical, prickly. Leaves simple, silvery white (Fig. 640).

Family 3. Papilionaceae-Herbs, shrubs, or trees with, as a rule, imparipinnate leaves. Flowers always markedly zygomorphic. Calyx of fire sepals. Corolla of fire petals, papilionaceous, with descending imbricate aestivation (Fig. 6+1). Stamens 10 ; filaments either all coherent into a tubu surromnding the pistil, or the posterior stamen is free. Seerls with a curved embryo. 
Abundantly represented in the temperate zones; fewer in the tropics.

The component parts of a papilionaceous flower are seen separately in Fig. 642 . The posterior petal, which overlaps the others in the bud, is termed the standard (vexillum). The two adjoining, lateral petals are the wings (alae), and the two lowest petals, usually coherent by their lower margins, together form the keel (carina). The upper ends of the stamens are usually free and eurve upwards, as does also the style bearing the stigna.

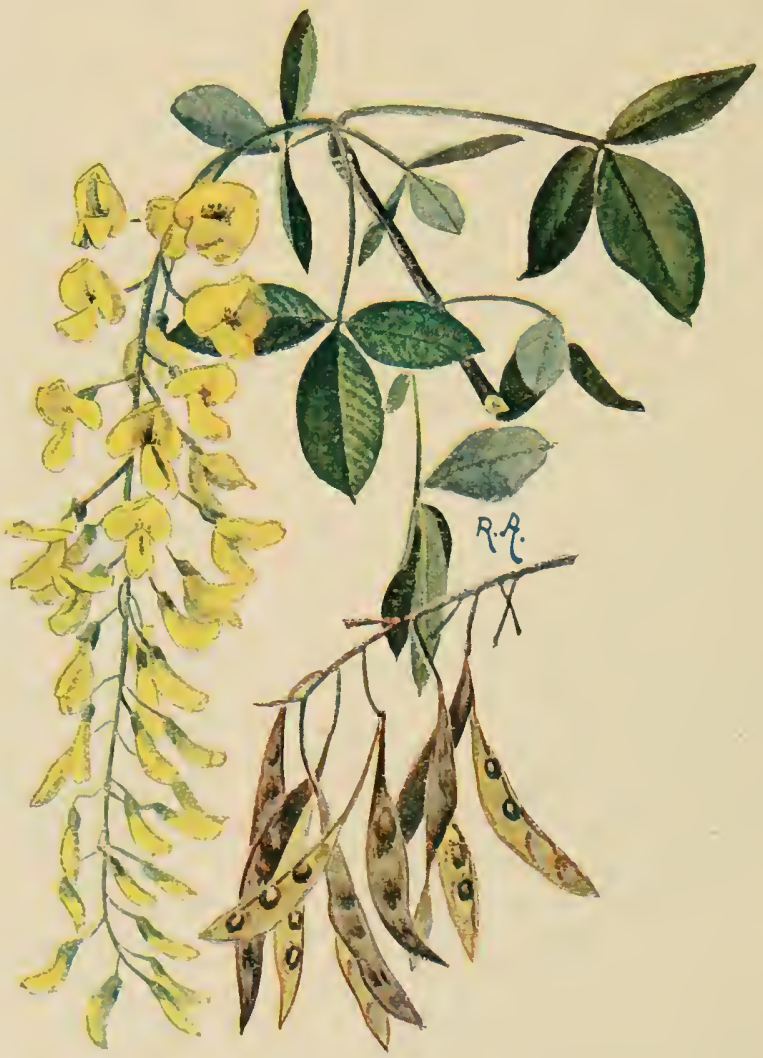

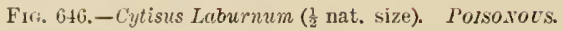

Importani Sub-Families and Genera.-The (1) Sophoreae and (2) Podulyricae approach the Caesalpiniaceae in having the stamens more or less free. The former is characterised by pinnate leaves, the latter by simple or palmate leaves. The genus Myroxylon, belonging to the Sophoreae, is of importance on account of the balsam obtained from species belonging to it. Myroxylon Pcreirce is a tree of moderate height with alternate, imparipinnate leaves (Fig. 6t3). The flowers are borne in the terminal racemes and have a large vexillum, the other petals remaining narrow and ineonspicuous. The stamens are only coherent at the base, and bear 
conspicuous, reddish-yellow anthers (Fig. 644). The firuit is very peculiar. The ovary has a long stalk and bears two ovules near the tip. One of these develops into the seed of the indehiscent, compressed pod, which has a broad wing along the ventral suture and a narrower wing along the dorsal suture (Fig. 645). The bell-shaped calyx persists on the stalk.-3. Ginisteae. All ten stamens are coherent (Fig. $641 \mathrm{~B}$ ). Leaves pinuate or simple, margin entire. Genista, Saro. thamuse, Lupinus, Cytisus (Fig. 646). The Laburnum (Cytisus Laburnum) is one of the commonest ornamental trees of our gardens and grows wild in tlie Alps. It has tripinnate leaves and long pendulous racemes of yellow flowers. C. Adami, which is found occasionally in gardens, was sulposed to have arisen by the grafting of $C$. purpureus on C. Laburnum. The racemes and flowers of one and the same individual sometimes resemble the former and less commonly the latter ancestral form (Fig. 221). The intermediate form is however usually sterile. Llex, Furze, a characteristic British plant. Spartium, distributed in the Mediterranean region.-4. Trifolicue. Leaves trifoliate, serrate. Flowers aggregated in heads or in spikes or umbels. Stamens $(9)+1$. Indehiscent fruits. Trifolium, Clover, with persistent calyx and corolla. Mcdicrgo, Melick, with deciduous corolla; fruit sickleshaped or spirally twisted. Melilotus, Nelilot, with racemose inflorescences. $T_{r} i$ yonella. Ononis, Rest-Harrow. The increase in the amount of nitrogen in the soil effected by the root-tubercles (cf. p. 231, Figs. 201, 202), of Leguminosae

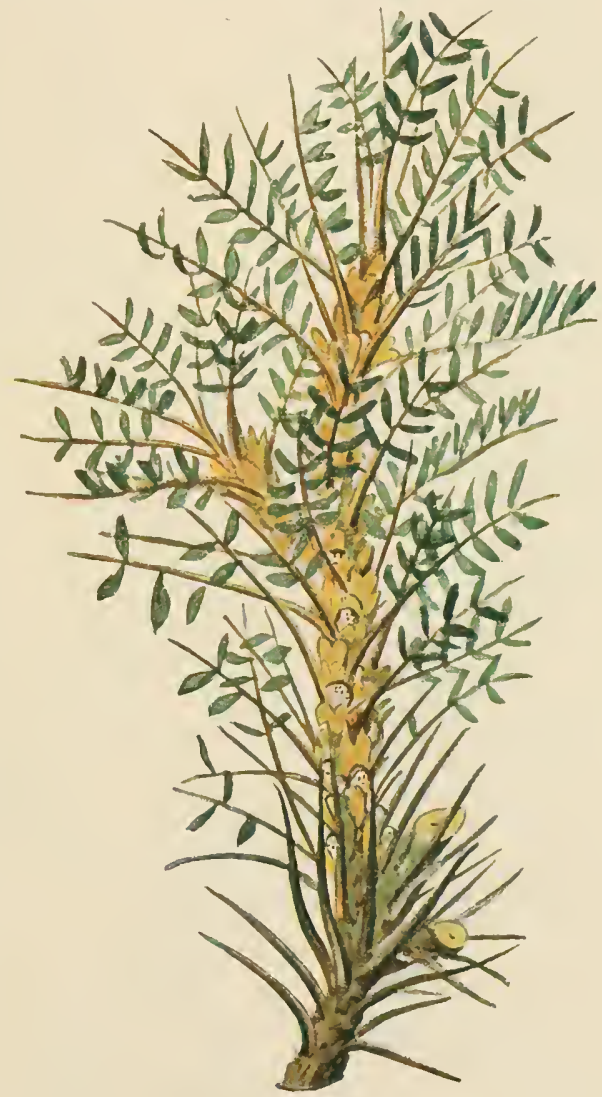

Fis. 647.-Astregelus gummifer. (t nat. size. After A. Meyer and S'HuMaNx.) OFFICIAL.

finds its practical application in European agriculture in the cultivation of species of Trifolium, Heclicago and Lupinus. -5. Loteue. Lotus Bird's-foot Trefoil (Fig. 612). Leaves imparipinnate, lowest pair of leaflets owing to the absence of the petiole resembling stifules. Anthyllis, lidney-T'teh. Tetragonolobus.-b. Galegeace or Astrayaleae. Leaves imparipinnate; a very large sub-family, the plants belonging to which show much diversity in habit. In species of Astragalus $\left({ }^{57}\right)$, which are low shrubs of the eastern Mediterranean region and of western Asia, the rhachis of the leaf persists as a sharply pointed thorn for years after the leaflets have fallen. 
These spines serve to protect the young shoots, leares, and flowers (Fig. 647).

Our native species are herbaceous. liobinia is an American tree of rapid growth

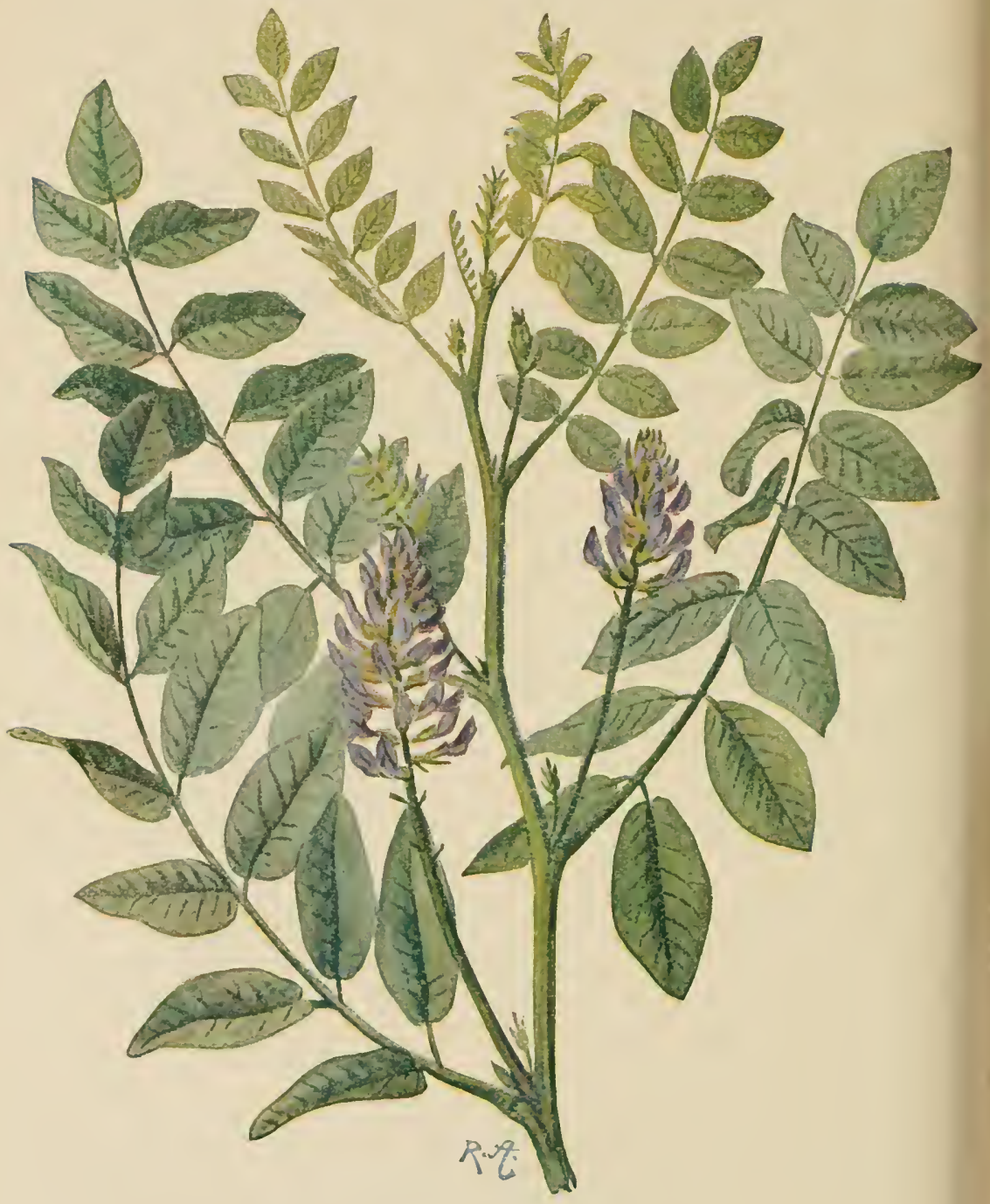

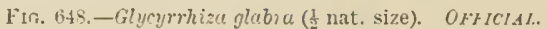

with rery brittle woorl, which is often planted and known as False Acacia. Flycyrrhiza, Liquorice, is a native of S. Europe (Fig. 64S). Colutea, Carayana, Indigofera. II istaria sinensis is a climber with beautiful blue flower's, often grown against the walls of houses. - - Hedysareae. Distinguished by the jointed pods, 
in which the seeds are isolated by transverse septa. Coionille (Fig. 649). Ornithopus satives, Birl's.Foot. Arechis hypoyreet, Grouml-nut, an important, oil-yielding fruit of the tropies and sub-tropies. After flowering the flower-stalks penetrate the soil in which the fruts ripen.-8. Vieicue. Leaves with terminal tendrils, corresponding to the terminal leaflet; the leaves may thus appear to be paripinnate. The cotyledons remain within the seed-coat and do not beeome green. Stamens $(9)+1$. Ticio, Vetch ; Pisum, Pea ; Ervum, Lentil ; Lathyrus, Everlasting Pea. Vicia Faba, the BroadBean, is an ereet plant, without tendrils; the terminal leaflet is reduced to a bristle-shaped stump. 9. Phuseolece. Twining plants with tripinnate leaves. Cotyledons usually come above ground and turn green. Stamens (9) + 1. Phaseolus, Kidney Bean. Physostigme.

Porsosous. - Among our common Leguninosae only Cytisus Laburnum is extremely poisonous. The other species of the genus, e.g. C. alpinus, C. purpureus, C. Weldeni, and C. bifiorus are poisonous, but are more rarely met with than the ordinary Laburnum. Coronille varia (Fig. 649), with umbels of rose-coloured flowers, and Wisterict sinensis are also poisonous.

OFFICIA L. - Astragalus gummifer and other species yield tragacastha. GlycirRHIZAE RADIX is obtained from Glyeyrrhiza glabre. Spertium scoparinm yields SCOPARII CA. cumina. Physostigme renosum,

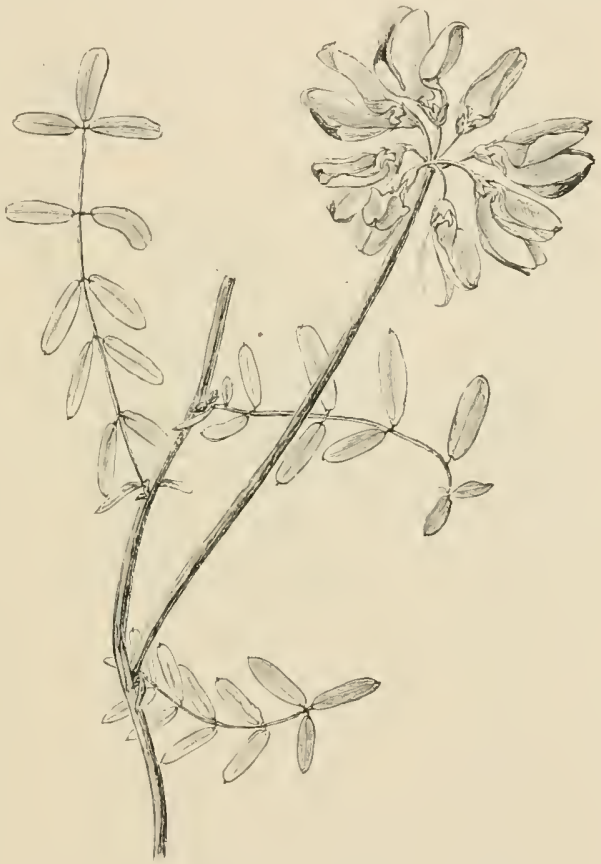

Fir. 649.-Coronille veria (nat. size). PoIsosoes.

a West African climber, yields physostrgutiss semisa, Calabar Bean. Andirt araroba, a Brazilian tree, contains a powdery excretion in cavities of the stem ealled ARARoBa; CHRYsarobixum is obtained from this. The heart-wood of Pteroecipus santalinus, an East Indian tree, is PTERocARPI LIGNun. Kro is obtained from the juice flowing from incisions in the trunk of Pterocarpus marsupium. Myroxylon toluifere (S. America) yields BaLsaytur toltiaxis, and 1 . Pereirce (San Salvador) baLsamum PERuvixum.

\section{Order 21. Passiflorinae}

Flowers radial, perigynous or epigynous. Ovary of three carpels, unilocular, with parietal placentation; usually three bifid stigmas.

Family Passifloraceae.-Plants climbing by means of tendrils. Flowers large, 
complicated by outgrowths from the floral axis (corona and disc). Passiflore, Passion Flowers; ornamental plants from South America.

Family Caricaceae.-Carica papaya, the Pajaw, has in its latex a ferment (papayotin) resembling pepsin. Tropical.

Family Begoniaceae.-Herbs with obliquely cordate leares. Flowers unisexual. Ovary inferior. Mostly tropical. Many species of Begonia are in cultivation.

\section{Order 22. Thymelaëinae}

Slırubs or trees, with simple, entire leaves, often closely crowded. Flowers perigynous, hermajhrodite, actinomorphic, tetramerous or pentamerous. Corolla

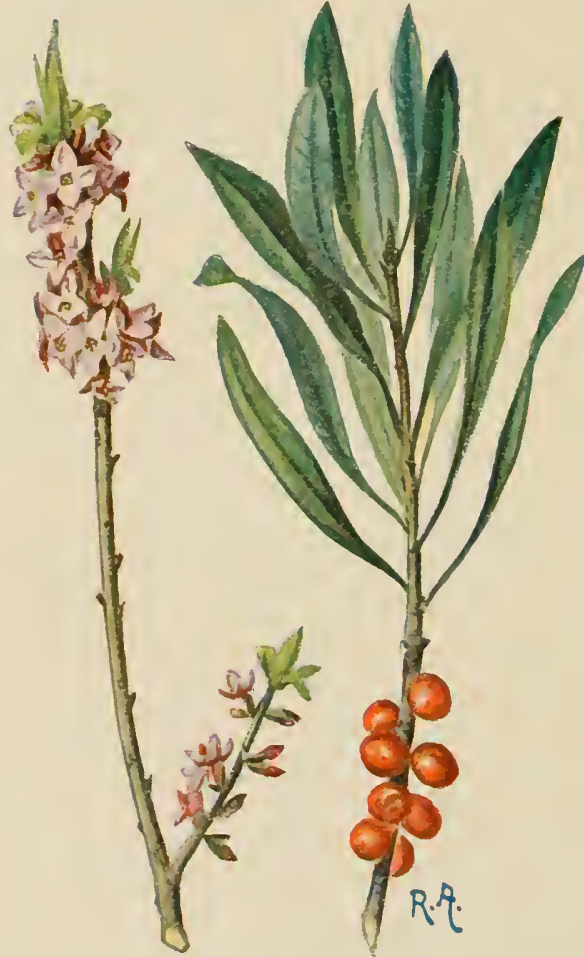

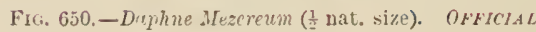
and Polsoloc's. often wanting. Stamens in one or two whorls. Carpel, one. Orary with a single ovule.

Family 1. Thymelaeaceae. -Orule pendulous. Daphine Merereum (Fig. 650) is a poisonous slirub, possibly natire to Britain, which flowers in February and March before the leaves appear. The flowers are rosecoloured, scented, tetramerous, and have no corolla. The leares form a close tuft until the axis elongates. The fruit is a bright red berry. In the Alps and in the Mediterranean region there are several species of Daphne, all of which are poisonons.

Offictal. - Daphline Mezer. cum, D. Laureole, and $D$. Gnidium yield MEZEREI COR'TEx.

Family 2. Elaeagnaceae.Orule erect. Hippophä̈. Elaeugnus. The leaves and young twigs are covered with shining peltate hairs.

\section{Order 23. Myrtiflorae}

Leaves opposite, simple, entire, exstipulate; flowers hermaphrodite, actinomorphic, tetramerous or pentamerous, hypogynous, or at most perigynous. Ovary septate. Increase in number of the stamens is frequent.

Family 1. Lythraceae. Lythrum solicerie. Purple Loosestrife. Flowers typically hexamerous with two inferiur carpels. Heterostyled with three forms of flower (cf. p. 501). 
Family 2. Melastomaceae. - An exclusively tropical family, easily reeognised by the beautifully shaped and regularly veined leaves. Favourite hothouse plants.

Family 3. Onagraceae. - Flower tetramerous throughout. Androceinm obdiplostemonous. Ovary inferior (Figs. 651, 652). Mainly in temperate America.

More Important Genera.-Epilulium, Willow-herb, with numerous species ; the fruit is a capsule, and the seeds have hairs serving for wind-dispersal. Oenothera. The power of mutating possessed by plants of this genus was recognised by DE VRIEs and fornts the experimental basis of his hypothesis of mutation. Cireaer, Enchanter's Nightshade. Trapa, Water Nut. Nany forms arc in enltivation, for instance the species of Fuchsia, in which the calyx is petaloid. These plants are natives of America. Fruit a berry.

Family 4. Halorrhagidaceae. - Aquatic plants with small, inconspicuous flowers. Myriophyllum. Hip. puris.

Family 5. Callitrichaceae. -Aquatic plants with naked unisexual flowers. Stamen 1 ; Carpel 1. Cullitriche.

Family 6. Rhizophoraceae $\left({ }^{58}\right)$. - Plants occurring in the Mangrove fornation along tropical coasts, characterised by vivipary and the possession of

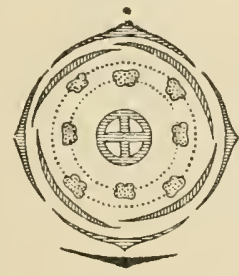

F16. 651.-Floral diagram of Oenotherr (Onagraceae).

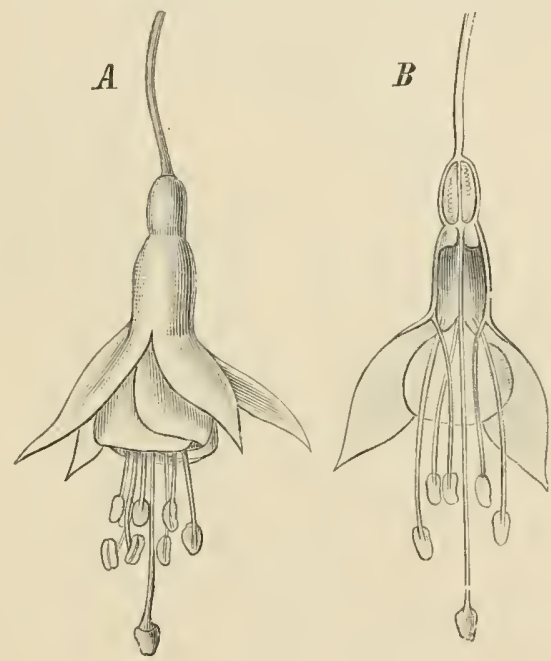

Frg. 652.-Fuchsia globosn. Flowers (nat. size).

stilt-roots, or respiratory roots. These adaptations are related to the preculiarities of the situations in which the trees grow. Rhizophore (Fig. 653); Bruguicra ; Ceriops. Faudetia (Fig. 496).

Family 7. Combretaceae.-Terminalic Chebula yields mromalans.

Numerous hook-climbers such as Quisqualis indica, ete.

Family 8. Myrtaceae.-Evergreen shrubs or trees; leaves opposite, leathery, often aromatic. Flowers actinomorphic, tetramerous or pentamerous. Androecinm of many stamens, which are often arranged in bundles which have originated by branching. Carpels two or many (Fig. 654) united with the floral axis to form the inferior ovary. Fruit, usually a berry or a capsule.

Mainly distributed in tropical America and in Australia.

Important GeNera. - The Yhytte (Myptus communis), which oceurs in the Mediteranean region, is the only European species. Sprecies of Eucalyptus $\left({ }^{59}\right)$ from 
Australia, especially $E$. globulus, are commonly planted in Italy, on account of their rapid growth and useful timber. Young plants have opposite, sessile leaves, but older trees bear stalked, sickle-shaped leaves which hang vertically. The shadeless condition of the Australian forests formed by these trees, depends in part on

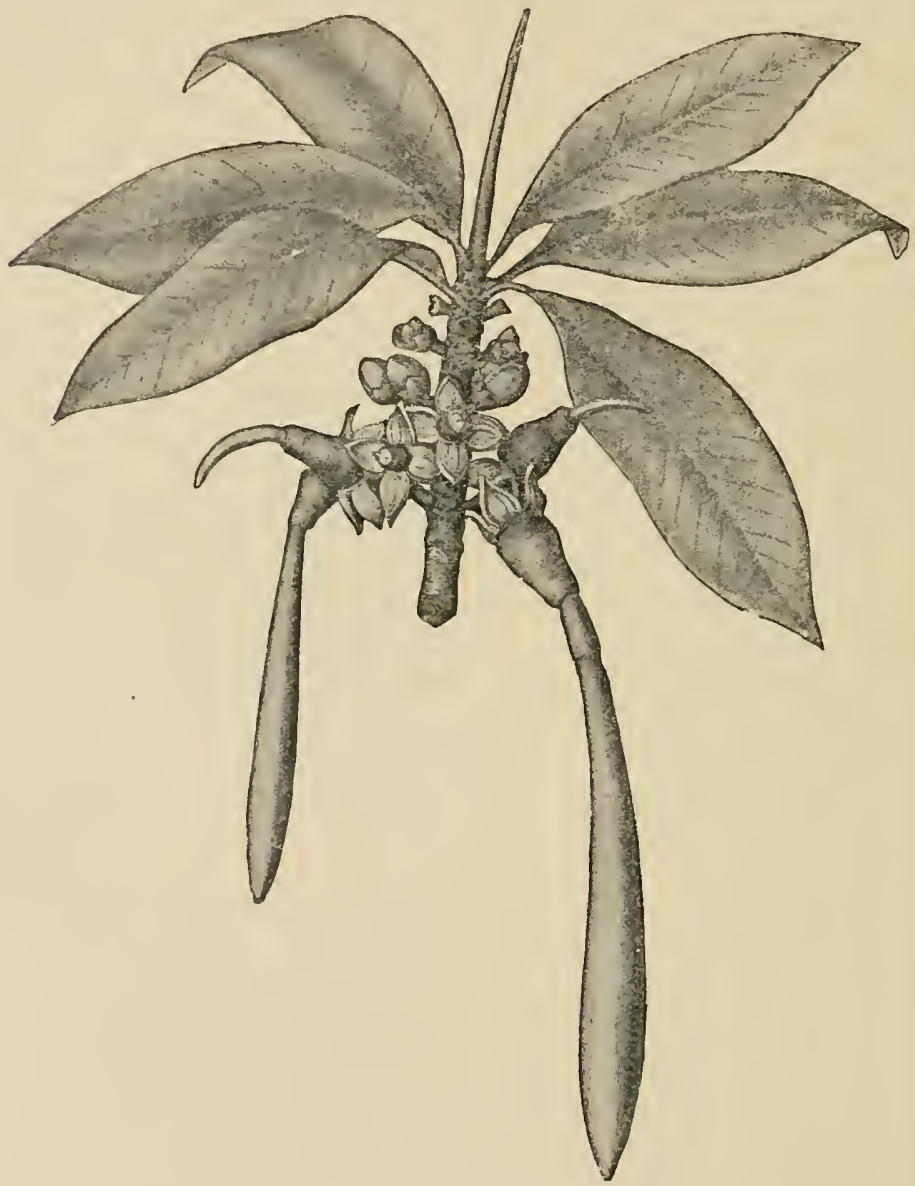

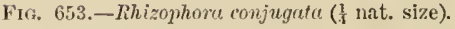

this character, but is partly duc to the distanee apart of the individual trees. E. amygdulinu, which reaches a height of $155 \mathrm{~m}$. and a cireumference of $30 \mathrm{~m}$. at the base of the trunk, is one of the largest forest trees known. Psillium guayara and some species of Jambosa bear edible fruits; the former is especially ralued. Éuyenia caryophyllata (Moluceas) is of economic importanee, its mopened flowerluds forming Cloves (Fig. 655). This tree is commonly cultivated in the tropies. It has a beantiful appearnuee when the terminal groups of flowers (whieh in bud are of a bright red colour with four united, white petals, and when opened exhibit 
mmerous whitish stamens) are seen through the shining foliage composed of entire

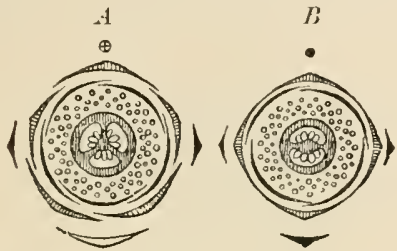
leaves. The corolla is thrown off when the flower opens. In Fig. 655 the inferior ovary, formed of tro carpels, is also seen in longitudinal section.

OfFICIAL. - Eugenia caryophyllata yields caryophylum, Clores. Prmenta, Allspice, from Pimenta officinalis. OLEur CAJUPUTI from Melaleuca leucadendron, a

FIr. 654.--Floral sliagrams of Myrtaceae. $A$, tree of less height but resembling the Myrtus communis ; B, Eugenic caryomyllute. Encalyptus trees; it is cultivated in the (After Eichler.)

Mlolnccas (Buru) for the sake of the oi] it yields; its specific name refers to the white colour of the bark. OLEur EUCALYPTI and EUCALYPTI GUMAI from Eucalyptus globutus and otlier species.

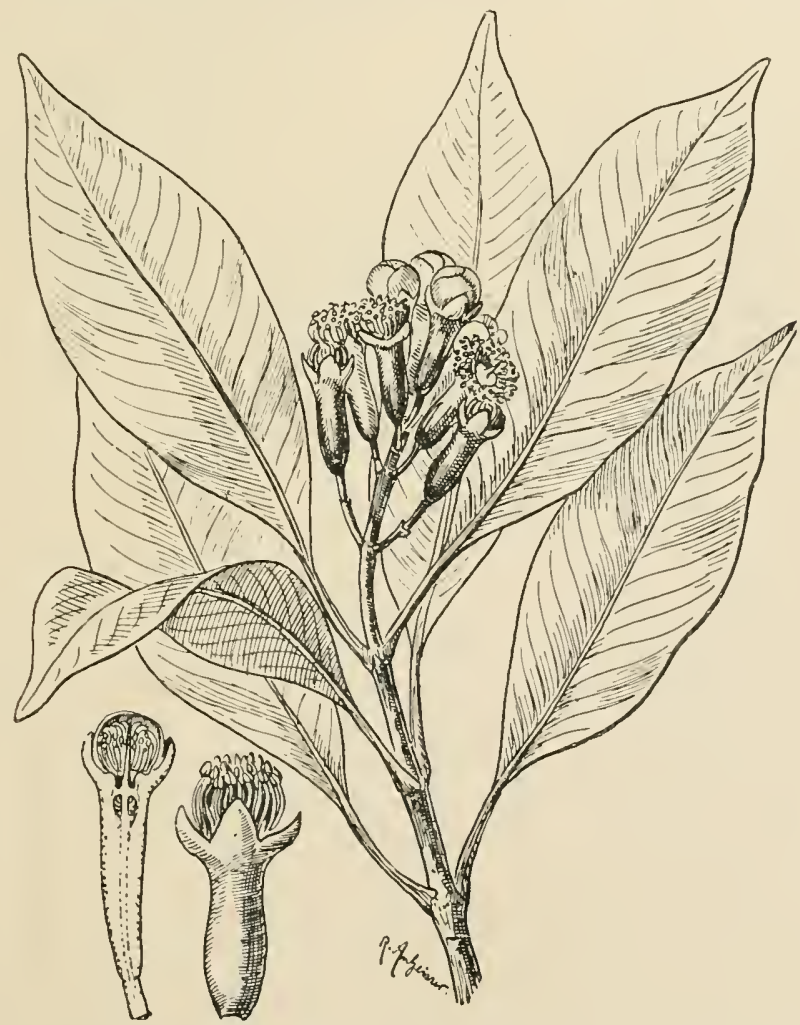

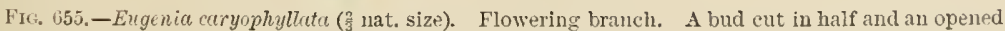
flower (about nat, size). OFFICIAL.

Family 9. Punicaceae. - Single genus Punica. Punica granatum is a tree originally introduced from the East and now largely cultivated in the Mediterranean 
region on account of its acid refreshing fruits known as Pomegranates (Fig. 656).

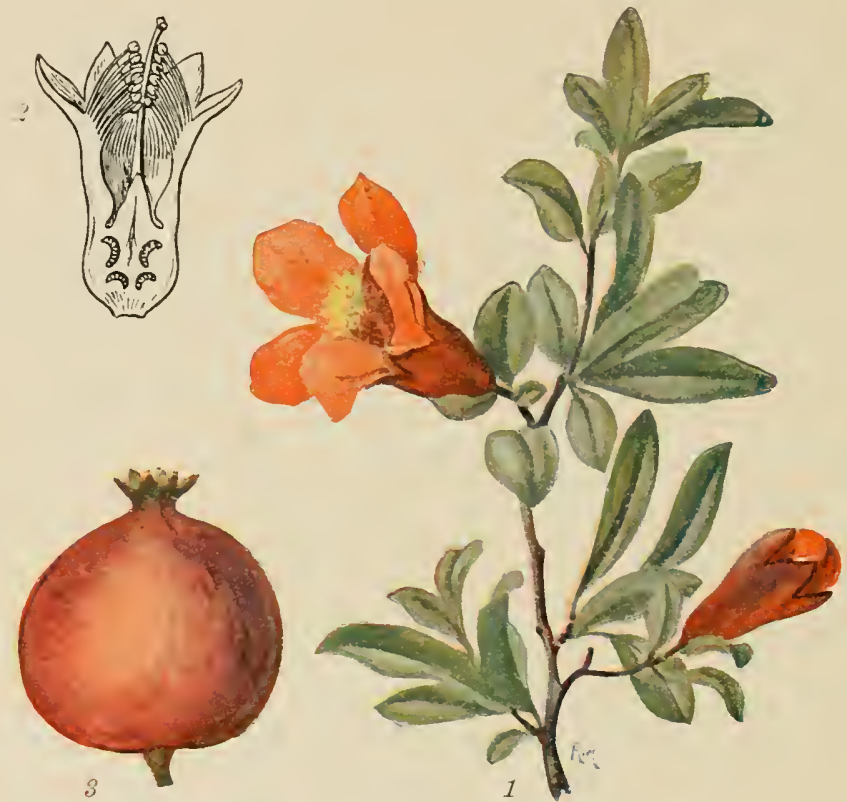

Fig, 656.-Punice gromatum (1 nat. size). 1, Branch bearing a flower and a bud. 2, Flower in longitudinal section. 3, Fruit. (See text.) OFFICIAL.

Leares small, entire. Flower with a stiff, red calyx, an indefinite number of

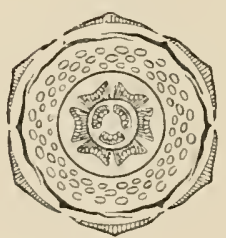

Fro, 657.-Floral diagram of I'unico gronatum. (After EIcHLER.) petals, and numerous stamens; the $7-14$ carpels are arranged in two tiers, the upper of which corresponds in number to the sepals, the lower to the half of this (Fig. 65\%). Fruit enclosed by a leathery pericarp with numerous seeds in the locnli of both tiers. The external layers of the seed-coat become succulent and form the edible portion of the fruit.

OfFicial. - Punica granatum, from which GRANATI COITEX is obtained.

\section{Order 24. Umbelliflorae}

Inflorescence as a rule an umbel. Flowers hermaphrodite, aetinomorphic, tetramerous or more usually pentamerous; calyx only slightly developed; a single whorl of stamens and an inferior bilocular ovary, the upper surface of which forms the nectary. 
Carpels two. A single pendulous orule in each loculus. Seeds with abundant endosperm.

Family 1. Cornaceae.-For the most part shrubs or small trees, rarely herbs. Leaves simple, usually decussate. Flowers tetramerous, with two inferior carpels. Fruit, a berry or a drupe.

Cornus mas, the Cornelian Cherry (Fig. 658), expands its umbels of yellow flowers before the leaves appear. Each umbel is subtended by four bracts. The inflorescences for the succeeding year are already present in the axils of the leares by the time the fruit is ripe. In Britain two species occur; $C$. sanguinea, the Dogwood, and C. suecica, an arctic and alpine plant which reaches its southem limit in Germany.

Family 2. Araliaceae.Trees or shrubs with alternate leaves, which are often of considerable size and simple, lobed, or compound in shape. Flowers ventamerous throughout; in umbels or heads, often further grouped in a panicle-like inflorescence. The carpels vary in number from 2-5 or more. Centres of distribution in tropical America and Malaya.

In Britain the only representative of the family is the Iry (Hoderc Helix), a rootclimber. The proper elliptical leaf form reappears on the orthotropus shoots of older plants, which in late summer

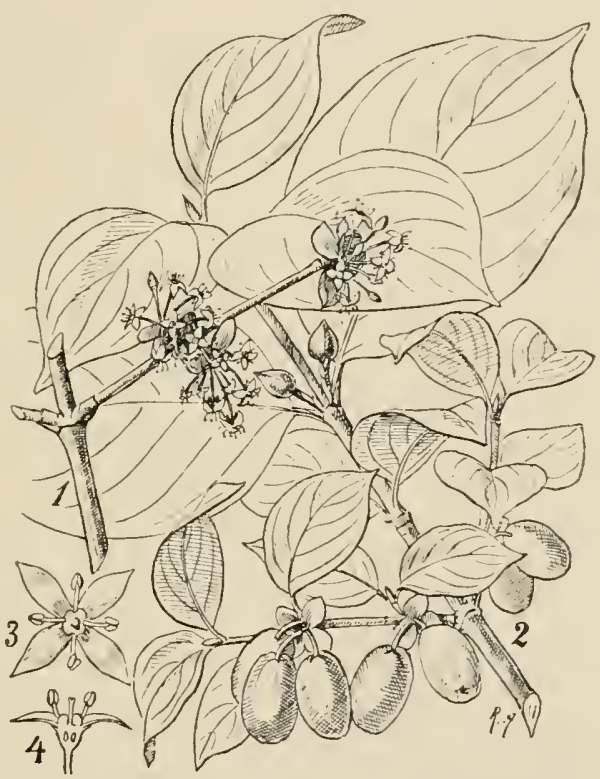

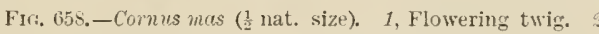
Twig with fruits. 3, Flower seen from above. 4, Flower it longitudinal section. (3, 4, enlarged.)

or autumn bear the flowers. The leares of the creeping or climbing plagiotropons shoots are lobed and usually have shorter stalks (Fig. 659). Calyx with five pointed sepals corresponding to the five ribs on the inferior ovary. The corolla is greenish in tint; the large disc on the upper surface of the ovary attracts the visits of bees. The fruits ripen during the winter and become blackish-blue berries; these are eaten by birds and in this way the seeds are distributed.

Family 3. Umbelliferae.-Herbaceous plants sometimes of large size. The stem, which has hollow internodes and enlarged nodes, bears alternate leaves; these completely encircle the stem with their sheathing base, which is often of large size. The leaves are only rarely simple; usually they are highly compound. Inflorescence terminal, frequently overtopped by the next younger lateral shoot. It is an umbel, or more frequently a compound umbel, the bracts forming the involucre and partial involucres, or an involucre may be 


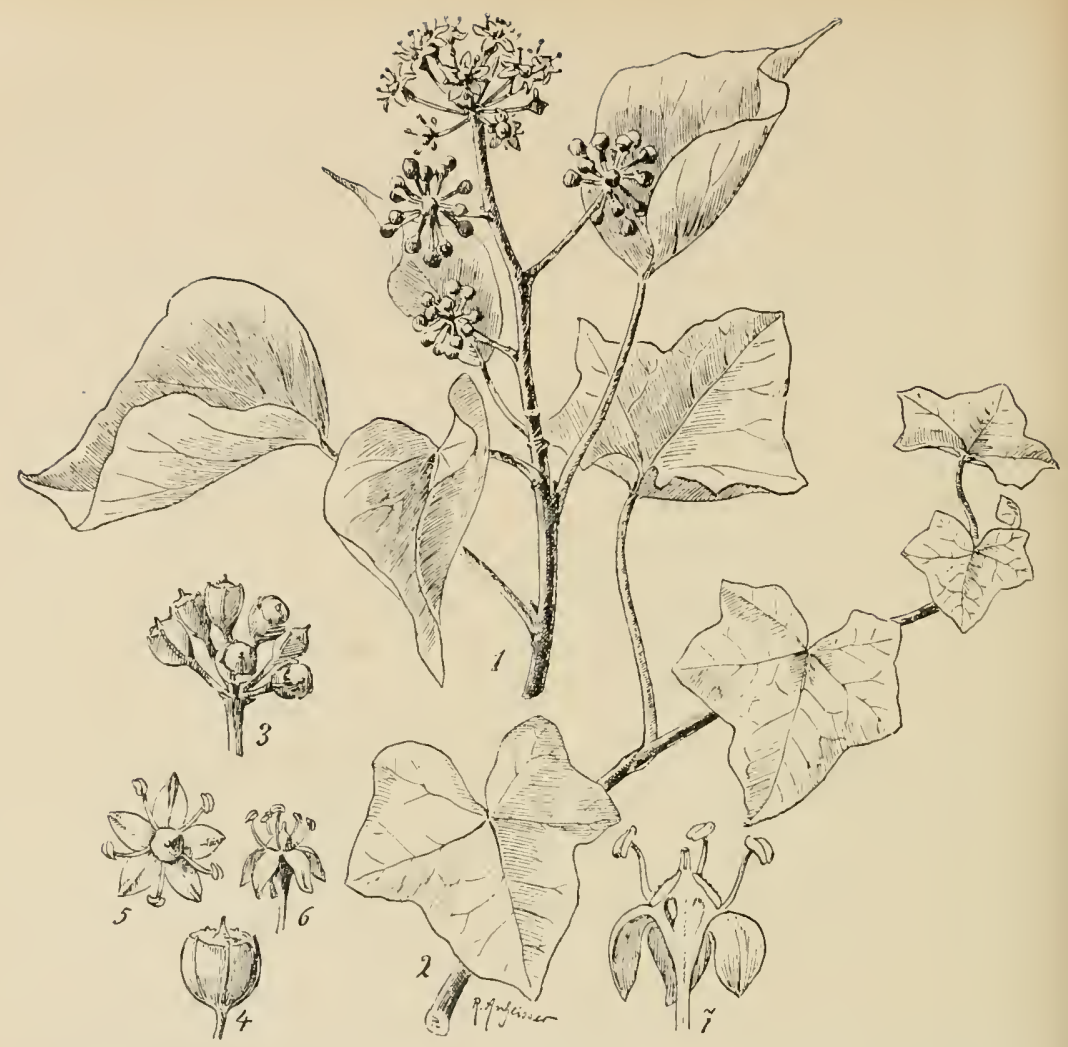

Fis, 659.-Heileru Helix ( $\frac{1}{2}$ nat. size). 1, Erect flowering shoot. ?, Creeping shoot showing the distinct form of the leaves. 3 , Fruits. 4, Single fruit. 5, Flower from above. 6, Flower from the side. $\%$, Flower cut through longitudinally. (4-7 eulargerl.) Polsowot:s.
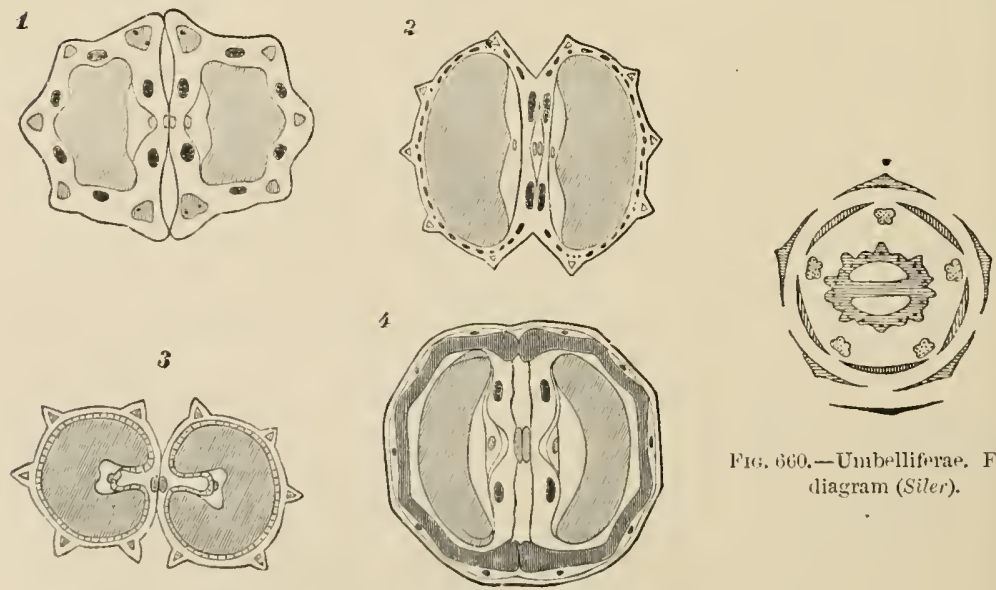

Fu: bi60.-Ǔmbellifirae. Floral diagram (Siler).

lis. Git.- Fruits of Umbelliferae in cross section. 1, Foeniculum officinule. 2, l'impinellu Anisum. 8, Conium maculutum. I, Coriandrum suticum (' 4 modified after a figure by DRUDF). 
wanting. Flowers white, greenish, or yellow; other colours are rare. $\mathrm{K} 5, \mathrm{C} 5, \mathrm{~A} 5, \mathrm{G}(\overline{2})$. The sepals are usually represented by short teeth. The flowers at the circumference of the compound umbel sometimes becone zygomorphic by the enlargement of the

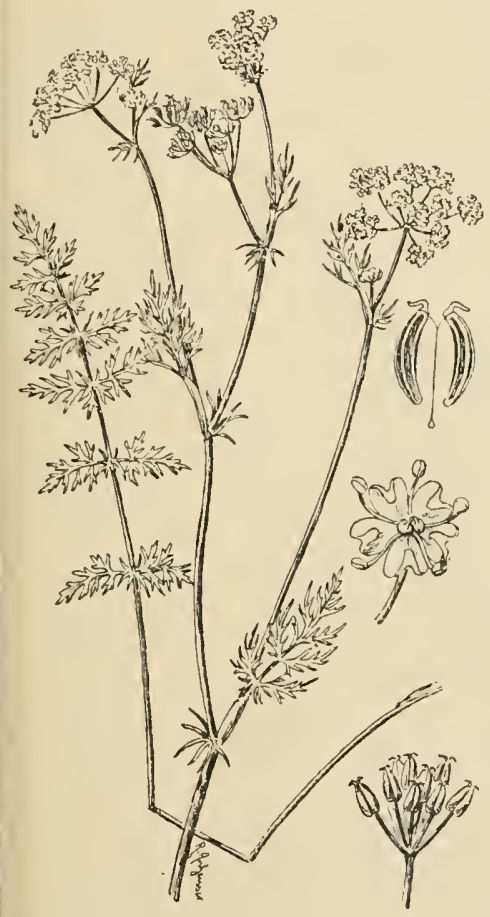

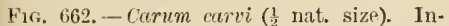
floreseence bearing fruits. Single Hower, and carpophore bearing the mericarps (enlarged). OFFICIAL.

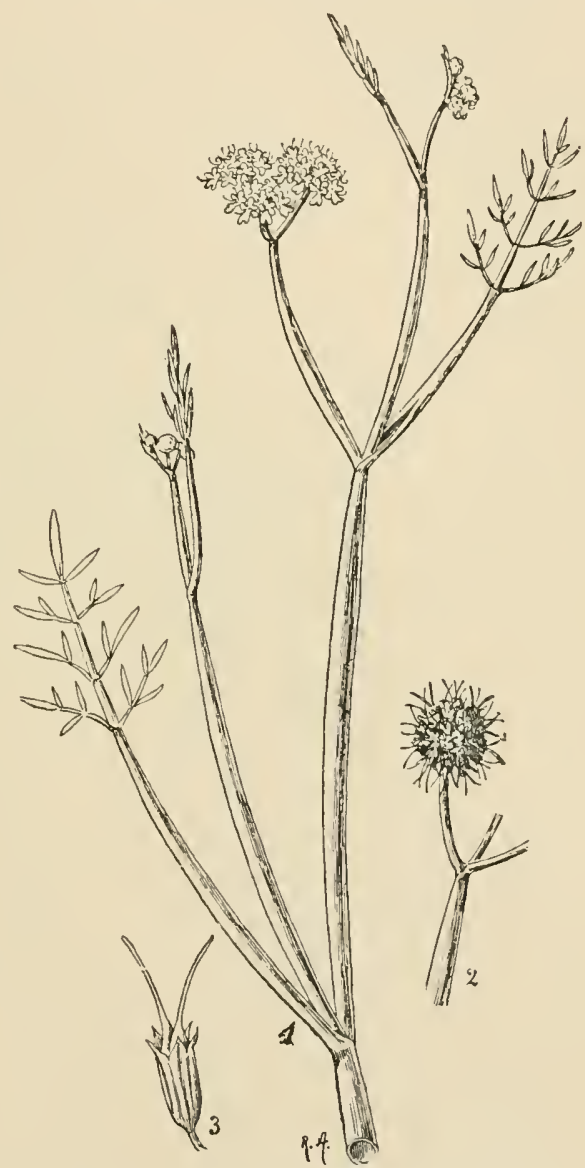

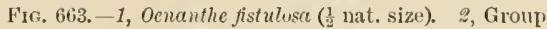
of fruits. 3, Single fruit (enlarged). P'orsovocs.

outwardly directed petals. Ovary always bi-carpellary and bilocular; in each loculus a single ovule which hangs from the median septum with its micropyle directed upwards and outwards. The upper surface of the carpels is occupied by a swollen, nectar-secreting disc continuing into the longer or shorter styles, which terminate in spherical stigmas. Fruit a schizocarp, splitting in the plane of the septum into two partial fruits or mericarps. In many cases the latter remain for a 
time attached to the carpophore, which originates from the central portion of the septum ; this separates from the rest of the septum and bears the mericarps hanging from its upper forked end (Figs. 660-667).

The main areas of distribution of the Umbelliferae are the steppe region of Western Asia, Central North Ameriea, Chile, and Australia.

For systematic purposes the fruits are of great importanee. Each half of the fruit has five ribs, beneath which the vascular bundles lie. The marginal ribs of each partial fruit frequently lie close together at the septum or they may be distinet ; they may resemble the three dorsal ribs or differ more or less from them.

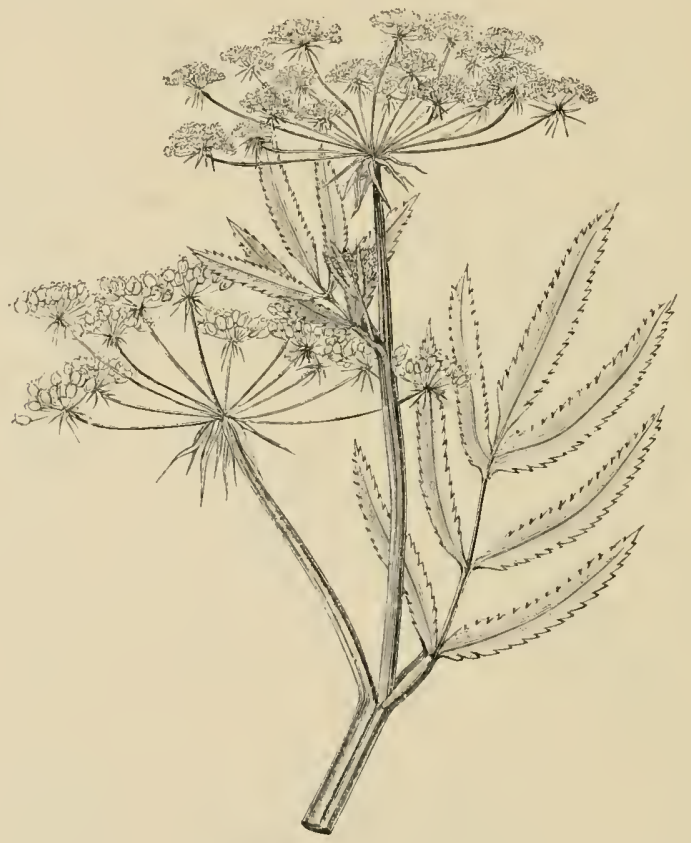

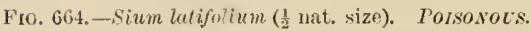

Between the five primary ribs four secondary ribs are sometimes present. Usually furrows (valleculae) oceur between the ridges, and beneath each furrow a large oil duct (vitta) is found, extending the whole length of the fruit. On either side of the earpolihore a similar oil duct is present in the septum, so that each meriearp has six of these vittae (Fig. 661). In some species additional small ducts are present. The form of the fruit as seen in a cross section differs aceording to whether the diameter is greater in the plane of the septum or at right angles to this. The character of the marginal and dorsal ridges and the presence or absence of secondary ridges or vittae serve to distinguish the fruits, and are indispensable aids in determining the speeies. Since many of the finits are cmployer in medicine or as spices, while others are poisonons, their distinetion beeomes a matter of inportance. The endosperm of the seeds contains a fatty oil as reserve material. 
The most recent revision of the family is by Drude in Engler-Prantl, $N$ ort. P.fanzenfom. ; an older useful division is founded on the shape of the endosperm.

1. Orthospermoe.-The endosperm flat or slightly convex on the rentral side, i.e. on the side towards the plane of junction of the two mericarps (Fig. 66'1, 1, 2). The majority of the species belong to this group. Hydrocotyle is a creeping

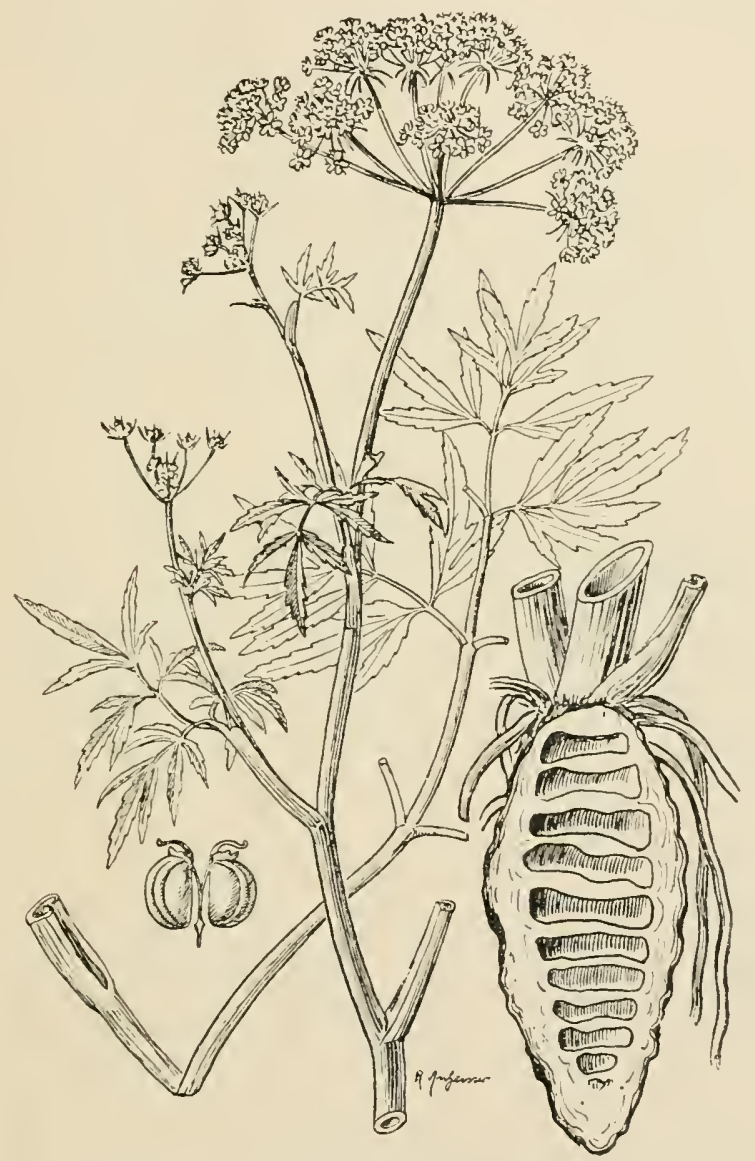

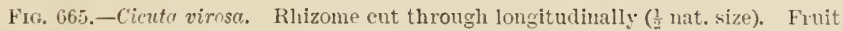
(enlarged), Porsowots.

plant growing in marshy places with entire, peltate leaves and simple umbels. Saniculce and Astrantia have simple umbels, which in the latter are surrounded by a petaloid involucre. In Eryngium the plant is usually spiny and bears simple umbels, which approach closely to being capitula ; the involucral leares are often coloured. Bupleurum has entire leares. Pimpinella, Burnet-Saxifrage. $P$. Anisum, Anise, is an annul plant, the seedlings of which exhibit increasing subdivision of the lamina in successive leaves. Camu Carvi, Carroway, has 
long been cultivated (Fig. 662); leaves bipinnate, the lowest pinnae resembling stipnles. The large lower pinnules are usually placed horizontally on the vertieal rliachis of the leaf; the terminal pinnules are simple and linear. The terminal umbel, the flowers of which open first, is orertopped by the lateral umbels arising from the leaf-axils. Biennial. Curum Bulbocastanum has a perennial, tuberous rhizome; its seedlings have only one cotyledon. Foeniculum (Fennel) and Levistieum (Lovage) have yellow flowers. Petroselinum (Parsley), Pastinuea (Parsnip), Duueus (Carrot), Apium (Celery), and Anethum (Dill), are used as

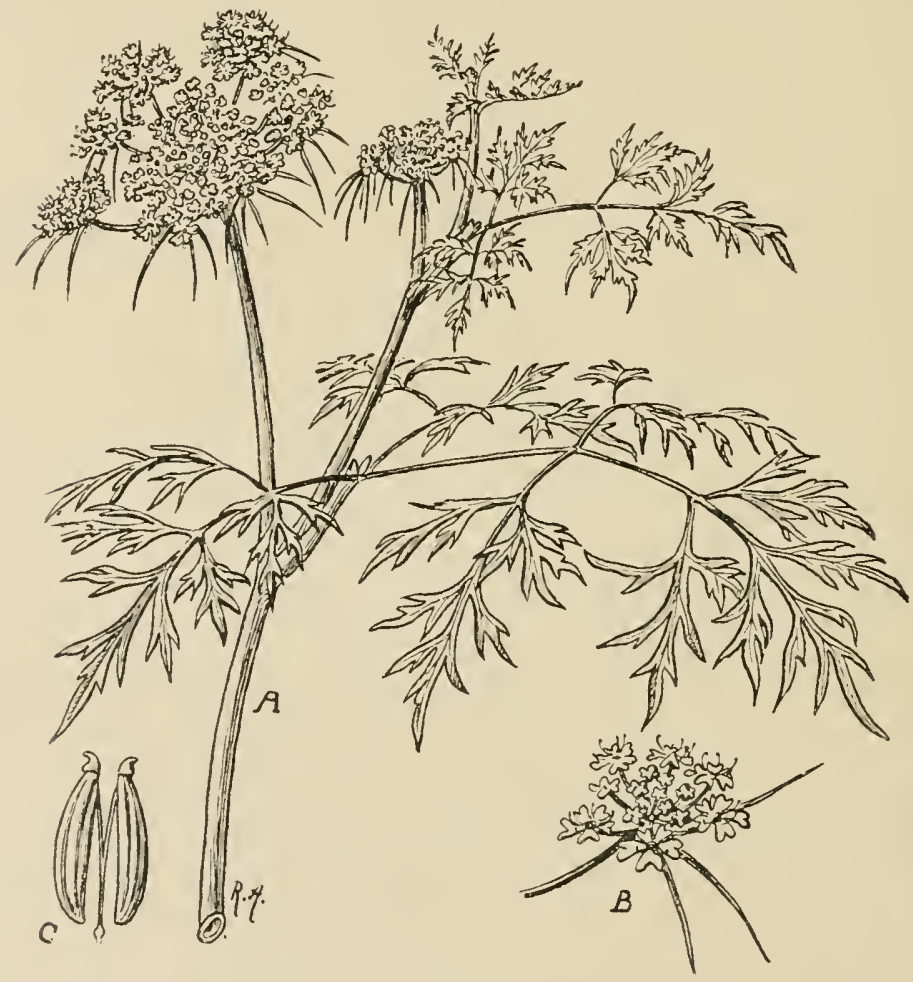

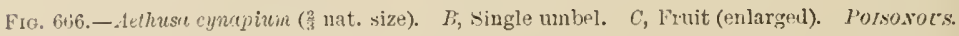

vegetables. Cicutu (Water-Hemlock, Fig. 665), Sinu (Water-Parsnip, Fig. 664), Ocuanthe (Fï. 663) and Berula, are marsl- or water-plants. Acthusa eynapizm (Fool's Parsley, Fig. 666) has the ribs of the fruit keeled; umbels with three elongated, linear, involueral leaves directed ontwards. All the last-named plants are poisonous. Arehorgelica officinalis is a conspicuous plant reaehing a height of 2 metres, with large bipinnate leaves provided with saccate, sheathing bases; the greenish flowers are markedly protandrous, the styles and stigmas only developing after the stamens have fallen. In Carum, Oencuntue, Cicuta, and Heraeleum, and notably in the large species of Fermbla, the flowers become polygamous or of 
seprate sexes by abortion of stamens or carpels; sometimes the plants become dioecious. The ovary is completely wanting in the male flowers.

2. Campylospermac. - The rentral side of the endoslerm is traversed by a longitudinal groove (Fig. 661,3). Seandix, Anthriscus (Beaked Parsley), Chaevophyllum (Chervil). Comium maculatum, the Hemlock, is a biennial plant often of

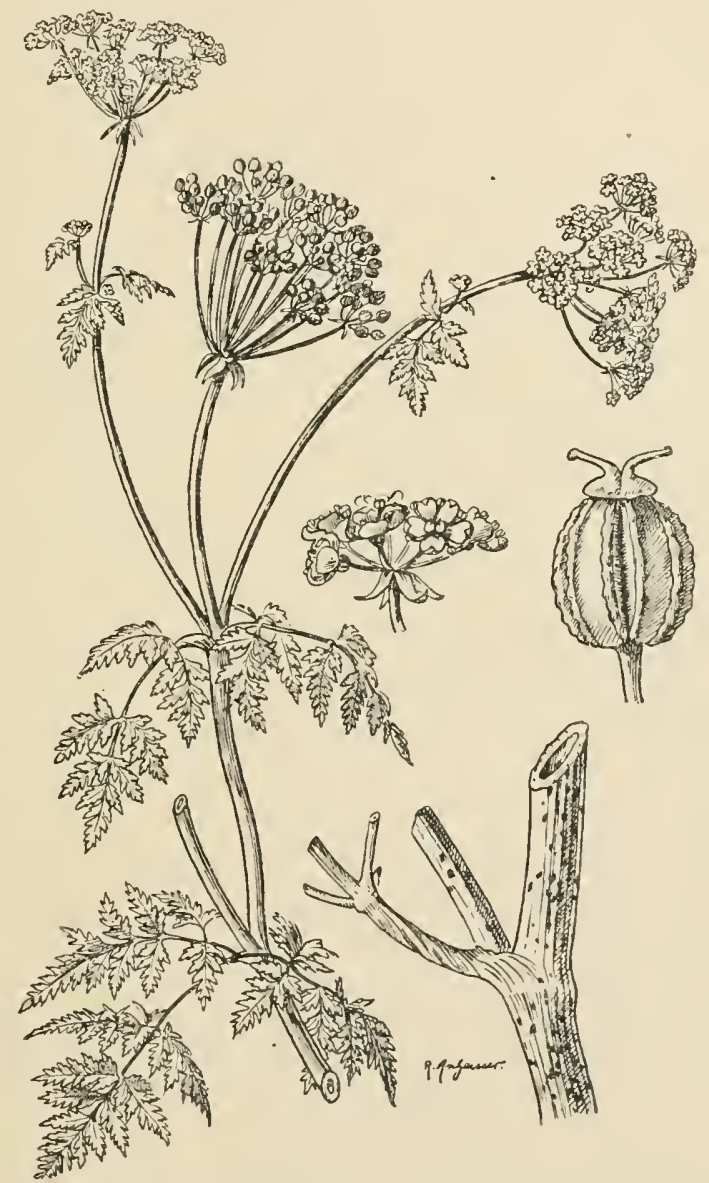

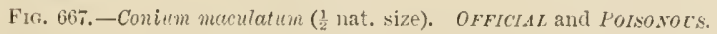

considerable height; it is completely glabrous, the stem and leaf-stalks often with purple spots; leaves dnll green, bi- to tri-pinnate. The ultimate segments end in a small, colourless, bristle-like tip. Fruit with wavy, crenate ridges and without oilducts in the valleculae. The whole plant has a peculiar, unpleasant odour (Fig. 667).

3. Coelospermae. - The rentral side of the endosperm is concave (Fig. 661, 1). Coriandrum sativum is an annual plant; Howers zygomorphic owing to the enlargement of the sepals and petals at the periphery of the umbel. Fruit spherical; 
mericarps closely united, with ill-marked primary ridges and somewhat more distinet secondary ridges.

OfFicial. - Conium maculatum yields conil folia and conil Fructus. Ferula foctille (Persia), AsAFETIDA. F. galbaniflua and other species (Persia), galbaxum. Dorema Ammoniaeum (Persia), AMIOXTACUM. Pimpinella anisum, ANIsI FRUCTts. Coriundrum sativun, CoIIAxDr Frudotus. Foeniculum, a apillaceum, FoeNICULI Fructes. Corum earvi, CAnu Feuctus. Anethum (Peucclanum) graveolens, Axethi FRUCTUs. Forule sumbul, sumbul radix.

\section{Series II. Sympetalae $\left(^{3}\right)$}

Perianth differentiated into calyx and corolla. Corolla gamopetalous. Flowers usually pentamerous, always cyclic. Two groups of Sympetalae can be distinguished. A. Pentacyclicae. Flowers with five regularly alternating whorls. K $5, \mathrm{C}(5), \mathrm{A} 5+5, \mathrm{G}(5)$. B. Tetrucyclicue. Flowers, by omission of the inner whorl of stamens, no trace of which persists, composed of four regularly alternating whorls. K $5, \mathrm{C}(5)$, A $5, \mathrm{G}(5)$ or more commonly $\mathrm{G}(2)$ by reduction in the number of carpels.

\section{A. Pentacyclicale}

\section{Order 1. Ericinae $\left({ }^{(0)}\right)$}

Plants with actinomorphic flowers; androecium obdiplostemonous; stamens not adherent to the corolla. Pollen-sacs with an "exothe-

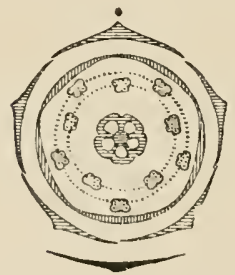

F10. 60s.-Floral diagram of Vaccinium (Ericacrae). cium"; pollen-grains frequently cohering in tetrads. Orary, as a rule superior, multilocular.

Family 1. Ericaceae.-Evergreen, shrubby plants with small, often needle-shaped leaves. Anthers opening by pores or splits, frequently provided with horn-like appendages, on which account the group is also termed Bicornes. Fruit, a capsule, berry, or drupe. Seeds with a well-developed embryo and abundant endosperm (Figs. 668, 669).

Important SUB-Familes Axd Genepa.-A. With a superior ovary: 1. Ericeae. Flowers tetramerous thronghont. Corolla persistent. Erica, calyx shorter than the corollit, includes some British species ( $E$. Tetralix) and many native to the Mediterranean region an! the Cape. Calluna, calyx longer than the corolla. C. culyeris, Hcather or Ling, occmrs on both dry and wet soils in western Europe. It ascends into alpine regions, and by itself or in association with a few other flants covers extensive tracts of conntry known as heaths or moors. 2. drbutece Flowers rentanerous. Corolla decidnous. Andromelle occnrs on moors in the northern hemisphere; fruit, a capsule. Arctostupllylos Uva ursi, circumpolar, in similar localities, has small, entire, leathery leaves. Fruit, a five-seeded drupe 
(Fig. 669). 3. Rhodoreae. Corolla deciduous. Capsule septicidal. Rhododendron. Alpine Rose. There are a few European species; many forms, especially Asiatic species, are cultivated as ormamental shrubs. Ledum palustre is a poisonous, evergreen shrub, occurring on moors in Enrope; leaves rolled ronnd at the margins: beantiful white umbels of flowers. Corolla polypetalous, star-shaped.

B. Ovary inferior: Taccineae. Taccinium myrtillus, Blaeberry, is a low, decidnons, shrubby plant. $\quad V$. ritis idaca, Cowberry, is evergreen, aud together with the preceding species is found in hilly regions.

OfFICIAL. - Aretostaphylos t've ursi yields UVAE uRs Folia.

Family 2. Pyrolaceae.-Peremial, sometimes evergreen, herbaceous plants. Corolla often polypetalons. Seeds very small; embryo composed of only a few cells, Pyrola, several British species, with the flowers solitary or in racemes. Monotrope is a sajrophyte devoid of chlorophyll. M. hypopitys, Birds' Nest, occurs
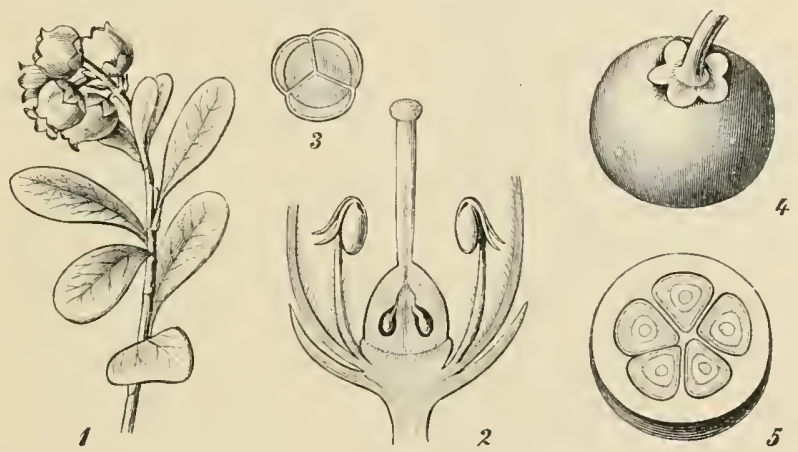

FIG. 669.-Arctostuphylos Uva ursi. 1, Flowering branch; 2, flower in longitudinal section; 3 , pollen-grain : 4 , fruit; 5 , fruit in transverse section. (After BERG and SchuIDT.) OFFICIAL.

larely in woods, has a yellowish succulent stem, bearing scale leaves below and ending in a racemose inflorescence with a few flowers.

\section{Order 2. Diospyrinae}

Actinomorphic, usually pentamerous flowers with a diplostemonous androecium. Antisepalous stamens frequently reduced. The Sapotaceae is a tropical family; the plants contain latex. Species of Palaquium and Payena from the Malayan Archipelago are the trees from which gutta-percha is obtained. Flowers hexamerous (Fig. 670). Balata is obtained from Mimusops; trees found throughout the tropics.

Ebenaceae.-Diospmos Kaki is a Japanese fruit tree; D. Ebenum, ebony.

Styracaceae.-The origin of Benzoin (BFinzornum), an official resin, from Styrax Benzoin, though generally assumed, is open to doubt.

\section{Order 3. Primulinae}

Flowers sympetalous, ac inomorphic with only one whorl of stamens; the latter are antipetalous, and are adherent to the corolla. 
Ovary unilocular, superior, with a free-central placenta. K $5, \mathrm{C}(5)$, $\mathrm{A} 0+5, \mathrm{G}(5)$.

Family 1. Primulaceae, Herbs, often with conspicuons flowers. Calyx green. Style, unbranched. Numerous ovules. Fruit, a capsule (Figs. 671-673).

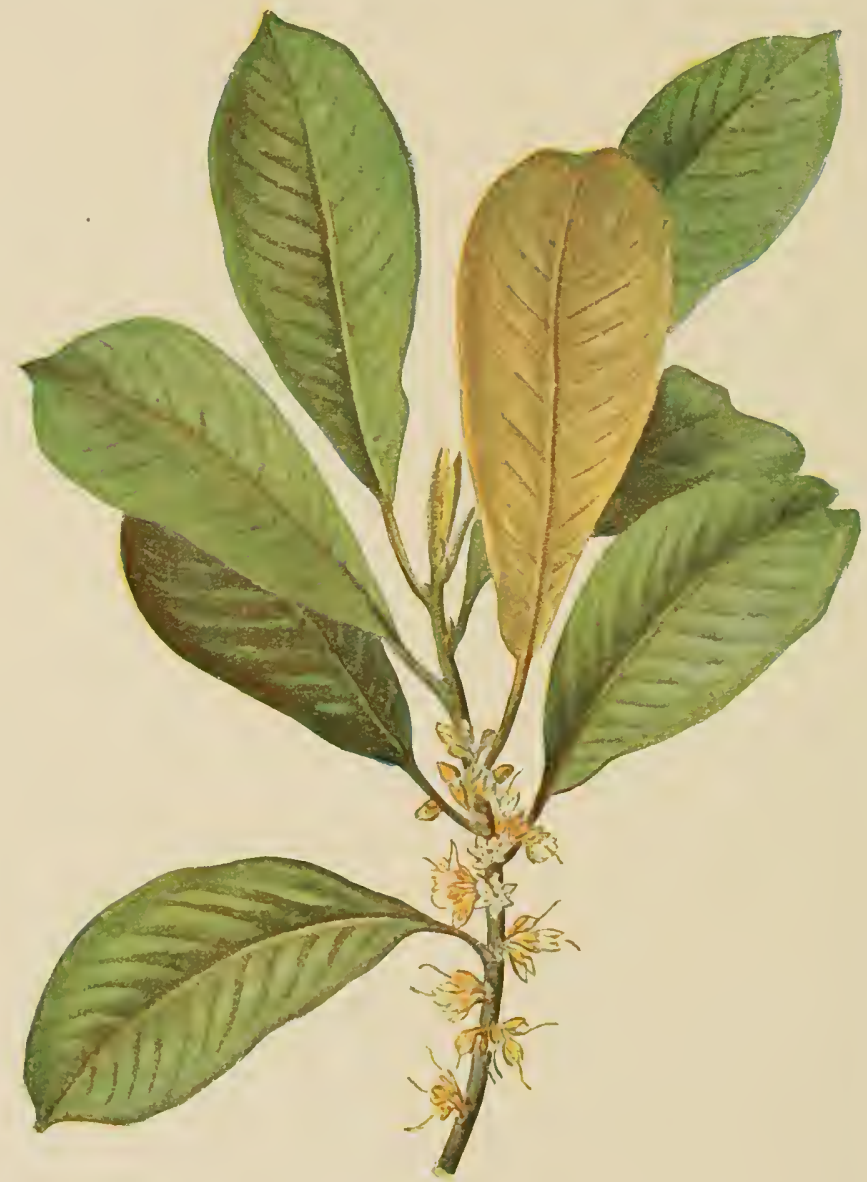

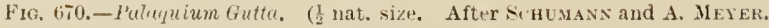

Generally distributed, but espeeially in the northern hemispliere.

Impontant Genera. - Primula, with several British speeies. Herbs with rosettes of leaves. Flowers solitary or in umbellate inflorescences. The eapsules open by fire teeth at the summit. Commouly grown as ormamental plants. Anagallis, eapsule opens by a lid (pyxiclium). Stem prostrate, with leaves in decussate pairs (Fig. 672). Lysimachice, large herbaceous plants, with ereet or creeping stems and 
decussate leaves. Cyclamen $\left({ }^{61}\right)$, flowers bent back on long stalks; tips of the petals reflexed. Many species and hybrids are in cnltivation. C'. curopocum, the Alpine Violet (Fig. 673), is a herbaceous plant found in the Alps; the somewhat fleshy leaves have loug stalks, and are borne on a large perenuial tuber, which

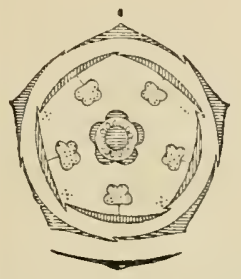

प1\%. 671.-Primulaceap. Floral diagram (Primula).

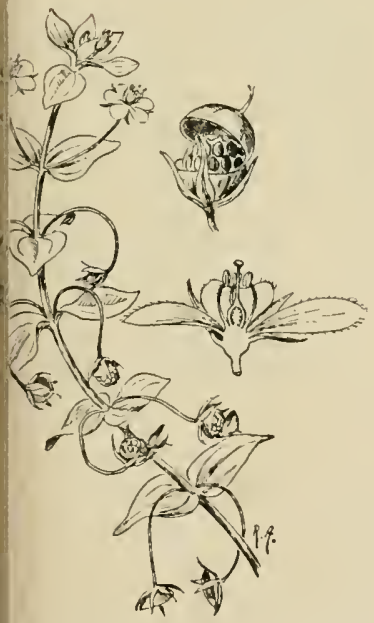

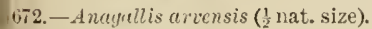
ongitudiual section of flower, anil psule at dehiscence (enlarged).

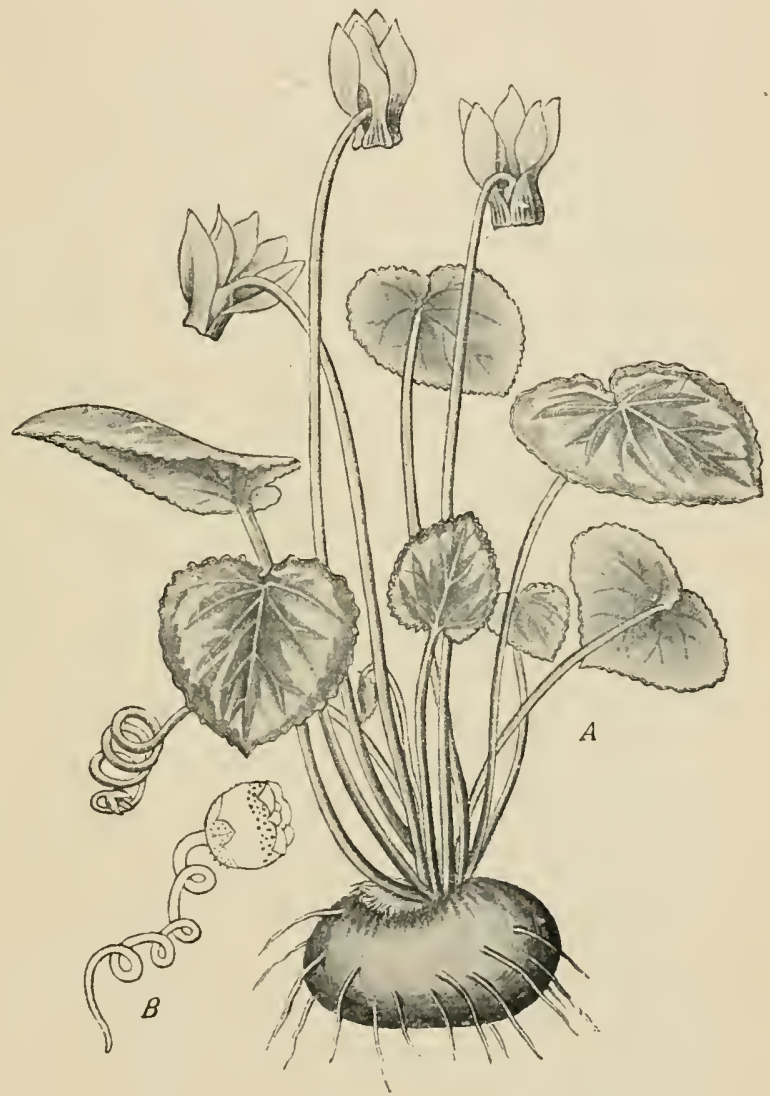

Fif. 673.-Cyetincn eleropueum. A, Entire plant; $B$, fruit. (After Reichexbach.) Polsovocs.

originates from the liypocotyl of the seedling. The stalks of the fruits become spirally rolled.

Porsonots. - The tubers of Cyclamen europaeum, though harmless when cooked, are poisonous in the fresh state. Anagall is is slightly poisonous. Primula obconica (and $P$. sinensis) secrete in their glandular hairs certain substances which frequently give rise to rashes and to inflammation of the eyes of those handling the plants.

Family 2. Plumbaginaceae. - ilerbs with a dry, membranous, but often brightly coloured calyx. Style branched. The ovary contains a single orule. Species of 
Armerite and Statice are common plants of salt marshes and salt-steppes in all parts of the world.

\section{B. TetraciclicaE}

\section{Order 4. Contortae}

Plants with decussate, usually simple leaves and actinomorphic flowers, the corolla of which is often contorted in the bud. Stamens epipetalous. Ovary of two carpels, superior.

Family 1. Oleaceae.-Shrubs or trees without stipules. Flowers

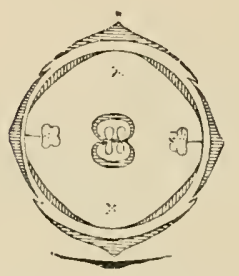

FI: 674.-Oleaceae. Floral diagram (Syringu). tetramerous, but with only two stamens. K4, C (4), A 2, G (2). Corolla with valvular or imbricate aestivation. Ovary bilocular; two ovules in each loculus (Fig. 674).

Distributed in all regions and zones; especially in South and East Asia.

Important Genera.-Olea europea, the Olive $\left({ }^{62}\right)$, a native of the Mediterranean region and of Western Asia, where also it is cultivated. It is a tree with a poorly developed crowu of slender pendulons branches bearing lanceolate, simple, entire leaves, which are dark green above, greyish green beneath. The flowers are borne in axillary racemes or panicles. The fruit is a drupe, both the sucenlent exoearp and the endosperm of which contain a fatty oil (Figs. 676-678). Ligustrum vulgare, the Privet. Jasminum and Syringa (Fig. 674) are grown as flowering shrubs. Fraxinus, the Asl, has imparipinnate leaves; $F$. cxcclsior has apetalous, anemophilons flowers, whieh appear before the leaves. F. orous, the Flowering Ash, has a donble perianth and is entomophilons; it is polygamous, having hermaphrodite Howers as well as female flowers with blaek sterile anthers; the corolla is divided to the base (Fig. 675).

OFFICIAL.-Olea europec yields OLEUM OITAE.

Family 2. Loganiaceae.-Herbs, shrubs, or trees with stipulate leaves. Flowers pentamerous with two carpels. Tropical. Species of Strychnos, which are trees or lianes climbing by means of look-tendrils, yield the arrow poison as well as the well-known Curare of South America, and that used by the Malays.

OFFiciA L. - Strychnos nue vomica is a small tree or shrub of Southern Asia, the fruits of which are leerries with a firm rind; in the succulent pulp a small number of erect, circular, disc-shaped seeds are embedded (Fig. 679). It yields Nux Vomica and strycirina. Gelsenil RaIIx is obtained from Gelsemium nitidum, which is a native of North America.

Family 3. Gentianaceae. - Herbs, with exstipulate leaves. Corolla contorted in the bud (Fig. 680). The two carpels are united to form a unilocular ovary. Ovules numerous.

Generally distributed.

liritisir Grinera. - Gentiana (63) is a genns with mumerons species. Plants of larger or smaller size, espeeially abundant in the Alps. Flowers bightly eoloured. This gemms affords one of the best examples of seasonal dimorphism, i.e. the split- 
ting of a species into two closely related forms which develop at different seasons. Since the height of the regetative period of the alpine meadows coineides with their annual mowing, this expresses itself in the distinction of an early form, fruiting before the meadows are cut, and a late form developing after this has taken plaee. Erythraea, Centaury (Fig. 681), anthers spirally twisted. Menyanthes, Bog-Bean, with alternate, trifoliolate leaves and long-stalked racemes of white flowers with hairy petals. Limnanthemum, aquatic plants witl floating leaves.

OFFICIAL.-Gentiana lutea and other speeies yield GENTIANAE RADIX, ChIRATA is obtained from Suertic chirate (N. India).

Family 4. Apocynaceae. -Evergreen herbs, shrubs or trees, without stipules. Especially numerous in the tropics. Laticiferous cells in all parts of the plant. Petals contorted in the bud. Stigma ring-shaped. Carpels only united in the region of the style, free below (Fig. 682 ) and separating after fertilisation. Usually two follicles. Seerls provided with a tuft of hairs.

IMPORTANT GeNerA. - The only British speeies is Tined minor, the evergreen Periwinkle, oceurring in woods (Fig. 685). Nerium oleander (Fig. 684), a uative of S. Europe, is commonly cultivated. It has greyish-green lanceolate leaves whieh are decussate or in whorls of three ; flowers rose-colonred, sweet-scented, and conspicuous. The whole plant

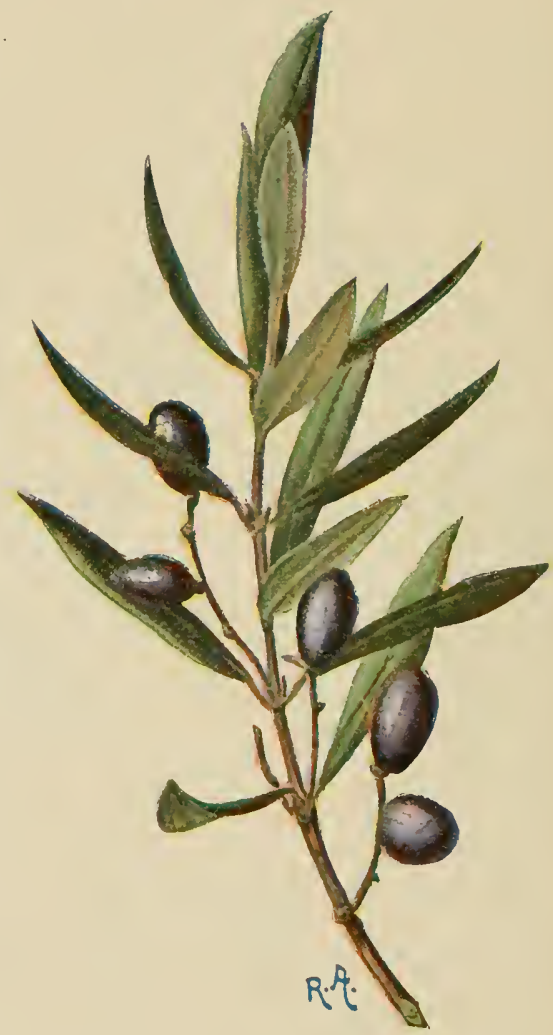

Fia. 678.-Olea evronea in fruit. ( $\frac{1}{2}$ nat. size.)

is extremely poisonons. The floating fruit of Cerbera (tropical) is shown in Fig. 493.

OFFICIAl. -Strophenthus kombe and S. hispridus ${ }^{64}$ ) (Fig. 724), lianes of tropical Africa, yield strophasthr semiNa.

Caontchone $\left({ }^{65}\right)$ is obtained from Fickicia elastica and other species, trees of tropieal W. Afriea. It is also obtained from numerous speeies of Landolphia (L. Kirlii, Heulelotii, comorrnsis, ete.), lianes which are, or formerly were, common throughont tropical Africa. Together with species of Carpodinus (Angola) whieh yield thc root-rubler, these plants supply the main part of the rubber obtained from Africa. Ilanconice speciose, a tree of the dry Brazilian Campos to the south of the Amazon region, yields the "mangabeira" rubber. Willoughbeia firmo, 
H. Hovesiens, and other species of this Malayan genus of lianes are also rubber-

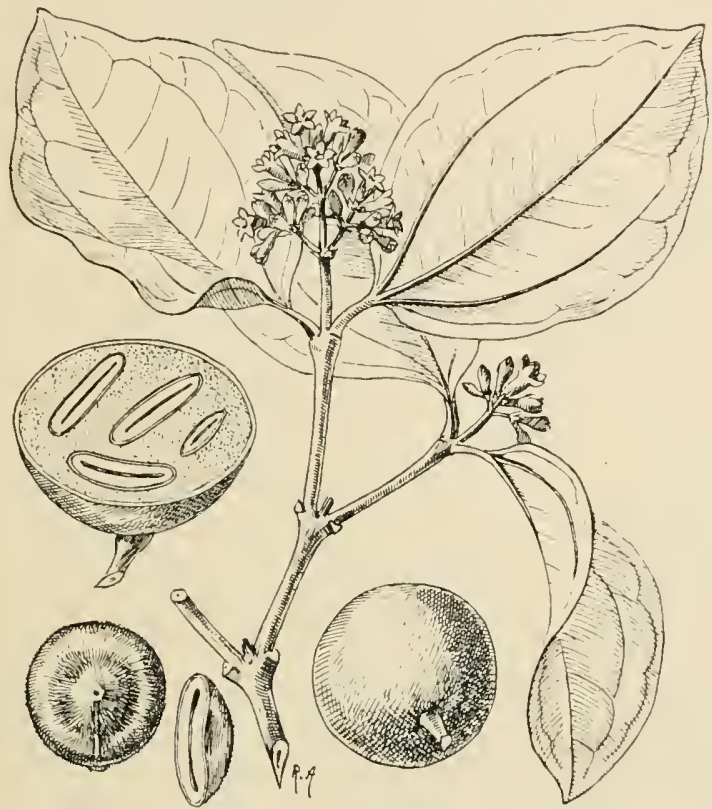

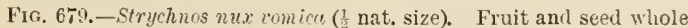
and in cross-section. OFFICIAL and POISONOCS.

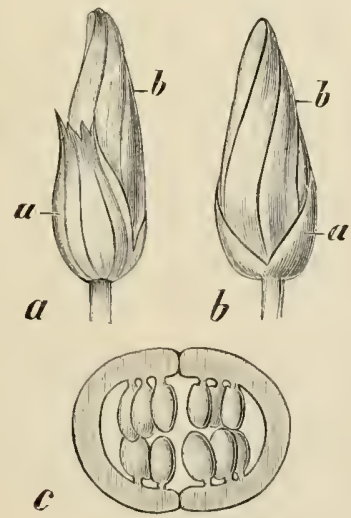

Fig. 6so.-Genticence lutere. "e and $b$, Flower-buds (nat. size), showing calyx $(t)$ and twisted corolla $(b) ; r$, transverse section of ovary. OFFICIAL. (After BERG and SCHMIDT.)

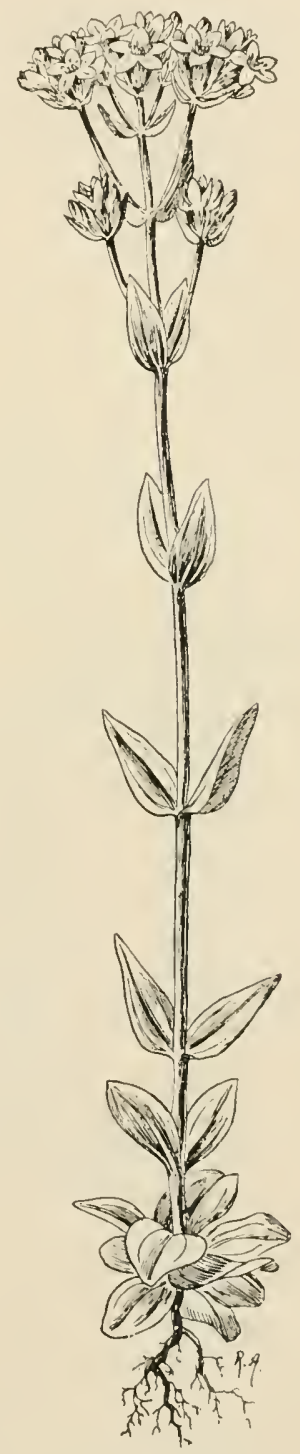

FIG. 6S1.-Erythrara con-

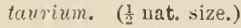

yielding plants. Gutta-percha is present in the latex of Tabernaemontana Donnell Smithii, which is used as a shade-tree on coffee plantations in Central America. 


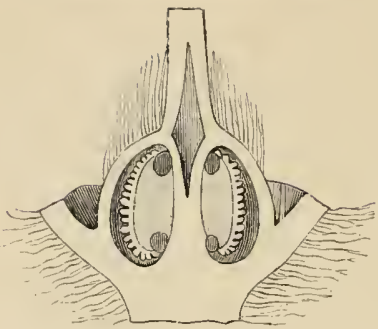

Fig. 682.-Strophenthushispidus. Ovary in longitudinal section. ( $1_{1}^{\circ}$; after Engler-Prantl.)
Since, hitherto, only some Sapotaceous plants, which are difficult to cultivate, have yielded gutta, this plant will soon take an important place in the supply.

Family 5. Asclepiadaceae.-Similar and closely related to the Apocynaceae and, like them, mainly tropical. Corolla contorted in the bud; carpels free, only united by the prismatic stigma; latex in all the organs. Stamens united at the base with dorsal, nectar-secreting

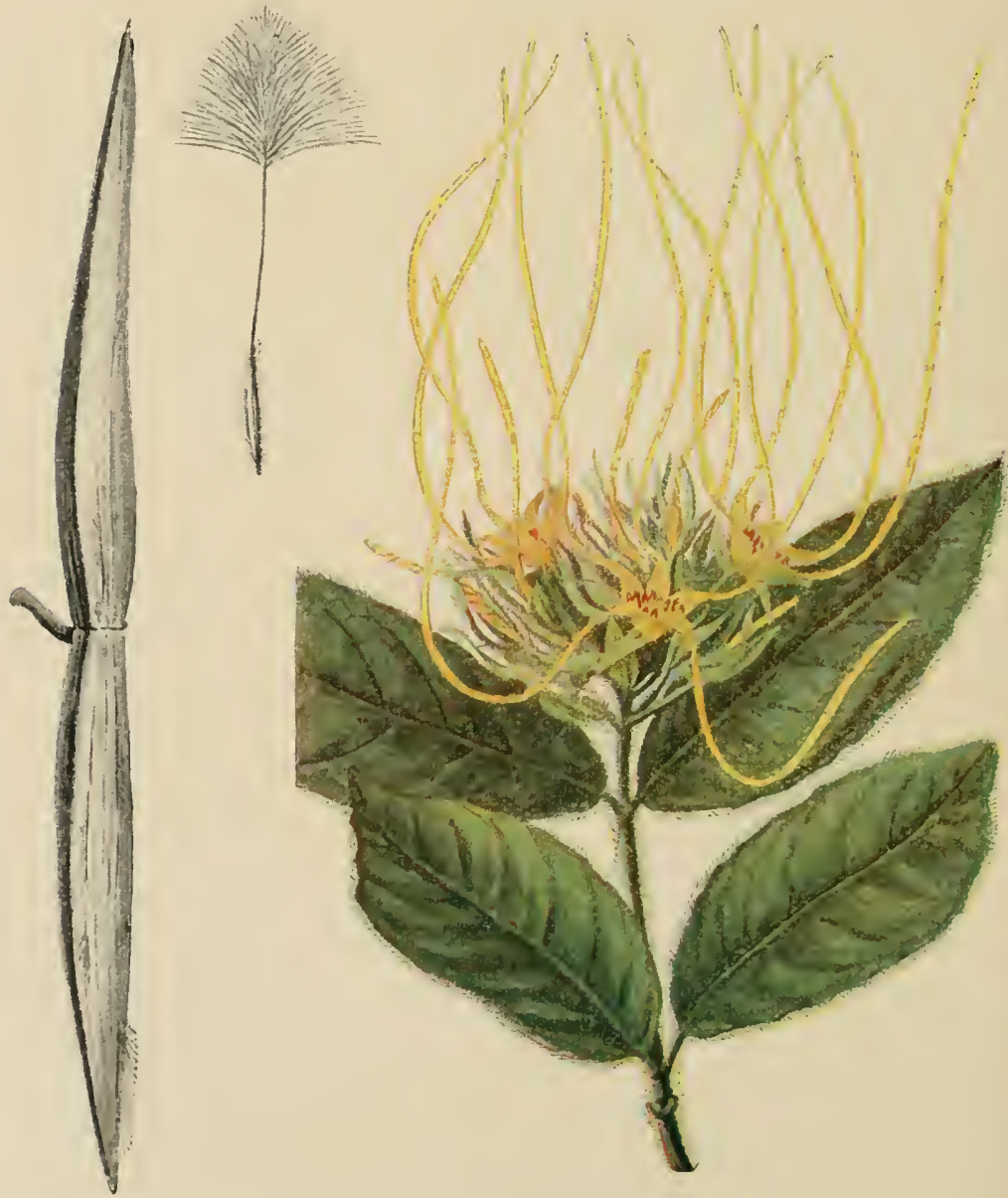

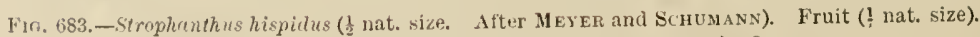

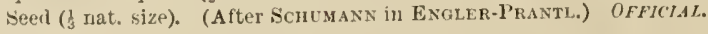


appendages forming a corona. The pollen of each pollen-sac is united into a pollinium, the stalk of which is attached to a glandular swelling (adhesive disc) of the angular stigma.

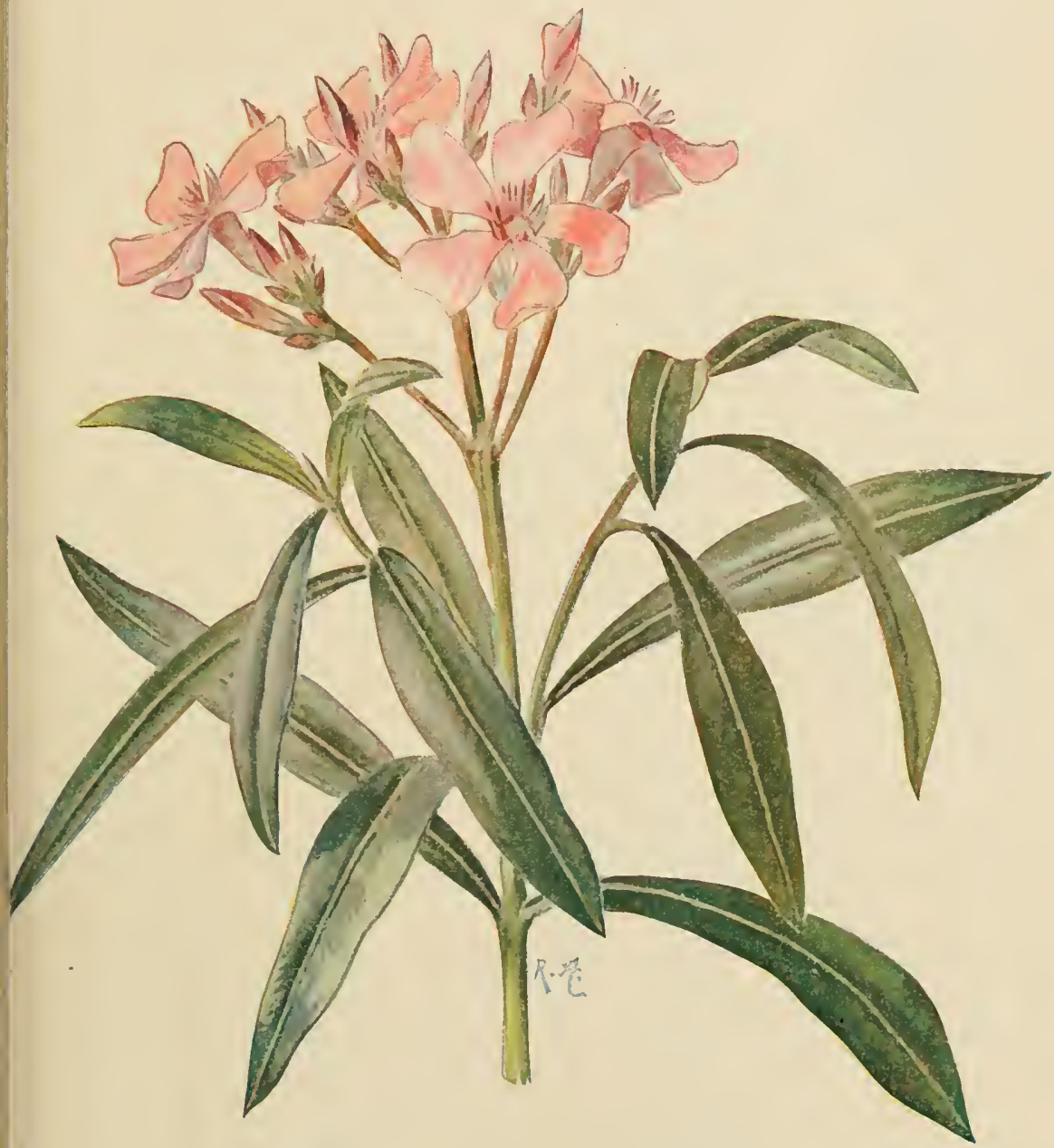

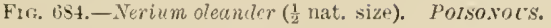

These adhesive dises alternate with the stamens so that the two pollinia attached to each dise belong to the halves of two adjoining stamens. Visiting insects remove, as in the Orchidaceae, he pollinia and carry them to another flower (Fig. 686).

Important Gexera.-Fincetoxicum officinale (Fig. 687) is a Europeau herb 

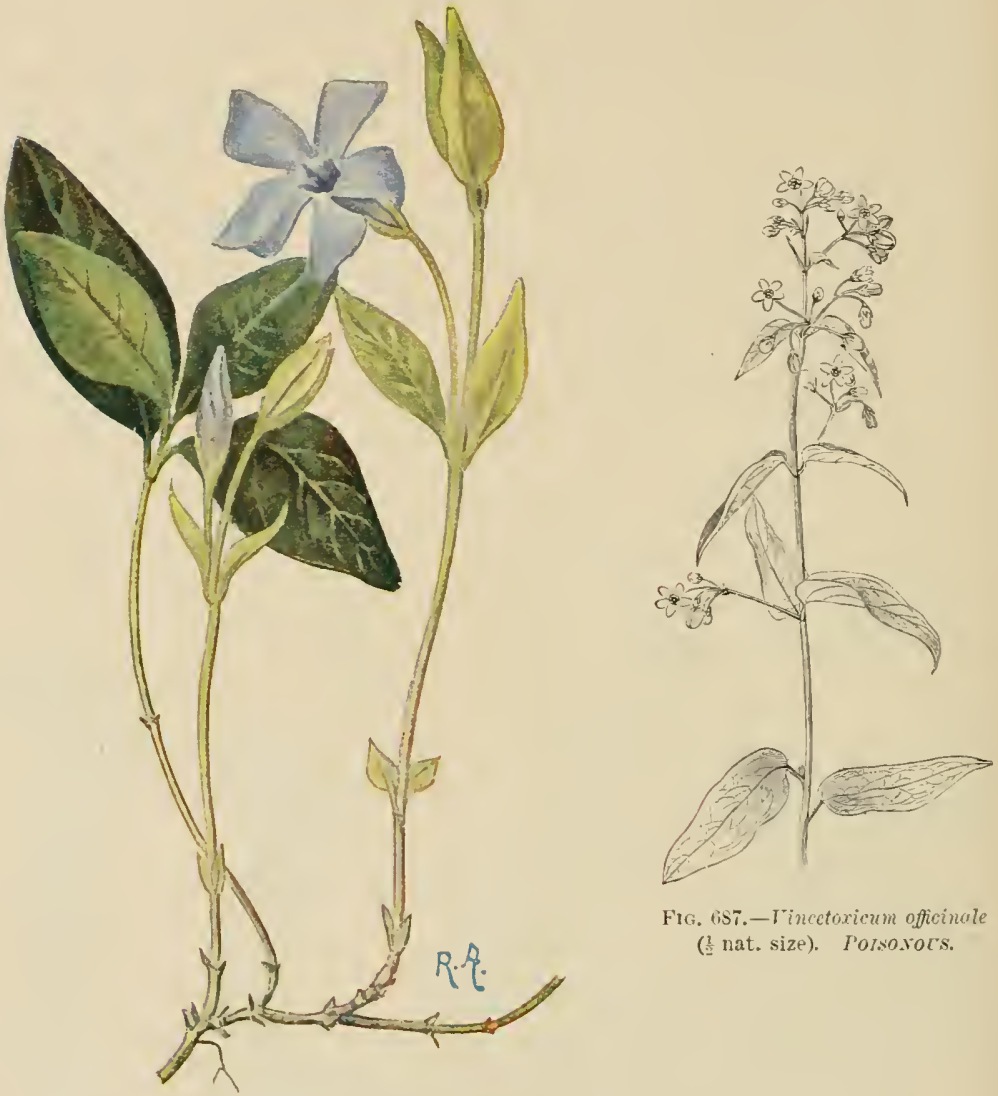

Fig. cist.-Tincetoxicum officinole (논 nat. size). Porsorors.

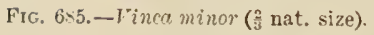

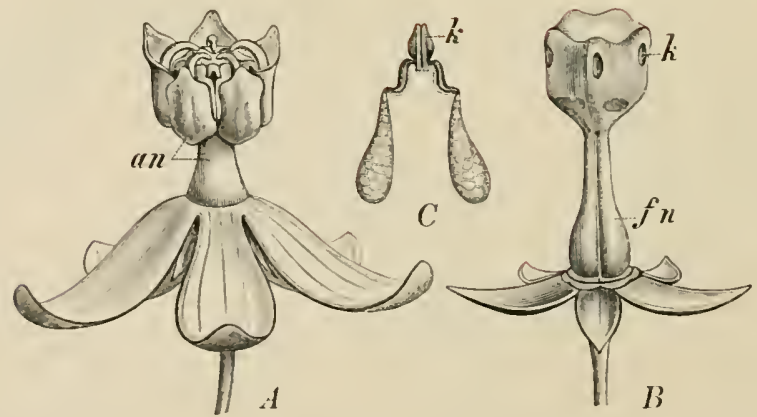

Fig. 686.-Asclepios curassovice. A, Flower; on, androecenm $(\times 4) ; B$, calyx and gynaeceum ; $f n$, ovary $;$, corpuscula $(\times 6) ; C$, pollinia (more highly magnified). (After Bailion.) 
with inconspicuous white flowers and hairy seeds which are borne in follicles; poisonous. Other forms are mostly tropical or sub-tropical. The succulent species of Stapelia, Hootia, Trichocaulon, etc., which resemble Cactaceae in habit, and inhabit S. African deserts, and Dischidia raftesiana $\left({ }^{66}\right)$, the peculiar pitcher plant of the Malayan region, deserve special mention. Hoya earnosa is frequently enltivated.

OFFICIAL.-Hemidesmus indicus yields HeMIDEs.II RADIX.

\section{Order 5. Tubiflorae}

Flowers pentamerous, actinomorphic, or zygomorphic. Carpels 2. Orary superior, bilocular, with two orules, which are frequently separated by a false septım, in each loculus.

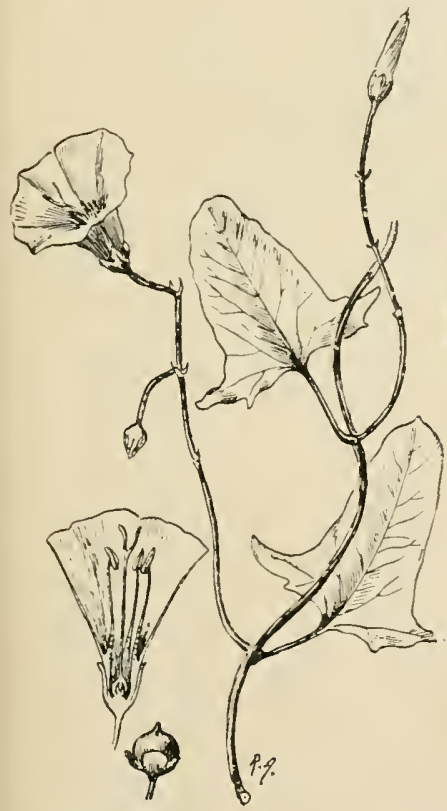

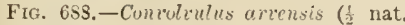
size). Longitudinal section of the flower and a capsule (enlarged).

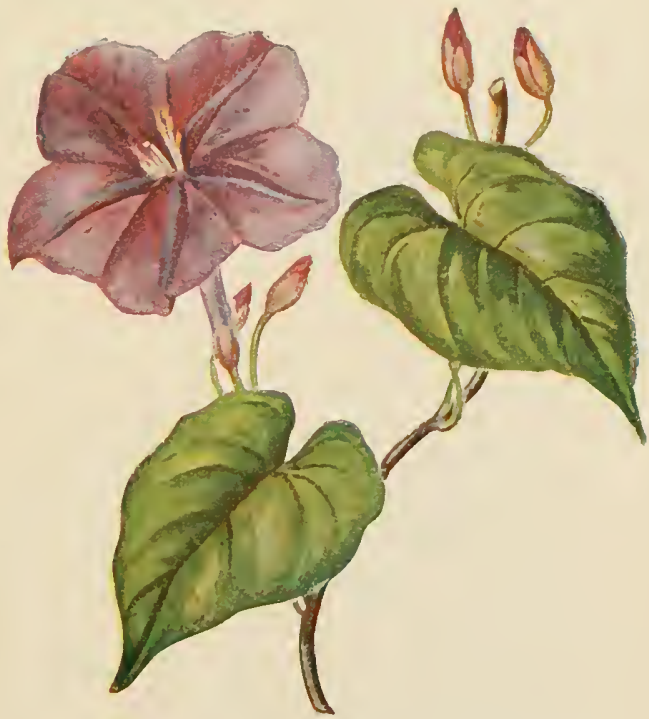

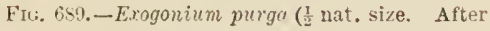
BERG and S(HMIDT). OFFICIAL.

Family 1. Convolvulaceae. - Herbs or shrubs, less commonly trees, with alternate, sagittate, or cordate leaves. The majority are twining plants. Many contain latex. Corolla widely fumnel-shaped, only slightly lobed; in the bud it is longitudinally folded and twisted to the right. Stamens five. Orules basal in the two or four carities of the ovary. Fruit a capsule.

Generally distributed ; especially in tropical Asia and America. 
Impontaxt Genera.-Convolvulus arvensis (Fig. 688), a peremial, twining, herbaceous plaut oeenrring everywhere hy waysides, and as a weed in corn-fields. Flowers solitary, long-stalked, situated in the axils of the leaves and sometimes in the axils of the bracteoles of another flower. Calystegia has two large bracteoles placed immediately beneath the calyx, C. sepium. The Dodder (Cusente) ${ }^{6 \pi}$ ) is a slender parasitic plant containing very little chlorophyll, wlich attaehes itself by means of haustoria to a umber of different host plants. The small flowers are borme in dense elusters (ef. p. 223, Fig. 196). Ipomoca is for the most part a
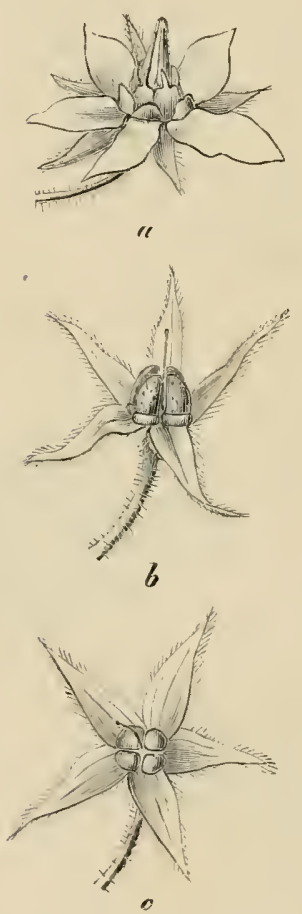

FIG, 6!lo,- Boreyo officinalis. a, Flower; $b$ and $c$, fruit (nat. size).

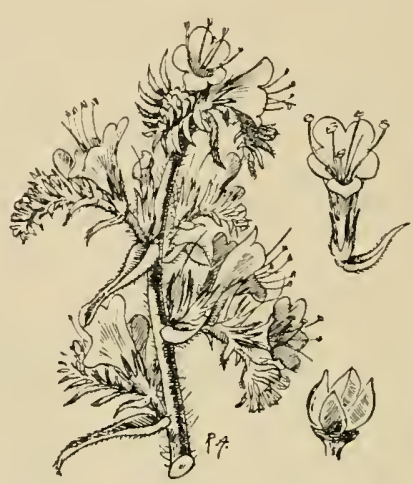

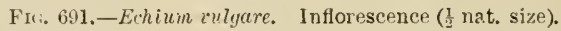
single flower and fruit, composed of four nutlets (enlarged).

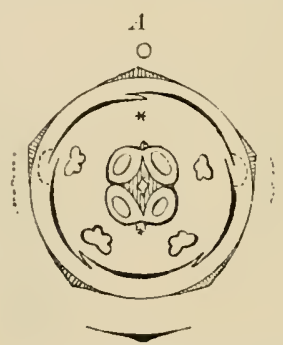

B

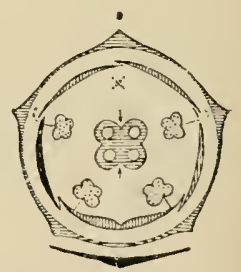

FIi, 602.-FloraI diagrams of (A) I'enlence officinalis (after Eichler), and (B) Lamium (Labiatas).

tropical gemus; several species are eultivated as ornamental plants. I. pescaprue is one of the strand plants of trojical countries.

OFFICIAL. - JALAPA is obtained from Exogonium purga (Fig. 689), a twining plant, with tuberous lateral roots, oceurring on the wooded, eastern slopes of the Mexican tableland. ScAmoride raDix is the dried root of Convolvulus Secammonia (Asia Minor).

Family 2. Polemoniaceae.-Carpels nsually three. No milky juice. Polemonium cocruleum oceurs in Britain. Cobcece scendens and Phlox are eultivated.

Family 3. Hydrophyllaceae.-.Phacelia tanacetifulia is often enltivated for the sake of bees. Infloreseence a cincinnus.

Family 4, Boraginaceae.-Herbs, with alternate leaves. These and the stems 
are covered with coarse hairs (Asperifoliaceae). Inflorescence always cincinnal $\left({ }^{68}\right)$. Flowers actinomorplice or zygomorphic. Petals frequently provided with scales standing in the throat of the corolla. Ovary always bilocular but divided by false septa into four one-seeded nutlets. The style sjrings from the midst of the four-lobed ovary. Orules pendulous. Fruit, a schizocarp, separating into four portions (Figs. 690, 691). Family distributed in the temperate and tropical zones; especially abundant in the Mediterranean region.

Gexera. - Symphytum (Comfrey), Borago (Borage), Anchusi (Alkanet), Echium (Bugloss), Myosolis (Forget-menot), are among the commonest and most conspicuous herbaceous plants of our flora; all have entire, alternate leaves, covered with harsh hair's and relatively large flowers of a lighter or darker blue, grouped in complicated intlorescences. In Echium, and especially in Pulmonaria officinalis, which flowers in spring, the colour of the corolla changes from red to a

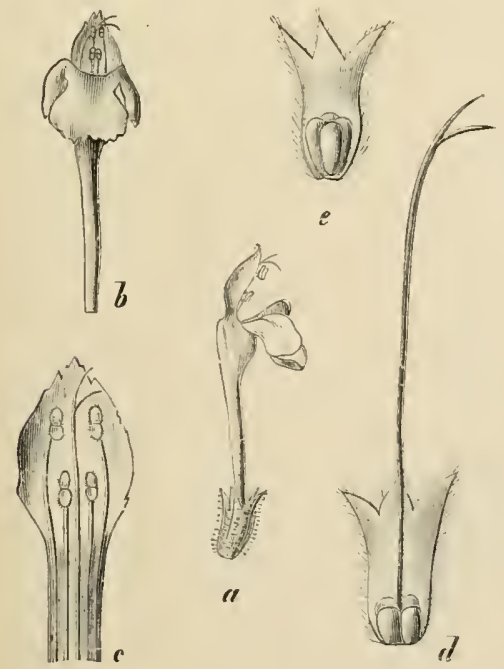

Fic, 6\$3.--Galeopsis orh roleuca. $a$, Flower; $b$, the same with calyx remover : c corolla sut open, showing stamens and style; $d$, calyx and gynaeceum; $e$, fruit. $(a, b$, nat. size; $c, a$, $e \times 2$.)

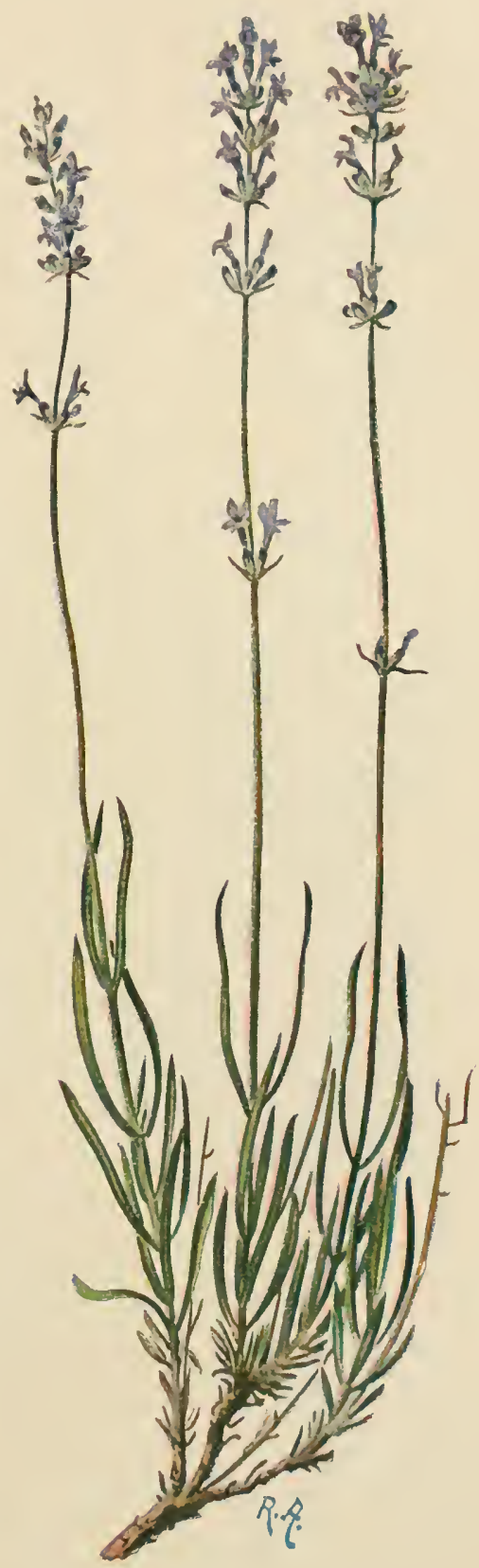

Fig. 694.-Lavandulu resa (13 nat. size). OFEICLAL. 


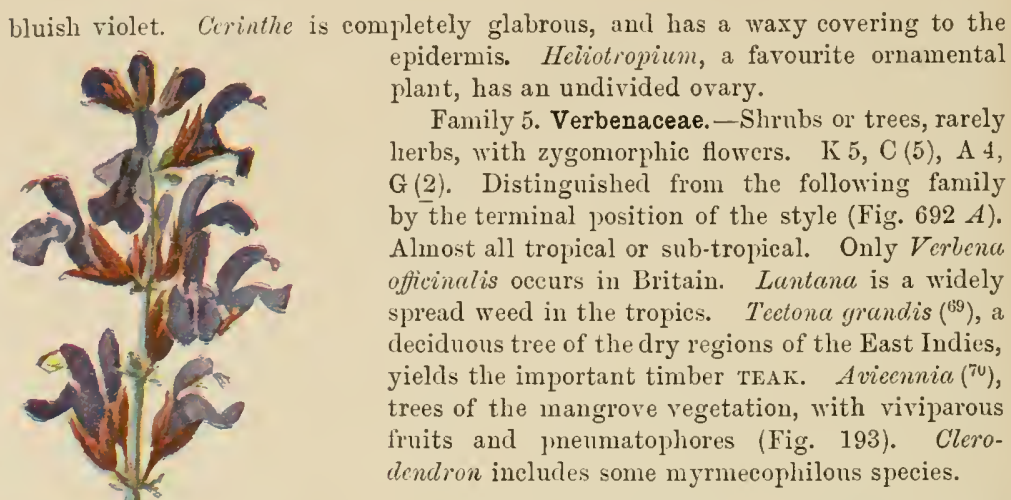

Family 6. Labiatae.-Distributed over the earth. Herbs or shrubs with quadrangular stems and decussate leaves without stipules. Leaves simple; plants often aromatic owing to the presence of glandular hairs. Flowers solitary in the axils of the leaves, or forming apparent whorls. The small inflorescences are dichasia or double cincinni, and are often united in larger spike- or capitulum-like inflorescences. Flower zygomorphic (Fig. 693). Calyx gamosepalous, with five teeth; corolla twolipped, the upper lip eonsisting of two, the lower of three petals ; stamens in two pairs, two long and two short, rarely only two.

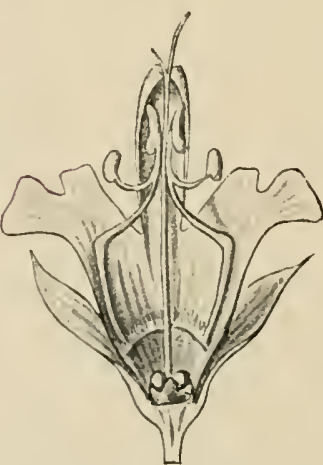

Fus. 695. - Salvia offrinalis. Flowering shoot (12 nat. size). Tubular corolla slit open to displity the stamens (rnlatrged).
Ovary of two carpels, each of which is deeply indented in the plane of the false septum. Style springing from between the lobes; stigma bificl (Fig. 692 li). A ring-shaped nectary situated at the base of the ovary. Fruit, a schizocarp, consisting of four nutlets.

Impoltant Gex-

EnA. - The Labiatae include a considerable proportion of our commonest native 
spring and summer flower's; Lamium, Galcopsis, and Stachys have the npper lip helmet-shaped, Ajuge has it very short, while in Teucrium the upper lip is deeply divided. Nepcte and Glechoma differ from the majority of the order, in having the posterior stanens longer than those of the anterior pair. Salvia, Sage, is a genus containing numerons species; the flowers are protandrons and are characterised by the suppression of two of the stamens usmally present (Fig. 695). The two fertile stamens have a very long connective, with the anterior theca, in which pollen is formed, protected beneath the upper lip. The posterior theea, the development of which differs in the species, projects into the entrance of the corolla tube leading to the nectary (cf. p, 502 Fig. 458) A bee visiting the flower presses the theca npwards, and thus brings down the other arm of the lever, formed by the elongated connective, upon its back. In older Howers the bifid stigma occupies such a position that it will rub off pollen brought by an insect from another flower. Many species of Salvio are cultivated as ornamental plants, and are often conspicnous, rather by reason of their brightly coloured bracts than by their flowers. Labiatae are especially abundant in the xerophytic formation of shrub. by plants in the Mediterranean region to which the name Maquis is given : Salvic ofjicinalis, Hamulizm, Phlomis, and species of Lavanclulu (Fig. 694). Rosinarinus officinalis is a showy slurub with small narrow leaves revolute at

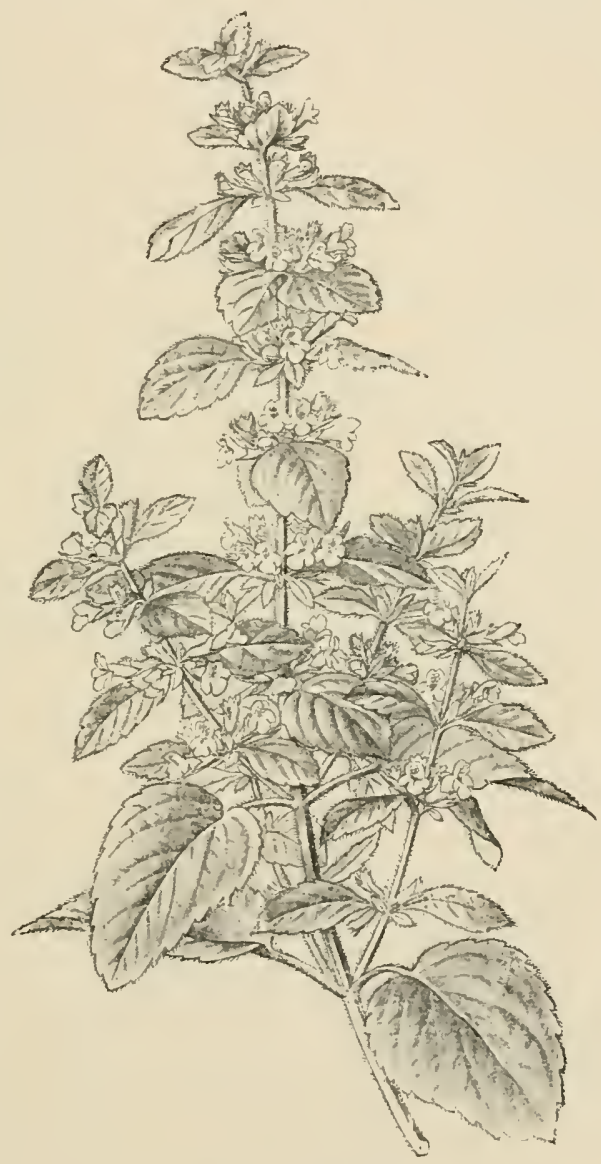

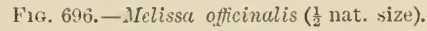
(After Bert and Schmidt.)

the margin, and bright blue flowers with only two fertile stamens. Many species are grown as kitchen herbs, e.g. Origanum majorana, Satureja hortensis, Ocimum basilicum, Salviu, and Thymus. Thymus vulyaris from the Mediterranean, like our native $T$. serpyllum, is a low, shrubby plant with polygamons flowers; there are larger, hermaphrodite, and small, purely female flowers. Some species of Menthe are similar. The widel $J$ cultivated $.1 \%$. piperite is a hybrid between II. viridis and $M$. aquatica; it is completely sterile, and has been propagated by 
runners from ancient times. $M$. crispa, another commonly cultivated form, is a crispate variety of $M$. vividis; $M$. longifolia, var. undulata, $M$. sylvestris, etc.

OfFICIAL. - Rosmariuus officinalis yields oleun Rosmarini. Lavandula vera (Mediterranean region), OLEUM LAVANDULAE. Mentha piperita, OLEUM MENTHAD PIPERTAE. M. viridis, OLEUM MExTHAE vilIDIs. M. arensis and M. piperite yield MeNrHoL. Thymus vulgaris and Monardu punctata yield thrmoL.

\section{Order 6. Personatae}

The Personatae are connected by the small family Nolanaceae to the Convolvulaceae, from which the Tubiflorae are also derived. The flowers are actinomorphic or zygomorphic. Their typical form has also the floral formula $\mathrm{K} 5, \mathrm{C}(5), \mathrm{A} 5, \mathrm{G}(2)$. There are, however, no false septa in the ovary, and the number of ovules is usually a larger one.

Family 1. Solanaceae.-Herbs or small woody plants, with alternate, exstipulate leaves and nearly always actinomorphic flowers. Corolla expanded or tubular; petals plaited

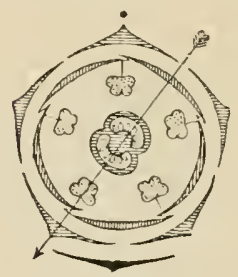

F'ic. 647-Solanaceae. Floral diagram (Petunia). in the bud. Ovary bilocular, septum inclined obliquely to the median plane. Ovules numerous, on a thick placenta (Fig. 697). Fruit, a capsule or a berry. Seeds with endosperm; embryo usually curved.

Family generally distributed, especially in tropical America. In many Solanaceae, as will be further referred to in the special descriptions below, the inflorescences exhibit apparent extra-axillary branches and paired leaves. Anatomically the order is characterised by possessing bicollateral vascular bundles.

Important Genera and Siecies. - (a) Fruit, a berry: The Deadly Nightshade (Atrope Bellatonna, Fig. 698) is a perennial herb of shrubby labit, springing from an nnderground rhizome. It is a native of Enrope and western Asia, occurring in less dense woods. The shoots are, to begin with, orthotropons and radial, and bear alternate leaves and a terminal flower, which only rarely produces fruit. Below this terminal flower branching and the development of leares commences in, as a rule, three equally vigorous, lateral shoots. Each lateral branch, with its further cincinnal branching, forks and assumes a dorsiventral habit. By the predominance of one of the two axillary shoots and the carrying up of the subtending bract upon it, the teminal flower at each grale of branching becomes aprarently axillary. The large, subtending bract is borne up beside the smaller one belonging to the next higher axillary bud, which is usually undeveloped, so that the leaves appear to be borne in pairs. Flower with a sliort, wide, tubular corolla of a dirty purple colour. Calyx enlarging after fertilisation beneath the bluish-black fruit; the position of the obliquely placed septum of the latter is recognisable externally by the presence of a shallow groove.

Many splecies of Solenum occur as weeds. Flowers actinomorphic. S. niyrum, Nightshade ; S. dulcamard, Bitter-sweet (Fig. 699), is a shrubby plant, climbing by means of its stems and petioles, and especially common in thickets by the banks of streams and similar situations. S. tubrosum, the potato. Lycopcrsicum, the 
Tomato. Caysicum annum, Spanish Pepper, has a dry, berry-like fruit. These plants resemble Atrope in their branching and the position of their leares.

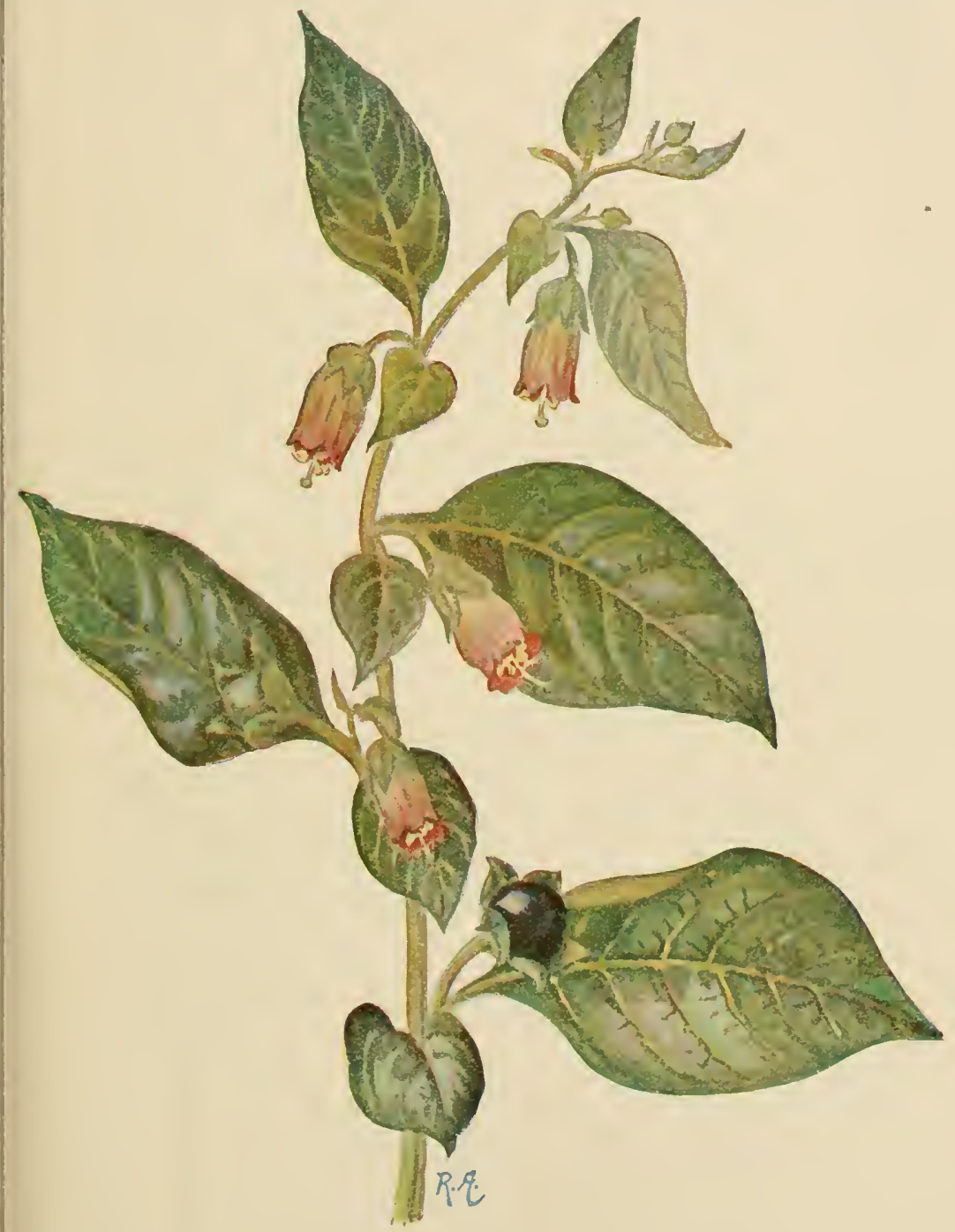

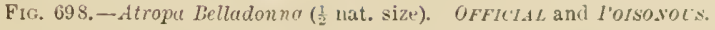

(b) Fruit a capsule : Datura Strumonium, Thorn-apple (Fig. 702), is an amnual plant, widely spread in Europe, Asia, and N. America. It has incised, palmately veined leaves and large, white, terminal flowers. The spiny fruits split at the 
summit into four valves. The first terminal flower is developed early, and the plant then exhibits profuse dichasial branching. Since the subtending leaves are adherent to the axillary shoots, which as a rule develop equally, the branching appears to be extra-axillary, a terminal flower or fruit being situated in the fork. Nicotiana tabacum (Figs. 700,701 ) is a South American plant with mumerous cultivated varieties, which are grown both in Europe and the tropics. Its large alternate leaves, which bear numerous glandular hairs, form, after being dried and prepared, товассо. N. rustica, Tree-tobacco. Flowers elongated and tubular, borne

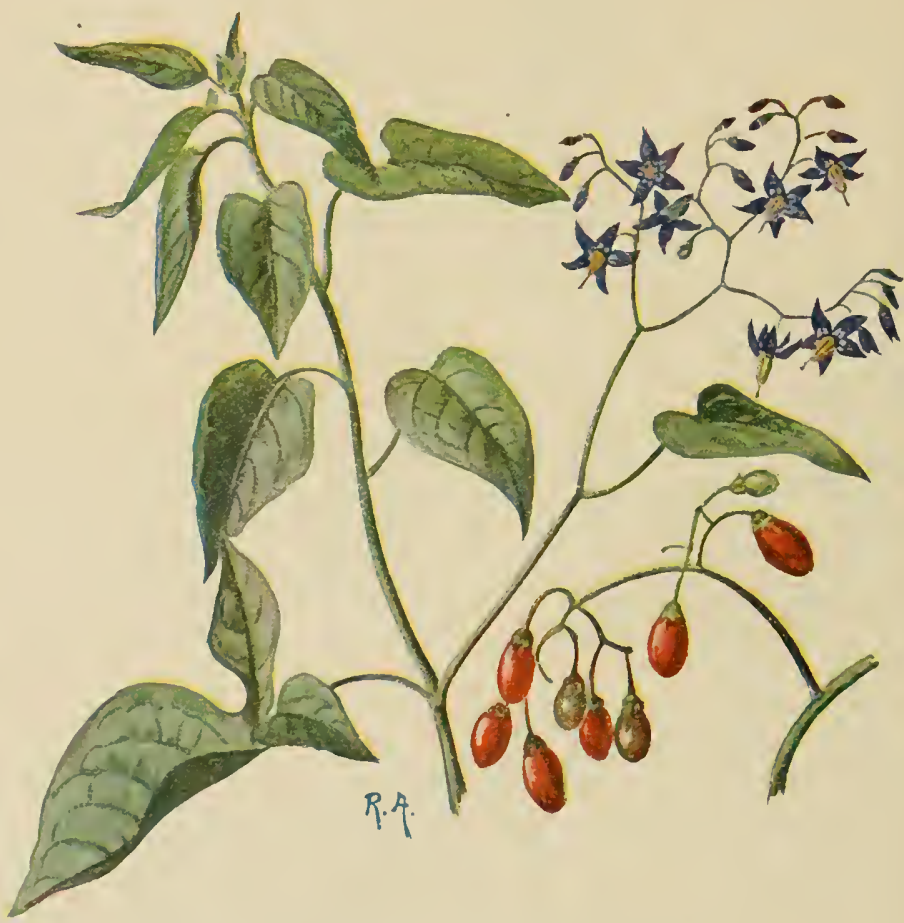

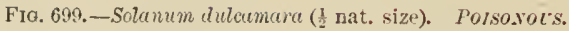

in terminal panicles. Hyoscyamus niycr, the Henbane (Fig. 703), is an annual plant occurring in Central Europe, North Africa, and Western Asia. The radical leaves have long stalks, those of the flowering stem are sessile; they are all clothed with glandular hairs. Flowers slightly zygomorlhic, of dull yellowish-violet colour with darker markings; inflorescence, a cincinms. Fruit a pyxidim. Pctunice ank Salpiglossis are farourite garden plants with obliquely zygomorphic flowers.

All Solanaceac are more or less poisonous partly on account of the presence of consirlerable amounts of alkaloids or poisonous glncosides. Sprecies of Solcmum, Alrope, Dutura, Hyoscyumus, and Vicutiance are among the most poisonous plants met with in this country.

OfFICLAL-C'upsicum minimum yields Carsicr fructus, Atrope belladonna 
yields belladoxiae folia, Belladornae iadix and atropina. Duturt, Stramonizm, straHoNiI sEMINA and stramoxil Folia. Hyoseyginus niger, HYOSCYAMI FOLIA.

Family 2. Scrophulariaceae.-Herbs, with opposite or alternate, exstipulate leaves. Flowers zygomorphic. Corolla not plaited in

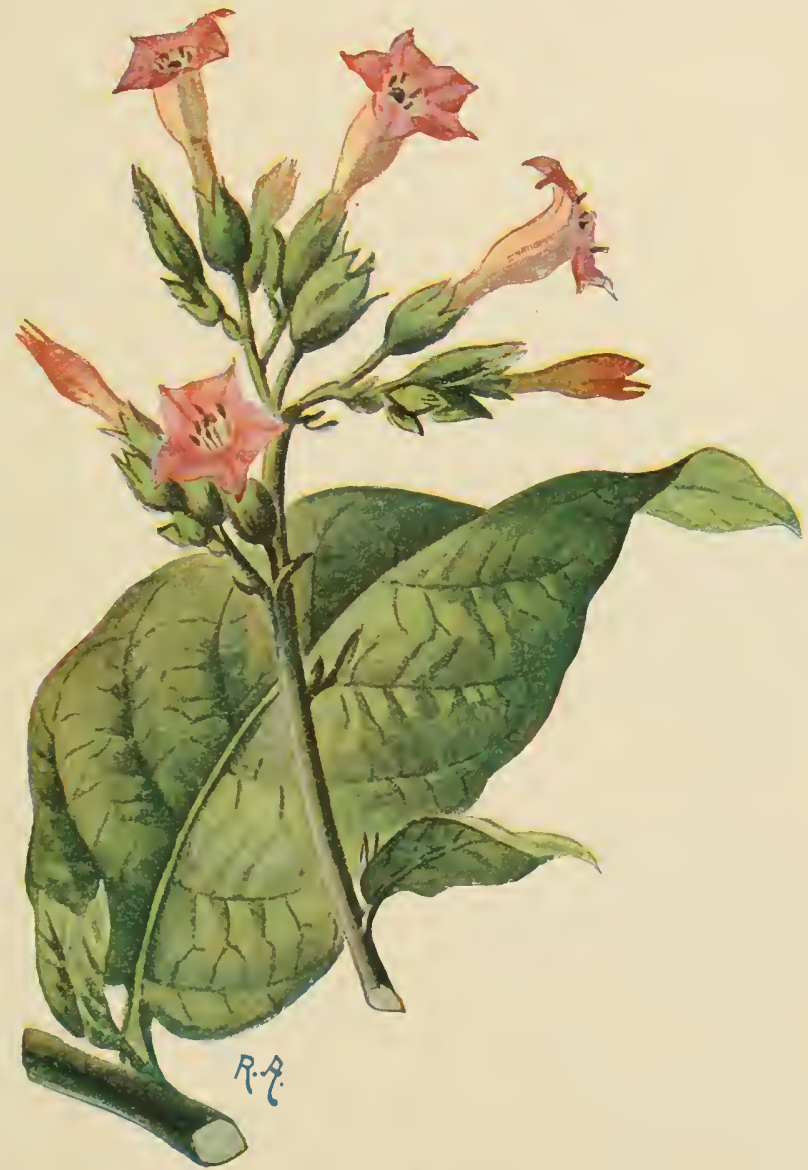

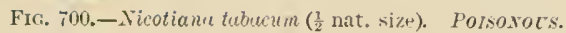

the bud. Number of stamens nearly always incomplete. Carpels median (Fig. 704). Fruit, a bilocular capsule.

Generally distributed; esprecially in the temperate zones.

Importaxt SUb-Families axd Genera.-(a) Antirhinece, not parasitic. Verbascum (Fig. 705), the MInllein; biennial herbs, which in the first season form a large rosette of leaves from which the erect iuflorescence arises in the second 
year. The inflorescence sometimes bears sessile dichasia of $2-3$ flowers in a terminal spike; in other cases by the development of branches from the lower leafaxils it bccomes a branched panicle. The single flowers have five stamens, and are only slightly zygomorphic; the three posterior stamens have hairy filaments, and are further distinguished from the two anterior stamens by the transverse josition of their anthers. Scrophlularia has a two-lipped corolla with a rery short lower lip, four stamens and one staminode. Digitalis, Foxglove (Figs. 706, 707), has an obliquely campanulate corolla and four stamens. The flowers hang from one side of the obliquely ascending raceme. The corolla in Linaria and Antirrhinum
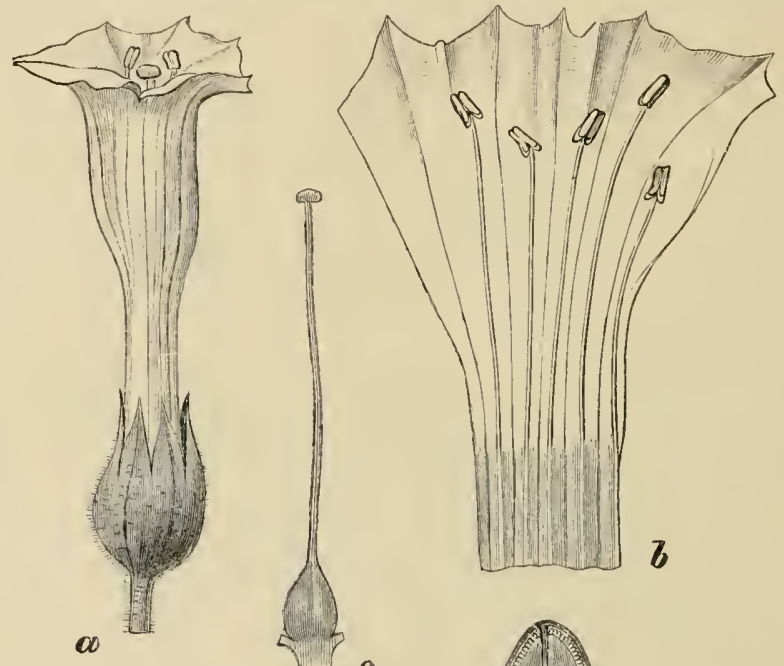

O
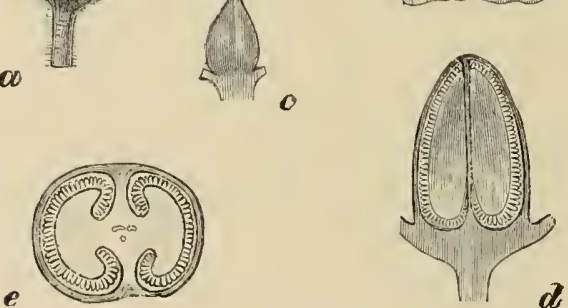

Fug. T01.-Wicotianu trbacum. a, Flower; $b$, corolla, cut open and spread out flat ; $r$ ovary it and $e$, youmg fruit. ( $(t, b, c$, nat. size; $e, i, \times 2$.

is spurred. Gratiole with two fertile stamens and two staminodes. Feronica with only two fertile stamens.

(b) Rhinontheae.-This group ineludes a number of closely related genera which have adopter a more or less completely parasitic mode of life. The nost comJiletely prarasitic form is Lathraed, the species of which have no trace of chlorophyll ; L. squamaria, the Toothwort, is parasitic on the roots of the Hazel. Many (e.y. Tusia, Bartsia, Euphrasia, Odontites, Pedicularis, Melammyrum, Alectorolophus) are semiparasitic. Althongh they possess green leaves they attach themselves by means of luanstoria to the roots of other plants, from which they obtain nutrient materials. Further details regarding the uode of life and development of these forms and the seasonal dimorphism they exhibit, will be found in the literature eited $\left({ }^{71}\right)$. 
in the Scrophulariaceae, but with a milocnlar orary. Several British species of Orobanche, parasitic on various host plants (Fig. T0S).

Family 4. Bignoniaceae.-Tropical woody plants, in many cases climbers. Stamens 4, corolla two-lipped. Seeds winged. Catalpa bignonioidcs, Tccoma radicurs, ornanental plants from $\mathrm{N}$. America.

Family 5. Gesneriaceae.-Tropical herbs and shrubs with a unilocular ovary which is sometimes superior, in other cases inferior, and 4 or 2 stamens. Frequently cultivated on account of the beantiful colons of their flowers, c.\%. Gloxinia, Aeschynaibthus, Achimcnes. Fiamondia pyrenaica is one of the few European representatives. Streptocarpus $\left.{ }^{\left({ }^{2}\right.}\right)$ polyanthus only derelops one of its cotyledons, which persists and attains a large size; the inflorescences arise at the base of the cotyledon.

Family 6. Lentibulariaceae.-Marsh. or water-plants with a spured corolla and only two (anterior) stamens. They capture and digest insects. Utricularia $\left({ }^{73}\right)$, aquatic plants provided with bladder-like traps; in the tropics also terrestrial and epiphytic forms (cf. Fig. 47, p. 41). Pinguicula with a rosette of radical leaves, the margins of which are inrolled (p. 22s).

Family 7 . Acanthaceae.-Herbs with decussately arranged leares and quad. rangular stems. The fruits are bilocular capsules and spring open when mature. Numerous species occur as undergrowth in tropical forests. Species of Acarthus occur in the Ilediterranean region. Their large, pinnately-lobed leares, the lobes terminating in spines. figure in Grecian art on the capitals of pillars, etc.

Family 8. Plantaginaceae.--Herbs witl a basal rosette of leaves and longstalked spikes of crowded flowers. Flowers tetramerous, actinomorphic. Corolla membranous. Orary bilocular. Style long and papillate. Family generally distributed.

Gesert. - The native species of Plantago, the Plantain, are markedly protogynous (cf. Fig. 455, 1) 500); the joung heads or spikes sliow the pale-coloured stigmas projecting before the corolla has opened (Fig. 709). Transitional forms from anemophily to eutomoplily are found. Litorclla lacustris is an aquatic plant with a spike of three flowers; two female flowers are situated at the base, while the male flower has a long stalk.

\section{Order 7. Rubiinae}

Plants of diverse habit with opposite leaves. In contrast to the preceding order the flowers have a sympetalous corolla associated with an inferior ovary. Flowers tetramerous or pentamerous. Orary bi- or tri-locular. Stamens epipetalous. Calyx very inconspicnous.

Family 1. Rubiaceae.-Herbs, shrubs, or trees, with simple, decussate leaves and stipules. Flowers actinomorphic. Orary bilocular.

Chiefly tropical; only some tribes are represented ontside the tropics.

Sub-Famlies Axp Importaxt Gexera.-(a) Cinchoncae, woody plants with scaly stipules and numcrous seeds in each carity of the ovary. Cinchone is a genus from the S. American Andes, now cultivated in the mountains of nearly all tropical colonies (Figs. 710, 711). Stipules decidnous. Flowers in terminal panicles; corolla tubular, with an expanded terminal portion fringer at the margin. Fruit, a septicidal capsule, the ralres of which, after dehiscence has 


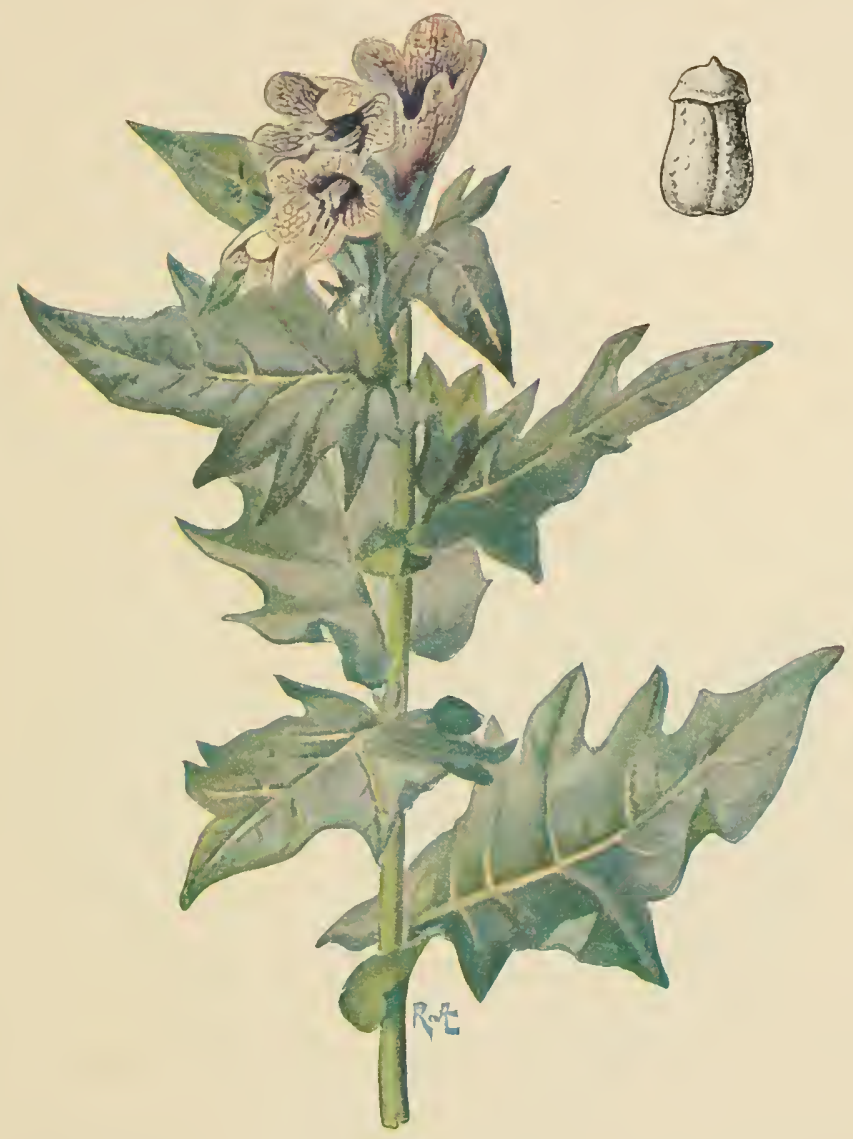

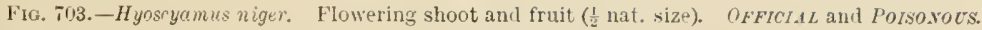
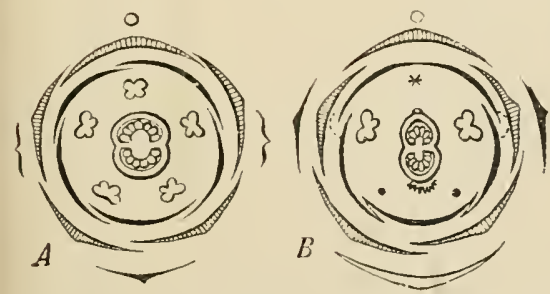

F1G. 704.-Scrophulariaceae. Floral diagrants. A, I'erbascum; B, Grativla. (After Eichler.)
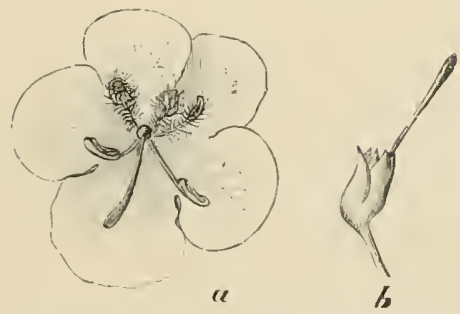

FIG. 705.-Terbascum thansifome. a, Flower; $h$, ealy'x anil st yle (nat, size). 
taken place, are still held together above by the small calyx. Seeds with a broad, membranous wing. Ourouparia $\left(^{-4}\right)$ is a genus of climbing plants found in the Malayan Archipelago; the hook-like organs specialised for climbing are the stalks of reduced inflorescences, which are sensitive to contact. The flowers are associated together in spherical inflorescences resembling those of the commonly grown ornamental shrub Cephalanthus.

(b) Coffeac. - Stipules scaly. Each loculus of the ovary with a single seed. Coffec, the Coffee plant, is a shrub; C. arabica (Fig. 712) and C. lilerica are important economic plants, originally derived from Africa, and now enltivated throughout the tropics. The pentamerous, snow-white flowers, which have a similar scent to that of Orange blossom, and the bright red fruits contrast with

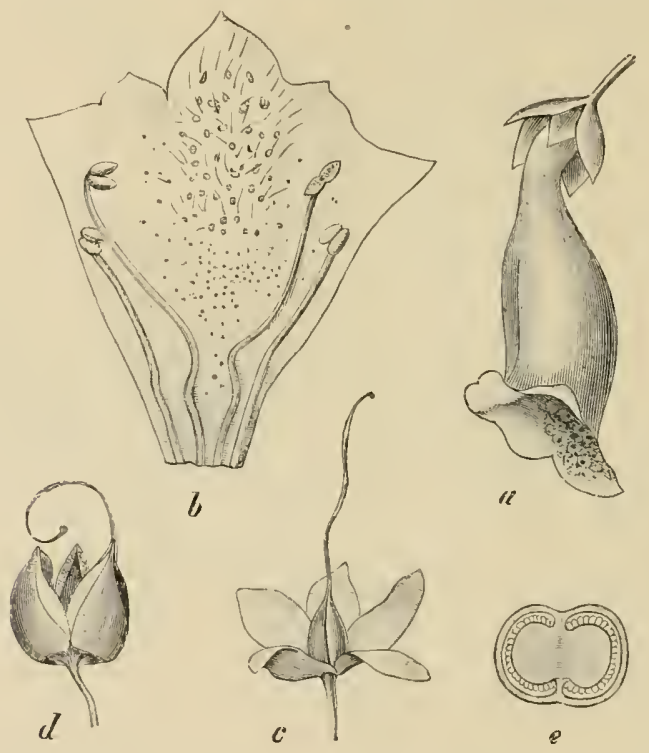

Fur. Tyd.-Divitalis purmuer. u, Flower; $b$, corolla cut open and spread ont: $c$, calyx and pistil; $d$, fruit after dehiscence ; $e$, transverse section of fruit (nat. size). OFFICIA L.

the shining, dark-green foliage, and make a coffee plantation attractive both in appearance and in scent. The pericarl, becomes differentiated into a succulent exocarp and a stony endocarp. The minute embryo is embedded in the horny endosperm with which the secd is fillod; the seed-coat is very thin. The remarkable tuberous plants of the Malayan Arehipelago, Myrmecoctia $\left({ }^{75}\right)$ and Hyclnophytum, also belong to this group; the former has spiny roots. Lragoge Ipceacuanha, a small herbaceous plant or nulershrub, is a native of Brazil, especially of the jrovince of Matogrosso. The stipules have an incised margin, and the inflorescence is a terminal head of flower's surrounded by a number of bracts (Fig. 713). The fruits are small berries. The plant is eultivated in suitable localities in valleys on the south side of the Himalayas.

(c) Stellutae.-This is the only subdivision of the family which is represented in Europe; Galium, Rubia, Asperuln (Woodruft). These genera are characterised 
by the resemblance of the stipules to the leaves (Fig. 714); usually a whorl of

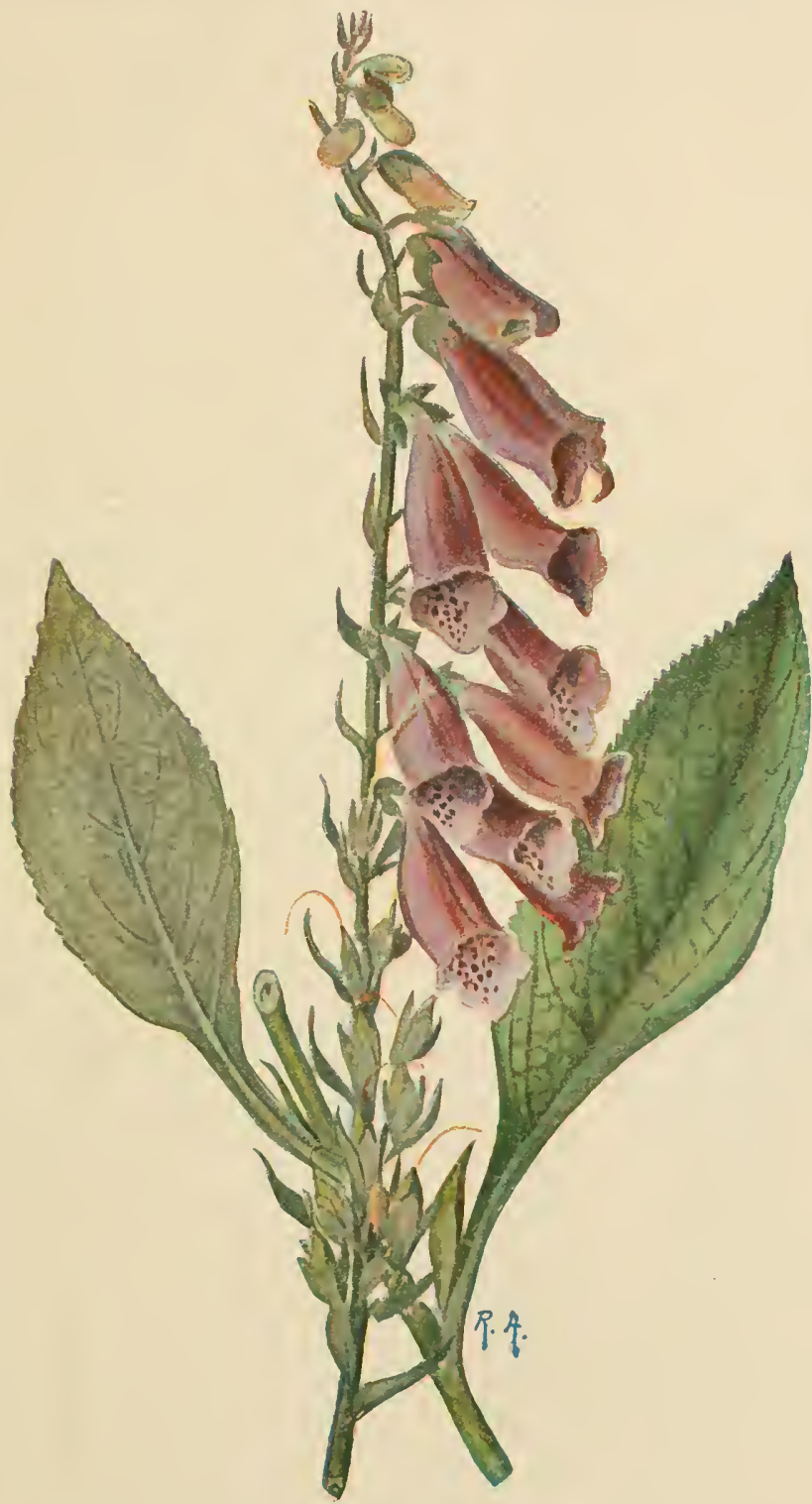

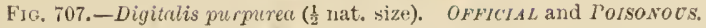

six members is borne at each node, but sometimes the number is increased, and in 
liubiu and some species of Gatium it is rednced to four by the mion of the stipules in pairs. The leaves are easily distinguished from the stipules by the presence of buds in their axils. Flowers usually tetramerous; a single seed in each loculus of the ovary. Fruit a schizocarp splitting into nut-like, partial fruits. Fruits often provided with hooks.

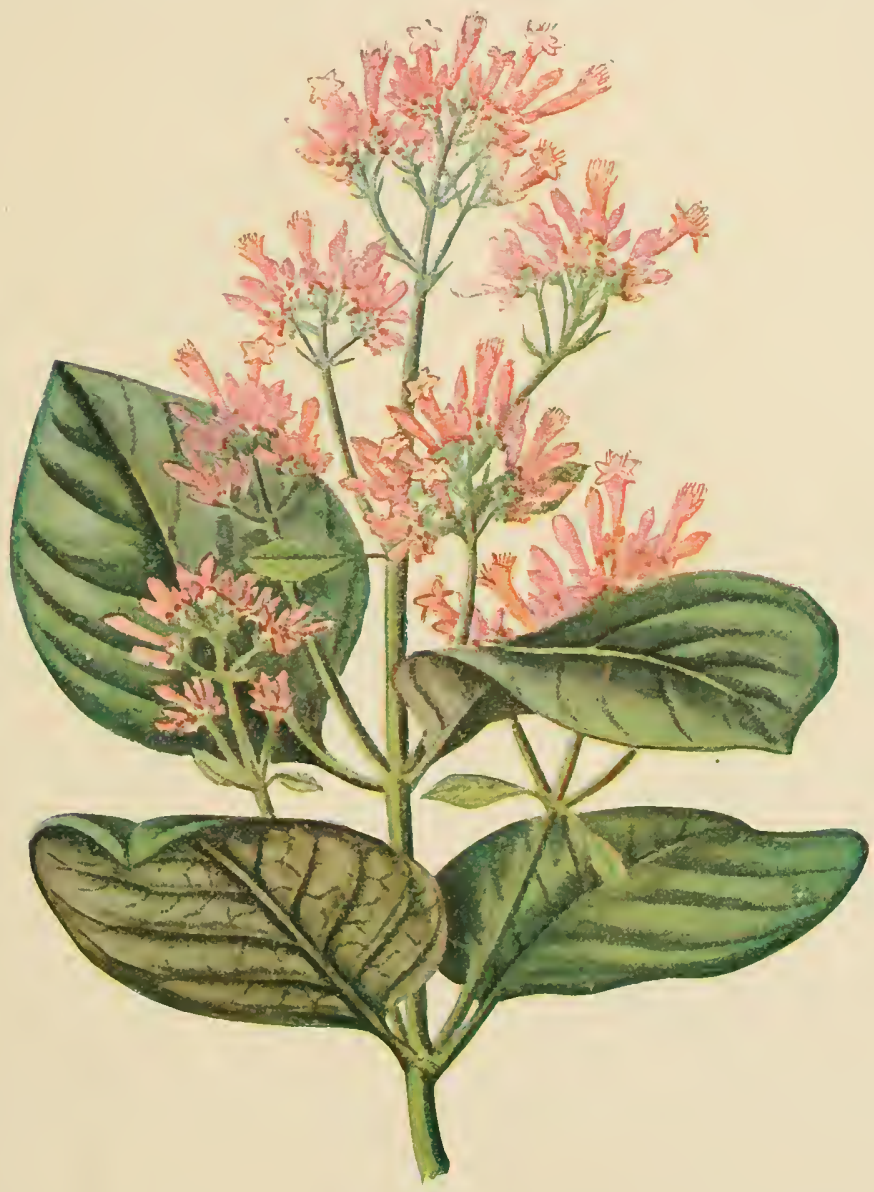

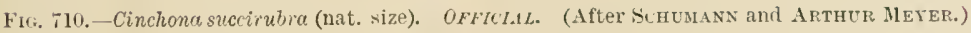

OfFicial. - Cinchona suceirubre yields cinchosate Rubrae cortex. Quinine is obtained from this and other species of Cinchone. Uragoga (Psychotria) Ipecacuanhe yields IPECACUAXHA. CATECHU is obtained from Ouroupreria (Unearia) gamlbir.

Family 2. Caprifoliaceae. - Woody plants, usually without stipules. 
Flowers sometimes zygomorphic. Ovary usually trilocular. Fruit a berry or diupe.

Mainly inhabitants of the temperate zone.

Srb-Fanilies And Inportant Gexera.-( $(e)$ Sambuccae, witl actinomorphic flowers and drupes. Viburnum, leaves simple, fruit one-seeded. Sambucus, Elder, with imparipinnate leaves, glandular stipules, and three stones in each fruit. S. nimra (Fig. 715) is a common European shruh. The flat-toplerl inflorescences

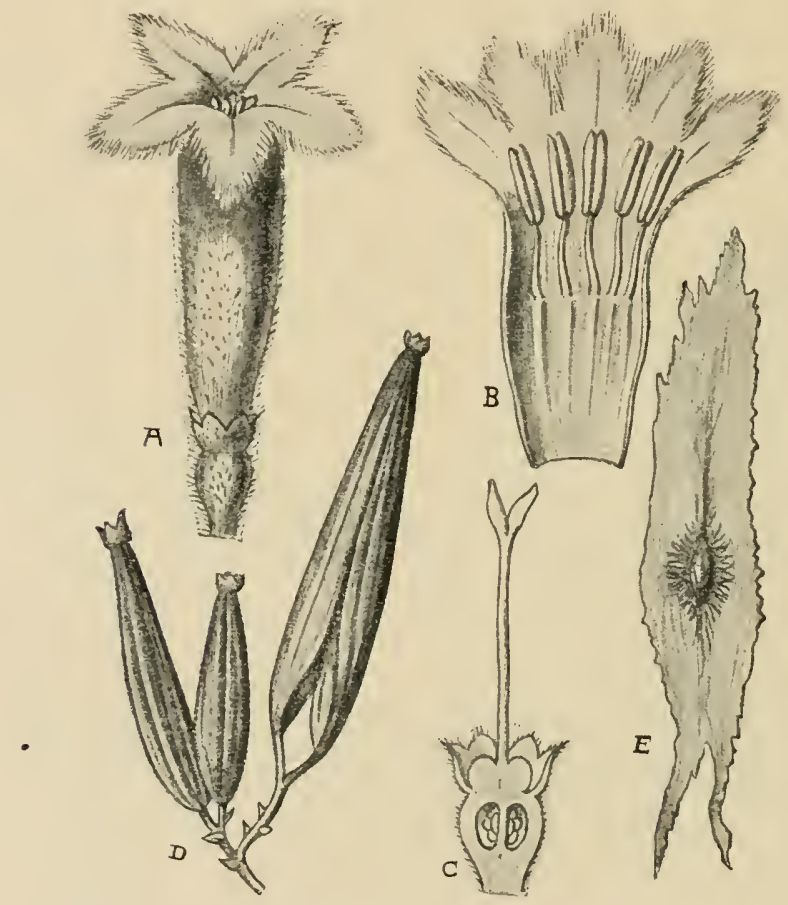

Fis. 711.-Cinchonu succirubra. .1, Flower. B, Corolla split open. C, Ovary in longitudina section. $-D$, Fruit. E, seed. (D, nat. size, the others enlarged.) (After A. MEYER and SCHCMANN.) OFFICIAL.

are panicles consisting of decussately arranged main branches which nltimately bear the flowers in small cymes.

(b) Lonicereac, flowers zygomor]lice, fruit a berry. The Honeysuckle (Loniccre periclymenum) is one of our native lianes. Dicreilla (IVcigclia) is a favourite flowering shrub.

OFFICIAL.-Sambueus nigra yields sAMELCI FLORES.

Family 3. Valerianaceae.-Herbs or small shrubs, with decussately arranged leaves and asymmetrical flowers. Calyx only developed 
with the fruit as a pappus. Corolla pentamerous, spurred. Stamens 4 , 3, or 1 . Carpels 3, but only one loculus of the ovary is fertile, and contains a single, pendulous ovule (Figs. 716, 717).

Family mainly distributed in the Mediterranean region and in South America. Gexeri. - Taleriand, Vilerian. $I$. officinat is is a lerbaceous plant widely

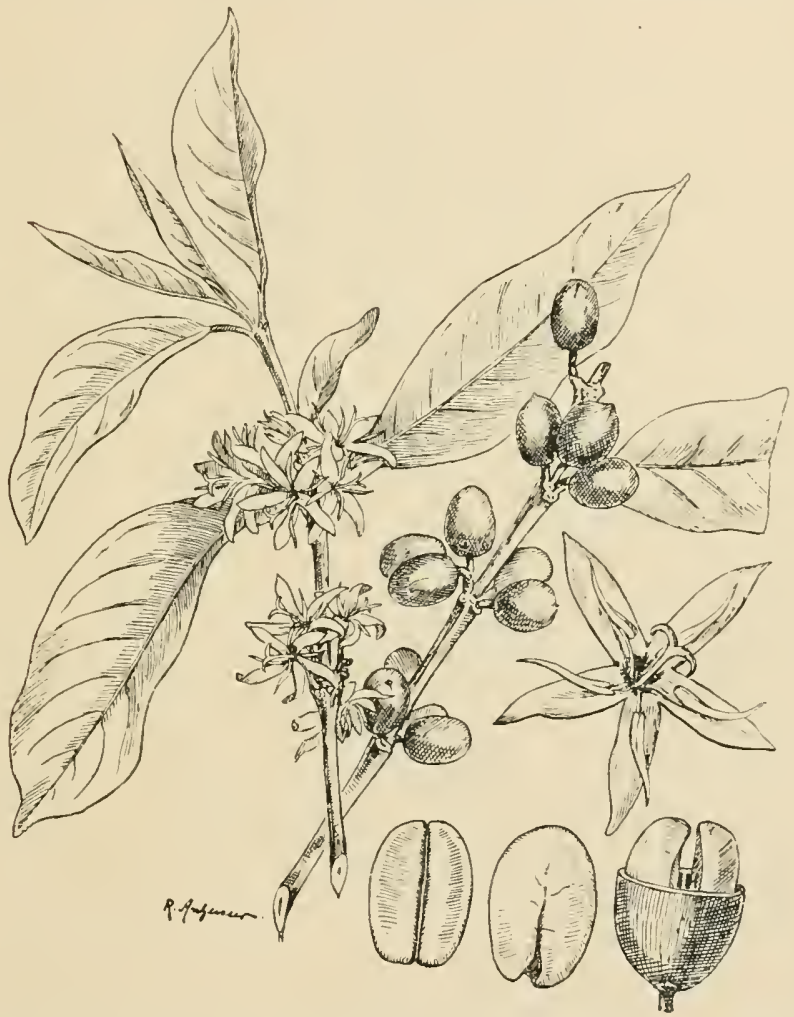

Fis. 712.-Cofiea arabica (1 nat. size). single flower, fruit, seed enclosed in endocarp, and freed from it (about nat. size).

distributed throughout Europe. It has a short, thick, chambered rhizome, which often sends out subterranean ofl'sets. Leaves imprapimnate. Inflorescence a panicle. Spur short. The hairy calyx developed on the single-seeded fruit assists in its dispersal by the wiml. Iraleriumella, small, inconspicnous plants. $I$. olitoria, Lamb's Lettuce. Centranthus ruber from the Mediterranean region las a long spur to the flower; it is commonly cultivated in gardens.

OFFICIAL. - Íaleriane officinalis yields VALERIANAE RHIZOMA. 


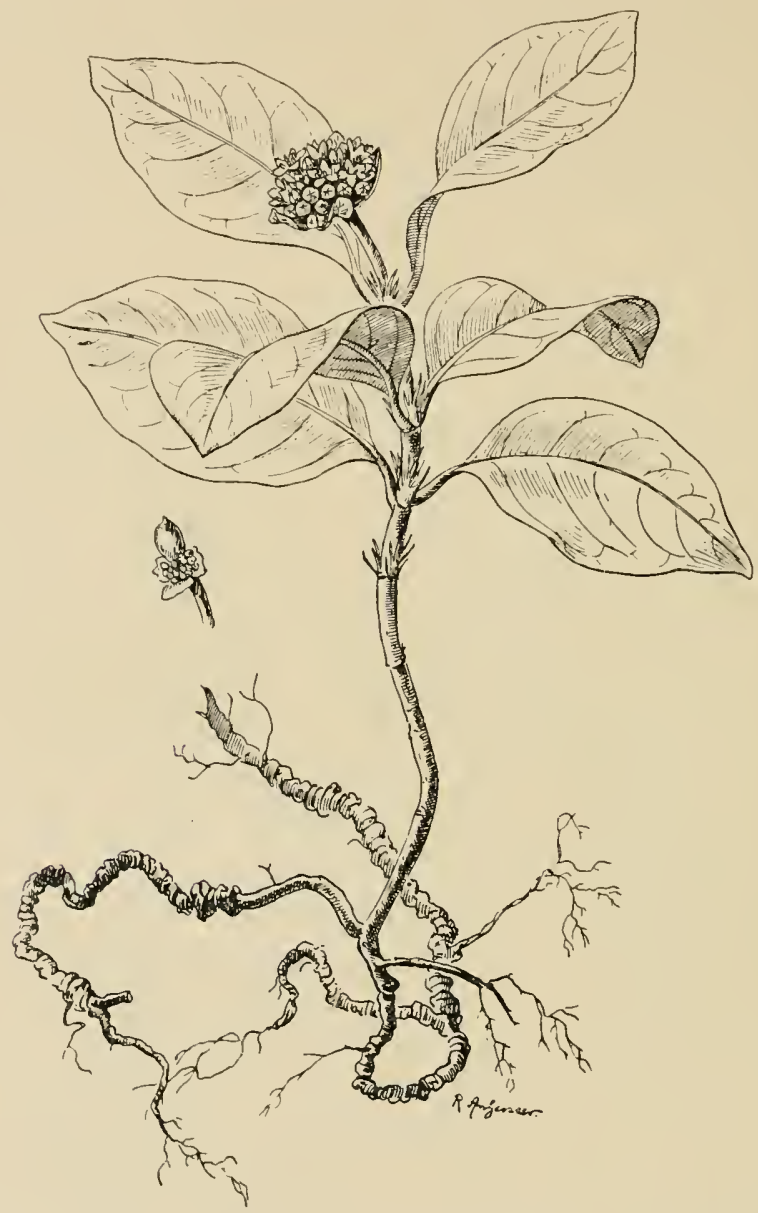

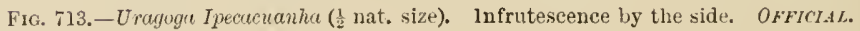

\section{Order 8. Campanulinae}

Herbs, with simple, entire, alternate, exstipulate leaves. Floral formula usually $\mathrm{K} 5, \mathrm{C}(5), \mathrm{A} 5, \mathrm{G}(\overline{2-3})$; in other cases there are 5 carpels. A well-cleveloped calyx, and stamens inserted on the floral axis with their antleers coherent are characteristic of the order.

Family 1. Campanulaceae.-Herbs with milky juice; flowers actinomorphic; ovary as a rule trilocular. Fruit a capsule (Figs. 718, 719). Representatives of the family occur in all regions. 
British GeNerA $\left({ }^{76}\right)$.-Campanula, numerous species with showy flowers.

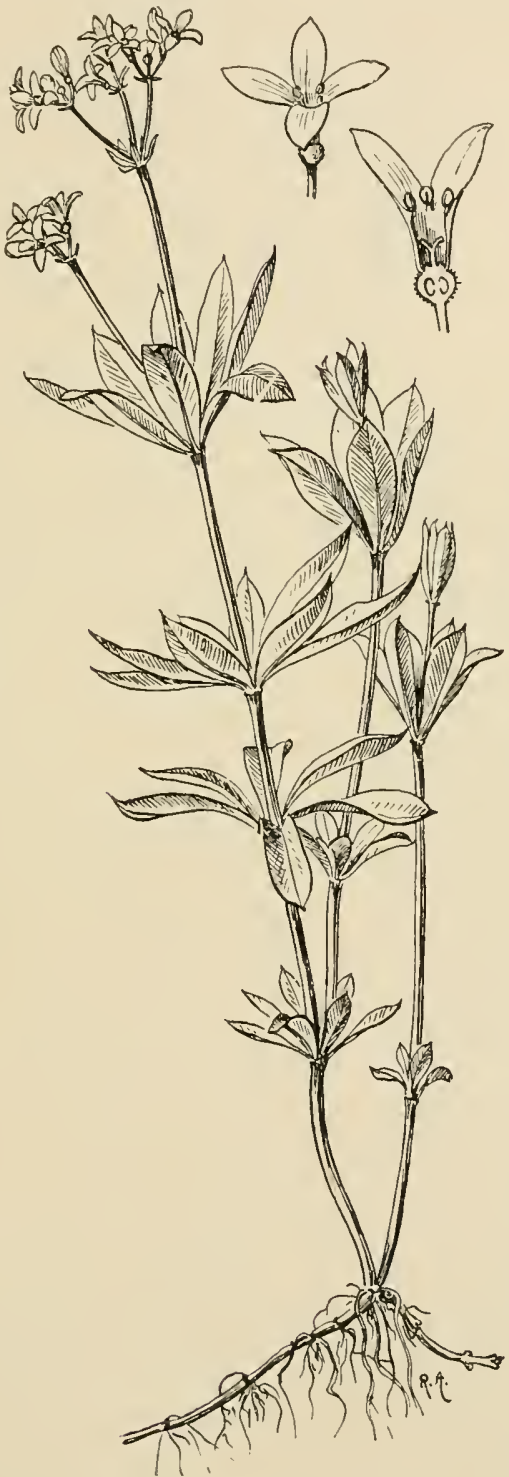

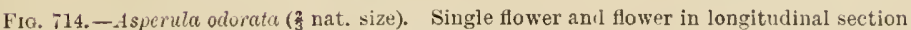
(enlargert).

Phyteuma, with spike-like inflorescences. The petals separate at the base, remaining 


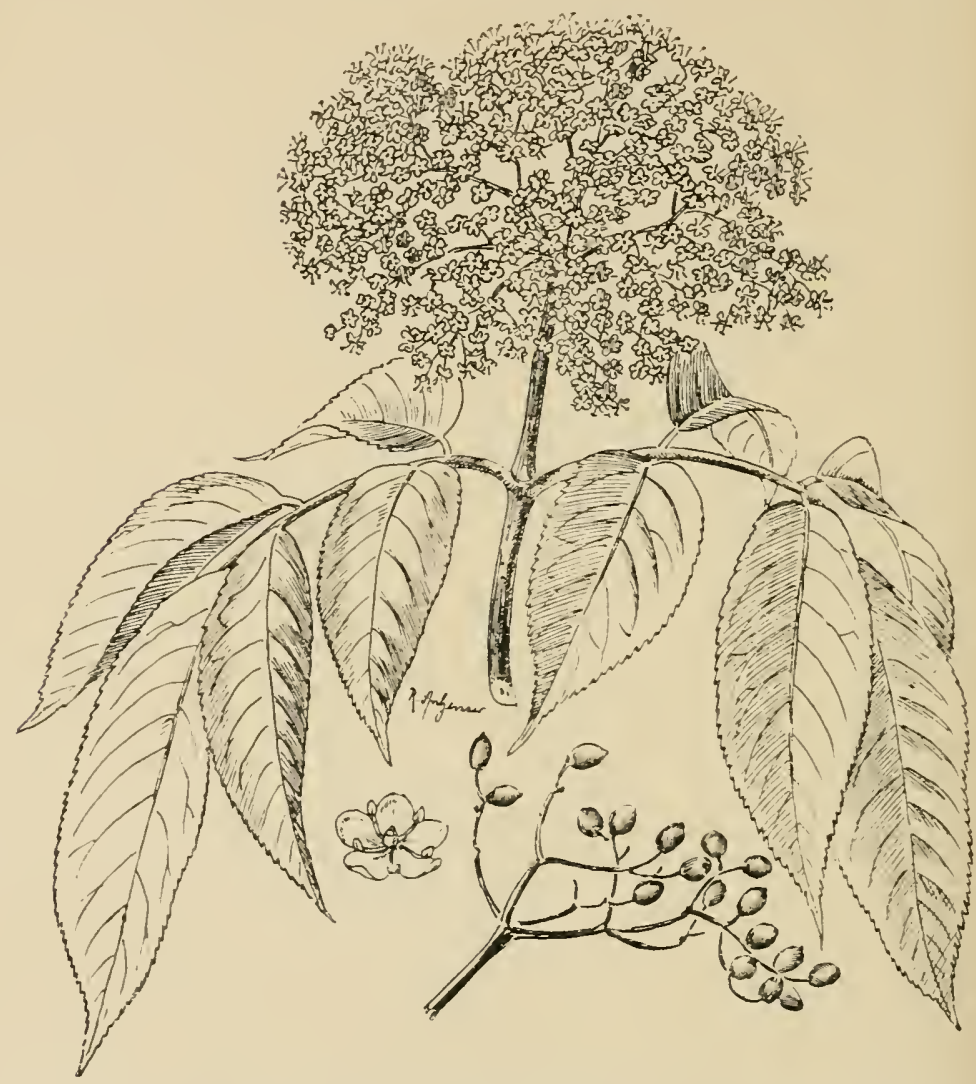

Fis. 715.-Sambucus nigra. Flowering shoot and infrutescence ( $\frac{1}{2}$ nat. size). Single flower (enlarsed). OFFICIAL.

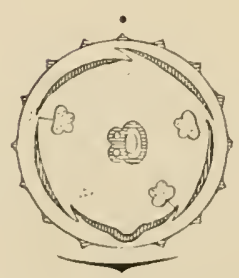

Fug, 716,-Faleriuna. Floral diagram.
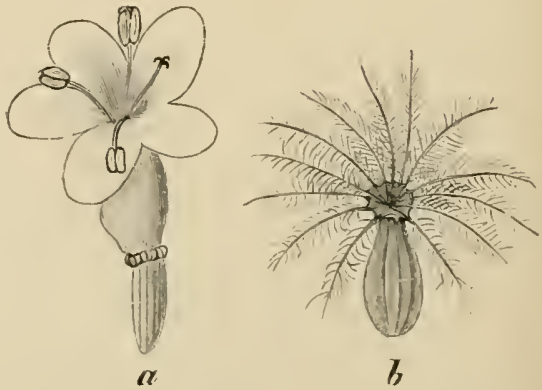

FIg. 717.-Fuleriana officinalis. $a$, Flower $(\times s) ; b$, fruit $(\times 4)$. OFFICIAL. 
united at the tip until the pollen, which is shed in the bud, is swept out by the hairs on the style; after this the lobes of the stigma, which until now have been

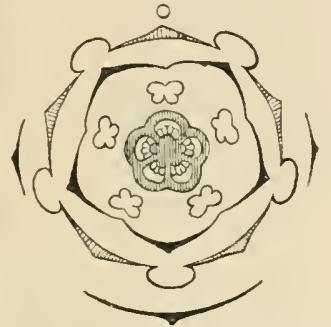

FIG. 718.-Floral diagramof Campanules medium. (After Eichler.)
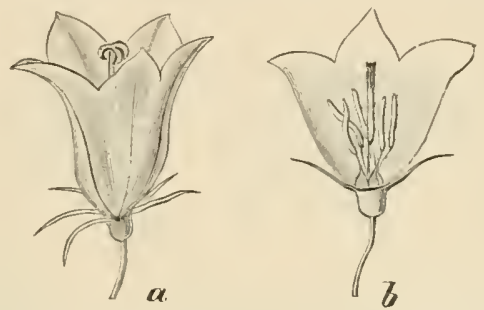

FLG. 719.-Campanula rotundifolia. $a$, Flower ; $b$, the same cut through longitudinally. (Nat. size.)

closed, expand. Jasione resembles the Compositae in having its flowers in heads and its anthers united to form a tube.

Family 2. Lobeliaceae. - Herbs witl milky juice, closely related to the Campanulaceae. Flowers zygomorphic ; carpels 2. The median sepal is anterior and comes below a deep incision in the corolla. The normal position is assumed by torsion of the whole flower through $180^{\circ}$ or inversion of the flower; these methods also occur in the Orchidaceae (Fig. 720). In Britain Lobelio. Dortmanna, an aquatic plant of northern regions which reaches its southern limit in the north of Germany. The family is chiefly distributed in the tropics and in the southern temperate zone.

OfFicial. - Lobelia inflate from N. America (Fig. 721) yields LOBEIIA.

Family 3. Cucurbitaceae (iٓ).-Herbs, withont milky juice, climbing by means

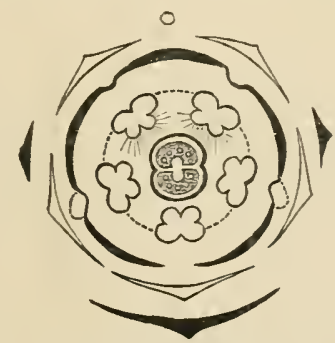

FIG. 720.-Floral diagram of Lobelia fulgens. (After Etchler.)

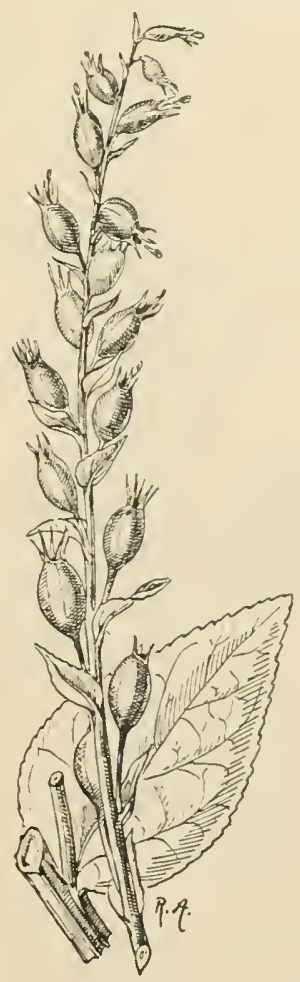

FIc. 721.-Lobelia infata ( $\frac{2}{3}$ nat. size). OEFICLAL.

of tendrils; the cordate or palmately lobed leaves bear coarse hairs 
Flowers diclinous; monoecious or less commonly dioecious. Calyx and corolla adherent belor. Anthers united in pairs or all colerent. $\boldsymbol{c}$-shaped. Ovary

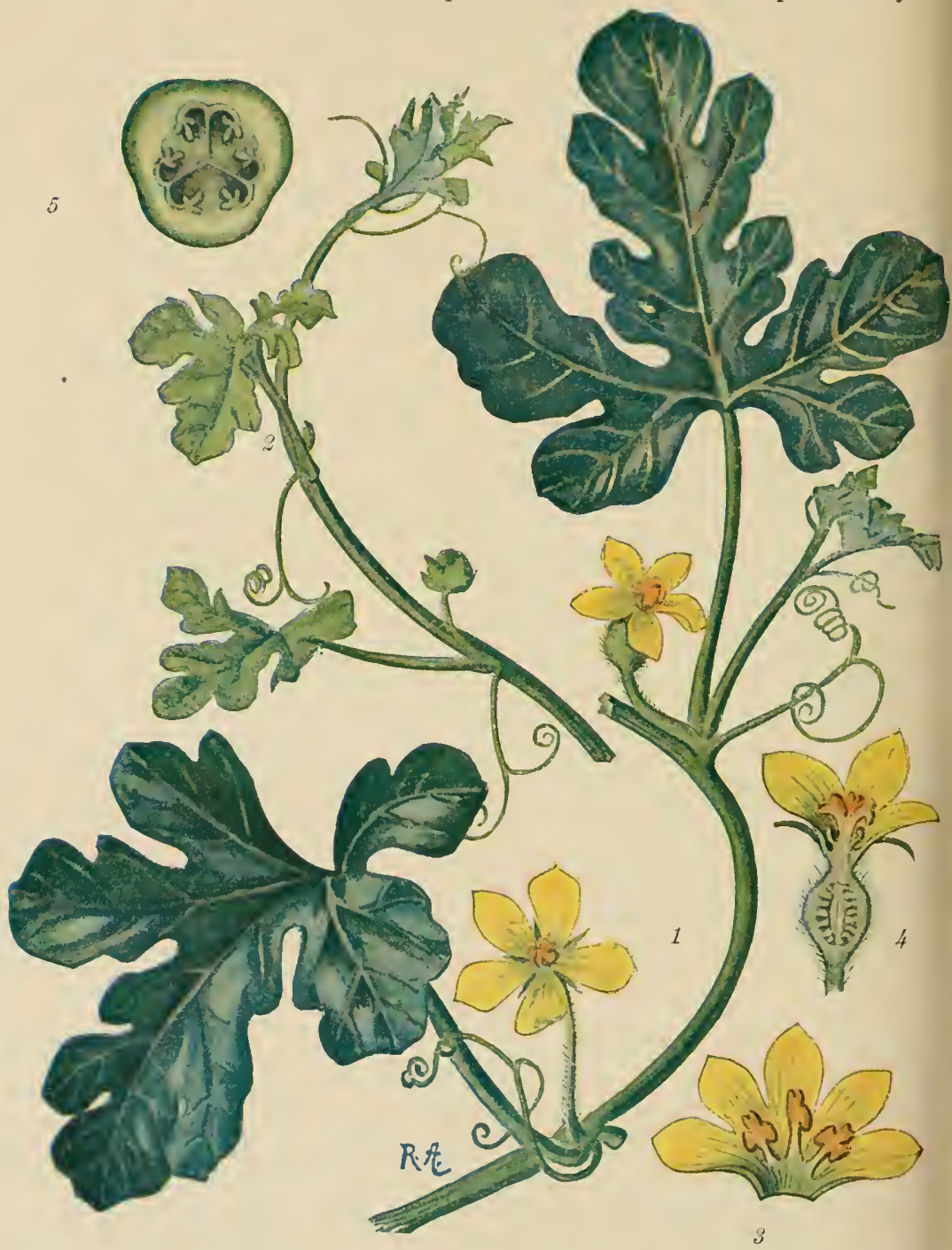

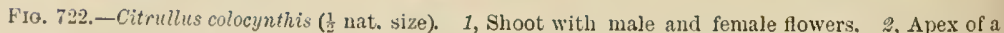
shoot with a male flower-bud and tendrils. 3, Male flower with corolla spread out. 4, Female Hower cut through longitudinally. j, Young fruit cut transwersely. OFFICIAL.

trilocular (Fig. 723). Fruit, a berry, with a firm rind and six large, succulent, parietal placentas. The family is confined to tropical and warm temperate regions. 
Impontaxt Genera.--Cucumis sativus, the Cucumber, and C. Helo, the M[olon, are commonly eultivated. Tendrils unbrancherl; the tendril corresponds to a bract and arises nearer to the apex of the shoot than the leaf nearly opposite to which it stands. The female flowers are solitary, the male are grouped in small inflorescences in the axils of the leaves. Fertilisation is not a neecssary preliminary to the development of the fruit of the Cucumber; it is said to be parthenocarpous. Cucurbite pepo, the Pumpkin, has branched tendrils, which represent axillary shoots of the simple tendrils. Each branch of the tendril corresponds to a leaf of the shoot, and may sometimes subtend an axillary bud. Both male and female flowers are solitary in the leaf-axils. Bryonia, the Bryony, is British (Fig. 724); it is poisonous and has thick, swollen, fleshy roots, long unbranched tendrils, and axillary inflorescences ( $\left.{ }^{78}\right)$. Citrullus Colocynthis is a perennial plant inhabiting the Asiatic and African deserts north of the equator. Leaves deeply three-lobed and pinnately divided. Tendrils simple or forked; male and female flowers solitary in the axils of the leaves. The fruit is a dry berry (Fig. 722).
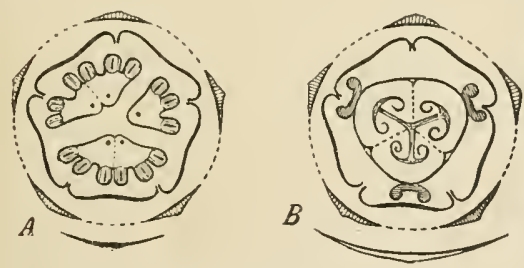

F19. 723.-Ecballium (Cucurbitaceae). Diagrams of $(A)$ a male and of $(B)$ a female flower. (After EICHLER.)

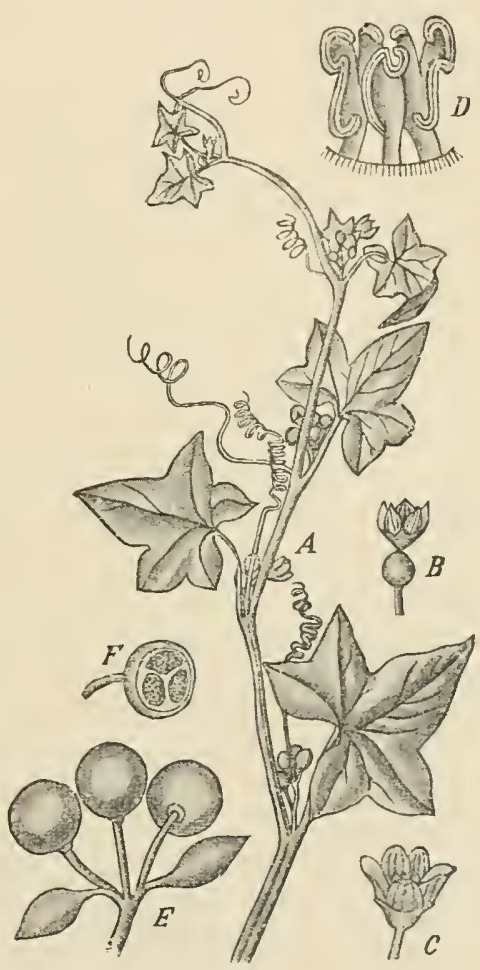

Fı. 724. - Bryonia dioica. A, Flowering branch (reduced); $B$, female, $C$, male flower (nat. size) $D$, androecium (magnifierl); $E$, fruits; $F$, fruit in section. PoISOSOCS.

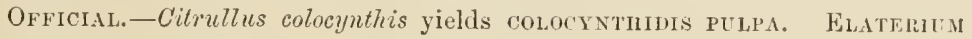
from Ecbullium eluterium.

\section{Order 9. Aggregatae}

For the most part herbs with the flowers in heads, surrounded by a common involucre. In relation to this the calyx of the individual flowers is reduced. Stamens epipetalous. Ovary inferior, unilocular with a single ovule. Fruit indehiscent.

Family 1. Dipsacaceae.-Herbs with opposite leaves. Flower with an epicalyx which persists on the fruit. Tetramerous or pentamerons. Stamens 4, anthers 
free. Orule pendulous, anatropous. Seed with endosperm. The fanily is wanting in the tropies and especially represented in the Mediterranean recrion and in the Himalayas.

InPortaxt Genera.-Dipsucus, the Teazel, has recurved hooks on the involucral

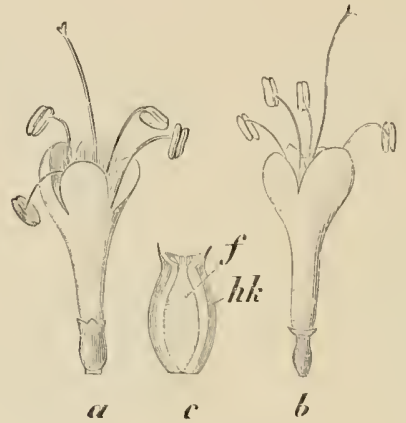

Fig. 725.-Succise pratensis, a, Flower with epicalyx; $b$, the same after removal of ejicalyx; $c$, fruit in

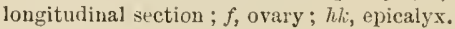

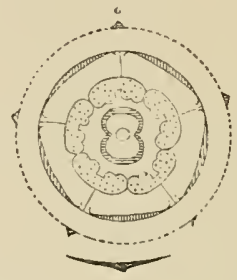

FI: 726.-Compositae. Floral diagram (Cretuus).

and floral bracts. The capitula of $D$. fullonum are employed in the carding of woollen clotll. Corolla with four lobes. Szccisa (Fig. 725) has a four-lobed corolla; bracts are present on the common receptacle. Scobiosa las similar bracts but has pentamerous flowers; the marginal flowers of the head are larger and dorsiventral.

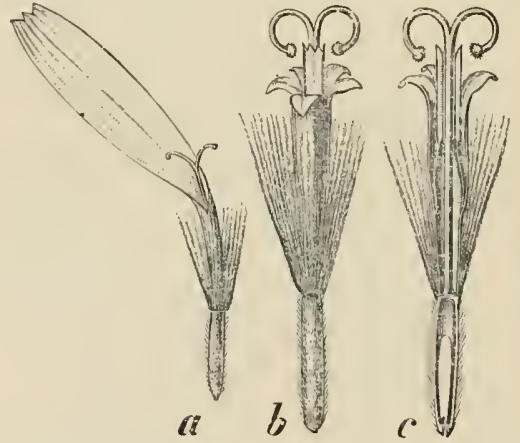

Fis. 72\%.-Amier montrence. a, lay-llower; $b$, disc-flower; $c$, the latter cut throngh longitudinally. (After BERG and ScHMid, magnified.) It is cultivated as an ornamental jlant. Kuautia has tetramerous flowers ; no floral bracts.

Family 2. Compositae ( $(9)$. -Distributed over the whole earth. For the most part herbs of very various habit; some tropical forms are shrubs or trees. Flowers actinomorphic or zygomorphic with no epicalyx. Stamens five; anthers introrse, cohering by their cuticles to form a tube which is elosed below by the unexpanded stigma. The pollen is shed into the tube formed by the anthers and is swept out by the brush-like hairs of the style as the latter elongates. The style is bifid above. Ovule erect, anatropous (Fig. 729). Seed exalbuminous. The fruits are achenes, often bearing at the upper end a crown of hairs, the pappus. This corresponds to the calyx and aids in the dispersion of the fruit by the wind (Figs. 726-732). 'The replacement of reserve starch by imulin is characteristic of the Compositae. 
The individual flowers are either radially symmetrical with a fire-lobed coroila (Fig. 727, b, c) or they are two-lipjed as in the Sonth American Nutisieae, the upper lip having two teeth, the lower three. By suppression of the upper lip Howers with a single lip are derived; such flowers exhibit three tceth at the tip (Fig.
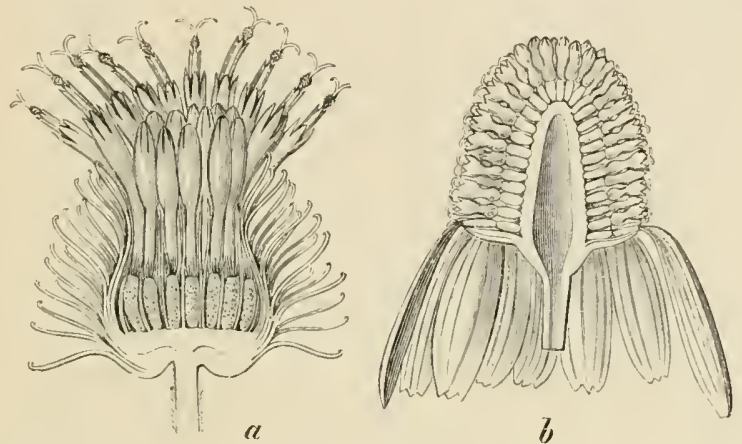

FIG, 725.-Longitudinal section of capitulum-a, of Lupye mujor with floral bracts; $b$, of Matricarin (hamomilla without floral bracts. (After BERG and ScHuIDT, magnified.)

727 a). The ligulate flowers (c.g. of Toraxacum, Fig. 734) are similar in general appearance to the latter; the corolla is here deeply split on one side and its margin bears five teeth. In addition to those Compositae which have only lignlate or only tubular florets in the head, there are many which have tubular Horets (disc-florets) in the centre, surrounded by one-lipped florets (ray-florets) (Fig. 728 b). These usually differ from one another in sex as well as in colour; the disc-florets are hermaphrodite, the ray-Horets purely female. 'The flower-heads are thus heterogamons (Matricaria, Arnica). Lastly, the marginal florets may be completely sterile (Centaurea Cyanus) and serve only to render the capitulum conspicuous to insects.

IMPORTANT SUB-FAMILIES AND GENERA. 1. Tubuliflorae, the heads contain only tubular florets; (a) Cynureac. The enlarged axis of the inflorescence or common receptacle has setaceous Horal bracts; the involucral leaves form several series and are prickly or have membranous margins. The Howers are either all hermaphrodite
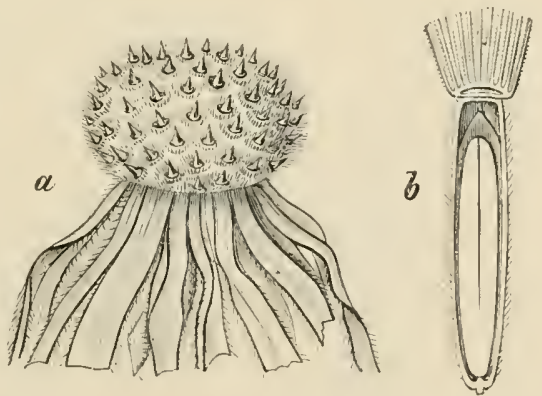

Fig. 729.-Arnire montana. a, Receptacle of capitulum after removal of fruit; $b$, fruit in longitudinal section, the pappus only partly sliown. (After BERG anil SCHMIDT, magnitier.) or the marginal florets are sterile. Style swollen below the stigmas into a cushion-like ring. Fruits with a papjus. Corduus (Plumeless Thistle), pappos of simple, hair-like bristles. Cirsium, with feathery papuus. Echinops, witl single-flowered capitula associated in numbers. Lajpe (Burdock), inrolucral bracts with recurred, hook-like tips (Fig. 728 a). Cynare Scolymus (Artichoke). Cnicus benedictus (Fig. 733), capitula solitary, terminal, surrounded by foliage leaves. Involucral bracts with a large, sometimes 
finnate, terminal spine and a felt of hairs. Marginal florets sterile. Pappus double. Cenforece with dry, sealy involncral braets and large, sterile marginal

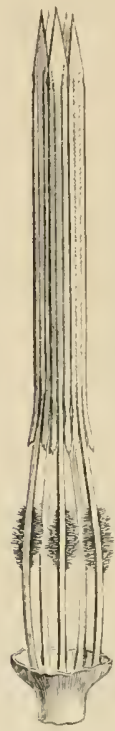

FIG. 730, - Androecium of Carduus crispus $(\times 10)$. (After BaILLoN.) Horets. On the irritability of the stamens ef. Fig. 241 and p. 324.

(b) Eupatoricae. Flowers hermaphrodite. Receptacle withont tloral bracts. Inrolucral leares herbaceous. Expatorium cannatinum (British). Aggeratummexicanum, commonly enltirated.

2. Labiatiflorae. Mutiseat ocomr in tropical America.

3. Liguliftorue. Cichorieae with only zygomolphic, ligulate, florets with a fire-toothed corulla in the Howerhead. All the flowers are hermaphrodite. Laticiferons ressels in all orrans of the plant. Turaxacum officinale (Dandelion, Fig. 734 ) is a common plant throughout the northern hemisphere. It has a long, carrot-shaped tap-root, a rosette of coarsely tootled leares, and terminal influrescences, borne singly on hollow stalks (apogamy, cf. 1. 511). Fruits with an elongated beak, carrying u1) the pappus as a stalked, umbrella-shajed crown of hairs (Fig. 732). Lactuce satira, Lettuce. L. virosa, a herbaceous plant of considerable height with a branehed stem, sessile sagittate leares and numerous, sinall, fer. flowered intlorescences grouped in panicles. Fruits like those of Taraxacum. L. Scariola $\left({ }^{80}\right)$, Compass plant, has leaves which take a rertical position. Cichorium Intybus (Chicory), C. cndivia, Endive, with heads of blue flowers; pappus of short erect scales (Fig. $731 \mathrm{C}$ ). Tragopogon and Scorsonerce have a feathery pappus; Sc. hisponica. Crepis has a soft, flexible, hairy pappus of brownish colour. Sonchus, pappus of several series of bristles. Hieracium $\left({ }^{81}\right)$, a large European genus with many forms. (Apogamy and apospory, of. 13. 514.) Paplus white, rigid, and brittle (Fig. 731 B).
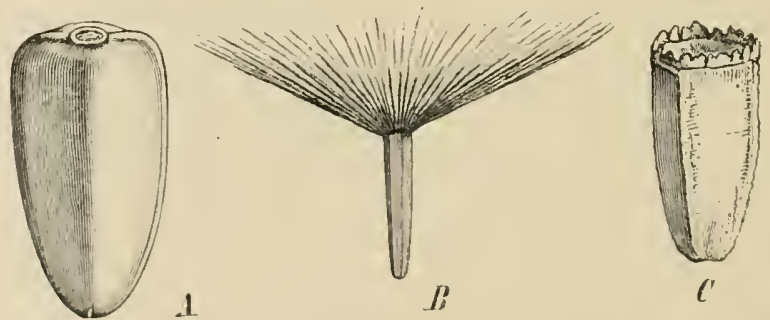

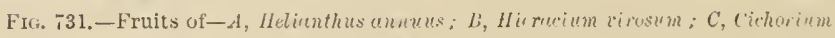
Intylus. (After Banlox:)

4. Diversiftorce. 'Two distinet types of flower or flowers of distinet sexes in the cajoitulum.

(a) Astercer, receptacle naked, without floral bracts. Involucral bracts, numerous, imbricate. Hermaphrodite tubular flowers in centre, surrounded by onelipued ray-florets. Paprus as a rule of bristle-like hairs. Style with straight 


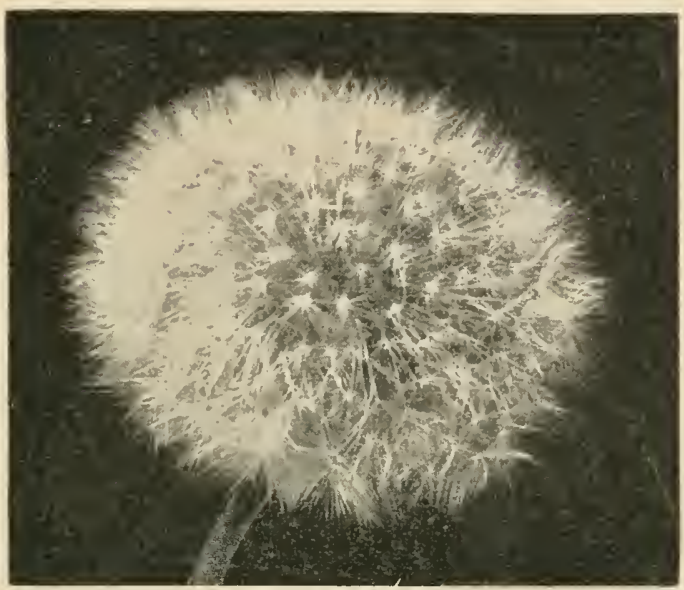

F1G, 732.- Heal of fruits of Teraramm offeincle. The pappus is raised on a stalk-like prolongation of the fruit. (Nat. size.)

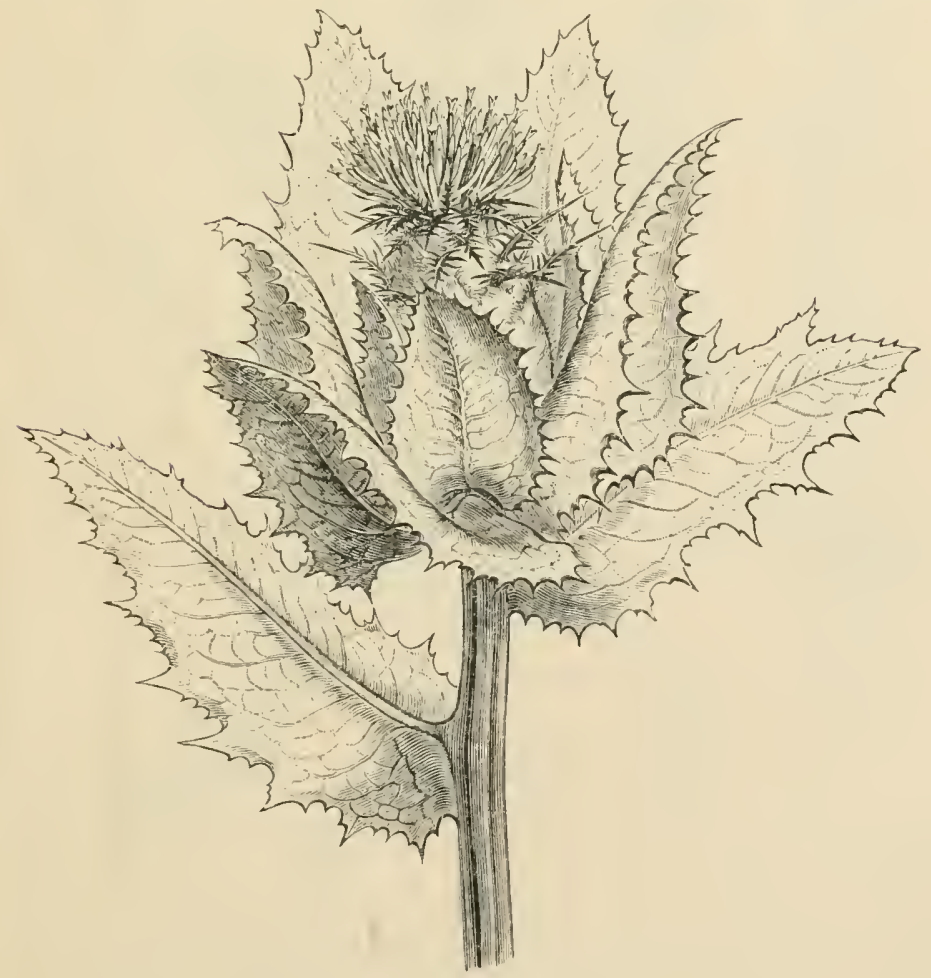

Fi:. 733.-Cnicus benuliste. (After B.ILLox.) 


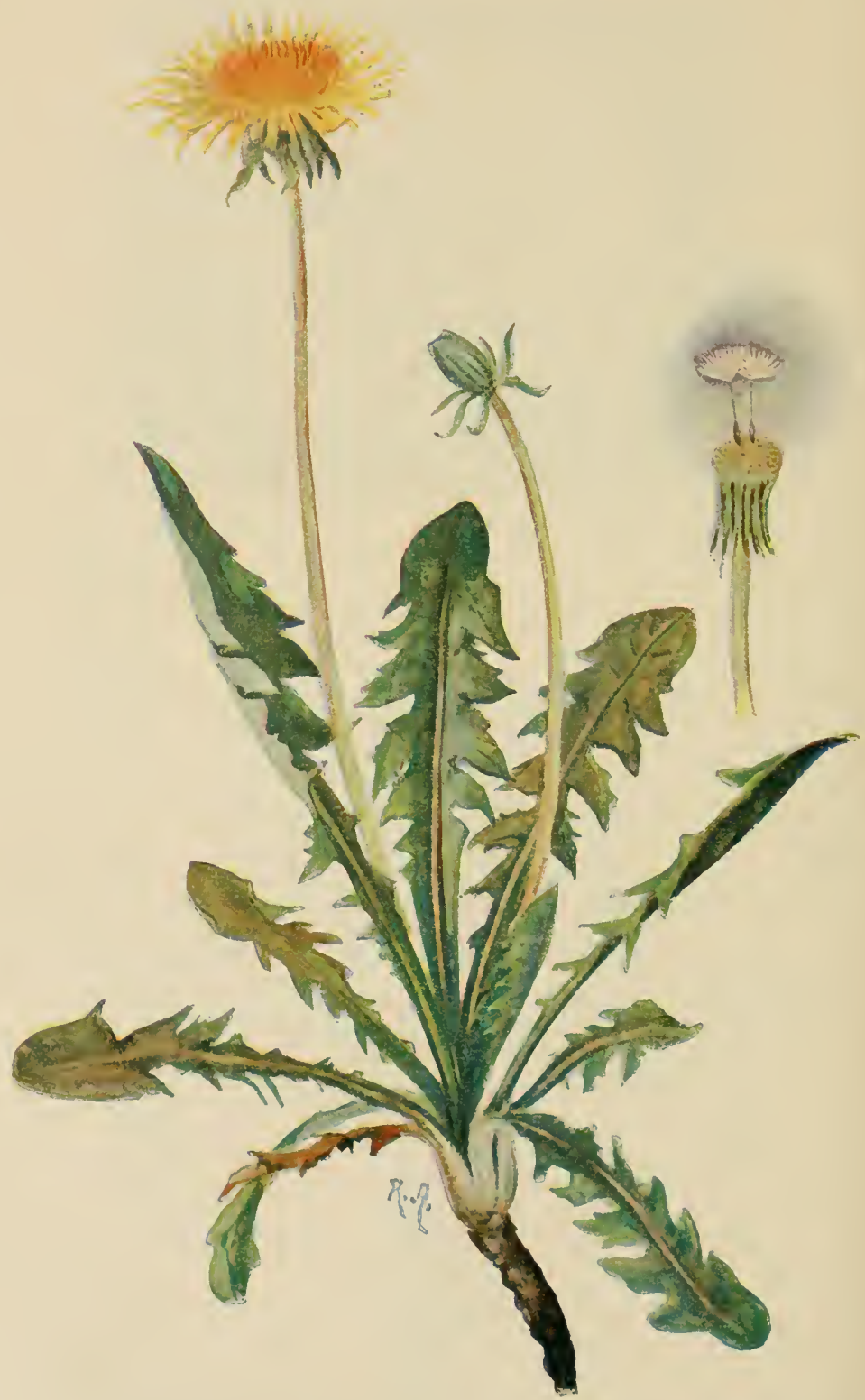

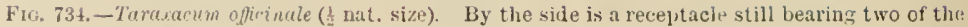
fruits ; the jallu,us is raised on a stalk-like beak of the frttit. OFFICIAI. 
branches; stigmas terminal. Numerons species of Aster, Sotidign, and Erigerom

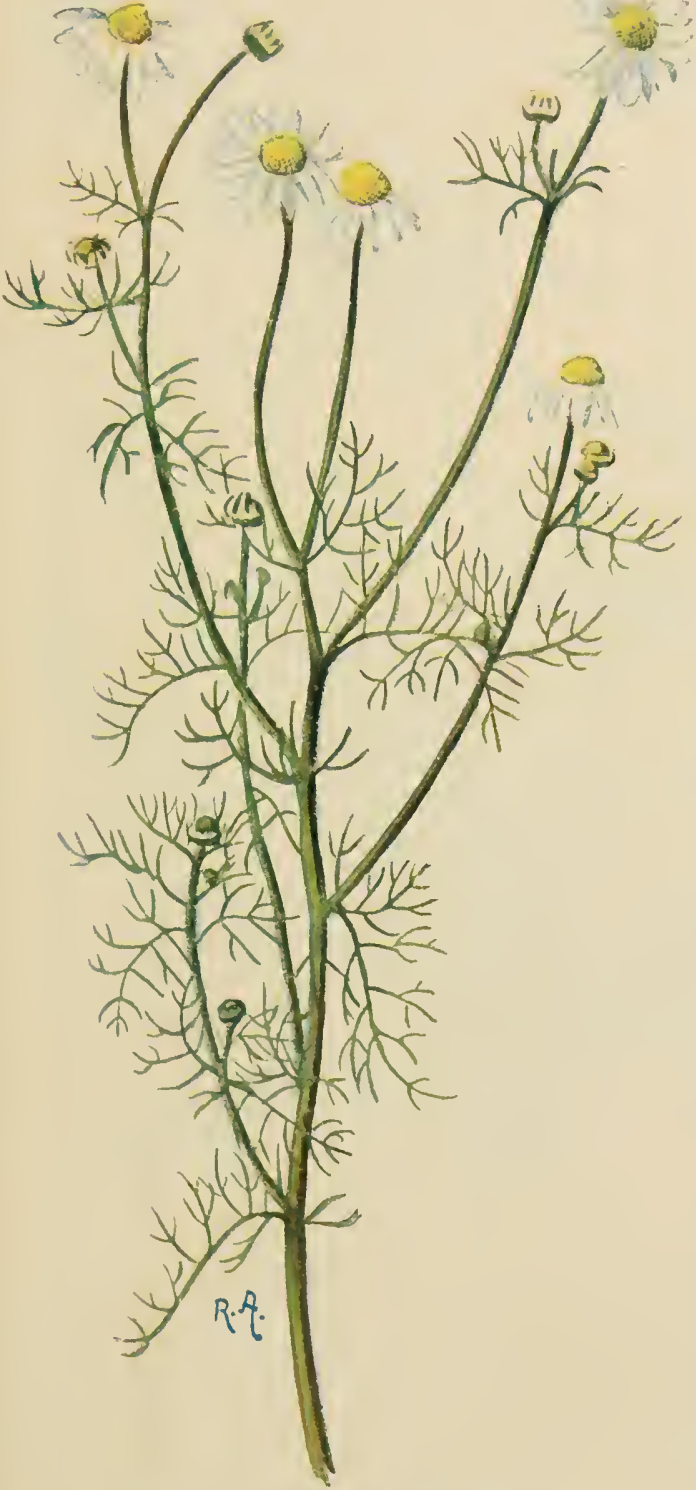

F1.. 735.-Matricaria Chamomilla (ङ nat. size).

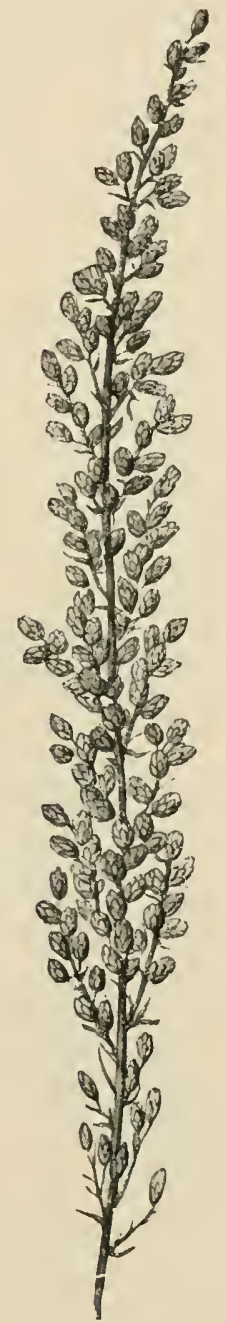

Fir. T36.-Artemisiu Cina. (Aftel siru. MANN and ARTHR MEYER.)

occur in Europre, America, and Asia. Species of Aster are cultirated. Baccharis 
shrubby dioecions plants from America. Species of Haustia $\left({ }^{82}\right)$ are cushion-shaped plants with woolly hairs in New Zealand (Tegretable Sheep).

(b) Iruleac resemble the preceding group but have tailed anthers. Involucral leaves frequently dry and membranons. Inule occurs in Britain; I. helcnium is cultivated. In Guuphalizin, Antennuria ( $\left.{ }^{83}\right)$, Helichrysum (Everlasting:flowers), Lcontopodium (Edelweiss), Filago. etc., the dry involncral bracts are coloured and

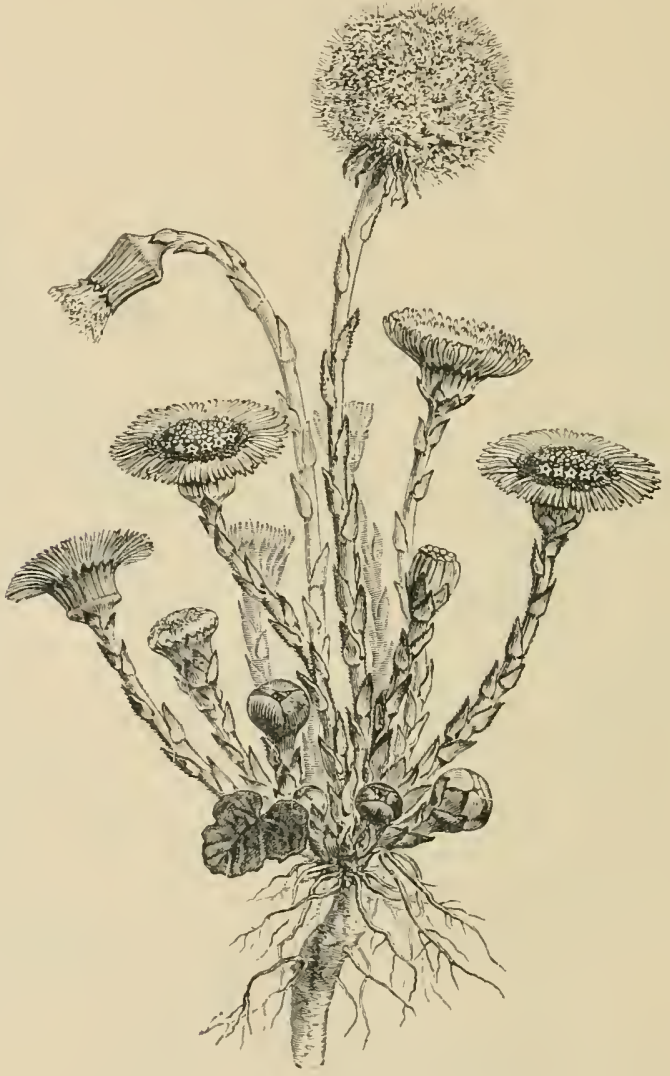

FI: 737.-Tissilugo Furfure. (After BaIllox.)

have flat, expanded appendages; the flowers are all tubular but the marginal florets are fentale, the dise-florets hermaphrodite. Picoulia ( $\left.{ }^{84}\right)$ resembles Hactiu in habit and in distribution (ef. Fig. 182). Odontospermum pygmaeum of the Sahara closes its involncral bracts orer the fruits when dry and expands them when moistened. It resembles the true Rose of Jericho, the cruciferous plant inrestatica hicrochuntica (cf. p. 592).

(c) Helientheae. Receptacle with floral bracts. Involucral bracts herbaceous. Disc-florets hernaplirodite, tubular. Ray-florets one-lipyed, female, or hermaphrodite. Anthers without tails. Papjus wanting or formed of awns or 
scales, Helianthus annums (Sunflower, Fig. 731 A), H. tuberosus (Jertisalem Artichoke), Dahlia, are all from America and in enltivation. In Britain Iidens: herbs with opposite leaves, sometimes heterophyllons. Espeletiu ( $\left.{ }^{85}\right)$, characteristic

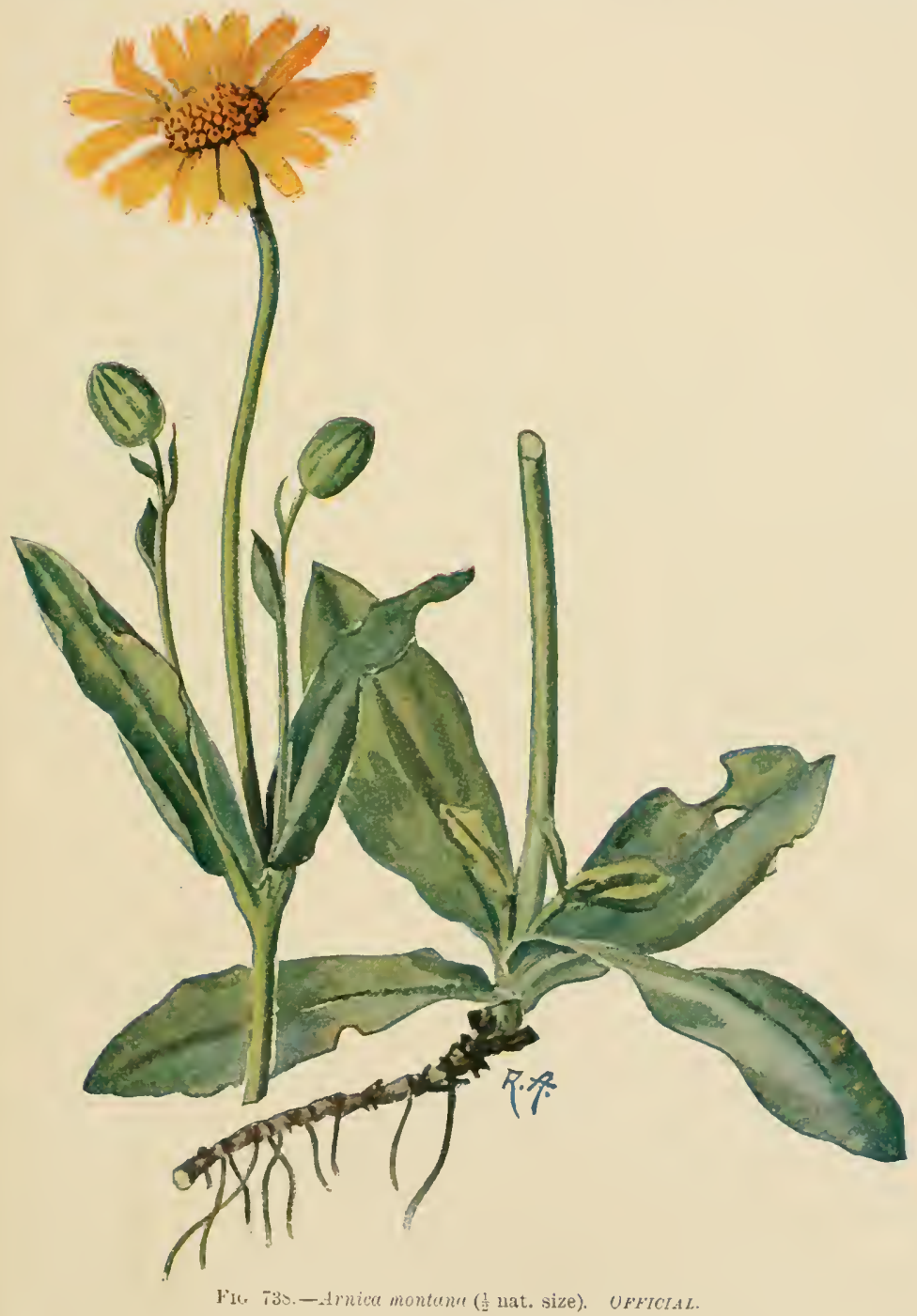

trees or herbs of the Paramos of Colombia and Veneztula. Tuyctes, Zinum, ornamental plants from America.

(d) Anthemideae. Receptacle with or without floral bracts or hairs ; involucral bracts with dry, nembranous margins; in other respects like the preceding. 
Aehillea, Milfoil; Anthemis, Anacyclus, with floral bracts. Anthemis notilis, capitula composed of disc-florets only, or with these more or less replaced by irregular florets. Anacyclus officincomo. Watricuria has no floral bracts. I. Chamomille (Chamomile, Figs. $728 \quad l, 735$ ) is an annual, copiously branched herb with a hollow, conical, common receptacle, yellow disc-florets and white, recurved, female ray-florets, in the terminal capitula. Chryscuthemum, C. segetum, Tencectum, flowers all tubular, marginal florets female. Artconisic has all the florets tubular and usnally the peripheral ones female (A. Absinthium, Wormwood); in the few-flowered capitula of $A$. Cinc (Fig. 736) all the florets are hernajihrodite.

(c) Senccioncuc. Receptacle naked, inrolucral bracts in one or two series. Pappus hairy, delicate, white; in other respects like the preceding. Tussilago Furfure, Coltsfoot, flowers appear before the leaves; the flowering stem bears scaly leares and a single capitulum (Fig. 737). Female flowers at periphery in several series. Leaves large, cordate, thick, covered beneath with white hairs. Petasites officinalis, Butter-Bur. Senecio, plants of diverse habit, including some trees and sucenlent plants; of world-wide distribution. S. vulyciris has no rayflorets but only tubular, hermaphrodite florets. Doronicum, Cineraric are commonly cultivated. Ariuice montence (Figs. $727,729,738$ ) has a rosette of radical leaves in two to four opposite pairs and a terminal inflorescence bearing a single capitulum; from the axillary buds of the two opposite bracts one (rarely more) lateral inflorescence derelops.

$(f)$ Culendulece. Fruits of the capitnlum of varied and irregular shapes. Culendula. Dimorphotheca $\left.{ }^{86}\right)$.

Official. - Anceyelus Pyrethrum yields pyrethri madix. Saxtoxixim is lrepared from Artemisic maritima, var. Stcchnnnicunc. Anthemis nobilis yields

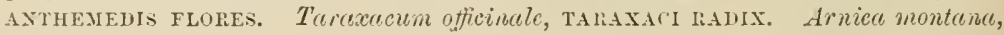
IRYICAE IIHIZOMA.

\section{Sub-Class II}

\section{Monocotylae}

The Monocotyledons, or Angiosperms which possess a single cotyledon, are in general habit mostly herbaceous, less frequently shrulss or trees.

In germination the radicle and hypocotyl of the small embryo emerge from the seed-coat, while the sheath-like cotyledon usually remains with its upper end within the seed and absorbs the materials stored in the endosperm, which is usually well developed. The growth of the main root is sooner or later arrested and its place taken by numerous adventitious roots springing from the stem. In the Grasses these are alrealy present in the embryo within the seed. Thus a single root system derived by the loranehing of a main root, such as the Gymnosperms and Dicotyledons possess, is wanting throughout the Monocotyledons.

The growing point of the stem remains for a longer or shorter time encloserl by the sheath of the cotyleilon. Later it bears in 
two-ranked or alternate arrangement the leaves, which have long sheaths and continne to grow for a considerable time at their bases. The growth of the stem is often limited; branching is in many cases entirely wanting, and rarely results in the development of a highly branched shoot-system. The leaves are mostly sessile and parallelveinerl, and of a narrow, elongated, linear, or elliptical shape (Fig. 739).

Anatomically the Monoeotyledons are characterised by their elosed vascular bundles in which no cambium is developed; these are uniformly scattered in the cross section of the stem (ef. Fig. 137),

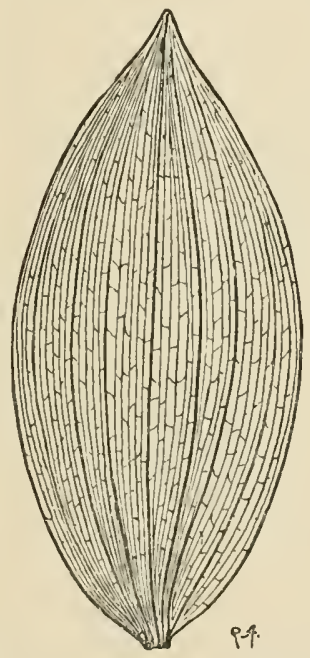

Fis: 739.-Leaf of Pulygonatum multiflorum with parallel venation. ( ${ }_{4}^{3}$ nat. size.) Secondary thickening is consequently wanting in Monocotyledons, and in the rare cases in which it is found results from the formation at the periphery of the central eylincler of additional elosed bundles embedded in ground-tissue (cf. p. 155).

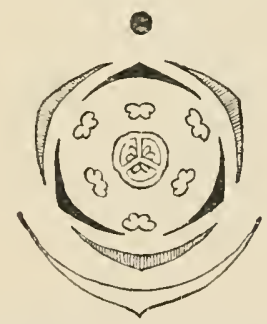

Fic. 740.-Diagram of a typical Monocoty. ledonous Hower.

The flower in the Monocotyledons is usually pentacyclic and has two whorls constituting the perianth, an androecium of two whorls, and a gynaeceum of a single whorl. The typical number of members in each whorl is three. The two whorls of the perianth are usually similarly formed and thus constitute a perigone (Fig. 740 ). The floral formula of such a flower is P $3+3, \mathrm{~A} 3+3, \mathrm{G}(3)$. An inereased number of whorls, or of the members within a whorl, is only found in the Helobiae.

In this fcatureand in the a pocarpous gynaeceum of the Helobiae an approach to the Polycarpicae, among the Dicotyledons, can be recognised, and the attempt has been made to derive the Monocotyledons from the polyearpic Dicotyledons by means of this order $\left({ }^{\top}\right)$. This assumption is further sirpported by the spiral arrangement (88) of the carpels, and apparently of the stamens also, in the genus Sagittariu. This possible origin of the Monocotyledons, since no other has yet been indicated, and the Polycarpicac have formed the point of departure of a number of divergent 
lines of descent, has been taken into consideration in the arrangement of the Mouocotylae in relation to the Dicotylae.

\section{Order 1. Helobiae}

Water or marsh plants with actinomorphic flowers. Gynaeceum, frequently apocarpous; carpels in two circles. Seeds, exalbuminous; embryo, large. Indehiscent fruits or fruitlets. .

Family 1. Alismaceae $\left.{ }^{89}\right)$.-Widely spread in the warm and temperate zones. Alisma Plantago, Sagittaria sagittifolia, and Butomus umbellatus have longstalked panicles or umbels, and oeeur as marsh-plants. The individual flowers have a ealyx and a white (in Butomus, reddish) corolla. Androecium, in Butomus A $6+3$, in Alisma A 6. Gynaecenm apocarpous, in Butomus G 3+3, in Alisma $\mathrm{G} \infty$. Sagittaria is monoecious with flowers that, by suppression of stamens or carpels, are unisexual. Male flowers, with numerous stamens and sterile carpels;

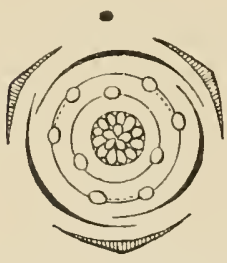

Fis. 741. - Floral diagram of Echinolorus parvulus, one of the Alismaceae. (After EICHLER.)

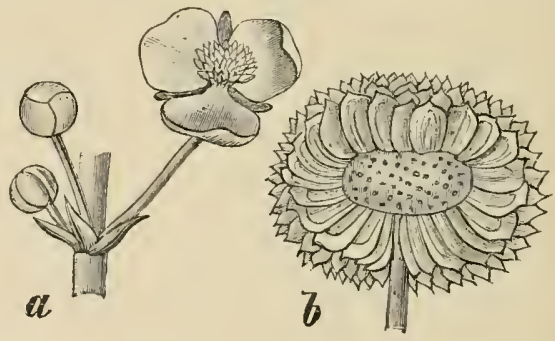

FIa. 742.-Sugittaria sugittifulia. $a$, Flower; $b$, fruit after re. moval of some of the carpels. (Magnified; $b$, after Engler and Pranti.)

female flowers, with staminodes and numerous free carpels inserted on the eonvex floral reeeptaele (Figs. 741, 742). Leaves in Butomus, linear, chanuelled, and triangular in cross-section; in Alisma and Sagittaria, long-stalked with spoonshaped and sagittate leaf-blades respeetively. Individuals of both genera growing in deep flowing water have long ribbon-shaped leaves, similar to those that ajpear as a transition type in germination; such plants do not flower.

Family 2. Juncaginaceae.-Habit grass-like, Triglochin.

Family 3. Potamogetonaceae.-Many speeies of Potamogeton are distributed over the earth in standing or flowing water. Flowers hermaphrodite, tetramerons. Gynaccenm anoearpous. Inflorescence a spike. Leaves usually submerged, with a long sheath, slit on one side, formed from the axillary stipnles. P. natans, the eommon Pond-weed (Fig. 743), at the time of flowering has usually only floating leaves, the eylindrical, submerged water-leaves having disappeared by then. liuppia maritima and Zanichellia palustris grow in brackish water. Zostera marina, Grass-wrack, ocenrs commonly on all nortl temperate coasts and is used for stuffing cushions (cf. p. 495).

Family 4. Naiadaceae. - The single genus Nuias contains a number of freshwater plants with diclinous flowers. It oceurs all over the earth.

Family 5. Hydrocharitaceae.-IIyelrocheris morsus renac and Stratiotes aloides are floating plants occurring in Britain, which are vegetatively propagated by 
runners; they pass the winter at the bottom of the water, in some cases as special winter buds (cf. p. 277), and grow up again in the spring. Flowers dioecions; perianth differentiated into calyx and corolla. The male flower has several trimerous whorls of stamens; the female flower possesses staminodes and two trimerous whorls of carpels. Ovary inferior. Entomophilons. Vallisneric spiralis

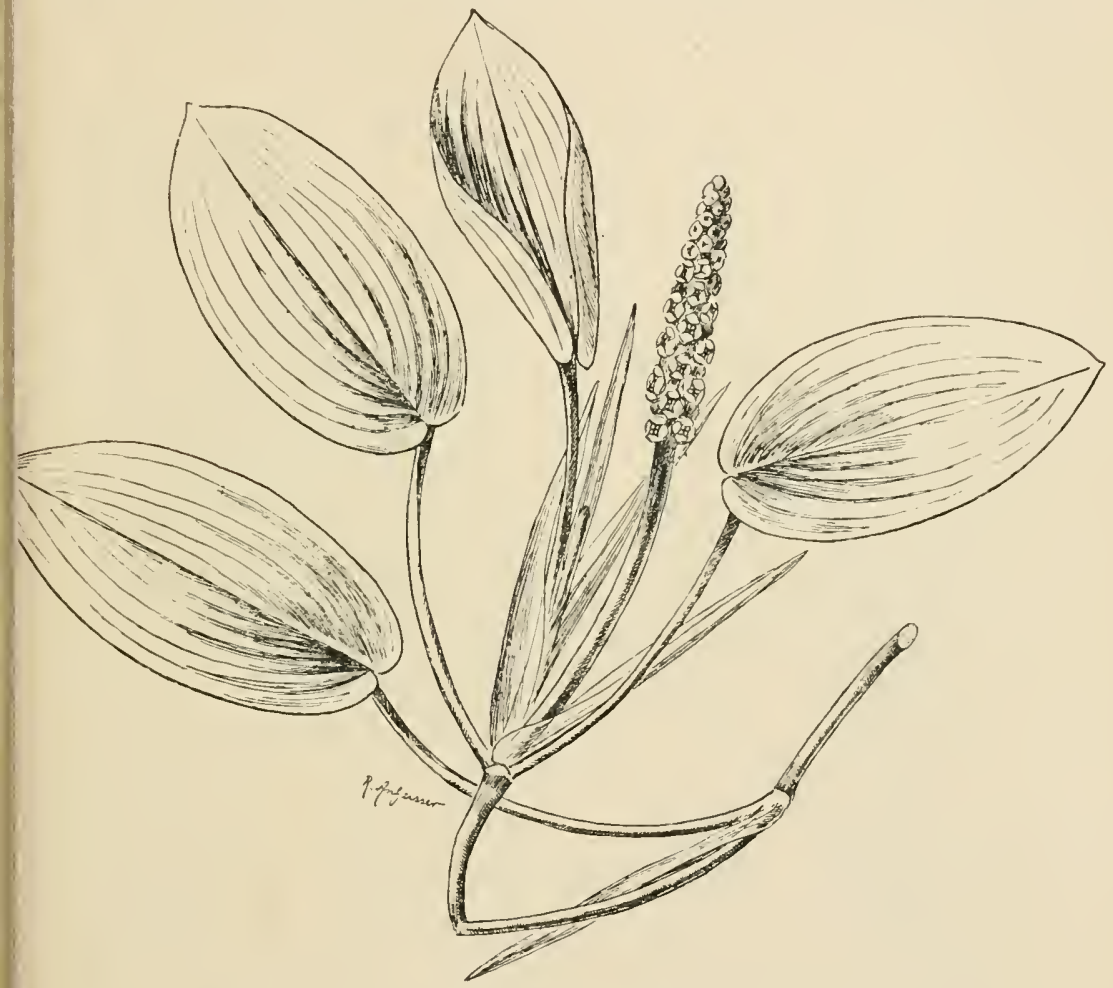

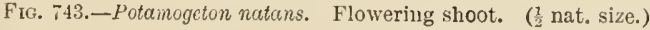

(cf. p. 495), a fresh - water plant of the tropics extending to the Italian lakes. Elodece canadensis, the Canadian water-weed.

\section{Order 2. Glumiflorae}

This order consists entirely of annual or peremnial plants of grasslike habit. A woody stem only appears in the genus Bumbusa. The association in more or less complex inflorescences of numerous flowers, which lack a proper perianth but are enclosed by scaly bracts (glumes), is a common character of the order. The perianth is either completely wanting or reduced to a series of scales or bristles. The inner whorl of stamens is also usually wanting, The superior ovary is always 
unilocular and contains only one ovule; it is formed of three, two, or of a single carpel. The large size and feathery and papillose form of the stigmas stand in relation to the wind pollination. Fruits indehiscent.

Family 1. Cyperaceae.-The Sedges are characterised by their triangular stems, which are usually neither swollen at the nodes nor

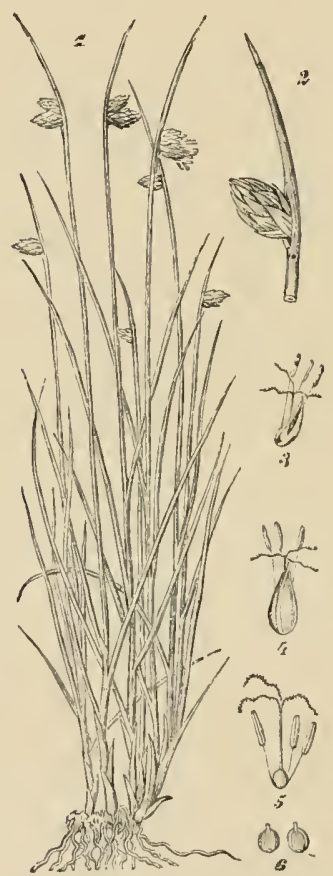

Fic. 744. - Scirpus setaceus. 1, plant in flower; 2, upper portion of a flowering shoot; 8 , single flower; 4 , the same from behind ; 5 , the same without the bract; 6 , fruit. (After Hofralans. 1, nat. size, the others $\times 2-6$.)

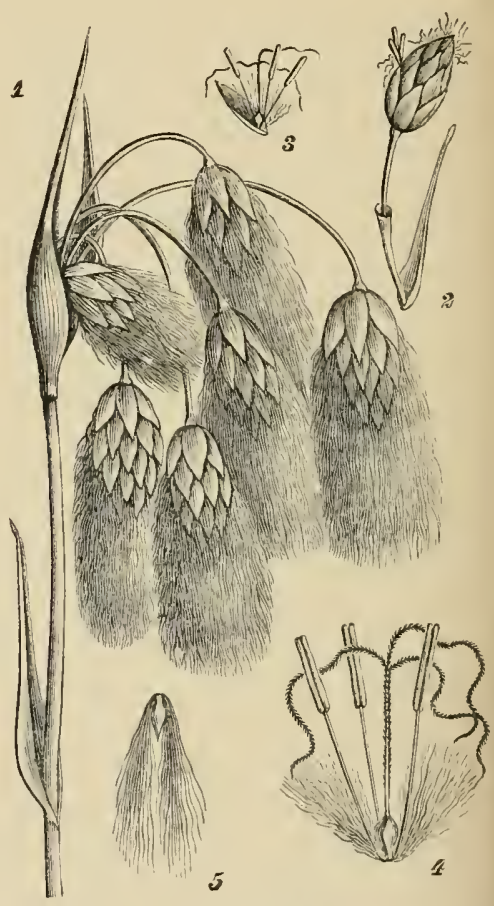

FI0. 745.-Eriophorum angustifolium. 1, Inflores cence; 2 , a single spikelet; 3 , single flower; 4, flower with bract removed; 5 , fruit. (After Hoffmass ; 1 , about nat. size; the others $x$ 3-5.)

hollow, and by their closed leaf-sheaths. The flowers are unisexual and usually monoecious or are hermaphrodite; ovary formed of two or three carpels with an erect, basal, anatropous ovule. Pericarp not coherent with the seed-coat; embryo small, surrounded by the endosperm.

The genera Cyperus, Scirpus, and Eriophorum have hermaphrodite flowers. Fig. 744 represents a plant of Scirpus setaceus, which is an annual, in flower. Leaves rigid, channelled above. Fertile shoots with the uppermost internode elongated. Spikes 1-3, terminal; enclosed by imbricating bracts and displaced 
to one side by the subtending bract the line of which continues that of the stem. Only the large, lowermost bracts are sterile, the others have each a naked hermaphrodite flower in their axils. Other species have the perianth
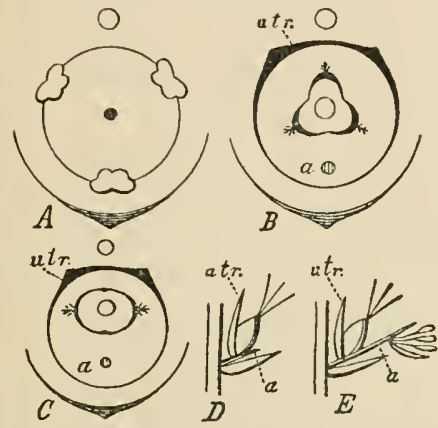

Fig. 746. $-A$, Floral diagram of a male tlower of Carex; $B$, of a female flower with three stigmas; $C$, of a female flower with two stigmas; $D$, diagram of female flower of Carex; $E$, diarram of the hermaphrodite spikelet of Elyna; $a$, secondary axis; utr, utriculus or bract of the secondary axis. (After Eichler.) represented by bristles. The Cotton-grass (Eriophorum angustifolium), which when flowering is inconspicuous, bears at the summit of its fertile shoots 3-7 long-stalked, erect spikelets with numerons, imbricate bracts. Around the base of each flower are numerous hairs, which are concealed by the projecting stamens and style. When the plant is in fruit the hairs, which have become about $3 \mathrm{~cm}$. long, project freely from between the bracts and constitnte a valuable means of dispersal for the fruits. The white colour of the hairs makes the now pendulous spikelets of the Cotton-grass a conspicnons feature of peat-moor vegetation (Fig. 745). Cyperus paryrus, in Egypt and Sicily.

The genus Carex is for the most part monoecions, and its flowers are naked and unisexual. Male spikes simple; in the axil of each bract is a male flower formed of three stamens. The female spikes bear in the axil of each bract a secondary shoot; the axis of this is included in the tubular subtending bract (utriculus) together with the pistil (formed of 2 or 3 carpels) which is borne in the axil of the bract (Fig. 746).

Family 2. Gramineae $\left({ }^{90}\right)$. - The stems of the true Grasses are cylindrical, and have hollow internodes (exceptions Maize and sugar-eane); the nodes are swollen; the leaves are two-ranked

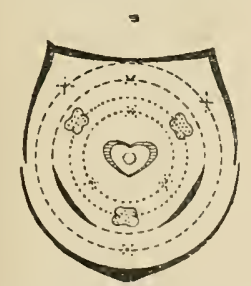

Fic. 747.-Floral diagram of the Granineae (A vena). The absent members are represented by $x$. and their sheath is usually split and thickened at the norle. At the junction of the sheath and leaf-blade, a membranous structure (the ligule) projects (cf. Fig. 35). The flowers of the Gramineae are grouped in spicate, racemose, or paniculate inflorescences, which are always composed of partial infiorescences, the spikelets. Usually each SPIKELET bears several

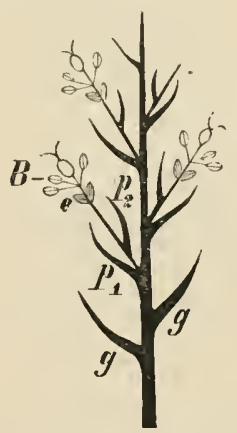

FIG. 748.-Diagrammatic representation of a Grass spikelet. $g$, The glumes ; $p_{1}$ and $\gamma_{2}$, the inferior and superior palea; $e$, lodicules ; $B$, flower. The axial parts are represented as elongated.

flowers. At the base of the spikelet there are usually a pair of sterile bracts (GLUMAE) ; sometimes there is only one or 3-4, glimes. Continuing the two-ranked arrangement of the glumes, come the fertile subtending bracts (PALEA INFERIOR) in the axil of each of which 
stands a flower. The sul,tending bracts are often awned, i.e. they bear terminally or springing from the dorsal surface a stiff loristle with backwardly directed hairs (the Awr). The bracteole of each

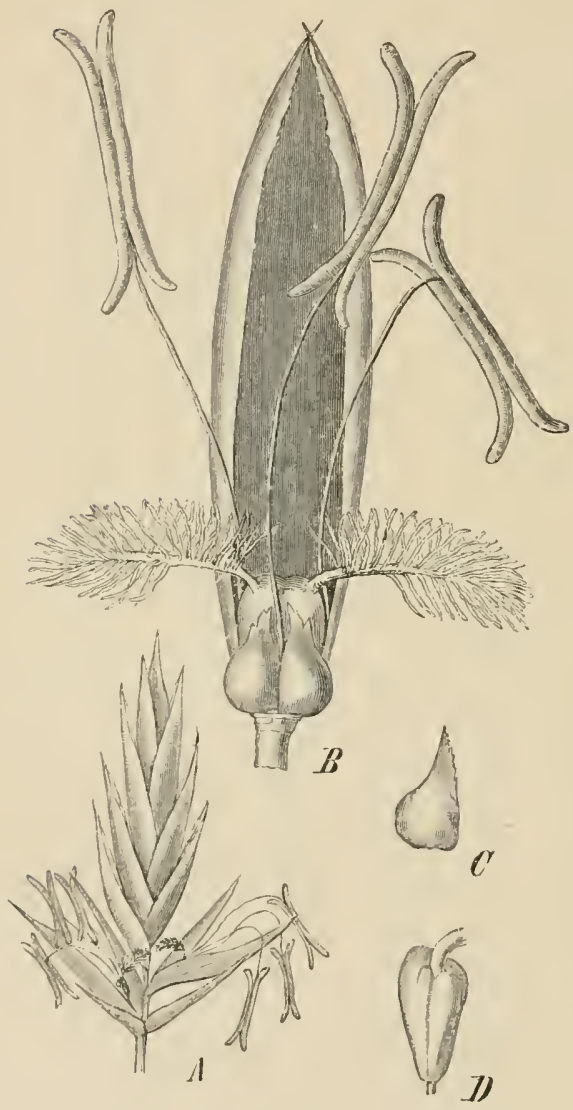

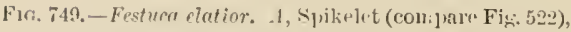
with two open flowers below which the two sterile glumes are sern $(\times 3)$; $B$, Flower ; the two lodicules are: in front, the suprior lalea behint; the ovary bears two feathery stirmas $(\times 12) ; r$, a single lodicule $(\times 12) ; D$, ovary seen from the side witl, the stalk of one of the removed stigmas ( $\times 14$ ). flower is represented by another scale-like bract, the PALEA SUPERIOR. Above this come two small scales, the LODICULAE, the distension of which assists in opening the flower. Lastly the axis bears the androecium consisting of a whorl of three stamens, and the ovary composed of one carpel and bearing two feathery papillose stigmas. The ovary contains an anatropous, or slightly campylotropous ovule (cf. Figs. $7+7-749)$.

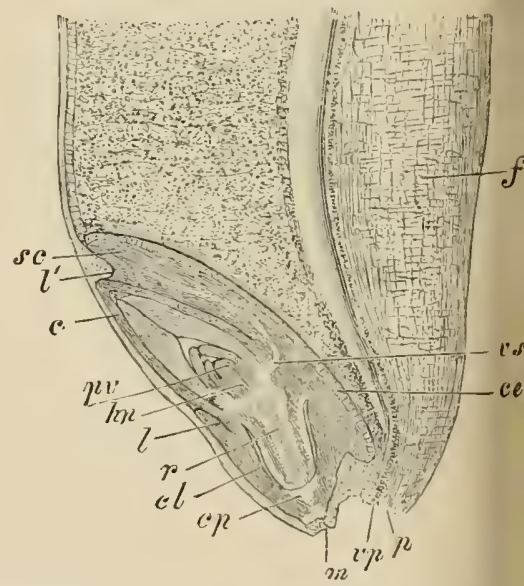

Fuc. 750.-Part of median longitudinal section of grain of Wheat, showing embryo and seutellut $(s c)$; $\imath$ 's, vaseular bundle of scutellum; $c$, it columnar epithelium; $l$, its ligule; $c$, sheathin part of the cotyledon; $p v$, vegetative colle ' stem ; $h l$, hypocotyl; $l$, epiblast ; $r$, radicle; $r$ root-sheath; $m$, micropy]e; $p$, funiculus ; $m$, it vascular bundle; $f$, lateral wall of groove; pericarp. $(\times 14$.

The flowers do not always show such extreme reduction; thus the flower of Rice (Fig. 75.3) has a complete androecium ; that of the bambuseac is similar and also has three lodicules, and in streptochactre there is a nomal monocotyledonous type of flower with all five whorls of members present (cf. the diagram in Fig. 740). The lodicules can on this evidence be regarded as corresponding to the inmer whorl 
of the perianth. Possibly the superior palea represents two coherent leaves of the outer whorl, but proof of this is at present wanting.

The length of the staminal filaments, their attachment a little
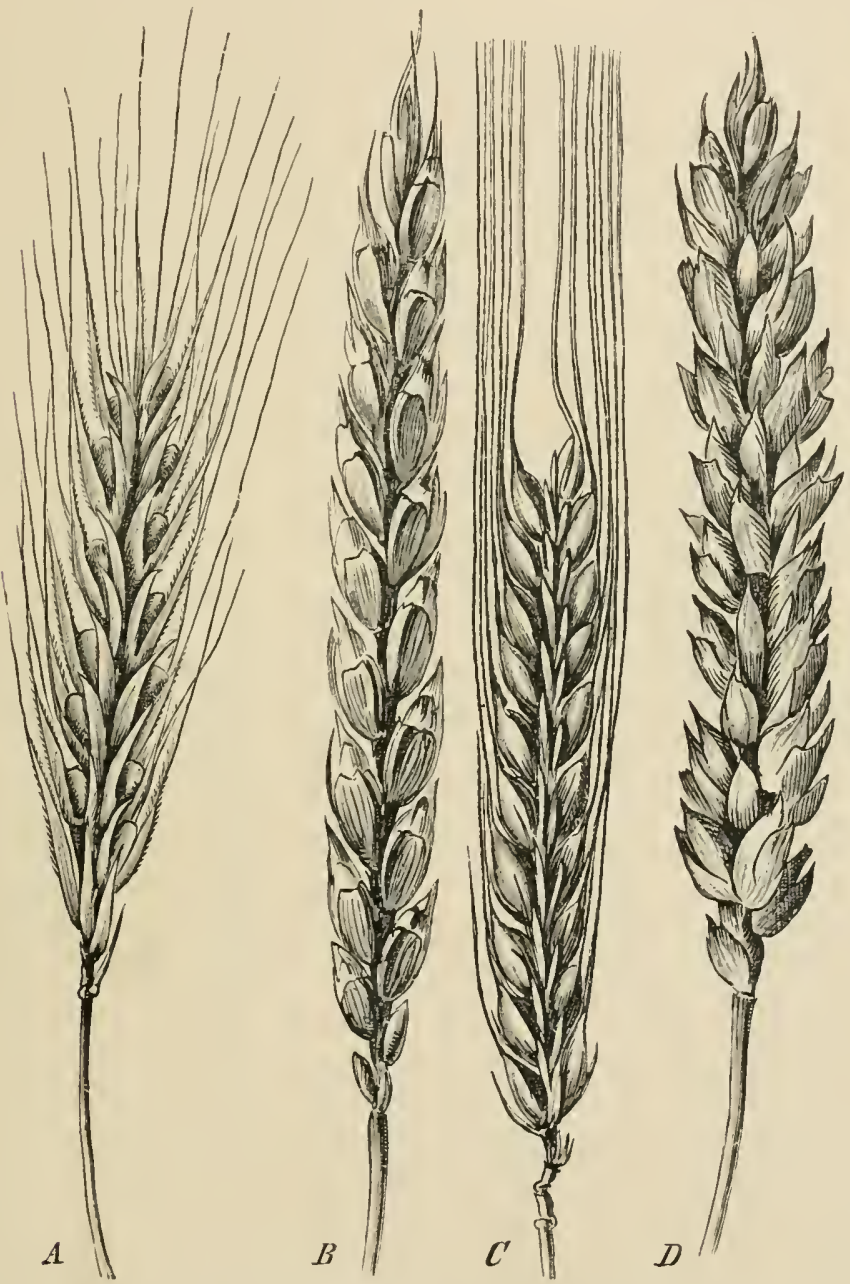

Fig. 751.-Cereals. A, Rye, Secale cereale; $B$, Spelt, Triticum Spelta; C, Two-ranked barley, Hordeum vulgare, distichum; $D$, Wheat, Triticum iulgare.

below the middle of the anthers, and the extended surface offered by the feathery stigmas are of value for wind-pollination (Fig. 749). The fruit of the Grasses is termed iv caryopsis ; in it the pericarp and seedcoat are intimately united. The embryo lies in contact with the 


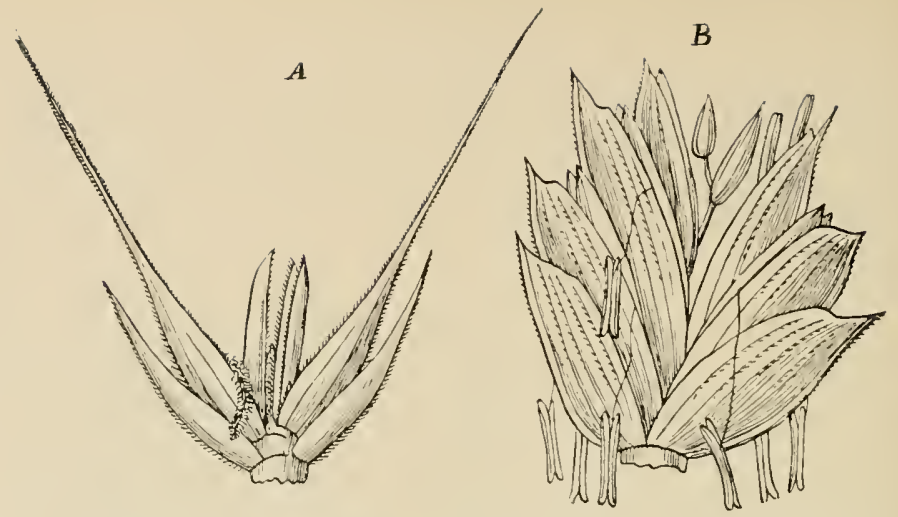

Fic. 752.-A, Spikelet of Rye; two-flowered. $B$, Spikelet of Wheat with a number of flowers.

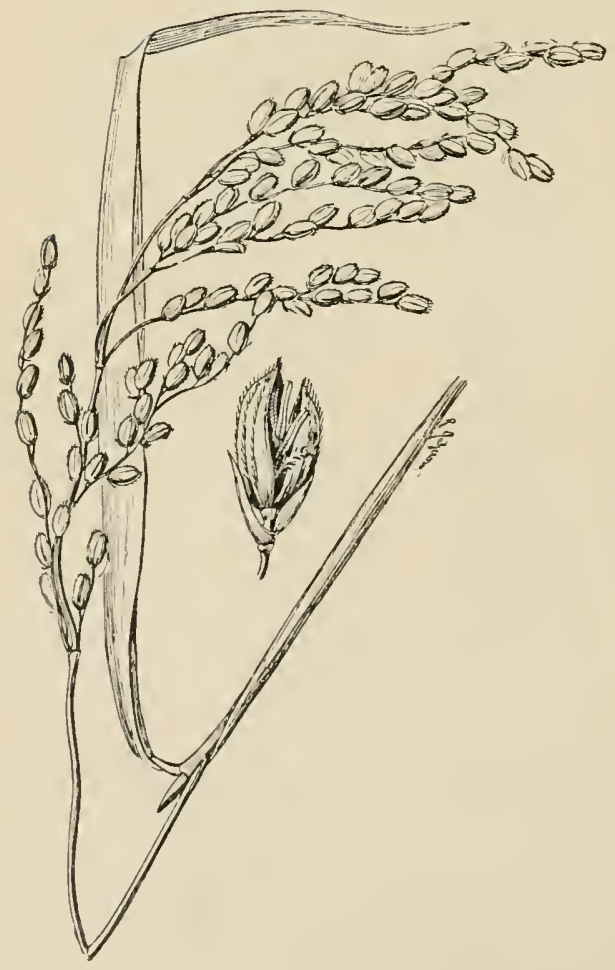

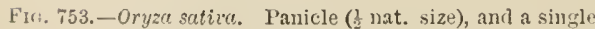
spikelet (enlarged). OFFICIAL.

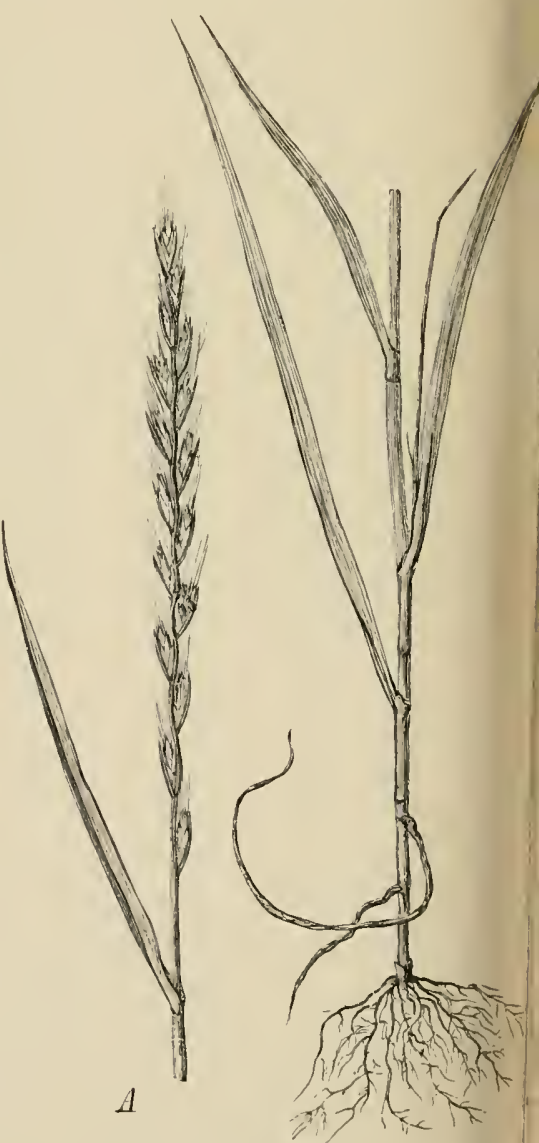

Fui. 754.-Lolium temulentum. Polsovors. 
endosperm by means of its cotyledon; this forms the sctTELLCM and in germination serves as an absorbent organ by means of which the leserve materials in the endosperm are taken up by the seedling (Fig. 750 ).

The most important economic plants belonging to this order are the Cereals (Fig. 751). Wheat, Triticum. Spikelets single, with two or more flowers; glumes broadly ovate. LuERICKE distinguishes as species of Wheat, (1) Tr.vulgare, with a number of sub-species; (2) Tr. polonicum; (3) Tr. monocoecun. Rye, Secalo, ccreule; spikelets single, 2-flowered; glumes acute. Barley, Horleum vulgare; spikelets one-flowered, in groups of three; in the sub-species $H$. hexastichum and $H$. tetrastichum all the rows of spikelets are fertile, in $H$. distichum only the middle row. Oat, Avena sutiru. Maize, Zece mais. The above are all cultivated in temperate climates, the Maize, largely in America, the others also in Western $A$ sia, and the sonth-east of Europe. In the wild state only Triticum aegilopodioides (from which $T r$. monococeum is derived), Secale montanum, and Hordeum spontcuenum (allied to $H$. distichum) are known. In these wild forms, the spikelets fall from the rhachis at maturity, a character that would be unsuitable in cultivated forms. The most important tropical food-plant of the order is Rice, Orysca sative (Fig. 753), which is largely cultivated to the limits of the warmer temperate regions, and, when sufficient moisture is available, yields an enormous harvest. In Africa, several varieties of Millet, Andropogon Sorghum, are cultivated, and it forms the most important cereal for that continent. Punicum miliaccum and $P$. italicum, of Asiatic origin, are still cultivated, though to a diminished extent, in the Mediterranean region. The Sugar-cane, Skccharum offieinarum, is another important food-plant; it is a perennial, growing more than six feet high, and occurs in tropical Asia. The sugar-cane is cultivated in all tropical countries, and cane-sugar is obtained from the sap expressed from the solid stem.

Among the most important of our meadow-grasses may be mentioned Agrustis culbu, Alopecurus protensis, Anthoxunthum odoratum, Arrhenatherum elatius Avenu flarescens, A. pubescens, Brisa media, Dactylis glomeruta, Holous laiatus, Lotium perenne, Phlcum protense, Poc pratensis, and species of Aira, Bromus, Calamagrostis, Festuca, Mclice, etc. The tropical species of Bambusa, which grow to the height of trees, are utilised in many ways; from the stems are constructed houses, walls, flooring, ladders, bridges, cordage, water-vessels, cooking utensils, water-pipes, etc., and the plant is indispensable in the countries in which it occur's.

Po1soxots. - Lolium temulentum (Fig. 751) has its fruits sometimes infested with fungal hyphae. These fruits owing to the alkaloids they contain are poisonous but fruits free from fungus are harmless $\left({ }^{91}\right)$; these plants are both annuals, and can be distinguished by the absence of sterile shoots from the comnon Lolium perene and $L$. multiflorum.

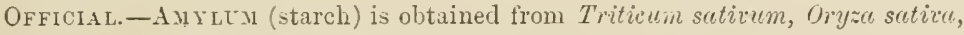
etc. ; Sucehurum officinurum provides sacchartu.

\section{Order 3. Spadiciflorae}

The common character of this order is afforded by the peculiar inflorescence; this is a spike with a thick, swollen, often fleshy axis and is termed a spadix. The flowers are mostly diclinous, monoecions or more rarely dioecious. 


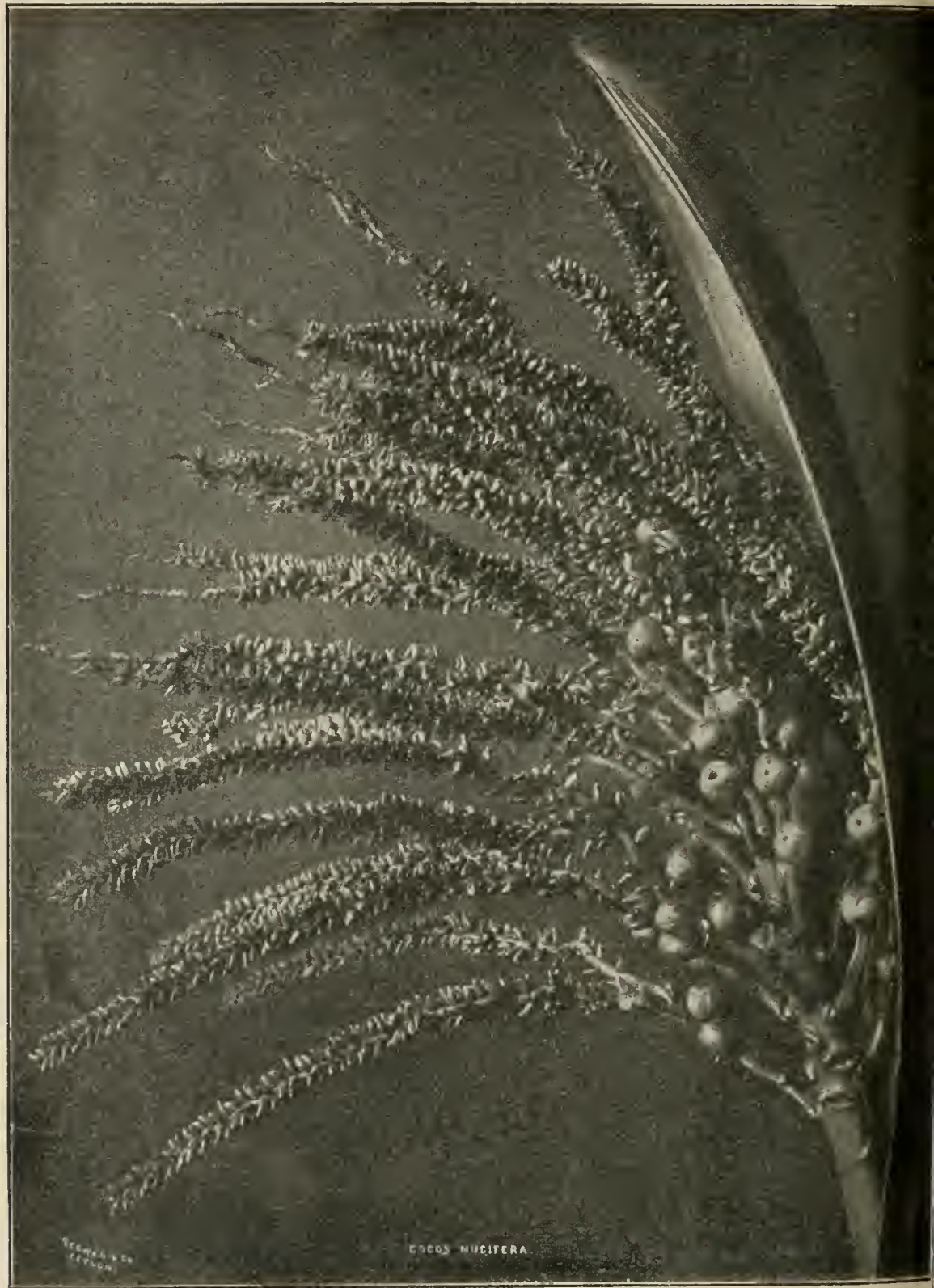

F'16. 755.-Cucus nuciftr. Inflorescence of the Coco-nut Palm, (Greatly relucen.) 
Fanily 1. Typhaceae.-Marsh plants, with long, linear leaves and longstalker spikes, which bear a large nmmber of flowers, the male above, the fenale lower down. Perianth wanting.

Family 2. Sparganiaceae.-Connectel with the preceding family. Spikes spherical. Flowers with a perigone, but otherwise like the Typhaceae.

Family 3. Pandanaceae.-Trees of peculiar appearance, supported by proproots, or climbing, shrubby plants ; all belong to the tropical countries around the Indian Ocean and to the Pacific islands. Growth in thickness as in Pahms. Leaves elongated spiny, channelled above, arranged without bare internodes in three ranks on the axis. Inflorescences, $\delta$ or $q$, are terminal spikes in the axils of

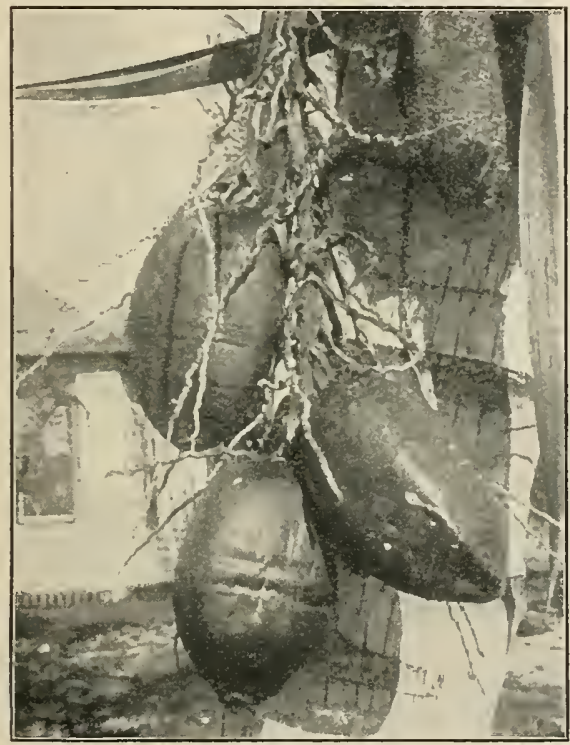

Fir, 756.-Coco-nuts on the stem. sheathing bracts. Flowers withont perianth, Pandunus (cf. Fig. 758 in front of the Palms), Freycinetiu (ef. p. 497).

Family 4. Palmae $\left({ }^{92}\right)$. - The Palms are an exclus. ively tropical and sub-

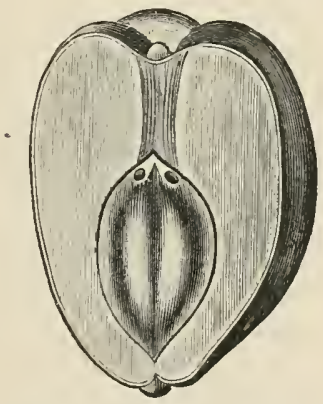

Fis. 757.-Coco-nut after partial removal of the fibrous exocarp. (After WarntsG, reduced.)

tropical family, the members of which mostly attain the size of trees. Their slender stem is simple and usually of uniform diameter throughout; only the African species of Hyphaene have branched stems. Other forms show evident growth in thickness towards the base and sometimes for half the height of the stem; this either depends on enlargement of the elements already present, or to a limited extent on new formation of tissues when required. The leaves, which are often of gigantic size, form a terminal crown. They are either pinnately or palmately divided, the division coming about by the death of definite portions of tissue in the young leaf in the bud, and subsequent tearing along these lines. The inflorescence is in some cases terminal (Metroxylon), and the individual perishes with the development of the fruits. IIore often the inflorescences are axillary. When young, they are cnclosed by a massive resistant sheath, the 
spathe; this bursts open and permits of the unfolding of the simple, or more usually branched, inflorescence.

The individual flowers are as a rule unisexual and constructed on the ordinary monocotyledonous type ; P $3+3, \mathrm{~A} 3+3$, in the male flowers, and $\mathrm{P} 3+3, \mathrm{G}(3)$, in the female flowers. In Cocos their distribution is monoecious. Fig. 755 repre-

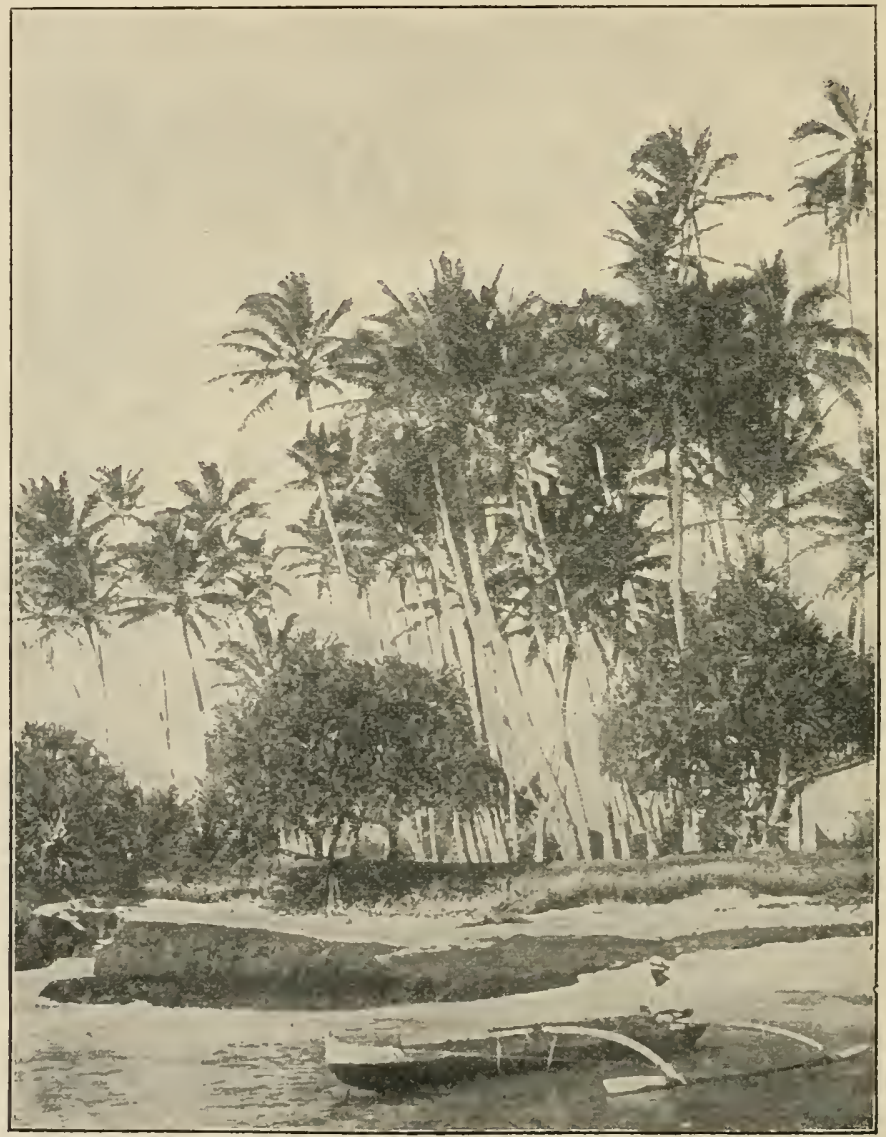

Frg. 758.-Coco-nut Palms at Hilo, Hawaii ; Punclenus odoretissimus in front of the Palms.

sents the inflorescence of Cocos nucifera, still partly enclosed by the spathe. The male flowers are crowded on the terminal branches of the inflorescence, while the female lowers are considerably larger and stand single lower down. The orary, which is here composed of three united carpels, becomes, as a rule, unilocular in the fruit, since only one carpel develops further. The ripe fruits (Fig. 756) are borne in small numbers on each inflorescence. Each consists of a coarse, fibrous exocarp, which contributes to the buoyancy of the frnit in water, and thus leads to the wide distribution of this palm on tropical coasts, and a hard endocarp on 
which the sutures of the three carpels can be plainly distinguished. At the base of each carpel a germinal pore is present in the endocarp (Fig. 757 ), but only the one in relation to which the embryo lies, remains permeable. The endosperm forms a thick layer within the endocarp; it is rich in fatty substances and produces the

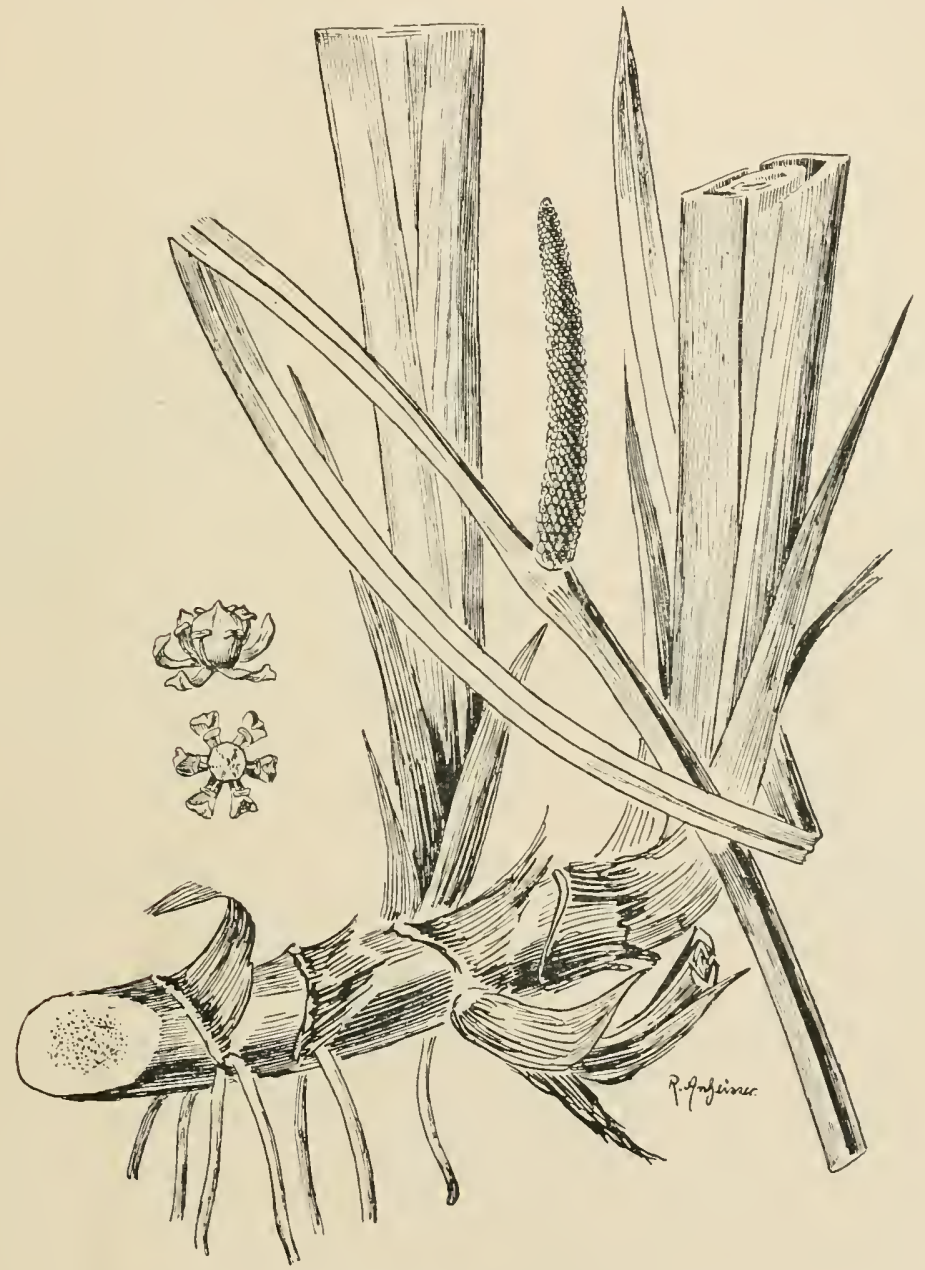

Fig. 759.-Aconus calamus. Flowering plant. Single flowers seen from above and from (the side. ( $\frac{1}{2}$ nat. size.)

COPRA of commerce. The space within the endosperm is partially filled with fluid, the "milk" of the coco-nut, which is possibly of service in germination. The embryo on germination develops a massire absorbent organ which grows into the cavity of the fruit and serves to absorb the reserve materials. Fig. 758 shows the general habit of Coco-nut palms. 
Differences are, however, found within the order. In Areck eatechu, the fruit developed from a similar ovary to that of Cocos is a berry, the exocarp becoming partly fibrous and partly succulent. The white endosperm is here of stony consistence, celhulose being stored as a reserve material; the endosperm is ruminated, i.c. the dark seed-coat grows into it at many points and gives it a veined appearance. The fruit of the Date Palm (Phoenix dactylifera) is also a berry, but this arises from one of the carpels of the apocarpus gynaeceum, the other two not developing. In contrast to the other genera mentioned, Phoenix is dioecious. Other important economic plants among the Palms are Elacìs yuincensis, the African Oil Palm, species of Calamus which yield Malacea Cane, and species of Mctroxylon, from which Sago is obtained; the two latter are found in the Asiatic-Australian region of the tropics. Phytelephas macrocarpa, an American Palm which does not form a trunk, yields vegetable ivory (the hard endosper'n!). Several species yield a flow of sugary sap on cutting off the inflorescence, and this is sometimes fermented to make Palm-wine and sometimes used as a source of cane-sngar (Aienga sacharifera).

Family 5. Araceae.-The Araceae are mostly herbs or shrubs; they take a conspicuous place as root-climbers in the damp tropical forests. The leaves of some species (e.g. Monstera) have the large lamina incised or perforated; this comes about by the death of definitely limited areas and is comparable to the method by which the leaves of Palms become componnd. Flowers are greatly reduced, usually diclinous, borne on a swollen, fleshy axis; a spathe, often of bright colour and serving to render the inflorescence conspicuons, is present at the base of the spike (e.g. Anthurium scherzerianum, Richurctic aethiopica, both of which are commonly cultivated). Fruit nsually a berry.

Acorus colcumus has, in the course of the last two or three centuries, spread to this country from the East. It has complete, hermaphrodite flowers $\left({ }^{93}\right)$; orary trilocular. The short spadix is terminal, but is displaced to one side by the spathe which resembles the foliage leaves (Fig. 759).

Porsorous.-Many Araceae are poisonous. Culle palustris in peaty swamps. Aruin maculatun (Fig. 760), a perennial herb with tuberous rhizome, common in woods. It develops a number of stalked, hastate leares, the brown spots on which give the plant its specitic name. The flowers are monoecious, without perianth; the female flowers stand at the base of the spadix and the male a short distance above them. Above the latter come a number of sterile flowers with downwardly directed, hair-like points, which stand at the level of the constricted portion of the spathe; this is widely open above. These hairs allow insects, attracted by the peculiar scent or seeking warmth (cf. 1.248), to creep into the lower expanded portion of the spathe, but prevelt their return until the female flowers have been pollinated from another individual. When this is accomplished the hair's wither and the anthers open. The escaping insects, now dusted with pollen, may enter other inflorescences and pollinate the flowers.

Family 6. Lemnaceae.-The Dnck-weeds of our pronds and streams have naked monoecions fiowers borne in depressions of the body of the plant. The flowers are surrounded by a small siathe. Lemna, Wolfina. 


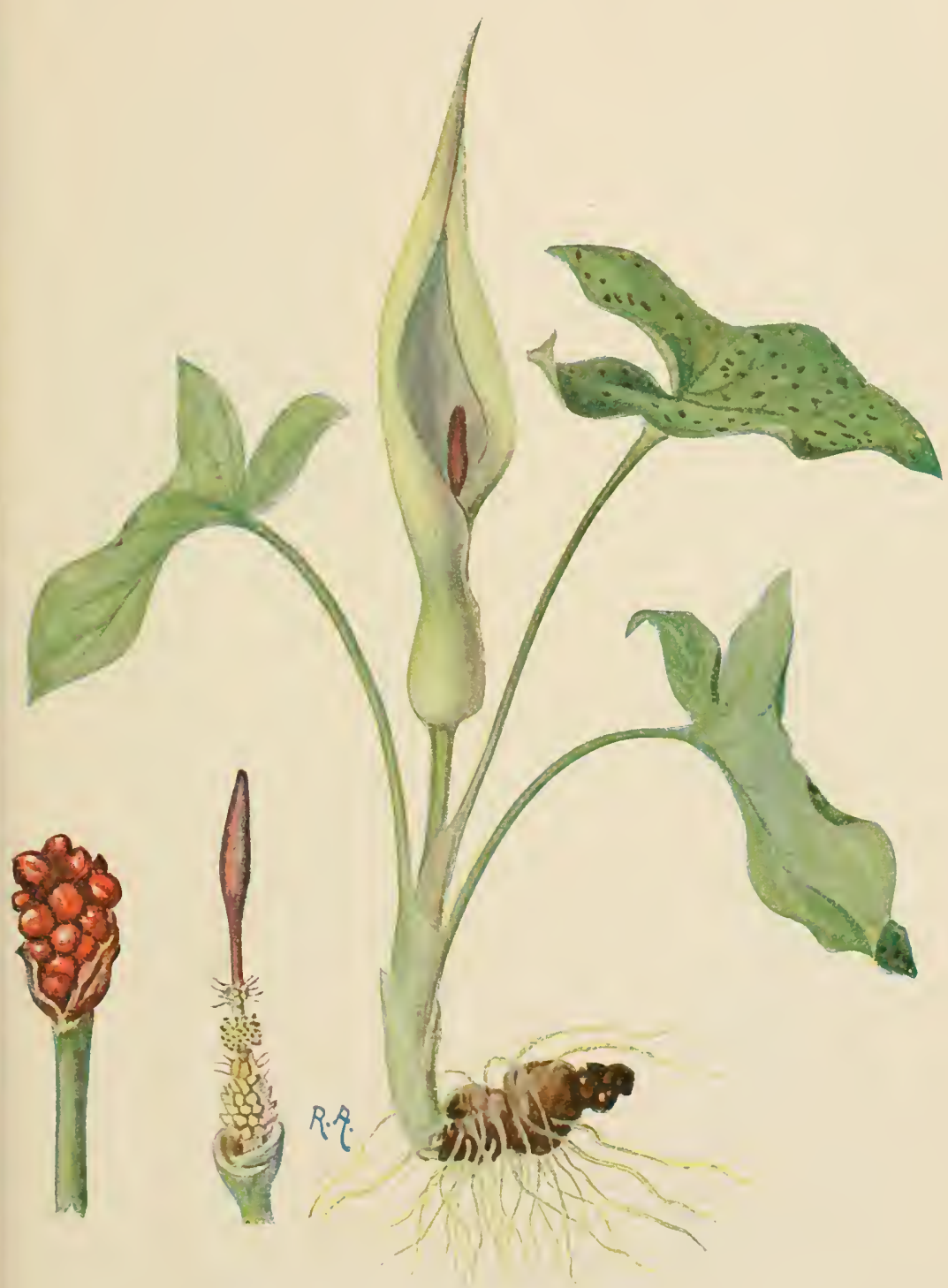

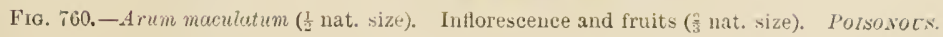

\section{Order 4. Enantioblastae}

A small order. Orules orthotropons; embryo at summit of endosperm at opposite end from the hilum. 
Family Commelinaceae. - Tropical and sub-tropical. Periauth developed as calyx and corolla. The hairs of the stamens afford well-known objects for the

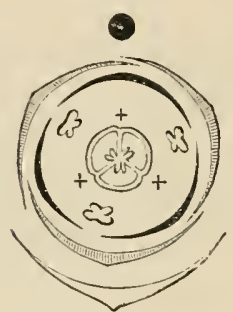

F1s. 761.-Diagram of a typical Liliaceous flower.

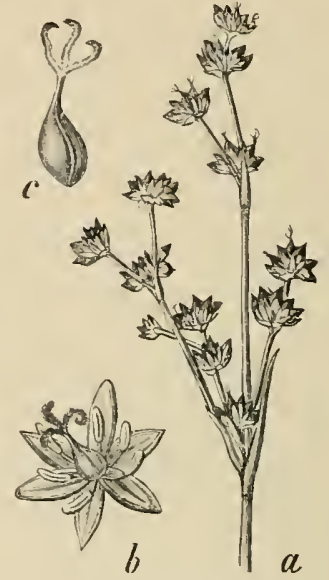

Fic. 762.-Juneus lamprocarpus. a, Part of an inflorescence: single flower $(b)$ and gynaeceum (c) magnified.

study of movements of protoplasm and nuelear divisions. Fruit a capsule. Cominetina, Tradescantia.

\section{Order 5. Liliiflorae $\left({ }^{9 \frac{1}{}}\right)$}

Hlowers actinomolphic, composed of five whorls, with superior or inferior ovary. Both whorls of the perianth developed alike. Only in the Iridaceae is one whorl of the androecium suppressed. The gynaeceum varies in position, but it is always formed of three carpels and in most cases has a trilocular ovary.

Family 1. Juncaceae.-Plants of grass-like habit. Flower of complete Liliaceous type; with scaly perianth. Wind-pollination. Pollen-grains united in tetrads. Ovary superior, uni- or trilocular, bearing three, long, papillose stigmas. Eudosperm floury. Fruit a capsule. Distributed in the temperate zones of both hemisplueres.

Numerous species of Juncus (Rush) occur in our flora, in marshy ground; the leaves are cylindrical and have large intercellular spaces. The clusters of small, anemophilous flowers (Fig. 762) are borne on the end of a shoot but are often displaced to the side by the bract which contiumes the line of the axis. Fruits with many seeds. $L w \approx u l u$, with flat leaves and three-seeded fruits, one of the earliest spuring-flowering plants.

Family 2. Liliaceae.-Typical flower, with coloured, conspicuous perianth. Ovary superior. Enclosperm horny or fleshy. Divided into three sub-families according to the construction of the fruit. 


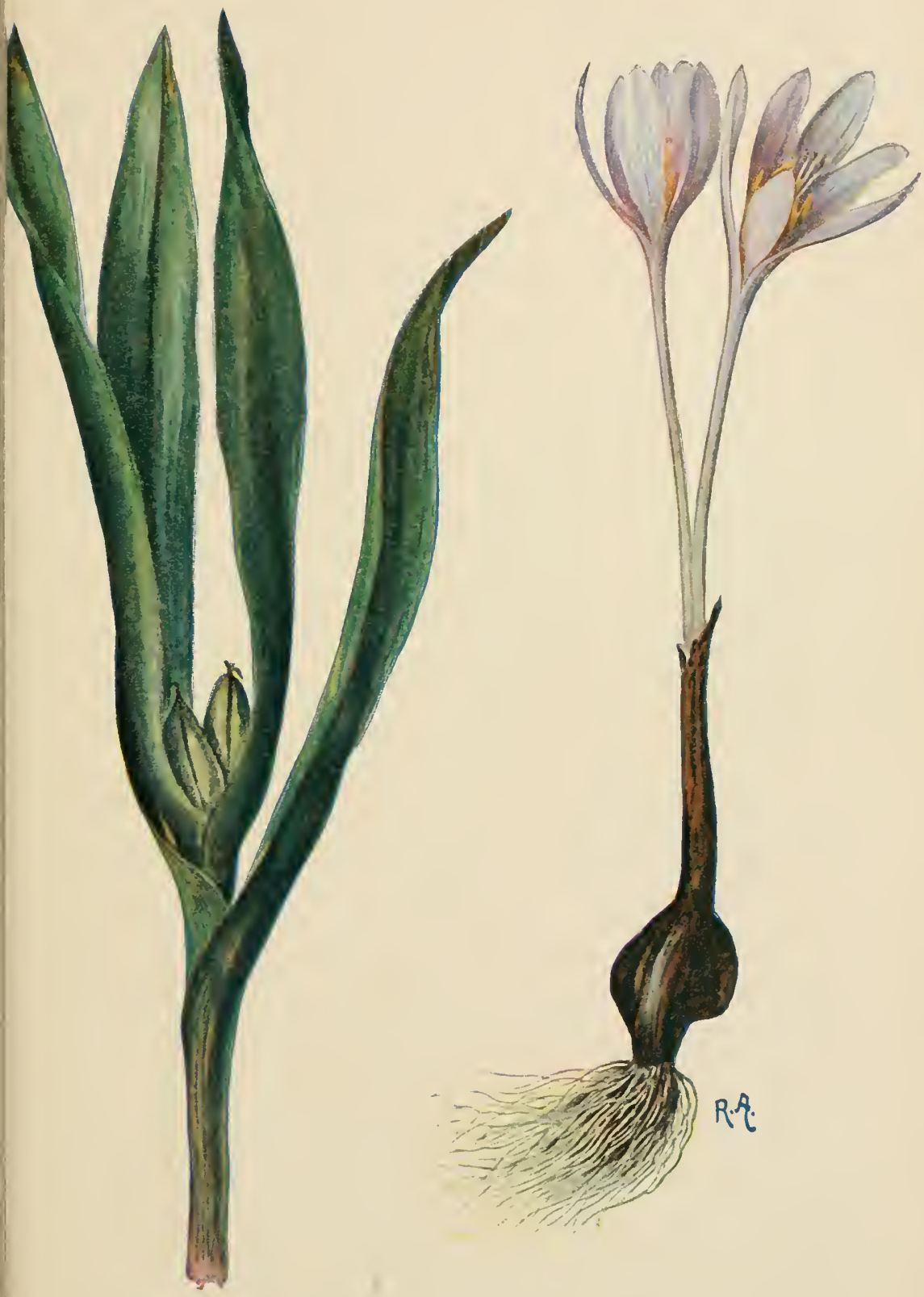

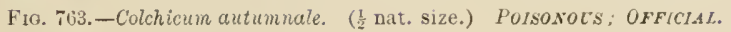


(a) Capsule with three styles; dehiscence septicidal, i.e. fruit splits through the septa. Melanthieae.

(b) Capsule with one style; dehiscence loculicidal, i.e. fruit splits

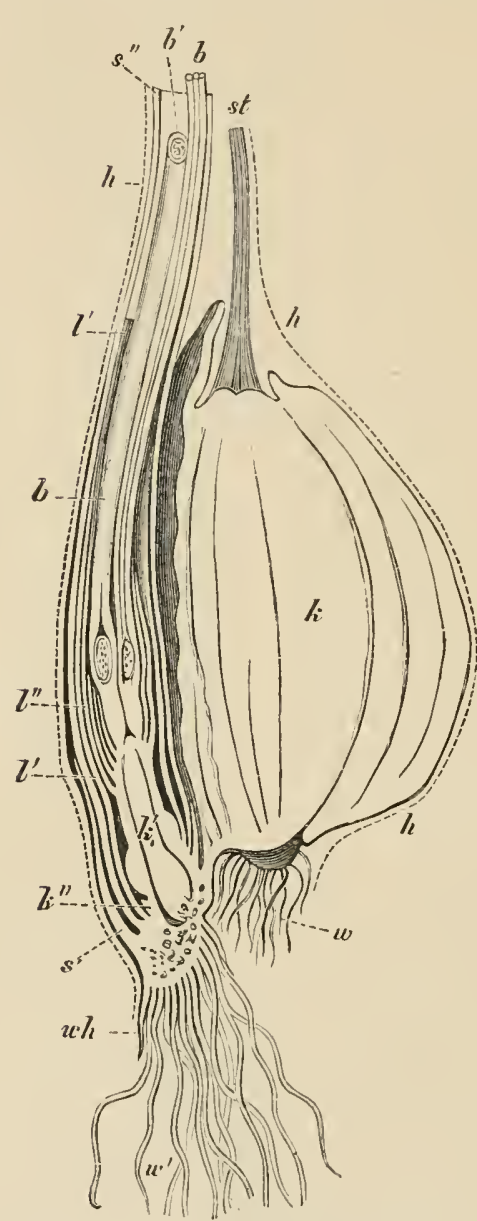

Fra. 764.-Colchicum autumnale. Longitudinal section through the corm of a flowering plant. Explanation in text. (After SAcHs.) OFFICIAL.

The three foliage leaves expand their long soil ; their shenthing portions closely surr , their slicathing portions closely strround the axis. The latter bears the fruits, which contain numerous, spherical, black seeds; these are liberated by the dehiscence of the capsule at the sutures. The aerial shoot then dies, the leafsheaths surrounding the new corm, which bears a lateral bud $\left(h^{\prime \prime}\right)$ in the axil of its opening the chambers of the ovary. Lilieae.

(c) Fruit a berry. Asparageae.

The majority of the Liliaceae are perennial herbs with bulbs, tubers, or rhizomes. They mainly inlubit the warm temperate regions, and utilise the cool and moist spring or autumn seasons as their vegetative period, passing the dry or cold seasons beneath the soil.

Colchicum autumnale, the Autumn Crocus (Figs. 763, 764) is a perennial herb growing in meadows. If a plant is examined in autunin at the time of flowering, the corm $(k)$, to the base of which is attached the lateral shoot bearing the flowers, will be seen to be enclosed in a brown envelope (Fig. 764, $h$ ). Roots spring from the base of this lateral shoot $\left(w^{\prime}\right)$, while those of the old corm $(w)$ are in a withered condition. At the summit of the corm the remains or scar of a dead aerial shoot will be seen (st). The lateral flowering shoot bears at its base three sheatling leares $\left(s^{\prime}, s^{\prime \prime} l^{\prime}\right)$ not separated by elongated internodes, In the axil of the third of these $\left(l^{\prime}\right)$ is a bud $\left(k^{\prime \prime}\right)$ which will form the flowering shoot of the next season; this third leaf will develop a lamina and appear above ground in spring as the first foliage leaf. A thickened internode $\left(k^{\prime}\right)$ separates it from the two leaves $\left(l^{\prime \prime}\right)$ situated higher up on the axis. Above them come the flowers $\left(b, b^{\prime}\right)$, which may be four in number, and stand in the axils of reduced leaves; by the arrest of the growing loint of the axis the flowers appear to be terminal. In spring the reserve materials from the tuber $(k)$ are absorbed and the old tuber is pushed aside by the swollen internode $\left(k^{\prime}\right)$, which in its turn enlarges to form a new corm. channelled, dark green laminae above the 
first foliage leaf; this bud was already evident in the preceding season. Ferotrum album is a conspicuous herb with a rosette of large elliptical, longitudinally folded leaves. The growth of the main axis is terminated by an inflorescence, which is a panicle more than a metre in height; the leaves borne on it have long sleaths and diminish in size from below npwards. The greenish-white flowers are

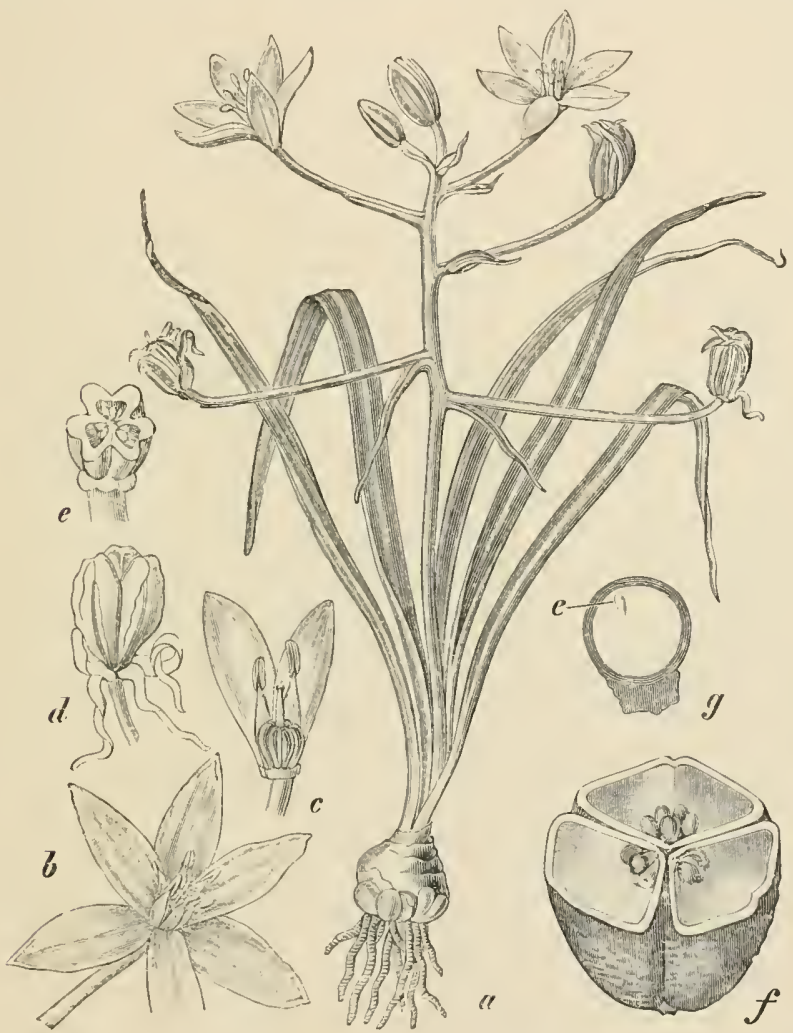

Fif. 765.-16-e, Ornithogulum unbellatum: a, entire plant (reduced); b, flower (nat. size); $c$, flower, part of perigone and androecium removel ; $d$, fruit; $e$, fruit in transverse section. $f-g$, fol. $h i$ cum autumnule: $f$, fruit in transverse section; $y$, section through seed showing endosperm $(c)$. (c-lf magnitied.)

polygamous, i.c. partly hermaphrodite and partly unisexual ; the ovary bears three widely-sprearling styles.

Such popular flowers as Tulipe (Fig. 25), IIyacinthus, Litium, Mruserri, and Scille, and vegetables as Allimm, together with Urginea (Fig. 766), which occurs in the Mediterramean region, belong, on the other hand, to the Lilieae. Ormithogatum umbellatum (Fig. 765) will serve as an example of this group. In autumu the plant consists of a bulb, each of the lleshy scales of which has a scar at the upper end; numerous roots sjring from the base of the bulb. The bulb-scales are more or less grown together. In the axil of the innermost scale is the stalk of the 


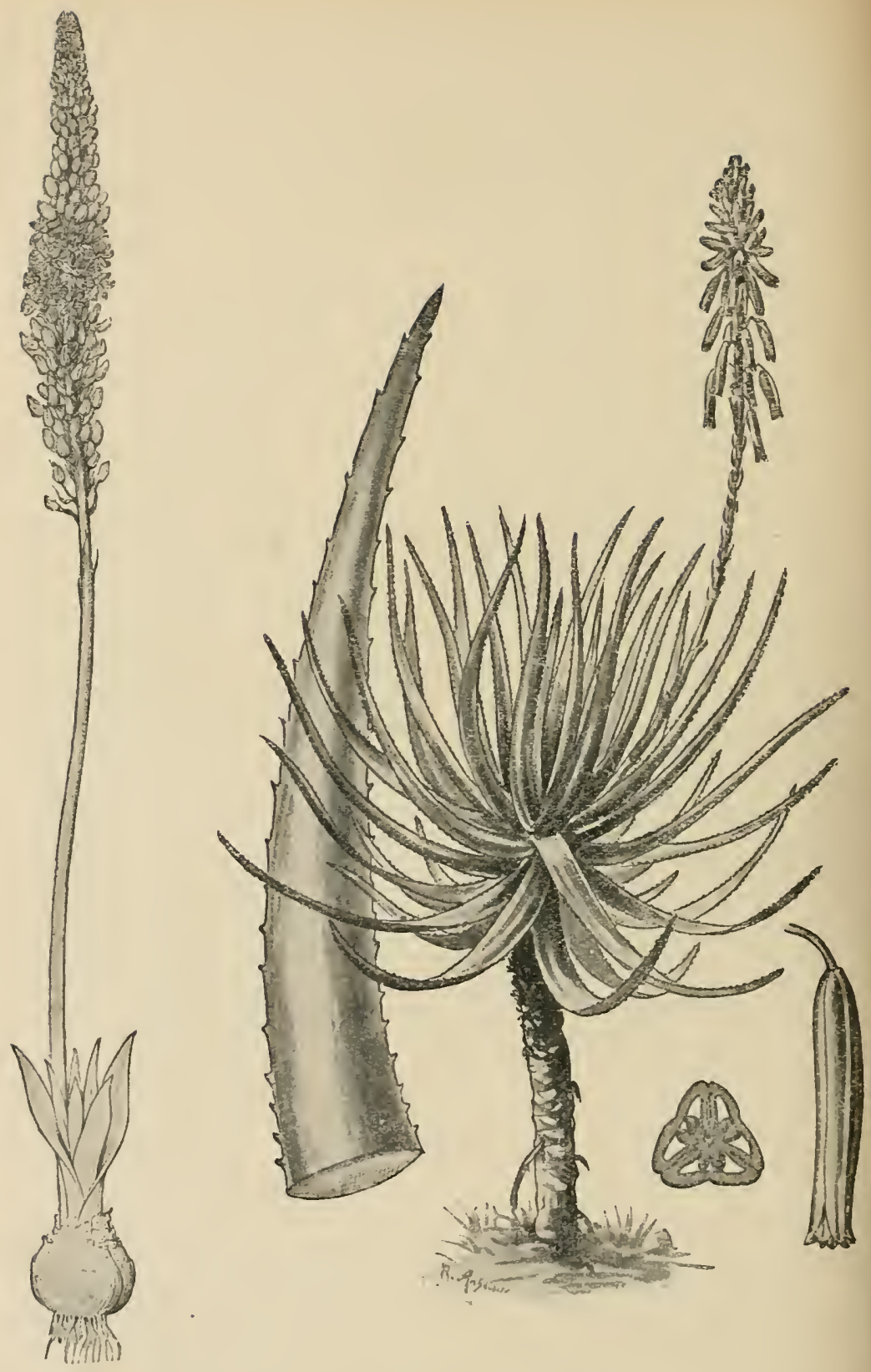

Fur, 766,- Lryinea muritime (about $\frac{1}{10}$ nat. size). OFF'TAl. (After BERG and S(HMIDT.)

F'1, 767.-Aloë sucutrinu. Plant in flower (greatly reduced); tip of leaf, single flower, and cross-section of ovary. (3 nat. size.) OFFICIAL. 
spent inflorescence togrether with a young burl bearing a number of leaves. Eacls of these leaves is provided with an embryonic lanina, while the continuation of the shoot is the embryonic inflorescence. In spring the leaves grow into long, linear structures, and, together with the inflorescence, appear above ground. The inflorescence is sparingly branched; the white Howers have a trilocular ovary bearing a common style. The upper larts of the leaves wither while the basal portions become swollen and fleshy and stored with reserve materials; the scar at the upper part of each scale marks the place of separation of the leaf-blade. The annual course of development is essentially similar in other bulbous plants. The vegetative period is restricted to a few months, while during the cold or, in the numerous bulbous plants of warin-temperate climates, the dry seasons, the bulb is

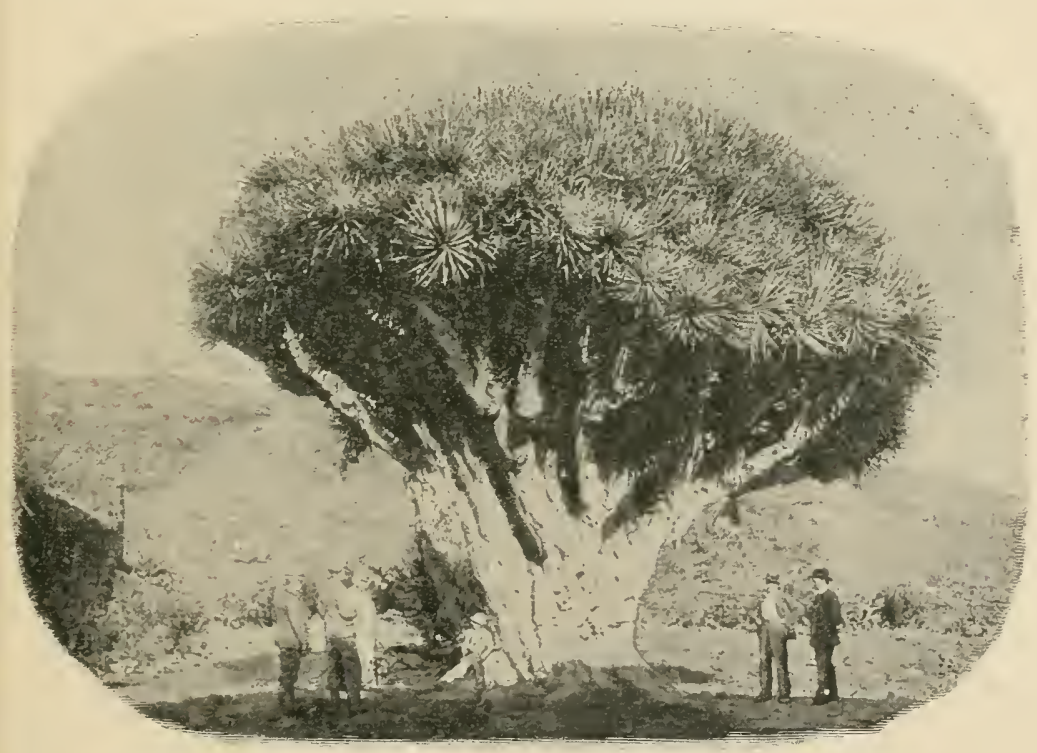

Fis. T65.-Dreetena truev. The Dragon Tree of Laguna in the Canary Islands. (From Ches, A us den Tirfen des Weltmeeres.)

protected by its subterranean situation. Aloe, a genus of African plants containing many species (Fig. $\mathbf{7 6 7}$ ) may be mentioned as an example of an arborescent member of the Lilieae.

Drucuenc (Fig. 768), an arborescent form which attains a great age and a characteristic aplearance, together with the similar genera, Cordyline and Fucc, belong to the Asparageae. To the same sub-fanily belongs Similax (Sarsaparilla), a slirubby plant of warmer countries, climbing by the help of tendril-like emergences at the base of the petioles. Other examples are Asparayus with bunches of phylloclades (p. 26) in place of leaves, Conrallarice (Fig. 34), Muianthemum, Polygonatum, and Paris quadrifolic (Fig. 769); the latter bears whorls of four leaves, sometimes $3-6$ leaves. All these plants liave creeping rhizomes bearing scale-leares; either the apex of this rhizome grows annually into the erect shoot bearing the foliage leaves and inflorescences, while the growth of the rhizome is continued by a lateral branch (Polygonetum, Fig. 23), or the rhizome 
continues its subterramean growth, the leafy shoots being developed from axillary buts (Puris) (Fig. 769).

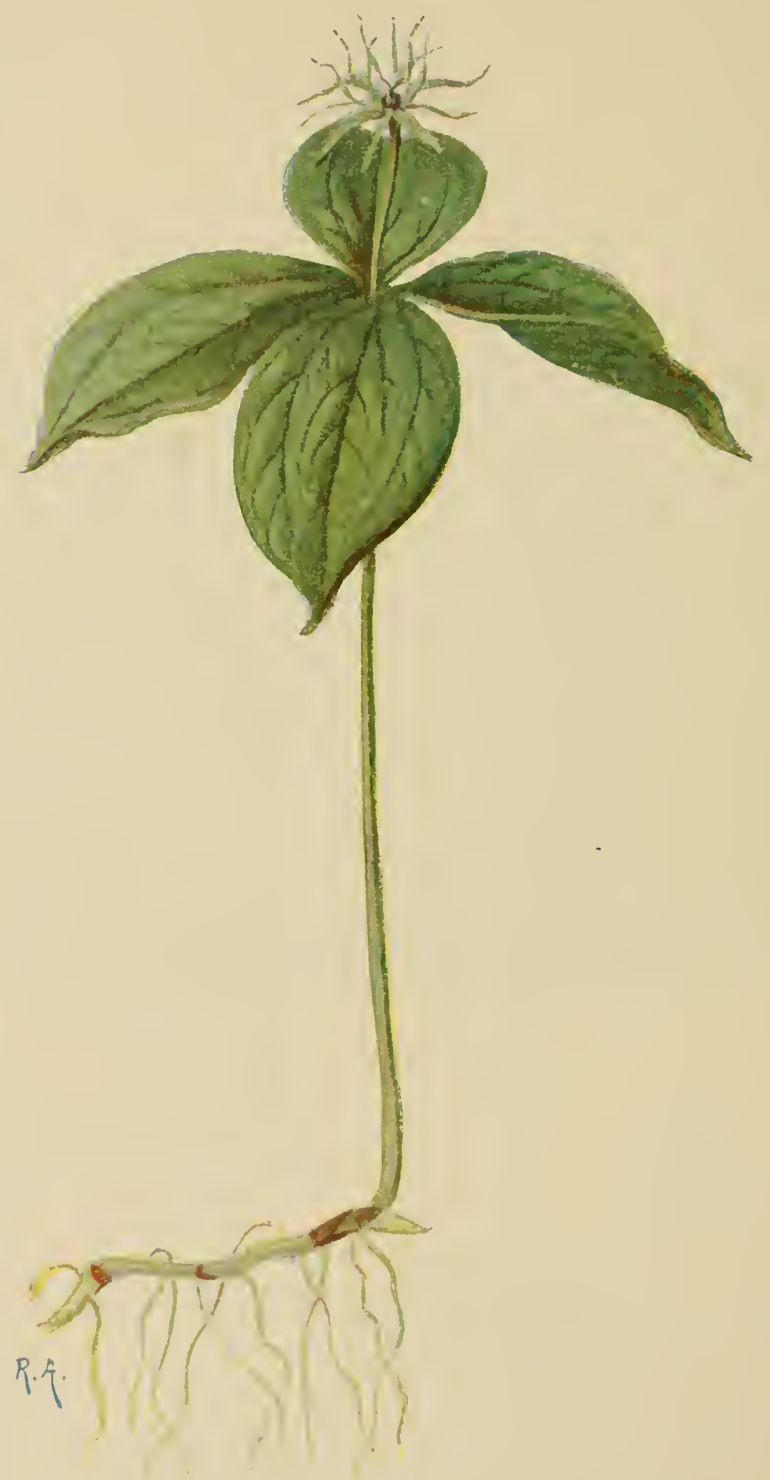

FIG. 769.-l'aris quadrifolio. (3 nat size.) I'orsoroc's. 
P'orsorous.-Numerons Liliaceae are more or less poisonous, e.1. Lily of the Valley, Tulip, Fritilleria, Culchicum, Foverum, Paris.

OFFICIAL. - Colchicum autumnale, seeds and corm; Schocnoceuton (Sabadilla)

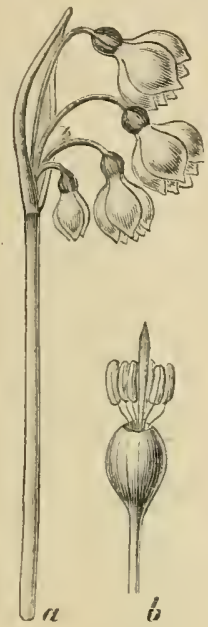

Fri. Tт0. - Leucojum aestirum. (c, Inflorescence (reduced); $b$, gynaecum and androecium (nat. size).

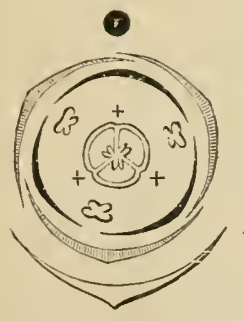

Fic. 7\%1.-Floral diagram of the Iridacene (Iris).

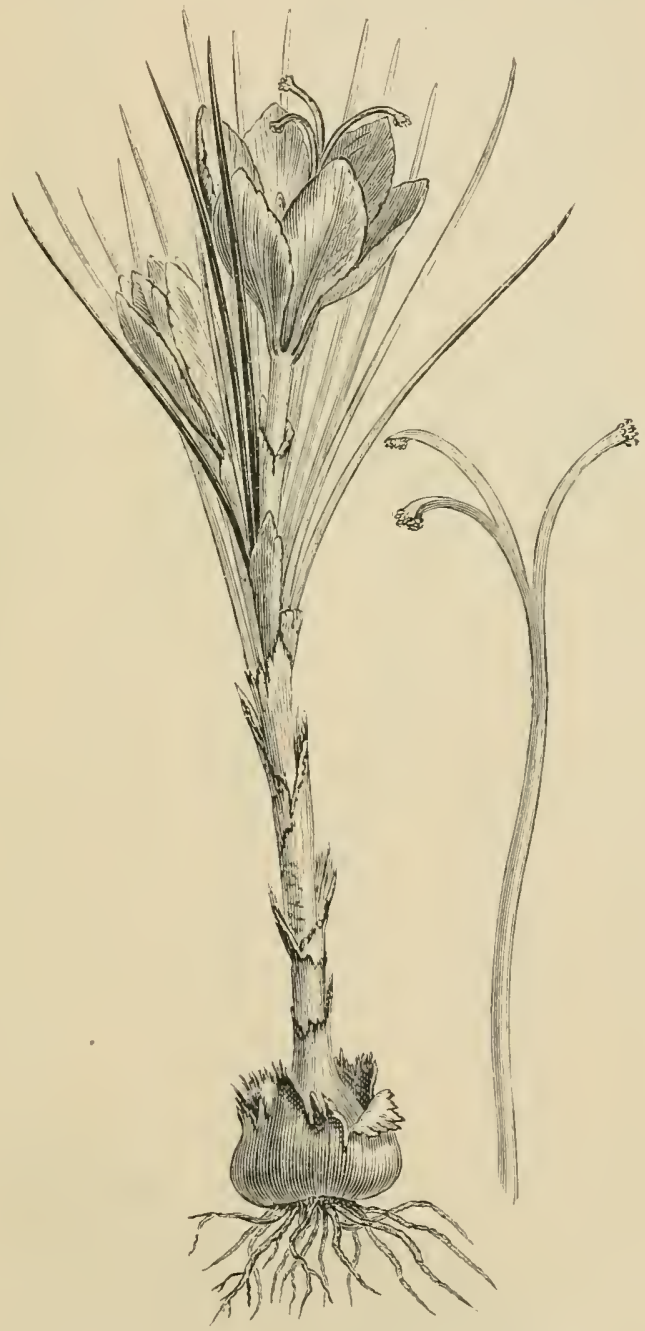

Fir. Tis.-Cincus sutims. Style with tripartite stigma. OFFICIAI. (After BaILLOX.)

ofncinatis, a bulbous plant with grass-like foliage from mountains of Central America and Venezuela; the seeds yield veratrixta. Aloever A. chinensis, A. perryi, and other species yield ALOES BARIAUENSIS and ALOES SOCOTRIXA. Cryinere scillae yields SQLILL. Smilax ornatu, etc., yield SARSAPARILLA. 


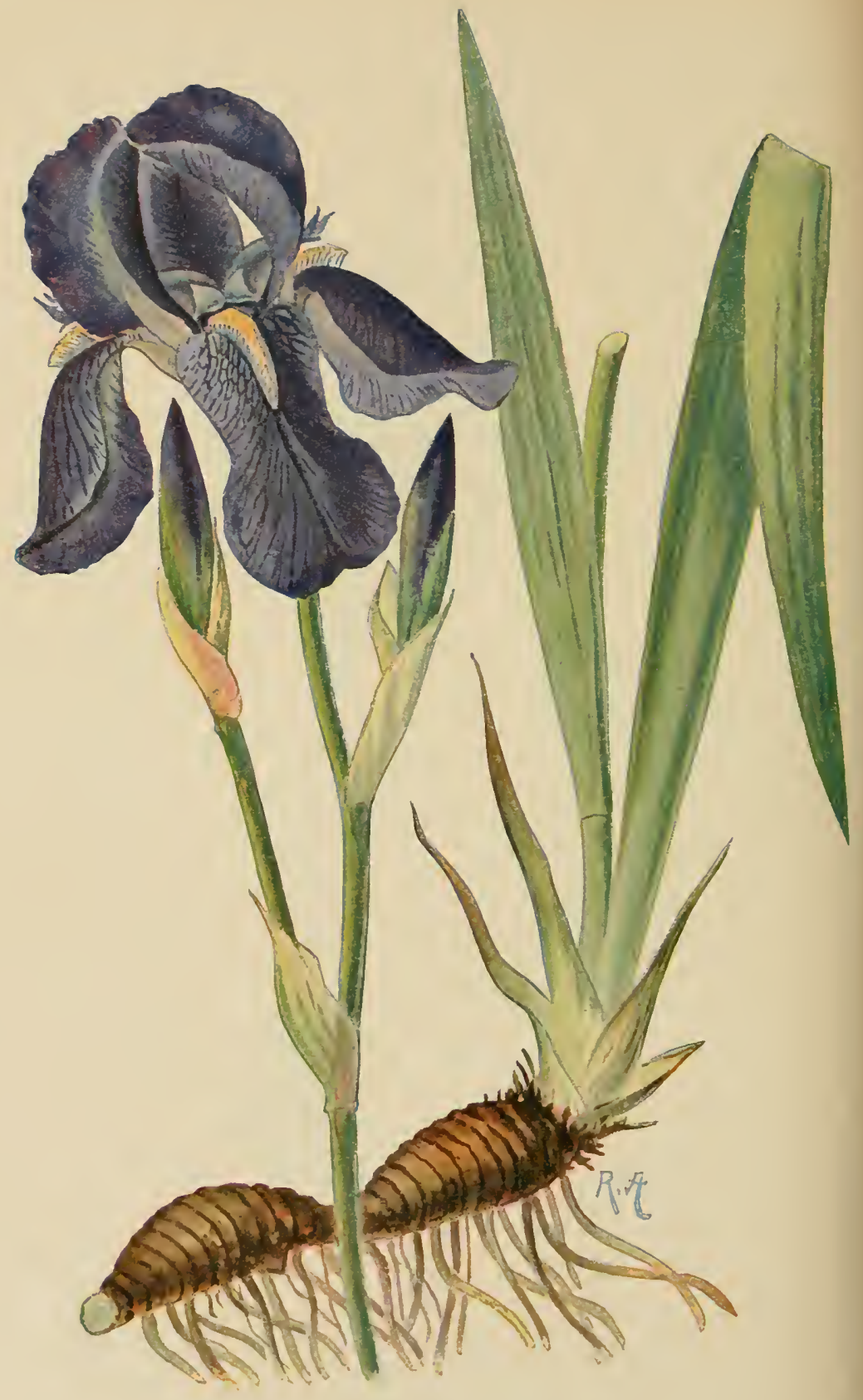

Frr. 773.-Iris germanicre. (l nat. size.) 
Family 3. Amaryllidaceae. - Distinguished from Liliaceae by the inferior orary. Mostly tropical and sub-tropical. Leucojum (Fig. 770), the Snowdrop' (Galunthus), and Larcissus resemble the bnlbons Liliaceae in habit. Ayare, large plants with succulent leaves from the warmer regions of America, provide fibres. A. mexicana provicles the national drink of IIexico (prlque), obtained by fermenting the sap that flows on cutting off the inflorescence. Species of Ayare are naturalised in the Mediterranean region, but none are native there.

Family 4. Iridaceae. - Distinguished from Liliaceae by their inferior ovary and by the suppression of the inner whorl of the androecium (Fig. 771 ). The two whorls of the perianth are not always similar. Anthers extrorse. The leaves of the Iridaceae are always sessile; the underground portion is a tuberous or elongated rhizome, rarely a bulb. Capsule loculicidal.

This family is nainly represented in the Cape and the warmer parts of America.

Crocus sutivus, Saffron (Fig. 772) is a plant which has long been cultivated in the East; it lias a tuberous rhizone and narrow, grass-like leaves. The flowers are sterile nnless pollinated with pollen of the wild form. The large stigmas furnish Saffron. Other species are cultivated as ornamental plants.

Iris, leaves overlapping in two ranks. The leaf-sheath surrounds the thick fleshy rhizome, while the sword-shaped blade stands erect and has its two lateral surfaces alike (Fig. 7\%3). Outer perianth segments bent downwards, inner erect. The three anthers are roofed orer by the three leaf-like styles. In Gladiolus the Howers are dorsiventral, and the dissimilarity of the perianth leares is more marked.

OFFICIAL. - Croeus sotivus yields SAFFRON.

Family 5. Dioscoreaceae. -Climbing slirubs with diclinous flowers, sagittate or cordate, frequently net-reined leares and large, tuberons rhizomes. Mostly tropical. Dioscorea batutas, Yam (China); Testudinaria clopheantipes is often cultivated. Tamus communis, the Bryony, is British.

Family 6. Bromeliaceae $\left.{ }^{95}\right)$.- Nlostly epiphytes; flowers hermaphrodite, 1 osition of ovary rariable. Limited to tropical and sub-tropical parts of America. The leares are in rosettes and are typically xerophytic; in the forms which grow in the soil they are spiny. Ananassa sativa is eultivated and has spread in the wild state in the tropics : its inflorescence forms the Pineal'ple.

\section{Ordel' 6. Scitamineae}

Tropical plants, sometimes of large size, in a few cases arborescent. Flowers dorsiventral or asymmetrical. Perianth differentiated into calyx and corolla. Androecium greatly reduced; some of the stamens represented by staminodes, and resembling the segments of the corolla. Ovary inferior, trilocular. Seeds with perisperm.

Family 1. Musaceae.-The Banana (Musci) is one of the most important plants of all tropical countries. The apparent, erect stem is formed of the closely overlapping, sheathing bases of the large leaves. Inflorescence, terminal. Fruit, a berry. M. textilis yields Manilla Heml'.

Family 2. Zingiberaceae.-Flowers in spikes, which in some cases 


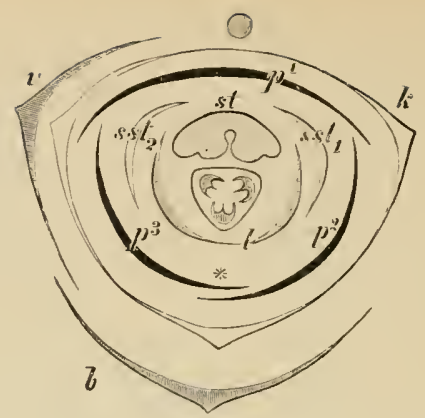

F1G. 774.-Floral diagram of Zingiberacene (after E1chLER). $b$, Bract; $c$, bracteole; $k$ calyx; $p^{13}$, segments of corolla; $s_{1} t_{1}, s t_{2}$, staminorles of the outer whorl of the androecium ; - the suppressed stamen of this whorl; st, the single fertile stamen; l, petaloid staminodes of the inner whorl of the androeceum forming what is known as the labellun.

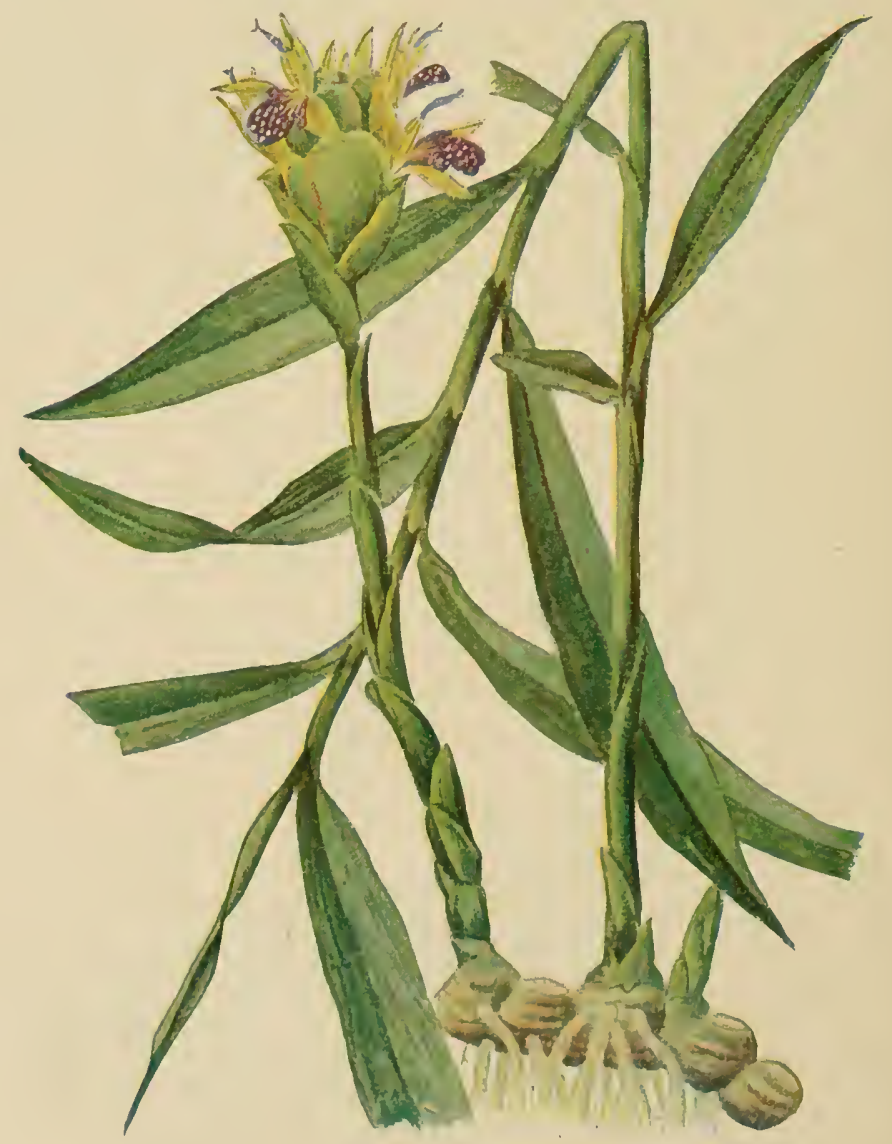

Fu. 775.-Zingiber officinele. (l nat size.) After BERo and ScHMDT. 
resemble capitula. Flower dorsiventral. Calyx inconspicuous, tubular. Corolla with three lobes. The outer whorl of the androecium is wanting or represented by two lateral staminodes (Fig. $77 t$, sst $t_{1}, s_{2}$ ). Only the posterior stamen of the inner whorl (st) is fertile; the two others are joined to form the brightly coloured, petaloid labellum $(l)$. The style lies in the tubular groove between the thecae of the stamen. Fruit a capsule. Most plants of the family belong to tropical Asia.

Zingiber officincte, the Ginger, is an ancient cultivated plant of Sonthern Asia, now cultivated throughout the tropies (Fig. 775). The flattened branched rhizome is in contact with the soil by its narrow side. Leaves, two-ranked; main shoot continued by the growth of axillary buds of the lower surface. The leafy shoots, in spite of their length, are composer of the sheaths of the large, simple, entire leaves, the axis remaining extremely short. Bracts large and, especially at their margins, brightly colonred. Flowers, bright yellow, with a conspicuous, violet and spotted labellum. Eletturie Curdumomum and Curcumu have the stalks bearing their inflorescences similarly composed of leaf-sheaths. Alpinic and Hedychinan, the latter of which is often cultivated, have on the other hand normal, leafy shoots bearing the terminal inflorescence.

OFFICIAL.-Zingiber officinale, rhizome yields GINGER. Eletturia Cardamomum yields CARDAHOM SEEDS.

Family 3. Cannaceae.-Large-leaved herbs; often in cultivation. Flowers asymmetrical (Fig. 76 ). Only one half stamen fertile (i.e. anther with only one theca), the other half being yetaloid.

Family 4. Marantaceae.-Large-leaved herbs. Leaves with pulvinus at junction of stalk and lamina. Stamen as in preceding order. Arrowroot is obtained from Larante arkindinacca.

\section{Order 7. Gynandrae}

Family Orchidaceae.-Perennial, herbaceous plants growing as epiphytes or in the sround, with hermaphrodite, zygomorphic flowers. Perianth petaloid, the posterior segment of the inner whorl developed as a lip or labellum, which frequently bears a spur. (The "labellum" of the Scitamineae being formed of two staminodes, is entirely different morphologically.) Androecium formed of the three anterior stamens only; the middle stamen, belonging to the onter whorl, is fertile; the other two are represented by staminodes. Cypripedium has these two lateral stamens of the inner whorl fertile. Gynaeceum formed of three carpels, syncarpous; ovary inferior, uni locular. Fruit, a capsule. Seeds extremely numerous, borne on parietal placentas (Fig. $7 T 7$ ). The fertile stamen is adherent to the style and forms with it the COLUMN or GYNOSTEMIUM ; this projects more or less in the centre of the flower. 'The labellum, which serves as an alighting place for visiting insects, becomes anterior either by the torsion of the whole flower through $180^{\circ}$ (cf. Figs. $777-780$ ) or by the flower being bent backwards. 
This order of $6000-10,000$ species is abundantly represented in the tropics and primarily divided into Muncentrae and Diondrae, in which one stamen of the onter whorl or two stamens of the inner whorl are fertile respectively.

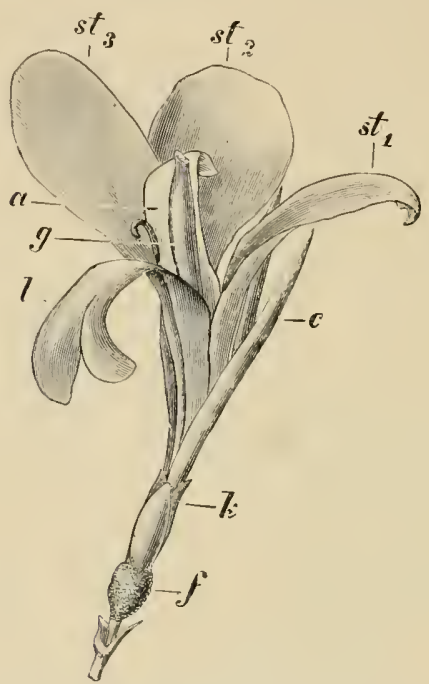

Examples of Bittish Gexera: -1. Nonandrae: Orchis, Ophrys, Gymnadenia witl tubers; Epipactis, Cephalanthera, Listera with branched rhizomes; Neottia, the Bird's-nest Orchid, Epiporgon, Coralliorhise, sa prophytic and almost destitute of chlorophyll. 2. Diandrae: Cypripodium, Ladies' Slipper.

Orchis militaris, which is represented in Fig. 782, will serve as an example for more detailed consideration. At the period of flowering a pair of fleshy tubers will be found

Fis. Thi.-Flower of Canna iridifore. $f$, wary ;

i, calyx; $c$, corolla; 1 , labellnm ; st $1-3$, the other starninodia; $"$ fertile stamen; $g$, style. ( $\frac{1}{2}$ nat. size.)

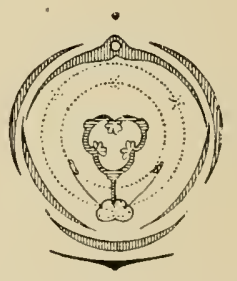

Fıx. 77.-Orehidacear. Floral cliagram (Orehis).

at the base of the plant, both of which are covered with root hairs. The large or brown tuber of more slongy texture continues above into the stem which

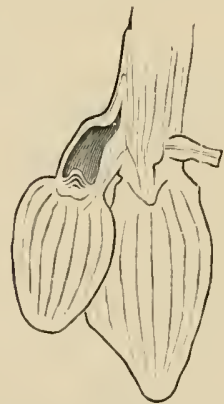

Fis. Tis.-oreh is militeris. Loneriturlinal section lassing through throlil and new tubers. (After I,terssex.)

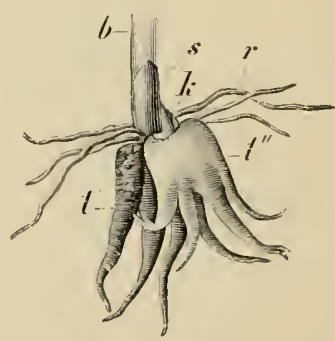

Fil. Fi!r,- Root-system of Orchis lutifolice. b, liase of stim ; $s$, catalhyllary leaf ; $t^{\prime}$, old, $t^{\prime \prime}$, gouns" tubers: ; $k$, burl ; $r$, root.

terminates in the pyramilal inflorescence; this stem is surrounded at the base by a pair of scale-leaves and the sheaths of the 2-4 elongated, elliptical foliage leaves. The smaller tuber is of firmer consistence and of a white colour ; it bears, 
as is shown in the longitudinal section (Fig. Tis), a but on its summit which already shows a pair of scale leaves. This tuber has arisen as an axillary bud in relation to one of the first scale-leaves of the plant, and with its tuberons, swollen, first root las broken through the subtendiug scale-leaf (Fig. 782 \%. It is destined to replace the parent plant in the succeeding season.

In considering the flower, the spiral torsion of the ovary, which brings the labellum into the anterior position, must first be recognised. The labellum is

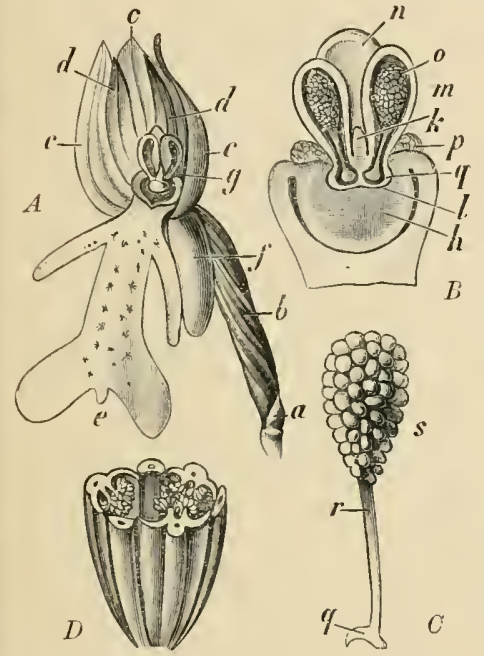

Fic, 780.-Orchis milituris. A, Flower: ", bract; $b$, ovary; $c$, the outer, and $d$, the two anterior inner perigone leaves : $e$, labellum with the sjur $f ; g$, gynostemium. $L$, Flower after removal of all of the perigone leaves with exception of the upper part of the labellum: $h$, stigma: $l$, rostellum; $l$, tooth-like prolol sation of the rostellum : $m$, anther ; $n$, connective ; $o$, pollinium ; ', viseid dise; $p$, staminodium. C, A jolliniun: $r$, eaudicle; $s$, pollen. $D$, Ovary in transverse section. (After Berg and ScHMIDT.)

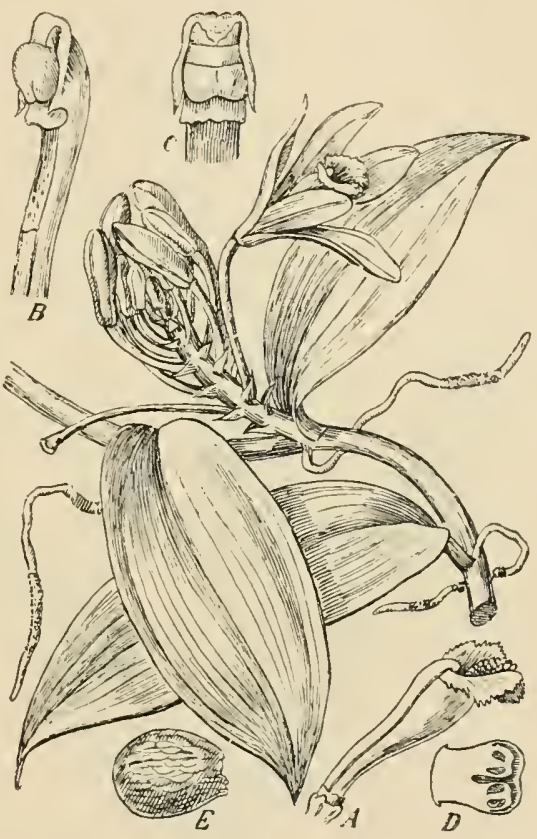

Fsc. Ts1.-Fanilla planifotia (reshuced. After Bene and SCHMIDT; from FistLer and l'RANTL). A, Labellum and gynostemium ; $B$, gynostemium from the side; $C$, summit of the gynosteminu from in front; $D$, anther ; $E$, seel. (Magnifierl.)

tripartite and the larger middle segment is bifid at its free end. At the base of the labellum a spur is formed by the bulging out of this segment of the perianth: this serves as the nectary and the opening leading into it is situated just below the gynostemium (Fig. $780, d, B)$. The latter bears on the side that is turned towarts the lower lip, and to an insect alighting on this, the large stigmatic surface $(h)$ corresponding to two confluent stigmatic lobes. The third stigmatic lobe is transformed into a structure termed the rostellum $(l, k)$ and stands in relation to the male organ. The single fertile anther consists of two thece joined together by the comective which appears as the end of the gynostemium. The whole mass of pollen of each of the two pollen-sacs is joined together by an interstitial substance which continues below to form a stalk: the whole structure, which has a waxy consistence, is called a pollinium, and the stalk goes by the name of the caudicle. 


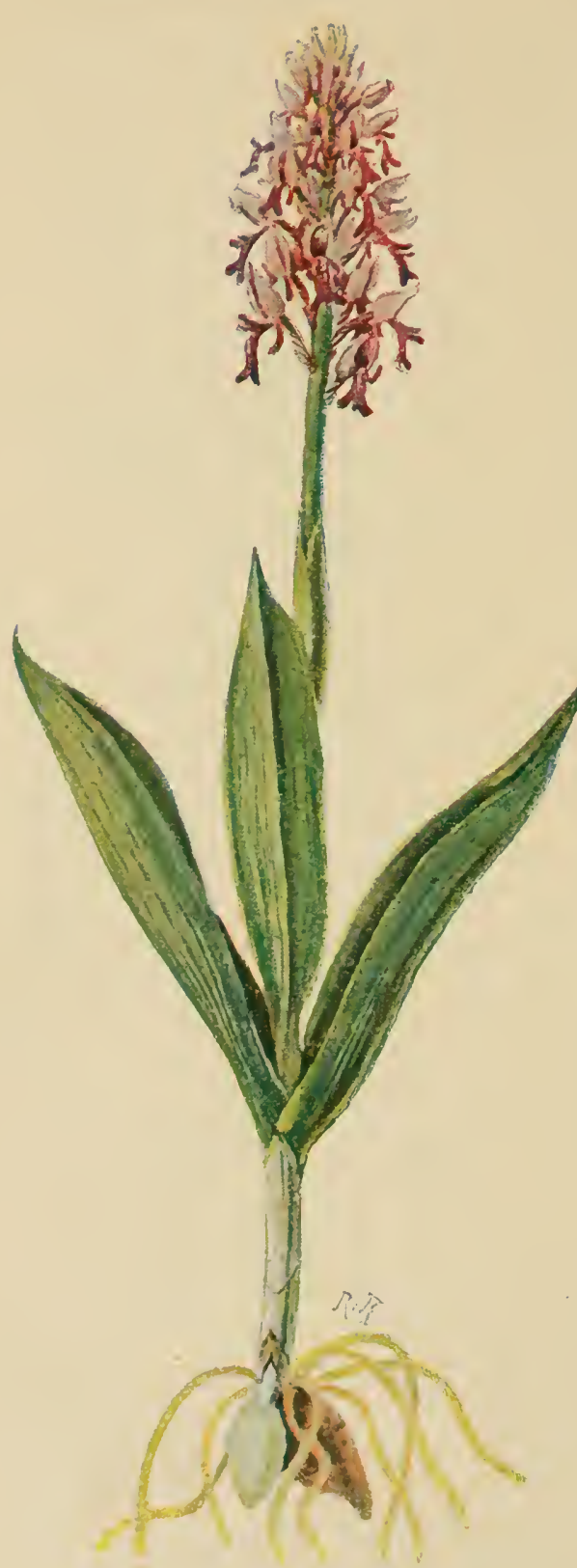

F'u, 782.-Orchis milituris. ( $\frac{1}{2}$ nat. size.)
The candicles terminate below in contact with the rostellum which forms tough adhesire discs. This relation to the rostellum serves to keep the pollinia, which lie free in the pollen-sacs, in position, and the adhesive discs attach the pollinia to any body that comes in contact with them. If an insect alights on the lower lip and attempts to reach the nectar secreted in the spur, its lead or tongne must touch the rostellum and the pollinia will become attached to it. As the adhesive discs dry they cause the pollinia to bend forward, so that when the insect visits a second flower they will be brought in contact with the stigmatic surfaces.

All Orchids are similarly adapted to insect visitors, thongh in many the contrirances are far more complicated; pollination does not take place in the absence of the insects. In many cases the adajtations are so specialised to particular insects that no other insect will do instear. Thus Vanille brought from its American habitats to other tropical countries remains sterile on acconnt of the absence of the pollinating insect. On this fact being discovered artificial pollination was resorted to and the plants can thus be induced to bear fruits regularly. It should be mentioned that in some forms, e.g. Tranille, the pollen remains powdery. Nany tropical Orchids are cultirated in greenhonses on account of the beauty of their flowers.

\section{Fossil Angiosperms ( $\left.{ }^{96}\right)$}

The first undoubted Angiosperms appear in the Upper 
Cretaceons. They are represented by numerous species which, like the recent forms, can be divided into Monocotyledons and Dicotyledons. The most ancient forms are known only as leaves, so that their determination is a matter of difficulty. They agree essentially with living Angiosperms, and since they show no similarities to Gymnosperms or Pteridophytes, do not aid in bridging over the gap between the Angiosperms and these groups.

Of IIonocotyledous examples of the Palmae are known from the Cretaceons period onwards. The leares of Dicotyledons from the Cretaceous are doubtfully placed in various orders which contain the more lowly organised type (Quercitlorae, Platanaceac); some are ascribed to Euculyptus. The Angiosperms of the Eocene and the Oligocene can be determined with greater certainty; even in Northern Europe representatives of existing tropical and sub-tropical families occurred, e.g. Palmae, Dracacna, Suilax among Monocotyledons, numerons Querciflorae (es]. Qucrens), Lauraceae (Cinibmomum, etc.), Leguminosae, etc. among Dicotyledons.

As the present period is approacher the fossil Angiosperms throw even less light on the systematic arrangement of the groul. The few genera that have become extinct (e.g. Dryophyllum, a suplosed ancestral form of the Oaks) are wanting even in the Eocene. From the Hiocene onwards the specific forms are in part identical with those now living, and in the Qnaternary strata all the remains are of existing species. The general character of the Tertiary flora in Europe was, however, very different from that of the present day. It had the aspect of the flora of a mnch warmer region and (as in the case of the Gymnosperms) contained forms which now exist only in distant regions. 



\section{INDEX OF LITERATURE}

Sratements which alpeared to be too special for inclusion in a text-book, but could not be entirely omitted, are briefly referred to and are printerl in italics.

\section{INTRODUCTION AND MORPHOLOGY BY E. STRASBURGER}

(1) E. Hanckel, Generelle Mlorphologie der Organismen, 1866, 1) 52. ( ${ }^{(2)}$ Fritz Müller, Für Darwin, 1864. $\left({ }^{3}\right)$ Charles Danwin, On the Origin of Species by IIeans of Natural Selection, 1859. Cf. also Ludwig Plate, Selektionspriuzip und Probleme der Artenbildung, Ed. 3, 190S. (4) Hugo DE Vries, Die Mrutationstheorie, 1901-1903. ( $\left.{ }^{5}\right)$ CARL NïGELr, Nechanisch-physiologische Theorie der Abstammungslehre, 1883; Julits SAcus, Flora, vol. Ixxxii. 1896, 1. 173. ( $\left.{ }^{6}\right)$ R. v. WETTSTEIs, most recently in Handbuch der systematischen Botanik, 1901, p. 40. (') Cf. John Butler-Burke in "Nature," 1905, pp. 78, 294, 492; this investiyator's results hare been widely published in the daily press. On the other side see especially the review by W. Rotx, Wochenschrift iiber die Fortschritte und Bewegungen auf dem Gesamtgebiete der Wissenschaft und Techuik, 1906, No. 8. ${ }^{8}$ ) Often termed Biology, but this concept is better used for the whole science of liviny beings. $\left({ }^{9}\right)$ K. Goesel, V'ergleichende Eutwicklungsgeschichte der Pflanzenorgane, 1883, and Organographie der Pflanzen, 1898-1901. F. Pdx, Allgemeine Morphologie der Pflanzen, 1890. $\left({ }^{10}\right)$ K. Goebel, Organographie der Pflanzen, 1898, 1'1. 15, 261, 448. (11) K. Goebel, in $\left({ }^{10}\right)$, 1. 35. (12) H. Graf Zu Solus-Laubach, Bot. Ztg. 1907, I. Abt. 1. 16. (13) A. W. EICHLER, Zur Entwicklungsgeschichte des Blattes,

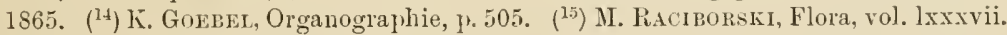
1900 , p. 1. (16) v. Deinega, Flora, vol. lxxxr. 1898, p. 439. (17) W. Schuster, Festschr. der dentsch. bot. Gesell. 1908, 1. 194. (18) E. STahL, Ann. du Jard. Bot, de Buitenzorg, vol. xi. 1893, p. 98. $\left({ }^{19}\right)$ K. Goenel in $\left({ }^{10}\right)$, p. 543, Einleitung in die exper. Norphol. d. Pflanzen, 1908, p. 36 ff. $\quad\left({ }^{20}\right)$ K. GoebeL, Bot. Ztg. 1880, 1. 753. (21) S. Schwexdexen, Mechanische Theorie der Blattstellungen, 1878 ; together with numerous papers in the Stzber. d. Akad. d. Wiss. zu Berlin. ( $\left.{ }^{22}\right)$ HAxs Wixkler, Jahrb. f. wiss. Bot. vol, xxxvi, 1901, 1) 1, and vol. xxxriii. 1903 , p. 501 ; further literature in these papers. $\quad\left({ }^{23}\right)$ J. WiEsser, Biol. Zentralbl.

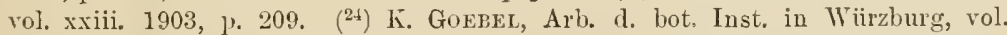

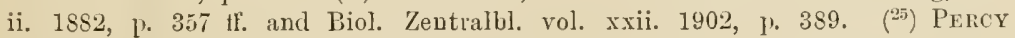
Groon, Phil. Transact. Roy. Soc. London, ser. B, vol. cc. 1908, p. 57. ( $\left.{ }^{26}\right)$ Friedr. Wettstern, Beihefte zum bot. Centralbl. vol. xx. 2, 1906, p. 1. ( $\left.{ }^{27}\right)$ Postowzew, Flora, vol. xlviii. 1890, 1. 155 ; K. Goeber, Organographie, 1. 436 ; J. Pexlo, Flora, vol, xevi. 1906, J. 267. (28) J. H. White, University of Toronto Studies, Biol. Ser. 1907, 1. 165; the oldest and fundamental work is THILO Ifxisch, Zur Iforphol. d. monok. Knollen- und Zwiebelgew., 1850, p. 12:3 ff. $\left({ }^{29}\right)$ Eug. 
Warusa, mont recently in Exgler u. Praxte, Nat. Pfanzenfamilien, Ill. Teil, II. Abt. a, 1891, 1. 2. $\left.\quad{ }^{30}\right)$ Ki. Goebel, Flora, rol. xcr. 1905, 1) 165. $\left({ }^{31}\right)$ E. STIiAs. BL'RGer, Plogressus rei botanicae, rol. i. 1906, l’ 1. ( $\left.{ }^{32}\right)$ The literature is collected by A. Guilternord, Revie gén. de Bot. vol. xriii. 1906, p. 392 ; E. Zacharias, Bot. Ztg. 1907 , p. 265. Cf. also Arthut Mever, Flora, vol, xeviii. 1908, p. 335. ${ }^{(33)}$ Fr. Brieck, Zeitschr. fuir allg. Physiol. rol. vii. [1. 506, 1908. (34) N. Gaidukov, Ber. d. dentsch. bot. Ges. 1906, 1 p. 155 and 551. ( ${ }^{35}$ ) Pall KiretzschMA l, Jahrb. f. wiss. Bot. vol. xxxix. 1904, p. 273 ; W. Brenberg, Flora, rol. xcix. 180s, 1. 70. (36) FR. MEJEs has given the name of Chondromites to thicher fitaments of special nature which he observed in the tupetul cells lining the pollen chamber in some cuses, Ber. d. deutsch. bot. Gesell. 1904, p. 254; ef. further under ${ }^{\left({ }^{31}\right)}$. $\left.\quad{ }^{\left({ }^{3}\right.}\right)$ Ayeinst the distinction of Kinoptasm and Trophoplasin cf. the vicues of T. GRÉGOIRE and his mupils in La Cellule from 1904 onverds; ef. especially A. Fıscher, Fixierung, Färlung und Ban des Protoplasma, 1899, and A. DEges, Bot. Ztg. 1905, I. Abt. 1. 202. ("3s) Cf. the most recent works of Greguine and his pupils, and also of E. Strasbliger. $\left.{ }^{39}\right)$ Cf. the literature in $\left.{ }^{31}\right)$; against the existence of true Centrosomes in Stypocauton and their increcese in number by division see more recently $F$. Evcorez in La Cellule,

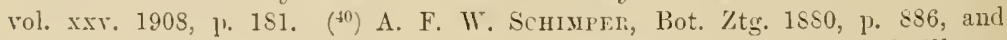
Jahrb. f. wiss. Bot. vol. xri. 1\$\$5, 1. 1. Arth L MEYer, Das Chlorophyllkorn, 1853, and Bot. Ztg. 1Sss, p. 489; Bexgt Linfoliss, Lund Unir. Mrsskr. Afd. 2, rol. iv. No. 1, 1908; Fritz Kxoln, Sitzb. d. Wien. Akad. d. Wiss., Math.-natwiss. Kl. vol. exrii. 1908, P. 122 $\mathrm{i}$; ef. also G. SExN, Die Gestalts- und Lagenverändernng der Pflanzenehromatophoren, 190s; J. H. Priestly and A. A. Irving state for certain chlorophyll grains that the chlorophyll is only prescni at the periphery and occupies the meshes of a netrurk, Anm. of Bot. rol. xxi. 1907,

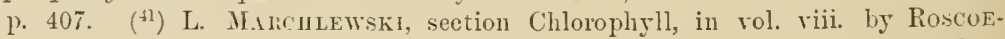
Schorleaer, Org. Chemie, 1901, 1. 83 ; C. A. Schunch, Proceed. Roy. Soc. London, rol. lxw. 1900 , p. $17 \bar{t}$, rol. lxviii. 1901, p. 474, and rol. lxxii. 1904 , p. 165; A. Tschnich, Ber. d. deutsch. bot. Gesell. 1904, l’. 414; R. Willstätel: in Liebig's Anmalen, vol, el., eliv, elv., elviii. with Mieg, vol. clv.. with Bexz, vol. clviii. p. 272 ; J. STokLAsA, V. BrDLIK and A. Ensest, Ber. der deutsch. Bot. Gesell. 1909, 1. 10. A smmnary of the whole literature on the absorption spectra of the components and derivatives of chloroplyyll to 1907 will be found in KaYsen, Spectroscopie, vol, ir. Kap. i. ( ${ }^{+2}$ ) A. Tsснirch, Untersuch. iiber d. Chlorophyll, 1SS4; especially IV. Kïstri, Ber, d. deutsch. bot. Gesell.

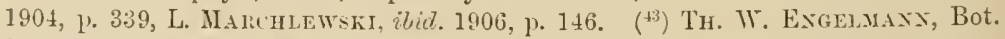

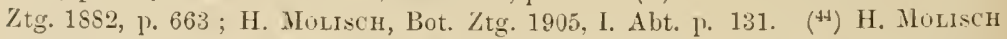
in $\left({ }^{43}\right)$; against lis views see M. TswerT, Ber. der dentsch. bot. Gesell. 1906, 1. 235. ${ }^{(45)}$ Erxst Stahl, Znr Biologrie des Chloroplyylls, 1909, 1) 135; M. TsweTt, Ber. der dentseh. bot. Gesell. 1905, 1) S5, hulds thet only the return of the nitroyen is

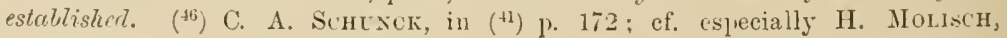
Ber. d. dentsch. bot. Gesell. 1596, p. 27; T. T.umEs, Flora, vol. lxxxvii. 1902, p. 205, and F. G. Kont, Untersnch. iiber d. Karotin, ete. 1902; A. T'schnch, and

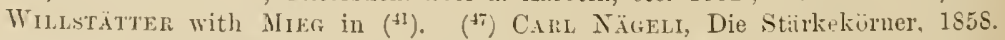

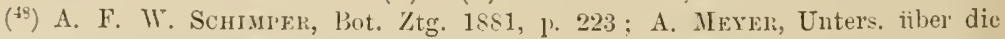

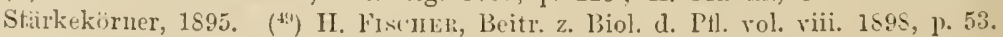
$\left({ }^{50}\right)$ L. Maçuxxie et Ero. liorx, Anu. rle Chimie et de l'hys. vol. ix. 1906, 1. 179, and Comp. Rend. Paris, vol. exlyi. 1908 p. 542 . ( ${ }^{51}$ ) \%. GATIX-Grezewsia, Compt. Rend. Paris, vol. exlvi. 1905, p. 540; M. E. Isarve, Bull. internat. de l'Acad. des Sc. de Cracorie, 1907,1 . 203, relates the colorations of sturel by iodine 
to the presence of aromatic bodues, of which one stains blue, another ree, and " third yellow. ( $\left.{ }^{52}\right)$ O. Bürschu, Verh. d. naturhistmed. Ver. zu Heidelberg, 1903,

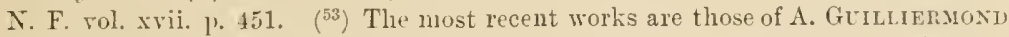
and J. Beatrenie. Summary of literature, Ann. des sc. nat. Bot. ge sél. rol. viii. 1908, p. 173. (5t) W. PFefFer, Jahrb. f. wiss. Bot. vol. viii. 1572, p. 472. (55) A. Znmmenmasx, Beitr. z. Morph. u. Phys. der Pllanzenzelle, vol. i. 1891, 1. 113. $\left.{ }^{56}\right)$ L. KNT, Ber. d. dentsch. bot. Gesell. 1887, p. 387. $\left({ }^{57}\right)$ M. RACiborskr, Anz. d. Akad. d. Wiss. in Krakau, 1893, 1. 259, and Abl. of the same Akad. rol. xxvii. 1891, p. 1 ; Rudolf BeEr, Ann. of Bot. vol. xxiil. 1909, p. 63 . ( $\left.{ }^{58}\right)$ Cf. O. Bü Tschut in $\left({ }^{52}\right)$, 1. 436 and 506. $\left({ }^{59}\right)$ L. EnRER, L'Épiplasme des Ascomycetes, 1892, and most recently Recueil de l'Inst. Bot. de Bruxelles, rol. i. 1906, 1. 343, and A. Guilliervond, Rer. gén. de Bot. vol. xvi. 1903, p. 50 . $\left.{ }^{60}\right)$ Another recetion is given by A. Fiscrer, Bot. Ztg. 1905, I. Abt. 1. 65. $\left.{ }^{61}\right)$ G. Berthols, Studien iiber Protoplasmamechanik, 1856, p. 24. G. Haberlasit, Physiol. Pflanzenanatomie, 3rd ed. 1904, P. 462. ( $\left.{ }^{62}\right)$ A. Tschinch, Die Harze und die Harzbehälter, 1900. $\quad{ }^{(63)}$ KAnL Mikosch, Stzber. der Wiener Akad., math.naturw. Kil. vol. cxr. Abt. I. 1906, p. 911 ; KArL Bonesch, Ibid. vol. exvii. 1908, p. 1033. (64) J. R. Grees, Ferments, 1901; MI. RAcibnnski, Ber. d. deutsch. bot. Geseil. 1598, pp. 52, 119, and Flora, 1598, 1. 362 ; R. Chodst and A. BAch, Archives des sciences phys. et matlı. de Genève, 1901, etc.; then W. Paldanin, Zeitschr. f. physiol. Chemie, rol. xlvii. 1906, p. 407, and Ber. d. dentseh. bot. Gesell. 1908, p. 378. H. Sunnider, Bot. Ztg. 1908, p. 273, Srdsey H. Vaxes in Ann. of Bot., most recently rol, xxiii. 1909, p. 13 ; F. W. R. DE JoxG, Ams. du jard. bot. de Buitenzorg, vol. vii. 190s, p. 1. $\left({ }^{65}\right)$ M. TReds, Ann. d. Jardin bot. de Buitenzorg, rol. xiii. 1895, p. 1,2 sér. vol. ir. $1905, \mathrm{l}$. 86 , and rol. vi. $1907,1.79$; L. Grigsiri, Rer. de Vitie. 1906, Bull. des se. pharmac. vol. xii.

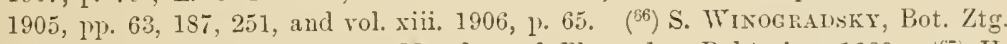
188i, p. 493, and Beiträge zur Morph. und Phys. der. Bakterien, 18ss. ( $\left.{ }^{6 \pi}\right) \mathrm{H}$. MIolisch, Bot. 7tg. 1905, I. Abt. P. 161 ; O. Gentz, Inang. Diss. Lund, 1906 ; L. vox Portuerm and E. Scholl, Ber. d. deutsch. bot. Gesellsch. 1908, l'. 480. Compare also the work of M. WHELDALE on colours and pigments of flowers in relation to their inheritance in the Proceed. of the Roy. Soc., Ser. B, vol. Ixxxi. 1909, p. 44. ( $\left.{ }^{68}\right)$ Complete literature in L. GAtcher, Étude générale sur la membrane cellulaire chez les végétaux, 1904. On the striation of cell walls see most reently W. Krieg, Beil. z. bot. Zentralbl. vol. xxi. 1907, p. 215 . (69) W. Pfenfer, Unters. aus dem bot. Inst. zu Tïbingen, vol. i. 1S55, p. 525 ; G. HarerLAxit,

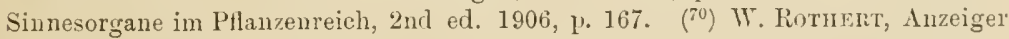
der Akad. d. Wiss. in Krakan, 1897, p. 11 ; Abhandl. of the same Akad. 1899, 1. 43.3 ; M. Kürxicke, Sitzber. d. Niederrh. Gesell. f. Natur-u. Heilkunde zu Boun, 1599,

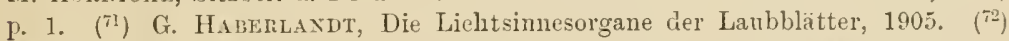
Many investigations by Julüs WresNer summarised in his Anatomie und Physiologie der Pflanzen, 4th ed. 189S, l'P. 39 ff. and 339 ; L. M.Axgry, Journ. de Bot. vol. vii. 1893, pl. 37, 121, 325 ; complete literature to 1904 in L. GAtcher. in $\left.{ }^{68}\right)$, since then Fr. CzApek, Biochemie d. Ptlanz. 1905, vol. i. p. 506, and O. Richter, Zeitschr. f. wiss. Mikr. vol. xxii. 1905, p. 194. (i3) E. Gilsos, La Cristall. de la cell, in La Cellule, vol. ix. 1893, 1'. 397. (it) E. Grisos, Rech. chim. sur la Membr. cell. des Champ', in La Cellule, vol, xi. 1894, 1. 7 . E. Scroll recently obtained pure Chitin from Boletus edulis, Stzher. der Wiener Akad., math.-natwiss. Kl. rol. cxvii. 1908, 1. 547. (5) FR. Cz.1PEK, Biochemie der Pflanzen, vol. i. 1905 , p. 539 , vol. ii. 1) 552. (i6) T. Grafe, Stzber. d. Wiener Akad. vol. exiii. Abt. I. 1904, 1. 26\%. Cf. also F. C. vos FabE1, Ber. 
d. dent-cl. Bot. Ciesell. 1904, 1). 180. ("7) Fu. CzAper, Flora, vol. lxxxvi. 1899, p. 361. (78) Paul Bäsecke, Bot. Ztg. 1. Abt. 1908, p. 74. (79) VAN Wisselingh, Arehives Néerland. vol. xxvi. 1892, p. 305, and vol. xxviii. 1898, p. 373. ( $\left.{ }^{80}\right)$

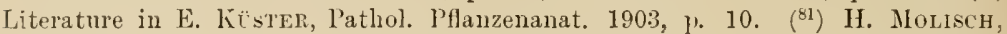
Studien ïber Milchsaft und Schleimsaft der Pflanzen, 1901. ( ${ }^{82}$ ) Richard Hentwit, Biol. Centralbl. vol. xxiii. 1903, p. 56. $\left.{ }^{83}\right)$ On the botanical side of this subject the numerous works of E. Strasburger, M. Treud, L. Guignard, Wh. BeldjefF, J. B. Farmer, B. Nëhec, V. Grégolie, A. Wrgaents, E. Escoyez, J. Berghs, O. Rosenlerg, Ch. Allex, K. Miyake, J. B. Overton, and others; cf. also TH. Borers, Ergebnisse iiber die Konstitution der chromatischen Substanz des Zellkerns, 1904. ( $\left.{ }^{(4)}\right)$ J. B. FAruir, Quart. Jolu. Micr. Se. vol. xlviii. part iv. 1905 , 1. 489, and his pupils, and more recently D. M. MotTier, Ann. of Bot. vol. xxi. 1907, 1. 309, derive these double chromosomes of our Fig. 8s, 8 not fiom the carly pairing of tuo chromosomes but from their later folding. The worls on the reduction of chromosomes must be combined with those of the authors eited in $\left.{ }^{82}\right)$. The proposal to term the reduction division and the homotypic dirision Miosis ue mate by J. B. Falineli and J. E. S. Moure,

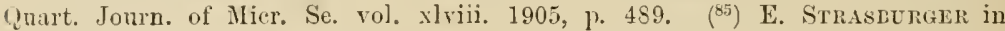

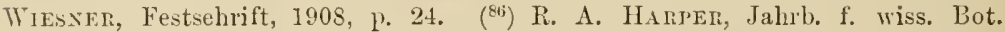
vol. xxx. 1897, p. $249 . \quad\left({ }^{87}\right)$ On the botanical side numerons works by G. Thu ret, N. Prisgheri, E. Strasbuliger, L. Guignard, S. Nawaschis, and other's. ( ${ }^{88}$ ) Especially the works of WL. BeLAJEFF, most recently in Ber. d. dentsch. botan. Gesell. 1897, p. 337 ti.. $\left({ }^{89}\right)$ See the works eited under $\left({ }^{39}\right)$ by S. LkExo, S. Hruase, H. J. Weber and K. Mryake. (99) F. Strasbunger in papers in rols. xhi. xliv, and xlv., of the Jahrb. f. wiss. Bot. from 1906 to 190S, and in Heft vii.

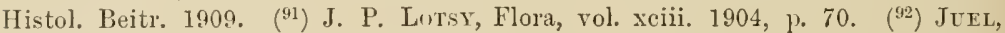
Botan. Zentralbl, rol. lxxiv. 1S98, p. 369, Abh. d. Kil. Schwed. Akad. d. Wiss. vol. xxxiii. 1900, No. 5. $\left({ }^{93}\right)$ J. B. Oventon, Bot. Gazette, vol. xxxiii. 1902, p. 363. C. RAlxhlater, Archiv fiir Botanik, vol. ii. N. 4, p. 7 ; O. Juel, Botan. Tidsskr. vol. xxv. 1903, p. 109. CH. Ostenfeld and C. Ratinkiakr, Bot. Tidsskr. vol. xxv. 1903, p. 409, and Ber. d. deutsch. bot. Gesell. 1904, p. 376, O. Hosexpera, ibri. 1906, 1. 157. ( $\left.{ }^{94}\right)$ Sw. Murbeck, Lunds Univ. Arskrift, vol. xxxvi. Aft. II. No. 7 ; Kong]. Fysiogr. Sallsk. Handlingar, rol. xi. No. 7 , 1901 ; E. Strasburger in $\left.{ }^{99}\right)$. (95) Haxs Winkler, Bot. Unters. ans Buitenzorg, 2 S., vol. v. 1906, p. 208. E. Strasbuliger, Histol. Beitr. 1909, p. 47, (96) JACOE JODLEwsKY, Flora, vol. xeviii. 1908, 1. 423. ( $\left.{ }^{97}\right)$ The works of J. B. Farver, J. E. Moore, and L. Digby in Proc. of the Roy. Soc. vol. Ixxi. 1903 , p. 453, and vol. B lxxri. 1905, p. 463, and in Am. of Bot. vol. xxi. 1907, p. 161. (97) E. Strasbutger, Flora, vol. xevii. 1907, p. $123 . \quad\left({ }^{98}\right)$ Cf. the literature under $\left.{ }^{(31}\right)$ and espeeially on the sieve-tubes, A. W. HiLL, Ann. of Bot. vol. xr. 1901, p. 575, ant vol. xxii. 1908, p. 245. (99) Cf. most reently espeeially Altiler W. Hill, Ann. of Bot. vol. xv. 1901, p. 575, and vol, xxii. 1908, p. 245. (100) A. DE BArr, Comparative Anatomy of the Phanerogams and Ferns. G. Haberlaxd, l'liysiol. I'flanzenanat. 3rd ed. 1996 ; H. Solenener, Syst. Anat. d. Dikotyledonen, 1899. (101) E. 1) Whnents, vol. liii. of the Mémoires conronnés unbliés par l'Acal. de science de Belgique, 1893. (102) H. LerTGEn, Untersuehungen iiber die Lebermoose, Heft iii. 187\%, gives the other literatmre. (103) W. HorueIster, Die Lehre von der Pflanzenzelle, 1867, p. 135 ; this gives the older literature ; later in many special pitpers by Leitged ; for Equisetum ef. also E. Strasburger, Bot. Praktikum, ed. 4, 1). 312, gives the literature. (104) J. SAcis, Arbeiten des bot. list. in Wurzburg, vol, ii. 1878 and 1879 , H'p. 46, $185 . \quad\left({ }^{105}\right)$ J. Haxstein, 
Festschr. d. niederrh. Gesell. f. Natur- und Heilkunde, 1868, p. 109. (10i) L. Errera, Bull. de la soc. Belge de Nieroseopie, vol. xiii. p. 1·2, 1856, and in 60. Vers. deutsch. Naturforscher u. Ärzte zu Wiesbaden, Biol. Zentralbl. 1887-88, p. 728 ; G. Berthold, Studien iiber Protoplasmamechanik, 1886, 1. 219; ef. also de Wildeman in $\left({ }^{146}\right)$; K. Glesenhagen, Flora, vol. xeix. 1909, p. $355 . \quad\left({ }^{107}\right) \mathrm{C}$. Nïrell and H. Leitgeb, Beitr. z. wiss. Bot. von C. Nägeli, iv. Heft, 1868, p. 73. ${ }^{\left({ }^{10}\right)}$ K. Goebel, Organographie der Pflanzen, 1898, p. $435 . \quad\left({ }^{109}\right)$ Especially E. v. Jaxczewski, Ann. des se. nat. Bot. 5. Ser. vol. xx. 1874, pl. 162, 208, and Ph. van Trighem, Traité de Bot. 2nd ed. 1891, p. 694, where the literature is given. ( $\left.{ }^{110}\right) \mathrm{K}$. Goebel in $\left({ }^{109}\right)$, p. 448. (111) L. Kuch, Jahrb. f. wiss. Bot. vol. xxv. 1893, p. $380 . \quad\left({ }^{112}\right)$ H. Devaux, llém. de la Soc. des Soc. phys. et nat. de Bordeaux, vol. iii. 1903, p. 89. (113) G. GentNeli, Flora, vol. xcix. 1909, p. 337. ${ }^{114}$ G. Haberlandt in (i1) and in Biol. Zentralbl. vol. xxvii. 1907, p. 289, most recently in Stzber. der Wiener Akad. vol. exvii. 1908, p. 620. For a eriticism of this work see H. Kixinp, Biol. Zentralh]. vol. xxvii. 1907, p. 289, and G. Alerecht, Ber. d. deutsch. bot. Gesell. 1908, p. 182 . (115) On Stomata, E. Strasburger, Jahrb. f. " iss. Bot. vol. v. 1866, p. 297 ; S. Schwendener, Nonatsber. d. Berl. Akad. d. Wiss. 1881, p. 883, and others. Most recently S. H. Eokerson, Bot. Gaz. vol. xivi. 1908, 1. 221. liecently M. TswetT has stated that the Lobeliaceae hate water-stomata, the pores of which are permanently closed, over their hydathodes, Rev. gén. de Bot. vol. xix. 1907, p. 305. (116) 0. Renxer, Flora, vol. xeix. 1908, 1. 127. (117) G. HabeliLANDT, Stzber. der Wiener Akad. d. Wiss. vol. xeiii. i. Abt. 1886, p. 123 . (118) HaberLañt, Phys. Pflanzenauatomie, 3ril ed. 1896, p. 430 ; collected works of SchwexDener, 1899, p. 104. (119) A. Nestler, Berichte der deutschen botanischen Gesellselıft, 1900, pp. 189, 327 ; Peters, Stzber. d. Niederrh. Gesell. Bonn, Med. Sekt. 1900, p. 33. (120) G. Haberdandt, Die Simesorgane im Pflanzenreich, 2nd ed. 1906, and Flora, vol, xeix. 1909, p. 281, the latter against the views of O. RENNER in $\left(^{116}\right)$. ( $\left.{ }^{121}\right)$ Cf. N. WILLE, Beitrige zur plyysiol. Anatomie der Laminariaceen, 1897 ; M. G. Srkes, Ann. of Bot. vol. xxii. 1908, p. 29. (122) A. G. TANster and E. CHuck, Annals of Botany, vol. xr. 1901, p. 13. $\left({ }^{123}\right)$ in $\left({ }^{117}\right)$, p. $308 . \quad\left({ }^{124}\right)$ The opposite view is held by Gwrxue-VAughax, Ann. of Bot. rol. xxii. 1908, p. 517. $\left.{ }^{125}\right)$ A. Frscher, Studien iber die Siehröhren der Dikotylenblätter, 1885 ; E. Strasburger, Über den Ball und die Verrichtung der Leitungsbahnen in den Pflanzen, 1891, pp. 98, 297. (126) Ph. van Tieghen, Traité de Botanique, 2nd ed. 1891, 1. 737 ; E. Strasbunger, the work cited under $(125)$; J. C. Schoute, Die Stelartheorie, $190 \%$. ( $\left.{ }^{12 \pi}\right)$ Against the stelar theory ef. especially SounsLaUbach. But. Ztg. 1903, ii. Abt. pp. 37, 147. (128) G. Haberlandr, Jahrb. f. wiss. Bot. vol. xxxviii. 1902, p. $450 . \quad\left({ }^{129}\right)$ G. HABERLANdt in (117), p. 325. (130) Especially PH. VAx TIEghex in $\left({ }^{109}\right)$, p. 700 ; the literature is given here. (131) G. Haberlandt in $\left({ }^{127}\right)$, p. 244. (132) C. Sauvagead, M. von Minden, P. Weingowsky, ef. G. Haberlandt in (117), pp. 437, 475. (133) In Nägeli, Beiträge zur wiss. Bot. Heft i. 1858, and especially in the works eited in $\left({ }^{100}\right)$ by $\mathrm{DE}$ Barr, p. 243 fr. (134) Literature in A. Gravis, Mém. publ, par l'Acad. roy. de Belgique, vol. lvii. 1898 ; R. Sterckx, Arch. Inst. bot. univ. Liège, vol. ii. 1900. $\left({ }^{135}\right)$ J. C. Schonte, Flora, vol. xeii. 1903, p. 32. ( $\left.{ }^{136}\right)$ G. Zodd A, Malpighia, 1904, p. 512 ; E. Strasburger, Jahrb. f. wiss. Bot. vol. xliii. 1906, J. 580 ; P'. Baccarini, Nuovo Giorn. bot. ital. Bd. xiv. 1907, 1. 56 ; Exrico Caraxo, Ann. di Bot. vol. v. 1906, p. 1. (137) Especially the work of DE BARY eited under $\left({ }^{100}\right)$, that of STHASBURGEl under $\left({ }^{125}\right)$, th at of HABERLANDT under $\left({ }^{117}\right)$, and the works of Burgersters, maiuly in the publications of the Academy of Vienna. (138) J. C. 
Schoute, Verhandl. d. Koninkl. Akad. van Wetenseh. Amsterdam, Tweede Seetie, Deel ix. No. 4, $1902 . \quad J$. C. Schovte terms a cambium active to both sides dipleuric, chul active on only one side nonopleuric. He terms a cambium provided with a single initial layer an initial cambium, and one in which other layers later reinforce the first, a stratified cambium (Etagencambicn). $\left.{ }^{(139}\right)$ H. MArk, Zeitschr. f. Forst- u. Jagdwesen, Jahrg. xxv. 1893, p. 313, ete. (110) Alfnen Fischer, Jahrb. f. wiss. Bot. vol. xxii. 1890 , p. 73 ; E. Strasburger under $\left({ }^{125}\right)$, p. 883 ff. $\left({ }^{141}\right)$ L. Kixy, Ber. d. dentsch. bot. Gesellseh. 1890, p. 176, and E. STrasburger under ( $\left.{ }^{125}\right)$. (142) Especially Ph. var Trfahem, Traité de Botanique, 2nd ed. 1891, p. 719. Here also 'T. Freinenfelt, Flora, vol. xei. 1902, p. 115, and M. Büsgen, Flora, vol. xev. 1905, p. 58. (143) Especially H. Schenck, Beiträge zur Biologie und Anatomie der Lianen, 1892. Recently Gravis and Cosstantinesco, Areh. de l'Inst. bot. de. l'Uuiv. de Liège, vol. iv. 1907, p. 43. (14t) L. Lindinger, Beilefte z. bot. Zentralbl. vol. xix. 1, 1906, p. 321 ; S. Rxwosch, Zeitschrift für Botanik, vol. i. 1909, p. 274. (145) A. B. Frank, Bot. Ztg. 1864, l). 186 ; G. Krraus, Abh. d. naturf. Ges. zu Halle, vol. xri. 1885, p. 365 ; E. Straseurger in $\left({ }^{125}\right)$, p. 107 ; R. Meissner, Bot. Ztg., i. Abt. 1894, p. 55, and 1901, p. 25. ( $\left.{ }^{146}\right) \mathrm{S}$. Simon, Ber. d. deutsch. bot. Gesell. 1902, p. 229. (14ī) Espreeially de BAry in $\left({ }^{100}\right)$, P. 560, and F. V. HöHnel, Stzber. der Wiener Akad., math.-naturwiss. Kl. vol. lxxvi. Heft 4 and 5, 1877. Also O. Daym, Beihefte z. bot. Zentralbl. vol. xi. 1902, 1. 222, and 11. Prodinger, Denkschriften der math.-naturwiss. Kl. der Wiener Akad. vol. lxxxiv. 1908, p. 329. (148) l'. B̈̈sıcke, Bot. Ztg. i. Abt. 1908, p. 55. (149) E. Stahl, Bot. Ztg. 1873, p. 561 ; H. Devaux, Amu. des Soc. nat. Bot. viii. ser. 1900 , rol. xii. p. 1 ; the further literature in G. HABEliLANdt in $\left({ }^{100}\right)$, p. 419. (150) Hermans von Alten, Bot. Ztg. i. Abt. 1909, p. 1 ; the literature is given liere. ( $\left.{ }^{15 l}\right)$ H. v. MoHL, Bot. Ztg. 1860, pp. 1, 132, 273 ; H. v. Bretfeld, Jahrb. f. wiss. Bot. vol. xii. 1879-81, p. 133 ; Рh. vas Tieghem, Traitè de Bot. 2nd ed. 1891, vol. i. p. 865 ; L. Stabr, Flora, 1886, p. 158 ; A. Tison, Mém de la Soe. Linn. de Normandie, vol. xx. 1900 ; J. Wiesner, most recently in Ber. d. dentsch. bot. Gesell. 1906, p. 32 ; E. Löwı, Stzber. d. Wiencr Akad. d. Wiss., math.-naturwiss. Kl. vol. exvi. Abt. i. 1907, p. 983. (152) In (145), pp. 68,71 . ( $\left.{ }^{153}\right)$ The literature is in the work of Küster cited nuder $\left({ }^{160}\right)$. ( $\left.{ }^{154}\right)$ In $\left({ }^{145}\right)$, p. 61. (155) H. Devaux, Actes de la Soe. Linn. de Bordeaux, 6. sér. vol. viii. 1903, p. 98. (156) O. APPEL, Ber. d. deutscl. bot. Gesell. 1906, p. 118. ( ${ }^{157}$ ) A. Tisox, Bull. de la Soc. Linnéenne de Normandie, ser. 5, vol. viii. 1904, p. 176. (158) S. Simos, Jahrb. f. wiss. Bot. vol. xlv. 1908, p. 351. ${ }^{(159)}$ Cf. B. Nemec, Studien iiber die Regeneration, 1905 ; W. FigDoR, Ber. d. deutsch. bot. Gesell. 1906, p. 13. (160) H. WINkLER, Ber. d. deutsch. bot. Ges. 1902, p. 81 ; K. Goebei, Biol. Zentralbl. vol. xxii. 1902, p. 385 ; Flor., vol. xcii. 1903, p. 132 ; E. Küster, Pathologisehe Pflanzenanatomie, 1903, p. 8; Fr. Hildeblisd, Ber. d. deutsch. bot. Gesell. 1906, p. 39 ; ef. also W. FigDol, Jahrb. f. wiss. Bot. vol. xliv. 1907, P. 41. (161) C. R. Barses and W. J. G. LAND, Bot. Gazette, 1907, p. 197. (162) Augusté Pyrane de Candolle, Théorie élémentaire de la Botanique. (163) K. Goener, Organographie der PHanzen, 1898, p. 121. Goeber distinguishes between the juvenile form and the adult form. If these differ but slightly the development is homoblustic; in the contrary case heteroblastic. L. Dicis in his work Jugend formen und Blätenreife in Pflenzenrich, 1906, brings the heterollastic forms of development of the vegetutive urgans under the concept of helicomorphy, which is especially prevelent amony Dicotyledons, 1. 22. (164) Especially O. PexzIG, Pflanzen. Teratologie, 1890, gives the literature; K. Goeber, Organographie der Pflanzen, 1898, p. 152 ; E, Kitster in $\left({ }^{160}\right)$; W. Magnus, Ber. d. deutseh. bot. Gesell. 1903, 
P. 129. Abnormal change of the contents of the cells are termad by KüsTER metaplasy, excessive division of eells hyperplasy, and an arrest in the course of their develop. ment hypoplesy.

\section{PHYSIOLOGY BY L. JOST.}

For more advanced study PFeffer's Physiology of Plants and Jost's Lectures on Plant Physiology, both of which are translated into English, may be consulted.

(1) Berivard (1878), Leçons sur les phénomènes de la vie, Paris. Sachs (1582), Vorlesungen uber Ptanzenphysiologie, Leipzig, Vorlesung 12. (Eng. Translation.)

(2) Blackmax (1908), British Assoc. for Adv. of Sciences, Dublin. Address to the Bot. Section. Also (1905), Annals of Botany, 19. Jost (1906), Biolog. Centraibl. 26.

$\left({ }^{3}\right)$ Molisch (1897), Das Erfrieren der Pflanzen, Jena. Mez (1905), Flora, 94. ApPELT (1907), Kältetod der Kartoffel, Halle (Dissertation).

The significance of the temperature for the geographical distribution of plants is treated at length in Schinper's Plant Geography. Solvs-Laubach, Gesichtspunkte der Pflanzengeographie, Leipzig, 1905. IHNE's Phenological Diagrams of the Onset of Spring in Middle Europe, 1605 , Heft 5, may also be mentioned.

It is true that often the life of the plant is not terminated by the low temperature, but results fiom drought, beeuse the transpiration continues while the absorption of water from the frozen soil bccomes impossible. Cf., e.g., ScHINPER, l'lant Geography, and Kinduaxx (1890), Pflanzenbiologische Studien aus Lajplitnd, Helsingfors.

(`) CzapeK (1905), Biochemic der Pflanzen, Jena. Eulen (1908), Grundlagen und Ergebnisse der Ptlanzenchemie, Braunschweig. Hörer (1906), Physikal. Chemie der Zelle, erl. 2. Leipzig.

$\left.{ }^{5}\right)$ WoLf, E. $(1871,1880)$, Aschenanalysen von land- und forstwirtschaftlichen Produkten, Berlin. Kösig (1882), Zusammensetzung der menschlichen Nahrungsи. Genussmittel, Berlin.

(6) Pfeffer: (1877), Osmotische Untersuchungen, Leipzig ; also (1886), Unters. a. d. bot. Institut, Tübingen, 2 ; also (1890), Abb. d. math. phys. Kil. d. sächs. Gesellsch. Leipzig. DE VriEs (1877), Die mechan. Ursachen d. Zellstreckung, Leipzig ; also (1884), Jahrb. wiss. Botanik, 14. RuhlaND (1908), Jahrb. wiss. Botanik, 46. Meurer (1909), ibid. Errerd (1907), Cours de physiologie moléculaire, Bruxelles. Livingston (1903), Role of Diflusion, etc. in Plants, Chicago.

(7) Brows and Escombe (1900), Phil. Trans. B, 193.

$\left.{ }^{(}\right)$Burgerstein (1904), Transpiration d. Pflanzen, Jena.

(9) Schimper (1898), Ptlanzengeographie, Jena. Goebel (1889), Pflanzenbiolog. Schilderungen, i., Marburg. STAнL, Annales du jard. de Buitenzorg, 11 and 13 ; Botan. Ztg. 52. Volkess (1887), Flora d. ägypt,-arab. Wüiste, Berlin.

(10) Burgenstein, see $\left({ }^{8}\right)$. Haberlaxdt (1904), Physiolog. Anatomie, ed. 3, Leipzig. Wilsox (1881), Unter's. bot. Inst. Tübingen, 1. LepeschKin (1906), Beihefte bot. Centralbl. 19.

(11) Brücke (1844), Annalen d. Physik, 63. (Ostwalds, Klassiker, No. 95.) Pfeffer (1877), Osmotische Untersuchungen, Leipzig; (1890), Abh. d. ligl. Gesellsch. d. Wiss. Leipzig. Wieler (1893), Colns Beitr. z. Biologie, 6.

(12) Pfeffel, Lepeschkis, see $\left({ }^{10}\right)$ and $\left({ }^{11}\right)$.

(13) Milisch (1902), Bot. Ztg. 30.

(14) Strasburger (1891), Bau u. Verrichtungen d. Leitungsbahnen, Jena. 
Ursprung (1907), Biolog. Centralbl. 27 ; Jahrb. wiss. Bot. 14. Ewant (1908), Phil. Trans. Roy. Soe. B, 199.

(15) Cf. MoEbius (1907), Beihefte bot. Centralbl. 21, i.

(16) Dixon and Joly (1894), Aunals of Botany, 8. Askxrasy (1895, 1896), Verl. naturwiss. Verein Heidelberg, N. F. 5. Steisвиiscr (1906), Jahrb. wiss. Bot. 42.

(17) Höh Sitzungsber. Berlin. Akarlemie.

(18) Wiegans und PolstorfF (1942), Über die anorganischen Bestandteile der Pflanzen, Braunsehweig.

(19) SACHs (1860), Landw. Versuchsstation, 2. Krop (1861), Landw. Versuchsstationen, 3. BHNECKE (1909), Ztsehr. f. Bot. 1.

(20) Molisch (1895-96), Sitzungsber. Wien. Akad. 104, i. 105, i. Вехеске (1907 and earlier), Bot. Ztg. 65.

(i) Gris (1857), Annales sc. nat. Bot. (iv.) 7. MoLisch (1592), Die Jflanze in ihrer Beziehung z. Eisen, Jena.

(22) Richter (1906), Sitzungsber. Wien. Akad. 115, i.

(23) Roтнепт (1906), Bot. Ztg. 64.

(24) Nägeli (1893), Denksehr. Schweiz. Naturf. Ges. 33. Benecke (1904), in Lafar, Technische Mykologie, i. 42. Jena.

(25) Goebel (1891), Pflanzenbiologische Sehilderungen, 2, Marburg. PoND (1905), United States Fish Commission Report, 1903, Washington. SNELL (1908), Flora, 98.

(26) SAchs (1865), Handbueh der Experimentalphysiologie, Leipzig. Kivaz (1906), Jahrb. wiss. Bot. 42. SToklas. (1908), Jahrb. wiss. Bot. 46.

(2i) Mayer, Anolf (1901), Agrikulturchemie, ed. 5. Heidelberg.

(28) Schimper (1898), Ptlanzengeographie anf biolog. Grundlage, Jena. ExGLEI: (1879-82), Vers, einer Entwicklungsgesehichte d. Pflanzenwelt, L. SuLxs-Ladrach (1905), Die leitenden Gesichtspunkte d. Pfianzengeographie, L.

(29) Brown and Escunbe, see (i).

(30) Irgaxhousz (1786), Versuche mit Pflanzen, dentsch. Saussune (1804), Rech. sur la végétation (Ostwalu's lilassiker, 15, 16). On the listory of the assimilation of Carbon Dioxide see lurther in SACHs, History of Botany, and WIESNER (1905), Jan Ingen-Housz, Wieu.

(31) Engelmint (1883), Bot. Ztg. Gaunukuw (1906), Beriehte D. bot. Ges. 24. STAHL (1909), Z. Biologie des Chlorophylls, Jena.

(32) Kreusler (1985), Landw. Jahrb. 14. Brow and Escombr (1902), Proe. Roy. Soe. 70 .

(32a) KrReusler, Landw. Jahrb. 14, 16, 17, 19. Giltay (1898), Aunales Jardin. bot. de Buitenzorg, 15. SAchs (1884), Arbeiten Bot. Institut Wrirzburg, 3. Brown and Escombe (1900), Phil. Trans. Roy. Soe. B, 193. Blakmas (1905), Annals of Botany, 19. Also Proeeedings Royal Society, B, 76.

(33) Winogradsii (1890/91), Annales Institut Pasteur, 4 and 5. Huppe (1906), Ergebnisse d. intrnat. bot. Congr. Wien. Krzemieniewsi (1908), Bull. aead. Cracuvie.

(34) Kocr, L. (1880), Die Klee- uml Flachsseide, Heidelberg. P'EnRe (1894), Aunals of Botany, 8 .

${ }^{(35}$ Koun (1887), Entwicklungsgeseh. d. Orobanchen, Heidelberg.

(36) Solms-Laubar ir (1901), Rafflesiacene in Exglen, Das Pflanzenreich, Lyzg.

(37) Daliwix (1876), Insectivorous J'lants. Guebru (1893), Pflanzenbiolog. Sehilderungen, ji. Marburg. Chautriau (1900), Mém. publ. l. l'acad. de Belgique, 59 . 
(38) Heivfichen, Jahrb. wiss. Bot. 31, 32, 36, 37, 46.

$\left({ }^{39}\right)$ Winogradski (1895), Arehives d. se. biologiques, 3. Also (1902), Central-

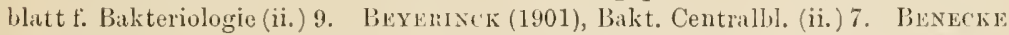
(1903), Berichte hot. Gesellseh. 21. Lïch (1901), in LAfan, Technische Mykologie, 3, Jena. LAwes, fribkit, and Pugil (1862), I'hil. Trans. 151. StiultzLupitz (1881), Landw. Jahrb. 10. Hehllegel and Wrefneri, Stickstoffuahrung 1. Gramineen u. Leguminosen, Berlin. Hntiver (1904) in LAFAr, Technische Mykologie, 3, Jena. Froenlich (1908), dahrb. wiss. Bot. 45. ne Bari (1879). Erscheinung d. Symbiose, Strassburg. Fischer, A. (1903), Vorlesungen über Bakterieu, ed. 2, Jena. Buedemann (1909), Centralbl. Bakt. ii. Abt. 23.

('0) K.Miexski (1881), Botall. Ztg. 39. Fraxk (1887, 1888), Berichte botan. Gesellsch. 5, 6. Srant (1900), Jahrb. wiss. Bot. 34. Shubata (1902), Jahrb. wiss. Bot. 37.

(11) Green (1901), Ferments. Duclaux (1899), Traité de microbiologie, 2, Paris. Bredig (1891), Anorgan. Fermente. Leipzig. Höвer (1907), Pliysikal. Chemie d. Zelle. ed. 2, Leipzig.

(42) Schulze (1906), Landw. Jahrb. 25.

( $\left.{ }^{+3}\right)$ Cf. Czapek and EULer, cit. in $\left(^{4}\right)$.

(4t) Saussure (1822), Aniales d. chimie, 21. Dutrochet (1837), Mémoires, Bruxelles.

( $\left.{ }^{+5}\right)$ Wabura (1886), Unters. a. bot. Institut Tuibingen, 2. AUber'f (1892), Revue gréu. de bot. 4 .

(46) Wortmaxi (1880), Arb. bot. Institut Wiuzburg, 2. Preffer (1885), Unters. bot. Inst. Tübingen, 1. Jonaxnsen (1885), Unters. a. d. Lot. Inst. Tübingen, 1. Sтісн (1891), Flora, 74.

( $\left.{ }^{+7}\right)$ Cf. the summary by Schrö̀tr, Bot. Ztg. 66.

$\left({ }^{48}\right)$ Wrogradski (1887), Botan. Ztg. 45 ; (1890/91), Anuales Institut Pasteur, 4, 5. Niklewsis (1907), Bull. aead. Cracovie. S̈̈hnges (1906), Cbl. Bakt. (ii.), 15 .

(49) Bucinei, E. and H. and HAHN (1903), Die Zymasegärung, Miunehen. Buchxer (1908), Biochem. Ztsehrift. Fischer, A. (1903), Vorles. uiber Bakt. ed. 2, Jena. MAYE⿺, AD. (1906), Lehrb) d. Agrikulturehemie, 3. Bd. 6 Aufl. Heidelberg.

(19a) Mrene (1907), Die Selbsterhitzung des Heus. Jena. Houscu (1908),

Botan. Ztg. 66 .

$\left({ }^{50}\right)$ MoLiscu (1904), Lenehtende PHanzen, Jena.

(51) SAchs (1882), Leetures on the Physiology of Plants. Bentholi (1904),

Unters. z. Phissiol. d. pflanzl. Organisation, Leipzig.

(52) Stahl (1884), Berichte Deutsch. bot. Ges. 2. Winklei (1900), ibil. 18.

LEITGke (187S), Sitzungsb. Wieu. Akad.

(53) Nohl (1888), Arb. bot. Inst. Würzburg, 3. GoveEl (1898), Organography of Plants, Jena.

(5i) Bettholp (1852), Jahrb. wiss. Bot. 13. NĚMeC (1906), ibil. 43. Preffeli (1871), Arb. bot. Institut Wiirzburg, 1.

(55) Vöchtıng (1878/81), Organbildung im Ptlanzenreich, Bonn. Nold (1900), Jahrbiicher, landw. 29.

${ }^{(56)}$ Küster (1903), Pathologische Pflanzenanatomie, Jena.

$\left.{ }^{57}\right)$ Vöchtrág (1892), Die Trans]lantation, Tübingen. Also (1885), Jahrbieher f. wiss. Bot. 16 ; (1906), Bot. Ztg. 64. Mrene (1905), Ber. bot. Ges. 23.

On Regeneration ef. alıo VüchTs Regeneration, Berlin. Konschelt $(1907)$, Regeneration und Transplantation, 
Jena. Morgan (1907), Regeneration ; Dtsch. v. Moszkowski, Leipzig. Vü̈hting

(1908), Unters. z. exper. Anatomie u. Pathologie des Pflanzenkörpers, Tiibingen.

${ }^{(58)}$ V̈̈снтіхG, Organbildung, see $\left({ }^{55}\right)$.

$\left({ }^{59}\right)$ V̈̈̈nтsxe, Transplantation, see $\left({ }^{57}\right)$.

$\left({ }^{60}\right)$ Goebel (1880), Bot. Ztg. 38.

(61) Vöchting, Transplantation, see ${ }^{(57}$ ). Lindemuti (1901), Ber. d. bot.

Gesellsch. WinkLER (1909), Ztschr. f. Bot. 1.

${ }^{\left({ }^{62}\right)}$ NÄGELI (1858), Die Stärkeküruer. Bütschli (1896), Baı quellbarer Körper

(Verh. Ges. Wiss. Göttingen).

${ }^{(63)}$ Kraus (1867), Bot. 7tg. 25. Sachs (1874), Lehrbuch d. Botanik, erl. 4, Lpzg.

$\left(^{(4)}\right)$ DF Vries (1880), Landw. Jahrb. 9. Rimbach (1897), Fünfstücks, Beitr. z. wiss. Bot.

("Б̄5) Sachs (1863), Bot. 7tg. Beilage. Kraus (1969/70), Jahrb. wiss. Bot. 7. Godlewski (1889), Biolog. Centralbl. 9. Fittixg (1907), Jahrb. wiss. Bot. 45. Stahl (1909), see ( ${ }^{31}$ ). Wiesner (1907), Der Lichtgenuss d. Pflanzen, Leipzig.

$\left({ }^{66}\right)$ Körnicke (1904), Ber. d. bot. Ges. 22.

${ }^{(67)}$ Sohexck (1886), Biologie der Wassergewächse, Bonn. Kansten (1888),

lotan. Zeitung, 46. GoebEL (1908), Experimentelle Morphologie, Leipzig.

(68) RaUlin (1869), Aunal. sc. nat. Bot. $\left({ }^{5}\right)$; 11. Richalids (1897), Jahrb. wiss. Bot. 30. Oxo (1900), Journal Coll. Sc. Tokyo.

(69) Burck (1900), Kon Akad. Amsterdam, Proceedings. Frscher, A. (1907), Ber. bot. Ges. 25. Racr borski (1896), Flora, 82.

$\left({ }^{70}\right)$ Hegler (1593), Cohus Beitr. z. Biologie, 6. B̈̈cher (1906), Jahrb. wiss. Bot. 43.

(71) V̈̈сntiNa (1878), Organbildung, see $\left(^{(55}\right)$; also (1908), Untersuchungen z. exp Anatomie u. Pathologie, Tiibingen. Simox (1908), Jahrb. wiss. Bot. 45 ; Berichte bot. Ges. 26. Goeber (1902), Biolog. Centralbl. 22.

(72) Staml (1883), Jen. Zeitschr. f. Naturwiss. 16. Nordhatsen (1901), Jahrb. wiss. Bot. 37.

( ${ }^{73}$ ) Schenck (1886), Anatomie d. submersen Gewächse (Bibl. Botanica, 1). Kонl (1886), Die Transpiration. Braunschweig.

( $\left.{ }^{7 \dagger}\right)$ Schwendener (1874), Das mechanische Prinzip im Bau d. Monokotylen, Lyzg. Haberland (1904), Physiologische Pflanzenanatomie, ed. 3, Lpzg. Axirroxn (1879), Jahrib. wiss. Bot. 12.

( $\left.{ }^{75}\right)$ On Red-wood, etc. : Hartig (1901), Holmuntersuchungen, Berlin. SonvtaG (1904), Jahrb, wiss. Botanik, 39. Ewalit (1906), Annals of Botany, 20.

On Physiological Systems of Tissue: HABERLANDT, cited in $\left({ }^{i 4}\right)$.

$\left({ }^{76}\right)$ KLEBs (1903), Willkiirliche Entwicklungsänderungen, Jena. Assexasy (187T), Botan. Ztg. 35.

(77) Johannsex (1906), Ätherverfahren b. Treiben. Jena. Mourscu (1909), Das Warmbad. Jena.

$\left({ }^{78}\right)$ Goebel (1880), Bot. Ztg. 38. V̈̈сnтsкa (1857), Bibl. bot. 4. Also (1889, 1895), Bot. Ztg.

(79) Strasbutigr (1898/99), Deutsche liundschan.

$\left({ }^{80}\right)$ Noli (1902), Sitzungsberichte niederrh. naturf. Gesellsch. Ewart (1907), Parthenokarpie ... d. Obstbäume. Berlin. HÜLler-Thurgat (1908), Landw. Jahrb. d. Schweiz.

${ }^{(81)}$ KLEBs (1903), see $\left({ }^{76}\right)$. Also (1896), Fortpflanzungsphysiologie niederer Organismen, Jena.

(82) Winklik (1908), Progr. rei bot. 2. Strasburger (1909), "reitpunkt der 
Bestimmung des Geschlechts, A pogamie, Parthenogenesis usw. Tena. Ersst (1909), Ber. bot. Gesellsch. 27.

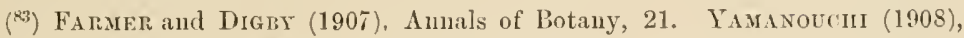

Botanieal Gazette, 45. Woronin (1908), Floria, 98.

(84) Beyerixck (1900), Verh. Akad. Amsterdam.

( $\left.{ }^{55}\right)$ Kölneuter (1761-66), Vor]. Nachr. v. einigen d. Geschlecht d. Pflanzen betreffenden Versuchen und Beobachtungen (Ostwald's Klassiker, No. 41). Focke (1881), Die Pflanzemmischlinge. Berlin. DE Trifs (1903), Die Mutationstheorie, Yol, 2, Leipzig.

$\left({ }^{56}\right)$ Mendel (1901), Flora, 89 (Ostwald's Klassiker, No. 121). Correxs (1903), Mexdels, Briefe an Nägeli (Abh. Sächs. Ges. d. Wiss. 29). DE Vries (1900), Berichte Bot. Ges. 18. Also (1903), Die Mntationstheorie, Leipzig. Curuexs (1900), Berichte bot. Ges. 18. Also (1905), Vererbungsgesetze, Berlin. Tscherмak (1900), Ztschr. f. landw. Versuchswesen in Österreieh. On the whole subjeet ef. also the Zeitschrift für indnktive Abstammungs- und Vererbungslehre, Berlin, 1909.

(87) Winkler (1908), Ber. D. bot. Ges. $26^{\mathrm{a}}$; (1909), Ztselır. f. Bot. 1. Noli. (1905), Sitzungsher. niederrhein Gesellsehaft f. Natur- und Heilkunde. STIisBURGer (1907), Jahrb. wiss. Bot. 42, 44.

(88) DARWIN (1868), Animals and Plants under Domestication. DE VRIES (1903), see $\left.{ }^{86}\right)$. Johanssen (1909), Elemente der exakten Erblichkeitslehre, Jena. Losschinsky (1906), Flora, 89.

(89) Arthur (1897), Annals of Botany, 11. Ternetz (1900), Jahrb. wiss. Bot. 35.

(90) MüLler, O., Ber. D. bot. Ges. 27 (and earlier).

( ${ }^{91}$ ) Steinbirixck (1873), Dissertat. Berlin ; (1895), Jaarboek Dodonaea ; (1906),

Biolog. Centralb]. 26.

(92) Steinbrinck (1898), Berichte bot. Ges. 16 (and later years); (1906), see $\left({ }^{91}\right)$. Kamerling (1898), Botan. Centralbl. 73. Ursprung (1906), Ber. D. bot. Ges. 24.

( $\left.{ }^{93}\right)$ Pfeffer (1893), Die Reizbarkeit d. Pfl. (Verh. d. Ges. d. Naturforseher). Nol, (1896), Sinnesleben d. Pllanze (Ber. Senckenberg. Gesellseh.). Fitrixa (1905/7), Reizleitung (Ergelnisse d. Physiologie, 4, 5) und Jahrb. wiss. Bot. 44 и. 45. Haberlandt (1901), Sinnesorgane im Planzenreich, Leipzig. Also (1905), Lichtsinnesorgane der Laubblätter, Leipzig.

(94) Strasburger (1878), Wirkung des Liehts u. d. Wärme auf Schwärmsporen,

Jena. Oltuanss (1892), Flora, 75. Rothert (1901), Flora, 88.

$\left({ }^{95}\right)$ Frank (1872), Jahrb. wiss. Bot. 8. Staul (1880), Bot. Ztg. 38. SENa (1908), Die Gestalts- nnd Lageveränderungen der Pflanzen-Chromatophoren, Leipzig.

(96) Wiesner (1878/80), Heliotrop. Erscheinungen (Denkschriften k. k. Akad. Wien). Oltmanns, see (94). Ibid. (1897), Flora, S3. Stahl (1881), Kompasspflanzen, Jena. Frösches (1908), Sitzber. Wiener Akad. 117, i. BuAauw (1909), Die Perzeption des Lichtes, Nymwegen.

(97) Molisch (1905), Ber. bot. Ges, 23. Richten (1906), Sitzungsber. Wien. Akad. 115 ; (1909), Jahrb. wiss. Bot. 46.

(98) Da Rwin (1881), Power of Movement in Plants. Vöchticg (1888), Bot. Ztg. 46. Rothert (1894), Cohns Beitr. z. Biolog. 7. HaberLandt (1905), Lichtsinuesorgane L. ; (1909), Jahrb. wiss. Bot. 46. FitTixg (1907), Jahrb. wiss. Bot. 44 and 45. Kixiep (1907), Biolog. Centralbl. 27. Nordiatsex (1907), Ber. bot. Ges. 25. Grus (1907), Sitzber. Wien. Akad. 116. i.

(98a) BlaAtiw, see $\left({ }^{96}\right)$.

(99) Kinight (1806), Ostwali's Kilassiker, 62. Dutrochet (1824), Rech. s. l. strueture intime (Ostwald's Klassiker, 154). HofMerster (1863), Jahrb. wiss. Bot. 
3. Frank (1868), Beitr. 7. Pflanzenphys. Leipzig. Sachs (1874), Arb. bot. Inst. Wiirzburg, 1 : (1879), ibin. 2. Fiтting (1905), Jahrb. wiss. Bot. 41. Luxbera (1905), Jahrb. wiss. Bot. 41. Schoner (1899), Anschaungen iiber freotropismus seit KNight. Hamburg, Programm.

$\left({ }^{100}\right)$ Nold (1885), Arb. bot. Instit. Wirzburg, 3 ; (1892), Wlora. Scriveninexer 1. Krabbe (1892), Abh. Berliner Akademie.

(100a) NoLı (1892), Heterogene Induktion. Leipzig. NĔmec (1900), Berichte bot. Gesellsch. 18 ; further Jahrb. wiss. Bot. 36 ; Studien iiber Regeneration, Berlin, 1905. Haberlandt (1900), Berichte d. bot. Gesellsch. 18 ; further Jahrb. wiss. Bot. 3S, 42, 44. Buder (1908), Ber. botan. Gesellsch. 26. Darwin (1899), Annals of Botany, 13 ; (1903), Proc. Roy. Soc. 71 ; (1904). ibid. 73, and British Assoc. Cambridge. NolL (1902), Berichte bot. Ges. 20 ; (1905), Sitzber. niederrhein. Gesellsch. CzAPEK (1895 and 1898), Jahrb. wiss. Bot. 27, 32. FitTing, cited in $\left({ }^{99}\right)$.

(101) Schwexdener (1881), Sitzungsber. Berlin. Akad. Wortann (1886), Botan. Ztg. 44. Nolı(1892), Heterogene Induktion, Leipzig. (1901), Sitzungsber. niederrhein. Ges. Molisch (1889), Sitzungsanzeiger Wien. Akad.

$\left({ }^{102}\right)$ Miyoshi (1894), Flora, 78, and Botan. Ztg. 52. Samiet (1905), Jahrb. wiss. Bot. 41. Lilifífeld (1905), Ber. bot. Ges. 23.

$\left({ }^{103}\right)$ SACHS (1872), Arb. bot. Instit. Wirzburg, 1. MoLISCH (1SS3), Sitzungsber. Wien. Akad. 88.

(104) Molisch (1884), Sitzungsber. Wien. Akad. 90. Porowzow (1909), Untersuchungen iiber Reizerscheinungen bei den Pflanzen, Jena.

(105) Pfeffer (1681), Unters. Bot. Inst. Tiibingen, 1. Rothert (1901), Flora, 88. KNIEP (1906), Jahrb. wiss. Bot. 43.

(106) Darwex (1876), Climbing Plants. Pfeffer (1885), Unters, bot. Institut Tübingen, 1. Fitring (1903), Jahrb. wiss. Bot. 38. Screnck (1892), Beiträge zur Biologie der Lianen, Jena.

(107) Periee (1894), Annals of Botany, 8.

(108) Preffer (1875), Periodische Bewegungen, Leipzig; (1907), Unters, iiber Entstehung d. Schlafbewegungen (Abh. k. Ges. d. Wiss. Leipzig). Fischle (1890), Bot. Ztg. 48. Oltuaxss (1895), Bot. Ztg. 53. Stahl (1897), Bot. Ztg. 55.

(109) Darwin (1876), Insectivorous Plants. Conkexs (1896), Bot. Ztg. 54. BeNeске (1909), Z. f. Botanik, 1.

(110) Brücke (1848), Archiv f'. Anatonie u. Physiol. (Ostwali's Klassiker, 95). Bert (1867/70), Mém. Soc. Bordcaux, Paris. Pfeffer (1873), Physiolog. Untersuchnngen. Haberlaxdt (1890), Das reizlcitende Syst. đ. Sinnpflanzen. Leipzig. Haberlaynt (1901), Sinnesorgane im Pflanzenreich, Leipzig. Fitting (1903), Jahrb. wiss. Bot. 39. JuEL (1906), Botan. Studien till. Kjellmann, Upsala. MinneN (1901), Flora, 88.

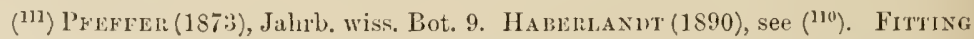
$(1903,4,5)$, see $\left({ }^{110}\right)$ ant $\left({ }^{93}\right)$. Ijissbauen (1908), Wiesner-Festschrift, Wien.

(112) Sarils (1863), Flora, 46. Correns (1892), Flora, 75. Fitring (1903), Jahrb. wiss. Bot. 39 .

(113) Burck (1901), Botan. Centralblatt, 89, 1. 645 (Review).

\section{CRYPTOGAMS, BY H. SCHENCK.}

(1) KL.EBs, Die Berling. der Fortpllanz. bei niederen Algen unl Pilzen, 1896, and Jahrb. f. wiss. Botanik. xxxii.-xxxiv, futher Willkiirl. Entwicklgsänd. bei 
Pflanzen, 1903. (2) A. Fiscier, Vorlesnngen iiber Bakterien, 1897, erd. 2, 1903.

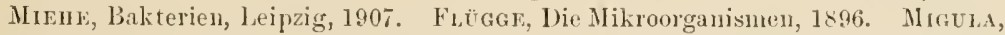
System der Bakterien, 1897 to 1900 , and Nat. Plfam. i. ${ }^{\prime}$ MigulA, A. de Bary's Vorlesungen iiber Bakterien, 3. Aufl. 1900. Kolle n. WAssisuxi, Handb. der pathogen. Mikroorganismen, 1904. Lenuax and Neumaxx, Bakteriologie. A.

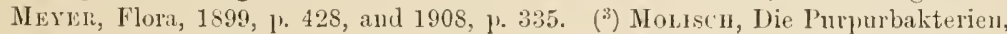

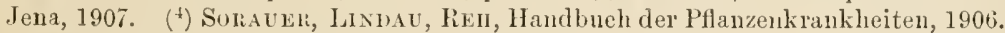

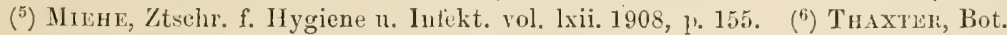
Gaz. xiv. 1892, p. 389, xxiii. 1897, p. 395, and xxxvii. 1904, p. 405. QuenL, Ctrbl. fiir Bakt., Parasitenkunde, ete. xvi. 1896, p. 9. ( $\left.{ }^{7}\right)$ Kinchnez, in Nat. Pflfan. i. ${ }^{1}$ A. Frscher, Unters. iiber den Ban der Cyanophyeeen n. Bakterien, 1897 ; further Bot. Zeitg. 1905, p. 51. Zachaliss, A bhand. aus dem Geb. der Naturw. Hamburg, 1900, and Jahrb. d. Hamburger wiss. Anstalten, xxi. 1903; further loot. Ztg. 1907, p. 265. Hegler, Jahrb. f. wiss. Bot. xxxvi. 1901, p. 229. Massart, Recueil de l'inst. bot. de Bruxelles, v. 1902. Brisu, Ber. dentsch. bot. Ges. 1901, p. 152, 1905, p. 62, and Beihefte bot. /trbl. xv. 1903, 1) 31. KоHL, Organisation u. Pliysiol. d. Cyanophyceenzelle, Jena, 1903, and Beihefte hot. Zentralbl. 1905, xviii. p. 1. Fritsch, Beihefte bot. Zentrbl. 1905, xviii. p. 194. OLrve, Beihefte bot. Ztrlbl. 1905, xviii. 1. 9. l'nilipi's, Contrib. bot. Lab. Penusylvania, ii. 1904, 1) 237. Guilleraund, Revue génér. de bot, xviii. 1906, 1\% 392. ( $\left.{ }^{8}\right)$ Oltaniss, Morpho-

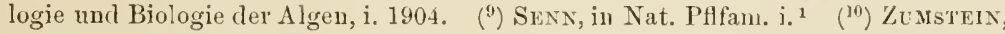
Jahrb. f. wiss. Bot. xxxiv, 1900, p. 149. ("1) Schröter, in Nat. Pffam. i. ${ }^{1}$ Dr Barr, Comprative Morph. and Biol. of the Fungi, 18s4. Zorf, Die Pilatiere, 1855. Lister, A Monograph of the Myeetozoa, 1894. Harier, Bot. Gaz. xxx. 1900, p. 217. JAHN, Ber. deutseh. bot. Ges. 1904 , p. 84, 1905, p. 489, 1906, p. 538, 1907, 1. 23. (12) H. Kn̈̈хиц, Archiv f. Protistenk. ix. 1907, 1' 170. JAнs, Ber. deutsch, bot. Ges. 1907, p. 23, and 1908, p. 342. (13) Worosin, Jahrb. f. wiss. Bot. xi. 1878, 1. 548. Nawascuis, Flora, 1899, p. 404. Prowazek, Arb. kais. Gesundheitsannt, xxii. 1905, p. 396. (14) Pınoy, Rôle des Bactéries dans le devel. de certains Myxomyc. Paris, 1907. ( $\left.{ }^{15}\right)$ Sснӥтr, in Nat. Pflfan. i. ${ }^{1}$ and Die Peridin. der Planktonexpedition, 1895. Schlllis, Flora, 1891, p. 220. (16) Scнütт, Das Pflanzenleben der Hochsee, 1893. Gras, Das Plaukton des norwegisehen Nordmeeres, 1902. Kalisten, Wiss. Ergeb. der dentsehen Tiefsee-Expedition, 1898-99, ii. 2. Teil, 1905-1907. (17) Schillixg, Ber. dentseh. bot. Ges. 1891, p. 199. (18) Zenenbauer, Ber. dentseh. bot. Ges. 1904, p. 1. (19) De BarY, Unter's. iber die Konjugaten, 1858. Ralfs, The British Desmidieae, 1848. Wille, in Nat. Pffam. i. ${ }^{2}$ W. West and G. S. West, A Nonograph of the Brit. Desmid. i. 1904. Lütkemüller, Beitr. z. Biol. d. Pflanz. viii. 1902, p. 347. Klebahn, Jahrb. f. wiss. Bot. xxii. 1891, p. 415. $\left({ }^{20}\right)$ ChMelewskr, Arb. d. Gesellseh. d. Naturf. d. Charkower Universität, xxv. 1890. Tröxdef, Bot. Ztg. vol. lxv. 1907, p. 1S7.

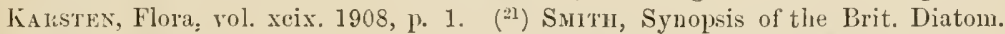
1853-56. ScunidT, Atlas der Diatomeenkunde, Leipzig, 1874-1877. VAx Hetrok, Symopsis des Diat. 1850-85 and Traité des Diat. Anvers, 1899. Dippel, Diatomeen der Rhein-Mainebene, 1905. Vox Scü̈nfeld, Diatomaceae Gemaniae, 1907. Peragallo, Diatom. marines de la France. Pfitzer, in Bot. Abh. von Hanstein, i. ${ }^{2} 1871$. Klebahs, Jahrb. f. wiss. Bot. xxix. 1896, p. 595. Kalistex, Flora, 1896, p. 286, 1897, pp. 33 and 203, 1900, 1. 253 and Die Diatomeen der Kieler Bueht, 1899. Scnütr, in Nat. Pflfam. i., and Jahıb. f. wiss. Bot. 1899-1900. O. Müller, Ber. deutseh. bot. Ges. 1898-1909. Hernzerling, Bibl. bot. Heft 69, 1908. Maxgin, Anu. se. nat. 9 sér. viii. 1908, p. 17\%. ( $\left.{ }^{22}\right)$ BenEcke, Jahrb. f. wiss. Bot. xxxv. 1900, p. 535 . Ka ristea, Flora Ergzb. 1901, p. 404. ( $\left.{ }^{23}\right)$ SAuvag.EAU, 
Station d'Arcachon, Travaux des labor, ix. 1906, p. 49, and x. 1907, p. 1. (24) Grax, Die Diat. der arkt. Neere, Fauna arctica, iii. 1904. KAnsten, Ber. dentsch. bot. Ges. 1904, 1. 544, and Wiss. Ergebn. der d. Tiefseeexped. ii. 2. Th. 1907, 1, 496. P. Bergos, Bull. Soc. hot. France, rol. liv. 1907, 1. 327. (25) Ǩ̈rixg, Tabulae phycologicae. ( $\left(^{26}\right)$ Wrlle, in Nat. Pfffam. i. ${ }^{2}$ (27) Wrlle, Algolog. Notizen, ix.xiv. Christiania, 1903. Schmder, Ber. deutsch. bot. Ges. 1903, 1. 346 . WollexWEBEl, Ber. dentsch. bot. Ges. vol. xxvi. 1908, p. 238. ( $\left.{ }^{28}\right)$ Golioschaskix, Flora, 1905, p. 420. (29) KLeis, Jahrb. f. wiss. Bot. xx. 1859, p. 133, and Ber. nat. Ges. Freiburg, v. 1890. Oventon, Bot. Ztrbl. xxxix, 1889, p. 65. A. Merer, Bot. Ztg. 1896, 1. 187. $\left({ }^{30}\right)$ Beyerinck, Bot. Ztg. 1890, p. 720. Gerxeck, Beihefte bot. Zentralbl. xxi. ${ }^{2}$ p. 221 . ( $\left.{ }^{31}\right)$ Grixtzesco, Rev. génér. de bot. xv. 1903, p. 5. $\left({ }^{32}\right)$ SExx, Bot. Ztg. 1899, p. 39 . (23) Askexasy, Ber. deutsch. bot. Ges. 1889, p. 129. ( $\left.{ }^{34}\right)$ Klebs, Bot. Ztg. 1891, p. 789, and Flora, 1890, p. 351. Timberlake, Trans. Wiscons. Acad. xiii. and Annals of Botany, xv, 1901, p. 619. HAliper, Bull. Unir. Wisconsin, No. 207, 1908, p. 2S0. (35) Doder, Jahrb. f. wiss. Bot. x. 1876, 1. 417. Klebs, Beding. der Fortpfl. bei Algen u. Pilzen, 1896. ( ${ }^{36}$ ) Pringsheid, Jahrb. f. wiss. Bot. i. 1858, p. 1. JunANi, ibid. ix. 1873-74, 1. 1. Klebahr, ibiul. xxiv. 1892, p. 235. PAscher, Hedwigia, xlvi. 1907, p. 265. VAN Wisselingh, Beih. bot. Ctrbl. rol. xxiii. i. 1908. ( $\left.{ }^{3 \pi}\right)$ Prixgshern, Jahr̈b. f. wiss. Bot. ii. 1860, 1. 1. Oltulaxys, Flora, 1898, p. 1. Allex, Ber. d. bot. Gesellsch. 1905, p. 285. (38) De Bali and Strasblrger, Bot. Ztg. 187 7 , p. 713 . Solms-Laubach, Trans. Limn. Soc. 1895. ('99) Reinke, Wiss. Meeresunters, Kiel, 1899. Weber van Bosse, Annales jard. Buitenzorg, xv. 1898, p. 243. HaberLAxdt, Sitzb. Akad. Wien, cxv. i. 1906, p. 1. Srebelrus, Ceylon Marine Biolog. Reports, No. 4, 1900. ( $\left.{ }^{40}\right)$ Freusd, Beih. bot. Ztrbl. vol. xxi. i. 1907, 1) 55. ( $\left.{ }^{11}\right)$ Elisst, Beiheft bot. Ztrbl. xiii. 1903, 1. 115. Oltmaxss, Flora, 1895, p. 388. Davis, Bot. Gazette, xxxviii. 1904, 1. 81. Heidivger, Ber. deutsch. bot. Ges. vol. xxvi. 1908, p. 312. ( ${ }^{42}$ ) KíneldaAa, in Nat. Pflam. i. ${ }^{2}$ Postels et Rurrecht, Illustr. algarum Oceani pacifici, 1840. Hоокеr, Flora Antarctica, i. 1844. Reivke, Atlas deutscher Meeresalgen, 1859-92. Reinke, Studien zur vgl. Entwicklgsgesch. der Laminarien, Kiel, 1903. ( ${ }^{+3}$ ) SkotTsbeng, Bot. Notiser, 1903, p. 40, and Wiss. Ergeb. der schwed. Suidpolarcxpedition, iv. ${ }^{6} 1907$, 1. 80. (H) SAUVAGEAT, C. rend. Soc. de biolog. Paris, rol. lxii. 1907, p. 1082. ("55) Haxsteen, Jahrb. f. wiss. Bot. xxxy. 1900, p. 611. Hunger, ibid. xxxriii. 1903, p. 70. ( $\left.{ }^{46}\right)$ WILLN, Univers. Festschrift Christiania, 1897. Srkes, Annals of Botany; vol. xxii. 1908, p. 292. ( ${ }^{47}$ ) BERThold, Flora, 1897, p. 398. Oltuaxs, Flora, 1897, p. 398, 1599, p. S6. Satvagedu, Jomru. de botan. 1896

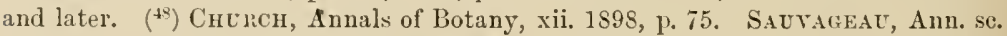
nat. 8 sér. x. 1899, p. 265. ( $\left.{ }^{49}\right)$ Williams, Annals of Botany, xi. 1897, p. 545, and x viii. 1904, pp. 141 and 183, xix. 1905, p. 531. ( $\left(^{50}\right)$ MotriEk, Annals of Botany, xiv. 1900, p. 163. Stuasburger, Bot. Ztg. 1906, ii. p. 3. ( ${ }^{51}$ Thunet et Bornet, Etud. phycolog. 1877. Oltiasss, libl. bot. Heft 14. Strasburger, Jahrb. f. wiss. Bot. xxx. 1897, p. 351. FAruer and Wildias, Phil. Trans. Roy. Soc. Lond. vol. cxc. 1898. Yamaxoucir, Bot. Gaz. vol. xlvii. 1909, p. 173. ( $\left.{ }^{52}\right)$ Schuitz and Hadptaleisch, Nat. Pflfam. i. ${ }^{2}$ Falkexberg, 26, Nonogr. Fauna und Flora Neajel, 1901. Kolkwitz, Wiss. Meeresunters, Kiel, 1900. Wíle, Ber. deutsch. bot. Ges. 1894, 1) (57) and Nova Acta, lii. 1887, 1). 51. Osткинет, Flora, 1900, p. 109. Oztmaxis, Bot. Ztg. 1898, p. 99 . Hassexkamp, Bot. Ztg. 1902, p. 65. Wolfe, Annals of Botany, xviii. 1904, 1.607. Yamaxodchi, Bot. Gazette, xli.

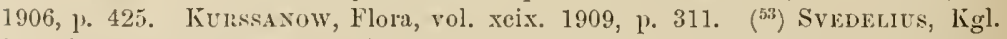
Srensk. Vetenskapsakad. Handl. vol. xliii. 1908, 1) 76. ( $\left.{ }^{54}\right)$ Kuckeck, Sitzb. Aliad. Berlin, 1894, p. 983 . STurerr, Anuals of liotany, xiii. 1899, p. 83 . ( ${ }^{55}$ ) DE Bari, 
Comparative Morph. and Biol. of the Fungi. $\left({ }^{56}\right)$ Brefeln, Bot. Unters. iiber Schimmelpilze, Unters. ans dem Gesantgehiet d. Mykologie, i.-xiv. 1872-1908.

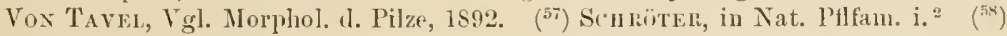
Conxi, Ann, se. nat. 1872. Thaxten, Bot. Gaz. 1895. LAgerhem, Bihang till Srensk. Akad. Hanll. xxv. Wonoxix, Mém. de l'Acad. imp. des Sciences de St. Pétersbourg, 1904, 8 sér. vol. xvi. No. 4, p. 1. $\quad\left({ }^{59}\right)$ Trow, Aunals of Botany, ix. 1895 , p. 609, xiii. 1S99, p. 130, xviii. 1904, p. 541. Kiebs, Jahrb. f. wiss. Bot. xxxiii. 1899, p. 513. Davis, Bot. Gaz. xxxv. 1903, 1. 233. Cudtesex, Beriehte deutsch. bot. Ges. xxvi. 1908, p. 144. Müскв, Berichte deutsch. bot. Ges. xxri.a 1908, p. 367. (6i) Worosin, Jahrb. f. wiss. Bot. xi. 1878, p. 556. (6I) WAGER, Annals of Botany, iv. 1Ss9-91, 1. 127, x. 1896, lp. $\$ 9$ and 295, xiv. 1900, 1. 263. Berlese, Jahrb. f. wiss. Bot. xxxi. 1S98, 1. 159. DAvis, Bot. Gaz. xxix. 1900, 1. 297. Stevess, Bot. Gaz. 1899, xxviii. p. 149, 1901, xxxii. p. $7 \tau, 1902$, xxxiv. 1. 420 , and Ber. dentsch. bot. Ges. 1901, 1. 171. Trow, Annals of Botany, xr. 1901, 1. 269. Mryake, Annals of Botany, xv. 1901, 1. 653. Rosexbers, Bihang till Svensk. Ak. vol. xxviii. 1903. RuHLAxh, Jahrb. f. wiss. Bot. xxxix. 1904, I. 135. Rostowzew, Flora, 1903, p. 405. ( $\left.{ }^{62}\right)$ Harpeli, Anuals of Botany, xiii. 1899, p. 467. Gríber, Ber. deutsch. bot. Ges. 1901, 1. 51. DAxgeant, Compt. rend. acad. Paris, exlii. 1906, P. 645. Lenderer, Les Mlicorinées de la Suisse, Bern, 1908. ( ${ }^{63}$ ) BlaAreslee, Proceed. Americ. Acar. xl. 1904; further Science, xxiv. 1906, p. 11s; Bot. Gaz. xhii. 1906, p. 161, and xliii. 1907, p. 415. HAsEl, Vidensk. Selskab. Skrifter Clnistiania, 1907, No. 7. (i (id) Brefeld, Abh. Nat. Ges. Halle, xii. 1873,

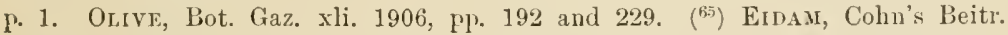
z. Biol. iv. 1S87, p. 181. Raciborski, Flora, 1906, 1. 106. Farnchild, Jahrb. f: wiss. Bot. xxx. 1897, p. 285 . Worcicki, Flora, 1904, p. S7. ( $\left.{ }^{65}\right)$ Tulasse, Selecta Fungorum Carpologia, 1861-65. Srupiöter, Lixpav, Fischer in Nat. Pflfam. i. ${ }^{1}$ (67) HAnPEI, Ber. deutsch. bot. Ges. 1895, p. (67), ani Jahrb. f. wiss. Bot. xxx. 1597, p. 249 ; further Annals of Botany, xiii. 1899, p. 467 ; xiv. 1900, ['. 321. Guillermosi, Revue génér. de bot. xvi. 1904, pp. 49 and 130. Clatsses, Bot. Ztg. 1905, p. 1. MAIRE, C. r. soc. Biol. Wviii. 1905, p. 726. Fraser and WelsFolid, Amuals of Botany, xxii. 1908, 11. 465. ("68) Schikorra, Ztsch. f. Bot. Bd. 1, 1909, p. 379. (69) DE Barr, Beitr. z. Molphol, u. Phys, der Pilze, ini. 1870. Harper, Ber. deutech. bot. Ges. 1895, p. 475, and Jahrb. f. wiss. Bot. xxix. 1895, p. 655. Neger, Flora, 1901, p. 333, aud 1902, p. 221. SALגox, Annals of Botany, xx. 1906, 1. 187. HA rePEr, Carnegie Institution of Washington, publ. No. 37, 1902

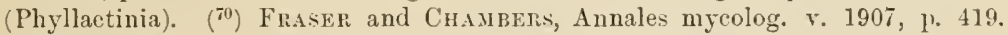
(i1) Míne, Nedic. Klinik, 1906, p. 943. (j2) HAlPER, Annals of liotany, xiv. 1900, p. 321 (Pyronema). Clatsses, Bot. Ztg. 190\%, p. 1 (Boudiera) and berichte der deutsch. bot. Ges. 1906, p. (11). Cladussex, (Pyronema) Ber. d. bot. Ges. 1907, 1. 586. (i3) Fraser, Annals of Botany, xxi. 1907, 1).349. (it) Blackdax and Fraser, Proc. Roy. Soc. Ser. B, lxxvii. 1906, p. 35\%. (i5) Fraser (Humaria rutilans) Annals of Botany, xxii. 1908, p. 35. (क5) Krosbrolz, Abb. u. Beschreib. der Schwämme, 1831-46. LExz, Nitzl., selädl. u. verdächt. Schwämme, 1890. Schlitzerger, Pilzbuch. Michael, Fiihrer fiir Pilzfrennde. Rioll, Unsere exsb. Pilze. Sydow, Taschenbuch der wichtigeren essbaren tr. giftigen Pilze. (ï) GoETHE, Über den Krebs der Obstbäume, Berlin, 1904. ( ${ }^{(8)}$ FisfHE in Rabenhorst. Krypt. flora, i. ${ }^{5}$ and Bot. Ztg. 190S, 1. 141. BuchHoltz, Ann. myeol. ir. 1908, p. 539. ( $\left.{ }^{79}\right)$ S.LDEBECK, Jahrb. Hamburg. wiss. Anst. 1884, 1890, 1893, and Ber. d. bot. Ges. 1903, p. 539, 1904, p. 119. GIEsexhaGex, Flora Ergzb. 1895, p. 267, and Bot. Ztg. 1901, p. 115. IkEN. , Flora, 1901, p. 229, and 1903, p. 1. ( $\left.{ }^{80}\right)$ Guiluieryond, Rev, génér. de bot. 1903, p. 49. E. C. HAxsex, Ztrbl. f. Bakt. Abt. ii. vol. 
xii. 1904. Lafar, Handb. der techn. Mykologie, iv. Gunlliermond, Rev. génér. de bot. 1905, p. 337. ( $\left.{ }^{91}\right)$ Thaxtel, Mem. of Amer. Acad. Boston, 1896, and xiii. 1905. Iindau, in Nat. Pflfam. i. $\left.{ }^{1} \quad{ }^{(: 3}\right)$ Dietel, Lindat, Hexings, Fischen, in Nat. Pffam. i. ${ }^{1}$ ( $\left.{ }^{83}\right)$ Jule, Jahrl. f. wiss. lot, xxxii. 1898, 1.361. Ruhlasi, Bot. Ztg. 1901, p. 187. HARPEI, Bot. Gaz xxxiii. 1902, p. 1. Malie, Rech. eytol. et taxon. sur les Basidionycètes, Thèses, Paris, A, No.429, 1902. ( $\left.{ }^{*}\right)$ R. HAlrig, Krankh. der Waldbänme, 1874, and Lehrb. der Pllanzenkraukheiten, $\left.1900 . \quad{ }^{(85}\right)$ HAliper, Transact. Wisconsin Acad, 1899, p. 475. Brefeld and FAlck, Unt. ans dem Gesamtgeb. d. Mykologie, xiii. 1905. Hecke, Ber. d. bot. Ges. 1905, p. 248. ${ }^{\left({ }^{6}\right)}$ Many papers by Magnus, Klebahr, Sydow, Erikssox, Tischler, E. Fischeir, LAgerheim, etc. ( $\left.{ }^{87}\right)$ Blackmas, Annals of Botany, xviii. 1904, p. 323. BlackMan and Fraser, ibid. xx. 1906, 1. 35. Christman, Bot. Gaz. xxxix. 1905, p. 267. Christa.ts, Trans. Wisconsin Academy, xv. 1907, p. 517, and Bot. Gazette, xliv. 1907, 1. 81. Olive, Annals of Botany, xxii. 1908, p. 331. ( ${ }^{88}$ ) Kilebain, Die wirtswecliseluden Rostpilze, 1904. ( $\left.{ }^{(49}\right)$ Ericksson und Tischler, Svenska Vet. Akad. Handl. 1904, vols. xxxvii. xxxviii. KLEBAHN, Ber. dentsch. bot. Ges. 1904, P. 255. E. Fischer, Bot. Ztg. 1904, p. 327. Malishall Wali, Annals of Botany, xix. 1905, p. ]. $\left({ }^{90}\right)$ R. Haitig, Der echte Haussehwamm, 1885, 2ud edition by von Tubeuf, 1902. MÏLlę und FALCK, Hausschwammforschungen, 1907 and 1909. MEz, Der

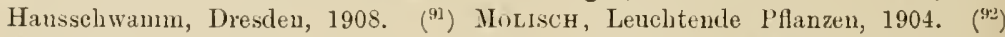
Möller, Pilzgärten siidamerik. Ameisen, 1893. Holtkimax, Schwendener Festschrift, 1899. FureL, Biolog. Zentralbl. 1905, p. 170. Huber, Biol. Zentralbl. 1905, p. 606. ( $\left.{ }^{93}\right)$ E. FisehEr, Denkschr. Schweiz. nat. Ges. xxxii. and xxxvi.

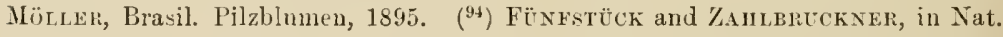
Plfam. i. ${ }^{1}$ Rernke, Jahrb. f. wiss. Bot. 1894-96. Schwendexer, Algentypen der Flechtengonidien, 1869. Bonsier, Ann. se. nat. 1889. Bitten, Hedwigia, xl. 1901, 1\% 171, and Jahrb. f. wiss. Bot. xxxvi. 1901, I1. 421. ( $\left.{ }^{95}\right)$ PErree, Proc. Calif. Acad. 1899, p. 207, and the Amer. Naturalist, 1900, 1. 245. Elexks, Bull. Jard. bot. St. Pétersb. iv. 1904. ( $\left({ }^{96}\right)$ ZopF, Beih. bot. Ztrbl. xiv. 1903; 1. 95, and

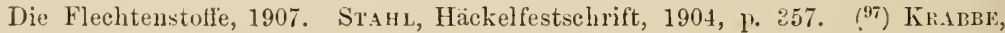
Cladonia, 1891. BAU I, Bot. Ztg. 1904, p. 21. ( $\left.{ }^{98}\right)$ STAH L, Beitr. z. Entw. d. Flechten, 1877. B.tre, Ber. dentsch. bot. Ges. 1898, 1. 363, and Flord, 1901, p. 319, further Bot. Ztgr. 1904, p. 21. DilisishlRe, Jahrb. f. wiss. Bot. xxxiv. 1900, p. 329. LiNDAU, Flora, 1888, p. 451, and Schwendenerfestschrift, 1899. WoLfF, Flora, Ergzsb. 1905, 1. 31. N1ExbuRg, Flora, vol. xeviii. 1908, p. 1. (99) M̈̈Llel, Kinltur flechtenbild. Ascomyceten, 1887, and Bot. Ztg. 1888, p. 421. GLück, Flechtensprermogonien. Habilitationsschr. Heidelberg, 1899. (19r) Jonow, Jalirb. f. wiss. Bot. xv. 1884, p. 361. Mïlleji, Flora, 1893, p. 254. Pullsex, Vid. Mledd. Kopenhagen, 1899. (10]) WrLle, in Nat. Pffam. i. ${ }^{2}$ Migula, in Rabenhorst, lirypt. Flora Dentschland, 1890. Götz, Bot. Ztg. 1899, p. 1. Gresenhagex, Flora, 1896, p. 381, and 1898, p. 19. Goeber, Flora, 1902, p. 279 . Motrier, Annals of Botany, xviii. 1901,1 1. 245. Strasbutiger, Wiesner Festschrift, 1908, 1. 24. (10:) Goenen, Die Muscineen, Schenks Hdb. d. Bot. ii. 1882 ; further Organographie, ii. ${ }^{3} 1898$, and Flora, 1902. (103) CAMPbeld, The Structure and Development of Mlosses and Ferns, 2ud Ed. 1905. (104) GoEbEL, Flora, 19ง2, J. 279. DAVIs, Anuals of Botany, xvii. 1903, 1) 477. Holferty, Bot. Gaz. xxxvii. 1901, p. 106. (105) Ikkxo, Beil. bot. Ztrbl. xv. 1903, 1. 65 (Alarchantia). Johssos, Bot. Gaz. xxxviii. 1904, p. 185 (Monoclea). Lewls, Bot. Gaz. xli. 1906, j) 110 (Riccia). Bulleter, Beil. bot. 7trbl. xviii. ${ }^{1}$ 1905, 1. 327 (Fegatella). Aress, Spernatogenese der Laubmoose, Dissert. Bonn, 1907 (Polytriehum). (10i) l'FefFer, Unters. bot. J. Tübingen, i. ii. Linfules, Jahrb. f. wiss. Bot, xli. 1904, J. 65. (107) W. 12. J. VAx LEEUwEN-REIJN- 
VAAN, Recueil Trav. bot. Neerland. ir. 1907, and Ber. deutsch. bot. Ges. xxvi. a 1908 ,

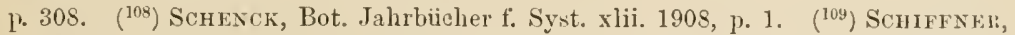
in Nat. Pflfam. i. ${ }^{3}$ Leitgeb, Unters. über Lebermoose, 1874-18s2. Gokrel, Flora, 1895, p. 1. Axpleas, Flora, 1899, p. 161. (110) Garber, Bot. Gaz. xxxvii. 1904, 1. 161. Lewis, Bot. Gaz. xli. 1906, p. 110. (111) KNr, Botan. Wandtafeln, viii. 1890. In fxo, Beih. bot. Ztrbl. xv. 1903. Kayerling, Flora Ergzb. 1897, 1. 1. Bolleter, Beih. bot. Ztrbl. xviii. ${ }^{1}$ 1905, p. 327. (112) Barxes and Laxp, Bot. Gaz. xliv. 1907, 1. 197. (113) LANe, Amuals of Botany, xxi. 1907, 1. 201. CAMPBELL, Annals of Botany, xxi. 1907, p. 467, and xxii. 1908, p. 91. (114) PEIleE, Bot. Gaz. xlii. 1906, 1. 55. (115) Gotтsche, Haplomitrium, Nova Acta Acad. Leop. xx. 1843, j. 267. Goeber, Ann. jard. Buitenzorg. ix. 1890, p. 11, and Organographie, ii. ${ }^{1}$ P. 266. K. MíleE in Rabenhorst, Krypt. Flora, vi. 1909, p. 396. (116) K. Mi (itere, Ruhlani), Warstorf, Brotherus, in Nat. Pllfam. i." Lonestz, Jahrb. f. wiss. Bot. vi. 1567/68, p. 363. Haberlanot, ibid. xvii. 1856, p. 359. TANsLeY and ChICK, Ann. of Bot. xv. 1901, p. 1. Conrexs, Vermehrung der Laubmoose, 1899. Valpic, Flora, 1903, p. 346. (117) Zenelibaúer, Oestr. bot. Ztschr. 1902. (138) Steinbrixck, Ber. dentsch. bot. Ges. xxvi.a $190 \mathrm{~S}$, p. 410, and xxvii. 1909, p. 169. (119) HALERLANDT, Jahrb. f. wiss. Bot. xvii. 1880, p. 357. Porseh, Der Spaltïflnungsapparat im Lichte der Phylogenie, 1905, p. 33. $\left({ }^{120}\right)$ Рн. W. Schrmper, Torfmoose, 1858. Nawascinx, Flora, 1897, p. 151. (121) Lantzius-Bexisga, Der innere Ban der Mooskapsel, 1850. Diня, Flora Ergzbd. 1894, p. 2\$6. Goebel, Flora, 1895, p. 459.

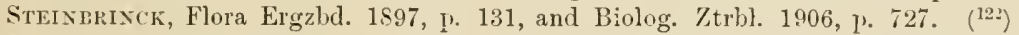
SADEBEck, in Nat. Pflfam. i. G Goebel, Organographie ii. ${ }^{2}$ 1900. Bower, The Origin of a Land Flora, London, 1908. (123) PFEFFEI, Unters. bot. Inst. Tübingen, i. P. 363 (Farne, Selaginella). Shibata, Bot. Mag. Tokyo, xix. 1905, p. 39 (Salrinia); ibud. S. 79 and 126 (Equisetum); Ber. d. bot. Ges. 1904, S. 47s, und Jahrb. f. wiss. Bot. xli, 1905, S. 561 (Isoëtes). Linfors, Ber. d. bot. Ges. 1905, 1. 314 (Equisetums). Butchuaxi, Flora, vol. xcix. 1909, p. 193 (Lycopodium). (124) SAlnebeck, Diels, Bitter in Nat. Phfam. i. ${ }^{*}$ Hooklr, Synopsis filicum, 1883. Baker, Fern Allies, 1887. Снгist, Farukränter der Erde, 1897. Christensen, Index Filicum, 1906. (125) Jefrlier, Univers. of Toronto, biolog. series, No. 1, 1898 (Botrychium). BrUChMANx, Bot. Ztg. 1904, p. 1 (Ophiogl.), and Flora, 1906, p. 203 (Botrychium). CardffF, Bot. Gaz. xxxix. 1905, p. 340. CAMrbell, Annales Jardin Buitenzorc, xxi. 1907, p. 138 (Ophiogl.). Burlinghas, Bot. Gaz. xliv. 1907, p. 34 (Ophiogl.). (126) Lrox, Bot. Gaz. xl. 1905, p. 455 (Botrychinm). (125) CAmpbels, The American Naturalist, xlii. 1908, p. 154, and Annal. Buitenzorg, xxii. 1908, p. 99. ( ${ }^{128}$ ) STErsBrisck, Ber. deutsch. bot. Ges. 1903, p. 217, and Biolog. Ztrbl. 1906, p. 674. Unspricg, Jahrb. f. wiss. Bot. xxxviii. 1903, p. 635, and Ber. deutsch. bot. Ges. 1904, p. 73. (129) Strasburger, Jahrb. f. wiss. Bot. vii. $1869 / 70$, p. 390. $\left({ }^{130}\right)$ DE Barr, Bot. Ztg. 1878, p. 449. Bower, Trans. Linn. Soc. 1887. Laxg, Phil. Trans. vol. cxe. 1898, p. 187. Falmek, Moore, Digby, Proc. Roy. Soc. lxxi. 1903, and Ann. of Bot. xxi. 1907, p. 161. Yamaxorehi, Bot. Gaz. xiv. 1908, p. 289. Woroxix, Flora, vol. xeviii. 1907, p. 101. (131) SADEBECk, in Nat. PHfam. i." p. 381. (132) Pringanima, Jahrb. f. wiss. Bot. iii. 1863, p. 484 . Belajeff, Bot. Ztg. 1898, p. 141. (123) Striasbuhiger, Azolla, 1873. Pfeiffer, Bot. Gaz. xliv. 1907 , 1). 445. (134) Strasburger, Flora, xcvii. 1907, p. 123. (135) SAfDEBCK, in Nat. Ptlfam. i. ${ }^{+}$Jeffrer, Mem. of Boston Soc. of Nat. Hist. v. Urispliuxg, Jahrb. f. wiss. Bot. xxxviii. 1. 655, and Ber. deutsch. bot. Ges. 1904, p. 73. STEIxвпгхск, Ber. dentsch. bot. Ges. 1903, 1. 217. (136) Unspruxg, Jahrb. f. wiss. Bot. xxxviii. p. 635. Steinerixck, Biolog. Zt.bl. 1906, p. 724. (13i ) Pritzel, in Nat. Pflfam. i. ${ }^{4}$ Goebel, Bot. Ztg. 1887, p. 161. Treve, Ann. Jard. Buitenzorg, 1884-1890. 
Bruchuans, Über die Prothallien u. Keimptl. der Lycop. 1898. Laxg, Annals of Botany, xiii. 1899, p. 279. WIGGLesworth, Ann. of Bot. xxi. 1907, p. 211. (138) Heronymus, in Nat. Pllfam. i. ${ }^{4}$ Pfeffer, in Hanstein's bot. Abh. 1871. BelaJEFF, Bot. Ztg. 1885, p. 793. Bhuсhмans, Unters. über Selaginella spimulosa, 1897, and Flora, vol. xcix. 1908, pp. 12 and 436. FitTixg, Bot. Ztg. 1900, 1) 107. GoebeL, Flora, 1901, p. 207. Lyon, Bot. Gaz. xxxii. 1901, p. 124, and xl. 1905, p. 285. CAxipBeLL, Annals of Botany, xvi. 1902, p. 419. Denke, Beiheft z. bot. Ztrbl. xii. 1902, p. 182. Steinbrinck, Ber. deutsch. bot. Ges. 1902, p. 117, and Biolog. Ztrbl. 1906, p. 737. (139) Bruchuane, Flora, 1905, p. 150. Goebel, Flora, 1905, p. 195 . $\left({ }^{140}\right)$ Hłaberlandt, Flora, 1888, p. 291, and Ber. d. bot. Ges. 1905, p.441. (141) SADEBECK, in Nat. Pflfam. i. ${ }^{4}$ Famer, Ann. of Bot. v. 1890/91, p. 37. ScotT and Hill, ibid. xiv. 1900, p. 413 . Sмiтh, Bot. Gaz. xxix. 1900, p. 225. Fitrixg, Bot. Ztg. 1900, p. 107. Solms-Latbach, Bot. Ztg. 1902, p. 178. BelajefF, Bot. Ztg. 1885, p. 793. Campbell, Mosses and Ferus, 1. 536. Stockey, Bot. Gaz. vol. xlvii. 1909, 1. 311. (1+2) W. Ph. Schimper, Traité de Paléontologie végétale, Paris, 1866-1874. W. Ph. Schimper and A. Schenk, Palaeophytologie in Zitrel's Handbuch der Pal. 1890. A. Schenk, Die fossilen PHanzenreste, 1888. B. Renault, Cours de bot. fossile, 1881-1885. G. SAPolta et Manion, Evolution du règne végétal, 1881 and 1885. Solms-Lavbach, Ein'eitung in die Palaeophytologie, 1857. Potonié, Lehrb. der PHlanzenpalaeontologie, 1899. D. H. Scort, Studies in Fossil Botany, 1900 ; 2nd Ed. vol. i. 1908. Potoxié, Fossile Pteridophyten in Nat. Pflanzenfam. i. R. Zeillei, Eléments de Paléobotanique, 1900, and Progressus rei bot. ii. 1907, p. 171. (1+3) Oliver, Biol. Ztrbl. 1905, xxv. p. 401, and Anu. of Bot. xxiii. 1909, p. 73. Scurt, Wiss. Erg. Wiener bot. Kongr. 1905, p. 279, further Progressus rei bot. i. 1907, p. 139, and Smithsonian Report, 1907, 1. 371. Chodat, Archives se. phys, et nat. 4. pér. xxvi. genève, 1908.

\section{PHANEROGAMS BY G. KARSTEN}

(1) W. Hur yeister, Vergleich. Untersuch. der. Keim., Entfalt. u. Fruchthild. höherer hiryptogamen und der Samenbild. der Koniferen, Leipzig, 1851. ( $\left.{ }^{2}\right)$ E. Strasbuiger, Angiospermen und Gymnospermen, Jena, 1S79. Overton, Reduktion der Chromosomen, Vierteljahrschr. d. naturf. Ges. Ziirich, 1893. Jues, Tetradenteilg., Jahrb. f. wiss. Bot. xxxv, 1900. Coulter and CHamberlain, Morphology of Spermatophytes, i. ii. New York, 1901 and 1903. K. Goeber, Organographie, Jena, 1898-1901. E. Waring, Pollenbildende Phyllome u. Caulome, Hanst. bot. Abh. ii. 1873. Strasburger, Befruchtungsvorgang b. d. Phanerogamen, Jena, 1884. Wille, Pollenkörner d. Angiospermen, 1856. Belajeff, Pollenschlauch d. Gymnospermen, Ber. d. deutsch. bot. Ges. 1891, 280, and 1893, 196. STrasburger, Verhalten d. Pollens u. Befruchtungsvorgänge bei den Gymnospermen, Jena, 1892. (2a) E. Strisburger, Reduktionsteilung. Sitzgsber. K. Akad. d. W. Berlin. xviii. 1904. Shrasburgen, Ch. Allen, Kifhi Miyake, I. Bentr. Ovelton, Histolog. Beitr. Jahrb. f. wiss. Bot. xlii. Lpzg. 1905. Strasburger, Stolll. Grundlagen der Vererbung. Jena, 1905. STrusburger, Chromosomen-Zahlen u. Reduktionstlg. I'ringsh. Jahrb. xly. 479, 1908. O. Rosknbelig, Reduktionsteilung. Botan. Notiser. 1905. Also, Tetradenteilungen der Compositen. Srensk. Bot. Tidskr. 1909, iii. 1) 64. (3) Elculen, Bliitendiagramme i. and ii. Lpzg. 1875, 1878. PAYer, Organogenie de la fleur, 1857. A. ExGlen, Prinzipien d. systemat. Anordnung in his Syllabus, 3rd ed., Berlin, 1903. Also, Das Pflanzenreich from 1900. Égglel: u. P'lista, Naturl. PHanzenfamilien ii. iui. iv. from 1889. 
Balluon, Histoire des plantes, i.-xiii. 1867-1894. Berg and Schmit, Atlas d. offizin. Pflanzen, 1863, and 2nd ed. by A. Meyer and Schumaxn, 1891. 1902. R. v. Wetrsteis, Handb. system. Botanik. i. and ii. 1901-8. ( $\left.{ }^{\dagger}\right)$ W. Hofmeister, Vergl. Untersuchungen, 1851. Strasburger, Befruchtg. bei d. Lioniferen, Jena, 1869. Koniferen u. Gnetaceen, Jena, 1872. Angiosperm u. Gymnospermen, Jena, 1879. Covltei and Chamberlain, Morph. of Spermatophytes, i. and ii. N.Y. 1901 and 1903 ; K. GoebeL, Vergl. Entwicklungsgeseh, 1884. Also Organographie, i. and ii. Jena, 1898 and 1901. The literature under $\left(^{3}\right)$ and $\left(^{4}\right)$ inelucles the most important and fundamental works betring on the Phanerogums as a whole; they will not be further referred to. ( $\left.{ }^{5}\right)$ G. Kraus, Gynacceum. Verh. phys. u. medic. Ges. Wïzburg, 1907. E. Негxнгене, Androdioecie u. Andrononoecie. Flora, 1906, 363. $\quad\left({ }^{6}\right)$ Chr. K. Sprexged, Das entrleckte Geheimnis der Natur, 1793. (Ostwald's Kilassiker, Nos. 48-51.) Ch. Darwin, Cross- and Self-fertilisation, and Fertilisation of Orchids. Heri. MüLLER, Insektenbefruchtung, 1873. F. HiLinerBRANDT, Geschlechtsverteilung, 1867. KNuth, Handbuch der Bliitenbiologie. K. Goeber, Pollenentleerung, Flora, Ergbd. 1902, 237. C. Stopes and K. Fudi, Bot. Centralbl. xx. 1, 1906. Also Bestüubungstropfen, Ber. Dentsch. Bot: Ges. 1903. W. Burick, Daliwin's Kreuzungigenetz, Rec. trav. bot. néerl. 1907, 4, 17. H. Schencк, Wassergewächse, 1S86. ( $\left(^{7}\right)$ K. Goebel, Kleistogame Bliten, Biolog. Centralbl, xxiv. 1904. Also Viola, Flora, Ergbd. 1905. H. Ritzerow, Kleistogame Bluten, Flora, 1907, 163. ( ${ }^{(8)}$ Literature $\left({ }^{+}\right)$, and : BelajefF, Ber. Dentsch. Bot. Ges. 1891, 280, and 1893, 196. Alixold, Gymnospermen, 1, 2, and 5, Bull. de Moscou, 1899, 1900 ; 3 and 4, Flora, 1900 ; 6, Russian with German Resmué. K. Mryake, Abies balsamea, Beih. z. bot. Centralbl. 1903. Also Picea excelsa, Annals of Botany, xvii. 1903. A. LAwsos, Sequoia, Annals of Botany, xviii, 1904. Cryptomeria, Annals of Botany, xviii. 1904. Cephalotaxus, Anuals of Botany, xxi. 1907, 1. Libocedrus, Annals of Botany, xxi. 1907. Psendotsuga Douglasi, Annals of Botany, xxiii. 1909. E. Strasburgeh, Eibe. НAEckel-Festsehrift,Jena, 1904. W. C. Coker, Taxodium, Bot. Gaz. Jul. and Aug. 1903, Bot. Gaz. xxxviii. 1904. Cephalotaxus, Bot. Gaz. xliii. 1907. Margaret Ferguson, Pinus, Annals of Botany, xv. 1901. Proc. Washington Acad. of Sc. vi. Oct. 1904. Covlter and LAnn, Torreya, Bot. Gaz. xxxix, 1905. E. Stahl, Mexik. Nadelhölzer, and L. Kleis, Mitteleurop. Waldbäume in "Vegetationsbilder," ii. 3 and 5-7, Jena, 1904. G. Loprior., Arancaria. Publ. sc. assoc. internat. Bot. i. 1906. A. RoBertson, Taxoideae, New Phytologist, vi. 3, 4, 1907. MI. S. Toung, Daerydium, Bot. Gaz. xliv. 1907. C. O. Norés, Juniperus, Upsala Un. Årskr. 1907. Kildathl, Pinus Laricio, Bot. Gaz. xliv. 1907. O. Renseli, Juniperus, Flora, 1907, 421. L. L. Burlisane, Podocarpus, Bot. Gaz. xlvi. 161, 1908. K. MrYake, Cunninghamia, Bot. Mag. Tokyo, 1908. $\left({ }^{9}\right)$ E. WA ring, Cyeadeerne, li. D. Vidensk. Selsk. Forh. 1877 and 1879. M. Trevb, Cycadées, Anu. de Buitenzorg, 2 and 4, 1885. H. J. WEвbEr, Spermatogenesis and fecundation of Zamia, U.S. Dep. of Agricult. Washington, 1901. S. Ikevo, Cyeas revoluta, Jahrb. f. wiss. Bot. xxxii. 1598. Coulter and Chamberlais, Zamia, Bot. Gaz. March 1903. M. C. Stopes, Cyeadeen, Flora, 1904, 435. H. MAtTe, Cycadacées, Caen, 1904. K. Mra KE, Cyeas-Spermatozoiden, Ber. der deutschen botan. Gesellsch. 1906. G. J. Chamberhain, Dioon. Bot. Gaz. 1906, 42. Spermatogenesis in Dioon. Bot. Gaz. xlvii. 215, 1909. OTIS W. CALdwell, Microcyeas, Bot. Gaz. xliv. 1907. Multicellular Antheridium in the Pollen-tube. Sakugoro Hiass, Ginkgo biloba, Bot. Centralbl. vol. Ixix. No. 2, 1897. Journ. of the College of Science, Univ. Imp. Tokio, viii. 1895, and xii. 1898. K. MIYAKE, Spermatozoids of Ginkgo, Journ. Appl. Microse. etc. N.Y. v. 5. Carothers Ginkgo, Bot. Gaz. xliii. 1907. $\left({ }^{10}\right)$ Literatur $\left({ }^{4}\right)$, and F. O. Bower, Welwitschia, Quart. Journ. Micr. Soc. 
xxi. 1881. Gnetum Gnemon, ibid. xxii. 1882. H. H. W. Peansox, Welwitschia, Phil. Trans. Roy. Soc. Lond. B, 198, 265, 1906 ; Proc. Roy. Soc. Ser. B, vol. lxxx. B, 544, 1908. G. Kinrsten, Gnetum, Bot. Ztg. 1892; Cohns Beitr. z. Biol. vi. 1893. JACCARd, Ephedra helvetica, Diss. Ziirich, 1893. Lotsy, Gnetum, Ann. de Buitenzorg, xvi. 1899. Parthenogenesis, Flora, 1903. J. M. Covlter, Gnetum Gnemon, Bot. Gaz, xlvi. 1908, xliii. W. J. G. Land, Bot. Gaz, xxxviii. 1904. (11) SrrasBUR:Er, Befruchtung und Zellteilung, 1878. Befruchtungsvorgang b. d. Phanerogamen, 1884, "Doppelte Befruchtung," Bot. Ztg. ii. Abt. 1900. Befruchtung, Bot. Ztg. ii. Abt. 1901. L. Gulgna RD, Vol. jubil. soc. d. Biologie, 1899. Anthérozoides et double fécond., Comptes rend. Paris, 1899. Tulipres, Anu. se. nat. 8 sér. xi. 1900, Mais; Najas major; Renonculacées, Journ. de Botan. xv. 1901. M. Treub, Loranthacées, Ann. d. Buitenzorg, ii. and iii. 1883 and 1885. Casuarina, Aun. d. Buitenzorg, x. 1891. Balanophora elongata, Amn. d. Buitenzorg, xv. 1898. S. Nawaschin, Birke, Mém. acad. imp. St. Pétersbourg, vii. sér. 42, No. 12, 1894. Ulmus, Bull. acad. imp. St. Pétersbourg, 1898. Lilium Martagon and Fritillaria tenella, Bull. acad. imp. St. Pétersbourg, 1898. Corylus A vellana, Bull. 1899. Dicotylertonen, Ber. d. deutsch. bot. Ges. 1900. Westerinane, Antipodal cells, Ber. d. deutsch. bot. Ges. 1898. Benson, Amentiferae, Linn. Soc. Lond. 1894. Lotsy, Rhopaloenemis phalloides, Ann. d. Buitenzorg, 2 sér. ii. 1900. G. Kansten, Juglandaceae, Flora, 1902. F. E. Lloyd, Rubiaceae, Mem. of the Torrey Bot. Club, viii. 1, 1899, and 2, 1902. Dovglas H. CaMpbelt, Peperomia, Ber. d. deutsch. bot. Ges, 1899. Duxcan S. Johxson, Peperomia, Bot. Gaz. xxx. 1900. J. Hanstein, Entwicklung des Keimes, Bot. Abhandlung, i. 1, 1870. TH. C. Frye, Casnarina, Bot. Gaz. Aug. 1903. Juel, Casuarina, Flora, 1903. l'. k. Loetscher, Antipodal Cells, Flora, xeiv. 213, 1905. E. Strasburger, Drimys, Flora, Ergzbg. 1905. Сн. H. Shatruck, Ulmus americana, Bot. Gaz. xl. 1905. A. Habermann, Synergidae Diss. 1905. O. Porsch, Phylogenie d. Embryosackes, Zool. bot. Ges. Wien, 1907, p. 120, and Vortrag. Dresden, 1907. N. Alвen v. J. Parkis, Origin of Angiosperms. A. Ennst, Phylogenie des Embryosackes, Ber. Deutsch. Bot. Ges. 1908, 419 . K. Strasburanl, Chromosome numbers, ete. Pringsh. Jahrb. xlv. 479, 1908. ("1a) Sr. Murbecr, Alehimilla. Lunds Univ. Arssk. 36, 1901. H. O. Juel, Antennaria. K. Srensk. Ak. Handl, xxxiii. 1900. Taraxacum, Bot. Tidsskr. 25, Kiobh. 1903, and Arkiv f. Bot. ii. 4, 1904. J. B. OverTox, Thalictrum, Bot. Gaz, xxxiii, 1902, and Ber. d. deutsch. Bot. Ges, 1904. C. RAunkiate and C. H. Ostexfeld, Hieracium, Bot. Tidsskr. xxv. 1903. Ostenfeld, Ber. d. Bot. Ges. 1904, 376 and 537. Sı rasburger, Reduktionsteilg., Sitz. Ber. Ak. W. Berlin, xviii. 1904, Apogamie der Eualchimillen, Pringsh. Jahrb. xli. 1905. G. Bitter, Bryonia, Abh. nat. Verein Bremen, 1904. H. Winkler, Parthenogenesis, Ber. Deutsch. Bot. Ges. xxii. 573, 1905 . Wickstroemia, Ann. de Buitenzorg. xx. 1906, 208. Progressus, ii. 3, 1908. M. Treub, Elatostemma, Ann. de Buitenzorg. 2, ser. v. 1905. O. H. Juel, Taraxacum and Cichorieae, K. Srensk. Vet. Ak. Handlingar, xxxix. 1905. Sv. ALrbeck, Taraxacum and Hieracium, Bot. Notiser, 1904. O. Rosenberg, Hieracium. Ber. Deutsch. Bot. Ges. xxiv. 1906, 157. C. H. Ostexfeid and O. Rosenberg, Experimental and Cytological Sturlies in the Hieracia, iii. O. Rosenberg, A pogamy in Hieracium, Bot. Tidsskr. xxviii. 143. 1907. F. Sthasidugli, Histolog. Beiträge vii. (Apogamie, Parthenogenesis und Reduktionsteilung) 1909. (12) .J. GïrTwel, De fructibus et seminibus flantarmu, i. and ii. Stuttgart, 1789-91. A. P. DE CAvuolet, Pllanzenphysiologie. (13) F. Hildiblanit, Verbreitungsmittel der Pllanzen, Lpzg. 1873. A. F. W. SCHлper, Epiphytische Vegetation Amerikas, Jena, 1888. Indomalayisehe Strandllora, Jena, 1891. Pflanzengeographie, etc., Jena, 1898. M. TRFub, Krakatau, Auu. 
de Buitenzorg, vii. 213, 1s8s. II. Divglesr, Peweg. der pllanzlichen Flugorgane, 1859. (14) G. KíLeBs, Keimnng, Unters. bot. Inst. Tübingen, i. 536. J. Lubbork, Seedlings, i. and ii. 1892. $\left({ }^{15}\right)$ Gorrel, Pflanzenbiol. Schillerungen, j. 1889. Treub, Aricennia, Anu. de Buitenzorg, iii. G. Karstex, Mangrove, Bibliotheca botanica, xxii. 1890. S Hupler, Strandflora, 1891. HAberLANDT, Mangrove, Aun. de Buitenzorg, xii. 1895. (다) The Literature under $\left({ }^{3}\right)$, also: H. HALlin, Polyphylet. Ursprung der Sympetalen n. Apetalen, 1901. Naturw. Verein Hamburg, Abh. xvi. Vorläufger Entwurf des natiirl. (phylogenctischen) Systems der Bliitenpflanzen, Bull. d. l'herbier Boissier, 2. sér. iii. 1903. Umfang, Gliederung u. Verwandtschaft der Familie der Hamamelidaceen, 1903. Verwandtschaftsverhältuisse bei Exglen's Rosalén, Parietalen, Myrtifloren, etc. Abhandl. d. Naturw. Vereins Hamburg, 1903. Daphniphyllum, Tokio Bot. Nag. xviii. 1904. E. SARgant, Origin of Monocotyledons, Ann. of Bot. xvii. 1903 . Bot. Gaz. xxxvii. 1904. K. Fritsch, Stelhng d. Monokotylen, Beibl. 79 zu Engler's Bot. Jahrb. xxxiv. p. 22, 1905. E. Strasburger, Drimys, Flora Ergbd. 1905, 215. (17) The modifications of the system adopted in earlier editions are besed essentially on vox WErTsters's "IIandbuch der Systematischen Botanit." This holds for the inchusion of the Cephalotaceae with the Sarraccniaceae and their approximation to the Polycarpicae. The Droseraceac, however, have been left with the Nepenthaceae. Similarly following vos Wettstwix, the Aristolochiacene and Rafflesiaceae in spite of thein inferior ovary, have been inchuded in the Polyearpicae. Thus the rest of the earlier group of Hysterophyta find their natural place among the Chorinetalae as the Loranthiflorre. The Hamanclidaceat are, on the suggestion of HALLIER, kept independent, as WeItstein has also done. The Hamameledinae, Tricoccae, and Centrospermae are parallel series not related to one another, but all leading from anemophitous apetalou.s forms (Monochlamydeae) to pentacyctic (I)ialypetalae) forms. Thave left the Polygonaceae with the Centrospermae and introduced into this order the Cactaceae in relation to the Aizodeae in aceordance with the riews of both WA RMING and WETTSTFI. The rosition of the orders Sarifraginac, Rosiflorat, and Leguminosae after the Cistiflorae, Columniforae, Gruinales, Sapindince, and Frangulinae which they formerly preceded in this text-book, has becn adopted becausc otherwise the connection to the Rhoeadinae (especially of the Reseduceac to the Cistcecte) would otherwise have becn concealed. Other rewrangements of dctail have bcen adoptel without houever modifying the gencral arrangement as much as those mentioned. $\left({ }^{18}\right)$ Cf. Literatur $\left({ }^{9}\right)$, and also L. CL. Richard, Commentatio des Coniferis et Cyeadeis, Stuttgart, 1826. H. Graf zu Sol.ss-Laubach, Stangeria, Bot. Ztg. 1890. W. H. Laxg, Stangeria, Annals of Botany, xi. 1897, and xiv. 1900. Frances Grace Surth, Trunk of Cyeads, Bot. Gaz. xliii. 1907. A. SPPecher, Le Ginkgo biloba, Diss. Genf, 1907. $\left({ }^{19}\right)$ Cf. Literatur $\left.{ }^{8}\right)$, and also L. Chlakowskr, Gymnospermen, Abh. kg. böhm. Ges. d. W. 1890, and Nachtrag dazı, Exclen's Jahrb. 1898. Noll, Abietineenzapfen, Sitzber. Niederhein. Gesellsch. 1894. J. Wiesner, Rohstoffe des Ptlanzemreichs, ii. Aufl. 1900. $\left.{ }^{(20}\right)$ Cf. Literatur $\left({ }^{10}\right)$, especially I. D. Hooken, Welwitschia, ctc. Trans. Linn. Soc. Lond, xxiv. 1863. G. KAnstex, Gnetum, Ann. de Buitenzorg,

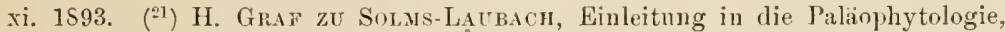
1587. The older literature will be found here. Potorie, Lehrbnch der P'flanzenpalaeontologie, 1899 ; D. H. ScotT, Studies in Fossil Botany, 1900 ; R. ZeIller, Eléments de Paléobotaniqne, 1900. ( $\left.{ }^{21 a}\right)$ Potoxié, Cycarlofilices in Exgler, Pranti, i. 4, 1901. Scott, Origin of Seed-bearing Plants, R. Inst. of Great Britain, 1903. Oliver, Older Gymnosperms, Amals of Botany, xvii. 1903. Oliver and ScotT, Phil. Trans. Roy. Soc. Lond. Ser. '3, 197, 1904. M. C. STopes, Flora, 1904. (11b) D. H. Scort, Palaeozoic Botany in Progressus rei hot. i. Jena, 1907, with a full list 
of recent literature. $\quad\left({ }^{21 c}\right)$ G. R. Winland, American Fossil Cycads, 1906. Carnegie Institution, Washington. D.'H. Scotr, Journ. Micr. Soc. Lond. April 1907, 129141. Newelt A rber, Origin of Angiosperms, Journ. Linn. Soc. xxxviii. No. 263, p. 29, 1907. R. Kinston, Mikrosporangia of Pteridospermeae, Phil. Trans. 1906, Ser. 13, 198, 413. F. W. Oriver, Physostoma elegans, Ann. of Bot. xxiii.

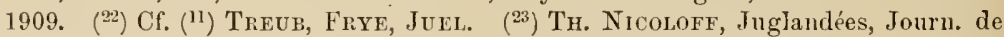
Botanique, T. xxviii.-xxix. 1904-1905. ( ${ }^{24}$ C. ScoTTsBEll, in "Vegetationsbilder," iv. 3 and 4, Jena, 1906. $\left({ }^{95}\right)$ H. Graf zu Solms-Laubach, Herkunft, Domestikation u. Verbreitung d. gew. Feigenbaumes, Abh. d. líg. Ges. d. W. Güttingen, 1882. Also Geschlechtsdifferenz, etc., Bot. Ztg. 1885. Fritz MÜller, Caprificus u. Feigenbaum, Kosmos, vi. 1882. G. King, Ficus, etc., Linn. Soc. xxiv. Also Species of Ficus, Amn. Royal Bot. Garden, Caİcutta, 1887. A. DE CANdolle, The Origin of Cultirated Plants, 1884. O. WA R'RG, Kautschukpflanzen, Berlin, 1900. E. ULE, Kautschukp,fl. der Amazonasexped. Exgler's Jahrb. xxxv. 663, 1905. M. TrEUB, Ficus hirta, Ann. de Buitenzorg, 2. ser. A, 3, 1902. ( $\left.{ }^{26}\right)$ M. Golenkin, Urticaceen und Moraceen, Flora, 1394. K. GoebeL, Verzweigung dorsiveutraler Sprosse, Arb. d. Bot. Inst. zu Wïrzburg, ii. 3, 1880. (27) BELT, Naturalist in Nicaragua, 1874. A. F. W. Schimper, Pflanzen und Ameisen, Bot. Mitteil. a. d. Tropen, i. 1888. Alfr. MöLler, Pilzgärten einiger sïdamerikan, Ameisen, Jena, 1893. E. Ule, Ameisenpflanzen, ENgLer's Jahrb. xxxvii. 335, 1906. H. v. Iherixg, Cecropien und Schutzameisen. Exgler's Jahrb. xxxix. 1907. (28) WIEsxer, Rohstoffe des Pflanzenreichs, 2nd Ed. 1900, ii. 305. ( $\left.{ }^{29}\right)$ H. Graf zU Solms-Laubach, Bau und Entwicklung parasitischer Phanerogamen, Pringsh. Jahrb. vi. 1868. J. Scotr, Loranthaceae, Journ. of Agricult. and Horticult. Soc. of India, 1S71, and Auszug resp. Übers. (Santalum album) by H. Graf zu Solms-Laubach, Bot. Ztg. 1874, No. 9. $\left.{ }^{(30}\right)$ M. Trwub, Loranthacées, Ann. de Buitenzorg, ii. and iii. 1883, and 1885. L. Josr, Mistel, Bot. Ztg. 1888. T. Jounson, Arceuthobium Oxycerlri, Annals of Botany, ii. F. Johow, Chilen. Blüten, Verh. d. Deutsch. wiss. Ver. Santiago, iv. 1900. L. KLein, Forstbotanik, Lorey's Handb. d. Forstwissenschaft, 2nd Ed. 1903. K. Reichs, Phrygilanthus aphyllus, Flora, 1904. Ban und Leben der hemiparasitischen Phrygilanthusarten Chiles in Flora, 1907, 375. (30a) O. WARBURG, Kautsehukmisteln. Tropenpflanzer, ix. 1905, p. 633. ("il) M. Treub, Balanophora elongata, Ann. de Buitenzorg, xv. 1895. P. Lotsy, Balanophora globosa, Ann. de Buitenzorg, xvi. 1899. Rlopalocnenis plalloides, Ann. de Buitenzorg, xvii. 1900. (32) E. Waliming, Pollenbild. Phyllome u. Caulome in Hanstein, bot. Abh. ii. 2, 1873. R. Brown, Vermisclite Schriften, i. 56, Ljzg. 1825. Kautschukpllauzen, ef. (25). Jos. Schweiger, Samenentwieklung der Euphorbiaceen, Flora, 94, 339, 1905. ( $\left.{ }^{33}\right)$ F. Roth, Rumex, Diss. Bonn, 1907. ( $\left.{ }^{34}\right)$ E. A. Besser, Russio-Turkestan, in "Vegetationsbilder," iii. 2, Jena, 1905. ( $\left.{ }^{35}\right)$ H. DE VRIEs, Mutationstheorie, i. 72, and ii. 662, 1901-1903. ( $\left.{ }^{36}\right)$ Cf. $\left({ }^{17}\right)$, ENGELMANN, Botanical works coll. for II. Shaw, edit. by W. Trelisali and Asa Gray, Cambridge, 1887. Goebel, Pflanzenbiol. Schilderungen i. Sukkulenten, 1889. G. Heru, Cacteen, Archiv d. Pharmacie, 1901, witl further literature. G. KAnsten and E. STAlı, Mexikan. Cacteen in "Vegretationsbilder," i. 8, 1903. E. STAнL, Mexikan. Xerophyten. ibid. ii. 4, 1904. A. and C. Purpus, Arizona, "Vegetationsbilder," ir. 7, 1907. ( ${ }^{37}$ ) M. Raciborski, Cabombeen, ctc. Flora, 1894. H. L. Lyon, Nelumbo, Minnesota Bot. Stud. ii. 1901. BüsGen, Jexsen, Busse in "Vegetationslilder," iii. 3, Jena, 1905. E.

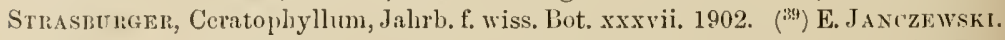
Anemone, Rev. gén. de Bot. 1892. O. StapF, Aconites of India, Ann. R. Bot. Garden, Calcutta, 10, 1905. Wolsness, Anatomy of Ranales, Ann, of lot. xxii.

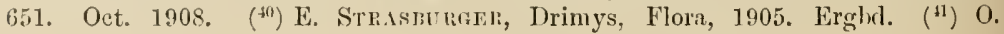


Warbure, Muskatnuss, Leipzig, 1897. J. M. JANse, Am. de Buitenzorg, 16, 1899. ( $\left.{ }^{42}\right)$ V. Hens, Kulturpflanzen und Haustiere, Ed. 7, 1902. H. Schenck,

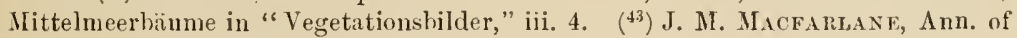
Bot. iii. and vii. 1859, 1893. K. GoEBEI, Pflanzenbiolog. Schilderungen, ii. 18911893. ( $\left.{ }^{4}\right)$ L. Diels, Droseraceae, Leipzig, 1906. K. Gosbes, Brutknospen bei Drosera, Flora, 1906, 324. $\left.{ }^{(45}\right)$ O. GRAF ZU Solds-LAUbaCh, Rafflesiaceen und Hyduoraceen, Bot. Z/tg. 18 74 . Brugmansia Zippelii und Aristolochia Clematitis, Bot. Ztg. 1876. Pilostyles Hausknechtii, Bot. Ztg. 1874. Rafflesia, Ann. de Buitenzorg, ix. 1889, Rafflesia und Brugmansia, Ann. de Buitenzorg, suppl.ii. 1897. E. Heinricier, Rafllesiaceae, Denkschr. Akad. Wien., matl. naturw. Ǩl. 78, 1905. (46) H. Graf zu Solms-Latbach, Cruciferenstudien, i.-iv. Bot. Ztg. 1900-1906. HANNig, Bot. Ztg. 1904 and 1906. C. Steindrink and H. S'Hinz, Hygrochastische Beweg. der Jerichorosen, Flora, 1908, 471. $\left({ }^{47}\right)$ J. Wressen, Rohstoffe des Pflanzenreichs, Ed. 2, 1900. ( $\left.{ }^{48}\right)$ O. Preuss, Expedition nach Central- und Siidamerika, 1901. H. Sснехск, Trop. Nutzpflanzen, "Vegetationsbilder," i. 3, 1903. $\quad\left({ }^{49}\right)$ A. de Candolle, Ursprung d. Kulturptlanzen, 1884. V. HehN, Kulturpflanzen u. Hanstiere, 7 th ed. 1902. (5v) Schweinfurtir, Erythraea in "Vegetationsbilder," ii. 8, 1905. ( $\left.{ }^{51}\right)$ Jolrs. Schnivт, Koh Chang, "Vegetationsbilkler," iii. 8, 1906. ${ }^{52}$ ) K. Goeber, Pflanzenbiolog. Schilderungen, ii., Wasserpflanzen, 1893. R. v. Wertstein, Vegetationsbilder aus Siidbrasilien, Wien, 1904, Taf. $\left.62 .{ }^{(53}\right) \mathrm{K}$. Gosbel, Pfianzenbiolog. Schilderungen i. 1889. ( $\left.{ }^{54}\right)$ E. Janczewski, Ribes, 1901, Bull. acad. Cracovie. G. Tischler, Ribes-Hybriden, Jahrb. wiss. Bot. 1906, 42. ( $\left.{ }^{55}\right)$ K. Gonbel, Bot. Ztg. 1882, 353. A. de CANDolle, Origin of Cultivater Plants. H. Graf ze Solms-Laubach, Erdbecren. Bot. Ztg. 1907, i.

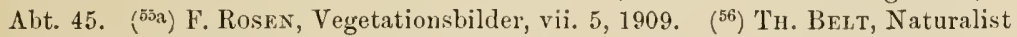
in Nicaragua, 1888, 218. H. DE Vries, Mutationstheoric, i. ii. 1901-1903. G. Tischler, Cytisus Adami, Ber. d. deutsch. bot. Ges. 1903. J. Reinke, Leguminosen, i.-vii. Pringsh. Jahrb. 30, 1896-1897. F. NoLl, Pfropfbastarde, Sitzber. d. Niederthein. Ges. f. Nat. u. Heilk. Bonn, 1905. E. Strasburger, Typ. u. Allotyp. Kernteilung. Jahrb. f. wiss. Bot. vol. xlii. 1905, 62. (57) E. Zederbauer, Kleinasien, "Vegetationsbilder," iii. 6, 1906. $\left({ }^{58}\right)$ A. F. W. Sснгмper, Indomalayische Strandflora, 1891. G. KAnstex, Mangroveveget. Bibl. bot. 22, 1891. Also in "Vegetationsbilder," ii. 2, 1904. G. Haber LANdt, Mangrovepflanzen, Ann. de Buitenzorg, xii. 1893. Jонs. Sch м1nт in "Vegetationsbilder," iii. 7, 1906. " $\left({ }^{59}\right)$

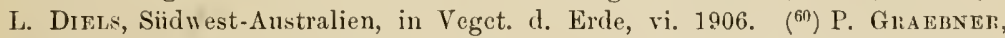
Heide Norddeutschlands, Veget. d. Erde, v. 1901. A. A rтopoeus, Ericaceen, Flora, 1903. ( $\left.{ }^{(6)}\right)$ F. Hildebrandt, Monogr. Cyclamen, 1898. K. Goeber, Regeneration, 1902, Biolog. Centra]bl. H. Winkler, Regeneration, Ber. d. deutsch. bot. Ges. 1902. ("62) A. DE CANnolLE, Origin of Cultivated Plants. V. Hern, Kulturpfianzen und Hanstiere, 7th ed.1902. H. SrHexck, Mittelmeerbänme, "Vegetationsbilder," iii. 4, 1905. P. KNuth, Handbuch der Blütenbiologie, ii. 1899. ( $\left.{ }^{63}\right)$ R. V. Wetrstern, Saison-Dimorphismus, Ber. d. dentsch. bot. Ges. xiii. 303. Deszendenztheoret. Unters. i. Denkschrift d. k. Akad. d. W. Wien, 1900. (6t) E. Gil.G, Strophanthus, Tropenpflanzer, 1902, xi. E. Grug, H. Thoms, H. Scheder, Strophanthus, Ber. D. Pharmac. Ges. 1904. ( $\left.{ }^{65}\right)$ Rubber Plants, ef. $\left({ }^{25}\right)$. P. Preuss, Exp'. nach Zentral- und Suidamerika, Berlin, 1901. Kolon. Wirtsch. Kom., KuneneZambesi-Expedition, heransgeg. von O. WArbusc, Kolon. Wirtsch. Kom. 1903. ${ }^{(66)}$ M. Tren b, Dischidia Raftlesiana, Ann. de Buitenzorg, iii. 1883. ( $\left.{ }^{67}\right)$ G. J. PeInce, Hanstoria, Ann. of Bot. 1893. Cuscuta, Ann. of Bot. 1894. (68) F. Mutr, Symphytum oflicinale, Floria Ergl d. 1902. K. GosBri, Boragoid, Flora Ergbd. 1902. ('99) Koorders, Tectona grandis, Naturk. Tydskr. v. Ned. Ind, 1893. 
Büsgen, etc., "Yegetationsbilder," iii. 3, 1905. $\left({ }^{70}\right)$ M. Treub, A ricennia officinalis, Ann. de Buitenzorg, iii. 1883. (i1) E. Hernnchen, Lathraea, Ber. k. k. Akad. d. W. Wien, 1892. Ber. Deutsch. Bot. Ges. 1893. Grüne Halbschmarotzer i.-v. Jahrb. f. wiss. Bot. 1897, 1898, 1901, 1902, 1909 . R. v. Wettstein, Euphrasia, Öst. bot. Zt:chır. 1894, 1895. Monogr. Euphrasia, 1896. STEnNEck, Alectorolophus, 1901. L. Hoffmann, Odontites, Öst. bot. Ztschr. 1897. K. Gosber, Tozzia Lathraea, Flora, 1897. G. Haberlandt, Hydathoden, Jahrb. wiss. Bot. 1897. ( $\left.{ }^{72}\right)$ Hielscher, Streptocarpus, Cohns Beiträge, iii. 1878. $\left({ }^{73}\right)$ K. Goebel, Morph. u. biolog. Studien v., Ann. de Buitenzorg, ix. Pflanzenbiol. Schilderungen, ii. 116. Lentibularieae, 1891. Flora, 1904, 98. ( $\left.{ }^{74}\right)$ M. Treub, Plantes grimpantes, Ann. de Buitenzorg, iii. 1883. (75) M. Treur, Mylmecodia, Ann, de Buitenzorg, iii. 1883, and vii. 1888. ( $\left.{ }^{76}\right)$ K. GoEBEL, Campanula rotundifolia, Flora, 1896, and Flora Ergbd. 1905. P. KNuti, Bliitenbiologie. R. Schultz, Phyteuma, Monogr. 1904. (7i) F. Nolu, Cucurbitaceen, Landw. Jahrb. xxx. Ergbd. P. 1901. Parthenocarpie. Sitzber. d. Niederrh. Ges. Bonn, 1902. O. MüLler, Cucurbitaceen, Cohns Beitr. iv. 1887. G. Bitrer, Bryonia, Abh. Nat. Ver. Bremen, 1904. ( $\left.{ }^{78}\right)$ C. Connens, Bestimnung und Vererbung des Geschlechts, Berlin, 1907. $\left.{ }^{79}\right)$ M. Y. UExKüLLGyllenband, Phylogenie der Bliitenformen und Geschlechtsverteilung b. d. Kompositen, Bibl. bot. 52, 1901. A. Tsснивсн, Kompositen-Antheren, Flora, 1904, 51. $\left(^{80}\right)$ E. STAll Lompasspflanzen, 1883. ( $\left.{ }^{81}\right)$ C. v. NïgeLI, Hieracien, Bot. Mitt. iii. 1866. Piloselloiden, ibid. 1867. Piloselliformia, ibid. 1867. Abstanmungslehre, 1884. A. Petfr, Hieracium, Eugler's Jahrb. v. C. Raunkiaer and C. H. Ostenfeld, Bot. Tidsskr. 25, 1903. Ostenfeln, Ber. d. Dentsch. Bot. Ges. 1904, 376 and 537. O. Rosenbera, ibid. xxiv. 1906, 157. ( $\left.{ }^{82}\right)$ A. F. W. Schmper, Plant-Geography, 1898. $\left.\quad{ }^{83}\right)$ O. H. JuEL, Antennaria, Kg. Svensk. Vet. Ak. Handl. 33, 1900. ( $\left.{ }^{84}\right)$ Cf. $\left({ }^{82}\right)$ and K. Gonbel, Ptanzenbiol. Schildermingen, ii. 1891. ( $\left.{ }^{85}\right)$ K. Goeber, ibiu. 1891. ( $\left.{ }^{86}\right)$ C. Cornens, Dimorphotheca, Ber. Deutseh. Bot. Ges. 1906. $\left({ }^{87}\right)$ E. SArGANT, Theory of the Origin of Monocotyledons, etc., Ann. of Bot. xvii., Jan. 1903. Bot. Gaz. 37, 1904. K. Fritsch, Stellung der Nonokotylen,

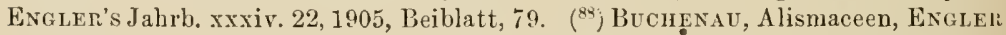
u. Pranta, ii. 1, ef. p. 229. The resemblance in habit of some Alismaceae with the Ranunculaceae is very striking. $\quad\left({ }^{89}\right)$ H. GL ש̈ck, Alismaceen, Jena, $1905 . \quad\left({ }^{90}\right)$ K. GoEber, Streptochaeta, Flora, 1895, Ergbd. F. Kïrnicke, Arten u. Varietäten des Getreides, Handbuch d. Getreidebaues von Kïrxicke u. Wenner, i. Bom, 1855. E. Bruns, Grasembryo, Flora, 1892, Ergbd. Alph. DE Candolle, Origin of Cultivated Plants. A. R. WALLACE, Tropical Vegetation, 1879. ( $\left.{ }^{91}\right)$ E. HAN IG, Pilzfreies, Lolium, Bot. Ztg. 1907, 25. (92) E. STrasburgen, Verdickungsweise v. Palmen, Pringsh. Jahrb. f. w. Bot. xliii. 1906, 580. D. H. CAMPBell, Araceae, Ann. of Bot. xix. 1905. (93) H. Mücke, Frichte von Acorus, Bot. Ztg. 1908, J. Тн. Irurscr, Knollen- n. Zwiebelgewächse, Berlin, 1850. Beitr. z. vergl. Morphologie, 1-ô, Halle, 1853-1879. ( $\left.{ }^{94}\right)$ J. Persks, Asparageen, Pringsh. Jahrb. 31, 1897. G. Karstex, Monokotylenbäume in "Vegetationsbilder," i. 6, Jena, 1903. R. von WerTstein, Sokotra in "Vegetationsbilder," iii. 5, Jena, 1905. ( $\left.{ }^{95}\right)$ A. F. W. Schimper, Epiphyt. Veget. Amerikas, Bot. Mitteil. a. d. Tropen, 2, Jena, 1888. C. MEz, Jahrb. f. wiss. Bot. 40, 1904. $\left(^{96}\right)$ Cf. the literature citer under (2i) to $\left({ }^{2 \mathrm{I}}\right)$. 


\title{
SYSTEMATIC [NDEX
}

OF THE

\section{OFFI(TAL, ANI) POISONOUS PLANTS}

\author{
() Ofticial in Great Britain. \\ + Poisonons. \\ * Official and Poisonous. \\ * before the page indicates figure.
}

\section{Thallophyta}

* Claviceps purpurea, * 394, 395

+ Boletus Satanas, *412, 413

+ Amauita unsearia, *413, 414

+ Amanita bulbosa, * 114

+ Russula entetica, 414

+ Lactarius torminosus, 414

+ Selerorlerma vulgare, *415, 416

\section{Pterioophyta}

- Aspidiun filix mas, * 451,454

+ Equisetmm, ${ }^{*} 460,462$

\section{Gymnospermae}

+ Taxus baceata, *532, *533, 540

- Juniperns communis, *534, 540

+ Jnniperus sabina, *534, *535, 540

( Junipertus oxycerlrus, 540

- Picea excelsa, *537, 540

- Abies balsamea, 540

- Pinus sylvestris, *538, 540

- Pinus pallustris, 540

- Pinus taerla, 540

-) Piuss puntio, 540

\section{Querciflorae}

() Qnercus infectoria, 553

\section{Salicifiorae}

- Salix and Populus, species of, ${ }^{*} 553$, *5. 4

\section{Urticinae}

-) Ficus carica, *556, 557

- Camalis sativa, 558

- Humulus lı1ulus, *557, 558

\section{Loranthiflorae}

(-) Sautalıu album, 558

+ Viseum album, 5.5, *559

\section{Piperinae}

() Piper nigrum, *560

-) Piprr erabba, *560, 561

\section{Hamamelidinae}

-) Liquidauliar orientalis, 561

$\odot$ Hanamelis virginiana, 561

\section{Tricoccae}

+ Mereurialis. anuma, *561

+ Euphorbia, species of, *562, *563, 564

- Croton Elenteria, 56t; 
- Croton tiglium, 566

- Ricimus communis, *561, *565, 566

+ Buxus sempervirens, 567

\section{Centrospermae}

(-) Rheum, species of, *561, *565, $56 \mathrm{~S}$

†-Agrostemuna Githago, *569, 570

+ Saponaria ofticinalis, "570

+ Anhalonium, species of, 571

\section{Polycarpicae}

+ Ranuneulus sceleratus, *574, *575

+ Ranunculus arveusis, *574

+ Caltha palustris, ${ }^{*} 577$

+ Anemone pulsatilla, $574,{ }^{*} 576$

+ Anemone nemorosa, 574

+ Clematis, species of, 574

+ Adonis autumnalis, *573

+ Helleborus, species of, *577

\ Aconitum Napellns, ${ }^{*} 578,579$

+ Aconitum lyeoctonum, and other species, * 579

(-) Hydrastis canarlensis, $579, * 580$

* Delphinium staphisagria, 579

( Cimicituga racemosa, 579

$\odot$ Illicium anisatum, 580

+ 1llieium religiosmu, 580

( Myristica fragrans, 580, * 581

๑ Polophyllum peltatum, $580,{ }^{*} 581$

○ Jatrorrhiza palmata, *582

- Cimamomum Camphora, 585

- Cinuamonum zeylanieum, 585

$\odot$ Sassafras ollieinale, *583, 585

\section{Rhoeadinae}

- Papaver somnifermm, 588

$\odot$ Papaver Rhoeas, ${ }^{*} 588$

- Simapis alba, 593

- Cochlearia armoracia, 593

ค Brassiea nigra, *091, 593

\section{Cistiflorae}

- Garcinia Hanburyi, 595

\section{Columniferae}

- Gossypium, species of, 597

-) 'Theolsoma cacao, * 599,600

\section{Gruinales}

- Linum usitatissimum, *601

- Erytliroxylon Coea, *601, 602

- Guiacum officinale, 602

- Citrus Aurmtimu, var. Bigararlia, 6o5
(P) Citrus medica, var. limommm, 605

- Barosma betulina, 605

Cusparia fehrifuga, 605

- Pilocarpus juborandi, 605

- Pierasma exeelsa, 605

- Quassia amáa, *603, 605

- Balsamolendron myrrha, 605

Polygalir senega, "604, 605

\section{Sapindinae}

+ Enonymus emropaeus, *606

+ Rhus toxicolendron, 605

\section{Frangulinae}

- Phamus purshianus, 609

-) Vitis vinifera, 609

\section{Rosiflorae}

- Rosa gallica, 615

- Fiosa damascena, 616

- Prunus anygdalus, 616

-) Prunus domesticus, 616

Prumus serotina, 616

* Prunus laurocerasus, 615,616

D Hagenia abyssinica, "614, 616

\ Quillaja saponaria, ${ }^{*} 613,616$

\section{Leguminosae}

- Acacia senegal, 620

- Cassia angustifolia, *619, 623

- Cassia acutifolia, 623

- Cassia fistula, 623

- Copaitera Langsiorfi, *621, 623

- Tamarindus indica, * 620,623

- Haematoxylon eamjechianum, 623

- Krameria triandra, 622,623

+ Cytisus labunum, *624, 627

+ Cytisus, other speeies of, 627

+ Coronilla varia, ${ }^{*} 627$

+ Wistaria sinensis, 627

- Astragalus gummifer, ${ }^{*} 625,627$

- Glyeyrrhiza glabra, ${ }^{*} 626,627$

- Spartium scoparinm, 627

* Physustigna venosum, 627

- Andira araroba, 6:27

- Pterocarpus santalinus, 627

(-) Pteroearpus marsujuin, 627

- Myroxylon toluifera, 627

$\odot$ Myroxylon Pereirae, ${ }^{*} 622,{ }^{*} 623,62 \tau$

\section{Thymelaëinae}

* Taplne Mezerenm, *62S

* Daphne Laureola, 628

\$ Ditplune Guilimm, 6.25 


\section{Myrtiflorae}

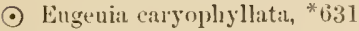

( ) Pimenta oflicinalis, 631

๑) Melalenca leucadendron, 631

$\odot$ Encalyptus globulus, 631

$\odot$ Punica granatum, 63:2

\section{Umbellifiorae}

+ Hedera heli.s, 633, *634

\# Coniun maculatum, * 639,640

- Ferula loetida, 640

- Ferula galbiuitlua, 640

$\odot$ Dorema ammoniteum, 610

$\odot$ Pinpinella anisum, *634, 640

$\odot$ Coriandrum sativun, ${ }^{*} 634,640$

ค) Foeniculum capillaceum, 640

$\odot$ Carmm carvi, *635, 640

$\odot$ Anethum (F'encelanum) graveolens, 640

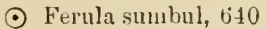

+ Cicuta virosa, ${ }^{*} 637$

+ Sium latifolinm, *636, 635

+ Oenanthe fistulosa, *635, 638

+ Aethusa cynapium, *638

+ Berula angustifolia, 638

\section{Ericinae}

$\odot$ Aretostaphylos Uva ursi, *611,

+ Phorlodendron, 641

+ Lerlum, 6.1

\section{Diospyrinae}

$\odot$ Styrax Benzoin, 641

\section{Primulinae}

+ Cyclamen europaeun, ${ }^{*} 613$

$\div$ Anagallis arvellsis, ${ }^{*} 643$

+ Primula obconica, 643

+ Primula sinensis, $6 \pm 3$

\section{Contortae}

๑ Olea europaea, $614, * 615,646$

* Strychnos uux-romica, $614,{ }^{*} 647$

ค Gelsemium nitidum, 644

$\odot$ Gentiana lutea, $64 \hat{j},{ }^{*} 64 \bar{\jmath}$

$\odot$ Swertia chirata, 646

+ Menyanthes trifoliata, 646

$\odot$ Strophanthus kombe, $640^{\circ}$

$\odot$ Strophanthins hispidus, 646 , "64s

+ Nerium Oleander, 646, *649

+ Vincetoxicum ofticinale, $649,{ }^{*} 650$

ค Hemidesmus indicus, 651

\section{Tubiflorae}

- Exogonium purga, *65], 65.2

-) Convolvulus Śanmonia, 652

-) Rosnarinus ofticinalis, 658

- Latvanrlula vera, *65:3, 658

- Menthat piperita, $65 \mathrm{~s}$

-) Mentla virirlis, 658

- Hentha arvensis, 658

-) Thymus vulgaris, 658

- Momarla punetata, 658

\section{Personatae}

+ Nicotiaua tabacum, 658. "659

+ Lycopersienm esculentum, 658

+ Solanum duleamara, 656 , *658

+ Solanum tnherosum, 656

+ Solanmm nigrum, 656

-) Cap̧sicum minimum, 658

+ Atropa Belladoma, *6.5, 655

+ Datura stramonimu, 657,659, *661

+ Hyoseyamus niger', $657,{ }^{*} 663$

+ Digitalis purpurea, 661, *664, *665

\section{Rubiinae}

-) Cinchona suecirnbra, 667, *66s

() Uragoga I pecacuimha, $667, * 670$

$\odot$ Ourouparia gambir, ${ }^{6} 67$

$\odot$ Sambucus nigra, $668,{ }^{*} 67 \cdot 2$

$\odot$ Valeriana ofticinalis, $669,{ }^{*} 672$

\section{Campanulinae}

ค) Lobelia inflatal, ${ }^{*} 673$

$\odot$ Citrullus Colocynthis, *674, 675

$\odot$ Ecballium Elaterimm, * 675

+ Bryonia diojea. *675

\section{Aggregatae}

- Anacyclus Pyrethrum, 684

- Artemisia maritima, 684

- Antlemis nolilis, $65 t$

-) ''araxacum officinale, *680, 654

- Arnica noutana, * 683,684

\section{Glumiflorae}

+ Lolium temulentum, *692, 698

ค Triticun sativum, 693

-) Oryza sativa, *692, 69:3

- Saccharum ofticinarum, 693

\section{Spadiciflorae}

+ Arum inaculatmm, $698,{ }^{*} 699$

+ Calla palustris, 698 


\section{Liliiflorae}

* Colchicum antumuale, *701, *702, 707

* Schoenocanlon ofticinalis, 707

๑ Aloe, species of, *704, 707

- Urginea scillae, 707

- Sullax ornata, 707

+ Paris yuarlrifolia, *706, 707

+ Teratrmu allum, 703, 707
+ Convallaria majalis, 707

• Crocus sativms, * 707,709

\section{Scitamineae}

-) Zingiber ofticinale, * 710,711

- Hilettaria cardamomm, 711 


\section{N D E X}

\section{(Asterishis tenute Illustrutions)}

Alies, ${ }^{*} 5: 36,537,539,543$; pollination, 495

Abietineate, 535

Alssciss layer's, 161

A bsorbed sulstances, significanee of, 189

Alsorption of gases, 211 ; of snlostances, 182 ; in the multicellular plant, 186 ; into the cell, 182; of water, 191

Absynthin, 240

Acaciu, ${ }^{*} 165,169,{ }^{*} 197,{ }^{*} 617,{ }^{*} 618$; pliyllodes, * $19 \%$; seerlling, ${ }^{*} 168$

Acanthacere, 662

Acunthus, 662

Acer, ${ }^{*} 32,157,606,{ }^{*} 607$

Aceraceat, 606

Acctubularia, 363

Acliene, 519

A chillea, 684

Achimenes, $66^{2}$

Achlyu, *382

Achmunthes. 352

Aconitine, 240

1 conitum, *573, *578, *579

- leores, *482, *697, 698 ; Hower of, * 482 ; root, 124

Actinomorphic Howers, *48S

Aclenis, ${ }^{*} 573$

Adventitious organs, 250 ; formations, 251

Aecidium, *406, 407, 408

Aeschynanthus, biti

Aesculin, 239

Aesculus, ${ }^{*} 489,607$

Aestivation, 38

Aethrelium, 344

Aethusa, ${ }^{*} 638$

Agar-agar, 379

Agaricineat, 41:3

Aguthis, 537

Ayace, 709

Agyeratum, 678

Aggregatae, 675

Agrimonia, 613
Ayrostemme, ${ }^{*} 569,570$

Agrostis, 693

A ive, 693

Aizoaceae, 571

Ajuigu, 655

Albugo, 383, *384

Albumen erystals, 66 ; synthesis of, 226

Alburumn, 143

Alchemille, ${ }^{*} 487$, *612, 613; aplogamy, 514

Aller, Alnus glutinosut

Ildrovanda, 587

Alectoroloplirs, 660

Aleurone, 66 ; grains, ${ }^{*} 67,238$

Ilismu, ${ }^{*} 514,686$; embryo, ${ }^{*} 514$

Alismaceae, 686

Alkaloids, 70, 240

Alkanet, Anchusc

Allivem, 20, 703 ; root, * 129 , *130

Almond, Promes Amygulalus

Aluus, 231, *547, 547

Iloe, * 114,155 , $704,705,707$

Aloin, 240

Alopecurus, 693

1lpinial, 711

Alsinece, 570

Ilsoplitu, 449, *450, *45:-

Alternation of generations, 333, 425, 413 , 475 ; scheme of, 479

Ilthaea, *596, 597

Altingie, 561

Amonitu, 413 , * 414

Amaryllidaceae, 709

1 micice, * 321

Amides, 70, 237

Amoeboid movements, 29"2

Ampelopsis, *319, *08 ; tendrils, *319

Amygdalin, 239

Amyloerythrin, 66

Amyiopectin, 66

Amylose, 66

Anabaena. :311 
Anacardiaceae, 605

Anacyclus, 684

Auagallis, 6+2, *643

Analogy, 9

Ancunassa, 709

Anapliase, 84

Amuptychia, * 420,421

Anastatica, 592, 682

Anatomy, 10

Anchuse, 653

1ndire, 627

1 ndreceu, * 438,440

Andreaenceae, 440

Androecium, 483

Andromede, 640

Antropogon, 693

Androspores, 362

Aneimia, * 452

Anemone, ${ }^{5} 573,574,{ }^{*} 576,577$

Anemophilous plants, 494

Anethum, 638, 640

Angiopteris, 449

Angiospermae, 480, 526, 54t; development of the macro-sporangium, 510 ; fossil, 714 ; microspores, $こ 10$

Anheloninm, 571

Anuual plants, 273 ; rings, 141

Annularia, 171

Annulus, of Filices, 452; of Musci, 441

1 ит) 580

Anonaceae, 580

Antenuariu, 682

Anthemideue, 683

1 nthenis, 684

Anther, $47 \%,{ }^{*} 478,483$

Antleridia, 425

Antleridiun,, *365, *371, *373, *376, *384, *390, *400, *426, *427, 45t

Anthecros, * 433

Anthocerotaceae, 433

Anthocyauin, 70

Anthoranthum, 693

Authriscus, 639

Anthurium, 698

Anthyllis, 625

Anticlina! walls, 103

Antiporlal cells, 511

Antirlineue, 6.59

Autirhinum, 660

Apicil cell, $101,{ }^{*} 102,{ }^{*} 10$ :

Apium, 638

A pocarpous gynaecum, 484

A procynateae, $646^{\circ}$

Apogany, 96, 283, 45-1, 459,51t

Apolliysis, 440

Apospory, 154

A potheciun, *395

Aluple, I'yrus malus

Apposition, growth by, 71, 25t5

Apricot, P'runus cormeniece
Aqnifolinceae, $606^{\circ}$

Aquilcgin, *573, 579

Araceac, 698

-1 rachis, 627

Ar:liaceae, 633

Arewerice, 142, 537

Arbuteae, 640

Archaeocalamites, 471

I rehangelica, 638

Archegoniatue, 331, 425

Archegoninm, 425, * $42 \overline{7}, 454$

Archetypes, 3

Archiplasm, 59

A ictostaphylos, $640,{ }^{*} 641$

Arcyrie, $* 343$

Arece, 698

Ateneria, 570

Arenga, 698

Aryemone, 587

Arillus, 517, *532

Aristolochia, ${ }^{*} 140,{ }^{*} 586,587$; Howers, *501; pollination, 496, 501; stem,

${ }^{*} 129$, *139; vascular bundle, * 140

Aristolochiaceate, 587

Armeria, $6+4$

Armillaria, *402, 414

1) rice, *676, *677, *683, 684

Arrhenatherum, 693

Artemisia, ${ }^{*} 681,684$

Artichoke, Cynuce Scolymus

Artificial system of elassification, 329

Artocarmes, 556

A rum, 698, *699

1 sarum, 587

Asclepiadaceae, 648

Asclepias, ${ }^{*} 650$; pollination, 496

Ascodesmis, 388

Ascolichenes, 418

Ascomycetes, 388 ; alternation of generations, 389 ; sexual organs of, 388

Ascuis, 92, 388, 389

Ash, Fraxinus

Ash of plants, constituents of, 180, 233

Asparageae, 702

Asparagin, 70, 237

Asparagus, 705

Aspergillaceae, 392

Aspergillus, $388,{ }^{*} 391,392$

Asperila, $664,{ }^{*} 671$

Aspidistra, pollination, 497

Aspitium, *443,450, ${ }^{*} 451,{ }^{*} 452,454$; prothallinm, * 143

Asplenirm, ${ }^{2} 277$

Assinilates, translocation and transformation of, 234

Assimilation, of carbon, 213; of carbon dioxide, products of, 218 ; experiInent, 219; of food-materials, 213; of nitrogen, 226 ; Stchls' half-leaf methor!, 220 ; of water, 233

Aster, 681 
I sterewe, 678

I stragulcue, 625)

Astruyalus, *625, 6.27

Astruntie, $6: 37$

Asymuletricil Howers, 48s; nemlers, 16

Atavism, 169, 286

Atipler, 570

Atrope, 656, *657, 658

Atropine, 210

Aubrietia, 593

Aurcularia, 410

Auricularieae, 409

Autonomic novements, 297

Autumn Crocus, Colchicum

Auxanometer, *258

Alxiliary cells, 377

Auxospore, *350, 353 ; formation of, 352

Lenu, *689, 693 ; starch graius, *6.1

licennia, 212,654 ; root, respiratory, *212

Axis, 22

Azolla, 456, 458

Azotolucter, 231, 339

Bacchuris, 681

Bacillariacene, see Diatomeite

Bucillus, 334, *335, *337, 338 ; subtilis, $335,{ }^{*} 336$

Brecillus rulicicole, 231

Bacteria, 334 ; denitrifying, 339 ; nitrate, 310 ; nitrifying, *339; nitrite, 340 ; parasitic, 337 ; pathogenie, 338 ; jhosphorescent, 337

Bucterium, 334

Baiera, 5.12

Bulunophore, 559

Balanophoraceae, 559

Balsaminaceae, 601

Bulsomolentron, 605

Bambusu, 657

Banana, Musu

Banyan, Ficus benyalensis

Bark, 159 ; ringed, 159 ; sculy, 159

Barley, Hordeum vulyare

Burosmu, 605

Bartsia, 230, 660

Basiciobolacene, 387

Busidiubolus, 387

Basilliolichenes, $42 \mathrm{I}$

Busiclionycetes, 401

Basilimm, $388,401,{ }^{*} 402, * 403,406$,

$$
{ }^{*}+10, * 115
$$

Bist, secondary, 140

Batruchium, $5 \div 4$

Butrochospermum, 374, *376

Beakel Parsley, Anthriscus

Beech, Fagws sylratica

Beet, Betu inlyaris

Begyiatur, $336^{\circ}$
Bergonia, 21, 628

Begoniaceae, 628

Benrettites, 542, *543; fruit, 513

Berberirlaceae, 580

Berberis, 580

Berry, 5:20

linvlu, 638

Beter, *568, 569, 570

Betula, $547, * 54 \mathrm{~S}$

Betulaceae, 547

Bidclupliu, *358, 354

Biclens, 683

Bignoniaceae, *151, 662 ; stem, *154

Bilatera] Howers, 488 ; symmetry, 16

Biophytum, 601

Birch, Betula verruouse

Biril's-foot Trefoil, Lotus minieuletus

Birl's-nest Orchir, Neottia

Bisynumetrical flowers, 458

Bitter principles, 240

Bitter-sweet, Solunum alucamum

Blackberry, Rubus

Black Mustard, Biussieu nigre

Blackler plums, 399

Bilcsict, * 14, *4 434, 435

Bleterling, 201

Blue-green Algae, see Cyanophyeeac

Boehmeria, 558

Bog-Bear, Henyunthes

Boletus, ${ }^{*} 101,{ }^{*} 412$

Borage, Borago

Boraginaceae, 652

Borugo, *652, 653

Bostryx, * 493

Boswellia, 605

Botrychium, 447, * 448

Botrydium, *355

Boristu, 416

linvenia, 529

Box, Buxus sempervirens

Bract, 489 ; scale, 536

Bracteal leaves, 489

Bracteole, 459

Branch systems, *17

Brussicu, *589, *590, *591, 59:-59:3

Bristles, 116

Brize, 693

Broat-Bean, I icie Fube

Bromeliaceate, 709

liromus, 69:3

Brown Algae, see Phaeopliyceate

Brucine, 210

Bruyuiera, 629

Biyinae, 440; acrocarpue, 442 ; plewir. carpae, 412

Bryonia, 675

Bryony, Tamzs communis

Bryophyllum, 21, 010

Bryoplyta, 331, 425; fossil, 471

Bryupsis, 364

Buckwheat, Fegomyram exculentum 
Bud, 21, *23, *32; dormant, 23 ; metamorphosis of, 23 ; resting, 22: scales, 23,37 ; variation, 284

Burling, 255

Bugloss, Echium

Bulh, 24. *25

Bulbils, *23, 276

Bulburhate, $361, * 362$

Bundles, canline, 137 ; common, 137 ; foliar, 137

bullewnin, 637

Burrlock, Lelpper

Burnet-Saxifrage, Pimpinella

Burseraceae, 605

Butomus, 656

Butter-Bur, Petusites officinulis

Buxaceae, 567

Buxus, 567

Cabomba, *573

Cactaceae, 571

Caesaluiniaceae, 620

Catteine, 240

Cakile, 592

Calamagrostis, 693

Calamarieae, 171

Calamostachys, 471

Culamus, 698

Calcium earbonate, 78 ; oxalate, $6 \overline{7}, 78$

Calendula, 684

Caleudn]eae, 684

Calla, 698 ; polliuation, 497

Callithamnion, $375,{ }^{*} 376$

Callitrichaceae, 629

Cullitriche, 629

C'allitris, 543

Callose, 77

Callune, 610

Callus, 98, 162 ; wood, 163

Culobrym, 435

Caltha, ${ }^{*} 577$

Calyutra, 440

Calyptrogen, * 106

Calystegia, 652

Calyx, 483

Cambium, 138; cork, 157; fascicular, 139 : interfascicular, 139

Compunule, 75, 671, *67:3

Campanulaceae, 670

Campanulinae, 670

Campylospermae, 639

Canarlian water-weerl, Eloter conulensis

Canumga, 580

C'unurim, 605

Cane sugar, 70, 218, 2.36

Canu, * 488 , *712

Cannabis, 558

('annaceae, 711

Canthurellus, 414

Cantclinue, 69, $240 \quad 564$

Capitulum, 490
Ca]paridacene, 593

Cuppuris, ${ }^{*} 592,59: 3$

(aprifoliaceae, 667

Capsella, *514, *517, 590, 593 ; emlryo, *511; seerl, *517

Capsicum, 657, 658

capsule, 440, *518, 518; moss-, 110 ; lehiscence, * 518

r'munu, 626

Carliohyiluates, hylrolysis of, 235

Carbon, assimilation of, 213

Carbon lioxide, absorption of, 211 ; anount in air, 217 ; assimilation of, 213 ; formed in respiration, 242

Carlamine, ${ }^{*} 589$

Cardinal points, 178

Carluxs, *676, 677, *678

Curet, *689

Curica, 628

Caricaceae, 6:28

Carnivorous plants, 227

Carpels, 38, 476, 484

Curpinus, ${ }^{*} 167,{ }^{*} 192.548,{ }^{*} 549$ : germination, ${ }^{*} 167$; root-liairs, ${ }^{*} 192$

Carpoulinus, 646

Carpogonium, 377, 339

Carroway, Carum Cari

Carum, ${ }^{*} 635,637,638,640$

Caruncula, 517, 562

Caryu, 546

Caryophyllaceae, 570

Caryopsis, 519

Cassiu, *619, 620, 623

Cussythe, 585

Custrinea, *551, 552

Castillou, 556

Cesuarina, 512

Casuarinaceae, 545

Cutalpa, 662

Catkin, *492

Caxlerpe, 363 , *364

Caulitlory, 600

Cecropia, 556

Ceslivs, 540, 543

Celery, 1 pizm

Cell, hulding, 91 ; division, * 89 ; embry onic, *52; filanents, surfices, an1 masses, 166 ; for'ul of, 79 ; fusious, 97 ; in fertilisation, 92 ; internal pressure of, 183 ; multinncleate, 60 ; ontogeny of, 81 ; plate, 89 ; sap, 53,69 ; size of, 80 ; structure of, 52

Cell wall, 71; growth in surface of, 71 ; growth in thiekness of, 71 ; lignitied, 77 ; suberised, 77

Cellular plants, 331

Cellulose, 76 ; as reserve substance, 236

Celtis, 555

Centaurea, *325, 678: movements of stanens, ${ }^{*}: 325$ 
Centaury, Erythreu

Central eylinder, 128

Centrunthus, 669

Centrioles, 53, 61, ${ }^{*} 87$

Centrosone, 5.3, 86

Centrospermae, 567

Ceprolanthere, 712

'ephalanthus, 664

Cephalotaceae, 585

C'eplactotus, 586

Cerustiun, * 494,570 ; diclasium, ${ }^{*} 494$

Ceratiomyxa, 343,344

Ceratixm, ${ }^{*} 346$

Cerutocorys, $* 316$

Ceratonia, 623

Ceratophrllaceae, 573

Cercutoph yllum, 573

Ceratozcmid, *50:3, 529, *52!) ; macrosporophyll, *529; ovule, *503

Cerbere, ${ }^{*} 522,646$; fruit, ${ }^{*} 522$

Cercis, ${ }^{*} 619,623$

Cercus, *571

Cerinthc, 654

Ceriops, 629

Cetraria. *418, * 419,422

Chaerophyllum, 639

Chaetocladium, 386

Chalaza, 476

Chalazogamy, 512, *512

Chara, *92, 96, 422, ${ }^{*} 423$, *424 ; erinitu, 425 : jarthenogenesis, 425

Characeae, 422

Chasmogamous flowers, 499

Cheiranthus, *590, 592

Cheirostrobus, 472

Chelidonium, *517, 587 ; seed of, ${ }^{*} 517$

Chenical composition of plants, 180

Chemical stimuli, 264; influence on growth, 264 ; as cause of movement, 315 ; in development, 252

Chemonasty, 322

Chemosynthesis, 221

Chemotaxis, 316

Chemotropism, 315

Chenoporiaceae, 568

Chenopolium, 570

Cherry Laurel, Prunus laurocerasus

Chervil, Chaerophyllum

Chestunt, Castenea Irulgaris

Chicory, Cichorium Intybus

Chiropteropliilous plants, ta7

Chitin, 77

rhlamydmnanas, 356,358

Chloremocha, 354, * 354

Chlorella, 358, *359

Chlorine, 207

Chlorococeum, *358

Chlorophyceae, 356

Chlorophyll, necessary for assimilation, 216 ; pigments of, 61
Chloroplasts, 61, ${ }^{*} 61$; pllototaxis, 302 , *302

Chlor-zinc-iodide, 76

Choanephora, 386

Choiromyces, 399

Chondrioderma, ${ }^{*} 55,343$

chondromyees, *339

Chomdrus, *374, 375,379

Choripetalae, 526, 545

Chromatin, 57,59

Chromatophores, 53, 61 ; multiplication of, 97

Cliromogens, 69

Chromoplasts, 61 , ${ }^{*} 63$

Chromosomes, 81

rhroococeus, 341

Chroolemus, 360

Chrysunthemum, 684

Chrysobalaneae, 615

Chrysosplenium, pollination, 497

Chytridiaceae, 381

r'ibotium, 455

Cichorieae, 678

('ichorium, 678, *678

Cicuta, ${ }^{*} 637,638$

Cilia, 293

Cimicifuge, *573, 579

Cinchona, 662, ${ }^{*} 667,{ }^{*} 668$

rinchonea, 662

Cincinnus, 493, *493

Cineraria, 684

Cinnamomum, 585

Cimnamon tree, Cinnamomum

circuea, 629

Circulation, 58

Cirsinm.67\%

Cissus, 609

Cistaceae, 593

Cistiflorae, 593

Citrullus, ${ }^{*} 674,675$

Citrus, ${ }^{*} 602,603,604$

Cladoules, 26

Cladonia, 419 , *420

Clatimphora, ${ }^{*} 12,{ }^{*} 60,{ }^{*} 90,362$. ${ }^{*} 363$

Clarlostephus, *12

Cladothri, *335, 336

Classification, artificial system, 329 ; natural system, 329 ; of phaneroyams, 525

cluerria, *411, 411

Clavarieae, 411

Clariceps, *101, 393, *394, 395

Cleistocarpae, spe Pliascaceat

Cleistogamous Howers, 499

Clematis, ${ }^{*} 72,135,{ }^{*} 136,574,576$

rerodendion, 654

r'losterium. *348

Clost,ilium, 231, *337, 339

Clover, Trifolium

Club mosses, see Lycopodinae

Cnicres, 67T, * 679 
Cohcert, 652

Cocaine, 240

Cocci, 334

Coceoneis, 35:2, *352

Cochlaria, *59], 593

Coco-nut Paln, Cocos

Cocoa. Theobrome Cacao

Cocos, *694, 696

Codeine, 240

Coelospermae, 639

Coenogamctes, 380

Coffec, 664, *669

Coffere, 664

Coffee, Coffea

Cohesion, curvature, ${ }^{*} 296$; mechanisms, 297

Cola, 600

Colchicine, 240

Colchicum, *701, 702,*702, 707

Coleochaete, 362

Collema, * 420

Collenchyma, 74, 75, 267

Colleters, 119

Colletia, 609

Coloeasia, 200

Colonring matters, 240

Coltsfoot, Tussilago Farfara

Column, 711

Columniferae, 596

Colutea, $626^{\circ}$

Comfrey, Symphytum

Commelina, 700

Commelinaceae, 700

Commiphor $\alpha, 605$

Companion cells, 122, 149

Complementary cells, 160

Compositne, 676

Conluction of water, 202

Conferve, 354, *355

Coniferne, 531

Coniferin, 240

Conine, 240

Conium, ${ }^{*} 634,{ }^{*} 639,640$

Conjugatae, 346

Conjugation, 349 ; of spirogyra, ${ }^{*} 349$

Connective, 483

Consortium, 416

Contact, sensitiveness to, 323

Contortae, 644

Comallaria, *33,705

Convolvulaceae, 651

Convosmulus, * 651,652

Copaifera, ${ }^{*} 621,623$

Cora, 418, 421, * 121

Corallorhiza, *21, 712

Corchorus, 598

Corlaiteae, 472,542

Corluites, 542

Comlyline, * 156,705 ; sten, ${ }^{*} 156$

Corethrm, *35.3, 35.1

Coriondrum, *634, 639, 640
Cork, 157 ; cambium, 157

Cork-oak, see Qnercus suber

Cormophytes, 14

Cormus, 14

Connaceae, 633

Corn-cockle, Agrostema Vithago

Cornelian Cherry, Cornus mas

Cornus, 633, ${ }^{*} 633$

Corolla, 483

Coronilla, $627,{ }^{*} 627$

Correlation, 264,280 ; in growth of fruits, 280 ; of growth, 254,264

Cortex, 127

Coryulatis, *459, 499, *517, *589 ; seed of, *517

Corylus, *492, 548, *550 ; catkin, ${ }^{*} 492$

Cosmarium, ${ }^{*} 347$

Cotton, Gossypinm

Cotton-grass, Eriophorum

Cotyledons, 167

Crambe, *590, 592

Cressula, 610

Crassulaceae, 610

Crataegus, *204, *514, 613 ; venation, * 204 , *5 54

Crenothrix, 336

Crepis, 678

Cribraria, ${ }^{*} 343,344$

Crocus, *707, 709

Cross-pollimation, 279

Croton, 563, 566

Cruciferae, 589

Cryptogams, 329, 3.30, 475

Cryptomeriu, *18, 543

Cryptospowa, *393

Crystal aggregates, 68

Crystals, 67

Cucumber, Cucumis sativus

Cucumis, 675

Cuevrbita, *72, *74, *76, *483, 675; pollen-grain, * 483

Cucurbitaceae, 673

Cupressineae, 53.3

Cupressus, 534

Cupule, 549

Cnumliferae, 548

Curcuma, 711

Curvatures, 294

Cuscuta, 26, 223, *224, 585, 652

Cusparia, 605

Cuticle, 110

Cutinisation, 77

Cutleriu, ${ }^{*} 370$

Cuttings, 253

Cyaıojhyceae, 340

Cyather, 449

Cyatheaceae, 458

Cyathium, 56.3

Cyculaceae, 472, 50\%, 528 ; sexmal generation, $50 \%$

cycudeniler, 542, *543; flower, ${ }^{*} 543$ 
Cycadinae, 528

Cycadites, 542

Cycarlotilices, 540

Cycas, 528, 529, *529; carpel, *529; stamen, *529, 530

Cyclamen, *643

Cycle, 42

Cyclosporeae, 3 ito

Cydonia, 612

Cylindrocystis, $3 \$ 7$

Cymose intlorescence, 490, 491

Cynara, 67т

Cynarene, 675

Cyperaceae, 688

Cyperus, 685, 689

Cypress, Cupressus sempervirens

Cypripetium, 712

Cystocarp, 377

Cystolith, * 75,76

Cystomus, see Illungo

Cytase, 236

Cytisus, 499, ${ }^{*} 622,{ }^{*} 624,625,627$

Cytoplasu, 53, 57; movementi of, 58

\section{Daetylis, 693}

Dahlia, 683

Dammara, see Agathis

Dandelion, Turaxacum officinale.

Daphne, ${ }^{*} 628$

Darlingtonia, 586

Date Palm, Phoenic dactylifera

Dotura, 657, 658, 659, *661

Dareus, 638

Deally Nightsharle, Itrope Belladonne

Delesseria, 375

Delphinim, *484, 579

Lentaria, 23

Dermatogen, * 104

Desmidiaceae, 347

Desmids, 294 ; movements of, 294

Desmolixm gyrans, movement, 299

Dentzia, 611

Development, 17 $7,249,250$; stages of, 250

Dextrin, 66

Diakinesis, 81

Dialypetalae, 527,572

Diandrae, 712

Irianthus, 570

Diastase, 235

Diatomeae, 350 ; centricae, 353 ; 1ennatae, 351

Diatons, 294 ; movenuents of, 294

Dicentra, 589

Dichasium, 491, *493, *494

Dichogamy, 500

Dichotomosiphon, 361

Dichotomous branching, 17

Dichotomy, 18; faise, 18

Diclinous flower, 482

Dicotylae, 526 , 544
Dicotyledons, 513, 544; embryo, 513; elements of secomlary growth in, 145 ; elements of seconlary phloem in, 149

lieranophyllum, 542

Jictammes, 603

lictyonema, 421

liclyotu, *13, *102, *371

Dictyotaceae, 370

Iniervilla, 668

Digitalin, 239

Digitalis, 660, 661, *664, ${ }^{*} 665$

1)ill, inethum

Dinotlagellata, 345,

l)ioecious plants, 481

lionaca, 22S, *229, $322,323,586$

lioon, 529

Dioscorea, 709

Dioscoreaceae, 709

Diospyrinae, $6 \notin 1$

biospyros, 641

Diplocaulescent, 28

Diploir, 94 ; generation, 96

Diplostemonous flowers, 487

Dipsacaceae, 675

Jipsacus, 676

Diptero carpaceae, 595

Directive movements, 301

I ischidia, 651

Discomycetes, 395

Dissolverl substances, alsorption of, 185

Distribution, of the primary tissues, 127 ; of seeds, 520

liversiflorae, 678

Dodiler, Cuscute

Dogwoorl, Cornus sanguineu

I) rema, 640

Doronicum, 684

Dorsal suture, 4S5

Dorsiventral Howers, 488 ; symmetry, 16

Double fertilisation, 512

Traba, 593

I) racaena, *68, 155, *705 ; raphides, *6s ; secondary growth of, ${ }^{*} 156^{\circ}$

Drefanium, 491, *493

l)rimys, wool, 147

I)rip tips, 35

Inusera, *228, 322, 586 ; rhemonastic movements, 322 ; digestive gland, *118

Droseraceae, 586

Drosophyllum, 586

1)rupe, 520

1)ryas, 615

Inyobalanops, 595

l' ryop,hyllum, 715

J) unesnaya, $377, * 378$

1) mamen, 113

Whenaceae, 641

Echullium, ${ }^{\circ} 675$

Echinocactus, 571 
Echinodorus, ${ }^{*} 686$

Echinops, 67T

Echium, *652, 653

Ectocurpus, 369, *370

Elelweiss, Lenntopodium

Egg, 92 ; apparatus, 511

Elaeagnaceae, $6: 8$

Elueagnus, 231, 628

Elceës, 698

Elaphomyees, 392

Elaphom ycetaceae, 392

Elasticity, 207 ; of plants, 267

Eliler, sumlnucus

Elettarire, 711

Elm, $C l m u s$ eampestris

Elodea, 687 : pollination, 495

Elongation, phase of, 255

Elyna, *68?

Embryo, 513, ${ }^{*} 514,515$; sac, 476, ${ }^{*} 510$, $* 513$

Embryonal development, 250

Emergences, 51, 115, 117

Empusa, *356, 357

Enalus, pollination, 495

Enantioblastae, 699

Eneephalurtos, 529, 543

Enchanter's Nightshade, Circoet

Endocarp, 518

Endocarpon, 418

Endorlermis, 128

Endogenons, 21

Endophyllum, * 402

Enrlospern, $477,513,515,516$; in angiosperms, 513 ; nucleus, 512

Eudothecium, 483

Enteromorpha, *360

Entomophilous plants, 495

Entomoplily, 496; influence on floral construction, 496

Entomophthorineae, $38 \overline{7}$

Enzymes, 69, 235, 240

Ephedra, 540, *540, *541; sexual generation, 509

Ephemerum, *438

Epillermis, $110,{ }^{*} 112$

Epigeal germination, 523

Epigynous, flowers, *486

Eipilobium, 629

Epinasty, 298

Evipuctis, *89, 712

Epiphyllum. 571

Eviphytes, 45, 195

Eivipogon, 712

Epithema, 13:3

Equisetinat, 45!!, 471; fossil, 471

Equisetum, * $10: 3,{ }^{*} 104,{ }^{*} 459,{ }^{*} 160,{ }^{*} 461$, 462 ; prothallium, ${ }^{*}+61$

Frgot, 393, 395

Evirn, 640

Ericaceate, 640

Erieede, tit0
Ericinae, 640

Eivigeron, 681

Eriobotrye, 613

Eriophorum, ${ }^{*} 658,689$

Erodium, ${ }^{*} 296,600$; fruit, ${ }^{*} 296$

Lirum, 627

Eryngizun, 637

Erysiphe, *92, 391

Erysipheae, 389, 391, 392

Erythraed, 646 , " 647

Erythroxylaceae, 602

Erythroxylon, ${ }^{*} 601,602$

Escholtria, 587

Espeletia, 683

Ether'eal oils, 240

Etiolation, *263

Eucalyptus, 629, 631

Evedorina, 358

Eugenia, 630. ${ }^{*} 631$

Euglena, *342

Eumycetes, 387

Euonymus, *30, *605, *606

Euputoriece, 678

Eupatorium, $67 \mathrm{~s}$

Euphorbia, *561, *562, *563, 564; globosa, *199

Euphorbiaceå, 561

Euphrasio, 230, 660

Euryule, 573

Ensporangiatae, 447

Everlasting Pea, Lathyms

Evolution, 2 ; theory of, 1

Excretion of water, causes of, 202

Exint, 477

Exoasci. 399

Exobasilineate, 411

Exohasidium, * 410,411

Exocarp. 518

Exolermis, 130

Exogenous, 21

Exogonium, *651, 6.52

Exothecium, 483

Extrorse, 483 ; anthers, $18: 3$

Exurlation, *200

Fagypyrum, *519, 568; achene of, *519

Furus, ${ }^{*} 23,549,{ }^{*} 551$; burl, ${ }^{*} 23$; leaf. * $1: 33$

Fats, 68 ; hydrolysis of, $23 \mathrm{~T}$

Feyretella, *427

Fennel, Foeniculum

Fermentation, $241,246,-48$; production of heat in, 248

Ferns, see Filicinae

Fertilisation, 92, ${ }^{*} 93,278,{ }^{*} 513$; in an angiosperm, *93,512

Fivlu, 638, 640

Festuca, *690. 699

Fibrous cells, 146,149

Ficus, 556 ; pollination, 496 
Fig, Ficus carica

Filago, 682

Filament, 483

Filices, 449

Filicinae, 284, 447, 472 ; apogamy, 284 ; apospory, 2S4; fossil, 472

Fir, Piceu excelsu

Flagella, 293

Flagellata, 341

Floral axis, form of, 486 ; rlagram, 488 ; formula, 488; -oecology, 493; sym. metry, 488

Flowering, time of, 495

Flowers, 28, 320, 475; of gymuosperms, 481; morpliology and oecology, 480 ; opening and closing of, 320

Fveniculum, *6.31, 638, 640

Foliage-leaves, 321 ; form of, 215 ; nyctinastic movements, $* 321$

Follicle, 518

Fontinatis, 442

Food-materials, 190 ; absorptiou, 190 ; assimilation of, 213 ; indispensable, 206 ; translocation, 190

Food solntion, 206

Fool's Parsley, Aethusa cynapium

Forget-me-not, Myosutis

Fossil angiosperms, 714 ; cryptogans, 470 gymnosperms, 540

Foxglove, Digitulis

Fragaria, 26, 615

Fragmentation, 8.8

Frangulinae, 608

Froininus, 614, *645

Free cell formation, 91

Free central placentation, 485

Freycinetio, 695 ; pollination, 497

Fritillaria, 707

Fruit, 518; rispersal by animals, 522; dispersal by water, 522 ; wind-dispersal of, 521

Frullaniu, 434, 435, *435

Fucacene, 367, 371

Fuchsia, 629, *629

Fucus, *53, 367, *365, *372, *373

Fuligo, 344

Fumurio, *519, 588 ; nut of. ${ }^{*} 519$

Fumariareae, 588

Funaric, *61, *426, 436,442; chlosopliyll grains, 97 ; chloroplasts, ${ }^{*} 61$

Findamental tissue system, 126

Fingi, nutrition, 221

Funiculus, 476

Funkia, *512 ; enbryo sac, *512

Finze, Ulex

Galanthes, 709

Galegeue, 625

Vialeopsis, *653, 655

Galium, $* 519,664$, 667 ; schizocar?, *5 519
Galls, 170, 252, 553

Gamboge, 595

Gametes, 92, 278

Gametophyte, 443

Gurcinia, 595

Gases, absorption of, 186

Gasteromycetes, 415

Gean, I'runus avim

Gieaster, ${ }^{*} 415,416$

Gelsemixum, 644

Gennmae, 23, 276

Genetic spiral, 42

Genista, 625

Genisteae, 625

Gentiuna, 644, 645, *647

Gentianaceae, 644

Geotaxis, 315

Geotropism, 307, 312

Geraniacene, 600

Geranium, *488, *600

Germination, * 167,523 ; epigeal, 523 ; hypogeal, 524

Gesmeriaceae, 662

Geum, 615

Gigartina, $375, * 375,379$

Tinger, Zingiber officinule

Ginligo, *503, *506, 507, 508, 530, *530,

543 ; fertilisation, 508 ; macro-sporanginm, *506; pollen - tubes, ${ }^{*} 506$; sexual generation, 507

Ginligoaceat, 530

Giulgoinae, 530

viladiolus, 709

Glaucium, 587, *588

Gleba, 415

(ileclioma, 655

Gleclitschia, 20, *28, 623

Globoids, 66

Glococepsa, *11, *340, 341

Gloxinia, 662

Glueosides, 69, 70, 239

Glumiflorae, 687

Glutamin, 70

Glycogen, 68

Glycym iza, ${ }^{*} 626,62 \bar{t}$

Ginahalium, 68:2

Gnetaceae, 540

Gnetinae, 510 ; sexual generation, 509

Cinctum, 153, 508, 509, 516, 540,*541 ; embryo sac, *508; sexual generation, 509

Ginilium, 628

(ionotokont, 95

G'nssypim, * 597 ; seed-liairs, *116

Gralt liylurid, *2s8

(irafting, 253, *254

Gramineae, 689

Grand period of growth, 257

Grape Vine, Vitis vinifere

Grass-wrack, Zostere marine

Grutiolı, 660, *662 
Gravity, 307 ; as cause of movement, 307 ; primary effect of in the plant, 312

Ground-nut, Arachis hypogaed

Growing point, 101, 166, 250

Growtl, 250; grand period of, 257 ; intercalary, 22 ; in thickness, anomalous forms of, 153 ; in gymuosperms and dicotyledons, 139 ; in monocotyledons, 137 ; rate of, 257 ; in thickness, 260; exterual influences upon, 262

Gruinales, 600

Guard-cells, 113, 195

Guiacum, 602

Gum, 69, 78

Gummosis, 78

Gutta-percha, 69, 240

Guttiferae, 595

Gymnalenia, 712

Gymmocludus, 20

Gymnolinium, 345

Gymnospermae, 480, 495, 526, 528 ; elements of secoudary growth in, 114 ; embryo, 505 ; elements of secondary phloem in, 148 ; female flowers, 481 ; fossil, 540 ; male flowers, 181 ; microspores, 502; ovule, 504 ; pollengrains, *503; pollination, 495 ; sexual generation, 502

irymnosporangium, *406

Gynaeceum, 4S3, 481, *485

Gynandrae, 711

Gynostemium, 711

Gyromitra, 397

\section{IIcestia, 682}

Habit of plants, 29

Haemutoeoccus, *357

Haematorylon, 623

Hayenia, $613,{ }^{*} 613,616$

Hairs, 115; glaudular, *118; nulticellular, 117 ; stingiug, 117 ; unicellnlar, 117

Hales' experiment, 203

Halimeala. 361

Halophile, polliuation, 495

Halor'rhagidaceae, 629

Hamamelidaceae, 561

Hamamelidinae, 561

Hancomia, $6 \pm 6$

Haplocaulescent, 28

Haploid, 94 ; generation, 96

Haplomitrieae, 135

II (1plumitrium, *435, 435

Hajlostemonous flowers, 487

Harreyella, 378

Haustoria, 49

Hawthorn, Crataegus (Mespilus) vayeanthe Hazel, Corylus arelluna

Heart-woorl, 143, 144
Heat, 247 ; produced in respiration, 247 ; produced in fermentations, 248

Heclera, 633, ${ }^{*} 631$

IIeclychium, 711

Hedysureue, 626

Heliantheae, 682

Helianthemam, 593, *594

Helianthus, *513, *678, 683 ; tmbryo sac, ${ }^{*} 513$

IIelichrysum, 682

Heliotropism, *303

Heliotropium, 654

Helleborus, ${ }^{*} 37,{ }^{*} 112,{ }^{*} 577$

Helobiae, 686

Hemerocullis, ${ }^{*} 478$

Hemilesmus, 651

Henbaue, Hyoscyomus niger.

Hepaticae, 425,429

Herracleum, 638

Herbs, 29 ; perennial, 29

Hercogamy, 501

Hermaphrodite flower, 482

Herniaria, 570

Heterobasidion, 413

Heterocontae, 354

Heteromerous lichens, 417

Heterophylly, 36

Heterospory, 446, 475

Heterostyly, 500 ; dimorphic, 501 ; trinorphic, 501

Heterothallic mucorineae, 385

Heterotroplic plants, gain in carbon in, 221

Ilevea, 564

II ibisceue, 597

Hibiscus, 597

Hierceium, 678; apogamy, 514

Hilum, 515

Hippocastanaceae, 607

Hippophä̈, 628

Hippuris, *104, 629

Holcus, 693

Holly, Ilex aquifolium

Homoionerous lichens, 417

Homology, 9

Homospory, 446

Homothallic mucorineae, 385

Honeysnckle, Loniceru perielymenum

Hualiu, 651

Hop, Humulus lupulus

Horleum, *106, *691, 693 ; root-ajex, * 106

Hornbeam, Carpinus Betulus

Horse-chestuut, A'sculus

Horse-tails, see Equisetinae

IIoya, 651

Humaria, 397

II umulus, *557; glaudular scale, *118

Hyucinthus, 703

Hyaloplasm, 58

Hybridisation, *287 
Hybrils, 285 ; derivative, 289 ; heterodynamie, 286; homo-rlynanic, 286

Hydathodes, I I9, 134, 200

Hylneae, 411

IIydnophytum, 664

Iydnum, * 411,412

Uydrengea, 611

Hyulrastine, 579

Hydrustis, $579,{ }^{*} 580$

IIyclrillu, pollination, 495

IIydrocharis, 686

Hydroebaritaceze, $686^{\circ}$

Hydrocyanic acid, 69, 210

IIyclrodictyon, 359

Hydrolepathum, *13

Hyilrolysis of earbohydrates, 235

Hydrophilous plants, 495

Hydrophyllaceae, 652

Hydropterileae, 455,472 ; fossil, 472

Hygroscopic movements, 295

IIylocomium, 412

Hymenolichenes, 421

Hymenom ycetes, 410

Hymenophyllaceae, 453

Hyoscyamus, *517, 658, 659, *663; seet of, * 517

Hypanthium, 486

IIypecoum, 588

Hyperieum, 595

Hyphae, 60

IIyphaene, 695

IIypholoma, ${ }^{*} 402$

IIprum, *439, 442

Hypocotyl, 167,506

Hypoderma, 129

Hypogeal germination, 524

Hypogynous flower, * $486,{ }^{*} 487$

Hyponasty, 298

Hypophysis, 513

Iheris, 593

Irlioblasts, 80, 127

Iler, ${ }^{*} 605,606$

Jllicimm, 580

Imbibition neehanisms, 295

Imputiens, 74, ${ }^{*} 126,499,602$

Indian hemp, Connatis sativa

Indican, 239

Indigofere, 626

Indusium, 452

Inferior gynaeceum, 486

Inflorescence, 489 ; monopolial, 490 : racemose, 490

Insectivorous plants, 227

Integuments, 476

Intercellular spaces, I08, I88; Iysigenic, 108

Interual construction of organs, 265 ; structure, pliylogeny of, 163

Internode, 22

Intine, 477
Intramolecular respiration, 244

Introrse, 483 ; anthers, 483

Intussusception, 71, 256

Inulu, 68:

Inuleae, 682

Inulin, 70, 236

Iridaceae, 709

Iris, * $707,{ }^{*} 708,709$; root, ${ }^{*} 131$

Iron, assimilation of, 232 ; bacteriu!n, 337

Irritability, 4, 176

Isatin, 240

Isutis, 593

Isocontae, see ChIoroliyceae

Isoetaceae, 469

Isoetes, *469, *470

Isogamy, 333

Ivy, Hedera Heli:

Jambosa, 630

Jusione, 673

Jusminum, 611

Jatrorrhiza, ${ }^{*} 5 \mathrm{~S} 2$

Juglandaceae, 545

Juglandiflorae, 545

Juglens, *512, 545, *546; chalazogamy, *512

Juncaceae, 700

Juncaginacea, 686

Juncus, 499, *700, 700

Jungermannia, 435

Jungermanniaceae, 43 t

Juniper, Juniperus commuis

Juniperus, * $134,{ }^{*} 534,{ }^{*} 535$

Jute, Corchorus

Juvenle form, 169

Kancleliu, *524, 629 ; fruit, ${ }^{*} 524$

Karyokinesis, 81

Kickiria, 646

Kidney Bean, Phoseulus

Kiriney-vetch, Anthyllis

Kinoplasm, 59, 89

Klinostat, 308

Inuutia, 676

Knight's experiments, 308

Kinots, formation of, 154

Irameria, ${ }^{*} 622,623$

Labiatre, 654

Labiatiflorae, 678

Laboulbeniaceae, 388, 401

Labnemum Itumi, *2SS

Laburumu, Cytisus Luburnum

Luehnea, 388, *395

Erecturius, 114

Lactuca, 678

Lalies' Slipper, Cypripedium

Lagenostomn, 542

Lamina, 3 I

Laminaria, $366,{ }^{*} 367,374$

Laminariaceae, 366, 369 
Lamium, 499, *652, 65.5

Landolphia, 646

Lantane, 654

Laportea, 558

Lajpa, ${ }^{*} 677$

Larch, Lavix eumpaea

Larix, * 503,539

Latex cells, 80 ; vessels, * 99

Lathraca, 660

Lathyrus, *45, 62 T

Luedatcu, 121

Lauracene, 582

Laurus, 583, *584

Laranclula, ${ }^{*} 653,655,656$

Leaf, * 133 ; absciss layer, 161 ; base, 31 , 35 ; cushion, 33 ; development of, 30 : scars, 38 ; sheath, 31,35 ; stalk, 31 ; temlrils, 45 ; thorns, 45 ; traces, 134

Leaves, 131 ; arrangement of, 39 ; bracteal, 38 ; divergence, 41 ; floral, 38,132 ; foliage, 32,132 ; forms of, 31 ; netamorphosis of, 43 ; scale, 37 ; seconclary growtl of, 155 ; shade, 266

Lecanora, 422

Ledum, 611

Legume, 518

Leguninosae, 616

Lcmanea, 374

Lemna, 695

Lemnaceae, 69.8

Lemon, Citrus Limonum

Lentibulariacene, 662

Lenticel, * 159 , 160

Lentil, Ervum

Lcocarpus, ${ }^{*} 344$

Leontodon, *321

Leontopodium, 682

Lepidium, *590

Lepidocarpon, 472

Lepidolendreae, 471

Lepidostrobus, 471

Lepiota, 414

Leptosporangiatae, 449

Leptothrix, *11, 334, 337

Lettuce, Lactuce sutive

Lexcojum, *707, 709

Lenconostoc, 337

Leucoplasts, 61,63 , *65

Levisticum, 638

Lianes, 30

Libriforı libres, 116

liahenes, 416

Licmophore, ${ }^{*} 350$

life, duration of, 274 ; phenomena of: 177

light, 262, 281 ; intluence on the formation of Howers, 281; influence on growtl, 262 ; movements eilusel by; 301 ; necessary for assiunilation, 215

Ligule, 466; of Selaginella, 466
Liguliflorue, $67 \mathrm{~s}$

Ligustrum, 644

liliaceae, 700

Liliene, 702

Liliiflorae, 700

Lilium, ${ }^{*} 509,{ }^{*} 513,703$; fertilisation *513 ; pollen-grain, *509

Lime, Tilia

Limnanthemum, 616

Limonum, 604

Linaria, *492, 660 ; raceme, ${ }^{*} 492$

Limm ${ }^{*} 601$

Lipase, 237

Liquidambar, 561

Liquorice, Glycyrhiza

Liriodendron, 580

Listera, 712

Litmus, 422

Litorclla, 662

Liverworts, see IIepaticae

Lobelia, 499, *673

Loheliacere, 673

Locomotion, 292

Lodiculae, 689

Loganiaceae, 644

Lolium, *692, 693

Lomiccra, 20.668; pollination, 496

Lonicereac, 668

Lophospermum, ${ }^{*} 319$

Loranthaceae, $55 \mathrm{~s}$

Loranthiflorae, 558

Loranthus, $55 \mathrm{~S}$

Lotecue, 625

Lotus, ${ }^{*} 622,625$

Lovage, Levisticum

Lunaria, *590, 593

Lupinus, 625

[u] uliu, 119, 240

Lu:ulu, 700

Lychnis, 570

Lycoperdon, *415, 416

Lycopcrsicum, 6.56

Lycoporliaceae, 463

Lycopodinae, 462,471 ; fossil, 471

Lycopodium, *20, *444, 463, *464, *465; prothallus, *465; stem, 444

Lyginodculron, 472,542

Ly crinopterideae, 542

Lysimachiu, 642

Lythraceae, 6:2S

Lythrum, 628

Mecrocystis, $366, * 367$

Mrecrozamia, 529

Magnesium, assimilation of, 232

Magnuliu, 580

Magnoliaceae, 579

Muianthemum, 705

Maize, Zea

Malacoplitous plants, 497

Malve, ${ }^{*} 483,596$; pollen-grain, ${ }^{*} 483$ 
Malvaceate, $596^{\circ}$

Muliece, 596

Mummillariu, 571

Mangifera, 605

Mangosteen, Gareinia Mangustana

Munihot, 564

Mantle-leaves, 37

Manures, 209

Maquis, 655

Merentre, 711

Marantaceae, 711

Marattiaceae, $\mathbf{1 4 9}$

Murchantia, *164, *426, *427, $430, * 431$, ${ }^{*} 432$; air-pore, ${ }^{*} 164$

Marelantiaceae, 430

Margruvie, inflorescence, ${ }^{*} 499$; pollination, $497, * 499$

Marvubizm, 655

Marsh Marigold, Cultha palustris

Marsilia, * $455.456,472$; fossil, 472

Marsiliaceae, 455 ; sporocarps, 459

Matricaria, ${ }^{*} 677,{ }^{*} 6 \mathrm{~S} 1,684$

Mutthiole, 592

Maximun, 178

Mechanical inthences, 264; in revelopment, 252 ; on growtl, 264 ; stimuli, as cause of movement, 317 ; timine system, 266

Meconopis, 587

Median plane, 488 ; of Hower, 488

Mealicago, 625

Merlick, Medicargo

Meullar, Mespitus germaniea

Medulla, 127

Medullary ray cells, horizontal, 151 ; vertieal, 151

Medullary rays, 128,150 ; secoulary, 140 ; sheath, 141

Medullosere, $54: 2$

Meiosis, $86,{ }^{*} 95$

Melalenca, 631

Melampyrum, 660

Melanthicae, 702

Melastomaceae, 629

Melica, 693

Melilot, Melilotus

Melilotus, 625

Melissa, ${ }^{*} 65.5$

Melon, Cucumis Melo

Members of indepentent origiu, 15, 50

Mendel's laws, 286

Menispermacene, 582

Mentha, 655, 656

Menyanthes, 616

Mercurialis, ${ }^{*} 112,{ }^{*} 561,563$

Meristen, 107

Merulius, 413

Mescmbryanthemum, 571

Mesocal'p, 518

Hesocripus, 302

Mesotaeniaceae, 347
Mesntuenimm, 347

Mespilus, 613

Metabolism, 17\%, 180

Metals, assimilation of, 232

Metamorphosis, 10 ; of Primary Mcmbers, 15

Metapliase, 84

Metaplasm, 57

Metroxylon, 695, 698

Metzgeria, * $102,434,435$

Miadesmia, 472

Micrusterias, "317

Wicrocuecus, * 11,338

Microcyces, 529

Micropyle, 515

Microsomes, 58

Microspores, 457, 467, 469, 510

Middle lamella, 109

Midsunmmer growth, 142

Mignonette, Resedu oclorata

Milfoil, tehillea

Millet, A ulropogon

Mimosa, *617, 618 ; malicu, 323, *323

Mimosiceae, 618

Mimusops, 611

Minimum, 178

Mistletoe, Tiscum album.

Mnium, *165, 436, *439, 440, *441; stein, ${ }^{*} 165$

Monambrae, 712

Moncerda, 656

Wonascus, 388

Moukshood, Aconitum

Monoblepharideae, 380

Monoblepharis, *380

Monochasium, 491

Honochlumydere, 526,545

Monocotylae, 527, 684

Monocotyledons, 513 ; embryo, 513 ; germination of, 525 ; secondary growth of, 155

Monoecious plants, 181

Monoporial branching, 17 ; inflorescences, 490

Nonopodium, 17

Mono-symuetrical flowers, 488

Homotropa, 641

Jonsterc, 35, 695

Ioraceae, 555

Worchella, ${ }^{*} 390,{ }^{*} 397$; asei, ${ }^{*} 390$

Morphiue, 240

Morphology, 6, 9 ; external, 10 ; interna], 52

1/orus, *520, 556 ; fruit, ${ }^{*} 520$

Mosses, see Musci

Movement, 177, 291; ciliary, 292; of protoplasin in cells, 292 ; various kinds of, 291

Movenents, amoeboid, 292; antonomic, 297; directive, 301; hygroscopic, 295 ; nastic, 300,319 ; nyetinastic, 
320 ; paratonic, 299 ; protoplasmic, 292, stimulns, 299; swimming, 29.2 ; tropic, 300

Mucilage, 69, 78

Irucor, 384, *355, *386

Mucorineae, 384

Mrcuna, *153; stem, *153

Mulberry, Mortus alba

Mullein, Tresbascum

Multicellular formation, $90,{ }^{*} 91$; plant, absoiption of sulstances in the, 186

Multiplication of the individual, 275

Musa, 35, 709

Musaceae, 709

Muscari, 20, 703

Muscarine, 240

Musci, 425, 429, 436

Muscineae, 425

Mushrooin, see Psalliota

Mutations, 3, 169, 290

Nutisecue, 678

Mycorhiza, ectotrophic, 232 ; endotrophic, 232

Myosotis, 653

Myosumes, 577

Myrica, 546

Myricacene, 546

Myriophyllum, 629

Myristice, ${ }^{*} 517,580,{ }^{*} 581$; seed, ${ }^{*} 517$

Myristicaceae, 580

Myrmecodia, 664

Myrmecophily, 556

Myronic acid, 239

Myroxylon, ${ }^{*} 622,{ }^{*} 623,624,627$

Myrsiphyllum, 313

Myrtaceae, 629

Myrtiflorae, 628

Myrtle, Myrtus

Myrtus, 629, *631

Myxobacteriaceae, 340

Wyxососеиs, *339

Myxomycutes, 54, 342 ; sclerotia, 56

Naiadaceae, 686

Naias, 686

Narcissus, 709

Nastic movement, 300, 319

Natural selection, 2

Natural system of classification, 329

Araviculu, *350, 352

Neckera, 442

Nectary, 487

Nectriu, 393, 395

Nchumbium, 573

Neottiu, 47, 712

Nepenthaceae, 586

Nepcnthes, ${ }^{*} 43,44$, ${ }^{* 229}$, 586 ; jitcher, * 229

Nepete, 655

Nephromium, 421

Ncrimm, 646, *619
Nervature, 34

Nest-leaves, 37

Neuropteris, 472

Nicotiana, 658, *659, *650

Nicotine, 240

Nitella, *183, 422

Nitrate-bacteria, $220,24 \overline{5}$

Nitrifying bacteria, ${ }^{*} 339$; gaiu in carbon by, 220

Nitrite-hacteria, 220, 245

Nitrobacter, 340

Nitrogen, assimilation of, 226

Nitrosomonas, 340

Nitzschia, 352

Norte, 22

Nolanaceae, 656

Nopalea, 571

Nostoc, *341

Nothofayus, 549

Nucellus, 476

Nuclear, cavity, 60 ; division, *82, ${ }^{*} 87$; division, lirect, 88 ; indirect, 81 ; division, free, 90 ; division, lieterotype, $\$ 6$; division, lomotype, $86^{\circ}$; sap, 60 ; spintle, 82

N'ucleoli, 59

Nucleus, 53, 59

Tuphar, 573

Nut, *519

Nutations, 298

Nutrient salts, 205 , 282 ; influence on reproluction, 282

Nyctinastic movements, 320

Nymphace, *517, *572, *573; seed of, *517

Nymplraeacene, 572

Oali, Quercus

Oat, Arence

Obdiplostemonous androecium, 488

Ocelli, 113

Ochrea, 36, 567

Ochrolechea, 422

Ocimum, 655

Oclontites, 660

Odontospermum, 682

Oecology, 6 ; floral, 493

Oelogonium, 361, *362

Ocnanthe, *635, 638

Oenothera, 629, *629 ; lamarikina, 291

Oils, 68 ; ethereal, 69

Olea, 644, ${ }^{*} 645,{ }^{*} 646$

Oleaceac, 644

Olive, Olea europea

(tpidium, *382

Onagraceac, 629

unoclea, *92, 452

()homis, 625)

Ontogeny, 2, 9 ; of the form and structure of plauts, 166

Oogany, 333 
Oomycetes, 350

Ophiocytium, 355

Ophioglossaceae, 447

Ophioylossum, 47, $447,{ }^{*} 418,{ }^{*} 449$

Ophrys, 712

Opium Poppy, Papacer somniferum

Optimum, 178

Opuntia, ${ }^{*} 27,571$

Orchiclaceae, 711 ; tubers of, $4 \mathrm{~S}$

Orchis, *48, 712, *712, *713, *\%14; pollination, 496

Organic acirls, 70

Organography, 10

Organs, internal construction of, 265

Origanum, 655

Ornithorgalum, $* 73, * 703$

Ornithophilous plants, 497

Ornithophily, 496

Ornithoms, 627

Orobanchaceae, 661

Orobanche, 22t, 662, *666

Orthospermate, 637

Orthostichies, * 41

Diy:a, ${ }^{*} 6292,693$

Oscillaria, ${ }^{*} 3 \pm 0,311$

Osmotic pressure, 183, 181

Osmunda, *452, 453

Osmundacene, 453

Ostrich ferm, Struthiopteris

Ourouperia, $66 \pm, 667$

Ovary, *484, *486

Ovule, $279,476,485$; anatropous, 476 ; atropous, 476 ; campylotropous, 476 ; position of, 485

Ovuliferous scale, 536

Ovum, 511

Oxalidaceae, 601

Oxulis, 601 ; hedysaroiles, movement, 299

Oxillation of inorganic material, 245

Oxygen, 264; absorption of, 211 ; evolution of, 215 ; influence on growth, 264

Pudina, 370

I'ceonia, * 482,579 ; flower of, $37,{ }^{*} 482$

Palaquium, 641, *642

Paleae, 450

Palisarle cells, 132

Palmae, 695

Pandanaceae, 695

Pandanus, 695, *696

l'andorina, 358

Panicle, 490, * 492

Panicum, 693

Papaver, ${ }^{*} 517,587,{ }^{*} 588$; seed of, ${ }^{*} 517$

Papaveraceae, 587

Papaw, Carica papaye

Papilionaceae, 623

Parallel venation, 685

Parasites, 222, 229 ; partial, 229 ; reduction of the shoot in, 26 ; roots of, 49

Parasitic bacteria, 337
Parastichies, $* 41$

Paratonic movements. 299

Parenchyma, 107

l'uris, 705, *706, 707

l'urmelia, 421

Parnassia, 611

Puronychiene, 570

Parsley, Petroselinum

Parsuip, Pastinaer

Partherogenesis, 96, 283, 425

I'ussiflora, 628

Passitloraceae, 627

Passitlorinae, 627

Passion Flower, P'ussiflort

Pustinaea, 638

Pathogenic bacteria, 337

Paullinia, 607

P'uyena, $6 \pm 1$

Pea, *516 ; reserve material, * 516

Pea, I'isum

Peach, Prunus persica

Pear, Pyrus communis

Pectin substances, 77

Petiastrum, *359

l'elicularis, 230, 660

l'eireskia, 571

I'elurgonizm, *600

l'ellia, 434, 435

Peltigera, 421

P'enicillium, *391, 392

Pennatae, diatomeae, 351

Pentacyclicae, 640

Peperomia, 560

Periantlı, 40, 482

Periblem, * 104

Pericarp, 518

Perichaetium, 437

Periclinal walls, 108

Pericycle, 128

Perillerm, 156

Peridineae, 345

Perigone, 483

Perigynous flowers, * 456

Periodicity, 271

Perisperm, 516

Peristome, 441, *411, 442

Periwinkle, Tinca

Peronospore, 383, *384

Peronosporeae, 382

Persea, *582, 585

Personatae, 656

Petals, 38

l'etasites, 684

l'etites espèces, 291

l'elroselinum. 638

'etunia, *656, 658

l'erize, *395

Ihucelia, 652

Phaeophy*ceae, 366

Phaeophyll, 62, 365

Phreosporeae, 369 
Pheijus, *65 ; leueoplasts, *65

Plialloirleac, 416

Phullus, *415, 416

Phanerogamia, 475

Phamerogams, 322 ; classification of, 525 ; alternation of generations in, 479 ; sexual generation in, 502 ; transition from cryptogams, 475

Pharbitis, 313

Phascacene, 440

Phaseoleae, 627

Phaseolus, 627 ; starelı grains, ${ }^{*} 64$

Phelloderm, 158

Phellogen, 157

Philadelphus, 611 ; pollination, 496

Phleum, 693

Phloem, 121

Phlomis, 655

Phlox, 65:

Phoenix, 698

Phormium, *269

Phosphorescence, 248, 346

Phosphorescent bacteria, 337

Fhosphoric acitl, assimilation of, 232

Photosynthesis, 221

Phototaxis, 301

Phototropic perception, localisation of, 306

Phototropism, *303; transverse, 305

Phragnidium, 407, *408, *409

Phragmoplast, 89

J'hthiruse, 559

Pliycocyanin, 62

Phycoerythrin, 62, 375

Phycomycetes, 379

Phyllactinia, 391

Phyllocactus, 571

Phylloclades, 26

Phyllodes, 45, * $168,169,197$

Pliylogeny, 1, 9

Physalis, *519 ; fruit of, ${ }^{*} 519$

Physcia, 421

Physiological anatomy, 266, 270

Physiology, 6, 175

Physostigma, 627

I'hytelephes, 78, *97, *516, 698; endosperm, *516

Phyteuma, 671

Phytopathology, 171

Phytowhthon, 382, *383

Phytotomy, 10

l'icea, *537, 539 ; cmlıryo, *505; ovule, *504, *505; polliuation, 495

P'ierasma, 605

piler, pollination, 495

P'ilobolus, 304, *304, 385

Pilocarpine, 240

Pilocirpus, 605

J'ilostyles, " 225

l'ilularia, *455, 456

I'imentr, 631

l'impinelle, * $634,637,640$ l'inaceae, 533

Pineapple, 1 nanassu satica

I'inguiculu, 228, 322, 662

Pinks, Dianthats

I'innularia, *11

I'inus, *73, *141, *143, *503, *505, *536, *538, 539, 543 ; nale flower, *481; stem, ${ }^{*} 141,{ }^{*} 145$; woor, ${ }^{*} 143,{ }^{*} 146$

Piper, ${ }^{*} 560$

Piperaceae, 559

Piperinae, 559

l'istueia, 606

l'isum, * 45,627

Pit, 74 ; bordered, *73, 74 ; branched, 74 ; membrane, 74 ; tactile, *72

P'ithecoctcnium, ${ }^{*} 521$; winged seed, ${ }^{*} 521$

Placenta, 476, 485

Placentation, 485

Plagiochile, * $14,{ }^{*} 134,435$

Plankton, 353, 367

Planktoniella, *353

Plantaginaceae, 662

l'luntago, 29, *492, 662, "666; intlorescence, 500 ; spike, 492

Plantain, l'lantago

Platanaceae, 561

Plutunus, 561

Plants, carnivorous, 227 ; cellular, 165 , 331 ; chemical composition of, 180 ; insectivorous, 227 ; vascular, 165,331

Plasmodesms, *97

Plasmorlia, 342

Mlasmodiophora, 344

Plasmodium, 54

Plasmolysis, * 184

Plasmopart, 383

Piutycerium, 47

Plectascineae, 392

Plectriulium, *337

Pleiochasium, 491

Plerome, "104

I'leuroclatia, *369

Pleurosigma, 352, 354

Plum, Prinus elomestica

Plumbaginaceae, 643

Pneumatophores, *212

Poce, 693

Podalyrieae, 624

'Podocurpus, 531

I'viophyll wm, 580, *581

l'oclospor $a$, *393

l'odlostemaceae, hapterae, 51 ; roots, 49 ; shoots, 29

Pollostemonaceae, 609

Polar nuclei, 511

Polarity, 252

Polemoniaceae, 652

I'olemonixum, 652

Polioplasm, 58

l'ollen-chamber, 507 ; graill, 279 , *483, 477 ; -sacs, 477 , *478; -tule, 477 
Pollination, 48*

Polyangium, *339

Polyblephuris, 350

Polycarpicae, 57:2

l'olycaipon, 499

Polyembryony, 283

Polygala, *604, 605

Polygalaceae, 605

Polygany, 482

Polygonaceae, 567

Polygunutum, *24, 705, ${ }^{*} 655$; leaf of, *6s5 ; rlizone of, *24

Polyyonum, *510, *511, 565; development of the embryo-sac, ${ }^{*} 510$, $* 511$; fertilisation, *511; ovary, *511

Polyporliaceae, 453

Polyportium, 450, *453, *454

Polyporeae, 412

Polyporus, *412, 413, 415

Polystigme, 388

Polytome, 356, 358

Polytonty, 18 ; false, 18

Polytrichum, 436, *435, 441, 412

Pomeae, 612

Poplar, l'opulus

Populus, *39, 553, *554; bud of, *39

Porogamy, 512

I'otamogetom, 686, "687

Potamogetonaceae, 686

Potasium, assinilation of, 232

Potato, Solenum tuberesum

P'otentilla, *487, *612,615

P'otentilleae, 615

Primulu, 642, ${ }^{*} 643,643$; hair, ${ }^{*} 115$; heterostylerl flowers, ${ }^{*} 501$

l'rimulaceae, 642

Primulinae, 641

Privet, Ligustrum velgare

Procambium, 124

Proembryo, 505, 513; of gymuospernis, 505

Promeristem, 107

Propliase, 84

Prosenchyua, $10 \%$

Protandry, 500

Proteids, 237 ; liyiluolysis of, 237

Prothallium, 443, * 443,477

Protococcales, 358

Protogyny, 500

Protonema, 425, * 426

Protophloem, 125

Protoplasm, 54, 175

Protoplasmic novements, 292

Protoplast. 53 ; differentiation of, 80 ; external prorlucts of, 71 ; inclusions of, 63

Protoxylem, 125

I'runeae, 615

Prunus, ${ }^{*} 34$, *612, 615, *616 ; burl-scales, *3.1

l'salliwtu, 60, *412, 411
I'seudomonas, 337

I'sidium, 630

l'silutum, 472

Pteridophyta, 331, 442, 446,471 ; classification, 446 ; fossil, 471

Pteridospermae, 472,540

Pteris, ${ }^{*} 105, * 125,{ }^{*} 443, * 444$; concentric bunlle, * 125 ; embryo, ${ }^{*} 413$; rhizome, * 444 ; root ajex, 105 ; scalariform vessel, $* 99$

I'teroeuipus, 627

Puceinic, * $405,{ }^{*} 406,408$

I'ulmoneria, 653

Pulvinus, 33, 321 ; of Pluaseolus, *299

Punplin, Cucurtritu pep

P'unica, 631, ${ }^{*} 632$

Punicaceae, 631

Purple Bacteria, 337

Purple Loosestrife, Lythrum salicaria

I'yeniclia, 393

Pyrenomycetes, 392

I'yrole, 641

Pyrolaceae, 641

I'yronema, 388, *396, *397

P'yrus, *158, *487, *612, * 613 ; perirleru1, *158

Pythium, 383

Pyxidium, 519

Quassir, *603

Quercitlore, 546

Quercus, ${ }^{*} 160,{ }^{*} 550,{ }^{*} 551,{ }^{*} 552.553$; cork, * 160

Quercus subcr, cork, 158

(juillaju, 611, *613, 616

Quinaria, ${ }^{2} 23,609$

Quince, Cydonia valyaris

Quinine, 240

()uisqualis, 629

Raceme, $490,{ }^{*} 492$

liacemose intlorestences, $490, * 491$

liarial walls, 103

Rarlially symmetrical tlower, 488

Radicle, 168,506

Rarlish, Raphanus sutivus

liuffesiu, 27, 587

Raftlesiaceae, 587

liemaline, 419

Ramenta, 450

Riamonelio, 662

Ramnculaceae, 573

liununculus, *36, ${ }^{*} 123,{ }^{*} 457,574,{ }^{*} 575$; vascular bumlle, ${ }^{*} 123$

licontive, ${ }^{*} 197,682$

Retpluanus, 592

Raphlic, $351,476,515$

Raplicles, 68, ${ }^{*} 68$

Rasplerry, Rubus iduens

Perl Algae, sce Rhodopliycere

Rerlneerl structures, 10 
Reuluction division, $84,{ }^{*} 8 T$, ${ }^{*} 280$; stage of, *8.5

Regeneration, 16\%, 253

Rejuvenation, 275

Reproduction, 177, 274; conditions of, 280 ; sexual, 278 ; significance of sexual, 282 ; vegetative, 276

Resela, ${ }^{*} 91$, 593 ; multicellular formation, * 91

Resedaceae, 593

Reserve cellulose, 236; materials, 234, 235 ; materials, mobilisation of, 235 ; regeneration of, 239 ; transport of, $2: 38$

Resins, 69

Respiration, 241, *242 ; intramolecular, 214 ; of fatty seels, 213 ; production of heat in, 247

Respiratory cavity, 114

Rest-Harrow, Ononis

liesting period, for growth, 272

Reticulate venation, $5 \pm 4$

Rhabdonema, 352

Rhannaceae, 609

Rhamnus, *608, 609

Hheum, *566, *567, 507, 568

Rhinantheae, 660

Whiventhrs, 230

Rhipidium, 491, *493

Rlipjsalis, 571

Rhizomes, 24

Rhizophork, 629, *630

Rhizophoraceac, 525, 629 ; vivipary, 525

Phizophores, 51

Rhizupus, *384

Fhododendron, 641

Rhorlophyceae, 374

Rilodoreac, 641

Phoeadinae, 587

Phubarb, Rheum

I'hus, 605

Ribes, ${ }^{*} 610,611$

Riccia, ${ }^{*} 14,{ }^{*} 430$

Ricciacae, 430

Rice, Ory:a

Richardia, 698

Ricinus, ${ }^{*} 564,{ }^{*} 565,566$; aleurone grains, 66

Pigielity, against benling, ${ }^{*} 268$; against pnlls, 269 ; against tearing, 269

Rigor, 271, 324

Rialinia, *46, *161, 626 ; tyloses, ${ }^{*} 161$

livecella, 419, 422

Rock Rose, IJeliunthemun vulgare

lioot, 14, 46, *129, ${ }^{*} 130,{ }^{*} 131,191$; allventitious, 47 ; aerial, 46,49 ; apical cell, 105 ; branching of, 47 ; -cap, 46 , 105; climbing, 49 ; form of, 48 ; -hairs, 47, 191, *192; lateral, 48; metamorpliosis of, 48 ; - jockets, 46 ; - jressure, *201; rexluction of, 49; respiratory, 49 ; -stocks, 24 ; system, 192 ; tap, 48 ; -thorns, 49 ; -tip, growtl of, *259; tubercles, *230, 339 ; of leguminosae, 231 ; tubers, * $4 \mathrm{~S}$

Rosa, ${ }^{*} 519,{ }^{*} 612,615,616$; fruit of, *519

Rosaceae, 611

Rose of Jericho, Anastatica hierochuntica, 592

Rosillorae, 611

Rosmarinus, 655, 656

Rotation, 58

Rowan, Sorbus (Pyrus) aucuparia

Royal tern, Osmunca

Rozites, 414

Rubber, see Caontehone

Rubia, 664, 667

Rubiaceae, 662

Rubiinae, 662

Rubus, *520, *615 ; fuit, *520

Rudimentary structures, 10

Rumex, 568

Runners, 26

Ruppie, $6 \mathrm{S6}$

Iiuscus, 26, *27

Rush, Juncus

Russula, ${ }^{*} 410,414$

Rust-fungi, see Uredineae

Ruta, ${ }^{*} 602,603$

Rntaceae, 602

Rye, Sccule

\section{Sabaclilla, 707}

Saccharom yces, * $11,246, * 400$

Saccharomycetes, 400

Soccharum, * 111,693

Salfron, Crocus sativus

Śregittarie, *686, 686

Salicaceae, 553

Saliciflorae, 553

Salicin, 239, 554

Salicornia, ${ }^{*} 207$

Salix, ${ }^{*} 553,553$

Salpiglossis, 658

Salvia, ${ }^{*} 654,655$; pollination, 496 , *502

Salvinia, *456, ${ }^{*} 457,{ }^{*} 458,472$; fossil, 472

Salviniaceae, 456

Sambuccue, 668

Sumbucus, $158,{ }^{*} 484,668,{ }^{*} 672$; lenticel, * 159 ; pliellogen, 158

Sumolus, *2:2

Sianguisorba, ${ }^{*} 612,614$

suricula, 637

Santalaceac, 558

sontulum, 558

Sapindaceate, 607

Sapintinae, 605

supponaria, $570, * 570$ 
Sapotaceate, 641

suproleguiu, 280, *:381; conulitions of rejurorluction, 280

Saprolegniaceae, 380

Saprophytes, $22: 2$

Sap-wood, 143, 144

Suryassum, 367

Sarothamnus, 625

Surracenia, 586

Sarraceniaceat, 586

Sutureju, 655

Siessufrus, 582, *583

Saxifraya, 611

Saxifragacene, 610

Saxifrage, Sarifruga

Saxifraginae, 609

Scalivosa, 670

Sealariform vessel, 100

Scundix, 639

Scenclesmus, *359

Schistostega, $248, * 219, * 439,442$; protonema of, *248, $* 249$

Schizaeaceae, 453

Schizocarp, 519

Schizogenic intercellular spaces, 108

Schizomycetes, 341

Schizonema, 350

Schizophyceat, 341

Schizophyta, 341

Schizasuccharomyces, 400

Schoenocaulon, 707

Schulze's macerating mixture, 109

Sciaclium, 355

Scilla, 703

Sirpus, "688

Scitamineae, 709

Seleranthus, 570

Sclerenchyoia, 79, 267

Scleroderma, * 415,416

Selerosporn, 353

Ścolopenelrium, 450, *452, 453

Scorzonera, 678

Scotch fir, I'inus silvestris

Scrophularia, 660

Scrophulariaceae, 659

Seurvy Grass, Cochleariu officinalis

Scutellariu, *4S9

Secule, ${ }^{*} 691$; spikelet, ${ }^{*} 692,693$

Secondary growth of a gymnosperm or dicotyledon, *142; growth, elements of, 144 ; meristem, 107 ; mucleus, 511 ; phloem, elements of, 118 ; thickening of root, ${ }^{*} 152$

Scdum, ${ }^{*} 610$

Seerl, 477, 515, *517, 520; dispersal by animals, 522 ; dispersal by water, 522 ; distribution of, 520 ; wind-dispersal of, 521

Seerl leaves, see Cotyledons

Seedlings, * 521

Seismonasty, 323
Selaginella, 465, *466, *467, *468; microspore, *467; prothullus, ${ }^{*} 467$; rhizopliores, *50

Selaginellaceae, 465

Selective power of cells, 185

Self-pollination, 279 ; sterility, 499

Semi-permeable merml,rane, ] 33

Sempervivum, 2S1, 610 ; conclitions of reproduction, 281

Senecioneat, 681

Seusitiveness to contact, 323

Sensitive Plant, Mimose puelicu

Sepals, 38

Separation, 275

Sequoic, 537, 543

Serjunia, *154; stens, *154

Sexual generation in the Phanerogams, development of, 502 ; reprorluction, 278 ; reproduction, significance of, 282

Shaule-leaves, 266

Shoot, 19 ; accessory, 20 ; alventitious, 21 ; aerial, 26 ; npex of, * 19 ; axillary, 20 ; development of, 19 ; further development of, 22 ; normal, 21 ; origin of new, 19 ; subterranean, 24

Shored, 595

Shrubs, 29

Sicyos, ${ }^{*} 318$; tenriril, *318

Sieve-plate, ${ }^{*} 73,98$; tuhes, ${ }^{*} 98,122,149$

sigillaria, 471

Sigillarieae, 471

Silene, *568, 570

Sileneae, 570

Siler, ${ }^{*} 634$

Siliea, 78

Siliceous borlies, 68 ; earth, 207, 354

Silicon, 207

Siliculosae, 591 ; dehiscentes, 591 ; nucumentacecie, 591

Siliqua, 519

Siliquesue, 591 ; dehiscentes, 591 ; lomentaceae, 591

Silver fir, Abies pectinata

Simarubaceae, 605

Sinapis, 592

Siphonales, 363

Siphonoclarliales, 362

Siphonoclalus, 362

Sisymbrium, ${ }^{*} 590$

Sium, ${ }^{*} 636,638$

Sline-fungi, see Mlyxomycetes

smilax, 705, 707

Simut, 403 ; -fingi, see Ustilagineae

Sollium, 207

Soil, absorptive power of, 192

Solanaceae, 656

Solanin, 239

Solanum, *25, $056, * 658$; tuber, *25

Solerinu, 421 
Solidengn, 681

Sonchus, 6is

Sophoreae, 624

Sorbus, ${ }^{*} 612$

Soredia, 418

Sorus, 452

Spadiciflorie, 693

Spanish Pepler, Coussicum annum

Sparassis, 411

Sparganiacene, 695

Spartium, 625, 627

spccularia, 499

sipergule, 570

Spermaphyta: 477

Spremlatozoils, 92,508 ; of Cycals, 508 ; of Ginkigo, 508

Spermogonium, ${ }^{*} 406,407$

sphacria, 393

Sphacrites, 65

Siphacroplea, 362

siphaerothece, ${ }^{*} 390$

Sphagnaceae, 436, 439

spherymum, 437, 439

Sphenophyllinae, 472

Sphenophyllum, 472

Spike, $490,{ }^{*} 492$

Slikelet of Gramineae, 689

Spinaeh, Spinacia oleracea

Spinacia, 569

spirceet, ${ }^{*} 612$

spircene, 611

Spirillum, *11, 334, *335

Spirochuete, *11,334, 339

Spirogyra, *90, 348, *349

spirotueniu, * $346,347,352$

splachnum, 441

Splint wood, 143

Spongy parenchyma, 132

Sporangia, $445,{ }^{*} 452$; of filices, ${ }^{*} 452$; of pterilophyta, 445

Spore mother cell, *95

spores, $27 \pi$

sporodinia, *385

Sporogrenesis, 95

Sporogoninm, 428

Sporophylis, 38

Spurges, Exphorbiu

Spurious fruit, 520

stuchys, 655

Stamens, 38, 324, 177, *483 ; variation movements of, 321

Staminodes, 484

śtungerie, 529, 530

Strupelice, 651 ; pollination, 496

siuphylococess, 338

Starch, 64, 218, 235; assinilation, 64 ; glutinous, 66 ; grains, *64 ; grains, size of, 65 ; reserve, 64

Stutice, 644

Stegocarpae, see Bryinate

Stele, 128
Stellaria, 499, 570

Stellatue, 664

Stem, 129 ; distribution of tissues in, 128

stemonitis, * 343,344

Stereuliaceae, 598

Stereome, 267

Stereum, 411

sticte, 421,422

Stigma, 485

Stigmatomyces, ${ }^{*} 400,401$

Stimulus, movements, 299 ; reception of, 301

Stinging nettles, Urtice

Stipa, ${ }^{*} 198$; leaf, ${ }^{*} 198$

Stipules, 31,35

Stolons, 25

Stoma, 196

Stomata, *112, 113, 165, 195 ; diffusion through, 213

Stoneworts, sce Cliaraceae

strutiotes, 686

Streaning protoplasm, 293, 294

Strelitzie, flower, *498; jollinatiou, 497, * 498

Streptocarmes, 662

Streptochatete, 690

Streptocuccus *3:6, 337

Strickeria, ${ }^{*} 393$

Stroma, 393

Strophanthus, $646,{ }^{*} 648$

Structural ieviations, 169

Struthantus, 559

Struthiopteris, 452

Strychnine, 240

Strychnos, 644, *647

Style, 485

Styracacene, 641

Niyrax, 641

Submergerl leaves, 36

Subsidiary cells, 114

Subtending leaf, 20

surecisa, ${ }^{*} 676$

Sugar Beet, Beta patula

Sugar-cane, Stecchurrm

Sulphur, 69 ; bacteria, 220, 245, 336

Sulphuric aeid, assimilation of, 232

Sun-dew, Drosem

Suntlower, llelianthes anmus

Survirella, 352

Suspensor, 505; of gymnosperms, 505

Swarm-spore, 55

Surertia, 646

Swimming movements, 292

Symmetry, 265 ; floral, 488 ; of structure, 265 ; relations of, 15

Sympetalae, 527, 640

Symmplytum; 653 ; seorpioill cyme, *494

Sympodial inflorescence, 490

Symporlium, 18

Synapisis. 81 
Sуnеarpous gуnаесени, 484

Siymedice, 352

Synergitine, 511

Syrivinge, ${ }^{*} 644$

Tubernuemontana, 647

Trugetes, 683

Tumurindus, ${ }^{*} 619,{ }^{*} 620,{ }^{*} 621,623$

Temus, 709

Tanucetum, 684

Tamin, 68, 70

Tiphrina, *399

Tuнхасит, 678. *679, *680, 684; a)ogamy, 514

Taxaceae, 531

Taxis, 300

Turodium 534,54:3

Tuxus, ${ }^{*} 503,531$, ${ }^{*} 532$, *533 ; alraugement of the bunlles in, 134, *135; embryo-sac mother cell, $* 503$; pollination, 495

Teazel, Jipsucus

Teromu, 662

Tectona, 654

Tegumentary system, 110

Teleutospores, 406

Telophase, 81

Temperature, 262, 282 ; influence on growth, 262 ; influence on reprorluction, 282

Teurlrils, 27, 317, 318 ; climbers, 317

Teriatologr, 171

Terfcsia, $39^{2}$

Terfeziaceae, 392

Terminulia, 629

Terustrimiacene, 594

Testudinuria, 709

Tetracyclieae, 644

Tetragonolobus, 625

Tetraspores, 376

Tencrium, 655

Thatictrum, 577 ; apoganny, 514

Thallophyta, 331 ; phylogeny, 14, 332, 470 ; fossil, 470

Thallus, 10

Thamnitizm, 386

Theu, 594, ${ }^{*} 595$

Thecae, 48:3

Thelephoreat, 411

Theobromu, *598, *599, 600

Theobromine, 240

Thesium, 229, 558

'lhigmotaxis, 319

Thigmotropisn1, 317

Thluspi, 593

'lhorn-apple, Dature stromonim

Tliorns, 27

Thuju, ${ }^{*} 167$; germination, * 167

'T'h y'melatacene, $6: 8$

Thymelaeinat, 625

Thymrs, 655, 656
Tiliu, "150, *151, *598; phlorm, *151; stem, *118; wool, *148, ${ }^{*} 149$, * 150

Tiliaceae, 598

Tilletia, * 401

Tilletiaceae, 404

'Tissues, 100 ; kinds of, 107 ; origin of, 100 ; prinary, 110 ; secondary, 138 ; system, 110 ; tension, 260 , ${ }^{261}$

T'mesipteris, 472

'Tolypellopsis, 425

Tomato, Lycopersicum

'Tonoplast, 58

Toothwort, Lathraece squanuria.

'Torus, 74

Tozzia, 230, 660

Tracheae, 99, 146

Tracheidal vessels, 146

Tracheide, * $73,79,146$; fibre, 146 ; vascular, 146

Traclescantia, *89, *113, 700 ; stamina] hair of, * 59

Trugopoyon, 678

Transfusion cells, 130

'Transition cells, 126

Translocation of assinilates, 234; of substances, 186

Transpiration, 193; amount of, 196 ; cuticular, 195 ; stomatal, 195

Trimspiration stream, 203 ; eauses of, 204

Tivence, 629

Traunotaxis, 316

Tree-ferns, 449

Trees, 29 ; longevity of, $27 \pm$

Tremella, *402

Tremellineae, 410

Trentepohlice, 360

Trichia, *344

Trichocaulon, 651

'Trichogyne, 377

Trichomanes, * 453

'l'richones, 115

Tricoccae, 561

Trifolieue, 625

Trifolium, 625

Trigluchin, 686

Trigonella, 625

Triplocaulescent, 28

Triticum, ${ }^{*} 67,{ }^{*} 691,693$; spilielet, ${ }^{*} 692$

'Tropaeolaceae, 601

Tropreolum, *63, *200, 601 ; water-jore, *115

'Trophoplasm, 59

Tropism, 300

Truflles, see Tuber

Tsuga, 39 ; bud of, *39

Tuber, 24, *398

Tuberaceae, 398

Tubiflorae, 651

Tululiflorre, 677

Tulipe, *25, 703 ; bull, *25 
Tulip tree, Liriodendron

Turuip, liressice napnes

Tussilugo, *682, 684

Twining plants, 30,312 , *313

Tyloses, * $16 \mathrm{l}$

Typhaceae, 695

Ulex, 625

Ullmannia, 542

Ulmacene, 554

Ulmus, *31, *511, $555, * 555$; apex, *31; ovule, ${ }^{*} 511$

Ulothrix, ${ }^{*} 92,360,{ }^{*} 361$

Ulotrichales, 360

Ulva, ${ }^{*} 12,360$

Unbel, 490, *492

Unbelliferae, 633

Unbellitlorae, 632

Uncinulu, *391, 391, 392

Urayoga, 664, 667

Uredineae, *670

Uredospores, 407

Urgince, 703, *704, 707

Urtica, *116, *287, 558 ; stinging hair, *116 : hybridisation, *287; pollination, 495

Urticaceae, 558

Urticinae, 554

Usnce, * 419

Ustilagineae, 402

Ustilaginaceae, 403

Ustilago, *403, 403

I'tricularia, 44, *44, 228, 662

Vraccinecte, 641

Vaccinium, *640, 641

Vacuole, 53, ${ }^{*} 54$; contractile, 56

Valerian, Valeriana

Taleriana, $669,{ }^{*} 672$

Talerianaceae, 668

I'alerianella, 669

Vullisneria, 687 ; pollination, 495

Vanille, *713; 714

Vanillin, 240

Variation, 290 ; external causes of, 170 ; fluctuating, 3, 169

Vascular, bundles, 120, *121 ; cauline, 137 ; closed, 124; common, 137 ; course of, 134 ; foliar, 137 ; system, 120 ; terminations of, 126

Vaseular eryptogans, see Ptericlophyta

Vasenlar plants, 331

I aucherie, 364, *365

Vegetalile Sheep, IIaastiu

Vegetative cone, $19,{ }^{*} 104$; reproduction, 276

Velamen, 19, 120

Telum, 413

Venation, 34

Tentral suture, 485

Veratrine, 240
Verutrum, 703, 707

Verbuscum, 659, *662

Verbena, *652, 654

Verbenaceae, 654

Vernation, 38

I'eronica, 660 ; cupressoiles, *199

Termecaria, 418

Verticillatae, 545

Vesicaria, 593

Vessel, *73, 99 ; scalariform, 99

Vetch, Ticiu

Tibrio, *335, 338

Tiburnum, 668

licia, ${ }^{*} 230,{ }^{*} 622,627$; root tubercles, *230

Vicicae, 627

Iictoria, 573

Iinca, 646, *650 ; fibre, ${ }^{*} 72$

I incetoxicum, 649, ${ }^{*} 650$

rivla, *488, 499, 593, *594, *595; colleter, *115; epitermis, * 115

Violaceac, 593

Violet, Viole

Viscaria, *568

Viscum, *97, 156, 230, 558, ${ }^{*} 559$

Vituceae, 609

I'itis, ${ }^{*} 608,609$

Vivipary, 525

Toltzia, 542

Volva, 413

Volvocales, 356

Tolvox, *357, 358

\section{Walchia, 542}

Walltlower, Cheiranthus

Walunt, Juglans regice

Water, 263; absorption of, 182, 191 assimilation of, 233 ; concluction of, 202 ; culture, 205, *206 ; as fooclmaterial, 190 ; influence on growth, 263 ; movement of, in the plant, 193 ; plants, 266 ; stomata, 115 ; supply, special contrivanees for regulating, 196

Water-ferns, see Hyirapterideae

Water Hemlock, Cicuta

Water Nut, Trapat

VVater Parsnip, Sium

Water-pores, ${ }^{*} 115$

Wax, deposits of, 111

Teigelia, 668

Welwitschia, 540 ; sexual generation, 509

Wheat, Triticum

White Mustard, Sinapis alba

White Water Lily, Nymphaea alba

Wild Cherry, Pronus cerasus

Willoughbeia, 646

Willow, Salix

Willow-herb, Epilobium.

Wind-rispersal of seeds, 521 ; - pollination, 494 
IVistaria, 626

Witches'-brooms, 399

Woarl, Isatis tinctoria

Woltia, 698

IVool, autumu, 142 ; elements of, ${ }^{*} 147$; fibres, 146; living elements in, 148 ; secondary, 110 ; septate, 146 ; spring, 142

Woorluff, Asperules.

Wood Sorrel, oxalis

Wounds, healing of, 161

Xauthein, 71

Xanthophyll, 71

Tanthoria, *418

Xerophytes, 197

Tylen, 121

Xylochrome, 143

Yam, Dioscoren

Yeast fungus, see Saccharomyccs
Yew, Turus

Yucct, 155, 705; Hower, *492, *497; panicle, *492; pollination, $496,{ }^{*} 497$

Zumia, *506, *50\%, 529 ; fertilisation, *507 ; speruatozoirls, *506, *507

Zanichellia, 686

Zea, ${ }^{*} 121,{ }^{*} 122,{ }^{*} 128,693$; vascular bumılle, * 121 , * 122

Zingiber, *710, 711

Zingiberaceae, 709

Zinnia, 683

Zoogloea, 334

Zostera, 686 ; pollination, 495

Zygnemaceae, 348

Zygomorphic flower, 488 ; symmetry, 16

Zygonycetes, 384

Zygopliyllaceae, 602

Zyyusaccharomyces, 400

Zymase, 246

THE END

Printed by R. \& R. CLARK, LIMITED, Edinburgh. 



\section{CAMBRIDGE NATURAL HISTORY}

Evited BY S. F. HARMER, Sc.1), F.I.S., AND

A. E. SHIPLEY, M.A., F.R.S.

In Ten Volumes. Fully Illustrated. Medium 8vo. 17s. net each.

Library Edition. In Ten Volumes. Half Morocco.

Gilt tops. In sets only. Fully Illustrated. Medimm 8ro. $£ 8: 8$ s. net.

Vol. I. Protozod, by Mareus Hartog, M.A., D.Sc.; Porifera (Sponges), by Igerna B. J. Sollas, B.Sc.; Coefenterata AND CTriopholid, by S. J. Hiekson, M.A., F.R.S.; Echinonemata, by E. W. MacBride, M.A., F.R.S.

Vol. II. Flatworms and Ifesozod, by F. W. Gamble, D. Se. ; Neuertines, by Miss L. Sheldon; Tureadworars axd Sagrte, by A. E. Shipley, M.A., F.R.S.; Rotilers, by Marens Hartog, M.A., D.Se. ; Polychaet Worns, by W. Blaxland Benham, D.Sc., M.A.; EARThworms AND LeEches, by F. E. Beddard, M.A., F.R.S.; Gerhyrea Axd Pholonis, by A. E. Shipley, M.A., F.R.S.; Polyzos, by S. F. Harmer, Se.D., F.R.S.

Vol. III. Moluuscs, by the Rev. A. H. Cooke, M.A.; Brachropods (Recent), by A. E. Shipley, M.A., F.R.S.; Briachopols (Fossil), by F. R. C. Reed, I.A.

Vol. IV. CrustackA, by Geoffrey Smith, M.A., and the late W. F. R. Weldon, M.A. : Trilobites, by Henry Woods, M.A.; Introduction to Arachnida Axd King-Crabs, by A. E. Shipley, M.A., F.R.S.; Eurypteirida, by Henry Wools, M.A.; Scorpions, Spiders, Mites, Ticks, ete., by Cecil Warburton, M.A.; Taldiglida (Water-Bears), by A. E. Shipley, M.A., F.R.S.; Pextastomida, by A. E. Shipley, M.A., F.R.S. ; Prconogonida, by D'Arey W. Thompson, C.B., M.A.

Vol. T. Peiripatus, by Adam Sedwick, M.A., F.R.S.; Mrriapods, by F. G. Sinclair, M.A.; Inser's, Part I., Introduction, Aptera, Orthoptera, Neuroptera, and a portion of Hymenoptera (Sessiliventres and Parasitiea), by David Sharp, M.A., M.B., F.R.S.

Vol. VI. Hymenoptera (continued) (Tubulifera and Aculeata), Coleoptera, Strepsiptera, Lepidoptera, Diptera, Aphaniptera, Thysanoptera, Hemiptera, Anoplura, by David Sharp, M.A., M.B., F.R.S.

Vol. VII. Hemichordata, by S. F. Harmer, Se.D., F.R.S.; Ascidians ani) Auphioxus, by W. A. Herdman, D.Se., F.R.S.; Fismes (Exclusive of the Systematic Account of Teleostei), by T. W. Bridge, Sc.D., F.R.S.; Fisurs (Systematic Accont of Teleostei), by G. A. Bonlenger, F.R.S.

Vol. VIII. Axphibia Axo Reptiles, by Hans Gadow, M.A., F.R.S.

Vol. IX. Birios, by A. H. Evans, MI.A.

Vol. X. MLmmali, by Frank Evers Betdard, M.A., F.R.S.

LONDON: MACMILLAN AND CO., LIMITED. 


\section{MACMILLAN'S}

\section{SCIENCE MONOGRAPHS}

\section{8vo.}

CRYSTALLINE STRUCTURE AND CHEMICAL CONSTITUTION. By A. E. H. Tиттох, D.Sc., M.A., F.R.S. 5s, net.

STABILITy IN AYIATION. By G. H. Bryan, Sc.D., F.R.S., Professor of Mathematics in the Unirersity College of North Wales. 5s, net.

STUDIES IN TERRESTRIAL MAGNETIS., By C. Chree, M.A., Sc.D., LL.D., F.R.S. 5s, net.

STUDiEs IN RADIOACTIVITY. By Prof. W. H. Brage, F.R.S., Cavendish Professor of Physics in the University of Leeds. 5s. net.

\section{IN THE PRESS'.}

THE COTTON PLANT IN EGYPT: its Genetics, Physiologs, and Economics. By W. Lawrexce Balls, M.A., Botanist to the Egyptian Gorermment Department of Agriculture.

\section{IN PREPAIATION.}

IMPROVEMENT OF WHEAT AND OTHER CEREALS. By R. H. BIFFEN, Professor of Agricultural Botany in the University of Cambridge.

THE ASCENT OF SAP. By Prof. H. H. Drxos, Professor of Botany in the University of Dublin.

THE ORIGIN OF ORE DEPOSITS AND THE EXTENT OF FUTURE SUPPLIES. By Dr. J. W. Gregory, F.R.S., Professor of Geology in the University of Glasgow.

SOLAR RESEARCHES. By Dr. G. E. HALE, For. Mem. R.S., Direetor of the Solar Observatory of the Carnegie Institution of Washington.

THE SHAPE OF THE EARTH. By Dr. A. E. H. Love, F.R.S., Sedleian Professor of Natural Philosop̧hy in the University of Oxford.

HYDROGRAPHY OF THE NILE BASIX. By Capt. H. G. Lroxs, F.R.S.

TRYPANOSOMES AND ALLIED ORGANISMS. By Prof. E. A. Mnchin, Professor of Protozoology in the University of London.

Wind PREssure. By Dr. T. E. Stantox, National Plysical Laboratory.

RESEARCHES IN MAGNETO-OPTICS. By Dr. P. ZeEman, Professor of Physics in the University of Amsterdam.

AXN MANY OTHERS.

LONIDON: MACMILLAN ANI) C'O., LIMITED. 


\section{WORKS ON GEOLOGY}

\section{By Sil ARCHIBALD GEIKIE, K.C.P., P.R.S.}

A PRIMER OF GEOLOGT. Hllustrated. Pott 8ro. 1s.

CLASS-BOOK OF GEOLOGY. Illustated. Crown 8vo. 5s.

GEOLOGICAL SKETCHES AT HOME AND ABROAD. Illustrated. 8 vo. $10 \mathrm{~s} .6 \mathrm{~d}$.

OUTLINES OF FIELD GEOLOGY. Illistrated. Globe 8vo. 3. $6 \mathrm{~d}$.

TEXT-BOOK OF GEOLOGI. Illustrated. 2 vols. Nedium 8ro. 30 s. net.

THE SCENERY OF SCOTJAND. Tiewed in connection with its Physical Geology. Crown 8vo. 10s. net.

THE ANCIENT VOLCANOES OF GREAT BRITAIN. Illustrated. 2 vols. Super royal 8ro. 36s, net.

THE FOUNDERS OF GEOLOGY. 8vo. 10s. net.

THE SCENERT OF ENGLAND, aNd THE CAUSES TO WHICH it is deE. By Lord Aveburi. Illustrated. Crown 8 vo. 6 s.

THE SCENERY OF SIVITZERLAND, AND THE CAUSES TO WHICH IT Is DUE. By Lord Avebury. Illustrated. Crown 8vo. 6s.

GEOLOGY AND GEOGRAPHY OF NORTHERN NIGERIA. By J. D. Falcosen, D.Se. With Notes by the late Arthur Longbottom, B.A., and an Appendix by Henry Woods, M.A. Illustrated. 8vo. 10s. net.

OBSERVATIONS OF A NATURALIST IN THE PACIFIC BETWEEN 1896 AND 1899 . By H. B. GUPPY, M.B. Illustrated. 8vo. Vol. I. Vanda Leve, Fist: Its Physical and Geological Characters. 15s. net. Vol. II. Plant Dispersal. 21s. net.

GEOLOGY OF SOUTH AFRICA. By Dr. F. 1I. Hatch and Dr. G. S. Corstorphine. Illustrated. 8vo, 21 s. net.

GEOLOGY AND (iENERAL PHYSICS. By Lord Kelvin. Crown 8 vo. 7 s. $6 \mathrm{~d}$.

THE AGE OF MAMMALS IN EUROPE, ASIA, AND NORTH AMERICA. By Prof. Henry F. Osbors, LL.D., D.Sc. Illustrated. 8 vo. 19s. net.

Text-BOOK of PAL.entology. By Karl A. Von Zitrel, Professor of Geology and Palieontology at Munich. Translated and edited by Charles R. Eastman, Pl.D. Revised and enlarged from the German original. Medium 8vo. Vol. I. 25s, net. Vol. II. 10s. net.

LONDON: MACMILLAN AND CO., LIMITED. 


\section{WORKS ON EMBRYOLOGY AND EVOLUTION}

COMPARATIVE EMBRTOLOGI. By F. M. BAfHOUR, M.A. Illustrated. 2 rols. Medium 8 ro. Vol. I. 18s. Tol. Il. $21 \mathrm{~s}$.

THE DEVELOPMEN'T OF THE FROG'S EGG. AN INTRODUCTION TO Experlanental Embryologr. By 'T. H. Morgan, Pli.D. 8ro. Ts. net.

THE CELL IN DEVELOPMENT AND INHERITANCE. By PROF. Ediond B. Wilson, Ph.D. Illustrated. 8vo. 15s. net.

CREATIVE EVOLUTION. By H. Bergson. Translated by A. Mrtehel, Ph.D. 8vo. 10s. net.

EVOLUTION AND MAN'S PLACE IN NATURE. By HENRY CaLderwood, LL.D., F.R.S.E. 8vo. 10s, net.

AN OUTIINE OF THE THEORY OF ORGANIC EVOLUTION. BY I. M. Metcalf, Ph.D. 8 vo. 10: 6d, net.

EVOLUTION AND ADAPTATION. By T. H. Morgan, Ph.D. 8vo. $12 \mathrm{~s} .6 \mathrm{l}$. net.

REgENERATiON. By T. H. Morgan, Ph.D. Illustrated. 8vo. 12s. 6it. net.

MAN AND HIS ANCESTOR. A Study in Evolution By C. Morris. Glohe 8vo. 5s. 6d, net.

EVOLUTION OF MAMMALIAN MOLAR TEETH TO AND FION THE TRIANGULAR TYPE, INCLUding Collected aNd REvised Researches on Trituberculy, and new Sections on the Forms and Homologies or the Molar 'Teeth in the Different Orders of Mammals. By Prof. H. F. Osborn, Sc.D., LL.D., D.Se. Edited by IV. K. Gregorx, M.A. Illustrated. 8vo. 8s. 6d. net.

CONCEALING-COLORATION IN THE ANIMAL RINGDON. AN Exposition of the Laws of Disguise throvgh Colour ani) Patterin: being a Sumiary of A. H. Thayer's Disconeries. by G. H. 'T'HAYER. Illustrated. Demy 4to. 31s. 6d. net.

DARIVINish : An Exposition of the Theory of Natural Selection. Illustrated. By Dr. Alfred R. Wallace, F.R.S. Extra crown 8ro. $7 \mathrm{~s} .6 \mathrm{~d}$.

CONTRIBUTIONS TO THE THEORY OF NATURAL SELECTION, AND TROPICAL NATURE: and other EssaYs. By Dr. Alfren R. Wallace, F.R.S. Extra crown 8vo. 7s. 6d.

THE GEOGRAPHICAL DISTRIBUTION OF ANIMALS. By Dr. Alried R. WALAACE, F.R.S. Hlustrated. 2 vols. Mediun Sro. $42 \mathrm{~s}$.

ISLAND JiFE. Tiy Dr: Alfred R. WALlace, F.R.S. Illustrated. Fixtra (rown 8vo. 7s. $6 \mathrm{~d}$.

LONDON : MACMILLAN AND CO, JIMITE1). 




\section{PLEASE DO NOT REMOVE CARDS OR SLIPS FROM THIS POCKET}

\section{UNIVERSITY OF TORONTO LIBRARY}

RinMed 
